15
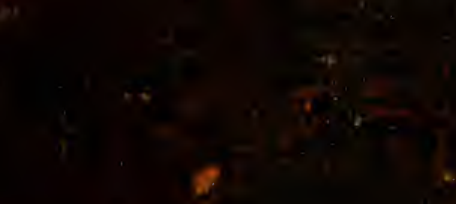
Tihrary

Alniurraity of Wittghurgh

Darlington Memorial Library

Class

Thank

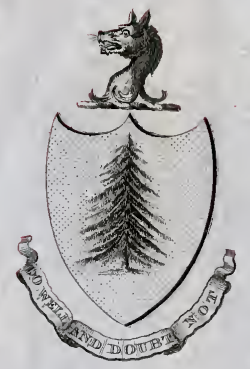

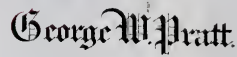
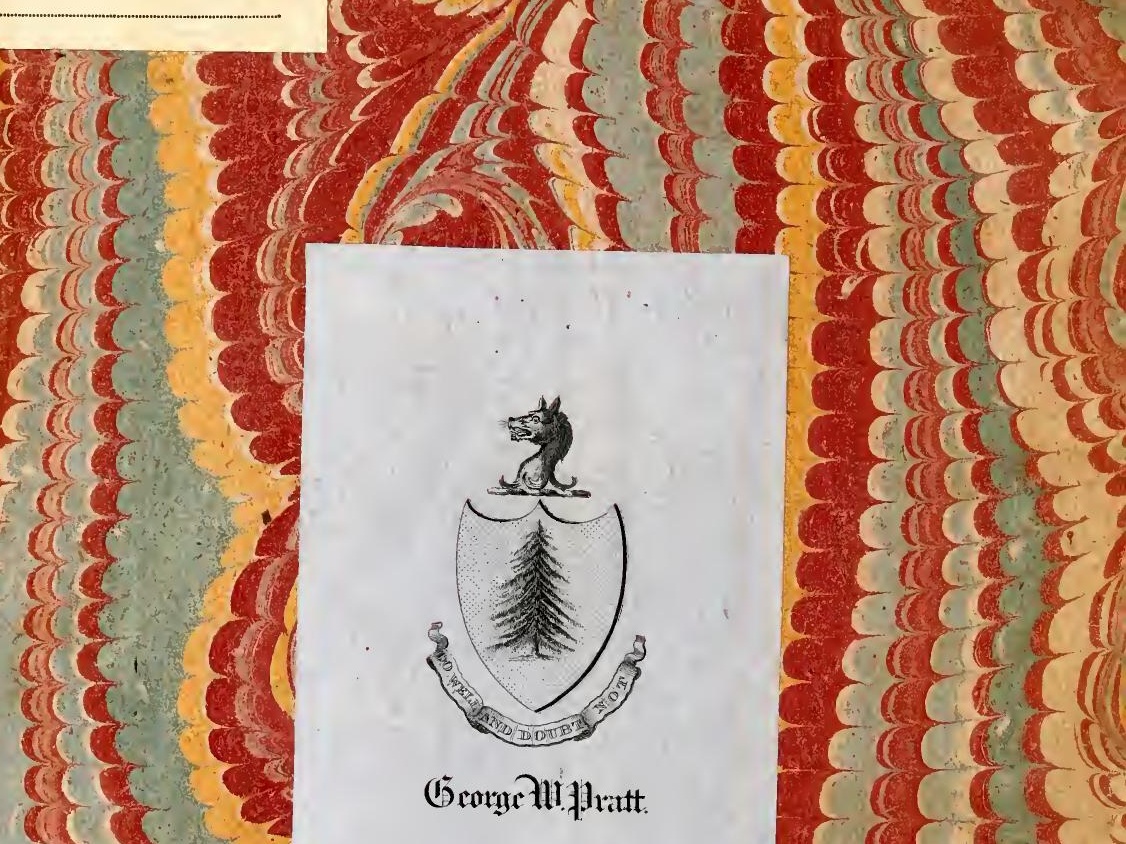

(I)

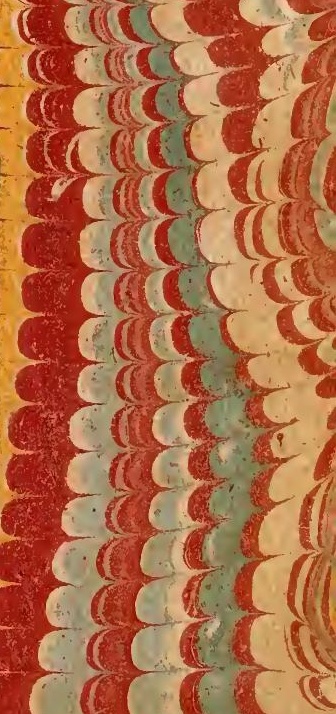

(c)

ic $(2)$

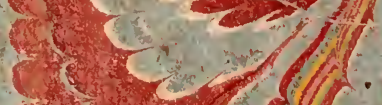

1
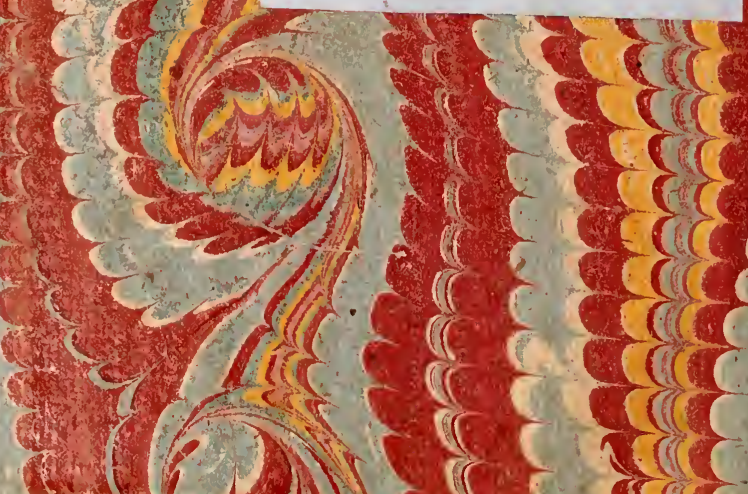
06 
Digitized by the Internet Archive in 2009 with funding from University of Pittsburgh Library System 


\section{HIS TOIRE}

D E L A

NOUVELLE FRANCE.

TOME III. 



\section{$D^{\prime} \mathrm{U} N$}

VO Y A G E

FAIT PAR ORDRE DU ROI

D A N S

L'AMERIQUE SEPTENTRIONNALE:

Adressé a Madame la Duchesse

D E L E S D I G U I E R E S.

Par le P. De Charlevoix, de la Compagnie de Jesus.

\section{TOME TROISIE'ME。}

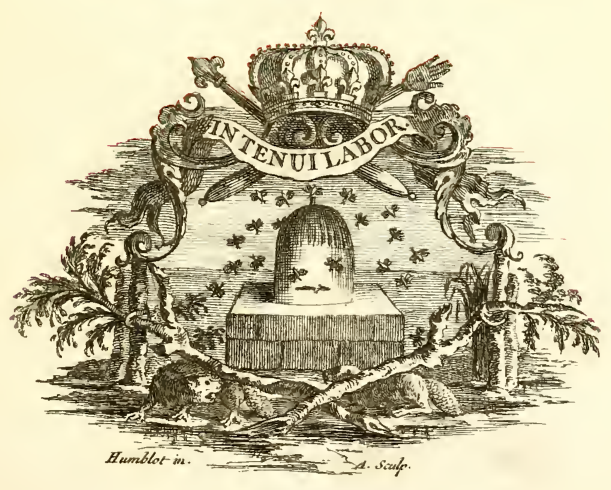

A P A R I ,

ChezROLIIN Fils, Quai des Auguftins, à Saint Athruafe, \& au Palmier.

M. D C C. X L I V.

AVEC APPROBATION ET PRIVILEGE DU ROI, 



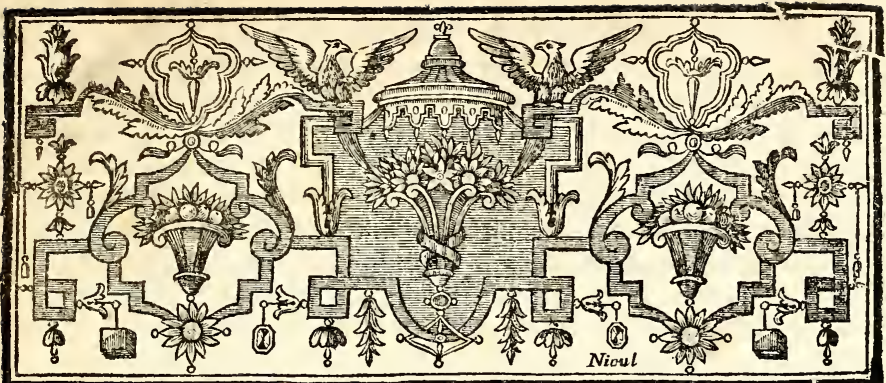

REMAR QUES D E

M. B E L L I N,

INGENIEUR DE LA MARINE,

SUR LES CARTES ET LES PLANS, qu'il a été chargé de dreffer, pour joindre à l'Hiftoire générale de la Nouvelle France du Réverend Pere DECHARLEvor X, dela Compagnie de Jesus: Et au Journal de fon Voyage dans cette Partie du Monde.

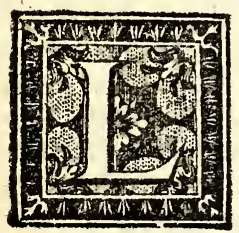

A Géographie répand un jour fi avantageux fur l'Hiftoire, qu'elle devroit en être inféparable. C'eft le fentiment des Sçavans, qui devient aujourd'hui un fentiment général. Tout le monde conviendra que des faits arrivés dans un Pays éloigné \& peu connu, exigent néceffairement, pour une plus parfaite intelligence, que l'on mette fous les yeux le théâtre, où ils fe font paffés : \& quelquefois la connoiffance des lieux intéreffe autant, que les faits mêmes,

Tom. III. 
L'Hiftoire de la Nouvelle France femble être faite pour prouver ce que j'avance; fon Auteur l'a traitée de façon, que la Géographie de ces Pays s'y trouve développée d'une maniere auffi claire $\&$ auffi jufte, qu'elle eft agréable \& amufante : chofe d'autant plus rare, que cette fcience eft fouvent obfcure, \& fes détails prefque toujours fecs $\&$ ennuyans.

Il eft vrai, que notre Auteur a un avantage bien grand, c'eft qu'il a vû par lui-même. Il a parcouru ces vaftes Pays par ordre de la Cour, \& les a parcourus en Homme attentif \& curieux, avec deffein formé de prendre toutes les connoiffances poffibles, \& d'en faire part au Public: auffi ai-je tiré de fes Mémoires particuliers beaucoup d'éclairciffemens, quej'aurois en vain cherchés ailleurs, \& dont j’avois befoin pour former des Cartes, qui puffent nous donner des idées géographiques un peu plus juftes, que celles, que l'on a aujourd'hui de ces Parties confidérables de l'Amérique Septentrionnale, connuës fous les noms de la Nouvelle France, ou Canada, \& de la Louyfiane.

Les Cartes, que j’ai dreffées pour cette Hiftoire, font fi différentes de tout ce qui a paru en ce genre, que je ne puis me difpenfer de rendre compte des principaux changemens, que j'ai été forcé d'y faire : de relever en même tems les erreurs confidérables, dans lefquelles ceux, qui m'ont précedé, font tombés; \& enfin de faire connoître les fources, où j’ai puifé.

Je dois au dépôt des Cartes, Plans, \& Journaux de la Marine, le goût, que jai pris pour ce genre d'étude ; \& le peu de connoiffances, que j'y acquifes. On y trouve une quantité de Cartes \& de Plans manufcrits, levés fur les lieux, \& envoyés aux Miniftres, foit par les Ingénieurs, foit par des Navigateurs habiles. On y trouve des Relations exactes \& circonftanciées de toutes les nouvelles découvertes, \& furtout un nombre prodigieux de Journaux de navigation, qui font la plûpart remplis de Remarques \& d'Obfervations, de la comparaifon \& de la réunion defquelles, la Géographie. \& l'Hydrographie peuvent tirer de très-grandes lumieres.

Avec de pareils fecours, \& un peu d'amour pour le travail, il n'eft point étonnant, que je fois en état de débrouiller un peu mieux, qu'on n'a fait jufqu'ici, la Géographie de ces Pays. 
Mon deffein n'eft point de faire la critique des Cartes, que I'on a de la Nouvelle France \& de la Louyfiane; il y en a peu, \& elles font à fi petit point, \& fi éloignées du vrai, que jofe dire, qu'elles ne méritent aucune attention. Cependant je ne puis me difpenfer de parler de la grande Carte Angloife de l'Amérique Septentrionnale en 20 feuilles, publiée depuis quelques années par M. Popple, fous le nom d'Empire Anglois dans l'Amérique.

Comme cette Carte eft à plus grand point $\&$ plus détaillée, qu'aucune autre : beaucoup de perfonnes l'ont regardée comme un bon Ouvrage, auquel on pourroit avoir quelque confiance; mais il s'en faut bien, que cela foit ainfi, \& je le prouverai dans la fuite.

Commençons par rendre compte de la conftruetion de nos Cartes, \& mettons fous les yeux les principales remarques, dont nous nous fommes fervis, \& les changemens, qui en ont réfulté.

Qu'il me foit permis de prier les Amateurs de la Géographie, d'examiner avec un peu d'attention la Carte, que j'ai nommée Partie Orientale de la Nouvelle France ou du Canada. Elle comprend l'Ille de Terre-Neuve \& Partie de Labrador, le Golphe de Saint Laurent, l'Ifle Royale, l'Acadie, le cours du Fleuve de Saint Laurent, \& les Rivieres, qui s'y déchargent, jufquà l'entrée du Lac Ontario: les Pays, qui font au Nord de ce Fleuve jufqu'à la Baye d'Hudfon, \& ceux, qui en font au Midi, jufqu'à la Nouvelle Angleterre. Je puis aflûrer, que j'ai rendu ce morceau entierement neuf, \& que les détails, dont il eft rempli, ont été ignorés jufqu’à préfent.

$1^{\circ}$. L'Ille de Terre-Neuve y eft reduite à fa jufte étenduë, $\&$ à la véritable configuration de fes Côtes. J'ai dans plufieurs Journaux de navigation (a) des obfervations de latitude, qui ont été faitès à la vûe du Cap de Rafe, qui eft la pointe la plus méridionnale de l'Ifle, \& qui toutes s'accordent à mettre ce Cap par les 46. dégrés 50. minutes de latitude : la Carte de M. Popple le met par 46 . dégrés 30 . minutes, ce qui fait 20. minutes trop Sud. J'ai des latitudes obfervées $(b)$ dans le

(a) J'avois deflein de citer ici les Journaux des Vaifleaux, dont j'ai tiré mes Remarques, mais cela meneroit loin, \& ne feroit d'aucune utilité pour la plûpart des Leç?urs. (b) Journal du Pilote du Brigantin du Roy la Reine Marie, envoyé de Quebec en 1735 . pour faire la vilite des Côtes, \& la découverte du Déuroir de Belle-Ifle. 
Détroit de Belle-Ifle, \& auprès de la Pointe la plus Septentrionnale de l'Ifle de Terre-Neuve, qui la mettent par $5 \mathrm{r}$. dégrés 30. minutes. Popple met cette Pointe par $5 \mathbf{2}$. dégrés 10. minutes, c'eft 40. minutes trop Nord. Ainfi nous conftatons avec la plus grande évidence la longueur de cette Ifle du Nord au Sud, que la Carte Angloife fait d'un' dégré trop grande. Sa largeur de l'Est à l'Oueft eft déterminée par les routes des Navigateurs, qui s'accordent à trouver du Cap de Rafe au Cap de Raye, environ 80 . lieuës; ils donnent auff la latitude du Cap de Raye de 47. dégrés, 30. à 35. minutes. La Carte de Popple ne met que 50 . lieuës entre ces deux Caps, \& place ce dernier 20. minutes trop Nord, de forte qu'elle donne entre le Cap de Rafe \& le Cap de Raye, un dégré 20. minutes, pour la différence en latitude, laquelle n'eft que de 40. minutes. Joignons cette erreur en latitude à celles des 30. lieuës en longitude, qui valent ici plus de 2 . dégrés 8 demi ; il en réfultera une prodigieufe difference pour le gifement de cette Côte. Si l'on entroit dans le détail de cette Partie, tout s'y trouveroit défectueux : par exemple entre le Cap de Rafe \& le Cap de Sainte Marie, qui n'en eft qu'à 20. lieuës, il n'y a que 5 . minutes de difference en latitude; c'eft un fait connu de tous les Navigateurs. Cette: Carte y en met plus de 30. L'ouverture de la Baye de Plaifance entre le Cap Sainte Marie \& le Chapeau Rouge, eft de 15 . lieuës au moins, \& nous l'avons marquée ainfi : la Carte de Popple n'y met que 8. lieuës, \&c. Je crois inutile d'obferver, qu'en lifant ceci, il faut avoir notre Carte fous les yeux.

La partie du Nord de Terre-Neuve, le Détroit de BelleInle, \& la Côte de Labrador, font ici bien autrement détaillés, \& très - differents de ce qu'on trouve dans toutes les Cartes , \& fur-tout de celle de Popple. Je dois ces connoiffances aux divers (a) Manufcrits du Dépôt, fur léfquels jai dreffé une Carte particuliere de l'Ifle de Terre-Neuve en affez grand point, poury employer les noms de prefque tous les Caps, Ports \& Havres; quoiqu'elle ne le foit pas cependant encore affez pour rendre bien fenfible le contour \& le gifement de

(a) Les Côtes de Terre-Neuve ont été / dans ces tems, plufieurs Vaiffeaux du Roy pendant plufieurs années fort fréquentées ont fait le tour de l'Ine, \& la vifite dess par les François, qui ont donné les noms Côtes.

2 prefque tous les Ports \& les Havres; \& 
la Cóte de proche en proche, \& telle, qu'il la faudroit pour l'ufage de la navigation, ce qui n'eft point l'objet prérent; mais elle eft fuffifante pour l'Hiftoire, à laquelle elle eft jointe. J'y ai ajoûté un Plan du Port de Plaifance $\&$ de fes environs, dont la connoiffance ne peut que faire plaifir. Avant de quitter Terre-Neuve, il eft bon d'avertir, qu'il s'eft gliffé une faute dans l'impréffion de cet Ouvrage, tom. I, page 8. En parlant de cette Ifle, le Cap de Bonnevifte y eft dit fitué par les 46. dégrés de latitude, il faut lire 49. degrés 30 . minutes: \& un peu plus bas on trouve, il defcendit au Sud Sud-Eft G. degrés, il faut lire 6 . lieuës.

2o. L'Ifle Royale \& le Golphe Saint Laurent font travaillés avec foin ; mais pour le faire connoitre, je ne puis que répeter ce que je viens de dire. Ce font toujours des latitudes obfervées; des diftances eftimées par les Navigateurs, $\&$ concluës de leurs routes; des relevemens de differens points, \& ce.

J'obferverai cependant que la latitude du Cap de Nord en l'Ifle Royale, eft de 47. degrés 5 . minutes; celle des Ifles aux Oifeaux de 48. degrés, \& celle du Cap des. Rofiers de 49. degrés : qu'entre l'Ine de S. Paul \& le Cap de Raye, il n'y a que I 4 . à I 5 . lieuës, \& qu'ils gifent entr'eux Nord-Eft-quartEft, \& Sud-Oueft-Quart-d'Oueft, \&c.

Voyons comment la Carte Angloife marque ces Parties. On y trouve entre l'flle de S. Paul \& le Cap de Raye 25. lieuës de diftance, \& leur gifement Nord-quart de Nord-Eft, \& Sud-Quart de Sud-Oueft : quelle prodigieufe différence, quatre rumbs de vent fur un gifement, \& dix lieuës de trop fur une diftance de 14 . lieuës? Mais ce qui doit furprendre, c'eft d'y voir par 50. degrés 20. minutes de latitude, le Cap des Rofrers, que nous avons dit ci-devant être par les 49. degrés; de forte que cette Carte met plus de 6o. lieuës des Ifles aux Oifeaux, au Cap des Rofiers, lorfqu'il n'y en a que 42. ou 43. au plus. L'Ine Royale \& l'Inle de S. Jean, de même que toute la Côte voifine, jufqu'à l'entrée du Fleuve S. Laurent, n'ont aucune précifion dans la Carte Angloife, ni les détails néceffaires pour donner des idées un peu juftes de ces Pays : pour en être convaincu, il ne faut que la comparer avec la mienne.

L'Ifle Royale m'a paru mériter une Carte particuliere; celle 
que l'on trouve ici, a été dreffée fur les divers Manufcrits du Dépôt, \& fur les Journaux des plus habiles Navigateurs: ainfi je crois, qu'on peut $y$ avoir quelque confiance : \& comme cette Ifle nous intéreffe, jy ai joint le plan du Port $\&$ de la Ville de Louyfbourg, qui eft la Capitale de l'fle ; \& un plan du Port Dauphin \& de fa Rade, dont la fituation eft des plus belles.

On fera peut-être furpris de ne pas trouver des fondes fur mes plans ; c'eft-à-dire, la quantité de braffes, ou de pieds d'eau ; je fçais que ces détails font extrêmement utiles, \& il m'auroit été facile de les remplir avec exactitude : mais des raifons particulieres, qui n'ont rien de commun avec la Géographie, m'en ont empêché. A l'égard des plans des Ports, qui n'appartiennent pas à la France, jy ai mis des fondes.

J'ai placé l'lle de Sable à environ 3o. lieuës au Sud de Louyfbourg, par la latitude de 44 . degrés I0. à 12 . minutes. Cette pofition ne s'accorde point avec ce qui eft dit à la page 109. du tome premier, que l'Ifle de Sable eft éloignée de l'IJle Royale, d'environ 23. lieuës au Sud-Eft; ni avec ce qui eft dit 2. lignes plus bas, qu'elle eft à 35, lieuës Nord \& Sud de Camceau. Ces deux gifemens fe détruifent l'un l'autre; mais l'Auteur, en les rapportant, n'a eu en vûe, que de faire connoître deux fentimens différens, fans y avoir égard; \& la preuve, c'eft qu'enfuite il nous donne la latitude de l'thle de Sable très-exactement, $\&$ telle que je l'ai trouvée dans les meilleurs Journaux de navigation.

$3^{\circ}$. J'ai fait toutes les recherches poffibles fur l'Acadie; jai tiré des Journaux des différentes Campagnes, que les Vaiffeaux du Roy y ont faites, des latitudes de la Pointe Orientale \& de la Pointe Occidentale; jai réduit leurs routes, \& j’ai trouvé que d'une Pointe à l'autre, elles donnoient 80 . lieuës; par ce moyen le gifement \& l'étenduë de la Côte font déterminés. J'ai détaillé l'intérieur du Pays, dont il paroît par toutes les Cartes Géographiques, qu'on n'avoit eu jufqu'ici aucune connoiffance ; \& j'ai tâché de conferver aux Bayes $\&$ aux Ports leurs véritables figures. Et pour rendre ces détails plus fenfibles, $j$ 'ai fait une Carte particuliere de l'Acadie.Sur quoi je remarquerai, que dans cette Carte, $j$ 'ai donné environ ${ }_{5}$. lieuës de trop du Cap Camceau, au Cap de Sable, Le dẹtạil m’a jetté infenfiblement dans cette erreur, 
\& $y$ jettera prefque toujours; car en voulant exprimer la configuration des Ports, \& tous les contours des Pointes \& des Ifles, il eft impoffible, lorfque la Carte eft fur une petite échelle, qu'on ne leur donne un peu plus d'étenduë, qu'elles ri'en ont réellement. C'eft le cas, où je me trouve, puifque l'échelle de ma Carte ne porte qu'une ligne au plus, pour la grande lieuë de France de 2853 . toifes: mais jai corrigé cette erreur dans ma Carte de la Partie Orientale du Canada , \& j'y ai réduit la prefqu'llfe de l'Acadie à fes juftes bornes, comme on l'a vî ci-devant. Et pour fatisfaire davantage la curiofité du Public, j’ai joint ici des Plans particuliers des principaux Ports. Ces Plans font celui de la Baye de Chedabouctou, appellée aujourd'hui le Havre de Milford. Celui de la Baye de Chibouctou, le Port de la Heve, \& le Port Royal, aujourd'hui Annapolis Royale. Je les ai tirés des Manufcrits de notre Dépôt, où l'on fçait qu'il y en a de toutes les parties de l'Univers, \& à plus fortes raifons de celles, que nous avons porfedées.

Avant que de quitter l'Acadie, jettons les yeux fur la Carte Angloife de Popple, je trouve qu'elle marque affez bien les latitudes \& la longueur de cette Peninfule, quoiqu'elle mette le Cap de Camceau 20. minutes trop Nord. Mais il n'y a rien d'exact fur la figure des Ports, ni fur le contour particulier de la Côte. A l'égard de l'intérieur du Pays, iln'en eft pas queftion fur cette Carte. Lc cours des Rivieres, \& les Lacs, qui font les communications des divers Cantons de cette prefqu'lfle, n'y font point marqués : elle a cela de commun avec toutes les Cartes, que je connois.

$4^{\circ}$. Le cours du Fleuve Saint Laurent, \& les Pays, quí en font au Nord \& au Sud, demanderoient une Differtation beaucoup plus étenduë, que celle, qu'il m'eft permis de faire ici.J'aurois même fouhaité de pouvoir donner une Carte particuliere de ce fameux Fleuve, \& de le faire connoître dans tout fon cours, qui a plus de 250 . lieuës, depuis $f a$ fortie du $L$ ac Ontario, jufqu'à fon embouchure dans le Golphe de Sainc Laurent, \& dont la moirié eft navigable pour de gros Vaiffeaux, de faire voir la quantité prodigieufe d'Inles de toutes grandeurs, dont il eft femé ; fes Ports \& fes mouillages; les. dangers, qu'il faut éviter; les Rivieres, qui s'y déchargent; les Lacs, qu'il forme; fes Rapides, ou Saults, \& fes Porta- 
ges ; en un mot, mille détails Géographiques auffi intereffans, que curieux, \& entierement ignorés. Mais pour exécuter un pareil projet, il auroit fallu multiplier les Cartes, \& les faire d'une grandeur fuffifante; or cela ne convenoit pas à la nature de l'Ouvrage, pour lequel je devois travailler, \& auroit jetté les Libraires dans une trop grande dépenfe, car mon projet ne fe feroit pas borné au Fleuve de Saint Laurent. J'aurois fait la méme chofe pour le Fleuve Miciffipi, dont j'aurois donné plus de 400. lieuës de cours, ce qui auroit entraîné le détail de diverfes parties de la Louyfiane, de la Nouvelle France, \&x.

Quoique je dife que jaurois pû entrer dans un plus grand détail, il ne faut pas croire, que j’aye rien négligé de ce qui peut contribuer à l'intelligence de l'Hiftoire, $\&$ à la fatisfaction des Lecteurs, pour laquelle on voit que les Libraires nont rien épargné. Car comme dans ma Carte de la Partie Orientale du Canada, le Fleuve Saint Laurent devient un peu petit, j’i fait des Cartes particulieres de certaines Parties, qui m'ont paru intéreflantes. On trouvera une Carte de l'Ifle d'Orleans, \& d'un paffage difficile, qui en eft proche, qu'on appelle la Traverfe; une Carte contenant le Baflin de Quebec \& fes environs, le Plan de la Ville de Quebec, une Carte de l'Ifle de Montreal \& des Ifles voifines; une Carte de la Riviere de Richelieu \& du Lac Champlain, enfin une Carte du Cours du Saguenay depuis Checoutimi, jufqu'à fon embouchure dans le Fleuve de Saint Laurent. Ce font des morceaux de détails, que je puis affûrer être curieux, \& avoir quelque exactitude, les ayant travaillés fur de bons Mémoires.

Donnons quelques momens à l'examen de ce travail. Les Vaiffeaux du Roy, qui font tous les ans la Campagne de Quebec, me fourniffent les remarques néceffaires pour dreffer une Carte du Fleuve depuis Quebec jufqu'à la Mer. J'ai des latitudes, des routes, des relevemens, des moiiillages. Les Pilotes les plus habiles \& les plus pratiques, avec lefquels je fuis en relation, m'ont communiqué leurs obfervations. 'Voilà mes matériaux, \& les fources, où j’ai puifé.

Que l'on compare à préfent la figure de mon Fleuve, avec celle, que Popple lui donne dans fa Carte, on fera furpris de la difference, qui fe trouve entre nous. Par exemple, la largeur du Fleuve devant Matane eft d'environ 12. lieuës, la Carte Angloife la fait de 28. Elle place les fept Ifles au

Nord 
Nord de Matane, elles en font au Nord-Eft.

Tout le refte du Fleuve eft auffi défectueux; près de la moitié des Ifles n'y font pas marquées, \& celles, qu'on $y$. trouve, ne font, ni dans leurs proportions, ni dans leur vrai gifement. La plûpart des Rivieres y font oubliées, les autres y font jettées au hazard, \& fans aucune précifion géographique : en voici la preuve.

Qu'on regarde fur ma Carte ce grand nombre de Lacs \& de Rivieres, qui font entre la Riviere du Saguenay, \& le Lac des Miftaffins; elles ont toutes des noms. On trouvera plus de 80. Lacs, dont la plûpart ont $5 . \& 6$. lieuës de tour, \& plufieurs bien davantage : ils ont auffi prefque tous des noms, ou Sauvages, ou François. Rien de tout cela dans la Carte Angloife, ni dans aucune autre. Le Lac des Miftafins y eft marqué, mais il y eft mal; fur ma Carte on voit qu'il forme trois Lacs différens, qui fe communiquent par des Détroits , \& chaque Lac a fon nom. Le plus grand eft le Lac des Miftaffins, le fecond le Lac Albanel, \& le plus petit le Lac Dauphin.

Au Nord \& à l'Oueft duLac de S. Jean, ily a des Rivieres remarquables, \& fingulieres par le nombre de leurs chutes, \& plufieurs Lacs, dont la Carte Angloife ne donne pas la moindre connoiffance.

Je ne crois pas devoir pouffer plus loin l'Analyfe de la Carte de la Partie Orientale du Canada : ce qu'on vient de voir fuffit pour faire connoître les recherches, que j’ai été obligé de faire; le travail, qui en a réfulté ; \& le dégré de confiance, qu'on y peut avoir : je dis le degré de confiance; car il s'en faut bien, que ma Carte foit au point, où je fouhaiterois : les connoiffances fuffifantes m'ont manqué dans quantité d'endroits : mais je ne crois pas qu'il foit poffible de faire mieux, quant à préfent. Ainfi il ne me refte plus qu'à dire un mot fur les longitudes.

L'Obfervation Aftronomique de Bafton, \& celle de Quebec, font les points fixes, aufquels je me fuis aflujetti. Jaurois fort fouhaité d'avoir une bonne Obfervation à l'Ifle de Terre-Neuve, ou à l'Ifle Royale. On fent de quelle importance elle feroit pour fixer la longitude de ces Parties, de façon, qu'on ne pût y rien oppofer.

Je fçai que quelquẹs Géographes, \& fur-tout les Anglois ; Tom. III. 
x REMARQUES DEM. BELL IN

prétendent, que Quebec eft plus Occidental, que Bafton, d'environ 40. ou 45 . minutes: mais je ne vois pas fur quel fondement.

J'ai examiné l'Obfervation de l'éclypfe de Lune, faite à Quebec par M. Deshayes, fur laquelle la longitude de cette Place a été déterminée 72 . degrés I 3 . minutes, plus Occidentale que Paris ; \& je l'ai comparée avec celle de Bafton, qui eft de 72. degrés 55 . minutes. J'ai trouvé que cette différence s'accordoit fort bien avec celle, qui réfultoit des Remarques des Voyageurs, avec les routes, que nous avons de Quebec à Bafton; \& enfin avec la difcuffion géographique la plus exacte, qu'on puiffe faire aujourd'hui. Monfieur Delille, dans fa Carte de l'Amerique de 1722 , a fuivi ces longitudes. Malgré cela, je fuis prêt d'abandonner mon fentiment, \& de me rendre à toute autre longitude pour Quebec, dès qu'elle me paroîtra prouvée. A l'égard de la longitude de Bafton, elle eft univerfellement reçûë.

Il eft bon de remarquer que, partant de Bafton, \& fuivant les Côtes d'Acadie $\&$ de Terre-Neuve, jufqu'au Cap de Rafe, les routes \& les diftances tirées des Journaux des meilleurs Navigateurs, déterminent ce Cap par les 53. degrés 10. minutes à l'Occident du Meridien de Paris, tandis que la Carte Angloife de Popple le met par les 56. degrés à l'Occident du Meridien de Londres, ce qui revient au 58 e. degré 25 . minutes de celui de Paris. C'eft une différence en longitude de 5. degrés 15 . minutes.

Ce n'eft pas là le feul endroit, où l'on trouvera des différences confidérables en longitude, entre la Carte Angloife \& la mienne; en voici une bien plus forte encore.

Entre Quebec \& le Fort de Rupert, qui eft dans la Partie Orientale du fond de la Baye d'Hudfon, je n'ai trouvé qu'environ 6. degrés de différence en longitude; la Carte de Popple en marque 14. J'avouë, que cette prodigieufe différence me furprend: je voudrois fçavoir fur quels Mémoires il a travaillé, \& ce qui peut l'avoir jetté dans une pareille erreur.

Je puis affûrer, que j'ai difcuté cette Partie avec toute l'at' tention, dont je fuis capable. Tous mes Manufcrits (a) s'ac-

(a) J'ai les Remarques de Louis Joliet, / fins \& la Riviere de Rupert, \& qui a dneffé qui a fait le voyage de Tadouf́ac à la Baye une Carte de fa route.

d'Hudfon en 1678 . par le Lac des Miftaf- J'ai le voyage de Pierre Allemand, qui 


\section{$S$ UR LES CARTES.}

cordent à ne donner que 6. à 7. degrés entre Quebec \& le fond de la Baye d'Hudfon. Le fieur Franquelin, Géographe du Roy, qui a paffé fa vie dans le Canada, qui a parcouru plufieurs Parties de ce grand Pays, \& qui a vêcu \& converfé avec ceux, qui en faifoient les découvertes; dans fes Mémoires $\&$ dans les Cartes, qu'il envoyoit aux Miniftres, n'a jamais mis que 6. degrés de longitude entre Quebec \& la Baye d'Hudfon: d'où il réfulte, que le Fort de Rupert eft au plus par les 78 . degrés 20 . ou 30. minutes de longitude Occidentale; au lieu que la Carte Angloife le met par 87. degrés 30. minutes.

La Baye d'Hudfon eft affez confiderable, pour meriter d'être connuë ; \& comme on n'en a point de Cartes exactes, j’en donne ici une, que j’ai dreffée fur les Mémoires \& les Journaux de plufieurs Navigateurs : \& pour rendre plus fenfibles toutes les Ifles, qui font au fond de cette Baye, j'en ai fait une petite Carte particuliere.

Je ne ferai point l'Analyfe de cette Partie; je remarquerai feulement, que la Partie Occidentale de cette Baye depuis le $60^{\mathrm{me}}$. degré de latitude en allant vers le Nord, a été jufqu'ici inconnuè : on croyoit même qu'il pouvoit y avoir un paffage par-là , pour aller dans la Mer du Sud. Les dernieres découvertes des Anglois ont éclairci ce point de Géographie, ainfi qu'on le peut voir fur ma Carte. C'eft fur le Journal $\&$ la Carte du Pilote Midleton, qui a été chargé de cette découverte en 174I, \& qui m’a été envoyée d'Angleterre, que j'ai travaillé.

Paffons à la Partie Occidentale du Canada, je veux dire, à la Carte des Lacs. On fera peut-être furpris de me voir avancer que je n'ai pu tirer aucun fecours de nos Géographes les plus habiles; ni des fieurs Sanfon, ni du P. Coronelli, ni du fieur Delille, tous Géographes du premier ordre, \& à qui nous fommes redevables des meilleures Cartes, que nous avons aujourd'hui. Ils ne m'ont rien fourni dans leurs Ouvrages, dont $j$ 'aye pû faire ici le moindre ufage. Pour en être convaincu, il ne faut que jetter les yeux fur ma Carte, \& la comparer avec ce que chacun d'eux a donné fur cette Partie.

a fait la route par les terres de Quebec à la \& Voyageur a fait auffi deux autres Voyages Baye d'Hudfon, \& qui en a envoyé la de Quebec à la Baye d'Hụdfon par Mer. Carte à M. de Seignelay en 1688. Ce mème

b ij 
Quoique je n'aye pas envie de faire une Analyfe particuliere de cette Carte, je crois devoir m'y'arrêter quelques infftans pour la fatisfaction de ceux, quir aiment la Géographie, \& $\mathrm{me}$ juftifier en quelque façon de n'avoir pas fuivi d'auffi grands Maîtres, qui avoient bien plus d'acquit que moi, en ce genre d'étude.

Rien de plus commun $\&$ de plus facile, que de faire des Cartes; rien de fi difficile, que d'en faire de paffables. Un bon Géographe eft d'autant plus rare, qu'il faut que la nature $\&$ l'art fe réuniffent pour le former. Il doit tenir de la premiere la mémoire, l'amour pour le travail, la patience, \& un efprit d'ordre \& d'arrangement; de l'autre des connoiffances fuffifantes dans la Géométrie \& dans l'Aftronomie, après lefquelles viennent l'étude longue \& fterile des Voyageurs, la difcuffion critique de leurs Relations \& $x$ de leurs Journaux, fources continuelles d'incertitudes \& d'erreurs, que fouvent le travail le plus affidu ne fçauroit vaincre : joignez à cela: quelque intelligence des Langues Etrangeres.

Eft-il aifé de réunir toutes ces Parties, fans lefquelies cependant on ne peut guere fe flatter de réuffir ? On doir donc quelque indulgence aux fautes, qui échapent à ceux, qui fe livrent à cette Science; \& je fçais que jen ai plus de befoin qu'un autre.

Revenons à ma Carte des Lacs. J'ai tiré du Journal du R.P. de Charlevoix, la plus grande partie de ce qu'on y trouvera de bon. Cet Hiftorien.Voyageur a traverfé dans toutes leurs longueurs le Lac Ontario, le Lac Erié, le Lac Huron \& le Lac Michigan. Par-tout la Bouffole à la main, il a relevé les principaux gifemens de pointe en pointe; toutes les fois, que le tems lui a permis, il a obfervé la hauteur du Pole, il a. eftimé avec le plus de précifion, qu'il étoit poffible, les diftances d'un lieu à un autre; enfin il n'a rien négligé de tout ce qui pouvoit fervir à la connoiffance de ce Pays.

Qu'on ne foit donc point furpris de voir que je fais courir le Lac Ontario Eft \& Oueft, tandis que la Carte de la Louyfiane de M. Delille le fait courir Eft Nord-Eft \& Oueft SudOueft ; \& la Carte de Popple, Nord-Eft \& Sud-Oueft. Cette derniere marque le Fort de Catarocoui à l'entrée du Lac Ontario, près d'un degré trop Septentrionnal.

On trouvera fur ma Carte feize Rivieres, qui fe déchạr- 
gent dans l'étenduë de la Côte méridionnale du Lac Ontario, parmi lefquelles il y en a une, qu'on prétend avoir cent lieuës de cours, \& dont il n'y a pas la moindre trace fur la Carte Angloife, ni fur celle de M. Delille.

J'ai travaillé avec le même foin le Lac Erié \& le Lac Huron : cependant la Côte du Sud du premier, \& celle du Nord du fecond, ne me paroiffent pas trop bien connuës, \& je ne fuis point content de ce que j'en ai donné : mais il ne ma pas été poffible de faire mieux.

Au Sud du Lac Erié, j’ai marqué quatre Rivieres, qui n'en font éloignées, que d'une lieuë ou deux, par lefquelles on peut defcendre dans l'Ohio, ou la belle Riviere: il n'y a point de Cartes, ò̀ elles foient marquées. J'ai changé auffi le cours de l'Ohio \& de la Riviere Ouabache. Je dois ces comnoiflances aux Manufcrits du Dépôt, parmi lefquels il y en a quelques-uns de $M$. de la Sale, que l'on fçait avoir traverfé plufieurs fois ces Cantons: \& ceux, qui me manquoient, mont été communiqués par M. le Baillif, Auditeur des Comptes, arriere-Neveu de ce fameux Voyageur, qui a facrifié fon bien $\&$ fa vie pour la découverte de la Louyfiane.

Le Pofte de Michillimakinac \& le Détroit du Sault Sainte Marie, qui fait la communication du Lac Huron avec le Lac Supérieur, m'a paru curieux, \& entierement ignoré des Géographes. Cela m’a engagé d'en faire une petite Carte particuliere, celle des Lacs n'étant pas en affez grand point, pour rendre ces détails géographiques bien fenfibles.

Le Lac Michigan eft affujetti aux Obfervations de latitude, qui ont été faites à l'entrée du Détroit, qui fait fa jonction avec le Lac Huron, \& auprès de la Riviere de Saint Jofeph, ce qui détermine fa longueur du Nord au Sud. J'ai des Remarques fur le gifement de la Côte Orientale, \& fur les Rivieres, qui s'y déchargent; \& ce font les fruits du voyage de notre Auteur, auffi-bien que les latitudes; de forte quej'ai fait courir cette Côte au Sud Sud-Eft : au lieu que la Carte de M. Delille l'a fait courir au Sud Sud-Oueft, d'où il réfulte plus de 60. lieuës de diftance entre le Lac Erié \& le Lac Michigan, tandis qu'il ne peut y avoir qu'environ 45 . lieuës.

Je remarquerai ici, que dans le Journal, page 3 12. en parlant de la Côte Orientale du Lac Michigan, on trouve: Je traverfai une Baye, qui a trente lietiës de profondeur; il faut- 
lire trois lieuës. L'infpection de la Carte fera fentir la nécefiité de la correction $(a)$.

Le cours de la Riviere de $S$. Jofeph, les fources du Thea$k i k i, \&$ celles de la Riviere Ouabache, ne font pas bien dans la Carte de M. Delille : j’ai changé tout cela, \& je fuis en état de rendre compte de ces changemens. Je ne dis rien ici de la Carte Angloife, qui dans toute cette Partie n'eft qu'une copie un peu défigurée de celle de M. Delille.

Le Lac Superieur, le plus grand \& le plus confidérable de ceux, que nous connoiffons dans l'Amérique, n'eft pas bien fur toutes les Cartes, \& l'on peut voir du premier coup d'œil, combien j'y ai fait de changemens. Les Mémoires particuliers, qui font au Dépôt, m'ont donné les moyens de le repréfenter un peu plus fidelement, qu'on ne l'a vạ jufqu’à préfent. Cependant je crois, qu'il faut attendre encore d'autres éclairciffemens, car toutes les Parties ne m'en paroiffent pas également conftatées ; mais c'eft toujours beaucoup pour la Géographie de ces Pays-là , que de commencer à fe développer. Il eft inutile de remarquer, que les François font les feuls, qui puiffent donner des connoiffances fideles de ces Lacs; les noms des Ifles, qui y font répanduës, \& des Rivieres, qui s'y déchargent, qui iont les unes \& les autres en grand nombre, font voir que ce n'eft qu'à nos Voyageurs, \& fur-tout aux Miffionnaires, qu'on eft redevable de leurs découvertes.

Avant que de quitter la Carte des Lacs, il eft bon d'obferver, que j’ai donné plus de 21 . dégrẻs de longitude depuis l'entrée du Lac Ontario jufqu'au fond du Lac Superieur; je crois que c'eft un peu trop: c'eft le détail des routes \& l'eftime des Voyageurs, qui m'ont jetté $f$ fort vers l'Oueft. J'ai remarqué que dans tout le Canada les lieuës font très - petites, la difficulté des chemins en eft fans doute la caufe : d'ailleurs le nombre de détours, qu'il faut faire en remontant une Riviere, ou en côtoyant un Lac, augmentent de beaucoụp Le chemin, fans augmenter les diftances. Ainfi il n'eft point étonnant que le Géographe, qui a fuivi fes Itinéraires, ne fe trouve trop d'étenduë, lorfqu'il veut rapporter fa Carte au

(a) Leireur eft dans le mot de profon- aufi,que la Baye ne fuịe pas tonjours le mêdeur, au lieu duquel il faut dire de circuit; car l'Auteur fçait très-bien, que s'il avoit été tourne au Midi, \& alors il n'y auta poin: obligé de faire le tour de certe Baye, il luj au- | d'erreur.

roir fallu faire trente lieuis. Il fe peut faire 
Ciel , c'eft - ̀̀ - dire, y marquer les latitudes $\&$ les longitudes. Le feul moyen d'y remédier, eft d'avoir quelques Obfervations de latitudes \& de longitudes. Ce font des Points fixes, dont la Géographie ne peut fe paffer, \& $f_{a}$ perfeetion dépendra toujours du nombre de ces fortes d'Obfervations.

Il ne me refte plus quà dire un mot fur la Carte de l'Amérique Septentrionnale, que jai mife à la tête de cet Ouvrage. On auroit peut-être fouhaité de trouver ici une grande Carte, où toutes les Parties euffent été plus fenfibles, \& mieux développées ; \& j’aurois été bien plus fatisfait, fi j’avois pû la faire: mais on a vû les raifons, qui m'ont forcé de me borner aux grandeurs convenables à un in-quarto \& un in-douze. Il ne faut donc regarder cette Carte, que pour y voir la fituation, que les diverfes Parties, que nous avons données féparément, ont entr'elles, le tout, qu'elles forment fur le globe de la Terre, \& leur rapport au Ciel. Cependant je puis dire que, quoiqu'à petit point, \& par conféquent peu fufceptible de ce détail, elle mérite quelque attention, tant par les chofes neuves, qui s'y trouvent, que par les corrections, qu'on a faites fur les précédentes.

$1^{\circ}$. Le Golphe du Mexique \& les Inles de l'Amérique y font affujettis à plufieurs Obfervations fûres de longitude $\&$ de latitude. Les Journaux des Navigateurs mont fourni le gifement des Côtes $\&$ des Ifles de proche en proche; de forte que je fuis en état de prouver la jufteffe de la plâpart des pofitions. Ainfi qu'on ne foit pas furpris de trouver cette Partie de ma Carte fi différente de tout ce qui a paru, $\&$ fur-tout de celle de $\mathbf{M}$. Popple. Je n'ai point envie de faire la critique de cette derniere, je remarquerai feulement, qu'entre Carthagene 8x.Portobelo, elle marque 6 . degrés de longitude, \& qu'il n'y en a que 4 . \& 10. minutes au plus. C'eft afûrément une grande erreur en Géographie, que de mettre I 20. lieuës d'un endroit à un autre, lorfqu'il n'y en a guere plus de 80 . La Havane y eft par les 83. degrés 10. minutes du Méridien de Londres, ce qui revient à 85 . degrés, 35 . minutes, du Méridien de Paris. L'Obfervation Aftronomique, qui y a été faite., la détermine à 84 . degrés, c'eft un degré 35 . minutes de différence. L'Ifle de S. Domingue n'a qu'environ 100 . lieuës de longueur de l'Ifle à l'Oueft, la Carte de Popple y met 130 . 
xvj REMAR Q UES DE M. BELLIN

lieuës. Elle donne à l'Ifle de Cuba 240. lieuës de la pointe de Mefy au Cap Saint Antoine, \& il n'y en a que 200. au plus. La Vera-Cruz, au fond du Golphe du Mexique, eft déterminée par Obfervation Aftronomique à 100. degrés à l'Occident du Méridien de Paris. Cette Carte met la Vera-Cruz par les ror. degrés du Méridien de Lonáres, ce qui revient au 103. degrés 25. minutes, de celui de Paris. Enfin je ne finirois point, fi je voulois relever toutes les erreurs, qui fe font gliffées dans cette Carte fur le Golphe du Mexique, \& les Inles de l'Amérique. Un de mes étonnemens, c'eft qu'un de nos plus habiles Géographes fe foit laiffé prévenir en faveur de cette Carte, au point de publier une Copie de cette Partie, quill a prétendu rendre à l'ufage des Navigateurs, où il a laiffé fubfifter toutes les fautes mêmes les plus préjudiciables à la navigation, lefquelles, avec le moindre examen, ne pouvoient manquer de fauter aux yeux d'un Homme de l'art。

$2^{\circ}$. La Louyfiane \& le cours du Fleuve Miciffipi auroient merité un tout autre détail, que celui, qu'il ma été poffible de faire entrer dans une Carte générale ; \& je m’y ferois livré avec d'autant plus de plaifir, que j’ai beaucoup de matériaux à pouvoir mettre en ouvre : mais comme cela m’auroit jetté un peu loin, \& auroit multiplié les Cartes, je me fuis contenté de charger en quelques endroits ma Carte générale, de façon, qu'on y trouvât ce qui m’a paru de plus intérefflant $\&$ de plus néceffaire à l'intelligence de l'Hiftoire. J'ai fait plus ; jai donné quelques morceaux particuliers , que j’ai cru devoir faire plaifir au Public. Par exemple, on trouvera une Carte d'une partie de la Côte de la Louyfrane \& de la Floride, depuis la Nouvelle Orleans jufqu'à Saint Marc d'Apalache, une petite Carte des embouchures du Miciffipi, un Plan dé la Nouvelle Orleans, \& un de la Baye de Penfacole.

Les Obfervations Aftronomiques, qui ont été faites à la Nouvelle Orleans \& à l'Ifle Dauphine, m'ont fervi à placer la Côte de la Louy fiane par fa véritable latitude \& longitude.' M. Baron nous a donné celle de la Nouvelle Orleans par 92. degrés 16 . minutes, à l'Occident du Méridien de Paris. Et la Société Royale de Londres nous domne celle de l'thle Dauphine, de 90. degrés 25. minutes. Cette derniere eft fort différente de celle, qui réfultoit des Obfervations Aftronomiques 
miques, que le Pere Laval y avoit faites en $1720, \&$ qui étoit de 103 . degrés. Mais on a f̧̧u depuis, que l'erreur venoit du dérangement de fa pendule, ce qu'il ignoroit alors ; erreur, dont M. Delille s'apperçut par fes détails géographiques, \&c fur laquelle il donna un fort bon Mémoire, qui eft inféré dans les Mémoires de l'Académie de l'année i 726 . Cependant M. Delille n'avoit point alors d'Obfervations immédiates, comme nous les avons aujourd'hui ; \& voilà pourquoi dans fa Carte de la Louyfiane, quil a publiée en 1718. il a mis la Nouvelle Orleans par 94. degrés 15 - minutes, à l'Occident du Méridien de Paris, c'eft-à-dire, 2. degrés trop à l'Occident. I.a Carte de Popple la met par 93. degrés 40. minutes, du Méridien de Londres, qui revient au 96. degré 5 . minutes, du Méridien de Paris erreur bien plus confidérable, \& qui ne fe peut excufer dans M. Popple, qui devoit avoir connoiffance, en dreffant fa Carte, des deux Obfervations Aftronomiques, que nous venons de rapporter.

Je ne parlerai point du détail de la Côte depuis la Nouvelle Orleans jufqu'à Saint Marc d'Apalache, que j’ai tiré de nos meilleurs Navigateurs, \& fur-tout du Journal du R. P. de Charlevoix : on verra que j’ai profité des Remarques, qu'il a eu occafion de faire fur plufieurs endroits de cette Côte, dont avant lui on n'avoit prefque point de connoiffance. II nous fait connoître, par exemple, l'Ifle des Chiens, à 10. lieuës de Saint Marc d'Apalache ; \& le paffage, qui eft entre la Terre ferme \& cette Ifle, laquelle a 9 . a 10 . au moins de longueur, ce qui n'eft marqué fur aucunes Cartes.

J'aurois beaucoup de chofes à dire fur ces vaftes Contrées, qui font à l'Orient \& à l'Occident du Fleuve Miciffipi ; fur les Rivieres, qui les arrofent; les Nations, qui les habitent; les Voyageurs, qui les ont parcouruës; \& t la maniere, dont les Cartes nous les repréfentent. Mais cela demanderoit une Differtation particuliere, \& je fuis obligé de finir celle-ci, qui n'eft déja que trop longue : peut-être quelque jour aurai-je occafion de travailler fur cette Partie, \& de m'étendre autant que le fujet me paroît l'exiger. Cependant avant que de finir, il faut néceffairement dire un mot fur les Pays, qui font à l'Oueft \& au Nord de nos Lacs du Canada, dont la Géographie eft très-imparfaite, pour ne pas dire entierementignorée. Il n'eft pas douteux, fẹlon moi, qu'à l'Occident du $\mathrm{Ca}$ Tome III. 


\section{xviij R E M A Q UES DE M. B E L L I N}

nada, on ne trouve la Mer, qui fépare cette Partie de l'Amérique de l'Afie, que nous nommons $M e r$ de l'Oueft, mais qui eft proprement la Mer du Sud; \& j'ai lieu de croire qu'elle n’eft pas éloignée de plus de 300. lieuës du Lac Supérieur. II eft même prefque certain qu'il y a une fuite de Lacs \& de Rivieres, par lefquelles on peut communiquer du Lac Supérieur avec cette Mer.

Ce n'eft pas d'aujourd'hui, que l'on a raffemblé diverfes conjectures, qui fembloient prouver l'exiftence \& la découverte d'une Mer dans cette Partie : il ne faut que voir ce que dit Gomara (liv. 6. chap. 18.) des Efpagnols, qui virent la Mer, quand ils furent à Quivira, \& qui apperçurent même des Vaiffeaux fur la Côte. Jean de Laët, ( chap. du Nouveau Mexique ) parlant du voyage de Vafq Coronat, dit que les Habitans de Cibola, qui font un peu à l'Occident du Nouveau Mexique, vont querir des cuirs de Bœufs à huit journées de chez eux du côté du Nord; \& Ramufio, ( tom: 3. pag. 359.) qui rapporte auffi ce voyage, dit que les Plaines, dans lefquelles ils les vont querir, font du côté de la Mer. Witfliet, (dans fa Defcription du Nouveau Monde, au titre Quivira \& Anian) marque une Mer au Nord de la Californie, \& du Nouveau Mexique, ajoûtant que les Côtes de Quivira ne font connuës, qu'en quelques endroits, parce qu'elles font hors de toutes les routes des Navigateurs. Nicolofi, dans fon Hercule Sicilien, marque auffi une Mer au Nord du Nouveau Mexique: j'ignore fur quels Mémoires cet Auteur a travaillé, mais je fçai qu'il a eu communication de ceux, que l'on envoye à la Congrégation de la Propagande. On peut encore voir ce que dit Purchas fur cette Mer, (tome 3. de fes navigations. ) Joignez à ces diverfes Relations, celle du voyage de Martin d'Aguilard, \& de l'entrée, qu'il découvrit au Nord de la Californie. De tout cela il me paroît, qu'on doit hardiment conclure l'exiftence d'une Mer au Nord de la Californie \& du Nouveau Mexique , \& par conféquent à l'Oueft du Canada.

Je pourrois encore rapporter les connoiffances, que nos Voyageurs François \& des Miffionnaires ont eu de cette Mer par leur Comm rce avec les Sauvages; mais cela feroit trop long. Il fuffit que l'on fçache que c'eft de quelques Mémoires particuliers, \& qui ne font point encore publiés, que jaj 
tiré les noms \& les fituations de ces Rivieres \& de ces Lacs, que j'ai marqués à l'Oueft du Lac Superieur, \& fur lefquels jattends des éclairciffemens. A l'égard du Lac des Affiniboils \& de celui des Criftinaux, les Relations, que l'on en a, font très-incertaines, pour ne pas dire fabuleufes : \& il me paroît, que c'eft auffi le fentiment du Révérend Pere de Charlevoix, page 184. de fon Journal, où il parle du Pays des Affiniboils. Cependant je n'ai pas laiffé de les marquer, les ayant trouvés fur une Carte manufcrite du Sieur Franquelin, dont j’ai parlé ci-devant, \& qui devoit connoitre ces Parties, mieux que perfonne. Ainfí l'on y ajoûtera telle foi , que l'on jugera à propos $(a)$.

(a) L'Auteur de l'Hiftoire \& du Journal a de bonnes raifons de croire que ce n'eft point par cette route, que l'on ira plus furement \& plus promptement $\dot{a}$ la Mer, dont il s'agir. Il s'en eft expliqué en plufieurs en: droits de fon Journal, \& il apporte de bon: nes preuves de ce qu'il avance.

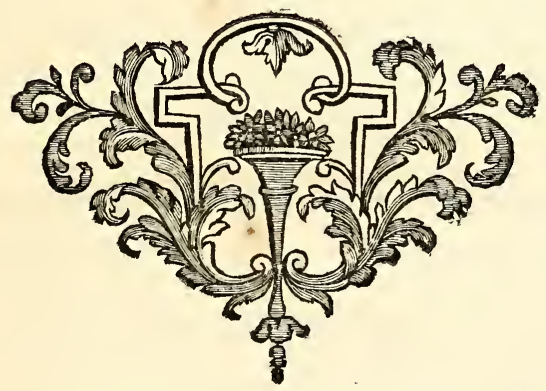


TABLE DES SOMMAIRES. 


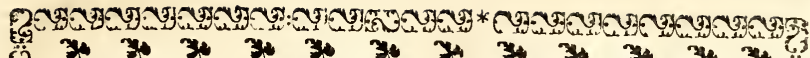

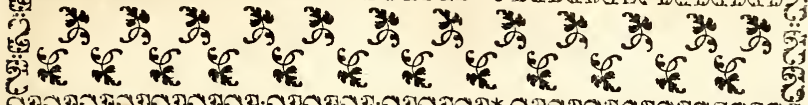
ก

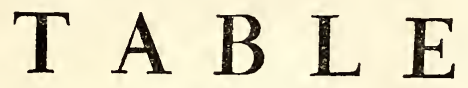

\section{ES SO M M A I E S}

POUR LE TROISIE'ME VOLUME.

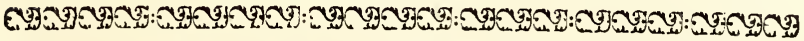

\section{DISSERTATION PRELIMINAIRE}

Sur l'Origine des Ameriquains.

ENTIMENS de plufeurs fçavans Auteurs, qui ont traité plus au long cette Queftion. Ce que Jean de Laet penfe de celui du Pere de Acofta, de ceux de Lefcarbot, de Breverood, $\mathcal{E}$ de Grotius. Ses démélés avec ce Dernier. Son fentiment particulier. Ce qu'il dit de celui de Moraez. Sentiment de George de Hornn. A quoi fe doit réduire la Queftion propofée, E comment on peut $y$ répondre.

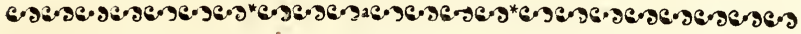

J O UR N A L D' U N VOY A GE

dans l'Amerique Septentrionale.

\section{LETTRE PREMIERE.} OYAGE de Paris à Rochefort. Danger, que courut l'Au-
teur fur la Loire.

Tome III. 


\section{E T T R E I I.}

'Auteur s'embarque Es met à la voile. Defcription.du grand" 1 Banc de Terre-Neuve. Caufes des vents E des brumes, qui y régnent. Tempête. Des Morues, É de la pếche de ce Poiffon. Combat de la Baleine Es de l'E fpadon. Du Flettan. Erreur des Pilotes, E le danger, oiu elle met le Vaiffeau du Roy. Du $C_{a p}$ de Raze. Des Ifles de S. Picrre. Du Golphe de S. Laurent, E des Ifles aux Oifeaux. Du Cap des Rofiers. De Gafpé, Es de l'entree du Fleuve S. Laurent. Defcriftion de l'Ifle d'Anticofly. Du Saguenay Es de Tadoufac. De l'Ifle aux Coudres, E du Goufre. De la Baye de S. Paul. Des Marées du Fleuve, Ė de la déclinaifon de la Boufóle. De l'Ifle d'Orleans.

\section{E T T R E III.}

Rigine du nom de Quebec. Du Sault de Montmorenci. Situation de Quebec. Defcription de cette Ville, de fes principaux Edifices. L'Evêché, la Cathedrale É le Seminaire. Du Fort, Eु du Cap aux Diamans. Des Recollets E des Urfulines, du College des Jéfuites, de l'Hôtel-Dieu, de l'Hôpital Géneral, des Fortifications, des Habitans de Quebec, différence des Colonies Angloijes Eै Francoifes.

\section{E T T R I V.}

A VENTURE d'un Navire Provençal. Defription de la A Miffion de Lorette. Ferveur des Sauvages. Idées faufjes, qu'on s'eft fait en France du Canada. Fautes, qu'on a faites dans l'Etabliffement de cette Colonie. Mauvaife conduite par rapport au Commerce des Pelleteries. Des Congés, Ė de leurs abus. Divers changemens dans les Monnoyes. 


\section{E T T R E V.}

IF Ference du Caftor du Canada, Es de celui de l'Europe. Du poil du Caftor. Defcription anatomique de cet Amphibie. Du Caftoreum. Du Caftor gras, $\mathcal{E}$ du Caftor fec. Differens ufages du poil de Caftor. Induftrie E travaux du Caftor, fa prévoyance. Des Caftors Terriers. De la Chaffe du Caftor. Quelques particularitez fur cet Animal. Du Rat mufqué.

\section{E T T R E VI.}

ANIERE de courir la pofte en Traîne. Des Seigneuries 11 du Canada. Dudroit de Patronnage. Le Commerce permis aux Gentils-Hommes. Situation de Beckancourt. D'où étoit venu le nom de Riviere puante à la Riviere de Beckiancourt. Du Village des Abénaquis de Beckancourt. Situation de la Ville des Trois Rivieres. Du Lac de S. Pierre. Defcription de la Ville des Trois Rivieres. Origine de fon Etabliffement. Du Cap de la Magdeleine. De la Chaffe de l'Ours. L'Ours paffe fix mois fans manger $\mathcal{E}$ Jans boire. Maniere, dont on chaffe cet Animal. Cérémonize ridicule, qui fe pratique, quand on a tué un Ours. Réception, qu'on fait aux Chafeurs à leur retour, quelques particularitezfur les Ours. Des Chiens de chafje.

\section{E T T R E V I I.}

Es Ifles de Richelieu E de S. François. Du Village des Abenaquis de S. François. Du Suc d'Erable, du Fort de de Richelieu. Autres Forts dans les Paroiffes. Belles actions d'une Dame E्E d'une Demoifelle Canadiennes. Det'Elan, ou de l'Orignal. En quel tems il faut le chaffer. Diverfes manieres de le chaffer. Comment le Carcajou lui donne la chalfe. Du Cerf $\mathcal{E}$ du Caribou. De la chaffe du Bouf. Defcription du Bouf Sauvage, E du Bouf mufqué. Du Chevreuil. Du Loup Servier, $\mathcal{E}$ du Renard. De ce qu'on appelle la menuë Pelleterie. 


\section{E T T R E V I I I.}

Es Ifles de Richelieu. Différence du Pays de Quebec, $\mathcal{E}$ de celui de Montreal. Defcription de l'Ifle de Monte al. Defcription de la Ville. De l'Ifle de Jefus, E de la Riviere des Prairies. Du Sault au Recollet. Des Environs de Montreal. Du Sault S. Louis. Des Iroquois de la Montagne. Défordres caufés par la Traite de l'Eau-de-Vie dans les Villages du Sault S. Louis, \& de la Montagne. De la Foire de Montreal. Calomnie du Baron de la Hontan à ce fujet. De la Pếche du Loup Marin. Defcription du Loup Marin. Ses diverfes efpéces. Ufage de la chair $\mathcal{E}$ de la peau de cet Animal. Particularités des Loups Marins. Des Vaches Marines. Marfouins de deux couleurs. De la Pếche du Marfouin. Des Baleines.

\section{LE T T R E IX.}

Orssons duGo'phe E du Fleuve S. Laurent.Du Lancornet. De la Goberge, de la Truite faumonée. De la Tortuë, $\mathcal{E}$ c. Du Poiffon armé: comment ce Poiffon chaffe aux Oifeaux. Mariage de la Seine. De la Pêche de l'Efturgeon. Poiffons particuliers au Canada. Aigles de deux ejpéces. Perdrix de trois efpéces. Autres Oifeaux. Des Cardinaux. De l Oifeau-Mouche : en quoi il differe du Colibry des Ifles. Du Serpent à Sonnettes. Des Bois du Canada. Des Pins de deux efpéces. Quatre efpéces de Sapin. Deux fortes de Cedres. Des Chênes, Erables, E⿱E⿰c. Arbres particuliers au Canada.

\section{E T T RE X.}

Durcuor on ne connoît en France le Canada, que par Jon mauvais côté. Excès du froid. Ses inconvéniens. Réflexions fur fes caufes. De la Péche des Anguilles. Du paffage 'les Tourtes. Heureufes conditions des Colons du Canada: piufieurs ne fcavent pas en profiter. Bonnes E mauvaifes qualités de ces Créales. 


\section{LETTRE XI.}

E la Bourgade Iroquoife du Sault faint Louis. Ferveur de fes premiers Habitans. Des Habitans de Terre-Neuve. Des Eskimaux. Des Peuples des Environs du Port Nellon. Etenduë de la Nouvelle France. Des Sioux. Des Afjiniboils. Du Lac des AJjiniboils. Des Peuples de la Langue Algonquine. Des Nations Abénaquifes. Des Algonquins inférieurs. Des Sauvages du Nord. Des Algonquins. Des Outaouais. Des Pouteouatamis, $\mathcal{E}$ des autres Sauvages des environs de la Baye. Des Outagamis, des Mafcoutins, E des Kicapous. Des Miamis $\&$ des Illinois. Des Peuples de la Langue Huronne.

\section{LETTRE XII.}

Es Rapides du Fleuve faint Laurent. Réflexions fur $\mathrm{Ca}$ tarocoui, E fur le chemin, qu'on prend pour y aller. Defcription des Canots d'écorce. Du Lac de laint Francois. De l'IJle Tonihata. Defcription du Fort de Catarocoui. Caractere de la Langue Huronne. Caractere de la Langue Algonquine. En quoi different les Peuples de ces deux Langues. Origine de la Guerre, que les Algonquins \& les Hurons ont eu à foutenir contre les Iroquois. Les fuites de cette Guerre.

\section{LETTRE XIII.}

Rute de Catarocouy à l'Anfe de la Famine: Defcription du Pays. Des Vignes du Canada. Defcription de l'Anfe de la Famine. Du flux $\mathcal{E}$ du reflux des Lacs. Pourquoi en $\mathrm{Ca}$ nada les Arbres n'ont point encore de feüllles au mois de May. Maniere de chanter la Guerre parmi les Sauvages. De leur Dieu de la Guerre. De la déclaration de Guerre. Digreffion fur la Porcelaine du Canada. Des Bracelets E des Coliers de Porcelaine. De leurufage. Du Calumet, de fon ufage Es de fon origine. 


\section{LET T R E X I V.}

Esagremens \& incommodités des Voyages en $C_{a-}$ nada. Defcription de la Côte du Sud du Lac Ontario. Motifs, qui engagent les Sauvages à faire la Guerre. De quelle maniere on s'y réfout. Préparatifs du Chef. Déliberation du Confeil. Mefures, qu'on prend pour avoir des Prifonniers. Chants, Danfes, Ef Feftins de Guerre. Idée, que ces Peuples ont du courage; épreuves, où l'on met les Guerriers pour connoître s'ils en ont. Précautions pour les Bleffés. Comment les Miamis fe préparent à la Guerre. Defcription des Raquettes pour marcher fur la neige, Ė des Traînes pour porter le Bagage. Adieux des Guerriers. Leurs Armes offenfives E' deffenfives. Du foin, qu'ils ont de porter leurs Dieux. Defcription de la Riviere de Cafconchiagon, \& de deux Fontaines fingulieres. Defcription de la Baye des Tfonnonthouans, Es de la Riviere de Niagara.

\section{E T T R E X V.}

DRojet d'un Etabliffement à Niagara. Oppofition inutile des Anglois à cet Etabliffement. Defcription du Pays de Niagara. Defcription de la Danfe du Feu. Hiftoire à ce fujet. Autre fait fingulier. Defcription du Sault de Niagara. Obfervations fur cette $C_{a}$ fcade. Circonftances de la marche des Guerriers. Du Campement : de l'entrée dans le Pays Ennemi. Des approches $\mathcal{E}$ de l'attaque. De la maniere de combattre. Infinit des Sauvages pour connoître les traces de leurs Ennemis. Des fignes, qu'on laiffe de la Victoire. Précautions pour afuürer la Victoire, $\mathcal{E}$ pour garder les Prifonniers. Comment on annonce la Victoire dans les Villages.

\section{LET TRE X V I.}

7 REMIERE réception des Prifonniers. Leurs bravades. $C_{e}$ qu'on leur fait fouffrir à leur entrée dans le Village. Diftribution, qu'on en fait. Comment on décide de leur fort. De l'a- 


\section{DES SO M M A R E. S.}

doption d'un Captif. De ceux, qui font deftinés au feu. Principes de la barbarie, qu'on exerce envers eux. Courage d'un Capitaine Iroquois brûlé par les Hurons. Habileté des Sauvages dans leurs négociations.

\section{E T T R E X V II.}

Escription du Lac Erié. De la Côte Septentrio. nale de ce Lac. Agrémens de ces Voyages. Des Cédres blancs E rouges. Arrivée au Détroit, de la nature du Pays. Des Sauvages établis auprès du Fort du Détroit. Confeil de trois Nations chez le Commandant du Détroit. Quel en fut le réfultat. En quelle difpofition l'Auteur trouve les Hurons du Détroit. Réception, que lui font les Pouteouatamis. Du Jeu du Plat, ou des Offelets. Ujage fuperftitieux de ce Jeu pour la guérifon des Malades. De l'herbe à la Puce, $\mathcal{E}$ de fes effets. Des Citrons du Détroit.

\section{LETTRE XVIII.}

DOvirevor les Sauvages font plus aifés à convertir, que les Nations policées. Idée générale de leur Gouvernement. Divifion des Nations en Tribus. Obfervation fur les noms des Chefs. De la fucceffion E de l'élection des Chefs. De leurs pouyoirs. Des Affitans, ou Confeillers. Du Corps des Anciens. Des. Chefs de Guerre. Pouvoir des Femmes dans quelques $N_{a}$ tions. Sagefje des Confeils. Des Orateurs. Des intérêts de ces Peuples. Politique des Iroquois. Du gouvernement des Villages. Ses défauts. Principes de ces défauts. De quelle maniere les Fiurons puniffent l'A Afafinat. Punition des Magiciens. Réglement pour les chofes trouvées. Trait. Iingulier à cette occafion. Combien les Sauvages font fenfibles au point d' honneur. 


\section{E T T R E X I X.}

FPa R $T$ du Détroit. Soin, que les jeunes Sauvages pren-
nent de fe parer. Defcription de la Côte Occidentale dut Lac Huron. Situation de Michillimakinac. Defcription du Lac fuperieur. Fable des Sauvages touchant ce Lac. Mines de Cuivre. Traditions des Sauvages fur Michillimakinac. Abondance de la Pếche dans ce Canton. Des Ifles $\mathcal{E}$ de la Nation du Caftor. Du Mariage des Sauvages. De la pluralité des Femmes, des degrez de parentés, qui empếchent les Mariages. Loix particulieres touchant les Mariages. Jaloufie des Sauvages. De quelle maniere fe traitent les Mariages. Des Cérémonies du $M a$ riage. Avantages des Meres fur les Peres. Des Accouchemens, $\mathcal{E}$ de leurs fuites. Du foin, que les Meres prennent de leurs Enfans. De l'impofition du nom. Obfervation à ce fujet.

\section{E T T R E X X.}

E la Baye des Noquets. Des Ifles des Pouteouatamis. Des Malhomines, ou Folles Avoines. Des Peuples appellés Puants. Du Fort É de la Miffron de la Baye. EJpagnols défaits par des Sauvages du Miffouri. Confeil des Sakis, E à quel fujet. Danfe du Calumet. Danfe de la Découverte. Des Traités, qui fe font par le moyen de la Danfe du Calumet. Autres Danfes. Danfes ordonnées par les Médecins. Superftitions des Peuples voifins de la Baye. Diverjes Nations au Nord Ė àl'Oueft.

\section{E T T R E. X X I.}

B Bervation fur les Courans des Lacs. Portrait des Sauvages. Leur force, leurs vices: pourquoi ils ne fe multiplient pas. Avantages, qu'ils ont fur nous. Leur mémoire, leur pénétration, Ė leur jugement. Leur grandeur d'ame; leur sonftance dans les douleurs: leur valeur. Les égards, qu'ils ont les uns pour les autres. Leur fierté E leurs autres défauts. Des qualités 
DES SOMMAIRES.

qualités du cour. Du peu de naturel des $E$ nfans pour leurs $P a-$ rents. Societés particulieres de deux Sauvages. De la couleur de ces Peuples.Pourquoi ils n'ont point de poil fur le corps.

\section{E T T R E X X I I.}

ANGER de la navigation du Lac Michigan. Obfervation fur les Rivieres, qui s'y déchargent du côté de l'Orient. Riviere du Pere Marquette. Aventure arrivée à l'Auteur dans la Riviere de, Saint Jofeph. Du Gin-Seng du Canada. Du Févier É du Safafras. Secret des Sauvages fur les Simples E. fur les Mines de leur Pays. Du Jeu des Pailles. Autres Jeux. Suites funeftes de l'yvrognerie. Bonheur des Sauvages. Mépris, qu'ils font de notre maniere de vivre. Du foin, que les Meres prennent de leurs Enfans. Figures ridicules, que quelques-unes leur donnent.

\section{E T T R E X X I II.}

CE qui fortifie les Sauvages, $\mathcal{E}$ les rend fi bien-faits. Leurs premiers exercices, $\mathcal{E}$ leur émulation entr'eux. A quoi $f e$ réduit l'éducation, qu'on leur donne. Leurs pafjons. Leur habillement. Comment $\mathcal{E}$ pourquoi ils fe peignent \&ै Je picquent le corps \& le vifage. Ornemens des Hommes: ornemens des Femmes, leurs occupations. De la culture des Terres. Des femences $\mathcal{E}$ des recoltes. Des différens grains $\mathcal{E}$ légumes, que les Sauvages cultivent, de leur façon de les accommoder, de leurs autres vivres. Ouvrages des Hommes $\mathcal{E}$ des Femmes. De leurs outils. Forme de leurs Villages. Leur maniere de fe fortifer. De leurs hyvernemens, $\mathcal{E}$ de ce qu'ils y ont à fouffrir. Leur malpropreté. Incommodité de l'Eté. Portrait en racourci des Sauvages.

\section{LETTRE X XIV.}

Es Traditions des Sauvages. Origine des Hommes felon eux. Ce qu'ils entendent par les Ejprits. Des bons \& des mauvais Génies. Difpofitions requifes pour avoir un Génie tutéTome III. 
laire. Ils en changent quelquefois, \& pourquoi. De leurs facrifices. Des jeûnes, des vœux. Rapport des Sauvages avec les Hébreux. Leurs Prêtres. Ce qu'ils penfent de l'immortalité de 'Ame. Leur idée fur ce qu'elle devient, quand elle eft féparée du corps. Pourquoi on porte à manger fur les Tombeaux. Préfens, qu'on fait aux Morts. Du Pays des Ames. Comment ils prétendent qu'on mérite d'être éternellement heureux. Des Ames des Bêtes. De la nature des Songes felon les Sauvages. Hiftoire à ce fujet. Maniere, dont on fe débarrafje d'un rêve, quand il en. coûte trop pour y fatisfaire. Defcription de la Fête des Songes.

\section{ETTRE X X V.}

Es mauvais Génies, É des Sorciers. Des Jongleurs : leurs preftiges. De la Pyromancie. Inftallation des Jongleurs. Des Prêtres. Maladies ordinaires parmi les Sauvages, UJage, qu'ils font de leurs Simples. Divers autres remedes. De la Sueur. Principes, fur quoi roule la Médecine des Sauvages. Idée extravagante fur les Maladies. Impofture des Jongleurs. Leur cruauté à l'égard des Malades défefperés. Des Autmoins de l'Acadie.

\section{E T T R E X X V I.}

EPART du Fort de lä Riviere de Saint Jofeph. Des Sources du Theakiki. Ce qui fe paffe à la mort des Sauvages. Leur générofité à l'égard des Morts. Des Funérailles. Des Tombeaux. Des Revenans. Diverfes pratiques au fujet des. Morts. Ce quit fe paffe aprés l'Enterrement. Du Deuil. Du Veuvage, Ė des Secondes Nốces. Idée des Sauvages fur ceux, qui meurent de mort violente. De la Fête des Morts.

\section{LET T R XXVII.}

EsCRiption du Theakiki. De la Riviere des Illinois. Réception des Prifonniers parmi les Illinois. Maniere, dont ils les brûlent. Particularités jur les $P$ artis de Guerre. Chant 
lugubre des Illinois. Des Perroquets de la Louyfane. Du Village de Pimiteouy. L' Auteur fe trouve entre quatre Partis ennemis. Son embarras. Hiftoire finguliere du Chef de Pimiteouy. Maniere, dont les Illinois pleurent les Morts. Attentions du Chef pour la füreté de l'Auteur, qui baptife fá Fille.

\section{E T T R E X X V I I I.}

TNDUSTRIE des Sauvages pour furprendre leurs Ennemis. Cours de la Riviere des Illinois. Son entrée dans le Micifipi. Village des Tamarouas. Des Mines de la Riviere Marameg. Defcription des Kaskaskias. Arbres Fruitiers de la Louyfiane. Differens Peuples établis fur le Miffouri $\mathcal{E}$ aux"environs. Defcription du Micifipi au-deffus des Illinois. Differentes Tribus des Illinois. Tradition du Péché de la premiere Femme, E du déluge. Idées des Sauvages fur les Aftres. Comment ils connoiffent le Nord, quand le Ciel eft couvert. Ce qu'ils penfent des ECclipfes $\mathcal{E}$ du Tonnerre. Leur maniere de divifer le tems.

\section{E T T R E X X I X.}

TTILITÉ du Pofte des Illinois. Froid extrême. Maniere de naviger fur le Miciffipi. Pourquoi les Feuilles tombent fz tôt $E$ pouffent fi tard aux Arbres de la Louyfiane. De la Riviere Ouabache. Mines de Fer. Chats fauyages. Noyers, E leurs Proprietés. Marques des Guerriers. Des Chicachas. Riviere des Chicachas. Forêts de la Louyfane. Riviere des Akanfas. Différentes Tribus de ces Sauvages. Conceffion de M. Law. Mortalité parmi les Akanjas.

\section{LETTRE XXX.}

E la Riviere des Yafous. Du Fort des François fur cette Riviere. Des Caïmans. Conce fron mal placée. Goufre, Carriere. Defcription du Pays des Natchez. Succés du Tabac dans ce Canton. Cotton, Indigo. Defcription du grand Village \& du Temple des Natchez. Particularités fur cette Nation. Du 
Grand Chef, ou Soleil, E्E de la Femme-Chef. Ce qui arrive à leur mort. Mours des Natchez: Leur Police. Defcription dune Fête. Premices offertes dans le Temple. De leurs Mariages. De la levée des Soldats, des Provifions. Des.Marches $\mathcal{G}$ des Campemens. Comment les Prifonniers font traités. Changement de noms. Récompenfe des Guerriers. Des Jongleurs. Du Deuil. Des Traités. Audience donnée aux Ambafjadeurs. Religion du Feu dans toute la Floride.

\section{LETTRE XXXI.}

ESCRIPTION de la Nouvelle Orleans. Miffronnaires aux $N$ atchez fans fruit. Les Francois dépourvîs de fecours Spirituels aux Natchez. Defcription de la Baye \& du Village des Tonicas. Du Chef des Tonicas. Etat de cette Nation. De la Riviere Rouge. Conceffions mal placées. Seconde Pointe coupée. Autres Conceflions en mauvais état. Obfervations. Des Bayagoulas, des Oumas, des Chetimachas, des Colapiffas. $\mathrm{Au}$ tres Conceffrons. Des Taenfas, des Chapitoulas.

\section{LETTRE XXXII.}

Emareves fur la fituation de la Nouvelle Orleans.Terres Rouvelles, É changemens arrivés à l'embouchure du Fleuve. Etat de la Nouvelle Orleans. Des Chaouachas. Des Paffes du Micifipi. De l'Ifle Touloufe, ou de la Balife. Salines. Defcription des Embouchures du Micifipi. De la principale Embouchure du Micifipi : des autres Pafjes. Moyen de creufer la principale. Où il faut placer les Habitations. Difficulté de naviger Jur ce Fleuve. D'où vient l'idée peu jufte, qu'on a en France de la Louy fiane.

\section{LETTRE X X XIII.}

RRIDÉE au Biloxi. Defcription de la Côte, de la Rade; A E de ce Pofte. De la Ca Jine, ou Apalachine. De la Cire de Myrthe. De la Riviere de la Maubile. De la Baye de Saint 
Bernard. Les Francois y font prévenus par les Efpagnols. Départ du Biloxi. Obfervations fur cette Côte. Tempête \&ै Jes fuites funeftes: Du Lac de Pontchartrain. L'Auteur s'embarque fur l'Adour. Ce Navire mal gouverné. Difficulté de naviger fur le Micifipi en le defcendant.

\section{E TTRE X X X I V.}

T'ADovr met à la Voile. Obfervation fur l'Eaudu MicifJipi. Defcription de la Côte Septentrionnale de l'Ifle de Cuba. Mauvaife manouvre faite fur $l$ 'Adour. Naufrage de ceNavire. Mefures de l'Equipage pour fe fauver. Sauvages für les Ifles des Martyrs. Ce qui $\int$ e paffe entr' eux $\mathcal{E}$ les François. Les Pafjagers entrent en défiance de l'Equipage. Plufieurs Paffagers fauvés par un coup de la Providence. Embarras caufés par les Sauvages. Qui étoient ces Sauvages. Diffenfion dans l'Equipage. Fermeté des Officiers. Un Navire Anglois tâche en vain 'de jecourir l' $E$ quipage. Defcription des Martyrs. Vifite du Cacique des Sauvages. Autorité de ce Cacique. Il refufe des Guides pour aller à Saint Auguftin. On délibere fur le parti, qu'on doit prendre: on fe divife. Le plus grand nombre retourne au Biloxi. Défefpoir des Matelots. Incommodités de cette Côte de la Floride: les vivres manquent. Deux fortes d' Huitres. Rencontre d'un Equipage Efpagnol, qui avoit aufji fait naufrage. Danger d'étre dégradé Jans refource. Arrivée à Saint Marc d'Apalache. Defcription du Pays. Départ de Saint Marc. Marées du côté de Penfacole. Fauffe allarme. Arrivée à Saint Jofeph. Defcription de ce Pofte. Politeffes du Gouverneur Efpagnol. Départ de Saint Jo/eph. Defcription de la Côte. Canal E Ifle de Sainte Rofe. Arrivée à Penfacole. Etat de ce Pofte. Arrivée au Biloxi.

\section{E T TR E X X X V。}

$D E_{N S A C O L E}$ rendu au $\dot{x}$ Espagnols. Ordre de tranfporter le Quartier Général à la Nouvelle Orleans. Interlope Anglois au Biloxi. Défertions fréquentes dans la Louyfane. Conjpiration découverte. Les Anglois tâchent d'attirer à eux nos Alliés. Départ du Biloxi. Obfervations fur le chaud, E fur les hauteurs. 
Defcription du Port de la Havane. Sort de l'Interlope Anglois. Le Gouverneur de la Havane refufe au Navire Francois la permiffion d'entrer dans fon Port. Defcription de la Baye de Matance. Débouquement du Canal de Bahama. Route, qu'il faut prendre pour aller de-là à Saint Domingue. Erreur des Pilotes. Embarras, où nous jette cette erreur. Quel Parii on prend. Defcription de la grande Caique. Succès inefperé du parti, qu'on avoit pris. Arrivee au Cap François de Saint Domingue.

\section{E T T R E X X X V I.}

DSCRiption du Cap Francois. De la Plaine du Cap. Obfervations. Remarquesfur les Dorades. Départ du Cap. Rencontre d'un Navire Anglois, \& ce qui fe paffe entre ce Capitaine, Es celui du Navire Francois. Arrivee à Plymouth. Defcription de ce Port. Induftrie des Anglois pour furprendre les Forbans. Arrivée au Havre de grace.

Fin de la Table des Sommaires: 



\section{Carte de i'Ocenn Occi.}

Que le R.P. de Charlevoix de la $\mathrm{C}$

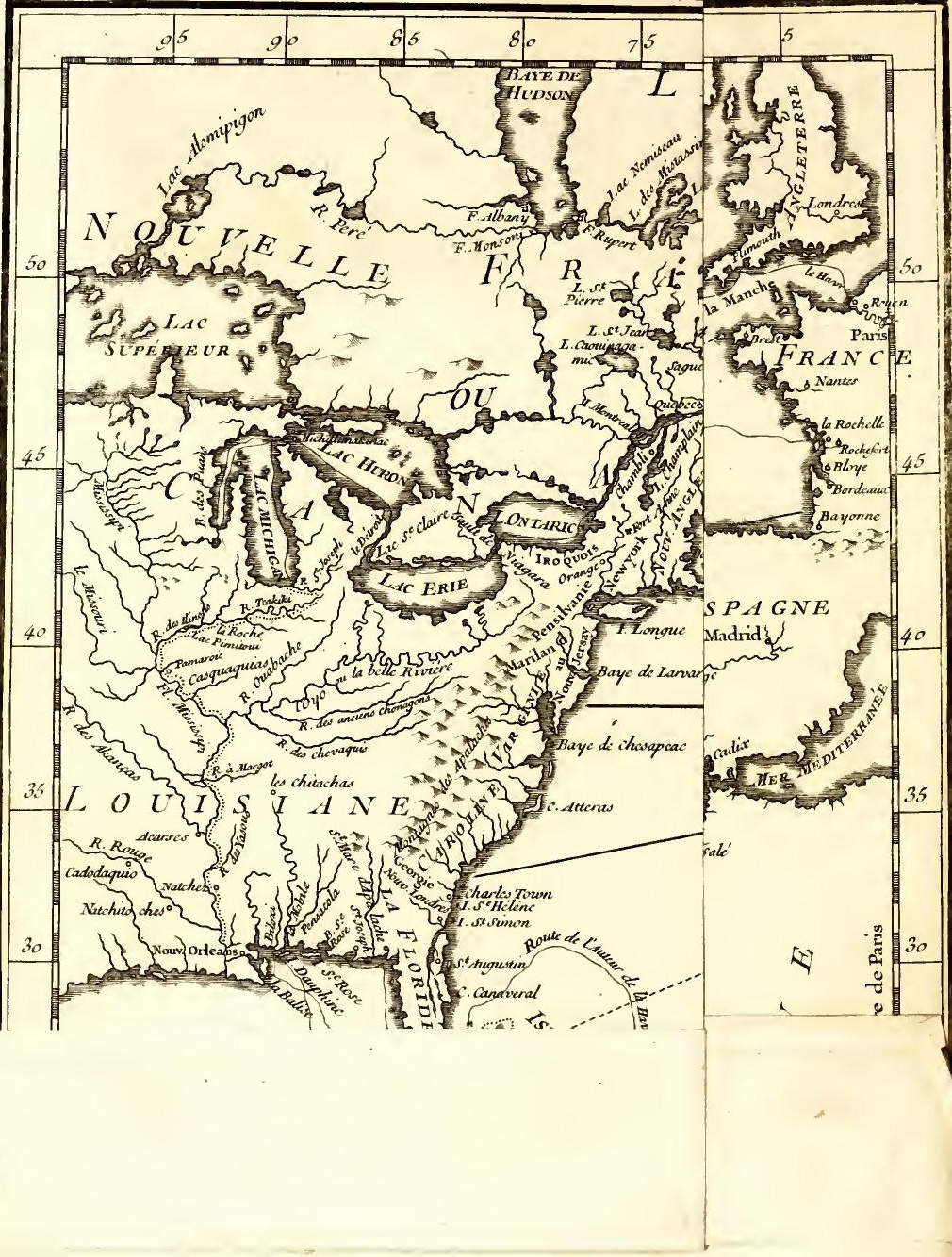




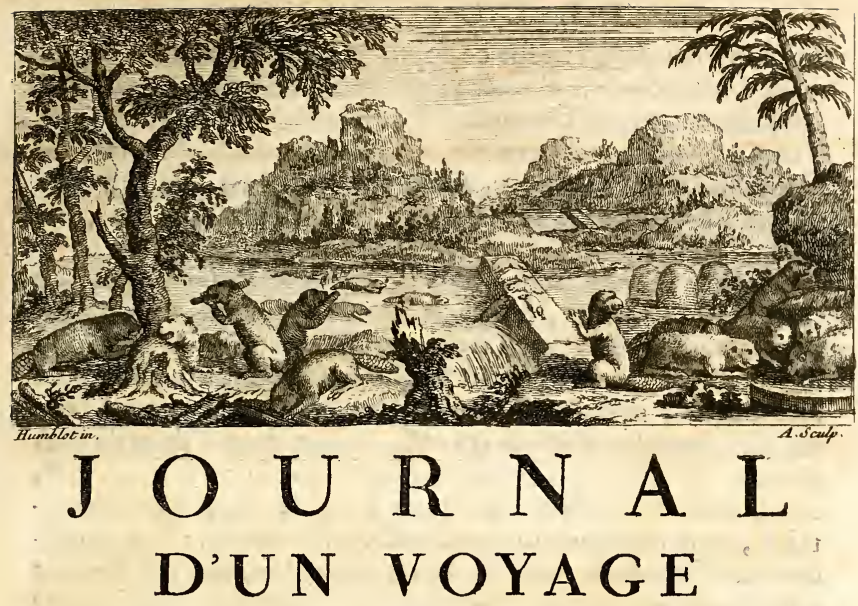

FAIT PAR ORDRE DU ROY dans l'Amérique Septentrionnale;

OUं L'ON TROUVERA LA DESCRIPTION Géographique, \& l'Hiftoire Naturelle des Pays, que l'Auteur a parcourus, les Coûtumes, le Caractere, la Religion, les Mœurs, \& les Traditions des Peuples, qui les habitent.

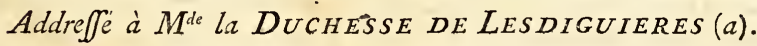

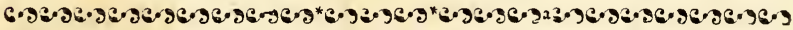
D I S ERTAT I O N P ÉLIM I N A IR E, SUR L'ORIGINE DES AMÉRIQUAINS.

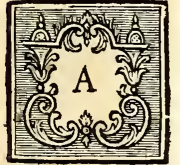

PRE's avoir lû prefque tout ce qui a été écrit fur la maniere, dont l'Amérique a pu être peuplée, il me paroît qu'on eft auffi peu avancé, qu'on pouvoit l'être, avant qu'on eût agité ce :te grande queftion. Cependaat on feroit un jufte Volume, 11 on vouloit feulement rapporter les differentes

(a) Gabrielle-Victoire de Rochechouart Mortemart, morte en 174 $\mathrm{I}$. Tome III. 
Carte de íOcenn Occidental et Partie de l'Amérique Septentrionale dressée pour lintelligence du Journal du Voyage. Que le R.P. de Charlevoix de la Compagnie de Jesus a fait en 1720, au Canada, à la Louisiane, \& à St Domingue. Par N Bellun Ingénicur de la Harine $17+4$

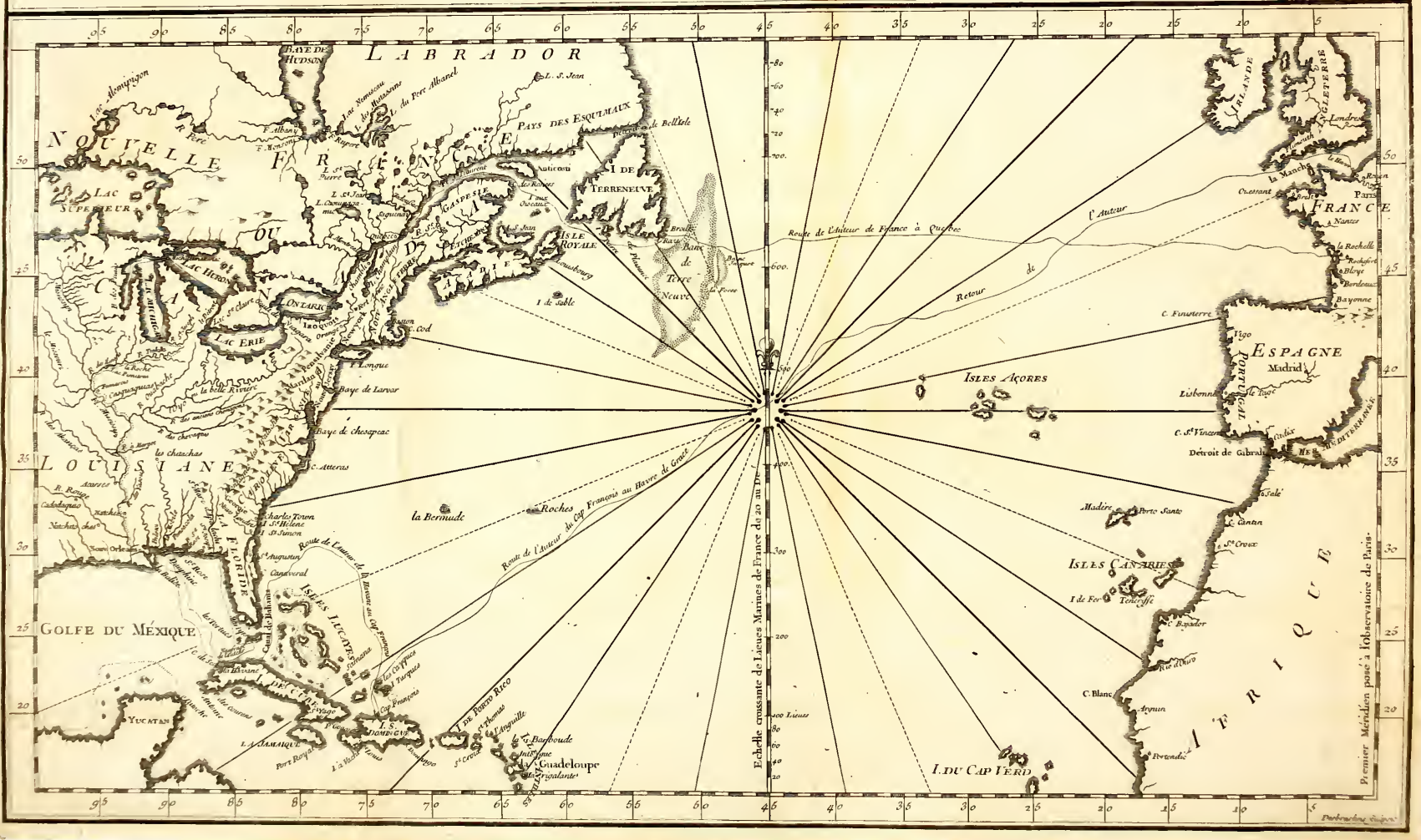




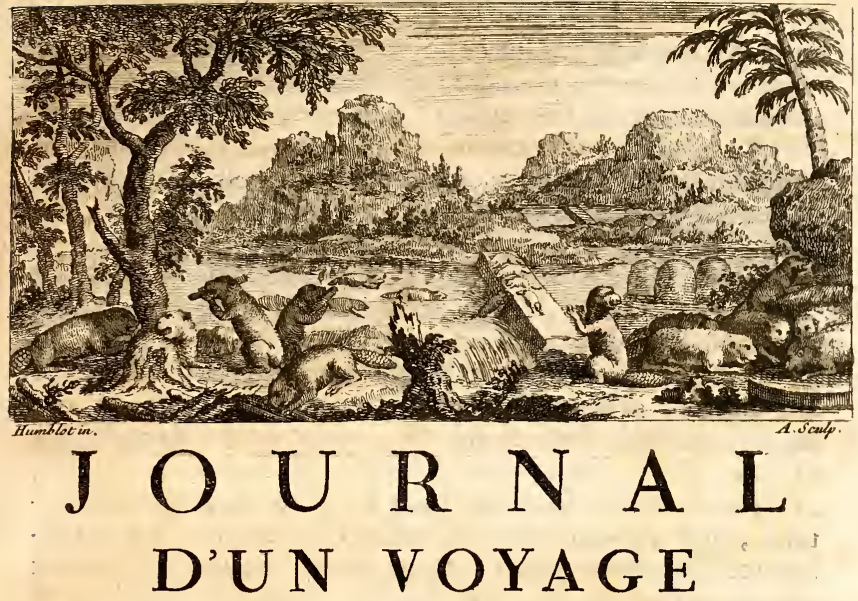

\section{FAIT PAR ORDRE DU ROY}

dans l'Amérique Septentrionnale;

OUं L'ON TROUVERA LA DESCRIPTION Géographique, \& l'Hiftoire Naturelle des Pays, que l'Auteur a parcourus, les Coûtumes, le Caractere, la Religion, les Mours, \& les Traditions des Peuples, qui les habitent. Addrefé à $M^{\text {de }}$ la DUCHESSE DE LESDIGUIERES (a).

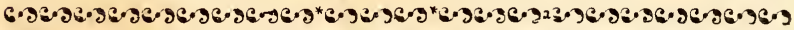
D IS S ERTAT I O P RÉLIM I N A R E, SUR L'ORIGINE DES AMÉRIQUAINS.

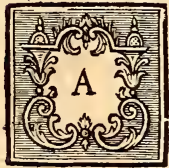

PrE's avoir lû prefque tout ce qui a été écrit fur la maniere, dont l'Amérique a pu être peuplée, il me paroît qu'on eft auffi peu avancé, qu'on pouvoit l'être, avant qu'on eût agité ce :te grande queftion. Cependaat on feroit un jufte Volume, 11 on vouloit feulement rapporter les differentes

(a) Gabrielle-Vittoire de Rochechouart Mortemart, morte en $174 \mathrm{I}$. Tome III. 
opinions des Sçavans fur ce fujet. Mais la plûpart ont tellement donné dans la chimére; prefque tous ont appuyé leurs conjectures fur des fondemens fi ruineux, ou ont eu recours à des convenances de noms, de mœurs, de Coûtumes, de Religion \& de langages, fi frivoles, quil eft, ce me femble, auffi inutile de les réfuter, qu'impoffible de les concilier.

Il n'eft peut-être pas étonnant que les Premiers, qui ont traité cette matiere, fe foient égarés dans une route, qui n'étoit pas frayée, \& où ils marchoient fans guide. Ma furprife eft que ceux, qui ont le plus approfondi la chofe, \& ont eu pour cela des fecours, que n'ạvoient pas ceux, qui les ont précedés dans ce travail, ayent donné dans de plus grands travers encore : ils auroient pourtant pû les éviter, s'ils s'étoient attachés à un petit nombre de principes certains, que quelques-uns ont affez bien établis ; les conféquences fimples \& naturelles, qu'on en doit tirer, fuffifoient à mon avis pour fatisfaire \& fixer la curiofité du Public, que le grand étalage d'une érudition mal placée, \& qui fouvent porte à faux, ne fait que rejetter dans fes premieres incertitudes, C'eft ce que je me flatte de rendre fenfible par le peu, que $j$ 'en vais rapporter.

On fut fans doute fort étonné dans notre Hemifphere, lorfqu'on y apprit que l'on avoit découvert un Nouveau Monde dans l'autre, où jufques-là on n'avoit imaginé qu'une vafte Mer, fur laquelle on ne croyoit pas qu'il fût de la prudence de s'expofer. Cependant, à peine Chriftophe Coroms y eut reconnu quelques Ifles, \& furtout celle, qu'il nomma I'Ifle Efpagnole, où il trouva des Mines d'Or, que lui-même fe perfuada que cette Inle étoit, tantôt l'Ophir de SALOMon, tantôt le Zipangri, ou le Cipango de Marc Pol de Venife. VATABLE \& Robert EstienNe ont cru auffi que c'étoit dans l'Amérique, que Salomon envoyoit fes Flottes chercher de l'or, \& Colomb a cru voir des reftes de fes Fourneaux dans les Mines de Cibao, les plus belles \& les plus abondantes de l'Ifle Efpagnole, \& peut-être de tout le Nouveau Monde.

Arias Mont anus non-feulement a placé Ophir \& $P$ arvaïm dans le Nouveau Monde, mais il donne pour Fondateur à Juktan, Ville chimérique du Perou, JECTAN, Fils d'He e er à l'Empire même du Perou, \& à celui du Mexique, 

ce nom. Il ajoûte qu'un autre Fils du même Patriarche, nommé dans l'Ecriture Jов A B, fut le Pere des Peuples de la Côte de Paria; que la Montagne Orientale Sephar, jufqu'où Moyfe dit que les Enfans de Jectan s'avancerent, en partant de $M e \int f a$, eft la fameufe Chaîne des Andes, qui s'étend du Nord au Sud le long du Perou \& du Chili. L'autorité de ce fçavant Interpréte de l'Ecriture a entraîné dans le même fentiment Postel , Becan , Possevin, Genebrard, \& quantité d'autres. Enfin les Efpagnols ont avancé quau tems de l'invafion de leur Pays par les Maures, une partie des Habitans fe réfugia en Amérique. Ils prétendirent même au quinziéme fiécle y retrouver des Provinces de leur Empire, que le malheur des tems leur avoit enlevées, \& fur lefquelles ils avoient, difoient-ils, des droits inconteftables. Oviedo, un de leurs plus célébres Auteurs, n'a pas craint d'avancer que les Antilles font les fameufes Hefpérides, fi vantées par les Poëtes, que Dieu, en les faifant paffer fous la domination des Rois Catholiques, n'a fait que leur reftituer ce qui leur avoit appartenu trois mil cent cinquante ans auparavant, du tems du Roy Hesperus, de qui elles aroient reçu le nom, qu'elles portoient, \& que Saint Jacques \& Saint Paul y ont prêché l'Evangile : ce qu'il appuye de l'autorité de Saint Gregoire dans fes Morales. Si on ajoûte à cela ce que Platon a dit qu'aude-là de fon Ifle Atlantide, il y avoit un très-grand nombre d'Ifles, derriere ces Ifles un très-vafte Continent, \& derriere ce Continent la vraie Mer, il fe trouvera que le N. Monde n'étoit rien moirs que nouveau pour les Anciens. Et que deviendroit alors l'opinion de THEOPRYRASTE PARACELSE, qui a foûtenu que chaque Hemifphere avoit eu fon Adam ?

Poftel, que j’ai déja cité, \& qui s'eft rendu fameux par fes opinions hafardées, a cru que toute l'Amérique Septentrionnale avoit été peupléelpar les Atlantides, Habitans de la Mauritanie, \& il eft le premier, qui ait féparé tellement les deux Amériques à l'Itthme de Panama, que les Habitans de l'une, felon lui, \& ceux, qui l'ont fuivi, n'ont rien de commun dans leur origine avec les Habitans de l'autre. Mais dans ce cas, $j$ 'aimerois mieux encore mettre, comme a fait BUD B ECKS l'Atlantide dans le Nord, auffi bien que les Colonnes d'Hercules, \& dire que c'eft la Scandinavie, qui a peuplé l'Amé- 
rique Septentrionnale, que d'y envoyer les Maures des Côtes d'Afrique. D'autre part, Gomara \& Jean de Ler y font defcendre tous les Amériquains des Cananéens chaffés de la Terre promife par Jofué: quelques - uns au contraire font paffer par le Nord de l'Afie en Amerique les Ifraëlites, que Salmanazar emmena Captifs dans la Médie. MaisThevet, qui croyoit comme eux que les Ifraëlites ont peuplé le N. Monde, conclut qu'ils fe font répandus par toute la Terre, de ce qu'on a trouvé dans une des Açorres une efpece de Tombeau a vec des caracteres Hébraïques. Cet Auteur n'étoit pas bien inftruit du fait. Ce n'eft pas un Tombeau, qu'on a trouvé dans l'Ifle de Corvo, la plus Septentrionnale des Açorres, mais une Statue Equeftre, montée fur un pied d'eftal, où il y avoit des caracteres, qu'on n'a pu déchiffrer.

Auguftin TORNIEL eftimoit que c'étoit par le Japon, \& par le Continent, qui étoit au Nord de cet Archipel, que les Defcendans de Sem \& de Japhet ont paffé en Amérique, \& de-là dans les Terres, qui font au Sud du Détroit de Magellan. Un Sicilien, nommí Marin $\Subset U S$, fur ce qu'on publia de fon tems qu'on avoit trouvé une Médaille d'Augufte dans une des Mines du Perou, ne douta point que les Romains n'euffent envoyé une Colonie dans ce Pàys-là, comme s'il n'eût pas été plus naturel de croire que quelque Efpagnol avoit laiffé tomber cette Médaille, en vifitant les Mines. Paul Jove a rêvé que les Méxiquains étoient venus dans les Gaules, \& fondoit cette opinion bifarre fur ce que l'un \& l'autre Peuple facrifioit des Hommes à fes Fauffes Divinités. Mais fi cette prétenduë reffemblance pouvoit faire une preuve, n'auroit-il pas mieux valu envoyer au Méxique des Gaulois, qu'on fçait avoir eu de tout tems beaucoup de goût pour les Voyages, \& peuplé un très-grand nombre de Provinces de leurs Colonies?

Les Frifons ont auffi eu leurs Partifans au fujet de l'Origine des Amériquains. Suffridus Petri \& Hamconius ont écrit que les premiers Habitans du Perou \& du Chili étoient fortis de la Frife. Jacques Char Ron \& Guillaume Poftel font le même honneur aux Gaulois; Abraham Milius aux anciens Celtes; le Pere Kir Ker aux Egyptiens; \& Robert LE CомтE aux Phéniciens, chacun à l'exclufion de tous les autres. Je paffe quantité d'autres opinions, beaucoup moins foûtenables encore, \& qui font toutes également fondées 


\section{E S A M E I Q U A I N S.}

fur de fimplesíconjectures, dénuées de vraifemblance, pour venir à ceux, qui ont le plus creufé la matiere.

Le Premier eft le P. Gregorio GAR CIA , Dominiquain Efpagnol, qui après avoir lontems travaillé dans les Miffions du Perou \& du Méxique, imprima en I 607 à Valence un Traité en Efpagnol de l'Orïgine des Indiens du Nouveau Monde ; où il rapporte \& difcute un très-grand nombre d'opinions diverfes fur ce fujet. Il propofe chaque opinion, comme on fait une Queftion en Philofophie : il nomme fes Auteurs \& fes Partifans, il apporte leurs preuves, il répond aux objętions, \& ne décide point. Il y a joint les traditions des Peruviens, des Méxiquains , \& des Infulaires d' Hä̈ti, qui eft l'Ine Efpagnole, \& qu'il avoit apprifes fur les lieux mêmes. Il dit enfuite fon fentiment, qui eft que plufieurs Nations differentes ont contribué à peupler l'Amérique : il auroit pu s'en tenir là. Ce fentiment a quelque chofe de plus, que de la vraifemblance, \& il devoit, ce femble, lui fuffire de l'appuyer, comme il fait, de quelques preuves tirées de la varieté des Langues, des Caracteres, des Coûtumes, \& des Religions, qu'on a remarquée dans les differentes Contrées du Nouveau Monde. Mais il en admet un fi grand nombre de celles, dont les Auteurs des autres opinions avoient fait ufage, qu'il affoiblit la fienne, en voulant la fortifier. En 1729 Dom André Gonzalez de BAR cra fit réimprimer à Madrid l'Ouvrage de ce Religieux, confidérablement augmenté ; mais en y ajoûtant beaucoup d'érudition, il n'a pas mis fes Lecteurs plus en état de prendre leur parti.

Le Second eft le Pere Jofeph de Acosta, Jefuite Efpagnol, qui a auffi paffé une grande partie de fa vie dans l'Amérique, $\&$ duquel nous avons deux excellens Ouvrages; l'un en Caftillan, intitulé : Hiftoria Natural y Moral de las Indias; l'autre en Latin, fous ce titre: De promulgando Evangelio apud Barbaros, fivè de procurandâ Indorum Salute. Cet Auteur, dans le Premier Livre de fon Hiftoire, après avoir rapporté le fentiment de Parmenide, d'Aristote, \& de Pline, qui ne croyoient pas qu'il y eut des Hommes entre les deux Tropiques, ni qu'on eût jamais navigué à l'Occident de l'Afrique, plus loin que les Canaries, regarde la prétenduë Prophétic de Medée dans Seneque, comme une fimple conjecture de ce Poëte, qui ne pouvant fe perfuader qu'il n'y eût point de 
Terre au-delà de l'Ocean Occidental, \& voyant que la navigation commençoit à fe perfectionner, jugeoit qu'on ne feroit pas lontems fans faire de ce côté - là quelque découverte. Quant à ce que j’ai déja cité du Timée de Platon, cela paroît à l'Hiftorien Efpagnol une pure fiction, dans laquelle des Difciples de ce Philofophe, zelés pour fa gloire, s'efforçoient, pour fauver fon honneur, de trouver quelque ingénieufe allégorie.

Au Chapitre feiziéme, le P. de Acofta commence à éxaminer par quelle voie les premiers Habitans de l'Amérique ont pu paffer dans ce grand Continent, \& il rejette d'abord la voye directe \& préméditée de la Mer, par la raifon qu'aucun ancien Auteur n'a parlé de la Bouffole. Il ne trouve pourtant point d'inconvénient à dire que des Bâtimens ont pû être jettés fur les Côtes de l'Amérique par quelque tempête, \& fur cela il cite (a), comme un fait conftant, la Fable du Pilote, qu'un vent forcé avoit pouffé vers le Brefil, \& qui laiffa en mourant fes Memoires à Chriftophe Colomb. Il rapporte enfuite ce que Pline a écrir de quelques Indiens, qu'un mauvais tems avoit dégradés fur les côtes de la Germanie, \& dont le Roi des Sueves fit prefent à Quintus Metellus Celer. Il ne trouve non plus rien que de croyable dans ce qui eft rapporté fous le nom d'Ariftote, qu'un Navire Carthaginois ayant été pris d'un Vent d'Eft forcé, qui le porta fort loin à l'Occident, l'Equipage y découvrit des Terres, jufques-là inconnuës ; \& il conclut de ces faits, que felon toutes les apparences, l'Amérique a reçu par de femblables voyes une partie de fes Habitans: mais il ajoûte qu'il en a fallu néceffairement chercher une autre, pour peupler cette Partie du Monde, quand ce ne feroit que pour y tranfporter certains Animaux; qu'on ne peut pas raifonnablement fuppofer avoir été embarqués fur des Navires, ni avoir fait à la nâge de fi grands Trajets.

Ce Paffage, continuë le Pere de Acofta, ne peut être que par le Nord de l'Afie ou de l'Europe, ou par les Terres, qui font au Sud du Détroit de Magellan, \& de ces trois routes, n'y en eût-il qu'une de pratiquable, c'en eft affez pour comprendre comment l'Amérique s'eft peuplée peu à peu, fans avoir recours à la navigation, dont on ne voit nulle trace dans les Traditions des Amériquains, Pour fortifier ce rai--

(a) Clapitre XIX. 
fonnement, il obferve que les Ifles, qui font trop éloignées du Continent, pour fuppofer qu'on puiffe y aller dans les petits Bâtimens, dont fe fervent les Peuples du Nouveau Monde, telle qu'eft la Vermude, fe font trouvées défertes; que la premiere fois, qu'on apperçut des Vaiffeaux à la Côte du Perou, les Peruviens en témoignerent une furprife extrême, $\& x$ que les Animaux, qui vraifemblablement y font allés par Terre, ou en traverfant tout au plus de petits Détroits, comme les Tygres \& les Lyons, étoient inconnus dans les Ifles de cet Hemifphere, même les plus peuplées.

Dans le Chapitre XXII. il revient à l'Atlantide de Platon, \& refute, peut-être un peu trop férieufement, l'opinion de quelques-uns, qui ont voulu réalifer cette chimere; car il ne balance pas à la traiter ainfi, \&x qui s'étoient mis dans la tête, que de cette Ifle prétenduë il n'y avoit qu'un très-court trajet en Amérique. Dans le Chapitre fuivant, il rejette le fentiment de ceux, qui s'autorifant du Quatriéme Livre d'Efdras, ont avancé que ce grand Pays a été peuplé par les Hébreux. Il leur objecte, $\mathbf{1}^{\circ}$. que les Hébreux avoient des Carazteres, \& qu'aucun Peuple Amériquain n'en connoiffoit l'ufage: $2^{\circ}$. que ceux-ci ne faifoient aucun cas de l'argent, \& que ceux-là en ont toujours été fort avides : $3^{\circ}$. que les Defcendans d'Abraham ont de tout tems été fort attachés à la Circoncifion, qui n'eft pratiquée en aucun endroit de l'Amérique : $4^{\circ}$. quils ont toujours confervé avec un grand foin leur Langage, leurs Traditions, leurs Loix , leurs Cérémonies, quilis n'ont jamais ceffé d'attendre un Meffie; que depuis leur difperfion dans toutes les Parties du Monde, ils ne fe font relâchés en rien de toutes ces chofes, \& qu'on n'a point de raifon de croire qu'ils y euffent plutôt renoncé en Amérique, où l'on n'en voit aucun veftige, que par-tout ailleurs.

Dans le vintquatriéme Chapitre, il obferve qu'il eft beaucoup plus aifé dans cette difcuffion de réfuter les fyftêmes des autres, que d'en établir un nouveau; que le défaut d'Ecriture \& de Traditions certaines dans les Amériquains rend leur origine très-difficile à découvrir, \& qu'on ne peut rien affûrer fur cela fans témerité : que tout ce qu'on y peut permettre à la conjecture, c'eft que ce grand Continent s'eft peuplé peu à peu par les voyes, dont nous avons fait mention: qu'il ne peut croire que ces tranfmigrations foient anciennes; 
\& que felon toutes les apparences, les Premiers, qui ont tenté ce Paffage, ont été plutôt des Chaffeurs, ou des Peuples errans, que des Honmes civilifés; mais que quand bien même les premiers Colons du Nouveau Monde auroient été tels, il n'y auroit pas lieu de s'étonner que leurs Defcendans euffent dégéneré, \& alteré la Religion \& les Mœurs de leurs Ancêtres: que le manque de plufieurs chofes fuffifoit pour leuî faire perdre leurs anciens ufages, \& que faute de fecours pour fe tranfmettre leurs Traditions d'âge en âge, ils ont dî les oublier infenfiblement, ou les défigurer de maniere à les rendre tout à fait méconnoiffables; que l'exemple de plufieurs Peuples de l'Efpagne \& de l'Italie, qui femblent n'avoir de l'Homme, que la figure, donne à tout ceci un grand air de vraifemblance : que le Déluge, dont les Amériquains ont confervé le fouvenir, ne lui paroît pas être celui, dont il eft parlé dans l'Ecriture, mais quelque inondation particuliere, dont de très-habiles Gens prétendent qu'il refte dans l'Amérique des preuves certaines : enfin qu'on ne fçauroit démontrer que les plus anciens monumens de l'Amérique foient anté. rieurs au treiziéme, ou au quatorziéme fiécle, \& qu'en remontant plus haut, on ne trouve que des Fables \& des Contes fi pueriles, qu'il n'eft pas poffible d'en tirer même une conjecture raifonnable.

Jean de LAET, le troifiéme Auteur, dont je dois rapporter le fentiment, trouve qu'il y a bien du bon $\&$ du folide dans celui du Pere de Acofta. Voici ce qu'il n'en approuve point. $I^{\circ}$. Il prétend que ce Jéfuite fuppofe mal à propos qu'on ne peut faire de longs trajets fur Mer fans le fecours de l'Aiguille aimantée, puifqu'abfolument parlant, on peut naviger en obfervant le cours des Aftres: qu'il femble même fe contredire en foutenant que la Bouffole eft une invention récente, après avoir rapporté lui-même que l'ufage en étoit ancien au Mofambique dès le quinziéme fiécle : qưil avance fans le prouver, que les Orientaux ne l'avoient pas, avant qu'elle eût été trouvée par les Occidentaux : quil falloit bien enfin qu'on pût s'en paffer, ou qu'elle fut connuë dans les premiers tems, puifque dans notre Hemifphere même plufieurs Ifles affez éloignées da Continent, ont été peuplées peu de tems après le Déluge.

$2^{\circ}$. Qu'il donne pour des faits certains l'Hiftoire du Pilote, dont 
dont on a prétendu que les Memoires avoient appris la route du Nouveau Monde à Chriftophe Colomb, \& celle des Indiens envoyés par le Roi des Sueves à Metellus Celer; qu'on fçait que les Efpagnols n'ont publié la premiere, que par jalou. fie contre le Grand Homme, à qui ils avoient obligation de la poffeffion de tant de riches Pays, mais qui avoit le malheur de n'être pas né en Efpagne; \& qu'ils n'ont donné cours à la feconde, que pour enlever aux Portugais la gloire d'avoir les Premiers ouvert un chemin aux Indes, en faifant le tour de l'Afrique : quil fe trompe, sil croit poffible le paffage des Terres Auftrales jufqu'au Détroit de Magellan, fans traverfer la Mer; puifque la découverte du Détroit de le Maire en a fait voir l'impollibilité. Mais l'erreur du P. de Acofta, fi c'en eft une, étoit excufable, car lorfqu'il écrivoit, le Maire n'avoit point encore trouvé le Détroit, qui porte fon nom.

$3^{\circ}$. Qu'il fait peupler l'Amérique trop tard, \& qu'il eft contre toute apparence que ce vafte Continent, \& quelques-unes des Ifles, qui l'environnent, ayent eu un fi grand nombre d'Habitans à la fin du quinziéme fiecle, fi on n'avoit commencé à les habiter, que depuis deux cent ans. Jean de Laët prétend qu'il n'y a aucune raifon de juger que le Déluge, dont la tradition s'eft confervée parmi les Amériquains, n'eft pas le Déluge Univerfel, dont Moyfe nous a décrit l'Hiftoire dans la Genefe.

Outre le Jéfuite Efpagnol, trois autres Ecrivains ; un François, un Anglois, \& un Hollandois, qui ont traité le même fujet, ont paffé par l'examen du docte Flamand. Ce font LESCAR BOT, BREVEROOD, \& GROTIUS. Il ne connoiffoit apparemment pas l'Ouvrage du P. Garcia, dont j’ai déja parlé, non plus que celui de Jean de Solorzano Pereyra, Jurifconfulte Efpagnol, qui a pour titre: De Jure Indiarum, dont le premier Volume, où l'Auteur rapporte toutes les opinions des Sçavans fur l'Origine des Amériquains, fut imprimé en 1629 .

Quoiqu'il en foit, Marc Lefcarbot, Avocat au Parlement de Paris, étoit un Homme d'efprit, \& qui avoit de l'érudition, mais qui donnoit un peu dans le merveilleux. J'ai parlé de lui en plufieurs endroits de mon Hiftoire. En rapportant les diverfes opinions fur la'queftion prefente, qui étoient en vogue de fon tems, il rejette comme frivoles les applicaTome III. 
tions, que l'on faifoit de quelques Prophéties à ce fujet, furtout de celle d'ABDIAS à la converfion des Indes Occidentales par le miniftere des Efpagnols \& des François, les feules Nations, qui ayent véritablement entrepris ce grand œuvre; car les Fortugais, qui ont converti le Brefil, peuvent être compris fous le nom d'Efpagnols, \& les Miffionnaires des autres Nations de l'Europe, qui ont eu part à la Publication de l'Evangile dans le Nouveau Monde, n'y font allés que fous la Banniere des Couronnes de France, d'Efpagne \& de Portugal. En effet Abdias n'a eu certainement en vûë que les Iduméens, \& iln'y a pas un mot dans fa Prophétie, qui puiffe, avec quelque forte d'apparence, être appliqué à l'A mérique.

Lefcarbot panche un peu plus vers le fentiment de ceux, qui ont tranfporté dans le Nouveau Monde les Cananéens chaffés de la Terre promife par Jofué. Il y trouve au moins quelque vraifemblance, en ce que ces Peuples, auffi-bien que les Amériquains, avoient la coûtume de faire fauter leurs Enfans par-deffus le feu, en invoquant leurs Idoles, \& de manger la chair humaine. Il approuve ce que le Pere de Acofta dit des accidens, qui peuvent avoir fait aborder quelques Navires en Amérique, \& du paffage par le Nord de l'Europe \& de l'Afie. Il croit que toutes les Parties du Continent fe touchent, ou du moins que, s'il y a quelque Détroit à paffer, conme celui de Magellan, qu'il fuppofoit féparer deux Continens, il fe pourroit bien faire qu'ils n'euffent point arrêté les Animaux, qu'on trouve dans le Nouveau Monde, puifque Jacques CARTIER a vâ un Ours de la groffeur d'une Vache, faire à la nâge un trajet de quatorze lieuës. Enfin il propofe fon fentiment propre, qu'il ne paroît pourtant donner, que comme une fimple conjecture.

Eft-il croyable, dit-il, que Noé, qui a vêcu trois cent cinquante ans après le Déluge, ait ignoré qu'au-delà de l'Océan Occidental il y a une grande partie du Monde; \& s'il l'a connu, manquoit-il de moyens pour la peupler ? Y avoitil plus de difficulté à paffer des Canaries aux Açorres, \& des A çorres au Canada, ou des Ifles du Cap-Verd auBrefil, que du Continent de l'Afie au Japon, ou à d'autres Ifles encore plus éloignées? Il rapporte à ce fujet tout ce qu'on trouve dans les Anciens, fur-tout dans Elien \& dans Platon, des veftiges, qui reftoient, dit-il, encore de leur tems, de la connoifance 
de l'Amérique. Il ne voit rien, qui empêche de dire que les Hefperides des Anciens font les Antilles, \& $x$ il explique la Fable du Dragon, qui, felon les Poëtes, en gardoit les Pommes d'or, des differens Détroits, qui ferpentent autour de ces Illes, $\&$ que de fréquens naufrages ont pu faire regarder comme impratiquables. Il ajoûte à cela beaucoup d'autres obfervations géographiques, qui ne font pas toutes fort éxątes, \& que Jean de Laët réfute très-bien.

Ce Critique remarque aufi avec raifon que, fi les Cananéens facrifoient leurs Enfans à leurs Idoles, on ne lit dans aucun endroit des Livres Saints qu'ils fuffent Anthropophages. Il convient de la poffibilité \& $x$ de la vraifemblance du paffage des Hommes \& des Animaux par le Nord dans l'Amérique, \& il avouë qu'il eft aifé de comprendre comment des Hommes ainfi tranfplantés dans un Pays défert, \& fi éloigné, y font devenus Sauvages \& Barbares; mais il regarde comme un vrai Paradoxe, il trouve même du ridicule à imaginer que Noë ait jamais penfé à peupler ce grand Continent. Sa mauvaife humeur, excitée fans doute par quelques-unes des preuves de Lefcarbot, qui véritablement ne font pas de trop bon alloy, l'a empêché de voir ce qu'il peut y avoir de fenfé dans cette conjecture. Il eft affez ordinaire aux Sçavans d'en ufer de la forte : comme fi la verité \& la vraifemblance ceffoient d'être telles, parce qu'on mêle de mauvaifes preuves parmi celles, dont on les appuye.

EDOUARD DE BREVEROOD, fçavant Anglois, après avoir réfuté le fentiment infoûtenable, qui fait defcendre tous les Tartares des Ifraëlites, \& montré que l'ignorance de la véritable étymologie du nom de Tartares, laquelle vient, non de l'Hebreu, ni du Syriaque, mais du Fleuve Tartar; veut que ce foit uniquement cette nombreufe Nation, qui ait peuplé le Nouveau Monde : $8 z$ voici fes preuves. 1 ${ }^{\circ} . L^{\prime} A-$ mérique a toujours été plus peuplée du côté de l'Afie, que du côté de l'Europe. $2^{\circ}$. Le génie des Amériquains a un trèsgrand rapport avec celui des Tartares, qui ne fe font jamais appliqués à aucun Art; ce qui n'eft pourtant pas univerfellement vrai. $3^{\circ}$. La couleur des uns $8 x$ des autres eft à peu près la même: il eft certain que la difference n'eft pas confiderable, \& peut être l'effet de celle du Climat, \& des Drogues, dont les Amériquains fe frottent. $4^{\circ}$. Les Animaux féroces, 
qu'on voit en Amérique, \& qu'on ne peut raifonnablement jugery avoir été tranfportés par Mer, ne peuvent y avoir paffé que par la Tartarie. Il répond enfuite à une objection, qu'on lui peut faire fur ce que les Tartares font circoncis, \& il foûtient que la circoncifion n'a jamais été en ufage parmi les Tartares, qu'après qu'ils eurent embraffé le Mahométifme.

De Laët fe contente d'expofer cette opinion du doete Anglois, laquelle confifte à rejetter le fentiment, qui fait defcendre les Tartares des Ifraëlires, transferés par Salmanafar ; \& à donner à tous les Amériquains les Tartares pour Ancêtres. Nous verrons ce qu'il penfe lui-même de cette origine, lorfque nous expoferons fon fentiment propre. Mais il faut auparavant examiner ce qui fe paffa entre lui \& le fameux Hugues Grotius, fur le fujet que nous traitons. La difpute fut très-vive de part $\&$ d'autre, $\&$ ne fit guéres qu'embrouiller la queftion.

En 1642. Grotius publia un petit Ouvrage in-quarto fous ce Titre : De Origine Gentium Americanarum, où il commence par fuppofer que l'Ifthme de Panama fut jufqu'au tems de la découverte du Nouveau Monde par les Efpagnols une barriere regardée comme impénétrable entre les deux parties de l'Amérique; d'où il conclut, que les Habitans de l'une $\& \times$ de l'autre n'avoient rien de commun dans leur Origine. Milius, qu'il ne cite point, avoit avancé ce Paradoxe avant lui. Or, fi on en croit le docte Hollandois, à l'exception de l'Yucatan, \& de quelques autres Provinces voifines, dont il fait une claffe à part, toute l'Amérique Septentrionnale a été peuplée par les Norvégiens, qui y pafferent par l'lflande, le Groenland, l'Eftotiland, \&x la Norimbegue. Il avouë néanmoins qu'ils y furent fuivis quelques fiécles après par des Danois, des Suédois, \& d'autres Peuples Germaniques.

Il tire la plus grande partie de fes preuves de la conformité des mœurs \& de la reffemblance des noms; mais il faut convenir, que rien n'eft plus forcé que ces prétendus rapports, dont il paroît néanmoins fort perfuadé, \& qu'il ne perfuade à perfonne. Ce qui l'oblige de mettre à part l'Yucatan, c'eft l'ufage de la Circoncifion, dont il s'eft mis dans la tête qu'on a trouvé des traces dans cette Province, \& une prétenduë Tradition ancienne des Habitans, qui portoit que 
leurs Ancêtres avoient été fauvés des flots de la Mer; ce qui a fait croire à quelques-uns, ajoûte-t'il, qu'ils étoient iffus des Hébreux. Il réfute néanmoins cette opinion avec les mêmes argumens à peu près, dont s'eft fervi Breverood, \& $x$ il eftime, avec Dom Pierre MART Premiers, qui peuplerent l'Yucatan, furent des Ethiopiens jettés fur cette Côte par une tempête, ou par quelque autre accident. Il juge même que ces Ethiopiens eroient Chrétiens, ce qu'il infere d'une ef́péce de Baptême uficé dans le Pays. Il ne fçauroir difconvenir, que le langage des Amériquains Septentrionnaux n'eft proprement ni Lthiopien, ni Norvégien, mais cette difficulté ne l'arrête point : il en cherche, comme il peut, la folution dans le mêlange des Peuples divers, qui fe font établis dans la fuite des tems dans cetre partie du Nouveau Monde, \& dans leur vie errante, qui les a obligés, dit-il, de fe faire de nouveaux jargons.

Il paffe de-là aux Nations les plus voifines du Détroit do Magellan, \& s'imaginant voir beaucoup de reffemblance entre celles, qui font établies en-deçà dans le Continent de l'Amérique Méridionnale ; \& celles, qui demeurent au-delà, il décide que les Premieres tirent leur Origine des Dernieres; \& que celles-ci, auffi-bien que les Habitans de la Nouvelle Guinée, font venuës des Moluques \& de l'llle de Java. Néanmoins le génie particulier des Peruviens, leurs Loix, leurs Coûtumes, leur Police, les fuperbes édifices, qu’ils avoient conftruits, \& les débris des Navires Chinois, que des Efpagnols, dit-il, ont aperçus à l'entriée de la Mer llacifique, au fortir du Détroit de Magellan, ne lui permettent point de douter, que cette Nation ne foit originairement une Colonie Chinoife ; ce qui fe confirme, ajoûte-t-il, par le culte du Soleil également établi dans l'un \& dans l'autre Empire, par la reflemblance de leurs carakteres \& $\mathrm{x}$ de leur maniere d'écrire, \& par la réputation, qu'ont eu les anciens Chinois, d'exceller dans la Navigation. Enfin il rejette l'Origine Tartare ou Scythe des Amerriquains par le peu de conformité, qui fe trouve, felon lui, entre les mœurs \& les coûtumes des uns \& $\&$ des autres : il infifte principalement fur ce que ceux-ci n'ont point de chevaux, dont on fçait, dit-il, que les Schythes ne peuvent abfolument fe paffer.

Pour faire tomber ce fyftême, il fuffit de montrer, qu'il 
porte prefque toujours à faux, \& c'eft ce que le Critique Flamand rend très-fenfible. Il ne prouve pas moins bien que Grotius n'eft pas plus heureux à attaquer les fentimens des autres, qu'à établir le fien. En effet il obferve que tous les Scythes n'ont pas l'ufage des chevaux, puifque plufieurs habitent des Pays, qui n'en peuvent pas nourrir ; à quoi il ajoûte, que dans le fentiment de ceux, qui prétendent que c'eft par la Scythie, que l'Amérique a été peuplée, il n'eft pas néceffaire de dire, que tous ceux, qui ont pénétré par-là dans le Nouveau Monde, étoient Scythes ou Tartares; que les Pays, qu'il a fallu traverfer, n'étoient nullement propres pour les chevaux; que la coûtume des Scythes, quand ils fe voyent contraints de paffer quelque Détroit de Mer, eft de tuer leurs chevaux, de les écorcher, \& de couvrir de leurs peaux les Bâtimens, fur lefquels ils s'embarquent. Il foûtient enfin que, felon toutes les apparences, ces tranfmigrations fe font faites affez peu de tems après la difperfion des petits-fils de Noë, \& qu'alors les Scythes \& les Tartares pouvoient bien ne pas encore faire ufage de Chevaux.

Il prouve l'antiquité de ces Colonies par la multitude des Peuples, qui habitoient l'Amérique Septentrionnale, lorfqu'on en fit la découverte; \& quant à l'impoffibilité prétenduë de franchir l'Ifthme de Panama, il en fait voir l'abfurdité par le peu d'obftacles, que les Européens ont trouvés dans ce paffage. Il entreprend enfuite de montrer, que les Amériquains les plus Septentrionnaux ont beaucoup plus de reffemblance, foit dans les traits du vifage, foit dans la couleur, foit dans la maniere de vivre avec les Scythes, les Tartares \& $\&$ les Samojedes, qu'avec les Norvégiens \& les Peuples Germaniques ; \& fur ce que Grotius fait partir ceuxci de l'Illande, il remarque fort bien que cette flle n'a commencé d'être peuplée par les Norvégiens qu'à la fin du IXe. fiécle de l'Ere Chrétienne; qu'alors même il n'y paffa que quelques Familles, \& qu'ainfi elle ne fut pas fi-tôt en état d'envoyer en Amérique des Colonies affez nombreufes, pour avoir produit tant de milliers d'Hommes, qui dans le quinziéme fiécle rempliffoient ces vaftes Contrées.

La route, que Grotius fait prendre à fes Norvégiens, fournit encore à fon Adverfaire de puiflantes armes pour le combattre. Il lui fait obferver, que le Groënland eft en- 
trecoupé de vaftes \& profonds Détroits de Mer, prefque toujours glacés, que tout le Pays eft couvert de neiges trèshautes, \& qui ne fondent jamais entiérement; que la Friflande, fi elle exifte, ne peut être qu'une partie du Groënland, ou de l'Iflande; \& qu'il n'y a nul fond à faire fur tout ce qu'en ont débité les deux Freres Zanis: que l'Eftotiland, fuivant le rapport de ces deux Nobles Vénitiens, eft fort éloigné de la Friflande, puifque de leur tems il n'y avoit au. cun Commerce entre ces deux Pays, \& que ce fut par un pur hafard, que des Pêcheurs eurent connoiffance de ce Dernier : que ce Royaume enchanté, dont le Souverain avoit une fi magnifique Bibliothéque, a difparu depuis qu'on a parcouru le Nord de l'Amérique; que la Norimbegue, où Grotius conduit les Norvegiens, n'eft gueres moins fabuleufe; que ce nom, dans lequel ce Sçavant trouve avec complaifance un fi grand rapport avec celui de Norvege, n'eft pas le nom du Pays, mais un nom factice, dont perfonne ne connoit le Parrain; que les Naturels du Pays l'appelloient Agguncia; que ce Pays eft bien éloigné au Sud de l'endroit, où l'on avoit fuppofé qu'étoit l'Éftotiland, puifqu'il fait partie de la Côte Méridionnale de la Nouvelle France, entre l'Acadie \& la Nouvelle Angleterre.

Grotius avoit beaucoup appuyé fur la terminaifon en are, fi commune dans l'Ancien \& le Nouveau Méxique. Laët le tire de ce retranchement, en faifant voir que prefque tous ces noms font modernes, \& de la façon des Éfpagnols. Il renverfe avec la même facilité l'argument, que Grotius tiroit des Traditions des Méxiquains, en obfervant que quand ces Peuples fe font placés aux environs du Lac de Mexico, ils y ont trouvé quantité de Barbares, qui parloient toutes fortes de Langues, entre lefquelles il n'y avoit aucune affinité, ni aucune forte d'analogie; de forte qu'après les avoir fubjugués, ils furent contraints d'établir des Interprétes pour les pouvoir gouverner. Cette vaine reffemblance de noms avoit encore fait imaginer à Grotius dans la Californie un Peuple Alavard, quil fait defcendre des Lombards; Laët lui répond que le nom d'Alavard pourroit bien n'avoir point d'autre fondement, que celui d'Alvarado, Capitaine Efpagnol, qui avoit fuivi Fernand Cortez au Méxique, \&x peut-être auffi dans la Californie, dont on fçait que 
ce Conquerant en a fait la premiere découverte.

Laët fait voir enfuite que Grotius ne réuflit pas mieux à montrer une conformité de Mœurs, de Coûtumes, de Traditions, $\&$ de Forme de gouvernement entre les Amériquains Septentrionnaux $\&$ les Norvegiens; prefque tout ce qu'il en rapporte, étant fondé fur de faux Mémoires. Puis il vient à l'argument, que tire fon Adverfaire de la Circoncifion \& du Baptême prétendu des Peuples de l'Yucatan. Il foûtient d'abord quil eft contre toute vraifemblance d'aller chercher un Pays renfermé entre des Colonies Norvegiennes, pour y placer des Afriquains, qui auroient dû plus naturellement prendre Terre au Brefil, ou du moins s'arrêter aux Antilles, qu'il auroient rencontrées fur leur paffage, en fuppofant qu'ils auroient paffé le Tropique. Il avouë que $D$. Pierre Martyr d'Anglerie en parlant des Peuples de l'Yucatan, dit que plufieurs étoient circoncis, mais il prétend que cet Auteur Italien a été mal informé, puifque, ni Antoine de HERrERA, ni le Pere de Acofta, ni Oviedo, dont l'autorité eft fort fupérieure à la fienne, n'ont parlé, ni de cette Circoncifion, ni de ce Baptêne, ni des Croix dreffées fur les Tombeaux, que comme de pures Fables. Enfin, pour faire paffer des Abyflins en Amérique, il falloit les faire partir de la Côte Occidentale d'Afrique, \& Laët affûre que Grotius s'eft trompé, en avançant que les Etats du Roi d'Ethiopie s'étendoient jufques - là. Il eit cependant certain par des Relations Portugaifes que le Roi de Benin relevoit du Monarque Abyfin.

Laët dit peu de chofes fur la maniere, dont Grotius prétend que l'Amérique Méridionnale a été peuplée par les $\mathrm{Ha-}$ bitans des Terres, qui font au Sud du Détroit de Magellan; il fe contente de remarquer que ces Terres ne font que des Ifles, \& qu'au-delà, jufqu'aux Terres Aufrales, il y a une étenduë immenfe de Mer : qu'on ne fçait pas encore au jufte ce qu'il y a entre ces Terres \& $x$ la Nouvelle Guinée, \& que tous les Amériquains Méridionnaux, fans en excepter les Peuples, qui étoient foumis aux Incas du Perou, parloient une infinité de Langues differentes. Les preuves, fur lefquelles Grotius établifoit l'Origine Chinoife des Peruviens, ne pàroiffent pas beancoụp plus folides à fon Cenfeur.

Premierement, dit-il, le carabtere des deux Nations, \& 


\section{DES A M E R I Q UA I N S.}

leur goût pour les Arts font extrémement oppofés. En fecond lieu, perfonne n'a encore dit que les Chinois ayent jamais adoré le Soleil ; \& quand cela feroit, ce culte eft commun à tant de Peuples, qu'on n'en peut tirer aucun argument dans la queftion préfente. Il eft vrai que les Incas du Perou, auffi-bien que les Monarques Chinois, fe difoient les Fils du Soleil ; mais combien d'autres Princes ont pris ce titre, ou l'ont reçû de leurs Sujets ? Les Méxiquains ne le donnerentils pas même à Cortez, foit pour lui faire honneur, foit parce qu'il venoit de l'Orient. En troifiéme lieu, Grotius s'eft encore plus groffiérement trompé, en affùrant que les Peruviens fe fervoient de Caracteres figurés, comme les Chinois, \& les plaçoient comme eux, en lignes perpendiculaires; puifque le Pere de Acofta, qui a demeuré lontems au Perou, \& Garcilaffo de la VEGA, qui y étoit né du Sang même des Incas $(a)$, affûrent qu'on n'y connoiffoit ni Caracteres, ni l'ufage d'aucune forte d'écriture. Ce que le Docte Hollandois avoit ajoûté, que MANGo CAPA, le Premier des Incas, étoit Chinois, ne pouvoit être qu'une conjecture, ou une fable inventée par quelque Voyageur; car il n'en eft fait aucune mention dans les Traditions du Perou.

Enfin, Laët déclare qu'il n'a jamais lû dans aucun Auteur qu'on ait trouvé des débris de Navires Chinois dans la Mer Pacifique. La chofe lui paroît même affez difficile à croire, par la raifon, que, pour aller de la Chine au Perou, les Vents font toute l'année tellement contraires, qu'il feroit plus court de prendre le grand détour par l'Occident, que la route directe. Il ajoûte que, fi les Péruviens defcendoient des Chinois, ils auroient confervé du moins quelques veftiges de l'art de naviguer, \& l'ufage du fer, au lieu qu'ils ne connoiffoient ni l'un, ni l'autre; qu'il étoit donc bien plus naturel de faire venir les Peruviens \& les Peuples du Chili, leurs Voifins, de quelque Nation Indienne. Il y en a toujours eu d'affez policées, pour être capables de donner naiffance à un Empire tel, qu'étoit celui du Perou.

Grotius répliqua; mais en Ambaffadeur, \& en Sçavant étonné de ce qu'on avoit ofé le contredire. Laët un peu piqué, le ménagea moins dans fa repartie : il lui fit voir qu'il ne difoit rien de nouveau, que des injures, \& prétendit que

(a) Il en defcendoit par fa Mere.

Tome III. 
dans une difpute purement litteraire, le caractere d'Ambaffadeur ne donnoit aucun avantage à un Ecrivain, ni aucun poids à fes raifons.

Grotius triomphoit de ce que fon Adverfaire étoit convenu que le Groenland avoit été peuplé par les Norvégiens : voilà donc, difoit-il, une partie de l'Amérique : donc les Habitans tirent leur origine de la Norvege. Or qui auroit empéché ces Norvégiens Groenlandois d'aller plus loin? Il ne s'agit pas, répond de Laët, de fçavoir fi quelques Peuples du Nord ont paffé en Amérique par le Groenland; mais fi tous les Amériquains viennent de la Norvége ; \& je foûtiens que cela eft impoffible. ANGRIMUS Jonas, Iflandois, affurre que la premiere découverte du Groenland n'a été faite qu'en 964. Herrera \& GOMARA nous apprennent que les Chichimeques s'établirent fur le Lac de Mexico en 721 . Ces Sauvages venoient du Nouveau Mexique \& du voifinage de la Californie. Telle eft la Tradition conftante des Méxiquains: l'Amérique Septentrionnale avoit donc des Habitans plufieurs fiécles avant qu'elle en ait pû recevoir de la Norvege par le Groenland.

Il n'eft pas moins conftant que les vrais Méxiquains fonderent leur Empire en 90.2 , après avoir fubjugué les Chichimeques, les Otomias, \& les autres Barbares, qui s'étoient emparés des environs du Lac de Mexico: \& le Pere de Acofta nous affûre que chacun de ces Peuples avoit fa Langue particuliere. On fçait d'ailleurs que les Méxiquains venoient eux-mêmes de la Californie, ou du Nouveau Méxique, \& qu'ils avoient fait, du moins pour la plûpart, le voyage par Terre. lls ne font donc point venus de la Norvege.

Grotius ayant ainfi erré dans le principe par un Anachronifme évident, tout ce qu'il bâtit fur ce fondement, n'eft plus qu'une fuite de ce premier égarement: \& fon Antagonifte, qui avec toute la liberté Belgique, croit être en droit de ne le regarder que comme un Sçavant, dont le fyftême lui paroît ruineux, \& qui, offenfé à fon tour de ce que l'ayant attaqué avec affez de modération, il n'en avoit pas reçû le retour de politeffe, qu'il en attendoit, le fuit pas à pas dans tous fes écarts, \& les lui remet fans ceffe devant les yeux.

Le docte Ambaffadeur s'imaginoit avoir lû dans Herrera 
que les Infulaires de Baccalaos reffemblent parfaitement aux Lappons. Laët, après avoir protefté qu'il n'a pu trouver ce fait dans l'Hiftorien Efpagnol, repete ce qu'il avoit déja dit, qu'il ne nie point que quelques Amériquains n'ayent pu avoir tiré leur origine de l'Europe; puis ramenant fon Adverfaire au Mexique, il lui demande ce que peuvent avoir de commun les Mexiquains avec les Habitans de liIfle Baccalaos? Il avouë enfuite qu'Herrera parle d'une efpece de Baptême, \& de Confeffion ufitée dans l'Yucatan \& dans les Ifles voifines, mais il foûtient que le Culte de ces Barbares étoit mêlé de tant d'impiétés, \& fi manifeftement Idolâtre , qu'on ne peut raifonnablement fuppofer qu'ils l'euffent reçû́ des Abyffins Chrétiens. Il ajoûte qu'il eft bien plus naturel d'attribuer toutes ces marques équivoques de Chriftianifme $\&$ de Judaifme, qu'on a cru appercevoir en plufjeurs Provinces du Nouveau Monde, au Démon, qui a toujours affecté de contrefaire le Culte du Vrai Dieu. Cette remarque eft de tous les bons Auteurs, qui ont parlé de la Religion des Peuples nouvellement découverts, \& fondée fur l'autorité des Peres de l'Eglife.

Sur ce que Grotius ne trouvoit point de difficulté à dire que les Ethiopiens avoient pû, avèc le tems, changer leur couleur fous un Soleil moins brûlant, que celui, quils avoient quitté, Laët lui répond que les Peuples Blancs peuvent bien perdre un peu de leur blancheur fous un Climat plus chaud, que celui, où ils font nés; mais quili eft fans exemple que les Defcendans d'un Noir foient devenus blancs dans un Pays froid, \& que la couleur des Negres ne vient pas feulement de l'ardeur du Soleil, puifque les Brafiliens \& tant d'autres; qui habitent fous les mêmes paralleles, ne l'ont point. Enfin, il releve une derniere erreur de Grotius, qui s'ettoit perfuadé que les Chinois ne connoiffoient point l'Imprimerie avant l'arrivée des Portugais dans leur Pays, \& par-là vouloit fe tirer d'une objection, qu'on auroit pû faire contre fon fyftême de l'Origine Chinoife des Peruviens.

Il me paroît qu'il n'y a rien à ajoûter à la Critique, que Jean de Laët a publiée du fentiment du célébre Grotius; il faut voir maintenaint, s'il a été aufi heureux à bièn établir le fien. Il rapporte d'abord, fur l'autorité de quelques Auteurs cités par Pline, mais qui ne paroiffent pas avoir été fort 
habiles Géographes, que dans quelques Ifles peu éloignées de l'Afrique, \& du nombre defquelles font les Canaries, on a vû des Edifices anciens, preuve certaine qu'elles avoient été habitées avant leur découverte par les Européens. Il faut convenir, dit-il, que puifqu'elles ont été dans la fuite entierement défertes, les Habitans fe font retirés ailleurs, \& il y a bien de l'apparence qu'ils ont paffé en Amérique, le trajet n'étant ni long, ni difficile.

Cette Tranfmigration, fuivant le calcul de ces Auteurs, doit être arrivée il y a environ deux mille ans: alors les Efpagnols étoient fort inquiettés par les Carthaginois, \& peu de tems après ils ne le furent pas moins par les Romains. Or n'eft-il pas naturel de penfer que plufieurs d'entre eux fongerent à fe réfugier en des Pays', où ils n'euffent pas à craindre qu'on vînt encore troubler leur repos? Et qui a pu les empêcher de fe retirer dans les Antilles, en paffant par les Açorres, qui font à moitié chemin ? Les Bâtimens des Carthaginois étoient fort propres pour cette navigation, \& pouvoient fervir aux Efpagnols de modéles pour en conftruire de femblables. Ils avoient devant les yeux l'exemple affez récent du célébre HANNON, Carthaginois, qui avoit navigué fort loin à l'Occident. 11 n'y a pas moins de vraifemblance à dire que des Ifles du Cap Verd on ait traverfé au Brefil. Les Autololes, que Pline a placés dans leur voifinage, étoient Getules, \& non pas Ethiopiens; leur couleur \& leurs mœurs conviennent affez avec celles des Brafiliens.

La Grande-Bretagne, l'Irlande, \& les Orcades paroiffent auffi au Sçavant d'Anvers très-propres à fonder une conjecture toute femblable en faveur de l'Amérique Septentrionnale. Il rapporte à ce fujet ce qui eft marqué dans l'Hiftoire du Pays de Galles, écrite par le Docteur David Pow EL, fous l'annee I I 70. MADOC, dit cet Hiftorien, un des Fils du Prince OWen Guyneth , las \& rebuté des Guerres Civiles, qui s'étoient élevées entre fes Freres après la mort de leur Pere, arma plufieurs Vaiffeaux, les pourvut de tout ce qui étoit néceffaire pour un voyage de long cours, \& alla chercher de nouvelles Terres à l'Occident de l'Irlande. Il en trouva de très-fertiles, \& qui n'étoient point habitées : il y débarqua une partie de fon Monde, puis retourna en Angleterre, où il fit de nouvelles Recruës, qu'il mena dans fa Colonie. Laët 


\section{DES A $\mathrm{M}$ ER I $Q U$ A I N S.}

paroît faire beaucoup de fond fur cette Hiftoire, $\&$ il en conclut qu'on a pu former de pareilles Entreprifes dans toutes les Ifles Britanniques. Il feroit à fouhaiter, ajoûte-t'il , qu'on fe fût appliqué à comparer les Langues de quelques-unes des Régions de l'Amérique Septentrionnale avec celles de l'Irlande \& du Pays de Galles.

De-là il vient aux Scythes, \& fait un parallele de leurs mours avec celles des Amériquains. Il prouve d'abord par le témoignage de Pline, que ce nom etoit autrefois commun à toutes les Nations Septentrionnales de l'Afie \& de l'Europe ; \& qu'on le donnoit même quelquefois aux Sarmates \& aux Germains, quoique dans la fuite on l'ait reftraint aux Peuples, qui habitoient à l'extrémité du Nord, où plufieurs ont été lontems ignorés du refte du Monde. II prétend que parmi eux il y avoit beaucoup d'Anthropophages; que tous ont pû envoyer des Colonies en Amérique, $\&$ que fi on lui objecte qu'il n'y a d'Antropophages, que dans l'Amérique Méridionnale, c'eft que tous ceux, qui étoient dans ce déteftable ufage y ont paffé. Il pouvoit fans doute s'épargner la peine de répondre fi mal à une objection, que Perfonne ne lui auroit apparemment faite, puifque plufieurs Amériquains Septentrionnaux ont toujours été , \& font encore Anthropophages : mais continuons de le fuivre dans l'expofition de fon fyftême. Je dis fon fyftême, car où les Mémoires manquent pour conftater le vrai, c'eft une néceffité pour lui, comme pour tous ceux, qui traitent cette quettion, d'avoir recours au vrai-femblable, \& il doit fuffire de ne s'en pas éloigner.

Pline, à la vérité, dit que les Scythes fe picquoient d'avoir beaucoup de Chevaux; mais il ne le dit point de tous les Scythes. Strabon parle de plufieurs, qui étoient au Nord de la Mer Cafpienne, \& dont une partie menoient une vie errante: ce quil rapporte de leurs mours \& de leur façon de vivre, s'accorde en bien des chofes avec ce qu'on a remarqué dans les Sauvages de l'Amérique : $\&$ il n'eft pas fort étonnant, ajoûte Laët, que ces rapports ne foient pas abrolument parfaits; car ces Peuples, avant même que de fortir de leur Pays, differoient déja les uns des autres, \& ne portoient pas le même nom : le changement de demeure a fait le refte. On trouve les mêmes rapports entre plufieurs Nations 
Amériquaines, \& les Samojedes établis fur le grand Fleuve Oby, tels que les Ruffiens nous les ont repréfentés ; \& il eft bien plus naturel de fuppofer que des Colonies de ces Peuples ont paffé en Amérique, en traverfant la Mer Glaciale fur leurs traînes, que de faire faire aux Norvégiens tout le chemin, que Grotius leur a tracé. Outre que les Amériquains tiennent beaucoup moins de ceux-ci, que des $\mathrm{Sa}-$ mojedes \& des Scythes Nomades.

De l'Amérique Septentrionnale Laët paffe à la Méridionnale, \& examine fi elle a pu recevoir des Habitans par la Mer Pacifique. Les Inles de Salomon font à huit cent lieuës des Côtes du Perou , \& on fçait aujourd'hui qu'elles font féparées des Terres Auftrales par une Mer, dont on ne connoît point encore toute l'étenduë. Le Pere de Acofta ne les croyoit pas fort éloignées de la Nouvelle Guinée, qu'il jugeoit être un Continent : mais le Chevalier Richard $\mathrm{HAW}_{\mathrm{A}}$ kins Anglois, prétend avoir vérifié que c'êt une Ifle. Il faut donc, continué le doßte Flamand, que l'Amérique Méridionnale ait été peuplée par cette grande Terre Auftrale, la même que Dom Pierre Ferdinand Giros, Portugais, \& Dom Ferdinand de Quiros, Efpagnol, rangerent l'efpace de huit cent lieuës en I 609. \& en I6Io. (a) Ce Dernier, qui a donné fon nom à une partie de cette Terre, marque dans fa Lettre au Roy Catholique que le Pays, où il débarqua en plufieurs endroits, étoit fort peuplé, \& qu'il y avoit vû des Hommes de toutes les couleurs. Mais n'eft-il pas étrange que Laët aime mieux faire peupler l'Amérique Méridionnale par une Terre, qui en eft féparée par une Mer immenfe, \& beaucoup plus que du refte du Monde, que par la Septentrionnale, laquelle, en fuppofant qu'elle a été peuplée la premiere, doit naturellement avoir fourni des $\mathrm{Ha}-$ bitans à tout le Nouveau Monde.

Pour appuyer ce qu'il avoit déja dit, que l'Amérique n'a pû être peuplée par la Mer Pacifique, il obferve que les vents de la partie de l'Eft, qui y regnent toujours, ne permettent point de naviguer d'Occident en Orient; puis il examine plufieurs Langues Amériquaines pour les confronter, \& ce n'eft point-là le meilleur endroit de fon Ouvage;

(x) Voyez dans les Faftes Chronologiques à quoi il faut réduire ce Voyage de Quitos ; \& quelle eit la vraie fituation dics Ifles de Salomon. 
au moins fi nous en jugeons par l'Extrait, qu'il nous donne d'un Vocabulaire Huron, pour oppofer cette Langue à celle du Mexique ; car il l'a tiré du Frere Gabriël Saghart, Recollet, qui entendoit très-peu le Huron.

Il ne paroît pas mieux inftruit de la Religion des Sauvages du Canada, dans laquelle il tâche de trouver des veftiges, qui le puiffent conduire à leur premiere Origine ; \& en effet tout cet étalage d'érudition ne le mene pas bien droit à fon but. D'ailleurs, quoique Perfonne de fon tems n'ait fait une étude plus fuivie, \& n'ait parlé plus exactement que lui des Indes Occidentales, il trouveroit aujourd'hui bien des chofes à réformer dans fon Ouvrage.

Il finit par l'expofition, qưil fait en peu de mots du fentiment d'Emmanuel de MoraEz, Portugais, tiré du vintiéme Livre de fon Hiftoire du Brefil, laquelle n'eft pas encore imprimée. Suivant cet Auteur, ce font les Carthaginois \& les Ifraëlites, qui ont peuplé toute l'Amérique. Sa preuve, à l'égard des Premiers, eft qu'ils ont fait des découvertes bien loin de l'Afrique, \& que le Sénat de Carthage en interrompit le cours, d'où il eft arrivé que ceux, qui fe trouvoient alors dans les Pays nouvellement découverts, n'ayant plus aucun commerce avec leurs Compatriotes, \& manquant de beaucoup de chofes, font tombés dans la barbarie. Quant aux Ifraëlites, Moraëz prétend que, pour trouver un rapport parfait entre eux \& les Brafiliens, il ne manque à ceux - ci que la Circoncifion. Ce feroit encore beaucoup, fi on confidére l'attachement invincible de ceux - là à cette pratique. Mais il y a bien d'autres points auff effentiels, en quoi ces deux Nations different, \& je puis affûrer que cette prétenduë reffemblance, qui a tant frappé l'Hiftorien Portugais, eft tout au plus un faux air, qui faifit au premier coup d'œil, \& $\&$ difparoît, quand on y regarde de près, \& qu'on ne s'eft pas laiffé prévenir.

Jean de Laët ayant donc bien réfuté les opinions, qu'on avoit avancées jufqu’à lui ; \& n'ayant pas prouvé la fienne avec le même fuccès, un Sçavant Hollandois, nommé Georges de HornN, entra dans la lice; $\&$ il y entra avec d'autant plus de confiance, qu'il crut tirer un grand avantage des nouvelles découvertes, que fes Compatriotes \& les Anglois venoient de faire au Nord de l'Afie, de l'Europe, \& de l'Amérique. 
Après avoir rapporté tout ce qu'on a jamais imaginé, c'eft-à-dire, tout ce qu'on trouve dans le Pere Garcia, \& dans Solorzano fur le fujet, qu'il entreprend de traiter, il met dans tout fon jour la difficulté de prendre fon parti ; difficulté fondée fur le peu de connoiffance, que nous avons des extrémités de la Terre, du côté du Nord \& du côté du Sud, \& fur ce que les Efpagnols, qui les Premiers ont découvert le Nouveau Monde, en ont ruiné les plus anciens monumens : témoin ce grand Chemin double de Quito à Cuzco ; Entreprife, à laquelle les Romains mêmes n'ọnt rien exécuté de comparable ( $a$ ). Il ne craint pourtant pas de fe promettre un heureux fuccès de fes recherches, \& trouve que le Pere de Acofta décide bien légerement qu'on ne peut fans témérité fe répondre de réuffir dans cette Entreprife. Voyons s'il n'a pas lui-même juftifié ce qu'il blâme dans l'Auteur Efpagnol,

Il déclare d'abord qu'on ne croit pas poffible que l'Amérique ait été peuplée avant le Déluge, vû le peu de tems, qui s'eft écoulé depuis la Création du Monde, jufqu’à ce grand événement. De très - habiles Gens ont pourtant cru que dès-lors il $y$ avoit autant d'Hommes fur la Terre, qu'il y en a aujourd'hui, du moins la chofe eft-elle poffible, $\&$ c'en eft affez pour ne point affûrer le contraire. Il faut avoüer néanmoins que de Hornn n'eft pas feul de fon fentiment; mais ce qu'il ajoûte, ne donne pas une grande idée de fon exactitude, ou de fa bonne foi. Selon lui , Lefcarbot fait naître Noë dans le Nouveau Monde ; cependant l'Hiftorien François n'a rien écrit, qui approche de ce Paradoxe.

Il pofe enfuite pour principe qu'après le Déluge, les Hommes \& les Animaux Terreftres ont pénétré dans l'Amérique par Terre, par Mer, de deffein formé, \& par hafard; que les Oifeaux y ont paffé en volant; ce qui ne doit point paroître étrange, puifqu'on en a vû fuivre pendant trois cent lieuës des Vaiffeaux, fans s'arrêter, \& qu'il fe rencontre par-tout des Rochers, \& des Ifles, où ils peuvent fe repofer. Ainfi, felon lui, Jean de Laët a eu raifon de dire que l'article des Oifeaux ne fait aucune difficulté. Tout le monde ne fera pourtant pas de leur avis, car combien connoiifonsnous de Volatilles, qui ne peuvent ni nâger, ni voler filoin ?

(a) Voyez M, BERG IER, fur les Grands Chemins des Romains. 


\section{DES A M E I Q UA INS.}

Le Pere de Acofta a aufli très-bien obfervé, au jugement du docte Hollandois, que les Bêtes Fauves ont pu trouver un paffage libre par les Terres, \& que , fi l'on n'a rencontré dans le Nouveau Monde, ni Chevaux, ni Bœufs, il pouvoit ajoûter, ni Elephans, ni Chameaux, ni Rhinoceros, ni beaucoup d'autres; c'eft que les Nations, qui y ont paffé, n'en avoient point l'ufage, ou n'ont pas eu la commodité de les y conduire. Il y a cependant des Bœufs en Amérique, mais d'une efpece très-differente de tous ceux, que nous connoiffons dans notre Hémifphere.

Pour ce qui eft des Hommes, de Hornn exclut de l'Amérique, I ${ }^{\circ}$. Les Ethiopiens, \& tous les Noirs, tant de l'Afie que de l'Afrique : le peu de Negres, qu'on a trouvé dans la Province de Careta, y ayant fans doute été conduits par quelque accident, ou par quelque hazard peu de tems auparavant. $2^{\circ}$. Les Norvégiens, les Danois, les Suédois, les Celtes, en un mot, tous les Peuples du Nord \& du milieu des Terres de l'Europe $\&$ de l'Afie. Cependant les Celtes $\&$ les anciens Bretons étoient grands Navigateurs \& autant à portée qu'aucun autre Peuple de fe tranfporter en Amérique. $3^{\circ}$. Les $\mathrm{Sa}$ mojedes \& les Lappons. Sa raifon pour exclure toutes ces Nations, eft qu'en Amérique on ne voit perfonne, qui ait les cheveux blonds \& frifés, ni qui porte de la barbe, fi ce n'eft les Miges, dans la Province de Zapoteca, les Scheries, vers Rio de la Plata, \& les Malopoques, dans le Brefil. Les Efquimaux ont auffi les cheveux blonds; \& ces exceptions ne laiffent pas d'embarraffer.

Tous les Indiens de l'Afie, continue de Hornn, croyent la Métempfycofe : donc ils n'ont point paffé en Amérique, où on ne la connoît point. Cependant de bons Auteurs, \& furtout le Sçavant K EMPFER, prétendent que la Métempfycofe n'a été portée aux Indes, que par $\mathrm{X}_{\mathrm{ACA}}$, qui vraifemblablement étoit un des Prêtres Egyptiens, que Cambife chaffa de leur Pays, quand il en eut fait la conquête. Avant lui, la Religion duFeu, \& le Culte du Soleil, étoient répandus dans la Perfe \& dans les Indes, \& l'un \& l'autre font fort anciens dans une bonne partie de l'Amérique. Autre preuve, qui ne me paroît pas plus convainquante, quoiqu'appuyée de l'autorité de Diodore de Sicile. Les Indiens n'ont jamais, diton, envoyé de Colonies hors de chez eux: donc ils n'one Tome III. 
point contribué à peupler le Nouveau Monde. Ces propofitions générales font bien difficiles à démontrer, fur-tout par rapport à un Pays tel que les Indes, occupé par tant de $\mathrm{Na-}$ tions, de mœurs, d'ufages, \& de génies fi differens.

Les Grecs \& les Latins font encore exclus du Nouveau Monde. Ils ne pouvoient pas, felon notre Auteur, naviguer au-delà de Cadix, par la raifon, que les Carthaginois, puiffans fur la Mer Atlantique, ne les y auroient pas foufferts. Cette preuve me paroît bien foible, fur-tout par rapport aux Grecs, qui ayant fondé Cadix, pouvoient y être affez forts pour tenir la Mer malgré les Carthaginois. J'aimerois mieux dire qu'Her CULES s'étant perfuadé qu'il n'y avoit rien au-delà de cette Mer, il n'eft pas venu à l'efprit de fes Compatriotes de s'y embarquer, ce qui ne feroit pourtant qu'une conjecture affez aifée à détruire.

Enfin, les Chrétiens, les Hébreux, les Mahométans, fi on en croit de Hornn, ne fe font point établis dans le Nouveau Monde ; \& fi ce Sçavant ne rejette pas abfolument tout ce qu'on a publié des Croix, du Baptême, de la Circoncifion, de la Confeffion, des Jeûnes, \& des autres pratiques de Religion, dont on a prétendu avoir trouvé des veftiges dans l'Yucatan \& ailleurs, nous allons voir quel égard il y a eu dans l'arrangement de fon fyftême, dont voici le plan.

Il fuppofe d'abord que l'Amérique a commencé d'être peuplée par le Nord ; \& regardant comme une fuppofition dénuée de fondement, la Barriere de l'Ifthme de Panama, que Grotius a cru n'avoir point été franchie avant les Efpagnols, il foûtient que les premieres Colonies font allées beaucoup au-delà, puifque l'on rencontre dans toute l'étenduë de ce Continent, dans la Partie Méridionnale, comme dans la Septentrionnale, des traces certaines du mêlange des Nations du Nord avec celles, qui font venuës d'ailleurs. Il croit que les premiers Fondateurs de ces Colonies font des Scythes; que les Phéniciens \& les Carthaginois ont abordé enfuite en Amérique par l'Ocean Atlantique, \& les Chinois par la Mer Pacifique, mais que de tems en tems d'autres Peuples ont pû y paffer par quelqu'une de ces voyes, ou y avoir été jettés par la Tempête; enfin, que quelques Chrétiens \& quelques Juifs ont pû s'y trouver tranfportés par quelque événe- 
ment femblable, mais dans un tems, où tout ce Nouveau Monde étoit peuplé.

Il obferve, ce me femble, très-bien que les Géans, qu'on a pu voir en quelques endroits de l'Amérique, ne prouvent rien; que fi dans les premiers fiécles ils étoient moins rares, on ne peut pas dire qu'ils ayent jamais fait un Corps de $\mathrm{Na}$ tion; que comme leurs Defcendans n'ont pas tous hérité de leur taille, des hommes d'une ftructure ordinaire ont pu produire, \& produifent encore aujourd'hui de ces Coloffes, ainfi qu'on le peut voir dans les Relations modernes de la Virginie, \& du Sénegal. Jufqu'ici il ne dit rien de nouveau, \& la plupart de fes obfervations avoient été faites avant lui : mais voici du neuf, qui lui eft propre: il paffe de la poffibilité au fait, \& des conjectures aux affertions, \& cet effor une fois pris, il va fort loin: fuivons-le, il nous divertira, \& de tems en tems il nous dira d'affez bonnes. chofes.

Laiffant à part les Scythes, qu'il fuppofe avoir paffé par le Nord en Amérique, \& y avoir formé les premieres Peuplades, il établit une premiere tranfmigration de Phéniciens, en pofant pour principe que dès les premiers tems ils ont été Navigateurs, \& ont rempli tout notre Hemifphere de leurs Colonies: mais il eft bon d'obferver, que fous le nom de Phéniciens, il comprend auffi les Cananéens. Il trouve dans Strabon que les Phéniciens font entrés dans la Mer Atlantique, \& ont bâti des Villes au-delà des Colonnes d'Hercules. Appien, continuë-t'il, \& Pausanias ont écrit que les Carthaginois, qui étoient originaires de Phénicie, ont couvert toutes les Mers de leurs Flottes: Hannon a fait le tour de l'Afrique; les Canaries étoient connuës des Anciens. On fçait d'ailleurs que les premiers Phéniciens établis en Afrique y ont eu à 1oûtenir de grandes guerres contre les Naturels du Pays, qui leur ruinerent plus de trois cent Villes dans la Mauritanie. ERAstot HenE eft ici fon garant, \& il préfere l'autorité de cet ancien Ecrivain à celles de Strabon \& d'ARTEMIDORE, qui le contredifent. Oì ces Phéniciens, ajoûte-t'il, auroient-ils pû fe retirer, après de fi grandes pertes, que dans l'Amérique?

Cette premiere Tranfmigration lui paroît certaine, dès qu'elle eft poffible, \& il la juge très-ancienne; mais il fe 
mocque d'OpMéER, qui a avancé que les Afriquains des environs du Mont Atlas ont navigué en Amérique avant le Déluge. Il croit bien que tout ce que Platon a dit de l'Atlantide, n'eft pas exact, mais il prétend qu'il y a du vrai dans la defcription, qu'il en fait. Il obferve qu'on a nommé Atlantides toutes les Ifles, qui font à l'Occident de l'Afrique, \& il eftime vraifemblable que l'Atlantide de Platon étoit dans l'Amérique, \& qu’elle a été fubmergée par le Déluge, dont il refte encore quelque leger fouvenir parmi les Amériquains. Il dit encore que, felon Pierre Martyr d'Anglerie, les Infulaires des Antilles racontoient que leurs Illes avoient été autrefois jointes à la Terre-ferme, \& n'en avoient été féparées, que par des Tremblemens de Terre, \& de grandes Inondations: qu'on trouve encore dans le Pérou des veftiges d'un Déluge, \& que toute l'Amérique Méridionnale eft pleine d'eau. Il auroit pû y joindre la Septentrionnale, où la Nouvelle France feule a plus d'eaux, que tout le refte de ce grand Continent.

Diodore de Sicile a écrit que les Phéniciens avoient navigué fort loin dans l'Océan Atlantique, \& forcés par des Tempêtes, avoient pris Terre à une grande Ifle, à l'Occident de la Lybie, où ils avoient trouvé un Terrein fertile, dez Fleuves naviguables, \& de fomptueux Edifices. De Hornn explique ceci de la feconde Tranfmigration de ces Peuples en Amérique. Diodore ajoûte que dans la fuite les Carthaginois, vexés par les Tyriens \& par les Habitans de la Mauritanie, qui ne leur donnoient ni paix, ni tréve, menerent dans cette Inle des Colonies, \& tinrent la chofe fecrette, afin d'avoir toujours de ce côté-là une retraite affûrée, en cas de difgrace. D'autres Auteurs, que de Hornn ne nomme pas, ont prétendu que ces Voyages fe faifoient à l'infçû des Magiftrats, lefquels s'appercevant que leur Etat fe dépeuploit, \& ayant découvert la fource de ce défordre, défendirent cette navigation fous de très - griéves peines.

Enfin, la troifiéme Tranfmigration des Phéniciens dans le Nouveau Monde fut occafionnée, felon notre Auteur, par un Voyage de trois ans, que fit la Flotte Tyrienne, qui étoic au fervice de Salomon. D'abord, fur l'autorité de Jofeph, il affûre qu'Afion-Gaber, où fe fit l'embarquement, eft un Port de la Méditerranée. La Flotte, ajoûte-t’il, alloit cherchez 
des Dents d'Eléphans \& des Paons fur la Côte Occidentale d'Afrique, qui eft Tharf $\mathrm{is}$ : c'eft auffi le fentiment de M. HUET : puis de l'Or à $O$ phir, qui eft $H a ̈$ äti, l'Ifle Efpagnole: Chriftophe Colomb l'avoit dit avant lui, felon quelques-uns, \& Vatable a certainement été du même fentiment. De Hornn revenant enfuite aux Inles Atlantiques, veut nous perfuader que les Phéniciens y ont eu en divers tems des Colonies, \& que la Cerné des Anciens eft la Grande Canarie, laquelle doit fon nom aux Cananéens, qui s'y réfugierent.

Une des Canaries s'appelle la Gomera: le docte de Hornn ne doute point qu'elle ne doive fon nom aux Amorrhéens, qui vinrent l'habiter, après avoir été chaffés de la Paleftine par les Hébreux. Faut-il s'étonner après cela, s'il retrouve le Cham des Phéniciens dans les Chemez de l'Ifle Haiti, dans les Camis du Japon, \& dans le Chile Cambal de l'Yucatan? Tout eft à peu près de la même force $\&$ du même goût dans le détail, où il entre enfuite pour découvrir des traces de la Religion \& des Mœurs Phéniciennes dans le Nouveau Monde. Mais il fait ici une remarque, que je ne dois point paffer fous filence, c'eft que les premiers Phéniciens, qui s'établirent dans l'Afrique, \& dans les Ifles Baleares, n'avoient ni Caracteres, ni aucun ufage de l'Ecriture, \& que Cadnus, qui étoit Phénicien, porta dans la Grece, non les Caracteres, dont fa Nation s'eft fervie depuis, mais ceux, dont fe fervoient de fon tems les Egyptiens.

Toutes ces Tranfmigrations ont précédé de plufieurs fiécles la Venuë de Jefus-Chrift : en voici de plus modernes. Notre Auteur diftingue trois fortes de Scythes, qui ont paffé dans le Nouveau Monde, des Huns, des Tartares du Cathay, \& des Chinois. A coup fûr, les Partifans de l'Antiquité de la Nation Chinoife ne lui pafferont pas que ce grand Empire a eu des Scythes pour Fondateurs, \& ceux mêmes, qui n'admettent point ce qu'il y a d'incertain dans les prétentions de quelques Chinois, ne feront pas de fon avis. Il eft aujourd'hui: conftant que l'Empire Chinois n'eft pas fort poftéricur aux. Petits -Fils de Noë. Mais nous ne finirions point, fi nous voulions relever toutes les fuppofitions fauffes $\&$ hafardées de l'Ecrivain Hollandois.

Sous le nom de Huns, il comprend des Nations fans nombre, qui occupoient un Pays immenfe : 8 l'occafion du paf- 
fage de plufieurs en Amérique fut, felon lui, leur multitude \& leurs guerres inteftines. Pour ce qui eft de la route, qu'il leur fait prendre, il prétend qu'ils pafferent par l'extrémité du Nord, où ils trouverent des Mers glacées. Puis oubliant ce qu'il venoit de dire du nombre infini de ces Barbares, que leurs vaftes Contrées ne pouvoient plus contenir ; comme il avoit déja oublié ce qu'il avoit dit d'abord, que les premieres Peuplades de l'Amérique s'étoient formées par les Scythes, il nous avertit que fi les Quartiers Septentrionnaux de l'Amérique font les moins peuplés, c'eft que le Pays des Huns l'a été fort tard, \& qu'encore aujourdhui il ne l'eft pas beaucoup.

Mais, allerent-ils tous par le même chemin? Non, car tandis que le plus grand nombre tournoit à droite, vers l'Orient, ceux, qu'on appelloit Finnes, \& que Corneille TACITE place dans la Finlande, les Samojedes, \& les Caroliens prirent à gauche par l'Occident, traverferent la N. Zemble, la Lapponie, \& le Groënland, d'où il juge auffi que des Norvegiens, qui avoient été autrefois débarqués dans le Groënland, \& dont on ne trouva plus un feul en I 348 , ont pénétré dans le Nord de l'Amérique, pour y chercher des Pays plus habitables. Rien dans le fond n'empêche de croire que les Eskimaux \& quelques autres Nations voifines de la Baye d'Hudfon, tirent leur Origine des Norvégiens Groënlandois, s'il y en a jamais eu. Ce qui eft certain, c'eft que les Eskimaux n'ont rien de commun, ni pour le langage, ni pour les mours, ni pour la maniere de vivre, ni pour la couleur du Corps \& des.Cheveux avec les Peuples du Canada même, leurs plus proches Voifins.

Quant à certains Animaux, tels que les Lions \& 2 les Tygres, qui, felon toutes les apparences, ont paffé de la Tartarie \& de l'Hircanie dans le Nouveau Monde, leur paffage pourroit bien être une preuve que les deux Hemifpheres fe touchent par le Nord, du côté de l'Afie, \& ce n'eft pas la feule, que nous en ayions, fi ce que iai fouvent oui raconter, comme un fait certain, du Pere GRELLON, Jéfuite François, eft véritable. Ce Pere, dit-on, après avoir travaillé quelque tems dans les Miflions de la Nouvelle France, paffa à celles de la Chine. Un jour, qu'il voyageoit en Tartarie, il rencontra une Femme Huronne, qu'il avoit connuë en 
Canada : il lui demanda par quelle aventure elle fe trouvoit dans un Pays fi éloigné du Sien ? Elle répondit qu'ayant été prife en guerre, elle avoit été conduite de Nation en Nation jufqu'à l'endroit, où elle fe trouvoit. On m'a encore affûré qu'un autre Jéfuite paffant par Nantes au retour de la Chine, $\mathrm{y}$ avoit rapporté un trait affez femblable d'une Femme Efpagnole de la Floride : elle avoit été prife, difoit-il, par des Sauvages, \& donnée à une Nation plus éloignée, \& par celleci à une autre; elle avoit ainfi fucceffivement pafé de Pays en Pays, traverfé des Régions très-froides, \& s'étoit enfin rencontrée en Tartarie, y avoit époufé un Tartare, qui avoit paffé en Chine avec les Conquérans, \& s'y étoit établi.

$A$ la vérité ceux, qui ont navigué le plus loin à l'Orient de l'Afie, en fuivant les Côtes d'Yeffo, ou de Kamtfchatka, ont prétendu appercevoir l'extrémité de ce Continent, \& ont conclu qu'entre l'Afie \& l'Amérique, il n'y avoit point de communication par Terre; mais outre que François GUELLA, Efpagnol, fi on en croit Jean Hugues de Linschooten, a vérifié que cette féparation n'étoit qu'un Détroit de cent milles de large, les dernieres navigations des Japonnois donnent lieu de juger que ce Détroit n'eft qu'une Baye, au-deffus de laquelle on peut paffer parTerre.

Revenons à Georges de Hornn. Cet Ecrivain ne s'exprime pas exactement, lorfqu'il dit que l'Amérique Septentrionnale eft remplie de Lions \& de Tygres. On trouve bien dans le Pays des Iroquois une efpece de Tygres, dont le poil eft de petit gris, qui ne font pas mouchetés, dont la queuë eft fort longue, \& dont la chair eft bonne à manger: mais à cela près, ce n'eft que vers le Tropique, que l'on commence à voir de vrais Tygres \& de vrais Lions, ce qui ne prouve pourtant point, qu'ils n'y foient point venus de la Tartarie $\&$ de l'Hircanie : mais comme en avançant toujours au Sud, ils y ont trouvé des Climats, qui leur convenoient davantage, on peut croire qu'ils ont tout-à-fait abandonné les Pays Septentrionnaux.

Ce que Solin \& Pline rapportent, que les Scythes Anthropophages ont dépeuplé une grande étenduë de Pays, jufqu'au Promontoire Tabin : \& ce que Marc Pol de Venife nous apprend, qu'au. Nord-Eft de la Chine \& de la Tartarie il y a de vaftes $P$ ays inhabités, pourroient bien confirmer la conjec- 
ture de notre Auteur touchant la retraite d'un grand nombre de Scythes en Amérique. On trouve dans les Anciens les noms de quelques-uris de ces Peuples : Ptolémée parle des Tabiens; Solin nomme les Apaléens, qu'il dit avoir eu pour Voifins les Meffagetes, \& que Pline affûre avoir difparu. Ammien MARCELLIN dit expreffément que la crainte des Anthropophages obligea plufieurs des Habitans de ces Contrées à fe réfugier ailleurs. Toutes ces Autorités forment, ce me femble, au moins une forte conjecture, que plus d'une $\mathrm{Na}$ tion Amériquaine a une Origine Scythe ou Tartare.

Jufques-là de Hornn ne s'égare donc pas fi loin de fon but, qu'il n'y revienne de tems en tems, \& l'on reconnoît le Sçavant jufques dans fes écarts. Mais à la fin on diroit qu'à force de vouloir conjecturer fur des convenances de noms, la tête lui a tourné. Qui ne riroit, par exemple, en lui voyant avancer férieufement que les Apalaches, Nation Floridienne, font les Apaléens de Solin, \& que des Tabiens de Ptolémée font defcendus les Tombas du Perou? Ce qui fuit eft encore plus rifible. Il y a, dit-on, un Peuple Voifin des Mogols, qu'on appelle Huyrons. Voilà les Hurons du Canada : Herodote donne aux Turcs le nom d'Yrcas. Voilà les Iroquois $\& \tau$ les Souriquois de l'Acadie. Par malheur pour de fi rares découvertes, la conjecture porte à faux : car tous ces noms des Sauvages de la Nouvelle France, ou prefque tous, font de la'façon des François.

Il y a plus, les Hurons \& les Iroquois, à qui notre Auteur donne des Origines fi differentes, parlent à peu près la même langue; l'une eft une Dialecte de l'autre : au lieu que les Souriquois, auxquels de Hornn donne les mêmes Ancêtres, qu'aux Iroquois, n'ont abfolument rien de commun avec eux dans le Langage, ni dans le caractere d'efprit. La Langue, qu'ils parlent eft une Dialęte Algonquine, \& le Huron ent auffi different de l'Algonquin, que le Latin l'eft de l'Hébreu. Ne faut-il pas auffi avoir l'imagination bien frappée, pour fe perfuader que le Meyra Humona des Brafiliens, \& le Pä̈euma des Habitans de Santa-Cruz, viennent de Saint Thomas, \& font dérivés de la Langue des Turcs, qui avant que de paffer en Amérique, avoient eu quelque connoiffance de cet Apôtre?

La confiance abandonne notre Auteur, lorfqu'il femble qu'elle 

qu'elle devroit moins lui manquer; il n'ofe décider, fi l'Amérique Méridionnale a peuplé les Terres Auftrales, ou fi elle en a reçu fes Habitans: mais il la retrouve bientôt, \& elle lui fait entreprendre de débrouiller l'Origine des Empires du Pérou \& du Méxique. Il convient avec plufieurs Hiftoriens, que ces Monarchies n'étoient pas fort anciennes, lorfque les Efpagnols les détruifirene, \& que leurs Fondateurs ont eu à combattre des Peuples Barbares, établis depuis lontems dans les Pays, qu'ils avoient choifis, fur-tout dans le Méxique, où les mœurs étoient bien moins douces au tems de Cortez, que parmi les Péruviens. Cette difference venoit apparemment de ce que les Conquerans du Méxique n'étojent pas auffi policés, que ceux du Perou.

Les uns \& les autres, fi on en croit de Hornn, font néanmoins fortis des mêmes lieux : ce font, dit-il, les Peuples du Cathay; les Japonnois, qui en font originaires; les Chinois, qu'il fuppofe toujours defcendus des Scythes ; quelques Egyptiens \& quelques Phéniciens, de qui ces deux Empires ont reçu toute leur Police, leur Religion, \& les Arts. Voilà affûrement une Origine bien mélangée, \& bien bifarrement affortie. Mais enfin le Scavant Hollandois veut que tous ces Peuples ayent envoyé des Colonies en Amérique , \& pour le prouver, il n'eft pas concevable où il va chercher des noms Cathayens, Coréens, Chinois, \& furtout Japonnois dans toutes les Parties du Nouveau Monde. Il y a fouvent entre ces noms à peu près le même rapport, qu'entre l'Alfana \& l'Equus de MÉNAGE ; mais auffi on leur fait faire un fi long chemin, qu'on ne doit pas être furpris, s'ils ont fi fort changé fur la route.

Il n'y a pas jufqu'aux Chiquites du Paraguay, dont il ne faffe dériver le nom, lequel eft purement de la façon des Efpagnols, de celui de Cathay. Le nom d'Incas, qui étoit celui de la Famille Impériale du Perou, a, felon lui, trop de reffemblance avec le même nom de Cathay, pour qu'il foit permis de douter que ces Souverains ne tiraffent leur Origine de ce grand Pays. En un mot, chercher des Catayens en Amérique, c'eft, dit-il, chercher des Grecs en Italie, \& des Phéniciens en Afrique. Les Coréens appellent leur Pays $C_{a o}$. $l i$ : donc la Californie a été peuplée par une Colonie Coréenne: Chiappa, Province du Méxique, peut-il venir d'ailleurs Tome III. 
que de Giapan, nom, que quelques-uns donnent au Japon ? Motezuma, Empereur du Méxique, avoit une Barbe â la Chinoife : il n'en faut pas davantage pour le faire Originaire de la Chine. Ce n'eft pourtant pas fans fcrupule, que notre Auteur quitte les étymologies pour la figure de la Barbe : mais cette Barbe eft fort finguliere dans un Méxiquain. D'ailleurs il trouve que le nom du Monarque a beaucoup d'affinité avec celui de Motuzaïuma, quilil prétend, je ne fçai fur quelle autorité, être un titre d'honneur au Japon : ainfi ce Prince pourroit bien tirer fon Origine de ces Ifles.

Cependant ce ne font ni les Cathayens, ni les Japonnois, qui ont fondé la Monarchie Méxiquaine: de Hornn en fait honneur à Facfur, Roy de la Chine, qui, détrôné par Cublay, Grand Cham des Tartares, s'enfuit avec cent mille Hommes fur mille Vaiffeaux en Amérique, \& y devint le Fondateur d'un nouvel Empire. Manco, autre Prince Chinois, Originaire du Cathai , avoit fondé deux fiécles auparavant celui du Perou. Voilà bien des noms, que les Peres Couplet, le Comte \& du Halde ne fçavoient pas. Manco avoit porté les Arts à une très-grande perfection, \& ce fut lui, qui éleva ces Edifices fomptueux , qui étonnerent fi fort les Efpagnols. Il ne mena point de Chevaux en Amérique, parce que de fon tems, dit Marc Pol de Venife, il n'y en avoit point à la Chine. Mais pourquoi les Chinois du Perou n'ont-ils pas confervé leurs caraeteres? c'eft, répond de Hornn, qu'ils étoient trop difficiles à écrire; ils ont trouvé qu'il étoit plus court \& plus aifé d'y fuppléer par des figures fymboliques.

Voilà une partie de ce qui a été écrit fur la queftion préfente, \& je fuis bien trompé, fi la fimple expofition de tant d'opinions diverfes n'eft pas fuffifante pour fournir à tout Lecteur attentif les lumieres, dont il a befoin pour prendre le feul parti, qui convienne fur cette grande controverfe, qu'on n'a fait qu'embrouiller, en voulant l'éclaircir. Il me paroît qu'elle fe réduit à ces deux points. $1^{\circ}$. Comment le Nouveau Monde a-t-il pu être peuplé ? $2^{\circ}$. Par qui, \& par quelle voye l'a-t'il été?

Rien, ce me femble, n'eft plus aifé que de répondre au premier. L'Amérique a pu être peuplée, comme les trois autres parties du Monde. On s'eft formé fur cela des diffi- 
cultés, qu'on croyoit infolubles, \& qui ne l'étoient point. Les Habitans de l'un \& de l'autre Hemifphere, font certainement les Defcendans d'un même Pere. Ce Pere commun avoit reçu du Ciel un ordre précis de peupler toute la Terre, \& elle l'a été. Il a fallu pour cela franchir des difficultés, \& on les a franchies. Y en avoit-il de plus grandes pour les extrêmités de l'Afie, de l'Afrique, \& de l'Europe ; pour fe tranfporter dans des Ifles affez éloignées de ce grand Continent, que pour paffer en Amérique ?non fans doute. La navigation, qui s'eft $\mathrm{fi}$ fort perfectionnée depuis trois ou quatre fiécles, étoit peut-être plus parfaite dans les premiers tems, qu'elle ne l'eft aujourd'hui. Du moins ne peut-on pas douter qu'elle ne fût alors dans le dégré de perfection néceffaire, pour le deffein, que Dieu avoit de peupler toute la Terre.

Tant que les Auteurs, que j’ai cités, s'en font tenus à cette poffibilité, qu'on ne fçauroit nier, ils ont raifonné fort jufte ; car s'il n'eft pas démontré qu'il y ait un paffage par Terre en Amérique, foit au Nord de l'Afie \& de l'Europe, foit au Sud; le contraire ne l'eft point: d'ailleurs des Côtes de l'Afrique au Brefil ; des Canaries aux Açorres, des Açorres aux Antilles, des Inles Britanniques \& des Côtes de France en Terreneuve, la Traverfée n'eft ni longue ni difficile: $j$ 'en pourrois dire autant de la Chine au Japon, du Japon \& $\&$ des Philippines aux Inles Mariannes, \& de-là au Méxique. Il y a dans l'Afie des Ifles auffi éloignées de tout Continent, où l'on n'a pas été furpris de trouver des Hommes; pourquoi le feroiton d'en avoir trouvé dans l'Amérique ? \& peut-on concevoir que les Petits-Fils de Noë, lorfqu'ils furent obligés de fe féparer, \& de fe répandre, felon les deffeins de Dieu, par toute la Terre, ayent été dans l'impoffibilité de peupler prefque la moitiê de l'Univers ?

Il falloit donc s'en tenir là ; mais la queftion êtoit trop fimple , \& la réponfe trop aifée à faire. Les Sçavans veulent difcuter, \& ils ont cru pouvoir décider comment, \& par qui l'Amérique a été peuplée : \& parce que les Hiftoires ne leur fourniffoient rien pour cela, plûtôt que de demeurer court, ils ont réalifé les conjectures mêmes les plus frivoles. Une fimple convenance de noms, une légere apparence leur ont paru des preuves, \& fur ces fondemens ruineux ils ont bâti 
des fyftêmes, dont ils fe font entêtés, dont les plus ignorans peuvent appercevoir le faux, \& quón renverfe fouvent par un feulfait, qui ne peut être contefté. De-là il eft arrivé que la maniere, dont le Nouveau Monde a reçu fes premiers Habitans, demeurant fort incertaine, on a imaginé des difficultés, où il n'y en avoit point; on a "porté l'extravagance jufqu'à fe perfuader que les Amériquaius n'étoient point iffus du premier Homme, que nous reconnoiffons pour notre Pere commun; comme fi l'ignorance de la maniere, dont un fait eft arrivé, devoit le faire juger impo Tible, ou lui donnoit même un dégré de difficulté,

Ce qu'il y a en ceci de plus fingulier, c'eft qu'on n'a pas pris, pour fçavoir ce qu'on cherchoit, le feul moyen, qui nous reftoit: je veux dire, la confrontation des Langues : en effet dans la recherche, dont il s'agit, il me paroît que la connoiffance des Langues principales de l'Amérique, \& leur comparaifon avec celles de notre Hemifphere, qui font regardées comme Primitives, pourroient nous faire parvenir à quelque heureufe découverte; \& que ce moyen le moins équivoque de tous, de remonter à l'origine des $\mathrm{Na}$ tions, n'eft pas auffi difficile, qu'on pourroit le croire. Nous avons eu , \& nous avons encore des Voyageurs \& des Miffionnaires, qui ont travaillé fur les Langues, qu'on parle dans toutes les Provinces du Nouveau Monde. Il ne faudroit que faire un Recueil de leurs Grammaires \& de leurs Vocabulaires, \& les rapprocher des Langues mortes, ou vivantes de l'ancien Monde, qui paffent pour être originales. Les Dialectes mêmes, malgré l'altération, qu'elles ont fouffertes, tiennent encore affez de la matrice, pour nous fournir dé grandes lumieres.

Au lieu de ce moyen, qu'on a négligé, on a cherché dans les Mœurs, les Coûtumes, la Religion, \& les Traditions des Amériquains, leur premiere Origine : cependant je fuis perfuadé que cet examen ne peut produire qu'un faux jour, plus capable d'éblouir \& d'égarer, que de conduire fûrement au but, qu'on fe propofe. Les anciennes Traditions s'effacent de l'efprit de ceux, qui n'ont, ou qui pendant plufieurs fiécles n'ont eu aucun fecours pour les conferver; \& la moitié du Monde eft dans le cas. De nouveaux événemens, un nouvel ordre de chores, font naître d'autres Tra- 
ditions, qui effacent les premieres, \& font effacées à leur tour. Au bout d'un fiécle ou deux on n'a plus rien, qui puiffe fervir de guide pour retrouver la trace des premieres Traditions.

Les Mœurs dégénerent en très-peu de tems par le Commerce avec d'autres Nations, par le mélange de plufieurs Peuples, qui fe réuniffent; par le changement de domination, toujours fuivi d'une nouvelle forme de gouvernement. $\vec{A}$ combien plus forte raifon cette altération de mours \& de caractere doit-elle être fenfible parmi des Peuples errans, devenus Sauvages, vivant fans principe, \& fans regles, qui les rappellent aux Mours antiques, telles que font l'éducation, \& la fociété. Les Coûtumes s'aboliffent encore pius aifément. Un nouveau genre de vie en introduit de nouvelles, \& l'on a bientôt oublié celles, que l'on a abandonnées. Que dirai-je de la privation des chofes les plus néceffaires à la vie? La néceffité, où l'on eft de s'en paffer, en fair perdre les noms avec l'ufage.

Enfin rien n'a effuyé de plus promptes, de plus fréquentes $\&$ de plus étranges révolutions, que la Religion. Quand une fois on a renoncé à l'unique véritable, on ne tarde point à la perdre de vûë, \& on s'engage dans un labyrinthe d'erreurs fi peu liées entr'elles, parce que l'inconféquence $\&$ les contradictions font l'appanage effentiel du menfonge, qu'il ne refte pas le moindre fil, qui puiffe ramener à la vérité. Nous en avons vî dans le fiécle précédent un exemple bien fenfible. Les Boucaniers de S. Domingue étoient Chrétiens, \& n'avoient de commerce qu'entr'eux : toutefois en moins de trente ans, par le feul défaut d'exercice de Religion, d'inftruction, \& d'une autorité, qui les retînt dans le devoir, ils en étoient venus jufquà n'avoir plus du Chrétien que le Baptême. S'ils avoient fubfifté feulement jufqu’a la troifiéme génération, leurs Petits-Fils auroient été auffi peu inftruits des principes du Chriftianifme, que les Habitans de la Nouvelle Guinée, ou des Terres Auftrales. Peut-être auroientils confervé quelques pratiques, dont ils n'auroient pû rendre raifon, \& n'eft-ce pas de cette forte que tant de Nations Infidéles fe font trouvées avoir mélé dans leur Culte Idolatre, des Cérémonies, qui paroiffoient copiées d'après les nôtres?

Il n'en eft pas de même des Langues. Je conviens qu'une 
Langue vivante eft fujette à de continuels changemens, \& comme toutes l'ont été, on peut dire qu'aucune ne s'eft confervée dans fa pureté originale. Mais il n'en eft pas moins vrai, que malgré les changemens, que l'ufage y a faits, elles n'ont pas perdu tout ce qui les diftinguoit des autres, ce qui fuffit pour ce qu'il nous faut dans le cas préfent; \& que des ruiffeaux, qui font fortis des principales fources, je veux dire des dialectes, on peut remonter jufqu'aux Langues Meres, comment cela? c'eft que, fuivant la remarque d'un fçavant Académicien ( $a$ ), les Langues Meres fe reconnoiffent en ce qu'elles font plus énergiques, que celles, qui en font dérivées, parce qu'elles ont été formées fur là nature; qu'elles contiennent un plus grand nombre de mots imitatifs des chofes, dont ils font les fignes; qu'elles doivent moins au hazard, \& que le mêlange, qui a formé les dialectes, fait toujours perdre à celle-ci une partie de l'énergie, que leur donnoit le rapport naturel de leur fon avec les chofes, dont ils étoient les fignes inftitués.

De-là je conclus, que fil l'on trouve dans l'Amérique des Langues, qui ayent ces carąteres, il n'eft pas permis de douter qu'elles ne remontent à la premiere origine des Langues; \& par conféquent que les Nations, qui les parlent, n'aycnt palfé dans cet Hemifphere affez peu de tems après la premiere difperfion des Peuples; furtout, fi dans notre Continent elles font entierement inconnuës. J'ai déja obfervé, qu'on fuppofe gratuitement que les arrieres Petits-Fils de Noë, ou n'ont pu paffer dans le Nouveau Monde, ou n'y ont pas penfé. Je ne vois en effet aucune raifon, qui puiffe autorifer une pareille fuppofition; \& qui peut croire de bonne foi, que Noè \& fes Enfans en fçavoient moins que nous : que l'Ârtifan \& le Pilote du plus grand Navire, qui ait jamais été, d'un Navire, qui devoit voguer fur une Mer, laquelle n'avoit plus de bornes, \& qui avoit à fe garantir de tant d'écuëils, ait ignoré, \& n'ait pas communiqué à ceux de fes Defcendans, qui ont vécu avec lui , \& par qui devoit s'exécuter l'ordre du Créateur, de peupler l'Univers, ne leur ait pas, dis-je, communiqué l'art de naviguer fur un Océan plus calme, \&x renfermé dans fes anciennes limites?

Eft - il même bien décidé, que l'Amérique n'a point eu (a) M. l'Abbé Dubos, Hiftoire de la Peinture ón de la Poëfęe. 
dHabitans avant le Déluge? Eft.il vraifemblable que Noë \& fes Enfans n'ont connu que la moitié du Monde ; \& Moyfe ne nous apprend-il pas que toutes les Terres \& les Ifles les plus éloignées ont été peuplées ? Comment accorder cela avec la pretention de ceux, qui foûtiennent que les Premiers Hommes ignoroient l'art de naviguer ; \& peut-on bien dire férieufement, contre l'autorité d'un témoignage fi refpectable, comme a fait Jean de Laët, que la navigation eft un effet de l'audace des Hommes; qu'elle n'entroit point dans les vûës directes du Créateur, \& que Dieu avoit abandonné la Terre aux Hommes, \& l'Eau aux Poiffons ? D'ailleurs les Ifles ne font-elles point partie de la Terre, \& n'y at-il point des endroits du Continent, où il étoit plus naturel d'aller par Mer, que par de longs détours, fouvent impratiquables, ou du moins d'une difficulté capable de faire tout entreprendre pour les éviter ?

Il eft certain que l'art de naviguer a eu le fort de quantité d'autres, dont on n'a aucune preuve que nos premiers Peres ont été privés, dont quelques-uns font perdus, \& d'autres n'ont été confervés que dans un petit nombre de Nations : mais qu'eft-ce que cela prouve ? Il faut toujours en revenir à ce principe, que les Arts néceffaires aux deffeins de Dieu n'ont point été ignorés de ceux, qui les devoient remplir. L'induftrie en a peut-être fait inventer, qui n'étoient qu'utiles ; \& la cupidité en a fait découvrir, qui ne pouvoient fervir, qu'à fatisfaire nos paffions. On peut croire auffi que ce qui en a fait tomber plufieurs dans l'oubli, c'eft qu'ils n'étoient plus néceffaires, \& que telle a été la navigation de long cours, dès que toutes les parties de la Terre ont eu des Habitans. Il fuffifoit pour le Commerce de ranger les Côtes, $\&$ de traverfer aux Ifles les plus proches. Faut -il s'étonner que, faute d'ufage, on ait perdu le fecret de faire de longues courfes fur un Elément fi inconftant, \& fi fouvent orageux?

Qui peut même affûrer qu'on l'ait perdu fi-tôt ?' Strabon dit en plufieurs endroits que les Habitans de Cadix \& tous les Efpagnols avoient de grands Vaiffeaux, \& excelloient en l'art de naviguer. Pline fe plaint de ce que de fon tems la navigation n'étoit pas auffi parfaite, qu'elle l'avoit été plufieurs fiécles auparavant; les Phéniciens \& les Carthaginois ont eu lontems la réputation d'être habiles \& hardis 
Navigateurs. Le P. de Acofta convient que Vafco de Gama rrouva parmi les Habitans du Mozambique l'ufage de la Bouffole. Les Infulaires de Madagafcar ont une Tradition, qui porte que les Chinois ont envoyé une Colonie dans leur Inle. Rejetter cette Tradition fur l'impoffibilité de naviguer' fi loin fans Bouffole, n'eft-ce pas une pure pétition de principe? Car enfinfi la Bouffole eft néceffaire pour aller de la Chine à Madagafcar, j'ai autant de droit de dire, fur la foi d'une Tradition conftante dans une grande Inle; les Chinois ont paffé à Madagafcar, donc ils connoiffoient l'ufage de la Bouffole; qu'on en a de raifonner ainfi: les Chinois ignoroient l'ufage de la Bouffole, donc ils n'ont point paffé à Madagafcar. Je n'entreprends pourtant pas de foûtenir le fait, quoique je puiffe le faire avec de bons Auteurs; mais je ferois auff fondé à l'avancer, que d'autres à le rejetter.

Les Chinois, dont l'Origine remonte aux Petits-Fils de Noë, ont eu anciennement des Flottes; c'eft un fait affez bien établi dans l'Hiftoire: Qui a pu les empêcher de paffer au Mexique par les Philippines? Les Efpagnols font tous les ans cette route. De-là ils ont pu en rangeant la Côte peupler toute l'A mérique du côté de la Mer du Sud. Les Ifles Mariannes, \& tant d'autres, qu'on découvre tous les jours dans l'efpace de Mer, qui fépare la Chine \& le Japon de l'Amérique, ont pu être peuplées de la même maniere, les unes plûtôt, \& les autres plus tard. Les Habitans des Ifles de Salomon, ceux de la Nouvelle Guinée, de la Nouvelle Hollande, \& des Terres Autrales reffemblent trop peu aux Amériquains, pour qu'on puife imaginer qu'ils ayent la même origine, fi on ne remonte pas nux tems les plus éloignés. Leur ignorance ne permettra jamais de fçavoir d'où ils la tirent ; mais enfin tous ces Pays iont peuplés : il eft bien vraifemblable que quelques-uns l'ont été par accident. Or s'ils l'ont pu être de cette maniere, pourquoi veut-on qu'ils ne l'ayent pas été dans le même tems \& par la même voye, que les autres parties de la Terre?

Les anciens Celtes \& les Gaulois, fi renonmés par leur habileté dans la Navigation, qui ont envoyé tant de Colonies jufqu'aux extrémités de l'Afie \& de l'Europe, \& $\&$ dont on nge fçauroit prefque nier que l'Origine ne remonte jufquaux 
Enfans de Japhet, n'ont-ils pas pu pénétrer par les Açorres jufqu'en Amérique? \& fi on objecte que les Açorres étoient fans Habitans au quinziéme fiécle, je réponds que ceux, qui les Premiers ont découvert ces Ifles, les ont fans doute négligées, pour aller s'établir dans de plus grandes, de plus fertiles, \& dans un Continent immenfe, dont elles ne font pas fort éloignées. Les Eskimaux \& quelques autres Nations de l'Amérique Septentrionnale reffemblent fi fort à ceux du Nord de l'Europe \& de l'Afie, \& fi peu aux autres Peuples du Nouveau Monde, qu'il n'eft pas difficile de reconnoître qu'ils defcendent des Premiers, \& qu'ils n'ont rien de commun dans leur Origine moderne avec les Seconds ; je dis leur Origine moderne, car il n'y a guéres d'apparence qu'elle foit ancienne; 8 il n'y a aucun inconvénient à fuppofer que des Pays fi peu habitables, ont été habités plus tard que les autres.

Il n'en eft pas de même du refte de l'Amérique; on ne me perfuadera jamais qu'une partie fi confidérable de la Terre air été ignorée ou négligée des premiers Fondateurs des Nations; \& la raifon, qui fe tire du caractere des Amériquains, \& de la peinture affreufe, qu'on en a faite d'abord, ne prouve rien contre leur antiquité. Il y a trois mille ans au plus, que l'Europe étoit pleine de Peuples auffi Sauvages $\&$ auffi peu policés, que la plûpart d'entr'eux, $\&$ elle en a encore quelques reftes. L'Afie, le premier féjour des Hommes, \& par conféquent le premier fiége de la Religion, des bonnes mœurs, des Sciences \& des Arts, \& le centre des plus anciennes $\&$ des plus pures Traditions, ne voit-elle pas encore fes plus floriffants Empires environnés de la plus epaiffe barbarie? L'Egypte, qui s'eft vantée d'avoir eté la fource des plus belles connoiffances, \& qui eft retombée dans l'ignorance la plus profonde; l'Empire des Abyffins fi ancien, \& autrefois fi floriffant ; la Lybie, qui a produit tant de Grands Hommes; la Mauritanie, d'où font fortis tant de Sçavants en tout genre, n'ont-ils pas toujours eu dans leur voifinage des Peuples, qui fembloient n'avoir de l'Homme que la figure ? Pourquoi s'étonner que les Amériquains, fi lontems ignorés du refte du Monde, foient devenus Barbares \& Sauvages, \& que leurs plus floriffants Empires fe foient trouves dénués de tant de chofes, qu'on croyoit d'une nẹ́ceffité indifpenfable dans notre Hemifphere. Tome III. 
Qu'on recherche ce qui avoit rendu fi feroces les Montagnards des Pyrenées, dont plufieurs le font encore; quelle eft l'Origine des Lappons \& des Samojedes, d'où font venus les Cafres \& les Hottentots. Pourquoi fous les mêmes paralleles il y a des Noirs en Afrique, $\&$ il n'y en a point ailleurs; $\&$ on pourra trouver de quoi répondre aux mémes queftions touchant les Eskimaux \& les Algonquins, les Hurons \& les Sioux, les Guayranis \& les Patagons. Que fi on demande pourquoi les Amériquains n'ont point de barbe, ni de poil par tout le corps, \& pourquoi la plûpart font de couleur rougeâtre, je demanderai à mon tour pourquoi la plûpart des Afriquains font noirs? Cette queftion n'entre pour rien dans la difpute fur l'Origine des Amériquains.

Les Nations Primitives fe font mêlées \& divifées à diverfes reprifes; les guerres étrangeres \& domeftiques, auffi anciennes que la paffion de dominer; la néceffité de fe féparer $\&$ de s'éloigner, foit parce qu'un Pays ne pouvoit plus contenir fes Habitans, qui fe multiploient à l'infini, foit parce que les plus Foibles étoient obligés de fuir devant les plus Forts ; linquiétude \& la curiofité , fi naturelles aux Hommes, mille raifons, qu'il eft aifé d'imaginer, \& qui entroient toutes dans les deffeins de la Providence; la maniere, dont fe font faites ces tranfmigrations; la difficulté de conferver les Arts \& les Traditions parmi des Fugitifs tranfplantés dans des Pays incultes, \& hors de portée d'avoir quelque Commerce avec les Nations civilifees : tout cela eft aife à concevoir. Les accidens imprévûs, les tempêtes \& les naufrages ont certainement contribué à peupler toute la Terre habitable ; \& faut -il s'étonner après cela de certains rapports, qu'on apperçoit entre des Peuples aujourd'hui fi éloignés les uns des autres, \& de la difference, qui fe trouve entre des Nations voifines?

On peut comprendre encore qu'il a du arriver qu'une partie de ces Hommes errants, ou forcés par la néceflité de fe réunir pour fe défendre, \& fe fouftraire à la domination d'un Peuple puiffant, ou entraînés par l'éloquence \& l'habileté d'un Légiflateur, ayent formé des Corps de Monarchies, fe foient foumis à des Loix, fe foient raffemblés en Corps de Nations. Tels ont été les commencemens des plus anciens Empires dans l'Ancien Monde; tels ont pu être ceux du Perou \& du Mexique 


\section{DE S A M E R I Q U A I N S.}

dans le Nouveau; mais les monumens hiftoriques nous manquent pour en fçavoir davantage, \& il n'y a, je le répete, que la connoiffance des Langues primitives, qui puiffe porter quelque jour dans ces ténébres. Il eft affez étonnant qu'on ait négligé jufqu'à préfent un moyen fi naturel, \& d'une exécution fi facile, de faire des découvertes auffi intéreffantes pour le moins, que la plûtpart de celles, qui occupent les Sçavans depuis deux fiécles: On connoitroit du moins parmi ce prodigieux nombre de Peuples divers, qu'on voit dans l'Amérique, \& differens entr'eux de Langage, quels font ceux, qui parlent des Langues totalement differentes de celles de l'Ancien Monde, \& qui par conféquent doivent être cenfés avoir paffé en Amérique dans les premiers tems , \& ceux, qui, par I'Analogie de leur Langue avec celles, qui font en ufage dans les trois autres Parties du Monde, donnent lieu de juger que leur Tranfmigration eft plus récente, \& doit être attribuée, ou à quelque naufrage, ou à quelque accident femblable $\grave{a}$ ceux, dont jai parlé dans le cours de cette Differtation.

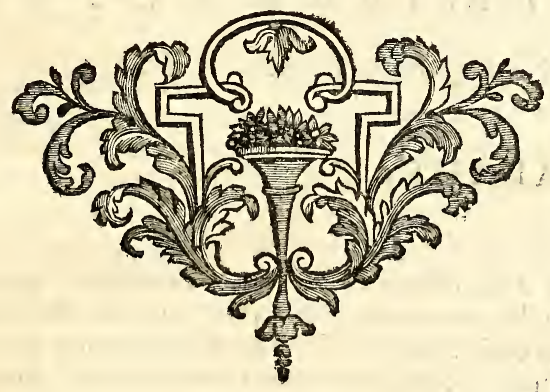




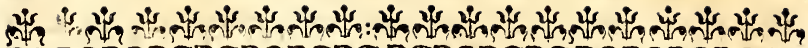
जी गु जी

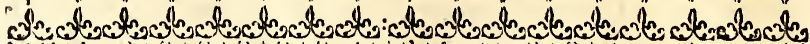

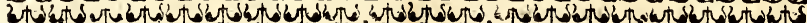

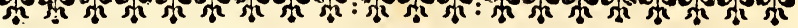

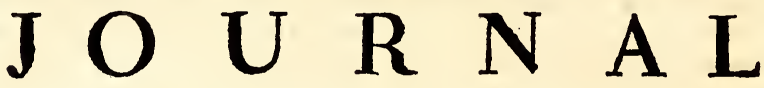 H IS T O R I QUE}

D' U N VO Y A G E D E L'A M E R I Q U E.

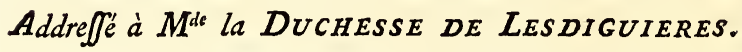

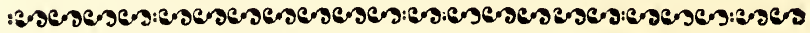

1720. Juin.

P R E M I E R E L E T T R E. A Rochefort, ce trentiéme de Juin, 2720.

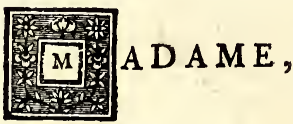

V o u s avez fouhaitté que je vous écriviffe régulierement par toutes les occafions, que j'en pourrois trouver, \& je vous l'ai promis, parce qu'il ne m'eft pas permis de vous rien refufer: mais je crains fort que vous ne vous laffiez bientôt de recevoir mes Lettres : car je ne puis me perfuader que vous les trouviez aufi intéreffantes, que vous avez cru qu'elles le devoient être.En effet, c'eft fur un Journal fuivi, que vous avez compté ; mais en premier lieu, je prévois que les Meffagers, dont je me fervirai, pour vous faire tenir mes Lettres, ne feront pas tous bien fidéles, ni des plus exacts; \& fi cela eft, vous n'aurez qu'un Journal tronqué $\&$ fans fuite : d'ail- 
VOYAGE DE L'AMERIQUE. LET. I.

leurs je ne fçai pas trop de quoi je les remplirai. Car vous n'ignorez pas que l'on m'envoye dans un Pays, où je ferai fouvent cent lieuës, \& davantage, fans rencontrer un Hom$172 \mathrm{C}$. Juin. me, \& fans voir autre chofe que des Bois, des Lacs, des Rivieres \& des Montagnes. Et quels Hommes encore, que ceux, qu'on y peut rencontrer? Des Sauvages, dont je n'entends point la Langue, \& qui ne fçavent pas la mienne. De plus, que me diroient-ils? Ils ne f̧çavent rien; \& que leur dirai-je? Ils ne font pas plus curieux d'apprendre des nouvelles d'Europe, que vous ni moi, Madame, ne le fommes d'être inftruits de leurs affaires.

En fecond lieu, quand je ferois Homme à ufer du privilége des Voyageurs; je vous connois trop, pour ofer prendre cette liberté avec vous, \& $\&$ pour me flatter de vous en faire accroire. Mais ne craignez rien, je ne me fens point d'inclination à forger des aventures; j’ai déja fait l'expérience de ce que dit un Ancien qu'on ne change point de caraktere en paffant la Mer, ni en changeant de Climat, \& j'efpere conferver celui de fincérité, que vousime connoiffez, en parcourant l'Amérique, \& les Mers, qui la féparent de nous. Vous étiez en peine de ma fanté, qui ne vous paroiffoit pas en affez bon état pour entreprendre un Voyage fi pénible; graces au Seigneur, elle fe fortifie de jour en jour, \& je voudrois bien être auffi fûr d'avoir toutes les autres qualités néceffaires, pour m'acquitter, comme il faut, de la Commiflion, dont on m'a chargé. Mais croiriez-vous bien, Madame, que j'ai déja penfé perir à moitié chemin de Paris à Rochefort? Vous n'avez, peut-être pas oublié que je vous ai fouvent dit que nos $\mathrm{Ri}$ vieres de France ne font que des Ruiffeaux, en comparaifon de celles de l'Amérique : il s'en eft peu fallu que la Loire n'ait été vengée de cet outrage.

J'avois pris une Cabanne à Orleans avec quatre ou cinq Officiers du Régiment de Conti , Infanterie. Le feize, étant vis-à-vis de Langets, \& ne pouvant avancer à caufe d'un vent contraire affez fort, nous voulûmes gagner cette Bourgade pour nous affûrer d'un bon gîte, au cas qu'il fallût y paffer la nuit. Il falloit pour cela traverfer la Riviere, \& nous le propofâmes à nos Bateliers, qui y témoignerent de la répugnance ; mais c'étoit de jeunes Gens, \& comme nous infiftâmes, ils n'oferent nous contredire. Nous n'étions pas encore 


\section{J O UR N A L HISTORIQU E}

I 720 . au milieu du Canal, que nous aurions bien voulu être à recommencer; mais il n'étoit plus tems, \& ce qui me fâchoit Juin. le plus, c'eft que c'étoit moi, qui avoit ouvert l'avis, qu'on fe repentoit fort d'avoir fuivi. Nous étions véritablement en grand danger, \& $x$ on le voyoit bien fur le vifage de nos Conducteurs; ils ne fe démonterent pourtant point, \& manœuvrerent $f i$ bien, qu'ils nous tirerent d'affaire.

Le danger paffé, quelqu'un de la Compagnie, lequel avoit été plufieurs fois fur le point de fe déshabiller pour fe jetter à la nâge, fe mit à crier de toute fa force, mais d'un ton, qui faifoit voir que le Cœur lui battoit encore, que javois eu grand'peur. Il difoit peut - être plus vrai, qu'il ne penfoit ; mais à coup fûr, il devinoit, car pour écarter les reproches, que l'on commençoit à me faire, \& pour tâcher de perfuader les autres, qu'il n'y avoit pas de danger, j'avois fait affez bonne contenance. On rencontre affez fouvent de ces faux Braves, qui, pour cacher la frayeur, dont ils font faifis, veulent faire diverfion, en donnant fur ceux, qui font beaucoup plus raffûrés qu'eux-mêmes. Cependant, Madame, fị je croyois aux préfages, voilà bien de quoi augurer mal d'un Voyage, où je dois faire plus de trois mille lieuës fur Mer, \& naviguer en Canot d'Ecorce fur deux des plus grands Fleuves du Monde, \& fur des Lacs prefque auffi grands \& pour le moins auffi orageux, que le Pont Euxin \& la Mer Cafpienne.

La Loire ne fut point traitable tout le refte du jour, \& nous couchâmes à Langets; nos Officiers, qui avoient à leur tête leur Lieutenant de Roi , étoient de fort honnêtes gens, \& d'un aimable commerce. Ils avoient d'ailleurs beaucoup de Religion, \& ils en donnerent une preuve, qui n'avoit rien d'équivoque. Une efpece d'Aventurier, moitié PetitMaître, \& moitié Bel-efprit, s'étoit joint à eux à Paris : jufqu'à Orleans il s'étoit affez contenu, mais du moment que nous fûmes embarqués, il commença de s'émanciper un peu, $\&$ infenfiblement il tint des propos fort libres fur la Religion. J'eus la confolation de voir que tous nos Officiers en furent offenfés au point, qu'aucun ne voulut loger avec lui à Langets. Ce fut un jeune Lieutenant, quilui en fit la déclaration, $\&$ qui l'obligea d'aller chercher ailleurs un gîte.

J'arrivai ici le dix-neuf; on m'y attendoit, parce que j'é- 
D'UN VOYAGE DE L'A ERII Q. LET. I. 47 tois chargé des Pacquets de la Cour; mais on y attendoit auffi de l'argent, \& il n'eft arrivé qu'aujourd'hui. Je vais demain m'embarquer fur le Chameau, grande \& belle Flûte du Roi, laquelle eft en Rade fous l'lfle d'Aix, \& j'y ferai en pays de connoiffance. J'ai déja fait Campagne avec M. de Voutron, qui la commande, \& avec Chaviteau, fon premier Pilote : j’ai eu à Quebec pour Difciple M. le Comte de VAUDREUIL, fon Capitaine en fecond, \& j’ai vécu en Canada avec quelques-uns des Officiers \& des Paffagers. On nous affûre que nous avons un très-bon Equipage, \& il n'eft point d'Officier de Marine, qui ait plus d'expérience pour la navigation, que nous allons faire, que notre Commandant. Ainfi je ne pouvois rien défirer de mieux, \& pour la fûreté du Navire, \& pour l'agrément de la Sociéte.

$$
\text { Je fuis, \&cc. }
$$

\section{S E C O N D E L E T T R E. $\begin{aligned} & 1720 . \\ & \text { Juillet. }\end{aligned}$}

Voyage de la Rochelle à Quebec: Quelques Remarques Jur cette Navigation, fur le Grand Banc de Terre-neuve, \& fur le Fleuve Saint Laurent.

A Quebec, ce vint-quatre Septembre, 1720.

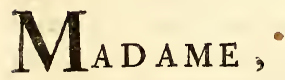

J'A R R I V A I hier en cette Ville, après quatre-vint-trois jours d'une lente \& affez fâcheufe Traverfée : nous n'avions pourtant que mille lieuës à faire; ainfi vous voyez qu'on ne va pas toujours fur Mer per la via delle Pofte, comme difoit M. l'Abbé de Choisy. Je n'ai point fait de Journal de ce Voyage, parce que le mal de Mer m'a beaucoup fait fouffrir pendant plus d'un mois. Je m'étois flatté d'en être quitte, parce que j’avois déja payé deux fois le tribut; mais il y a des tempérammens, qui ne peuvent fympathifer avec cet Elément, \& le mien eft de cette efpece. Or, dans l'état, où ce mal nous réduit, il n'eft pas poffible de faire attention iे

1720. Juin. 
ce qui fe paffe fur le Vaiffeau. D'ailleurs rien n’eft plus ftérile qu'une Navigation comme celle-ci ; aufli n'y eft-on occupé Juiliet. qu'à examiner d'où vient le Vent, combien on avance, \& fi lon eft en route : car pendant les deux tiers du chemin, on ne voit que le Ciel \& l'Eau. Je vais néanmoins vous marquer ce que ma mémoire me fournira de plus propre à vous amufer pendant un quart-d'heure, pour tenir, autant qu'il m'eft portible, la parole, que je vous ai donnée.

Nous reftâmes en Rade tout le premier de Juillet, \& le fecond nous appareillâmes à la faveur d'un petit foufle du Nord-Eft. Les trois premiers jours les Vents furent toujours du bon côté, mais bien foibles, \& on s'en confoloit, parce que la Mer étoit belle. Il fembloit qu'elle voulût nous amadoüer, avant que de fe montrer dans toute fa mauvaife humeur. Le quatriéme, ou le cinquiéme le Vent tourna \& nous mit à la Boulịne ( $a$ ). La Mer devint groffe, \& pendant près de fix femaines nous fûmes fecoués de la bonne maniere. Les Vents ne faifoient que tourner, mais ils nous prenoient bien plus fouvent par devant que par derriere, $\&$ nous étions prefque toujours au plus près $(b)$.

Defeription Le neuviéme d'Août nos Pilotes fe croyoient fur le Grand du grand Banc.

1720 . Banc de Terre-neuve, \& ils ne fe trompoient pas de beaucoup. Ils étoient mêmê en regle; car un bon Pilote doit toujours être un peu de l'Avant de fon Vaiffeau $(c)$; mais deAoût puis le neuf jufqu'au feize, nous ne fimes prefque point dẹ chemin. Ce qu'on appelle le Grand Banc de Terre-neuve, eft proprement une Montagne cachée fous les Eaux, environ à fix cent lieuës de France du côté de l'Occident. Le Sieur Denys, duquel nous avons un très-bon Ouvrage fur l'Amérique Septentrionnale, \& un Traité fort inftructif de la Pêche de la Moruë, donne à cette Montagne cent cinquante lieuës d'étenduë du Nord au Sud; mais, felon les Cartes Marinẹs les plus exactes, fon commencement, du côté du Sud, eft par les quarante \& un dégrez de Latitude Nord, \& fon extrémité Septentrionnale eft par les quạañante-neuf dégrez, vint-cinq Minutes.

(a) Aller à la Bouline, c'eft prendre le / qu'il vient prefque de devant. Vent de biais.

(b) Etre au plus près, c'eft quand on qu'il n'eft. pince le Vent, en le prenant de biais, parce 
La verité eft que fes deux extrémités fe terminent tellement en pointe, qu'il eft mal aifé d'en marquer exactement les bornes. Sa plus grande largeur, d'Orient en Occident, 1720 . eft d'environ quatre-vint-dix lieuës Marines de France $\&$ d'Angleterre, entre les quarante $\&$ les quarante-neuf dégrez de Longitude. J'ai oui dire à des Matelots qu'ils y avoient moüillé l'Ancre à cinq braffes; ce qui eft encore contre le Sieur Denys, lequel prétend qu'il n'y en a jamais trouvé moins de vint-cinq. Mais il eft certain qu'en plufieurs endroits il y en a plus de foixante. Vers le milieu de fa Longueur, du côté de l'Europe, il forme une efpece de Baye, qu'on a nommée la Fo/fe ; \& c'eft ce qui fait que de deux Navires, qui font fur la même ligne, \& à la vûè l'un de l'autre, l'un trouvera fond, \& l'autre ne le trouvera pas.

Avant que d'arriver au Grand Banc, on en rencontre un plus petit, qui s'appelle le Banc Jacquet. Il eft par le travers du milieu de fa longueur: quelques-uns même le font précéder d'un autre, auquel ils donnent la figure d'un Cône : mais j’ai vû des Pilotes, qui des trois n'en font qu'un, \& fe tirent des objections, qu'on leur fait, en difant, qu'il y a fur le Grand Banc des cavités, dont la profondeur a trompé ceux, qui n'en diftinguent trois, que pour n'avoir pas filé affez de Cable. Quoiquil en foit de la grandeur $\&$ de la figure de cette Montagne, dont il n'eft pas poffible d'être inftruit au jufte, on y trouve une quantité prodigieufe de Coquillages, \& plufieurs efpéces de Poiffons de toutes grandeurs; la plûpart fervent de nourriture ordinaire aux Moruës, dont le nombre femble égaler celui des Grains de Sable, qui couvrent le Banc. Depuis plus de deux fiécles on en charge tous les ans deux à trois cent Navires, \& il n'y paroît prefque point. On ne feroit pourtant pas mal de difcontinuer de tems en tems cette Pêche, d'autant plus que le Golphe de Saint Laurent, le Fleuve même, pendant plus de foixante lieuës, les Côtes de l'Acadie, celles de l'Ille Royale $\&$ de Terre-neuve, ne font guéres moins fournies de ce Poiffon, que le Grand Banc. Ce font là , Madame, de vraies Mines, qui valent mieux, \& demandent beaucoup moins de frais, que celle du Perou $\&$ du Méxique.

Nous eûmes beaucoup à fouffrir tout le tems, que les Vents Vents \& des des contraires nous retinrent fur les Frontieres du Royaume des Tome III. 
5o J OUR NAL HIS T ORIQUE

1720. Moruës; car c'eft bien le plus défagréable \& le plus incommode Parage de tout l'Océan. Le Soleil ne s'y montre Août. prefque jamais, \& la plûpart du tems l'air y eft couvert d'une Brume froide \& épaiffe, qui fait connoître les approches du Banc, de maniere à ne s'y pas méprendre. Quelle pourroit être la caufe d'un Phénomene fi marqué \& fi conftant! Seroit-ce le Voifinage des Terres \& des Forêts, qui les couvrent? Mais outre que le $C_{a p}$ de Raze, qui eft la Terre la plus proche du Grand Banc, en eft éloigné de trente - cinq lieuës, la même chofe n'arrive point de tous les autres côtés de l'Ifle ; \& de plus, l'Ifle de Terre-neuve n'eft embrumée, que du côté du Grand Banc : par-tout ailleurs fes Côtes joüiffent d'un air pur, \& d'un Ciel ferein. Il eft donc vraifemblable que c'eft la proximité du Grand Banc, qui caufe les Brouillards, dont le Cap de Raze eft ordinairement enveloppé, \& il en faut chercher la caufe fur le Banc même. Or voici fur cela ma conjecture, que je foumets à la décifion des Sçavans.

Je commence par obferver que nous avons un autre figne de l'approche du Grand Banc: c'eft que fur toutes fes extrémités, qu'on appelle communément fes $E$ corres, la Mer eft toujours glapiffante, \& les Vents impétueux. Ne pourroit-on point regarder cela comme la caufe des Broüillards, qui y regnent, \& dire que l'agitation de l'Eau, dont le fond eft mêlé de Sable \& de Vafes, épaiffit l'Air \& l'engraiffe, \& que le Soleil n'en attire que des Vapeurs groffieres, qu'il ne peut jamais bien réfoudre ? On me demandera d'où vient cette agitation de la Mer fur les Ecorres du Grand Banc, tandis que par-tout ailleurs, \& fur le Banc même, il regne un calme profond? La voici, fi je ne me trompe. On éprouve tous les jours dans ces Parages des Courans, qui portent tantôt d'un côté , \& tantôt d'un autre. La Mer irrégulierement pouffée par ces Courans, \& heurtant avec impétuofité contre les bords du Banc, qui font prefque partout à pic, en eft repouffée avec la même violence, ce qui caufe l'agitation, qu'on y remarque.

Que fi la même chofe n'arrive point aux approches de tous les Hautsfonds, c'eft que tous n'ont pas une auffi grande étenduë, que celui-ci; qu'il n'y a point de Courans aux environs, qu'ils n'y font pas fi forts, ou qu'ils ne s'y croifent pas, 
D'UN VOY A G E DE L'A MERIQ. LET. II. ; $\mathrm{f}$ qu'ils ne rencontrent pas des bords auffi roides, \& n'en font point repouffés avec autant de force. Il eft certain d'ailleurs, comme je l'ai déja obfervé d'après les Marins, que l'agitation de la Mer, \& les Vafes, qu'elle remuë, contribuent beaucoup à épaiffir l'Air, \& à engraiffer les Vents; mais que ces Vents, quand ils n'ont point d'autre caufe, ne s'étendent pas bien loin, \& que fur le Grand Banc, à quelque diftance des Bords, on eft tranquille comme dans une Rade, à moins d'un Vent forcé, qui vienne d'ailleurs.

Ce fut un Vendredi, feiziéme d'Août, à fept heures du foir, que nous nous trouvâmes fur le Grand Banc, par foixante \& quinze Braffes d'eau. Arriver au Grand Banc, cela s'appelle bancquer; en fortir, c'eft débancquer; ce font deux mots, dont la Péche des Moruës a enrichi notre Langue. C'eft la coûtume, quand on a trouvé fond, de crier : Vive le Roi, \& on le fit de bon cœur. Notre Equipage foupiroit après la Moruë fraîche ; mais le Soleil étoit couché, le Vent étoit bon, \& on jugea à propos d'en profiter. Vers les onze heures du foir, Vent forcé de Sud-Eft, lequel, avec la feule Miféne, nous auroit fait faire trois lieuës par heure. Sil n'y avoit eu que cela, en ferrant, comme on fit dans la minute, toutes les autres Voiles, nous n'aurions pas été à plaindre; mais il furvint une Pluie $f_{1}$ abondante, qu'on auroit dit que toutes les Cataractes du Ciel étoient ouvertes. Ce qu'il y eut de pis, c'eft que le Tonnerre commença par où il finit ordinairement; il tomba fi près de nous, que le Gouvernail en fut engourdi, \& que tous les Matelots, qui faifoient la Manouvre, en reffentirent le contre-coup. Il redoubla enfuite, \& cent Piéces de Canon n'auroient pas fait plus de bruit. On ne s'entendoit point ; un coup n'attendoit pas l'autre; on ne fe voyoit point au milieu des Eclairs, parce qu'on en étoit ébloui. Enfin pendant une heure $\&$ demie, il fembloit que nous étions à la Tranchée ; le Cœur battoit aux plus intrépides; car le Tonnerre reftoit toujours fur notre tête, \& s'il étoit tombé une feconde fois, nous aurions pû aller fervir de pâture aux Moruës, aux dépens defquelles nous avions compté de faire bientôt bonne chere. Caftor ou Pollux, car je ne fçai lequel des deux étoit en faction, fous le nom de Feu Saint Elme (a), nous avoit bien avertis de tout ce fra-

(a) On ne manque guéres de voir ces Feux fur les. Vergues, à l'approche d'une Tempêtes 


\section{J O UR N A L. H IS T O R I Q U E}

I 720 . cas, \& fans cela, nous aurions bien pû être furpris, \& tourner fous Voiles.

Août. Au bout d'une heure \& demie, la Pluye ceffa, le Tonnerre ne grondoit plus que de loin, \& les Eclairs n'étoient plus que de foibles lueurs à l'Horifon. Le Vent étoit toujours bon, \& n'étoit plus fi brutal, \& la Mer paroiffoit unie comme une Glace. Chacun alors voulut aller fe coucher, mais tous les Lits étoient inondés, la Pluye ayant pénétré par les fentes les plus imperceptibles, ce qui eft inévitable, quand le Vaiffeau eft fort agité. On fit comme on put, \& on fe trouva encore très-heureux d'en être quitte à fi bon marché. Tout ce qui eft violent ne dure point, fur-tout le Vent de Sud-Eft, au moins dans ces Mers. Il n'eft conftant, que lorfqu'il fe fortifie peu à peu, \& fouvent il finit par une Tempête. Le Calme revint avec le jour ; nous n'avancions pas, mais nous nous défennuyâmes en pêchant.

Des Moruës, Tout eft bon dans la Moruë, quand elle eft fraîche; elle \& de la Pêche ne perd même rien de fa bonté, \& elle devient un peu plus ferme, quand elle a été deux jours dans le Sel; mais ce font les Pêcheurs feuls, qui en mangent ce qu'elle a de plus excellent, c'eft-à-dire, la Tête, la Langue, \& le Foye, qui délayé dans l'Huile \& $\mathrm{x}$ le Vinaigre, avec un peu de Poivre, lui fait une Saufle exquife. Pour conferver tout cela, il faudroit trop de Sel : ainfi on jette à la Mer tout ce qu'on n'en peut pas confommer dans le tems de la Pêche. La plus grande Moruë, que j’aye vûë, n'avoit pas trois pieds : cependant celles du Grand Banc font les plus fortes : mais il n'y a peutêtre point d'Animal, qui, à proportion de fa grandeur, ait la Gueule plus large, ni qui foit plus vorace. On trouve de tout dans le Corps de ce Poiffon, jufqu'à des têts de Pots caffés, du Fer, \& du Verre. On s'étoit imaginé qu'il digeroit tout cela, mais on eft revenu de cette erreur, qui n'étoit fondée que fur ce qu'on lui avoit trouvé des morceaux de Fer à moitié ufés. On eft perfuadé aujourd'hui que le Gau; c'eft le nom, que les Pêcheurs ont donné à l'Eftomach de la Moruë, fe retourne comme une Poche, \& que ce Poiffon fe décharge, en le retournant, de tout ce qui l'incommode.

On appelle en Hollande Cabeliau, une forte de Moruë, qui fe pêche dans la Manche $\&$ dans quelques autres endroits, \&z qui ne differe des Moruës de l'Amérique, que par- 
ce qu'elle eft plus petite. On fe contente de faler celle du Grand Banc, \& c'eft ce qu'on appelle Moruë Blanche, \& plus communément, Moruë Verte. M. DENYS dit à cette oc1720 . cafion qu'il a vû faire en Canada d'auffi beau Sel, que celui, qu'on y porte de Brouage, mais quaprès qu'on en eut fait l'effai dans des Marais creufés exprès, on les reboucha. Ceux, qui ont le plus crié que ce Pays n'étoit bon à rien, ont été plus d'une fois ceux mêmes, qui ont empêché qu'on n'en retirât aucun avantage.

La Moruë féche, ou la Merluche ne fe peut faire que fur les Côtes : cela demande de grands foins, \& beaucoup d'expérience. M. Denys, quir convient que tous ceux, qu'il a vû faire ce Commerce en Acadie, s'y font ruinés, prouve parfaitement, \& rend très-fenfible qu'on a eu tort d'en conclure que la Moruë n'y eft pas abondante. Mais il prétend que pour $\mathrm{y}$ faire la Pêche avec fuccès, il faut que les Pêcheurs foient établis dans le Pays; \& voici quel eft fon raifonnement. Toute Saifon n"eft pas propre pour cette Pêche; on ne la peut faire que depuis le commencement du Mois de Mai jufqu'à la fin du Mois d'Août. Or fi vous faites venir des Matelots de France, ou vous les payerez pour toute l'année, \& les frais abforberont les profits, ou vous ne les. payerez que pendant la Pêche, \& ils n'y trouveront pas leur compte. Car de dire qu'on les employera le refte du tems à fcier des Planches, \& à couper du Bois, c'eft une erreur; ils n'y gagneront certainement pas ce qu'ils dépenferont; ainfi, ou il faudra qu'ils ruinent l'Entrepreneur, ou ils mourront de faim.

Mais s'ils font Habitans, on en fera mieux fervi, \& il ne tiendra qu’à eux d'être à leur aife. On connoîtra les bons $\mathrm{Ou}$ vriers; ils prendront leur tems pour la Pêche, ils choifiront les bons endroits, ils gagneront beaucoup pendant quatre mois, \& le refte de l'année ils travailleront pour eux dans. leurs Habitations. Si on $s^{\prime} y$ étoit pris de cette forte il y a cent cinquante ans, l'Acadie feroit devenuë une des plus. puiffantes Colonies de l'Amérique. Car tandis qu'on publioit. en France, avec une forte d'affectation, qu'il n'étoit pas poffible d'y rien faire, elle enrichiffoit la Nouvelle Angleterre par la ieule Pêche, quoique les Anglois n'y euffent pas tous: les avantages, que nous y pouvions avoir。 Août. 


\section{4 \\ J O URAL HISTORIQUE}

1720. Quand on eft forti du Grand Banc, on en rencontre plufieurs autres plus petits, \& tous prefque également poilfonAoût. neux. La Moruë n'eit pas même le feul Poiffon, qu'on trouve dans cette Mer. On y voit à la verité peu de Requins, point du tout de Dorades, de Bonites, ni de tous ces autres Poiffons, qui demandent des Mers plus chaudes : mais en récompenfe elle eft remplie de Baleines, de Soufleurs, d'Efpadons, de Marfoüins, de Flettans, \& de quantité d'autres de moindre valeur. Nous y avons eu plus d'une fois le plaifir du Combat de la Baleine contre l'Efpadon, \& rien n'eft plus amufant. L'Efpadon eft de la groffeur d'une Vache, long de fept à huit pieds, \& fon Corps va toujours en rétrécififant vers la queuë. Son nom vient de fon arme, efpece d'Efpadon long de trois pieds, \& large de quatre doigts. Il eft pofé fur fon nez, \& de chaque côté il a une fuite de Dents de la longueur d'un pouce, rangées dans une diftance égale les unes des autres. Ce Poiffon fe met à toute fauce, \& c'eft un excellent manger. Sa Tête eft plus délicate, que celle du Veau, plus groffe \& plus quarrée. Il a les yeux extrémement gros.

Combat de Jamais la Baleine \& l'Efpadon ne fe rencontrent, quils 1a Baleine \& ne fe battent, \& c'eft, dit-on, celui-ci, qui eft toujours l'Agde l'E $E$ padon. greffeur. Quelquefois deux Efpadons fe joignent contre une Baleine, \& alors la partie n'eft pas égale. La Baleine n'a pour Arme offenfive \& défenfive, que fa Queuë: pour s'en fervir contre fon Ennemi, elle plonge la Tête, \& fi elle peut frapper l'Efpadon, elle l'affomme d'un coup de fa Queuë, mais il eft fort adroit à l'efquiver, \& auffi-tôt il fond fur la Baleine, \& lui enfonce fon Arme dansle Dos. Le plus fouvent il ne la perce pas jufqu'au fond du Lard, \& ne lui fait pas grand mal. Quand elle le peut voir s'élancer pour la frapper, elle plonge, mais l'Efpadon la pourfuit dans l'Eau, \& l'oblige à fe remontrer. Alors le Combat recommence, \& dure jufqu'à ce que l'Efpadon perde de vûë la Baleine, qui bat toujours en retraite, \& qui nâge mieux que lui à fleur d'eau.

Wu Flettan. Le Flettan eft comme une grande Plie : il paroît que ce qu'on appelle $F$ let, eft fon diminutif. Il eft gris fur le Dos, \& blanc fous le Ventre. Sa longueur eft ordinairement de quatre à cinq pieds, fa largeur au moins de deux, \& il en a un d'épaiffeur. Il a la Tête fort groffe; tout en eft exquis \& 
D'UN VOYA GE DE L'A MERIQ. LET. II. 55 fort tendre: on tire des $\mathrm{Os}$ un Suc, qui vaut mieux que la moële la plus fine. Ses yeux, qui font prefque auffi gros que ceux de l'Efpadon, \& les bords des deux côtés, qu'on ap1720. Août. pelle Relingues, font des morceaux très-délicats. On jette tout le Corps à la Mer pour engraiffer les Moruës, dont le Flettan eft le plus dangereux ennemi, \& qui ne fait qu'un repas de trois de ces Poiffons. Je ne vous dirai rien, $\mathrm{Ma}$ dame, de toutes les efpeces d'Oifeaux, qui vivent fur ces Mers, \& qui n'y fubfiftent, que de la Pêche, car tous font Pêcheurs. Bien des Voyageurs en ont parlé, \& $\&$ ils n'en ont rien dit, qui mérite qu'oll s'y arrête.

Le dix-huit, bon vent : nous croyons que les Vents nous ont porté un peu trop au Sud, \& nous faifons l'Oueft-NordOueft, pour nous remettre dans notre latitude. C'eft que depuis dix ou douze jours nous n'avons point vû le Soleil, $\&$ que par conféquent nous n'avons pû prendre hauteur. Cela arrive affez fouvent, \& c'eft ce qui fait le plus grand danger de cette navigation. Vers les huit heures du matin on apperçoit un petit Bâtiment, quifembloit venir à nous, on va au-devant, \& quand il eft proche, on lui demande par quelle latitude nous fommes? C'étoit un Anglois, \& le Capitaine répondit dans fa Langue : on crut entendre que nous étions par les 45 dégrés. Il n'y avoit pourtant pas trop à s'y fier, car il pouvoit être dans la même erreur que nous. Cependant on fe raffûre, \& c comme le Vent continuoit à être bon, on fe flatte, s'il ne change point, d'avoir paffé le Golphe dans deux jours.

Vers les quatre heures du foir le Vent tomba, \& nous en fûmes confternés; c'étoir cependant notre falut. A onze heures de nuit l'Horifon parut fort noir devant nous, quoique par-tout ailleurs le Ciel fût très-ferein. Les Matelots de quart (a) ne balancerent point à dire que c'étoit la Terre. L'Officier fe mocqua d'eux, mais comme il les vit perfifter dans leur fentiment, il commença à croire qu'ils pouvoient bien avoir raifon. Par bonheur il faifoit fi peu de vent qu'à peine le Navire gouvernoit ; ainfi il efpera que le jour viendroit avant qu'on approchât cette Terre de trop près. A mi-

(a) L'Equipage d'un Vaifleau eft par-/ qu'on appelle faire le Quart. Chaque Bands tagé en quatre Bandes, dont chacune eft en eft commandée par un Officier.

Jaction pendant quatre heures. C'eft ce

Erreur des Pilotes, \& le danger, où elle met le Yaí. feau. 
56- JOURNAL HISTOR I Q U E

I 720 . nuit le quart changea. Les Matelots, qui fuccederent aux Août.

Premiers, furent d'abord de leur avis; mais leur Officier entreprit de leur prouver par de bonnes raifons que la Terre ne devoit point être là, \& que ce qu'ils voyoient, étoit une Brume, qui fe diffiperoit avec l'Aurore. Il ne les perfuada point, \& ils s'obstinerent à foûtenir que le Ciel étoit trop pur, pour être embrûmé de se côté-là, s'il n'y avoit point de Terre.

Au point du jour, ils fe mettent tous à crier qu'ils voyent la Terre. L'Officier, fans daigner même y regarder, leve les épaules, \& quatre heures fonnant, il va fe coucher, en difant qu'à fon reveil il trouvera cette prétenduë Terre fonduë. Son Succeffeur, qui étoit le Comte de Vaudreuil, plus circonfpect, commence par faire ferrer quelques Voiles, \& ne fut pas lontems fans s'appercevoir que cette précaution étoit néceffaire. Dès que le jour parut, on vit l'Horifon prefque tout bordé de Terres, \& on découvrit un petit Navire Anglois mouillé à deux portées de Canon de nous. M. de Voutron, qui en fut averti, fit auffi-tôt appeller l'Officier incrédule, qu'on eut bien de la peine à faire fortir de fa Chambre, d'où il proteftoit que nous ne pouvions pas avoir une Terre fi près de nous. Il vint cependant après deux ou trọis femonces, \& à la vûë du danger, que fon entêtement nous avoit fait courir, il fut faifi d'étonnement. C'eft pourtant le plus habile Homme de France pour naviguer fur ces Mers, mais trop d'habiletẹ nuit quelquefois, quand on s'y fie plus que de raifon.

Cependant, Madame, fi le Vent n'étoit point tombé la veille à quatre heures du foir, nous nous ferions perdus dans la nuit ; car nous courions à pleines Voiles fur des Brifans, dont il ne nous auroit pas été poffible de nous tirer. L'embarras étoit de fçavoir où nous étions. Ce qu'il y avoit de certain, c'eft que la veille nous n'étions point par les quarantecinq dégrez. Mais étions-nous plus au Nord, ou plus au Sud ? C'eft fur quoi les fentimens furent partagés, Un de nos Officiers affûra que la Terre, qui paroiffoit devant nous, étoit l'Acadie; qu'il y avoit fait un voyage, \& qu'il la reconnoiffoit : un autre foûtint que c'étoit les Ifles de Saint Pierre. Mais quelle apparence, lui dit-on, que nous foyions fi avancés? Il n'y a pas encore vint-quatre heures que nous étions 
D'UN VOYAGE DE L'AMERIQ. LET. II. 57 étions fur le Grand Banc, \& il y a plus de cent lieuës du Grand Banc aux Ines de Saint Pierre. Le Pilote Chaviteau prétendit que c'étoit le Cap de Raze. Qu'il y ait de l'erreur dans notre Eftime, dit-il, cela n'eft plus douteux, $\&$ il ne faut pas s'en étonner, vû qu'il n'eft pas poffible de fe regler fur des Courants, quion ne connoît pas, \& qui varient fans ceffe, \& que la hauteur nous a manqué pour nous redreffer. Mais il eft hors de toute vraifemblance que nous puiffions être ni fur les Côtes de l'Acadie, ni aux Ifles de S. Pierre (a).

Son raifonnement nous parut jufte, nous aurions néanmoins bien défiré qu'il fe fût trompé, car nous comprenions combien il étoit fâcheux d'être affalés fous le Cap de Raze. Dans cette incertitude on prit le parti d'aller confulter le Capitaine du Navire Anglois, que nous avions devant nous, \& Chaviteau en reçut l'ordre. A fon retour il nous rapporta q̧ue les Anglois avoient été auffi furpris que nous, de fe troulver dans cette Baye, mais avec cette difference, que c'étoit là, où ils avoient affaire : que le Cap de Raze étoit devant nous, le Cap de Brolle par notre travers, dix lieuës au-deffous; que du milieu de ces Brifants, fur lefquels nous avions couru rifque de nous perdre, il fortoit une Riviere, à l'entrée de laquelle il y avoit une Bourgade Angloife, où le petit Navire alloit porter des Provifíns.

Il y a quinze ans qu ill nous arriva dans ce même Parage une aventure fort finguliere, \& qui nous fit courir un auffi grand rifque peut-être que celui, dont je viens de vous entretenir. C'étoit peu de jours après la Notre-Dame d'Août, 8 nous avions effuyé jufques-là d'affez grandes chaleurs. Un matin, en nous levant, nous fûmes faifis d'un froid, qui fit recourir tout le monde à fes Habits d'Hyver. Nous ne pouvions comprendre d'où cela venoit, le tems étant fort beau, \& le vent ne venant point du Nord. Enfin, le troifiéme jour à quatre heures du matin un Matelot fe mit à crier de toute fa force au Lof, c'eft-d̀-dire, mettez le Gouvernail à venir au Vent. Il fut obéi , \& un moment après on apperçut une Glace énorme, qui rafoit le Vaiffeau, \&x contre laquelle il fe feroit brifé,

(a) En i 725 le même Chaviteau fe/d'Août ce Navire fe brifa fur un Rocher, trompa dans fon Eltime d'une maniere près de Louyfourg, dans l'ille Royale, \& bien plus funefte. Il étoit encore Pilote du perfonne ne fe fauva. On rrouva fur les Roifur le Chameau, \& ayant été plufieurs Journaux des Pilotes qu'ils s'en croyoient jours fans prendre hauteur, la nuit du 27 encore à 70 lieuës.

Tome III. 
fi le Matelot n'avoit pas eu des yeux marins, car à peine $y$ voyoit-on, \& fi le Timonnier eût été moins prompt à changer fon Gouvernail.

Je n'ai point vû, Madame, cette Glace, car je n'étois point levé; mais tous ceux, qui étoient alors fur le Pont, nous affurerent qu'elle paroiffoit aufi haute que les Tours de Notre-Dame de Paris, \& qu'elle paffoit du moins de beaucoup les Mâts du Navire. J'ai fouvent vî foûtenir que cela étoit impoffible, parce qu'il eût fallu qu'elle eût été prodigieufement profonde pour s'élever fi haut au-deffus de la Mer, \& qu'il n'eft pas polfible qu'il fe forme une Glace de cette hau-teur. A cela je réponds en premier lieu, que pour nier le fait, il faut donner le démenti à bien du Monde, car ce n'eft pas la premiere fois que l'on a vû en Mer de ces Ecueils flottans. La Mere de l'INCARNATION faifant la même route que nous, courut le même danger en plein jour : la Glace, qui penfa la faire perir, faute de vent pour l'éviter, fut apperçuë de tout l'Equipage, \& jugée beaucoup plus grande encore, que celle, que nous rencontrâmes. Elle ajoûte que l'on donna l'Abfolution Générale, comme on fait dans les plus grands perils.

Il eft certain en fecond lieu que dans la Baye d'Hudfon il y a de ces Glaces formées par la chûte des Torrents, qui tombent du haut des Montagnes, \& qui fe détachent avec un grand fracas pendant l'Eté, \& 8 font enfuite portées par les Courants de côté \& d'autre. Le Sieur JÉrÉmie, qui a paffé plufieurs années dans cette Baye, dit qu'il a eu la curio- fité de faire fonder au pied d'une de ces Glaces, qui étoit échoüée, \& qu'on fila cent braffes de ligne, fans trouver le fond. Je reviens à notre aventure.

Da Cap de Le Cap de Raze, Madame, eft la Pointe du Sud-Eft de Raze. l'fle de Terre-neuve : il eft fitué par les quarante-fix dégrez, $8 \alpha$ environ trente minutes de Latitude-Nord. La Côte court de-là cent lieuës à l'Oueft, prenant un peu du Nord, \& fe termine au Cap de Raye, qui eft par les quarante-fept dégrez. Prefque à moitié chemin eft la Grande Baye de Plaifance, qui forme un des plus beaux Ports de l'Amérique. A l'OueftSud-Oueft de cette Baye il y a un Morne, qu'on apperçoit de loin, \& qui fert à la reconnoître: on l'a nommé le Chapeau Rouge, parce qu'en effet il paroît de loin avoir la forme 
D'U N V OYA GE DE L'A M ER I Q. LET. II. 59 d'un Chapeau, \& que la couleur en eft rougâtre. Le vinttrois à midi nous étions par fon travers, \& le foir nous rangeâmes les Inles de Saint Pierre, que nous avions à ftribord, c'eft-à-dire, à main droite.

Ce font trois Ifles, dont les deux Premieres font fort hautes, \& du côté, où nous étions, il ne paroiffoit que des Montagnes couvertes de mouffe. On prétend que cette mouffe couvre en quelques endroits de très-beau Porphyre. Du côté de Terre-neuve il y a quelques Terres labourables, \& un affez bon Port, où nous avons eu quelques Habitations. La plus grande \& la plus Occidentale des trois, qu'on appelle plus communément l'ifle Maguelon, n'eft pas fi haute que les deux autres, \& fon Terrein paroit fort uni. Elle a environ trois quarts de lieuës de long. Le vint-quatre au point du jour elle reftoit cinq ou fix lieuës derriere nous, mais depuis minuit nous n'avions pas eu de vent. Vers les cinq heures du matin il s'éleva un petit foufle de Sud-Eft. En attendant qu'il fût affez fort pour enfler nos Voiles, on s'amufa à pêcher, \& $x$ on prit une affez grande quantité de Moruës. On s'arrêta deux heures plus qu'il ne falloit à cette Pêche, \& nous eûmes bientôt tout lieu de nous en repentir.

11 étoit huit heures, quand on appareilla, \& nous courûmes tout le jour, dans l'efperance de découvrir le Cap de Raye, qui etoit fur notre droite, ou la petite Ifle de Saint $P$ aul, que nous devions laiffer à la gauche, \& qui eft prefque vis-à-vis du Cap de Raye; mais la nuit fe ferma, fans que nous euffions rien vû. On eut bien voulu alors avoir profité du tems, que nous avions perdu. Ce qu'il y eut de plus fâcheux, c'eft que vers le minuit nous effuyâmes une Tempête affez femblable à celle, que nous avions effuyée fur le Grand Banc, \&z que ne pouvant douter que nous ne fuffions près de l'une des deux Terres, entre lefquelles nous devions paffer, nous n'ofâmes profiter du Vent, qui nous auroit fait faire bien du chemin. Ainfi, malgré l'avis de Chaviteau, qui répondoit de paffer fans rifque, on mit en Panne (a).

(a) Mettre en Panne, c'eft arrêter le / dans la grande Mifene pour lui faire battre Vaifleau, quand il eft fous Voiles. Pour cela le Mât, \& dans la petite, pour l'éventer. on cargue les grandes Voiles, \& on difpofe Ainfi, le Vaiffeau pouffé des deux côtés, les Huniers de telle forte, que le Vent fouffe n'avance point.

$\mathrm{H}$ ij

1720. Août.

Des ines de Saint Pierie. 
1720.

A้oût.
D. 1 Golphe de Saint Laurent, \& des 1jes aux Oifexux.

Au point du jour nous apperçûmes le Cap de Raye, fur lequel les Courants nous portoient, \& pour furcroît de difgrace, nous n'avions plus de Vent pour nous foûtenir. Nous étions prefque deffus, lorfque fur les cinq heures \& demie du matin un petit air de Vent de Nord-Oueft vint fort à propos à notre fecours. Nous n'en perdimes rien, \& nous nous tirâmes du mauvais pas, où nous étions. Le Nord-Oueft, après nous avoir rendu ce bon office, nous auroit fait bien plaifir de céder la place à un autre; mais il ne le fit point, $\&$ pendant deux jours il nous retint à l'entrée du Golphe de Saint Laurent. Le troifiéme jour nous paffâmes entre l'Ifle de Saint Paul, \& le Cap Saint Laurent, qui eft la pointe la plus Septentrionnale de l'Ifle Royale. Ce Paffage eft fort étroit, \& on ne s'y hazarde point, quand le Ciel eft embrumé, parce que l'Ifle de Saint Paul eft fi petite, que la Brume la cache aifément. Celui, qui eft entre cette lne \& le Cap de Raye eft beaucoup plus large: mais nous étions parés pour prendre l'autre, lorfque le Vent changea, \& nous en profitâmes.

Le Golphe de Saint Laurent a quatre-vint lieuës de long, qu'un bon Vent de Sud-Eft nous fit faire en vint-quatre heures à l'aide des Courants. Environ à moitié chemin on rencontre les Ifles aux Oifeaux, que nous rangeâmes à la petite portée du Canon, \& qu'il ne faut pas confondre avec celles, que Jacques Cartier découvrit auprès de l'Ifle de Terreneuve. Celles, dont il s'agit, font deux Rochers, qui m'ont paru s'élever à pic, environ foixante pieds au-deffus de l'Eau, \& dont le plus grand n'a gueres que deux ou trois cent pas de circuit. Ils font fort près l'un de l'autre, \& je ne crois pas qu'il y ait entre les deux affez d'Eau pour une grande Chaloupe. Il eft difficile de dire de quelle couleur ils font, car la fiente des Oifeaux en couvre abfolument la furface, \&. les bords. On découvre néanmoins en quelques endroits, des veines d'une couleur rougeâtre.

On les a vifitées plufieurs fois; on y a chargé des Chaloupes entieres d' $E$ ufs de toutes les fortes, \& on affure que l'infection y eft infupportable. On ajoûte qu'avec les Goëlans $\&$ les Tangueux, qui y viennent de toutes les Terres voifines, on y trouve quantité d'autres Oifeaux, qui ne fçauroient voler. La merveille eft que dans une multitude fi pro- 
D'U N V O Y A GE DE L'A MER I Q. LET. II. GI digieufe de Nids, chacun trouve d'abord le Sien. Nous tirâmes un coup de Canon, qui mit l'allarme dans toute cette République Volatille, \& il fe forma au-deffus des deux Iles I 720 . Août. un nuage épais de ces Oifeaux, lequel avoit bien deux ou trois lieuës de circuit.

Le lendemain, vers le point du jour, le Vent tomba tout-dेcoup. Encore deux heures, \& nous doublions le Cap des Rofiers, nous entrions dans le Fleuve de Saint Laurent, qui coule Nord-Eft, \& Sud-Oueft ; \& le Vent de Nord-Oueft, qui s'éleva bientôt, nous eût fervi, mais nous avions perdu deux heures le vint-quatre à pêcher, \& en conféquence deux jours à l'Entrée du Golphe; il fallut attendre ici que le NordOueft tombât, \& nous attendìmes cinq jours, pendant lefquels nous ne fìmes pas cinq lieuës. Ce retardement ne fut pas même le plus grand mal, qu'il nous fit : il étoit très-froid, il nous fecoua beaucoup, \& peu s'en fallut qu'en tombant, il ne nous fit perir de la maniere, que vous allez voir. Mais il faut auparavant vous faire la Carte du Pays, où nous étions.

Le Cap des Rofiers eft proprement l'entrée du Fleuve Saint Laurent, \& c'eft de-là, qu'il faut mefurer la largeur de fon Embouchure, qui eft d'environ trente lieuës. Un peu enDu Cap des Rofiers Gafpé, à de deçà, plus au Sud, font la Baye \& la Pointe de Gafpé, ou Gachepé. Ceux, qui prétendent que le Fleuve Saint Laurent nurree du Fleuve S.ins Laurent. a quarante lieuës de large à fon Embouchure, le mefurent apparemment de la Pointe Orientale de Gafpé. Au-deffous de la Baye on apperçoit une efpece d'Ine, qui n'eft au fond, qu'un Rocher efcarpé, d'environ trente toifes de long, de dix de haut, \& de quatre de large. On diroit un Pan de vieille Muraille, \& on aftûre qu'il touchoit autrefois au Mont Joli, qui eft vis-à-vis, dans le Continent. Ce Rocher a dans fon milieu une ouverture en forme d'Arcade, par laquelle une Chaloupe Bifcayenne peut paffer à la Voile, \& c'eft ce qui lui a fait donner le nom d'IRe Percée. Les Navigateurs reconnoiffent qu'ils en font proches, lorfqu'ils apperçoivent une Montagne plate, qui s'éleve au-deffus de plufieurs autres, \& qu'on a nommée la Table à Roland. L'Ihe Bonaventure eft à une lieuë de l'lfle Percée, \& prefque à la même diftance eft l'Ifle $M i j c o u$, laquelle a huit lieuës de circuit, \& un très-bon Havre. Un peu au large de cette Ille 


\section{2 \\ JOUR NAL HISTORIQUE}

1720 . il fort du milieu de la Mer une Source d'Eau Douce, qui bouillonne, \& jaillit affez haut.

Tous ces Parages font excellens pour la Pèche, \& le Mouillage y eft bon partout. Il feroit même aifé d'y établir des Magafins, qui ferviroient d'Entrepôt pour Quebec. Mais on a perdu à faire le Commerce des Pelleteries un tems infini, qu'on auroit dû employer à affûrer celui des Moruës, \& de quantité d'autres Poiffons, dont cette Mer abonde, $\&$ à fe forrifier dans des Poftes, dont on a connu trop tard l'importance. Il étoit naturel quayant fi près de nous des abris fûrs \& commodes, nous allaffions y attendre le retour du bon Vent, mais on efperoit de moment en moment qu'il reviendroit, \& on vouloit en profiter à l'heure même.

1720. bre.

Septem-

Enfin le Jeudi deuxiéme de Septembre le Nord-Oueft tomba fur le midi; alors nous trouvant fans pouvoir avancer, ni prefque manœuvrer, nous nous amufâmes à pêcher, \& cet amufement nous fut encore fatal. Car le Timonnier, plus attentif à la Pêche, qu’à fon Gouvernail, laiffa venir le Vent fur les Voiles, ce qui s'appelle en termes de Marine, prendre Chapelle. Pendant le calme nous avions déja beaucoup dérivé fur l'Ine d'Anticofy, l'accident, dont je parle nous en fit approcher de fi près, parce que les Courants nous y portoient, que nous voyions déja tout à découvert les Brifants, dont l'Ifle eft bordée en cet endroit. Pour comble de difgrace, le petit foufle de vent, qui venoit de s'élever, nous manqua au befoin.

Pour peu que ce Calme eùt duré, c'étoit fait de nous. Un moment après nos Voiles s'enflerent un peu, \& nous voulûmes revirer de Bord; mais le Navire, contre fon ordinaire, refufa de venir au Vent $(a)$, \& cela deux fois de fuite: preuve certaine que le Courant, qui l'entrainnoit, étoit bien fort. Nous nous crûmes fans reflource, parce que nous étions bien près des Ecueils pour rifquer de revirer de Vent arriere $(b)$. Mais après tout, il n'y avoit point d'autre parti à prendre. On mit donc la main à l'œuvre, plutôt pour n'avoir rien à nous reprocher, que dans l'efperance de nous fauver; \& dans l'inftant même nous éprouvâmes que Dieu vient au fecours de ceux, qui s'aident. Le Vent tourna au (a) Tourner en préfentant la Prouë au $\left.\right|_{\text {aL Yent. }}$ (b) Tourner en préfentant la Poure
Vent. 
D'UN VOYAGE DE L'A MERIQ. LET. II. $\sigma_{3}$ Nord, il fraîchit peu à peu, \& vers les fept heures du foir la Pointe d'Anticofty, qui nous avoit fait tant de peur, étoit parée.

Cette Ifle s'étend environ quarante lieuës Nord-Eft \& SudOueft, prefque au milieu du Fleuve Saint Laurent. Mais elle a fort peu de largeur. Elle fut concédée au Sieur Joliet à fon retour de la Découverte du Miciffipi, mais on ne lui fit pas un grand préfent. Elle n'eft abfolument bonne à rien. Elle eft mal boifée, fon Terroir eft ftérile, \& elle n'a pas un feul Havre, où un Bâtiment puiffe être en fûreté. Il courut un bruit, il y a quelques années, qu'on y avoit découvert une Mine d'Argent, \& faute de Mineurs, on fit partir de Quebec, où j'étois alors, un Orfévre, pour en faire l'épreuve : mais il n'alla pas bien loin. Il s'apperçut bientôt aux difcours de celui, qui avoit donné l'avis, que la Mine n'exiftoit que dans le Cerveau bleffé de cet Homme, lequel lui recommandoit fans ceffe d'avoir confiance en Dieu. Il jugea que fi la confiance en Dieu pouvoit par miracle faire trouver une Mine, il n'étoit pas néceffaire d'aller jufqu’à Anticofty, \& il revint fur fes pas. Les Côtes de cette lile font affez poifconneufes; toutefois je fuis perfuadé que les Héritiers du Sieur Joliet troqueroient volontiers leur vafte Seigneurie pour le plus petit Fief de France.

Quand on a paffé cette Ifle, on a le plaifir de fe voir toujours entre deux Terres, \& de s'affûrer du chemin, que l'on fait: mais il faut naviguer avec bien de la circonfpection fur le Fleuve. Le Mardi troifiéme nous laiffàmes à gauche les Monts Notre-Dame, \& le Mont-Louys; c'eft une Chaîne de Montagnes fort hautes, \& entre lefquelles il y a quelques Vallons, qui étoient autrefois habitées par des Sauvages. Les environs du Mont-Louys ont même de fort bonnes Terres, \&x on y trouve quelques Habitations Françoifes. On y pourroit faire un Etabliffement fort avantageux pour la Pêche, furtout pour celle de la Baleine, \& il ne feroit pas inutile aux Navires, qui viennent de France ; ils y trouveroient des fecours, dont ils ont quelquefois un extrême befoin. La nuit fuivante, le Vent augmenta, \& peu s'en fallut qu'il ne nous jouât d'un mauvais tour. Nous n'étions pas loin de la Pointe de la Trinité, que nous devions laiffer fur notre droite; mais nos Pilotes ne s'en croyoient pas fi proches;

1720

Septembre.

Defcription de l'Ifle d'Anticolty. 
I720. d'ailleurs ils s'eftimoient affez au large, pour ne rien craindre. M. de Voutron s'éveilla en furfaut, en criant de bander bie.

Septen- au large. Si cet ordre eût été differé d'un quart d'heure, le Navire étoit brifé contre la Pointe, qui parut quelques momens après. Le quatriéme au foir nous mouillâmes, pour la premiere fois, un peu au-deffous de ce qu'on appelle les Mammelles de Matance. Ce font deux Têtes d'une même Montagne, laquelle eft éloignée du Rivage de deux lieuës. Je ne crois pas qu'on paiffe voir un Pays plus fauvage. On n'y apperçoit que de mauvais Bois, des Rochers, du Sable, \&x pas un pouce de bonne terre. A la vérité il y a de belles Fontaines, de bon Gibier \& en abondance, mais la Chaffe y eft prefque impraticable à tout autre, qu'à des Sauvages \& à des Canadiens.

Nous reftâmes là pendant quatre jours, parce que de l'autre côté du Fleuve nous avions à parer la Batture de Manicouggan, fameufe par plus d'un naufrage, $\&$ qui avance deux lieuës dans le Fleuve. Elle tire fon nom d'une Riviere, qui fort des Montagnes de Labrador, forme un affez grand Lac, qui porte le même nom, \& plus communément celui de Saint Barnabé, \& fe décharge dans le Fleuve au travers de la Batture même. Quelques-unes de nos Cartes l'appellent la Riviere Noire.

Le huitiéme nous appareillâmes : ce n'étoit pas la peine, pour le chemin, que nous fîmes; mais la varieté défennuye, \& l'exercice eft bon aux Matelots. La nuit du dix á l'onze nous fìmes quinze lieuës; encore la moitié d'une, \& nous aurions paré le Paflage le plus important du Fleuve. D'ailleurs nous aurions gagné les fortes Marées, car jufques-là elles ne font prefque pas fenfibles, fi ce n'eft fur les Bords : mais le Vent tourna tout-à-coup au Sud-Ouert, \& nous obligea de chercher un abri: nous le trouvâmes fous l'Ifle Verte, où nous reftames cinq jours. Nous n'y manquions de rien, mais au bout de ce tems-là nous voulumes voir fi du côté du Nord nous trouverions, comme on nous l'avoit fait efperer, des $V$ ents de Terre, qui pourroient nous faire entrer dans les grandes Marées.

Du Sazuenay

Nous allâmes donc mouiller au Moulin Baude; la traverfe \&c tu lort de eft de cinq lieuës. En arrivant je demandai à voir ce Moulin, T.doullac.

\& on me montra quelques Rochers, d'où fort un Ruiffeau d'une 


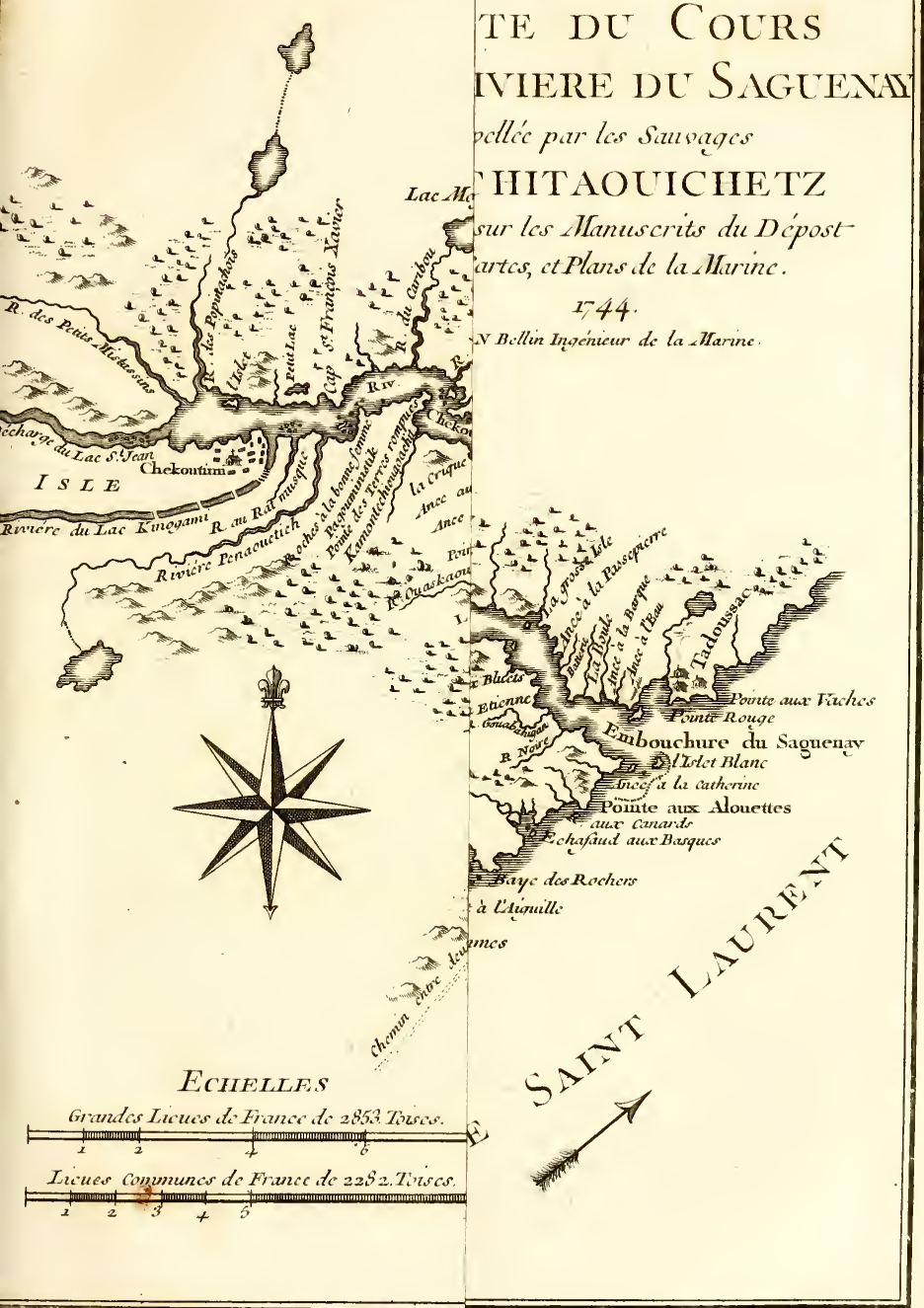


1720. d'ailleurs jls s'eftimoient affez au large, pour ne rien craindre. M. de Voutron s'éveilla en furfaut, en criant de bander

Septen- au large. Si cet ordre eût été differé d'un quart d'heure, le bre. Navire étoit brifé contre la Pointe, qui parut quelques momens après. Le quatriéme au foir nous nouillâmes, pour la premiere fois, un peu au-deffous de ce qu'on appelle les Mammelles de Matance. Ce font deux Têtes d'une même Montagne, laquelle eft éloignée du Rivage de deux lieuës. Je ne crois pas qu'on paiffe voir un Pays plus fauvage. On n'y apperçoit que de mauvais Bois, des Rochers, du Sable, $8 x$ pas un pouce de bonne terre. A la vérité il y a de belles Fontaines, de bon Gibier \& en abondance, mais la Chaffe y eft prefque impraticable à tout autre, qu’à des Sauvages \& à des Canadiens.

Nous reftâmes là pendant quatre jours, parce que de l'autre côté du Fleuve nous avions à parer la Batture de Manicouogan, fameufe par plus d'un naufrage, \& qui avance deux lieuës dans le Fleuve. Elle tire fon nom d'une Riviere, qui fort des Montagnes de Labrador, forme un affez grand Lac, qui porte le même nom, \& plus communément celui de Saint Barnabé, \& fe décharge dans le Fleuve au travers de la Batture même. Quelques-unes de nos Cartes l'appellent la Riviere Noire.

Le huiriéme nous appareillâmes : ce n'étoit pas la peine, pour le chemin, que nous fimes; mais la varieté défennuye, \& l'exercice eft bon aux Matelots. La nuit du dix á l'onze nous fimes quinze lieuës ; encore la moitié d'une, \& nous aurions paré le Paffage le plus important du Fleuve. D'ailleurs nous aurions gagné les fortes Marées, car jufques-là elles ne font prefque pas fenfibles, fi ce n'eft fur les Bords: mais le Vent tourna tout-à-coup au Sud-Ouert, \& nous obligea de chercher un abri: nous le trouvâmes fous l'Ifle Terte, où nous reftâmes cinq jours. Nous n'y manquions de rien, mais au bout de ce tems-là nous voulûmes voir fi du côté du Nord nous trouverions, comme on nous l'avoit fait efperer, des Vents de Terre, qui pourroient nous faire entrer dans les grandes Marées.

Du Sazuenay

Nous allâmes donc mouiller au Moulin Baude; la traverfe \&. tu lort de eft de cinq lieuës. En arrivant je demandai à voir ce Moulin, Tidoulfac. \& on me montra quelques Rochers, d'où fort un Ruiffeau d'une 


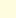

\section{-}


DUN VOYAGE DE L'A MERIQ. LET. II. 65 d'une Eau claire. C'eft du moins de quoi bâtir un Moulin à l'Eau; mais il n'y a gueres d'apparence qu'on n'y en bâtiffe jamais. Il n'eft peut-être pas au Monde un Pays moins habitable, que celui-là. Le Saguenay eft un peu au-deffus, c'eft bre. une Riviere, que les plus gros Vaiffeaux peuvent remonter vint-cinq lieuës. En y entrant on laiffe à main droite le Port de Tadouffac, où la plupart de nos Géographes ont marqué une Ville; mais où il n'y a jamais eu qu'une Maifon Françoife, \& quelques Cabannes de Sauvages, qui y venoient au tems de la Traite, \& qui emportoient enfuite leurs $\mathrm{Ca}$ bannes, comme on fait les Loges d'une Foire : \& ce n'étoit en effet que cela.

Il eft vrai que ce Port a été lontems l'abord de toutes les Nations Sauvages du Nord \& de l'Eft; que les François s'y rendoient, dès que la Navigation étoit libre, foit de France, foit du Canada; que les Miffionnaires profitoient de l'occafion, \& y venoient négocier pour le Ciel. La Traite finie, les Marchands retournoient chez eux, les Sauvages reprenoient le chemin de leurs Villages, ou de leurs Forêts, \& les Ouvriers Evangéliques fuivoient ces Derniers pour achever de les inftruire. Cependant les Relations \& les Voyageurs parloient beaucoup de Tadouffac, \& les Géographes ont fuppofé que c'étoit une Ville: quelques Auteurs ont même avancé qu'elle avoit une Jurifdiction $(a)$.

Au refte, Tadouffac eft un bon Port, \& on m'a affûré que vint-cing Vaiffeaux de Guerre y pouvoient être à l'abri de tous les Vents, que l'Ancrage y eft fûr, \& que l'Entrée en eft facile. Sa figure eft prefque ronde, des Rochers efcarpés d'une hauteur prodigieufe l'environnent de toutes parts, $\&$ il en fort un petit Ruiffeau, qui peut fournir de l'Eau à tous les Navires. Tout ce Pays eft plein de Marbre, mais fa plus grande richeffe feroit la Pêche des Baleines. En 1705 , étant mouillé avec le Heros dans ce même endroit, je vis en même tems quatre de ces Poiffons, qui entre Tête \& Queuë, étoient prefque de la longueur de notre Vaiffeau. Les Bafques ont fait autrefois cette Pêche avec fuccès, \& on voit encore fur une petite Ifle, qui porte leur nom, \& qui eft un peu plus bas que l'Ifle Verte, des reftes de Fourneaux, \& des Côtes de Baleines. Quelle difference entre une Pêche féden.

(a) M. l'Abbé LANGLET DU FRESNOY。

Tome III. 


\section{J O U R N A L H I S T O R I Q U E}

1720. taire, qu'on pourroit faire tranquillement dans un Fleuve; 8 celle, qu'on va faire fur
Septem- de rifques $\&$ de dépenfes !

bre.

Les deux jours fuivans point de Vent de Terre, \& nous regrettons fort notre premier mouillage, auprès duquel il y avoit des Habitations Françoifes; au lieu qu'ici on ne voit ni Hommes, ni Bêtes. Enfin le troifiéme jour à midi nous levons l'Ancre, \& nous franchiffons le Paffage de l'Ifle Rouge; qui n'eft pas aifé. Il faut d'abord porter fur cette Ifle, comme fi on vouloit y aborder; c'eft pour éviter la Pointe aux $A l$ louettes, qui eft à l'Entrée du Saguenay, fur la gauche, \& qui s'avance beaucoup dans le Fleuve. Cela fait, on revire de bord. Le Paffage au Sud de l'Ifle Rouge eft beaucoup plus fûr ; mais il auroit fallu pour cela retourner fur nos pas, \& le Vent auroit pû nous manquer. L'Ifle Rouge n'eft qu'un Rocher prefqu'à fleur d'Eau, qui paroît véritablement rouge, \& fur lequel plus d'un Navire a fait naufrage.

De l'thle aux Coudres, \& du Goufre:

Le lendemain, avec un peu de Vent \& de Marée, nous allâmes mouiller au-deffus de l'I/le aux Coudres, qui eft à quinze lieuës de Quebec \& de Tadouffac. On la laiffe à gauche, \&. ce Paffage eft dangereux, quand on n'a pas le Vent à fouhait. Il eft rapide, étroit, \& d'un bon quart de lieuë. Du tems de Champlain il étoit beaucoup plus aifé; mais en $166_{3}$ un Tremblement de Terre déracina une Montagne, la lança fur l'Ifle aux Coudres, qu'elle aggrandit de moitié, \& à la place, où étoit cette Montagne, il parut un Goufre, dont il ne fait pas bon de s'approcher. On pourroit paffer au Sud de l'Inle aux Coudres, \& ce Paffage feroit facile \& fans danger, il porte le nom de M. d'îberville, qui l'a tenté avec fuccès, mais la coûtume eft de paffer au Nord, \& r la coûtume eft une loi fouveraine pour le commun des Hommes.

De la Baye

Au-deffus du Goufre, dont je viens de parler, eft la Baye de Saint Paul. de Saint Paul, où commencent les Habitations du côté du Nord, \&x où il y a des Pinieres, qu'on eftime beaucoup; on y trouve furtout des Pins rouges d'une grande beauté, \& qui ne caffent jamais. Meffieurs du Séminaire de Quebec font Seigneurs de cette Baye (a). Six lieuës plus haut eft un Promontoire extrémement élevé, où fe termine une Chaîne de Montagnes, qui s'étend plus de quatre cent lieuës à l'Oueft.

(a) On y a découvert depuis peu une fort belle Mine de Plomb. 
66 J O U R N A L H I S T O R I Q U E

1720 . taire, qu'on pourroit faire tranquillement dans un Fleuve,

\& celle, qu'on va faire fur les Côtes du Groenland avec tant bre.

Les deux jours fuivans point de Vent de Terre, \& nous regrettons fort notre premier mouillage, auprès duquel il y avoit des Habitations Françoifes; au lieu qu'ici on ne voit ni Hommes, ni Bêtes. Enfin le troifiéme jour à midi nous levons l'Ancre, \& nous franchiffons le Paffage de l'I le Rouge; qui n'eft pas aifé. Il faut d'abord porter fur cette Ifle, comme fi on vouloit y aborder; c'eft pour éviter la Pointe aux $\mathrm{Al}$ louettes, qui eft à l'Entrée du Saguenay, fur la gauche, $8 x$ qui s'avance beaucoup dans le Fleuve. Cela fait, on revire de bord. Le Paffage au Sud de l'Ifle Rouge eft beaucoup plus fûr ; mais il auroit fallu pour cela retourner fur nos pas, $8 \tau$ le Vent auroit pû nous manquer. L'Ine Rouge n'eft qu'un Rocher prefqu'à fleur d'Eau, qui paroît véritablement rouge, $\&$ fur lequel plus d'un Navire a fait naufrage.

De l'Ine aux Coudres, \& du Goufre:

Le lendemain, avec un peu de Vent \& de Marée, nous allâmes mouiller au-deffus de l'I le aux Coudres, qui eft à quinze lieuës de Quebec \& de Tadouffac. On la laiffe à gauche, \& ce Paffage eft dangereux, quand on n'a pas le Vent à fouhait. Il eft rapide, étroit, \& d'un bon quart de lieuë. Du tems de Champlain il étoit beaucoup plús aifé; mais en $166_{3}$ un Tremblement de Terre déracina une Montagne, la lança fur l'Ifle aux Coudres, qu'elle aggrandit de moitié, \& à la place, où étoit cette Montagne, il parut un Goufre, dont il ne fait pas bon de s'approcher. On pourroit paffer au Sud de l'Ifle aux Coudres, \& ce Paffage feroit facile \& fans danger, il porte le nom de M. d'íberville, qui l'a tenté avec fuccès, mais la coûtume eft de paffer au Nord, \& $\&$ la coûtume eft une loi fouveraine pour le commun des Hommes.

De la Baye

Au-deffus du Goufre, dont je viens de parler, eft la Baye de Saint Paul. de Saint Paul, où commencent les Habitations du côté du Nord, $8 x$ où il y a des Pinieres, qu'on eftime beaucoup; on y trouve furtout des Pins rouges d'une grande beauté, \& qui ne caffent jamais. Meflieurs du Séminaire de Quebec font Seigneurs de cette Baye ( $a$ ). Six lieuës plus haut eft un Promontoire extrémement élevé, où fe termine une Chaîne de Montagnes, qui s'étend plus de quatre cent lieuës à l'Oueft.

(a) On y a découvert depuis peu une fort belle Mine de Plomb. 


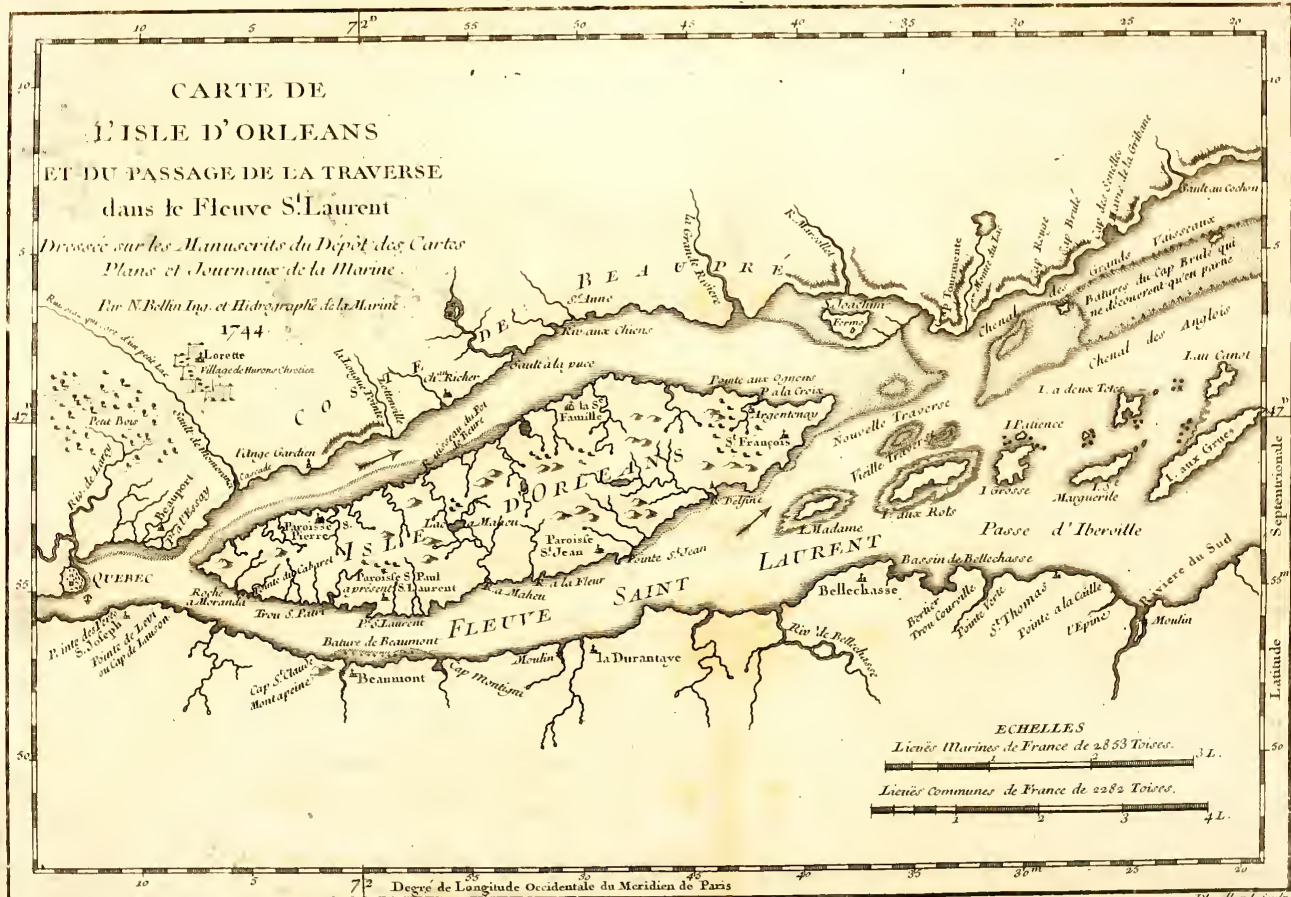



D'UN V OYAGE DE L'A MER I Q. LET. II. $6_{7}$ On l'appelle le Cap-Tourmente, apparemment parce que celui, qui l'a ainfi baptifé, y a effuyé quelques coups de Vent. Le mouillage y eft bon, \& on y eft environné d'llles de toutes les grandeurs, qui forment un très-bon abri. La plus confidérable eft l'IJle d'Orleans, dont les Campagnes, toutes cultivées, paroiffent comme un Amphithéâtre, \& terminent gracieufement la vûë. Cette lile a environ quatorze lieuës de circuit, \& en 1 676 elle fut érigée en Comté, fous le nom de Saint Laurent, en faveur de François BERT HELOT, Secretaire Général de l'Artillerie, qui l'avoit acquife de François de Laval, Premier Evêque de Quebec. Elle avoit déja quatre Villages, \& on y compte aujourd'hui fix Paroiffes affez peuplées.

Des deux Canaux, qui forment cette Ifle, il n'y a que celui du Sud, qui foit naviguable pour les Vaifleaux. Les Chaloupes mêmes ne fçauroient paffer par celui du Nord, que de Marée haute. Ainfi du Cap-Tourmente il faut traverfer le Fleuve, pour aller à Quebec, \& cette traverfe a fes difficultés. Il s'y rencontre des Sables mouvans, fur lefquels il n'y a pas toujours affez d'Eau pour les plus gros Navires, ce qui oblige à ne s'y engager jamais, que quand la Marée monte. On éviteroit encore cet embarras en prenant le $\mathrm{Paf}$ fage de M. d'Iberville. Le Cap-Tourmente, d'où l'on part pour faire la traverfe, eft éloigné de cent dix lieuës de la Mer, \& l'Eau du Fleuve y eft encore Saumâtre. Elle n'eft bonne à boire qu'à l'Entrée des deux Canaux, qui féparent l'Ifle d'Orleans. C'eft un Phénoméne affez difficile à expliquer, furtout, fi on fait attention à la grande rapidité du Fleuve, malgré fa largeur.

Les Marées montent ici réguliérement cinq heures, \& baiffent pendant fept. A Tadouffac elles montent $\&$ defcendent pendant fix heures; $\&$ plus on monte le Fleuve, plus le Flux diminuë, \& le Reflux augmente. A vint lieuës au-deffus de fole.

Quebec le Flux eft de trois heures, \& le Reflux de neuf. Au-delà il n'y a plus de Marée fenfible. Quand elle eft à demi flot dans le Port de Tadouffac, \& à l'Entrée du Saguenay, elle ne fait que commencer à monter à Checoutimi, vint-cinq lieuës plus haut fur cette Riviere, \& néanmoins elle fe trouve haute aux trois endroits en même tems. Cela vient fans doute de ce que la rapidité du Saguenay, plus grande encore que bre. 
ธ720. celle du Fleuve Saint Laurent, refoulant la Marée, fait penbre.

Septemdant quelque tems l'équilibre de Checoutimi avec l'Entrée de la Riviere dans le Fleuve. Cette rapidité au refte n'eft aus point, où on la voit, que depuis le Tremblement de Terre de 1663 . Ce Tremblement renverfa une Montagne dans la Riviere, dont elle rétrécit le Lit, \& forma une Peninfule, qu'on appelle Checoutimi, au-deffus de laquelle il y a un Rapide, que les Canots mêmes ne peuvent pas franchir : la profondeur du Saguenai, depuis fon Embouchure jufqu’à Checoutimi, eft égale à fa rapidité. Auffi n'oferoit-on pas y jetter les Ancres, fi on n'avoit pas la facilité d'amarrer les. Vaiffeaux aux Arbres, qui couvrent les Bords de cette Riviere.

On a encore obfervé que dans le Golphe Saint Laurent, à huit ou dix lieuës au large, les Marées font differentes, felon les diverfes pofitions des. Terres, ou la variété des Saifons; qu'en quelques endroits elles fuivent les Vents, \& qu'en d'autres elles vont contre le Vent; qu'à l'Embouchure: du Fleuve, en certains mois de l'année, les Courants portent toujours en pleine $\mathrm{Mer}$, \& en d'autres, toujours à Terre; enfin, que dans le Fleuve même, jufques vers les Sept Ifles, c'eft-à-dire, pendant foixante lieuës, il n'y a point de Flux du côté du Sud, ni de Reflux du côté du Nord. Il n'eft pas trop aifé d'apporter de bonnes raifons de tout. cela; ce qu'on peut dire, ce femble, de plus raifonnable, c'eft qu'il fe fait fous l'Eau des mouvemens, qui produifent ces irrégularités, ou qu'il y a des Courants, qui vont \&viennent de la furface au fond, \& du fond à la furface, à la maniere des Pompes.

Une autre obfervation à faire ici, c'eft que la déclinaifon de la Bouffole, qui dans quelques Ports de France n'eft guéres que de deux ou trois dégrez Nord-Oueft, va toujours en diminuant jufques par le travers des Açorres, où elle n'eft plus fenfible; mais qu'au-delà elle augmente de telle forte que fur le Grand Banc de Terre-neuve elle eft de vintdeux dégrez \& plus; qu'enfuite elle commence à diminuer, mais lentement, puifqu'elle eft encore de feize dégrez à Que$\mathrm{bec}, \&$ de douze au Pays des Hurons, où le Soleil fe couche trente-trois minutes plus tard, qu'à Quebec. H'Orleans.

De i'ine Le Dimanche vint-deux nous étions mouillés par le tra- 
D'UN VOYA GE DE L'A MERIQ. LET. II. 69 vers de l'The d'Orleans, où nous allâmes nous promener en attendant le retour de la Marée. Je trouvai ce Pays beau, les Terres bonnes, \& les Habitans affez à leur aife. Ils ont la réputation d'être un peu Sorciers, \& on s'addreffe, dit-on, à eux, pour fçavoir l'avenir, ou ce qui fe paffe dans des lieux éloignés. Par exemple, fi les Navires de France tardent un peu trop, on les confulte pour en avoir des nouvelles, \& on affure qu'ils ont quelquefois répondu affez jufte. C'eft-à-dire, qu'ayant deviné une ou deux fois, \& ayant fait accroire, pour fe divertir, qu'ils parlojent de fcience certaine, on s'eft imaginé qu'ils avoient confulté le Diable.

Lorfque Jacques Cartier découvrit cette Ifle, il la trouva toute remplie de Vignes, \& la nomma l'Ifle de Bacchus. Ce Navigateur étoit Breton; après lui font venus des. Normands, qui ont arraché les Vignes, \& à Bacchus ont fubftitué Pomone \& Céres. En effet elle produit de bon Froment \& d'excellens Fruits. On commence auffi à y cultiver le Tabac, $\& \alpha$ il n'eft pas mauvais. Enfin le Lundi vint-trois, le Chameau. mouilla devant Quebec, où je m'étois rendu deux heures auparavant en Canot d'Ecorce. J'ai un millier de lieuës à faire dans ces fragiles Voitures, il faut que je m'y accoutume peu à peu. Voilà, Madame, ce que j’ai pû me rappeller des particularités de mon Voyage. Ce font, comme vous voyez, des bagatelles, qui feroient tout au plus bonnes à amufer des Perfonnes défœuvrées dans un Vaiffeau. J'aurai peut - être dans la fuite quelque chofe de plus intéreffant à vous mander : mais je n'ajoûterai rien à cette Lettre, parce que je ne veux pas manquer l'occafion d'un Navire Marchand, qui eft fur le point de mettre à la Voile. J'aurai l'honneur de vous écrire encore par le Vaiffeau du Roi.

Je fuis, \&c.

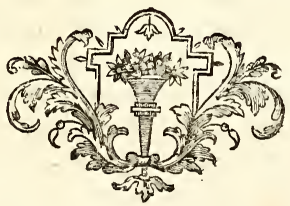

1720.

Septembre. 


\section{T R OISIÉ ME LETTRE.}

1720 .

OEtobre.

\section{Defcription de Quebec, Caractere de fes Habitans, $\mathcal{E}$ de la façon de vivre dans la Colonie Francoife.}

A Quebec, ce vint-huit Octobre, 1720.

\section{NA D A ME,}

J E vais vous parler de Quebec ; toutes les Defcriptions; que j'en ai vûes jufqu'ici, font fi défectueufes, que j'ai cru vous faire plaifir, en vous repréfentant au vrai cette Capitale de la Nouvelle France. Elle mérite véritablement d'être connuë, n'y eût-il que la fingularité de fa fituation; car il n'y a au Monde que cette Ville, qui puiffe fe vanter d'avoir un Port en Eau douce, à fix-vint lieuës de la Mer, \& capable de contenir cent Vaiffeaux de ligne. Auffi eft-elle placée fur le Fleuve le plus naviguable de l'Univers.

Origine du

Ce Fleuve, jufqu'à l'Ifle d'Orleans; c'eft-à-dire, à cent nom de Qucbec.

dix ou douze lieuës de la Mer, n'a jamais moins de quatre à cinq lieuës de large; mais au-deffus de l'Ille il fe rétrécit tout-àcoup de telle forte, que devant Quebec il n'a plus qu'un mille de largeur; c'eft ce qui a fait donner à cet endroit le nom de Quebeio, ou Quebec, qui en Langue Algonquine fignifie Retrécifement. Les Abénaquis, dont la Langue eft une Dialecte Algonquine, le nomment Quelibec, qui veut dire ce qui eft fermé, parce que de l'entrée de la Petite Riviere de la Chaudiere, par où ces Sauvages venoient à Quebec du voifinage de l'Acadie, la pointe de Levi, qui avance fur l'Ifle d'Orleans, cache entierement le Canal du Sud; l'Ifle d'Orleans cache celui du Nord, de forte que le Port de Quebec ne paroît de-là qu'une grande Baye.

Du Sault de Montmogenci.

La premiere chofe, qu'on apperçoit en entrant dans la Rade, eft une belle Nappe d'Eau, d'environ trente pieds de large, \& de quarante de haut. Elle eft immédiatement à l'Ens 


\section{T R O IS IÉ ME LETT T E.}

1720.

Octobre.

Defcription de Quebec, Caractere de fes Habitans, $\mathcal{E}$. de la façon de vivre dans la Colonie Françoife.

\section{A Quebec, ce vint-huit Octobre, 1720.}

\section{Madame,}

$\mathbf{J}_{\mathrm{E}}$ vais vous parler de Quebec ; toutes les Defcriptions, que $j$ 'en ai vûës jufqu'ici, font fi défectueufes, que j'ai cru vous faire plaifir, en vous repréfentant au vrai cette Capitale de la Nouvelle France. Elle mérite véritablement d'être connuë, n'y eût-il que la fingularité de fa fituation; car il n'y a au Monde que cette Ville, qui puiffe fe vanter d'avoir un Port en Eau douce, à fix-vint lieuës de la Mer, \& capable de contenir cent Vaiffeaux de ligne. Auffi eft-elle placée fur le Fleuve le plus naviguable de l'Univers.

Origine du Ce Fleuve, jufqu’à l'Ifle d'Orleans; c'eft-à-dire, à cent nom de Qucbec. dix ou douze lieuës de la Mer, n'a jamais moins de quatre à cinq lieuës de large; mais au-deffus de l'Ifle il fe rétrécit tout-àcoup de telle forte, que devant Quebec il n'a plus qu'un mille de largeur; c'eft ce qui a fait donner à cet endroit le nom de Quebeio, ou Quebec, qui en Langue Algonquine fignifie Retrécifement. Les Abénaquis, dont la Langue eft une Dialecte Algonquine, le nomment Quelibec, qui veut dire ce qui eft fermé, parce que de l'entrée de la Petite Riviere de la Chaudiere, par où ces Sauvages venoient à Quebec du voifinage de l'Acadie, la pointe de Levi, qui avance fur l'Ifle d'Orleans, cache entierement le Canal du Sud; l'Ifle d'Orleans cache celui du Nord, de forte que le Port de Quebec ne paroît de-là qu'une grande Baye.

Du Saule de Montmorenci.

La premiere chofe, qu'on apperçoit en entrant dans la Rade, eft une belle Nappe d'Eau, d'environ trente pieds de large, \& de quarante de haut. Elle eft immédiatement à l'En. 


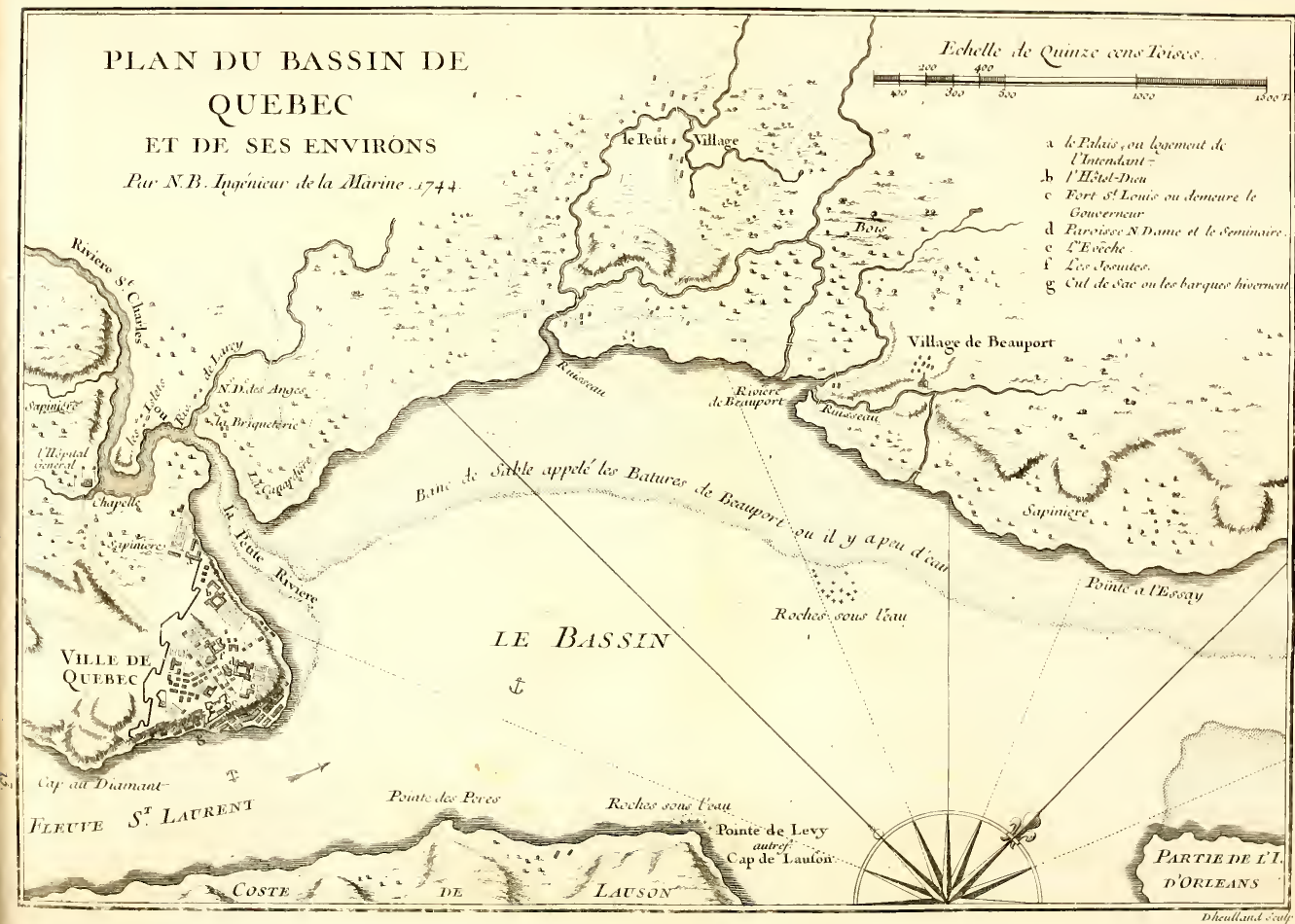


$-$ 
D'U N V O Y A GE DE L'A MER IQ. LET. III. 7I trée du Petit Canal de l'Ifle d'Orleans, \& on la voit d'une longue Pointe de la Côte Méridionnale du Fleuve, laquelle, comme je l'ai déja obfervé, paroît fe recourber fur I'Inle d'Orleans. Cette Cafcade a été nommée le Sault de Montmorenci, \& la Pointe porte le nom de Levi. C'eft que la Nouvelle France a eu fucceffivement pour Vice-Rois l'Amiral de Montmorenci, \& le Duc de Ventadour, fon Neveu. Il n'y a perfonne, qui ne crût qu'une Chûte d'eau fi abondante, \& qui ne tarit jamais, ne foit la décharge de quelque belle Riviere : elle ne l'eft pourtant que d'un chetif Ruiffeau, où en quelques endroits on n'a pas de l'Eau jufqu'à la cheville du pied; mais il coule toujours, \& il tire fa Source d'un joli Lac éloigné du Sault d'environ douze lieuës.

La Ville eft une lieuë plus haut, \& du même côté , à l'endroit même, où le Fleuve eft le plus étroit. Mais entr'elle, \& l'Ifle d'Orleans il y a un Baffin d'une bonne lieuë en tout fens, dans lequel fe décharge la Riviere de $S$. Charles, qui vient du Nord-Oueft. Quebec eft entre l'Embouchure de cette Riviere, \& le Cap aux Diamants, lequel avance un peu dans le Fleuve. Le mouillage eft vis-à-vis, il a vint-cinq braffes d'Eau, \& l'Ancrage y eft bon : toutefois, quand le Nord-Eft foufle violemment, les Vaiffeaux chaffent quelquefois fur leurs Ancres, mais fans danger.

Lorfque Samuel de Champlain fonda cette Ville en 1608 , la Marée montoit quelquefois jufquau pied du Rocher. Depuis ce tems-là le Fleuve s'eft retiré peu à peu, \& a enfin laiffé à fec un grand Terrein, où l'on a bâti la Baffe Ville, laquelle eft préfentement affez élevée au-deffus du Rivage, pour raffûrer les Habitans contre l'inondation du Fleuve. La premiere chofe, qu'on rencontre en 'débarquant, eft une Place de médiocre grandeur, \& de figure irréguliere, laquelle a en face une fuite de Mairons affez bien bâties, \& addoffées contre le Rocher, ainfi elles n'ont pas beaucoup de profondeur. Elles forment une Ruë affez longue, qui occupe toute la largeur de la Place, \& s'étend à droite $\& \grave{a ̀ ~}$ gauche jufqu'aux deux Chemins, qui conduifent à la Haute Ville. La Place eft bornée fur la gauche par une petite Eglife, \& fur la droite par deux rangées de Maifons placées paralellement. Il y en a une de l'autre côté entre l'Eglife \& le Port, $\&$ au détour du Cap aux Diamants, il y a encore une fuite

1720. Octobre.

Situation de Quebec.

Defcription de Quebsc. 


\section{$72 \mathrm{~J} O U \mathrm{U} N \mathrm{AL}$ H IS T ORI Q U E}

I 720 . aflez longue de Maifons fur le bord d'une Anfe, qu'on appelle l'Anfe des Meres. On peut regarder ce Quartier comme une OAtobre. efpece de Fauxbourg de la Baffe Ville.

Entre ce Fauxbourg \& la Grande Ruë on monte à la Haute Ville par une Pente fi roide, qu'il a fallu y faire des Dégrez, de forte qu'on n'y peut monter qu'à pied. Mais en prenant de la Place fur la droite, on a pratiqué un Chemin, dont la pente eft plus douce, \& qui eft bordé de Maifons. C'eft à I'endroit, où les deux Montées fe réuniffent, que commence la Haute Ville du côté du Fleuve; car il y a encore une Baffe Ville du côté de la Riviere Saint Charles. Le premier Bâtiment de remarque, qu'on trouve à droite du premier côté, eft le Palais Epifcopal: toute la gauche eft bordée de Maifons. Vint pas plus loin on fe trouve entre deux Places affez grandes : celle de la gauche eft la Place d'Armes, fur laquelle donne le Fort, où loge le Gouverneur Général : les Récollets font vis-à-vis, \& d'affez belles Maifons occupent une partie du contour de la Place.

Dans celle de la droite on rencontre d'abord la Cathédrale, qui fert auffi de Paroiffe à toute la Ville. Le Séminaire eft à côté, fur l'Angle, que forment le Fleuve \& la Riviere Saint Charles. Vis-à-vis de la Cathédrale eft le College des Jéfuites, \& dans les entredenx il y a des Maifons affez bien bâties. De la Place d'Armes on enfile deux Ruës, qui font traverfées par une troifiéme, \& qui forme une affez grande Ifle, toute occupée par l'Eglife \& le Couvent des Récollets. La feconde Place a deux Defcentes à la Riviere Saint Charles, l'une fort roide, à côté du Séminaire, \& où il y a peu de Maifons ; l'autre, à côté de l'Enclos des Jéfuites, laquelle tourne beaucoup, a l'Hôtel-Dieu à mi-côte, eft bordée de Maifons affez petites, \& aboutit au Palais, où demeure l'Intendant. De l'autre côté des Jéfuites, où eft leur Eglife, il y a une Ruë affez longue, où font les Urfulines. Au refte toute la Haute Ville eft bâtie fur un Fond, partie de Marbre, \& partie d'Ardoife (a).

Defcription Telle eft, Madame, la Topographie de Quebec, qui, de fes princi- comme yous voyez, a une affez grande étenduë, dont prefparı Edifices. que toutes les Maifons font bâties de Pierres, \& où l'on ne

(a) On peut voir par le Plan gravé de cette Ville qu'elle a crû affez confidérablement depuis vint ans. 


\section{$72 \mathrm{~J} O U R \mathrm{~N}$ A L H IS TOR I Q U E}

7 20. affez longue de Maifons fur le bord d'une Anfe, qu'on appelle l'Anfe des Meres. On peut regarder ce $Q$ uartier comme une OAtobre. efpece de Fauxbourg de la Baffe Ville.

Entre ce Fauxbourg \& la Grande Ruë on monte à la Hauté Ville par une Pente fi roide, qu'il a fallu y faire des Dégrez, de forte qu'on n'y peut monter qu'à pied. Mais en prenant de la Place fur la droite, on a pratiqué un Chemin, dont la pente eft plus douce, \& qui eft bordé de Maifons. C'eft à I'endroit, où les deux Montées fe réuniffent, que commence la Haute Ville du côté du Fleuve; car il y a encore une Baffe Ville du côté de la Riviere Saint Charles. Le premier Bâtiment de remarque, qu'on trouve à droite du premier côté, eft le Palais Epif́copal: toute la gauche eft bordée de Maifons. Vint pas plus loin on fe trouve entre deux Places affez grandes: celle de la gauche eft la Place d'Armes, fur laquelle donne le Fort, où loge le Gouverneur Général : les Récollets font vis-à-vis, \& d'affez belles Maifons occupent une partie du contour de la Place.

Dans celle de la droite on rencontre d'abord la Cathédrale, qui fert auffi de Paroife à toute la Ville. Le Séminaire eft à côté , fur l'Angle, que forment le Fleuve \& la Riviere Saint Charles. Vis-à-vis de la Cathédrale eft le College des Jéfuites, \& dans les entredeux il y a des Maifons affez bien bâties. De la Place d'Armes on enfile deux Ruës, qui font traverfées par une troifiéme, \& qui forme une affez grande Ifle, toute occupée par l'Eglife \& le Couvent des Récollets. $\mathrm{La}$ feconde Place a deux Defcentes à la Riviere Saint Charles, l'une fort roide, à côté du Séminaire, $\&$ où il y a peu de Maifons ; l'autre, à côté de l'Enclos des Jéfuites, laquelle tourne beaucoup, a l'Hôtel-Dieu à mi-côte, eft bordée de Maifons affez petites, \& aboutit au Palais, où demeure l'Intendant. De l'autre côté des Jéfuites, où eft leur Eglife, il y a une Ruë affez longue, où font les Urfulines. Au refte toute la Haute Ville eft bâtie fur un Fond, partie de Marbre, \& partie d'Ardoife (a).

Defription Telle eft, Madame, la Topographie de Quebec, qui, de fes princi- comme yous voyez, a une affez grande étenduë, dont prefque toutes les Maifons font bâties de Pierres, \& où l'on ne

(a) On peut voir par le Plan gravé de certe Ville qu'elle a crû affez confidérablement depuis yint ans. 


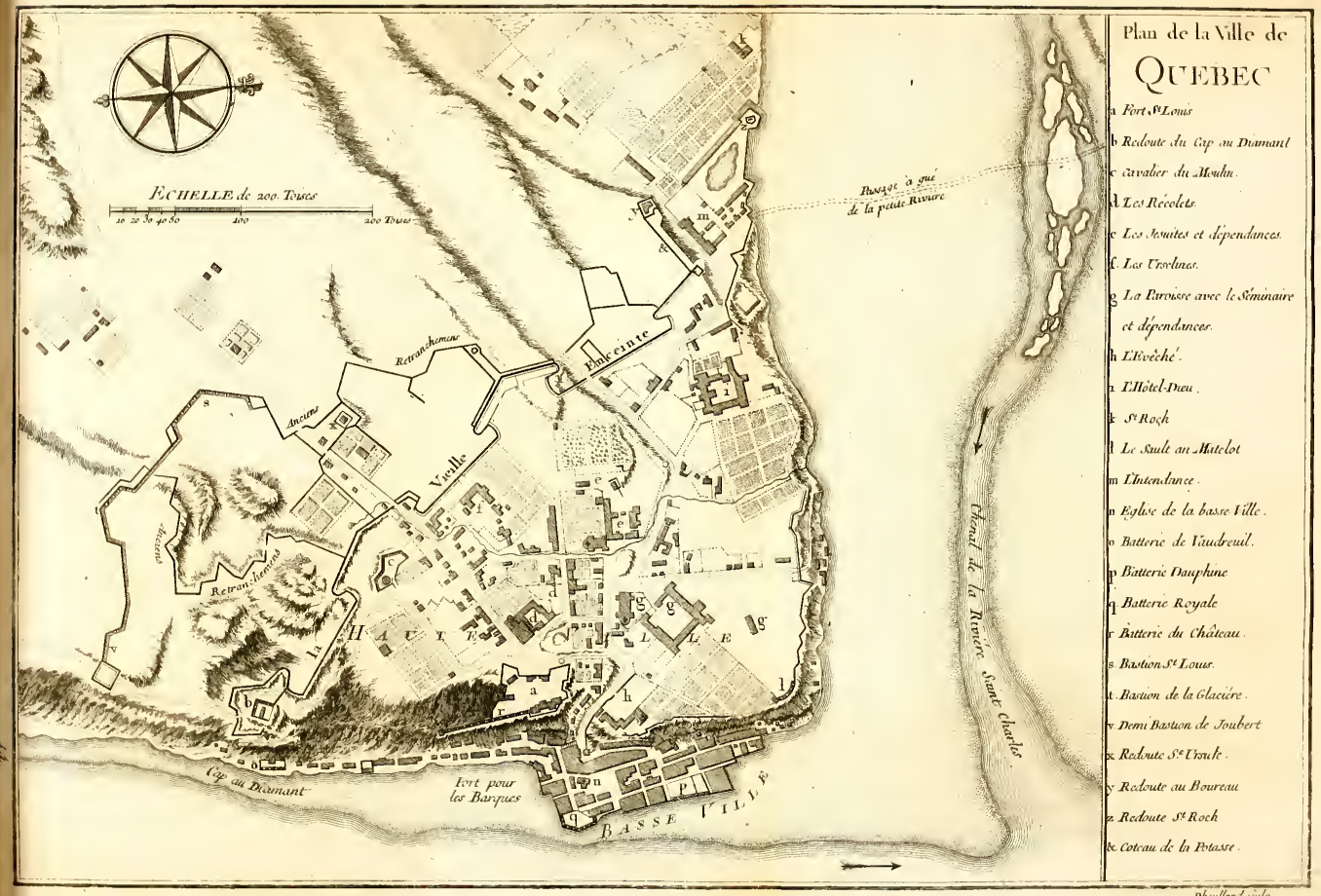



D'UN J OURNA L DE L'A MER I Q. LET. III. 73 compte pourtant qu'environ fept mille Ames. Mais pour achever de vous donner une jufte idée de cette Ville, je vais vous faire comnoître plus particulierement fes principaux Edifices. Je vous parlerai enfuite de fes Fortifications. L'Eglife de la Baffe-Ville a été bâtie en conféquence d'un Vœu fait pendant le Siége de Quebec en I 690. Elle eft dédiée fous le nom de Notre-Dame de la Victoire, \& elle fert de Succurfale pour la commodité des Habitans de la Baffe Ville. Sa ftructure eft très-fimple, une propreté modefte en fait tout l'ornement. Quelques Sours de la Congrégation, dont je vous parlerai dans la fuite, font logées entre cette Eglife \& le Port : elles ne font que quatre ou cinq, \& tiennent une Ecole.

Le Palais Epifcopal n'a de fini que la Chapelle, \& la moitié des Bâtimens, que porte le Deffein, fuivant lequel ce doit être un Quarré long. S'il eft jamais achevé, ce fera un très-bel Edifice. Le Jardin s'étend jufques fur la Croupe du Rocher, \& domine toute la Rade. Quand la Capitale de la Nouvelle France fera auffi floriffante que celle de l'Ancienne ( \& il ne faut déféfpérer de rien, Paris a été lontems beaucoup moins que n'eft Quebec aujourd'hui) qu'autant que les yeux pourront porter, ils ne verront que Bourgs, Châteaux , Maifons de Plaifance, \& tout cela eft déja ébauché : que le Fleuve de Saint Laurent, qui roule majeftueufement fes Eaux , \& les amene de l'extrémité du Nord, ou de l'Oueft, y fera couvert de Vaiffeaux : que l'Ifle d'Orleans \& les deux Bords des deux Rivieres, qui forment ce Port, découvriront de belles Prairies, de riches Côteaux \& des Campagnes fertiles, \& il ne leur manque pour cela que d'être plus peuplées: qu'une partie de la Riviere Saint Charles, qui ferpente. agréablement dans un charmant Vallon, fera jointe à la Ville, dont elle fera fans doute le plus beau Quartier : que l'on aura revêtu toute la Rade de Quays magnifiques: que le Port fera environné de Bâtimens fuperbes, \& qu'on y aura trois ou quatre cent Navires chargés des richeffes, que nous n'avons pas encore fçu faire valoir, \& y apporter en échange celles de l'Ancien \& du Nouveau Monde, vous m'avouerez, Madame, que cette Terraffe offrira un point de vûë, que rien ne pourra égaler, \& que dès à préfent ce doit être quelque chofe de fort beau. La Cathédrale ne feroit pas une belle Paroiffe dans un des naire.
Tome III.

La Catléinale, \& le Sémi- 
74 JOURNAL HISTORIQUE

1720 . plus petits Bourgs de France; jugez fi elle mérite d'être le O\&tcbre. Siége du feul Evêché, qui foit dans tout l'Empire François de l'Amérique, beaucoup plus étendu, que n'a jamais été celui des Romains. Son Architecture, fon Chœur, fon Grand'Autel, fes Chapelles fentent tout-à-fait l'Eglife de Campagne. Ce qu'elle a de plus paffable, eft une Tour fort haute, folidement bâtie, \& qui de loin a quelque apparence. Le Séminaîre, qui touche à cette Eglife eft un grand Quarré, dont les Bâtimens ne font point encore finis. Ce qui eft fait, eft bien conftruit, \& avec toutes les commodités néceffaires en ce Pays-ci. C'eft pour la troifiéme fois qu'on bâtit cette Maifon. Elle fut brûlée toute entiere en 1703 . Et au mois d'Octobre de l'année 1705, comme on achevoit de la rétablir, elle fut de nouveau prefque toute confumée par les flammes. Du Jardin on découvre toute la Rade, \&x la Riviere de Saint Charles, autant que la vûë peut s'étendre.

DuFort\&du Le Fort eft un beau Bâtiment, qui doit être flanqué de Cap aux Dia- deux Pavillons faillans; mais il n'y en a encore qu'un de mants. fait. On va, dit-on, travailler inceffamment à l'autre (a). On y entre par une Cour affez fpacieufe \& réguliere, mais il n'y a point de Jardin, parce que le Fort eft conftruit fur le bord du Roc. Une belle Galerie avec un Balcon, qui regne tout le long des Bâtimens, y fupplée en quelque forte. Elle commande la Rade, au milieu de laquelle on peut fe faire entendre aifément avec un porte-voix, \& on y voit toute la Baffe Ville fous fes pieds. En fortant du Fort, \&z prenant fur la gauche, on entre dans une affez grande Efplanade, \& par une pente douce on arrive à la cime du Cap aux Diamants, qui eft une fort belle Plate-forme. Outre l'agrément de la vîé, on refpire en ce lieu l'air le plus pur; on y voit quantité de Marfouins, blancs comme la Nége, jouer fur la furface des Eaux, \&x on y ramaffe quelquefois des Diamants, plus beaux que ceux d'Alençon. J'y en ai vî d'aufi bien taillés, que s'ils fuffent fortis de la main du plus habile Ouvrier. Autrefois ils y étoient fort communs, \& c'eft ce qui a fait donner au Cap le nom, qu'il porte. Préfentement ils y font fort rares. La Defcente du côté de la Campagne eft encore plus douce, que du côté de l'Efplanade.

Des Récollets \& des Urfulines.

Les Peres Récollets ont une grande \& belle Eglife, \& qui (a) Il eft achevé. 
D'UN VOY A GE DE L'A MER IQ. LET. III。 75 leur feroit honneur à Verfailles. Elle eft proprement lambriffée, ornée d'une large Tribune; un peu maffive, \& d'une Boiferie bien travaillée, qui regne tout au tour, \& dans la1720 . quelle font pris les Confeffionnaux. C'eft l'Ouvrage d'un de leurs Freres Convers. Enfin rien n'y manque, mais il faudroit en ôter quelques Tableaux, qui font fort groffierement peints; Le Frere Luc y en a mis de fa façon, qui n'ont pas befoin de ces ombres. La Maifon répond à l'Eglife : elle eft grande, folidement bâtie, commode, accompagnée d'un Jardin fpacieux \& bien cultivé. Les Urfulines ont effuyé deux incendies, aufi-bien que le Séminaire; avec cela elles ont fi peu de Fonds ; \& les Dots, qu'on reçoit des Filles de ce Pays, font $\mathrm{fi}$ modiques, que dès la premiere fois que leur Maifon fut brûlée, on penfa à les renvoyer en France. Elles font néanmoins venuës à bout de fe rétablir toutes les deux fois, \& l'on acheve actuellemeut leur Eglife. Elles font proprement, \& commodément logées: c'eft le fruit de la bonne odeur, qu'elles répandent dans la Colonie, de leur œconomie, de leur fobriété, \& de leur travail : elles dorent, elles brodent, toutes font utilement occupées, \& ce qui fort de leurs mains eft ordinairement d'un bon goût.

Vous aurez fans doute vû, Madame, dans quelques Rela. tions que le College des Jéfuites eft un très-bel Edifice. Il eft certain que, quand cette Ville n'étoit qu'un amas informe de Barraques Françoifes \& de Cabannes Sauvages, cette Maifon, la feule, avec le Fort, qui fût bâtie de Pierres, faifoit quelque figure : les premiers Voyageurs, qui en jugeoient par comparaifon, l'avoient reprefentée comme un très-beau Bâtiment; ceux, qui les ont fuivis, \& qui, felon la coûtume, les ont copiés, ont tenu le même langage. Cependant les Cabannes ont difparu, \& les Barraques ont été changées en Maifons, la plûpart bien bâties, de forte que le College dépare aujourd hui la Ville, \& menace ruine de toutes parts $(a)$.

La fituation n'en eft pas même avantageufe; il eft privé du plus grand agrément, qu'on eût pu lui procurer, qui eft celui de la vûê. Il avoit d'abord celle de la Rade en perf́pective, \& fes Fondateurs avoient été affez bons, pour simaginer qu'on les en laifferoit jouir ; mais ils fe font trompés. La Cathédrale \& le Séminaire leur font un mafque, qui ne leur

(a) On a depuis peu rebâti tout le College, \& il eft maintenant fort beau. 


\section{J OUR NAL H I S T O R I Q U E}

1720 . laiffe plus que la vîë de la Place, laquelle n'a pas de quoi les dédommager de celle, qu'ils ont perduë. La Cour de ce College eft petite \& mal-propre, rien ne reffemble mieux à une Cour de Métairie. Le Jardin eft grand \& bien entretenu , \& il eft terminé par un Petit Bois, refte précieux de l'antique Forêt, qui couvroit autrefois toute cette Montagne.

L'Eglife n'a rien de beau en dehors, qu'un affez joli Clocher : elle eft toute couverte d'Ardoifes, \& c'ent la feule du Canada, qui ait cet avantage ; car tout eft ici couvert de Bardeaux. En dedans elle eft fort ornée. Une Tribune hardie, légere, bien pratiquée, \& bordée d'une Baluttrade de Fer, peint, doré, \& d'un bon Ouvrage : Une Chaire de Prédicateur toute dorée, \& bien travaillée en Fer \& en Bois : trois Autels bien pris; quelques bons Tableaux; point de Voûte, mais un Lambris plat affez orné; point de Pavé, mais un bon Plancher, qui rend cette Eglife fupportable en Hyver, tandis qu'on ent tranfi de froid dans les autres. Je ne vous parle point des quatre grandes Colonnes cilyndriques $\mathcal{E}$ mafjives, d'un feul Bloc d'un certain Porphyre noir comme du Geay, fans taches $\mathcal{E}$ Jans fils, dont il a plu au Baron de LA Hont an d'enrichir le Grand'Autel : elles y feroient beaucoup mieux fans doute, que celles, qu'on y voit, qui font creufes, \& groffierement marbrées. On pardonneroit pourtant volontiers à cet Auteur, s'il n'avoit défiguré la vérité, que pour donner du luftre aux Eglifes.

L'Hôtel-Dieu a deux grandes Sales, l'une pour les HomDieu.

De l'Hôtelmes, \& l'autre pour les Femmes. Les Lits y font bien tenus, les Malades bien fervis, \& tout y eft commode \& d'une grande propreté. L'Eglife eft derriere la Sale des Femmes, \&r n'a de confidérable que le Maître-Autel, dont le Retable eft fort beau. Cette Maifon eft deffervie par des Religieufes. Horpitalieres de Saint Auguftin, de la Congrégation de la Miféricorde de Jefus, \& $\propto$ dont les premieres font venuës de Dieppe. Elles ont commencé à fe bien loger ; mais felon toutes les apparences elles n'acheveront pas fitôt, faute de fonds: Comme leur Maifon eft fituée à mi-côte, fur un platon, qui avance un peu fur la Riviere de Saint Charles, elles jouiffent d'une affez belle vûe.

La Maifon de l'Intendant fe nomme le Palais, parce que le Confeil Supérieur s'y affemble. C'eft un grand Pavillon, 
D'UN VOYAGE DE L'A MER IQ. LET. III. 77 dont les deux extrémités débordent de quelques pieds, \& oú l'on monte par un Perron à double Rampe. La Façade du Jardin, qui a la vûë fur la Petite Riviere, \& qui y conduit de plein pied, eft beaucoup plus riante, que celle de l'Entrée. Les Magafins de Roi font fur la Cour à droite, \& la Prifon eft derriere. La Porte d'entrée eft mafquée par la Montagne, fur laquelle eft la Haute Ville, \& qui ne préfente en cet endroit, qu'un Roc efcarpé fort défagreable ià la vûë. C'étoit bien pis encore avant l'incendie, qui réduifit, il y a quelques années, tout le Palais en Cendres; car il n'y avoit point d'Avant-Court, \& les Bâtimens étoient fur la Ruë, qui eft affez étroite $(a)$.

En fuivant, cette Rûë, ou pour parler plus jufte, ce Chemin, on entre d'abord dans la Campagne, $\&$ au bout d'un demi quart de lieuë on trouve l'Hôpital Général. C'eft la plus belle Maifon du Canada, \& elle ne dépareroit point nos plus grandes Villes de France, Les Peres Récollets occupoient autrefois le Terrein, où elle eft fituée. M. de Saint VALLIER, Evêque de Quebec les a transferés dans la Ville, a acheté leur Emplacement, \& y a dépenfé cent mille écus en Bâtimens, en Emmeublemens \& en Fondations. Le feul défaut de cet Hôpital eft d'être bâti dans un Marais ; on efpere y remédier, en defféchant le Marais; mais la Riviere de S. Charles fait en cet endroit-là un Coude, où les Eaux ne coulent pas aifément, \& c'eft ce qu'on ne pourra jamais bien corriger.

Le Prélat Fondateur a fon Appartement dans la Maifon, \& y fait fa réfidence ordinaire; il a loué fon Palais, qui eft encore fon Ouvrage, au profit des Pauvres. Il ne dédaigne pas même de fervir d'Aumônier à l'Hôpital, auffi-bien qu'aux Religieufes, \& il en remplit les fonctions avec un zéle \& une affiduité, qu'on admireroit dans un fimple Prêtre, qui vivroit de cet Emploi. Des Artifans, ou autres, à qui leur grand âge, ou leurs infirmités ôtent le moyen de gagner leur vie, font reçûs dans cet Hôpital jufqu'à la concurrence du nombre de Lits, qui y font fondés, \& trente Religieufes font occupées à les fervir. C'eft un Effein de l'Hôtel-Dicu de Quebec; mais pour les diftinguer, l'Evêque leur a donné quelques Réglemens particuliers, \& leur fait porter une

(a) Ce Palais fut encose entierement brûté en 1726 .

1720.

Ostobre.

De l'Hôptral Général. 
720 . Croix d'Argent fur la Poitrine. La plûpart font Filles de ConOçobre. dition, \& comme ce ne font pas les plus aifées du Pays, le Prélat en a doté plufieurs.

Des Fortifi-

Quebec n'eft pas fortifié régulierement, mais on travaille cations. depuis lon-tems à en faire une bonne Place. Cette Ville n'eft pas même facile à prendre dans l'état, où elle eft. Le Port eft flanqué de deux Baftions, qui dans les grandes Marées font prefqu'à fleur d'Eau, c'eft-à-dire, qu'ils iont élevés de vintcinq pieds de Terre, car la Marée, dans les Equinoxes, monte à cette hauteur. Un peu au - deffus du Baftion de la droite, on en a fait un demi, lequel eft pris dans le Rocher, \& plus haut, à côté de la Galerie du Fort, il y a vint-cinq Pieces de Canon en batterie. Un petit Fort quarré, qu'on nomme la Citadelle, eft encore au-deffus̃ , \& les Chemins, pour aller d'une Fortification à l'autre, font extrémement roides. A la gauche du Port, tout le long de la Rade, jufqu'à la Riviere de Saint Charles, il y a de bonnes Batteries de Canon \& quelques Mortiers.

De l'Angle de la Citadelle, qui regarde la Ville, on a fait une Oreille de Baftion, d'où l'on a tiré un Rideau en équerre, qui va joindre un Cavalier fort exhauffé, fur lequel il y a un Moulin fortifié. En defcendant de ce Cavalier, on rencontre à une portée de Fufil, une premiere Tour baftionnée, \& à la même diftance de celle-ci, une feconde. Le deffein étoit de revêtir tout cela d'une Chemife, qui auroit eu les mêmes Angles, que les Baftions, \& qui feroit venuë fe terminer à l'extrémité du Roc, vis-à-vis le Palais, où il y a déja une petite Redoute, auffi-bien que fur le Cap aux Diamants. Je ne fçai pourquoi cela n'a pas été exécuté. Tel étoit, Madame, à peu près l'état de la Place en I7II, lorfque les Anglois firent pour la conquête du Canada un grand Armement, qui échoua par la témérité du Général de la Flotte, lequel, contre l'avis de fon Pilote, s'approcha trop près des Sept Ifles, y perdit tous fes plus gros Navires, \& trois mille Hommes de fes meilleures Troupes.

Quebec eft encore aujourd'hui dans le même état, ce que vous pourrez juftifier fur le Plan en Relief, que Monfieur de ChaUSSEgros DE LÉry, Ingénieur en Chef, envoye cette année en France, pour être mis au Louvre avec les autres. Mais après vous avoir parlé du matériel de notre Capitale, 
D'UN VOYAGE DE L'A MERIQ. Let. III. 79 il faut vous dire deux mots de fes principaux Habitans; c'eft fon bel endroit, \& fi , à ne confidérer que fes Maifons, fes Places, fes Ruës, fes Eglifes \& fes Edifices Publics, on 1720. pourroit la réduire au rang des plus petites Villes de France, la qualité de ceux, qui l'habitent, lui affure le titre de Capitale.

J'ai déja dit qu'on ne compte guéres à Quebec, que $\int_{\text {ept }}$ mille Ames; mais on y trouve un petit Monde choifi, où il tans. ne manque rien, de ce qui peut former une Société agréable. Un Gouverneur Général ( $a$ ) avec un Etat Major, de la Nobleffe, des Officiers, \& des Troupes. Un Intendant $(b)$, avec un Confeil Supérieur, \& les Jurifdictions Subalternes; un Commiffaire de Marine (c), un Grand Prevôt (d), un GrandVoyer, \& un Grand-Maître des Eaux \& Forêts (e), dont la Jurifdiction eft affûrément la plus étenduë de l'Univers; des Marchands aifés, ou qui vivent, comme s'ils l'étoient; un Evêque \& un Séminaire nombreux; des Récollets \& des Jéfuites ; trois Communautés de Filles, bien compofées; des Cercles auffi brillans, qu'il y en ait ailleurs, chez la Gouvernante, \& chez l'Intendante. Voilà, ce me femble, pour toutes fortes de Perfonnes de quoi paffer le tems fort agréablement.

Auffi fait-on, \& chacun y contribuë de fon mieux. On jouë, on fait des Parties de Promenades; l'Eté, en Caléche, ou en Canot; l'Hyver, en Traine fur la Nége, ou en $\mathrm{Pa}$ tins fur la Glace. On chaffe beaucoup; quantité de Gentilshommes n'ont guéres que cette reffource pour vivre à leur aife. Les nouvelles courantes fe réduifent à bien peu de chofes, parce que le Pays n'en fournit prefquespoint, \& que celles de l'Europe arrivent tout-à-la fois, mais elles occupent une bonne partie de l'année : on politique fur le paffé, on conjecture fur l'avenir ; les Sciences \& les Beaux Arts ont leur tour, \& la converfation ne tombe point. Les Canadiens, c'êt-à-dire, les Créoles du Canada, refpirent en naiffant un air de liberté, qui les rend fort agréables dans le commerce de la vie, \& nulle part ailleurs on ne parle plus purement notre Langue. On ne remarque même ici aucun Accent.

(a) M. le Marquis de Vaudreuil.

(b) M. Bégon.

(c) M. de Clerambaut d'Aigremont. (d) M. Denys de Saint Simon.

(e) M. le Baron de Békancours.
Des Habin 
I 720.0 On ne voit point en ce Pays de Perfonnes riches, \& c'eft Otobre bien dommage, car on y aime à fe faire honneur de fon bien, \& perfonne prefque ne s'amufe à théfaurifer. On fait bonne chere, fi avec cela on péut avoir de quoi fe bien mettre; finon, on fe retranche fur la Table, pour être bien vêtu. Auffi faut-il avouer que les Ajuftemens font bien à nos Créoles. Tout eft ici de belle Taille, \& le plus beau Sang du Monde dans les deux Sexes; l'efprit enjoué, les manieres douces \& polies font communs à tous; \& la rufticité, foit dans le Langage, foit dans les façons, n'eft pas même connuë dans les Campagnes les plus écartées.

Difference

Il n'en eft pas de même, dit-on, des Anglois nos Voifins, des Colonies \& qui ne connoîtroit les deux Colonies, que par la maniere Angloifes \& de vivre, d'agir \& de parler des Colons, ne balanceroit pas à
Françoifes. juger que la nôtre eft la plus florifiante. Il regne dans la N. Angleterre, \& dans les autres Provinces du Continent de l'Amérique foumifes à l'Empire Britannique, une opulence, dont il femble qu'on ne fçait point profiter; \& dans la Nouvelle France une pauvreté cachée par un air d'aifance, qui ne paroît point étudié. Le Commerce \& la Culture des Plantations fortifient la Premiere, l'induftrie des Habitans foûtient la Seconde, \& le goût de la Nation y répand un agrément infini. Le Colon Anglois amaffe du Bien, \& ne fait aucune dépenfe fuperfluë : Le François jouit de ce qu'il a, \& fouvent fait parade de ce qu'il n'a point. Celui-là travaille pour fes Héritiers; celui-ci laiffe les Siens dans la néceffité, où il s'eft trouvé lui-même, de fe tirer d affaire comme il pourra. Les Anglois Amériquains ne veulent point de Guerre, parce qu'ils ont beaucoup à perdre; ils ne ménagent point les Sauvages, parce qu'ils ne croyent point en avoir befoin. La Jeuneffe Françoife, par des raifons contraires, détefte la Paix, \& vit bien avec les Naturels du Pays, dont elle s'attire aifément l'eftime pendant la Guerre, \& l'amitié en tout tems. Je pourrois pouffer plus loin ce paralelle; mais il faut finir: le Vaiffeau du Roi va mettre à la Voile; les Navires Marchands fe difpofent à le fuivre, \& peut-être que dans trois jours il n'y aura pas un fẹl Bâtiment dans notre Rade. Je fuis, \&c, 
D'UN VOYA E DE L'A MERI Q. LET. IV. 8 I

\section{QUATR IÉ ME LETTRE.}

Du Village Huron de Lorette. Ce qui a empếché le progrès de la Colonie Françoife du Canada. Des Monnoyes, qui $y$ ont eu cours.
A Quebec, ce quinze Février, 1721 .

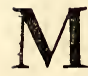

\section{A D A ME,}

J E reviens d'un petit Voyage de Dévotion, dont je veux vous rendre compte : mais il faut auparavant vous dire que je me fuis trompé, lorfqu'en finiffant ma derniere Lettre, je vous ai dit qu'avant trois jours la Rade de Quebec feroit vuide. Un Navire de Marfeille y eft encore, \& a même trouvé le moyen d'y être à l'abri des Glaces, dont le Fleuve eft couvert. C'eft un fecret, qui peut avoir fon utilité. Il eft bon d'avoir des reffources contre tous les accidens, qui peuvent furvenir.

Le Capitaine de ce Navire avoit levé les Ancres le fecond de Novembre, vers le foir, $\&$ après avoir fait environ une lieuë, il les rejetta, pour attendre quelques-uns de fes PaffaAventure d'un Navire Progers, qui s'embarquerent à l'entrée de la nuit. Il donna enfuite fes ordres pour appareiller dès que la Marée commenceroit à baiffer, \& s'alla mettre au Lit d'affez bonne heure. Vers le minuit on l'éveilla pour l'avertir que le Bâtiment fe rempliffoit d'Eau : il fit pomper, mais inutilement; l'Eau croiffoit toujours, au lieu de diminuer; enfin chacun fongea à mettre fa vie en fûreté, \& il étoit tems. Les Derniers n'étoient point encore arrivés à Terre, que le Navire difparut. Une Barque chargée de Marchandifes pour Montreal, a eu le même fort à l'entrée du Lac de Saint Pierre, mais on efpere bien relever l'un \& l'autre, quand la belle Saifon fera revenuë. On fe flatte même que la plûpart des Effets, dont ces deux Bâtimens font chargés, ne feron: point perdus. D'autres ne le croyent pas, \& je fuis de leur avis : je n'y ferai Tome III.

1721 .

Février. vençal. 
$172 \mathrm{I}$. point pour vous en mander des nouvelles. Mais l'affaire du Février. Navire Provençal pourra bien avoir des fuites, car le Capitaine foupçonne quelqu'un de lui avoir joué d'un tour. Venons à mon Pélerinage.

Defcription A trois lieuës 'd'ici vers le Nord-Eft, il y a un petit Village de Lorette. de Hurons Chrétiens, dont la Chapelle eft bâtie fur le modéle $\&$ avec toutes les dimenfions de la Santa $C_{a}$ fa d'Iralie, d'où l'on a envoyé à nos Néophy tes une Image de la Vierge, femblable à celle, que l'on voit dans ce célébre Sanctuaire. On ne pouvoit guéres choifir pour placer cette Miffion, un lieu plus fauvage. Cependant le concours des Fideles y eft fort grand, \& foit imagination, foit dévotion, foit prévention, ou tout ce que vous voudrez, bien des Perfonnes m'ont affûré qu'ils avoient été faifis, en y arrivant, d'une fecrete $\&$ fainte hrorreur, dont ils n'avoient pas été les Maîtres. Mais ce qui fait à tous une impreffion d'autant plus grande, que la réflexion même y contribuë, c'eft la folide pièté des Habitans de ce Défert.

Ferveur des Ce font des Sauvages, mais qui n'ont plus de leur naiffance Sauvages. $\&$ de leur origine, que ce qui en eft eftimable, c'eft-à-dire, la fimplicité \& la droiture du Premier Age du Monde, avec ce que la Grace y a ajoûté ; la Foi des Patriarches, une Piété fincere, cette droiture \& cette docilité de Cœur, qui font les Saints; une innocence de mours incroyable, un Chriftianifme pur, \& fur lequel le Monde n'a point fouflé l'air contagieux, qui le corrompt, \& fouvent des actes des plus héroïques vertus. Rien n'eft plus touchant, que de les entendre chanter à deux Chœurs, les Hommes d'un côté, \& les Femmes de l'autre, les Prieres de l'Eglife, $\&$ des Cantiques. en leur Langue. Rien n'eft comparable à la ferveur \& à la modeftie, qu'ils font paroître dans tous leurs exercices de Religion, \& je n'ai encore vû perfonne, qui n'en ait été touché jufqu'au fond de l'Ame.

Ce Village étoit autrefois beaucoup plus peuplé, mais les Maladies, \& je ne fçai quoi, qui réduit infenfiblement à rien toutes les Nations de ce Continent, ont fort diminué le nombre de fes Habitans. La vieilleffe \& les infirmités de quelques-uns de leurs anciens Pafteurs avoient auffi fait quelques bréches à leur premiere ferveur, mais il n'a pas été difficile de les y rappeller, \& celui, qui les gouverne préfentement, 
D'UN V OYA GE DE L'A MER IQ. LET. IV. : 83 n’a plus qu'à entretenir les chofes fur le pied, où il les a trouvées. Il eft vrai qu'on ne fçauroit porter plus loin les précautions, dont on ufe pour empêcher que le relâchement ne s'y introduife de nouveau. Les Boiffons enyvrantes, la plus ordinaire, \& prefque la feule pierre d'achopement, qui puiffe faire tomber les Sauvages, y font interdites par un Vou folemnel, dont la tranfgreffion eft foumife à la pénitence publique, auffi-bien que toute faute, qui caufe du fcandale; \& la rechute fuffit ordinairement pour bannir le Coupable, fans efperance de retour, d'un lieu, qui doit être l'afyle impénétrable de la Piété \& de l'Innocence. La paix \& la fubordination y regnent parfaitement; \& tout ce Village femble ne faire qu'une Famille, reglée fur les plus pures maximes de l'Evangile. Cela étonne toujours quiconque fçait jufqu'où ces Peuples, \& les Hurons fur-tout, portent naturellement la fierte \& l'efprit d'indépendance.

Le plus grand, \& peut-être le feul embarras du Miffionnaire eft à trouver de quoi faire fubfifter fon Troupeau; le Terrein, qu'il occupe n'y fçauroit fuffire, \& on a de bonnes raifons pour ne pas permettre qu'il l'abandonne; la Providence y fupplée. Monfieur \& Madàme Bégon étoient- de notre Pélerinage, \& furent reçüs de ces bons Néophytes, comme le devoient être des Perfonnes de ce rang, \& qui ne les laiffent jamais manquer du néceffaire. Après une réception toute Militaire de la part des Guerriers, \& les acclamations de la Multitude, on commença par les exercices de piété, où l'on s'édifia mutuellement. Ils furent fuivis d'un Feftin général, dont Madame Bégon fit les frais', \& reçut tous les honneurs. Les Hommes, fuivant l'ufage, mangerent dans une Maifon, \& les Femmes, avec les petits Enfans, dans une autre.'Je dis Maifon, \& non point Cabanne, car ces Sauvages fe font depuis peu logés à la Françoife.

Les Femmes dans ces' rencontres n'ont accoûtumé de témoigner leur gratitude, que par leur filence \& leur modeftie; mais parce que c'étoit la premiere Dame, qui fût alor's dans la Colonie, qui régaloit tout le Village, on accorda aux Huronnes un Orateur, par l'organe duquel elles déployerent à leur illuftre Bienfactrice tous lés fentimens de - leur Cœur. Pour les Hommes, après que le Chef eut harangué. l'Intendant, ils danferent $\&$ chanterent tant que l'on 

Chants \& ces Danfes. D'abord tous font affis à terre comme Février. des Singes, fans aucun ordre: de tems en tems un Homme fe leve, s'avance lentement au milieu de la Place, toujours, dit-on, en cadence, tourne la tête de côté \&x d'autre, chante un air, qui n'eft rien moins que mélodieux, pour quiconque n'eft pas né Sauvage, \& prononce des paroles, qui ne fignifient rien. Tantôt c'eft une Chanfon de Guerre, tantôt une Chanfon de Mort ; quelquefois une Attaque, ou une Surprife ; car comme ces Gens-là ne boivent que de l'Eau, ils nont point de Chanfon à boire, \& ils ne fe font pas encore avifés de mettre leurs Amours en chant. Tandis qu'on chante, le Parterre ne ceffe point de battre la Mefure, en tirant du fond de la Poitrine un hé, qui ne varie point. Les Connoiffeurs difent qu'ils ne perdent jamais la Mefure; je m'en rapporte à eux.

Quand l'un a fini, un autre prend fa place, \& cela dure jufqu'à ce que l'Affemblée les remercie, ce qui arriveroit bientôt, fans un peu de complaifance, qu'il eft bon d'avoir pour ces Gens-là. C'eft en effet une Mufique bien ennuyante $\&$ bien défagréable, du moins à en juger par ce que j'en ai vû. Des Gofiers ferrés, une Monotonie continuelle, des Airs, qui ont toujours quelque chofe de féroce, ou de lugubre. Mais leur voix eft toute autre, quand ils chantent à l'Eglife. Pour ce qui eft des Femmes, elles l'ont d'une douceur, qui furprend ; elles ont même beaucoup de goût $\&$ de difpofition pour la Mufique.

Dans ces rencontres, la Harangue eft ce qui vaut le mieux, on y explique en peu de mots, \& prefque toujours d'une maniere ingénieufe, le fujet de la Fête, à laquelle on ne manque jamais de donner des motifs relevés. Les louanges de celui, qui en fait les frais, ne font pas oubliées, \& l'on profite quelquefois de l'occafion des Perfonnes, qui font préfentes, quand on parle fur-tout devant le Gouverneur Général, ou l'Intendant, pour demander une Grace, ou pour faire quelque repréfentation. L'Orateur des Huronnes nous dit ce jour-là des chofes fi fpirituelles, qu'on foupçonna l'Interpréte, qui étoit le Miffionnaire même, de lui avoir prêté fon efprit $\&$ fa politeffe avec fa voix ; mais il protefta qu'il n'avoí rien ajoûté du fien, $\&$ on le crut, parce qu'il eft connu pour 
D'UN VOYAGE DE LAMERIQ. Let. IV. 85 un des Hommes du Monde le plus franc \& le plus vrai (a).

Avant ce petit Voyage, javois fait quelques excurfions aux environs de cette Ville, mais comme la Terre eft partout couverte de cinq ou fix pieds de neige, ces courfes ne m'ont pas mis beaucoup en état de vous parler de la nature du Pays. Je l'ai autrefois parcouru dans toutes les Saifons, \& je puis vous affùrer qu'on voit rarement ailleurs des Terres plus fécondes, \& d'une meilleure qualité. Je me fuis furtout fort appliqué cet Hyver à m'inftruire des avantages, qu'on pourroit retirer de cette Colonie, \& $\mathrm{je}$ vais vous faire part du fruit de mes recherches. Le Canada n'enrichit point la France; c'eft une plainte auffi ancienne, que la Colonie, \&x elle n'eft pas fans fondement. On n'y trouve point d'Habitans riches; cela eft encore vrai. Eft-ce la faute du Pays, \& n'y a-t'il pas beaucoup de celle des premiers Colons? C'eft fur quoi je vais tâcher de vous mettre à portée de prononcer.

La premiere fource du malheur des Provinces, qu'on a honorées du beau nom de Nouvelle France, eft le bruit, qui fe répandit d'abord dans le Royaume, qu'elles n'avoient point de Mines, \& on ne fit pas affez d'attention que le plus grand avantage, qu'on puiffe retirer d'une Colonie, eft l'augmentation du Commerce; que pour parvenir à ce deffein, il faut faire des Peuplades; que ces Peuplades fe font peu à peu , \& fans qu'il y paroiffe dans un Royaume, tel que la France, \& que les deux feuls objets, qui fe préfenterent d'abord dans le Canada \& dans l'Acadie, je veux dire, la Pelleterie, \& la Pêche, demandoient que ces Pays fuffent peuplés; que s'ils l'avoient été, ils euffent peut-être donné plus de retours à la France, que l'Efpagne n'en a tiré des plus riches Provinces du Nouveau Monde ; furr-tout, fi on y eût ajoûté la Conftruction des Vaiffeaux : mais l'éclat de l'or \& de l'argent, qui venoient du Mexique \& du Pérou, éblouit tellement les yeux de l'Europe entiere ; qu'un Pays, qui ne produifoit pas ces précieux Métaux, étoit regardé comme un mauvais Pays. Ecoutons fur cela un Auteur fenfé, qui avoit été fur les lieux.

Les demandes ordinaires, qu'on nous fait, dit Marc Lef- " carbot, font, Y a-t'il des Tréíors? Y a-t'il de l'Or \& de l'Ar- * gent ? Et perfonne ne demande, ces Peuples-là font-ils dif- " pofés à entendre la Doctrine Chrétienne? \& quant aux $\mathrm{Mi-}$

(a) Le Pere Pierre-Daniel RIєHER,

Idée fauffe: qu'on seft frite du Canada.
I 721 .

Février. 


\section{$86 \mathrm{~J} O \mathrm{U} R \mathrm{~N} A \mathrm{~L}$ H I S T O R I Q U E}

$172 \mathrm{r}$." nes, il y en a vraiment; mais il les faut fouiller avec indufFévrier." trie, labeur \& patience. La plus belle Mine, que je fçache, c'eft du Bled \& du Vin, avec la nourriture du Beftial; qui a de ceci, il a de l'Argent; \& des Mines, nous n'en vivons " point. Les Mariniers, qui vont de toute l'Europe chercher du "Poifion aux Terres-neuves \& plus outre à huit ou neuf cent "lieuës loin de leur Pays, y trouvent de belles Mines, fans n rompre les Rochers, éventrer la Terre, vivre en l'obfcurité des Enfers....... Ils trouvent, dis-je, de belles Mines au profond des Eaux, \& au Trafic des Pelleteries \& F Fourrures, dont ils retirent de bon argent.

Fautes, qu'on 3 faites dans fon Etabliffement.

Non-feulement on a fait à la Nouvelle France, fans la connoître, une fort mauvaife réputation; mais ceux mêmes, qui croyoient en pouvoir tirer quelque avantage, n'ont pris pour cela aucunes mefures. Premierement on a été un tems infini fans fe fixer : on défrichoit un Terrein, fans l'avoir auparavant bien examiné, on l'enfemençoit, on y élevoit des Bâtimens, puis, fans trop fçavoir pourquoi, le plus fouvent on l'abandonnoit, \& on alloit fe placer ailleurs. C'eft cette inconftance, qui a le plus contribuéà nous faire perdre l'Acadie, \& à nous empêcher d'en rien retirer, tandis que nous poffedions cette belle Peninfule. L'Auteur, que j'ai déja cité, \& qui avoit été témoin de nos irréfolutions, ne craignit point de les reprocher à ceux, qui en étoient les plus coupables. C'eft ainfi, dit-il, que de tout tems nous avons fait des levées de Boucliers, que nous nous fommes portés avec ardeur à de nouvelles Entreprifes, que nous avons projetté de beaux commencemens, \& puis que nous avons tout quitté ..... de verité , pour faire de telles Entreprifes, il faut de l'aide' $\& \cdot d u$ fupport ; mais auffi faut-il des Hommes de réfolution, qui ne reculent pas, \& qui ayent ce point d'honneur devant les yeux, Vaincre ou Mourir, étant une belle \& glorieufe mort celle, " qui arrive en exécutant un beau deffein, comme pour jetter "les fondemens d'un Royaume nouveau, \& établir la Foi Chré" tienne parmi des Peuples, entre lefquels Dieu n'eft pas con" nu. "Je pourrois, Madame, pouffer beaucoup plus loin ces réflexions ; mais je craindrois de m'engager trop loin dans des difcuffions, où je ne dois, ni ne puis entrer, avec les feules connoiffances, que j'ai préfentement.

Je viens au Commerce. Il a roulé lontems en Canada uni- 
D'UN VOYA GE DE L'A MERIQ. LET. IV. 87 quement fur la Pêche $\&$ la Pelleterie. La Pêche des Moruës fe faifoit fur le Grand Banc, \& fur les Côtes de Terre-neuve, lontems avant qu'on eût découvert le Fleuve Saint Laurent, mais on s'avifa bien tard de faire un Etabliffement dans l'Ifle, \& nous nous y laiffâmes prévenir par les Anglois. Nous y occupâmes enfin le Port \& la Baye de Plaifance, où l'on a vû plus d'une fois des Efcadres du Roi : nous y avons fouttenu des Siéges, \& les Milices Canadiennes y ont fait des exploits de guerre, qui ne le cedent point à ceux des plus braves Flibuftiers de Saint Domingue. Ils ont fouvent défolé les Habitations, \& ruiné le Commerce des Anglois dans cette Ifle; mais ceux-ci, à qui on enlevoit aifément leurs plus fortes $\mathrm{Pla}$ ces, connoiffoient trop bien leurs Ennemis, pour fe déconcerter. Accoûtumés à voir le feu Canadien s'allumer dans les Glaces du Nord, \& s'éteindre de lui-même au milieu de ce qui devoit lui donner plus d'activité, ils fe comportoient à l'approche de nos Braves, comme fait un habile Pilote à la vûee d'une Tempête inévitable. Ils cédoient fagement à l'Orage; ils réparoient enfuite fans obftacle le dégât, qu'il avoit caufé dans leurs Poftes, \& par cette conduite, toujours battus en Terre-neuve, foit qu'ils attaquaffent, ou qu'ils fe défendiffent, ils y ont toujours fait incomparablement plus de commerce, que leurs Vainqueurs, \& ils en font enfin demeurés les feuls Maîtres, \& Poffeffeurs tranquilles.

On s'eft encore plus mal comporté en Acadie : cette grande $\&$ riche Province a été lontems partagée entre differens Particuliers, dont aucun ne s'y eft enrichi, tandis que les Anglois faifoient fur fes Côtes un profit immenfe par la Pêche. Les Etabliffemens, que ces Propriétaires y ont faits, manquant de folidité, \& eux-mêmes manquant de vûës, \& fe détruifant les uns les autres, ils ont laiffé le Pays à peu près dans le même état, où ils l'avoient trouvé, $\&$ dans un décri, dont il ne s'eft bien relevé, qu'au moment, que nous l'avons perdu. Ce font nos Ennemis, qui nous ont fait comprendre ce qu'il valoit.

- Le feul Commerce, auquel on s'eft lontems borné dans cette Colonie, eft celui des Pelleteries, \& on ne fçauroir dire les fautes, qu'on y a faites. Jamais peut-être le génie de notre Nation n’a mieux paru qu'à ce fujet. Lorfque nous découvrîmes ce vafte Continent, il étoit rempli de Bêtes Fauves. Une

1721 .

Février.
Mauraife conduite pas rapport atl Commerce des Pelleteries. 
I 72 I. poignée de François eft venuë à bout de les faire difparoître Février. prefqu'entierement en moins d'un fiécle; \& il y en a, dont l'Efpéce manque tout à fait. On tuoit les Orignaux, ou Elans, par le feul plaifir de les tuer, \& pour faire montre de fon adreffe. On ne s'avifoit pas même d'interpofer l'Autorité du Prince, pour arrêter un défordre fi criant. Mais le plus grand mal eft venu de l'infatiable avidité des Particuliers, qui s'appliquoient uniquement à ce Commerce.

Ils arrivoient pour la plûpart de France comme Simonides, c'eft-à-dire, ne poffédant que ce qu'ils avoient fur le Corps, \& ils étoient dans l'impatience d'y reparoître dans une meilleure fituation. Dans les commencemens cela étoit aifé : les Sauvages n'ont connu le tréfor, que renfermoient leurs Bois, que par la fureur, avec laquelle on leur arrachoit des mains leurs Pelleteries, \& on en tira d'eux une prodigieufe quantité, en leur donnant des chofes, que bien des gens ne voudroient point ramaffer. Depuis même qu'ils ont eu les yeux ouverts fur les prix de cette Marchandife, \& qu'ils fe font un peu plus attachés au folide, il fut encore lontems très-aifé de les fatisfaire à peu de frais : avec un peu de conduite, on auroit pu continuer ce Commerce fur un affez bon pied.

On feroit néanmoins affez embarraffé à nommer aujourd'hui une feule Famille, que ce Trafic ait enrichie. On a vû des fortunes auffi immenfes, que rapides, s'élever $\&$ difparoître prefqu'en même tems, comme ces Montagnes mouvantes, dont parlent quelques Voyageurs, \& qu'un Tourbillon de Vent éleve \& applanit dans les Plaines fablonneufes de l'Afrique. Rien n'a été plus ordinaire dans ce Pays-ci, que de voir des Gens traîner dans la mifere $\&$ dans l'opprobre une languiffante Vieilleffe, après avoir été en état de fe faire un Etabliffement honorable. Après tout, Madame, ces Fortunes manquées par des Particuliers, qui ne les méritoient point, ne feroient nullement dignes des regrets du Public, fi le contrecoup n'en étoit pas retombé fur la Colonie, qui s'eft bien-tôt trouvée réduite au point de voir prefqu'abfolu. ment tarir, ou détourner ailleurs une fourçe, d'où il pouvoit couler tant de richeffes dans fon fein.

Sa ruine commença par fon ahondance. A force d'accumuler les Peaux de Caftor, qui ont toujours fait le principal objet de çe Commerce, il s'en trouva une fi grande quantité dans 
D'UN VOYA GE DE L'A MERI Q. LET. IV. 89 dans les Magafins, qu'on n'en pouvoit plus avoir le débit; d'où il arriva que les Marchands n'en voulant plus recevoir, nos Aventuriers, qu'on appelle ici Coureurs de Bois, prirent le parti de les porter aux Anglois, \& que plufieurs s'établirent dans la Nouvelle York. On fit plufieurs tentatives pour arrêter le cours de ces défertions, mais elles eurent très-peu de fuccès ; au contraire, ceux, que l'intérêt avoit conduits chez nos Voifins, y furent retenus par la crainte du châtiment, \& les Vagabonds, qui avoient pris du goût pour la liberté d'une vie errante \& pour l'indépendance, refterent parmi les Sauvages, dont on ne les diftinguoit plus, que par leurs vices. On eut recours en divers tems aux Amnifties, pour rappeller ces Transfuges, \& d'abord elles furent affez inutiles : à la fin cependant ce moyen, ménagé avec fageffe, eut une partie de l'effet, qu'on en avoit prétendu.

On en employa un autre, qui fut plus efficace encore; mais les Perfonnes zélées pour le bon ordre, \& pour le progrès de la Religion, trouverent le remede pire que le mal. Ce fut de permettre à Gens, dont on fe croyoit bien fûrs, d'aller faire la Traite dans les Pays Sauvages, \& de défendre à tous les autres de fortir de la Colonie. Le nombre de ces Congés fut limité, \& on les diftribua à de pauvres Veuves, \& $\grave{a}$ des Orphelins, qui les pouvoient vendre aux Traiteurs, plus ou moins, fuivant que la Traite étoit plus ou moins bonne, c'eft-à-dire, fuivant les endroits, où les Congés portoient qu'on pouvoit la faire ; car on avoit eu la précaution de marquer ces endroits, pour empêcher que tous n'allaffent du même côté.

Outre ces Congés, dont j’ai dit que le nombre étoit réglé par la Cour, \& dont la diftribution appartient au Gouverneur Général, il y en a pour les Commandans des Poftes, \& pour des befoins extraordinaires, \& le Gouverneur en donne encore fous le nom de fimple Permiffion. Ainfi une partie de la Jeuneffe eft continuellement en courfe, \& quoiqu'elle n'y. commette plus, au moins fi ouvertement, les défordres, qui ont fi fort décrié cette Profeffion, elle ne laiffe pas d'y prendre une habitude de libertinage, dont elle ne fe défait jamais parfaitement : elle y perd au moins le goût du travail, elle y épuife fes forces, elle y devient incapable de la moindre contrainte, \& quand elle n'eft plus propre aux fatigues Tome III. 
I 72 I. de ces Voyages, ce qui arrive bientôt, parce que ces fatigues F' font exceffives, elle demeure fans aucune reffource, \& n'eft Février. plus propre à rien. De-là vient que les Arts ont été lontems négligés, que quantité de bonnes Terres font encore incultes, \& que le Pays ne s'eft point peuplé.

On a fouvent propofé, pour abolir ces pernicieux Congés, fans que le Commerce en fouffrît, \& même dans la vûe de le rendre plus floriffant, de former quelques Peuplades Françoifes dans des endroits choifis, \& où il fût aifé de réunir les Sauvages, du moins en certains tems de l'année. Par-là ces vaftes Contrées fe peupleroient infenfiblement, \& il n'y auroit peut-être que ce moyen d'exécuter ce que la Cour a eu fi lontems à cœur, de Francifer ces Sauvages, c'eft le terme, dont on fe fervoit. Je crois du moins pouvoir affürer que, fi on avoit fuivi ce projet, le Canada feroit aujourd'hui beaucoup plus peuplé qu'il ne l'eft; que les Sauvages, attirés $\&$ retenus par les fecours \& les douceurs, quils auroient trouvés dans nos Habitations, auroient été moins errans, moins miferables, fe feroient par conféquent multipliés, au lieu qu'ils font diminués étonnemment, \& fe feroient attachés à nous de maniere, que nous en pourrions à prefent difpofer, comme des Sujets mêmes de la Couronne ; d'autant plus que les Miffionnaires auroient beaucoup moins rencontré d'obftacles à leur Converfion. Ce que nous voyons préfentement à Lorette, \& avec quelque proportion parmi les Iroquois, les Algonquins \& les Abénaquis, domiciliés dans la Colonie, ne laiffe aucun doute fur la vérité de ce que javance, \& il n'eft perfonne parmi ceux, qui ont le plus fréquenté les Sauvages, qui ne convienne qu'on ne doit jamais bien compter fur ces Peuples, que quand ils font Chrétiens. Je n'en veux point d'autre exemple, que celui des Abénaquis, lefquels , quoiqu'en petit nombre, ont été pendant les deux dernieres guerres le principal Boulevard de la Nouvelle France contre la Nouvelle Angleterre.

Au refte, Madame, le projet, que je viens de vous expofer, eft auffi ancien que la Colonie; c'étoit celui de M. de Champlain, fon Fondateur, \& il a été du goût de prefque tous les Miffionnaires, que j’ai connus, \& dont les pénibles travaux, dans la fituation, où font depuis lontems les chofes, ne produifent pas de grands fruits dans les Mifíions uss 
D'U N VOYA GE DE L'A MERIQ. LET. IV. 9I peu éloignées. Il feroit à la vérité bien tard aujourd'hui pour reprendre ce deffein par rapport aux Sauvages, qui difparoiffent d'une maniere auffi fenfible, qu'elle eft inconcevable. Mais qui empêcheroit de le fuivre par rapport aux François, \& de continuer la Colonie de proche en proche, jufqu’à ce qu'elle puiffe prêter la main à celle de la Louyfiane, pour for- , tifier l'une par l'autre ? C'eft ainfi que les Anglois en moins d'un fiecle \& demi font venus à bout de peupler plus de cinq cent lieuës de Pays, \& de former dans ce Continent une puiffance, qu'on n'envifage qu'avec frayeur, quand on la voit de près.

Le Canada peut faire, \& fait quelquefois avec les Ifles de l'Amérique un Commerce affez confidérable de Farines, de Madriers, \& d'autres bois propres pour les Bâtimens. Comme il n'y a peut-être pas au monde de Pays, qui porte de plus de fortes de Bois, ni de meilleure efpece, jugez quelle richeffe il en pourra un jour tirer. Il paroît que très-pen de perfonnes font bien inftruites fur cet article; je ne le fuis pas encore affez moi-même pour entrer dans un plus grand détail, je le fuis un peu mieux de ce qui regarde les Huiles, $\& x$ je vous en parlerai bientôt. Preffé de finir cette Lettre, je n'ai que le tems d'achever ce qui concerne le Commerce en général.

Rien n'a peut-être plus contribué à le faire languir, que les changemens fréquens, qu'on y a faits dans les monnoyes. En voici l'Hiftoire en peu de mots. En 1670. la Compagnie des Indes Occidentales, à qui le Roy avoit cédé le Domaine des Ifles du Continent de l'Amérique Françoife, eut permiffion de faire paffer dans les Ifles jufqu'à cent mille francs en petites efpeces, marquées à un coin particulier, avec une légende, qui lui étoit propre. L'Edit du Roy eft du mois de Février, \& $x$ il portoit que ces efpeces n'auroient cours, que dans les lnles. Mais fur quelques difficultés, qui furvinrent, le Confeil rendit le 18. de Novembre de l'année 1672. un Arrêt, par lequel il fut ordonné que la furdite monnoye, $\& x$ toutes les autres efpeces, qui auroient cours en France, l'auroient auffi, non-feulement dans les Ifles Françoifes, maîs encore dans la Terre ferme de l'Amérique, foumife à la Couronne, avec l'augmentation d'un quart en fus ; c'eft-à-dire, les piéces de quinze fols pour vint, \& le refte à proportion.

I $72 \mathrm{I}$.

Eévrier.
Divers changemens dans les Monnoyes. 
1721 .

Février.

Le même Arrêt ordonnoit que tous les contrats, billets, comptes, achats, \& payemens feroient faits entre toutes fortes de perfonnes au prix d'argent, fans qu'il pût être ufé d'échanges, ni compté en fucre, ou autres denrées, à peine de nullité des actes. Et pour le paffé, il fut réglé que toutes les ftipulations de contrats, billets, dettes, redevances, baux à ferme en fucre \& autres denrées, feroient réduites payables en argent, fuivant le cours des monnoyes fufdites. En exécution de cet Arrêt, la monnoye augmenta d'un quart dans la Nouvelle France, ce qui ne tarda guéres à y caufer bien des difficultés. En effet M. de Champigny Noroy, qui fut nommé Intendant de Quebec en 1684. \& qui l'eft aujourd'hui au Havre de Grace, fe trouva bientôt embarraffé, foit pour le payement des Troupes, foit pour les autres dépenfes, que le Roy faifoit dans cette Colonie.

Outre cela, les fonds, qui étoient envoyés de France, arrivoient prefque toujours trop tard, \& dès le premier de Janvier il falloit payer les Officiers \& les Soldats, \& fatisfaire à d'autres charges également indifpenfables. Pour obvier au plus preffé, M. de Champigny s'avifa de donner cours à quelques Billets, qui tenoient lieu d'argent, en y obfervant toujours l'augmentation de la monnoye. On dreffa un procèsverbal de cette Fabrique, \& en vertu d'une Ordonnance du Gouverneur Général \& de l'Intendant, on mit fur chaque piéce de cette monnoye, qui étoit de Carte, fa valeur, la fignature du Tréforier, une empreinte des Armes de France, $\&$ en cire d'Efpagne celle du Gouverneur \& de l'Intendant. On en fit enfuite imprimer en France fur des cartons avec les mêmes empreintes, qu'avoient les monnoyes courantes du Royaume, \& l'on ordonna qu'elles feroient repréfentées tous les ans avant l'arrivée des Vaiffeaux de France, pour y ajoûter une marque, afin d'empêcher qu'on n'en introduisît de contrefaites.

Cette monnoye de carton ne fubfifta pas lontems, \& l'on en revint aux Cartes, fur lefquelles on grava de nouvelles empreintes. L'Intendant fignoit celle, qui étoit de quatre livres \& au-deffus, \& fe contentoit de parapher les autres. Dans les derniers tems le Gouverneur Général fignoit auffi celles, qui étoient de fix livres $\&$ au-deffus. Au commencement de l'automne, toutes les Cartes fe rapportoient au Tré- 
DUN VOYAGE DE L'A MERIQ. LET. IV. 93 forier, qui donnoit pour leur valeur des Lettres de change fur le Tréforier Général de la Marine, ou fur fon Commis à Rochefort, à compte des frais de l'année fuivante. Celles, 1721 . Février. qui étoient gâtées, ne fe remettoient plus dans le Commerce, \& on les brûloit après en avoir dreffé un procès-verbal.

Tant que les Lettres de change ont été fidélement payées, on préféroir ces cartes aux efpéces fonnantes; dès qu'elles ont ceffé de l'être, on a difcontinué de rapporter les cartes au Tréforier, en forte qu'en 1702. M. de Champigny re donna inutilement bien des foins pour retirer toutes celles, qu'il avoit faites. Ses Succeffeurs furent obligés d'en faire tous les ans de nouvelles pour payer les charges, ce qui les multiplia tellement, qu'elles tomberent enfin en non-valeur, \& qus Perfonne n'en voulut plus recevoir. Le Commerce en fut entierement dérangé, \& le défordre alla fi loin, qu'en 1713. les Habitans propoferent d'y perdre la moitié , à condition que le Roi les reprît \& payât l'autre moitié.

Cette propofition fut agréée l'année fuivante, mais les ordres donnés en conféquence n'eurent leur entiere exécution qu'en 1717. Il fut alors rendu une Déclaration, qui aboliffoit la monnoye de carte, \& $\mathrm{r}$ l'on recommença à payer en argent les charges de la Colonie. L'augmentation du quart en fus fut abrogée en même tems : l'expérience ayant fait connoître que l'augmentation des efpéces dans une Colonie ne les y fait pas refter, qui étoit ce qu'on avoit prétendu, \& que l'argent n'y fçauroit bien rouler, que quand on y paye en denrées tout ce qu'on tire du Royaume. En effet, dans ce cas la Colonie conferve les efpéces chez elle, au lieu que, fi elle n'a pas affez. de marchandifes pour s'acquitter en entier, elle eft contrainte de payer le furplus en argent : \& comment reviendra-t'il ?

Enfin, Madame, vous ferez furpris d'apprendre qu'en 1706. le Commerce de la plus ancienne de nos Colonies ne rouloit que fur un fond de 650000. liv. (a) \& les chofes n'ont pas beaucoup changé depuis ce tems-là. Or cette fomme répanduë fur trente mille Habitans, ne peut les mettre à leur aife, ni leur donner le moyen d'acheter les marchandifes de France. Auffi la plûpart vont-ils tout nuds, fur tout ceux, qui font dans les Habitations un peu écartées. Ils ne vendent pas même tout le furplus de leurs denrées aux Habitans des Villes,

(a) Voyez le Second Tome de l'Hiftoire, Page 390. 
94 J O UR N A L H I S T OR I Q U E

1721 parce que ceux-ci font obligés pour fubfifter d'avoir des Terres à la Campagne, \& de les faire valoir par eux-mêmes.

Février. Lorfque le Roi eut retiré le Canada des mains des Compagnies, Sa Majefté y dépenfa pendant quelques années beaucoup plus, qu'elle n'a fait depuis; \& la Colonie dans ces tems-là a envoyé en France prefque la valeur d'un million en Caftors chaque année, quoiqu'elle ne fût pas auffi peuplée, qu'elle l'eft aujourd'hui : mais elle a toujours plus tiré de France, qu'elle n'a pu payer, \& elle a fait comme un Particulier, qui a trente mille livres de rente, \& qui en dépenfe quarante mille \& plus. Par-là fon crédit eft tombé, \& en tombant, a caufé la ruine de fon Commerce, qui, dès l'année 1706. ne rouloit prefque plus que fur les menuës Pelleteries. Tous les Marchands en vouloient avoir, \& c'eft ce qui les ruinoit, parce qu'ils les achetoient fouvent plus cher des Sauvages, qu'ils ne les revendoient en France.

Je fuis, \&c.

1721 .

\section{I N Q U I E M E L E T T R E.}

Mars. Des Caftors du Canada; de leur difference d'avec les Biévres ou Caftors d'Europe; de leur maniere de bâtir; de ce qu'ils peuvent procurer d'avantages à la Colonie; de la Chaffe dit Caftor, É du Rat Mufqué.
A Quebec, le premier de Mars, 1721.

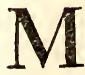

\section{A D A ME,}

$\mathbf{J}_{\mathrm{E}}$ devois partir un ou deux jours après que j'eus fermé ma derniere Lettre; mais je fuis encore arrêté faute de voiture. Je n'ai rien à faire de mieux en attendant, que de vous entretenir des curiofités de ce Pays-ci, \& je commence par ce qu'on y voit de plus fingulier; c'eft le Caftor. La dépouille de cet Animal a jufqu'à préfent fourni à la Nouvelle France le principal objet de fon Commerce. Il eft par lui-même une des merveilles de la nature, \& il peut être pour l'Homme une 
D'UN VOYA GE DE L'A MERIQ. LET. V. 95 grande leçon de prévoyance, d'induftrie, d'adreffe, \& de conftance dans le travail.

Le Caftor n'étoit pas inconnu en France avant la découverte de l'Amérique; on trouve dans les anciens Titres des Chapeliers de Paris des Réglemens pour la Fabrique des Chapeaux Biévres: or Biévre \& Caftor, c'eft abfolument le mê- rope.

me Animal, mais foit que le Biévre Européen foit devenu extrémement rare, ou que fon Poil n'eut pas la même bonté, que celui du Caftor Amériquain, on ne parle plus gueres que de ce dernier, fi ce n'eft par rapport au Caftoreum, dont je vous dirai deux mots à la fin de cette Lettre. Je ne fçache pas même qu'aucun Auteur ait jamais parlé de cet Animal, comme de quelque chofe de curieux : peut-être que c'eft faute de l'avoir obfervé de près : peut - être auffi que les Caftors d'Europe font comme les Caftors Terriers, dont je vous ferai bientôt connoître la difference d'avec les autres.

Quoiqu'il en foir, Madame, le Caftor du Canada eft un Quadrupéde Amphibie, qui ne peut pourtant pas refter lontems dans l'Eau, \& qui peut abfolument fe paffer d'y aller, pourvî quill ait la commodité de fe baigner quelquefois. Les plus grands Caftors ont un peu moins de quatre pieds fur quinze pouces de large d'une hanche à l'autre, \& péfent foixante livres. La couleur de cet Animal eft differente, felon les differens Climats, où il fe trouve. Dans les Quartiers du Nord les plus reculés, ils font ordinairement tout à fait noirs, mais il s'y en rencontre quelquefois de blancs. Dans les Pays plus tempérés ils font bruns, \& à mefure qu'ils avancent vers le Sud, leur couleur s'éclaircit toujours de plus en plus. Chez les Illinois ils font prefque fauves: on y en a même vî de couleur de Paille. On a encore obfervé que, moins ils font noirs, \& moins ils font fournis de Poil, \& que par conféquent leur dépouille eft moins eftimée. C'eft un effet de la Providence, qui les garantit contre le froid, à mefure qu'ils y font plus expofés. Leur Poil eft de deux fortes par tout le Corps, excepté aux Pattes, où il n'y en a qu'un fort court. Le plus grand eft long de huit à dix lignes: il va même jufqu'à deux pouces fur le Dos, mais il diminue avec proportion jufqu'à la Tête \& jufqu’à la Queuë. Ce Poil eft rude, gros, luifant, \& c'eft celui, qui donne la couleur à la Bête. En le regardant avec le Microfcope, on en trouve le milieu Du loil di

$172 \mathrm{I}$.

Mars.

Difference dus Caftor de $\mathrm{C}_{2}-$ nada, \& de celui de l'EuCaftor. 
96 J O U R N A L H IS T ORI Q U E

77 moins opaque, ce qui prouve qu'il eft creux; auffi n'en faiton aucun ufage. L'autre Poil eft un Duvet très-fin, fort épais, Mars. long tout au plus d'un pouce, \& c'eft celui, qu'on met en œuvre. On l'appelloit autrefois en Europe Laine de Miofcovie. C'eft-là proprement l'Habit de Caftor, le premier ne lui fert que d'ornement, \& peut-être pour l'aider à nâger.

Defription On prétend que le Caftor vit quinze à vint ans: que la de cet Animal. quatre Petits; quelques Voyageurs en ont fait monter le nombre jufqu'à huit; mais je ne crois pas que cela arrive fouvent. Elle a quatre Mamelles, deux fur le grand Pectoral, entre la feconde \& la troifiéme des vraies Côtes, \& deux environ quatre doits plus haut. Les Mufcles de cet Animal font extrémement forts, \& plus gros, que ne femble comporter fa taille. Ses Inteftins au contraire 1ont très-délicats, fes $\mathrm{Os}$ font fort durs, \& fes deux Machoires, qui font prefquégales, ont une force extraordinaire: chacune eft garnie de dix Dents, deux incifives, \& huit molaires. Les incifives fupérieures ont deux pouces $\&$ demi de long, les inferieures en ont plus de troịs, \& fuivent les courbures de la Machoire, ce qui leur donne une force prodigieufe, qu'on admire toujours dans de fi petits Animaux: On a remarqué encore que les deux Machoires ne fe répondent pas exactement, mais que les fupérieures débordent en avant fur les inférieures, de forte qu'elles fe croifent comme les deux tranchans des Cifeaux : enfin que la longueur des unes \& des autres eft précifément le tiers de leurs Racines.

La Tête d'un Caftor eft à peu près de la figure de celle d'un Rat de Montagne. Il a le Mufeau un peu allongé, les Yeux petits, les Oreilles courtes, rondes, veluës par dehors, fans Poil en dedans. Ses Jambes font courtes, particuliérement celles de devant; elles n'ont guéres que quatre ou cinq pouces de long, \& reffemblent affez à celles du Bléreau. Les Ongles en font taillés de biais , \& creux, comme des Plumes à écrire. Les Pieds de derriere font tout differens; ils font plats, garnis de Membranes entre les Doits; ainfi le Caftor peut marcher, mais lentement, \& nâge avec la même facilité que tout Animal Aquatique. D'ailleurs, par fa Queuë il eft tout à fait Poiffon, auffi a-t'il été juridiquement déclaré tel par la Faculté de Médecine de Paris, \& en conféquence 
D'UN VOYAGE DE L'A MERIQ. LET. V. 97 de cette Déclaration, la Faculté de Théologie a décidé qu'on pouvoit manger fa Chair les jours maigres. M. Lemery s'eft trompé, quand il a dit que cette décifion ne regardoit que le Mars。 train de derriere du Caftor. Il a été mis tout entier au même rang, que la Maquereufe.

Il eft vrai qu'on ne peut guéres profiter ici de cette condefcendance : les Caftors font préfentement $f i$ loin de nos Habitations, qu'il eft rare d'y en avoir, qui foient mangeables. Nos Sauvages domiciliés en gardent, après les avoir fait boucanner, c'eft-à-dire, fécher à la fumée, \& je puis vous affûrer, Madame, que je ne connois rien de plus mauvais. Il faut même, quand on a du Caftor frais, lui donner un bouillon, pour lui faire perdre un petit goût fauvage affez fade. Mais avec cette précaution, c'eft un très-bon manger. Il n'eft point de Viande plus légere, plus délicate, ni qui foit plus faine. On prétend même qu'elle eft auffi nourriffante, que celle du Veau : bouillie, elle a befoin de quelque chofe, qui en releve le goût, mais quand elle a été mife à la broche, il ne lui faut rien.

Ce qu'il y a de plus remarquable dans la figure de cet Amphibie, c'eft fa Queuë. Elle eft prefque ovale, large de quatre pouces dans fa racine, de cinq dans fon milieu, \& de trois dans fon extrémité, je parle toujours des grands Caftors. Elle eft épaiffe d'un pouce, \& longue d'un pied. Sa fubftance eft une graiffe ferme, ou un cartilage tendre, qui reffemble affez à la chair du Marfouin, mais qui fe durcit davantage, quand on la conferve lontems. Elle eft couverte d'une Peau écailleufe, dont les Ecailles font hexagones, ont une demie ligne d'épaiffeur, fur trois ou quatre lignes de longueur, \& font appuyées les unes fur les autres comme toutes celles des Poiffons. Une Pellicule très-délicate leur fert de fond, \& elles y font enchâffées de maniere, qu'on peut aifément les en féparer après la mort de l'Animal.

Voilà, Madame, en peu de mots la defcription de ce curieux Amphibie. Si vous voulez quelque chofe de plus détaillé, vous trouverez de quoi vous fatisfaire dans les Mémoires de l'Académie Royale des Sciences $(a)$. On y a inféré une Defcription Anatomique du Caftor, faite par M. Sarrasin, Correfpondant de l'Académie, Médecin du

(a) Année 1704, Page 48.

Tome III. 
72 Roi dans ce Pays, habile dans la Médecine, dans l'Anato721. mie, dans la Chirurgie \& dans la Botanique; qui a l'efprit Mars. fort orné, \& qui ne fe diftingue pas moins dans le Confeil Supérieur, dont il eft Membre, que par fon habileté dans tout ce qui eft de fa Profeffion. On eft véritablement furpris de trouver un Homme d'un mérite fi univerfel dans une Colohie. Revenons au Caftor.

Du Cafo- Les véritables Tefticules de cet Amphibie n'ont pas été ream. connus des Anciens, apparemment parce qu'ils font trèspetits \& fort cachés fous les Aînes. On avoit donné ce nom aux Bourfes, ou Poches du Caftoreum, qui font bien differentes, \& $\mathrm{x}$ au nombre de quatre dans le Bas Ventre du Caftor. Les deux premieres, qu'on appelle fupérieures, parce qu'elles font plus élevées, que les autres, ont la figure d'une Poire, \& communiquent enfemble, comme les deux Poches d'une Beface. Les deux autres, qu'on appelle inférieures, font arrondies par le fond. Celles-là renferment une matiere réfineufe, mollaffe, adhérente, mêlée de petites Fibres, de couleur grifâtre en dehors, jaunâtre en dedans, d'une odeur forte, défagréable $\&$ pénétrante, $\&$ qui s'enflamme aifément, c'eft le vrai Caftoreum. Il fe durcit à l'air dans l'efpace d'un mois, \& devient brun, caffant \& friable. Si l'on eft preffé de le faire durcir, il n'y a qu'à le mettre dans la Cheminée.

On prétend que le $C_{a f t o r e u m}$, qui vient de Dantzic, eft meilleur que celui de Canada; je m'en rapporte aux Droguiftes. Il eft certain que les Bourfes de celui-ci font plus petites, \& qu'ici même les plus groffes font les plus eftimees. Outre la groffeur, il faut qu'elles foient pefantes, de couleur brune, d'une odeur pénétrante $\&$ forte, remplies d'une matiere dure, caffante $\&$ friable, de même couleur, ou jaunâtre, entrelaffées d'une Membrane déliée, \& d'un goût âcre. Les Propriétés du Caftoreum font, d'atténuer les matieres vifqueufes, de fortifier le Cerveau, d'abaiffer les Vapeurs, de provoquer aux Femmes leurs Ordinaires, d'empêcher la Corruption, \& de faire évaporer les mauvaifes Humeurs par la Tranfpiration. On s'en fert auffi avec fuccès contre l'Epilepfie, la Paralyfie, l'A popléxie, \& la Surdité.

Les Poches inférieures contiennent une Liqueur onctueufe $\&$ adipeufe, qui reffemble au Miel. Sa couleur eft d'un jaune pâle, fon odeur fétide, peu differente de celle du Caftoreum; 
D'UN VOY A GE DE L'A MERIQ. LET. V. 99 mais un peu plus foible \& plus fade. Elle fe condenfe en vieilliffant, \& prend la confiftance du Suif. Cette Liqueur eft réfolutive, \& fortifie les Nerfs; il ne faut pour cela que l'appliquer fur le mal. Au refte c'eft une folie, que de dire comme font encore quelques Auteurs, fur la foi des anciens Naturaliftes, que quand le Caftor fe voit pourfuivi, il fe coupe ces prétendus Tefticules, \& les abandonne aux Chaffeurs, pour mettre fa vie en fûreté. C'eft de fon Poil, dont il devroit alors fe dépouiller, car au prix de fa Toifon, le refte eft prefque compté pour rien. C'eft néanmoins cette Fable, qui lui a fait donner le nom de Caftor. La Peau de cet Animal, dépouillée de fon Poil, n’eft point à négliger : on en fait des Gants \& des Bas; on pourroit en faire bien d'autres chofes encore, mais comme il eft difficile d'enlever tout le Poil fans le découper, on ne fait guéres ufage, que de celle des Caftors Terriers.

Vous aurez peut-être oui parler, Madame, de Caftor Gras \& de $\mathcal{C} a f t o r S e c$, \& peut-être ferez-vous bien aife d'en connoître la difference. La voici : le Caftor Sec eft la Peau de Du Caftor Gras \& du CalCaftor, qui n'a fervi à aucun ufage : le Caftor Gras eft celle, qui a été portée par les Sauvages, lefquels, après l'avoir bien grattée en dedans, \& frottée avec laMoële de certains Animaux, que je ne connois point, pour la rendre plus maniable, en coufent plufieurs enfemble, \& en font une maniere de Mante, qu'on appelle Robe, \& de laquelle ils s'enveloppent le Poil en dedans. Ils ne la quittent en Hyver ni le jour, ni la nuit; le grand Poil tombe bientôt, le Duvet refte \& s'engraiffe, \& en cet état il eft bien plus propre à être mis en œuvre par les Chapeliers; ils ne pourroient pas même employer le fec, s'ils n'y mêloient un peu de gras. On prétend qu'il doit avoir été porté quinze ou dix-huit mois, pour être dans fa bonté. Je vous laiffe à penfer, fi dans les commencemens on a été affez fimple pour faire connoître aux Sauvages que leurs vieilles Hardes étoient une Marchandife fi précieufe. Mais on n'a pû leur cacher lontems un fecret de cette nature: il étoit confié à la cupidité, qui n'eft jamais lontems fans fe trahir elle-même.

II y a environ trente ans, qu'un nommé Guigues, qui avoit eu la Ferme du Caftor, fe trouvant chargé d'une proAutre ufags du Caltor. digieufe quantité de cette Pelleterie, imagina, pour en faci- 
100 J O U R N A L H I S T O R I Q U E

I $72 \mathrm{I}$. liter la confommation, d'en faire filer \& carder avec de la Mars. Laine, \& de cette compofition il fit faire des Draps, des Flanelles, des Bas au Métier, \& d'aures Ouvrages femblables, mais avec peu de fuccés. Cet effai fit connoître que le Poil du Caftor n'eft bon qu'à faire des Chapeaux. Il eft trop court, pour pouvoir être filé feul, \& il en faut mettre beaucoup moins de la moitié avec la Laine, ainfi il y a peu de profit à faire dans cette Fabrique. On a pourtant confervé une de ces Munufaetures en Hollande, où on en voit des Draps $8 x$ des Droguets; mais ces Etofes font cheres, \& ne font pas d'un bon ufage. Le Poil de Caftor s'en détache bientôt, \& forme à la fuperficie comme un Duvet, qui leur ôte tout leur luftre. Les Bas, qu'on en a faits en France, a voient le même défaut.

Voilà, Madame, tout ce que les Caftors peuvent procu-

Induftrie 8: travaux des Caftors.

rer d'avantages à cette Colonie pour fon Commerce : leur induftrie, leur prévoyance, le concert \& la fubordination, qu'on admire en eux, leur attention à fe ménager des commodités, dont on n'avoit pas encore cru les Brutes capables de fentir la douceur, fourniffent à l'Homme encore plus d'inf-. tructions, que la Fourmi, à laquelle l'Ecriture Sainte renvoye les Pareffeux. Ils font au moins parmi les Quadrupedes ce que les Abeilles font parmi les Infeetes Volatilles. Je n'ai pas oui dire à Gens inftruits qu'ils ayent un Roi, ou une Reine, $\&$ il n'eft pas vrai que, quand ils travaillent en Troupe, il y ait un Chef, qui commande; \& punit les Pareffeux : mais par la vertu de cet inftinct, que donne aux Animaux celui, dont la Providence les gouverne, chacun fçait ce qu'il doit faire, \& tout fe fait fans confufion, fans embarras, avec un ordre, qu'on ne fe laffe point d'admirer. Peut-être après tout n'en eft-on fi étonné, que faute de remonter à cette Intelligence fuprême, qui אe fert de ces Etres dénués de raifon, pour mieux faire éclatter fa fageffe \& fa puiffance, \& pour nous faire fentir que notre raifon mème eft prefque toujours par notre préfomption la caufe de nos égaremens.

La premiere chofe, que font nos ingénieux Amphibies, lorfqu'ils veulent fe loger, c'eft de s'affembler : vous dirai-je en Tribus, ou en Sociétés ? ce fera tout ce que vous voudrez; mais ils font quelquefois trois ou quatre cent enfemble, formant une Bourgade, qu'on pourroit appeller une petite Venife. D'abord ils choififfent un Emplacement, où ils puiffent trou- 
D'UN VOYAGE DE L'A MERIQ. LET. V. 101 ver des vivres en abondance, $\&$ tout ce qui leur eft néceffaire pour bâtir. Il leur faut furtout de l'eau, $\&$ s'ils ne trouvent ni Lac, ni Etang, ils y fuppléent, en arrêtant le cours d'un 1721. Mars. Ruiffeau, ou d'une petite Riviere, par le moyen d'une Digue, ou , comme on parle ici, d'une Chauffée. Pour cela ils vont couper des Arbres au-deffus de l'endroit, où ils ont réfolu de bâtir. Trois ou quatre Caftors fe mettent autour d'un gros Arbre, \& viennent à bout avec leurs Dents de le jetter par Terre. Cè n'eft pas tout : ils prennent fi bien leurs mefures, qu'il tombe toujours du côté de l'Eau, afin qu'ils n'ayent pas tant de chemin à faire pour le voiturer, quand ils l'ont mis en piéces. Ils n'ont plus enfuite qu'à rouler ces piéces pour les pouffer dans l'Eau, \& ils les conduifent vers l'endroit, où elles doivent être placées.

Ces piéces font plus ou moins groffes, plus ou moins longues, felon que la nature \& la fituation du lieu le demandent : car on diroit que ces Architectes ont tout prévû. Quelquefois ils employent de gros Troncs d'Arbres, qu'ils portent à plat : quelquefois la Chauffée n'eft compofée que de Pieux gros comme la Cuiffe, ou même plus menus, foûtenus de bons Piquets, \& entrelaffés de petites Branches; \& partout, les vuides font remplis d'une Terre graffe fi bien appliquée, qu'il n'y paffe pas une goutte d'eau. C'eft avec leurs Pattes, que les Caftors préparent cette Terre; \& leur Queuë ne leur fert pas feulement de Truelle pour maçonner, mais encore d'Auge, pour voiturer ce Mortier, ce qu'ils font en fe traînant fur leurs Pattes de derriere. Arrivés au bord de l'Eau, ils le prennent avec les Dents, \& pour l'employer, ils fe fervent d'abord de leurs Pattes, enfuite de leur Queuë. Les Fondemens de ces Digues ont ordinairement dix à douze pieds d'épaiffeur, \& elles vont en diminuant jufqu'à deux ou trois. Les proportions y font toujours exactement gardées. La Régle \& le Compas font dans l'Eili du Grand Maitre des Arts \& des Sciences. Enfin on a obfervé que le côté du Courant de l'Eau eft toujours en Talus, \& l'autre côté parfaitement à plomb. En un mot il feroit difficile à nos meilleurs Ouvriers de rien faire de plus folide \& de plus régulier.

La conftruction des Cabannes n'a rien de moins merveilleux. Elles font pour l'ordinaire bâties fur Pilotis au milieu de ces petits Lacs, que les Digues ont formés : quelquefois 
1721 . fur le Bord d'une Riviere, ou à l'extrémité d'une Pointe, qui avance dans l'Eau. Leur figure eft ronde, ou ovale, \& elles Mars. font voutées en Anfe de Panier. Les Parois ont deux pieds d'épaiffeur, les Matériaux en font les mêmes, que dans les Chauffées, mais moins gros; \& tout eft fi bien enduit de Terre Glaife en-dedans, qu'il n'y entre pas le moindre air. Les deux tiers de l'Edifice font hors de l'Eau, \& dans cette Partie chaque Caftor a fa Place marquée, qu'il a foin de joncher de Feuillages, ou de petites Branches de Sapin. On n'y voit jamais d'ordures, \& $\&$ pour cela, outre la Porte commune de la Cabanne, \& une autre Iffuë, par laquelle ces Animaux fortent pour aller fe baigner, il y a plufieurs Ouvertures, par où ils vont fe vuider dans l'Eau. Les Cabannes ordinaires logent huit ou dix Caftors: on en a vû, qui en renfermoient jufqu'à trente, mais cela eft rare. Toutes font affez près les unes des autres, pour avoir entr'elles une communication facile.

Leur Pré-

L'Hyver ne furprend jamais les Caftors. Tous les Ouvravoyance, ges, dont je viens de parler, font achevés à la fin de Septembre, \& alors chacun fait fes provifions pour l'Hyver. Tandis quils vont $\&$ viennent dans la Campagne, ou dans les Bois, ils vivent de Fruits, d'Ecorces \& de Feuilles d'Arbres; ils pêchent auffi des Ecreviffes \& quelques Poiffons: alors tout leur eft bon. Mais quand il s'agit de fe pourvoir pour tout le tems, que la Terre couverte de Neiges ne leur fourniroit rien, ils le contentent de bois tendre, comme de Peupliers, de Trembles, ou d'autres femblables. Ils le mettent en piles, \& le difpofent de façon, qu'ils puiffent toujours prendre les morceaux, qui trempent dans l'Eau. On a remarqué conftamment que ces Piles font plus ou moins grandes, fuivant que l'Hyver doit être plus ou moins long, \& c'eft pour les Sauvages un Almanach, qui ne les trompe jamais fur la durée du troid. Les Caftors, avant que de manger le Bois, le découpent en petits morceaux fort menus, \& les apportent dans leur Loge; car chaque Cabanne n'a qu'un Magafin pour toute la Famille.

Quand la Fonte des Néges eft dans fa force, comme elle ne manque pas de caufer de grandes inondations, les. Caftors quittent leurs Cabannes, qui ne font plus logeables, \& chacun va de fon côté, où bon lui femble. Les Femelles y re- 
DUN V OYA G E DE. L'A MER IQ. LET. V. IO3 tournent, dès que les Eaux font écoulées, \& c'eft alors, qu'elles mettent bas. Les Mâles tiennent ła Campagne jufques vers le mois de Juillet, qu'ils fe raffemblent pour réparer les bréches, que les Crûës d'eau ont faites à leurs Cabannes, ou à leurs Digues. Si elles ont été détruites par les Chaffeurs, ou fi elles ne,valent point la peine d'être réparées, ils en font. d'autres; mais bien des raifons les obligent fouvent à changer de demeure. La plus ordinaire eft le défaut de Vivres: ils y font encore forcés par les Chaffeurs, ou par les Animaux Carnaciers, contre lefquels ils n'ont point d'autre défenfe, que la fuite. On pourroit s'étonner que l'Auteur de la Nature ait donné moins de force à la plûpart des Animaux utiles, qu'à ceux, qui ne le font pas ; fi cela même ne faifoit éclatter davantage fa puiffance \& $\mathrm{fa}$ fageffe, en ce que ceux-là, malgré leur foibleffe, multiplient beaucoup plus que ceux-ci.

Il y a des endroits, que les Caftors femblent avoir tellement pris en affection, qu'ils ne fçauroient les quitter, quoiqu'ils y foient toujours inquiettés. Sur le Chemin de Montreal, au Lac Huron, par la Grande Riviere, on ne manque point de trouver tous les ans au même lieu un Logement, que ces Animaux y bâtiffent ou réparent tous les Etés: car la premiere chofe, que font les Voyageurs, qui y arrivent les Premiers, c'eft de rompre la Cabanne \& la Chaufée, qui lui donne de l'Eau. Si cette Chauffée n'eût pas retenu les Eaux, il n'y en auroit pas affez pour continuer la route, $\&$ il faudroit faire un Portage : de forte qu'il femble que ces offcieux Caftors vont fe pofter là, uniquement pour la commodité des Paffans. On voit, dit-on, la même chofe du côté de Quebec, où des Caftors, en travaillant pour eux, fourniffent de l'Eau à un Moulin à Planches.

Les Sauvages étoient autrefois perfuadés, $f i$ on en croit quelques Relations, que les Caftors étoient une efpece d'Animal raifonnable, qui avoit fes Loix , fon Gouvernement, \& fon Langage particulier: que ce Peuple Amphibie fe choififfoit des Commandans, qui dans les travaux communs diftribuoient à chacun fa tâche, pofoient des Sentinelles, pour crier à l'approche de l'Ennemi, puniffoient, ou exiloient les Pareffeux. Ces prétendus Exilés font apparemment ceux, qu'on appelle $C_{a f t o r s}$ Terriers, qui en effet vivent féparés des 
1721 . autres, ne travaillent point, \& fe logent fous Terre, où Mars. leur unique attention eft de fe ménager un chemin couvert pour aller à l'Eau. On les connoît au peu de Poil, qu'ils ont fur le Dos, ce qui vient fans doute de ce quils fe frottent continuellement contre la Terre. Avec cela, ils font maigres; c'eft le fruit de leur Pareffe: on en trouve beaucoup plus dans les Pays Chauds, que dans les Pays Froids. J'ai déja remarqué que nos Caftors, ou Biévres d'Europe, tiennent plus de ceux-ci, que des autres; en effet M. Lémery dit qu'ils fe retirent dans les Creux \& dans les Cavernes, qui fe rencontrent fur les Bords des Rivieres, furtout en Pologne. Il y en a auffi en Allemagne, le long de l'Ebre, \& en France fur le Rhône, l'Ifere \& l'Oife. Ce qui eft certain, c'eft que nous ne voyons point dans les Caftors Européens ce merveilleux, qui diftingue fi fort ceux du Canada. C'eft bien dommage, $\mathrm{Ma-}$ dame, qu'ilne fe foit point trouvé de ces admirables Animaux, ni dans le Tybre, ni dans le Permeffe : que de belles chofes ils auroient fait dire aux Poëtes Grecs \& Romains !

Il paroît que les Sauvage's du Canada ne les moleftoient pas beaucoup avant notre arrivée dans leur Pays. Les Peaux de Caftors n'étoient pas celles, dont ces Peuples faifoient plus d'ufage pour fe couvrir, \& la Chair des Ours, des Elans, \& de quelques autresBêtesFauves leur fembloit ap. paremment meilleure, que celle des Caftors. Ils les chaffoient néanmoins, \& cette Cliafie avoit fon tems $\&$ fon cérémonial marqué, mais quand on ne chaffe, que pour le befoin, \& que ce befoin eft borné au pur néceffaire, on ne fait pas de grandes deftructions; auff, lorfque nous arrivâmes en $\mathrm{Ca}$ nada, nous y trouvâmes un nombre prodigieux de ces Amphibies.

Dela Chaffe

La Chaffe du Caftor n'eft pas difficile ; car il s'en faut bien du Caftor. que cet Animal ait autant de force pour fe deffendre, ni d'adreffe pour éviter les embuches de fes Ennemis, qu'il montre d'induftrie pour fe bien loger, \& de prévoyance pour fe pourvoir de tous les befoins de la vie. C'eft pendant l'Hyver, qu'on lui fait la Guerre dans les formes : c'eft-à-dire, depuis le commencement de Novembre jufqu'au mois d'Avril. Alors il a , comme tous les autres Animaux, plus de Poil, \& la Peau plus mince. Cette Chaffe fe fait de quatre manieres, qui font les Filets, l'Affut, la Tranche, \& la Trappe. La premiere 
D'UN VOYAGE DE L'A MER IQ. LET. V. I0; premiere eft ordinairement jointe à la troifiéme ; \& on s'amufe rarement à la feconde, parce que les petits Yeux de cet Amphibie font fi perçans, \& il a l'Oreille fi fine, qu'il eft malaifé de l'approcher affez, pour le tirer, avant qu'il ait gagné l'Eau, dont il ne s'écarte pas beaucoup dans cette Saifon, \& où il plonge d'abord. On le perdroit même, quand il auroit été bleffé, avant que de s'être jetté à l'Eau, parce qu'il ne revient point au-deffus, s'il meurt de fa Bleffure. C'eft donc à la Tranche \& à la Trappe, qu'on s'attache plus communément.

Quoique les Caftors ayent fait leurs Provifions pour l'Hyver, ils ne laiffent pas de faire de tems en tems quelques excurfions dans les Bois, pour y chercher une nourriture plus fraîche \& plus tendre, \& cette délicateffe coûte la vie à plufieurs. Les Sauvages dreffent fur leur chemin des Trappes, faites à peu près comme un 4 de chifre, \& pour appas ils $y$ mettent de petits morceaux de bois tendres \& fraîchement coupés. Le Caftor n'y a pas plutôt touché, qu'il lui tombe fur le Corps une groffe Buche, qui lui caffe les Reins, \& le Chaffeur, qui furvient, l'acheve fans peine. La Tranche demande plus de précaution, \& voici de quelle maniere on y procéde. Quand la Glace n'a encore qu'un demi pied d'épaiffeur, on y fait une ouverture avec la Hache : les Caftors y viennent pour refpirer plus à leur aife; on les y attend, \& on les fent venir de loin, parce qu'en fouflant ils donnent un affez grand mouvement à l'Eau: ainfi il eft aifé de prendre fes mefures pour leur caffer la Tête, au moment qu'ils la mettent dehors. Pour agir encore plus fûrement, \& n'être pas apperçu des Caftors, on jette fur le Trou, qu'on a fait dans la Glace, de la Bourre de Rofeaux, ou des Epis de Typha, \& quand on connoît que l'Animal eft à portée, on le faifit par une de fes Pattes, \& on le jette fur la Glace, où on l'affomme, avant qu'il foit revenu de fon étourdiffement.

Si la Cabane eft proche de quelque Ruiffeau, la Chaffe fe fait encore plus aifément. On coupe la Glace en travers pour y tendre un Filet : enfuite on va brifer la Cabanne. Les Caftors, qui y font renfermés, ne manquent point de fe fauver dansleRuiffeau, \& fe trouvent pris dans le Filet. Mais il ne faut pas les y laiffer lontems, ils s'en feroient bientôt débarrafés en le coupant. Ceux, dont les Cabannes font dans des Lacs, Tome III. 
1721 . Ont à trois ou quatre cent pas du Rivage une efpece de Maifort Mars. de Campagne, pour y refpirer un meilleur air : alors les Chaffeurs fe partagent en deux Bandes, l'une va rompre la $\mathrm{Ca}-$ banne des Champs, l'autre donne en même tems fur celle du Lac ; les Caftors, qui font dans celle-ci, \& on prend le tems qu'ils y font tous, veulent fe réfugier dans l'autre, mais ils n'y trouvent plus qu'une Pouffiere, qu'on y a jettée exprès, \& qui les aveugle, deforte qu'on en a bon marché. Enfin en quelques endroits on fe contente de faire une ouverture aux Chauffées; par ce moyen les Caftors fe trouvent bientôt à fec, \& demeurent fans deffenfe : ou bien ils accourent pour remédier d'abord au mal, dont ils ne connoiffent pas les $\mathrm{Au}-$ teurs; \& comme on eft bien préparé à les recevoir, il eft rare qu'on les manque, ou qu'on n'en attrape au moins qu'elques-uns.

Quelques Voici d'autres particularités fur les Caftors, que je trouve Iarticuiarités fur ces Amphibies. dans quelques Mémoires, dont je ne vous garantis pas la fidélité. On prétend que quand ces Animaux ont découvert des Chaffeurs, ou quelques-unes de ces Bêtes Carnacieres, qui leur font la Guerre, ils plongent en battant l'Eau de leur Queuë, avec un fi grand bruit, qu'on les entend d'une demie lieuë. C'eft apparemment pour avertir tous les autres d'être fur leurs gardes. On dit encore quils ont l'Odorat fi fin, qu'étant dans l'Eau, ils fentent un Canot de fort loin. Mais on ajoûte qu'ils ne voyent que de côté, non plus que les Lié-vres, \& que ce défaut les livre fouvent aux Chaffeurs, qu'ils veulent éviter. Enfin on affüre que, quand un Caftor a perdu fa Femelle., il ne s'accouple point avec une autre, comme on le rapporte de la Tourtereille.

Les Sauvages ont grand foin d'empêcher que leurs Chiens ne touchent aux $O$ s du Caftor, parce qu'ils font d'une dureté, à laquelle les Dents des Chiens ne réfifteroient pas. On dit la même chofe des Os clu Porc-Epi. Le commun de ces Barbares apporte une autre raifon de cette précaution; c'eft, difent-ils, pour ne point irriter les efprits de ces Animaux, qui empêcheroient qu'une autre fois la Chaffe ne fût heureufe. Mais je crois que cette raifon eft venuë après coup; \& c'eft. ainfi que la fuperftition a fouvent pris la place des caufes naturelles, à la honte de l'Efprit Humain. Au refte, Madame, je m'étonne qu'on n'ait pas encore effayé de tranfporter en 
DUN VOYAGE DE L'A MERIQ. LET. V. IOJ France quelques-uns de ces merveilleux Amphibics : nous avons affez d'endroits, où ils pourroient trouver de quoi vivre \& bâtir, \& je crois qu'ils y mulțiplieroient en peu 1721 . Mars. de tems.

Nous avons encore ici un petit Animal de même nature, Du Rat Mufà peu-près, que le Caftor, qui, à bien des égards, en paroît qué. un Diminutif, \& qu'on nomme Rat Mufqué. Il a en effet prefque toutes les Propriétés du Caftor : la ftructure du Corps, $\&$ fur-tout de la Tête de l'un \& de l'autre, eft fi femblable, qu'on prendroit le Rat Mufqué pour un petit Caftor, fi on lui avoit coupé la queuë, en quoi il differe peu des nôtres; \& fi on lui avoit ôté les Tefticules, qui renferment un Mufc très-exquis. Cet Animal, qui pefe environ quatre livres, eft auffi affez femblable à celui, que M. RaI a décrit, fous le nom de Mus Alpinus. Il fe met en Campagne au mois de Mars , \& fa nourriture eft alors de quelques morceaux de Bois, qu'il pele, avant que de les manger. Après la fonte des Néges il vit de racines d'Orties, puis des tiges $\&$ des feuilles de cette Plante. En Eté il ne mange guéres que des Fraifes \& des Framboifes, aufquelles fuccedent d'autres Fruits dans l'Automne. Durant tout ce tems-là on voit rarement le Mâle fans la Femelle.

A l'entrée de l'Hyver ils fe féparent, \& chacun va de fon côté fe loger dans un trou, ou dans le creux d'un Arbre, fans aucunes Provifions, \& les Sauvages affurrent, que tant qu'il fait froid, ils ne mangent quoi que ce foit. Ils bâtiffent auffi des Cabanes à peu-près de la forme de celles des Caftors; mais il s'en faut beaucoup qu'elles foient $\mathrm{fi}$ bien travaillées. Quant à leur fituation, elle eft toujours au bord de l'eau; ainfi ils n'ont pas befoin de faire de Chauffée. On dit que le poil du Rat Mufqué entre dans la Fabrique des Chapeaux avec celui du Caftor, \& n'y gâte rien. Sa chair n'eft pas mauvaife, fi ce n'eft, lorfqu'il eft en rut ; car alors il n'eft pas poffible de lui ôter un goût de Mufc, qui ne flatte point le Palais auffi agréablement que le Nez. J'étois, Madame, fort en train de vous parler des autres Chaffes de nos Sauvages, \& des Animaux, qui font particuliers à ce Pays : mais il faut remettre la partie à une autre fois, on vient de m'avertir que ma Voiture eft prête, \& je pars. Je fuis, \&x. 
1721 .

Mars.

\section{S I X I E M E L E T T R E.}

Voyage de Quebcc aux Trois Rivieres. Comment on peut courir la Pofte fur la Nége. Des Seigneuries de la Nouvelle France. Defcription de Beckancourt. Tradition fur le nom de la Riviere Puante. Defcription des Trois Rivieres. Suite des Chaffes des Sauvages.

Aux TroisRivieres, le fixiéme de Mars, 1721 .

Maniere de courir la l'ofte en Iraîne.

\section{WADAME,}

J'AR RIVAI hier en cette Ville, après deux jours de marche, \& quoiqu'elle foit éloignée de Quebec de vint-cinq lieuës, jaurois pu fort aifément faire ce chemin en douze heures, parce que javois pris la voye d'une Cambiatura, que la Nége \& la Glace rendent très-facile en ce Pays pendant l'Hyver, $\&$ qui ne coûte pas plus que les Voitures ordinaires. On fe fert pour cela d'une Traîne, ou, comme on parle ici, d'une Cariole, qui coule fi doucement, qu'un feul Cheval fuffit pour la traîner, \& va toujours le galop. On en change de tems en tems, \& à bon marché. Dans un befoin on feroit ainfi en vint-quatre heures foixante lieuës, beaucoup plus commodément, que dans la meilleure Chaife de Pofte.

Des Sei- Mon premier gîte fut à la Pointe aux Trembles, à fept lieuës oneuries du de la Capitale, d'où je n'étois parti qu'une heure avant
Canada.

la nuit. C'eft une des bonnes Paroiffes du Pays. L'Eglife eft grande, \& bien bâtie, \& les Habitans y font fort à leur aife. En général les anciens Habitans font ici plus riches que les Seigneurs, \& en voici la raifon. Le Canada n'étoit qu'une grande Forêt, quand les François ont commencé de s'y établir. Ceux, à qui l'on a donné des Seigneuries, n'étoient pas gens à les mettre par eux-mêmes en valeur. C'étoit des Officiers, des Gentilshommes, des Communautés, qui n'avoient pas des fonds affez confidérables, pour y loger affez d'Ouvriers pour cela. Il a donc fallu quils y établiffent des $\mathrm{Ha}$ - 
D'U N V OYA GE DE L'A MERIQ. Let. VI. 109 bitans, qui avant que de pouvoir y recueillir dequoi fubfifter, ont été obligés de travailler beaucoup, \& de faire même toutes les avances. Ainfi ils n'ont pû s'engager envers les Seigneurs, qu’à une Redevance fort modique. De forte qu'avec les Lods \& Ventes, qui font ici bien peu de chofes, le Droit du Moulin, \& la Métairie, une Seigneurie de deux lieuës de front, \& d'une profondeur illimitée, n'eft pas d'un grand revenu dans un Pays fi peu peuplé, \& où il y a fi peu de Commerce au-dedans.

C'eft-là fans doute une des raifons, qui ont engagé le feu Roi Louis XIV. à permettre à tous Nobles \& Gentilshommes habitués au Canada, de faire le Commerce, tant par Mcr, que par Terre, fans qu'ils puiffent être recherchés, ni réputés avoir dérogé. Ce font les termes de l'Arrêt, qui fut rendu par le Confeil le dixiéme de Mars i68.5. Au refte, il n'y a en ce Pays aucune Seigneurie, même de celles, qui font Titrées, à laquelle le Droit de Patronnage foit attaché : car fur la prétention de quelques Seigneurs, fondée fur ce qu'ils a voient fait bâtir l'Eglife Paroiffiale, Sa Majefté étant en fon Confeil , prononça la même année 1685. que ce Droit n'appartenoit qu'à l'Évêque, tant parce qu'il eft plus en état, qu'aucun autre, de juger de la capacité des Sujets, que parce que la portion congruë des Curés eft payée fur les Dixmes, qui appartiennent à l'Evêque. Le Roi dans ce même Arrêt déclare, que le Droit de Patronnage n'eft point cenfé Honorifique:

Je partis de la Pointe aux Trembles le quatre avant le jour avec un Cheval Borgne, je le changeai enfuite contre un Boiteux, \& celui-ci contre un Pouffiff. Avec ces trois Relais je fis dix-fept lieuës en fept ou huit heures, \& jarrivai de très-bonne heure chez le Baron de Beckancourt, Grand Voyer de la Nouvelle France, lequel ne voulut jamais me permettre d'aller plus loin. D'ailleurs ce Gentilhomme a fur fes Terres un Village d'Abénaquis, gouverné, pour le Spirituel, par un Jéfuite, que j'étois bien aife de faluer en paffant. Le Baron demeure à l'entrée d'une petite Riviere, qui vient du Sud, qui coule toute entiere dans fon Domaine, $\&$ qui porte fon nom. Ce n'eft pourtant pas cette grande Terre, qui a éré érigée en Baronnie ; mais celle de Portneuf, qui eft de l'autre côté du Fleuve.

Du Droit de Patronage. Le Commerce permis aux Gentilshommes.

Situation de Beckancour. 


\section{IIO JO U R N A L H IS T OR I Q U E}

1721 La vie, que mene M. de Beckancourt dans ce Défert, car on n'y voit point encore d'autre Habitant que le Seigneur, Mars. rappelle affez naturellement le fouvenir de ces anciens $\mathrm{Pa}$ triarches, qui ne dédaignoient point de partager avec leurs Domeftiques le travail de la Campagne, \& vivoient prefque auffi fobrement qu'eux. Le profit, qu'il peut faire par le Commerce avec les Sauvages, fes Voifins, en achetant d'eux les Pelleteries de la premiere main, vaut bien les Redevances, qu'il pourroit tirer des Habitans, à qui il auroit partagé fes Terres. Avec le tems il ne tiendra quà lui d'avoir des Vaffaux , \& il fera des conditions beaucoup meilleures, quand il aura fait défricher tout fon Terrein. La Riviere de Beckancourt fe nommoit auparavant la Riviere Puante: je minformai de la caufe de ce nom, car l'Eau de la Riviere me parut fort belle, on m'affura qu'elle eft trè̀s-bonne, \& il n'y a aucune mauvaife odeur dans tout ce Canton. Les uns me dirent néanmoins, que cette caufe étoit la mauvaife qualité des Eaux : d'autres l'attribuoient à la grande quantité de Rats Mufqués, qu'on y trouve, \& dont les Sauvages ne peuvent fouftrir l'odeur; mais voici une troifiéme Verfion, que ceux, qui ont fait plus de recherches fur l'Ancienne Hiftoire du Pays, prétendent être la véritable.

D'où étoit

Des Algonquins étoient en Guerre contre les Onnontchavenu le nom de Riviere P...nte à la Riviere de Eickrancourt. ronnons, plus connus fous le nom de Nation de l'Iroquet, $\&$ dont l'ancienne demeure étoit, dit-on, dans l'!lle de Montreal. Le nom, qu'elle porte, prouve qu'elle étoit de la Langue Huronne : cependant on prétend que ce font les Hurons, qui l'ont chaffée de leur ancienne Demeure , \& qui l'ont même en partie détruite. Quoiqu'il en foit, elle étoit, au tems, dont je parle, en Guerre contre les Algonquins, qui, pour finir d'un feul coup cette Guerre, dont ils commençoient à fe laffer, s'aviferent d'un ftratagême, qui leur réuffit. Ils fe mirent en embufcade fur les deux bords de la petite Riviere, qui porte aujourd'hui le nom de Beckancourt. Enfuite ils détacherent quelques Canots, dont les Conducteurs firent femblant de pêcher dans le Fleuve. Ils fçavoient que leurs Enmemis n'étoient pas loin , \& ils ne doutoient point qu'ils ne couruffent d'abord fur les prétendus Pêcheurs : en effet, ceux-là ne tarderent pas à voir fondre fur eux une flotte de Canots ; ils firent femblant d'avoir 
DUN VOYA GE DE L'A MERIQ. Let. VI. III peur, prirent la fuite, \& gagnerent la Riviere. Ils y furent fuivis de fort près par un Ennemi, qui croyoit avoir bon marché de cette poignée d'Hommes, \& pour l'engager plus avant, ils affecterent de paroître fort épouvantés. Cette feinte leur réuffit; ceux, qui les pourfuivoient, avancerent toujours, \& jettant, felon la Coûtume de ces Barbares, des cris effroyables, ils fe croyoient au moment de tomber fur leur proye.

Alors une grêle de Fleches décochées de derriere tous les Buiffons, qui bordoient la Riviere, les jetta dans une confufion, dont on ne leur donna point le tems de fe remettre. Une feconde décharge, qui fuivit de fort près la premiere, acheva leur déroute. Ils voulurent fuir à leur tour, mais ils ne pouvoient plus fe fervir de leurs Canots, qui étoient percés de toutes parts. Ils fe lancerent dans l'eau, efperant de fe fauver à la nage; mais outre que la plûpart etoient bleffés, ils trouverent, en arrivant à terre, la Mort, qu'ils fuyoient, \& pas un feul n'échapa aux Algonquins, qui ne pardonnerent à Perfonne, \& ne s'amuferent pas même à faire des Prifonniers. La Nation de l'Iroquet ne s'eft point relevée de cet échec, \& quoi qu'on ait encore vû quelquesuns de ces Sauvages depuis l'arrivée des François en Canada, il n'en eft plus du tout queftion aujourd'hui. Cependant la quantité de Corps morts, qui refterent dans l'eau, \& fur les bords de la Riviere, l'infeeta de telle forte, que le nom de Riviere Puante lui en eft demeuré.

Le Village Abénaqui de Beckancourt n'eft pas préfentement aufii peuplé, qu'il l'étoit, il y a quelques années. Il ne laifferoit pourtant pas de nous être d'un grand fecours, fi la Guerre recommençoit. Ces Sauvages font les meilleurs Partifans du Pays, \& toujours difpofés à faire des courfes dans la Nouvelle Angleterre, où leur nom feul a fouvent jetté l'epouvante jufques dans Bafton. Ils ne nous ferviroient pas moins bien contre les Iroquois, à qui ils ne cédent point en valeur, \& qui ne font pas auffi bien difciplinés qu'eux. Ils font tous Chrétiens, \& on leur a bâti une jolie Chapelle, où ils pratiquent avec beaucoup d'édification tous les Exercices du Chriftianifme. Il faut pourtant avoüier que leur fervęur n'eft plus au point, où on l'a vîë les premieres années de leur Etablifiement parmi nous. On leur a porté de

$172 \%$

Mars。
Du Village Abénaqui de Beckancoust. 
112 J O U R N A L H IS T O R I Q U E

I 7 21. l'Eau-de-Vie, ils y ont pris goût, \& les Sauvages ne boivent Mars. jamais, que pour s'eny.vrer. Cependant une funefte Expérience nous a appris, qu'à mefure que ces Peuples s'éloignent de Dieu, ils ont moins de déférence pour leurs Pafteurs, \&. fe rapprochent des Anglois. Il eft bien à craindre que le Seigneur ne permette quilis deviennent nos Ennemis, pour nous punir davoir contribué, par un fordide intérêt, à les rendre vicieux, comme il eft déja arrivé à quelques autres Nations.

Situation de Après avoir embraffé le Miffionnaire de Beckancourt $(a)$, la vilie des vifite fa Bourgade, \& fait avec lui de triftes réflexions, que Trois Rivie- ne peut manquer de fournir le défordre, dont je viens de
riss.

parler, \& dont il eft fouvent réduit à gémir devant Dieu, je traverfai le Fleuve Saint Laurent, pour me rendre en cette Ville. Rien n'eft plus charmant, Madame, que fa fituation. Elle eft bâtie fưr un Côteau de Sable, qui n'a guéres de ftérile, que l'efpace, qu'elle peut occuper, fi elle devient jamais une Ville confidérable : car à préfent c'eft fort peu de chofes. Du refte, elle eft environnée de tout ce qui peut rendre une Ville agréable \& opulente. Le Fleuve, large de près d'une demie lieuë, eft à fes pieds. Au-delà on ne voit que Campagnes cuitivées, fertiles, \& couronnées des plus belles Forêts du Monde. Un peu au-deffous, \& du même côté, que la Ville, le Fleuve reçoit une affez belle Riviere, qui, avant que de confondre fes Eaux avec les Siennes, en reçoit en même tems deux autres, l'une à fa droite, $\&$ l'autre à $\mathrm{fa}$ gauche, $\&$ c'ctt ce qui a fondé le nom de Trois Rivieres, que porte la Ville.

Au-deffus, \& prefqu'à la même diftance, commence le $L a c$ Du lac de de Saint Pierre, lequel a environ trois lieuës de large, \&
Saziz Pierre. fept de long. Ainfi rien ne borne la vûë de ce côté-là, \& le Soleil paroît fe coucher dans les Ondes. Ce Lac, qui n'eft qu'un élargiffement du Fleuve, reçoit plufieurs Rivieres. Il y a affez d'apparence que ce font ces Rivieres, qui avec le tems ont mangé le Terrein bas $\&$ mouvant, à travers duquel elles couloient ; cela eft furtout fenfible à l'égard de celle de Saint François, dont l'Embouchure eft femée de plufieurs Ifles, qui pourroient bien avoir été jointes au Continent. D'ailleurs dans tout le Lac, fi ce n'eft au milieu du Canal, dont la force

(a) Le Pere Euftache LE SU E UR. 
D'U N V OYA GE DE L'A MER IQ. LET. VI. II 3 du Courant du Fléuve a confervé toute la profondeur, on ne peut aller qu'en Canots, encore y a-t'il des endroits, d'où les grands Canots, pour peu qu'ils foient chargés, ne fe ti1721 .

Mars. rent pas aifément. En récompenfe, il eft partout fort Poiffonneux, \& le Poiffon y eft excellent.

On ne compte guéres que fept ou huit cent Perfonnes dans la Ville des Trois Rivieres : mais elle a dans fon Voifnage de quoi enrichir une grande Ville. Ce font des Mines de Fer très-abondantes, qu'on fera valoir , quand on voudra. (a) $\mathrm{Au}$ refte, quelque peu peuplée que foit cette Ville, fa fituation la rend très-importante, \& c'eft un des plus anciens Etabliffemens de la Colonie. Dès les premiers tems ce Pofte a eu un. Gouverneur. Il a mille Ecus d'Appointemens, \& un EtatMajor. On voit auffi dans cette Ville un Couvent de Récollets; une affez belle Eglife Paroiffiale, deffervie par ces mêmes Religieux ; \& un très-bel Hôpital joint à un Monaftere d'Urfulines, qui y font au nombre de quarante, \& qui y font l'office d'Hofpitalieres. C'eft encore une Fondation de M. de Saint Vallier. Dès l'année 1650 le Sénéchal de la Nouvelle France, dont la Jurifdiction a été abforbée par le Confeil Supérieur de Quebec , \& par l'Intendant, avoit un Lieutenant aux Trois Rivieres; aujourd'hui cette Ville a une Juftice ordinaire, dont le Chef eft un Lieutenant Général.

Elle doit fon origine au grand abord, qui dans les commencemens de la Colonie fe faifoit en ce lieu-là des Sauvages de differentes Nations. Il en defcendoit furtout plufieurs des Quartiers les plus reculés vers le Nord, par les Trois Rivieres, qui ont donné le nom à la Ville, \& qu'on remonte fort loin. La fituation du lieu, joint au grand Commerce, qui s'y faifoit, engagea quelques François à s'y établir, \& la proximité de la Riviere de Sorel, alors nommée la Riviere des Iroquois, \&x dont je vous parlerai bientôt, obligea les Gouverneurs Généraux à y conftruire un Fort, où ils entretenoient une bonne Garnifon, \& qui eut d'abord fon Gouverneur Particulier. Ainfi ce Pofte fut dès-lors regardé comme un des plus importans de la Nouvelle France. Au bout de quelques années les Sauvages fe laffant d'y être continuellement harcelés par les Iroquois, dont les François eux-mêmes avoient affez de peineà fe deffendre; n'ayant plus la li-

(a) On y travaille actuellement, $\&$ on en tire le meilleur Fer du Monde.

Tome III. 
114

J O UR N A L H IS T ORI Q U E

berté des Paffages, où ces fiers Ennemis leur dreffoient fans

1721 . ceffe des Embuches, \& n'étant pas même toujours en fûreté Mars. à la vûë \& fous le Canon de notre Fort, cefferent d'y porter leurs Pelleteries. Les Jéfuites, avec ce qu'ils y avoient affemblé de Néophytes, fe retirerent trois lieuës au-deffous, fur un Terrein, que leur avoit donné l'Abbé DE LA MADELEINE, un des Membres de la Compagnie des Cent Affociés, formée par le Cardinal DE RICHELIEU : d'où ce Terrein a pris le nom de Cap de la Madeleine, qu'il porte encore aujourd'hui (a).

Ducapde la La Miffion, qu'on y avoit tranfportée, n'y a pourtant pas Madcleine. fubfifté lontems. C'eft en partie l'effet de l'inconftance desSauvages, \& principalement une fuite des Guerres \& des Maladies, qui ont prefqu'entierement détruit cette Eglife naiffante. On voit bien encore aux environs une troupe d'Algonquins, dont la plûpart ont été baptifés dans leur Enfance, mais qui n'ont aucun Exercice réglé de Religion. $M^{\text {ss }}$ de la Compagnie des Indes Occidentales, qui ont aujourd'hui la Traite des Caftors, ont inutilement tenté de les attirer à Checoutimi, où ils ont déja réuni plufieurs Familles de la même Nation, \& de celle des Montagnez, fous la conduite d'un Miffionnaire Jéfuite. D'autres ont voulu les joindre aux Abénaquis de Saint François. Leur unique réponfe à ces invitations a été qu'ils ne pouvoient fe réroudre à quitter un lieu, où les $\mathrm{O}$ de leurs Peres repofent; mais quelques Perfonnes font perfuadés, \& ce n'eft pas fans fondement, que cette réfiftance vient moins de leur part, que de Gens, à qui leur Voifinage eft utile, \& qui fans doute ne font pas affez réflexion qu'ils facrifient le falut de ces Sauvages à un affez leger interêt.

On vient de m'affurrer, Madame, que dans quelques jours il y aura une occafion d'envoyer cette Lettre à Quebec, d'où elle pourra aller en France de bonne heure par l'Ifle Royale. Je vais achever de la remplir de ce qui regarde les Chaffes des Sauvages. Celle du Caftor, ainfi que je l'ai déja remarqué, n'eft devenuë leur principal objet, que depuis qu'ils ont vû́ le cas, que les François faifoient de la Dépouille de cet Animal. C'étoit auparavant celle de l'Ours, qui tenoit le pre-

(a) Outre les Mines de Fer, qui font plufieurs Sources d'Eaux Minérales, qũ affez abondantes au Cap de la Madeleine, font des mêmes qualités, que celles de on $y$ a découvert, il y a quelques années, Forges. 
D'UN VOYA GE DE L'A MERIQ. LET. VI. II mier rang, \& où la Superftition avoit le plus de part. Voici ce qui fe pratique encore aujourd'hui dans cette Chaffe parmi ceux, qui ne font pas Chrétiens.

C'eft toujours un Chef de Guerre, qui en marque le tems, \& qui a foin d'inviter les Chaffeurs. Cette invitation, qui fe fait en grande cérémonie, eft fuivie d'un Jeûne de huit jours, pendant lefquels il n'eft pas même permis de boire une goutte d'Eau : \& je vous dirai en paffant, Madame, que ce que les Sauvages appellent jeûner, c'eft ne rien prendre du tout. Ce n'eft pas tout, malgré l'extrême foibleffe, qu'une fi exceffive abitinence ne fçauroit, ce femble, manquer de leur caufer, ils ne ceffent de chanter, tant que le jour dure. Ce Jeûne s'obferve pour obtenir des Efprits quils faffent connoître où l'on tronvera beaucoup d'Ours. Plufieurs même font bien davantage pour mériter cette faveur. On en a vû fe découper la Chair en plufieurs endroits du Corps pour fe rendre propices leurs Génies. Mais il eft bon de fçavoir qu'ils ne leur demandent point leur fecours, pour venir à bout de ces furieux Animaux, il leur fuffit de fçavoir où il y en a : comme Ajax ne demandoit point à Jupiter qu'il le rendît Victorieux de fes Ennemis, mais feulement affez de jour, pour achever de les vaincre.

Les Sauvages addreffent auffi pour le même fujet des Vœux aux Mânes des Bêtes, qu'ils ont tuées dans les Chaffes précédentes, \& comme ils ne font occupés que de cette penfée, tandis qu'ils veillent, il eft naturel que pendant leur fommeil, qui ne doit pas être bien profond avec des Eftomachs vuides, ils rêvent fouvent aux Ours. Mais ce n'eft pas encore affez pour les déterminer, il faut que tous, ou du moins le plus grand nombre, ayent vû des Ours dans le même Canton; \& le moyen que tous les rêves s'accordent fur cela ? Toutefois, pourvû qu'un habile Chaffeur ait cru voir en fonge deux ou trois fois de fuite des Ours dans un lieu marqué, foit complaifance, car rien n'eft plus complaifant que nos Sauvages, foit qu'à force d'en entendre parler, leur Cerveau creux en prenne enfin l'impreffion, tout le Monde y rêve bientôt, ou fait femblant d'y avoir rêvé, \& la réfolution eft prife d'aller de ce côté-là.

Le Jeûne fini , \& le lieu de la Chaffe arrêté, le Chef choifi pour le Parti de Chaffe donne à tous ceux, qui en doivent

I 72 I.

Mars.

De lachaff: de l'Ours. 
1721 . être, un grand Repas, \& perfonne n'oferoit s'y préfenter, fans Mars. avoir prís auparavant le Bain,c'cet-à-dire, fans s'être jetté dans la Riviere, quelque tems qu'il faffe, pourvû que la Riviere ne foir point glacée. Ce Feftin n'eft pas, comme beaucoup d'autres, où il faut tont manger: quoiqu'on ait lontems jeûné, \& peut-être par cette rairon, on y mange fobrement : celui, qui en fait les homneurs, ne touche à rien, \& toute fon occupation, tandis que les autres font à Table, eft de raconter fes anciennes proueffes à la Chaffe : de nouvelles invocations aux Mânes des défunts Ours terminent la Fête. On fe met enfuite en marche barbouillé de noir, équippé comme pour la Guerre, \& parmi les acclamations de tout le Village. Auffi la Chaffe n'eft-elle pas moins noble parmi ces Peuples, que la Guerre : l'Alliance d'un bon Chaffeur eft même plus recherchée, que celle d'un Guerrier fameux, parce que la Chaffe fournit à toute la Famille la Vie \& le Vêtement, \& que les Sauvages ne fouhaittent rien au-delà. Mais un Homme n'eft pas réputé grand Chaffeur, s'il ne tuë douze grandes Bêtes en un jour.

Ces Peuples ont pour cet Exercice deux grands avantages fur nous : car en premier lieu, rien ne les arrête, ni Buiffons, niFoffés, ni Ravines, ni Etangs, ni Rivieres. Ils vont toujours devant eux, par la ligne la plus droite. En fecond lieu, il eft peu, ou plutôt il n'eft point d'Animaux, qu'ils ne gagnent à la courfe. On en a vû arriver dans un Village conduifant avec une Houffine des Ours, qu'ils avoient laffés, comme ils auroient mené un Troupeau de Moutons; \& le Cerf le plus agile ne l'eft pas plus qu'eux. Au refte le Chaffeur doit profiter peu pour lui-même de fa Chaffe. Il eft obligé d'en faire de grandes libéralités. Si on le prévient, \& qu'on la lui enleve, il faut qu'il fe laiffe dépouiller fans rien dire, \& qu'il fe contente de la gloire d'avoir travaillé pour le Public. On ne trouve pourtant pas mauvais que dans la difribution, qu'il fait du produit de fa Chaffe, fa Famille foit partagée la premiere. Mais il faut avoüer que ceux, avec qui nous avons plus de commerce, ont déja un peu perdu de cette antique générofité, \& de cet admirable défintéreffement. Rien n'eft plus contagieux, que l'efprit d'intérêt, $\&$ rien n'eft plus capable d'altérer les mœurs.

L'Ours paffe Le tems de la Chaffe de l'Ours eft l'Hyver. Alors ces Animanger. 
D'UN VOYAGE DE L'A MER I Q. LET. VI. II maux font cachés dans des creux d'Arbres; ou, s'ils en trouvent d'abattus, ils fe font de leurs Racines une Taniere, dont ils bouchent l'entrée avec des Branches de Sapin , \& où ils font parfaitement à l'abri des rigueurs de la Saifon. Si tout Mars. cela leur manque, ils font un Trou en Terre, \& ont grand foin, quand ils y font entrés, d'en bien fermer l'ouverture. On en a vû, qui s'étoient cantonnés dans le fond d'une Caverne, de maniere à n'être pas apperçus, quoiqu'on y regardât de bien près. Mais de quelque maniere qu'un Ours foit logé , il ne fort point de fa retraite de tout IHyver: c'eft ce qui n'eft plus révoqué en doute. On n'eft pas moins affûré qu'il n'y porte aucune provifion, \& par conféquent que pendant tout ce tems-là il ne boit, ni ne mange; qu'il tire alors de fes Pattes, en les lêchant, une fubftance, qui le nourrit, comme quelques-uns l'ont avancé : c'eft fur quoi ii eft permis à chacun de croire ce qu'il voudra. Ce qui eft certain, c'eft qu'on en a tenu à la Chaine pendant tout un Hyver, fans leur donner ni à boire, ni à mạnger, \& qu'au bout de fix mois ils étoient auffi gras qu'auparavant. Il eft fans doute affez furprenant qu'un Animal pourvu d'une fi bonne Fourrure, \& qui n'a point la mine d'être bien délicat, prenne contre le Froid des précautions, dont aucun autre que lui ne s'avife. Cela montre qu'il ne faut pas juger fur les apparences : chacun fent fes befoins.

Il n'eft donc pas néceffaire de courir beaucoup pour attraper les Ours ; il n'eft queftion que de reconnoître les endroits, où il $\mathrm{y}$ en a un plus grand nombre de cachés. Dès que les Chaffeurs croyent en avoir trouvé quelqu'un, ils forment un grand cercle d'un quart de lieuë de circonférence, plus ou moins, fuivant le nombre des Chaffeurs. On avance enfuite en fe refferrant toujours, \& chacun cherche devant foi s'il ne découvrira point la retraite de quelques Ours. De cette maniere, s'il y en a, il eft difficile quil en échappe aucun; car nos Sauvages font d'excellens Furêts. Le lendemain la même manœuvre recommence à quelque diftance de-là , \& tout le tems de la Chaffe s'employe de cette forte.

Dès qu'un Ours eft tué, le Chaffeur lui met entre les Dents Cérémonietile Tuyau de fa Pipe allumée, foufle dans le Fourneau, \& dicule, qui fe rempliffant ainfi de Fumée la Gueule \& le Gofier de fa Bête, pratiquequand il conjure fon Efprit de n'avoir aucun reffentiment de ce, on a tué un

dont fe faic cet: te Chaffe.

Manicie, 


\section{I18 J O URNAL H IS T OR I Q U E}

Mars. l'Efprit ne répond point, le Chaffeur ; pour fçavoir fi fa priere a été exaucée, coupe le Filet, qui eft fous la Langue de l'Ours, \& le garde jufqu’à ce qu'il foit de retour au Village. Alors tous jettent en grande cérémonie, \& après bien des invocations, ces Filets dans le Feu. Sils y pétillent, \& fe retirent, comme il ne peut guéres manquer d'arriver, cela eft pris pour une marque certaine que les Efprits des Ours font appaifés : finon, on fe perfuade qu'ils font irrités, \& que la Chaffe de l'année fuivante ne fera pas heureufe, à moins qu'on ne trouve le fecret de fe les réconcilier : car enfin il y a remede à tout.

Les Chaffeurs font bonne chere, tant que dure la Chaffe, Réception, \& pour peu qu'elle ait réuffi, ils emportent encore avec eux aux Chaffeurs de quoi régaler leurs Amis, \& nourrir lontems leurs Familles. à leur retour.

Ce n'eft pas à la vérité un grand ragoût que cette Viande boucanée, mais tout eft bon pour des Sauvages. A voir la réception, qu'on leur fait; les louanges, qu'on leur donne; l'air content \& fuffifant, qu'ils prennent, vous diriez qu'ils reviennent de quelque grande Expédition, chargés des dépouilles de toute une Nation détruite. Il faut être Homme, leur dit-on, \& difent-ils fans façon eux-mêmes, pour combattre \& pour vaincre ainfi les Ours. Une autre chofe, qui ne leur attire pas de moindres éloges, \& dont ils ne tirent pas moins de vanité, c'eft de ne rien laiffer du grand Repas, que leur donne encore au retour de la Chaffe celui, qui y a commandé. On y préfente, pour premier Service, le plus grand Ours, qui ait été pris, \& on le fert tout entier avec fes Entrailles : il n'eft pas même écorché; on s'eft contenté de lui griller la Peau, comme on fait aux Porcs. Ce Feftin eft voué à je ne fçai quel Génie, dont on croiroit s'attirer l'indignation, fi on ne mangeoit pas tout. Il ne faut même rien laiffer du Bouillon, où les Viandes ont été cuites, \& qui n'eft guéres qu'une Graiffe fonduë, \& réduite en Huile. Rien n'eft plus mauvais : auffi y a-t'il toujours quelqu'un, qui en créve, \& plufieurs en font fort incommodés.

Qnelquespar- Les Ours ne font méchants, en ce Pays, que quand ils ont sicularités fur faim, ou quand ils ont été bleffés. On prend néanmoins toutes Qurs. joursfes précautions, quand on les approche. Rarement ils 
D'UN V OYA GE DE L'A MERIQ. Let. VI. II9 attaquent; ils fuyent même, dès qu'ils voyent quelqu'un ; $\& x$ il ne faut qu'un Chien pour les faire courir bien toin. S'ils font donc partout comme en Canada, on auroit pû répondre à la demande de M. Defpreaux, que c'eft l'Ours, qui a peur du Paffant, \& non le Paffant de l'Ours. Au mois de Juillet, l'Ours eft en rut. Il devient alors fi maigre, fa chair eft fi fade, \& d'un fi mauvais goût, que les Sauvages mêmes, eux qui mangent fouvent des chofes, qui nous feroient bondir le cœur, ont de la peine à y toucher. Qui le croiroit, que cette paffion maigrit plus en un mois un Animal de cette efpece $\&$ de cette figure, que ne fait une abftinence totale de fix mois! Il eft moins furprenant qu'il foit alors fi farouche $\&$ de fi mauvaife humeur, quil ne fait pas bon de fe rencontrer fur fon chemin. C'eft un effet de fa jaloufie.

Ce tems-là paffé, il reprend fon embonpoint, \& rien n'y contribuë davantage, que les fruits, qu'il trouve partout dans les Bois, \& dont il eft extrêmement friand. Il aime furtout le Raifin; \& comme toutes les Forêts font remplies de Vignes, qui s'élevent jufqu'à la cime des plus hauts Arbres, il ne fait aucune difficulté d'y grimper. Mais fi un Chaffeur l'y apperçoit, $f$ a friandife lui coûte la vie. Quand il a ainfi bien mangé des fruits, fa chair a un très-bon goût, \& elle le conferve jufqu'au Printems. Elle a néanmoins toujours un grand défaut ; elle eft trop huileufe, \& fi on n'en ufe pas modérément, elle donne la dyfenterie. A cela près, elle eft nourriffante; $\&$ un petit Ourfon vaut bien un Agneau.

J'oubliois, Madame, de vous dire que les Sauvages menent toujours à leurs Chaffes un grand nombre de Chiens; ce font les feuls Animaux domeftiques, qu'ils élevent; \& ils ne les élevent, que pour la Chaffe. Tous paroiffent de la même efpece : ils ont les oreilles droites, \& le mufeau allongé à peu près comme les Loups : mais ils font fort fidéles, \& fort attachés à leurs Maîtres, qui les nourriffent pourtant affez mal, \& ne les careffent jamais. On les dreffe de très-bonneheure à l'efpece de Chaffe, à laquelle on les deftine, \& ils font excellents Chaffeurs. Je n'ai pas le tems de vous en dire davantage, parce qu'on m'appelle pour m'embarquer.

Je fuis, \& c.

1721 .

Mars.

Des Chiens de Chaffe des Sauvages, 
$172 \mathrm{I}$.

Mars.

\section{SEPTIÉM E LET TRE.}

Defcription du Pays E des Ifles de Richelieu E de Saint Francois. Du Village Abénaqui. De l'Ancien Fort de Richelieu, $\mathcal{E}$ de ceux, qu'on avoit conftruits dans chaque Paroiffe. Belles Ations de deux Dames Canadiennes. Des autres Chaffes des Sauvages.

A Saint François, l'onziéme de Mars, 1721.

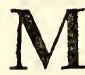

\section{A D A ME,}

$\mathrm{J}_{\mathrm{E}}$ partis le neuf des Trois Rivieres. Je ne fis que traverfer le Lac de S. Pierre, en tirant au Sud; je fis ce Voyage en Carriole, parce que la Glace étoit encore affez forte pour toutes fortes de Voitures; \& jarrivai vers le midi à $S$. François. J'employai l'après-dîné \& toute la journée d'hier à vifiter ce Canton, \& je vais vous rendre compte de ce que jy ai obfervé.

Des Ifles de Richelieu \& de Saint François.

A l'extrêmité Occidentale dú Lac de S. Pierre, il y a un nombre prodigieux d'Ifles de toutes grandeurs, qu'on appelle les Ifles de Richelieu; \& en tournant fur la gauche, quand on vient de $Q$ uebec, on en trouve fix autres, qui bordent une Ance affez profonde, dans laquelle fe décharge une jolie Riviere, dont la Source eft au voifinage de la Nouvelle York. Les Ifles, la Riviere, \& tout le Pays, qu'elle arrofe, portent le nom de $S$. François. Chacune des Ifles a plus d'un grand quart de lieuë de long; leur largeur eft inégale : la plûpart de celles de Richelieu font plus petites. Toutes étoient autrefois remplies de Cerfs, de Daims, de Chevreuils \& d'Orignaux; le Gibier y foifonnoit d'une maniere étonnante, \& n'y eft pas encore trop rare; mais les grandes Bêtes ont difparu.

On pêche auffi d'excellents Poiffons dans la Riviere de S. François \& à fon Embouchure. L'Hyver on fait des trous dans la Glace, on y paffe des Filets de cinq ou fix braffes de long, \& on ne les retire guéres à vuide. Les Poiffons, qu'on 
D'UN V OYA GE DE L'A MER I Q. LET. VII. I 2 I Y prend plus communément, font les Bars, les Poiffons dorés, les Achigans, \& fur-tout les Mafquinongez; efpece de Brochets, qui ont la Tête plus groffe, que les nôtres, \& la 1721 . Mars. Bouche fous un Mufeau recourbé, ce qui leur donne une figure affez finguliere. Les Terres de $S$. François, à en juger par les Arbres, qu'elles portent, \& par le peu, qu'on en a déja cultivé, font fort bonnes. Les Habitans y font néanmoins affez pauvres , \& plufieurs feroient réduits à la derniere indigence, fi le Commerce avec les Sauvages, leurs Voifins, ne les foûtenoit un peu. Mais ne feroit-ce pas ce Commerce-là même, qui les empêcheroit d'être plus à leur aife, en les rendant fainéans?

Les Sauvages, dont je parle, font des Abénaquis, parmi lefquels il y a quelques Algonquins, des Sokokis \& des Mahingans, plus connus fous le nom de Loups. Cette Nation étoit autrefois établie fur la Riviere de Manhatte, dans la Nouvelle York, \& il paroît qu'ils en font originaires. Les Abénaquis font venus à $\mathrm{S}$. Françoịs des Côtes Méridionnales de la Nouvelle France, les plus proches de la Nouvelle Angleterre. Leur premiere Station, en quittant leur Pays, pour venir demeurer parmi nous, fut une petite Riviere, qui fe décharge dans le Fleuve Saint Laurent, prelque vis-à-vis de Sylleri; c'eft-à-dire, environ une lieuë \& demie au-deffus de Quebec, du côté du Midi. Ils y étoient placés aux environs d'une chute d'Eau, qu'on nomme le Sault de la Chaudiere. Ils font préfentement fur le bord de la Riviere de Saint François, à deux lieuës de fon Embouchure, dans le Lac de Saint Pierre. L'endroir eft fort agréable, \& c'eft dommage : ces Peuples ne goûtent pas les agrémens d'une belle fituation, \& des Cabannes de Sauvages, fur-tout d'Abénaquis, n'embellifient pas un Pays. Le Village eft nombreux, \& n'eft habité, que par des Chrétiens. Cette Nation eft docile, \& de tout tems affectionnée aux François : mais le Miffionnaire (a) n'a pas de moindres inquiétudes à leur fujet, que fon Confrere de Beckancourt. Les raifons en font les mêmes.

On me régale ici d'Eau d'Erable : c'eft la faifon, où elle Du Suc d'Fcoule. Elle ełt délicieufe, d'une fraîcheur admirable, \& fort rable. faine. La maniere de la tirer eft fort fimple. Lorfque la Séve commence à monter aux Arbres, on fait une entallle dans le - (a) Le Pere Jofeph Aubery.

Tome III.

Q 
Tronc de l'Erable, \& par le moyen d'un morceau de bois ; Mars. qu'on y infére, fur lequel l'Eau coule, comme fur une Gouttiere, cette Eau eft reçûë dans un Vaiffeau, qu'on met deffous. Pour qu'elle coule avec abondance, il faut qu'il y ait beaucoup de Néges fur la Terre, qu'il ait gelé pendant la nuit, que le Ciel foit ferein, \& que le Vent ne foit pas trop froid. Nos Erables auroient peut-être la même vertu, fi nous avions en France autant de Néges qu'en Canada, \& fi elles y duroient auffi lontems. A mefure que la Séve s'épaiflit, elle coule moins, \& $x$ au bout de quelques tems, elle s'arrête toutà-fait. Il eft aifé du juger qu'après une telle Saignée, l'Arbre ne s'en porte pas mieux; on affure cependant, qu'il la peut fouffrir plufieurs années de fuite. On feroit peut-être mieux. de les faire repofer un ou deux ans, pour lui laiffer le tems de reprendre fes forces. Mais enfin, quand il eft épuifé, on en eft quitte pour le couper, \& fon Bois, fes Racines, fes Nœuds font propres à bien des chofes. Il faut que cet Arbre foit iç bien commun, car on en brûle beaucoup.

L'Eau d'Erable eft affez claire, quoiqu'un peu blanchâtre : elle eft extrêmement rafraîchiffante, \& laiffe dans la Bouche un petit goût de Sucre fort agréable. Elle eft fort amie de la Poitrine ; \& en quelque quantité, qu'on en boive, quelqu'échauffé que l'on foit, elle ne fait point de mal. C'eft qu'elle n'a point cette crudité, qui caufe la Pleuréfie; mais au contraire, une vertu balfamique, qui adoucit le Sang, \& un certain Sel, qui en entretient la chaleur. On ajoûte, qu'elle ne fe criftalife jamais; mais que fi on la garde un certain tems, elle devient un excellent Vinaigre. Je ne garantis point ce fait , \& je fçai qu'un Voyageur ne doit point adoptere indifféremment tout ce qu'on lui dit.

Il y a bien de lapparence que les Sauvages, qui connoiffent fort bien toutes les vertus de leurs Plantes, ont fait de tout tems de cette Eau l'ufage, qu'ils en font encore aujourd'hui; mais il eft certain qu'ils ne fçavoient pas en former le Sucre, comme nous leur avons appris à le faire. Ils fe contentoient de lui donner deux ou trois Bouillons, pour l'épaiffir un peu, \& en faire une efpece de Sirop, qui eft affez agréable. La façon, qu'on y ajoûte, pour en faire du Sucre, eft de la laiffer bouillir, jufqu'à ce qu'elle prenne une confiftance fuffifante, \& elle fe purifie d'elle-même, fans qu'on y mêle 
D'U N V OYA G E DE L'A MER IQ. LET. VII. I23 tien d'étranger. Il faut feulement avoir foin de ne pas trop faire cuire le Sucre, \& de le bien écumer. La plus grande faute, qu'on y fait, c'eft de le laiffer trop durcir dans fon Sirop, c'eft ce qui fait quil eft trop gras, \& qu'il conferve toujours un goût de Miel, qui le rend moins agréable au goût, à moins quili ne foit purifié.

Ce Sucre fait avec attention, \& il en demande beaucoup moins que le nôtre, eft naturel, pectoral, ne brûle point l'eftomach. Outre que la façon en eft d'une très-petite dépenfe, on penfe affez communément qu'il eft impoffible de le rafiner, comme celui, qu'on tire des Cannes. Je n'en vois point la raifon, \& il eft certain qu'au fortir des mains des Sauvages, il eft plus pur, \& beaucoup meilleur, que celui des Ifles, qui n'a pas reçû plus de façoṇs. Enfin, j'en ai donné à fondre à un Rafineur d'Orleans, qui n'y a trouvé d'autre défaut, que celui que j'ai déja remarqué, \& qu'il attribuoit uniquement à ce quil n'avoit pås été fuffifamment égouté. Il le croyoit même de meilleure qualité que l'autre, $\&$ il en fit des Tablettes que j'ai eu l'honneur de vous préfenter, \& que vous trouvâtes, Madame, fi excellentes. On objectera que s'il étoit d'une bonne nature, on l'auroit fait entrer dans le Commerce : mais on n'en fait pas affez pour que cela devienne un objet, \& peutêtre a-t-on tort; il y a bien d'autres chofes, que l'on néglige dans ce Pays-ci.

Le Plane, qu'on appelle ici Plaine, le Merifier, le Frêne, $\&$ les Noyers de differentes efpeces, donnent auffi de l'Eau, dont on fait du Sucre : mais elle rend moins, \& le Sucre n'en eft pas fi bon. Quelques-uns néanmoins donnent la préference à celui, qui fe tire du Frêne; mais on en fait fort peu. Auriez-vous cru, Madame, qu'on trouve en Canada ce que Virgile dit en prédifant le renouvellement du fiécle d'Or, que le Miel couleroit des Arbres (a)?

Tout ce Pays a été lontems le Théatre de bien des Scenes fanglantes, parce que pendant la Guerre des Iroquois, il étoit Du Fort de Richelieu. le plus exporéa aux incurfions de ces Barbares. Ils defcendoient dans la Colonie pár une Riviere, qui fe décharge dans le Fleuve de Saint Laurent, un peu au-deffus du Lac de Saint Pierre, du même côté que celle de Saint François, \& à laquelle pour cette raifon, on avoit d'abord donné leur nom:

(a) Et dura'Quercus fudabunt rofrida Molla?

$Q$ ij 
1721 .

Mars.

Autres Forts duns toutes ces laroifles.
Belles Actions d'une $\mathrm{Da}$ me \& d'une Demoifelle Canadiennes.

elle a porté depuis quelque tems celui de Richelieu, \& on la nomme préfentement la Riviere de Sorel. Les Ifles de Richelieu, qu'ils rencontroient d'abord, leur fervoient également, \& pour les Embufcades, \& pour la Retraite; mais quand on leur eut fermé ce Paflage par un Fort, qu'on bâtit à l'entrée de la Riviere, ils prirent leur chemin par les Terres au-deffus \& au - deffous , \& fe jetterent fur - tout du côté de Saint Franıçois, où ils trouvoient les mêmes commodités pour exercer leurs brigandages, \& ils y ont commis des cruautés, dont le récit feroit horreur.

Ils fe répandoient de-là dans toute la Colonie, \& il fallut, pour fe garantir de leur fureur, conftruire fur chaque Paroiffe des efpeces de Forts, où les Habitans puffent fe réfugier à la premiere allarme. On y entretenoit nuit \& jour un ou deux Factionnaires, \& tous avoient quelques Pieces de Campagne, ou tout au moins quelques Pierriers, tant pour écarter l'Ennemi, que pour avertir les Habitans d'être fur leurs gardes, ou pour demander du fecours. Ces Forts n'étoient que de grands Enclos fermés de Paliffades, avec quelques Redoutes : I'Eglife \& la Maifon du Seigneur y étoient renfermées, \& il $y$ avoit encore affez d'efpace, pour y retirer, en cas de befoin, les Femmes, les Enfans, \& les Beftiaux. C'en étoit affez pour fe mettre hors d'infulte, \& je ne fçache pas que les Iroquois ayent jamais pris aucun de ces Forts.

Ils fe font même rarement arrêtés à les tenir bloqués, plus rarement encore les ont-ils attaqués à force ouverte. L'un eft trop périlleux pour des Sauvages, qui n'ont aucune arme défenfive, \& n'aiment point une Victoire teinte de leur Sang. L'autre ne convient pas à leur maniere de faire la Guerre. Deux attaques du Fort deVercheres font néanmoins fameufes dans les faftes Canadiens, \& il femble que les Iroquois ne s'y foient attachés par deux fois, contre leur coûtume, que pour faire éclater la valeur \& l'intrépidité de deux Amazones.

En 1690 . ces Barbares ayant fçu que Madame de Vercheres étoit prefque feule dans fon Fort, s'en approcherent, fans être apperçus, \& fe mirent en devoir d'efcalader la Paliffade. Quelques coups de Fufil, qu'on tira fort à propos au premier bruit, qu'ils firent, les écarterent ; mais ils revinrent bientôt : ils furent encore repouffés, \& ce qui leur caufoit plus d'étonnement, c'eft qu'ils ne voyoịent qu'une Femme, $\&$ qu'ils la 
D'U N VOYA GE DE L'A MERIQ. LET. VII. I 25 voyoient par-tout. C'étoit Madame de Vercheres, qui fairoit paroître une contenance auffi affûrée, que fi elle avoit eu une nombreufe Garnifon. L'efperance, que les Affiegeans avoient conçuë d'abord, d'avoir bon marché d'une Place, qu'ils fçavoient être dégarnie d'Hommes, les fit retourner plufieurs fois à la charge; mais la Dame les écarta toujours. Elle fe battit de la forte pendant deux jours, avec une bravoure $\&$ une préfence d'Efprit, qui auroient fait honneur à un vieux Guerrier; \& elle contraignit enfin l'Ennemi de fe retirer, de peur d'être coupé, bien honteux d'être obligé de fuir devant une Femme.

Deux ans après, un autre Parti de la même Nation, beaucoup plus nombreux, que le premier, parut à la vîë du même Fort, tandis que tous les Habitans étoient dehors, \& la plûpart occupés dans la Campagne. Les Iroquois les trouvant ainfi difperfés \& fans défiance, les faifirent tous les uns après les autres, \& marcherent enfuite vers le Fort. La Fille duSeigneur, âgée de quatorze ans au plus, en étoit à deux cens pas. Au premier cri, qu'elle entendit, elle courut pour y rentrer : les Sauvages la pourfuivirent, \& l'un d'eux la joignit, dans le tems, qu'elle mettoit le pied fur la Porte; mais l'ayant faifie par un Mouchoir, qu'elle avoit au $\mathrm{Col}$, elle le détacha, \& ferma la Porte fur elle.

Il ne fe trouva dans le Fort, qu'un jeune Soldat, \& une Troupe de Femmes, qui, à la vûë de leurs Maris, qu'on garrotoit, \& qu'on emmenoit Prifonniers, jettoient des cris lamentables : la jeune Demoifelle ne perdit ni le jugement, ni le cœur. Elle commença par ôter fa Coëffure, elle noua fes Cheveux, prit un Chapeau, \& un Jufte-au-Corps, enferma fous la clef toutes ces Femmes, dont les gémiffemens $\&$ les pleurs ne pouvoient qu'infpirer du courage à l'Ennemi ; puis elle tira un coup de Canon, \& quelques coups de Fufil, $\&$ fe montrant avec fon Soldat, tantôt dans une Redoute, $\&$ tantôt dans une autre, changeant de tems en tems d'iliabit, \& tirant toujours fort à propos, dès qu'elle voyoit les Iroquois s'approcher de la Paliffade, ces Sauvages fe perfuaderent qu'il y avoit beaucoup de Monde dans le Fort; \& lorfque le Chevalier de Crifafy, averti par le coup de Canon, parut pour fecourir la Place, l'Ennemi avoit déja levé lé Camp. 
I 721 .

Mars. moins avantageufe aujourd'hui pour nous, que celle du Caf-

De l'Elan ou tor, fi ceux, qui nous ont précédés en ce Pays, avoient fait Orignal. plus d'attention aux profits, qu'on en pouvoit tirer, \& n'en avoient pas prefqu'entierement détruit l'Efpece, au moins dans les endroits, qui font à portée de nous.

Defcription Ce qu'on appelle ici Orignal, c'eft ce qu'en Allemagne, ae l'Orignal. en Pologne \& en Mofcovie on nomme Elan, ou la Grand'Bête. Cet Animal eft ici de la groffeur d'un Cheval, ou d'un Mulet d'Auvergne. Il a la Crouppe large, une Queuë de la longueur d'un Doit feulement, le Jarret fort haut s des Jambes \& des Pieds de Cerf; un long Poil lui couvre le Garrot, le Col, \& le haut du Jarret. Sa Tête a plus de deux pieds de long, \& il la porte de longueur, ce qui lui donne un mauvais air. Son Mufle eft gros \& rabbatu par-deffus à peu près comme celui du Chameau ; \& fes Nafeaux font fi grands, qu'on y peut aifément fourrer la moitié du Bras. Enfin fon Bois n'eft guéres moins long, que celui du Cerf, \& il eft beaucoup plus large; il eft plat \& fourchu, comme celui du Daim, \& il fe renouvelle tous les ans; mais je ne fçai, fi en fe renouvellant, il prend un accroiffement, qui marque les années de l'Animal.

On prétend que l'Orignal eft fujet à l'Epilepfie, \& q que quand fes accés le prennent, il les fait paffer en fe grattant l'Oreille de fon Pied gauche de derriere, jufqu'à en tirer du Sang; ce qui a fait regarder la Corne de ce Pied, comme un Spécifique contre le Haut-Mal. On l'applique fur le Cœur du Malade, \& on fait la même chofe pour la Palpitation : on la lui met dans la Main gauche, $\&$ on lui en trotte l'Oreille. Mais pourquoi ne lui en pas tirer du Sang, comme fait l'Orignal ? On juge auffi cette Corne très-bonne contre la Pleuréfie, les Douleurs de Colique, le Cours de Ventre, les Vertiges \& le Pourpre, en la pulvérifant, \& la faifant boire dans de l'Eau. J'ai oui dire que les Algonquins, qui faifoient autrefois leur nourriture ordinaire de la Chair de cet Animal, étoient fort fujets à l'Epilepfie, \& n'ufoient point de ce reméde. Ils en avoient, peut-être, de meilleurs.

Le Poil de l'Orignal eft mêlé dè gris-blanc, \& de rougenoir. Il devient creux, quand la Bête vieillit, ne fe foule pas, \& ne perd jamais fa Vertu élaftique : ainfi on a beau le 
D'UN VOYAGE DE L'A MER IQ. LET. VII. I 27 battre, il fe redreffe toujours. On en fait des Matelats \& des Selles de Chevaux. Sa Chair eft d'un très-bon goût, legere, \& nourriffante ; ce feroit dommage qu'elle donnât le Hautmal; mais nos Chaffeurs, qui en ont vécu des Hyvers entiers, ne fe font point apperçus qu'elle eût aucune mauvaife qualité. Sa Peau eft forte, douce, moëleufe : elle fe paffe en Chamois, \& fait d'excellens Bufles, qui péfent très-peu.

Les Sauvages regardent l'Orignal comme un Animal de bon augure, \& fe perfuadent que ceux, qui y rêvent fréquemment, peuvent fe flatter d'une longue vie: C'eft tout le contraire pour les Ours, excepté le tems, où l'on fe difpofe à la Chaffe de ces Animaux. Il court auffi parmi ces Barbares une affez plaifante tradition d'un grand Orignal, auprès duquel les autres paroiffent des Fourmis. Il a, difent-ils, les Jambes fi hautes, que huit pieds de Nége ne l'embarraffent point : fa Peau eft à l'épreuve de toutes fortes d'Armes, \& il a une maniere de Bras, qui lui fort de l'Epaule, \& dont il fe fert, comme nous faifons des nôtres. Il ne manque jamais d'avoir à fa fuite un grand nombre d'Orignaux, qui forment fa Cour, \& qui lui rendent tous les fervices, qu'il exige d'eux. C'eft ainfi que les Anciens avoient leur Phénix \& leur Pégafe ; \& que les Chinois \& les Japonnois ont leur Kirin, leur Foë, leur Dragon d'Eau, \& leur Oifeau de Paradis. Tutto' l Mondo e Paefe.

L'Orignal aime les Pays froids : il broutte l'Herbe en Eté, \& l'Hyver il ronge les Arbres. Quand les Néges font hautes, ces Animaux s'affemblent en troupe dans quelque Piniere, pour fe mettre fous la verdure à couvert du mauvais tems, \& ils y demeurent tant qu'ils y trouvent à manger. C'eft alors qu'il eft aifé de leur donner la Chaffe, mais plus encore, quand le Soleil commence d'avoir affez de force, pour fondre la Nége : car la Gelée de la nuit faifant comme une Croute fur la fuperficie de cette Nége fonduë pendant le jour, l'Orignal, qui eft pefant, la caffe avec fon Pied fourchu, s'écorche la Jambe, \& a de la peine à fe tirer des trous, qu'il s'eft creufés. Hors de-là, \& $\&$ furtout quand il y a peu de Néges, on ne l'approche pas de près fans peine, ni fans danger, parce que, quand il eft bleffé, il eft furicux, retourne brufquement fur le Chaffeur, \& le foule aux pieds. Le moyen de l'éviter, eft de lui jetter fon Habit, fur lequel il décharge fas

1721 . Mars.
En quel terms il faut chaffert l'Orignal. 


\section{J O UR N A L H I S T O R I Q U E}

1721 . colere, tandis que le Chaffeur caché derriere un Arbre peut Mars. prendre toutes fes mefures pour l'achever. L'Orignal va toujours un grand trot, qui égale prefque la courfe du Bœuf Sauvage, \& ille foûtient très-lontems : mais les Sauvages courent encore mieux que lui. On prétend qu'il fe met à genoux pour boire, pour manger, \& pour fe coucher, \& qu'il a dans le Cœur un petit Os, lequel, réduit en Poudre, \& pris dans du Bouilion, facilite les Couches, \& appaife les douleurs de l'Enfantement.

Diverfes ma-

Les Nations les plus Septentrionnales du Canada ont une nieres de le maniere de faire cette Chaffe, qui eft fort fimple \& fans auchafter. cun rifque. Les Chaffeurs fe divifent en deux Bandes; l'une s'embarque dans des Canots, \& ces Canots fe tenant à quelque diftance les uns des autres, ils forment un demi cercle affez. grand, dont les deux bouts touchent le Rivage. L'autre Bande, qui eft reftée à Terre, y fait à peu près la même manœuvre, $\&$ embraffe d'abord un grand Terrein; alors ces Chaffeurs lâchent leurs Chiens, \& font lever tous les Orignaux, qui font renfermés dans cet efpace, les pouffent toujours en avant, \& les obligent de fe jetter dans la Riviere, ou dans le Lac; ils n'y font pas plutôt entrés, qu'on tire dẹfus de tous les Canots : tous les coups portent, \& il eft rare qu'il en échape un feul.

Champlain parle d'une autre maniere de chaffer, nonfeulement les Orignaux, mais encore les Cerfs \& les Caribous, laquelle a quelque rapport à celle-ci. On enferme, dit-il, un efpace de Forêt avec des Pieux entrelaffés de Brạnches d'Arbres, \& on n'y laiffe qu'une ouverture affez étroite, où l'on tend des Laffets de Peaux cruës. Cet efpace eft de forme triangulaire, $\&$ de l'angle, où eft l'entrée, on tire un autre triangle beaucoup plus grand. Ainfices deux Enclos ont communication l'un dans l'autre par ces deux angles. Les deux côtés du fecond triangle font auffi fermés de Pieux, \& les Chaffeurs rangés fur une ligne, en font la bafe. Ils avancent enfuite, fans rompre la ligne, \& en fe rapprochant toujours les uns des autres, ils jettent de grands cris, \& frappent fur je ne fçai quoi, qui raifonne beaucoup : les Bêtes chaffées d'une part, \& ne pouvant échaper, ni à droite, ni à gauche, étourdies d'ailleurs \& épouvantées par le bruit, ne fçauroient fuir, que dans l'autre Enclos, \& plufieurs, en y entrant, 
D'UN VOYA GE DE L'A MER I Q. LET. VII. I 29 fe trouvent prifes par le Col,ou par leurs Cornes. Elles font de grands efforts pour fe débarraffer, \& quelquefois elles emportent, oubrifent les Lacets; quelquefois auffi elles s'étran$172 \mathrm{I}$. Mars. glent, ou du moins donnent aux Chaffeurs le tems de les tirer à leur aife. Celles mêmes, qui s'échappent, n'en font guéres plus avancées, elles fe trouvent renfermeés dans un trop petit efpace, pour éviter les Fleches, qu'on décoche de toutes parts contre elles.

L'Orignal a d'autres Ennemis, que les Sauvages, \& qui ne lui font pas une moins rude guerre. Le plus terrible de tous eft le Carcajou, ou Quincajou, efpece de Chat, dont la Queuë eft fi longue, quil en fait plufieurs tours fur fon Corps, \& d'un Poil roux-brun. Dès que ce Chaffeur peut joindre un Orignal, il faute deffus, \& s'attache à fon Col, qu'il entoure de fa longue Queuë, après quoi il lui coupe la Veine jugulaire. L'Orignal n'a qu'un moyen d'éviter ce malheur, c'eft de fe jetter à l'Eau, dès qu'il fe voit faifi par cet Ennemi dangereux. Le Carcajou, qui ne peut fouffrir l'Eau, lâche prife fur le champ. Mais fi l'Eau eft trop loin, il a le tems de faire perir l'Orignal, avant qu'il puiffe y arriver. Ordinairement le Chaffeur, qui n'a pas l'Odorat des plus fins, mene trois Renards à cette Chaffe, \& les envoye à la découverte. Dès quilis ont éventé un Orignal, deux vont fe ranger à fes côtés, le troifiéme fe place derriere lui, \& tous trois manœuvrent fi bien, en harcelant la Bête, qu'ils l'obligent d'aller, où ils ont laiffé le Carcajou, avec lequel ils s'accommodent enfuite pour le partage du Gibier. Une autre rufe du Carcajou pour atraper fa Proye, eft de grimper fur un Arbre : là, couché de fon long fur une Branche avancée, il attend qu'il paffe un Orignal, \& faute deffus, dès qu'il le voit à fa portée. Bien des Gens, Madame, fe font mis dans l'efprit que les Relations du Canada donnent aux Sauvages plus d'efprit, qu'ils n'en ont. Ce font pourtant des Hommes : fous quel Climat trouvera-t'on des Brutes, qui ayent l'inftinct plus induftrieux, que le Caftor, le Carcajou \& le Renard?

Le Cerf en Canada eft abfolument le même, qu'en France, peut-être communément un peu plus grand. Il ne paroit pas Du Ceif \& que les Sauvages l'inquietent beaucoup. Je ne trouve pas du moins qu'ils lui faffent la guerre dans les formes, \& avec ap.pareil. Il n'en eft pas de même du Caribou. C'eft un Animal un Tome III. $\mathrm{R}$

Comment le Carcajou leur donnelaChalfe. 


\section{$130 \mathrm{~J} O \mathrm{U} R \mathrm{~N}$ A L H IS T OR I Q U E}

$172 \mathrm{I}$. peu moins haut que l'Orignal, qui tient plus de l'A fne, que dix

Mars. Mulet pour la figure, \& qui égale pour le moins le Cerf en agilité. Il y a quelques années, qu'il en parut un fur le Cap aux Diamans, au-deffus de Quebec ; il fuyoit apparemment des Chaffeurs, mais il s'apperçut bientôt qu'il n'etoit pas en lieu fûr, \& il ne fit prefqu'un faut de-là dans le Fleuve. C'eft tout ce qu'auroit pu faire un Chamois dans les Alpes. Il pailla enfuite le Fleuve à la nâge avec la même célérité, mais il n'y gagna rien. Des Canadiens, qui alloient en Guerre, \& qui étoient campés vers la Pointe de Levi, l'ayant apperçu, l'attendirent à fon débarquement, \& le tuerent. On eftime fort la Langue de cet Animal, dont le vrai Pays paroît être aux environs de la Baye d'Hudfon. Le fieur Jéremie, qui a paffé plufieurs années dans ces Quartiers Septentrionnaux, dit qu'entre la Riviere Danoife \& le Port Nelfon pendant tout l'Eté il en paffe des quantités prodigieufes, qui, chaflés des Bois par les Maringoins \& les Tons, viennent fe rafraîchir au bord de la Mer, \& que dans l'efpace de quarante ou de cinquante lieuës on en rencontre continuellement des Troupeaux de dix mille au moins.

Il paroît que le Caribou n'a jamais beaucoup peuplé dans les lieux les plus fréquentés du Canada ; mais les Orignaux y étoient par-tout à foifon, lorfque nous découvrimes ce Pays; $\&$ ils pouvoient faire un objet pour le Commerce, \& une douceur pour la Vie, fi on les avoit mieux ménagés. C'eft ce qu'on n'a point fait ; $\&$ foit qu'à force d'en tuër, on en ait apauvri l'efpece; foit qu'en les effarouchant, on les ait obligés de fe retirer ailleurs, rien n'eft plus rare aujourd'hui.

De la Chaffe

Dans les Quartiers Méridionnaux \& Occidentaux de la du Rutuf, Nouvelle France, en deça \&x au-delà du Miciffipi, la Chaffe la plus célébre eft celle du Bøuf, \& voici de quelle maniere elle fe fait. Les Chaffeurs fe rangent fur quatre Lignes, qui fớrment un très-grand Quarré, \&z commencent par mettre le feu aux Herbes, qui font féches alors, \& fort hautes; puis, à mefure que le feu gagne, ils avancent en fe referrant. Les Bœufs, qui craignent extrêmement le feu, fuyent toujours, \& fe trouvent à la fin fi ferrés les uns contre les autres, qu'on les tuë ordinairement jufqu'au dernier. On prétend qu'il ne revient jamais un Parti de Chaffe, qui n'ait ainfi jetté par terre quinze cens ou deux mille Bœufs. Mais de peur que les 
D'UN VOYAGE DE L'A MER IQ. LET. VII. I3I différentes bandes de Chaffeurs ne fe nuifent les uns aux autres, tous conviennent auparavant de leur Marche, \& du Lieu, où ils chafferont. Il y a même des Peines ftatuées contre 1721 . Mars. les Tranfgreffeurs de ce Réglement, auffi-bien que contre ceux, qui en quittant leur Pofte, donnent moyen aux Bœufs d'échaper. Ces Peines confiftent en ce que chaque Particulier a droit de dépouiller les Coupables, de leur ôter jufqu’à leurs Armes, ce qui eft le plus grand affront, qu'on puiffe faire à un Sauvage, $8 x$ de brifer leurs Cabannes. Les Chefs y font foumis comme les autres; \& qui entreprendroit de les y fouftraire, s'expoferoit, dit-on, à fufciter une Guerre, qui ne finiroit pas fitôt.

Le Bœuf du Canada eft plus grand que le nôtre. Il a les Cornes baffes, noires, \& courtes; une grande Barbe de crin du Bouf saufous le Mufeau, \& autant fur la Tête, d'où elle lui tombe fur les Yeux, ce qui lui donne un air hideux. Il a fur le Dos une Boffe, qui commence fur les Hanches, \& va en augmentant jufques fur les Epaules. La premiere Côte de devant eft plus haute d'une coudée, que les autres au-deffus du Dos, \& large de trois Doits, \& toute la Boffe eft couverte d'un Poil un peu rouffàtre \& fort long; le refte du Corps l'eft d'une Laine noire, qui eft fort eftimée. On affûre que la dépouille d'un Bouf eft de huit livres de Laine. Cet Animal a le Poitrail fort large, la Croupe affez fine, la Queuë fort courte, $\&$ on ne lui voit prefque point de Cou; mais fa Tête eft plus groffe que celle des nôtres. Il fuit ordinairement, dès qu'il apperçoit quelqu'un, \& il ne faut qu'un Chien, pour faire prendre le galop à un Troupeau entier. Il a l'odorat fin, \& pour l'approcher, fans qu'il s'en apperçoive, d'affez près pour le tirer, il faut prendre le deffous du Vent. Mais quand il eft bleffé, il eft furieux \& fe retourne fur les Chạfeurs. Il n'eft pas beaucoup plus traitable, quand les Vaches ont des Veaux nouvellement nés. Sa Chair eft bonne, mais on ne mange guéres que celle des Vaches, parce que celle des Taureaux eft trop dure. Quant à fa Peau, on n'en connoît guéres de meilleure, elle fe paffe aifément, \& quoique très-forte, elle de-. vient fouple $\&$ moëleure comme le meilleur Chamois. Les Sauvages en font des Boucliers, qui font très-legers, \& que les Bales de Fufil ne percent pas aifément.

On trouve aux environs de la Baye d'Hudfon un autre Du Bea? $\mathrm{R}$ ij MLIqué。 
172 . Bœuf, dont le Cuir \& la Laine ont les mêmes avantages que Mars. ceux des Bœufs, dont je viens de parler. Voici ce qu'en dit "M. Jeremie : "A quinze lieuës de la Riviere Danoife fe " trouve la Riviere du Loup Marin , parce qu'effectivement il y " en a beaucoup dans cet endroit. Entre ces deux Rivieres, it " y a une efpece de Bœufs, que nous nommons Bceufs mufqués, " à caufe quils fentent fi fort le Mufc, que dans certaine Saifon, " il eft impoffible d'en manger. Ces Animaux ont de très-belle "Laine; elle eft plus longue, que celle des Moutons de Bar" barie. J'en avois apporté en France en 1 708. dont je m'étois "fait faire des Bas, qui étoient plus beaux que des Bas de "Soye.... Ces Bœufs, quoique plus petits que les nôtres, " ont cependant les Cornes beaucoup plus groffes \& plus lon" gues. Leurs Racines fe joignent fur le haut de la Tête, \& def" cendent à côté des Yeux prefqu'auffi bas que la gueule ; en" fuite le bout remonte en haut, qui forme comme un Croiffant. "Il y en a de fi groffes, que j’en ai vû étant féparées du Crane, " qui pefoient les deux enfemble foixante livres. Ils ont les Jam" bes fort courtes, de maniere que cette Laine traîne toujours " par terre, lorfqu'ils marchent ; ce qui les rend fi difformes, "que l'on a peine à diftinguer d'un peu lojin, de quel côté eft la Tête. Il n'y a pas une grande quantité de ces Animaux, ce qui feroit que les Sauvages les auroient bientôt détruits, fr on en faifoit faire la Chaffe. Joint à ce que, comme ils ont les jambes très-courtes, on les tuë, lorfqu'il y a bien de la Neige, à coups de Lances, fans qu'ils puiffent fuir.

Le Quadrupede le plus commun aujourd'hui en Canada, eft le Chevreuil, lequel ne differe en rien des nôtres. On dit qu'it jette des larmes, lorfquil fe voit pouffé à bout par les Chaffeurs. Quand il eft jeune, fon Poil eft rayé de plufieurs couleurs en long : dans la fuite ce Poil tombe, \& il en revient un autre, qui eft de la couleur des Chevreuils ordinaires. Cet Animal n'eft point farouche, $\&$ s'apprivoife aifément ; il paroît naturellement ami de l'Homme. Une Femelle devenuë domeftique fe retire dans le Bois, quand elle eft en chaleur, $\&$ dès qu'elle a été couverte, elle revient au Logis de fon Mâ̂tre. Lorfque le tems eft venu de mettre bas, elle retourne dans le Bois , \& y demeure quelques jours avec fes Petits, puis elle revient fe montrer à fon Maitre : elle vifite affiduëment fes Petits. On la fuit, quand on le juge à propos, on prend fes 
Nourriffons, \& elle continuë de les nourrir dans la Maifon. Il eft affez étonnant que toutes nos Habitations n'en ayent pas desTroupeaux entiers : les Sauvages ne leur donnentla chaffe, que par occafion.

Il y a auffi dans les Bois du Canada beaucoup de Loups, ou plûtôt de Chats ferviers ; car ils n'ont du Loup, qu'une efpece de hurlement; en tout le refte, ils font, dit M. Sarrafin, ex genere felino. Ce font de vrais Chaffeurs, qui ne vivent que des Animaux, qu'ils peuvent attraper, \& qu'ils pourfuivent jufqu’à la cime des plus grands Arbres. Leur Chair eft blanche, \& bonne à manger. Leur Poil \& leurs Peaux font fort connus en France : c'eft une des plus belles fourures de ce Pays, \& qui entre le plus dans le Commerce. On eftime encore plus celle de certains Renards noirs, qui font dans les Montagnes du Nord. J'ai cependant oüi dire que les Renards noirs de Mofcovie, \& ceux du Nord de l'Europe, font plus eftimés. D'ailleurs ils font ici fort rares, apparemment à caufe de la difficulté de les avoir.

Il y en a de plus communs, dont les uns ont le Poil noir ou gris, mêlé de blanc; les autres font tout gris, d'autres d'un rouge tirant fur le roux. On en trouve, en remontant le $\mathrm{Mi}$ ciffipi, d'une grande beauté, dont le Poil eft argenté. On y rencontre auffi des Tygres \& des Loups plus petits, que les nôtres. Les Renards donnent la chaffe aux Oifeaux de Riviere d'une maniere fort ingénieufe. Ils s'avancent un peu dans l'Eau, puis fe retirent, \& font cent cabrioles fur le Rivage. Les Canards, les Outardes, \& d'autres Oifeaux femblables, que ce jeu divertit, s'approchent du Renard; quand il les voit à fa portée, il fe tient fort tranquile d'abord, pour ne les point effaroucher, il remuë feulement fa Queuë, comme pour les attirer de plus près, \& ces fots Anımaux donnent dans le piége, jufqu’à becquetter cette Queuë. Alors le Renard faute deffus, \& manque rarement fon coup. On a dreffé des Chiens au même manége avec affez de fuccès, \& ces mêmes Chiens font rudement la Guerre aux Renards.

Une forte de Fouine, qu'on a nommée Enfant du Diable, ou Bête Puante, parce que fon Urine, qu'elle lâche, quand elle eft pourfuivie, empefte l'Air à un demi-quart de lieuë à ia ronde, eft d'ailleurs un fort joli Animal. Elle eft de la grandeur d'un petit Chat, mais plus groffe, d'un Poil luifant,

1721 .

Mars.

Des Loups Serviers \& des Renards. 
I 721 . tirant fur le gris, avec deux lignes blanches, qui lui forment

Mars. Cette Queuë eft touffuë, comme celle du Renard, \& elle la redreffe comme fait l'Ecureuil. Sa Fourure comme celle des Pekans, autres Chats Sauvages à peu près de la grandeur des nôtres, des Loutres, des Fouines ordinaires, des Pitois, du Rat de Bois, de l'Hermine, des Martres, font ce qu'on appelle la Menuë Pelleterie. L'Hermine eft de la groffeur de nos Ecureuils, mais un peu moins allongée; fon Poil eft d'un très-beau blanc, \& elle a une longue Queuë, dont l'extrémité eft d'un noir de Jay. Nos Martres font moins rouges, que celles de France, \& ont le Poil plus fin. Elles fe tiennent ordinairement au milieu des Bois, d'où elles ne fortent que tous les deux ou trois ans, mais elles en fortent toujours en grandes Troupes. Les Sauvages font perfuadés que l'année, où ils les voyent fortir, fera bonne pour la Chaffe; c'eft-à-dire, qu'il négera beaucoup. Les Peaux de Martres fe vendent ici actuellement un Ecu Piece, jentends les communes, car celles, qui font brunes, vont jufqu'à vint-quatre francs \& plus.

Le Pitoi ne differe de la Foüine, qu'en ce qu'il a le Poil plus noir, plus long \& plus épais. Ces deux Animaux font la Guerre aux Oifeaux, même aux plus gros, \& font de grands ravages dans les Poulalliers $\&$ dans les Colombiers. Le Rat de Bois eft deux fois de la groffeur des nôtres. Il a la Queuë veluë, \& fon Poil eft d'un très-beau gris argenté. On en voit mêmes, qui font tout blancs, \& d'un très-beau blanc. La Femelle a fous le Ventre une Bourfe, qui s'ouvre \& fe ferme, quand elle veut : elle y met fes Petits, quand elle eft pourfuivie, \& fe fauve avec eux.

Pour ce qui eft des Ecureuils, on les laiffe affez en repos, auffi y en a-t'il en ce Pays un nombre prodigieux. On en diftingue de trois efpeces; les rouges, qui ne different point des nôtres; les Suiffes, qui font un peu plus petits, \& qu'on a ainfi nommés, parce que leur Poil eft rayé en longueur de rouge, de blanc $\&$ de noir, à peu près comme les Suiffes de la Garde du Pape ; \& les Ecureuils Volans, à peu près de la même taille que les Suifies, \& qui ont le Poil d'un gris obfcur. On les appelle Volans, non pas qu'ils volent véritablement, mais parce qu'ils fautent d'un Arbre à l'autre, l'efpace 
D'UN V OYA GE DE L'A MERIQ. LET. VII. I 35 de quarante pas au moins. De haut en bas, leur faut pourroit être du double. Ce qui leur donne cette facilité de fauter, ce font deux Peaux, qu'ils ont des deux côtés, entre les Pattes 1721 . de derriere, \& celles de devant, \& qui s'étendent de la largeur de deux pouces. Elles font fort minces, \& ne font couvertes que d'un Poil folet. Ce petit Animal s'apprivoife facilement; il eft fort vif, quand il ne dort point; mais 'il dort fouvent, \& par-tout, où il peut fe fourrer; dans les Poches, dans les Manches, dans les Manchons. Il s'attache d'abord à fon Maître, \& le diftingue parmi vint Perfonnes.

Le Porc Epy du Canada eft de la groffeur d'un moyen Chien, mais plus court, \& moins haut. Son Poil, d'environ quatre pouces de longueur, eft gros comme une Paille des plus minces, blanc, creux, \& très-fort, particulierement fur le Dos. C'eft fon Arme, \& elle eft offenfive \& deffenfive. Il le lance d'abord fur ceux, qui attentent á fa Vie, \& pour peu qu'il entre dans la Chair, il faut l'en retirer à l'inftant, finon, il s'y enfonce tout entier. C'eft pour cette raifon, qu'on eft fort attentif à empêcher les Chiens d'approcher de ces Animaux, dont la Chair eft bonne à manger. Un PorcEpy à la Broche, vaut bien un Cochon de Lait.

Les Liévres \& les Lapins font ici comme en Europe, excepté qu'ils ont les Jambes de derriere plus longues. Leurs Peaux ne font pas d'un grand ufage, parce qu'ils muënt continuellement: c'eft dommage, car leur Poil eft très-fin, \& ne gâteroient rien dans la Fabrique des Chapeaux. L'Hyver, ces Animaux grifonnent, \& fortent rarement de leurs Tannieres, où ils vivent des plus jeunes Branches du Bouleau. L'Eté, ils ont le Poil roux. Les Renards leur font une cruelle guerre en toute Saifon, \& les Sauvages les prennent en $\mathrm{Hy}-$ ver, fur la Nége avec des Collets, quand ils vont chercher des Vivres.

J'ai l'honneur d'être, \&c. 
1721 .

Mars.

\section{HU I T IE'ME L'E T T RE.}

Defcription du Pays entre le Lac Saint Pierre \& Montreal: En quoi il differe de celui de Quebec. Defcription de l'Ifle $\mathcal{E}$ de la Ville de Montreal, É des Environs. De la Péche du Loup Marin, de la Vache Marine, du Marfouin, E des Baleines.

\section{A Montreal, ce vintiéme de Mars, 1721.}

\section{WADAME,}

Des Ines de

$\mathrm{J}_{\mathrm{E}}$ partis le treiziéme de Saint François, \& le lendemain Richelieu.

Difierence du jarrivai en cette Ville. Je n'ai pas eu dans ce Trajet, qui eft d'environ vint lieuës, le plaifir, que $j$ 'avois eu autrefois en faifant la même route en Canot, par le plus beau tems du Monde, de voir s'ouvrir devant moi, à mefure que javançois, des Canaux à perte de vûë, entre ce prodigieux nombre d'Ifles, qui de loin, ne fembloient faire qu'une même Terre avec le Continent, \& arrêter le Fleuve dans fa courfe : Ces agréablesPoints de vûë,qui changeoient à chaque inftant, comme des Décorations de Théâtre, \& qưon croiroit avoir été ménagées exprès pour récréer les Paffans : mais je ne laiffai pas d'en être un peu dédommagé d'abord par la fingularité du fpectacle d'un Archipel devenu ęn quelque façon un Continent, \& par la commodité de fe promener en Carriole fur des Canaux entre des Ifles, qui paroiffent avoir été plantées à la ligne, comme des Orangers.

Pour le coup d'œil, il n'eft pas beau dans cette Saifon. Pays de Quebec \& de celui đ’c Montreal. Rien n'eft plus trifte, que ce Blanc répandu par-tout, \& qui prend la place de cette belle variété de couleurs, le plus grand agrement des Campagnes; que des Arbres, qui paroiflent plantés dans la Nége, \& ne préfentent aux yeux, que des Têtes chenuës, \& des Branches chargées de Glaçons. Au refte, Madame, le Lac de Saint Pierre eft ici ce qu'eft la Riviere de Loire en France. Du côté de Quebec, les Terres fonę bonnes, 
D'UN V OYA GEDE L'A M ERIQ. LET. VIII. 137 bonnes, mais on n'y voit ordinairement rien, qui puifie récréer la vûë : d'ailleurs le Climat y eft fort rude; car plus on defcend le Fleuve, \& plus on avance au Nord; plus par conféquent le froid eft piquant. Quebec eft par les quarantefept Degrés cinquante-fix Minutes d'Elevation du Pole; les Trois Rivieres par les quarante-fix Dégrés \& quelques Minutes, \& Montreal entre les quarante-quatre \& les quarantecinq, le Fleuve, au-deflus du Lac de Saint Pierre, faifant un Coude au Sud. Il femble donc, lorfqu'on a paffé les Ifles de Richelieu, qu'on foit tout-à-coup tranfporté fous un autre Climat. L'Air eft plus doux, le Terrein plus uni, le Fleuve plus beau : fes Bords ont je ne fçai quoi de plus riant. On y rencontre de tems en tems des lifles, dont quelques-unes font habitées, les autres, dans leur état naturel, offrent aux yeux les plus beaux Payfages du Monde : en un mor, c'eft la Touraine \& la Limagne d'Auvergne comparées avec le Maine \& la Normandie.

L'Ifle de Montreal, qui eft comme le Centre de ce beau pays, a dix lieuës de long, de l'Eft à l'Oueft, \& près de quatre lieuës dans fa plus grande largeur. La Montagne, d'oì elle tire fon nom, \& qui a deux Têtes, de hauteur inégale, eft prefque dans le milieu de la longueur de l'Ifle, mais elle n'eft qu’à une demie lieuë de la Côte Méridionnale, fur laquelle on a bâti la Ville. Cette Ville a été nommée Ville-Marie par fes Fondateurs, mais ce nom n'a pu paffer dans l'ufage ordinaire, il n'a lieu, que dans les Actes publics, \& parmi les Seigneurs, qui en font fort jaloux. Ces Seigneurs, qui ont le Domaine, non - feulement de la Ville, mais encore de toute l'Ifle, font Meffieurs du Séminaire de Saint Sulpice ; \& comme prefque toutes les Terres y font trìs-bonnes, \& en valeur, \& que la Ville n'eft guéres moins peuplée, que celle de Quebec, on peut affurer que cette Seigneurie vaut du moins une demie douzaine des meilleures du Canada. C'eft le fruit du travail \& de la bonne conduite des Sëigneurs de cette Ifle, \& certainement vint Particuliers, entre lefquels on l'auroit partagée, ne l'auroient pas mife dans l'Etat, où nous la voyons, \& n'y rendroient pas les Peuples auff. heureux.

La Ville de Montreal a un afpect fort riant; elle eft bien fituée, bien percée, \& bien bâtie. L'agrément de fes envi. de la Ville. Tome III.

Defcription de linfe de Montreal.

Mars. Monerealo 


\section{I38 J O U R N A L H I S T O R I Q U E}

I 7 2 I. rons \& de fes vûës infpirent une certaine gayeté, dont tout Mars le Monde fe reffent. Elle n'eft point fortifiée, une fimple $\mathrm{Pa}$ liffade baftionnée, \& affez mal entretenuë, fait toute fa défenfe, avec une affez méchante Redoute fur un petit Tertre, qui fert de Boulevard, \& va fe terminer en douce pente à uné petite Place quarrée. C'eft ce qu'on rencontre d'abord en arrivant de Quebec. Il n'y a pas même quarante ans, que la Ville êtoit toute ouverte, \& tous les jours expofée à être brûlée par les Sauvages, ou par les Anglois. Ce fut le Chevalier de Callieres, Frere du Plénipotentiaire de Rifwick, qui la fit fermer, tandis qu'il en étoit Gouverneur. On projette depuis quelques années de l'environner de Murailles (a), mais il ne fera pas aifé d'engager les Habitans à y contribuer. Ils font Braves \& ils ne font pas riches: on les a déja trouvé difficiles à perfuader de la néceffité de cette dépenfe, \& fort convaincus que leur valeur eft plus que fuffifante pour défendre leur Ville contre quiconque oferoit l'attaquer. Nos Canadiens ont tous, fur cet article, aflez bonne opinion d'eux-mêmes, \& il faut convenir qu'elle n'eft pas mal fondée; mais par une fuite de la confiance, qu'elle leur infpire, il n'eft pas fi mal airé de les furprendre, que de les vaincre.

Montreal eft un quarré long, fitué fur le bord du Fleuve, lequel s'élevant infenfiblement, partage la Ville dans fa longueur en Haute \& Baffe ; mais à peine s'apperçoit-on que l'on. monte de l'une à l'autre. L'Hôtel-Dieu, les Magafins du Roi \& la Place d'Armes, font dans la Baffe Ville; c'eft auffi le Quartier de prefque tous les Marchands. Le Séminaire \& la Paroiffe, les Récollets, les Jéfuites, les Filles de la Congrégation, le Gouverneur \& la plûpart des Officiers font dans la Haute. Au-delà d'un petit Ruiffeau, qui vient du Nord-Oueft, \& borne la Ville de ce côté-là, on trouve quelques Maifons, \& l'Hôpital Général ; \& en prenant fur la droite au-delà des Récollets, dont le Couvent eft à l'extrèmité de la Ville du même côté, il commence à fe former une efpece de Fauxbourg, qui avec le tems fera un très-beau Quartier.

Les Jéfuites n'ont iciqu'une petite Maifon; mais leur Eglife qu'on acheve de couvrir, eft grande \& bien bâtie. Le Couvent des Récollets eft plus vafte, \& la Communauté plus nombreufe. Le Séminaire eft au centre de la Ville : il paroît

- (a) Ce Projet eft préfentement exécuté. 
D'UN VOYAGE DE L'A MERIQ. LET. VIII. 139 qu'on a eu plus en vîe de le rendre folide \& commode, que magnifque; on ne laiffe pourtant pas de fentir que c'eft la Maifon Seigneuriale, elle communique avec l'Eglife Paroiffrale, qui a bien plus l'air d'une Cathédrale, que celle de Quebec. Le Service s'y fait avec une modeftie \& une dignité, qui infpirent du ref́pect pour la Majefté du Dieu, qu'on y adore.

La Maifon des Filles de la Congrégation, quoiqu'une des plus grandes de la Ville, eft encore trop petite pour loger une di nombreufe Communauté. C'eft le Chef d'Ordre \& 8 le Noviciat d'un Inftitut, qui doit être d'autant plus cher à la Nouvelle France, \& à cette Ville en particulier, qu'il y a pris naiffance, \& que toute la Colonie fe reffent des avantages, que lui procure un fi bel Etabliffement. L'Hôtel-Dieu eft deffervi par des Religieufes, dont les premieres ont été tirées de celui de la Fléche en Anjou. Elles font pauvres, cependant il n'y paroît ni à leur Sale, qui eft grande, bien meublée, \& 8 bien garnie de Lits; ni à leur Eglife, qui eft belle \& très-ornée ; ni à leur Maifon, qui eft bien bâtie, propre $8 x$ commode ; mais elles font mal nourries, quoique toutes infatiguablement occupées, ou de l'inftruction de la Jeuneffe, ou du foin des Malades.

L'Hôpital Général doit fon établiffement à un Particulier, nommé Charron, qui s'étoit affocié plufieurs perfonnes de pieté, non-feulement pour cette bonne œuvre, mais auffi pour fournir les Paroiffes de la Campagne de Maîtres d'Ecole, qui fiffent pour les Garçons ce que les Sours de la Congrégation font pour les Filles : mais la Societé fe diffipa bientôt ; des affaires furvenuës aux uns, l'inconftance des autres, réduifirent le Sieur Charron à lui feul. Il ne fe découragea pourtant point; il vuida fa bourfe, il eut le fecret de faire ouvrir celles de quelques perfonnes Puiffantes; il a bâti, il a affemblé des Maîtres \& des Hofpitaliers; on s'ent fait un plaifir d'aider \& d'autorifer un Homme, qui n'épargnoit, ni fon bien, ni fa peine, \& que rien ne rebutoit. Enfin, avant fa mort, qui arriva en 1719 , il a eu la confolation de voir fon projet hors de tout rifque d'échouer, au moins quant à l'Hôpital Général. La Maifon eft belle, \& l'Eglife fort jolie. Les Maitres d'Ecole ne font pas encore bien établis dans les Paroiffes, \& la défenfe, qu'ils ont euë de la Cour, de prendre un Habit uniforme, 
I $72 \mathrm{I}$. \& de s'engager par des Voux fimples, pourra bien les emMars. pêcher de fe perpétuer.

De rinfe de Entre l'Inle de Montreal \& la Terre Ferme, du côté du Jefus, sc de la Nord, il y a une autre Ine d'environ huit lieuës de long, \& Kiviere des Prairies.

Le Sault aux Récollets. qui a bien deux lieuës dans fa plus grande largeur. Elle fut d'abord nommée I'I le de Montmagny, du nom d'un Gouverneur Général du Canada : elle fut enfuite concédée aux Jéfuites, qui l'appellerent l'Ifle de Jefus, \& elle a confervé ce dernier nom, quoiqu'elle ait paffé des mains des Jéfuites en celles de Meffieurs du Séminaire de Quebec, qui ont commencé d'y mettre des Habitans; \& comme les Terres en font bonnes, il y a lieu d'efperer qu'elle fera bientôt toute défrichée.

Le Canal, qui fépare les deux Inles , porte le nom de Riviere des Prairies, parce qu'elle coule au milieu de fort belles Prairies. Son Cours eft embarraffé vers le milieu par un Rapide, qu'on appelle le Saut au Récollet, en mémoire d'un Religieux de cet Ordre, qui s'y eft noyé. Les Eccléfiaftiques du Séminaire de Montreal ont eu lontems affez près de-là une Miffion de Sauvages, quils ont depuis peu tranfportée ailleurs.

Le troifiéme Bras du Fleuve eft femé d'un nombre d'Illes î

Des Environs de Montreal,

prodigieux, qu'il y a prefque autant de Terre que d'Eau. Ce Canal porte les noms de Milles-Ifles ou de Riviere de Saint Jean. A la Tête de l'Ifle de Jefus, eft la petite Ifle Bizard, ainfín appellée du nom d'un Officier Suiffe, à qui elle appartenoit, \& qui eft mort Major de Montreal. Un peu plus haut vers le Sud, on trouve l'Ifle Perrot, ainfi nommée par M. Perrot, qui a été le premier Gouverneur de Montreal, \& qui étoit le Pere de Madame la Comteffe DE la Roche-Allard, \& de $M^{\text {de }}$ la Préfidente De Lubert. Cette Ifle a prefque deux lieuës en tout fens, \& les Terres en font bonnes. On commence à la défricher. L'Inle Bizard termine le Lac des deux Montagnes, \& l'Ille Perrot fépare ce même Lac de celui de Saint Loüis.

Le Lac des deux Montagnes eft proprement l'Embouchure de la grande Riviere, autrement appellée la Riviere des Outaouais, dans le Fleuve Saint Laurent. Il a deux lieuës de longueur, \& à peu près autant de largeur. Celui de Saint Louys eft un peu plus grand, ce n'eft encore qu'un élargiffement du. Fleuve Saint Laurent. Jufqu'à préfent, la Colonie Françoife n'alloit pas plus loin à l'Ouent; mais on commence à faire de 
D'UN V OYA GE DE L'A M ER IQ. LET. VIII. I 4 I nouvelles Habitations un peu plus haut, $\&$ les Terres font partout excellentes.

Ce qui a fait la fûreté de Montreal \& de tous fes Environs pendant les dernieres Guerres, ce font deux Villages d'Iro- Louys. quois Chrétiens, \& le fort de Chambly. Le premier des deux Villages, eft celui de Sault Saint Loüis, fitué dans le Continent du côté du Sud, trois lieuës plus haut que la Ville de Montreal. Il eft fort peuplé, \& a toujours été regardé comme une de nos plus fortes Barrieres contre les Iroquois Idolâtres, \& contre les Anglois de la Nouvelle York. Il a déja changé deux fois de place dans l'efpace de deux lieuës. Sa feconde ftation, où je l'ai vû en 1708 , étoit vis-à-vis un Rapide, qu'on nomme le Sault Saint Loüis, \& il en a confervé le nom, quoiqu'il en foit aujourd'hui affez éloignê. Il paroît qu'on l'a enfin fixé ; car l'Eglife, qu'on ne fait que d'achever, \& la Maifon des Miffionnaires, font, chacun dans leur genre, deux des plus beaux Edifices du Pays. La fituation en eit charmante. Le Fleuve fort large en cet endroit y eft femé de plufjeurs Ifles, qui font un très-bel effet. L'Ine de Montreal toute peuplée eft en perfpective d'un côté, \& la vîë n'eft prefque point bornée de l'autre à caufe du Lac de Saint Loüis, qui commence un peu plus haut.

Le fecond Village porte le nom de la Montagne, parce qu'il fut lontems fur la double Montagne, qui a donné fon nom à l'Ine. On l'a depuis tranfporté au Sault au Récollet, comme je vous l'ai dit ; il eft préfentement en Terre Ferme vis-à-vis l'extrêmité Occidentale de l'Inle. Ce font les Eccléfiaftiques du Séminaire de Montreal, qui le gouvernent. Il eft forti bien des Braves de ces deux Bourgades, \& la ferveur y étoit admirable avant que l'avarice de nos Traitans y eût introduit l'Yvrognerie, qui y a fait de bien plus grands ravages encore, que dans les Miffions de Saint François \& de Beckancourt.

Envain les Miffionnaires ont employé, pour arrêter ce defordre, toute leur induftrie \& toute leur vigilance : ils ont eu beau implorer le fecours des Puiffances, menacer de la colere du Ciel, apporter les raifons les plus perfuafives, tout a été inutile : les accidens même les plus funeftes, \& où il n'étoit pas poffible de méconnoître la main de Dieu appefantie fur les Auteurs du mal, n'ont pas été fuffifans pour faire rentrer en eux -mêmes des Chrétiens, que l'avidité d'un gain fordide

Des Iroquois de la Montagne.
Défordires caufés, par la Traite del'Eau de-Vis, dans ces deux Villages. 
avoit aveuglés. On voit jufques dans les Places \& les Ruës de Montreal, les Spectacles les plus affreux, fuites inévitables de Mars. l'Yvrefie de ces Barbares : les Maris \& les Femmes; les Peres, les Meres \& les Enfans ; les Freres \& les Sœurs, fe prendre à la Gorge, s'arracher les Oreilles, fe mordre à belles Dents comme des Loups enragés. Les Airs retentiffent pendant les nuits de hurlemens beaucoup plus horribles que ceux dont les Bêtes féroces font retentir les Bois.

Ceux qui ont peut-être le plus à fe reprocher ces horreurs, font les premiers à demander fi ces gens-là font des Chrétiens? on pourroit leur répondre : ouii ce font des Chrétiens \& des Néophytes, qui ne fçavent ce qu'ils font; mais ceux, qui de fang froid, \& avec connoiffance de caufe, les réduifent par leur avarice en cet état, ont-ils de la Religion ? On fçait que les Sauvages donneroient tout ce qu'ils ont pour un Verre d'Eau de Vie; c'eft une tentation pour les Traitans, contre laquelle, ni les cris des Pafteurs, ni le zéle \& l'autorité des Magiftrats, ni le refpect des Loix, ni la févérité de la Juftice fouveraine, ni la crainte des Jugemens de Dieu, ni la penfée de l'Enfer, dont ces Barbares dans leur Yvreffe préfentent une Image bien fenfible, n'ont encore pû tenir. Mais détournons la vûë de ces objets défagréables.

De la Foire de Montreal. Calomnie de la Hontan àce Łujet.

Le grand Commerce des Pelleteries, après que la Ville des Trois Rivieres eut ceffé d'être fréquentée par les Nations du Nord \& $x$ de l'Oueft, fe fit pendant quelques années à Montreal, où les Sauvages abordoient en certains tems de toutes les parties du Canada. C'étoit une efpece de Foire, qui attiroit beaucoup de François dans cette Ville. Le Gouverneur Général $\&$ l'Intendant s'y rendoient auffi, \& l'on profitoit de l'occafion pour accommoder les différens, qui pouvoient être furvenus entre nos Alliés. Mais fi par hazard, Madame, vous tombez fur le Livre de la Hontan, où il eft parlé de cette Foire, donnez-vous bien de garde de prendre tout ce qu'il en dit pour des vérités. La vraifemblance n'y eft pas même gardée. Les Femmes de Montreal n'ont jamais donné licu à ce que cet $\mathrm{Au}$ teur y met fur leur compte, \& il n'y a rien à craindre pour leur honneur de la part des Sauvages. Il eft fans exemple qu'aucun d'eux ait jamais pris la moindre liberté avec les Françoifes, lors même qu'elles ont été leurs Prifonnieres. Ils n'en font pas même tentés, \& il feroit à fouhaiter que les François euffent 
D'UN V OYA GE DE L'A MERIQ. LET. VIII. I 43 le même dégoût des Sauvageffes. La Hontan ne pouvoit pas ignorer ce qui eft de notorieté publique en ce Pays ; mais il vouloit égayer fes Mémoires, \& pour y réuflir, tout lui étoit Mars. bon. On eft toujours fûr de plaire à certaines gens, quand on ne garde aucune mefure dans la liberté, qu'on fe donne d'inventer, de médire, \& de s'exprimer fur certaines matieres.

On voit encore de tems en tems arriver à Montreal de petites Flottes de Sauvages, mais ce n'eft plus rien en comparaifon du paffé. C'eft la Guerre des Iroquois, qui a interrompu ce grand concours des Nations dans la Colonie. Pour y fupléer, on a établi chez la plûpart des Magafins avec des Forts, où il y a toujours un Commandant $\& x$ affez de Soldats, pour mettre les Marchandifes en fûreté. Les Sauvages y veulent toujours avoir un Armurier, \& dans plufieurs il y a des Miffionnaires, qui y feroient plus de bien, s'ils y étoient feuls de François. On auroit bien dû, ce femble, rétablir les chofes fur l'ancien pied, depuis que tout eft en Paix au dedans $\&$ au dehors de la Colonie : ce feroit le moyen d'y retenir les Coureurs de Bois, à qui leur avidité, fans parler de tous les défordres, qu'attirent le libertinage, fait faire tous les jours des baffeffes, qui nous rendent méprifables aux yeux des Barbares, ont avili nos Marchandifes, \& encheri les Pelleteries. Outre que les Sauvages, naturellement fiers, font devenus infolens, depuis qu'ils fe voyent recherchés.

La Pêche pourroit bien plus enrichir le Canada, que la Chaffe, \& on n'y dépend point des Sauvages. Deux raifons de s'y appliquer, qui n'ont pourtant pû jufqu'ici engager nos Colons à en faire le principal objet de leur Commerce. Jen'ai rien à ajoûter à ce que j’ai déja eu l'honneur de vous dire de la Pêche des Morues, qui feule nous vaudroit plus que le Perou, $f_{1}$ les Fondateurs de la Nouvelle France euffent pris les mefures convenables pour s'en affurrer la poffeffion. Je commence par celle du Loup Marin, des Vaches Marines \& des Marfouins, qu'on fait faire partout dans le Golphe Saint Laurent , \& bien avant dans le Fleuve même.

Le Loup Marin doit fon nom à fon cri, qui eft une efpece de hurlement; car dans fa figure, il n'a rien du Loup, ni d'aucun Animal terreftre, que nous connoiffions. Lefcarbot afture qu'il en a entendu, qui crioient comme les Chathuants; mais ce pouvoit être de jeunes Bêtes, dont le cri n'étoit pas encore

De la Pêche du Loup $\mathrm{Ma}_{\mathrm{a}}=$ rin. 
bien formé. Au refte, Madame, on ne balance pas ici à mettre le Loup Marin au rang des Poiffons, quoiquil ne foit pas Mars. muet, qu'il naiffe à Terre, qu'il y vive pour le moins autant que dans l'Eau, qu'il foit couvert de Poil; en un mot, qu'il ne lui manque abfolument rien, pour être regardé comme un véritable Amphibie. Mais nous fommes dans un nouveau Monde, il ne faut pas exiger que nous y parlions toujours le Langage de l'ancien, \& l'ufage, contre lequel on ne raifonne point, s'y eft mis en poffeffion de tous fes droits. Ainfi la Guerre, qu'on fait au Loup Marin , quoiqu'on la faffe fouvent à Terre, \& à coups de Fufils, fe nomme une Pêche; \& celle qu'on fait aux Caftors dans l'Eau, \& avec des Filets, s'appelle une Chaffe.

Defcription

La Tête du Loup Marin approche un peu de la figure de du Loup Ma- celle du Dogue : il a quatre Pattes fort courtes, fur-tout celles rin.

de derriere : dans tout le refte, il eft Poiffon. Il fe traîne plûtôt qu'il ne marche fur les Pieds ; ceux de devant ont des Ongles, ceux de derriere font en forme de Nageoires. Sa Peau eft dure, \&x couverte d'un Poil ras de diverfes couleurs. Il y a de ces Animaux, qui font tout blancs, \& tous le font en naiffant; quelques-uns, à mefure quils croifient, deviennent noirs, d'autres roux; plufieurs ont toutes ces couleurs enfemble.

Ses diverfes Les Pêcheurs diftinguent plufieurs efpeces de Loups MaEfpeces. rins; les plus gros péfent jufqu'à deux mille, \&r l’on prétend qu'ils ont le Nez plus pointu que les autres. Il y en a, qui ne font que fretiller dans l'Eau; nos Matelots les appellent Braffeurs, ils ont donné à une autre efpece le nom de $N a u$ : je n'en fçai ni la raifon, ni la fignification : à une autre, celui de Grofjes Tétes. Il y en a de petits fort éveillés, \& $\&$ fort adroits à couper les Filets, qu'on leur tend: leur couleur eft tygrée, ils font badins, pleins de feu, \& jolis, autant que des Animaux de cette figure le peuvent être: les Sauvages les accoûtument à les fuivre, comme fi c'étoient de petits Chiens, \& ne laiffent pourtant pas de les manger.

M. Denys parle de deux fortes de Loups Marins, qui fe rencontrent fur les Côtes de l'Acadie : les uns, dit-il, font fi gros, que leurs Petits ont plus de volume, que nos plus grands Porcs. Il ajoûte que peu de tems après qu'ils font nés, le Pere \& la Mere les amenent à l'Eau, \& de tems en tems les rame- 
D'UN V OYA GE DE L'A MERIQ. LET. VIII. 145 nent à Terre, pour les faire téter: que la Pêche s'en fait au mois de Février, lorfque les Petits, auxquels on en veut principalement, ne vont prefque point encore dans l'Eau : qu'au premier bruit, les Peres \& Meres prennent la fuite, en faifant un fort grand bruit, pour avertir leurs Petits de les fuivre, ce que ceux-ci ne manquent point de faire, fi les Pêcheurs ne fe hâtent de leur donner un coup de Bâton fur le Nez, \& que cela fuffit pour les tuer. Il faut que le nombre de ces Animaux foit bien grand fur ces Côtes, s'il eft vrai, comme le même Auteur l'affûre, qu'en un feul jour on prend de cette forte jufqu’à huit cent de ces Petits.

$\mathrm{L}$ a feconde Efpece, dont parle M. Denys, eft fort petite, \& chaque Bête ne donne guéres d'Huile, que ce qu'il en peut tenir dans fa Veffie. Ces Derniers ne s'éloignent jamais beaucoup du Rivage, \& il y en a toujours quelqu'un, qui fait la Sentinelle. Au premier fignal, qu'il donne, tous fe jettent à la Mer; au bout de quelque tems ils fe rapprochent de Terre, $\&$ fe levent fur leurs Pattes de derriere, pour voir s'il n'y a rien à craindre : mais, malgré toutes leurs précautions, onen furprend un grand nombre à Terre, \& il n'eft prefque pas poffible de les avoir autrement.

On convient que la Chair du Loup Marin n'eft pas mauvaife à manger, mais on trouve beaucoup mieux fon compte à en faire de l'Huile : la façon n'en eft pas difficile. On en fait fondre la Graiffe fur le feu, \& elle fe réfout en Huile. Souvent même on fe contente de faire des Charniers, c'eft le nom, qu'on donne à de grands Quarrés de Planches, fur lefquels on étend la Graiffe de plufieurs Loups Marins : elle s'y fond d'elle-même, \& l'Huile coule par une ouverture, qu'on y a pratiquée. Cette Huile, quand elle eft fraîche, eft fort bonne pour la Cuifine, mais celle des jeunes Bêtes rancit bientôt, \& celle des autres, pour peu qu'elle commence à vieillir, defféche trop : on s'en fert alors pour brûler, ou pour paffer les Peaux. Elle eft lontems claịre, elle n'a point d'odeur, \& ne laiffe point de Lie, ni aucune forte d'immondices au fond de la Barrique.

Dans les premiers tems de la Colonie on a employé une grande quantité de Peaux de Loups Marins à faire des Manchons. La mode en eft paffée, \& leur grand ufage aujourd'hui eft de couvrir les Malles \& les Cofres. Quand elles font Tome III.

UTare de la Chair \& de la Peau du Loup Marin.
1721 . Mars. 
I 721 . tannées, elles ont prefque le même grain que le Maroquin : Mars elles font moins fines, mais elles ne s'écorchent pas fi aiféMars. ment, \& elles confervent plus lontems toute leur fraîcheur. On en fait de très-bons Souliers, \& des Bottines, qui ne prennent point l'Eau. On en couvre auffi des Siéges, dont le Bois eft plutôt ufé que la Couverture. On tanne ici ces Peaux avec l'Ecorce de Peruffe, \& dans la Teinture, dont on fe fert pour les noircir, on mêle une Poudre, qui fe tire de certaines Pierres, qu'on trouve fur les Bords des Rivieres. C'eft ce qu'on appelle Pierres de Tonnerre, ou des Marcaffites. de Mines.

Particularités C'eft fur les Rochers, \& quelquefois fur la Glace, que les: de ces Ani- Loups Marins s'accouplent, \& que les Meres font leurs Pemaลdx. tits. Leur Portée ordinaire eft de deux, \& elles les allaitent affez fouvent dans l'Eau, mais plus fouvent à Terre; quand elles veulent les accoûtumerà nâger, elles les portent, dit-on, fur leur Dos; les laiffent aller de tems en tems dans l'Eau, puis les reprennent, \& continuent ce manége, jufqu’à ce que ces Petits puiffent nâger tous feuls. Si ce fait eft vrai, voilà un étrange Poiffon, à qui la Nature n'a pas même appris ce que la plupart des Animaux Terreftres fçavent prefqu'en naiffant. Le Loup Marin a les fens fort vifs, \& c'eft fon unique défenfe : elle ne les empêche pourtant pas d'être fouvent furpris, comme je l'ai déja remarqué ; mais la plus ordinaire façon de les pêcher eft celle-ci.

La coûtume de cet Animal, quand il eft dans l'Eau, eft d'entrer avec la Marée dans les Anfes : quand on a reconnu les Anfes, où il en entre un grand nombre, on les ferme avec des Filets \& des Pieux; on n'y laiffe de libre qu'un affez petit efpace, par où les Loups Marins fe gliffent. Dès que la Marée eit haute, on bouche cette ouverture; ainfi, après que la Mer s'eft retirée, ces Poiffons demeurent à fec, \& on n'a que la peine de les affommer. On les fuit auffi en Canot dans les endroits, où il $\mathrm{y}$ en a beaucoup, \& quand ils mettent la Tête hors de l'Eau pour refpirer, on tire deffus. Sils ne font que bleffés, on les prend fans peine : s'ils font tués roides, ils vont d'abord à fond, comme il arrive aufi aux Caftors : mais on a de gros Chiens, qui font ftilés à les pêcher à fept ou huit brafes de profondeur. Enfin j'ai oui dire qu'un Matelot en ayant un jour furpris à Terre un grand: 
D'UN VOYAGEDE L'A MERIQ. LET. VIII. 147 Troupeau, il les avoit conduits à fon Logement avec une Gaule , comme il auroit pû faire un Troupeau de Bœufs, \&z que lui \& fes Camarades en avoient tué jufqu’à neuf cent. Sit I $72 \mathrm{I}$. Mars. fides pones Autorem.

Nos Pêcheurs prennent aujourd'hui affez peu de Vaches Marines fur les Côtes du Golphe de Saint Laurent, \& je ne f̧̧ai point $f_{i}$ on en a jamais pris ailleurs. Les Anglois en avoient autrefois établi une Pêche à l'Ille de Sable, mais elle ne leur a pas fait beaucoup de profit. La figure de cet Animal n'eft pas fort differente de celle du Loup Marin, mais il eft plus gros. Ce qu'il a de fingulier, ce font deux Dents de la groffeur $\& x$ de l̀ longueur du Bras, un peu recourbées en haut, \& qu'on prendroit de loin pour des Cornes : c'eft apparemment de-là que leur eft venu le nom de Vaches Marines. Les Matelots l'appellent plus fimplement la Bête à la Grande Dent. Cette Dent eft d'un très-bel Yvoire, auffi bien que toutes celles, qui compofent la Macheoire de ce Poiffon, $\&$ qui ont quatre doits de longueur.

Il y a dans le Fleuve Saint Laurent des Marfouins de deux couleurs : dans l'Eau Salée, c'eft -à-dire, jufqu'un peu audeffous de l'Ifle d'Orleans, ils ne different point de ceux, qu'on trouve dans la Mer: dans l'Eau Douce ils font tout blancs, \& de la groffeur d'une Vache. Les Premiers vont ordinairement par Bandes : je n'ai point remarqué la même chofe des autres, quoique jen aye beaucoup vû fe divertir dans le Port de Quebec. Ils ne montent guéres plus haut que cette Ville; mais il y en a beaucoup fur les Côtes de l'Acadie, auffi bien que de la premiere Efpece; ainfi la difference de leur couleur ne vient point de la difference de l'Eau Salée $\&$ de l'Eau Douce.

Les Marfouins Blancs rendent une Barrique d'Huile, \& cette Huile eft peu differente de celle du Loup Marin. Je n'ai vû perfonne, qui ait mangé de la Chair de cet Animal, mais pour ce qui eft des Pourcelles, c'eft le nom, que l'on donne aux Marfouins Gris; on dit que ce n'eft pas un mauvais manger ; on fait des Boudins \& des Andouilles de leurs Boyaux, la Freffure en eft excellente en Fricaffée, \& la Tête meilleure, que celle du Mouton, mais moins bonne que celle de Veau.

La Peau des uns \& des autres fe tanne \& fe paffe en façon de Maroquin. D'abord elle eft tendre comme du Lard, \& a leurs Peaur. T ij

Marfouins de deux couleurs.

Des Vaclies Marines. 


\section{J O UR N A L H I T T O R Q U E}

1721. un pouce d'épaiffeur. On la gratte lontems, \& elle devient Mars comme un Cuir tranfparent ; \& quelque mince, qu'elle foit, jufqu'à être propre à faire des Veftes \&र des Hauts-de-Chauffes, elle eft toujours très-forte, \& à l'épreuve d'un coup de feu. Il y en a de dix-huit pieds de long fur neuf de large : on prétend que rien n'eft meilleur pour couvrir une lmperiale de Caroffe.

De ì Pêche

On a établi depuis peu deux Pêches de Marfouins aua. Marfouin.

deffous de Quebec ; l'une dans la Baye Saint Paul, \& l'autre fept ou huit lieuës plus bas, vis-à-vis une Habitation, qu'on appelle Camourafca, du nom de certains Rochers, qui s'élévent confidérablement au-deffus de l'Eau. Les frais n'en font pas grands, \& les profits iroient fort loin, fi les Marfouins. étoient des Animaux d'habitude : mais foit infinct, ou caprice, ils trompent fouvent toutes les mefures des Pêcheurs, \& prennent une autre route, que celle, où on les attend. D'ailleurs ces Pêches, qui n'enrichiroient que des Particuliers, ont occafionné un inconvénient, qui fait crier le Peuple : c'eft qu'elles ont beaucoup diminué celle des Anguilles, laquelle eft une grande reffource pour les pauvres Habitans. Car les Marfouins fe trouvant inquiettés au-deffous de Quebec, fe font retirés ailleurs, \& $x$ les Anguilles ne trouvant plus fur leur paffage ces gros Poiffons, qui les obligeoient de rebrouffer chemin, defcendent le Fleuve fans obftacles; d'où il arrive qu'entre Quebec \& les Trois Rivieres, oì l'on en prenoit une quantité prodigieufe tous les ans, on n'en prend prefque plus.

La maniere", dont fe fait la Pêche du Marfouin eft peu differente de celle, dont j'ai parlé en dernier lieu au fujet du Loup Marin. Quand la Marée eft baffe, on plante dans la Vafe, ou dans le Sable des Piquets affez près les uns des autres, \& l'on y attache des Filets en forme d'Antonnoirs, dont l'ouverture eft affez large; de forte néanmoins que, quand le Poiffon y a pafé, il ne la peut plus retrouver pour en fortir. On a foin de mettre au haut des Piquets des Bouquets de Verdure. Quand la Marée monte, ces Poiffons, qui donnent la Chaffe aux Harengs, lefquels gagnent toujours les Bords, \& attirés par la Verdure, qu'ils aiment beaucoup, s'engagent dans les Filets, \& s'y trouvent enfermés. A nefure que la Marée baifle, on a le plaifir de voir leur em: 
D'UN VOYAGE DE L'A MERIQ. LET. VIII. I 49 barras, \& les mouvemens inutiles, qu'ils fe donnent pour échaper ; enfin ils reftent à fec, \& fouvent échoués les uns fur les autres en fi grand nombre, que d'un feul coup de Bâton on en affomme deux ou trois. On prétend qu'il s'en eft trouvé parmi les Blancs, qui pefoient jufqu'à trois mille.

Tout le Monde fçait de quelle maniere fe fait la Pêche de la Baleine, ainfi je ne vous en dirai rien. On dit ici que les Bafques, qui la faifoient autrefois dans le Fleuve Saint Laurent, ne l'ont interrompuë, que pour s'addonner tout entiers au Commerce des Pelleteries, qui ne demandoient, ni tant de dépenfes, ni tant de fatigues, \& dont les profits étoient alors plus confidérables $\&$ plus prompts. D'ailleurs iIs n'avoient pas pour cette Pêche toutes les commodités, qu'on peut avoir préfentement, qu'il $\mathrm{y}$ a des Habitations fort avancées vers le Golphe. Il y a quelques années, quon effaya de la rétablir, mais fans fuccès: les Entrepreneurs, ou n’avoient pas les fonds néceffaires pour en faire les avances, ou ont voulu être dédommagés trop tôt de leurs frais, ou ont manqué de conftance. Il paroît néanmoins certain que cette Pêche pourroit être un grand objet dans le commerce de cette Colonie, \& qu'elle fe peut faire avec beaucoup moins de dé. penfes \& de périls, que fur les Côtes du Grö̈nland. Qui empêcheroit même de la rendre fédentaire, comme M. Denys propofoit de faire celle de la Moruë en Acadie ? Voilà, Madame, tout ce qui regarde les Pêches, qui peuvent enrichir le Canada: Je vous parlerai des autres, quand je vous entretiendrai de la maniere de vivre dans ce Pays.

J'ai l'honneur d'être,

1721 . Mars.

Des Balcines; 
I 721 .

Avril.

\section{NEU VIEME LETTRE.}

Du Fort de Chambly, des Poiffons, des Oifeaux, de quelques Animaux propres du Canada. Des Arbres, qui lui font communs avec la France, $\mathcal{E}$ de ceux, qui lui font particuliers.

A Chambly, ce premier Avril, 1721.

M

\section{A D A ME,}

U N E des principales défenfes de Montreal contre les Iroquois \& la Nouvelle York eft le Fort de Chambly : c'eft de ce Fort que j'ai l'honneur de vous écrire. J'y fuis venu pour rendre vifite au Commandant, qui eft M. DE SABREvoIs, d'une des meilleures Maifons de Beauce, mon Ami, mon Compagnon de Voyage, \& bon Officier. Je vais en deux mots vous marquer la fituation de cette Place importante, $8 x$ vous en faire la defcription.

Dans les premieres années de notre Etabliffement en ce Pays, les Iroquois, pour faire des courfes jufques dans le centre de nos Habitations, defcendoient une Riviere, qui fe déchảrge dans le Fleuve Saint Laurent, un peu au-deffus du Lac de Saint Pierre, à laquelle, pour cette raifon on donna d'abord le nom de Riviere des Iroquois. On l'a depuis appellée la Riviere de Richelieu, à caufe d'un Fort, qui portoit ce nom, \& qu'on avoit conftruit à fon Embouchure. Ce Fort ayant été ruiné, M. de Sorel, Capitaine dans CarignanSalieres, en fit conftruire un autre, auquel on donna fon nom: ce nom s'eft communiqué à la Riviere, qui le conferve encore aujourd'hui, quoique le Fort ne fubfifte plus depuis lontems. Quand on a remonté la Riviere, environ dix-fept lieuës, allant toujours au Sud, mais prenant un peu du Sud-Oueft, on trouve un Rapide, \& vis-à-vis une efpece de petit Lac formé par la Riviere même. C'eft fur le Bord même du Rapide, \& vis-à-vis du Lac, qu’eft fitué le Fort. Il fut d'abord bâti de Bois par M. de Chambly, Capitaine 
D'UN V OYA GE DE L'A MERIQ. LET. IX. I5I dans le Régiment de Carignan-Salieres, en même-tems, que $M$. de Sorel conftruifit le Sien : mais on l'a depuis peu bâti de Pierres, \& flanqué de quatre Baftions, \& on y enI 721 . Avril, tretient toujours une affez bonne Garnifon. Les Terres des Environs font fort bonnes, on commence à y établir des $\mathrm{Ha}$ bitations, \& bien des Gens croyent qu'avec le tems on $y$ bâtira une Ville.

De Chambly au Lac Champlain, il n'y a que huit lieuës; la Riviere de Sorel traverfe ce Lac, \& il n'eft peut-être point de Canton de la Nouvelle France, qu'il foit plus à propos de peupler. Le Climat y eft plus doux, qu'en aucun endroit de la Colonie, \& les Habitans y auront pour Voifins les Iroquois, qui dans le fond font de bonnes Gens, qui ne chercheront pas à fe brouiller avec nous, quand ils nous verront en état de ne les pas craindre, \& qui s'accommoderont, je crois, encore mieux de ce Voifinage, que de celui de la nouvelle York. Bien d'autres raifons devroient nous engager à cet Etabliffement ; mais fi je vous écrivois tout, je naurois plus rien à vous dire, quand j'aurai l'honneur de vous revoir. Je vais profiter des heures de loifir, que j'ai ici pour continuer à vous entretenir des particularités de ce Pays. J'en fuis demeuréà ce que le Golphe \& le Fleuve de Saint Laurent peuvent fournir au Commerce de la Nouvelle France; il me refte à parler des reffources, que les Habitans y peuvent trouver pour la vie.

Partout, où l'Eau du Fleuve eft falée, c'eft-à-dire, depuis le Cap Tourmente, jufqu'au Golphe, on peut pêcher prefque tous les Poiffons, qui vivent dans l'Ocean ; comme le Saulmon, le Thon, l'Alofe, la Truite, la Lamproye, l'Eperlan, l'Anguille de Mer, le Maquereau, la Sole, le Hareng, l'Anchois, la Sardine, le Turbot, \& beaucoup d'autres, qui font inconnus en Europe. Tous fe prennent à la Senne \& aux Filets. Dans le Golphe, on pêche des Flettans, trois fortes de Rayes, la Commune, la Bouclée, qui eft, dit-on, de meilleur goût qu'en France, \& le Pofteau, qui n'eft pas eftimé; des Lencornets, efpece de Séches; des Goberges, ou Poiffons de Saint Pierre; des Plies, des Requiems, des Chiens de Mer, autre efpece de Requiems, beaucoup moins mauvais pendant leur vie, \&, fans comparaifon, meilleurs après leur mort. Les Huitres font très-abondantes pendant l'Hyver, fur toutes les.

Poiffons, qui fe trouvent dans le Golphe, \& dans le Fleuve Saint Laurent. 


\section{JOUR NAL HISTORIQUE}

- Côtes de l'Acadie, \& la maniere de les y pêcher eft affez fin-

1721. guliere. On fait un Trou à la Glace, on y enfonce deux PerAvril. ches liées enfemble de telle forte, qu'elles font le même jeu que les Tenailles, \& il eft rare qu'on les retire fans une Huitre.

act. eft néanmoins affez différente de la Séche ordinaire. Il eft tout rond, ou plûtôt oval; il a au-deffus de la Queuë une maniere de rebord, qui lui fait comme une rondache, \& la Tête eft environnée de Barbes de la longueur d'un demi pied, dont il fe fert pour prendre d'autres Poiffons. Il y en a de deux efpeces, qui ne différent que par le volume ; les uns font de la groffeur d'une Barrique; les autres ont un pied de long : on ne prend guéres que de ceux-ci, \& on les prend au Flambeau: ils aiment fort la lumiere, on leur en montre fur le Rivage, quand la Marée eft haute, ils s'en approchent, $\&$ ils y demeurent échoués. Le Lencornet roti, bouilli \& fricaffé, eft un fort bon manger; mais il rend la Sauffe toute noire.

De la Go- La Goberge eft comme une petite Moruë; elle en a le goût, berge, de la \& on la fait auffi fecher. Elle a deux Taches noires aux deux

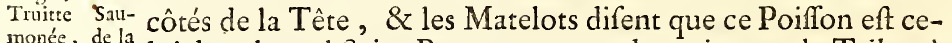
monée, de la lui dans lequel Saint PIERRE trouva dequoi payer le Tribut à l'Empereur Romain, pour Nôtre Seigneur \& pour lui, \& que fes deux Taches font les deux endroits, par où il le prit: $c^{\prime}$ eft pour cela qu'ils lui ont donné le nom de Poiffon Saint Pierre. La Plie de Mer a la Chair plus ferme $8 x$ de meilleur goût, que celle des Rivieres : on la prend, auffi-bien que les Hommarts, ou Ecreviffes de Mer, avec de longs Bâtons armés d'un Fer pointu, terminé par une échancrure, qui empêche les Poiffons de fe débarraffer. Enfin, en plufieurs endroits, fur-tout vers l'Acadie, les Etangs font remplis de Truites Saumonnées longues d'un pied , \& de Tortuës de deux pieds de diametre, dont la Chair eft excellente, \& l'Ecaille fuperieure rayée de blanc, de rouge \&x de bleu.

Dn Poifon Parmi les Poiffons, dont le Lac Champlain, \& les RivieArmé.

res, qui s'y déchargent font remplis, M. de Champlain en a remarqué un affez fingulier, qu'il appelle Chaoufarou; apparemment du nom, que lui donnoient les Sauvages. C'eft une efpece particuliere du Poiffon armé, qu'on trouve en plufieurs autres endroits. Celui-ci a le Corps à peu près de la figure d'un Brochet; 
D'UN VOYA GE DE L'A MER IQ. LET. IX. I 33 Brochet; mais il eft couvert d'une Ecaille à l'épreuve du Poignard: fa couleur eft d'un gris argenté, \& il lui fort de deffous la Gueule une Arrête platte, dentelée, creufe, \& percée par le bout ; ce qui peut faire juger que c'eft par-là qu'il refpire. La Peau, qui couvre cette Arrête, eft tendre, \& fa longueur eft proportionnée à celle du Poiffon, dont elle fait la troifiéme partie. Sa largeur eft de deux doits dans les plus petits. Les Sauvages affurrerent à $\mathbf{M}$. de Champlain qu'il fe rencontroit de ces Poiffons, qui avoient huit à dix pieds de largeur; mais les plus grands, qu'il vit, n'en avoient que cinq, \& ils étoient de la gronfeur de la Cuiffe d'un Homme.

On conçoit bien qu'un tel Animal eft un vrai Pirate parmi les Habitans des Eaux ; mais on n'imagineroit peut-être pas qu'il fait auffi la Guerre aux Habitans des Airs : il la fait néanmoins, \& en habile Chaffeur : voici comment. Il fe cache dans les Rofeaux, de telle forte qu'on ne peut voir que fon Arme, qu'il tient élevée perpendiculairement au-deffus de l'Eau. Les Oifeaux, qui viennent pour fe repofer, prennent cette Arme pour un Rofeau fec, ou un morceau de Bois, \& fe perchent deffus. Ils n'y font pas plûtôt, que le Poiffon, ouvre la Gueule, \& fait fi fubitement le mouvement néceffaire pour ravir fa Proye, que rarement elle lui échape. Les Dents, qui bordent l'Arrête, dont il fe fert fi utilement, font affez longues, \& fort pointuës. Les Sauvages prétendent qu'elles font un Reméde fouverain contre le mal de Tête, \& qu'en picquant, avec une de ces Dents, l'endroit, où la douleur eft la plus vive, on la fait paffer dans l'inftant même.

Ces Peuples ont une adreffe merveilleufe à darder les Poiffons dans l'Eau, fur-tout dans les rapides. Ils pêchent auffi avec la Seine, \& ils s'y difpofent par une Cérémonie affez bizare. Avant que de fe fervir de ce Filet, ils le marient avec deux Filles Vierges, \& pendant le Feftin de Nôce, ils le placent entre les deux Epoufes. On l'exhorte enfuite fort férieufement à prendre beaucoup de Poiffon, \& on croit l'y engager, en taifant de grands préfens à fes prétendus BeauxPeres.

L'Efturgeon eft ici un Poiffon de Mer \& d'Eau douce ; car on en prend fur les Côtes du Canada, \& dans les grands Lacs, qui traverfent le Fleuve de Saint Laurent. Bien des Gens croient que c'eft le véritable Dauphin des Anciens; fi cela eft, Tome III.

Comment ce Poiffon chafe aux Oifeaux.
Mariage de la Seine.
1721 .

Avril. 
1721 . il convenoit que ce Roi des Poiffons dominât également, \& Avril. dans l'Ocean, \& dans les Rivieres. Quoiquil en foit, on voit ici des Efturgeons de huit, dix \& douze pieds de long, \& d'une groffeur proportionnée. Cet Animal a fur la Tête une maniere de Couronne relevée d'un pouce, \& il eft couvert d'Ecailles d'un demi pied de diametre, prefque ovales, $\&$ parfemées de petites figures, qui approchent de celle des Fleurs de Lys des Armes de France. Voici de quelle maniere les Sauvages le pêchent dans les Lacs. Deux Hommes font aux deux extrémités d'un Canot ; celui qui eft derriere, gouverne, l'autre fe tient debout, tenant d'une main un Dard, auquel eft attachée une longue Corde, dont l'autre bout eft noué à une des Barres du Canot. Dès qu'il voit l'Efturgeon à fa portée, il lui lance fon Dard, \& tâche de prendre le défaut des Ecailles. Si le Poiffon eft bleffé, il fuit, \& entraîne le Canot avec affez de rapidité ; mais après avoir nagé l'efpace d'environ cent cinquante pas, il meurt, \& alors on retire la Corde, \& on le prend. Il y a une petite efpece d'Efturgeon, dont la Chair eft fort tendre , \& très-délicate.

Poiffons par-

Le Fleuve de Saint Laurent nourrit plufieurs Poiffons, qui riculiers enca- ne font point connus en France. Les plus eftimés font l'Achinada. gan, \& le Poiffon Doré. Les autres Rivieres du Canada, \& fur-tout celles de l'Acadie, ne font pas moins bien partagées, que ce Fleuve, le plus Poiffonneux peut-être de tout l'Univers, \& celui où il y a de plus de fortes de Poiffons, \& des: meilleurs. Il y a des Saifons, où le feul Poiffon pourroit nourrir toute la Colonie. Mais je ne fçai quelle croyance on doit donner à ce que j'ai vû dans la Relation Manufcrite d'un Ancien Miffionnaire, qui affûre avoir vû un Homme Màrin dans. la Riviere de Sorel, trois lieciës au-deffous de Chambly. La Relation eft écrite avec beaucoup de jugement ; mais pour mieux conftater le fait, $\&$ pour montrer qu'une premiere apparence ne l'a point trompé, l'Auteur auroit dû ajoûter à fon Récit la Defcription de ce Monftre. On eft quelquefois faifi au premier coup d' $\mathbb{E}$ il d'une reffemblance, qui avec des yeux attentifs, \& des regards réfléchis, s'évanouit d'abord. Au refte, fi ce Poiffon de figure Humaine étoit venu de la Mer, il auroit fait bien du chemin pour remonter fi près de Chambly, \& il feroit affez furprenant qu'on ne l'eût apperçu qu'en cet endroit. 
Il s'en faut beaucoup que nos Forêts foient aufi-bien partagées en Oifeaux, que nos Lacs \& nos Rivieres le font en Poiffons. Il y en a néanmoins, qui ont leur mérite, \& qui font particuliers à l'Amérique. On voit ici des Aigles de deux efpeces. Les plus gros ont la Tête \& le Cou prefque blancs; ils donnent la Chaffe aux Lapins $\& x$ aux Lievres, les prennent dans leurs Serres, \& les emportent dans leurs Magafins \& dans leurs Nids. Les autres font tout gris, \& fe contentent de faire la Guerre aux Oifeaux : tous font auffi d'affez bons Pêcheurs. Le Faucon, l'Autour, le Tiercelet, font abfolument les mêmes, qu'en France; mais nous avons une feconde efpece de Faucons, qui ne vivent que de la Pêche.

Nos Perdrix font de trois efpeces; des grifes, des rouges, $\& x$ des noires : celles-ci font les moins eftimées; elles fentent trop le Raifin , le Genievre \& le Sapin : elles ont la Tête \& les Yeux de Faifans, \& la Chair brune. Toutes ont la Queuë longue, \& l'ouvrent en Evantail, comme le Cocq-d'Inde : ces Queuës font fort belles; les unes font mêlées de rouge, de brun \& $x$ de gris; les autres de gris clair \& de gris brun. J'ai dit que les Perdrix noires ne font pas les plus eftimées; quelques-uns néanmoins les préferent aux rouges mêmes. Toutes font plus groffes qu'en France ; mais fi fottes, qu'elles fe laiffent tirer, \& même approcher, fans prefque remuer.

Outre les Bécaffines, qui font excellentes en ce Pays, \& le petit Gibier de Riviere, qui y eft partout en abondance, on trouve quelques Bécaffes autour des Fontaines; mais en petit nombre. Aux Illinois, \& dans toute la Partie Méridionnale de la Nouvelle France, elles font plus communes. M. Denys affurre que les Corbeaux de Canada font auffi bons à manger, que les Poules. Cela peut être vrai du côté de l'Acadie ; mais je ne vois pas qu'en ces Quartiers-ci, on en foit bien perfuadé. Ils font plus gros qu'en France, un peu plus noirs, \& ont un cri différent de celui des nôtres. Les Orfrayes, au contraire, font plus petites, \& leur cri n'eft pas auffi défagréable. Le Chathuant Canadien, n'a de différence duFrançois, qu'une petite Fraife blanche autour du Cou, \& un cri particulier. Sa Chair eft bonne à manger, \& bien des Gens la préferent à celle de la Poule. Sa Provifion pour l'Hyver font des Mulots, aufquels il caffe les Pattes, \& qu'il engraiffe $\&$ nourrit avec foin, jufqu’à ce qu'il en ait befoin. La

Des Perdrix de trois efpééces.

I 721 .

Avril.

Aigles de deux efpéces.

\author{
.
}


I 72 I. Chauve-Souris eft ici plus groffe qu'en France. Les Merles \& Avril les Hyrondelles, y font des Oifeaux de Paffage, comme en Europe. Les premiers ne font pas noirs, mais tirant fur le rouge. Nous avons trois fortes d'Allouettes, dont les plus petites font de la groffeur du Moineau. Le Moineau lui-même eft un peu différent du nôtre : il a bien les mêmes inclinations, mais fa phyfionomie eft affez mauvaife.

On voit dans ce Pays une quantité prodigieufe de Canards; \& j’en ai oüi compter jufqu'à vint-deux efpeces différentes. Les plus beaux, \& ceux, dont la Chair eft plus délicate, font les Canards Branchus : on les appelle ainfi, parce qu'ils perchent fur les Branches des Arbres. Leur Plumage eft extrêmement varié, \& fort brillant. Les Cygnes, les Poulesd'Inde, les Poules-d'Eau, les Gruës, les Serfelles, les Oyes, les Outardes, \& autres grands Oifeaux de Riviere, fourmillent partout, fi ce n'eft au Voifnage des Habitations, dont ils n'approchent point. Nous avons des Gruës de deux couleurs; les unes font toutes blanches; les autres d'un gris de lin. Toutes font d'excellens Potages. Nos Picverts, ou Picque-Bois, font d'une grande beauté. Il y en a, qui ont toutes les couleurs; d'autres font noirs, ou d'un brun obfcur partout le Corps, excepté la Tête $\&$ le Cou, qui font d'un très-beau rouge.

Le Roffignol du Canada eft à peu près le même, que celui de France pour la figure; mais il n'a que la moitié de fon Chant; le Roitelet lui en a dérobé l'autre moitié. Le Chardonneret n'a pas la Tête auffi belle, qu'en Europe, \& tout fon Plumage eit mêlé de jaune \& de noir. Comme je n'en ai point vî en Cage, je ne fçaurois vous rien dire de fon Chant. Tous nos Bois font remplis d'une forte d'Oifeau de la groffeur d'une $\mathrm{Li}-$ notte, lequel eft tout jaune, \&x a le Gofier affez fin; mais fon Chant eft fort court, \& n'eft point varié. Il n'a point d'autre nom, que celui de fa coukeur. Une efpece d'Ortolan, dont le Plumage eft cendré fur le Dos, \& blanc fous le ventre, \& qu'on a nommé l'Oifeau Blanc, eft celui de tous les Hôtes de nos Bois, qui chante le mieux. Il ne le céde guéres au Roffignol de France; mais il n'y a que le Mâle, qui fe faffe entendre; la Femelle, dont la couleur eft plus foncée, ne dit mot, même en Cage. Ce petit Animal a la phyfionomie fort belle, \& il eft bien nommé Ortolan pour le goût. Je ne fçai où il fe retire pendant l'Hyver; mais il eft toujours le premier, qui 
D'U N VOYA GE DE L'A MERIQ. LET. IX. I 57 nous annonce le retour du Printems. A peine la Neige eft-elle fonduë en quelques endroits, qu'il y accourt en grande troup$\mathrm{pe}, \& \mathrm{x}$ on en prend alors tant que l'on veut.

Ce n'eft guéres qu'à cent lieuës d'ici, en tirant au Sud, que l'on a commencéa voir des Cardinaux. Il y en a quelques-uns à Paris, qu'on y a tranfportés de la Louyfiane, \& je crois quils feront fortune en France, s'ils peuvent y multiplier, comme les Serins. La douceur de leur Chant, l'éclat de leur Plumage, qui eft d'un beau rouge incarnat; une petite Aigrette, quilis ont fur la Tête, \& qui ne reffemble pas mal à ces Couronnes, que les Peintres donnent aux Rois Indiens \& Amériquains, femblent leur affûrer l'Empire des Airs. Ils ont pourtant ici un Rival, qui auroit même pour lui l'unanimité des fuffrages, s'il flatoit aufi agréablement les Oreilles, qu'il charme les Yeux: c'eft ce qu'on appelle en ce Pays-ci l'Oifeau Mouche.

Ce nom a deux origines. La premiere, eft fa petiteffe même; car avec fes Plumes, il n'eft guéres d'un plus gros volume, que Moushe. le Hanneton ordinaire. La feconde, eft un Bourdonnement affez fort, quill fait avec fes Aîles, \& $x$ qui eft affez femblable à celui, que font les groffes Mouches. Ses Pattes, qui ont un pouce de long, font comme deux Aiguilles; fon Bec eft de même, \&x il en fait fortir une petite Trompe, qu'il enfonce dans les Fleurs, pour en attirer le Suc, dont il fe nourrit. La Femelle n'a rien de brillant, un affez beau blanc fous le Ventre, \& un cendré clair fur-tout le refte du Corps, font toute fa parure : mais le Mâle eft un vrai Bijoux. Il a fur le haut de la Tête une petite Touffe d'un beau noir, la Gorge rouge, le Ventre blanc, le Dos, les Aîles \& la Queuë d'un verd de Feuilles de Rofiers; une couche d'Or répanduë fur tout ce Plumage, y ajoûte un grand éclat, \& un petit Duvet imperceptible y produit les plus belles nuances, qui fe puiffent voir.

Quelques Voyageurs l'ont confondu avec le Colibry; \& en effet il paroit quil en eft une efpece : mais le Colibry des difiereduccolInles eft un peu plus gros, a le Plumage moins brillant, \& le Bec un peu recourbé en bas. Je pourrois néanmoins me tromper fur l'éclat de fon Plumage, parce que je n'en ai point vû de vivant : quelques-uns ont avancé qu'il a un Chant fort mélodieux : fil le fait eft vrai, c'eft un grand avantage, qu'il a fur l'Oifeau Mouche, que perfonne n'a encore entendu chan-

1721.

Avril.

Des Cardinaux. 
I 72 I. ter. Mais j’ai entendu moi - même une Femelle, qui fifloit Avril. l'Aîle extrêmement forte, \& le Vol d'une rapiditéfurprenante. Vous le voyez fur une Fleur, \& dans le:moment il s'éleve en l'Air prefque perpendiculairement. Il eft Ennemi du Corbeau, \& Ennemi dangereux. J'ai oüi dire à un Homme digne de foi, qu'il en a vâ un quitter brufquement une Fleur, qu'il fuçoit, s'élever comme un Eclair, aller fe fourrer fous l'Aîle d'un Corbeau, qui planoit fort haut, le percer de fa Trompe, \& le faire tomber mort, foit de fa chute, foir de la bleffure, qu'il avoit reçûë.

L'Oifeau Mouche s'attache aux Fleurs, qui ont l'odeur plus forte, \& il les fuce en voltigeant toujours : mais il fe repofe de tems en tems, \& alors on a tout le loifir de le contempler. On en a nourri quelque tems avec de l'Eau fucrée \& des Fleurs. J'en ai gardé autrefois un pendant vint-quatre heures : il fe laiffoit prendre, \& manier, \& contrefaifoit le mort ; dès que je le làchois, il reprenoit fon vol, \& ne faifoit que papillonner au tour de ma Fenêtre. J'en fis prélent à un de mes Amis, qui le lendemain matin le trouva mort, \& cette nuit-là même il avoit fait une petite gelée. Auffi ces petits Animaux ont - ils grand foin de prévenir les premiers froids.

Il y a bien de l'apparence qu'ils fe retirent vers la Caroline, où l'on affûre qu'on ne les voit qu'en Hyver. Ils font leurs Nids en Canada, où ils les fufpendent à une Branche d'Arbre, $\&$ les tournent de telle forte, qu'ils font à l'abri de toutes les injures de l'Air. Rien n'eft fi propre que ces Nids. Le fond en eft de petits brins de Bois entrelaffés en maniere de Pannier, $\& x$ le dedans eft revêtu de je ne fçai quel Duvet, qui paroît de Soye. Les Eufs font de la grofleur d'un Pois, \& ont des taches jaunes fur un fond blanc. On dit que la portée ordinaire eft de trois, \& quelquefois de cinq.

Du Serpent

Parmi les Reptiles de ce Pays, je ne connois encore que le as sonnetres. Serpent à Sonnettes, qui mérite quelque attention. On en voit qui font gros comme la Jambe d'un Homme, quelquefois même il s'en trouve de plus gros, \& ils font longs à proportion. Mais il y en a, \& je crois que c'eft le plus grand nombre, qui ne furpaffent, ni en groffeur, ni en longueur nos plus grandes Couleuvres de France. Leur figure eft affez finguliere. Sur un Cou plat \& fort large, ils ont une affez petite Tête. 
D'UN VOYAGE DE L'A MERIQ. LeT. IX. I59 Leurs Couleurs font vives, fans être brillantes, le jaune pâle y domine avec d'affez belles nuances.

Mais ce que cet Animal a de plus remarquable, c'eft fa Queuë : elle eft écailleufe en cotte de maille, un peu aplatie, $\&$ elle croît, dit-on, tous les ans d'une rangée d'Ecaille. Enforte qu'on connoît fon âgeà fa Queuë, comme celui de Chevaux à leurs Dents. En la remuant il fait le même bruit, que la Cigale en volant; car vous fçavez fans doute, Madame, que le prétendu chant de la Cigale, n'eft que le bruit, qu'elle fait avec fes Aîles. Au refte, la reffemblance, dont je parle, eft fi parfaite, que j’y ai été trompé moi-même. C'eft ce bruit, qui a fait donner à ce Serpent le nom, qu'il porte.

Sa morfure eft mortelle, fi on n'y remédie fur le champ, mais la Providence y a pourvû. Dans tous les endroits, où fe rencontre ce dangereux Reptile, il croît une Plante, à laquelle on a donné le nom d'Herbe à Serpent à Sonnettes, \& dont la Racine eft un Antidote fûr contre le Venin de cet Ani$\mathrm{mal}$ : il ne faut que la piler, ou la mâcher, \& l'appliquer comme un Cataplafme fur la Playe. Cette Plante eft belle $\&$ facile à reconnoître. Sa Tige ronde, un peu plus grofle, qu'une Plume d'Oye, s'éleve à la hauteur de trois ou quatre pieds, $\&$ fe termine par une Fleur jaune de la figure, \& de la grandeur d'une Marguerite fimple. Cette Fleur a une odeur trèsdouce. Les Feuilles de la Plante font ovales, étroites, foûtenuës cinq à cinq en Patte de Poule-d'Inde, par un pédicule d'un pouce de long.

Il eft rare que le Serpent à Sonnettes attaque les Paffans, qui ne lui cherchent point noife : j'en ai eu un à mes Pieds, qui eut affûrément plus de peur, que moi, car je ne l'apperçus, que quand il fuyoit. Mais fi on marche fur lui, on eft piqué d'abord, \& fi on le pourfuit, pour peu qu'il ait le loifir de fe reconnoître, il fe replie en rond, fa Tête au milieu, \& s'élance d'une grande roidèur contre fon Ennemi. Les Sauvages ne laiffent pas de lui donner la chaffe, \& trouvent fa Chair très-bonne: j’ai même oui dire à des François, qui en avoient goûté, que ce n'étoit pas un mauvais manger. Mais c'étoit des Voyageurs, \& ces Gens - là trouvent tout bon, parce quils ont fouvent faim. Du moins eft-il certain qu'elle ne fait point de mal.

Je ne fçai, Madame, fi je dois entreprendre de vous parler 
des Bois du Canada. Nous fommes au milieu des plus grandes

I 72. I. Forêts du Monde; felon toutes les apparences, elles font Avril. auffi anciennes que le Monde même, \& n'ont point été plantées de Mains d'Hommes: à la vûe, rien n'eft plus magnifique, les Arbres fe perdent dans les Nuës, \& il y a une variété d'efpeces differentes fi prodigieufe, que parmi ceux mêmes, qui fe font le plus appliqués à les connoître, il n'eft peut-être perfonne, qui n'en ignore plus de la moitié. Quant à leur qualité, \&x à l'ufage, où on les peut employer, les fentimens font $\mathrm{fi}$ differens, $\&$ dans le Pays, où nous fommes, $\&$ dans celui, où vous êtes, que je déferpere même d'être jamais en état de vous inftruire, autant que je le fouhaiterois, fur cet article. Au moins pour le préfent dois-je me borner à quelques obfervations fur ce que jai vû par moi-même, \& fur ce que j’ai oui dire à Gens, "qui ont, \& plus d'expérience, \& plus d'habileté que moi en cette matiere.

Ce qui a d'abord le plus frappé mes yeux, en arrivant la

Des pins de
dea: efpeces. premiere fois en ce Pays, ce font les Pins, les Sapins, \& les Cédres, qui font d'une groffeur $\&$ d'une hauteur furprenante. Il y a jci deux fortes de Pins, tous produifent une Réfine fort propre à faire le Bray \& le Godron. Les Pins Blancs, au moins quelques-uns, jettent aux extrémités les plus hautes une efpece de Champignon femblable à du Tondre, que les Habitans appellent Guarigue, \& dont les Sauvages fe fervent avec fuccès contre les Maux de Poitrine, \& contre la Dyffenterie. Les Pins rouges font plus gourmeux \& plus mafifis, mais ne viennent pas fi gros. Les Terroirs, qui produifent les uns \& les autres, ne font pas les plus propres à produire du Grain ; ils font ordinairement compofés de Gravier, de Sable, \& de Terre-Glaife.

Cuarre ef-

Il y a quatre efpeces de Sapin en Canada. La premiere refpeces desapin. femble à la nôtre; les trois autres font l'Epinette blanche, l'Epinette rouge, \& la Peruffe. La feconde \& la quatriéme s'élevent fort haut, \& font excellentes pour la Mâture, furtout l'Epinette blanche, dont on fait aufi de bonne Charpente. Elle croît ordinairement dans des Terres humides \& noires, mais qui étant defféchées, peuvent porter toutes fortes de Grains. Son Ecorce eft unie \& luifante, \& $\mathrm{x}$ il s'y forme de petites Veffies de la groffeur d'une Féve de Haricot, qui contient une efpece de Térebenthine fouveraine pour les Playes, 
D'U N VOYAGE DE L'A MERIQ. LET. IX. I6I Playes, qu'elle guérit en très-peu de tems, \& même pour les Fractures. On affûre qu'elle chaffe la Fiévre, \& guérit les Maux d'Eftomach \& de Poitrine. La maniere d'en ufer eft d'en mettre deux gouttes dans un Bouillon. Elle a auff la qualité de purger. C'eft ce qu'on appelle à Paris le Baume Blanc.

L'Epinette rouge ne reffemble prefque en rien à l'Epinette blanche. Son Bois eft maffif, \& peut être d'ufage pour la Conftruction \& la Charpente. Les Terres, où elle croît ne font que Gravier \& Argile. La Peruffe eft gommeufe, mais elle ne jette pas affez de gomme, pour qu'on en puiffe faire ufage: Son Bois dure lontems en Terre fans fe pourrir, ce qui le rend très-propre à faire des Clôtures. Son Ecorce eft fort bonne pour les Tanneurs, \& les Sauvages en font une Teinture, qui tire fur le Turquin. La plupart des Terres, où croît cet Arbre, font Argilleufes, j’en ai pourtant vû de trèsgros dans des Terres Sablonneufes, mais peut-être que fous le Sable il y avoit de l'Argile.

Les Cédres font de deux fortes, blancs \& rouges. Ceux-là font les plus gros: on en fait des Clôtures, \&r c'eft le Bois, qu'on employe plus ordinairement pour faire des Bardeaux, à caufe de fa légereté. Il diftile une efpece d'Encens, mais il ne porre point de Fruits femblables à ceux du Mont Liban. Le Cédre rouge eft plus petit, \& moins gros à proportion. La difference la plus fenfible, qui fe remarque entre l'un $\&$ l'autre, c'eft que toute l'odeur du Premier eft dans fes Feuilles, \& celle du Second dans le Bois ; mais celle-ci eft beaucoup plus agréable. Le Cédre, au moins le blanc, ne vient que dans de très-bonnes Terres.

Il y a par-tout en Canada des Chênes de deux fortes, diftingués par les noms de Chênes Blancs, \& de Chênes Rouges. Les Premiers fe trouvent fouvent dans des Terres baffes, hu- fiers, Noyers, mides, fertiles, \& propres à produire des Grains \& des Légumes. Les Rouges, dont le Bois eft moins eftimé, croiffent dans les Terres féches \& Sablonneufes. L'un \& l'autre portent du Gland. L'Erable eft auffi très-commun en Canada, \& $x$ il y en a de fort gros; dont on fait d'affez beaux Meubles. Le Terroir, qui le produit, eft élevé, \& le plus propre aux Arbres Fruitiers. On appelle ici Rhene l'Erable Femelle, dont Le Bois eft fort ondé, mais plus pâle que le Mâle ; d'ailleurs, Tome III.

Deux fortes de Cédres.

721

Avril. Cedresions 

il en a toute la figure \& les proprietés; mais il lui faut un TerAvril. roir humide \& fertile.

Le Mérifier, qui fe trouve pêle-mêle avec l'Erable, \& avec le Bois Blanc, eft très-beau pour faire des Meubles; il jette beaucoup plus d'Eau que l'Erable, mais elle eft amere, \& le Sucre, qu'on en fait, ne perd jamais fon amertume. Les Sauvages fe fervent de fon Ecorce contre certaines Maladies, qui furviennent aux Femmes. Il y a en Canada trois fortes de Frênes; le Franc, le Metif \& le Bâtard. Le Premier, qui vient parmi les Erables, eft propre pour la Charpente, \& pour faire des Futailles deftinées aux Marchandifes féches. Le Second a les mêmes propriétés, \& ne vient, non plus que le Bâtard, que dans des Terres baffes \& fertiles.

On compte auffi dans ce Pays trois efpeces de Noyers; le Dur, le Tendre, \& un Troifiéme, qui a l'Ecorce très-fine. Le Noyer Dur produit de très-petites Noix, bonnes à manger, mais difficiles à vuider. Son Bois n'eft bon qu'à brûler. Le Noyer Tendre a des Noix longues, \& auff groffes que celles de France, mais les Coques en font très-dures. Les Cerneaux en font excellens. Le Bois n'en eft pas $f i$ beau que le nôtre; mais en récompenfe il eft prefque incorruptible, \& en Tcire, \& $x$ dans l'Eau, \& difficile à confumer par le Feu. Le Troifiéme produit des Noix de la groffeur de celles du Premier, mais en plus grande quantité, ameres, \& renfermées dans des Coques fort tendres : on en fait de très-bonne Huile. Cet Arbre produit de l'Eau plus fucrée que celle de l'Erable, mais en petite quantité. Il ne vient, non plus que le Noyer Tendre, que dans les meilleures Terres.

Les Hêtres font ici fort abondans par Contrées : j’en ai vî fur des Côteaux fablonneux, \& dans des Terres baffes trèsfertiles. Ils portent beaucoup de Faynes, dont il feroit aifé de tirer de l'Huile. Les Ours en font leur principale nourriture, auffi-bien que les Perdrix. Le Bois en eft fort tendre, \& bon à faire des Rames pour les Chaloupes: mais les Avirons de Canots fe font de Bois d'Erable. Le Bois Blanc, qui

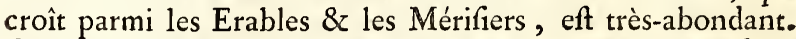
Ces Arbres viennent fort gros , \& droits; on en peut faire des Planches \& des Madriers, \& même des Futailles pour les Marchandifes féches. Il eft doux, \& fort aifé à mettre en $œ u-$ vre. Les Sauvages en levent les Ecorces pour couvrir leur\$ Cabannes. 
DUN VOYAGE DE L'A MERIQ. LET. IX. 163

Les Ormes font fort communs dans tout le Pays. Il y en a de blancs \& de rouges. Le Bois de ceux-ci eft plus difficile à travailler, mais il dure plus. C'eft de l'Ecorce de l'Orme rouge, que les Iroquois font leurs Canots: on en voit d'une feule piéce, où il peut tenir vint Hommes. Il y en a aufi de creux, où les Ours $\&$ les Chats Sauvages fe retirent depuis le mois de Novembre, jufqu'en Avril. Le Tremble vient ordinairement le long des Rivieres, \& des Mares.

On trouve dans les Bois les plus touffus un grand nombre de Pruniers, chargés de Fruits, mais fort âcres. Le Vinaigrier eft un Arbriffeau très-moëleux, qui produit un Fruit aigre en Grappes, de couleur de Sang de Bœuf. On les fait infufer dans de l'Eau, \& 2 on en fait une efpece de Vinaigre. Le $P$ emine eft une autre efpece d'Arbriffeau, qui croît le long des Ruiffeaux $\&$ des Prairies : il porte auffi un Fruit en Grappe d'un rouge très-vif \& aftringent. Il y a trois fortes de Grofeilles naturelles au Pays. Ce font les mêmes qu'en France. Le Bleuet eft ici comme en Europe, par Contrées. Ce Fruit eft merveilleux pour guérir en peu de tems la Dyfenterie. Les Sauvages le font fécher, comme on fait en France les Cerifes.

L'Atoca eft un Fruit à Pepins, de la groffeur des Cerifes. La Plante, qui eft rampante dans les Marais, produit fon Fruit dans l'Eau. Ce Fruit eft âcre, \& on en fait des Confitures. L'Epine blanche fe trouve le long des Rivieres, \& produit beaucoup de Fruits à trois Noyaux. C'eft la nourriture de plufieurs Bêtes Sauvages. On appelle ici Cotonnier une Plante, qui pouffe, comme l'Afperge, à la hauteur d'environ trois pieds, $8 x$ au bout de laquelle viennent plufieurs Touffes de Fleurs. Le matin, avant que la Rofée foit tombée, on fecouë ces Fleurs, \& $\&$ il en tombe avec l'Eau une efpece de Miel, qui fe réduit en Sucre, après qu'on l'a fait bouillir. La Graine fe forme dans une Gouffe, qui contient une forte de Cotton.

Le Soleil eft une autre Plante fort commune dans les Champs des Sauvages, \& qui vient de la hauteur de fept à huit pieds. Sa Fleur fort groffe a la figure de celle du Souci, \& fa Graine eft rangée de même. Les Sauvages, en la faifant bouillir, en tirent une Huile, dont ils fe graillent les Cheveux. Les Légumes, que ces Peuples cultivent le plus, font $X$ ij

I 721 . Avril.

Ormes de deux efpeces.

Arbres particuliers au Pays. 


\section{J O UR NAL HISTOR I Q U E}

$172 \mathrm{I}$. le Maï, ou Bled de Turquie, le Haricot, les Citrouilles, $\&$ les Melons. Ils ont une efpece de Citrouilles plus petites Avril. que les nôtres, \& qui ont un goût fucré. On les fait cuire toutes entieres dans l'Eau, ou fous la Cendre, \& on les mange ainfi, fans y rien ajoûter. Les Sauvages connoiffoient, avant notre arrivée dans leur Pays, les Melons ordinaires, $\&$ les Melons d'Eau. Les Premiers font aufii bons qu'en France, furtout dans cette Inle, \& ils y font très-abondans. Le Houblon \& le Capillaire font auffi des productions naturelles du Canada; mais le Capillaire y croît beaucoup plus haut, \& il eft infiniment meilleur qu'en France. Voilà, Madame, une Lettre, à laquelle vous reconnoîtrez aifément un Voyageur, qui fe promene dans les Forêts \& dans les Plaines du Canada, \& qu'on y entretient de tout ce qui fe préfente à fa vûë. Mais que pouvez-vous attendre d'un Homme, qui parcourt un Pays comme celui-ci?

Je fuis, \&c.

\section{IXIE ME L ETTRE.}

Des Caufes du Froid du Canada. Des Reffources, qu'on y trouve pour la Vie. Du Carastere des Francois Canadiens.

A Montreal, ce vint-deuxiéme d'Avril, $172 \mathrm{I}$.

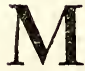

A D A M E,

On ne con-

IL eft furprenant qu'en France, où l'on voit fi fouvent des noît en France le Canada que par fon mauvais côté.

Perfonnes, qui ont paffé une bonne partie de.leur vie en Canada, on ait une idée fi peu jufte de ce Pays. Cela vient fans doute de ce que le plus grand nombre de ceux, à qui on s'adreffe, pour en apprendre des nouvelles, ne le connoiffent, que par fon mauvais côté. L'Hyver eft ordinairement commencé avant que les Vaiffeaux mettent à la Voile pour retourner en France, \& il commence toujours de maniere à étonner quiconque n'y eft pas fait. Les premieres Gélées rem- 
D'U N V OYA GE DE L'A MERIQ. LET. X. I 65 pliffent en peu de jours les Rivieres de Glaçons, \& bientôt la Terre eft couverte de Néges, qui durent fix mois, \& s'élevent toujours à la hauteur de fix pieds dans les endroits, 1721. où le vent n'a point de prife.

A la vérité on ne manque point de Bois pour fe précautionner contre le Froid, qui devient bientôt extrême, \& empiette Froid. Excès du beaucoup fur le Printems: mais c'eft quelque chofe de fort trifte, que de ne pouvoir fortir au-dehors, fans être glacé, : moins que d'être fourré comme les Ours. D'ailleurs, que fpectacle, qu'une Nége, qui vous éblouit, \& vous cach toutes les beautés de la Nature? Plus de difference entre le Rivieres \& les Campagnes, plus de variété, les Arbres même font couverts de Frimats, \& il pend à toutes leurs Branches des Glaçons, fous lefquels il n'y a pas trop de fûreté à fe trouver. Que peut-on penfer, quand on voit aux Chevaux des Barbes de Glaces d'un pied de long, \& comment voyager dans un Pays, où les Ours mêmes pendant fix mois n'ofent fe montrer à l'Air? Auffi n'ai-je jamais paffé d'Hyver dans ce Pays, que je n'aye vû apporter à l'Hôpital quelqu'un, ̀̀ qui il falloit couper des Bras \& des Jambes gelés. En effet, fi le Ciel eft ferein, il foufle de la Partie de l'Oueft un Vent, qui coupe le Vifage. Si le Vent tourne au Sud, ou à l'Ent, le tems s'adoucit un peu, mais il tombe une Nége fi épaife, qu'on ne voit pas à dix pas en plein midi. S'il furvient un Dégel dans les formes, adieu les Chapons de rente, les Quartiers de Boufs ou de Moutons, les Volailles \& les Poiflons, qu'on avoit mis dans les Greniers fur la bonne foi de la Gelée; enforte que, malgré les rigueurs d'un Froid exceffif, on eft encore réduit à fouhaiter qu'il ne difcontinuë pas.

On a beau dire que les Hyvers ne font plus auffi rudes, qu'ils l'étoient il y a quatre-vint ans, \& que felon toutes les apparences ils s'adouciront encore dans la fuite : le mal de ceux, qui font venus avant nous, $\&$ le bonheur de ceux, qui viendront après, ne guérit point le mal préfent, que nous fouffrons. Un Créole de la Martinique, qui feroit débarqué pour la premiere fois en France pendant le grand Froid de 1709, auroit-il été fort foulagé de m'entendre dire à moi, qui revenois alors de $Q u e b e c$, que ces Froids n'étoient pas encore au point de ceux du Canada? Je lui aurois pourtant dit vrai, \& j'en avois de bons témoins; mais il auroit pu me ré- 
1721 . pondre qu'il n'en trouvoit pas le Froid de France moins piAvril. quant, en apprenant qu'il en faifoit encore de plus vifs dans le Canada.

Cependant, dès que le mois de Mai eft venu, on change bientôt de langage; la douceur de cette fin du Printems, d'autant plus agréable, qu'elle fuccede à une Saifon plus rigoureufe : la chaleur de l'Eté, qui nous fait voir en moins de quatre mois les Semences \& les Recoltes $(a)$, la ferenité de l'Automne, pendant lequel on jouit d'une fuite de beaux jours, qu'on voit rarement dans la plûpart des Provinces de France : tout cela, joint à la liberté, dont on jouit en ce Pays, forme une compenfation, qui en fait trouver à bien des Gens le féjour pour le moins auffi agréable, que celui du Royaume, où ils font nés, \& il eft cêrtain que nos Canadiens ne balancent pas à lui donner la préférence.

InconvéAprès tour, il y a dans ces Froids î âpres \& fi longs, des niens du grand inconvéniens, auxquels on ne fçauroit jamais bien remédier. froid.

Je mets au premier rang la difficulté de nourrir les Beftiaux, qui pendant tout l'Hyver ne peuvent abfolument rien trouver dans les Campagnes; par conféquent coûtent beaucoup à nourrir, \& dont la Chair, après fix mois d'une nourriture féche, n’a prefque point de goût. Il faut auffi bien du Grain pour les Volailles, \& de grands foins pour les conferver pendant un fi long tems. Si on évite la dépenfe, en tuant à la fin d'OEtobre toutes les Bêtes, qu'on veut manger jufqu'au mois de Mai ; vous jugez bien qu'une telle Viande eft fort infipide, $\&$ de la maniere, dont je vous ai dit qu'on pêche le Poiffon à travers la Glace, il ne fçauroit être fort abondant; outre qu'il eft d'abord gelé: de forte qu'il eft prefqu'impoffible d'en avoir de frais dans la Saifon, où il eft plus difficile de s'en paffer. On feroit même fort embarrafré pendant le Carême, fans la Moruë \& les Anguilles. De Beure \& d'CEufs frais, il n'en eft point queftion, \& il n'y a guéres plus à compter fur les Légumes, qu'on garde comme on peut dans des Celiiers, mais qui n'ont prefque plus aucune vertu, quand ils y ont été pendant quelques mois.

(a) On laboure les Terres pendant l'Automne: on feme depuis la mi-Avril jufqu'au dixiéme de $\mathrm{Mai}$. On coupe les Bleds depuis le quinziéme d'Août jufquau vintiéme de
Septembre. Les Terres, qu'on n'a labourées qu'au Printems, rapportent moins, parce que les partics nitreufes de la Nége ne $\$^{2} y$ infinuent pas fi bien. 
D'UN VOYAGE DE L'A MERIQ. LET. X. Í́7

Ajoûtez à cela, qu'à l'exception des Pommes, qui font ici d'une excellente qualité, $\&$ des petits Frtits d'Eté, qui ne fe gardent point, les Fruits de France n'ont point encore réufin 1721 . en Canada. Voilà, Madame, tous les défavantages, que Avril. nous caufe le grand Froid. Nous fommes cependant auff près du Soleil, qu'on y eft dans les Provinces les plus Méridionnales de France, \& à mefure qu'on avance dans la Colonie, on s'en approche encore. D'où peut donc venir cette différence de Température fous les mêmes Paralleles ? C'eft ce que perfonne, à mon avis, n'a encore bien expliqué.

La plupart des Auteurs, qui ont traité cette matiere, fe font contentés de dire que ces Froids fi longs $\&$ fi durs viennent de ce que la Nége demeure fi lontems fur la Terre, qu'il n'eft pas poffible, qu'elle s'échauffe jamais bien, furtout dans les endroits couverts : mais cette réponfe ne fait qu'éloigner la difficulté; car on demandera, qu'eft-ce qui produit cette abondance de Néges fous des Climats auffi chauds que le Languedoc \& la Provence, \& $x$ dans des Cantons beaucoup plus éloignés des Montagnes?

Le Sieur Denys, que j'ai déja cité plus d'une fois, affûre que les Arbres reprennent leur Verdure avant que le Soleil foit affez élevé fur l'Horifon, pour fondre la Nége, \&z pour échauffer la Terre; cela peut être vrai en Acadie \& fur tous les Bords de la Mer, mais par-tout ailleurs il eft certain que toutes les Néges font fonduës dans les plus épaiffes Forêts, avant qu'il y ait une Feuille aux Arbres. Cet Auteur ne paroît pas mieux autorifé à prétendre que les Néges fondent plutôt par la chaleur de la Terre, que par celle de l'Air, \&que c'eft toujours par-deffous qu'elles commencent à fe fondre : car à qui perfuadera-t'il qu'une Terre couverte d'une Eau gelée, ait plus de chaleur que l'Air, qui reçoit immédiatement les Rayons du Soleil. D'ailleurs il ne répond point à la queftion fur la caufe de ce Déluge de Néges, qui inonde des Pays immenfes, fous le milieu de la Zone temperée.

Il n'eft pas douteux qu'à parler en général, les Montagnes, les Eois, \& les Lacs, n'y contribuent beaucoup, mais il me paroît qu'il en faut encore chercher d'autres caufes. Le Pere Jofeph BRESSANI, Jéfuite Romain, qui a pafié les plus belles années de ra vie en Canada, nous a laiffé dans fa Langue naturelle une Relation de la Nouvelle France, où il s'attache

Rétexiors fur les caufis de ce graud froid. . 
1721 .

Avril.

à éclaircir ce point de Phyfique. Il ne peut fouffrir qu'on attribuë les Froids, dont nous cherchons la caufe, à tout ce que je viens de dire; mais il me femble quil va trop loin; car il n'y a rien à répliquer contre l'expérience, qui nous rend fenfible la diminution du Froid, à mefure que le Pays fe découvre, quoique ce ne foit pas à proportion de ce qu'elle devroit être, fi l'épaiffeur des Bois en étoit la caufe principale.

Ce qu'il avouë lui-même, qu'il n'eft point rare de voir en Eté de la Gelée pendant la Nuit après une Journée fort chaude, me paroît une démonftration contre lui : car comment expliquer ce Phénomene autrement, qu'en difant que le Soleil ayant ouvert pendant le jour les Pores de la Terre, l'humidité, qui y étoit encore renfermée, les Parties de Nître, que la Nége y a laiffées en quantité, \& la chaleur, que conterve après le Coucher du Soleil un Air auffi fubtile, que celui, qu'on refpire en ce Pays, forment ces petites Gelées de la même maniere, que nous faifons de la Glace fur le Feu. Or l'humidité de la Terre entre évidemment pour beaucoup dans les grands Froids de ce Climat, \& d'où viendroit cette humidité dans un Pays, où le Sol eft ordinairement mêlé de beaucoup de Sable, fi ce n'eft de la multitude $\&$ de l'étenduë des Lacs \& des Rivieres, de l'épaiffeur des Forêts, des Montagnes couvertes de Néges, qui, en fe fondant, arrofent les Plaines, \& des Vents, qui en portent par-tout les exhalaifons?

Mais fi le Pere Breffani s'eft trompé, comme je le crois, en excluant toutes ces chofes du principe des Froids exceffifs du Canada, ce qu'il y fubftituë me paroît y contribuer véritablement beaucoup. Il y a, dit-il, fous les Climats les plus chauds des Terres Humides, \& il y en a de fort féches dans les Pays les plus froids: mais un certain mêlange de fec \& d'humide forme les Glaçons \& les Néges, dont la quantité fait l'excès $\&$ la durée du Froid. Or, pour peu qu'on ait voyagé en Canada, on fçait que ce mêlange s'y rencontre d'une maniere très-marquée. C'eft fans contredit le Pays du Monde, où il y a plus d'Eau, \& il en eft peu, dont le Terroir foit plus mêlé de Pierres \& deSable. Avec cela il y pleut affez rarement, \& l'Air y eft extrêmement pur \& fain ; preuve certaine de la fécherefle naturelle de lạ Terre. En effet le Pere Breflani affûre 
D'UN VOYAGE DE L'A MERIQ. LET. X. I 69 fûre qu'en feize ans qu'a fubfifté la Miffion dans le Pays des Hurons, il s'y eft trouvé en même tems jufqu'à foixante François, dont plufieurs étoient d'une complexion affez délicate; que tous étoient fort mal nourris, \& qu'ils avoient d'ailleurs à fouffrir au-delà de ce qui fe peut imaginer, \& que perfonne n'y mourut.

A lavérité cette prodigieufe multitude de Rivieres $\&$ de Lacs, qui occupent autant d'efpace dans la N. France, qu'en occupe la moitié des Terres de l'Europe, devroit fans ceffe fournir à l'Air de nouvelles Vapeurs; mais outre que la plûpart de ces Eaux font extrèmement claires, \& fur un fond de Sable, leur grande \& continuelle agitation en émouffant la pointe des rayons du Soleil, empêche qu'il n'en éleve beaucoup de Vapeurs, ou les font retomber d'abord en Brouillards. Car les Vents excitent fur ces Mers douces d'auffi fréquentes \& d'auffi violentes Tempêtes, que fur l'Ocean : \& c'eft auffi la véritable raifon pourquoi il pleut rarement fur Mer.

La feconde caufe des Froids exceffifs du Canada, felon le Pere Breffani, eft le voifinage de la Mer du Nord, couverte de Glaces énormes pendant plus de huit mois de l'année. Vous pouvez, Madame, vous rappeller ici ce que j'ai raporté dans ma feconde Lettre du froid, que nous caufa dans les jours Caniculaires le voifinage d'une Glace, ou plûtôt le Vent, qui foufloit fur nous du côté où elle étoit, \& qui ceffa au moment, qu'elle fût fous le Vent. Il eft certain d'ailleurs, qu'il ne neige ici, que du Vent de Nord-Eft, lequel nous vient du côté, où font les Glaces du Nord, \& quoiqu'on ne fente pas un aufi grand froid tandis que ces Neiges tombent, il ne faut point douter qu'elles ne contribuent beaucoup à rendre fi picquants les Vents d'Oueft \& de Nord-Oueft, lefquels, pour parvenir jufqu'à nous, traverfent des Pays immenfes, \& une grande Chaîne de Montagnes, qui en font couvertes.

Enfin , fi l'on en croit le Miffionnaire Italien, l'élevation du Terrein n'eft pas la moindre caufe de la fubtilité de l'Air, qu'on refpire en ce Pays, \& par une fuite néceffaire, de la rigidité du froid, qu'on y reffent. Le Pere Breffani s'efforce de prouver cette élevation par la profondeur de la Mer, qui augmente, dit-il, à mefure qu'on approche du côté du Canada , \& par le nombre \& la hauteur des Chutes, qui fe rencontrent dans les Rivieres. Mais il me femble que la profondeur de Tome III. 


\section{J O UR N A L HISTORIQ U E}

$172 \mathrm{I}$. la Mer ne prouve abfolument rien, \& que les Chutes du FleuAvril ve Saint Laurent $\&$ de quelques Rivieres de la Nouvelle France, ne prouvent rien de plus que les Cataraetes du Nil. D'ailleurs, nous ne remarquons point, que depuis Montreal, où commencent les Rapides, jufqu’à la Mer, le Fleuve Saint Laurent foit beaucoup plus rapide, que quelques-unes de nos Rivieres d'Europe. Je penfe donc qu'il faut s'en tenir au voifnage des Glaces du Nord, \& que même malgré ce voifinage , fi le Canada étoit auffi découvert \& auffi peuplé que la France, les Hyvers y feroient moins longs \& moins rudes. Ils le feroient pourtant toujours plus qu'en France, à caufe de la férénité \& de la pureté de l'Air ; car il eft certain qu'en Hyver, toutes chofes égales d'ailleurs, la gelée eft plus rude, quand le Ciel eft pur, \& que le Soleil a rarefié l'Air.

De la Pìche

L'Hyver paffé, la Pêche \& la Chaffe fourniffent abondamdes Anguilles. ment dequoi vivre à ceux, qui veulent s'en donner la peine; outre les Poiffons \& le Gibier, dont je vous ai déja parlé, le Fleuve Saint Laurent \& les Forêts fourniffent aux Habitans deux fortes de Manne, qui leur font d'une grande reffource. Depuis Quebec jufqu'aux Trois Rivieres, on pêche dans le Fleuve une quantité prodigieufe de groffes Anguilles, qui defcendent, à ce qu'on prétend, du Lac Ontario, où elles prennent naiffance dans des Marais, qui font au bord de ce Lac du côté du Nord, \& comme elles rencontrent, ainfi que je l'ai déja remarqué, des Marfouins blancs, qui leur donnent la Chaffe, la plûpart veulent retourner fur leurs pas, \& c'eft ce qui eft caufe qu'on en prend un fi grand nombre. Voici de quelle maniere fe fait cette Pêche.

Dans l'étenduë du Terrein , que couvre la haute Marée, \& 8 qu'elle laiffe à fec en fe retirant, on difpofe des Coffres de diftance en diftance, \& on les appuye contre une Paliffade de Clayes d'Ofier, qui ne laiffe aucun paffage libre aux Anguilles. De grands Eperviers de même matiere \& de même ftructure font enchâffés par le bout le plus étroit dans ces Coffres, \& l'autre extrémité, qui eft fort large, eft adoffée contre les. Clayes, fur lefquelles on met par intervalle des Bouquets de verdure. Lorfque le tout eft couvert par la Marée, les Anguilles, qui cherchent toujours les bords, \& que la verdure attire, fe trouvent en grand nombre le long de la Paliffade, entrent dans les Eperviers, qui les conduifent dans les Pri- 
D'UN V OYA GE DE L'A MERIQ. LeT. X. I7I fons, qu'on leur a préparées ; \& fouvent d'une feule Marée les Coffres s'en trouvent remplis.

Ces Anguilles font plus groffes, que les nôtres, \& rendent 1721 . Avril. beaucoup d'Huile. J'ai déja obfervé qu'à quelque Sauffe, qu'on les mette, elles confervent toujours un goût fauvage, auquel on ne s'accoutume pas fans peine. C'eft peut-être la faute de nos Cuifiniers. Leurs Arrêtes fe terminent toutes en pointe un peu recourbée, ce que je ne me fouviens pas d'avoir jamais vû dans celles de France. La meilleure maniere d'aprêter ce Poiffon, eft de le fufpendre dans la Cheminée, $\&$ de l'y laiffer cuire lentement dans fa Peau. Cette Peau fe leve d'elle-même, \& toute l'Huile s'écoule. Comme on en fait de grandes provifions pendant trois mois, que dure cette Pêche, on les fale, \& on les met en Barriques, comme les Harengs.

L'autre Manne, dont j’ai parlé, eft une efpece de Ramiers, qui paffent ici dans les mois de Mai \& de Juin : on dit qu'au- Du Paflage trefois ils obfcurciffoient l'Air par leur multitude; mais ce n'eft plus la même chofe aujourd'hui. Il en vient encore néanmoins jufqu'aux environs des Villes un affez grand nombre fe repofer fur les Arbres. On les appelle communément Tourtes, \& ils different en effet des Ramiers, des Tourterelles $\&$ des Pigeons d'Europe, affez pour en faire une quatriéme efpece. Ils font plus petits que nos plus gros Pigeons, dont ils ont les Yeux, \& les Nuances de la Gorge. Leur Plumage eft d'un brun obfcur, à l'exception des Aîles, où il y a des Plumes d'un très-beau bleu.

On diroit que ces Oifeaux ne cherchent qu'à fe faire tuer; car s'il y a quelque Branche féche à un Arbre, c'eft celle-là, qu'ils choififfent pour s'y percher, \& ils s'y rangent de maniere, que le plus mal-adroit Tireur en peut abbatre une demie douzaine au moins d'un feul coup de Fufil. On a aufi trouvé le moyen d'en prendre beaucoup en vie: on les nourrit jufqu'aux premieres Gélées; alors on leur coupe la Gorge, $\&$ on les jette au Grenier, où ils fe confervent tout l'Hyver.

Il s'enfuit de-là, Madame, que tout le Monde a ici le né- Heureufe Conceffaire pour vivre: on y paye peu au Roi; l'Habitant ne connoît point la Taille; il a du Pain à bon marché, la Viande \& le Poifon n'y font pas chers; mais le Vin, les Etoffes, \& tout ce qu'il faut faire venir de France, y coûtent beaucoup. nada. 
$172 \mathrm{I}$. Les plus à plaindre font les Gentilshommes, \& les Officiers, Avril. qui n'ont que leurs Appointemens, \& qui font chargés de Familles. Les Femmes n'apportent ordinairement pour Dot à leurs Maris que beaucoup d'efprit, d'amitié, d'agrémens, $\&$ une grande fécondité; mais Dieu répand fur les Mariages dans ce Pays la bénédiction, qu'il répandoit fur ceux des $\mathrm{Pa}$ triarches : il faudroit pour faire fubfifter de fị nombreufes Familles, qu'on y menât auffi la vie des Patriarches; mais le tems en eft paffé. Il y a dans la Nouvelle France plus de Noblefle, que dans toutes les autres Colonies enfemble. Le Roi y entretient encore vint-huit Compagnies des Troupes de la Marine, $\&$ trois Etats-Majors. Plufieurs Familles y ont été annoblies, \& il y eft refté plufieurs Officiers du Régiment de Carignan-Salieres, ce qui a peuplé le Pays de Gentilshommes, dont la plupart ne font pas à leur aife. Ils y feroient encore moins, fi le Commerce ne leur étoit pas permis, \& fi la Chaffe \& la Pêche n'étoient pas ici de droit commun.

Plufieurs ne fçavent pas en profiter.

Après tout, c'eft un peu leur faute, s'ils fouffrent de la difette: la Terre eft bonne prefque par-tout, \& l'Agriculture ne fait point déroger. Combien de Gentilshommes dans toutes les Provinces envieroient le fort des fimples Habitans du Canada, s'ils le connoiffoient? Et ceux, qui languiffent ici dans une honteufe indigence, font-ils excufables de ne pas embraffer une Profeffion, que la feule corruption des mours, $\&$ des plus faines maximes a dégradée de fon ancienne nobleffe ? Nous ne connoiffons point au Monde de Climat plus fain, que celui-ci : il n'y regne aucune Maladie particuliere, les Campagnes \& les Bois y font remplis de Simples merveilleux, \& les Arbres y diftilent des Baumes d'une grande vertu. Ces avantages devroient bien au moins y retenir ceux, que la Providence y a fait naître; mais la lẻgereté, l'averfion d'un travail affidu $\&$ réglé, \& l'efprit d'indépendance en ont toujours fait fortir un grand nombre de jeunes Gens, \& ont empêché la Colonie de fe peupler.

Bonnes \& Ce font-là, Madame, les défauts, qu'on reproche le plus, mauvaifesqualités des Créoles du Canada. \& avec plus de fondement aux François Canadiens. C'eft auffi celui des Sauvages. On diroit que l'air , qu'on refpire dans ce vafte Continent, y contribuë, máis l'exemple \& la fréquentation de fes Habitans naturels, qui mettent tout leur bonheur dans la liberté \& l'indépendance, font plus que fuffi- 
D'U N V OYA GE DE L'A MERI Q. LET: X. 173 fans pour former ce carątere. On accufe encore nos Créoles d'une grande avidité pour amaffer, \& ils font véritablement pour cela des chofes, qu'on ne peut croire, fi on ne les a point vûës. Les courfes, qu'ils entreprennent; les fatigues, qu'ils effuyent; les dangers, à quoi ils s'expofent; les efforts, qu'ils font, paffent tout ce qu'on peut imaginer. Il eft cependant peu d'Hommes moins intéreffés, qui diffipent avec plus de facilité ce qui leur a coûté tant de peines à acquerir, \& qui témoignent moins de regret de l'avoir perdu. Auffi n'y a-t'il aucun lieu de douter qu'ils n'entreprennent ordinairement par goût ces courfes fi pénibles \& fi dangereufes. Ils aiment à refpirer le grand air, ils fe font accoûtumés de bonne heure à mener une vie errante; elle a pour eux des charmes, qui leur font oublier les perils \& les fatigues paffés, \& ils mettent leur gloire à les affronter de nouveau. Ils ont beaucoup d'efprit, fur-tout les Perfonnes du Sexe, qui l'ont fort brillant, aifé, ferme, fécond en reffources, courageux, \& capable de conduire les plus grandes affaires. Vous en avez connu, Madame, plus d'une de ce caractere, \& vous m'en avez témoigné plus d'une fois votre étonnement. Je puis vous affûrer qu'elles font ici le plus grand nombre, \& qu'on les trouve telles dans toutes les conditions.

Je ne fçai fi je dois mettre parmi les défauts de nos $\mathrm{Ca}$ nadiens la bonne opinion, qu'ils ont d'eux-mềmes. Il eft certain du moins qu'elle leur infpire une confiance, qui leur fait entreprendre \& exécuter, ce qui ne paroîtroit pas poffible à beaucoup d'autres. Il faut convenir d'ailleurs qu'ils ont d'excellentes qualités. Nous n'avons point dans le Royaume de Province, où le Sang foit communément fi beau, la Taille plus avantageufe, \& le Corps mieux proportionné. La force du Tempéramment n'y répond pas toujours, \& fi les Canadiens vivent lontems, ils font vieux $\&$ ufés de bonne heure. Ce n'eft pas même uniquement leur faute; c'eft aufi celle des Parens, qui, pour la plupart, ne veillent pas affez fur leurs Enfans, pour les empêcher de ruiner leur fanté dans un âge, où, quand elle fe ruine, c'eft fans reffource. Leur agilité \& leur adreffe font fans égales : les Sauvages les plus habiles ne conduifent pas mieux leurs Canots dans les Rapides les plus dangereux, \& ne tirent pas plus jufte.

Bien des Gens font perfuadés qu'ils ne font pas propres aux

1721

Avril. 
I 721 . Sciences, qui demandent beaucoup d'application, \& une étu-

I 21. de fuivie. Je ne fçaurois vous dire fi ce préjugé eft bien ou Avril. mal fondé ; car nous n'avons pas encore eu de Canadien, qui ait entrepris de le combattre, il ne l'eft peut-être que fur la diffipation, dans laquelle on les éleve. Mais perfonne ne peut leur contefter un génie rare pour les Méchaniques; ils n'ont prefque pas befoin de Maîtres pour y exceller, \& on en voit tous les jours, qui réuffiffent dans tous les Métiers, fans en avoir fait d'apprentiffage.

Quelques-uns les taxent d'ingratitude, ils m'ont néanmoins paru avoir le cœur affez bon; mais leur légereté naturelle les empêche fouvent de faire attention aux devoirs, qu'exige la reconnoiffance. On prétend qu'ils font mauvais Valets; c'eft qu'ils ont le cœur trop haut, \& qu'ils aiment trop leur liberté, pour vouloir s'affujettir à fervir. D'ailleurs ils font fort bons Maîtres. C'eft le contraire de ce qu'on dit de ceux, dont la plupart tirent leur origine. Ils feroient des hommes parfaits, fi avec leurs vertus ils avoient confervé celles de leurs Ancêtres. On s'eft plaint quelquefois qu'ils ne font pas Amis conftans : il s'en faut bien que cela foit général, \& dans ceux, qui ont donné lieu à cette plainte, cela vient de ce qu'ils ne font pas accoûtumés à fe gêner, même pour leurs propres affaires.S'ils ne font pas aifés à difcipliner, cela part du même principe, ou de ce qu'ils ont une difcipline, qui leur eft propre, \& qu'ils croyent meilleure pour faire la Guerre aux Sauvages; en quoi ils n'ont pas tout-à-fait tort. D'ailleurs il femble qu'ils ne font pas les maîtres d'une certaine impétuofité, qui les rend plus propresà un coup de main, ou à une expédition brufque, qu'aux opérations régulieres \& fuivies d'une Campagne. On a encore obfervé que parmi un très-grand nombre de Braves, qui fe font diftingués dans les dernieres Guerres, il s'en eft trouvé affez peu, qui euffent le talent de commander. C'eft peut-être, parce qu'ils n'avoient pas affez appris à obéir. Il eft vrai que, quand ils font bierr menés, il n'eft rien, dont ils ne viennent à bout, foit fur Mer, foit fur Terre; mais il faut pour cela qu'ils ayent une grande idée de leur Commandant. Feu M. d'Iberville, qui avoit toutes les bonnes qualités de fa Nation, fans en avoir les défauts, les auroit menés au bout du Monde.

Il y a une chofe, fur quoi il n'eft pas facile de les excu- 
D'UN VOYAGE DE L'A MERIQ. LET. X. 175 fer : c'eft le peu de naturel de plufieurs pour leurs Parens, qui de leur côté ont pour eux une tendreffe affez mal entenduë. Les Sauvages tombent dans le même défaut, $\&$ il produit parmi eux les mêmes effets. Mais ce qui doit fur toutes chofes faire eftimer nos Créoles, c'eft qu'ils ont un grand fonds de piété $\&$.de religion, \& que rien ne manque à leur éducation fur ce point. Il eft vrai aufli que hors de chez eux ils ne confervent prefqu'aucun de leurs défauts. Comme avec cela ils font extrémement braves $\&$ adroits, on en pourroit tirer de grands fervices pour la Guerre, pour la Marine \& pour les Arts, \& je crois qu'il feroit du bien de l'Etat de les multiplier plus qu'on n'a fait jufqu'à préfent. Les Hommes font la principale richeffe du Souverain, \& le Canada, quand il ne pourroit être d'aucune utilité à la France, que par ce feul endroit, feroit encore, s'il étoit bien peuplé, une des plus importantes de nos Colonies.

Je fuis, \&c.

\section{ON Z I E M E LE T.TRE.}

\section{De la Bourgade Iroquoife du Sault Saint Louys. Des differens Peuples, qui habitent le Canada.}

Au Sault Saint Louys, ce premier de May, 1721 .

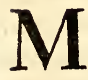

A D A ME,

$J_{E}$ fuis venu ici pour y paffer une partie de la Quinzaine de Pâques. C'eft un tems de dévotion, $\&$ tout infpire la piété dans cette Bourgade. Tous les exercices de la Religion s'y pratiquent d'une maniere très-édifiante, $8 x$ on y reffent encore l'impreffion, qu'y a laiffée la ferveur de fes premiers Habitans : car il eft certain qu'elle a été lontems le lieu du Cana$\mathrm{da}$, où l'on voyoit les plus grands exemples de ces vertus héroïques, dont Dieu a accoûtumé d'enrichir les Eglifes naiffantes. La maniere même, dont elle a été formée, a quelque chofe de fort merveilleux.

1721 .

Avril. 
1721 .

May.

Origine de la Bourgade da Sault S. Louys.

\section{I76 J O UR N A L H IS T ORI Q U E}

Les Miffionnaires, après avoir lontems arrofé les Cantons Iroquois de leurs Sueurs, \& quelques-uns mêmes de leur Sang, perdirent enfin toute efperance d'y établir la Religion Chrétienne fur des fondemens folides; mais non pas de réduire un affez grand nombre de ces Sauvages fous le joug de la Foy. Ils avoient reconnu que Dieu avoit parmi ces Barbares des Elus, comme il y en a dans toutes les Nations; mais ils étoient perfuadés que, pour afJürer leur vocation $\mathcal{E}$ leur élection, il falloit les féparer de leurs Compatriotes, \& ils prirent la réfolution d'établir dans la Colonie tous ceux, qui fe trouveroient difpofés à embraffer le Chriftianifme. Ils propoférent leur deffein au Gouverneur Général \& à l'Intendant, qui portant leurs vûës plus loin, non-feulement l'approuverent, mais comprirent que cet Etabliffement feroit très - utile à la Nouvelle France, comme il l'a été en effet, auffi-bien qu'un autre tout femblable, qui a été fait depuis dans l'Ifle de Montreal, fous le nom de la Montagne, \& dont MM. du Seminaire de Saint Sulpice ont toujours eu la direction.

Pour revenir à celui, qui a fervi de modele à l'autre, un des Miffionnaires des Iroquois s'ouvrit à quelques Agniers de fon deffein ; ils le goûterent, \& c'eft particulierement de ce Canton, de tout tems le plus oppofé aux Miniftres de l'Evangile, \& où ils avoient été le plus cruellement traités, que s'eft formée cette Peuplade. Ainfi, au grand étonnement des François \& $\&$ des Sauvages, on vit ces redoutables Ennemis de Dieu $\&$ de notre Nation, touchés de cette Grace viktorieufe, qui fe plaît à triompher des Cœurs les plus durs \& les plus rebelles, abandonner ce qu'ils avoient de plus cher au monde, pour n'avoir plus rien, qui les empêchât de fervir le Seigneur en toute liberté : Sacrifice plus héroïque encore pour des Sauvages, que pour tout autre Peuple, parce qu'il n'eft point d'Hommes plus attachés qu'eux à leurs Familles, \& à leur Pays natal.

Ferveur de

Leur nombre s'accrut beaucoup en peu de tems, \& ce proSes premiers Habitans. grès fut en bonne partie l'effet du zéle des premiers Neophytes, qui compoférent ce Troupeau choifi. On les voyoit dans le fort même de la Guerre, parcourir , au péril même de leur vie, tous les Cantons, pour y faire des Profelytes, \& quand ils tomboient entre les mains de leurs Ennemis, qui fouvent étoient leurs plus proches Parens, s'eftimer heureux de mourir 
D'UN V OYA GE DE L'A MER I Q. LET. XI. 177 au milieu des plus affreux Supplices, par la raifon qu'ils ne s'y étoient expofés, que pour procurer la gloire de Dieu \& le falut de leurs Freres. Ainfi penfoient des Meurtriers mêmes des Miniftres de Jefus-Chrift, \& l'on ne vit peut-être jamais s'accomplir plus à la lettre cet Oracle de Saint Paul, ubi autem abundavit deliátum, fuperabundavit gratia. (a) Le plus fouvent on leur laiffoit le choix, ou de renoncer à Jefus-Chrift, \& de retourner dans leur Canton, ou de fouffrir la Mort la plus cruelle, \& il n'y a point d'exemple qu'aucun ait accepté la vie à cette condition. Quelques-uns mêmes ont péri, confumés de miféres dans les Cachots de la Nouvelle York, d'où ils pouvoient fortir, en changeant de Croyance, ou du moins en renonçant à vivre parmi les François, ce qu'ils ne croyoient pas pouvoir faire, fans s'expofer à perdre la Foi.

Des Neophytes, qui dans des occafions pareilles faifoient paroître tant de fidélité $\&$ de grandeur d'Ame, devoient affûrement s'y être préparés par des vertus bien pures: on ne peut en effet révoquer en doute certains traits, qui ont éclaté dans toute la Colonie, \& qui rendent bien croyables ceux, qui n'ont eu pour Témoins, que les Sauvages mêmes \& leurs Pafteurs. Voici ce qu'en écrivoit en I 688. M. de Saint Valier, qui gouverne encore aujourd'hui cette Eglife. "La vie " commune de tous les Chrétiens de cette Miffion ı'a rien de commun, \& l'on prendroit tout ce Village pour un Monaftere. Comme ils n'ont quitté les commodités de leur Pays, " que pour affûrer leur Salut, on les voit tous portés à la prati-" que du plus parfait détachement ; \& ils gardent parmi eux un fi bel ordre pour leur fanctification, qu'il feroit difficile d'y rien ajoûter.

Cette Bourgade fut d'abord placée à la Prairie de la Madeleine, environ une lieuë plus bas que le Sault Saint Louys, du côté du Sud. Les Terres ne s'y étant pas trouvées propres pour la culture du Maiz, on la tranfporta vis-à-vis le Sault même, d'où elle a pris fon nom, qu'elle porte encore, quoiqu'elle ait été transferée de-là , il y a peu d'années, une autre lieuë plus haut. J'ai déja dit que la fituation en eft charmante, que l'Eglife \& la Maifon des Miffionnaires font deux des plus beaux Edifices du Pays, \& que c'eft ce qui fait juger qu'on a pris de bonnes mefures pour n'être plus

(a) Ad Rom. Cap. 20.

Tome III, 


\section{${ }_{178} \mathrm{~J} O \mathrm{URN}$ A L H I S T O R I Q UE}

I 72 I. obligé de faire de nouvelles tranfmigrations.

May. J'avois compté en arrivant ici d'en partir immédiatement après les Fêtes; mais rien n'eft plus fujet aux contretems de toutes les efpeces, que ces fortes de Voyages. Je fuis donc encore incertain du jour de mon départ, \& comme ii faut tout mettre à profit, quand on fait des courfes, comme les miennes, j'y ai mis ce retardement. J'ai paffé le tems à entretenir quelques anciens Miffionnaires, qui ont vécu lontems avec les Sauvages , \& j'en ai tiré plufieurs connoiffances touchant les Peuples divers, qui habitent ce vafte Continent, \& dont

Des Habitans de Terreneuve. je vais, Madame, vous faire part.

La premiere Terre de l'Amerique, que l'on apperçoit en venant de France en Canada, eft l'Ifle de Terre-Neuve, une des plus grandes, que nous connoiffions. On n'a jamais pu fçavoir au jufte, fi elle a des Habitans naturels, \& fa ftérilité, fût-elle par-tout auffi réelle, qu'on la fuppofe, n'eft pas une raifon pour prouver qu'elle n'en a point. Car la Pêche \& la Chaffe fuffifent à des Sauvages pour fubfifter. Ce qui eft certain, c'eft qu'on n'y a jamais vû que des Eskimaux, qui n'en font pas originaires. Leur véritable Patrie eft la Terre de Laborador, ou Labrador; c'eft-là du moins, qu'ils paffent la plus grande partie de l'année; car ce feroit, cefemble, profaner le doux nom de Patrie, que de le donner à des Barbares errans, qui ne s'affectionnent à aucun Pays, \& qui pouvant à peine peupler deux ou trois Villages, embraffent un Terrein immenfe. En effet, outre les Côtes de Terre-Neuve, que les Eskimaux parcourent pendant l'Eté , dans tout ce vafte Continent, qui eft entre le Fleuve Saint Laurent, le Canada, \& la Mer du Nord, on n'a encore vû que des Eskimaux. On en a même trouvé affez loin en remontant le Fleuve Bourbon, qui fe décharge dans la Baye d'Hudfon, venant de l'Occident.

Des Eski- L'origine de leur nom n'eft pas certaine; toutefois il y a bien max. de l'apparence qu'il vient du mot Abénaqui E fquimant $2 c$, qui veut dire, Mangeur de Viande cruë. Les Eskimaux font en effet les feuls Sauvages, que nous connoiffions, qui mangent la Chair cruë, quoiqu'ils ayent auffi l'ufage de la faire cuire, ou fecher au Soleil. Il eft encore certain que de tous les Peuples connus de l'Amerique, il n'en eft point, qui rempliffe mieux, que celui-ci, la premiere idée, que l'on a euë en Europe des Sauvages. Il eft prefque le feul, où les Hom- 
D'UN V OYA G E DE L'A MERIQ. LET. XI. 179 mes ayent de la Barbe, \& ils l'ont fi épaiffe jufqu'aux Yeux, qu'on a peine à découvrir quelques Traits de leur Vifage. Ils ont d'ailleurs je ne fçai quoi d'affreux dans l'Air, de petits Yeux effarés, des Dents larges \& fort fales, des Cheveux ordinairement noirs, quelquefois blonds, fort en défordre, \& tout l'exterieur fort brute. Leurs Mœurs \& leur Caraktere ne démentent point cette mauvaife phyfionomie. Ils font féroces, farouches, défiants, inquiets, toujours portés à faire du mal aux Etrangers, qui doivent fans ceffe être fur leurs gardes avec eux. Pour ce qui eft de leur Efprit, on a fi peu de commerce avec cette Nation, qu'on ne fçait pas encore de quelle trempe il eft : mais on en a toujours affez pour faire du mal.

On les a fouvent vû aller la nuit couper les Cables des $\mathrm{Na}$ vires, qui étoient à l'Ancre, pour les faire périr fur la Côte, \& profiter de leur Naufrage : ils ne craignent pas même de les attaquer en plein jour, quand ils ont reconnu que leurs Equipages font foibles. Il n'a jamais été poffible de les apprivoifer, \&x l'on ne peut encore traiter avec eux, qu'au bout d'un long bâton. Non-feulement ils ne s'approchent point des Européens, mais ils ne mangent rien de ce que ceux-ci leur préfentent ; \& en toutes chofes, ils prennent à leur égard des précautions, qui marquent une grande défiance, \& en infpirent réciproquement beaucoup de tout ce qui vient de leur part. Ils ont la Taille avantageufe, \& font affez bien faits. Ils ont la $P$ eau du Corps auffi blanche que nous, ce qui vient, fans doute de ce qu'ils ne vont jamais nuds, quelque chaud qu'il faffe.

Leurs Cheveux blonds, leurs Barbes, la blancheur de leur Peau, le peu de reffemblance $\&$ de commerce, qu'ils ont avec leurs plus proches Voifins, ne laiffent aucun lieu de douter qu'ils n'ayent une origine différente de celle des autres Ameriquains ; mais l'opinion, qui les fait defcendre des Bafques, me paroît peu fondée, fur-tout s'il eft vrai, comme on me l'a affûré, qu'il n'y a aucun raport entre les Langues des uns \& des autres. Au refte, cette alliance ne fçauroit faire honneur à aucune Nation; car s'il n'eft point fur la Terre de Région moins propre à être habitée par des Hommes, que TerreNeuve \& Labrador, il n'eft peut-être pas un Peuple, qui mérite mieux d'y être confiné, que les Eskimaux. Pour moi je fuis perfuadé qu'ils font originaires du Groenland.

(a) Voyez l'Hiftoire de la Nouvelle France, Livre I, page 17. É fuiv. 


\section{J O UR N A L H I S T OR I Q U E}

I 72 I. Ces Sauvages font tellement coúverts, quà peine on leur172 I. voit une partie du Vifage, \& le bout des Mains. Sur une efMay. pece de Chemife faite de Veffies, ou d'Inteftins de Poiffons, coupées par bandes, \& affez propremsnt coufuës, ils ont une maniere de Cafaque de Peau d'Ours, ou de quelque autre Bête fauve, quelquefois même de Peaux d'Oifeaux, un Capuchon de même Etoffe que la Chemife, \& qui y eft attaché, leur couvre la Tête, du haut de laquelle fort un Toupet de Cheveux, quileur offufque le Front. La Chemife ne defcend que jufqu'aux Reins, la Cafaque pend par derriere jufques fur les Cuiffes, \& fe termine par devant en pointe plus bas que la ceinture ; mais aux Femmes, elle defcend des deux côtés jufqu'à mi-Jambe, \& elle eft arrêtée par une ceinture, d'où pendent de petits Offelets. Les Hommes ont des Culotes de Peaux, dont le Poil eft en dedans, \& qui font revêtuës en dehors de Peaux d'Hermines, ou d'autres femblables. Ils ont auffi aux Pieds des Chauflons de Peaux, dont le Poil eft pareillement en dedans, \& par deffus une Botte fourée de même, puis de feconds Chauflons \& $x$ de fecondes Bottes. On prétend que ces Chauffures font quelquefois triplées \& quadruplées, ce qui n'empêche pas ces Sauvages d'être fort leftes. Leurs Fleches, qui font les feules Armes, dont ils ayent l'ufage, font armées de pointes faites de Dents de Vaches Marines, \&z ils y ajoûtent encore du Fer, quand ils en peuvent avoir. Il paroît qu'en Eté ils font à l'Air la nuit \& le jour ; mais l'Hyver ils fe logent fous Terre dans des efpeces de Grottes, où ils font tous les uns fur les autres.

Des Peuples des Environs du l'ort Nelfon.

On connoit peules autres Peuples, qui font aux environs \& au-deffus de la Baye d'Hudfon. Dans la partie Méridionnale de cette Baye le Commerce fe fait avec les Miftafins, les Monfonis, les Criftinaux \& les Affiniboils; ceux-ci y viennent de fort loin, puifqu'ils habitent les bords d'un Lac, qui eft au Nord, ou au Nord-Oueft des Sioux, \& que leur Langue eft une Dialecte Sioufe. Les trois autres font de la Langue Algonquine. Les Criftinaux ou Killiftinons, viennent du Nord du Lac fuperieur. Les Sauvages des environs du Fleuve Bourbon, (a) \& de la Riviere de Sainte Therefe,

(a) On dit que quand on a remonté ce $\mid$ à côté par des Rivieres \& des Lacs, qui s'y Fleuve cent lieuës, on le trouve impratiquable pendant cinquante, mais qu'on prend d'un très-beau Pays, \& que cela dure juf- 
D'U N VOYA GE D E L'A MERIQ. LET. XI. I8I n'ont aucune affinité de Langage, ni avec les uns, ni avec les autres. Peut-être s'entendent-ils mieux avec les Eskimaux, qu'on a rencontrés, dit-on, affez loin de l'Embouchure du Fleuve. On a remarqué qu'ils font extrêmement fuperftitieux, $\&$ quils ont quelque forte de Sacrifices. Ceux, qui les ont plus fréquentés, alfûrent qu'ils ont, comme ceux du Canada, lidée d'un bon \& d'un mauvais Génie, que le Soleil eft leur grande Divinité, \& que quand ils veulent déliberer fur une Affaire importante, ils le font fumer, ce qui fe pratique en cette maniere. Ils s'affemblent à la pointe du jour dans la $\mathrm{Ca}$ banne d'un de leurs Chefs, qui, après avoir allumé fa Pipe, la préfente trois fois au Soleil levant, puis la conduit des deux Mains d'Orient en Occident, en priant cet Aftre d'être favorable à la Nation. Cela fait, tous ceux, qui compofent l'Affemblée, fument dans la même Pipe. Tous ces Sauvages, quoique de cinq ou fix Nations différentes, font connus dans les Relations Françoifes fous le nom générique de Savanois, parce que le Pays, qu'ils habitent, eft bas, marécageux, mal boifé, \& qu'en Canada on appelle Sayanes ces Terreins mouillés, qui ne font bons à rien.

En remontant au Nord de la Baye, on trouve deux Rivieres, dont la premiere fe nomme la Riviere Danoife, \& la feconde la Riviere du Loup Marin : il y a le long de ces deux Rivieres des Sauvages, aufquels on a donné, je ne fçai pourquoi, le nom, ou plûtôt le fobriquet de Plats côtę de Chiens. Ils font fouvent en Guerre contre les Savanois; mais ni les uns, ni les autres ne traitent leurs Prifonniers avec cette barbarie, qui eft en ufage parmi les Canadois ; ils fe contentent de les retenir dans l'efclavage. La mifére réduit quelquefois les Savanois à d'étranges extrêmités ; foit pareffe de leur part, foit que leurs Terres ne puiffent abfolument rien produire, ils fe trouvent, lorfque la Chaffe \& la Pêche leurmanquent, fans aucunes Provifions, \& alors on prétend qu'ils ne font point difficulté de fe manger les uns les autres. Les plus chetifs paffent les premiers; on affûre que la coûtume eft parmi eux, que quand un Homme eft parvenu à unâge, où il ne peut plus être qu'à charge à fa Famille, il fe paffe lui-même un Cordon autour du Cou, \& en préfente les deux extrêmités à celui de fes

qu'au Lac des Affiniboils, d'ou il fort. On $\mid$ depuis quinze ans qu'on a un peu plus batt: peut en avoir des nouvelles plus certaines, 1 ces Pays Septentrionnaux. 
$172 \mathrm{I}$. Enfans, quilui eft le plus cher, \& quil'étrangle le plus promMay. ptement qृn'il peut : il croit même faire en cela une bonne action, non-feulement parce qu'il met fin aux foufrances de fon Pere, mais encore parce quil eft perfuadé qu'il avance fon bonheur ; car ces Sauvages s'imaginent qu'un Homme, qui meurt vieux, renaît dans l'autre Monde à l'áge d'un Enfant à la Mamelle ; \& qu'au contraire, ceux qui finiffent leurs jours de bonne heure, font vieux, quand ils arrivent au Pays des Ames.

Les Filles parmi ces Peuples ne fe marient, que quand, \& avec qui il plaît à leurs Parens, \& le Gendre eft obligé de demeurer chez fon Beau-Pere, \& de lui être foumis en tout, jufqu’à ce qu'il ait des Enfans. Les Garçons quittent de bonne heure la Maifon Paternelle. Ces Sauvages brûlent les Corps morts, \& en envelopent les Cendres dans une Ecorce d'Arbre, qu'ils mettent en Terre. Ils dreffent enfuite fur la Tombe une efpece de Monument avec des Perches, aufquelles ils attachent du Tabac, afin que le Défunt y trouve dequoi fumer dans l'autre Monde. Si c'étoit un Chaffeur, on y fufpend auffi fon Arc \& fes Fleches. Les Meres pleurent leurs Enfans pendant vint jours, \& l'on fait des préfens au Pere, qui y répond par un Feftin. La Guerre eft bien moins en honneur chez eux, que la Chaffe; mais pour être eftimé un bon Chaffeur, il faut jeûner trois jours de fuite, fans rien prendre abfolument, \& avoir pendant tout ce tems-là le Vifage barbouillé de noir. Le jeûne fini, le Candidat fait au grand Efprit un Sacrifice d'un morceau de chacune des Bêtes, qu'on a accoutumé de chaffer, \& c c'eft ordinairement la Langue \& le Mufle, qui hors de ces occafions, font la part du Chaffeur. Ses Parens n'y touchent point, \& fe laifferoient plûtôt mourir de faim, que d'en manger ; il n'en peut régaler que fes Amis, ou les Etrangers.

Au refte, on affûre que ces Sauvages font d'un definterreffement parfait, \&xd'une fidélité à toute épreuve; qu'ils ne peuvent fouffrir le menfonge, \& qu'ils ont la fourberie en horreur. Voilà, Madame, tout ce que j’ai pu apprendre de ces Peuples Septentrionnaux, avec lefquels nous n'avons jamais eu un Commerce bien réglé, \& que nous n'avons vûs qu'en paffant. Venons à ceux, qui nous font plus connus. On les peut divifer en trois Claffes diftinguées par leurs Langues, \& par leur génie particulier. 
D'UN VOYAGE DE L'A MERI Q. Let. XI. 183

Dans cette étenduë de Pays, qu'on appelle proprement la Nouvelle France, qui n'a de bornes au Nord, que du côté de la Baye d'Hudfon, laquelle en a été démembrée par le Traité

la Baye d'Hudfon, laquelle en a été démembrée par le Traité Etenduë de
d'Utrecht, qui n'en a point d'autre à l'Êt, que la Mer, les France. Colonies Angloifes au Sud, la Louyfrane au Sud-Eft, \& les Terres des Eipagnols à l'Oueft; dans cette étenduë, dis-je, de Pays, il n'y a que trois Langues Meres, dont toutes les autres font dérivées. Ces Langues font la Sioufe, l'Algonquine, \& la Huronne; nous connoiffons peu les Peuples, qui appartiennent à la Premiere, \& perfonne ne fçait jufqu'où elle s'étend. Nous n'avons eu jufqu'ci de commerce, qu'avec les Sioux \& les Affiniboils, \& ce commerce môme n’a pas été fort fuivi.

Nos Miffionnaires ont tenté de faire un Etabliffement parmi les Premiers, \& jen ai connu un, qui regrettoit fort de n'y avoir pas réuffi, ou plutôt de n'avoir pas pu demeurer plus lontems avec ce Peuple, qui lui paroiffoit docile. Il n'en eft peut-être pas non plus, de qui nous puiffions tirer plus de lumieres fur tout ce qui eft au Nord-Oueft du Micifipi ; par la raifon qu'ils font en commerce avec toutes les Nations de ces vaftes Contrées. Ils habitent ordinairement dans des Prairies fous de grandes Tentes faites de Peaux, \& bien travaillées; ils vivent de Folle-Avoine, qui croît en abondance dans leurs Marais \& dans leurs Rivieres, \& de Chaffe, furtout de celle de ces Boufs, qui font couverts de Laine, \& qui font par milliers dans leurs Prairies. 1ls n'ont point de demeure fixe, mais ils voyagent en grandes Troupes à la maniere des Tartares, \& ne s'arrêtent en aucun lieu, quautant que la Chaffe les y retient.

Nos Géographes diftinguent cette Nation en Sioux Errans, \& Sioux des Prairies, en Sioux de l'Eft, \& en Sioux de l'Oueft. Ces divifions ne me paroiffent pas trop bien fondées. Tous les Sioux vivent de la même maniere, d'où il arrive que telle Bourgade, qui étoit l'an paffé fur le Bord Oriental du Miciffipi, fera l'année prochaine fur la Riviere Occidentale, \& que ceux, qu'on a vûs dans un tems le long de la Riviere de Saint Pierre, font peut-être préfentement aîfez loin de-là dans une Prairie. Le nom de Sioux, que nous avons donné à ces Sauvages, eft entierement de notre façon, ou plutôt ce n'eft que les deux dernieres fyllabes de celui de Nadoueffoux,

Des Sioux.

721.

May. 


\section{J O U R N A L H IS T O R I Q U E}

1721 . que plufieurs $N$ ations leur donnent. D'autres les appellent $N a$ douefis. C'eft le Peuple le plus nombreux, que nous connoifMay. fions en Canada. Il étoit affez paifible $\&$ peu aguerri, avant que les Hurons \& les Outaouais fe fuffent réfugiés dans fon Pays, en fuyant la fureur des Iroquois. Ils voulurent fe moquer de fa fimplicité, \& ils l'aguerrirent à leurs dépens. Les Sioux ont plufieurs Femmes, \& ils puniffent févérement celles, qui ont manqué à la fidélité conjugale. Ils leur coupent le bout du Nez, ils leur cernent en rond une partie de la Peau fur le haut de la Tête, \& l'arrachent enfuite. J'ai vû quelques Perfonnes perfuadées que ces Sauvages ont l'Accent Chinois ; il ne feroit pas difficile de vérifier ce fait, ni de fçavoir fi leur Langue a quelque rapport avec celle de la Chine.

Des Affini- Ceux, qui ont pratiqué les Affiniboils, difent qu'ils font boils. grands, bien faits, robuttes, agiles, endurcis au froid \& à toutes fortes de fatigues; qu'ils fe piquent par tout le Corps, \& y tracent des figures de Serpens, ou d'autres Animaux; \& qu'ils entreprennent de très-grands voyages. Il n'y a rien en cela, qui les diftingue beaucoup des autres Sauvages de ce Continent, que nous connoiffons; mais ce qui les caractérife particulierement, c'eft qu'ils ont beaucoup de flegme, du moins ont-ils paru tels au prix des Criftinaux, avec qui ils font en commerce ; ceux - ci font en effet d'une vivacité extraordinaire; on les voit toujours danfans $\&$ chantans, \& ils parlent avec une volubilité de Langue, \& une précipitation, qu'on n'a remarquées dans aucune autre Nation Sauvage.

Du Lac des

Le véritable Pays des Afliniboils eft aux environs d'un Lac, Aliniboils. qui porte leur nom, \& que l'on connoît peu. Un François, que j'ai vû à Montreal, m’a affûré y avoir été, mais il l'avoit vû, comme on voit la Mer dans un Port, \& en paffant. L'opinion commune eft que ce Lac a fix cent lieuës de circuit; qu'on ne peut $y$ aller que par des chemins prefqu'impratiquables; que tous les Bords en font charmans; que l'Air y eft fort tempéré , quoiqu'on le place au Nord-Oueft du Lac Supérieur, oì il fait un froid extrême, \& qu'il comprend un fi grand nombre d'Illes, qu'on l'appelle dans le Pays, le Lac des Ifles. Quelques Sauvages le nomment Michinipi, qui veut dire la Grande Eau, \& il femble en effet qu'il foit le Réfervoir des plus grandes Rivieres, \& tous les grands Lacs de l'Amérique Septentrionnale : car on en fait fortir fur plu- 
D'UN VOYAGE DE L'A MERIQ. LET. XI. I8s fieurs indices le Fleuve Bourbon, qui fe jette dans la Baye d'Hudfon; le Fleuve Saint Laurent, qui porte des Eaux dans l'Ocean ; le Miciffipi, qui a fa décharge dans le Golphe Mé1721 . May. xique ; le Miffouri, qui fe mêle avec ce Dernier, \&x qui jufquà leur jonction ne lui eft inférieur en rien, \& $x$ un cinquiéme, qui coule, dit-on, à l'Oueft, \& par conféquent ne peut fe rendre, que dans la Mer du Sud. C'eft bien dommage que ce Lac n'ait pas été connu des Sçavans, qui ont cherché parrout le Paradis Terreftre; il auroit été pour le moins auffibien placé là que dans la Scandinavie. Je ne vous"garantis pourtant pas, Madame, tous ces faits, qui ne font appuyés que fur rapports de Voyageurs; encore moins ce que des Sauvages ont rapporté, qu'aux environs du Lac des Affiniboils, il y a des Hommes femblables aux Européens, \& qui font établis dans un Pays, où l'Or \& l'Argent font fi communs, qu'on les employe aux ufages les plus ordinaires. Le Pere Marquette, qui découvrit le Miciffipi en 1673 , dit dans fa Relation que des Sauvages, non-feulement lui avoient parlé de la Riviere, qui fortant de ce Lac coule à l'Oueft, mais lui avoient encore ajoûté qu'on avoit vû de grands $\mathrm{Na}$ vires à fon Embouchure. Il paroît au refte que les Affiniboils font les mêmes Peuples, qui font marqués dans de vieilles Cartes fous le nom de Poualaks, \& dont quelques Relations äifent que le Pays eft limitrophe à celui des Criftinaux, ou ou Killiftinons.

Les Langues Algonquine \& Huronne partagent toutes les Nations Sauvages du Canada, avec lefquelles nous fommes en commerce. Qui les fçauroit bien toutes deux pourroit parcourir fans Interpréte plus de quinze cent lieuës de Pays, \& fe faire entendre à plus de cent Peuples divers, qui ont chacun leur Langage propre. L'Algonquine fur-tout a une étenduë immenfe. Elle commence à l'Acadie \& au Golphe de Saint Laurent, \& fait un circuit de douze cent lieuës, en tournant du Sud-Eft par le Nord jufqu'au Sud-Oueft. On prétend même que les Loups, ou Mahingans, \& la plupart des Peuples de la Nouvelle Angleterre \& de la Virginie parlent des Dialectes Algonquines.

Les Abénaquis, ou Canibas Voifins de la Nouvelle An- Des Nations Les Abenaguis, ou Canibas Voifns de la Nouvelle An- Abénaquifesä gleterre, ont pour plus proches Voifins les Etechemins, \& des Algonou Malécites, aux environs de la Riviere de Pentagoët, \& quins Infé-

$$
\text { Tome III. }
$$

Des Peliples de la Langue Algonquine, 


\section{6 \\ J O UR NAL H IS T OR I Q U E}

172 I. plus à l'Ett font les Micmaks, ou Souriquois, dont le Pays propre eft l'Acadie, la fuite de la Côte du Golphe de Saint Laurent jufquà Gafpé, d'où un Auteur les a appellés Gafpéfiens, \& les Inles, qui en font proches. En remontant le Fleuve Saint Laurent, on ne rencontre plus aujourd'hui aucune Nation Sauvage jufqu'au Saguenay. Cependant, lorfque le Canada fut découvert, $\&$ bien des années après : on comptoit dans cet efpace plufieurs Nations, qui fe répandoient dans l'Ifle d'Anticofty, vers les Monts NotreDame, \& le long de la Rive Septentrionnale du Fleuve. Celles, dont les anciennes Relations parlent plus fouvent, font les Berfamites, les Papinachois, \& les Montagnez. On les appelloit auffi, fur-tout ces derniers, Algonquins Inférieurs, parce qu'ils habitoient le bas du Fleuve par rapport à Quebec : mais la plupart des autres font réduits à quelques Familles, que l'on rencontre tantôt dans un endroit, \& tantôt dans un autre.

Des Sauva- Il y en avoit, qui defcendoient dans la Colonie des Quarges du Nord. tiers du Nord, quelquefois par le Saguenay, \& plus fouvent par les Trois Rivieres, \& dont on n'entend plus parler depuis lontems. Tels étoient entr'autres les Attikamegues : ces Sauvages venoient de fort loin, \& ils étoient environnés de plufieurs autres Peuples, qui s'étendoient aux environs du Lac Saint Jean, \& jufqu'aux Lacs des Miftafins \& Nemifcau. Prefque tous ont été détruits par le Fer des Iroquois, ou par les maladies, fuite de la mifere, où la crainte de ces Barbares les avoient réduits : c'eft bien dommage, ils étoient fans vice, d'une grande douceur, on n'avoit eu aucune peine à les gagner à Jefus-Chrift, \& à les affectionner aux François. Entre Quebec \& Montreal on rencontre encore vers les Trois Rivieres quelques Algonquins, qui ne forment point un Village, \& qui trafiquent avec les François. Dans les premiers tems cette Nation occupoit tout le Bord Septentrionnal du Fleuve, depuis Quebec, où $\mathbf{M}$. de Champlain les trouva établis, \& fit alliance avec eux, jufqu'au Lac de S. Pierre.

Des Algonquins, des Outaouais \& autres Algonquins fupérieurs.

Depuis l'Ifle de Montreal, en fuivant toujours le Nord, on rencontre quelques Villages de Nipiffings, de Temifcamings, de Têtes de Boule, d'Amikoués \& d'Outaouais (a). Les premiers, qui font les vrais Algonquins, \& qui ont feuls con-

(b) Plufieurs éctivent \& prononcent OUTAOUAKS. 
D'UN VOYA GE DE L'A MER IQ. LET. XI. I87 fervé la Langue Algonquine fans altération, ont donné leur nom à un petit Lac fitué entre le Lac Huron, \& la Riviere des Outaouais. Les Temifcamings occupent les Bords d'un 1721 . May. autre petit Lac, qui porte auffi leur nom, \& qui paroît être la vraie fource de la Riviere des Outaouais. Les Têtes de Boule n'en font pas loin, leur nom vient de la figure de leur tête; ils trouvent dans cette figure une grande beauté, \& il $\mathrm{y}$ a bien de l'apparence que les Meres la donnent à leurs Enfans, lorfqu'ils font encore au Berceau. Les Amikoués, qu'on appelle aufifi la $N$ ation du $C_{\text {aftor, }}$, font réduits prefqu'à rien : on en trouve les reftes dans l'Ifle Manitoualin, qui eft dans le Lac Huron vers le Nord. Les Outaouais, autrefois très-nombreux, bordoient la grande Riviere, qui porte leur nom, \& dont ils fe prétendoient les Seigneurs. Je n'en connois aujourd'hui que trois Villages affez peu peuplés, dont je parlerai dans la fuite.

Entre le Lac Huron \& le Lac Supérieur, dans le Détroit même, par où le fecond fe décharge dans le premier, il y a un Rapide, que nous avons appelle le Sault Sainte Marie. Ses environs étoient autrefois peuplés de Sauvages, qui y étoient venus, dit-on, de la Rive Méridionnale du Lac Supérieur, \& qu'on appelle Saulteurs, c'eft-à-dire, Habitans du Sault. On leur a apparemment donné ce nom , pour s'épargner la peine de prononcer celui, qu'ils portoient, car il n'eft pas poffible d'en pouvoir venir à bout, fans reprendre deux ou trois fois haleine (a). Il n'y a aucune Nation établie, au moins que je fçache, fur les Bords du Lac Supérieur; mais dans les Poftes, que nous y occupons, on fait la Traite avec les Criftinaux., qui y viennent du Nord-Eft, \& qui appartiennent à la Langue Algonquine , \& avec les Affiniboils, qui font au Nord-Oueft.

Le Lac Michigan, qui eft prefque parallele au Lac Huron, dans lequel il fe décharge, \& qui n'en eft féparé que par une Peninfule de cent lieuës de long, laquelle va toujours en fe rétréciffant vers le Nord, a peu d'Habitans fur fes Bords; je ne fçai même fi aucune Nation y a jamais été fixe, \& c'eft fans fondement, que dans plufieurs Carres on le nomme $L a c$ des Illinois. En remontant la Riviere de Saint Jofeph, dont il reçoit les Eaux, on trouve deux Bourgades de differentes

(a) PAUOIRIGOUEIOUHAK. 
188 J O UR N A L H I S T O R I Q U E

I 72 I. Nations, qui y font venuës d'ailleurs, il n'y a pas même lontems. Ce Lac a du côté de l'Oueft une grande Baye, qui s'é-

May. tend vint-huit lieuës au Sud, \& qu'on nomme la Baye des Puans, ou fimplement la Baye. Son entrée eft fort large, \& femée d'Ifles, dont quelques-unes ont jufqu'à quinze ou vint lieuës de circuit. Elles étoient autrefois habitées par les Pouteouatamis, dont elles portent le nom, à l'exception de quelques-unes, qu'on laiffe à droite, où il y a encore quelques Sauvages, appellés Noquets. Les. Pouteouatamis occupent aujourd'hui une des plus petites de leurs Ifles, \& ils ont encore deux autres Villages, l'un dans la Riviere de Saint Jofeph, $\&$ l'autre au Détroit. Dans le fond de la Baye il y a des $S a k i s$ $\&$ des Otchagras. Ce font ces derniers, qu'on appelle Puans, je n'en fçai point encore la raifon; mais avant que d'arriver chez eux, on laiffe à droite une autre petite Nation, qu'on appelle Malomines, ou Folies Avoines.

Des Outaga- Une petite Riviere, fort embarraffée de Rapides, fe démis, des Mafcoutins \& des Kicapous. charge dans le fond de la Baye : elle eft connuë fous le nom de Riviere des Renards, à caufe du voifmage des Outagamis, vulgairement appellés les Renards. Tout ce Pays eft fort beau, \&x plus encore celui, qui s'étend au Sud jufqu'à la Riviere des Illinois : il n'eft pourtant habité que par deux Nations très. peu nombreufes, qui font les Kicapous \& les Mafcoutins. Il a plu à quelques-uns de nos Géographes d'appeller ces derniers la Nation du Feu, \& leur Pays, la Terre de Feu. Une équivoque a donné lieu à cette dénomination.

Des Miamis Il y a cinquante ans, que les Miamis étoient établis à l'extrémité Méridionnale du Lac Michigan, en un lieu, nommé Chicagou, du nom d'une petite Riviere, qui fe jette dans le Lac, \& dont la Source n'eft pas éloignée de celle des Illinois. Ils font préfentement féparés en trois Bourgades; dont l'une eft fur la Riviere de Saint Jofeph ; la feconde, fur une autre Riviere, qui porte leur nom, \& fe décharge dans le Lac Erié ; \& la troifiéme, fur la Riviere d'Ouabache, qui porte fes Eaux dans le Miciffipi : ces derniers font plus connus fous le nom d'Ouyatanons. On ne doute prefque point que cette Nation, \& celle des Illinois ne fuffent, il ny a pas trop lontems, un même Peuple, vû la grande affinité, qui fe remarque dans le Langage des uns \& des autres. Je pourrai vous en parler plus fûrement, lorfque je ferai fur les lieux. Au refte, la plûpar 
D'UN VOYA GE DE L'A MERIQ. LET. XI. $1 \& 9$ des Nations Algonquines, fi on en excepte celles, qui font plus avancées vers le Midi, s'occupent affez peu de la Culture des Terres, \& vivent prefque uniquement de Chaffe \& de 1721 . May。 Pêche; auffi font-elles peu fédentaires. La pluralité des Femmes eft en ufage parmi quelques-unes; cependant bien loin de multiplier, elles diminuent tous les jours. Il n'y en a pas une feule, où l'on compte fix mille ames; quelques-unes n'en ont pas deux mille.

Il s'en faut bien que la Langue Huronne s'étende auffi loin, que l'Algonquine; ce qui vient fans doute de ce que les Peuples, qui la parlent, ont toujours été moins errans que les Algonquins. Je dis la Langue Huronne, pour me conformer au fentiment le plus communément reçû́; car quelques-uns foutiennent encore, que c'eft l'Iroquoife, qui eft la Matrice. Quoiqu'il en foit, tous les Sauvages, qui font au Sud du Fleuve Saint Laurent, depuis la Riviere de Sorel, jufqu'à l'extrémité du Lac Erié , \& même affez proche de la Virginie, appartiennent à cette Langue; \& quiconque fçait le Huron, les entend tous. Les Dialectes s'en font extrêmement multipliées, \& il y. en a prefquautant, que de Bourgades. Les cinq Cantons, qui compofent la République Iroquoife, ont chacun la leur, $\&$ tout ce qu'on appelloit autrefois indifféremment Huron, n'avoit pas le même Langage.

Mais il eft bon d'obferver que comme la plûpart des Sauvages du Canada ont été de tout tems en Commerce entr'eux, tantôt Alliés, \& tantôt Ennemis, quoique les trois Langues Meres, dont j'ai parlé, n'ayent entr'elles aucune forte d'affinité, ni d'analogie, ces Peuples ont néanmoins trouvé le moyen de traiter enfemble fans avoir befoin de Truchement; foit que le long ufage leur donne la facilité de fe faire entendre par fignes; foit qu'ils fe foient formé une efpece de Jargon commun, quils apprennent par habitude. On vient m'avertir qu'il faut m'embarquer, je finirai cet article à mon premier loifir.

J'ai l'honneur d'être, \&c.

Des Peuples de la Langue: Huxronne. 
1721 .

\section{O UZIE ME LETTRE}

May.

Voyage jufqu'à Catarocoui. Defcription du Pays, E des Rapides du Fleuve de Saint Labrent. Defcription E fituation du Fort. Du Caractere des Langues du Canada, Es des Peuples, qui les parlent. Origine de la Guerre entre les Iroquois $\mathcal{E}$ les Algonquins.

\section{A Catarocoui, le quatorze de May, 1721.}

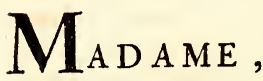

J E partis du Sault Saint Louys le premier de May, après avoir fermé ma derniere Lettre, \& j’allai coucher à la pointe Occidentale de l'Ifle de Montreal, où je n'arrivai qu'à minuit. Le lendemain j’employai toute la matinée à vifiter le Pays, qui eft fort beau. L'après-midi, je traverfai le Lac de Saint Louys, pour me rendre aux $C_{a}$ fcades, où je trouvai ceux de mes Gens, qui y étoient allés en droiture, occupés à recoudre leur Canot, qu'ils avoient laiffé tomber, en le portant fur leurs Epaules, \& qui s'étoit fendu d'un bout à l'autre. Voilà, Madame, l'agrément \& l'incommodité de ces petites Voitures : il ne faut rien pour les brifer; mais le reméde eft prompt $\&$ facile. Il fuffit de fe fournir d'Ecorces, de Gommes, \& de Racines : encore eft-il bien peu d'endroits, où l'on ne trouve des Gommes, \& des Racines propres à coudre les Ecorces.

Defcription des Rapides du Fleuve Saint Laurent.

Ce qu'on appelle les $C_{a}$ cades, eft un Rapide, fitué précifément au-deffus de l'Ifle Perrot, qui fait la féparation du Lac de Saint Louys, \& du Lac des deux Montagnes. Pour l'éviter, on prend un peu à droite, \& l'on fait paffer les Canots à vuide dans un endroit, qu'on appelle'le Trou : on les tire enfuite à Terre, \& on fait un portage d'un demi quart de lieuë ; c'eft-àdire, qu'on porte le Canot \& tout le Bagage fur fes Epaules. C'eft pour éviter un fecond Rapide, appellé le Buiffon; celuici eft une belle Nappe d'Eau, qui tombe d'un Rocher plat, élevé d'environ un demi pied. On pourroit fe délivrer de cet 
D'UN VOYAGE: DE L'A MERIQ. Let. XII. I9I embarras, en creufant un peu le Lit d'une petite Riviere, qui fe décharge dans une autre au-deffus des Cafcades. La dépenfe n'en feroit pas confiderable.

Au-deffus du Buiffon, le Fleuve a un grand quart de lieuë de large, \& les Terres des deux côtés font excellentes $\&$ bien boifées. On commence à défricher celles, qui font fur la $\mathrm{Ri}$ ve Septentrionnale, \& il feroit très-aifé d'y faire un grand Chemin depuis la Pointe, qui eft vis-à-vis de l'Ifle de MontMay.

Refléxion fur le Forr de $\mathrm{C}_{\mathrm{a}}$. tarocoui, \& fur le chemin, qu'on prend real, jufqu'à une Anfe, qu'on a nommée la Galette. On éviteroit par-là quarante lieuës d'une Navigation, que les Rapides rendent prefqu'impratiquable, \& toujours fort longue. Un Fort feroit même beaucoup mieux placé , \&x plus néceffaire à la Galette, qu'à Catarocoui, par la raifon qu'il n'y fçauroit paffer un feul Canot, qu'on ne le voye ; au lieu qu'à Catarocoui, on peut fe gliffer derriere des Ifles, fans être apperçu. D'ailleurs, les Terres des environs de la Galette font trèsbonnes, \& on pourroit par conféquent y avoir toujours des Vivres en abondance, ce qui épargneroit bien de la dépenfe. Outre cela, une Barque pourroit aller en deux jours de bon Vent, de la Galette à Niagara. Un des objets, qu'on a eu en vûë, en conftruifant le Fort de Catarocoui, a été le Commerce avec les Iroquois; mais ces Sauvages viendroient auffi volontiers à la Galette, qu'à Catarocoui. Ils auroient, à la vérité, un peu plus de chemin à faire; mais ils éviteroient une Traverfe de huit ou neuf lieuës, qu'il leur faut faire dans le Lac Ontario ; enfin, le Fort de la Galette couvriroit tout le Pays, qui eft entre la grande Riviere des Outaouais \& le Fleuve Saint Laurent ; car ce Pays n'eft point abordable du côté du Fleuve, à caufe des Rapides, \&xrien n'êt plus aifé, que de garder les bords de la grande Riviere. Je tiens ces Obfervations d'un Commiffaire de la Marine, (a) qui fut envoyé de la part du Roi en 1706. pour vifiter tous les Poftes éloignés du Canada.

Le même jour, troifiéme de May, je fis trois lieuës, \& j’arrivai aux Cedres. C'eft le troifiéme Rapide, qui a pris fon nom de la quantité de Cedres, qu'il y avoit en ce lieu là; mais on les a prefque tous coupés. Le quatriéme, je ne pûs aller que jufqu'au quatriéme Rapide, qu'on appelle le Cóteau $d u L a c$, quoiqu'il ne foit éloigné du précedent que de deux

(a) M. DE CIERAMBAUT D'A IGREMONT. 


\section{JOURNAL H ISTORIQUE}

ne ferez pas furprife, Madame, de ces fréquens Naufrages, May. quand vous fçaurez comment font faites ces petites Gondoles. Je crois vous avoir déja dit qu'il y en a de deux fortes; les uns d'Ecorce d'Ormes, plus évafés, affez groffierement conftruits; mais ordinairement plus grands. Je ne connois que les Iroquois, qui en ayent de cette efpece. Les autres font d'Ecorces de Bouleau, d'une largeur moins proportionnée à leur longueur, \& beaucoup mieux travaillés. C'eft de ceux-ci, que je vais vous donner la Defcription, parce que tous les François \& prefque tous les Sauvages s'en fervent.

Defcription On étend les Ecorces, qui font fort épaiffes, fur des VarandesCanots d'E- gues plattes \& très-minces, faites de Bois de Cedre. Ces Va-
corce. rangues font affujetties fur toute la longueur par de petites Barres de traverfe, qui font la féparation des Places dans le Canot; deux Maîtres, ou Précintes de même matiere, aufquels font coufuës ces petites Barres, affermiffent toute la Machine. Entre les Varangues \& les Ecorces, on infinuë de petites Cliffes de Cedre, moins épaiffes encore que les Varangues, \& qui ne laiffent pas de fortifier le Canot, dont les deux extrémités fe relevent peu à peu, \& \& font infenfiblement terminées en pointes tranchantes \& rentrantes. Ces deux extrémités font parfaitement femblables; enforte que pour changer de route, \& retourner en arriere, il fuffit que les Canoteurs changent de Main. Celui, qui fe trouve derriere, gouverne avec fon Aviron, en nageant toujours, \& la plus grande occupation de celui, qui eft fur le devant, eft de prendre garde que le Canot ne touche rien, qui puiffe le crever. Tous font affis à plat, ou fur leurs Genoux, \& leurs Avirons font des Pagayes de cinq à fix pieds de long, ordinairement de Bois d'Erable. Mais quand on va contre un Courant un peu fort, il faut fe fervir de la Perche, \& fe tenir de bout, \& cela s'appelle picquer de fond. Il eft befoin d'un grand ufage pour bien garder l'Equilibre dans cet exercice; car rien n'eft plus leger, par conféquent plus facile à tourner, que ces Voitures, dont les plus grandes, avec leur charge, ne tirent pas plus d'un demi pied d'Eau.

Les Ecorces, dont elles font compofées, aufi-bien que les Varangues \& les Barres, font coufuës avec des Racines de Sapin, lefquelles font plus pliantes, \& féchent beaucoup moins 
D'UN V OYA GE DE L'A MERI Q. LET. XII. I93 moins que l'Ofier. Toutes les Coutures font gommées en dedans \& en dehors; mais il faut les vifiter tous les jours, pour voir fi la Gomme ne s'eft point écaillée. Les plus grands Ca1721 . May. nots portent douze Hommes, deux à deux, \& quatre milliers pefant. De tous les Sauvages les plus habiles Conftructeurs font les Outaouais, \& en général les Nations Algonquines y réuffiffent mieux, que les Huronnes. Peu de François font venus à bout de les faire même paffablement ; mais pour les conduire, ils font pour le moins auffi fûrs, que les Naturels du Pays, auffi s'y exercent-ils dès la Bavette. Tous ces Canots, jufqu'aux plus petits, portent la Voile, \& avec un bon vent peuvent faire vint lieuës par jour. Sans Voiles, il faut avoir de bons Canoteurs pour en faire douze dans une eau morte.

Du Côteau du Lac au Lac de Saint François il n'y a qu'une Saint François. bonne demie lieuë. Ce Lac, que je paffai le cinquiéme, a fept lieuës de long, \& tout au plus trois dans fa plus grande largeur. Les Terres des deux côtés font baffes, mais elles paroiffent affez bonnes. La route depuis Montreal jufques-là tient un peu du Sud-Oueft, \& le Lac de Saint François court Oueft-Sud-Oueft, \& Eft-Nord-Eft. Je campai immédiatement au-deffus, \& la nuit je fus éveillé par des cris affez perçans, comme de gens, qui fe plaignoient. J'en fus d'abord effrayé, mais on me rafuûra bientôt, en me difant que c'étoit des Huars, efpece de Cormorans. On ajoûta que ces cris nous annonçoient du vent pour le lendemain, ce qui fe trouva vrai.

Le fixiéme je paffai les Chefnaux des Lacs. On appelle ainfi des Canaux, que forment un grand nombre d'Ifles, qui couvrent prefque le Fleuve en cet endroit. Je n'ai point vû de Pays plus charmant, \& les Terres y paroiffent bonnes. Le refte du jour nous ne fimes que franchir des Rapides : le plus confidérable, qu'on nomme le Moulinet, fait peur feulement à voir, \& nous ev̂mes bien de la peine à nous en tirer. Je fis néanmoins ce jour-là près de fept lieuës, \& j’allai camper au bas du Long Sault : c'eft un Rapide d'une demie lieuë de long, que les Canots ne peuvent monter, qu'à demie charge. Nous le paffâmes le fept au matin. Nous naviguâmes enfuite jufqu’à trois heures du foir à la Voile; mais alors la Pluye nous obligea de camper \& nous arrêta tout le jour fuivant. Il tomba même le huit un peu de Nége, \& la nuit il gela, comme il Tome III. $\quad \mathrm{B} \mathrm{b}$ Autres Rapides. 


\section{J OUR NA L HSTORIQUE}

I 72 I. fait en France au mois de Janvier. Nous étions néanmoins

May fous mêmes paralleles, que le Languedoc.Le neuf nous paf-

May. fàmes le Rapide Plat, éloigné du long Sault d'environ fept lievës, \& de cinq des Galots, qui eft le dernier des Rapides. La Galette eft à une lieuë \& demie plus loin, \& nous y arrivâmes le dix. Je ne pouvois me laffer d'admirer le Pays, qui eft entre cette Anfe \& les Gallots. Il n'eft pas poffible de voir de plus belles Forêts. J'y ai remarqué fur - tout des Chênes. d'une hauteur extraordinaire.

nel'rne To- A cinq ou fix lieuës de la Galette il y a une Ifle appellée nihata.

Tonihata, dont le Terrein paroît affez fertile, \& qui a environ une demie lieuë de long. Un Iroquois, qu'on a appellé le Quaker, je ne fçai pourquoi, homme de beaucoup d'efprit, $\&$ fort affectionné aux François, en avoit obtenu le Domaine du feu Comte de Frontenac, \& il montre la Patente de cette Conceffion, à quiconque la veut voir. Il a cependant vendu fa Seigneurie pour quatre Pots d'Eau-de-Vie; mais il s'en eft réfervé l'ufufruit, \& il y a raffemblé dix-huit ou vint Familles de fa Nation. J'arrivai le douze dans fon Ifle, \& je lui rendis vifite. Je le trouvai, qui travailloit dans fon Jardin : ce n'eft pas la coûtume des Sauvages; mais celui-ci affecte toutes les manieres des François. Il me reçut fort bien, \& il vouloit me régaler, mais le beau tems m'invitoit à continuer ma route. Je pris congé de lui, \& jallai paffer la nuit à deux lieuës de-là, dans un fort bel endroit. Il me reftoit encore treize lieuës à faire pour gagner Catarocoui; le tems étoit beau, \& la nuit fort claire; cela nous engagea à nous embarquer à trois heures du matin. Nous paffâmes au milieu d'une efpece d'Archipel, qu'on a nommé les Milles Ifles, \& je crois bien quil y en a plus de cinq cent. Quand on eft forti de-là , on n'a plus qu'une lieuë $\&$ demie à faire, pour gagner Catarocoui. Le Fleuve eft plus libre , \& a bien une demie lieuë de large. On laiffe enfuite fur la droite trois grandes Anfes affez profondes, \& c'eft dans la troifiéme, qu'eft bâti le Fort.

Defcription

Ce Fort eft un Quarré à quatre Baftions, bâti de Pierres, du Fort de Ca- \& qui occupe un quart de lieuë de circuit. Sa fituation a véritablement quelque chofe de bien agréable. Les Bords du Fleuve préfentent de toutes parts un Payfage bien varié, \& il en eft de même de l'Entrée du Lac Ontario, qui n'en eft qu'à 
DUN VOYA GE DE L'A MERIQ. LET. XII. I95 une petite lieuë : elle eft femée d'Ifles de differentes grandeurs, toutes bien boifées, \& rien ne termine l'Horifon de ce côté-

1721 . là. Ce Lac a porté quelque tems le nom de Saint Louis, on lui donna enfuite celui de Frontenac, auffi-bien qu'au Fort de Catarocoui, dont le Comte de Frontenac fut le Fondateur : mais infenfiblement le Lac a repris fon ancien nom, qui eft Huron, Qu lroquois, \& le Fort, celui du lieu, où il eft bâti.

Le Terrein depuis la Galette jufqu'ici paroît affez ftérile, mais ce n'eft que fur la lifiere: il eft très-bon au-delà. Il y a vis-à-vis du Fort une Inle fort jolie au milieu du Fleuve. On y avoit mis des Cochons, qui y ont multiplié, \& elle en porte le nom. De deux autres plus petites, qui font au-deffous, à une demie lieuë de diftance l'une de l'autre, l'une fe nomme l'Ifle aux Cédres, \& l'autre, l'Ifle aux Cerfs. L'Anfe de Catarocoui eft double, c'eft-à-dire, que prefque dans fon milieu il y a une pointe, qui avance beaucoup, \& fous laquelle il $y$ a un fort bon mouillage pour les grandes Barques. M. de la Sale, fi célébre par fes découvertes \& par fes malheurs, qui a été Seigneur de Catarocoui, \& Gouverneur du Fort, y en avoit deux ou trois, qu'on y a coulées à fond, \& qui y font encore. Derriere le Fort il y a un Marais, où le Gibier foifonne; c'eft une douceur \& une occupation pour la Garnifon. Il fe faifoit autrefois ici un très-grand Commerce, fur-tout avec les Iroquois, \&x c'étoit pour les attirer chez nous, pour les empêcher de porter leurs Pelleteries aux Anglois, \& pour les tenir eux-mêmes en refpect, qu'on avoit bâti le Fort: mais ce commerce n'a pas duré lontems, \& le Fort n'a pas empêché ces Barbares de nous faire bien du mal. Ils $\mathrm{y}$ ont actuellement encore quelques Familles en-dehors de la Place, $\&$ il y en a auffi quelques-unes de Mifj $\int a g u e z$, Nation Algonquine, qui a encore une Bourgade fur le Bord Occidental du Lac Ontario, une autre à Niagara, \& une troifiéme dans le Détroit.

Je trouve ici, Madame, une occafion pour envoyer mes Lettres à Quebec; je vais profiter de quelques heures de loifir pour remplir celle-ci de ce qui me refte à vous dire fur la difference des Langues du Canada. Ceux, qui les ont étudiées à fond, prétendent que les trois, dont je vous ai parlé, ont tous les Caracteres des Langues primitives; \& il eft certain $\mathrm{B} b$ ij 


\section{J OUR N A L H IS TOR I U E}

I 72 I. qu'elles n'ont pas une origine commune. La feule prononciaMay. tion fuffiroit pour le prouver. Le Siou fifle en parlant; le $\mathrm{Hu}$ ron n'a point de lettre labiale, qu'il ne fçauroit prononcer, parle du gofier, \& afpire prefque toutes les fyllabes; l'Algonquin prononce avec plus de douceur, \& parle plus naturellement. Je n'ai pu rien apprendre de particulier de la premiere de ces trois Langues; mais nos anciens Miffionnaires ont beaucoup travaillé fur les deux autres, \& fur les principales de leurs Dialectes : voici ce que j'en'ai oui dire aux plus habiles.

Caractere de Ia Langue $\mathrm{Hu}-$ ronne.

La Langue Huronne eft d'une abondance, d'une énergie, \& d'une nobleffe, qu'on ne trouve peut-être réunies dans aucune des plus belles, que nous connoiffons, \& ceux , à qui elle eft propre, quoique réduits à une poignée d'Hommes, ont encore dans l'ame une élévation, qui s'accorde bien mieux avec la majefté de leur Langage, qu'avec le trifte état, où ils font réduits. Quelques-uns ont cru y trouver des rapports avec l'Hebreu; d'autres en plus grand nombre ont prétendu qu'elle avoit la même origine, que celle des Grecs; mais rien n'eft plus frivole, que les preuves, qu'ils en apportent. Il ne faut point fur-tout compter fur le Vocabulaire du Frere Gabriel SAGHARD, Récollet, qu'on a cité pour foûtenir ce fentiment : encore moins fur ceux de Jacques Cartier \& du Baron de la Hontan. Ces trois Auteurs avoient pris à la volée quelques termes, les uns du Huron, les autres de l'Algonquin, qu'ils avoient mal retenus, \& qui fouvent fignifioient toute autre chofe, que ce qu'ils croyoient. Et de combien d'erreurs n'ont pas été caufe de pareilles méprifes de quantitê de Voyageurs?

Caractere de La Langue Algonquine n'a pas autant de force, que la $\mathrm{Hu}-$ 1a Langue Al-ronne, mais elle a plus de douceur \& d'élégance. Toutes gonquine. deux ont une richeffe d'expreffions, une varieté de tours, une propriété de termes, une régularité, qui étonnent : mais ce qui furprend encore davantage, c'eft que parmi des Barbares, qu'on ne voit point s'étudier à bien parler, \& qui n'one jamais eu l'ufage de l'écriture, il ne s'introduit point un mauvais mot, un terme impropre, une conftuction vicieufe, \& que les Enfans mêmes en confervent, jufques dans le difcours familier, toute la pureté. D'ailleurs la maniere, dont ils animent tout ce qu'ils difent, ne laiffe aucun lieu de douter qu'ils ne comprennent toute la valeur de leurs expreffions, \& toute 
D'UN V OYA GE DE L'A M ER IQ. Let. XII. I97 la beauté de leur Langue. Les Dialętes, qui font dérivées de l'une $\&$ de l'autre, n'en ont pas confervé toutes les graces, ni la même force. Les Tfonnonthouans, par exemple, c'eft un des cinq Cantons Iroquois, paffent parmi les Sauvages pour avoir un Langage groffier.

Dans le Huron tout fe conjugue; un certain artifice, que je ne vous expliquerois pas bien, $\mathrm{y}$ fait diftinguer les noms, les pronoms, les adverbes, \& c. des verbes. Les verbes fim- gueHuronne. ples ont une double conjugaifon, l'une abfoluë, l'autre réciproque. Les troifiémes perfonnes ont les deux genres, car il n'y en a que deux dans ces Langues, à fçavoir le genre noble, \& le genre ignoble. Pour ce qui eft des nombres $\&$ des tems, on y trouve les mêmes différences, que dans le Grec. Par exemple, pour raconter un voyage, on s'exprime autrement, $f i$ on l'a fait par Terre, ou fi on l'a fait par Eau. Les verbes actifs fe multiplient autant de fois, qu'il y a de chofes, qui tombent fous leur action; comme le verbe, qui fignifie manger, varie autant de fois, qu'il y a de chofes comertibles. L'action s'exprime autrement à l'égard d'une chofe animée, \& d'une chole inanimée: ainfi voir un Homme, \& voir une pierre, ce font deux verbes. Se fervir d'une chofe, qui appartient à celui, qui s'en fert, ou à celui, à qui on parle, ce font autant de verbes differens.

Il y a quelque chofe de tout cela dans la Langue Algonquine, mais la maniere n'en eft pas la même, $8 x$ je ne fuis tés de $l a t$ Lannullement en état de vous en inftruire. Cependant, Madame, gue Algonquifi du peu que je viens de vous dire, il s'enfuit que la richeffe \& la varieté de ces Langues les rendent extrémement difficiles à apprendre, la difette \& la ftérilité, où elles font tombées, ne caufent pas un moindre embarras. Car, comme ces Peuples, quand nous avons commencé à les fréquenter, ignoroient prefque tout ce, dont ils n'avoient pas l'ufage, ou qui ne tomboit pas fous leurs fens, ils manquoient de termes pour les exprimer, ou les avoient laifé tomber dans l'oubli. Ainfi n'ayant point de culte reglé, ne fe formant de la Divinité, \& de tout ce qui a du rapport à la Religion, que des idées confufes, ne faifant prefque aucune réflexion, que fur les chofes fenfibles, ou ne concernoit point leurs affaires, qui étoient très-bornées, n'étant pas accoûtumés à difcourir des vertus, des paffions, \& de beaucoup d'autres fujets de tés de la Lan- 
I 72 I. nos entretiens ordinaires; ne cultivant ni arts, que ceux, qui May leur étoient néceffaires, \& qui fe réduifoient à un très-petit nombre; ni aucune fcience, n'obfervant que ce qui étoit à leur portée, \& pour la vie n'ayant rien de fuperflu, ni aucun rafinement; quand il a été queftion de leur parler d'autres chofes, on a trouvé un grand vuide dans leurs Langues, \& il a fallu, pour fe rendre intelligible, les remplir de circonlocutions embarraflantes, \& pour eux, \& pour nous : de forte qu'après avoir appris d'eux leur Langage, on a été obligé de leur en enfeigner une autre, compofé en partie de leurs propres termes, \& en partie des nôtres traveftis en $\mathrm{Hu}$ ron ou en Algonquin, pour leur en faciliter la prononciation. Quant aux Caracteres, ils n'en avoient point, \& $x$ ils y fuppléoient par des efpéces d'Hiéroglyphes. Rien ne les a plus furpris que de nous voir nous expliquer aufi aifément par écrit, que par parole.

Que $f i$ on me demande à quoi on a reconnu que le Siou, le Huron, \& l'A Igonquin font plutitôt les Langues Meres, que quelques-unes de celles, que nous regardons comme leurs Dialectes, je répondrai qu'on ne peut guéres s'y méprendre, $\&$ je n'en veux point d'autre preuve, que les paroles de $\mathbf{M}$. l'Abbé Dubos, que jai déja citées (a); mais enfin, comme nous ne pouvons juger ici que par comparaifon, fi de ces réflexions on peut bien conclure que lesLangues de tous les Sauvages du Canada font dérivées des trois, que j'ai marquées, j’avouë qu'elles ne prouvent pas abfolument que celles-ci font primitives, $\&$ de la premiere inftitution des Langues. J'ajoûte que tous ces Peuples ont dans leurs difcours un peu de ce génie Afratique, qui donne aux chofes un tour $\&$ des expreflions figurées, \& c'eft peut-être ce qui a perfuadé à quelques-uns qu'ils tiroient leur origine de l'Afie, ce qui eft d'ailleurs affez vraifemblable.

Différence Non-feulement les Peuples de la Langue Huronne fe font des Peuples des toujours plus occupés que les autres de la culture des Terres; sonnes, \& de ils fe font auffi beaucoup moins étendus, ce qui a produit ceux des Na- deux effets; car en premier lieu ils fe font mieux établis, tions Algon- mieux logés, mieux fortifiés, il y a toujours eu parmi eux plus de police, \& une forme de gouvernement plus marquée. La qualité de Chef, au moins chez les vrais Hurons, qui (a) Page 38. 
D'U N V OYAGE DE L'A MERIQ. LET. XII. I9? font les Tionnontatés, eft héréditaire. En fecond lieu, jufqu'aux guerres des Iroquois, dont nous avons été les témoins, leur Pays étoir plus peuplé, quoique la Polygamie 1721 . May. n'y eût jamais été en ufage. lls ont auffí la réputation d'être plus laborieux, plus induftrieux, plus habiles dans leurs affaires, \& plus mefurés dans leurs démarches, ce qu'on ne fçauroit attribuer, qu’à l'efprit de focieté, qu'ils ont mieux confervé que les autres. Ceci fe remarque fur-tout dans les Hurons, qui ne faifant prefque plus un corps de Nation, $\&$ réduits à deux Villages médiocres, fort élorgnés l'un de l'autre, ñe laiffent pas d'être encore l'ame de tous les Confeils, quand il s'agit des affaires générales. Il eft vrai que malgré cette diverfité, qui ne fe remarque pas du premier coup d'oil, il y a bien de la refiemblance dans le caractere d'efprit, les mours, \& les coûtumes de tous les Sauvages du Canada; mais c'eft une fuite du commerce, qu'ils ont continuellement enfemble depuis bien des fiécles.

Ce feroit ici le lieu de vous parler du gouvernement de ces Peuples, de leurs coûtumes $\&$ de leur Religion; mais je n'y vois encore qu'un cahos, qu'il ne m'eft pas poffible de débrouiller. Vous ne voudriez pas fans doute qu'à l'exemple de certains Voyageurs, qui ne font point difficulté de remplir leurs Journaux de tout ce qu'ils entendent dire, fans s'embarraffer de rien vérifier, je vous débitaffe toutes les extravagances, qu'on a mifes fur le compte de nos Sauvages, ou qu'on a tirées, comme on a pu, de leurs traditions. Ces traditions d'ailleurs font fi peu fûres, \& fe contredifent prefque toujours fi groffierement, qu'il eft prefqu'impoffible d'y rien démêler de certain \& de fuivi. En effet comment des Peuples tels, qu'on a trouvé ceux-ci, anroient-ils pu fe tranfmettre bien fidelement ce qui s'eft paffé parmi eux depuis tant de fiécles, n'ayant eu aucun fecours pour foulager leur Mémoirc ? \& peut-on concevoir que des Hommes, qui penfent fi peu à l'avenir, fe foient jamais affez occupés du paffé, pour en conferver un fouvenir fidéle ? Auffi après toutes les recherches, qu'on a pu faire, on eft encore à fçavoir quelle étoit la fituation du Canada, lorfque nous en fìmes la premiere découverte vers le milieu du feiziéme fiécle.

Le feul point de leur Hiftoire, qui foit venu jufqu’à nous revêtu de quelque vraifemblance, eft l'origine de la guerre,

Origine de ia guerre, que kesAlgonquizas 
1721 . que M. de Champlain trouva fort allumée entre les Iroquois

May. d'une part, \& les Hurons \& les Algonquins de l'autre, \& \& les Hurons dans laquelle il s'engagea beaucoup plus qu'il ne convenoit à nir contre les nos véritables intérêts. Je n'en ai pû même découvrir l'époIroquois. que, mais je ne la crois pas fort ancienne. Je vais, Madame, finir par-là cette Lettre : mais je vous avertis d'avance que je ne garantis point la verité de ce trait hiftorique, quoique je le tienne d'affez bon endroit.

Les Algonquins, comme je l'ai déja obfervé, occupoient toute cette étenduë de Pays, qui eft depuis Quebec, \& peutêtre même depuis Tadouffac jufqu'au Lac de Nipiffing, en fuivant la Rive Septentrionnale du Fleuve Saint Laurent, \& en remontant la grande Riviere, qui fe décharge dans le Fleuve au-deffus de l'Ine de Montreal. Cela peut faire juger que cette Nation étoit alors affez nombreufe, \& il eft certain qu'elle a fait lontems une très-grande figure dans cette partie de l'Amerique, où les feuls Hurons étoient en état de leur difputer la prééminence fur toutes les autres. Par rapport à la Chaffe, ils n'avoient point d'égaux, \& pour la Guerre, ils ne reconnoiffoient point de fupérieurs. Le peu, qui en refte aujourd'hui, n'a point'dégéneré de l'antique valeur de cette $\mathrm{Na}$ tion, \& leur malheur ne leur a point fait perdre encore leur réputation.

Les Iroquois avoient fait avec eux une efpéce de confédération, fort utile aux uns $\&$ aux autres, mais qui, dans l'idée des Sauvages, chez qui un grand Chaffeur $\&$ un grand $G$ uerrier vont de pair, donnoit aux Algonquins une vraie fupériorité fur les Iroquois. Ceux-ci, prefqu'uniquement occupés de la culture des Terres, s'étoient engagés à faire part de leurs recoltes aux Algonquins, qui de leur côté devoient partager avec eux le fruit de leur Chaffe, \& les défendre contre quiconque entreprenciroit de les inquietter. Ces deux Nations vécurent ainfi affez lontems en bonne intelligence; mais une hauteur mal placée de la part des uns; un dépit, auquel on ne s'attendoit point de la part des autres, rompirent cette union, \& brouillerent irréconciliablement ces deux Peuples.

Comme l'Hyver eft le tems de la grande Chaffe, \& $x$ qu'alors la Terre couverte de Néges ne fournit pas d'occupation à ceux , qui la cultivent, les Sauvages des deux Nations conféderées fe joignoient enfęmble pour hyverner dans les Bois; 
D'UN VOYAGE DE L'A MERIQ. LET. XII. 201 mais les Iroquois pour l'ordinaire laiffoient chafer les Algonquins, \& fe contentoient d'écorcher les Bêtes, de faire fécher les Viandes, \& d'accommoder les Peaux. C'eft préfentement par-tout l'ouvrage des Femmes; peut-être qualors ce May. n'étoit pas encore l'ufage : quoiqu'il en foit, les Iroquois ne s'en faifoient pas une peine. De tems en tems néanmoins il prenoit envie à quelques-uns d'entr'eux de s'effayer à la Chaffe, \& les Algonquins ne s'y oppofoient pas; en quoi ils furent mauvais Politiques. Il arriva pendant un Hyver qu'une Troupe des deux Nations s'arrêta dans un endroit, où ils avoient compté de faire bonne Chaffe ; \& fix jeunes Algonquins, accompagnés d'autant d'Iroquois de mềme âge, furent détachés pour la commencer.

Ils apperçurent d'abord quelques Elans, \& tous fe prépparerent auffi-tôt à courir deffus; mais les Algonquins ne voulurent pas permettre aux Iroquois de les fuivre, \& leur firent entendre qu'ils auroient affez à faire pour écorcher toutes les Bêtes, qu'ils alloient tuer. Par malheur pour ces Rodomons trois jours fe pafferent, fans qu'ils puffent abbatre un feul Orignal, quoiquill s'en préfentât un grand nombre. Ce peu de fuccès les mortifia, $\alpha$ ne fit apparemment pas de déplaifir aux Iroquois, qui firent inftance pour avoir la permiffion d'aller d'un autre côté, où ils fe flattoient d'être plus heureux. Leur propofition fut reçûe des Algonquins, comme le fut autrefois des Freres de David celle, que fit ce jeune Berger d'aller combattre le Géant Goliath : on leur dit qu'ils étoient bien vains de prétendre avoir plus d'habileté que des Algonquins: que leur fait étoit de remuer la Terre, \& qu'ils devoient laiffer la Chaffe à ceux , à qui elle convenoit mieux.

Les Iroquois outrés de cette réponfe ne répliquerent point, mais la nuit fuivante ils partirent fecrétement pour la Chaffe. Les Algonquins furent furpris à leur réveil de ne les point voir, mais leur étonnement fe changea bientôt en un chagrin extrême. Car dès le foir du même jour ils apperçurent les Iroquois, qui revenoient chargés de Viandes d'Orignal. Il n'eft point d'Hommes auMonde, qui foient plus fufceptibles d'un dépit, \& quile portent plus loin, que les Sauvages de ce Pays. L'effet de celui des Algonquins fut prompt: à peine les Iroquois furent endormis, quilis eurent tous laTête caffée. Un tel affaffinat nẹ pouvoit pas demeurer lontems caché, \&x quoique Tome III.

$\mathrm{Cc}$ 
$172 \mathrm{I}$. les Corps euffent été enterrés fecrétement, on en fut bientôt informé dans la Nation. Elle fit d'abord fes plaintes avec moMíay. dération, mais elle voulut avoir juftice des:Meurtriers. On la méprifoir trop, pour la lui accorder: on ne voulut pas même s'abaiffer jufqu'à lui faire la moindre fatisfaction.

Iesfrites de Les Iroquois au défefpoir prirent une ferme réfolution de sette guerre.

fe venger du mépris, qu'on faifoit d'eux, \& qui les piquoit encore plus que laffaffinat, dont ils fe plaignoient. Ils jurerent de perir tous jufqu'au dernier, ou d'en avoir raifon; mais comme ils ne fe fentoient pas encore en état de fe mefurer avec les Algonquins, dont le nom feul tenoit en refpeet prefque toutes les autres Nations, ils s'éloignerent d'eux, allerent effayer leurs armes contre des Ennemis moins redoutables, qu'ils fe firent de gayeté de cœur, \& quand ils fe crurent fuffifamment aguerris, ils tomberent tout-à-coup fur les Algonquins, 8x commencerent une guerre, dont nous n'avons vû que la fin, \& qui a embrafé tout le Canada. Elle s'eft continuée de la part des Iroquois avec une férocité d'autant plus terrible, qu'elle étoit plus réflechie, \& qu'elle n'avoit rien de cette fureur précipitée, qui empêche de bien prendre fes mefures, \& qui fe ralentit d'abord. D'ailleurs les Sauvages ne fe croyent jamais bien vengés, que par la deftruction entiere de leurs Ennemis, \& cela eft encore plus vrai des Iroquois, que des autres. On dit communément, d'eux, qu'ils viennent en Renards, qu'ils attaquent en Lions, \& qu'ils fuyent en Oifeaux. Ainfi ils agiffent prefque toujours à coup fûr, \& cette conduite leur a fi bien réuffi, que fans les François il ne feroit peut-être plus mention aujourd'hui d'aucune des Nations, qui ont ofé s'oppofer à ce torrent.

Les plus maltraités de tous ont été les Hurons, qui fe font trouvés engagés dans cette guerre, comme Alliés, ou Voifins des Algonquins, ou parce qu'ils fe rencontroient fur le chemin des uns \& des autres. On a vû avec étonnement une Nation des plus nombreufes, $\&$ des plus guerrieres de ce Continent, \& la plus eftimée de toutes pour fa fageffe $\&$ pour fon. efprit difparoître prefque entierement en affez peu d'années. On peut dire même qu'il n'en eft aucune dans cette Partie de l'Amérique, à laquelle il n'en ait coûté beaucoup de ce qu'ón a forcé les Iroquois à prendre les armes, \& je ne connois dans tout le Canada, que les Abénaquis, qu'ils n'ont ofé inquieter 
D'UN V OYA GE DE L'A MERIQ. LET. XII. 203 chez eux. Car depuis qu'ils ont goûté de la guerre, ils ne fçauroient demeurer tranquilles, femblables aux Lions, dont la vûë \& le goût du Sang ne fait qu'augmenter la foif infatiable, qu'ils en ont. On auroit peine à croire jufqu'où ils font allés chercher des Hommes, pour les combattre. Cependant à force de faire la guerre, comme ils n'ont pas laiffé de recevoir de tems en tems d'affez grands échecs, ils fe font trouvés euxmêmes extrêmement diminués, \& fans les Efclaves, qu'ils ont amenés de toutes parts, \& dont ils ont adopté le plus grand nombre, leur fituation ne feroit guéres aujourd'hui plus heureufe, que celle des Peuples, qu'ils ont fubjugués.

Ce qui eft arrivé en cela aux Iroquois, on peut le dire à plus forte raifon de tous les autres Sauvages de ce Pays, \&il ne faut pas s'étonner fi, comme je l'ai déja remarqué, ces Nations diminuent tous les jours d'une maniere bien fenfible. Car encore que leurs guerres ne paroiffent pás d'abord auffi meurtrieres que les nôtres, elles le font beaucoup plus à proportion. La plus nombreufe de ces Nations n'a peut-être jamais été de plus de foixante mille Ames, \& de tems en tems il fe paffe entr'elles des actions, où il y a bien du fang répandu. Une furprife, ou un coup de main détruit quelquefois une Bourgade entiere; fouvent la crainte d'une irruption fait déferter tout un Canton, \& alors ces Fugitifs, pour éviter de mourir par le Fer de leurs Ennemis, ou dans les fupplices, s'expofent à périr de faim \& de mifere dans les Forêts, ou fur les Montagnes, parce que rarement ils ont le loifir, ou la précaution d'y porter des vivres. Cela eft arrivé le fiécle précédent à un très-grand nombre de Hurons $\&$ d'Algonquins, dont on n'a pu f̧avoir ce qu'ils étoient devenus.

Je fuis, \&c.

1721 .

May. 
1721 .

May.

\section{TREIZIEM E LETTRE.}

Defcription du Pays jufqu'à la Riviere des Onnontagués. Du Flux E du Reflux dans les grands Lacs du Canada. Maniere, dont les Sauvages chantent la Guerre. Du Dieu de la Guerre chez ces Peuples. De la Déclaration de la Guerre. Des Coliers de Porcelaine $\mathcal{E} d u$ Calumet, $\mathcal{E}$ de leurs ufages pour la Paix E pour la Guerre.

A l'Anfe de la Famine, ce feiziéme de May, 1721 .

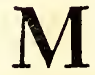

A D A ME,

Depart de ME voici dégradé par un Vent contraíre, qui a bien la Catarocoui. mine de durer lontems, \& de me retenir plus d'un jour dans Route jufquà à le plus mauvais endroit du monde. Je vais me défennuyer à mine. Defcrip. tion du Pays. vous écrire. Il paffe ici fans ceffe des armées entieres de ces Pigeons, que nous appellons Tourtes; fi quelqu'une vouloit fe charger de mes Lettres, vous fçauriez peut-être de mes nouvelles, avant que je forte d'ici: mais les Sauvages ne fe font point avifés de dreffer ces Oifeaux à ce manége, comme faifoient, dit-on, autrefois les Arabes, \& beaucoup d'autres Peuples.

Je m'embarquai le quatorze précifément à l'heure même; à laquelle jeétois arrivé la veille à Catarocoui. Je n'avois que fix lieuës à faire pour gagner l'Ifle aux Chevreuils, où il y a un joli Port, qui peut recevoir de grandes Barques; mais mes Canadiens n'avoient pas vifité leur Canot, dont le Soleil avoit fait fondre la gomme en plufieurs endroits, il faifoit eau de toutes parts, \& il me fallut perdre deux heures entieres pour le réparer dans une des Inles, qui font à l'entrée du Lac Ontario. Nous naviguâmes enfuite jufqu’à dix heures du foir, fans potivoir gagner l'Ifle aux Chevreuils, \& il nous fallut paffer le refte de la nuit dans un très-mauvais endroit.

Des vignes J'apperçus là pour la premiere fois des Vignes dans le Bois。' du Canada. Il y en avoit prefqu'autant de Seps, que d'Arbres, à la cime 
D'UN V OYA G E DE L'A MERIQ. LET. XIII. 205 defquels ils s'élevent. Je n'avois pas encore fait cette remarque, parce que je m'étois toujours arrêté jufques-là dans des endroits découverts; mais on m'affûre que c'eft par-tout la même chofe jufqu'au Mexique. Ces Vignes ont le pied fort gros, \& portent beaucoup de Raifins. Mais les grains n'en font guéres que de la groffeur d'un Pois; \& cela ne peut être autrement, les Vignes n'étant point taillées, ni cultivées. Quand ils font mûrs, c'ett une bonne manne pour les Ours, qui vont les chercher au haut des plus grands Arbres. Ils n'ont pourtant que le refte des Oifeaux, qui ont bientôt vendangé des Forêts entieres.

Je partis le lendemain de bonne heure, \& à onze heures du matin je m'arrêtai à l'Ifle aux Gallots, trois lieuës par-delà l'Ifle aux Chevres, par les quarante-trois degrés trente-trois minutes. Je me rembarquai un peu après midi ; $\&$ je fis une traverfe d'une lieuë \& demie pour gagner la Pointe de la Traverfe: fi pour venir là du lieu, où javois paffé la nuit, il m'avoit fallu côtoyer la Terre ferme, jaurois eu plus de quarante lieuës à faire, \& l'on eft bien obligé de prendre ce parti, quand le Lac n'eft pas bien calme; car pour peu qu'il foit agité, les vagues $\mathrm{y}$ font auffi groffes qu'en pleine Mer. Il n'eft pas même polfible de ranger la Côte, quand le vent vient du large.

De la pointe de l'ffle aux Gallots on voit à l'Oueft la Riviere de Chouguen, autrement appellée la Riviere d'Onnontagué, qui en eft éloignée de quatorze lieuës. Comme le Lac étoit tranquille, qu'il n'y avoit nulle apparence de mauvais tems, \& que nous avions un petit foufle de vent d'Eft, qui fuffifoit à peine pour porter la Voile, je réfolus de tirer droit fur cette Riviere, afin d'épargner quinze ou vint lieuës de circuit. Mes Conducteurs, plus expérimentés que moi, jugeoient l'entreprife hafardeufe; mais par complaifance ils déférerent à mon avis. La beauté du Pays, que je laiffois à ma gauche, ne me tenta point, non plus que les Saumons \& quantité d'autres Poiflons excellens, qu'on pêche dans fix belles Rivieres, qui font à deux ou trois lieuës les unes des autres $(a)$. Nous prîmes donc le large, \& jufqu’à quatre

(a) La Riviere de l'Affomption, à une lievë de la pointe de la Traveife : celle des Sables, trois lieuës plus loin: celle de la Planche, deux lieuës au-delà : celle de la

Grande Famine, à deux autres lieuës : celle de la Petite Famine, à une lieuë ; celle d's la Groffè Ecorce, à une lieue.
1721 . May. 


\section{JOURNAL HISTORIQUE}

$172 \mathrm{I}$. heures nous n'eûmes pas lieu de nous en repentir : mais alors May. le vent força tout-à-coup, \& nous aurions bien voulu être plus près de Terre. Nous tournâmes vers la plus proche, dont nous étions encore à trois lieuës, \& nous eûmes bien de la peine à la gagner. Enfin à fept heures du foir nous abordâmes à l'Anfe de la Famine, ainfi nommée depuis que M. de la Barre, Gouverneur Général de la Nouvelle France, penfa y perdre toute fon Armée par la faim \& par les maladies, en allant faire la guerre aux Iroquois.

Defription Il étoit tems que nous arrivaffions; le vent étoit fort, \& de l'Anfe de la les vagues fi groffes, qu'on n'auroit pas ofé paffer la Seine à Eamine.

Paris vis-à-vis du Louvre par le tems, que nous avions. Au refte cet endroit eft tout propre à faire perir une Armée, qui auroit compté fur la Chaffe $\&$ fur la Pêche, pour fubfifter, outre que l'Air y paroît fort mal fain. Mais rien n'eft plus beau que les Forêts, qui couvrent tous les Bords du Lac. Les Chênes blancs \& rouges s'y élevent jufqu'aux nuës, on y voit encore un Arbre de la plus grande efpece, dont le bois dur, mais caffant, reffemble beaucoup à celui du Plane, \& dont la feuille à cinq pointes, de médiocre grandeur, eft d'un très-beau verd en-dedans, \& blanchâtre en-dehors. On lui a donné le nom de Cotonnier, parce que dans une coque de la groffeurà pou près de celle du Maronnier d'Inde, il porte une efpece de Cotton, qui paroît pourtant n'être bon à rien.

Du Flux \& En me promenant fur le bord du Lac, j’ai obfervé qu'il perd du Reflux des fenfiblement de ce côté-ci. On le reconnoît en ce que dans Lacs.

l'efpace d'une demie lieuë en profondeur le Terrein eft beaucoup plus bas \& plus fablonneux qu'au-delà. J'ai auffi remarqué dans ce Lac, \& on m'affûre que la même chofe arrive dans tous les autres, une efpece de Flux \& de Reflux prefque momentané, des Rochers, qui font affez près du Rivage, fe couvrant $\&$ fe découvrant plufieurs fois dans l'efpace d'un quart-d'heure, quoique la furface du Lac fût fort calme, $8 x$ qu'il ne fit prefque point de vent. Après y avoir réflechi quelque tems, j'imaginai que cela peut venir des Sources, qui fe trouvent au fond des Lacs, \& du choc de ces Courans avec celui des Rivieres, qui s'y déchargent de toutes parts, \& qui produifent ces mouvemens intermittans.

pourquoi les Mais croiriez-vous bien, Madame, que dans la Saifon, Arbres n'ont
pas encore de où nous fommes, 8 par les quarante-trois dégrés de latitude, 
il n'y a pas encore une feuille aux Arbres, quoique nous ayions quelquefois des chaleurs telles, que vous en avez au mois de Juillet? Cela vient fans doute de ce que la Terre, qui a été couverte de Néges pendant plufieurs mois, n’eft pas encore affez échauffée pour ouvrir les pores des racines, \& faire monter la féve. Au refte la Grande \& Petite Famine méritent bien peule nom de Rivieres : ce ne font que des Ruiffeaux, fur-tout la derniere, mais elles font affez poiffonneufes. Il y a ici des Aigles d'une groffeur prodigieufe, mes Gens viennent d'en abbattre un Nid, où il y avoit la charge d'une Charrette de bois, \& deux Aiglons, qui n’avoient pas encore de Plumes, \& qui étoient plus gros que les Poules d'Inde les plus grandes. Ils les ont mangés, \& les ont trouvés fort bons. Je reviens à Catarocoui, où la nuit, que jy paffai, $j$ e fus témoin d'une fcene affez curieufe.

Vers les dix oi onze heures du foir, comme jétois fur le point de me retirer, j'entendis un cri, qu'on me dit être un cri de guerre, \& peu de tems après je vis une Troupe de Miffifaguez, qui entroient dans le Fort en chantant. Depuis quelques années ces Sauvages fe font laiffés engager dans la guerre, que les Iroquois font aux Cheraquis, Peuple affez nombreux, qui habite un très - beau Pays au Sud du Lac Erié ; $\&$ depuis ce tems-là les points demangent à leurs jeunes gens. Trois ou quatre de ces Braves, équippés comme sills avoient voulu faire une mafcarade, le Vifage peint de maniere à infpirer de l'horreur, \&z fuivis de prefque tous les Sauvages, qui demeurent aux environs du Fort, après avoir parcouru les Cabannes en chantant leurs chanfons de guerre, au fon du. Chichikoué $(a)$, venoient faire la même chofe dans tous les Appartemens du Fort, par honneur pour le Commandant \& pour les Officiers.

Je vous avoiieMadame, que cette Cérémonie a quelque chofe, qui infpire de l'horreur, quand on la voit pour la premiere fois, \& que je n'avois pas encore fenti jufques-là, comme je fis alors , que j'étois parmi des Barbares. Leur Chant a toujours quelque chofe de lugubre 2 de fombre ; mais ici j $y$ trouvai je ne fçai quoi d'éftrayant, caufé peut-être uniquement par l'obfcurité de la nuit, \& par l'appareil de la Fête ; car c'en eft une pour les Sauvages. C'eft aux Iroquois, que s'adreffois

(a) C'eft une erpece de Calebaffe remplie de perits Caillouz.

$172 \mathrm{~J}$.

May.

feuilles au

mois de May.
Maniere de chanter la Guerre parmi les Sauvages. 
1721 .

May.

Du Dieu de la Guerre.
De la Déclaration de la Euerre.

cette invitation; mais ceux-ci, à qui la Guerre des Cheraquis commence à devenir à charge, ou qui n'étoient pas en humeur, demanderent du tems pour déliberer, \& chacun s'en retourna chez foi.

Il paroît, Madame, que dans ces Chanfons on invoque le Dieude la Guerre, que les Hurons appellent Areskoui, \& les Iroquois Agreskoué. Je ne fçai pas quel nom on lui donne dans les Langues Algonquines. Mais n'eft-il pas un peu étonnant que dans le mot Grec Apns, qui eft le Mars \& le Dieu de la Guerre dans tous les Pays, où l'on a fuivi la Théologie d'Homere, on trouve la racine, d'où femblent dériver plufieurs termes de la Langue Huronne \& Iroquoife, qui ont rapport à la Guerre ? Aregouen fignifie faire la Guerre, \& fe conjugue ainfi : Garego, je fais la Guerre; Sarego, tu fais la Guerre; Arego, il fait la Guerre. Au refte, Areskoui n'eft pas feulement le Mars de ces Peuples, il eft encore le Souverain des Dieux, ou, comme ils s'expriment, le Grand Efprit, le Créateur \& le Maître du Monde, le Génie, qui gouverne rout ; mais c'eft principalement pour les expéditions Militaires, qu'on l'invoque, comme fi la qualité, qui lui fait le plus d'honneur, étoit celle de Dieu des Armées. Son nom eft le Cri de Guerre avant le Combat, \& au fort de la Mêlée : dans les Marches même on le répete fouvent, comme pour s'encourager, \& pour implorer fon affiftance.

Lever la Hache, c'eft déclarer la Guerre : tout Particulier a droit de le faire, fans qu'on puiffe y trouver à redire; fi ce n'eft parıni les Hurons, \& les Iroquois, où les Meres de Famil. les ordonnent \& défendent la Guerre, quand il leur plaît : nous verrons en fon lieu jufqu'où s'étend leur autorité dans ces Nations. Mais fi une Matrone veut engager quelqu'un, qui ne dépend point d'elle, à lever un Parti de Guerre, foit pour appaifer les Manes de fon Mari, de fon Fils, ou de fon proche Parent, foit pour avoir des Prifonniers, qui remplacent dans fa Cabanne, ceux que la mort, ou la captivité lui a enlevés; il faut qu'elle lui préfente un Colier de Porcelaine, $\&$ il eft rare qu'une telle invitation foit fans effet.

Quand il s'agit d'une Guerre dans les formes, entre deux ou plufieurs Nations, la façon de s'exprimer eft, Jufpendre la Chaudiere fur le feu; \& elle a fans doute fon origine dans la coutûme barbare de nịanger les Prifonniers, \& $x$ ceux, qui ont 
D'UN VOYA GE DE L'A MERIQ. LET. XIII. 209 été tués, après les avoir fait bouillir. On dit même tout fimplement qu'on va manger une Nation, pour fignifier qu'on veit lui faire la Guerre à toute outrance, \& il eft rare qu'on la faffe autrement. Quand on veut engager fon Allié dans fa querelle, on lui envoye une Porcelaine, c'eft-à-dire, une grande Coquille, pour l'inviter à boire le Sang, ou, comme portent les termes dont on ufe, du Bouillon de la Chair de fes Ennemis. Après tout, cette pratique pourroit être trèsancienne, fans qu'on puiffe en inferer que ces Peuples ont toujours éré Anthropophages. Ce n'étoit peut-être dans les premiers tems, qu'une façon de parler allégorique, telle que l'Ecriture même nous en fournit plufieurs. David n'avoit apparemment pas à faire à des Ennemis, qui fuffent dans l'ufage de manger de la Chair humaine, lorfqu'il difoit : Dum appropiant fuper me nocentes, ut edant carnes meas. (a) Dans la fuite certaines Nations devenuës Sauvages \& Barbares, auront fubftitué la réalité à la figure.

J'ai dit que les Porcelaines de ces Pays font des Coquilles: elles fe trouvent fur les Côtes de la Nouvelle Angleterre, \& fur celles de la Virginie : elles font cannelées, allongées, un peu pointuës, fans oreilles \& affez épaiffes. La Chair du Poiffon renfermé dans ces Coquillages, n'eft pas bonne à manger; mais le dedans eft d'un fi beau Verni, \& a des Couleurs fi vives, que l'Art ne peut rien faire qui en approche. $Q$ uand les Sauvages alloient tout nuds, ils en faifoient l'ufage auquel nos premiers Peres employerent les feuilles de Figuier, quand ils s'apperçurent de leur Nudité , \& qu'elle leur caufa de la honte. Ils les pendoient auffi à leur Cou, comme la chofe la plus précieufe qu'ils euffent, \& c'eft encore aujourd'hui une de leurs plus grandes richeffes, \& leurs plus belles parures; en un mot, ils en ont la même idée que nous avons de l'Or \& de l'Argent \& des Pierreries : en cela d'autant plus raifonnables, qu'ils n'ont, pour ainfi dire, qu'à fe baiffer pour fe procurer des Tréfors auffi réels que les nôtres; puifque tout cela dépend de l'opinion. Jacques Cartier parle dans fes Mémoires d'une efpece de Coquillage fait en Cornibot, qu'il trouva, dit-il, dans l'Ifle de Montreal : il le nomme E furgni, \& affûre qu'il avoit la vertu d'arrêter le faignement du Nez. Peut-être eft-ce la même dont il s'agit ici; mais on n'en ramaffe point fur les

(a) Pfeaume 26. 2 . Tome III.

$\mathrm{Dd}$ 
I 72 I. bords de l'Ifle de Montreal, \& je n'ai pas oüi dire que les CoMay. quillages de Virginie ayent la proprieté dont parle Cartier.

Des Branches \& des Coliers de Porceiaine.

Il y en a de deux fortes, ou pour parler plus jufte, de deux Couleurs, l'une blanche \& l'autre violette. La premiere eft plus commune, \& peuttêtre pour cela même, moins eftimée. La feconde paroît avoir le grain un peu plus fin, quand elle eft travaillée. Plus fa couleur eft foncée, \& plus elle eft recherchée. On fait de l'une \& de l'autre de petits Grains cilindriques; on les perce, $\&$ on les enfile; c'eft dequoi on fait les Branches \& les Coliers de Porcelaine. Les Branches ne font autre chofe, que quatre ou cinq fils, ou petites lanieres de Peaux d'environ un pied de long, où font enfilés les Grains de Porcelaine. Les Coliers font des manieres de Bandeaux ou de Diadèmes formés de ces Branches, affujetties par des fils, qui en font un tiffu de quatre, cinq, fix ou fept rangées de Grains, \&x d'une longueur proportionnée ; cela dépend de l'importance de l'affaire, qu'on veut traiter, \& de la dignité des perfonnes, à qui on préfente le Colier.

Par le mêlange des Grains de différentes Couleurs, on y forme telle figure $\&$ tel caractere, que l'on veut, ce qui fert fouvent à diftinguer les affaires, dont il eft queftion. On peint même quelquefois les Grains: du moins eft-il certain qu'on envoïe fouvent des Coliers rouges, quand il s'agit de la Guerre. Ces Coliers fe confervent avec foin, \& non-feulement ils compofent le Tréfor public, mais ils font encore comme les Regiftres \& les Annales, que doivent étudier ceux, qui font chargés des Archives, lefquels font dépofés dans la Cabanne du Chef. Quand il y a dans un Village deux Chefs d'une autorité égale, ils gardent tour à tour le Tréfor \& l'Archive pendant une nuit; mais cette nuit, du moins à préfent, eft une année entiere.

De leur ufa- Il n'y a que les affaires de conféquence, qui fe traitent par des Coliers; pour les moins importantes, on fe fert de Branches de Porcelaines, de Peaux, de Couvertures, de Maïz, ou en Grains, ou en Farine, \& d'autres chofes femblables : car il entre de tout cela dans le Tréfor public. Quand il s'agit d'inviter un Village, ou une Nation à entrer dans une Ligue, quelquefois au lieu de Colier, on envoye unPavillon teint deSang: mais cet ufage eft moderne, \& il y a bien de l'apparence que les Sauvages en ont pris lidée à la vûë des Pavillons blancs des 
D'UN VOYA GE DE L'A MER I Q. LET. XIII. 2II François, \& des Pavillons rouges des Anglois. On dit même que nous nous en fommes fervis les premiers avec eux, \& qu'ils ont imaginé d'enfanglanter les leurs, lorfqu'il eft queftion de déclarer la Guerre.

Le Calumet n'eft pas moins facré parmi ces Peuples, que le Colier de Porcelaine : il a même, fi on les en croit, une origine Célefte ; car ils tiennent que c'eft un préfent que le Soleil leur a fait. Il eft plus en ufage chez les Nations Meridionnales \& Occidentales, que dans celles du Nord \& de l'Eft, \& on l'employe plus fouvent pour la Paix, que pour la Guerre. Calumet eft un mot Normand, qui veut dire Chalumeau; \& le Calumet des Sauvages eft proprement le Tuyau d'une Pipe; mais on comprend fous ce nom la Pipe même \& fon Tuyau. Dans les Calumets de parade, le Tuyau eft fort long, \& la Pipe a la figure de nos anciens Marteaux d'Armes : elle eft ordinairement faite d'une efpece de Marbre rougeatre, fort aifé à travailler, \& qui fe trouve dans les Pays des Ajouez, au-delà du Miciffipi. Le Tuyau eft d'un Bois leger, peint de différentes Couleurs, \& il eft orné de Têtes, de Queuës.\& de Plumes des plus beaux Oifeaux; ce qui, felon toutes les apparences n'eft qu'un pur ornement.

L'ufage eft de fumer dans le Calumet, quand on l'accepte, $\&$ il eft peut-être fans exemple qu'on ait jamais violé l'engagement, que l'on a pris par cette acceptation. Les Sauvages font du moins perfuadés que le Grand Efprit n'en laifferoit pas l'infraction impunie. Si au milieu d'un Combat l'Ennemi préfente un Calumet, il eft permis de le refufer; mais fi on le reçoit, il faut mettre fur le champ les Armes bas. Il y a des Calumets pour tous les différens Traités. Dans le Commerce, quand on eft convenu de l'échange, on préfente un Calumet pour le cimenter, ce qui le rend en quelque forte facré. Quand il s'agit de la Guerre, non-feulement le Tuyau, mais les Plumes même, dont il eft orné, font rouges : quelquefois ils ne le font que d'un côté, \& on prétend que fuivant la maniere, dont les Plumes font difpofées, on reconnoît d'abord à quelle $\mathrm{Na}$ tion en veulent ceux, qui les préfentent.

On ne peut guéres douter que les Sauvages, en faifant fumer dans le Calumet ceux, dont ils recherchentl'alliance, oule com- gine. merce, n'ayent intention de prendre leSoleil pour témóin, \& en quelque façon pour garant de leurs Traités; car ils ne man-

Du Calumet \& de fon ufage.

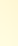


212 J O URNAL H ISTORIQUE

I $72 \mathrm{I}$. quent jamais de pouffer la fumée vers cet Aftre : mais que de cette pratique, \& de l'ufage ordinaire des Calumets on doiMay. ve inferer, comme ont fait quelques-uns, que cette Pipe pourroit bien dans fon origine être le Caducée de Mercure, c'eft. ce qui me paroît d'autant moins vraifembiable, que ce $\mathrm{Ca}$ ducée n'avoit aucun rapport au Soleil, \& que dans les Traditions des Sauvages on n'a rien trouvé, qui puiffe faire juger qu'ils ayent jamais eu aucune connoiffance de la Mythologie des Grecs. Il feroit, à mon avis, beaucoup plus naturel de penfer que ces Peuples, inftruits par leur expérience que la fumée de leur Petun abbat les vapeurs du Cerveau, rend la Tête plus libre, réveille les efprits, \& nous met plus en état de traiter d'affaires, en ont pour cette raifon introduit l'ufage dans les Confeils, où effectivement ils ont fans ceffe la Pipe à la Bouche, \& qu'après avoir mûrement déliberé \& pris leur parti, ils n'ont pas cru pouvoir trouver de fymbole plus propre pour mettre le fceau à ce qu'ils ont arrêté, ni de gage plus capable d'en affurrer l'exécution, que l'inftrument, qui a eu tant de part à leurs délibérations. Peut-être même vous paroîtra-t'il plus fimple, Madame, de dire que ces Peuples n'ont point imaginé de fignes plus naturels pour marquer une étroitte union, que de fumer dans la même Pipe, fur-tout fi la fumée qu'on en tire, eft offerte à une Divinité, qui y mette le fceau de la Religion. Fumer donc dans la même Pipe en figne d'alliance, eft la même chofe, que de boire dans la même Coupe, comme il s'eft de tout tems pratiqué dans plufieurs $\mathrm{Na}$ tions. Ce font-là de ces ufages, qui viennent trop naturellement à l'efprit, pour y chercher du myftere.

La grandeur \& les ornemens des Calumets, qui fe préfentent aux Perfonnes de diftinction, \& dans les occafions importantes, n'ont rien non plus, dont il faille chercher bien loin les motifs. Pour peu que les hommes ayent de commerce entr'eux, \& fe refpectent mutuellement, ils s'accoûtument à avoir certains égards les uns pour les autres, principalement dans les occafions, où il s'agit d'affaires publiques, ou quand on veut gagner la bienveillance de ceux, avec qui l'on traite, \& de-là le foin, qu'on apporte, pour donner plus de décoration aux préfens, qu'on leur fait. Au refte c'eft aux $P$ anis, Nation établie fur les Bords du Miffouri, \& qui s'étend beaucoup vers le Nouveau Mexique, qu'on prétend que le Calu- 
D'U N V OYA GE DE L'A MERIQ. Let. XIII. 213 met a été donné par le Soleil. Mais ces Sauvages ont apparemment fait comme beaucoup d'autres Peuples. Ils ont voulu relever par le merveilleux un ufage, dont ils étoient les $\mathrm{Au}$ teurs; \& tout ce qu'on peut conclure de cette tradition, c'eft que les Panis rendent au Soleil un culte plus ancien, ou plus marqué que les autres Nations de cette partie du Continent de l'Ámérique, \& qu'ils fe font avifés les premiers de faire du Calumet un fymbole d'alliance. Enfin fi le Calumet étoit dans fon inftitution le Caducée de Mercure, il ne feroit employé, que pour la Paix, ou pour le Commerce; \& il eft conftant qu'il eft d'ufage dans les Traités, qui ont la Guerre pour objet.

Ces Notions, Madame, m'ont paru néceffaires pour vous donner une connoiffance parfaite de ce qui regarde la guerre des Sauvages, dont je vous entretiendrai dans mes Lettres, jufqu’à ce que j’aye épuifé ce fujet, ou, fi ce font des digreffions, elles ne font pas tout-à-fait étrangeres à mon fujet. D'ailleurs un Voyageur tâche de placer le moins mal qu'il peut tout ce qu'il apprend fur fa route.

Je fuis, \&c.

\section{QUATORZIEME LETTRE.}

Defcription du Pays depuis l'Anfe de la Famine jufqu'à la Riviere des Sables. Motifs des Guerres des Sauvages. Départ des Guerriers, É tout ce qui précede leur départ. Leurs Adieux. Leurs Armes offenfives Eु défenfives. Le foin, qu'ils ont de porter avec eux leurs Dieux Tutélaires. Particularités du Pays jufqu'à Niagara.

A la Riviere des Sables, ce dix-neuf May, $\mathbf{7 2 1}$.

NA D A ME,

ME voici encore dégradé par un vent contraire, qui vient Déagrḱ de e voici encer de fe lever au moment que nous étions le plus en train d'a- commodités vancer. Il nous a même furpris fi brufquement, que nous au- $\mathrm{geses}_{\mathrm{ges}}$ Veya-

May. 
214 J O URNAL H IS TOR I Q U E

I $72 \mathrm{I}$. rions été fort en peine, fi nous n'euffions très-à-propos rencontré cette petite Riviere, pour nous y réfugier. Vous m'aMay. vouërez, Madame, qu’il y a bien des défagrémens \& des incommodités à efluyer dans un voyage tel que celui-ci.Il eft fort trifte de faire cent, \& quelquefois deux cent lieuës, fans trouver une Maifon, ni rencontrer un Homme; de ne pouvoir s'engager dans une traverfe de deux ou trois lieuës, pour éviter d'en faire vint inutilement, fans rifquer fa vie par le caprice des Vents; de fe voir arrêté, comme il arrive quelquefois, des femaines entieres, fur une Pointe, ou fur un livage ftérile, où, fi la Pluye furvient, il faut refter fous un Canot, ou fous une Tente: fi le vent eft impétueux, il faut chercher un abry dans le Bois, où l'on n'eft pas fans danger d'être écrafé par la chute d'un Arbre. On auroit paré à une partie de ces inconvéniens, en conftruifant des Barques pour naviger fur les Lacs; mais il faudroit pour cela que le Commerce en valût un peu plus la peine.

Nous fommes ici fur la lifiere des Cantons Iroquois, \& c'eft un fort beau Pays. Nous nous embarquâmes hier de grand matin par le plus beau tems du monde. Il ne faifoit pas un foufle de vent, \& le Lac étoit uni comme une Glace. Defcription Vers les neuf ou dix heures nous paffâmes devant l'Emboude la Côte. chure de la Riviere d'Onnontagué, \& elle me parut avoir un arpent de large. Les Terres y font un peu baffes, mais très-bien boifées. Prefque toutes les Rivieres, qui arrofent leś Cantons Iroquois, fe déchargent dans celle-ci, dont la Source eft un fort joli Lac, appellé Gannentaha, fur le bord duquel il y a des Salines. Vers les onze heures \& demie un petit vent de Nord - Eft nous fit mettre la Voile, \& nous pouffa en peu d'heures jufqu'à la Baye des Goyogouins, qui eft à dix lieuës de la Riviere d'Onnontagué. Toute la Côte dans cet efpace eft variée de Marais \& de Terres hautes, un peu fablonneufes, couvertes de très-beaux Arbres, \& furtout de Chênes, qui femblent avoir été plantés à la main.

Un vent de Terre violent, qui nous accueillit par le travers de la Baye des Goyogouins, nous obligea de nous y réfugier. C'eft un des plus beaux endroits, que j’aye jamais vû. Une prefqu'Ifle bien boifée s'avance au milieu, \& forme comme un Théàtre. Sur la gauche en entrant, on apperçoit dans un enfoncement une petite Ifle, qui cache l'entrée d'une 
D'UN V OYA GEDE L'A MERIQ. LeT. XIV. 215 Riviere, par où les Goyogouins defcendent dans le Lac. Le vent ne dura point; nous nous remîmes en route, \& nous fimes encore trois ou quatre lieuës. Ce matin nous nous fom1721 . May。 mes embarqués avant le Soleil levé, \& nous avons fait cinq ou fix lieuës. Je ne fçai combien le vent du Nord-Oueft nous retiendra ici. En attendant je vais reprendre mon récit fur les guerres des Sauvages, où je l'ai interrompu.

Il eft rare, Madame, que ces Barbares refufent de s'engager dans une guerre, quand ils y font invités par leurs Alliés. Ils n'ont pas même befoin pour l'ordinaire d'invitation pour prendre les Armes; le moindre motif, un rien fouvent les y détermine. La vengeance fur-tout: ils ont toujours quelque injure ancienne ou nouvelle à vénger; car le tems ne referme point ces fortes de playes, quelque legeres qu'elles foient. Auffi ne doit-on jamais compter que la Paix foit folidement établie entre deux Nations, qui ont été lontems ennemies; d'autre part le defir de remplacer des Morts par des Prifonniers, ou d'appaifer leurs ombres; le caprice d'un particulier; un fonge, qu'on explique à fa façon, \& d'autres raifons, ou prétextes auff frivoles, font qu'on voit fouvent partir pour la Guerre une troupe d'A venturiers, qui ne fongeoient à rien moins le jour précedent.

II eft vrai que ces petites Expéditions, fans l'aveu du Confeil, font ordinairement fans conféquence, \& comme elles ne demandent pas de grands préparatifs, on y fait peu d'attention; mais généralement parlant, on n'eft pas trop fàché de voir la Jeuneffe s'exercer \& fe tenir en haleine, \& il faudroit avoir de grandes raifons pour s'y oppofer; encore y employe-t-on rarement l'autorité, parce que chacun eft le maître de fes démarches: mais on tâche d'intimider les uns par de faux bruits, qu'on fait courir; on follicite fous main les autres; on engage par des préfens les Chefs à rompre la partie, ce qui elt fort aifé ; car il ne faut pour cela qu'un Songe vrai, ou prétendu. Dans quelques Nations, la derniere reffource eft de s'adreffer aux Matrones, \& elle eft prefque toujours efficace; mais on n'y a recours, que quand l'affaire eft d'une grande conféquence.

Une Guerre, qui interreffe toute la Nation, ne fe conclut pas fi aifément : on en balance avec beaucoup de maturité les inconveniens $\&$ les avantages, \& tandis qu'on délibere, on

Motifs, qui engagent les Sauvages à faire la guerre. 


\section{J O U R N A L H IS T O R I Q U E}

1721

apporte un très-grand foin à écarter tout ce qui pourroit donMay.

ner à l'Ennemi le moindre fujet de foupçonner qu'on veut rompre avec lui. La Guerre une fois réfoluë, on penfe d'abord aux Provifions \& à l'Equipage des Guerriers, \& cela ne demande pas beaucoup de tems. Les Danfes, les Chants, les Feftins, quelques Cérémonies fuperftitieufes, qui varient beaucoup felon les différentes Nations, en demandent beaucoup davantage.

Préparatifs Celui qui doit commander ne fonge point à lever des Sol$\mathrm{d}_{4}$ Chef. $\quad$ dats, qu'il n’ait jeûné plufieurs jours, pendant lefquels il eft barbouillé de noir, n'a prefque point de converfation avec perfonne, invoque jour \& nuit fon Efprit tutelaire, obferve fur-tout avec foin fes Songes. La perfuafion où il eft, fuivant le génie préfomptueux de ces Barbares, quili va marcher à une Victoire certaine, ne manque guéres de lui caufer des Rêves felon fes defirs. Le Jeûne fini, il affemble fes Amis, \& un Colier de Porcelaine à la Main, il leur parle en ces termes: Mes Freres, le Grand ECprit autorife mes fentimens, \& m'a infpiré ce que je dois faire. Le Sang d'un tel n'eft point "effuyé, fon Corps n'eft point couvert, \& je veux m’acquit" ter envers lui de ce devoir ". Il expofe de même les autres motifs, qui lui font prendre les Armes. Puis il ajoûte : "Je fuis donc réfolu d'aller en tel endroit lever des Chevelures, ou faire des Prifonniers; ou bien je veux manger telle ou telle Nation. Si je peris dans cette glorieufe entreprife, ou fi quelqu'un de ceux, qui voudront bien maccompagner, y perd la vie, ce Colier fervira pour nous recevoir, afin que nous ne demeurions pas couchés dans la Pouffiere, ou dans la Bouë a. C'eft-à-dire, apparemment, quili fera pour celui qui aura foin d'enfévelir les Morts.

En prononçant ces dernieres paroles, il met le Colier à terre, \& celui qui le ramaffe, fe déclare par-là fon Lieutenant ; puis il le remercie du zéle, quil témoigne pour venger fon'Frere, ou pour foutenir l'honneur de la Nation. On fait enfuite chauffer de l'Eau, on débarbouille le Chef, on lui accommode les Cheveux, \& on les graiffe, ou on les peint. On lui met différentes Couleurs au Vifage, \& on le revêt de fa plus belle Robe. Ainfi paré, il chante d'une voix fourde fa Chanfon de Mort ; fes Soldats, c'eft-à-dire, tous ceux, qui fe font offerts à l'accompagner, (car on ne contraint perfonne) en- 
D'UN VOYAGE DE L'A MER IQ. LET. XIV. 217 tonnent enfuite l'un après l'autre leur Chanfon de Guerre; car chacun a la fienne, qu'il n'eft pas permis à nul autre de chanter : il y en a auffi d'affectées à chaque Famille.

Après ce préliminaire, qui fe paffe dans un lieu écarté , \& fouvent dans une Etuve, le Chef va communiquer fon projet au Confeil, lequel en délibere, fans jamais admettre à cette déliberation l'Auteur de l'Entreprife. Dès que fon projet a été accepté, il fait un Feftin, dont le principal \& quelquefois l'unique Mets doit être un Chien. Quelques - uns prétendent que cet Animal eft offert au Dieu de la Guerre, avant que d'être mis dans la Chaudiere, \&x peut-être qu'on le pratique ainfi parmi quelques Nations. Je fuis même bien aife de vous avertir ici, Madame, que dans ce que je vous dirai fur cet article, je ne garantis pas que tout foit d'un ufage général parmi toutes les Nations. Mais il paroît certain que dans l'oc. cafion, dont il s'agit ici, on fait quantité d'invocations à tous les Efprits bons \& mauvais, \& fur-tout au Dieu de la Guerre.

Tout cela dure plufieurs jours, ou plûtôt fe réitere plufieurs jours de fuite : mais quoique tout le monde femble uniquement occupé de ces Fêtes, chaque Famille prend fes mefures pour avoir fa part des Prifonniers, qu'on fera, afin de réparer fes pertes, ou de venger fes Morts. Dans cette vûë, on fait des préfens au Chef, qui de fon côté donne fa parole $\&$ des gages. Au défaut des Prifonniers, on demande des Chevelures, \& cela eft plus aifé à obtenir. En quelques endroits, comme chez les Iroquois, dès qu'une expédition Militaire eft réfoluë, on met fur le feu la Chaudiere de Guerre, \& on avertit fes Alliés d'y apporter quelque chofe, pour faire connoître qu'ils approuvent l'Entreprife, \& qu'ils y prendront part.

Tous ceux, qui s'enrôlent, donnent auffi au Chef, pour figne de leur engagement, un morceau de Bois avec leur marque, \& quiconque après cela retireroit fa parole, ne feroit pas en fûreté de fa vie ; du moins il refteroit deshonoré pour toujours. Le Parti étant formé, le Chef de Guerre prépare un nouveau Feftin, où tout le Village doit être invité, \& avant qu'on touche à rien, il dit, ou un Orateur pour lui \& en fon nom : "Mes Freres, je fçai que je ne fuis pas encore un Hom- " me; mais vous n'ignorez pourtant pas que j’ai vû quelquefois " l'Ennemi d'affez près. Nous avons été tués; les Os de tels \& " de tels font encore découverts, ils crient contre nous, il faut " Tome III.

E e

1721 .

May.

Délibération du Confeil.

Mefures . qu'on prend pour avoir des Prifonniers. 


\section{J O UR N A L H I S T O R I Q U E}

1721. "les fatisfaire. C'étoient des Hommes; comment avons-nous

May. " pu fitôt les oublier, \& demeurer fi lontems tranquilles fur nos

"Nattes ? Enfin, l'Efprit, qui s'interreffe à ma gloire, m'a inf" piré de les venger. Jeuneffe, prenez courage, rafraîchiffez " vos Cheveux, peignez-vous le Vifage, rempliffez vos Car" quois, faifons retentir nos Forêts de Chants Militaires, def" ennuyons nos Morts, \& apprenons-leur qu'ils vont être " vengés.

Chants \& Après ce difcours, \& les applaudiffemens, dont il ne manDanfes \& Feftin des Guerriers. que pas d'être fuivi, le Chef s'avance au milieu de l'Affemblée, le Caffe-tête à la Main , \& chante; tous fes Soldats lui répondent en chantant, \& jurent de le bien feconder, ou de mourir à la peine. Tout cela eft accompagné de geftes trèsexpreffifs pour faire entendre quils ne reculeront pas devant l'Ennemi; mais il eft à remarquer qu'il n’échappe à aucun des Soldats aucune expreffion, qui dénote la moindre dépendance. Tout fe réduit à promettre d'agir avec beaucoup d'union \& de concert. D'ailleurs, l'engagement qu'ils prennent, exige de grands retours de la part des Chefs. Par exemple, à chaque fois que dans les Danfes publiques un Sauvage frappant de fa Hache un Poteau dreffé exprès, rappelle à l'Affemblée fes plus belles Actions, comme il arrive toujours, le Chef, fous la conduite duquel il les a faites, eft obligé de lui faire un préfent, du moins parmi quelques Nations.

Idée, que Les Chants font fuivis de Danfes ; quelquefois ce n'eft ces Peuples ont du Courage.

qu'une démarche fiere, mais en cadence; d'autres fois ce font des mouvemens affez vifs, figurés $\&$ repréfentatifs des operations d'une Campagne, \& toujours cadencés. Enfin le Feftin termine la Cérémonie. Le Chef de Guerre n'en eft que fpectateur la Pipe à la Bouche; c'eft même affez l'ordinaire dans tous les Feftins d'appareil, que celui, qui en fait les honneurs, ne touche à rien. Les jours fuivans, \& jufqu'au départ des Guerriers, il fe paffe bien des chofes, dont le recit n'a rien d'interreffant, \& qui ne font pas même d'une pratique uniforme \& conftante : mais je ne dois pas oublier une coûtume affez finguliere, dont les Iroquois fur-tout ne fe difpenfent jamais : elle paroît avoir été imaginée pour connoître ceux, qui ont l'efprit bien fait, $\&$ fçavent fe commander à euxmêmes; car ces Peuples, que nous traitons de Barbares, ne conçoivent pas qu'on puiffe avoir un véritable courage, $\mathrm{fl}_{\mathrm{f}}$ 
DUN V OYA GE DE L'AMERI Q. LET. XIV. 219 l'on n'eft pas maitre de fes paffions, \& fi on ne fçait pas foufrir ce qui peut arriver de plus fenfible. Voici de quoi il s'agit.

Les plus anciens de la Troupe Militaire font aux jeunes Gens, principalement à ceux, qui n'ont pas encore vû l'Ennemi, toutes les avanies, dont ils peuvent s'avifer. Ils leur jettent des cendres chaudes fur la tête ; ils leur font les reproches les plus fanglans; ils les accablent d'injures, \& pouffent ce jeu jufqu'aux plus grandes extrémités. Il faut endurer tout cela avec une infenfibilité parfaite; donner dans ces occafions le moindre figne d'impatience, c'en feroit affez pour être jugé indigne de porter jamais les armes: mais quand cela fe pratique entre gens de même âge, comme il arrive affez fouvent, il faut que l'Agreffeur foit bien affûré de n'avoir rien fur fon compte, fans quoi, le jeu fini, il feroit obligé de réparer l'infulte par un préfent. Je dis, le jeu fini, car tout le tems quili dure, il faut tout foufrir fans fe fâcher, quoique le badinage aille fouvent à fe jerter des tifons de feu à la tête, $\&$ à fe donner de grands coups de bâton.

Comme l'efperance de guerir de fes bleffures, fi on a le malheur d'en recevoir, ne contribuë pas peu à engager les plus braves à s'expofer aux plus grands perils, après ce que je viens de dire, on prépare les drogues, dont les Jongleurs font chargés. Je vous dirai une autre fois quelle forte de gens font ces Jongleurs. Toute la Bourgade étant affemblée, un de ces Charlatans déclare quili va communiquer aux Racines \& aux Plantes, dont il a fait bonne provifion, la vertu de guérir toutes fortes de playes, \& mème de rendre la vie aux morts. Auffi-tôt il fe met à chanter; d'autres Jongleurs lui répondent, \& l'on fuppofe que pendant le concert, qui ne vous paroîtroit pas fort mélodieux, \& qui eft accompagné de beaucoup de grimaces de la part des Acteurs, la vertu médicinale fe répand fur les drogues. Le principal Jongleur les éprouve enfuite : il commence par fe faire faigner les lévres; il y applique fon remede; le fang, que l'impofteur a foin de fuccer adroittement, ceffe de couler, \& on crie : miracle. Après cela il prend un Animal mort, il laiffe aux Affiftans tout le loifir de bien s'afturer qu'il eft fans vie, puis par le moyen d'une canule, qu'il lui a inférée fous la queuë, il la fait remuer, en lui fouflant des herbes dans la gueule, \& les cris Ee ij

$172 \mathrm{I}$.

May.

Epreuves; où l'on met les Guerriers.
Précautions pour les bleffés. 


\section{J O UR N A L H I S.T O R I Q U E}

$172 \mathrm{I}$. d'admiration redoublent. Enfin toute la Troupe des Jongleurs fait le tour des Cabannes en chantant la vertu des remedes. May. Ces artifices dans le fond n'en impofent à perfonne, mais ils amufent la multitude, \& il faut fuivre l'ufage.

Pratiques En voici un autre, qui eft particulier aux Miamis, \& peutpropres aux être à quelques autres Nations du Voifinage de la Louyfiane. Miamis pour Je l'ai tiré des Mémoires d'un François, qui en a été témoin,
fe préparer àla Guerre.

Après un feftin folemnel on plaça, dit-il, fur une efpece d'Autel des figures de Pagodes, faites avec des Peaux d'Ours, dont la tête étoit peinte de couleurs vertes. Tous les Sauvages pafferent devant cet Autel en faifant des génuflexions, \& les Jongleurs conduifoient la Bande, en tenant à la main un fac, où étoient renfermées toutes les chofes, dont ils ont accoûtumé de fe fervir dans leurs évocations. C'étoit à qui feroit plus de contorfions, \& à mefure que quelqu'un s'y diftinguoit, on lui applaudiffoit par de grands cris. Quand on eut ainfi rendu fes premiers hommages aux Idoles, tout le monde danfa avec beaucoup de confufion, au fon du Tambour \& du Chichikoué, \& pendant ce tems-là les Jongleurs faifoient femblant d'enforceler divers Sauvages, qui paroiffoient expirer: puis en leur mettant d'une certaine poudre fur les lévres, ils les faifoient revivre.

Quand cette farce eut duré quelque tems, celui, qui préfidoit à la Fête, ayant à fes côtés deux Hommes \& deux Femmes, parcourut toutes les Cabannes, pour avertir que les Sacrifices alloient commencer. Lorfqu'il rencontroit quelqu'un en fon chemin, il lui mettoit les deux mains fur la tête, \& celui-ci lui embraffoit les genoux. Les Victimes devoient être des Chiens, \& l'on entendoit de toutes parts les cris de ces Animaux, qu'on égorgeoit, \& les Sauvages, qui hurloient de toutes leurs forces, fembloient leur faire paroli. -Dès que les viandes furent cuites, on les offrit aux Pagodes, puis on les mangea, \& on brûla les os. Cependant les Jongleurs ne ceffoient point de refufciter de prétendus morts, \& le tout finit par la diftribution, qui fut faite à ces Charlatans de ce qui fe trouva le plus à leur bienféance dans toute la Bourgade.

Defcription Depuis la réfolution prife de faire la guerre, jufqu'au dédes Raquertes part des Guerriers, toutes les nuits on chante, \& les jours pour marcher fe paffent à faire les Préparatifs. On députe des Guerriers pour 
D'UN VOYAGE DE L'A MER IQ. Let. XIV. 22 I aller chanter la Guerre chez les Voifins \& les Alliés, qu'on a fouvent eu foin de difpofer, par des Négociations fecrettes. Si la Marche fe doit faire par eau, on conftruit, ou l'on répare les Canots : fi c'eft l'Hyver, on fe fournit de Raquettes Bagage.

$172 \mathrm{I}$.

May. des Traînes our porter le \& de.Traînes. Les Raquettes, dont il faut néceffairement fe fervir, pour marcher fur la Neige, ont environ trois pieds de long, \& quinze ou feize pouces dans leur plus grande largeur. Leur figure eft ovale, à cela près, que l'extrémité de derriere fe termine en pointe; de petits bâtons de traverfe, paffés à cinq ou fix pouces des deux bouts, fervent à les rendre plus fermes, \& celui, qui eft fur le devant, eft comme la corde d'une ouverture en arc, où l'on met le pied, qu'on y affujettit avec des courroyes. Le tiffu de la Raquette eft de lanieres de cuir de la largeur de deux lignes, \& le contour eft d'un bois leger durci au feu. Pour bien marcher fur ces Raquettes, il faut tourner un peu les genoux en-dedans, $\&$ tenir les jambes écartées. Il en coûte d'abord pour s'y accoûtumer; mais quand on y eft fait, on marche avec facilité \& fans $f e$ fatiguer davantage, que $f i$ on n'avoit rien aux pieds. Il n'eft pas poffible d'ufer de ces Raquettes avec nos Souliers ordinaires; il faut prendre ceux des Sauvages, qui font des efpeces de Chauffons de Peaux boucannées, pliffés en-deffus à l'extrémité du pied \& liés avec des cordons.

Les Traînes, qui fervent à porter le Bagage, \& dans un befoin, les Malades \& les Bleffés, font deux petites Planches fort minces de la largeur d'un demi-pied chacune, fur fix ou fept de long. Les devans en font un peu relevés, $\&$ les côtés font bordés de petites bandes, où l'on attache des courroyes, pour affujettir ce qui eft fur la Traîne. Quelque chargées que foient ces voitures, un Sauvage les peut tirer fans peine, ’̀ l'aide d'une longue bande de cuir, qu'il fait paffer fur fa poitrine, \& qu'on appelle Coliers. On en ufe auffi pour porter des fardeaux, \& les Meres s'en fervent pour porter leurs Enfans avec leurs Berceaux; mais alors c'eft fur le front, $\&$ non pas fur la poitrine qu'ils font appuyés.

Tout étant prêt, \& le jour du départ venu, les adieux fe font avec de grandes démonftrations d'une véritable tendreffe. Guerriers.

Chacun veut avoir quelque chofe, qui ait été à l'ufage des Guerriers, \& leur donne des gages de fon amitié, \& des affûrances d'un fouvenir éternel. Ils n'entrent dans prefqu'au- 
cune Cabanne, qu'on ne leur prenne leur Robe, pour leur

$172 \mathrm{I}$. en donner un autre meilleure, ou du moins auff bonne. EnMay. fin tous fe rendent chez le Chet. lis le trouvent armé comme le premer jour, qu'il leur a parlé; \& comme il a toujours paru en public depuis ce tems-la. Eux-mêmes fe font peints le vifage, chacun fuivant fon caprice, \& tous ordinairement de maniere â faire peur. Le Chet leur fait une courte harangue, puis il fort de fa Cabanne, en chantant fa chanfon de mort. Tous le fuivent à la file, gardant un profond filence, \& la même chofe fe pratique tous les matins, quand on fe remet en marche. Ici les femmes prennent les devans avec les provifions, \& quand les Guerriers les ont jointes, ils leur remettent en mann toutes leurs hardes, \& reftent prefque nuds : autant néanmoins que la Saifon le peut permettre.

Autrefois les armes de ces Peuples étoient l'Arc, la Fléche, Leirs Armes \& une efpece de Javelot, l'une \& l'autre armées de pointes

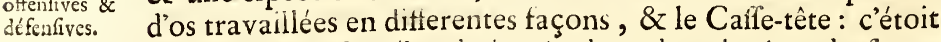
une petıte Mafíuë d'un bois très-dur, dont la tête, de figure ronde, avoit un côté trenchant. La plûpart n'avoient aucune arme défenfive, mass lorfqu'ils attaquoient unRetranchement, ils fe couvroient tout le corps de petites planches légeres. Quelques-uns ont une maniere de Cuiraffe faite d'un tilfu de Jonc, ou de petites Baguettes pliantes, affez proprement travaillées. Ils avorent meme anciennement des Cuiffarts \& des Braffades de même matiere, mais comme cette armure ne s'eft point trouvée à l'épreuve des armes à feu, ils y ont renoncé, $\measuredangle$ n'ont rien mis à la place. Les Sauvages Occidentaux fe fervent toujours de Boucliers de Peaux de Bœufs, qui font fort legers, \& que les Balles de Fufil ne percent pas. Il eft affez étonnant que les autres Nations n'en ufent point.

Quand ils font ufage de nos Epées, ce qui eft très-rare, ils s'en iervent comme d'Efpontons : mais quand ils peuvent avoir des Fufils, de la Poudre \& du Plomb, ils laiflent là leurs Fléches, \& tirent très-jufte. On n'eft pas à fe repentir de leur en avoir donné, mais ce n'eft pas nous, qui avons commencé : les Iroquois en ayant reçu des Hollandois, alors Poffeffeurs de la Nouvelle York, ç'a été pour nous une néceffité d'en faire prendre à nos Alliés. Ils ont des efpeces d'Enfeignes pour fe reconnoitre \& fe rallier; ce font de petits morceaux d'Ecorces coupées en rond', qu'ils mettent au bout d'une perche, 
\& fur lefquels ils ont tracé la marque de leur Nation, ou de leur Village. Si le Parti eft nombreux, chaque Famille, ou Tribu a fon Enfeigne avec fa marque diftinctive. Les armes font aufi ornées de différentes figures, $\&$ quelquefois de la marque particuliere du Chef de l'Expédition.

Mais ce que l'on oublieroit encore moins que les armes, \& ce que l'on conferve avec le plus grand foin, dont les Sauvages font capables, ce font les Manitous, j'en parlerai ailleurs plus amplement, il fuffit ici de dire que ce font les $1 \mathrm{ym}$ boles, fous lefquels chacun fe reprefente fon Efprit familier. On les met tous dans un Sac fait de Joncs, \& peint de différentes couleurs; $\&$ fouvent, pour faire honneur au Chef, on place ce Sac fur le devant de fon Canot. S'il y a trop de Manitous, pour tenir dans un feul Sac, on les diftribue dans plufieurs, qui font confiés à la garde du Lieutenant $\&$ des Anciens de chaque Famille. Alors on y joint les prefens, qui ont été faits pour avoir des Prifonniers, avec les langues de tous les Animaux, qu'on a tués pendant la Campagne, \& dont on doit faire au retour un facrifice aux Efprits.

Dans les marches par terre, le Chef porte lui-même fon Sac, qu'on appelle $\int a$ Natte; mais il peut fe décharger de ce fardeau fur qui bon lui femble, $\&$ il ne doit pas craindre que perfonne refufe de le foulager, parce qu'on y a attaché une diftinction : c'eft comme un droit de furvivance pour le Commandement, au cas que le Chef \& fon Lieutenant meurent pendant la Campagne. Mais tout en vous écrivant, Madame, me voici arrivé dans la Riviere de Niagara, où je vais trouver bonne Compagnie, \& où je refterai quelques jours. Je partis de la Riviere des Sables le vint-uniéme avant le Soleil levé; mais le Vent nous contrariant toujours, nous fûmes obligés d'entrer à dix heures dans la Baye desTfonnonthouans. A moitié chemin de la Riviere des Sables à cette Baye, il y a une petite Riviere que je n'aurois pas manqué de vifiter, fi j’avois été plûtôt inftruit de ce qu'elle a de fingulier, \& de ce que je viens d'apprendre en arrivant ici.

On l'appelle Cafconchiagon, \& elle eft fort étroite, \&x peu profonde à fa décharge dans le Lac. Un peu plus haut elle a
deux arpens de large, $\&$ on prétend que les plus grands Vaiffeaux y pourroient être à flot. A deux lieuös de fon Embouchure, on eft arrêté par une Chute, qui paroît bien avoir gulierss.

172 1.
May.
Du foir,
ils ont de

1721.
May.
Du foin,
quils ont de
orter leurs

1721.
May.
Du foir ,
qu'ils ont de
porter leurs

1721.
May.
Du foir ,
qu'ils ont de
porter leurs Dieux.

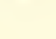


foixante pieds de haut, \& deux arpens de large; une portée de Fufil au-deffus, on en trouve une feconde de même larMay. geur, mais moins haute des deux tiers; \& une demie lieuë plus loin, une troifiéme de cent pieds de haut bien mefurés, \& de trois arpens de large. On rencontre après cela plufieurs Rapides, \& après avoir encore navigué cinquante lieuës, on apperçoit une quatriéme Chute, qui ne cede en rien à la troifiéme. Le cours de cette Riviere eft de cent lieuës, \& quand on l'a remontée environ foixante lieuës, on n'a que dix lieuës à faire par terre, en prenant à droite, pour arriver à l'Ohio, furnommé la belle Riviere. Le lieu, où on la joint, s'appellée Ganos, où un Officier digne de foi, (a) \& le même, de qui je tiens tout ce que je viens de vous dire, m'a affûré avoir vû une Fontaine, dont l'Eau eft comme de l'Huile, \& a le goût de Fer. Il m'a ajoûté qu'un peu plus löin, il y en a une autre toute femblable, \& que les Sauvages fe fervent de fon Eau, pour appaifer toutes fortes de douleurs.

Defcription de la Baye des Tfonnonthouans.

Dela Rivic- Je fus donc obligé de paffer le refte de la nuit dans mon Care de Niagara.

La Baye des. Tfonnonthouans eft un lieu charmant : une jolie Riviere y ferpente entre deux belles Prairies, bordées de Coteaux, entre lefquelles on découvre des Vallées, qui s'étendent fort loin, \& tout cela forme le plus beau point de vûë du monde, borné par une grande Forêt de haute-Futaye: mais le terrein me paroît un peu leger \& fablonneux. Nous nous remîmes en route à une heure $\&$ demie , \& nous voguâmes jufqu'à dix heures du fojr. Nous avions deffein de nous retirer dans une petite Riviere, qu'on appelle la Riviere aux Brufs; mais nous en trouvâmes l'entrée bouchée par les Sables, ce qui arrive fouvent aux petites Rivieres, qui fe déchargent dans fes Lacs, par la raifon qu'elles entraînent beaucoup de Sable avec elles : car quand le Vent vient du large, ces Sables font arrêtés par les Vagues, \& forment peu à peu une Digue fi haute $\&$ fi forte, que le courant des Rivieres ne la fçauroit franchir, fi ce n'elt quand les Eaux groffiffent par la fonte des Neiges. not, où j'effuyai unẹ affez forte gelée. Auffi à peine voyoit-on les Arbriffeaux bourgeonner. Tous les Arbres étoient comme dans le milieu de l'Hyver. Nous partîmes de-là à trois heures $\&$ demie du matin, le vint-deux, jour de l'Afcenfion, \& j’al.

(a) M. de Joncaire, aujourd'hui Capitaine dans les Iroupes de la N. France. 
D'U N VOYA GEDE L'A MERIQ. LET. XIV. 225 ai dire la Mefle à neuf heures dans ce qu'on appelle le Grand Marais. C'eft une Baye affez femblable à celle des Tfonnonthouans, mais où les Terres m'ont parû meilleures. Vers les 1721 . May. deux heures après midi, nous entrâmes dans la Riviere de Niagara, formée par la grande Chute, dont je vous parlerai bientôt, ou plûtôt c'eft le Fleuve Saint Laurent, qui fort du Lac Erié, \& paffe par le Lac Ontario après quatorze lieuës de détroit. On l'appelle Riviere de Niagara depuis la Chute, \& cet efpace eft de fix lieuës. On fait le Sud en y entrant. Quand on y a fait trois lieuës, on trouve fur la main gauche quelques Cabannes d'Iroquois Tfonnonthouans \& de Miffifaguez, comme à Catarocoui. Le Sieur de Jonquaire, Lieutenant dans nos Troupes, y a aufi fa Cabanne, à laquelle on donne par avance le nom de Fort (a) : car on prétend bien qu'avec le tems elle fera changée en une véritable Fortereffe.

J'ai trouvé ici plufieurs Officiers, qui doivent retourner dans quelques jours à Quebec. C'eft ce qui m'oblige à fermer cette Lettre, que j'enverrai par la même voye. Pour moi, je prévois que j'aurai après leur départ le tems de vous en écrire encore une, \& le lieu même me fournira prefque de quoi la remplir, avec ce que je pourrai apprendre d'ailleurs des Offciers, dont je viens de parler.

J'ai l'honneur d'être,

\section{A Niagara, ce vintrois May, i 72 .}

(a) Le Fort a été bâti depuis à l'Entrée | nonville en avoit bâti un, qui n’a pas fubde la Riviere de Niagara, du même côté, fifté lontems. 11 commence même à s'y fors précifément à l'endroit, où $M$. de Dé- Imer une Bourgade Françoife.

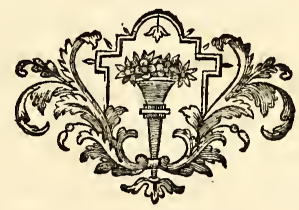


1721 . May.

\section{QUINZIEME LET TRE.}

Ce qui fe paffe entre les Tfonnonthouans $\mathcal{E}$ les Anglois à l'occafion de notre Etablifement à Niagara. Defcription du Pays. Danfe du Feu; Hiftoire à cette occafion. Defcription du Sault de Niagara.

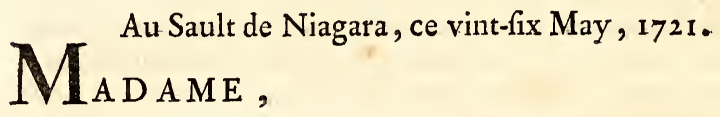

J'A I déja eu l'honneur de vous dire que nous avons. Projet d'un ici un projet d'Etabliffement : pour bien entendre ce qui Erabliftement ìniagara. y a donné lieu, il faut fçavoir que les Anglois prétendent, en vertu du Traité d'Utrecht, avoir la Souveraineté fur tout le Pays Iroquois, \& par conféquent n’être bornés de ce côté-là, que par le Lac Ontario; cependant on a compris que, fi leur prétention avoit lieu, il ne tiendroit bientôt plus qu'à eux de s'établir puiffamment dans le centre de la Colonie Françoife, ou du moins d'en ruiner abfolument le Commerce. On a donc jugé à propos de parer à cet inconvenient, en évitant néanmoins de donner atteinte au Traité , \& on n'a rien trouvé de mieux, que de nous placer en un lieu, qui nous affûrât la conmmunication libre des Lacs, \& où les Anglois ne fuffent pas les maîtres de s'oppofer à notre Etabliffement. LaCommiffion en a été donnée à M. de Jon CAIRE, lequel ayant été dans fả jeuneffe Prifonnier desTfonnonthouans, gagna fi bien les bonnes graces de ces Sauvages, que même dans le plus fort des Guerres, que nous avons euës contr'eux, \& quoiqu'il y ait très-bien fervi, il a toujours joui des privileges attachés à fon adoption.

Dès qu'il eut reçu fes ordres pour l'exécution du Projet, dont je vous ai parlé, ilfe rendit chez eux, affembla les Chefs, $\&$ après les avoir affûrés qu'il n'avoit point de plus grand plaifir au monde que de vivre avec fes Freres, il ajoûta qu'il les. vifiteroit bien plus fouvent, s'il avoit chez eux une Cabanne, où il pût fe retirer, quand il voudroit être en liberté. Ils lui. répondirent qu'ils n'avoient jamais ceffé de le regarder comme 
un de leurs Enfans; qu'il étoit le maître de fe loger par-tout, où bon lui fembleroit, \& qu'il pouvoit choifir le lieu, qu'il jugeroit le plus commode. Il n'en demandoit pas davantage, il vint auffi-tôt ici, choifit pour fon emplacement le bord de la Riviere, qui termine le canton de Tfonnonthouan, \& y dreffa une Cabanne. La nouvelle en fut bientôt portée dans la nouvelle York, \& elle y caufa d'autant plus de jaloufie, que les Anglois n'avoient jamais pu obtenir dans aucun canton Iroquois, ce qui venoit d'être accordé au Sieur de Joncaire.

Ils fe plaignirent avec hauteur, \& leurs plaintes appuyées de préfens, mirent d'abord les quatre autres Cantons dans leurs interêts : mais ils n'en furent pas plus avancés, parce que les Cantons Iroquois font indépendans les uns des autres, \& fort jaloux de cette indépendance. Il falloit donc encore gagner celui de Tfonnonthouan, \& les Anglois n'omirent rien pour y réuffir ; mais ils s'apperçurent bientôt qu'ils ne viendroient jamais à bout de déloger Joncaire de Niagara. Alors ils fe réduifirent à demander, qu'au moins il leur fut permis d'avoir auffi une Cabanne au même lieu : mais cela leur fut encore refufé. "Notre Terre eft en paix, leur dirent les Tfonnon- " thouans, les François \& vous n'y pourriez pas demeurer en- " femble, fans la troubler. Au refte, ajoûterent-ils, c'eft fans " conféquence, que Joncaire y demeure. Il eft Enfant de la Na- " tion, il jouit de fon droit, \& il ne nous eft pas permis de l'en “ fruftrer.

Il faut avouer, Madame, qu'il n'y a gueres que le zéle du bien public, qui puiffe engager un Officier, à demeurer dans un Pays tel que celui-ci, il n'eft pas poffible d'en voir un May.

Oppofition inutile des Anglois à cet Etabliflement. plus fauvage $\&$ plus affreux. D'un côté on voit fous fes pieds, $\&$ comme dans le fond d'un abîme, un grand Fleuve à la verité, mais qui en cet endroit, reffemble plus à un torrent par fa rapidité, \& par les Tourbillons, qu'y forment mille Rochers, au travers defquels il a bien de la peine à trouver paffage, $\&$ par l'écume, dont il eft toujours couvert : de l'autre, la vûë eft mafquée par trois Montagnes pofées les unes fur les autres, \& dont la derniere fe perd dans les Nuës. C'eft bien là que les Poëtes auroient pû dire, que les Titans avoient voulu efcalader le Ciel. Enfin de quelque part que les yeux fe tournent, ils ne découvrent rien, qui n'infpire une fecrette horreur. 


\section{J O UR N A L H I S T O R I Q U E}

$172 \mathrm{~J}$. Il eft vrai qu'il ne faut pas aller bien loin pour voir un May. grand changement. Derriere ces Montagnes incultes \& inhaques, des Côteaux agréables $\&$ fertiles; on refpire un air pur, \& on jouit d'un Climat temperé, entre deux Lacs, dont le moindre (a) a deux cent cinquante lieuës de circuit. Il me paroît que, fi de bonne heure on avoit eu la précaution de s'afsûrer par une bonne Fortereffe, \& par une Peuplade raifonnable, d'un Pofte de cette importance; toutes les forces des Iroquois \& des Anglois jointes enfemble, ne feroient pas aujourd'hui capables de nous en chaffer ; que nous ferions nousmêmes en état de donner la Loi aux Premiers, \& d'empêcher la plûpart des Sauvages, de porter leurs Pelleteries aux Seconds, comme ils font impunément tous les jours.

La Compagnie, que j'ai trouvée ici avec M.de JonCAIRE, étoit compofée du Baron de Longueil, Lieutenant de Roy de Montreal ( $b$ ), du Marquis de Cavagnal, fils du Marquis de Vaudreuil, actuellement Gouverneur Général de la Nouvelle France, de M. de Senneville, Capitaine, \& du Sieur de la Chauvignerie Enfeigne, \& Interprete du Roy: pour la Langue Iroquoife : ces Meffieurs vont négocier un Accommodement avec le Canton d'Onnontagué , \& avoient ordre de vifiter l'Etabliffement du Sieur de Joncaire, dont ils ont été très-contens. Les Tfonnonthouans leur ont renouvellé la parole, qu'ils avoient donnée de le maintenir. Cela s'eft fait dans un Confeil, où Joncaire, à ce qu'ils m'ont dit, a parlé avec tout l'efprit d'un François, qui en a beaucoup, \&r la plus fublime Eloquence Iroquoife.

Defcription

La veille de leur départ, c'eft - à-dire, le vint - quatre, un de la Danfe du seus.

Miffifagué nous régala d'une Fête, qui a quelque chofe d'affez fingulier. Il étoit tout-à-fait nuit quand elle commença; \& en entrant dans la Cabanne de ce Sauvage, nous trouvâmes un feu allumé, auprès duquel un Homme battoit en chantant, fur une efpece de Tambour : un autre fecouoit fans ceffe fon Chichicoué, \& chantoit auffi : cela dura deux heures, \& nous ennuya beaucoup, car ils difoient toujours la même chofe, ou plutôt ils formoient des fons à demi articulés, qui ne varioient point. Nous priâmes le Maître diı

(a) Le Lac Ontario. Le Lac Erié en a $\left.\right|_{\text {Ville. }}$ (b) Il eft mort Gouverneur de cette
ois centa 
D'UN VOYA GE DE L'A MERIQ. LeT. XV. 229

Logis de ne point pouffer plus loin ce Prélude, \& il eut bien de la peine à nous donner cette marque de complaifance.

Nous vîmes alors paroître cing ou fix Femmes, qui fe ran1721 . May。 geant côte à côte fur une mème ligne, fe tenant fort ferrées, \& ayant les bras pendans, danferent \& chanterent ; c'eft-àdire, que fans rompre la ligne, elles faifoient quelques pas en cadence, tantôt en avant, \& tantôt en arriere. Quand elles eurent fait ce manége environ un quart d'heure, on éteignit le feu, qui feul donnoit du jour à la Cabanne, \& on n'apperçut plus rien, qu'un Sauvage, qui avoit dans la bouche un charbon allumé, \& qui danfoit. La Symphonie du Tambour \& du Chichicoué, ne difcontinuoit point ; les $F$ emmes reprenoient de tems en tems leurs Danfes \& leur Chant : le Sauvage danfoit toujours, mais comme on ne le diftinguoit, qu'à la lueur du charbon allumé, qu'il avoit dans la bouche, il paroiffoit un Speetre, \& faifoit horreur à voir. Ce mélange de Danfes, de Chants, d'Inftrumens, \& ce feu, qui ne s'éteignoit point, avoient quelque chofe de bizarre \& de fauvage, qui nous amufa une demie heure, après quoi nous fortîmes de la Cabanne; mais le jeu dura jufquau jour : \& voilà, Madame, tout ce que j’ai vû de la Danfe du feu, je n'ai pû̉ fçavoir ce qui fe pailfa le refte de la nuit.La Mufique, que j'entendis encore quelque tems, étoit beaucoup plus fupportable de loin, que de près. Le contrafte des voix d'Hommes $\&$ de Femmes, faifoit à une certaine diftance, un affez bel effet; \& on peut dire, que fi les Femmes Sauvages avoient de la Méthode, il y auroit bien du plaifir à les entendre chanter.

J'avois fort envie de fçavoir, comment un homme pouvoit tenir $\mathrm{fi}$ lon-tems un charbon allumé dans fa bouche, fans la Hiftoire àces brûler, \& fans s'éteindre ; mais tout ce que j’en ai pû apprendre, c'eft que les Sauvages connoiffent une Plante, qui rend infenfible au feu la partie, qui en eft frottée, \& qu'ils n'en ont jamais voulu donner la connoiffance aux Européens. Nous fçavons que l'Ail \& l'Oignon peuvent produire le même effet, mais pour très peu de tems $(a)$. D'ailleurs, comment ce charbon peut-il refter fi lontems allumé ? Quoiqu'id en foit, je me fouviens d'avoir lû dans. les Lettres d'un de nos anciens Miffionnaires du Canada une chofe, qui a quelque:

(a) On prétend que la Feuille de la Plan- $\mid$ cauftique, a cetre vertu. te de l'Anemone de Canada, d'ailleurs fort 

2\% narre, lequel en avoit été témoin. Celui - ci lui montra un May. jour une pierre, qu'un Jongleur avoit jettée dans le feu en fa préfence, \& l'y avoit laiflée jufqu'à ce qu'elle en fût toute pénetrée. Après quoï entrant dans une eipece de fureur, il l'avoit prife entre les dents, \& la portant toujours ainfi, étoit allé voir un Malade, où le Miffionnaire l'avoit fuivi : en entrant dans la Cabanne, il jetta la pierre par terre, \& le Pere l'ayant ramaffée, il y trouva empreintes, les marques des dents du Sauvage, dans la bouche duquel il n’apperçût aucun indice de brûlure. Il ne dit point ce que le Charlatan fit enfuite, pour foulager le Malade ; mais voici en ce même genre un fait, qui vient de la même fource, \& $\&$ dont vous porterez tel jugement, qu'il vous plaira.

Autre fait Une Femme Huronne, après une Vifion vraye, ou imagifingulier d'une naire, fut attaquée d'un tournoyement de tête, \& d'une contraction de nerfs prefque générale. Comme depuis le com. mencement de cette maladie elle ne s'endormoit jamais, qu'elle n'eût quantité de Rêves, qui la fatiguoient beaucoup, elle y foupçonna du myftere, \& fe mit dans l'efprit, qu'elle guériroit par le moyen d'une Fête, dont elle regla elle - même le Cérémonial, fuivant qu'elle fe fouvenoit, difoit - elle, de l'avoir vû pratiquer autrefois. Elle voulut d'abord qu'on la portât dans le Village, où elle étoit née, \& les Anciens qu'elle fit avertir de fon deffein, exhorterent tout le monde à l'y accompagner. En un moment, fa Cabanne fe trouva remplie de gens, qui venoient lui offrir leurs fervices; elle les accepta, les initruifit de ce qu'ils devoient faire, \& auffitôt les plus Vigoureux la mirent dans unẹ efpece de hotte, $\&$ x la porterent tour à tour, en chantant de toutes leurs forces.

Quand on la fçut proche du Village, on y affembla un grand Confeil, \& par honneur on y invita les Miffionnaires, qui firent inutilement tous leurs efforts, pour diffuader une chofe, où ils foupçonnoient avec raifon autant de fuperftition, que de folie. On écouta tranquillement tout ce qu'ils voulurent dire à ce fujet, mais quand ils eurent ceffé de parler, un des Chefs du Confeil entreprit de réfuter leurs difcours, il n'y gagna rien non plus, puis laiffant là les Miffionnaires, il exhorta tout le monde à s'acquitter exactement de tout ce qui feroit prefcrit, \& à maintenir les anciens Ufages. 
D'UN VOYAGE DE L'A MERIQ. LET. XV. 231 Comme il parloit encore, deux Députés de la Malade entre. rent dans l'Affemblée, donnerent avis qu'elle alloit arriver, \& prierent de fa part, qu'on envoyât au devant d'elle deux jeunes Garçons \& deux jeunes Filles, parés de Robes $\&$ de Coliers, avec des Préfens, qu'elle marquoit, ajoutant qu'elle déclareroit fes intentions à ces quatre Perfonnes.

Tout cela fut executé fur le champ, \& peu de tems après les quatre jeunes gens revinrent les mains vuides, \& prefque nuds ; la Malade s'étant fait donner tout ce qu'ils avoient, jufqu'à leurs Robes. Ils entrerent en cet état dans le Confeil, qui étoit toujours affemblé , \& y expoferent les demandes de cette Femme ; elles contenoient vint - deux Articles, parmi lefquels étoit une.Couverture bleuë, qui devoit être fournie par les Miffionnaires; \& il falloit que toutes ces chofes fuffent livrées à l'heure même : on mit tout en ufage pour obtenir la Couverture, mais elle fût conftamment refúée , \& il fallut s'en paffer. Dès que la Malade eut reçû les autres Préfens, elle entra dans le Village, toujours portée, comme jai dit. Sur le foir, un Crieur Public avertit par fon ordre, de tenir des feux allumés dans les Cabannes, parce qu'elle devoit les vifiter toutes, ce qu'elle fit, dès que le Soleil fut couché , foûtenuë par deux hommes, \& fuivie de tout le Village. Elle paffa au milieu de tous les feux, les pieds \& les jambes nuds, $\&$ ne fentit aucun mal; tandis que fes deux Supports, quoiqu'ils s'ecartaffent du feu, autant qu'il leur étoit poffible, en fouffroient beaucoup; car il fallut la conduire ainfi, au travers de plus de trois cent Brafiers : pour elle, on ne l'entendit jamais fe plaindre, que du froid, $\& \grave{a}$ la fin de cette courfe, elle déclara qu'elle fe fentoit foulagéé.

Le lendemain au lever du Soleil on commença, par fon ordre encore, une efpece de Bacchanale, qui dura trois jours. Le premier jour tout le monde courut par les Cabannes brifant $\&$ renverfant tout ; \& à mefure que le bruit $\& x$ le défordre: augmentoient, la Malade affuroir que fes douleurs diminuoient. Les deux autres jours furent employés à parcourir tous les Foyers, par où elle avoit paffé, \& à propofer fes défirs en termes énigmatiques; il falloit les deviner, \& les accomplir fur le champ. Il y en avoit d'une obfcenité à faire horreur. Le quatriéme jour la malade fit une feconde vifite de 


\section{2

I 72 I toutes les Cabannes, mais bien differente de la premiere. Elle Ma étoit au milieu de deux bandes de Sauvages, qui marchoient May. à la file d'un air trifte $\&$ languiffant, \& gardoient un profond filence. Il n'étoit permis à perfonne de fe trouver fur fon che$\min , \&$ ceux, qui avoient la tête de fon efcorte, avoient foin d'écarter tous ceux, qu'ils rencontroient. Dès que la Malade étoit entrée dans une Cabanne, on la faifoit affeoir, on fe plaçoit autour d'elle; elle foupiroit, faifoit le récit de fes maux d'un ton de voix fort touchant, \& donnoit à entendre que fa guérifon parfaite dépendoit de l'accompliffement d'un défir, fur lequel elle ne s'expliquoit point, \& qu'il falloit deviner. Chacun y faifoit de fon mieux; mais ce défir étoit fort compliqué ; il comprenoit beaucoup de chofes; à mefure qu'on en nommoit une, il falloit la lui donner, \& pour l'ordinaire elle ne fortoit point d'une Cabanne, qu'elle n'en eût prefque tout enlevé.

Lorfqu'elle voyoit qu'on ne pouvoit rencontrer jufte, elle s'exprimoit un peu plus clairement, \& quand on eut tout deviné, elle fit rendre tout ce qu'elle avoit reçû. Alors on ne douta plus qu'elle ne fût guerie ; on en fit une Fête, qui confifta en des cris, ou plutôt des hurlemens affreux, \& des extravagances de toutes les fortes. Enfin elle fit fes remercimens, \& pour mieux témoigner fa reconnoiflance, elle vifita une tróifiéme fois toutes les Cabannes, mais fans aucune cérémonie. Le Miffionnaire témoin de cette ridicule fcene, dit que la Malade ne fut pas entierement guérie; mais qu'elle fe portoit beaucoup mieux : cependant une perfonne faine \& robufte $y$ auroit péri. Ce Pere eut grand foin de faire obferver que fon prétendu Génie lui avoit promis une guérifon parfaite, \& ne lui avoit pas tenu parole. On lui répondit que dans une fi grande quantité de chofes commandées, il étoit bien difficile qu'on n'en eût omis quelqu'une. Il s'attendoit qu'on infifteroit principalement fur le refus de la couverture bleuë; à la vérité on lui en dit un mot, mais on ajoûta qu'après ce refus le Génie s'étoit fait voir pendant la nuit à la Malade, \& lui avoit affúré que cet incident ne lui cauferoit aucun préjudice, parce que les François n'étant pas Naturels du Pays, les Génies n'avoient aucun pouvoir fur eux. Je reviens à mon voyage.

Defcription Meffieurs nos Ofticiers étant partis, je montai ces affreu- 
DUUN VOYA GE DE L'A MERIQ. LET. XV. 233 fes Montagnes, dont je vous ai parlé, pour me rendre au fameux Sault de Niagara, au-deffus duquel je devois m'embarquer. Ce voyage eft de trois lieuës ; il étoit autrefois de cinq, parce qu'on paffoit de l'autre côté de la Riviere, c'eft-à-dire, à l'Occident, \& qu'on ne fe rembarquoit, qu'à deux lieuës audeffus de la chute. Mais on a trouvé fur la gauche, à un demi quart de lieuë de cette cataracte, une Anfe, où le courant n'eit pas fenfible, \& où par conféquent on peut s'embarquer fans péril. Mon premier foin, en arrivant, fut de vifiter la plus belle Cafcade, qui foit peut-être dans la Nature; mais je reconnus d'abord que le Baron de la Hontan s'étoit trompé, fur fa hauteur \& fur fa figure, de maniere à faire juger qu'il ne l'avoit point vîe.

Il eft certain que, fi on mefure fa hauteur par les trois Montagnes, qu'il faut franchir d'abord, il n'y a pas beaucoup à rabattre des fix cent pieds, que luidonne la Carte de M. Delifle, qui fans doute n'a avancé ce paradoxe, que fur la foi du Baron de la Hontan, \& $\&$ du Pere Hennepin : mais après que je fus arrivé au fommet de la troifiéme Montagne, jobfervai que dans l'efpace des trois lieuës, que je fis enfuite jufqu'à cette chute d'eau, quoiqu'il faille quelquefois monter, il faut encore plus defcendre, \& c'eft à quoi ces Voyageurs paroiffent n'avoir pas fait affez d'attention. Comme on ne peut approcher la Cafcade que de côté, ni la voir que de profil, il n'eft pas aifé d'en mefurer la hauteur avec les inftrumens; on a voulu le faire avec une longue corde attachée à une longue perche, \& après avoir fouvent réiteré cette maniere, on n’a trouvé que cent quinze, ou frx vint pieds de profondeur : mais il n'eft pas poffible de s'affurrer fi la perche n'a pas été arrêtée fur quelque Rocher, qui avançoit : car quoiqu'on l'eût toujours retirée mouillée, aufi-bien qu'un bout de la corde, à quoi elle étoit attachée, cela ne prouve rien, puifque l'eau, qui fe précipite de la Montagne, rejaillit fort haut en écumant. Pour moi, après l'avoir confiderée de tous les endroits, d'où on peut l'examiner plus à fon aife, $j$ 'eltime qu'on ne fçauroit lui donner moins de cent quarante ou cinquante pieds.

Quant à fa figure, elle eft en fer à Cheval, \& elle a environ quatre cent pas de circonférence; mais précifément dans fon milieu elle eft partagée en deux par une Ifle fort étroite, Tome III.

G $g$ 


\section{4 \\ J O U R N A L \\ H I S T \\ O R I Q U E}

I 72 I. \& d'un demi-quart de lieuë de long, qui y aboutit. Il eft vrai May. que ces deux parties ne tardent pas à fe rejoindre. \& Celle, qui pointes, qui avancent, mais celle, que je découvrois en face, me parut fort unie. Le Baron de la Hontan y ajoûte un Torrent, qui vient de l'Oueft, mais s'il n'a pas été inventé par cet Auteur, il faut dire que dans le tems de la fonte des Néges, des eaux fauvages viennent fe décharger là par quelque ravine.

Vous pouvez bien juger, Madame, qu'au-deffous de cette chute la Riviere fe reffent lontems d'une fir rude fecouffe; auffi n'eft-elle naviguable qu'au bout de trois lieuës, \& précifément à l'endroit , où M. de Joncaire s'eft placé. Elle ne devroit pas être moins impratiquable au-deffus, puifque le Fleuve y tombe perpendiculairement dans toute fa largeur. Mais outre l'Ifle, qui la divife en deux, plufieurs écueils femés çà \& là à côté $\&$ au-deffus de cette île, ralentiffent beaucoup la rapidité du Courant. Il eft néanmoins fi fort malgré cela, que dix ou douze Outaouais ayant un jour voulu traverfer à l'Ifle, pour éviter des Iroquois, qui les pourfuivoient, furent entraînés dans le précipice, quelqu'effort qu'ils fiffent pour fe foûtenir.

obbervations J'avois oui dire que les Poiffons, qui fe trouvoient engafur certe Caf- gés dans ce Courant, tomboient morts dans la Riviere, \&
cade. que des Sauvages établis dans ces quartiers - là en faifoient leur profit ; mais je n'ai rien vû de femblable. On m'avoit encore affûré que les Oifeaux, qui s'avifoient de voler par-deffus, fe trouvoient quelquefois enveloppés dans le tourbillon, que formoit dans l'Air la violence de ce Rapide; mais jä ${ }^{3}$ remarqué tout le contraire. J'ai vû de petits Oifeaux voltiger affez bas directement au-deffus de la chute, $\& x$ s'en tirer fort bien.

C'eft fur un Roc, que cette nappe d'eau eft reçûe, \& deux raifons me perfuadent qu'elle y a trouvé, \& peut-être creufé avec le tems une Caverne, qui a quelque profondeur. La premiere eft que le bruit, qu'elle fait, eft fort fourd, \& comme d'un tonnere éloigné. A peine l'entend-on de chez M. de Joncaire, \& peut - être même ce qu'on y entend n'eft que les bouillonnemens caufés par les Rochers, qui rempliffent le lit de la Riviere jufques-là. D'autant plus quaau-deffus de la Cataracte, on ne l'entend pas à beaucoup près de fi loin. La. 
D'UN VOYAGE DE L'A MERIQ. Let. XV. 235 feconde eft qu'il n'a jamais rien reparu, dit-on, de tout ce qui y eft tombé, pas même les débris du Canot des Outaouais, dont je parlois tout-à-l'heure. Quoiqu'il en foit, Ovide nous donne la defcription d'une femblable Cataracte, qu'il dit être dans la délicieufe Vallẻe de Tempé. Il s'en faut bien que le Pays de Niagara foit auffi beau, mais je crois fa Cataracte beaucoup plus belle $(a)$.

Au refte je n'ai apperçû de brouillard au-deffus, que par derriere; de loin on le prendroit pour une fumée, \& il n'eft perfonne, qui n'y fût trompé, s'il arrivoit à la vûë de l'Tlle, fans être prévenu qu'il y a en cet endroit une Cataracte auffi furprenante que celle-là.

Le terrein des trois lieuës, que jai faites à pied pour venir ici, \& qu'on appelle le Portage de Niagara, ne paroît pas bon; il eft même affez mal boifé, \& l'on n'y fçauroit faire dix pas, fans marcher fur une Fourmiliere, \& fans rencontrer des Serpens à Sonnettes, fur-tout pendant la chaleur du jour. Je crois, Madame, vous avoir dit que les Sauvages mangent par délices la chair de ces Reptiles. En général les Serpens ne caufent point d'horreur à ces Peuples : il n'eft aucun Animal, dont on voye plus fouvent la figure marquée fur leur vifage, \& fur d'autres endroits de leur Corps, \& ils ne leur donnent ordinairement la chaffe, que pour les manger. Les Os \& les Peaux des Serpens fervent auffi beaucoup aux Jongleurs \& aux Sorciers pour faire leurs preftiges, \& ils fe font des bandeaux $\&$ des ceintures de leurs Peaux. Il eft encore vrai quils ont le fecret de les enchanter, ou, pour parler plus jufte, de les engourdir ; qu'ils les prennent tout vivans, les manient, les mettent dans leur fein, fans qu'il leur en arrive aucun mal, \& que c'eft ce qui contribuë davantage à leur donner le crédit, qu'ils ont fur ces Peuples.

J'allois fermer cette Lettre, lorfque l'on m'eft venu dire que nous ne partirions pas demain, comme je m'y attendois. que nous ne partirions pas demain, comme je m'y attendois. ces de la Mar-
ll faut bien prendre patience, \& 8 mettre le tems à profit: je riers, vais donc reprendre l'article des guerres des Sauvages, qui

1721 .

May.

(a) Eft Nemus Hamonie, prarupta quod undique claudit

Sylva; vocant Tempe, per qua Penêus ab imo

Effufus Pindo Jpumofis volvitur Undis,

Dejectisque gravi tenues agitantia Fumos

Nubila conducit, fummifque afpergine Sylvas

Impluit, és fonitu plufquam vicina fatigat. Métamorph. Liv. I. 


\section{J O UR N A L H IS TOR I Q U E}

- ne fera pas fitôt épuifé. Dès que tous les Guerriers font embarqués, les Canots s'éloignent d'abord un peu, \& $\mathrm{fe}$ tienMay. nent fort ferrés fur une même ligne; enfuite le Chef fe leve $\&$ tenant en main fon Chichikoué, il entonne fa Chanfon de guerre, \& fes Soldats lui répondent par un triple hé, tiré avec effort du creux de la poitrine. Les Anciens \& les Chefs du Confeil, qui font reftés fur le Rivage, exhortent alors les Guerriers à bien faire leur devoir, \& fur tout à ne pas fe laiffer furprendre. C'eit de tous les avis, qu'on peut donner aux Sauvages, le plus néceffaire, \& celui, dont, pour l'ordinaire, ils profitent le moins. Cette exhortation n'interrompt point le Chef, qui chante toujours. Enfin les Guerriers conjurent leurs Parens \& leurs Amis de ne les point oublier, puis pouffant tous enfemble des hurlemens affreux, ils partent de la main, \& nagent avec une telle vîtefle, qu'on les voit difparoître dans l'inftant.

Les Hurons \& les Iroquois ne fe fervent point du Chichikoué, mais ils en donnent à leurs Prifonniers, de forte que cet inftrument, qui eft pour les autres un inftrument de guerre, femble être parmi eux une marque d'Effclavage. Les Guerriers ne font prefque jamais que de petites journées, fur-tout quand ils font en grande troupe. D'ailleurs ils tirent des préfages de tout; \& les Jongleurs, à qui il appartient de les expliquer, avancent $\&$ retardent les marches comme il leur plait. Tant qu'on n'eft point en Pays fufpeet, on ne prend aucune précaution, \& fouvent on ne trouveroit pas deux ou trois Guerriers enfemble, chacun étant de fon côté à chaffer; mais quelqu'éloigné que l'on foit de la route, tous fe rendent ponctuellement au lieu $\&$ à l'heure marqués pour fe réunir.

Du Campe- On campe lontems avant le Soleil couché, \& $\quad$ pour l'orment. dinaire on laiffe devant le Camp un grand efpace environné d'une Paliffade, ou plûtôt d'une efpece de Treillis, fur lequel on place les Manitous, tournés du côté, où l'on veut aller. On les y invoque pendant une heure, \& $x$ on en fait autant tous les matins, avant que de décamper. Après cela on croit n'avoir rien à craindre, on fuppofe que les Efprits fe chargent de faire feuls la Sentinelle, \& toute l'Armée dort tranquillement fous leur fauve-garde. L'expérience ne détrompe point ces Barbares, \& ne les tire point de leur confance préfomptueufe. Elle a fa fource dans une indolence 
D'U N V OYA GE DE L'A MERIQ. LET. XV. 237 $\&$ dans une pareffe, que rien ne peut vaincre.

Tout eft Ennemi fur le chemin des Guerriers. Si néanmoins ils rencontrent de leurs Alliés, ou des Partis à peu près de force égale de Gens, avec qui ils n'ont rien à démêler, on fe fait amitié de part \& d'autre. Si les Alliés, qu'on rencontre, étoient en guerre contre les mêmes Ennemis, le Chef du Parti le plus fort, ou de celui, qui a armé le premier, donne à l'autre quelques Chevelures, dont on ne manque jamais de faire provifion pour ces occafions-là, \& lui dit : "Vous avez " coup ici, c'eft-à-dire, vous avez fatisfait à votre engage- « ment, votre honneur eft à couvert, vous pouvez vous en " retourner ". Mais cela s'entend, lorfque la rencontre eft for- " tuite, qu'on ne s'eft pas donné le mot, \& qu'on n'a pas befoin de renfort.

Quand on eft fur le point d'entrer dans le Pays ennemi, on s'arrête pour une cérémonie, qui a quelque chofe d'aflez fingulier. Le foir on fait un grand Feftin, après lequel on s'endort. Dès que tous font éveillés, ceux, qui ont eu des rêves, vont de feu en feu, chantant leur chanfon de mort, dans laquelle ils font entrer leurs fonges d'une maniere énigmatique. Chacun fe met l'efprit à la torture pour les deviner, \& i i perionne n'en peut venir à bout, il elt permis à ceux, qui ont révé de s'en retourner chez eux. Voila qui donne beau jeu aux Poltrons. On fait enfuite de nouvelles invocations aux Efprits, on s'anime plus que jamais à faire merveille: on jure de fe fecourir mutuellement; enfin on fe remet en marche; $\&$ fi on eft venujufques-là par Eau, on quitte fes Canots, qu'on a grand foin de bien cacher. Si tout ce qui eft prefcrit dans ces occafions s'obfervoit exactement, il feroit difficile de furprendre un Parti de guerre, qui eft entré dans le Pays ennemi. On ne doit plus faire de feu, plus de cris, plus de chaffe; il ne faut plus même fe parler, que par fignes. Mais ces loix font mal gardées. Tout Sauvage eft né préfomptueux, \& incapable de fe gêner le moins du monde. On ne néglige pourtant guéres d'envoyer tous les foirs des Coureurs, qui employent deux ou trois heures à aller de côté \& d'autre. S'ils n'ont rient vû, on s'endort tranquillement, \& on abandonne encore la garde du Camp aux Manitous.

Si-tôt qu'on a découvert l'Ennemi, on envoye le reconnô̂tre , \& fur le rapport de ceux, qu'on a envoyés, on tient

1721.

May.

De la rencontre des différens Partis de Guerre.
De l'entrée dans le Pays ennemi.
Des approches, \& de l'at= saque. 
$23^{8}$ JOUR N A L H IS T OR I Q U E

I 72 I. Confeil. L'attaque fe fait ordinairement au point du jour. C'eft le tems, où l'on fuppofe que l'Ennemi eft dans fon plus proMay. fond fommeil, \& toute la nuit on fe tient couché fur le ventre, fans remuer. Les approches fe font dans la même polture en fe traînant fur fes pieds \& fur fes mains jufqu’à la portée du Trait. Alors tous fe levent, le Chef donne le fignal par un petit cri, auquel toute la Troupe répond par de vrais hurlemens, \& fait en même-tems fa premiere décharge : puis, fans laiffer à l'Ennemi le tems de fe reconnoître, elle fond fur lui le Caffe-tête à la main. Depuis qu'aux Caffe-têtes de bois ces Peuples ont fubftitué de petites Haches, auxquelles ils ont donné le même nom, les mêlées font plus fanglantes. Le combat fini, on leve les Chevelures des Morts \& des Mourans, $\& x$ on ne fonge à faire des Prifonniers, que quand l'Ennemi ne fait plus aucune réfiftance.

Mais fi on l'a trouvé fur fes gardes, ou trop bien retranché, on fe retire, pourvû qu'il en foit encore tems. Sinon, on prend réfolument le parti de fe bien battre, $\&$ il y a quelquefois beaucoup de fang répandu de part \& d'autre. Un Camp forcé eft l'image de la fureur même, la férocité barbare des Vainqueurs, \& le défefpoir des Vaincus, qui fçavent à quoi ils doivent s'attendre, s'ils tombent vifs entre les mains de leurs Ennemis, font faire aux uns \& $x$ aux autres des efforts, qui paffent tout ce qu'on en peut dire. La figure des Combattans, tous barbouillés de noir $\&$ de rouge, augmente encore l'horreur du combat, \& l'on feroit fur ce modele un portrait bien naturel de l'Enfer. Quand la viktoire n'eft plus douteufe, les.Victorieux fe défont d'abord de tous ceux, qu'ils auroient trop de peine à emmener, \& ne cherchent plus qu'à laffer les autres, dont ils veulent faire des Prifonniers.

Les Sauvages font naturellement intrépides, \& malgré leur férocité brutale, ils confervent toujours dans l'ątion même, Leurmaniere beaucoup de fang froid. Cependant ils ne fe mêlent, \& ne de combattre. combattent en rafe campagne, que quand ils ne peuvent l'éviter. Leur raifon eft qu'une victoire teinte du fang des Vainqueurs n'eft pas proprement une victoire, \& que la gloire du Che f confifte principalement à ramener tout fon Monde fain $\&$ fauf. J'ai oui dire que quand deux Ennemis, qui fe font connus, fe rencontrent dans le combat, il fe fait entr'eux des dialogues aflez femblables à ceux des Heros d'Homere. Je ne crois 
D'UN V OYA GE DE L'A MERIQ. LET. XV. 239 pas que cela arrive dans le fort de la mêlée, mais il fe peut faire que dans de petites rencontres, ou bien avant que de paffer un ruiffeau, ou de forcer un retranchement, on fe dife quelques mots pour fe défier, ou pour fe rappeller quelqu'autre rencontre femblable.

La guerre fe fait prefque toujours par furprife, \& elle réuffit affez ordinairement; car autant que les Sauvages font accoûtumés à négliger les précautions néceffaires pour n'être point furpris, autant font-ils alertes \& habiles pour furprendre. D'ailleurs ces Peuples ont un talent admirable, je dirois volontiers un inftinct, pour connoître fi l'on a paffé par quelque endroit. Sur les herbes les plus courtes, fur la terre la plus dure, fur les pierres mêmes, ils découvrent des traces, \& par la façon, dont elles font tournées, par la figure des pieds, par la maniere, dont ils font écartés, ils diftinguent, dit-on, les veftiges des Nations differentes, \& ceux des Hommes d'avec ceux des Femmes. J'ai lontems cru qu'il y avoit de l'exaggération dans ce qu'on en racontoit, mais le rapport de tous ceux, qui ont vécu avec les Sauvages, eft fi unanime fur cela, que je ne vois aucun lieu d'en foupçonner la fincérité. Si parmi les Prifonniers il s'en trouve, que leurs bleffures mettent hors d'état d'être tranfportés, on les brûle d'abord, \& comme cela fe fait dans le premier emportement, \& qu'on eft fouvent preflé de faire retraite, ils en font pour la plupart quittes à meilleur marché, que les autres, qu'on réferve à un fupplice plus lent.

L'ufage eft parmi quelques Nations que le Chef du Parti vainqueur laiffe fur le champ de bataille fon Caffe-tête, fur lequel il a eu foin de tracer la marque de fa Nation, celle de fa Famille, \& fon portrait, c'eft-à-dire, un ovale, avec toutes les figures, qu'il a au vifage. D'autres peignent toutes ces marques fur le tronc d'un arbre, ou fur une écorce, avec du charbon pilé \& broyé, mêlé de quelques couleurs. On y ajoûte des carąteres hiéroglyphiques, par le moyen defquels les Paffans peuvent apprendre jufqu'aux moindres circonftancés, non-feulement de l'action, mais encore de tout ce qui s'eft paffé pendaat la campagne. On y reconnoît le Chef du Parti par toutes les marques, dont je viens de parler; le nombre de fes exploits, par autant de nattes; celui de fes Soldats, par des lignes; celui des Prifonniers, qu'il emmene, par de

1721 .

May.

Leur inftine pour connoître les traces de leurs Ennemis.
Des fignes, qu'on laiffe de la victoire. 


\section{J O UR A L HISTORIQUE}

petits Marmouzets, qui portent un bâton, ou un Chichikoué ; celui des Morts, par des figures humaines fans tête,

May. avec des differences, qui font diftinguer les Hommes, les Femmes, \& les Enfans. Mais ce n'eft pas toujours fi près du. lieu, où s'eft paffée l'action, qu'on trouve ces écriteaux, car quand un Parti craint d'être pourfuivi, il les place hors de fa route, afin de dépayfer ceux, quile cherchent.

Précautions Jufqu'à ce que les Vainqueurs foient en pays de fûreté, ils pour antirer la font affez de diligence; \& de crainte que les Bleffés ne les reretraite, $\&$ terter gardent dans leur retraite, ils les portent tour à tour fur des prifonniers. Brancarts, ou ils les tirent fur une Traîne, fi on eft en Hyver. En rentrant dans leurs Canots, ils font chanter leurs Prifonniers, \& la même chofe fe pratique chaque fois qu'ils rencontrent de leurs Alliés; honneur, qui coûte un feftin à ceux, qui le reçoivent, \& quelque chofe de plus, que la peine de chanter, aux malheureux Captifs : car on invite les Alliés à les careffer, \& careffer un Prifonnier, c'eft lui faire tout le mal, dont on peut s'avifer, ou le mutiler de maniere, qu'il en demeure eftropié. Il y a pourtant des Chefs, qui ménagent affez ces Miférables, \& ne foufrent pas qu'on les maltraite trop. Mais rien n'égale l'attention, avec laquelle on les garde. Le jour ils font liés par-le cou \& $x$ par les bras à une des barres du Canot. Quand on va parTerre, il y a toujours quelqu'un, qui les tient; \& la nuit ils font étendus à terre tout nuds, des cordes attachées à des crochets plantés en terre leur tiennent les jambes, les bras, \& le cou fi ferrés, qu'ils ne fçauroient remuer, \& de longues cordes leur ferrent encore les mains $\&$ les pieds de telle façon, qu'ils ne peuvent faire le moindre mouvement fans éveiller les Sauvages, qui font couchés fur ces cordes.

Comment on Quand les Guerriers font arrivés à une certaine diftance du annonce la vic- Village, d'où ils étoient partis, ils s'arrêtent, \& le Chef y foirc dans les envoye donner avis qu'il eft proche. Parmi quelques $\mathrm{Na}$ -
Villages. tions, dès que l'Envoyé eft à portée d'être entendu, il fait differens cris, qui donnent une idée générale des principales aventures, \& dufuccès de la campagne. Il marque d'abord le nombre des Hommes, qu'on y a perdus, par autant de cris de mort. Auffitôt les Jeunes Gens fe détachent pour avoir des connoiffances plus circonftanciées : fouvent même tout le Village y court, mais un feul Homme aborde l'Envoyé, apprend 
D'UN VOYAGE DE L'A MERIQ. LET. XV. 24 I apprend de lui tout le détail des nouvelles, dont il eft porteur; à mefure que celui-ci lui raconte un fait, il le répete tout haut en fe tournant vers cẹux, qui l'ont accompagné, \& I $72 \mathrm{I}$ May. ils lui répondent par des acclamations, ou par des cris lugubres, fuivant que la nouvelle eft funefte ou agréable.

L'Envoyé eft enfuite conduit dans une Cabanne, où les Anciens lui font les mêmes queftions, qu'on lui a déja faites; après quoi un Crieur public, invite toute la Jeunefie à aller à la rencontre des Guerriers, \& les Femmes à leur porter des rafraîchiffemens. Ailleurs on ne fonge d'abord qu’à pleurer ceux, qu'on a perdus. L'Envoyé ne fait que des cris de mort. On ne va point au-devant de lui ; mais à fon entrée dans le Village il trouve tout le monde affemblé, raconte en peu de mots tout ce qui s'eft paffé, puis fe retire dans fa Cabanne, où on lui porte à manger, \& pendant quelque tems on n'eft occupé qu’à pleurer les morts.

Ce terme expiré, on fait un autre cri pour annoncer la viktoire. Alors chacun effuye fes larmes, \& il n'eft plus queftion que de fe réjouir. Quelque chofe d'affez femblable fe pratique au retour des Chaffeurs : les Femmes, qui font demeurées au Village, vont au-devant d'eux, dès qu'elles font averties qu'ils approchent, \& avant que de s'informer du fuccès de la Chaffe, elles leur annoncent par leurs larmes les morts, qui font arrivées depuis leur départ. Pour revenir aux Guerriers, le moment, où les Femmes les joignent, eft à proprement parler le commencement du fupplice des Prifonniers : auffi lorfque quelques-uns ont d'abord été deftinés à être adoptés, ce qu'il n'eft pas permis de faire chez toutes les Nations, leurs futurs Parens, qu'on a foin d'avertir, les vont prendre un peu plus loin, \& les conduifent à leurs Cabannes par des chemins détournés. Pour l'ordinaire ils ignorent lontems quel doit être leur fort, \& il en eft peu, qui échappent aux premieres fureurs des Femmes. Mais cet article me meneroit trop loin, \& nous partons demain de grand matin. Je fuis, \& $\mathrm{x}$. 


\section{J O U R N A L H I S T O R I Q U E}

1721 .

May.

\section{SE I Z I E M E L E T T R E.}

Premiere Réception des Prifonniers. Triomphe des Guerriers. Diftribution, qu'on fait des Captifs: comment on décide de leur fort, $\mathcal{E}$ ce qui arrive enfuite. Avec quelle inhumanité on traite ceux, qui font deftinés à la mort. Courage, qu'ils. font paroître. Des Négociations des Sauvages.

A l'Entrée du Lac Erié, ce vint-feptiéme May, I 72 I.

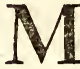

\section{A D A ME,}

J E fuis parti ce matin du Sault de Niagara; j’avois environ fept lieuës à faire pour gagner le Lac Erié, \& je les ai fait fans peine. Nous comptons bien de ne pas coucher ici cette nuit; mais tandis que mes Gens nageoient de toutes leurs forces, j'ai bien avancé une nouvelle Lettre, \& pendant qu'ils prennent un peu de repos je vais l'achever, pour la donner à des Canadiens, que nous avons rencontrés ici , \& qui vont à Montreal. Ja reprends mon récit, où j’en étois demeuré dans ma derniere.

Premiere réceprion des Prifonniers.

Tous les Prifonniers, qui font deftinés à la mort, \& ceux , dont le fort n'eft point encore décidé, font, comme je vous l'ai déja dit, Madame, abandonnés à la fureur des Femmes, qui vont au-devant des Guerriers, \& $\mathrm{x}$ il eft étonnant qu'ils réfiftent à tous les maux, qu'elles leur font foufrir. Si quelqu'une. fur-tout a perdu à la guerre, ou fon Fils, ou fon Mari, ou quelqu'autre perfonne, qui lui étoit chere, $y$ eût-il trente ans paffés, qu'elle eût fait cette perte, c'eft une Furie, qui s'attache au premier, qui lui tombe fous la main, \& l'on n'imagineroit pas jufqu'où fa'rage l'emporte. Elle n'a nul égard, ni à l'humanité, ni à la pudeur, \& à chaque coup, qu'elle lui porte, on croiroit qu'il va tomber mort à fes pieds, fi on ne fçavoit pas combien ces Barbares font ingénieux à prolonger les fupplices les plus inouis. Toute la nuit fe paffe de la forte au Campement des Guerriers. 
D'UN V OYA GE DE L'A MER I Q. Let. XVI. 243

Le lendemain eft le jour du Triomphe des Vainqueurs. Les Iroquois \& quelques autres affectent une grande modeftie, \& un plus grand défintéreffement encore dans ces rencontres. Les Chefs entrent d'abord feuls dans le Village, fans aucune marque de victoire, gardant un profond filence, $\&$ fe retirent dans leurs Cabannes, fans témoigner avoir la moindre prétention fur les Prifonniers. Chez d'autres Nations il n'en eft pas de même; le Chef marche à la tête de fa Troupe avec un air de Conquérant; fon Lieutenant vient après lui, \& il eft précédé d'un Crieur, qui eft chargé de recommencer les cris de mort. Les Guerriers fuivent deux à deux, les Prifonniers au milieu, couronnés de fleurs, le vifage \& les cheveux peints, tenant un bâton d'une main \& le Chichikoué de l'autre, le corps prefque nud, les bras liés au-deffus du coude, avec une corde, dont les Guerriers tiennent les bouts, \& chantent fans ceffe leur chanfon de mort au fon du Chichikoué.

Ce chant a quelque chofe de lugubre $\&$ de fier tout enfemble, \& le Captif n'a point du tout l'air d'un Homme, qui foufre, \& qui eft vaincu. Voici à peu près le fens de ces chanfons : "Je fuis Brave \& intrépide, je ne crains point la " mort, ni aucun genre de tortures : ceux qui les redoutent, " font des lâches, ils font moins que des Femmes: la vie n'eft " rien pour quiconque a du courage : que le défefpoir $\&$ la rage " étouffent tous mes Ennemis : que ne puis-je les dévorer, \& " boire leur fang jufqu'à la derniere goute " ! De tems en tems " on les arrête, on s'attroupe autour d'eux, on danfe $\&$ on les fait danfer : ils paroiffent le faire de bon cour, ils racontent les plus belles actions de leur vie; ils nomment tous ceux, qu'ils ont tués, ou brûlés. Ils font fur-tout remarquer ceux, auxquels les Affiftans doivent plus s'intéreffer: on diroit qu'ils ne cherchent qu'à animer de plus en plus contre eux les Arbitres de leur fort. Ces bravades en effet font entrer en fureur tous ceux, qui les entendent, \& leur vanité leur coûte cher. Mais de la maniere, dont ils reçoivent les plus durs traitemens, on diroit que c'eft leur faire plaifrr, que de les tourmenter.

Quelquefois on les oblige de courir entre deux rangées de Sauvages armés de pierres $\& x$ de bâtons, \& qui donnent fur eux, comme s'ils vouloient les affommer du premier coup.

Bravades des Prifonniers.

May.

Triomphe des Guerriers.

Ce qu'on leur fait foufrir à leur entrée dans le Villa$\mathrm{Hh}$ ij 


\section{J OUR N A L H T OR I Q U E}

$172 \mathrm{I}$ Il n'arrive pourtant jamais qu'ils y fuccombent, tant on obMay. que la feule fureur conduit le bras, de ne point toucher aux endroits, où il y auroit du rifque pour la vie. Dans cette marche chacun a droit de les arrêter ; il leur eft aufi permis de fe défendre, mais ils ne feroient pas les plus forts. Dès qu'ils font arrivés au Village, on les conduit de Cabanne en Cabanne, \& par-tout on leur fait payer leur bien-venuë. Ici on leur arrache un ongle, là on leur coupe un doit, ou avec les dens, ou avec un méchant couteau, dont on fe fert comme d'une fcie. Un Vieillard leur déchire la chair jufqu'aux os; un Enfant avec une alene les perce, où il peut; une Femme les fouette impitoyablement jufqu'à ce que les bras lui tombent de laffitude; mais aucun des Guerriers ne met la main fur eux, quoiqu'ils foient encore leurs Maîtres. On ne peut même les mutiler fans leur permifion, qu'ils accordent rarement: à cela près, on a toute liberté de les faire foufrir, \& fi on les promene dans plufieurs Villages, foit de la même Nation, foit de fes Voifins, ou de fes Alliés, qui l'ont fouhaité ; partout ils font reçûs de même.

Diftribution,

Après ces préludes, on travaille à la répartition des Captifs, \& leur fort dépend de ceux, à qui ils font livrés. Au fortir du Confeil, où on a déliberé de leur fort, un Crieur invite tout le monde à fe trouver dans la Place, où la diftribution fe fait fans conteftation \& fans bruit. Les Femmes, qui ont perdu leurs Enfans, ou leurs Maris à la guerre, font ordinairement partagées les Premieres. On fatisfait enfuite aux engagemens pris avec ceux, dont on a reçû des Coliers; sil ne íe trouve pas affez de Captifs pour tout cela, on y fupplée par des Chevelures, dont ceux, à qui on les donne, fe parent aux jours de réjouiffance. Le refte du tems elles demeurent fufpenduës à la Porte de la Cabanne. Si au contraire le nombre des Prifonniers excéde celui des Prétendans, on envoye le furplus aux Villages des Alliés. D'ailleurs un Chef ne fe remplace que par un Chef, ou par deux ou trois autres Efclaves, qui font toujours brûlés, quand bien même ceux, qu'ils remplaceroient, feroient morts de maladie. Les Iroquois ne manquent jamais de deftiner quelques Prifonniers pour le Public, \& alors le Confeil en difpofe, comme il le juge à propos. Mais les Meres de Famille peuvent encore caf- 
D'UN VOYAGE DE L'AMER IQ. LET. XVI. 245 fer leur Sentence, \& font Maitreffes de la vie \& de la mort de ceux mêmes, qui avoient été condamnés ou abfous par le Confeil.

Dans quelques Nations les Guerriers ne fe dépouillent pas entierement du droit de difpofer des Captifs, \& ceux, en faveur defquels le Confeil en avoit difpofé, font obligés de les remettre entre leurs mains, s'ils l'exigent; mais ils le font rarement, \& lorfqu'ils le font, ils font obligés de rendre les gages, qu'ils avoient reçus de ceux, à qui on les avoit donnés. Si en arrivant ils ont déclaré leurs intentions à ce fujet, on ne s'y oppore pas pour l'ordinaire. En général le plus grand nombre des Prifonniers de guerre eft condamné à la mort, ou ì un efclavage bien dur, \& qui ne les affûre jamais de la vie. Quelques-uns font adoptés, \& dès-lors leur condition ne differe plus de celle des Enfans de la Nation: ils entrent dans tous les droits de ceux, dont ils occupent la place, \& fouvent ils prennent tellement l'efprit de la Nation, dont ils font devenus membres, qu'ils ne font nulle difficulté d'aller en guerre contre leurs propres Compatriotes. Les Iroquois ne fe font guéres foûtenus jufqu'ici, que par cette politique : toujours en guerre depuis un tems infini contre toutes les Nations, ils feroient aujourd'hui prefque réduits à rien, s'ils n'avoient eu l'attention de naturalifer une bonne partie de leurs Prifonniers de guerre.

Il arrive quelquefois qu'au lieu d'envoyer dans d'autres Villages l'excédent des Captifs, on en donne à des Particuliers, qui n'en avoient pas demandé, \& pour lors, ou bien ils n'en font pas teliement les Maîtres, qu'ils ne foient tenus de confulter les Chefs du Confeil pour fçavoir ce qu'ils en feront: ou bien on les oblige de les adopter. Dans le premier cas, celui, à qui on fait préfent d'un Efclave, l'envoye chercher par quelqu'un de fa Famille; il le fait enfuite attacher à la Porte de fa Cabanne; puis il affemble les Chefs du Confeil, à qui il décare quelle eft fon intention, \& demande leur avis. Pour l'ordinaire cet avis eft conforme à ce qu'il défire. Dans le fecond cas, le Confeil en remettant le Prifonnier à celui, à qui on l'a deftiné, lui dit : "Il y a lontems que " nous fommes privés d'un tel, ton Parent, ou ton Ami, \& " qui étoit le foûtien de notre Village. Ou bien1, nous regret- " tions l'efprit d'un tel, que tu as perdu, \& qui par fa fageffe "

Comment on décide de leur fort. 


\section{J O URNA L H IS T O R I Q U E}

1721. "maintenoit la tranquillité publique; il faut qu'il reparoiffe auMay. "jourd'hui ; il nous étoit trop cher, \& trop précieux, pour

" differer davantage à le faire revivre : nous le remettons fur fa

"Natte en la perfonne de ce Prifonnier.

Il y a néanmoins des Particuliers, plus confidérés apparemment que les autres, à qui on fait préfent d'un Captif fans aucune condition, \& avec une pleine liberté d'en faire ce qu'ils jugeront à propos, \& le Confeil alors s'exprime en ces termes, en le remettant entre fes mains : "Voici de quoi répa"rer la perte d'un tel, \& de nétoyer le cœur de fon Pere, de fa Mere, de fa Fenme \& de fes Enfans ; foit que tu veuilles "leur faire boire du bouillon de cette chair, ou que tu aimes mieux remettre le défunt fur fa Natte en la perfonne de ce Captif. Tu peux en difpofer à ton gré.

De l'adop-

Dès qu'un Prifonnier eft adopté, on le conduit à la $\mathrm{Ca}$ banne, où il doit être, \& on commence par lui ôter fes liens. On fait enfuite chauffer de l'eau pour le laver : on panfe fes playes, s'il en a, \& fuflent-elles toutes pleines de Vers, il eft bientôt guéri : on n'omet rien pour lui faire oublier les maux, qu'il a foufferts, on lui donne à manger, on l'habille proprement. En un mot on ne feroit pas plus pour l'Enfant de la Maifon, ni pour celui, qu'il réfufcite, c'eft ainfi qu'on. s'exprime. Quelques jours après on fait un feftin, pendant lequel on lui donne folemnellement le nom de celui, qu'il remplace, \& dont, non-feulement il a dès-lors tous les droits, mais il contracte auffi toutes les obligations.

De ceux, Parmi les Hurons \& $x$ les Iroquois ceux, qui font deftinés

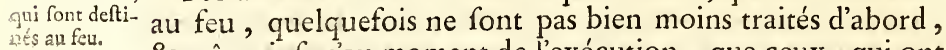
\& même jufqu'au moment de l'exécution, que ceux, qui ont été adoptés. Il femble que ce foit des victimes, qu'on engraiffe pour le Sacrifice, $8 x$ ils font effectivement immolés au Dieu de la Guerre : la feule difference, qu'on met entr'eux \& $\mathrm{x}$ les autres, c'eft qu'on leur noircit entierement le vifage. A cela près, on leur fait la meilleure chere, qu'il eft poffible; on ne leur parle qu'avec amitié ; on leur donne les noms de Fils, de Freres, ou de Neveux, fuivant la Perfonne, dont ils doivent par leur mort appaifer les mânes : on leur abandonne même quelquefois des Filles, pour leur fervir comme de Femmes pendant tout le tems, qu'il leur refte à vivre. Mais lorfqu'ils. font inftruits de leur fort, $i$ les faut bien garder, fi on ne 
D'UN VOYAGE DE L'A MERIQ. LET. XVI. 247 veut pas qu'ils s'échapent. Auffi le leur cache-t'on fouvent.

Quand ils ont été livrés à une Femme, au moment qu'on l'avertit que tout eft prèt pour l'exécution, ce n'eft plus une Mere, c'eft une Furie, qui paffe des plus tendres careffes aux derniers excès de la rage. Elle commence par invoquer l'ombre de celui, qu'elle veut venger. "Approche, lui dit-elle," tu vas être appaifée ; je te prépare un Feftin, bois à longs " traits de ce bouillon, qui va être verfé pour toi ; reçois le fa- "s crifice, que je te fais, en immolant ce Guerrier: il fera brûlé " \& mis dans la Chaudiere; on lui appliquera les Haches arden- " tes; on lui enlevera la Chevelure ; on boira dans fon crâne ; " ne fais donc plus de plaintes; tu feras parfaitement fatisfaite $\ldots$. Cette formule, qui eft proprement la Sentence de mort, varie beaucoup pour les termes, mais quant à la fubftance, elle eft à peu près toujours la même. Un Crieur fait enfuite fortir le Captif de la Cabanne, déclare à haute voix les intentions. de celui ou de celle, à qui il appartenoit, \& finit par exhorter les Jeunes Gens à bien faire. Un autre furvient, qui addreffe la parole au Patient, \& lui dit: Mon Frere, prends courage, tu vas être brûlé, \& il répond froidement : cela eft bien, je te remercie. Il fe fait auffi-tôt un cri dans tout le Village, \& le Prifonnier eft conduit au lieu deftiné à fon fupplice.

Ordinairement on le lie à un Poteau par les deux mains $\&$ par les pieds, mais de maniere, qu'il puife aifément tourner tout autour. Quelquefois néanmoins, quand l'exécution fe fait dans une Cabanne, d'où il n'y a pas de danger qu'il fe fauve, on ne le lie point, \& on le laiffe courir d'un bout à l'autre. Avant que l'on commence à le brûler, il chante pour la derniere fois fa chanfon de mort, puis il fait le récit de fes. proueffes, \& prefque toujours de la maniere la plus infultante pour ceux, qu'il apperçoit autour de lui. Il les exhorte enfuite à ne le pas épargner, \& à fe fouvenir qu'il eft Homme, \& Guerrier. Je fuis bien trompé au refte, ou ce qui doit le plus étonner dans ces fcenes tragiques \& barbares, n'eft pas qu'un Patient chante à pleine tête, qu'il infulte $\&$ qu'il défie fes Bourreaux, comme ils font ordinairement tous jufqu'au: dernier foupir ; car il y a là une fierté, qui éleve l'efprit, qü: le tranfporte, qui le diftrait un peu de la penfée de ce qu'il foufre, \& qui l'empêche même de marquer trop de fentibjorêt de leur coadamnation. . . (n)

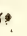




\section{J O UR N A L H IS T O R I Q U E}

$172 \mathrm{I}$.

May.

lité. D'ailleurs les mouvemens, qu'ils fe donnent, font diverfion, émouffent le fentiment, produifent le même effet, \& quelque chofe de plus, que les cris \& les larmes. Enfin on fçait qu'il n'y a point de grace à efperer, \& $z$ le défefpoir donne des forces, \& infpire de la hardieffe.

Principe de Cette efpéce d'infenfibilité n'eft pourtant pas auffi univerla barbarie qu'on exerce en ces occafelle, que bien des gens l'ont cru. Il n'eft point rare de voir fions. pouffer à ces Miférables des cris capables de percer les cœurs les plus durs; mais qui n'ont d'autre effet, que de réjouir les Acteurs $\&$ les Afliftans. Quant à ce qui produit dans les Sauvages une inhumanité, dont on n'auroit jamais cru que des Hommes fuffent capables, je crois qu'ils $y$ font parvenus par degrés, que l'ufage les y a accoûtumés infenfiblement; que l'envie de voir faire une lâcheté à fon Ennemi, les infultes, que les Patiens ne ceffent point de faire à leurs Bourreaux, le défir de la vengeance, qui eft la paffion dominante de ces Peuples, \& quils ne croyent pas fuffifamment affouvie, tảndis que le courage de ceux, qui en font l'objet, n'eft point abbatu; la fuperftition enfin, $y$ encrent pour beaucoup : car quels excès n'enfante point un taux zéle guidé par tant de paffions.

Je ne vous ferai point, Madame, le détail de tout ce qui fe paffe dans ces horribles exécutions. Il m'engageroit trop loin, parce qu'il n'y a point fur cella d'uniformité, ni d'autres regles, que la férocite \& le caprice. Souvent on y voit auttant d'Acteurs que de Spectateurs, c'eft-à-dire, que d'Habitans de la Bourgade, Hommes, Femmes \& Enfans, \& chacun fait du pis qu'il peut. Il n'y a que ceux de la Cabanne, à laquelle le Prifonnier avoit été livré, qui s'abftiennent de le tourmenter, au moins eft-ce la pratique de plufieurs Nations. Communément on commence par brûler les pieds, puis les jambes, \& ainfi en remontant jufqu'à la tête ; \& quelquefois on fait durer le fupplice une femaine entiere, comme il eft arrivé à un Gentilhomme Canadien parmi les Iroquois.

Les moins épargnés font ceux, qui ayant déja été pris, \& adoptés, ou mis en liberté, font repris de nouveau. On les regarde comme des Enfans dénaturés, ou des ingrats, qui ont fait la guerre à leurs Parens, ou à leurs Bienfacteurs, \& on ne leur fait aucune grace. Il arrive quelquefois que le $\mathrm{Pa}-$ tient, lors même qu'il n'eft point exécuté dans unẹ Cabanne, n'eft 
D'UN V OYA GE DE L'A MERI Q. LET. XVI. 249 n'eft point lié , \& qu'il lui eft permis de fe défendre, ce qu'il fait, bien moins dans l'efpérance de fauver fa vie, que pour venger par avance fa mort, \& pour avoir la gloire de mourir en Brave. On a vû dans ces occafions combien de force $\&$ de courage ces paffions peuvent infpirer : en voici un exemple, qui a pour garans des témoins oculaires \& dignes de foi.

Un Capitaine Iroquois, du Canton d'Onneyouth, avoit mieux aimé s'expofer à tout, que de fe déshonnorer par une fuite, qu'il jugea d'une conféquence dangereufe pour les Jeunes Gens, qui étoient fous fes ordres. Il fe battit lontems en Homme, qui vouloit mourir les armes à la main, mais les $\mathrm{Hu}-$ rons, qu'il avoit en tête, vouloient l'avoir vif, \& il fut pris. Par bonheur pour lui \& pour ceux, qui furent faits Prifonniers avec lui, on les mena dans une Bourgade, où il y avoit des Miffionnaires, qui eurent toute liberté de les entretenir. Ces Peres les trouverent d'une docilité, qu'ils' regarderent comme un commencement de la grace de leur converfion; ils les inftruifirent, \& les baptiferent: ils furent tous brûlés peu de jours après, \& témoignerent jufqu'à la mort une forte de conftance, que les Sauvages ne connoiffoient pas encore, \& que les Infidéles mêmes attribuerent à la vertu du Sacrement.

Le Capitaine Onneyoưth crut néanmoins qu'il lui étoit encore permis de faire à fes Ennemis tout le mal, qu'il pourroit, \& de reculer fa mort autant qu'il lui feroit poffible. On l'avoit fait monter fur une efpéce de Théâtre, où l'on commença à le brûler par tout le corps fans aucun ménagement, \& il parut d'abord auffi infenfible, que s'il n'eût rien fouffert: mais comme il crut appercevoir un de fes Compagnons, qu'on tourmentoit affez près de lui, donner quelque marque de foibleffe, il en témoigna une très-grande inquiétudé, \& il n'omit rien de ce qui pouvoit l'encourager à la patience, par l'efperance du bonheur, qui les attendoit dans le Ciel, \& il eut la confola. tion de le voir expirer en Brave $8 x$ en Chrétien.

Alors tous ceux, qui avoient fait mourir celui-ci, retomberent fur lui, avec tant d'acharnement, qu'on auroit cru qu'ils alloient le mettre en piéces. Il n'en parut pas plus ému, \& on ne fçavoit plus par où il pouvoit être fenfible, lorfqu'un de fes Bourreaux lui cerna tout-autour la peau de la Tome III. 


\section{JOURNA L H I T OR I Q U E}

$172 \mathrm{I}$. tête, \& la lui arracha avec violence. La douleur le fit tomber May. fans connoiffance, on le crut mort, \& chacun fe retira. Un moment après il revint de fon évanouiffement, \& ne voyant autour de lui, que le cadavre de fon Compagnon, il prend un tifon des deux mains, quoiqu'il les eût toutes écorchées $\&$ brûlées, rappelle fes Bourreaux, \& les défie de s'approcher. $S$ a réfolution les effraya, ils poufferent des cris affreux, s'armerent, les uns de tifons embrafés, les autres de fers rougis dans le feu, \& fondirent tous enfemble fur lui : il les reçut en Brave \& les fit reculer. Le feu, dont il étoit environné lui fervoit de retranchement; il s'en fit un autre avec les Echelles, dont on s'étoit fervi pour monter fur l'Echafaut, \& cantonné ainfi dans fon propre Bucher, devenu le théâtre de fa valeur, armé des inftrumens de fon fupplice, il fut quelque tems la terreur d'une Bourgade entiere, perfonne n'olant approcher d'un Homme plus qu'à demi brûlé, \& à qui le fang découloit de toutes les parties de fon Corps.

Un faux pas, qu'il fit en voulant éviter un tifon, qu'on lui lançoit, le livra de nouveau à fes Meurtriers, \& il n'eft pas néceffaire de vous dire qu'ils lui firent payer bien cher la frayeur, qu'il venoit de leur caufer. Après s'être laffés de le tourmenter, ils le jetterent au milieu d'un grand brafier, \& l'y laifferênt, ne pouvant fe perfuader qu'il s'en relevât: on fut trompé ; lorfqu'on y penfoit le moins, on le vit, armé de tifons, courir vers le Village, comme s'il eût voulu y mettre le feu. Tout le monde étoit glacé d'effroi, \& perfonne n'eut l'afurrance de fe préfenter devant lui pour l'arrêter : maiscomme il approchoit des premieres Cabannes, un bâton, qu'on lui jetta entre les jambes, le fit tomber, \& on fut fur lui, àvant qu'il eût pu fe relever. On lui coupa d'abord les piéds \& les mains, on le roula enfuite fur les charbons embrafés; enfin on le jetta fous un tronc d'Arbre, qui étoit en feu. Alors tout le Village fe rangea autour de lui, pour goûter le plaifir de le voir brûler.

Le fang, qu'il perdoit, éteignoit prefque le feu; mais on n'appréhendoit plus aucun effort de fa part. Il en fit pourtant un dernier, qui épouvanta les moins timides. Il fe traina fur les coudes \& fur les genoux avec un air menaçant $\&$ une vigueur, qui écarta les plus proches, plus à la vérité d'étonnement, que de crainte; car que pouvoit -il lẹur faire, 
DUN VOYAGEDE L'A MERIQ. LET. XVI. $25^{\text {t }}$ mutilé comme il étoit? Dans ce moment les Miffionnaires, qui ne l'avoient point perdu de vûë, s'étant approchés, \& lui ayant remis devant les yeux les vérités éternelles, dont il May. avoit été fi pénétré d'abord; il rentra en lui-même, \& ne parut plus occupé que de fon falut. Quelque tems apress un Huron le prit à fon avantage, \& lui coupa la tête.

Cependant, Madame, fi ces Peuples font la guerre en Barbares, il faut convenir que dans leurs Traités de paix , \& généralement dans toutes leurs négociations, ils font parồtre une habileté, \& une nobleffe de fentimens, qui feroient honneur aux Nations les plus policées. Il ne s'agit point entre eux de conquérir, \&x d'étendre leur domination. Plufieurs Nations mêmes ne connoiffent point de domaine proprement dit, \& celles, qui ne fe font point éloignées de leur Pays, \& qui fe regardent comme les Maitreffes de leurs Terres, n'en font point jaloufes jufqu'à trouver mauvais qu'on vienne s'y établir, pourvu qu'on n'entreprenne point de les inquietter. N n'eft donc queftion dans leurs Traités, que de fe faire des Alliés contre des Ennemis puiffans, de mettre fin à une guerre, qui devient onéreufe aux deux Partis, ou plutôt de furpendre les hoftilités, car j'ai déja obfervé que les guerres font éternelles parmi les Sauvages, quand elles font de Nation à Nation. Auffi ne faut-il pas compter fur un Traité de Paix, tant qu'une des deuxis Parties peut donner de la jaloufie à l'autre.

Tout le tems qu'on négocie, \& avant même que d'entrer en Négociation, le principal foin eft de ne point paroître faire les premieres démarches, ou du moins de perfuader à fon Ennemi, que ce n'eft ni par crainte, ni par néceflité, qu'on les fait ; \& cela eft manié avec la plus grande dextérité. Un Plénipotentiaire ne rabat rien de fa fierté, lors même que les Affaires de fa Nation, font dans le plus mauvais état ; \& il réuffit fouvent à perfuader ceux, avec qui il traite, qu'il eft de leur intérêt de mettre fin aux Hoftilités, quoique Vainqueurs. Auffi y va-t-il de tout pour lui, d'y employer tout ce qu'il a d'efprit \& d'éloquence ; car fi fes Propofitions ne font pas agréées, il faut qu'il fe tienne bien fur fes gardes. Il n'eft point rare qu'un coup de $\mathrm{Hache}$, foit l'unique Réponfe, qu'on lui fait. Il n'eft pas même hors de danger, quand il a évité la premiere furprife, il doit s'attendre à être 
I 72 I. pourfuivi, \& à être brûlé, s'il eft pris, \& qu'une telle vio7ence puiffe être colorée de quelque prétexte, comme de May. Reprefailles. Cela eft arrivé à quelques François, chez les Iroquois, où ils avoient été envoyés de la part du Gouverneur Général ; \& pendant bien des années, les Jéfuites, qui demeuroient parmi ces Barbares, quoiqu'ils y fuffent fous la Sauve-garde Publique, \& en quelque façon, les Agents ordinaires de la Colonie, fe trouvoient tous les jours à la veille d'être facrifiés à un reffentiment, ou d'ètre les victimês d'une intrigue des Gouverneurs de la Nouvelle York.

Enfin il eft furprenant que des Peuples, qui ne font nullement la guerre par intérêt, \& qui portent même le défintéreffement jufquau point que les Guerriers ne fe chargent jamais des dépouilies des Vaincus, ne touchent pas même aux habits des Morts, \& s'ils rapportent quelque butin, l'abandonnent au premier, qui veut s'en emparer; en un mot, qui ne prennent les armes, que pour la gloire, ou pour fe venger de leurs Ennemis : il eft, dis - je, étonnant de les voir auffi exercés, qu'ils le font dans le manége de la plus fine politique, \& entretenir des Penfionnaires chez leurs Ennemis. Ils ont même, par rapport à ces fortes de Miniftres, une coûtume, qui paroît d'abord affez bifarre, mais qu'on peut néanmoins regarder comme l'effet d'une grande prudence: c'eft qu'ils ne font jamais aucun fond fur les avis, qu'ils reçoivent de leurs Penfionnaires, fi ceux-ci ne les accompagnent de quelque préfent. Ils ont compris fans doute, que pour pouvoir fagement compter fur de pareils avis, il faut, non-feulement que celui, qui les donne, n'ait rien à efpérer; mais qu'il lui en coûte même pour les donner, afin que le feul intérêt du bien public puiffe l'y engager, \& qu'il ne le faffe pas trop légerement.

Je fuis, \&c. 
D'UN VOYA GE DE L'A MERIQ. Let. XVII. 253

\section{DIX-SEPTIEM E 'LETTRE.}

1721 .

Juin.

Defcription du Lac Erié. Voyage jufqu'au Détroit. Projet d'un Etabliffement en ce lieu-là. Ce qui l'a fait manquer. Confeil chez le Commandant du Fort de Pontchartrain, \& de quoi il s'agiffoit. Des Jeux des Sauvages.

Au Fort de Pontchartrain du Détroit, ce huit Juin, 1721 .

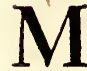

\section{$A D A M E$;}

JE partis le vint-fept de l'Entrée du Lac Erié, après avoir fermé ma derniere Lettre, \& quoiqu'il fût fort tard, je fis Defcription encore trois lieuës ce jour-là , à la faveur d'un bon Vent, \& du plus beau tems du monde. La route eft en côtoyant la côte du Nord , \& elle eft de cent lieuës. Depuis Niagara, en prenant par le Sud, elle eft beaucoup plus agréable, mais plus longue de moitié. Le Lac Erié a cent lieuès de longueur de l'Eft à l'Oueft. Sa largeur du Nord au Sud eft de trente, ou environ. Le nom, qu'il porte, eft celui d'une Nation de la Langue Huronne, qui étoit établie fur fes Bords, \& que les Iroquois ont entierement détruite. Erié veut dire Chat, \& les Eriés font nommés dans quelques Relations la Nation du Chat. Ce nom vient apparemment de la quanticé de ces Animaux, qu'on trouve dans ce Pays. Ils fone plus gros que les nôtres, \& leurs Peaux font fort eftimées. Quelques Cartes modernes ont donné au Lac Erié le nom de Conti; mais ce nom n'a pas fait fortune, non plus que ceux de Condé, de Tracy, \& d'Orleans donnés au Lac Huron, au Lac Supérieur, \& au Lac Michigan.

Le vint-huit je fis dix-neuf lieuës, \& je me trouvai vis-à-vis de la Grande Riviere, qui vient de l'Eft, par les quarantedeux dégrez quinze minutes. Cependant les grands Arbres n'étoient point encore verts. A cela près, le Pays me parut fort beau. Nous fimes peu de chemin le vint-neuf, \& point du tout le trentiéme. Nous nous embarquâmes le lendemain

De la Côte Septentrionnals. 


\section{4 \\ J O UR N A L H IS TOR I Q U E}

$172 \mathrm{I}$.

Iuin,

avant le lever du Soleil, \& nous avançâmes beaucoup. Le premier de Juin, jour de la Pentecôte, après avoir remonté pendant une heure une jolie Riviere, qui vient, dit-on, de fort loin, \& coule entre deux belles Prairies, nous fimes un Portage d'environ foixante pas, pour éviter de faire le tour d'une Pointe, qui avance quinze lieuës dans le Lac; on la nomme la Longue Pointe, elle eft fort fablonneufe, \& porte naturellement bea:coup de vignes. Les jours fuivans je ne vis rien de remarquable, mais je côtoyai un Pays charmant, caché de tems en tems par des rideaux affez défagréables, mais de peu de profondeur. Par-tout, où je mis pied à terre, je fus enchanté de la beauté $8 x$ de la varieté d'un Payfage, terminé par les plus belles Forêts du monde. Avec cela, le Gibier d'Eau y foifonne partout; je ne vous dirai pas fi la Chaffe eft auffi abondante dans le Bois : mais je fçai que du côté du Sud il y a une quantité prodigieufe de B̋œufs fauvages.

Agrément de

Sil'on voyageoit toujours, comme je faifois alors,'avec un ess yoyages.

Ciel ferein, \& un climat charmant, fur une eau claire, comme la plus belle Fontaine; qu'on rencontrât partout des campemens fûrs \& agréables, où l'on pût avoir à peu de frais le plaifir de la Chaffe, refpirer à fon aife un Air pur, \& jouir de la vîë des plus belles Campagnes, on pourroit être tenté de voyager toute fa vie. Je me rappellois ces anciens Patriarches, qui n'avoient point de demeure fixe, habitoient fous des Tentes, éroient en quelque façon les Maîtres de tous les Pays, qu'ils parcouroient, \& profitoient paifiblement de toutes leurs productions, fans avoir les embarras inévitables dans la porfeflion d'un véritable domaine. Combien de Chênes me reprefentoient celui de Mambré ? Combien de Fontaines me faifoient fouvenir de celle de Jacob? Chaque jour nouvelle fituation à mon choix : une Maifon propre \& commode, dreffée \& $x$ meublée du néceffaire en moins d'un quart d'heure, - jonchée de fleurs toujours fraîches fur un beau tapis verd: de toutes parts des beautés fimples \& naturelles, que l'art n'a point alterées, \& qu'il ne fçauroit imiter. Si ces agrémens iouffrent quelqu'interruption, ou par le mauvais tems, ou par quelquaccident imprévî, ils n'en ont que plus de vivaciré, quand ils reparoifient.

$\mathrm{Si}$ je voulois moralifer, jajoûterois que ces alternatives de 
DUU N V OYA GE DE L'A MERIQ. Let. XVII. 255 plaifirs \& de contretems, que j’ai déja affez effuyés, depuis que je fuis en route, font bien propres à faire fentir qu'il n'eft point de genre de vie plus capable de nous remettre fans ceffe devant les yeux que nous fommes fur la terre comme des Pélerins; que nous ne pouvons ufer, qu'en paffant, des biens dẹ ce Monde; qu'il faut peu de chofes à l'Homme, pour le rendre content, \& que nous devons prendre en patience les maux, qui furviennent à la traverfe, puifquils paffent également, \& avec la même rapidité. Enfin combien de chofes nous y rendent fenfible la dépendance, où nous vivons d'une Providence divine, qui ne fe fert point, pour ce mélange de bien \& de mal, des palfions des Hommes, mais de la viciflitude des Saifons, qu'on peut prévoir, \& du caprice des Elemens, auquel on doit s'attendre : par conféquent quelle facilité, $8 x$ combien d'occafions n'y a-t'on pas de meriter par fa confiance $\&$ fa réfignation aux volontés de Dieu ? on dit ordinairement que les longs voyages ne fanctifient pas; rien ne feroit pourtant plus capable de fanctifier, que la vie, qu'on y mene.

Le quatriéme, nous fûmes arrêtés une bonne partie du jour fur une Pointe, qui court trois lieuës Nord \& Sud, \& qu'on appelle la Pointe Pélée. Elle eft cependant affez bien boifée du côté de l'Oueft, mais celui de l'Eft n'a fur un terren fablonneux que des Cedres rouges, affez petits, \& en médiocre quantité. Le Cedre blanc eft d'un plus grand urage, que le rouge, dont le bois fe caffe aifément, \& dont on ne peut faire que de petits Meubles. On prétend ici que les Femmes enceintes n'en doivent point ufer pour lcurs Bufcs. La verdure de ce Cedre n'a point d'odeur, mais le bois en a. C'eft tout le contraire du blanc. Il y a beaucoup d'Ours dans ce Pays, \& l'Hyver dernier il en fut tué für la feule Pointe Pélée plus de quatre cent.

Le cinquiéme, vers les quatre heures du foir, nous apperçûmes la Terre du Sud, \& deux petites Ifles, qui en font trèsproches. On les nomme les Ifles des Serpens à Sonnettes, \& on affurre qu'elles font tellement remplies de ces Animaux, que l'Air en eft infecté. Nous entrâmes dans le Détroit une heure avant le Soleil couché, \& nous paffàmes la nuit audeffus d'une très-belle Inle, appellée l'Ifle du Bois Blanc. Depuis la longue Pointe jufqu'au Détroit, la route ne vaut guéres que l'Oueft: depuis l'enrrée du Détroit jufqu'à l'Ifle de

$172 \mathrm{I}$. Juin.
Des Cedres blancs \& rouges.
Artivéc au Dérroit. 


\section{J O UR N A L H IS T O R I Q U E}

- Sainte Claire, qui en eft à cinq ou fix lieuës, \& de-lá jufqu'au 2. Lac Huron, elle prend un peu de l'Eft, par le Sud. Ainfi Juin. tout le Détroit, qui a trente - deux lieuës de long, eft entre les quarante-deux Degrés, douze ou quinze Minutes, 8 les quarante - trois \& demi de Latitude-Nord. Au deffus de l'Ifle de $S^{\text {ec }}$ Claire, le Détroit s'élargit, \& forme un Lac, qui a reçu fon nom de l'Ifle, ou qui lui a donné le fien. Il a environ fix lieuës de long, fur autant de largeur en quelques endroits.

Dela nature On prétend, que c'eft ici le plus bel endroit du Canada, \& du Pays.

Des Sauvavéritablement, à en juger par les apparences, la Nature ne lui a 1 ien refufé de ce qui peut faire un Pays charmant: Côteaux, Prairies, Campagnes, Bois de Futaye, Ruiffeaux, Fontaines, Rivieres, tout cela eft d'une fi bonne qualité, \& dans un affortiment fi heureux, qu'on ne fçauroit prefque rien défirer de plus. Les Terres n'y font pourtant pas également bonnes pour toutes fortes de Grains, mais la plûpart font d'une fertilité admirable, \& j'en ai vâ, qui ont porté dix-huit ans de fuite du Froment, fans avoir été fumées. D'ailleurs toutes font bonnes à quelque chofe. Les Ifles femblent y avoir été placées à la main, pour l'agrément de la vûë; le Fleuve \& le Lac font fort poiffonneux, l'air pur, \& le Glimat temperé, \& fort fain.

Avant que d'arriver au Fort, qui eft fur la main gauche, ges établis au- une lieuë au-deffous de l'Ifle de Sainte Claire, on trouve près du Fort. fur la même main, deux Villages affez nombreux, \& qui font fort proches l'un de l'autre. Le premier eft habité par des Hurons Tionnontatez, les mêmes, qui après avoir lontemis erré de côté \& d'autre, fe font fixés d'abord au Saule Sainte Marie, \& enfuite à Michillimakinac. Le fecond l'eft par des Pouteouatamis. Sur la droite, un peu plus haut, ily en a un troifiéme d'Outaouais, Compagnons inféparables des Hurons, depuis que les Iroquois ont obligé les uns \& les autres, à abandonner leur Pays. Il n'y a point de Chrétiens parmi eux, s'il y en a parmi les Poutequatamis, ils font en très - petit nombre: les Hurons le font tous, mais ils n'ont point de Miffionnaires. On dit qu'ils n'en veulent point, mais cela fe réduit à quelques-uns des Principaux, qui n'ont pas beaucoup de Religion, \& qui empêchent qu'on n'écoute tous les autres, lefquels en demandent depuis lontems $(a)$.

(a) On leur en a enfin donné un depuis plufieurs années. 
Il y a lontems que la fituation, encore plus que la beauté du Détroit, a fait fouhaiter qu'on y fit un Etablilfement confidérable; il étoit affez bien commencé, il y a quinze ans, $172 \%$ Juin. mais des raifons, qu'on ne dit point, l'ont réduit à très peu de chofes. Ceux qui ne lui ont pas été favorables, difent: $\mathbf{I}^{\circ}$. Qu'il approcheroit trop les Pelleteries du Nord des Anglois, qui donnant leurs Marchandifes aux Sauvages à meilleur marché que nous, attireroient tout le Commerce dans la Nouvelle York. 2\%. Que les Terres du Détroit ne font pas bonnes, que toute leur fuperficie, jufqu'à neuf ou dix pouces de profondeur, n'eft que de Sable ; \& que fous ce Sable, il y a une Terre glaife fi dure, que l'Eau ne la fçauroit pénetrer; d'où il arrive, que les Plaines \& l'intérieur des Bois, font toujours noyés; qu'on n'y voit que de petits Chênes mal tournés, \& $x$ des Noyers durs, \& que les Arbres ayant toujours le pied dans l'Eau, les Fruits y mûriffent fort tard. Mais ces raifons n'ont pas été fans réplique. Il eft vrai qu'aux environs du Fort Pontchartrain les Terres font mêlées de Sable, \& que dans les Forêts voifines, il y a des fonds prefque toujours pleins d'Eau. Cependant ces mêmes Terres ont porté du Froment dix-huit années de fuite, fans être jamais fumées, \& il ne faut pas aller bien loin pour en trouver, qui font excellentes. Pour ce qui eft des Bois, fans trop m'éloigner du Fort, j'en ai vâ en me promenant, qui ne le cedent en rien à nos plus belles Forêts.

Quant à ce qu'on dit, qu'en s'établiffant au Détroit, on mettroit les Anglois trop à portée de faire le Commerce des Pelleteries du Nord; il n'eft Perfonne en Canada, qui ne convienne qu'on ne réuffira jamais à empêcher les Sauvages, de leur porter leurs Marchandifes, en quelque lieu qu'ils foient établis, \& quelque précaution qu'on prenne, fi on ne leur fait trouver avec nous les mêmes avantages, qu'ils trouvent dans la Nouvelle Y.ork. J'aurois fur cela, Madame, bien des chofes à vous dire, mais ces difcuffions me mene. roient trop loin. Nous en cauferons quelque jour à loifir.

Le feptiéme de Juin, qui étoit le lendemain de mon arrivée au Fort, M. de TontI, qui y commande, affembla les Chefs des trois Villages, dont je vous ai parlé, pour leur communiquer les Ordres, qu'il venoit de recevoir du Marquis de Vaudreuil. Ils l'écouterent tranquillement, \& fans l'inter.

Confeil de trois Nations Sauvages chez le Commandant da Détroit. 
1721 . rompre; \& quand il eut fini, l'Orateur Huron lui dit en peu Juin. pofé, \& qu'ils lui feroient Réponfe dans peu. C'eft la coûtume de ces Peuples, de ne jamais répondre fur le champ, lorfqu'il s'agit d'Affaires de quelque importance. Deux jours après ils fe raffemblerent en plus grand nombre chez le Commandant, qui fouhaita que je fuffe préfent à ce Confeil, avec les Officiers de la Garnifon. SASteratsi, que nos. François appellent le Roy des Hurons, \&x qui eft en effet le Chef Héreditaire des Tionnontatez, lefquels font les vrais Hurons, s'y trouva ce jour-là ; mais comme il eft encore Mineur, il n'y vint que pour la forme: fon Oncle, qui gouverne pour lui , \& qu'on a nommé le Régent, porta la parole, en qualité d'Orateur de la Nation; \& l'honneur de parler pour tous eft ordinairement déferé aux Hurons, quand il s'en trouve dans un Confeil. Le premier coup d'œil de ces Affemblées, n'en donne pas une idée bien avantageufe. Imaginez - vous, Madame, une douzaine de Sauvages prefque nuds, les Cheveux accommodés en autant de manieres différentes, \& toutes ridicules ; quelques-uns un Chapeau bordé par - deffus, tous la Pipe à la bouche, \& dans la contenance de gens, qui ne penfent à rien. C'eit beaucoup, fi quelqu'un laiffe échapper un mot en un quart d'heure, $\&$ fi on lui répond par un Monofyllabe. Nulle marque de diftinction, nulle préfeance; mais on change bien de fentiment, lorfqu'on voit le réfultat de leurs Délibérations.

Il s'agiffoit ici de deux Points, que le Gouverneur Géneral avoit fort à cœurr. Le premier étoit de faire trouver bon aux trois Villages établis au Détroit qu'on ne leur vendit plus d'Eau de Vie, dont le Confeil de Marine, avoit défendu abfolument la Traite. Le fecond étoit d'engager toutes les Nations à s'unir avec les François, pour détruire les Outagamis, communément appellés les Renards, aufquels on avoit fait grace quelques années auparavant, \& qui recommençoient leurs Brigandages. M. de Tonti fit d'abord répeter en peu de mots par fes lnterpretes ce qu'il avoit expofé plus au long, dans la premiere Affemblée, \& l'Orateur Huron, répondit au nom des trois Villages. Il ne fit point d'Exorde, \& alla droit au Fait. Il parla lontems, \& pofément, s'arrêtant à chaque Article, pour donner moyen à l'Interprete, 
D'U N V OYA G E D E L'A M ER I Q. LET. XVII. 259 d'expliquer en François, ce qu'il venoit de dire en fa Langue.

Son air, le fon de fa voix, \& fon action, quoiqu'il ne fit aucun gefte, me parurent a voir quelque chofe de noble $\&$ d'impofant, \& 8 il falloit que ce qu'il difoit, fût bien éloquent, puifque dépouillé dans la bouche de l'Interprete, qui étoit un Homme ordinaire, de tous les ornemens du Langage, nous en fûmes tous charmés. Je vous avouë mềme que, quand î. auroit parlé deux heures, je ne me ferois pas ennuyé un moment. Une autre preuve, que les beautés de fon Difcours ne venoient point de l'Interprete, c'eft que jamais cet Homme n'eût ofé prendre fur foi, tout ce qu'il nous dit. Je fûs même un peu furpris, qu'il osât répeter fi fidellement, qu'il faifoit, certaines chofes, qui ne devoient pas plaire au Commandant. Quand le Huron eut fini, ONanguicé, Chef $\&$ Orateur Pouteouatami, reprit en peu de mots, \& d'une maniere très-ingenieufe, tout ce que le Premier avoit expofé plus au long, \& conclut comme lui. Les Outaouais ne parlerent point, \& parurent approuver ce qu'avoiemt dit les autres.

La Conclufion fut, que les François étoient les maîtres de ne plus vendre d'Eau-de-vie aux Sauvages; qu'ils auroient très-bien fait de ne leur en avoir jamais vendu, \& il ne fe peut rien imaginer de plus fort, que ce que dit l'Orateur $\mathrm{Hu}-$ ron, en expofant les défordres, qu'a caufés cette Boifon, \& le tort, qu'elle a fait à toutes les Nations Sauvages. Le plus zelé Miffionnaire n'en auroit pas dit davantage: mais il ajoutta qu'ils y étoient tellement accoûtumés, quils ne pouvoient plus s'en paffer; d'où il étoit aifé de juger, qu'au défaut des François, ils s'adrefferoient aux Anglois. Quant à ce qui concernoit la Guerre des Outagamis, il déclara, qu'on ne pouvoit rien réfoudre, que dans un Confeil Géneral de tontes les Nations, qui reconnoiffent Ononthio (a) pour leur Pere; qu'elles conviendroient fans doute de la neceffité de cette Guerre, mais qu'elles auroient bien de la peine à fe fier. une feconde fois aux François; qui les ayant déja réunies, pour les aider à exterminer l'Ennemi commun, lui avoient accordé la paix, fans confulter leurs Alliés, \& fans qu'on pût ¿çavoir les raifons d'une telle conduite.

Le jour fuivant jallai vifiter les deux Bourgades Sauvages,

(a) C'eft le nom, que les Sauvages donnent au Gouverneur Général.

Quel en fut le réfulcat.

Juin.

Juin. reculcat. 
172 I. qui font voifines du Fort, \& je commençai par les Hurons: Juin. Je trouvai toutes les Matrones, parmi lefquelles étoit l'Ayeule vé les Hurons de Safteratfí, fort affligées de fe voir fi lontems privées des du Détroit.
fecours fpirituels. Bien des chofes, que jappris en même tems, me confirmerent dans la penfée, où j'étois déja, que des intérêts particuliers étoient les feuls obftacles à ce que défiroient ces bonnes Chrétiennes. Il faut cfperer que les derniers ordres du Confeil de la Marine leveront toutes ces oppofitions. M. de Tonti m'affûra qu'il-alloit y travailler efficacement (a).

Ceux, qui m'avoient conduit dans ce Village, m'affûrerent que fans les Hurons les autres Sauvages du Détroit mourroient de faim. Ce n'eft certainement pas la faute du Terrein, qu'ils occupent, pour peu qu'ils vouluffent le cultiver, ils y trouveroient au moins le néceffaire: la feule Pêche leur en fourniroit une bonne partie, \& elle ne demande pas un grand travail. Mais depuis qu'on leur a fait goûter de l'Eau-de-vie, ils ne fongent plus qu'à amaffer des Pelleteries pour avoir de quoi s'enyvrer. Le Huron plus fage, plus induftrieux, plus laborieux, plus prévoyant, \&x plus accoûtumé à la culture des Terres, penfe plus au folide, $\&$ par fon travail eft en état, non-feulement de fubfifter, fans avoir befoin de perfonne, mais encore de faire fubfifter les autres : ce qu'il ne fait pas à la vérité gratuitement, car parmi fes bonnes qualités, il ne faut pas compter le défintéreflement.

Réception,

Je fus encore mieux reçu des Pouteouatamis Infidéles, que qu'on lui fait des Hurons Chrétiens. Ces Sauvages font les plus beaux Homchez les pou- mes du Canada, ils font d'ailleurs d'un naturel fort doux , \&
reouatamis. nous les avons toujours eu pour Amis. Onanguicé, leur Chef, me traita avec une politeffe, qui me donna bien auffi bonne opinion de fon efprit, que le difcours, qu'il nous avoit fait dans le Confeil. Il eft véritablement Homme de mérite, \& Eouti-à-fait dans nos intérêts.

En repaffant par un Quartier du Village des Hurons, j’apperçus une troupe de ces Sauvages, qui paroiffoient fort animés au jeu; je m’approchai \& je vis qu'ils jouoient au Plat. C'eft celui de tous les jeux, qui attache le plus ces Peuples: ils en perdent quelquefois le repos, \& en quelque maniere la

(a) Les Hurons du Détroit ont enfin ob- $\mid$ parmi eux leur premiere ferveur. tenu un Miflionnaire, qui a renouvellé 
D'U N V OYA GE DE L'A MER I Q. LET. XVII. 26I taifon: ils y rifquent tout ce qu'ils ont, $\& \pi$ plufieurs ne le quittent, qu'après s'être mis prefque tout nuds, \& après avoir perdu tout ce quils avoient dans leurs Cabannes. On en a vû y engager leur liberté pour un tems. Cela prouve bien la paffion, car il n'eft point d'Hommes au monde plus jaloux de leur liberté, que nos Sauvages.

Le jeu du Plat, qu'on appelle auffi le jeu des Offelets, ne fe jouë qu'entre deux perfonnes. Chacun a fix ou huit Offelets, que je pris d'abord pour des noyaux d'Abricots : ils en ont la figure, \& font de même grandeur: mais en les regardant de près, je m’apperçus qu'ils étoient à fix faces inégales, dont les deux principales font peintes, l'une en noir, lautre en blanc tirant fur le jaune. On les fait fauter en l'air, en frappant la terre, ou la table, avec un Plat rond $\&$ creux, où ils font, \& qu'on fait pirouetter auparavant. Quand on n'a point de Plat, on fe contente de jetter en l'air les Offelets avec la main ; fi tous en tombant préfentent la même couleur, celui, qui a joué, gagne cinq points, la Partie eft en quarante, ' $\&:$ on défalque les points gagnés, à mefure que l'adverfaire en gagne de fon côté. Cinq Offelets d'une même couleur ne donnent qu'un point pour la premiere fois, mais à la feconde on fait rafle de tout. En moindre nombre on ne gagne rien.

Celui, qui gagne la Partie, continuë de jouer; le Perdant céde fa place à un autre, qui eft nommé par les Marqueurs de fa Partie. Car on fe partage d'abord, \& fouvent tout le Village s'intéreffe au jeu : quelquefois même un Village joüe contre un autre. Chaque Partie choifit fon Marqueur, mais il fe retire quand il veut, ce qui n'arrive, que quand la chofe tourne mal pour les fiens. A chaque coup, que l'on jouè, furtout, fi c'eft un coup décifif, il s'éleve de grands cris: les Joueurs paroiffent comme des forcenés, \& les Spectateurs ne font pas plus tranquilles. Les uns $\&$ les autres font mille contorfions, apoftrophent les Offelets, chargent d'imprécations les Génies de la Partie adverfe, \& tout le Village retentit de hurlemens. Si tout cela ne fait pas revenir la chanfe, les Perdans peuvent remettre ba Partie au lendemain, il ne leur en coûte que de faire à toute l'Affiftance un repas de peut de valeur.

On fe prépare enfuite pour retourner au combat, chacurs invoque fon Génie, \& jette en fon honneur du tabac dans.

1721 .

Juin.

Du Jeu da Plat ou des Cr(elets. 


\section{J O UR N A L H I S T O R I Q U E}

$172 \mathrm{I}$. le jour paroit, on fe remet au jeu; mais fi les Perdans fe font Juin. mis dans la tête que ce font les meubles de leứr Cabanne, qui leur ont porte malheur, ils commencent par les changer tous. Les grandes Parties durent ordinairement cinq ou fix jours, \& louvent la nuit même ne les interrompt pas. Cependant, comme tous les Affiftans, du moins ceux, qui font intéreffés au jeu, font dans une agitation, qui lès met hors d'eux-mêmes, qu'on fe querelle, qu'on fe bat, ce qui n'arrive jamais parmi les Sauvages, que dans ces occafions, \& dans l'yvrefle, on peut juger, fi à la fin de la Partie les uns $\&$ les autres ont befoin de repos.

UThage fut-

Il arrive quelquefois que ces Parties de jeu fe font par orperftitieux de ce jeu pour la hiálades. donnance du Médecin, ou à la priere d'un Malade : il ne faut pour cela qu'un rêve de l'un, ou de l'autre; ce rêve eft toujours pris pour un commandement de quelque Génie ; \& alors on fe prépare au jeu avec un très-grand foin. On s'affemble pendant plufieurs nuits pour s'eflayer, \& voir qui a la main plus heureufe. On confulte fon Génie, on jeûne, les Perfonnes mariées gardent la continence, \& le tout pour obtenir un fonge favorable. Tous les matins on raconte ceux, qu'oria eus, \& de toutes les chofes, qu'on a révées, \& qu'on simagine pouvoir porter bonheur, on en fait un amas, \& on les met dans de petits fachets, qu'ón porte fur foi. Si quelqu'un a la réputation d'être heureux, c'eft-à-dire, dans lè fens de ce Peuple, d'avoir un Génie familier plus puiffant, \& plus enclin à faire du bien, on ne manque point de le faire approcher de celui, qui tient le Plat. On va même quelquefois le cherchèr bien loin, \& fi la vieilleffe, ou quelqu'infirmité ne lui permettoit pas de marcher, on le porteroit fur fes épaules.

On a fouvent preffé les Miffionnaires de fe trouver à ces jeux, dans la perfuafion, où l'on eft, que leurs Génies tutélaires font les plus puiffans de tous. Il arriva un jour dans un Village Huron qu'une Malade ayant fait appeller un Jongleur, ce Charlatan lui ordonna le jeu du Plat, \& marqua un autre Village que le fien pour jouer. Elle envoya auffitôt demander au Chet de ce Village fon agrément ; il fut accordé, on joua, \& le jeu fini, la Malade fit aux Joueurs de grands remercimens de la guérifon, qu'ils lui avoient, difoit-elle, 
D'UN V OYA G E DE L'A M E R IQ. LET. XVII. 263 procurée. Il n'en étoit pourtant rien, au contraire elle étoit plus mal, mais il faut toujours paroître content, lors même qu'on a moins fujet de l'être.

La mauvaife humeur de cette Femme $\&$ de fes Parens tomba fur les Miffionnaires, qui avoient refufé d'affifter au jeu, quelque inftance, qu'on leurr eût faite pour les y engager, \& dans le chagrin de leur peu de complaifance en cette occafion, on leur reprocha que depuis leur arrivée dans ce Paýs, les. Génies des Sauvages n'avoient plus aucun pouvoir. Ces Religieux ne manquerent pas de profiter de cet aveu pour faire fentir à ces Intidéles la foibleffe de leurs Divinités, \& la fupériorité du Dieu des Chrétiens; mais outre que dans ces rencontres il eft rare qu'on foit affez bien difpofé pour entendre raifon, ces Barbares répondent froidement: "Vous avez " vos Dieux, \& nous avons les nôtres : c'eft un malheur pour " nous, qu'ils ne foient pas auffi puiffans que les vôtres.

Le Détroit eft une des Contrées du Canada, où un Botanifte pourroit faire plus de découvertes. J'ai déja obfervé que tout le Canada produit une grande quantité de Simples, qui ont de grandes vertus. On ne doute pas que les Néges n'y contribuent beaucoup, mais il y a ici une variété de terroir, qui jointe à la douceur du climat, $8 x$ à la liberté, qu'a le Soleil plus qu'ailleurs d'y échauffer la Terre, parce que le Pays eft plus découvert, donne lieu de croire que les Plantes y ont plus de force, qu'en aucun autre endroit.

Un de mes Conducteurs éprouvà dernierement la vertu d'une Herbe, qu'on rencontre par-tout, $8 x$ dont la connoiffance eft des plus néceffaires aux Voyageurs, non pas pour fes bonnes qualités, car je ne lui en ai encore vu attribuer aucune, mais parce qu'on ne fçauroit trop l'éviter. On l'appelle l'Herbe à la Puce, mais ce nom n'eft pas affèz expreffif pour marquer les effets, qu'elle produit. Ces effets font plus ou moins fenfibles, felon le tempéramment de ceux, qui la touchent: il en eft même, fur qui elle ne fait rien: mais les uns, en la regardant feulement, font attaqués d'une fiévre violente, qui dure plus de quinze jours, \& qui eft accompagnée d'une gale fort incommode, \& d'une grande demangeaifon par tout le Corps. Elle n'opere fur d'autres, que quand ils la touchent; \& alors la partie attaquée paroît comme toute couverte de Lépre. On en a vû, qui en avoient les mains toutes

De Herte à la Puce, $8 \mathrm{E}$ de fes effers, 


\section{JOUR NAL HISTORIQUE}

172 I. perduës. On n'y connoît point encore d'autre reméde, que Juin. la patience; au bout de quelque tems tout fe diffipe.

Des Citrons Il croît auffi au Détroit des Citroiniers en plein fol, dont du Détroit. les fruits ont la forme \& la couleur de ceux de Portugal, mais ils font plus petits, \& d'un goût fade : ils font excellens confits. La racine de cet Arbre eft un poifon mortel \& très-fubtil, $\&$ en même-tems un antidote fouverain contre la morfure des Serpens. Il faut la piler \& l'appliquer à l'inftant fur la playe : ce reméde eft prompt $\&$ immanquable.Des deux côtés du Détroit le Pays conferve, dit-on, toute fa beauté jufqu'environ dix lieuës dans la profondeur, après quoi on trouve moins d'Arbres fruitiers, \& moins de Prairies. Mais au bout de cinq ou fix lieuës, en tirant vers le Lac Erié au Sud-Oueft, on découvre d'immenfes Prairies, qui s'étendent plus de cent lieuës en tout fens, \& qui nourriffent une quantité prodigieufe de ces Bœufs, dont je vous ai déja parlé plus d'une fois.

Je fuis, \&c.

\section{DIX-HUITIEME LETTRE.}

Plufieurs traits du caractere, des ufages, $\mathcal{E}$ du gouvernement des Sauvages.

Au Détroit ce quatorziéme de Juin, 1721 .

NAD AME,

A P R E's avoir fermé ma derniere Lettre, \& l'avoir remife à une Perfonne, qui defcendoit à Quebec, je me difpofois moi-même à pourfuivre mon Voyage, \& je m'embarquai en effet le lendemain. Mais je n'ai pas été bien loin, \& $\mathrm{x}$ par le peu de précautions de ceux, qui me conduifent, me voici de retour au Fort de Pontchartrain, où je crains beaucoup d'être obligé de refter encore plufieurs jours. Ce font de ces contretems, aufquels il faut s'attendre avec les Voyageurs Canadiens, ils ne font jamais preffés, \& font fort négligens à pren- 
D'UN V OYA GE DE L'A MER IQ. LET. XVIII. 265 dre leurs mefures. Mais comme il faut tirer partie de tout, je vais profiter de ce retardement, pour commencer à vous entretenir du Gouvernement des Sauvages, \& de leur façon de fe conduire dans les Affaires. Cette connoiffance vous mettra plus en état de comprendre bien des chofes, que jaurai occafion de vous dire dans la fuite.

Je m'étendrai pourtant le moins que je pourrai fur ce fujet : premierement, parce que tout n'y eft pas fort intéreffant; en fecond lieu, parce que je ne veux rien vous écrire, qui ne foit appuyé fur de bons témoignages, \& qu'il n'eft pas aifé de trouver des perfonnes, dont la fincerité foit hors de toute atteinte, au moins d'exagération; ou qu'on ne puiffe foupçonner d'avoir trop légerement ajoûté foi , à tout ce qu'on leur a débité ; ou qui ayent enfin affez de difcernement, pour faifir les chofes dans leur vrai point de vûë ; ce qui demande un long féjour dans le Pays, \& une longue habitude avec fes Habitans. Je ne vous dirai donc rien de moi, fur cet article , \& cela m'empêchera de mettre beaucoup de fuite dans ce que je dirai : mais il ne vous fera pas difficile de raffembler, $\&$ de faire un tout affez régulier des traits, dont je parfemerai mes Lettres, à mefure, que j'en ferai inftruit.

Il faut convenir, Madame, que plus on voit nos Sauvages de près, \& plus on découvre en eux de qualités eftimables. La plûpart des Principes, qui fervent à regler leur conduite, les Maximes génerales, fur lefquelles ils fe gouvernent, \& le fond de leur Caractere, n'ont prefque rien, qui fente le Barbare. D'ailleurs les idées, quoiqu'entierement confufes, qui leur font reftées d'un Premier Etre, les veftiges prefque effacés du Culte Religieux, qu'ils paroiffent avoir autrefois rendu à cette Divinité fuprême ; \& les foibles traces, qu'on remarque, jufques dans leurs actions les plus indifférentes, de l'ancienne Croyance, \& de la Religion primitive, peuvent les remettre plus facilement qu'on ne croit, dans'le chemin de la Verité, \& donner à leur Converfion au Chriftianifme des facilités qu'on ne rencontre pas, ou qui font contre - balancées par de plus grands obftacles, dans les $\mathrm{Na}$ tions les plus civilifées. En effet l'expérience ne nous apprend - elle pas, que la Politeffe, les lumieres, les Maximes d'Etat, forment dans celles-ci un attachement $\&$ une prévention pour leur fauffe Croyance; que toute l'habileté, \& tout Tome III.

1721 .

Juin.

I.es Sauva ges du Canada font plus aifés à convertir, que les $\mathrm{Na}$ tions les plus policées. 
266 J O UR N A L HIST ORIQUE

I 72 I. le zele des Ouvriers Evangéliques, ont bien de la peine à Juin. détruire, \& qu'il faut que la Grace agiffe plus puiffamment fur des Infideles éclairés, que leur préfomption aveugle prefque toujours, que fur ceux, qui ne lui oppofent que des lumieres bornées. rale de géné- La plûpart des Peuples de ce Continent ont une forte de: Gouvernemast. Gouvernement Ariftocratique, dont la forme varie prefque à l'infini. Car encore que chaque Bourgade ait fon Chef indépendant de tous les autres de la même Nation, $8 x$ de qui les: Sujets dépendent en très peu de chofes, néanmoins il ne fe conclut aucune Affaire de quelque importance; que par l'avis des Anciens. Vers l'Acadie, les Sagamos étoient plus abfolus, \& il ne paroît pas quils fuffent obligés, comme les. Chefs le font prefque partout ailleurs, de faire des libéralités aux Particuliers. Au contraire, ils tiroient une efpece de Tribut de leurs Sujets, \& ne mettoient nullement leur grandeur, à ne fe rien réferver pour eux. Mais il femble, que la difperfion de ces Sauvages Acadiens , \& peut-être aufli leur Commerce avec les François, ont apporté beaucoup de changement à leur ancienne façon de fe gouverner, dont LESCARBot \& Champlain font les feuls, qui nous ayent donné quelque détail.

Divifion des Nations en Tribus.

Plufieurs Nations ont chacune trois Familles, ou Tribus. principales, auffi anciennes, à ce quỉl paroît, que leur Origine. Elles ont néanmoins une même Souche, \& il y en a du moins une, qui eft regardée, comme la premiere, qui a une forte de prééminence fur les deux autres, où l'on traite de Freres, ceux de cette Tribu; au lieu qu'entre elles, on ne 1e traite que de Coufins. Ces Tribus font mêlées, fans être confonduës, chacune a fon Chef féparé dans chaque Village ; \& dans les Affaires, qui intereffent toute la Nation, ces. Chefs fe réuniffent pour en déliberer. Chaque Tribu porte le nom d'un Animal, \& la Nation entiere a auffi le fien, dont elle prend le nom, \& dont la Figure eft fa Marque, ou fi l'on veut fes Armoiries. On ne figne point autrement les Traités, qu'en traçant ces Figures; fi ce n'eft que des raifons particulieres en faffent fubitituer d'autres.

Ainfi la Nation Huronme, eft la Nation du Porc-Epi : fa premiere Tribu porte le nom de l'Ours, ou du Chevreüil, les Auteurs varient fur cela; les deux autres ont pris pour leurs: 
D'UN V OYA GE DE L'A MER IQ. LET. XVIII. 267 Animaux le Loup, \& la Tortuë; enfin chaque Bourgade a auffi le fien, \& c'eft apparemment cette variété, qui a déforienté les Auteurs des Relations. D'ailleurs il eft bon d'obferJuin. ver qu'outre ces diftinctions de Nations, de Tribus, de Bourgades par les Animaux, il y en a encore d'autres, qui ont leur fondement dans quelque ufage, ou dans quelque évenement. particulier. Par exemple, les Hurons Tionnontatez, qui font de la premiere Tribu, s'appellent ordinairement la Nation du Petun , \& nous avons un Traité, où ces Sauvages, qui étoient alors à Michillimakinac, ont mis pour leur marque la figure d'un Caftor.

La Nation Iroquoife a les mêmes Animaux, que la Huronne, dont elle paroît être une Colonie, avec cette difference néanmoins, que la Famille de la Tortuë y eft divifée en deux, qu'on appelle la grande \& la petite Tortuë. Le Chef de chaque Famille en porte le nom, \& dans les actions publiques on ne lui en donne point d'autre. Il en eft de même du Chef de la Nation, \& de celui de chaque Village. Mais outre ce nom, qui n'eft, pour ainfi dire, que de repréfentation, ils en ont un autre, qui les diftingue plus particuliérement, \& qui eft comme un titre de dignité. Ainfi l'un eft appellé le plus noble, l'autre, le plus ancien, \&xc. Enfin ils en ont un troifiéme, qui leur eft perfonnel. Mais je croirois affez que cela n'eft en ufage que dans les Nations, où la qualité de Chef eft héréditaire.

Ces impofitions de titres fe font toujours avec de grandes cérémonies; le nouveau Chef, ou, s'il eft trop jeune, celui, qui le repréfente, doit faire un feftin $\&$ des préfens, prononcer l'éloge de fon Prédéceffeur, \& chanter fa chanfon. Il y a néanmoins tel nom perfonnel fi célébre, que nul n'ofe fe l'approprier, ou qui eft du moins fort lontems fans être relevé; quand on le fait, cela s'appelle refufciter celui, qui le portoit.

Dans le Nord, \& par-tout, où regne la Langue Algonquine, la dignité de Chef eft élective; mais toute la cérémonie de l'élection \& de l'inftallation fe réduit à des feftins, ac-Election des compagnés de danfes \& de chants. Le Chef élû ne manque auffi jamais de faire le panégyrique de celui, dont il prend la place, \& d'invoquer ion Génie. Parmi les Hurons, où cette dignité eft héréditaire, la fucceffion fe continue par les Fem. mes, enforte qu'à la mort du Chef ce n'eft pas fon Fils, qui lui fuccéde, mais le Fils de fa Soeur, ou à fon défaut, fon 


\section{J O UR N A L H IST ORIQUE}

I72 I. plus proche Parent en ligne féminine. Si toute une Branche Juin vient à s'éteindre, la plus noble Matrone de la Tribu, ou de la Nation choifit le Sujet, qui lui plaît davantage, \& le déclare Chef.

Deleur pou- Il faut avoir un âge mûr pour gouverner, \& $\mathrm{fi}$ le Chef hévoir.

réditaire n'y eft pas encore parvenu, on lui donne un Régent, qui a toute l'autorité, mais qui l'exerce fous le nom du Mineur. En général ces Chefs ne reçoivent pas de grandes marques de refpect, \& s'ils font toujours obéis, c'êft qu'ils fçavent jufqu'où ils doivent commander. Il eft vrai même qu'ils prient ou propofent plutôt qu'ils ne commandent, \& que jamais ils ne fortent des bornes du peu d'autorité, qu'ils ont. Ainfi c'eft la raifon, qui gouverne, \& le gouvernement eft d'autant plus efficace, que l'obéiffance eft plus libre, \& qu'on n’a pas à craindre qu'il ne dégénere en tyrannie.

Des Afiftans,

Il y a plus, chaque Famille a droit de fe choifir un Con- uConfeillers. feiller, \& un Affiftant du Chef, qui doit veiller à fes intérêts, \& fans l'avis duquel le Chef ne fçauroit rien entreprendre. Ces Confeillers font fur-tout obligés d'avoir l'œil fur le thréfor public, \& c'eft particuliérement à eux, qu'il appartient d'en marquer l'emploi. Leur réception fe fait dans un Confeil général; mais on n'en donne point avis aux Alliés, comme on le fait aux élections, \& $\mathrm{x}$ aux inftallations des Chefs. Dans les Nations Huronnes, ce font les Femmes, qui nomment les Confeillers, \& fouvent elles choifffent des perfonnes de leur Sexe.

DuCorpsdes Ce Corps des Confeillers, ou Affiftans eft le premier de Anciens.

tous; le fecond eft celui des Anciens, c'eft-à-dire, de tous ceux, qui ont atteint l'âge de maturité. Je n'ai pu fçavoir quel eft précifément cet âge. Le dernier eft celui des Guerriers. Il comprend tous ceux, qui font en état de porter les armes. Ce Corps a fouvent à fa tête le Chef de la Nation, ou celui de la Bourgade; mais il faut qu'auparavant il fe foit diftingué par quelque action de valeur; finon il eft obligé de fervir en qualité de Subalterne, c'eft-à-dire, de fimple Soldat, car il n'y a point de grades dans la Milice des Sauvages.

Des Chefs A la vérité un grand Parti peut avoir plufieurs Chefs, parce de Guerre. qu'on donne ce titre à tous ceux, qui ont déja commandé; mais ils n'en font pas moins foumis au Commandant du Parti, efpece de Général fans carątere, fans autorité réelle, qui ne 
D'UN V OYA GE DE L'A MER IQ. LET. XVIII. 269 peut ni récompenfer, ni punir, que fes Soldats peuvent quitter, quand il leur plaît, fans qu'il ait rien à leur dire, \&\& qui néanmoins n'eft prefque jamais contredit : tant il eft vrai que parmi des Hommes, qui fe conduifent par la raifon, \& qui font guidés par l'honneur $\&$ le zéle pour la Patrie, l'indépendance ne détruit point la fubordination, \& que fouvent l'obéiflance libre $\&$ volontaire eft toujours celle, fur laquelle on peut plus fûrement compter. Au refte les qualitez requifes pour un Chef de Guerrefont, d'être heureux, brave, \& défintéreffé. Il n'eft pas étonnant qu'on obéiffe fans peine à un Homme, en qui l'on reconnoît ces trois caradteres.

Les Femmes ont la principale autorité chez tous les Peuples de la Langue Huronne, fi on en excepte le Canton Iroples de la Langue Huronne, fi on en excepte le Canton Iro- Femmes dans
quois d'Onneyouth, où elle eft alternative entre les deux tions. Sexes. Mais $\mathrm{f}$ tel eft le droit, la pratique $\mathrm{y}$ eft rarement conforme. Dans le vrai les Hommes ne parlent aux Femmes, que de ce qu'ils veulent bien qu'elles fçachent, $\&$ rarement une affaire importante leur eft communiquée, quoique tout fe fafle en leur nom, 8 que les Chefs ne foient que leurs Lieutenans. Ce que je vous ai dit, Madame, de l'Ayeule du Chef héréditaire des Hurons du Détroit, qui n'avoit jamais pû obtenir un Miffionnaire pour fa Bourgade, eft une bonne preuve que l'autorité réelle des Femmes fe réduit à bien peu de chof́es. On m'a pourtant affûré que ce font encore elles, qui délibérent les premieres fur ce qu'on propofe dans le Confeil, \& qu'elles donnent enfuite le réfultat de leur délibération aux Chéfs, qui en font le rapport au Confeil Général, compofé des Anciens; mais il y a bien de l'apparence que tout cela fe fait pour la forme $8 x$ avec les reftrictions, que je viens de dire. Les Guerriers confultent auffi entre eux fur tout ce qui eft de leur reffort, mais ils ne peuvent rien conclure d'important, ni qui interefle la Nation ou la Bourgade. Tout doit être examiné $\&$ arrêté dans le Confeil des Anciens, qui juge en derniere inftance.

Il faut convenir qu'on procéde dans ces Aflemblées avec une fageffe, une maturité, une habileté je dirai même, sagefre ds communément une probité, qui auroient fait honneur à l'Aréopage d'Athênes, \& $\&$ au Sénat de Rome dans les plus beaux. jours de ces Républiques. C'eft qu'on n'y conclut rien avec précipitation, \& que les grandes paffions, qui ont fi fort altéré

I 721 .

Juin,

Pouvoir des tons. 
270 J OUR N A HIST ORIQUE

I 72 la politique, même parmi les Chrétiens, n'ont point encore 72. prévalu dans ces Sauvages fur le bien public. Les Intéreffés ne Juin. laiffent pas de faire jouer bien des refforts, \& d'employer un manége, dont on auroit peine à croire capables des Barbares, pour venir à bout de leurs deffeins. Ileft encore vrai qu'ils ont tous au fouverain dégré le grand art de cacher leur marche : mais pour l'ordinaire la gloire de la Nation, \& les motifs d'honneur font les principaux mobiles de toutes leurs Entreprifes. Ce qu'on ne peut excufer en eux, c'eft que le plus fouvent ils mettent leur honneur à fe venger, \& qu'ils ne donnent point de bornes à leur vengeance. Défaut, que le feul Chriftianifme peut bien corriger, \& que toute notre politeffe \& notre Religion ne corrigent pas toujours.

Des Ora. Chaque Tribu a fon Orateur dans chaque Bourgade, \& il teurs,

n'y a guéres que ces Orateurs, qui ayent droit de parler dans les Confeils publics, \& dans les Affemblées générales. Ils parlent toujours bien, \& à propos. Outre cette éloquence naturelle, que nul de ceux, qui les ont pratiqués, ne leur contefte, ils ont une connoiffance parfaite des intérêts de ceux, qui employent leur miniftere, $\&$ une dextérité à mettre leur bon droit dans tout fon jour, qui ne peut aller plus loin. En quelques occafions les Femmes ont un Orateur, qui parle en leur nom, \& comme s'il étoit uniquement leur Interpréte.

Des intérêts Des Peuples, qu'on peut dire ne poffeder rien, ni en public,

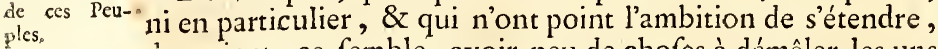
devroient, ce femble, avoir peu de chofes à démêler les uns avec les autres. Mais l'efprit de l'Homme naturellement inquiet ne fçauroit demeurer fans action, \& il eft ingénieux d̀ fe procurer de quoi s'occuper. Ce qui eft certain, c'eft que nos Sauvages négocient fans ceffe, \& qu'ils ont toujours quelque affaire fur le tapis. Ce font des Traités à conclure, ou à renouveller, des ofres de fervice, des civilités réciproques, des alliances, qu'on ménage, des invitations à la Guerre, des complimens fur la mort d'un Chef, ou d'une Perfonne confidérable. Tout cela fe fait avec une dignité, une attention, jofe même dire, une capacité digne des affaires les plus importantes; \& elles le font quelquefois plus qu'il ne paroît; car ceux, qu'on députe pour cela ont prefque toujours des inftructions fecrettes, \& le motif apparent de leur députa- 
D'UN V OYA G E DE L'A MERIQ. LET . XVIII. 271 tion n'eft fouvent qu'un voile, qui en cache un autre plis férieux.

La Nation du Canada, qui depuis deux fiécles y fait la pre1721 .

Juin. miere figure, eft l'Iroquoife. Ses fuccès à la guerre lui ont Iroquois. donné fur la plûpart des autres une fupériorité, qu'aucune d'elle n'eft plus en état de lui difputer, \& de pacifique qu'elle étoit autrefois, elle eft devenuë fort inquiette \& fort intriguante. Mais rien n'a plus contribué à la rendre formidable, que l'avantage de fa fituation, qu'elle fçut bientôt reconnồtre , $8 \tau$ dont elle a très-bien fçu profiter. Placée entre nous $\&$ les Anglois, elle a compris d'abord que les uns $\&$ les autres feroient obligés de la ménager, \& il eft vrai que la principale attention des deux Colonies, depuis leur Etabliffement, a été de la gagner, ou de l'engager au moins à demeurer neutre. Perfuadée de fon côté que, fi l'une des deux Nations prévaloit fur l'autre, elle en feroit bientôt opprimée, elle a trouvé le fecret de balancer leurs fuccès, \& fi l'on fait réflexion que toutes fes forces réunies n'ont jamais monté qu’à cinq ou fix mille Combattans, \& que depuis lontems siles ont diminué de plus de moitié, on conviendra qu'elle n'a pu y fuppléer que par beaucoup d'habileté $\&$ d'adreffe.

Pour ce qui eft des Particuliers, \& de l'intérieur des Bourgades, les affaires s'y réduifent à très-peu de chofes, \& font bientôt terminées. L'autorité des Chefs ne s'étend point, ou s'étend rarement jufques-là, \& généralement parlant ceux, qui ont quelque crédit, ne font occupés que du Public. Une feule affaire, quelque peu importante qu'elle foit, eft lontems en délibération; tout fe traite avec beaucoup de flegme \& de lenteur, \& rien ne fe décide, qu'on n'ait entendu tous ceux, qui veulent $\mathrm{y}$ entrer. Si l'on a fait fous main quelque préfent $\grave{a}$ un Ancien pour s'affurrer de fon fufrage, on eft fûr de l'obte.nir, dès que le préfent eft accepté. Il eft prefque inoui qu'un Sauvage ait manqué à un engagement de cette forte, mais il ne le prend pas aifément, \& jamais il ne reçoit des deux mains。 Les Jeunes Gens entrent de bonne heure en connoiffance des. affaires, ce qui les rend férieux $\&$ mûrs dans un âge, où nous fommes encore enfans; cela les intéreffe dès leur premiere jeuneffe au bien public, \& leur infpire une émulation, qu'on a grand foin de fomenter, \& dont il n'eft rien, qu'on ne puife fe promettre.

Du gouvernement des Villages. 
1721. Le plus grand défaut de ce Gouvernement, c'eft qu'il n'y a Juin. prefque point de Juftice Criminelle parmi ces Peuples; à la Ses Défauts. verité, ce défaut n'a point dans ce Pays les mêmes fuites, qu'il auroit parmi nous; le grand reffort de nos paffions, \& la fource principale des défordres, qui troublent le plus la Societé Civile, c'eft-à-dire, l'interêt, n'ayant prefque point de force fur des Gens, qui ne fongent point à théfaurifer, \& s'embarraffent fort peu du lendemain.

On peut encore leur reprocher avec juftice la maniere, dont ils élevent leurs Enfans : ils ne fçavent ce que c'eft', que de les châtier ; tant qu'ils font petits, on dit qu'ils n'ont point de raifon, \& les Sauvages ne font point dans le principe, que la punition fait venir le Jugement; quand ils font dans un âge à pouvoir raifonner, on prétend qu'ils font maîtres de leurs actions, \& qu'ils n'en doivent répondre à perfonne. On pouffe ces deux Maximes, jufquà fe laiffer maltraiter par des Yvrognes, fans même fe défendre, de peur de les bleffer: Pourquoi leur faire du mal, difent-ils, quand on veut leur montrer le ridicule de cette conduite, ils ne fçavent ce qu'ils font.

En un mot, ces Amériquains font parfaitement convaincus, que l'Homme eft né libre, qu'aucune Puiffance fur la Terre n’a droit d'attenter à fa liberté, \& que rien ne pourroit le dédommager de fa perte. On a même eu bien de la peine à détromper fur cela les Chrétiens, \& à leur faire entendre que, par une fuire de la corruption de notre Nature, qui eft l'effet du Peché, la liberté effrenée de faire le mal differe peu d'une efpece de neceffité de le commettre, vû la force du penchant, qui nous y porte; \& que la Loi, qui nous retient, nous rapproche de notre premiere liberté, en paroiffant nous la ravir: Heureufement pour eux, l'expérience ne leur fait pas fentir, fur bien des articles effentiels, toute la vivacité de ce penchant, qui produit ailleurs tant de crimes. Leurs connoiffances étant plus bornées que les nôtres, leurs défirs le font auffi davantage : réduits au fimple néceffaire, auquel la Providence a fuffifamment pourvû, à peine ont - ils l'idée du fuperflu.

Après tout , c'eft un grand défordre que cette tolérance, $\&$ cette impunité ; c'en eft un aufi, que ce défaut de fubordination, qui fe remarque dans le Public, \& encore plus dans 
D'UN V OYA GE DE L'A MERIQ. LET. XVIII. 273

le Domeftique, où chacun fait ce qu'il veut : où le Pere, la Mere, \& les Enfans vivent fouvent comme des perfonnes raffemblées par hazard, \& qu'aucun lien n'unit entre eux ; où de jeunes gens traitent des affaires de la Famille, fans en rien communiquer à leurs Parens, non plus que fi c'étoient des Etrangers; où les Enfans font élevés dans une indépendance entiere ; \& où on s'accoutume de bọnne heure à n'écouter, ni la voix de la Nature, ni les plus indifpenfables devoirs de la Societé.

Si dans les Nations les plus fagement gouvernées, \& qui font retenuës par le frein d'une Religion toute fainte, on ne laiffe pas de voir quelquefois de ces Monftres, qui deshonorent l'humanité, ils y font du moins horreur, \& les Loix les répriment, mais ce qui n'eft que le crime d'un Particulier, quand il eft fuivi du châtiment, devient le crime de la Nation, qui le laiffe impuni, comme le parricide même l'ent, parmi les Sauvages; y fut-il encore plus rare, qu'il ne l'eft, cette impunité eft une tache, que rien ne peut laver, \& qui fent tout-à-fait la Barbarie. Il y a pourtant en tout ceci quelexceptions, dont je parlerai bientôt; mais en géneral, lefprit de nos Sauvages eft tel.

Non-feulement ils font perfuadés qu'une perfonne, qui n'ert pas en fon bon fens, n'eft point réprehenfible, ou du moins ne doit pas être punie ; mais ils s'imaginent encore, qu'il eft indigne d'un Homme, de fe défendre contre une Femme, ou contre un Enfant ; bien entendu apparemment, lorfqu'il n'y va point de la vie, ou qu'il n'y a point de rifque d'être eftropié, encore prend-on alors, s'il eft poffible, le parti de fuir. Mais qu'un Sauvage en tuë un autre de fa Cabanne, s'il étoit Yvre, \& fouvent fait - on femblant de l'être, quand on veut faire de femblables coups, on fe contente de plaindre \& de pleurer le mort ; c'eft un malheur, dit-on, le Meurtrier ne f̧çavoit pas ce qu'il faifoit.

Sil étoir de fang froid, on fuppofe aifément, quili avoit de bonnes raifons, pour en venir à cette extremité. S'il eft évident qu'il n'en avoit point, c'eft à ceux de fa Cabanne, comme les feuls intereffés, à le châtier; ils peuvent le faire mourir, mais ils le font raremént, \& s sils le font, c'eft fans aucune forme de Juftice; de forte que fa mort a moins l'air d'une punition légitime, que d'une vengeance d'un ParticuTome III.

1721 . Juin.
Principes, fur quoi elle eft établie. 
274 JOURNAL HIST ORIQUE.

1721 . lier; quelquefois un Chef fera bien aife de profiter de l'occaJuin fion de fe défaire d'un mauvais Sujet. En un mot, le crime Juin. n'eft point puni d'une maniere, qui fatisfaffe à la Juftice, $\& x$ qui établiffe la sûreté \& la tranquillité publiques.

Un Affaflinat, qui interefferoit plufieurs Cabannes, auroit: cependant toujours des fuites fâcheufes, fouvent il n'en faut pas davantage pour mettre en combuftion toute une Bourgade, \& même toute une Nation. C'eft pourquoi dans ces. rencontres le Confeil des Anciens ne néglige rien pour accommoder de bonne heure les Parties, \& s'il en vient à bout, c'eft ordinairement le Public, qui fait les Préfens, \& toutes les démarches néceffaires auprès de la Famille offenfée. La prompte punition du Coupable finiroit d'abord toute l'affaire, \& $\mathrm{f}$ les Parens du Mort, peuvent l'avoir en leur puiffance, il leur eft permis d'en faire ce qu'ils veulent; mais fa Cabanne croit qu'il n'eft pas de fon honneur de le facrifier, \& fouvent le Village, ou la Nation, ne juge pas à propos de l'y contraindre.

De quelle J'ai lû dans une Lettre du P. de Brebeuf, qui a lontems maniere les Hurons puniffent l'Afraflinat. vécu parmi les Hurons, que ces Sauvages avoient accoutumé de punir les Affaffins, en cette maniere. Ils étendoien: le corps mort fur des Perches, au haut d'une Cabanne, \& le Meurtrier étoit obligé de fe tenir plufieurs jours de fuite immédiatement au deffous, \& de recevoir tout ce qui découloit de ce Cadavre, non - feulement fur foi, mais encore fur fon manger, qu'on mettoit auprès de lui, à moins que par un préfent confidérable, fait à la Cabanne du Défunt, il n’obtînt de garantir fes Vivres de ce Poifon. Mais le Miffionnaire ne dit point, fi cela fe faifoit par Autorité Publique, ou fi c'étoit feulement une Réprefaille, dont ufoient les Intereffés, quand ils pouvoient avoir l'Affaffin en leur puiffance.

Quoiqu'il en foi , le moyen le plus ufité parmi tous les Sauvages pour dédommager les Parens d'un Homme, qui a été affaffiné , c'eft de le remplacer par un Prifonnier de Guerre : alors ce Captif eft prefque toujours adopté : il entre dans tous les droits du Défunt, \& fait bientôt oublier celui, dont il occupe la place. Il eft néanmoins quelques crimes odieux, qui font fur le champ punis de mort, du moins parmi quelques Nations, tels font les Maléfices.

Punition des Magiciens.

Quiconque en eft foupçonné, n'êt en sûreté nulle part 3 
D'U N VOYA GE DE L'A MER IQ. LET. XVIII. 275 on lui fait même fubir, quand on s'eft faifi de lui, une forte de queftion, pour l'obliger à nommer fes Complices, après quoi il eft condamné au Supplice des Prifonniers de Guerre ; mais on demande auparavant le confentement de fa Famille, qui n'oferoit le refufer. Les moins criminels font affommés, avant que d'être brûles. On traite à peu près de même, ceux qui deshonorent leurs Familles, \& pour l'ordinaire, c'eft la Famille même, qui en fait juftice.

Parmi les Hurons, qui étoient fort enclins à dérober, \& qui le faifoient avec une dexterité, dont nos plus habiles Filoux fe feroient honneur, il étoit permis, quand on avoit découvert le Voleur, non-feulement dé lui reprendre ce quil avoit pris, mais encore d'enlever tout ce qui étoit dans fa Cabanne, \& de le dépouiller tout nud, lui , fa Femme \& fes Enfans, fans quilis puffent faire la moindre réfiftance. D'ailleurs, pour éviter toutes les conteftations, qui pouvoient naitre à ce fujet, on étoit convenu de certains points dont on ne s'écartoit jamais. Par exemple, toute chofe trouvée, n’y eut-il qu'un inftant, qu'elle eût été perduë, étoit à celui, qui l'avoit trouvée, pourvû que celui, à qui elle étoit auparavant, ne l'eût point déja reclamée. Mais pour peu qu'on remarquât de la fupercherie de part du Prenier, on l'obligeoit de reftituer; ce qui occafionnoit quelquefois des diffenfions affez difficiles à terminer : Voici un trait affez fingulier en ce genre.

Une bonne Vieille n'avoit pour tout bien au monde, qu'un Collier de Porcelaine, qui valoit environ dix Ecus de notre Monnoye, \& elle le portoit partout avec elle, enfermé dans un petit Sac. Un jour qu'elle travailloit aux Champs, elle avoit fufpendu fon Sac à un Arbre; une autre Femme, qui s'en apperçut, \& qui avoit grande envie de lui efcamoter fon Collier, crut l'occafion favorable de s'en faifir, fans qu'on pût l'accufer de Vol : elle ne le perdit point de vûë, \& au bout d'une heure ou deux, la Vieille étant paffée dans le Champ voifin, elle courut à l'Arbre, prit le Sac, \& fe mit à crier, qu'elle avoit fait une bonne trouvaille. La Vieille d̀ ce cri tourne la tête, \& dit que ce Sac lui appartient, que c'eft elle, qui l'a fufpendu à l'Arbre, qu'elle ne l'a ni perdu, ni oublié, \& que fon intention étoit de le reprendre à la fin de fon travail; fa Partie lui répond, qu'on ne juge pas des

Reglement pour leschofes trouvées. Trait fingu-
lier a l'occa-
fion d'une cho-
fe trouvée. Trait fingu-
lier à locca-
fion diune cho.
fe trouvée. Trait fingu-
lier à locca-
fion diune cho.
fe trouvée. Trait fingu-
lier à locca-
fion diune cho.
fe trouvée.

Juin. touress 


\section{J O UR NA L H IS T ORIQUE}

I 72 I. intentions, \& qu'étant fortie de fon Champ, fans avoir repris fon Sac, elle étoit cenfée l'avoir oublié.

Juin.

Après bien des conteftations entre ces deux Femmes, qui ne fe dirent pourtant pas un mot défobligeant, l'affaire fut portée devant un Arbitre, qui fut le Chef du Village, \& dont Cenfibles au point d'honreur. voici quelle fut la décifion: "A juger dans la rigueur, dit-il, le Sac appartient à celle, qui l'a trouvé; mais les circonftances font telles, que, fi cette Femme ne veut pas être taxée d'avarice, elle le doit rendre à celle, qui le réclame, $8 \times$ fe contenter de quelque petit préfent, que celle-ci ne peut fe difpenfer de lui faire ". Les deux Parties acquiefcerent à ce Jugement; $\&$ il eft bon d'obferver que la crainte d'être notée d'avarice a bien autant de pouvoir fur l'efprit des Sauvages, qu'en auroit la crainte du châtiment, \& qu'en général ces Peuples fe conduifent beaucoup plus par les principes d'honneur, que par tout autre motif.

Ce que je vais vous ajoûter, Madame, vous en donnera une nouvelle preuve. J'ai dit plus haut que pour empêcher les fuites d'un meurtre, le Public fe charge de faire les foumiffions pour les coupables, \& de dédommager les Intéreffés : croiriez-vous bien que cela même a plus de force pour prévenir ces défordres, que les Loix les plus féveres? Rien n'eft pourtant plus vrai: car comme ces fatisfactions coûtent beaucoup à des Hommes, dont la fierté paffe tout ce qu'on en peut dire, le Criminel eft plus fenfible à la peine, où il voit le Public à fon fujet, qu'il ne le feroit à la fienne propre, \& le zéle de l'honneur de la Nation retient beaucoup plus puiffamment ces Barbares, que ne pourroit faire la crainte de la mort \& des fupplices.

D'ailleurs il eft certain que l'impunité n'a pas toujours regné parmi eux, autant qu'elle a fait depuis, \& nos premiers Miffionnaires ont encore trouvé des traces de l'ancienne rigueur, avec laquelle ils fçavoient réprimer les crimes. Le vol en particulier a toujours été regardé comme une tache, qui déshonnoreroit une Famille, \& chacun étoit en droit d'en effacer la honte avec le fang du Coupable. Le Pere de Brebœuf apperçut un jour un jeune Huron, qui affommoit une Fille; il courut à lui pour l'arrêter, \& lui demanda ce qui le portoit à cette " violence. “ C'eft ma Sœur, lui répondit le Sauvage, elle a "volé, je veux expier par fa mort l'affront, qu'elle m'a fait * 


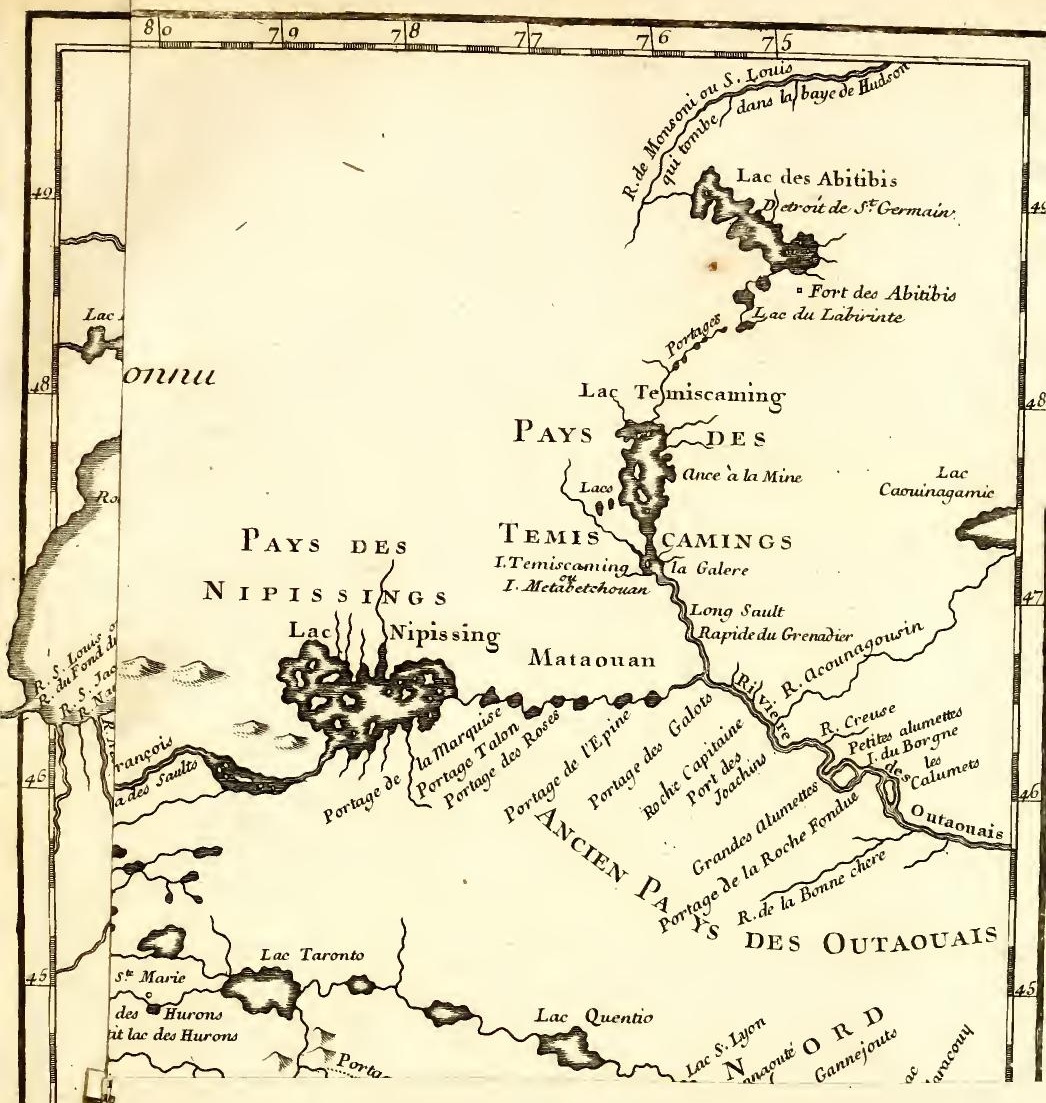




\section{J O U R NA L HISTORIQU E}

I 721 . intentions, \& qu'étant fortie de fon Champ, fans avoir repris Juin. fon Sac, elle étoit cenfée l'avoir oublié.

Après bien des conteftations entre ces deux Femmes, qui ne fe dirent pourtant pas un mot défobligeant, l'affaire fut portée devant un Arbitre, qui fut le Chef du Village, \& dont. " voici quelle fut la décifion: "A juger dans la rigueur, dit-il, " le Sac appartient à celle, qui l'a trouvé; mais les circonftances " font telles, que, fi cette Femme ne veut pas être taxée d'ava" rice, elle le doit rendre à celle, qui le réclame, \& fe conten" ter de quelque petit préfent, que celle - ci ne peut fe difpenfer " de lui faire ". Les deux Parties acquiefcerent à ce Jugement; $\&$ il eft bon d'obferver que la crainte d'être notée d'avarice a bien autant de pouvoir fur l'efprit des Sauvages, qu'en auroit la crainte du châtiment, \& qu'en général ces Peuples fe conduifent beaucoup plus par les principes d'honneur, que par tout autre motif.

Combien les Ce que je vais vous ajoûter, Madame, vous en donnera Sauvages font Senfibles au point d'honmeur. une nouvelle preuve. J'ai dit plus haut que pour empêcher les fuites d'un meurtre, le Public fe charge de faire les foumiffions pour les coupables, \& de dédommager les Intéreffés : croiriez-vous bien que cela même a plus de force pour prévenir ces défordres, que les Loix les plus féveres? Rien n'eft pourtant plus vrai: car comme ces fatisfactions coûtent beaucoup à des Hommes, dont la fierté paffe tout ce qu'on en peut dire, le Criminel eft plus fenfible à la peine, où il voit le Public à fon fujet, qu'il ne le feroit à la fienne propre, \& le zéle de l'honneur de la Nation retient beaucoup plus puiffamment ces Barbares, que ne pourroit faire la crainte de la mort \& des fupplices.

D'ailleurs il eft certain que l'impunité n'a pas toujours regné parmi eux, autant qu'elle a fait depuis, \& nos premiers Miffionnaires ont encore trouvé des traces de l'ancienne rigueur, avec laquelle ils fçavoient réprimer les crimes. Le vol en particulier a toujours été regardé comme une tache, qui déshonnoreroit une Famille, \& chacun étoit en droit d'en effacer la honte avec le fang du Coupable. Le Pere de Brebouf apperçut un jour un jeune Huron, qui affommoit une Fille; il courut à lui pour l'arrêter, \& lui demanda ce qui le portoit à cette " violence. “ C'eft ma Sœur, lui répondit le Sauvage, elle a " volé, je veux expier par fa mort l'affront, qu'elle m’a fait * 
D'UN VOYAGE DE L'A MERIQ. LET. XIX. 277 $\&$ à̀ toute notre Famille „. On me demande ma Lettre, \& je finis en vous affûrant que je fuis, \&c.

$172 \mathrm{I}$ Juin.

\section{DIX-NEUVIEME LETTRE.}

Voyage du Détroit à Michillimakinac. Defcription du Pays. Du Mariage des Sauvages.

A Michillimakinac, ce trentiéme de Juin, 1721 .

MADAME,

$\mathrm{C}_{\mathrm{E}}$ fut le dix-huitiéme de ce mois que je partis enfin tout de bon du Fort de Pontchartrain du Détroit, un peu avant le coucher du Soleil. A peine avois-je fait une lieuë qu'un orage accompagné d'un déluge de Pluye, me contraignit de gagner la Terre bien mouillé, \& nous paffàmes la nuit fort mal à notre aife : le lendemain tout ce que je pus faire, fut de traverfer le Lac de Sainte Claire, cette traverfe n'eft cependant que de quatre lieuës. Le Pays me parut bon des deux côtés. A moitié chemin on laiffe fur la gauche une Riviere, qui a bien un arpent de large à fon embouchure; on l'a nommée la Riviere des Hurons, parce que des Sauvages de cette Nation s'y réfugierent pendant la guerre des Iroquois. Sur la droite, \& prefque vis-à-vis, il y en a une autre, dont l'entrée eft une fois plus large, \& qu'on remonte quatre-vint. lieuës fans rencontrer aucun Rapide, ce qui eft rare dans les. Rivieres de ce Pays : on n'a pu me dire fon nom.

La route depuis le Fort du Détroit jufqu’à la fin de la traverfe, eft Eft - Nord-Eft : de - là on tourne au Nord par l'Eft jufqu'au Sud pendant quatre lieuës, au bout defquelles on trouve à main droite un Village de Miffiffaguez, placé fur un terrein fertile, à l'entrée de très-belles Prairies, \& dans la plus agréable fituation, qui fe puiffe voir. De-là jufqu'au Lac Huron, on compte douze lieuës, \& le Pays eft toujours charmant. C'eft un Canal magnifique, tiré au cordeau, bordé de Bois de hautes Futayes, féparées par de belles Prairies, \&

Départ dix. Détroit. 


\section{JOURNAL HIS TOR IQ UE}

172 I. femées d'Ifles, dont quelques-unes font affez grandes. Ony fait toujours le Nord-quart Nord-Eit, \& en entrant dans le Juin. Lac Huron, la route eft au Nord pendant douze autres lieuës.

Soin, que En faifant la traverfe du Lac de Sainte Claire, javois dans 1es jeunes Sauvages prennent de fe paret. mon Canot un jeune Sauvage, fort \& vigoureux, \& fur les bras duquel javois fort compté, en lui accordant le paffage, qu'il me demandoit : mais il ne me fut que d'un médiocre fecours. En récompenfe il me divertit beaucoup, jufqu'à ce qu'un orage, qui s'éleva fur notre tête, commença à m'inquietter. Ce jeune-Homme s'étoit mis à fa toilette, avant que de s'embarquer, \& $\&$ il ne donnoit pas trois coups d'aviron, qu'il ne prît fon miroir, pour voir fi le mouvement de fes bras n'avoit rien dérangé dans l'œconomie de fon ajuftement, ou fi la fueur n'avoit pas alteré les traits, qu'il s'étoit formés fur fon vifage avec le rouge, \& les autres couleurs, dont il l'avoit peint.

Je ne fçai s'il efperoit d'arriver au Village des Miffiffaguez avant la nuit, pour s'y trouver à quelque Fête; mais nous ne pûmes pas aller fi loin. L'orage creva, comme nous touchions prefque à une lille, où fe termine la traverfe du Lac, \& il fallut $y$ refter. Le jeune Sauvage ne parut pourtant pas fort déconcerté de ce contretems, car ces Gens-là fe confolent aifément de tout. Peut-être auffi n'avoit -il prétendu que fe montrer à nous dans toute fa beauté; mais fi c'étoit là fon deffein, il avoit bien perdu fa peine, je l'avois vû dans fon naturel peu de jours auparavant, \& je l'avois trouvé beaucoup mieux, qu'avec ce bifarre affortiment de couleurs, qui lui avoit tant coûté. On voit ici peu de Femmes fe peindre le vifage, mais les Hommes, \& fur-tout les Jeunes-Gens, font fort curieux de cette parure; il y en a , qui employent une demie journée à fe farder ainfi, uniquement pour aller de porte en porte fe faire regarder, \& qui s'en retournent enfuite fort contens d'eux-mêmes, quoiqu'on ne leur ait pas dit un mot.

Nous entrâmes dans le Lac Huron le vint-uniéme vers les dix heures du matin, \& nous y eûmes d'abord le divertiffement de la Pêche de l'Efturgeon. Le lendemain, malgré le Tonnerre, qui gronda tout le jour, mais qui fe contenta de nous menacer, j’avançai jufqu'à près de vint-cinq lieuës dans 
D'UN V OYA GE DE L'A MERI Q. Let. XIX. 279

le Lac, mais le vint-troifiéme une brume épaiffe, qui nous empêchoit de voir à quatre pas devant notre Canot, nous obligea d'aller plus lentement, parce que nous navigions fur un Banc de Roche, qui en bien des endroits n'eft pas couvert d'un demi pied d'Eau : il s'étend bien loin au large, \& a dix lieuës de long : nos Canadiens l'ont appellé les $P$ ays Plats.

Le jour fuivant nous gagnâmes la Baye de Saguinam, laquelle a cing ou fix lieuës d'ouverture, \& trente de profondeur. Les Outaouais ont un Village dans le fond de cette Baye, que l'on affûre être un très-beau Pays. De-là jufqu'à Michillimakinac on ne voit rien de beau, plus de Vignes, mauvais Bois, fort peu de Chaffe. Dix lieuës au-deffus de la Baye du Saguinam on apperçoit deux Rivieres affez grandes à une lieuë l'une de l'autre, \& quatre ou cinq lieuës plus loin l'Anfe au Tonnerre, qui a trois lieuës d'ouverture, $\&$ affez peu de profondeur.

Michillimakinac ( $($ ) eft par les quarante-trois dégrés trent? minuttes de latitude Nord, \& la route, qui eft de cent lieuës depuis la fortie du. Détroit, en côtoyant la Rive Occidentale du Lac Huron, vaut prefque le Nord. J'arrivai le vint-huit dans ce Pofte, qui eft bien déchû., depuis que M. de la Motte Cadillac a attiré au Détroit la meilleure partie des Sauvages, qui y étoient établis, \& fur-tout les Hurons. Plufieurs Outaouais les y ont fuivis. D'autres fe font difperfés dans les Ifles du Caftor, il n'en refte plus ici qu'un médiocre Village, où il fe fait néanmoins encore un affez grand commerce de Pelleteries, parce que c'eft le paffage, ou le rendez-vous de quantité de Nations Sauvages.

On y a confervé le Fort, \& la Maifon des Miffionnaires , qui n'y font pas préfentement fort occupés, r'ayant jamais trouvé beaucoup de docilité parmi les Outaouais, mais la Cour juge leur préfence nécurfaire dans un lieu, où il faut fouvent traiter avec nos Alliés, \& exercer leur miniftere auprès des François, qui s'y rendent en grand nombre. $\mathrm{O}$ a m'affûre que depuis l'Etabliffement du Détroit, \& la difper. fion des Sauvages, qu'il a occafionnée, plufieurs Nations du Nord, qui avoient accoûtumé d'apporter ici leurs Pelleteries, ont pris la route de la Baye d'Hudfon par la Riviere

(a) Quelques-uns prononcent Miffili- TINIERE, lequel en fait deux endroits difmakinac, ce qui a trom pé M. de LA MAR- ferens, 
2So JOURNAL HISTORIQUE

$172 \mathrm{I}$ Bourbon \& y vont commercer avec les Anglois ; mais M. de la Motte n'avoit garde de prévoir cet inconvénient, puifJuin. qualors nous étions en poffeffion de la Baye d'Hudfon.

La fituation de Michillimakinac eft très - avantageufe pour le Commerce. Ce Pofte eft entre trois grands Lacs; le Michigan, qui a trois cent lieuës de circuit, fans parler de la grande Baye, qui s'y décharge : le Lac Huron, qui a trois cent cinquante lieuës de circonférence, \& qui eft en forme de Triangle ; \& le Lac Supérieur, qui en a cinq cent. Tous trois font navigables pour les plus grandes Barques, \& les deux premiers ne font feparés, que par un petit Détroit, lequel a auffi affez d'eau, pour les mêmes Bâtimens, qui peuvent encore naviguer fans obftacle, dans tout le Lac Erié, jufqu’à Niagara. Ill eft vrai qu'il n'y a de communication entre le Lac Huron, \& le Lac Superieur, que par un Canal de vint-deux lieuës, fort embarraffé de Rapides ; mais ces Rapides n'empêchent point les Canots, de venir décharger à Michillimakinac, tout ce qu'on peut tirer du Lac Superieur.

Defrription du Lac Supérieur.

Ce Lac a deux cent lieuës de long, de l'Eft à l'Oueft, \& en plufieurs endroits quatre-vint de largeur, du Nord au Sud. Toute la Côte Meridionnale eft fablonneufe, \& affez droite ; il feroit dangereux d'y être furpris d'un Vent du Nord, la Rive Septentrionnale eft plus commode pour voyager, parce qu'elle eft toute bordée de Rochers, qui forment de petits Havres, où il eft très - aifé de fe réfugier; $\&$ rien n'eft plus néceffaire, quand on navige en Canot dans ce Lac, où les Voyageurs ont remarqué un Phénomene affez fingulier.

Quand il doit s'y élever quelque Tempête, difent-ils, on en eft averti deux jours auparavant. D'abord on apperçoit un petit frémiffemenr fur la furface de l'eau, \& cela dure toute la journée, fans croîtrt d'une maniere fenfible; le lendemain le Lac eft couvert de lames affe $\mathrm{z}$ groffes, mais elles ne fe brifent pas de tout le jour, de forte qu'on peut marcher fans crainte, \& qu'on fait même beaucoup de chemin, fi le Vent eft du bon côté ; mais le troifiéme jour, lorfqu'on y penfe le moins, le Lac eft tout en feu; l'Ocean, dans fa plus grande fureur, n'eft pas plus agité, \& il faut avoir à point nommé un afyle, pourfe mettre en sûreté : c'eft ce qu'on eft afsûré de trouver fur la Côte du Nord, au lieu que fur celle du Sud, il faut dès le fecond jour, camper affez loin du Rivage. 


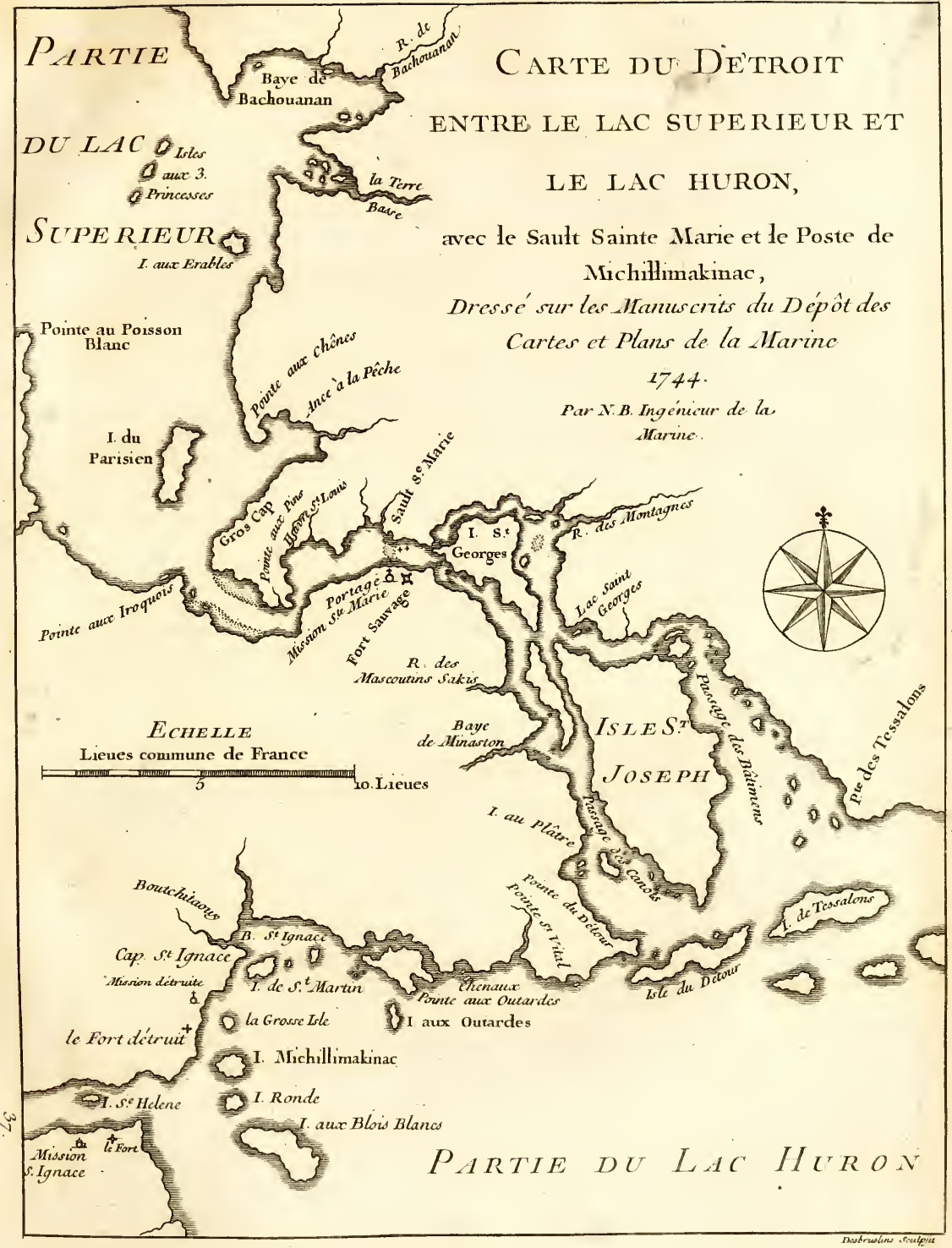


D'U N V OYA G E DE L'A M ERIQ. LET. XIX. 28I

Les Sauvages, par reconnoiffance, pour la quantité de Poiffons, que leur fournit ce Lac; \& par le refpect, que leur infpire fa vafte étenduë, en ont fait une efpece de Divinité, \& lui offrent des Sacrifices à leur maniere. Je penfe néanmoins, que ce n'êt point au Lac même, mais au Génie, qui y préfide, qu'ils adreffent leurs Voeux. Si on les en croit, l'origine du Lac a quelque chofe de Divin : c'eft Michabou, le Dieu des Eaux, qui l'a formé, pour prendre des Caftors. Dans le Canal, par où il fe décharge dans le Lac Huron, il y a un Rapide, caufé par de gros Rochers; nos Miffionnaires, qui $\mathrm{y}$ ont eu une très - floriffante Eglife, l'ont nommé, Le Sault de Sainte Marie : ces Rochers, felon la Tradition des Barbares, font les reftes d'une Chaufée, que le Dieu avoit conftruite, pour arrêter les Eaux des Rivieres, \& du Lac Alimipegon, qui ont rempli ce grand Lac.

Sur fes bords, en quelques endroits, \& autour de certaines Ifles, on trouve de groffes pieces de Cuivre, qui font encore l'objet du Culte Superfitieux des Sauvages; ils les regardent avec véneration, comme un préfent des Dieux, qui habitent fous les Eaux; ils en ramaffent les plus petits fragmens, \& les confervent avec foin, mais ils n'en font aucun ufage. Ils difent quautrefois on voyoit s'élever beaucoup au-deffus de l'Eau un gros Rocher tout de la même matiere ; \& comme il ne paroit plus, ils prétendent que les Dieux l'ont tranfporté ailleurs; mais il y a bien de l'apparence, qu'avec le tems, les vagues du Lac l'ont couvert de fable $\&$ de limon; $\&$ il eft certain, qu'on a découvert en plufieurs endroits une affez grande quantité de ce Métal, fans être même obligé de creufer beaucoup. A mon premier Voyage en ce Pays j’ai connu un de nos Freres, lequel étoit Orfevre de fon Métier, \& qui, pendant quili étoit dans la Miffion du Sault Sainte Marie, en étoit allé chercher là , \& en avoit fait des Chandeliers, des Croix, \& des Encenfoirs; car ce Cuivre eft fouvent prefque tout pur.

Lorfque Michabou, ajoûtent les Sauvages, forma le Lac Superieut, il demeuroit à Michillimakinac, où il étoit né ; ce nom eft proprement celui d'une petite Ifle, prefque ronde, fort haute, fituée à l'extremité du Lac Huron, \& il s'eft étenSuite des traditions des Sauvages fur Michillimakinac. du par l'ufage, à tout le Pays d'alentour. L'Ifle peut avoir trois ou quatre milles de circuit, \& on la voit de douze Tome III. 


\section{2 \\ J O U R N A L \\ H I S T \\ O R I Q U E}

$172 \mathrm{I}$. lieuës. Elle a deux autres Ifles au Sud, dont la plus éloignée Juin. a cinq ou fix lieuës de long; l'autre eft très-petite, \& tout-àfait ronde : toutes deux font bien boifées, \& les Terres y font bonnes, au lieu que celle de Michillimakinac n'eft qu'un Rocher tout - à - fait ftérile, \& à peine couvert d'un peu de mouffe \& d'herbes. Elle eft cependant un des lieux du Canada des plus célebres, \& elle a été lontems, felon quelques anciennes Traditions Sauvages, la principale demeure d'une Nation, qui portoit le même nom, \& dont on a compté, diton, jufqu'à trente Bourgades, répanduës aux environs de l'Ine. On prétend que ce font les Iroquois, qui l'ont détruite, mais on ne dit pas en quel tems, ni à quelie occafion. Ce qui eft certain, c'eft qu'il n'en refte plus aucun veftige; $j$ 'ai vûx quelque part que nos anciens Miffionnaires en ont encore vû quelques reftes $(a)$.

Abondance Les Michillimakinacs ne vivoient gueres que de Pêche, \& đe la Pêche dans ce Can200 .

il n'y a peut - être pas un feul endroit dans le Monde, où elle foit plus abondante. Les Poiffons les plus communs dans les trois Lacs, \& dans les Rivieres, qui s'y déchargent, font le Hareng, la Carpe, le Poiffon doré, le Brochet, l'Efturgeon, l'Aftikamegue, ou Poiffon blanc, \& furtout la Truite. On y en pêche de trois fortes, parmi lefquelles il y en a d'une groffeur monftrueufe, \& en fi grande quantité, qu'un Sauvage avec fon Epée en darde quelquefois jufquà cinquante, en trois heures de tems; mais le plus fameux de tous eft le Poiffon blanc: il eft à peu près de la groffeur, \& de la figure du Maquereau, à l'eau \& au fel, rien n'eft meilleur en fait de Poiffon. Les Sauvages racontent que ce fut Michabou, qui apprit à leurs Ancêtres à pêcher, quil inventa les Rêts, \& que ce fut la toile d'Araignée, qui lui en donna lidée. Ces Peuples, comme vous voyez, Madame, ne font plus pas d'honneur à leur Dieu, qu'il n'en mérite, puifqu'ils ne craignent point de l'envoyer à l'Ecole d'un vil Infecte.

Des lies du Tout ce qui paroît ici de Terres à la vûë, ne donne pas Caftor, \& de l'idée d'un bon Pays; mais il ne faut pas aller bien loin, pour Caftor. trouver des Terroirs propres à tout. Il faut dire la même chofe des Inles du Caftor, qu'on laiffe à main gauche, peu de tems. après qu'on eft entré dans le Lac Michigan. Les Outaouais,

(a) Le nom de Michillimakinac fignifie n'ai pas oui dire qu'on y en trouve aujour. une grande quantité de Tortuës: mais je d'hui plus qu'ailleurs. 
D'UN V OYA GE DE L'A MERIQ. LET. XIX. 283 qui s'y font retirés, y fement du Maiz, \& ils ont pris cette bonne coûtume des Hurons, avec lefquels ils ont lontems vécu dans ces Quartiers-ci. Les Amikoués faifoient autrefois $172 \mathrm{I}$. Juin. leur demeure dans ces Ifles; cette Nation eft aujourd'hui réduite à un très-petit nombre de Familles, qui ont paffé dans l'Ifle Manitoualin, au Nord du Lac Huron; elle eft pourtant une des plus nobles du Canada, fuivant les Sauvages, qui la croyent defcenduë du Grand Caftor, lequel eft après Michabou ; ou le Grand Lievre, leur principale Divinité, $\&$ dont elle porte le nom.

C'eft lui, dit - on encore, qui a formé le Lac Nipifing; $\&$ tous les Rapides, qu'on rencontre dans la grande Riviere des Outaouais, qui en fort, font des reftes de Chauffée, qu'il avoit conftruites pour venir à bout de fon deffein. On ajoûte qu'il eft mort au même endroit, \& qu'il eft enterré fur une Montagne, qu'on apperçoit fur le bord Septentrionnal, du Lac Nipiffing: Cette Montagne préfente affez naturellement, d'un certain côté, la figure d'un Caftor ; \& c'eft, fans doute, ce qui a donné lieu à faire tous ces Contes; mais les Sauvages foûtiennent que c'eft le grand Caftor, qui a donné cette forme à la Montagne, après l'avoir choifie pour le lieu de fa fépulture, \& ils ne paffent jamais par cet endroit, fans lui rendre leurs hommages, en lui offrant la fumée de leur Tabac.

Voilà, Madame, ce qui m'a paru digne d'obfervation fur ce Pofte, fị célebre dans les Voyages \& dans les Relations du Canada. Je reprends les Mœurs \& les Coutumes des Sauvages, $\&$ après avoir parlé de ce qui concerne leurs $G$ uerres, je vais vous entretenir de leurs Mariages.

La pluralité des Femmes eft établie dans plufieurs Nations Dela piurade la Langue Algonquine, \& il eft affez ordinaire d'époufer lité des Fermtoutes les Sœurs; cet ufage eft fondé fur ce qu'on fe perfuade, ris. que des Sours s'accommoderont mieux entre elles, que des Etrangeres. Dans ce cas, toutes les Femmes font fur le même pied, mais parmi les vrais Algonquins, il y en a de deux ordres, \& celles du fecond font les Efclaves des autres. Quelques Nations ont des Femmes dans tous les Quartiers, où ils doivent féjourner quelque tems pour la Chaffe; \& on m'a affuré que cet abus s'eft introduit depuis quelque tems parmi les Peuples de la Langue Huronne, qui de tout tems s'é-

$\mathrm{N}$ in ij 
$172 \mathrm{I}$. toient contentés d'une feule Femme. Mais il regne dans le Tanton Iroquois de Tfonnonthouan un bien plus grand déJuin. fordre encore, c'eft la pluralité des Maris.

Des dégrez Pour ce qui eft des degrés de Parenté, par rapport au Made Parente. riage, les Hurons \& les Iroquois y font fort fcrupuleux ; il faut chez eux n'être point du tout Parent pour s'époufer, l'adoption même eft comprife dans cette Loi. Mais le Mari, fi fa Femme meurt la premiere, doit en époufer la four, ou à fon défaut, celle que la Famille de la Défunte lui préfentera : la Femme, de fon côté, eft obligée à la même chofe, à l'égard des Freres, ou des Parens de fon Mari, fi elle le perd fans en avoir eu d'enfans, \& qu'elle foit encore en âge d'en avoir. Les raifons, qu'ils en apportent, eft la même, qui eft exprimée au Chapitre 23. du Deuteronome (a). Le Mari, qui refuferoit d'époufer la Sour, ou la Parente de la Femme, dont il eft veuf, s'expoferoit à tous les outrages, que lui voudroit faire la Perfonne, qu'il auroit rejettée, \& il faudroit qu'il les fouffrît en filence. Quand, faute de Sujets, on permet à une Veuve de fe pourvoir ailleurs, on doit lui faire des préfens; c'eft un témoignage, que l'on rend à fa bonne conduite, \& qu'elle a droit d'éxiger, fi véritablement elle s'eft bien comportée tout le tems qua duré fon premier Mariage.

Il y a dans toutes les Nations, certaines Familles confidéLoix parti- rables, qui ne peuvent s'allier qu'entre elles, fur - tout parmi culieres pour les Algonquins. Communément la ftabilité des Mariages eft los Mariages. facrée dans ce Pays, \& la plûpart regardent comme un vrai défordre ces conventions, que quclques - uns font de refter enfemble autant de tems, quils s'en trouveront bien, 8 de fe féparer, quand ils fe lafferont l'un de l'autre. Un Mari, qui abandonneroit fa Femme fans un fujet légitime, devroit s'attendre à bien des avanies de la part de ceux, à qui elle appartient ; \& une Femme, qui quitteroit fon Mari, fans y être forcée par fa mauvaife conduite, pafferoit encore plus mal fon tems.

Chez les Miamis le Mari eft en droit de couper le nez à fa Femme fugitive; mais chez les Iroquois $\&$ les Hurons on peut fe quitter de concert. Cela fe fait fans bruit, \& les Parties ainfi féparées peuvent prendre de nouveaux engagemens. Ces Sauvages ne peuvent pas même concevoir qu'il puiffe y avoir

(a) Sufcitabit Semen Fratris Jui, 25. 5. 
D'U N V OYA GE DE L'A MERIQ. Let. XIX. 285 fur cela aucune difficulté : "Nous ne pouvions pas vivre en "

bonne intelligence ma Femme \& moi ", difoit l'un d'eux, à “'Juin. un Miffionnaire, qui tâchoit de lui faire comprendre l'indécence de cette féparation. " Mon Voifin éţoit dans le même " cas, nous avons changé de Femmes, \& nous fommes tous " quatre contens : quoi de plus raifonnable, que de fe rendre " mutuellement heureux, quand il en coûte fi peu, \& qu'on " ne fait tort à perfonne ". Toutefois cet ufage, ainfi que je l'ai “ déja remarqué, eft regardé comme un abus, $\&$ n'elt pas ancien, au moins dans la Nation Iroquoife.

Ce qui trouble plus communément la paix des Ménages parmi les Peuples du Canada, c'eft la jaloufie, qui eft égale des deux côtés. Les Iroquois fe vantent de ne point donner dans ce travers; mais ceux, qui les ont le plus pratiqués, affûrent qu'ils font jaloux à l'excès. Quand une Femme a découvert que fon Mari a une inclination, fa Rivale doit bien fe tenir fur fes gardes, d'autant plus que l'infidéle Epoux ne peut, ni la défendre, ni prendre en aucune maniere fon parti. Un Homme, qui maltraitteroit fa Femme pour ce fujet, feroit déshonnoré.

C'eft uniquement entre les Parens, que fe traitent les Mariages : les Parties intéreffées n'y paroiffent point du tout, \& s'abandonnent aveuglément aux volontés de ceux, dont ils dépendent. Mais admirez la bifarrerie de ces Barbares, qui ne fe rendent dépendans de leurs Parens, que dans la chofe même, où il leur feroit plus permis de n'en point dépendre. On ne conclut pourtant rien fans leur confentement, mais cé n'eft qu'une formalité. Les premieres démarches doivent être faites par les.Matrones; mais il n'eft pas ordinaire qu'il fe faffe aucune avance du côté des Parens de la Fille. Ce n'eft pas que, fi quelqu'une tardoit trop à être recherchée, fa Famille n'agît fous main pour faire penfer à elle, mais on y apporte de grands ménagemens. En quelques endroits les Filles ne font pas preffées de fe marier, parce qu'il leur eft permis de faire, autant qu'elles veulent, l'effai du Mariage, \& que la cérémonie des Nôces ne changeleur condition, que pour la rendre plus dure. :

Ordinairement on remarque beaucoup de pudeur dans la' maniere, dont les Jeunes-Gens fe comportent, tandis qu'on traite de leur Mariage, \& l'on dit que c'étoit encore toute autre chofe dans les premiers tems. Mais ce qui eft prefque ges,

Dequelle ma-
niere fe trai-
tent les Maria-
ges.

Dequelle ma-
niere fe trai-
tent les Maria-
ges,

Dequelle ma-
niere fe trai-
tent les Maria-
ges,

Jaloufie des
1721 .

\author{
$\ll$
$\ll$
«aloufie
Sauvages.
}

. 
1721 incroyable, \& qui eft néanmoins attefté par de bons Auteurs, c'eft qu'en plufieurs endroits les nouveaux Epoux font enfemJuin. femble une année entiere, vivant dans une parfaite continence : c'eft, dit-on, pour faire voir qu'ils fe font époufés par amitié, \& non point pour fatifaire leur paffion. On montreroit même au doit une jeune Femme, qui feroit enceinte la premiere année de fes nôces.

Après cela on doit avoir moins de peine à croire ce qui $\mathrm{fe}$ raconte de la maniere, dont les Jeunes Gens fe comportent pendant la recherche dans les lieux, où il leur eft permis de fe voir en particulier. Car quoique l'ufage leur accorde de très-grandes privautés, toutefois dans le plus preffant danger, où puiffe être expofée la pudeur, \& $\&$ fous les voiles mêmes de la nuit, on "prétend qu'il ne fe paffe rien contre les regles de la plus auftere bienféance, \&x qu'il ne fe dit pas une parole, qui puiffe tant foit peu bleffer la modeftie. Vous trouverez bon fans doute, Madame, que je n'entre pas ici dans le détail, où font entrés quelques Auteurs; il vous feroit paroître la chofe encore moins vraifemblable.

Des Cérémo. wies du Mariage.

Je trouve dans tout ce qu'on a écrit des préliminaires \& des cérémonies du Mariage de ces Peuples bien des variétés; foit qu'elles viennent des differentes Coûtumes des Nations diverfes, ou du peu de foin, que les Auteurs des Relations ont eu de s'en inftruire exactement : d'ailleurs tout m'y a paru fi peu digne de votre curiofité, que je n'ai pas cru devoir m'y arrêter beaucoup. C'eft au futur Epoux à faire les préfens, \& en cela, comme dans tout le refte, il ne fe peut rien ajoûter aux manieres refpectueufes \& à la difcrétion, qu'il fait paroître à l'égard de fa future Epoufe: dans quelques endroits le jeune Homme fe contente d'aller s'affeoir à côté de la Fille dans fa Cabanne, $\&$ fi elle le foufre, $\&$ refte à fa place, on le prend pour fon confentement, \& le Mariage eft fait. Mais à travers ces déférences $\&$ ces refpects il ne laiffe pas de faire fentir qu'il fera bientôt le Maître.

En effet parmi les préfens, qu'elle reçoit, il y en a, qui doivent moins être regardés comme des témoignages d'amitié, que comme des fy mboles \& des avertiffemens de l'efclavage, où elle va être réduite; tels font le Collier $(a)$, la Chaudiere

(a) Ce Collier eft celui, dont j'ai parlé | bande de Cuir, qui fert à porter les Fars ailleurs, c'elt-à-dire, une longue \& large deaux. 
D'U N V OYA GE DE L'A MERI Q. Let. XIX. 287 $\&$ une Buche, qui fe portent dans fa Cabanne. C'eft pour lui faire entendre que ce fera à elle à porter les fardeaux, à faire la cuifine, \& à fournir la provifion de bois.

La coûtume eft même en quelques endroits qu'elle porte d'avance dans la Cabanne, où elle doit demeurer après fes Nôces, tout le bois, dont on aura befoin pour l'Hyver fuivant. Et il eft à remarquer qu'en tout ce que je viens de dire, il n'y a aucune difference entre les Nations, où les Femmes ont toute l'autorité, \& celles, où elles n'entrent pour rien dans le gouvernement : ces mêmes Femmes, qui font en quelque façon les Maîtreffes de l'Etat, du moins pour la forme, \& qui en font le Corps principal, quand elles font parvenuës à un certain âge, \& qu'elles ont des Enfans en état de les faire refpecter, n'ont avant cela nulle confidération, \& font dans le domeftique les Efclaves de leurs Maris.

En général il n'eft peut-être point de Peuples au Monde, qui méprifent plus le Sexe. Traiter un Sauvage de Femme, c'eft le plus fanglant affront, qu'on puiffe lui faire. Cependant, \& cela eft encore bien bizarre, les Enfans n'appartiennent qu’à la Mere, \& ne reconnoiffent qu'elle. Le Pere eft toujours comme Etranger par rapport à eux, tellement néanmoins, que, s'il n'eit pas regardé comme Pere, il eft toujours refpecté comme le Maître de la Cabanne. Je ne fçai au refte fi tout cela eft univerfel parmi tous les Peuples, que nous connoiffons en Canada, non plus que ce que j'ai encore trouvé dans de bons Mémoires, que les jeunes Femmes, outre ce que leurs Maris ont droit d'exiger d'elles pour le fervice de la Cabanne, font encore obligées de fournir à tous les befoins de leurs propres Parens, ce qui doit apparemment s'entendre de ceux, à qui il ne refte plus perfonne pour leur rendre ces fervices, \& qui ne font plus en état, à raifon de leur âge, ou de leurs infirmirés, de s'aider eux-mêmes.

Quoiqu'il en foit, le nouveau Marié ne laiffe pas d'avoir auffi fes charges : outre la Chaffe \& la Pêche, dont l'obligation dure autant que fa vie, il doit d'abord faire une Natte pour fa Femme, lui bâtir une Cabanne, ou réparer celle, qu'ils doivent habiter, \& tandis qu'il demeure avec fon BeauPere \& fa Belle-Mere, faire porter chez eux le produit de $f a$ Chaffe. Parmi les Iroquois la Femme ne fort jamais de fa Cabanne, parce qu'elle eft cenfée en être la Maîtreffe, ou du

1721 .

Juin.

A vantaces des Meres fir les Peres. 
172 1. moins l'Héritiere. Dans d'autres Nations elle va au bout d'un

Juin. ou deux ans de Mariage loger avec fa Belle-Mere.

Des Accouchemens, \& de leurs fuites.

Les Femmes Sauvages pour l'ordinaire, accouchent fans peine, \& fans aucun fecours. Il s'en trouve pourtant quelquefois, qui font lontems en travail, \& foufrent beaucoup. Quand cela arrive, on avertit la Jeuneffe, qui tout d'un coup, \& lorfque la Malade y penfe le moins, vient faire de grands cris à la Porte de fa Cabanne, \& la furprife lui caufe un faififfement, qui lui procure fur le champ fa délivrance. Ce n'eft jamais dans leurs propres Cabannes, que les Femmes font leurs Couches; plufieurs font furprifes, $\&$ accouchent en travaillant, ou en voyage : aux autres, dès qu'elles fe fentent près de leur terme, on dreffe une petite Hutte hors du Village, \& elles y reftent quarante jours après qu'elles font accouchées. Je crois pourtant avoir oui dire que cela ne fe pratique, que pour les premieres Couches.

Ce terme expiré, on éteint tous les Feux de la Cabanne, où elles doivent retourner; on en fecouë toutes les hardes, $\&$ à leur rentrée on allume un nouveau feu. On obferve à peu près les mêmes formalités à l'égard de toutes les Perfonnes du Sexe dans le tems de leurs Ordinaires ; \& non-feulement tant que durent ces incommodités, mais encore pendant qu'une Femme eft enceinte ou nourrice, \& elles nourriffent pour l'ordinaire trois ans, leurs Maris ne les approchent point. Rien ne feroit plus louable que cette coûtume, fi l'un \& l'autre fe gardoient alors la fidélité, qu'ils fe doivent; mais fouvent on y manque de part \& d'autre. Telle eft la corruption du Cour de l'Homme, que les plus fages Réglemens font fouvent l'occafion des plus grands défordres. On prétend même que l'urage de quelques Simples, qui ont la vertu d'empêcher dans les Femmes les fuites de leur infidélité, eft affez familier dans ce Pays.

Dufoin, que lcsimeres prennene de leurs Eufans.

Il ne fe peut rien imaginer au de-là du foin, que les Meres prennent de leurs Enfans, tandis qu'ils font au Berceau; mais du moment qu'elles les ont fevrés, elles les abandonnent abfolument à eux-mêmes; non par dureté, ou par indifference, car elles ne perdent quavec la vie la tendreffe, qu'elles ont pour eux ; mais parce qu'elles font perfuadées, quil faut laiffer faire la Nature, \& ne la gêner en rien. L'acte, qui termine la premiere enfance, eft l'impofition du nom, qui eft pour ces Peuples une affaire importante. 
La Cérémonie s'en fait dans un Feftin, où il ne paroît que des Perfonnes du même Sexe, que l'Enfant, qu'on doit nommer. Pendant le repas, cet Enfant eft fur les genoux de fon Pere, ou de fa Mere, qui ne cerlent point de le recommander I 72 I. Juin.

De l'impoaux Efprits, fur-tout à celui, qui doit être fon Génie tutélaire, car chacun a le fren, mais il ne l'a point en naiffant. On ne crée jamais de nouveaux noms, chaque Famille en conferve un certain nombre, qui reviennent tour à tour. Quelquefois même on en change avec l'âge, \& il y en a, qui ne peuvent être portés au-delà de certain âge, mais je ne crois pas que cela fe pratique par-tout; \& comme parmi quelques Peuples en prenant un nom, on fe met à la place de celui, qui l'a porté le dernier, il arrive quelquefois qu'un Enfant fe voit traiter de Grand-Pere par celui, qui pourroit être le fien.

On n'appelle jamais un Homme par fon nom propre, quand on lui parle dans le difcours familier, ce feroit une impoliteffe; on lui donne toujours la qualité, qu'il a à l'egard de celui, qui lui parle; mais quand il n'y a entre les deux ni parenté, ni affinité, on fe traite de Freres, d'Oncles, de Neveux, ou de Coufins, fuivant l'âge de l'un \& de l'autre, ou felon l'eftime, qu'on fait de la Perfonne, à qui on ádreffe la parole.

Au refte ce n'eft pas tant pour rendre les noms immortels, fi j'ofe ainfi m'exprimer, qu'on les releve, que pour engager ceux, à qui on les donne, ou à imiter les belles actions de ceux, qui les ont portés, ou à les venger, s'ils ont été tués, ou brûlés, ou enfin à foulager leurs Familles. Ainfi une Femme, qui a perdu fon Mari, ou fon Fils, \& ne fe trouve plus appuyée de perfonne, differe le moins qu'elle peut à faire paffer le nom de celui, qu'elle pleure, fur quelqu'un, quii puiffe lui en tenir lieu. Enfin on change encore de nom en plufieurs autres occafions, qu'il feroit trop long de détailler: il fuffit pour cela d'un fonge, ou d'une ordonnance du Médecin, ou de quelque raifon auffi frivole. Mais en voilà affez fur cette matiere, \& voici un Voyageur, qui vient me demander, fi je ne veux point le charger de quelque commiffion pour Quebec. Je vais donc fermer ma Lettre pour la lui donner.

$$
\text { Je fuis, \&c. }
$$


1721 .

\section{VIN T I E M E L ET.TR E.}

Juillet.

Voyage à la Baye. Defcription de la route, E de la Baye. Irruption des Efpagnols vers les Miffouris, \& leur défaite. Danfes des Sauvages.

A Michillimakinac, ce vint-uniéme de Juillet, 1721 。

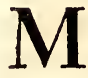

AD AME,

DE P U I s ma derniere Lettre écrite, j’ai fait un voyage à la Baye, éloignée de ce Pofte d'environ quatre-vint lieuës. Je profitai pour cela de l'occafion de M. de Montigni, Capitaine d'une Compagnie des Troupes, que le Roy entretient en Canada, Chevalier de Saint Louys, \& dont le nom eft célébre dans les $F$ aftes de la Colonie, mais pour le moins auffi eftimable pour fa probité, \& fon caractere plein de droiture $\&$ de franchife, que pour fa valeur $\&$ fes exploits de guerre.

De la baye Nous nous embarquâmes le deux de Juillet après midi, des Noquets. nous côtoyâmes pendant trente lieuës une Langue de terre, qui fépare le Lac Michigan du Lac.Supérieur; elle n'a en bien des endroits que quelques lieuës de large, \& il n'eft guéres poffible de voir un plus mauvais Pays; mais il eft terminé par une jolie Riviere, nommée la Maniftie, fort poiffonneufe, \& qui abonde fur-tout en Efturgeons. Un peu plus loin, en tirant au Sud-Oueft, on entre dans un grand Golphe, dont l'entrée cft bordée d'Ifles, on le nomme le Golphe, ou la Baye des Noquets. C'eft une très-petite Nation, venuë des Bords du Lac Supérieur, \& dont il ne refte plus que quelques Familles difperfées çà \& là , fans avoir de demeure fixe.

Ifks des Pou- La Baye des Noquets n'eft féparée de la Grande Baye, que scoutatamis. par les Ifles des Pouteouatamis, \& j'ai déja remarqué que c'eft là l'ancienne demeure de ces Sauvages. La plûpart font trèsbien boifées; mais la feule, qui foit encore peuplée, n'eft ni la plus grande, ni la meilleure, il n'y refte même qu'un affez petit Village, où, malgré que nous en euffions, il nous fallut 
D'U NIVOYA GE ĖDE L'A MERIQ. LET. XX. 29r paffer la nuit : nous ne pûmes jamais le refufer aux inftances des Habitans. Aufli n'y a-t'il point en Canada de Nation, qui ait toujours été plus fincérement attachée aux François.

Le fixiéme nous fûmes arrêtés prefque tout le jour par les vents contraires, mais le foir, le calme étant revenu, nous nous embarquâmes un peu après le coucher du Soleil par un très-beau clair de Lune, \& nous marchâmes vint-quatre heures de fuite, n'ayant fait qu'une très-petite paufe pour dire la Meffe, \& pour dîner. Le Soleil étoit fi ardent, \& l'Eau de la Baye fi chaude, que la Gomme de notre Canot fe fondit en plufieurs endroits. Pour comble de difgrace, l'endroit, où nous nous arrêtâmes pour camper fe trouva tellement infecté de Maringouins ( $a) \&$ de Brulots $(b)$, qu'il ne nous fut pas poffible de fermer l'œil, quoique nous n'euffions pas dormi depuis deux jours; \& comme le tems étoit beau, \& que la Lune nous éclairoit, nous nous remîmes en route dès les trois heures du matin.

Après avoir fait cinq ou fix lieuës, nous nous trouvâmes par le travers d'une petite Inle, qui n'eft pas loin de la Côte Occidentale de la Baye, \& qui nous cachoit l'entrée d'une Riviere, fur laquelle eft le Village des Malhomines, que nos François ont appellé Folles Avoines, apparemment parce qu'ils font leur nourriture ordinaire de ce légume. Toute la Nation confifte dans ce Village, qui n'eft pas même fort nombreux. C'eft dommage, car ce font de très-beaux Hommes, \& $\mathrm{x}$ des mieux faits du Canada. Ils font même plus grands que les Pouteouatamis. On m'a affûré qu'ils avoient la mème origine, \& à peu prèsla même langue, que les Noquets \& les Saulteurs. Mais on ajoûte qu'ils ont encore un Langage particulier, qu'ils ne communiquent à perfonne. On m'a fait auffi fur leur compte certains récits, comme d'un Serpent, lequel va tous les ans dans leur Village, \& y eft reçu avec de grandes cérémonies, qui me font croire quils fe mêlent un peu de fortileges.

Un peu au-deffous de l'Ifle, dont je viens de parler, le Pays change tout-à-coup de face, \& d'affez fauvage, qu'il eft jufques-là, il devient le plus charmant du Monde. Il a même quelque chofe de plus riant, que le Détroit, mais quoiqu'il foit par-tout couvert de très-beaux Arbres, il eft beau-

(a) Ce font des Coufins un peu plus gros que les nôtres.

(b) Moucherons beaucoup plus petits, \& dont la piquîre met tout le Corps en feu.

$\mathrm{O}$ o ij

1721 . Juin.

Des Malinomines, oufolles Avoines.
Des Peuples appellés Puans. 

appelle communément les $P$ uans, demeuroient autrefois fur les Bords de la Baye, dans une très-charmante fituation; ils y furent attaqués par les Illinois, qui en tuerent un très-grand. nombre; les autres fe réfugierent dans la Riviere des Outagamis, qui fe décharge dans le fond de la Baye.

Ils s'y placerent fur les Bords d'une efpéce de Lac; \& je ne fçai, fi ce n'eft pas là que vivant de Poiffons, dont le Lac leur fourniffoit une grande abondance, on leur donna le nom de Puans, parce que tout le long du Rivage, où étoient bâties leurs Cabannes, on ne voyoit que Poiffons pourris, dont l'air étoit infecté. Il paroît du moins que c'eft là l'origine de ce nom, que les autres Sauvages leur avoient donné avant nous, \& qui s'eft communiqué à la Baye, dont ils ne fe font jamais écartés beaucoup. Quelque tems après qu'ils eurent quitté leur ancien Pofte, ils voulurent avoir leur revanche de l'échec, qu'ils avoient reçu des Illinois, mais cette Entreprife leur caufa une nouvelle perte, dont ils ne fe font point relevés. Six cent de leurs meilleurs Hommes s'étoient embarqués pour aller chercher l'Ennemi; mais comme ils traverfoient le Lac Michigan, ils furent furpris d'un furieux coup de vent, qui les fit tous périr.

Du Fort, \& de la Miflion de la Baye.

Nous avons dans la Baye un Fort, qui eft placé fur la rive Occidentale de la Riviere des Outagamis, à une demie lieuë de fon Embouchure; \& avant que d'y arriver, on laiffe à main droite un Village de Sakis. Les Otchagras font venus depuis peu fe placer auprès de nous, \& ont bâti leurs $\mathrm{Ca}$ bannes tout-au-tour du Fort. Le Miffionnaire, qui eft logé affez près du Commandant, efpere, quand il aura appris leur Langue, de les trouver plus dociles que les Sakis, auprès defquels il travaille affez infructueufement. Les uns \& les autres paroiffent de très-bonnes Gens, fur-tout les Premiers, dont le plus grand défaut eft d'être un peu Voleurs. Leur Langue eft fort differente de toutes les autres, ce qui me fait croire qu'elle ne tient à aucune de celles du Canada. Auffi ont-ils toujours eu plus de commerce avec les Peuples Occidentaux, quavec ceux, que nous connoiffons en ce Pays.

Des Sakis. Les Sakis, quoiqu'en petit nombre, font divifés en deux Factions, dont l'une eft attachée aux Outagamis, \& l'autre aux Pouteouatamis. Ceux, qui font établis dans ce Pofte, font 
D'U N V OYAGE DE L'A MER IQ. LET. XX. 293 pour la plûpart de ce dernier parti, \& par conféquent dans nos intérêts. Ils reçurent le nouveau Commandant avec de grandes démonftrations de joye: dès qu'ils le fçurent près d'arriver, ils fe rangerent en armes fur le Rivage, \& au moment qu'ils le virent paroître, ils le faluerent d'une décharge de leurs Fufils, qu'ils accompagnerent de grands cris d'allegreffe. Enfuite quatre des Principaux entrerent dans la Riviere, où ils en eurent bientôt jufqu'à la ceinture, aborderent fon Canot, \& le reçurent dans une grande Robe compofée de plufieurs Peaux de Chevreuils bien coufuës enfemble, dont ils tenoient chacun un bout. Ils le porterent ainfi jufquà fon Logis, où ils le complimenterent, \& lui dirent des chofes extrémement flatteufes.

Le lendemain, les Chefs des deux Nations me rendirent vifite, \& un Otchagra me préfenta un Piftolet Catalan, une paire de Souliers Efpagnols, \& 'je ne fçai quelle Drogue, qui me parut une efpece d'Onguent. Il avoit reçu tout cela d'un Aiouez, \& voici à quelle occafion ces chofes étoient tombées entre les mains de celui-ci.

Il y a environ deux ans, que des Efpagnols, venus, dit-on, du Nouveau Méxique, à deffein de pénetrer jufqu'aux Illinois, \& d'en chaffer les François, quils voyoient avec une extrême jaloufie s'approcher fi fort du Miffouri, defcendirent ce Fleuve, \& attaquerent deux Villages d'Oztotatas, Peuples Alliés des Aiouez, dont on prétend même qu'ils tirent leur origine. Comme ces Sauvages n'avoient point d'Armes à feu , \& qu'ils furent furpris, les Efpagnois en eurent bon marché, \& en firent un grand carnage. Un troifiéme Village de la même Nation, \& qui n'étoit pas éloigné des deux autres, averti de ce qui fe paffoit, \& ne doutant point que ces Conquérans ne vinflent à eux, leur dreffa une Embufcade, où les Efpagnols donnerent étourdiment. D'autres difent, que les Sauvages ayant $\int c ̧ \hat{u}$, que les Ennemis s'étoient prefque tous enyvrés, \& dormoient profondément, tomberent fur eux pendant la nuit ; \& ce qui eft certain, c'eft qu'ils les égorgerent prefque tous.

Il y avoit dans ce Parti deux Aumôniers, dont l'un fut tué d'abord, \& l'autre fe fauva chez les Miffourites, qui le retinrent Prifonnier, mais il leur échappa fort adroitement. Il avoit un très-beau Cheval, \& les Miffourites prenoient plai-

1721 . Juillet.

Efpagnols défaits par les Sauvages du Miflouri. 
I 72 1. fir à lui voir faire le Manége, où il étoit fort habile; il profita de leur curiofité pour le tirer de leurs mains. Un jour Juillet. qu'il caracoloit en leur préfence, il s'éloigna infenfiblement, puis piquant des deux tout à coup, il difparut bientôt. Comme on n'avoit point fait d'autre Prifonnier, on n'a point fçû au jufte, ni de quel endroit du Nouveau Méxique étoient partis ces Efpagnols, ni quel étoit leur deffein; car ce que je vous en ai dit d'abord, n'étoit fondé que fur des bruits de Sauvages, qui peut-être ont voulu nous faire leur cour, en publiant que par cette défaite ils nous avoient rendu un grand fervice.

Tout ce qu'on m'apporta, étoit de la dépouille de l'Aumônier, qui avoit été tué, \& on lui trouva encore un Livre de Prieres, que je n'ai point vû : c'étoit apparemment fon Bréviaire. J'achetai le Piftolet, les Souliers ne valoient rien, \& le Sauvage ne voulut jamais fe défaire de l'Onguent, s'étant mis dans la tête, que c'étoit un remede fouverain contre toutes fortes de maux. Je fus curieux de fçavoir comment il prétendoit s'en fervir, \& il me répondit, qu'il fuffifoit d'en avaler un peu , \& que de quelque Maladie qu'on fût attaqué, on étoit guéri fur le champ; il ne m'afsûra pourtant pas qu'il en eût encore fait l'experience, \& je lui confeillai de ne la point faire. On commence ici à trouver les Sauvages bien groffiers; il s'en faut beaucoup qu'ils foient auffi fpirituels, ou du moins qu'ils ayent l'efprit auffi ouvert que ceux, qui ont plus de commerce avec nous.

Confeil des Le jour fuivant les Sakis vinrent en affez grand nombre Sakis, \& à quel fujet,

chez le Miffionnaire, avec qui je logeois, \& me firent prier de me trouver à une efpece de Confeil, qu'ils vouloient tenir. J'y confentis, \& quand tout le monde eut pris fa place, le Chef mit un Collier à terre devant moi, \& l'Orateur prenant la parole, me pria au nom de tous d'engager le Roy (a) à les prendre fous ia protection, à purifier l'air, qui depuis quelque tems, difoient-ils, étoit corrompu ; ce qui paroiffoit par le grand nombre de Malades, qu'ils avoient dans leurs Villages, \& à les défendre contre leurs Ennemis.

Je leur répondis, que le Roy étoit bien puiffant, \& peutêtre plus qu'ils ne croyoient, mais que fon pouvoir ñe s'étendoit pas fur les Elemens; \& que quand les Maladies, ou

(a) Ces Sauvages prononcent toujours le nom de Roi en François. 
D'U N V OYA GE DE L'A MERIQ. Let. XX. 295 d'autres accidens femblables défoloient fes Provinces, il s'adreffoit, pour les faire ceffer, au grand Efprit, qui a créé le Ciel \& la Terre, \& qui feul eft le Maître Souverain de la 1721. Nature : qu'ils en fiffent de même, \& qu'ils s'en trouveroient bien ; mais que pour mériter d'en être exaucé, il falloit commencer par le reconnoître, \& lui rendre le Culte $\&$ les hommages, qu'il a droit d'attendre de toutes les Créatures raifonnables: qu'ils ne pouvoient rien faire de mieux, ni-de plus agréable au Roy, que d'écouter le Pere $(a)$, que fa Majefté leur avoit envoyé, \& de fe rendre dociles à fes inftructions; que c'étoit un Homme chéri du Ciel; que la maniere, dont il vivoit parmi eux, ne pouvoit manquer de leur avoir fait concevoir une grande eftime pour lui ; \& que fa charité envers les Malades, $\&$ tous ceux, qui ont eu befoin de fon fecours, devoit les avoir convaincus de la tendre $\&$ fincere amitié, qu'il leur portoit : enfin que je ne recevrois point leur Collier, qu'auparavant ils ne m'euffent promis de fe comporter à l'égard de ce Miffionnaire tout autrement, qu'ils n'avoient fait par le paffé, \& de lui ôter déformais tout fujet de fe plaindre de leur indocilité.

"Quant à la protection du Roy, que vous demandez, \& " à la priere, que vous me faites de l'engager à prendre votre " défenfe contre vos Ennemis; ce grand Prince a prévenu vos " fouhaits, il a donné fur cela de bons Ordres à Ononthio $(b)$, " déja porté de lui-même à les executer avec un zéle $\&$ une " affection de Pere $(c)$. C'eft de quoi vous ne fçauriez douter, " fi vous faites attention au Commandant, qu'il vous envoye. " Il n'eft pas poffible que vous ignoriez , \& vous me paroifiez " en effet bien inftruits, que parmi les Capitaines François il y " en a peu, qui l'égalent en valeur, \& vous l'aimerez bien-tôt " encore plus, que vous ne l'eftimez déja. Cette réponfe parut " les contenter, \& ils me promirent beaucoup plus, quapparemment ils me tiendront. Cependant je pris leur Collier, $\&$ le Miffionnaire fe flatta que cette action produiroit un bon effet.

L'après-midi du même jour, les deux Nations nous donne-

(a) Le Pere PIERRECHARDON, je Montmagny, qui a été le fecond GouJéfuite.

(b) C'eft le nom, que les Sauvages donnent au Gouverneur Général, il veut dire, Grande Montagne, \& vient du Chevalier

Les Saura: ges de la Bays danlent le Caw lumet.

(c) 1 ls appellent toujours les Gouver.. neurs \& les Commandans leurs Peres. 


\section{J O U R N A L H I S T O R I Q UE}

rent l'une après l'autre, le divertiffement de la Danfe du CaLogis du Commandant. Il y eut quelque difference dans la maniere, dont les uns \& les autres executerent cette Danfe, mais elle ne fut pas confidérable. Elle me fit feulement connoître que ces Fêtes varient beaucoup : ainfi il n'eft pas poffible d'en donner une Defcription, qui convienne à toutes. Les Othagras diverfifient un peu davantage leur Jeu, \& firent paroître une agilité extraordinaire; auffi font-ils mieux faits, \& plus leftes que les Sakis.

Defcription Cette action eft proprement une Fête militaire, les feuls decette Danfe. Guerriers y font Acteurs, \& l'on diroit qu'elle n'a été inftituée, que pour leur donner occafion de publier leurs beaux faits d'armes. Je ne fuis pas l'Auteur de cette opinion, laquelle ne cadre pas bien avec le fentiment de ceux, qui ont foûtenu que le Calumet tiroit fon origine du Caducée de Mercure, \& que dans fon inftitution il fut regardé comme un fymbole de Paix. Tous ceux, que je vis danfer, chanter, \& jouer du Tambour \& du Chichikoué, étoient de Jeunes Gens équipés, comme quand ils fe préparent à marcher en Guerre; ils s'étoient peint le vifage de toutes fortes de couleurs; leurs têtes étoient ornées de Plumes, \& ils en tenoient à la main en guife d'Eventails: le Calumet en étoit auffi paré, \& on l'avoit placé dans le lieu le plus apparent: l'Orcheftre \&x les Danfeurs étoient tout-au-tour, les Spectateurs répandus çà \& $\&$ là par petites troupes, les Femmes féparées des Homınes, tous affis à terre, 8 parées de leurs plus belles Robes, ce qui faifoit d'un peu loin un affez beaucoup d'œil.

Entre l'Orcheftre \& le Commandant, qui étoit affis devant la Porte de fon Logis, on avoit dreffé un Poteau, auquel, à la fin de chaque Danfe, un Guerrier venoit donner un coup de fa Hache d'arme; à ce fignal il fe faifoit un grand filence, $\&$ cet Homme racontoit à haute voix quelques-unes de fes proueffes; il en recevoit enfuite les applaudiffemens, puis alloit fe remettre à fa place, \& le jeu recommençoit. Cela dura deux bonnes heures pour chacune des deux Nations, \& je vous avoue, Madame, que je n'y pris pas grand plaifir, non-feulement à caufe de la Monotonie, \& du peu d'agrément de la Mufique, mais parce que tout fe réduifoit dans les Danfes à des contorfions, qui, à ce qu'il me fembloit, n'expri- 
D'UN VOYAGE DE L'AMERIQ. LET. XX. 297 moient rien, $\&$ n'avoient rien de divertiffant.

La Fête fe faifoit en l'honneur du nouveau Commandant, toutefois on ne lui fit aucun des honneurs, dont parlent quel$172 \mathrm{I}$. Juillet. ques Relations. On ne vint pas le prendre, pour le mettre fur une Natte neuve, on ne lui fit point de préfent, au moins que je fçache; on ne lui paffa point de Plumages fur la tête, je ne lui vis point préfenter le Calumet; $\&$ il n'y eut point d'Hommes abfolument nuds, peints par tout le corps, parés de Plumes \& de Porcelaines, \& tenant un Calumet à la main. Peut-être que ce n'eft point l'ufage de ces Peuples, ou que M. de Montigny les avoit exemptés de ce cérémonial. Je remarquai feulement que de tems en tems toute l'Affiftance jettoit de grands cris pour applaudir aux Danfeurs, principalement durant la Danfe des Otchagras, qui, au jugement des François, eurent tout l'honneur de cette journée.

J'aurois apparemment eu plus de plaifir à voir la Danfe de la Découverte. Elle a plus d'action, \& on y exprime beaucoup mieux, que dans la précédente, la chofe, dont elle eft le fujet $\&$ la tigure. C'eft une repréfentation au naturel de tout ce qui fe fait dans une Expédition de Guerre, \& comme j'ai déja obfervé que les Sauvages ne cherchent ordinairement qu'à furpendre leurs Ennemis, c'eft fans doute pour cette raifon, qu'ils ont donné à cet exercice le nom de la Découverte.

Quoiqu'il en foit, un Homme y danfe toujours feul, \& d'abord il s'avance lentement au milieu de la place, où il demeure quelque-tems immobile, après quoi il repréfente tout de fuite le départ des Guerriers, la marche, les campemens; il va à la découverte, il fait les approches; il s'arrête, comme pour reprendre haleine, puis tout-à-coup il entre en fureur , \& on diroit qu'il veut tuer tout le monde; revenu de cet accès, il va prendre quelqu'un de l'Affemblée, comme s'il le faifoit Prifonnier de Guerre; il fait femblant de caffer la tête à un autre; il couche un troifiéme en jouë; enfin il fe met à courir de toute fa force. Il s'arrête enfuite, \& reprend fes fens : c'eft la retraite, d'abord précipitée, puis plus tranquille. Alors il exprime par divers cris les différentes fituations, où s'eft trouvé fon efprit pendant fa derniere Campagne, \& finit par le récit de toutes les belles actions, qu'il a faites à la Guerre.

Quand la Danfe du Calumet a pour objet, comme c'eft Des Traiés, l'ordinaire, la conclufion d'une Paix, ou d'un Traité d'allian- le moyen de $l_{d}$ Tome III. 
I 721 . ce contre un Ennemi commun, on grave un Serpent fur le Juillet. manche ou tuyau de la Pipe, \& l'on met à côté une planche, Danfe du Ca- où font repréfentés deux Hommes des deux Nations confédé-
Junier. rées, ayant fous les pieds l'Ennemi, défigné par la marque de fa Nation. Quelquefois à la place du Calumet, on met un Caffe-tête. Mais sil ne s'agit que d'une fimple alliance, on repréfente deux Hommes fe tenant d'une main, portant de l'autre un Calumet de paix , \& ayant chacun à fes côtés la marque de fa Nation. Dans tous ces Traités on fe donne mutuellement des gages, comme des Colliers de Porcelaine, des Calumets, des Efclaves: quelquefois des Peaux de Cerfs, \& d'Elans bien paffées, ornées de figures faites avec du Poil de Porc-Epy, \& alors c'eft fur ces Peaux , que font repréfentées les chofes, que j'ai dites, foit avec le Poil du Porc-Epy, foit avec de fimples couleurs.

fes.

Autres Dan- Il y a d'autres Danfes plus fimples, où l'on n'a eu en vûë que de donner aux Guerriers les occafions de raconter leurs belles actions. C'eft toujours ce que les Sauvages font le plus volontiers, \& ils ne s'en laffent jamais. Celui, qui donne la Fête, y fait inviter tout le Village au fon du Tambour, \& c'eft dans fa Cabanne, qu'on s'affemble, fi elle peut contenir tous les Conviés. Les Guerriers y danfent fucceffivement, puis frappent fur un Poteau ; on fait filence, ils difent tout ce qu'ils veulent, \& s'arrêtent de tems en tems pour recevoir les félicitations des Auditeurs, qui ne les épargnent point. Mais fi on s'apperçoit que quelqu'un fe vante à faux, il eft permis à quiconque de prendre de la terre, ou des cendres, de lui en frotter la tête, ou de lui faire quelqu'autre avanie, qu'il voudra. Ordinairement on lui noircit le vifage, en lui " difant: "Ce que j'en fais, c'eft pour cacher ta honte, car " la premiere fois que tu verras l'Ennemi, tu pâliras. "C'eft ainfi que tous les Peuples font perfuadés que c'eft le propre des Poltrons, que de fe vanter. Celui, qui a ainfi puni ce Fanfaron, prend fa place, \& s'il tombe dans la même faute, l'autre ne manque pas de lui rendre la pareille. Les plus grands Chefs n'ont fur cela aucun privilége, \& il ne faut point $\mathrm{fe}$ fâcher. Cette Danfe fe fait toujours pendant la nuit.

Danfe du Dans les Quartiers Occidentaux il y en a une autre, qu'on Berf. $\quad$ appelle la Danfe du Bøuf. Les Danfeurs forment plufieurs cercles, \& la Symphonie, toujours compofée du Tambour 
DUN VOYAGE DE L'A MERIQ. LET. XX. 299 $8 z$ du Chichikoué, eft au milieu de la place. On y obferve de ne point féparer ceux d'une même Famille; on ne fe tient point par la main, \& chacun porte à la main fes armes $\&$ fon Bouclier. Tous les cercles ne tournent pas du même côté, \& quoiqu'on faute beaucoup, \& qu'on s'éléve extrémement haut, on ne fort jamais de mefure ni de cadence.

De tems en tems un Chef de Famille préfente fon Bouclier, tous frappent deffus, \& à chaque fois il rappelle le fouvenir de quelqu'un de fes beaux faits, il va enfuite couper un morceau de Tabac à un Poteau, où l'on a eu foin d'en attacher une certaine quantité, \& il le donne à un de fes. Amis. Si quelqu'un peut prouver qu'il a fait de plus belles actions que lui, ou qu'il a eu part à celles, dont il vient de fe vanter, il eft en droit d'aller prendre le morceau de Tabac, dont celui-ci vient de faire un préfent, \& de le donner à un autre. Cette Danfe eft fuivie d'un Feftin, mais je ne vois pas bien d'où lui eft venu le nom, qu'elle porte, fi ce n'eft à caufe des Boucliers, fur lefquels on frappe, \& qui font couverts de Peaux de Bouf.

Il y a des Danfes ordonnées par les Jongleurs pour la guérifon des Malades; mais elles font ordinairement fort lafcives. Il y en a de pur divertiffement, \& qui n'ont rapport à rien. Elles fe font prefque toujours en rond, au fon du Tambour $\&$ du Chichikoué, \& les Femmes font toujours féparéęs des Hommes. Ceux-ci y danfent les armes à la main, \& quoiqu'on ne ne fe tienne point, on ne rompt jamais le cercle. Pour ce qui eft de ce que j'ai déja dit, qu'on ne fort point de mefure, cela ne doit point être difficile à croire, parce que la Mufique des Sauvages n'a que deux ou trois tons, qui reviennent fans ceffe. Auffi s'ennuye-t'on beaucoup à ces Fêtes, dès la premiere fois qu'on y affifte, parce qu'elles durent lontems, \& qu'on entend toujours la même chofe.

Comme les Nations voifines de la Baye, fi on en excepte les Pouteouatamis, font beaucoup plus groffieres que les au- des Peuples tres, elles donnent auffi beaucoup plus dans toutes fortes de voifins de la fuperftitions. Le Soleil \& leTonnere font leurs principales $\mathrm{Di}$ vinités, \& elles femblent être plus perfuadées que celles, que nous fréquentons davantage, que chaque efpéce d'Animal a un Génie, qui veille à fa confervation. Un François ayant un jour jetté une Souris, qu'il venoit de prendre, une petite

1721 .

Juillet.

Danfes ordonnées par les Médecins. Baye. 
1721 300 J OUR N A L H IS T O R Q U E

Juillet. lamalla pour la manger: le Pere de lEnfant, qui l'apperçut la lui arracha, \& fe mit à faire de grandes careffes à l'Animal, qui étoit mort : le François lui en demanda la rai" fon : “ C'eft, répondit-il, pour appaifer le Génie des Souris, " afin qu'il ne tourmente pas ma Fille, quand elle aura mangé " celle-ci. "Après quoi il rendit l'Animal à l'Enfant, qui le mangea.

Ils ont furtout beaucoup de vénération pour les Ours : dès qu'ils en ont tué quelqu'un, ils font un Feftin accompagné de cérémonies affez fingulieres. La tête de l'Ours peinte de toutes fortes de couleurs eft placée pendant le repas fur un lieu élevé, \& y y reçoit les hommages de tous les Convives, qui célébrent en chantant les louanges de l'Animal, tandis qu'ils mettent fon corps en piéces, \& s'en régalent. Non-feulement ces Sauvages ont, comme tous les autres, la coûtume de fe préparer aux grandes Chaffes par des jeûnes, que les Outagamis pouffent même jufqu'à dix jours de fuite, mais encore, tandis que les Chaffeurs font en campagne, on oblige fouvent les Enfans de jeûner, on obferve les fonges, qu'ils ont pendant leur jeûne, \& on en tire de bons ou de mauvais augures pour le fuccès de la Chaffe. L'intention de ces jeûnes eft d'appaifer les Génies tutélaires des Animaux, qu'on doit chaffer, \& l'on prétend qu'ils font connoître par les rêves , s'ils s'oppoferont, ou s'ils feront favorables aux Chaffeurs.

La Nation, qui depuis vint ans a plus fait parler d'elle dans ces Pays Occidentaux, eft celle des Outagamis. La férocité naturelle de ces Sauvages, aigrie par plufieurs mauvais traitemens, qu'on leur a faits, quelquefois affez mal à propos, \& leur alliance avec les Iroquois, toujours difpofés à nous fufciter de nouveaux Ennemis, les ont rendus redoutables. Ils fe font encore depuis étroitement unis avec les Sioux, $\mathrm{Na}$ tion nombreufe, qui s'eft auffi aguerrie peu à peu, \& cette union nous rend aujourd'hui prefqu'impratiquable la navigation de tout le haut du Miciffipi. 11 n'y a pas même trop de fûreté à naviguer fur la Riviere des Illinois, à moins qu'on ne foit en état de ne pas craindre une furprife, ce qui fait beaucoup de tort au Commerce réciproque des deux Colonies.

Diveres Na- J'ai rencontré à la Baye quelques Sioux, que 'j'ai fort queftions au Nord \&c à l'Oueft du Canada. tionnés fur les Pays, qui font à l'Oueft, \& au Nord-Oueft du Canada, \& quoique je fçache qu'il ne faut pas toujours 
D'UN VOYA GE DE L'A MERIQ. LET. XX. 30I prendre à la lettre tout ce que difent les Sauvages, en comparant ce que ceux-ci m'ont rapporté, avec ce que j'ai oui dire à plufieurs autres, $j$ 'ai tout lieu de croire qu'il y a dans ce Continent des Efpagnols, ou d'autres Colonies Européennes, beaucoup plus au Nord, que ce que nous connoiffons du Nouveau Mexique \& de la Californie, \& qu'en remontant le Miffouri auffi loin, qu'il eft poffible d'y naviguer, on trouve une grande Riviere, qui coule à l'Oueft, \& re décharge dans la Mer du Sud. Indépendamment même de cette découverte, que je crois plus facile par-là , que par le Nord; je ne puis douter, vû les indices, que j'ai eus de plufieurs endroits, \& qui font affez uniformes, qu'en effayant de pénétrer jufqu'à la fource du Miffouri, on trouvera de quoi fe dédommager des frais \& des fatigues, que demande une telle Entreprife.

Je fuis, \&xc.

\section{VINT-UNIËME LETTRE.}

Départ de Michillimakinac. Obfervations fur les Courans des Lacs. Portrait des Sauvages du Canada. Leurs bonnes $\mathcal{E}$ leurs mauvaijes qualités.

Du Lac de Michigan, ce trente-uniéme de Juillet, 1721 . MadAmE,

$J_{E}$ partis de Michillimakinac avant-hier à midi , \& me voici dégradé depuis hier dans une petite Ifle, qui n’a point de nom; un Canot, qui vient de la Riviere Saint Jofeph, où je vais, ne fçauroit en fortir, non plus que nous, quoiqu'il ait le vent favorable; mais il le trouve, dit-il, trop bourru, \& le Lac trop agité, ce qui me fournit une nouvelle occafion de vous écrire.

Quoique j'euffe le vent contraire, lorfque je m'embarquai le vint-neuf, je ne laiffai pas de faire ce jour-là huit bonnes furlescourans lieuës; ce qui prouve que les Courans me pouffoient. J'avois des Lacs. déja obfervé la même chofe en entrant dans la Baye, \& j’en 
1721. avois eté furpris. Il n'eft point douteux que cette Baye, qui Juillet. que le Michigan, qui eft auffi un cul-de-fac, ne porte fes Eaux dans le Lac Huron, d'autant plus que l'un \& l'autre; je veux dire, le Michigan \& la Baye, reçoivent plufieurs Rivieres, le Michigan fur-tout, qui en reçoit un très-grand nombre, dont quelques-unes ne font guéres infériẹres à la Seine : mais ces grands Courans ne fe font fentir qu'au milieu du Canal, \& produifent fur les deux bords des remouts, ou contre-courans, dont on profite, quand on va terre à terre, comme font obligés de faire ceux, qui voyagent en Canot d'Ecorce.

Je fis d'abord cinq lieuës à l'Oueft, pour gagner le Lac Michigan, enfuite je tournai au Sud, \& c'eft la feule route, que nous avons à faire pendant cent lieuës jufqu'à la Riviere Saint Jofeph. Rien n'eft plus beau, que le Pays, qui fait la féparation du Lac Michigan \& du Lac Huron. Hier je fis encore trois lieuës, \& un vent forcé m'obligea de m'arrêter dans cette Ifle. Je vais m'y défennuyer en achevant de vous faire connoître les Habitans Naturels de ce vafte Pays, dont jai déja parcouru une bonne partie.

Potrrait des Les Sauvages du Canada font communément bien faits, \& Sauvages. d'une taille avantageufe; il y a néanmoins quelques $\mathrm{Na}-$ tions, où il n'eft point rare d'en voir d'une taille médiocre; mais il l'eft infiniment d'en rencontrer, qui foient contrefaits, ou qui ayent quelque défaut extérieur. Ils font robuftes, \& d'une complexion faine. Ils vivroient très-lontems, s'ils fe ménageoient un peu plus; mais la plûpart ruinent leur tempéramment par des marches forcées, par des jeûnes outrés, par de grands excès dans le manger; outre que pendant leur enfance ils ont fouvent les pieds nuds dans l'eau, fur la néige, \& fur la glace. L'Eau-de-vie, que les Européens leur ont portée, pour laquelle ils ont une fureur, qui paffe tout ce qu'on peut dire, \& qu'ils ne boivent que pour s'enyvrer, a achevé de les perdre, \& n'a pas peu contribué au dépériffement de toutes ces Nations, qui fe trouvent aujourd'hui réduites à moins que la vintiéme partie de ce qu'ils étoient, il y a cent cinquante ans. Si cela continuë, on les verra difparoître entierement.

Leurtorce. Leurs corps ne font point contraints au Berceau, comme 
D'U N V OYA GE DE L'A MER I Q. LET. XXI. 303

les nôtres, \& rien n'eft plus propre à les dénouer, \& à leur donner cette foupleffe de tous leurs membres, que nous admirons en eux, que cette liberté, \& les exercices, aufquels les Enfans s'accoutument d'eux - mêmes de très bonne heure: les Meres les nourriffent lontems, \& l'on en voit quelquefois, qui à fix ou fept ans prennent encore la mamelle. Cela n'empêche pourtant pas, que dès la premiere année on ne leur donne toutes fortes de nourriture : enfin le granid air, auquel ils font continuellement expofés; les fatigues, qu'on leur fait effuyer, mais peu à peu, \& d'une maniere proportionnée à leur âge; des alimens fimples \& naturels, tout cela forme des corps capables de faire $\&$ de fouffrir des chofes incroyables, mais dont l'excès, ainfì que je viens de le dire, en fait périr plufieurs avant l'âge de maturité. On en a vû, qui avoient l'eftomach enflé de quatre doits, manger encore d'auffi bon appétit, que s'ils n'euffent fait que commencer; quand ils fe fentent trop chargés, ils fument, puis s'endorment, \& à leur réveil la digêttion eft faite. Quelquefois ils fe contentent de fe faire vomir, après quoi ils recommencent à manger.

Dans les Pays Méridionnaux ils gardent peu de mefures fur l'article des Femmes, qui de leur côté font fort lafcives. C'eft de - là qu'eft venuë la corruption des mœeurs, qui depuis quelques années a infeeté les Nations Septentrionnales. Les Iroquois en particulier étoient affez chaftes, avant qu'ils euffent Commerce avec les 11 linois, \& d'autres Peuples voifins de la Louyfiane : ils n'ont gagné à les fréquenter, que de leur être devenu femblables. Il eft vrai que la moleffe \& la lubricité étoient portées dans ces Quartiers-là, aux plus grands excès. On y voyoit des Hommes, qui n'avoient point de honte d'y prendre l'habillement des Femmes, \& de s'affujettir à toutes les occupations propres du Sexe, d'où s'enfuivoit une corruption, qui ne fe peut exprimer. On a prétendu que cet ufage venoit, de je ne fçai quel principe de Religion; mais cette Religion avoit comme bien d'autres, pris la naiffance dans la dépravation du cœur, ou fi l'ufage, dont nous parlons, avoit commencé par l'eéprit, il a fini par la chair : ces Effeminés ne fe marient point, \& s'abandonnent aux plus infâmes paffions; auff font-ils fouverainement meprifés.

1721 . Juillet.

Leurs vices. 
1721 .

Juillet.

peu fécondes. Outre les rairons, que j’en ai déja touchées, è fçavoir, le tems qu'elles mettent à nourrir leurs Enfans, Pays ne fe peu- l'ufage de ne point habiter avec leurs Maris tant que cela du-
ple pas.

Avantages, qu'ils ont fur nous.

re, \& le travail exceffif, qu'elles font obligées de faire, en quelque fituation qu'elles fe trouvent ; cette fterilité provient encore de la coûtume établie en plufieurs endroits, qui permet aux Filles de fe proftituer, avant que d'être mariées : ajoutez à cela l'extrême mifere, où ces Peuples fe trouvent fouvent réduits, \& qui leur ôte l'envie d'avoir des Enfans.

Du refte il eft certain qu'ils ont fur nous de grands avantages, \& je mets pour le premier de tous, la perfection de leurs fens, foit intérieurs, foit extérieurs. Malgré la Neige, qui les éblouit, \& la fumée, qui les accable pendant fix mois de l'année, leur vûë ne s'affoiblit point ; ils ont l'oüye extrêmement fubtil, \& l'odorat fi fin, qu'ils fentent le feu, lontems avant que de l'avoir pû découvrir. C'eft par cette raifon, qu'ils ne peuvent fouffrir l'odeur du Mufc, ni aucune fenteur forte; on prétend même, qu'ils ne trouvent d'odeur agréable, que celle des chofes comeftibles.

Leur imagination tient du prodige, il leur fuffit d'avoir été une feule fois dans un Lieu, pour en avoir une idée juite, qui ne s'efface jamais. Quelque vafte $\&$ peu battuë, que foit une Forêt, ils la traverfent, fans s'égarer, dès qu'ils fe font bien orientés. Les Habitans de l'Acadie, \& des environs du Golphe de Saint Laurent, fe font fouvent embarqués dans leurs Canots d'écorce, pour paffer à la Terre de Labrador, \& chercher les Efkimaux, avec qui ils étoient en Guerre : ils faifoient trente \& quarante lieuës en pleine Mer fans Bouffole, $\&$ alloient aborder précifément à l'endroit, où ils avoient projetté de prendre terre. Dans les tems les plus nébuleux, Is fuivront plufieurs jours le Soleil, fans fe tromper : le Cadran le plus jufte, ne nous inftruit pas mieux de la marche de ce bel Aftre, qu'ils ne le peuvent faire par la feule infpection du Ciel ; auffi quoiqu'on puiffe faire pour les déforienter, il eft bien rare qu'on vienne à bout de leur faire perdre leur route. lís naiffent avec ce talent, ce n'eft point le fruit de leurs Obfervations, ni d'un grand ufage; les Enfans, qui ne font point encore fortis de leur Village, marchent auffi sûrement que ceux, qui ont le plus parcouru de Pays. 
D'U N V OYA GE DE L'A MER I Q. LET. XXI. 305

La beauté de leur imagination en égale la vivacité, \& cela paroît dans tous leurs difcours. Ils ont la repartie prompte, $\&$ leurs Harangues font remplies de traits lumineux, qui.auroient été applaudies dans les Affemblées Publiques de Rome \& d'Athenes. Leur éloquence a cette force, ,ce naturel, ce pathétique, que l'art ne donne point, que les Grecs admiroient dans les Barbares; \& quoiqu'elle ne paroiffe point foûtenuë par l'action, qu'ils ne gefticulent point, qu'ils n'élevent point la voix, on fent qu'ils font penetrés de ce qu'ils difent, \& ils perfuadent.

Il feroit furprenant quavec une fi belle imagination, ils n'euffent point la mémoire excellente. Ils font dépourvûs de tous les fecours, que nous avons inventés pour foulager la nôtre, ou pour y fuppléer : cependant on ne peut dire de combien de chofes, avec quel détail de circonftances, \& avec combien d'ordre ils traitent dans leurs Confeils. En quelques occafions néanmoins ils fe fervent de petits bâtons, pour fe rappeller les articles, qu'ils doivent difcuter, \& ils s'en forment une maniere de mémoire locale fi sûre, qu'ils parleront quatre ou cinq heures de fuite, étaleront vint préfens, dont chacun demande un Difcours entier, fans rien oublier, \& même fans héfiter. Leur narration eft nette $\&$ précife, \& quoiqu'ils ufent beaucoup d'Allégories, \& d'autres figures, elle eft vive, \& a tous les agrémens, que comporte lẹur Langue.

Ils ont le jugement droit \& folide, \& vont d'abord au but, fans s'arrêter, fans s'écarter, \& fans prendre le change. Ils conçoivent aifément tout ce qui eft à leur portée, mais pour les mettre en état de réuffir dans les Arts, dont ils fe font paffés jufqu’à préfent, comme ils n'en ont pas la moindre idée, il faudroir travailler lontems; d'autant plus qu'ils méprifent fouverainement tout ce qui ne leur eft pas néceffaire, c'eft-àdire, ce dont nous faifons le plus de cas. Ce ne feroit pas non plus une petite affaire, que de les rendre capables de contrainte \& d'application aux chofes purement firituelles, ou qu'ils regarderoient comme inutiles. Pour ce qui eft de celles, qui les intéreffent, ils ne négligent $\&$ ne précipitent rien ; $\&$ autant qu'ils font paroître de flegme, avant que d'avoir pris leur parti, autant témoignent-ils de vivacité $\&$ d'ardeur, lorf quil faut executer; cela fe remarque furtout dans les Hurons Tome III.

Leur mémoire, leur pénétration , leurjugement.

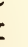


I 72 I. \& les Iroquois. Non feulement ils ont la repartie prompte, Juillet. Blanc, mauvais Chrétien \& grand Yvrogne, interrogé par le Comte de Frontenac, de quoi il penfoit qu'étoit compofée l'Eau de vie, dont il étoit fi friand, dit, que c'étoit un extrait de langues \& de cœurs : car, ajouta-t-il, quand jen ai bû, je ne crains rien, \& je parle à merveille.

teur gran- La plupart ont véritablement une nobleffe, \& une égalité ¿̇sur d'ame.

d'ame, à laquelle nous parvenons rarement avec tous les fecours, que nous pouvons tirer de la Philofophie, \& de la Religion. Toujours maitres d'eux-mêmes, dans les difgraces les plus fubites, on n'apperçoit pas même fur leur vifage la moindre altération. Un Prifonnier, qui fçait à quoi fe terminera fa captivité, ou, ce qui eft peut-être encore plus furprenant, qui eft encore dans lincertitude de fon fort, n'en perd pas un quart d'heure de fommeil ; les premiers mouvemens. mêmes ne les trouvent jamais en défaut. Un Capitaine Huron fut un jour infulté \& frappé par un jeune Homme, ceux qui étoient préfens, vouloient fur le champ punir cette audace : "Laiffez - le , reprit le Capitaine, n'avez - vous pas fenti la "Terre trembler, il eft fuffifamment averti de fa fottife.

Eeur conflín-

Leur conftance dans les douleurs eft au-deffus de toute exre dans les douleurs. preffion. Une jeune Femme fera une journée entiere en travail d'Enfant, fans jetter un cri; fi elle faifoit paroître la moindre foibleffe, on la jugeroit indigne d'être Mere, par la raifon qu'elle ne pourroit, dit - on, enfanter que des lậches. Rien n'eft plus ordinaire, que de voir des Perfonnes de tout âge, \& de tout fexe, fouffrir pendant plufieurs heures, \& quelquefois pendant plufieurs jours de fuite, tout ce que le feu a de plus cuifant, \& tout ce que la plus induftrieufe fureur peut inventer pour le rendre plus fenfible, fans quil leur échappe un ioupir; ils ne font même le plus fouvent occupés pendant leur fupplice, qu’à irriter leurs Bourreaux par les plus fanglans reproches.

Un Outagami, que des Illinois brûloient avec la derniere barbarie, ayant apperçu un François parmi les Spectateurs, le pria de vouloir bien aider fes Ennemis à le tourmenter ; \& celui-ci lui ayant demandé pourquoi il lui faifoit cette priere: "C'eft, répondit - il, que jaurois la confolation de mourir n par la main d'un Homme. Mon plus grand regret, ajouta-t-il, 
D'UN VOYAG EDE L'A MERIQ. LET. XXI. 307 c'eft de n'avoir jamais tué un Homme. Mais, reprit un Illi- " I721. nois : Tu as tué un tel \& un tel. Pour des Illinois, répliqua "Juillet. le Patient, j’en ai affez tué, mais ce ne font pas des Hom- " mes ".

Ce que jai remarqué ailleurs, Madame, pour diminuer la furprife, qu'une telle infenfibilité pourroit caufer, n'empêche point qu'on ne doive y reconnoitre un grand courage. Il faut toujours, pour élever l'ame au-deffus du fentiment à ce point là, un effort, dont les Ames communes ne font point capables. Les Sauvages s'y exercent toute leur vie, \& y accoutument leurs Enfans dès l'âge le plús tendre. On a vû de petits Garçons \& de jeunes Filles fe lier les uns aux autres par un bras, \& mettre entre les deux un Charbon allumé, pour voir qui le fecoueroit le premier. Enfin il faut encore convenir, que felon la remarque de Ciceron, l'habitude au travail, donne de la facilité à fupporter la douleur (a). Or il n'eft peut-être point d'Hommes au Monde, qui fatiguent plus que les Sauvages, foit dans leurs Chafles, foit dans leurs Voyages. Enfin ce qui prouve que cette efpece d'infenfibilité eft dans ces Barbares l'effet d'un véritable courage, c'eft que tous ne l'ont pas.

Il n'eft point étonnant qu'avec cette fermeté d'ame, \& des fentimens fi élevés, les Sauvages foient intrépides dans le danger, \& d'une valeur à toute épreuve. Il eft vrai néanmoins que dans leurs Guerres, ils s'expofent le moins qu'ils peuvent, parce qu'ils ont mis leur gloire à n'acheter jamais bien cherement la Victoire, \& que leurs Nations étant peu nombreufes, ils ont pour maxime de ne point s'affoiblir : mais quand il faut fe battre, ils le font en Lions, \& la vûë de leur fang, ne fait qu'augmenter leur force \& leur courage. Ils fe font trouvés plufieurs fois dans l'action avec nos Braves, qui leur ont vû faire des chofes prefqu'incroyables.

Un Miffionnaire ayant accompagné des Abénaquis dans une Expédition contre la Nouvelle Angleterre, \& fçachant qu'un grand Parti d'Anglois les pourfuivoit dans leur retraite, fit tout ce qu'il put pour les engager à faire diligence : il n'y gagna rien ; toute la réponfe, qu'il en reçut, fut qu'ils ne craignoient point ces gens-là. Les Anglois parurent enfin , \& ils étoient pour le moins vint contre un. Les Sauvages, fans

(a) Confuetudo enim laborum perpeffionem dolorum efficit faciliorem. 2. Tufc. Is. 


\section{J O UR N A L H I S T OR I Q U E}

s'étonner, mirent d'abord leur Pere en fûreté, puis allerent attendre de pied ferme l'Ennemi dans une campagne, où Juillet. il n'y avoit que des fouches d'Arbres. Le combat dura prefque tout le jour ; les Abénaquis ne perdirent pas un Homme, \& mirent en fuite les Anglois, après avoir couvert de Morts le champ de bataille. C'eft du Miffionnaire même $(a)$, que je tiens ce fait.

Les égards, Mais ce qui furprend infiniment dans des Hommes, dont qu'ils ont les uns pour les aucres. tout l'extérieur n'annonce rien que de barbare, c'eft de les voir fe traiter entr'eux avecune douceur \& des égards, qu'on ne trouve point parmi le Peuple dans les Nations les plus civilifées. Cela vient fans doute en partie de ce que le mien $\&$ le tien, ces paroles froides, comme les appelle SAINT GRÉGOIRE Pape, mais qui en éteignant dans nos cœurs le feu de la charité, $y$ allument celui de la convoitife, ne font point encore connus de ces Sauvages. On n'eft pas moins charmé de cette gravité naturelle \& fans fafte, qui regne dans toutes leurs manieres, dans toutes leurs actions, \& jufques dans la plupart de leurs divertiffemens; ni de cette honnêteté $\&$ de ces déférences, qu'ils font paroître avec leurs égaux, ni de ce refpęt des Jeunes Gens pour les Perfonnes âgées, ni enfin de ne les voir jamais fe quereller entr'eux avec ces paroles indécentes, \& ces juremens fi communs parmi nous. Toutes preuves d'un efprit bien fait, \& qui fcait fe poffeder.

J'ai dit qu'un de leurs principes, \& celui, dont ils font le plus jaloux, eft qu'un Homme ne doit rien à un autre; mais de cette mauvaife maxime ils en tirent une bonne conféquence, à fçavoir, qu'il ne faut jamais faire tort à perfonne, quand on n'en a reçu aucune offenfe. Il ne manque à leur bonheur que d'en ufer de Nation à Nation, comme ils font prefque toujours de Particulier à Particulier, de n'attaquer jamais des Peuples, dont ils n'ont aucun fujet de fe plaindre, $\&$ de ne pas pouffer la vengeance fi loin.

I.eur fierté \&

D'ailleurs il faut convenir que ce qu'on admire le plus dans leurs autres dé- les Sauvages, n'eft pas toujours vertu pure; que le tempé-
farts. ramment \& la vanité y ont beaucoup de part, \& que leurs plus belles qualités font obfcurcies par de grands vices. Ces Hommes, qui nous paroiffent fi méprifables au premier abord, font les plus méprifans de tous les Mortels, \& qui

(a) Le Pere VINCENT BIgOT. 
D'UN VOYAGE DE L'A MER I Q. Let. XXI. $3 \circ 9$ s'eftiment davantage. Les plus fuperbes de tous étoient les Hurons, avant que les fuccès euffent enflé le cœur des Iroquois, \& euffent enté en eux une hauteur, que rien n'a encore pu rabattre, fur une groffiereté féroce, qui faifoit auparavant leur caractere diftinctif.

D'un autre côté ces Peuples fi fiers \& fi jaloux de leur liberté, font au-delà de ce qu'on peut imaginer, efclaves du refpeet humain. On les accufe aufli d'être légers $\&$ inconftans, mais c'eft plutôt par efprit d'indépendance, que par caractere, comme je l'ai remarqué des Canadiens. Ils font ombrageux \& foupçonneux, furtout à notre égard; traîtres, quand il y va de leur intérêt; diffimulés, \& vindicatifs à l'excès: le tems ne ralentit point en eux le défir de fe venger; c'eft le plus cher héritage, qu'ils laiffent à leurs Enfans, \& il fe tranfmet de génération en génération, jufqu'à ce qu'on ait trouvé l'occafion de l'exécuter.

Quant à ce qu'on appelle plus particulierement les qualités du cour, les Sauvages ne s'en piquent pas, ou pour mieux dire, elles ne font point en eux des vertus : il femble même qu'ils ne les fçavent pas envifager fous ce point de vûë; amitié, compaffion, reconnoiffance, attache, ils ont quelque chofe de tout cela, mais ce n'eft point dans le cœur, \& c'eft moins en eux l'effet d'un bon naturel, que de la réflexion, ou de l'inftinct. Le foin, qu'ils prennent des Orphelins, des Veuves, \& des Infirmes; l'hof pitalité, qu'ils exercent d'une maniere fi admirable, ne font pour eux qu'une fuite de la perfuafion, où ils font, que tout doit être commun entre les Hommes. Les Peres \& les Meres ont pour leurs Enfans une tendreffe, qui va jufqu'à la foibleffe, mais qui ne les porte point à les rendre vertueux, \& qui paroît purement animale. Les Enfans de leur côté n'ont aucun retour de naturel pour leurs Parens, \& les traitent même quelquefois avec indignité, principalement leurs Peres. On m'en a raconté des exemples, qui font horreur, \& qu'on ne peut rapporter : mais en voici un, qui a été public.

Un Iroquois, qui a lontems fervi dans nos Troupes contre fa propre Nation, \& même en qualité d'Officier, rencontra fon Pere dans un combat, \& l'alloit percer, lorfqu'il le reconnut. Il s'arrêta, \& lui dit: "Tu m'as donné une fois la vie, je te.la donne aujourd'hui, mais ne te retrouves pas une au- "s

Des qualités du cœur.

Exemple du peu de naturel des Enfans pour leurs $\mathrm{Pa}$ rens.

\section{"s} $172 \mathrm{I}$. Juillet. 


\section{J O UR NA L H ISTORIQUE}

$172 \mathrm{I}$." tre fois fous ma main, car je fuis quitte de ce que je te devois ". Juillet. Rien ne prouve mieux la néceffité de l'éducation, \& que la nature feule ne nous inftruit pas fuffifamment de nos plus effentiels devoirs. Et ce qui forme, fi je ne me trompe, une démonftration encore plus fenfible en faveur de la Religion. Chrétienne, c'eft qu'elle a produit dans le cœur de ces Barbares à tous ces égards un changement, qui tient du miracle.

Sociétés par- Mais fi les Sauvages ne fçavent pas goûter les douceurs de ticulieres en- l'amitié, ils en ont au moins reconnu l'utilité. Chacun parmi

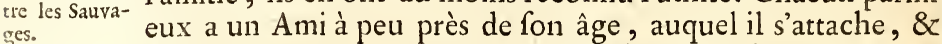
qui s'attache à lui par des liens indiffolubles. Deux Hommes ainfi unis pour leur intérêt commun, doivent tout faire $\&$ tout rifquer pour s'entr'aịder \& fe fecourir mutuellement : la mort mềme, à ce qu'ils croyent, ne les fépare que pour un tems : ils comptent biell de fe rejoindre dans l'autre Monde pour ne fe plus quitter, perfuadés qu'ils y auront encore befoin l'un de l'autre.

J'ai fur cela oui raconter qu'un Sauvage Chrétien, mais qui rie fe conduifoit pas felon les maximes de l'Evangile, étant menacé de l'Enfer par un Jéfuite, demanda à ce Miffionnaire, s'il croyoit que fon Ami décédé depuis peu fût allé dans ce lieu de fupplices : le Pere lui répondit qu'il avoit lieu de juger que Dieu lui avoit fait miféricorde : je n'y veux donc pas aller non plus, reprit le Sauvage, \& ce motif l'engagea à faire tout ce qu'on fouhaitoit; c'eft-à-dire, qu'il auroit été auffi volontairement en Enfer, qu'en Paradis, s'il avoit cru y retrouver fon Camarade; mais Dieu fe fert de tout pour le falut de fes Elus. On ajoûte que ces Amis, quand ils fe trouvent éloignés les uns des autres, s'invoquent réciproquement dans les perils, où ils fe rencontrent; ce quil faut fans doute entendre de leurs $G$ énies tutélaires. Les préfens font les nœuds de ces affociations, l'intérêt \& le befoin les fortifient; c'eft un fecours, fur lequel on peut prefque toujours compter. Quelques-uns prétendent qu'il s'y gliffe du défordre; mais j’ai fujet de croire qu'au moins cela n'eft pas général.

De ia Cou- La couleur des Sauvages ne fait point, comme plufieurs fe feur des sau- font perfuadés, une troifiéme efpéce entre les Blancs \& les vages,

Noirs. Ils font fort bafanés, \& d'un rouge fale \& obfcur, ce qui eft plus fenfible dans la Floride, dont la Louyfiane fait partie : mais cela ne leur eft point naturel. Les fréquentes fri- 
D'UN VOYA GE DE L'A MERIQ. LET. XXI. 3 II xions, dont ils ufent, leur donne ce rouge, \& il eft étonnant qu'ils ne foient pas encore plus noirs, étant continuellement expofés à la fumée en Hyver, aux plus grandes ardeurs du Soleil en Eté, \& dans toutes les Saifons à toutes les intempéries de l'Air.

Il eft moins airé de rendre raifon de ce qu'à la réferve des Cheveux, que tous ont fort noirs; des cils \& des fourcils, que quelques-uns même s'arrachent, ils n'ont pas un poil fur 1721 . Juillet. tout le corps; \& prefque tous les Amériquains font dans le même cas. Ce qui étonne le plus, c'eft que leurs Enfans naiffent avec un poil rare, \& affez long par tout le corps, mais qui difparoît au bout de huit jours. On voit auffi dans les Vieillards quelques poils au menton, comme il arrive parmi nous aux Femmes d'un certain âge ; j'ai vâ attribuer cette fingularité au continuel ufage qu'ont les Amériquains de fumer, \& qui eft commun aux deux Sexes : il paroît plus naturel à. d'autres de dire, que cela vient de la qualité de leur fang, qui étant plus pur, à caufe de la fimplicité de leurs alimens, produit moins de ces fuperfluités, dont le nôtre, plus groflier, fournit une fi grande abondance; ou qui ayant moins de fels, eft moins propre à ces fortes de productions. Il n'eft pas douteux au moins, que c'eft cette fimplicité des alimens, qui rend les Sauvages fi légers à la Courfe. J'ai vû un Infulaire, voifin du Japon, qui n’ayant jamais mangé de pain, m'afsûra qu'il faifoit fans peine à pied ordinairement trente lieuës par jour ; mais qui ayant commencé d'en ufer, n'avoit plus la même facilité.

Ce qui eft certain, c'eft que nos Sauvages trouvent une très-grande beauté, à n'avoir point de poil ailleurs qu'à la Tête, que fi quelquefois il leur en vient quelqu'un au menton, ils l'arrachent d'abord: que les Européens, quand ils les virent pour la premiere fois, leur parurent hideux avec leurs longues Barbes, comme on les portoit alors; qu'ils ne trouvent point belle notre couleur blanche, \& que la chair des François \& des Anglois, quand ils en ont voulu manger, leur a paru de mauvais goût, parce qu'elle étoit falée. Ainfi, Madame, l'idée, qu'on fe formoit autrefois en Europe des Sauvages, qu'on y repréfentoit comme des Hommes tout velus, non - feulement ne leur convient en aucune maniere, mais eft précifément celle, qu'ils ont d'abord euè de nous, parce

Pourquoi ils n'ont point de poils. 
312 JOUR NAL HIS TORIQU E

$172 \mathrm{I}$. quils crurent que nous avions tout le corps, comme le Août. menton \& l'eftomach.

\section{VINT-DEUXIEMME LETTRE.}

Voyage à la Riviere de Saint Jofeph. Obfervation fur les $R$ ivieres, qui Je jettent dans le Lac Michigan, du côté de l'E De celle du P. Marquette, $\mathcal{E}$ de l'origine de ce nom. Des $J$ eux des Sauvages. Quelques traits du Caractere de ces $P$ euples.

De la Riviere de S. Jofeph, ce feiziéme d'Août $\mathbf{1 7 2 1}$.

M

\section{A D A ME,}

Il y eut hier huit jours, que j’arrivai dans ce Pofte, où nous avons une Miffion; $\&$ où il y a un Commandant avec une petite Garnifon. La Maifon du Commandant, qui eft très - peu de chofe, s'appelle le Fort, parce qu'elle eft environnée d'une affez mauvaife Paliffade, \& c'eft à peu près le même partout, à l'exception des Forts de Chambly \& de Catarocouy, qui font de véritables Fortereffes. Il y a néanmoins dans tous quelques petits Canons, ou des Pierriers, qui dans un befoin fuffifent pour empêcher un coup de main, $\&$ pour tenir les Sauvages en refpect.

Danger de

Nous avons ici deux Villages de Sauvages, l'un de Miala Navigation mis , \& l'autre de Pouteouatamis, les uns \& les autres font la du Lac Michigan. plupart Chrétiens, mais ils ont été lontems fans Pafteurs, \& le Miffionnaire, qu'on leur a envoyé depuis peu, n'aura pas peu à faire, pour les remettre dans l'exercice de leur Religion. La Riviere de Saint Jofeph vient du Sud - Eft fe décharger dans le fond du Lac Michigan, dont il faut ranger toute la Côte Orientale, qui a cent lieuës de long, avant que d'entrer dans cette Riviere. On le remonte enfuite vint lieuës pour gagner le Fort, cette Navigation demande de grandes précautions, parce que, quand le vent vient du large, c'entà-dire, de l'Oueft, les lames y font de toute la longueur du Lac; or les Vents d'Oueft y font fort fréquens. Il y a bien de l'apparence 
D'UN VOYAG EDE L'A MERIQ. LET. XXII. 313

l'apparence auffi que lá quantité de Rivieres, qui fe déchargent dans le Lac, fur la Côte Orientale, contribuent par le choc de leurs courans avec les vagues, à rendre la Navigation plus périlleufe : ce qui eft certain, c'eft qu'il eft peu d'endroits dans le Canada ; où il fe foit fait plus de Naufrages. Mais je reprends mon Journal, où je l'ai interrompu.

Le premier jour d'Août, après avoir traverfé à la Voile une Baye, qui a trente lieuës de profondeur, je laiffai à droite les Ifles $d u$ Caftor, qui me parurent fort bien boif́es ; \& quelques lieuës plus loin fur la gauche, $j$ apperçus fur une éminence de Sable une efpece de Buiffon, lequel, quand on eft par fon travers, a la figure d'un Animal couché : les François l'ont nommé, l'Ours qui dort; \& les Sauvages, l'Ours couché: Je fis vint lieuës ce jour-là, \& je campai dans une petite Ifle, qui eft par les quarante-quatre degrés, trente minutes de Latitude - Nord; c'eft à peu près la hauteur de Montreal. Depuis l'entrée du Lac Michigan jufqu'à cette Ine, la Côte eft fort fablonneufe, mais pour peu qu'on avance dans les Terres, le Pays paroît fort bon, du moins à en juger par les magnifiques Forêrs, dont il eft couvert. Il eft d'ailleurs très-bien arrofé, car nous ne faifions pas une lieuë, fans découvrir, ou quelque gros Ruiffeau, ou quelque jolie Riviere, \& plus on avance au Sud, plus les Rivieres font grandes, auffi viennent-elles de plus loin, la Prefqu'Ifle, qui fépare le Lac Michigan du Lac Huron, s'élargiffant à mefure qu'on avance au Midi. La plûpart néanmoins de ces Rivieres font affez peu larges, \& ont peu de profondeur à leur embouchure: ce qu'elles ont de fingulier, c'eft qu'on y trouve prefque d'abord des Lacs de deux, de trois, ou de quatre lieuës de circuit ; cela vient fans doute de la quantité de Sables, qu'elles charient; ces Sables étant repouflés par les vagues du $\mathrm{Lac}$, qui viennent prefque toujours de l'Oueft, s'accumulent à l'embouchure des Rivieres, dont les eaux arrêtées par ces Digues, qu'elles ne franchiffent qu'avec peine, fe font creufé peu à peu ces Lacs, ou Etangs, qui empêchent que tout le Pays ne foit inondé à la fonte des Neiges.

Le troifiéme, $j$ 'entrai dans la Riviere du $P$. Marquette, Riviere du pour examiner fi ce qu'on m'en avoit dit, étoit vrai. Ce n'eft P. Marquette, d'abord qu'un Ruiffeau, mais quinze pas plus haut on entre dans un Lac, qui a près de deux lieuës de tour, Pour le faire Tome III.

$\mathrm{R} r$

1721 .

Août.

Obfervations fur les Rivieres, qu'on rencontre fur cette Route. 
décharger dans le Michigan, on diroit qu'on a coupé avec le

172 1. Pic un gros morne, quon laiffe à gauche en entrant, \& fur la Août. droite la Côte eft très-baffe, environ l'efpace d'une bonne portée de Fufil, puis tout d'un coup elle s'éleve fort haut. On me l'avoit véritablement repréfentée ainfi; \& fur cela, voici la Tradition conftante de tous nos Voyageurs, \& ce que d'anciens Miffionnaires m'ont raconté.

Le P. Jofeph Marquette, natif de Laon en Picardie, où fa Famille tient encore aujourd'hui un rang diftingué, a été un des plus illuftres Miffionnaires de la Nouvelle France; il en a parcouru prefque toutes les Contrées, \& il y a fait plufieurs Découvertes, dont la derniere eft celle du Miciffipi, où il entra avec le Sieur Joliet en I 673. Deux ans après cette Découverte, dont il a publié la Relation, comme il alloit de Chicagou, qui eft au fond du Lac Michigan, à Michillimakinac, il entra le dix-huitiéme de May 1675 dans la Riviere, dont il s'agit, \& dont l'embouchure étoit alors à l'extremité du Terrein bas, que j'ai dit qu'on laiffe à droite en y entrant, il y dreffa fon Autel, \& y dit la Meffe. Il s'éloigna enfuite un peu pour faire fon Action de Graces, \& pria les deux Hommes, qui conduifoient fon Canot, de le laiffer feul pendant une demie - heure. Ce tems paffé, ils allerent le chercher, \& furent très-furpris de le trouver mort; ils fe fouvinrent néanmoins qu'en entrant dans la Riviere, il lui étoit échapé de dire qu'il finiroit là fon voyage.

Cependant comme il y avoit trop ioin de-là à Michillimakinac, pour y porter fon Corps, on l'inhuma affez près du bord de la Riviere, qui depuis ce tems-là s'eft éloignée peu à peu, comme par refpect, jufqu'au Cap, dont elle baigne préfentement le pied, \& où elle s'eft fait un nouveau paffage. L'année fuivante un des deux Hommes, qui avoient rendu les derniers devoirs au Serviteur de Dieu, retourna à l'endroit, où ils l'avoient enterré, en tira ce qui en reftoit, \& le porta à Michillimakinac. Je n'ai pû fçavoir , ou j’ai oublié le nom, que portoit auparavant cette Riviere ; mais aujourd'hui les Sauvages ne l'appellent point autrement', que la Riviere de la Robe noire $(a)$, les François lui ont donné le nom du P. Marquette, \& ne manquent jamais de l'in-

(a) Les Sauvages appellent ainfi les Jé- blancs; \& les Récollets, les Robes grio fuites. Ils nomment les l'êtres, les Collets jes. 
voquer, quand ils fe trouvent en quelque danger fur le Lac Michigan. Plufieurs ont afsûré qu'ils fe croyoient redevables à fon interceffion, d'avoir échapé à de très-grands périls.

Je fis encore trois lieuës ce jour-là, \& j'allai camper à l'entrée de la Riviere de Saint Nicolas, fur le bord d'un joli Lac, plus long \& moins large que le précedent. J'y trouvai une grande quantité de Pins rouges \& blancs, ceux-ci ont l'écorce plus rude, mais le bois en eft meilleur, \& il en fort une Gomme affez fine; ceux-là ont l'écorce plus douce, mais le bois en eft plus pefant : on en tire le Bray, dont on fait le meilleur Godron. Je naviguai ainfi fort agréablemént jufqu'à la Riviere de Saint Jofeph, où j'entrai le fixiéme fort tard, ou le feptiéme de bon matin, car il étoit environ Minuit, lorfque nous y arrivâmes; nous étant repofés deux bonnes heures au bord du Lac de la Riviere noire, qui en eft à huit lieuës, \& où il y a beaucoup de Ging-Seng.

La Riviere de Saint Jofeph a plus de cent lieuës de cours, \& fa fource n'eft pas loin du Lac Erié; elle eft naviguable pendant quatre - vint lieuës, \&x dans les vint - cinq, que je la remontai pour me rendre au Fort, je n'y ai vû que de bonnes Terres, couvertes d'Arbres d'une hauteur prodigieufe, fous lefquels il croît en quelques endroits de très - beau $\mathrm{Ca}$ pillaire. Je fus deux jours à faire ce chemin, mais le foir du premier, je courus grand rifque de n'aller pas plus loin; je fus pris pour un Ours, \& il ne s'en fallut rien, que je ne fuffe tué en cette qualité par un de mes Conducteurs : Voici comment.

Après le Soupé \& la Priere, comme il faifoit fort chaud, jallai me promener en fuivant toujours le bord de la Riviere. Un Barbet, qui me fuivoit partout, s'avifa de felancer dans l'eau, pour y chercher je ne fçai quoi, que j'y avois jetté fans réflexion : mes Gens, qui me croyoient retiré, d'autant plus qu'il étoit fort tard, \& $x$ que la nuit étoit obfcure, entendant le bruit, que fit cet Animal, crurent que c'étoit un Chevreuil, qui paffoit la Riviere, \& deux d'entr'eux partirent de la main avec leurs Fufils chargés; par bonheur pour moi un des deux, qui étoit un étourdi, fut rappellé par les autres, de peur qu'il ne fit manquer la proye, mais il auroit bien pû fe faire que par étourderie il ne m’eût pas manqué.

L'autre avançant au petit pas, m’apperçut à vint pas de lui, R rij 


\section{J O U R N A L H I S T O R I Q U E}

\& ne douta point que ce ne fût un Ours, qui fe dreffoit fur 721. fes deux Pattes de derriere, comme ces Animaux font touAoût. jours, quand ils entendent quelque bruit. A cette vûë le Chaffeur bande fon Fufil, où il avoit mis trois poftes, \& fe courbant prefque à terre, fait fes approches le plus doucement quili peut. Il alloit tirer, lorfque de mon côté je crus voir quelque chofe, mais fans pouvoir diftinguer ce que c'étoit : ne pouvant néanmoins douter que ce ne fût quelqu'un de mes Gens, je m'avifai de lui demander, fi par hafard il ne me prenoit point pour un Ours; il ne me répondit point, \& lorfque je l'eus joint, je le trouvai tout interdit, \& comme faifi de l'horreur du coup, qu'il avoit été fur le point de faire. Ce furent fes Camarades, qui m’apprirent ce qui s'étoit paffé.

La Riviere de Saint Jofeph eft fi commode pour le Commerce de toutes les Parties du Canada, quili n'eft pas étonnant qu'elle ait toujours été beaucoup fréquentée par les Sauvages. D'ailleurs elle arrofe un Pays très-fertile, mais ce n'eft point là ce que ces Peuples eftiment le plus. C'eft même bien dommage de leur donner de bons Terreins; ou ils n'en font aucun ufage, ou ils l'ont bientôt dégraiffé en y femant leur Maï. Les Mafcoutins avoient, il n'y a pas lontems, un Etabliffement fur cette Riviere, mais ils font retournés dans leur Pays, qui eft , dit-on, encore plus beau. Les Pouteouatamis y ont occupé fucceffivement plufieurs Poftes, \& y font encore; leur Village eft du même côté que le Fort, un peu au deffous, \& fur un très-beau Platon : celui des Miamis eft de l'autré côté de la Riviere.

DuGing-Seng Les Sauvages qui fe font de tout tems plus appliqué que de Carada. les autres à la Medecine, font grand cas du Gin-Seng, \& font perfuadés que cette Plante a la vertu de rendre les Femmes fécondes. Je ne crois pourtant pas que ce foit par cette raifon, qu'ils l'ont nommée Abefoutchenza, qui veut dire un Enfant; elle doit ce nom à la figure de fa Racine, au moins parmi les Iroquois. Vous avez vû fans doute, Madame, ce que le P. Laffitau, qui le premier l'a portée en France, en a écrit fous le nom d'Aureliana Canadenfis: elle eft au moins pour la figure, abfolument la même que celle, qui nous vient de la Chine, \& que les Chinois tirent de la Corée $\&$ de la Tartarie. Le nom qu'ils lui donnent, \& qui fignifie la reffemblance de l'Homme; les vertus, qu'ils lui attribuent, \& qu'ont 
D'UN V OYA GE DE L'A MERIQ. LET.XXII. 317 experimentées en Canada ceux, qui en ont fait ufage, \& la conformité du Climat (a) font un grand préjugé, que fi nous la prenions comme venant de la Chine, elle feroit auffi 1721 . Août. eftimée que cellè, que les Chinois nous vendent ; peut - être n'a-t-elle fait fi peu de fortune parmi nous, que parce qu'elle croît dans un Pays, qui nous appartient, \&z qu'elle n'a pas le relief de nous être tout-à-fait étrangere.

En remontant la Riviere de Saint Jofeph, je remarquai quelques Arbres, que je n'avois point vâ ailleurs. Le plus fin- \& du Saffafras. gulier, que je pris d'abord pour un Frefne à fes feuilles, vient extrêmement gros, $8 x$ porte des Féves, qui font trèsbelles à la vûë, mais on a beau les faire bouillir, elles n'en font que plus dures, \& $\&$ il n'a jamais été poffible d'en faire aucun ufage. Les Campagnes, qui environnent le Fort, font tellement couvertes de Saffafras, que l'air en eft embaumé; mais ce n'eft point un grand Arbre, comme à la Caroline, ce ne font que de petits Arbriffeaux, qui rampent prefque à terre; peut-être aufi ne font-ce que des rejettons des Arbres, qu'on a coupés, pour défricher les environs du Fort, \& $\mathrm{des}$ Bourgades Sauvages.

Il y a ici quantité de Simples, dont on prétend que les Sauvages ufentun peu à l'aventure, fans autre principe que l'expérience hafardée légerement, \& qui les trompe quelquefois : car les mêmes Remedes n'agiffent pas également fur toutes fortes de Sujets, attaqués des mêmes Maladies, mais ces Peuples ne fçavent pas faire toutes ces differences. Une chofe, qui m'étonne toujours, c'eft l'impénetrable fecret, qu'ils gardent fur leurs Simples, ou le peu de curiofité des François, pour en avoir la connoiffance. S'il n'y a point de la faute de ceux-ci,rien ne montre mieux, ce me femble, que les Sauvages ne nous voyent pas volontiers dans leur Pays : mais nous en avons d'autres preuves, aufi peu équivoques que celles - ci. II fe pourroit bien auffi qu'ils fuffent au fujet de leurs Simples dans la même opinion, où l'on afsûre qu'ils font par rapport à leurs Mines ; à fçavoir, qu'ils mourroient, s'ils en découvroient quelques-unes aux Etrangers.

(a) La Riviere noire eft par les quaran- Ine. On en a porté à la Chine, \& préparé par te-un degrés, cinquante minutes; $c^{3} e f t$ par les Chinois, ils l'ont vendu comme vecette même Latitude, qu'on tire le Gin- nant de Corée, ou de Tartarie. Au refte Seng de Corée, pour l'Empereur de la Chi- cette préparation n'y ajoûte rien.

Secret des Sauvages fur leurs Simples, \& fur les Mines de lour Pays. 


\section{$3 i 8$ JOURNAL HISTORIQUE}

$172 \%$ Les Sauvages de ces Quartiers font naturellement voleurs, \& regardent comme de bonne prife, tout ce qu'ils peuvent Août. attraper. Il eft vrai que fi l'on s'apperçoit de bonne heure, Des Miamis. qu'on a perdu quelque chofe, il fuffit d'en avertir le Chef, on eft afsûré de la retrouver; mais il faut donner à ce Chef plus que la valeur de la chofe, \& il demande encore quelque bagatelle pour celui, qui l'a retrouvée, \& qui eft apparemment le Voleur même; je fus dans le cas dès le lendemain de mon arrivée, \& on ne me fit point de grace : ces Barbares foûtiendroient une Guerre, plutôt que de fe relâcher fur ce point.

Quelques jours après je fus rendre vifite au Chef des Miamis, qui m'avoit prévenu ; c'eft un grand Homme bien fait, mais fort difgracié, car il n'a point de $\mathrm{Nez}$ : on m'a dit que ce malheur lui étoit arrivé dans une débauche. Quand il fçut que je venois le voir, il alla fe placer au fond de fa Cabanne, fur une maniere d'Eftrade, où je le trouvai aflis les jambes croifées, à la façon des Orientaux. Il ne me dit prefque rien, \& me parut affecter une gravité fiere, qu'il foûtenoit affez mal ; c'eft le premier Chet Sauvage, à qui j’ai vû obferver ce Cérémonial, mais on m'avertit qu'il faut lui rendre la pareille, fi on ne veut pas en être méprifé.

Du Jeu des Ce jour - là les Pouteouatamis étoient venus jouer au Jeu Iailles. des Pailles chez les Miamis; on jouoit dans la Cabanne du Chef, \& dans une Place, qui eft vis-à-vis. Ces Pailles font de petits Joncs de la groffeur des tuyaux de Froment, \& de la longueur de deux pouces. On en prend un paquet, qui eft ordinairement de deux cent un, \& toujours en nombre impair. Après qu'on les a bien remués, en faifant mille contorfions, \& en invoquant les Génies, on les fépare avec une efpece d'aleine, ou un os pointu, en paquets de dix : chacun prend le fien à l'aventure, $\&$ celui, à qui échoit le paquet de onze, gagne un certain nombre de points, dont on eit convenu : les Parties font en foixante, ou en quatre-vint.

Il y a d'autres manieres de jouer ce Jeu, \& on a voulu me les expliquer, mais je n'y ai rien compris, finon que quelquefois le nombre de neuf gagne toute la Partie. On m'a ajoûté qu'il y avoit autant d'adrelle, que de hafard à ce Jeu, \& que les Sauvages y font extrêmement frippons, comme dans tous Les autres; qu'ils s'y acharnent fouvent jufqu'à y paffer les 
D'UN V OYA GE DE L'A MERIQ. LET. XXII. 319

jours $\&$ les nuits, \& que quelques - uns ne ceffent point de jouer, que quand ils font tout nuds, \& n'ont plus rien à perdre. Ils en ont un autre, qui ne pique point par l'envie de 1721 . Août. gagner; c'eft un pur divertiffement, mais il a prefque toujours des fuites funeftes pour les mours.

A l'entrée de la nuit on dreffe au milieu d'une grande Ca- Autre Jels; banne plufieurs Poteaux placés en rond, au milieu font les Inftrumens; on pofe fur chaque Poteau un paquet de duvet, $\&$ il doit $y$ en avoir de toutes les couleurs. Les jeunes gens. des deux Sexes mêlés enfemble, danfent en rond autour des. Poteaux, les Filles ayant auffi du duvet, de la couleur qu'elles aiment : de tems en tems un jeune Homme fe détache, \& va prendre fur un Poteau du duvet de la couleur, qu'il reconnoît être au gré de fa Maîtreffe, \& fe le mettant fur la tête, il danfe autour d'elle, \& lui donne par figne un Rendezvous : la Danfe finie, le Feftin commence, \& dure tout le jour ; le foir tout le monde fe retire, \& les Filles font $\mathrm{fi}$ bien leur compte, que malgré la vigilance de leurs Meres, elles fe trouvent au lieu qui leur a été affigné.

Les Miamis ont encore deux Jeux, dont le premier fe nomme, le Jeu de la Croffe. On y joue avec une Bale \& des Bâtons, recourbés $\&$ terminés par une efpece de Raquette. On dreffe deux Poteaux, qui fervent de Bornes, \& qui font éloignés l'un de l'autre, à proportion du nombre des Joueurs. Par exemple, sils font quatre-vint, il y a entre les Poteaux une demie lieuë de diftance. Les Joueurs font partagés en: deux bandes, qui ont chacune leur Poteau, \& il s'agit de faire aller la Bale, jufqu’à celui de la Partie adverfe, fans qu'elle tombe à terre, \& fans qu'elle foit touchée avec la main ; car fil l'un ou l'autre arrive, on perd la Partie, à moins que celui, qui a fait la faute, ne la répare, en faifant aller la Bale d'un feul trait au But, ce qui eft fouvent impoffible. Ces Sauvages font fi adroits à prendre la Bale avec leurs Croffes, que quelquefois ces Parties durent plufieurs jours de fuite.

Le fecond Jeu approche beaucoup de celui-ci, \& n'eft pas. fi dangereux. On marque deux Termes, comme au premier, $\&$ les Joueurs occupent tout l'efpace, qui eft entre deux. Celui qui doit commencer, jette en l'air une Bale le plus perpendiculairement qu'il eft poffible, afin qu'il puiffe plus aifé- 
172 ment la rattraper, \& la jetter vers le But. Tous les autres ont Août. les bras levés, \& celui, qui faifit la Bale, fait la même Manœuvre, ou jette la Bale à quelqu'un de fa Bande, qu'il eftime plus alerte, ou plus adroit que lui ; car pour gagner la Partie, il faut que la Bale, avant que d'arriver au But, ne foit jamais tombée entre les mains d'aucun des Adverfaires. Les Femmes jouent auffi à ce Jeu, mais rarement; leurs Bandes font de quatre ou cinq, \& la premiere, qui laifle tomber la Bale, perd la Partie.

Du Chef \&

Les Pouteouatamis ont ici un Chef \& un Orateur, qui de l'Orateur font gens de mérite. Le premier, nommé Pirémon, eft un Pouteouata mis.

Homme de plus de foixante ans, fort fage, \& d'un bon confeil; le fecond, appellé Ouilamek, eft plus jeune ; il eft Chrétien, \& bien inftruit, mais il ne fait aucun exercice de fa Religion. Un jour, que je lui en faifois des reproches, il me quitta brufquement, alla dans la Chapelle, \& $\mathrm{x}$ fit fa Priere à haute voix, de forte que nous l'entendions de chez le Miffionnaire: : il eft difficile de voir un Homme, qui parle mieux, \& qui ait plus d'efprit ; d'ailleurs il eft d'un caractere fort aimable, \& fincerement attaché aux François. Pirémon ne l'eft pas moins, \& je les ai entendu tous deux parler dans un Confeil chez le Commandant, où ils nous dirent de très-belles chofes.

suites fune- Plufieurs Sauvages des deux Națions, qui font établies fur ftes de l'Yvro- cette Riviere, ne font que d'arriver des Colonies Angloifes, gnerie. où ils étoient allé vendre leurs Pelleteries, \& d'où ils ont rapporté beaucoup d'Eau - de-vie. Le partage s'en eft fait à la maniere accoûtumée ; c'eft - à-dire, que chaque jour on en diftribuoit à un certain nombre de Perfonnes, autant qu'il en falloit à chacun pour s'enyvrer, \& tout a été bû en huit jours. On commençoit à boire dans les deux Villages, dès que le Soleil étoit couché, \& toutes les nuits les Campagnes retentiffoient de cris \& de hurlemens affreux. On eût dit qu'une Efcouade de Démons s'étoit échapée de l'Enfer, ou que les deux Bourgades étoient acharnées à s'entr'égorger; ily eut deux Hommes d'eftropiẹ́s, j’en rencontrai un, qui s'étoit caffé le Bras en tombant; \& je lui dis, que fans doute une autre fois il feroit plus fage : il me répondit, que cet accident n’étoit rien, qu'il feroit bientôt guéri, \& qu'il recommenceroit à boire, dès qu'il auroit dequoi. 
Jugez, Madame, ce que peut faire un Miffionnaire au milieu de tout ce défordre, \& ce qu'il en coûte à un honnête Homme, qui s'eft expatrié pour gagner des Ames à Dieu, de fe voir obligé d'en être le témoin, \& de n'y pouvoir apporter de remede. Ces Barbares connoiffent eux - mêmes, que l'Yvrognerie les ruine $\&$ les détruit; mais quand on veut leur perfuader, qu'ils devroient être les premiers à demander qu'on leur retranche une.Boiffon, qui a pour eux des fuites fi fâcheufes, ils fe contentent de répondre: "C'eft vous, qui nous y avez accoûtumé, nous ne pouvons plus nous en paf- " fer, \& fi vous refufez de nous en donner, nous en irons chercher chez les Anglois. Cette Liqueur nous tuë, \& nous dépouille, il eft vrai, mais c'eft vous, qui avez fait le mal, \& il eft fans remede ".. Hs n'ont pourtant pas raifon de s'en prendre ainf à nous feuls, fans les Anglois je crois qu'on auroit pû faire ceffer ce Commerce dans la Colonie, ou le réduire à fes juftes bornes; on fera même peut - être obligé bientôt de le permettre aux François, en prenant des mefures pour en empêcher l'abus, d'autant plus que l'Eau de vie des Anglois, eft beaucoup plus mal-failante, que la nôtre.

Un défordre, qui attaque les moeurs, ne va jamais feul; il eft toujours le principe, ou la fuite de pluficurs autres. Les Sauvages, avant que d'être tombés dans celui, dont nous parlons, à la Guerre près, qu'ils ont toujours faite d'une maniere barbare \& inhumaine, n'avoient rien, qui troublât leur bonheur; l'Yvrognerie les a rendus.intéreflés, \& a troublé la douceur, quils goûtoient dans le domeftique, 8 dans le commerce de la vie. Toutefois, comme ils ne font frappés que de l'objet préfent, les maux, que leur a caufé cette paffion, n'ont point encore tourné en habitude; ce font des orages, qui paffent, \& dont la bonté de leur caractere, \& le fond de tranquillité d'ame, qu'ils ont reçûe de la Nature, leur ôtent prefque le fouvenir, quand ils font paffés.

Il faut avouer que du premier coup d'œil la vie qu'ils me- Bonheur des nent, paroît bien dure, mais outre qu'en cela rien ne fait Sauvages. peine, que par comparaifon, \& que l'habitude eft une feconde nature, la liberte dont ils jouiffent, eft pour eux un grand dédommagement des commodités, dont ils font privés. Ce que nous voyons tous les jours dans quelques Mandians de profeffion, \& dans plufieurs Perfonnes de la Campagne,

1721. Août.

\section{"}

" " 
1721 . nous fournit une preuve fenfible, qu'on peut être heureux Août dans le fein même de l'indigence. Or, les Sauvages le font encore plus réellement; premierement, parce qu'ils croyent l'être ; en fecond lieu, parce qu'ils font dans la poffeffion paifible du plus précieux de tous les dons de la Nature; enfin parce qu'ils ignorent parfaitement, \& n'ont pas même envie de connoître ces faux biens, que nous eftimons tant, que nous achetons au prix des véritables, \& que nous goûtons fi peu.

Effectivement en quoi ils font plus eftimables, \& doivent être regardés comme de vrais Philofophes, c'eft que la vûë de nos commodités, de nos richeffes, de nos magnificences, les ont peu touchés, \& qu'ils fe fçavent bon gré de pouvoir s'en paffer. Des Iroquois, qui en 1666 allerent à Paris, \& à qui on fit voir toutes les Maifons Royales, \& $\mathrm{x}$ toutes les beautés de cette grande Ville, n'y admirerent rien, \& auroient préferé leurs Villages à la Capitale du plus floriffant Royaume de l'Europe, s'ils n'avoient pas vû la Ruë de la Huchette, où les Boutiques des Rotiffeurs, qu'ils trouvoient toujours. garnies de Viandes de toutes les fortes, les charmerent beaucoup.

Méprisqu'ils On ne peut pas mème dire quills ne font enchantés de leur font de notre maniere de vivre.

façon de vivre, que parce quils ne connoiffent point la douceur de la nôtre. Des François en affez grand nombre, ont vécu comme eux , \& s'en font fi bien trouvés, que plufieurs n'ont jamais pû gagner fur eux, quoiqu'ils puffent être fort à leur aife dans la Colonie, d'y revenir ; au contraire, il n'a pas été poffible à un feul Sauvage de fe faire à notre maniere de vivre. On a pris de leurs Enfans au Maillot, on les a élevés avec beaucoup de foin; on n’a rien omis pour leur ôter la connoiffance de ce qui fe paffoit chez leurs Parens : toutes ces précautions ont été inutiles, la force du fang l'a emporté fur l'Education : dès qu'ils fe font vûs en liberté, ils ont mis leurs Habits en pieces, \& font allés au travers des Bois chercher leurs Compatriotes, dont la vie leur a paru plus agríable, que celle qu'ils avoient menée chez nous.

Un Iroquois nommé la Plaque, celui-là même, dont je vous ai dit, Madame, qu'en fauvant la vie à fon Pere dans un Combat, il s'étoit cru dégagé de tout ce qu'il lui devoit, a vécu plufieurs années avec les François; on l'a même fais 
D'UN VOYAGE DE L'A MER IQ. LET. XXII. 323 Lieutenant dans nos Troupes, pour le fixer, parce que c'étoit un très - brave Homme. Il n'a pû y tenir, il eft setourné dans fa Nation, n'emportant de chez nous que nos vices, $\&$ n'ayant corrigé aucun de ceux, qu'il y avoit apportés. Il aimoit éperduëment les Femmes, il étoit bien fait, fa valeur $\&$ fes belles actions lui donnoient un grand relief, il avoit beaucoup d'efprit, $\&$ des manieres fort aimables; il fit bien des infidelles, \& fes défordres allerent fi loin , qu'on délibera dans le Confeil de fon Canton, fi on ne s'en déferoit pas. Il fut néanmoins conclu à la pluralité des voix qu'on le laifferoit vivre, parce qu'étant extrêmement courageux, il peupleroit le Pays de bons Guerriers.

Le foin, que les Meres prennent de leurs Enfans, tandis qu'ils font encore au Berceau, eft au - deffus de toute expreffion, \& fait voir bien fenfiblement que nous gâtons fouvent tout, par les réfléxions, que nous ajoûtons à ce que nous infpire la Nature. Elles ne les quittent jamais, elles les portent partout avec elles, \& lorfqu'elles femblent fuccomber fous le poids, dont elles fe chargent, le Berceau de leur Enfant n'eft compté pour rien : on diroit même que ce furcroît de fardeau eft un adouciffement, qui rend le refte plus léger.

Rien n'eft plus propre que ces Berceaux, l'Enfant y eft commodément $\&$ mollement couché : mais il n'eft bandé que jufqu'à la ceinture, de forte que quand le Berceau eft droit, ces petites Créatures ont la tête \& la moitié du corps pendant ; on s'imagineroît en Eưrope qu'un Enfant, qu'on laifferoit en cet état, deviendroit tout contrefait, mais il en arrive tout le contraire, cela leur rend le corps fouple, \& ils font en effet tous d'une taille \& d'un port, que les mieux faits parmi nous envieroient. Que pouvons - nous oppofer à une expérience fi génerale? Mais ce que je vais dire, n'eft pas auffi aifé à juftifier.

Il y a dans ce Continent des Nations, 'qu'on nomme Tétes plates, \& qui ont en effet le front fort applati , \& le haut de la tête un peu allongé. Cette conformation n'eft point l'ouvrage de la Nature, ce font les Meres, qui la donnent à leurs Enfans, dès qu'ils font nés. Pour cela elles leur appliquent fur le front, \& fur le derriere de la tête deux maffes d'argile, ou de quelquautre matiere pefante, qu'elles ferrent peu à peu, jufqu’à ce que le crâne ait pris lạ forme, qu'elles veulent lui $S$ sij

I 721 . Août.

Du foin, que les Meres prenent de leurs Enfans. 
I 72 I donner. Il paroît que cette opération fait beaucoup fouffrir I 72 I. ces Enfans, à qui on voit fortir par les narines une matiere Août. blanchâtre affez épaiffe ; mais ni ces accidens, ni les cris que font ces petits Innocens, n'allarment point leurs Meres, jaloufes de leur procurer une bonne grace, dont elles ne conçoivent pas qu'on puiffe fe paffer. C'eft tout le contraire parmi certains Algonquins, que nous avons nommés Têtes dé Boule, \& dont je vous ai déja parlé , car ils font confifter la beauté à avoir la tête parfaitement ronde, \& les Meres s'y prennent auffi de très-bonne heure, pour donner cette figure à leurs Enfans.

Je voulois, Madame, profiter du loifir, que j’ai ici, \& qui fera peut-être plus long, que je ne le voudrois, pour finir tout ce que jai à vous dire fur cette matiere, mais quelques embarras, qui me font furvenus, \& le départ prochain d'un Voyageur, qui s'en retourne dans la Colonie, m'obligent à interrompre ce Récit, que je reprendrai au premier jour.

Je fuis, \&x.

\section{VIN T-TROISIEME LETTRE.} Suite du Caractere des Sauvages, $\&$ de leur maniere.
de vivre.

De la Riviere de S. Jofeph, ce huitiéme Août $17^{2} \mathbf{I}^{\text {\%om }}$

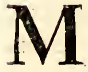

\section{A D A M E,}

JE reprends, la fuite de mes. Mémoires, où je l'ai interrompuë, vous troủverez peut - être que je n'y mets pas affez d'ordre, mais on excufe du moins dans une Relation, ce qu'on admire dans une Ode ; ce qui dans un Poëte Lyrique eft un effet de l'Art, eft une neceffité dans un Voyageur, qui ne peut raconter les chofes, qu'à mefure qu'il les appreñd, \& qui eft obligé d'écrire ce qu'il voit dans la crainte de les. oublier.

Cc qui fortifie les Sauva.

Les Enfans des. Sauvages, au fortir du Berceau; ne fons: 
gênés en aucune maniere, $\&$ dès qu'ils peuvent fe rouler fur les pieds \& fur les mains, on les laiffe aller où ils veulent tout nuds, dans l'Eau, dans les Bois, dans la Bouë, \& dans la. Neige; ce qui leur fait un Corps robufte, leur donne une grande foupleffe dans lès Membres, les endurcit contre les injures de l'Air ; mais auffi, comme je l'ai déja remarqué, leur caufe des foibleffes d'eftomach \& de poitrine, qui les ruinent de bonne heure. L'Eté ils courent, dès qu'ils font levés, à la Riviere, ou dans les Lacs, \& y demeurent une partie du jour à batifoler, comme on voit les Poiffons fe jouer, quand il fait beau tems, vers la furface de l'Eau. Il eft certain que rien n'eft plus propre que cet exercice, à les dénouer, \& à les rendre agiles.

On leur met auffi de très-bonne heure l'Arc \& la Fléche en main, \& pour exciter en eux cette émulation, qui eft la meilleure maîtreffe des. Arts, il n'eft pas néceffaire de placer leur déjeuner au haut d'un Arbre, comme on faifoit aux jeunes Lacédémoniens, ils naiffent tous avec cette paffion pour la gloire, qui n'a pas befoin d'être aiguillonnée ; auffi tirent -ils leurs Fléches avec unc jufteffe étonnante, $8 x$ il ne leur a prefque rien coûté pour en acquérir une femblable dans l'ufage de nas Armes à feu. On les fait encore lutter enfemble, \&z ils s'acharnent tellement à cet exercice, que fouvent ils fe tue. roient, fi on n'avoit pas le foin de les féparer; ceux qui ont du deffous en conçoivent un fi grand dépit, quils ne fe donnent pas le moindre repos, qu'ils n'ayent eu leur revanche.

En général on peut dire, que les Peres $\&$ les Meres ne négligent rien pour infpirer à leurs Enfans certains principes dhonneur, qu'ils confervent toute leur vie, mais qu'ils appliquent fouvent affez mal, \& c'eft à quoi fe réduit toute l'éducation, quils leur donnent. Quand ils les inftruifent fur cela , c'eft toujours d'une maniere indirecte; la plus ordinaire eft de leur raconter les belles. Actions de leurs. Ancêtres, ou de ceux de leur Nation : ces jeunes. Gens prennent feu à ces. Récits, \& ne foûpirent plus qu'après les occafions, d'imiter ce qu'on leur a fait admirer. Quelquefois pour les, corriger de leurs défauts, on employe les prieres $\&$ les larmes, mais. jamais les menaces; elles ne feroient aucune impreffion fur des êfprits prévenus, que perfonne au monde n'eft en droit de les contraindre.

1721 . Août.

ges, $\&$ les rend: fi bien faits.

Leurs pre miers exercices, \& leur émulation en. tr'cux.

A quoi: $\mathrm{fe}$ réduit l'éducation qu'on leur: donne. 
1721. Une Mere, qui voit fa Fille fe comporter mal, fe met à Août. pleurer ; celle - ci lui en demande le fujet, \& elle fe contente reprendre, ne foit pas efficace. Cependant depuis quills ont eu plus de commerce avec les François', quelques - uns commencent à châtger leurs Enfans, mais ce n'eit gueres, qué parmi ceux, qui font Chrétiens, ou qui fe font fixés dans la Colonie. Ordinairement la plus grande punition, que les Sauvages employent pour corriger leurs Entans, c'eft de leur jetter un peu d'eau au Vifage, les Enfans y font fort fenfibles, $\&$ généralement à tout ce qui fent le reproche, ce qui vientde ce que le dépit eft leur plus forte paffion à cet âge.

Des paftions On a vû des Filles s'étrangler, pour avoir reçû une réprides Sauvages. mande affez légere de leurs Meres, ou quelques goutes d'eau au Vifage, \& l'en avertir en lui difant, Tu n'auras plus de Fille. Le plus grand mal eft que ce n'eft pas toujours à la Vertu, qu'on exhorte ces jeunes Gens, ou ce qui vient au même, qu'on ne leur donne pas toujours de la Vertu, des idées bien juftes. En effet on ne leur recommande rien tant que la vengeance, \& c'eft de quoi on leur montre de plus fréquens exemples.

Il femble ,'Madame, qu’une enfance fi mal difciplinée doive être fuivìe d'une jeuneffe bien turbulente $\&$ bien corrompuë; mais d'une part les Sauvages font naturellement tranquilles, \& de bonne heure maitres d'eux-mêmes, la raifon les guide auffi bien plutôt que lés autres Hommes; \& de l'autre, leur temperamment, furtout dans les Nations du Nord, ne les porte point à la débauche. On y trouve bien quelques Ufages, où la Pudeur n'eft nullement ménagée, mais il paroît que la Superftition y a plus de part, que la dépravation du cœur.

Les Hurons, quand nous commençâmes à les pratiquer, étoient plus lafcifs, \& fort brutaux dans leurs plaifirs. Les jeunes Gens des deux Sexes s'abandonnoient tans honte à toutes fortes de diffolutions, \& c'étoit principalement parmi eux , qu'on ne s'avifoit pas de faire un crime à une Fille de s'être proftituée : leurs Parens étoient les premiers à les y engager, \& l'on voyoir des Maris en faire autant de leurs Femmes, pour un vil intérêt. Plufieurs ne fe marioient point, mais prenoient des Filles pour leur fervir, difoient - ils, de 
D'U N V OYA G E D E L'A MER IQ. LET. XXIII. 327 Compagnes, \& toute la difference qu'on mettoit entre ces Concubines \& les Epoufes légitimes., c'eft qu’avec les premieres on ne contractoit nul engagement; du refte leurs Enfans étoient fur le même pied que les autres, ce qui ne produifoit aucun inconvénient dans un Pays, où il n'y a point de fucceffions à recueillir.

On ne diftingue point ici les Nations par leur Habillement, les Hommes, quand il fait chaud, n'ont fouvent fur le Corps qu'un Brahier : l'Hyver ils fe couvrent plus ou moins, fuivant le Climat. Ils ont aux Pieds des efpeces de Chauffons de Peaux de Chevreuils paffées à la Fumée ; leurs Bas font auffi des Peaux ou des morceaux d'Etoffes, dont ils s'envelopent les Jambes. Une Camifole de Peau les couvre jufqu'à la ceinture, \& ils portent pardeffus une Couverture, quand ils peuvent en avoir ; finon ils fe font une Robed'une Peau d'Ours, ou de plufieurs Peaux de Caftors, de Loutres, ou d'autres femblables Fourures, le Poil en dedans. Les Camifoles des Femmes defcendent jufqu'au deffous des Genoux ; \& lorfqu'il fait bien froid, ou qu'elles font en voyage, elles fe couvrent la Tête avec leurs Couvertures, ou leurs Robes. J'en ai vû plufieurs, qui avoient de petits Bonnets, faits comme des Calottes; d'autres fe font une efpece de Capuce, qui tient à leurs Camifoles, \& $\&$ elles ont encore une piece d'Etoffe, ou: une Peau, qui leur fert de Juppe, \& qui les enveloppe depuis la Ceinture, jufqu’à mi-Jambe.

Tous font fort curieux d'avoir des Chemifes, mais ils ne: les mettent par-deffous la Camifole, que quand elles font fales, \& ils les y laiffent jufqu'à ce qu'elles tombent de pourriture, car ils ne fe donnent jamais la peine de les laver. Les Tuniques, ou Camifoles de Peaux font ordinairement paffées à la fumée, comme les Chauffons, c'eft-à-dire, qu'après qu'on les en a laiffé pénétrer, on les frotte un peu, \& alors elles fe peuvent laver comme du Linge. On les prépare auffi, en les faifant tremper dans l'eau, puis en les frottant dans les mains, jufqu’à ce qu'elles foient feches \& maniables. Mais nos Etoffes \& nos Couvertures paroiffent bien plus commodes aux Sauvages.

Plufieurs fe font piquer, comme autrefois les Piktes, par Dequelfe ma. tout le corps: d'autres en quelques endroits feulement. Ce n'eft pas pour eux un pur ornement; ils y trouvent encore, le corps. 


\section{J OUR N A L H IS T ORIQU E}

I 721 .

dit-on, de grands avantages : cela fert beaucoup à les garantir du froid, les rend moins fenfibles aux autres injures de Août. l'air, \& les délivre de la perfécution des Moucherons. Il n'y a néanmoins' que dans les Pays occupés par les Anglois, furtout dans la Virginie, que l'ufage de fe faire piquer partout le corps foit bien commun. Dans la Nouvelle France la plûpart fe contentent de quelques figures d'Oifeaux, de Serpens, ou d'autres Animaux, \& même des feuillages \& autres figures femblables, fans ordre ni fymétrie, mais fuivant le caprice d'un chacun, fouvent au vifage, \& quelquefois même fur les paupieres. Beaucoup de Femmes fe font piquer aux endroits du vifage, qui répondent aux machoires, pour fe garantir des maux de dents.

Cette opération n'eft pas douloureufe en elle-même: voici la maniere, dont elle fe fait. On commence par tracer fur la Peau bien tenduë la figure, qu'on y veut mettre. On pique enfuite avec des arrêtes de Poifions, ou des aiguilles, tous ces traits de proche en proche, jufqu'à en faire fortir le fang, puis on paffe par-deffus du charbon pilé \& $\&$ les autres couleurs bien broyées \& pulvérifées. Ces poudres s'infinuent fous la peau, \& les couleurs ne s'effacent jamais. Mais peu.de tems après la Peau s'enfle, il s'y forme une galle, accompagnée d'inflammation: la fiévre furvient ordinairement, \& fi le temps étoit trop chaud, ou que l'opération eût été pouffée trop loin, il y auroit du danger pour la vie.

Comment, Les couleurs, dont on fe peint le vifage, \& la graiffe, \& pourquoi ils dont on fe frotte partout le corps, produifent les mêmes avanre peignent le vifage. tages, \& donnent, felon ces Peuples, autant de bonne grace, que la picqûre. Les Guerriers fe peignent, lorfqu'ils fe mettent en campagne pour intimider leurs Ennemis, peutêtre auffi pour cacher leur peur, car il ne faut pas croire qu'ils en foient tous exempts, Les Jeunes-Gens le font pour couvrir un aị de jeuneffe, qui les feroit moins eftimer des vieux Soldats, ou la pâleur, qui leur feroit reftée d'une maladie, \& qu'ils craindroient qu'on ne prît pour un effet de leur peu de courage: ils le font encore pour fe rendre plus beaux, mais alors les couleurs font plus vives, \& plus variées : on peint les Prifonniers deftınés à la mort; je n'en fçai pas la raifon : c'eft peut-être pour parer la victime, qui doit être facrifiée au Dieu de la Guerre. Enfin on peint les 
D'UN V OYA GE DEL'A MERIQ. Let. XXIII. 329

Morts pour les expofer couverts de leurs plus belles robes, \& c'eft fans doute pour couvrir la pâleur de la Mort, qui les défigure.

Les couleurs, dont on fe fert dans ces occafions, font les mêmes, qu'on employe pour teindre les Peaux, \& elles fe des Hommes. tirent de certaines Terres, \& de quelques écorces d'Arbres. Elles ne font pas bien vives, mais elles ne s'effacent pas aifément. Les Hommes ajoûtent à cette parure du duvet de $\mathrm{Cy}-$ gnes ou d'autres Oifeaux, quils fement fur leurs cheveux graifés, en guife de poudre. Ils y joignent des plumes de toutes les couleurs, \& des Bouquets de poil de differens Animaux, tout cela bifarrement placé. La figure des cheveux, tantôt hériffés d'un côté, \& applatis de l'autre , ou acconmodés en mille manieres differentes; des pendans aux oreilles, \& quelquefois aux narines, une grande coquille de porcelaine, qui pend à leur cou, ou fur leur eftomach, des couronnes de plumes d'Oifeaux rares, des griffes ou des ongles, des ferres, des pattes, ou des têtes d'Oifeaux de proye, de petites cornes de Chevreuils, tout cela entre auffi dans leur ajuftement. Mais ce qu'ils ont de plus précieux eft toujours employé à parer lesCaptifs, lorfque ces Malheureux font leur premiere entrée dans le Village de leurs Vainqueurs.

Il eft à remarquer que les Hommes n'ont guéres foin de parer que leur tête. C'eft tout le contraire pour les Femmes. Elles ny mettent prefque rien; elles font feulement jaloufes de leurs cheveux, \& elles fe croiroient déshonnorées, fi on les leur coupoit. Auffi, lorfqu'à la mort de leurs Parens elles s'en coupent une partie, elles prétendent leur marquer la plus grande douleur, dont elles font capables. Pour les conferver elles les graiffent fouvent, les poudrent avec de l'écorce de Péruffe réduite en pouffiere, \& quelquefois avec du vermillon, puis elles les enveloppent d'une Peau d'Anguille ou de Serpent, en maniere de cadenettes, qui leur pendent jufqu'à la ceinture. Pour ce qui eft du vifage, elles fe contentent d'y tracer quelques lignes avec du vermillon, ou d'autres couleurs.

Leurs narines ne font jamais percées, \& il n'y a que parmi quelques Nations, qu'elles fe percent les oreilles. Alors elles $y$ inférent comme font auffi les Hommes, ou elles y lairent pendre des grains de porcelaine. Lorfqu'elles font dans leurs Tome III. 


\section{J O U R N A L H IS TOR I Q U E}

I 721 . plus beaux atours, elles ont des robes, où il y a toutes fortes Août. de fans beaucoup d'ordre petits colliers de Porcelaine attachés dure affez paffablement travaillée avec du poil de Porc-Epy, quelles peignent auffi de differentes couleurs. Elles ornent de la même maniere les berceaux de leurs Enfans, \& elles les chargent de toutes fortes de colifichets. Ces berceaux font d'un bois léger, \& ont à leur extrémité d'enhaut un ou deux demi-cercles de bois de Cédre, afin qu'on puiffe les couvrir fans toucher à la tête de l'Enfant.

Leurs occupations. De la culture de la terre.

Outre le foin du Ménage, \& la provifion de Bois, les Femmes font prefque toujours chargées feules de la culture de leurs Champs ; fitôt que les neiges font fonduës, \& les eaux fuffifamment écoulées, elles commencent à préparer la Terre, ce qui confifte à la remuer légerement avec un Bois recourbé, dont le manche eft fort long, après avoir mis le feu aux tiges féches de Maïz, \& aux autres Herbes, qui étoient demeurées depuis la derniere Récolte. Outre que les Grains, dont ces Peuples font ufage, font des Grains d'Eté, on prétend que la nature du Terroir de ce Pays-ci, ne permet pas d'y rien femer avant l'Hyver. Mais je crois que la véritable raifon pourquoi les Grains ne poufferoient pas, fi on les femoit en Automne, c'eft qu'ils fe gâteroient pendant l'Hyver, ou quils pourriroient à la fonte des Neiges. Il fe peut faire auffi, \& c'eft l'opinion de plufieurs, que le Froment, qu'on recueille en Canada, quoiqu'originairement venu de France, ait contracté avec le tems la proprieté des Grains d'Eté, qui n'ont pas affez de force pour pouffer plufieurs fois, comme il arrive à ceux, que nous femons en Septembre \& en Octobre.

Des semen- LesFéves, ou plutôt les Féverolesfe fement avec le Maïz, dont ces \& des Re- la tige leur fert d'appui; je crois avoir oüi dire que c'eft de nous,
coltes. que les Sauvages ont reçu ce légume, dont ils font grand cas, \& qui ne differe effectivement en rien du nôtre. Mais je fuis furpris qu'ils ne faffent point, ou qu'ils faffent peu d'ufage de nos Pois, qui ont acquis dans le terrein du Canada un dégré de bonté fort fupérieur à celle, qu'ils ont en Europe. LesTournefols, les Melons d'eau, \& les Citrouilles fe mettent à part, \& avant que d'en femer la graine, on la fait germer à la fumée dans une terre noire \& légere.

Pour l'ordinaire les Femmes s'aident mutuellement dans 
D'UN VOYA GE DE L'A MER I Q. LET. XXIII.33 I le travail de la Campagne, \& quand il eft tems de faire la recolte, elles ont quelquefois recours aux Hommes, qui ne dédaignent pas d'y mettre la main. Le tout finit par une Fête, \& par un feftin, qui fe fait pendant la nuit, les grains \& les autres fruits fe confervent dans des trous, que l'on creufe en terre, \& qui font tapiffés de grandes écorces. Plufieurs y laiffent le Maiz dans fes épys, qui font treffés, comme parmi nous les Oignons, \& les étalent fur de grandes perches audeffus de l'entrée des Cabannes. D'autres l'égrainent, \& en rempliffent de grands Paniers d'écorce, percés de toutes parts, pour empêcher qu'il ne s'échauffe. Mais lorfqu'on eft obligé de s'abfenter pour quelque tems, ou qu'on appréhende quelqu'irruption de l'Ennemi, on fait de grandes caches en terre, où ces grains fe confervent très-bien.

Dans les Quartiers Septentrionnaux on feme peu, \& en plufieurs endroits on ne feme point du tout. Mais on achete le Maïz par échange. Ce legume eft fort fain, il eft nourriffant, \& ne charge point l'eftomach. La plus ordinaire façon de l'accommoder parmi nos Voyageurs François eft de le léciver, c'eft-à-dire, de le faire bouillir quelque tems dans une efpéce de lécive. En cet état il fe garde lontems, on en fait fes provifions pour les voyages de long cours, \& à mefure qu'on en a befoin, on acheve de le faire cuire dans l'eau, ou dans du bouillon, fi on a de quoi en faire, \& on y met un peu de fel.

Ce n'eft pas un manger défagréable, mais bien des gens font perfuadés que le trop grand ufage en eft nuifible à la fanté, parce que la lécive lui laiffe une qualité corrofive, dont on fe reffent avec le tems. Lorfque le Maïz eft en épi, \& encore verd, quelques-uns le font griller fur le charbon, \& il a un très-bon goût. Nos Canadiens le nomment Bled groulé. Il y en a une efpéce particuliere, quii s'ouvre, dès qu'il a fenti le feu, on l'appelle Bled fleuri, \& il eft fort délicat. C'eft de quoi on régale ordinairement les Etrangers. On le porte en quelques endroits chez les Perfonnes de confidération, qui arrivent dans un Village, à peu près comme on fait en France le préfent de Ville.

Enfin c'eft de ce légume, que fe fait la Sagamité, qui eft la nourriture la plus commune de nos Sauvages. Pour cela on commence par le griller, enfuite on le pile, \& on en ôte la paille, puis on en forme une efpéce de bouillie affez infi-

Août.

Du Maïz 


\section{$332 \mathrm{~J} O \mathrm{O} R \mathrm{~N}$ A L H I S T O R I Q U E}

I 72 I. pide, quand on n'a pas de viande, ou de pruneaux pour en A relever le goût. On le réduit quelquefois en farine, que l'on appel!e ici Farine froide, \& c'eft une des plus commodes $\&$ des meilleures provifions, qu'on puiffe faire pour les voyages. Les Gens de pied ne fçauroient même en porter d'autres. On fait auff bouillir le Maiz dans fon épi, lorfqu'il eft encore tendre, puis on le grille un peu, on l'égraine, \& on le laiffe fécher au Soleil, on le garde lontems, \& la Sagamité, qu'on en fait, a un très-bon goût.

Le détail de ces mets vous fera comprendre, Madame; que les Sauvages ne font point délicats dans leur manger: nous trouverions même quils ont le goût fort dépravé, s'il étoit poffible de fixer le goût. Ils aiment la graiffe, \& elle domine dans tous leurs apprêts, quand ils peuvent en avoir : quelques livres de Chandeles dans une Chaudiere de Sagamité, la leur font trouver excellente: ils y mettent même quelquefois des chofes, qu'on ne peut dire; \& contre lefquelles ils font furpris de nous voir nous révolter.

Les Nations Méridionnales n'avoient pour toute batterie de Cuifine, que des Vaiffeaux de terre cuite. Dans le Nord on fe fervoit de Chaudieres de bois, \& $x$ on y faifoit bouillir l'eau, en y jettant des cailloux rougis au feu. Nos Marmites de fer ont paru aux uns $\&$ aux autres plus commodes que tout. cela, \& c'eft la Marchandife, dont on eft plus affûré d'avoir le débit, quand on trafique avec eux. Dans les Nations Occidentales la Folle Avoine prend la place du Maï : elle eft bien auffi faine, \& fi elle. eft moins nourriflante, la Chaffe du Bœuf, qui eft abondante dans ces Quartiers - là, y fupplée.

De la Trip- Parmi les Sauvages errans, \& qui ne cultivent point du

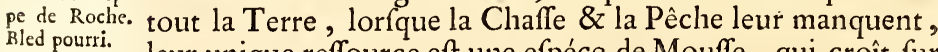
leur unique reffource eft une efpéce de Mouffe, qui croît fur certains Rochers, \& que nos François ont nommée Trippe de Roches: rien n'eft plus infipide que ce mets, lequel n'a pas même beaucoup de fubftance ; c'eft bien là être réduit au pur néceffaire pour ne pas mourir de faim. J'ai encore plus de peine à comprendre, ce qui m'a pourtant été attefté par des Perfonnes dignes de foi, que des Sauvages mangent par délices une efpéce de Maïz, qu'on laiffe pourrir dans une eau dormante, comme nous faifons le Chanvre, \& qu'on en re- 
D'UN VOYA GE DE L'A MER IQ. LET. XXIII. 333 tire tout noir \& puant. On ajoûte mêrme que ceux, qui ont pris goût à un mets auffi étrange que celui-là , ne veulent rien perdre de l'eau, ou plutôt de la fange, qui en découle, I $72 \mathrm{I}$. Août. $\&$ dont l'odeur feule feroit capable de faire bondir le cour à tout autre. C'eft apparemment la néceffité, qui a fait découvrir ce fecret, \& fi elle n'en fair pas encore tout l'affaifonnement, rien ne prouve mieux qu'on ne doit point difputer des goûts.

Les Femmes Sauvages font du Pain de Maï, \& quoique ce ne foit qu'une maffe de pâte mal pétrie, fans levain, \&z cuite fous la cendre, ces Peuples le trouvent très-bon, \&r en régalent leurs Amis; mais il le faut manger chaud; il ne fe conferve point, quand il eft froid. Quelquefois on y mêle des Féves, divers fruits, de l'Huile \& de la Graiffe, il faut de bons eftomachs pour digérer de tels falmigondis.

Les Tournefols ne fervent aux Sauvages, qu'à leur donner une huile, dont ils fe frottent : ils la tirent plus communément de la graine, que de la racine de cette Plante. Cette racine Differens Légumes, \& leurs ufages. eft un peu differente de ce que nous appellons in France To. pinambours, ou Pommes de Terre. Les Patates, fi communes dans les Ifles \& dans le Continent de l'A mérique Méridionnale, ont été femées avec fuccès dans la Louyfiane. L'ufage continuel, que faifoient toutes les Nations du Canada d'une efpéce de Petun, qui croît partout dans ce Pays, a fait dire à quelques Voyageurs qu'ils en avaloient la fumée, \& qu'elle les nourriffoit; mais cela ne s'eft point trouvé vrai, \& n'étoit fondé que fur ce qu'on les a fouvent vû refter fort lontems fans manger. Depuis qu'ils ont goûté de notre Tabac, ils ne peuvent prefque plus fouffrir leur Petun, \& il eft fort aifé de les contenter fur cela, car le Tabac vient fort bien ici, $8 x$ l'on prétend même qu'en choififfant bien les terreins, on en auroit d'excellent.

Les petits ouvrages des Femmes, \& ce qui les occupe ordinairement dans les Cabannes, font de faire du Fil des pellicules intérieures de l'écorce d'un Arbre, qu'on appelle le Bois Blanc, \& elles le travaillent à peu près, comme on fait parmi nous celui de Chanvre. Ce font encore les Femmes, qui font les teintures: elles travaillent auffi à plufieurs ouvrages d'écorce, où elles font de petires figures avec du poil de PorcEpi; elles font de petites Taffes, ou autres Uftencilles de

Ouvrages des Femmes.

Du Pain de Maiz.

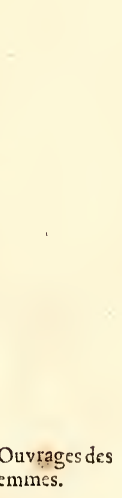


1721 . bois, elles peignent \& brodent des Peaux de Chevreuils, Août. elles tricotent des ceintures $\&$ des jarretieres avec de la Laine

Ouvrages des

Hoinmes. de Bœuf.

Pour les Hommes, ils font gloire de leur oifiveté, \& paffent en effet plus de la moitié de la vie fans rien faire, perfuadés que le travail journalier dégrade l'Homme, \& n'eft d'obligation que pour les Femmes. L'Homme, difent-ils, n'eft que pour la Guerre, la Chaffe, \& la Pêche. C'ert ceperdant à eux à faire tout ce qui eft néceffaire pour ces trois exercices: ainfi les Armes, les Filets, \& tout l'Equipage des Chaffeurs \& des Pêcheurs les regardent principalement, auffbien que les Canots, \& leurs Agrets, les Raquettes, la bâtiffe \& la réparation des Cabannes, mais ils fe font fouvent aider par les Femmes. Les Chrétiens s'occupent un peu davantage, mais ils ne travaillent que par efprit de pénitence. rils.

Leurs Ou- Ces Peuples, àvant que nous leur ayions donné des Haches, \& nos autres Outils, étoient fort embarraffés pour couper leurs Arbres, \& pour les mettre en œuvre. Ils les brüloient par les pieds, \& pour les fendre \& les couper, ils fe fervoient de haches faites avec des Cailloux, qui ne caffoient point, mais qu'ils mettoient un tems infini à aiguifer. Pour les emmancher, ils coupoient la tête d'un jeune Arbre, \& comme s'ils euffent voulu le greffer, ils y faifoient une entaillure, dans laquelle ils inferoient la tête de la hache. Au bout de quelque tems l'Arbre, en fe refermant, tenoit la hache fi ferrée, qu'elle ne pouvoit plus fortir : alors ils coupoient l'Arbre de la longueur, dont ils vouloient avoir le manche.

Forme des Les Villages n'ont point ordinairement de figure réguliere : Villages. la plupart de nos anciènnes Relations nous les repréfentent de figure ronde, \& peut-être leurs Auteurs n'en avoient-ils vâ que de cette forte. Du refte imaginez-vous, Madame, un amas de Cabannes fans ordre \& fans alignement : les unes comme des Hangarts, les autres comme des Tonnelles, bâties d'écorces, foûtenuës de quelques pieux, quelquefois revêtuës en dehors d'un bouzillage de terre affez groffier; en un mot conftruites avec moins d'art, de propreté, \& de folidité, que celles des Caftors. Ces Cabannes ont quinze ou vint pieds de large, \& quelquefois cent de long. Alors elles ont plufieurs Feux, car un Feu n'occupe que trente pieds.

Quand le Rez de Chauffée ne fuffit pas pour coucher tout 
D'U N V OYA GE DE L'A MER R Q. LET. XXIII. 335

le monde, les jeunes Gens ont leurs Lits fur une efpece d'Eftrade, élevée de cinq ou fix pieds, qui regne tout le long de la Cabanne; les Meubles \& $\&$ les Provifions font au-deflus, pofés fur des pieces de Bois mifes en traverfe fous le Toit. Pour l'ordinaire il y a devant l'entrée une maniere de Veftibule, où les jeunes Gens dorment pendant l'Eté, \& qui fert de Bucher pendant l'Hyver. Les Portes ne font que des écorces fufpenduës, comme des Stores, \& jamais elles ne ferment bien. Ces Cabannes n'ont, ni Cheminées, ni Fenêtres, mais on laiffe au milieu du Toit une ouverture, par où la fumée fort en partie, \& qu'on eit obligé de boucher quand il pleut, ou quand il neige; alors il faut éteindre le feu, fi on ne veut pas être aveuglé par la fumée.

Les Sauvages fe fortifient mieux, qu'ils ne fe logent ; on voit des Villages affez bien paliffadés avec des Redoutes, où l'on a toujours foin de faire de bonnes provifions d'Eau \& de Pierres. Ces Paliffades font même doubles, \& quelquefois triples, \& ont ordinairement des Crénaux à la derniere enceinte. Les Pieux, dont elles font compofées, font entrelaffés de Branches d'Arbres, qui ne laiffent aucun vuide. Il ne falloit rien de plus pour foûtenir un affez long Siége, lorfque ces Peuples ignoroient l'ufage des Armes à feu. Chaque Village a une affez grande Place, mais il eft rare qu'elles foient régulieres.

Autrefois les Iroquois bâtiffoient leurs Cabannes beaucoup mieux que les autres Nations, \& qu'ils ne font eux - mêmes aujourd'hui ; on y voyoit des Figures en relief, mais le travail en étoit fort groflier; depuis qu'en diverfes Expéditions on a brûlé prefque toutes leurs Bourgades, ils ne fe font pas donné la peine de les rétablir dans leur premier état. Cependant fi ces Peuples font fi peu curieux de fe procurer les commodités de la vie dans les Lieux de leur réfidence ordinaire, que peut-on penfer de leurs Campemens dans leurs Voyages, \& dans leurs Hyvernemens. Un ancien Miffionnaire $(a)$, qui pour fe mettre dans la neceffité d'apprendre la Langue des Montagnais, les voulut fuivre dans une Chaffe pendant l'Hyver, nous en a fait une Defcription, que je vais vous tranfcrire prefque mot à mot.

Ces Sauvages habitent un Pays extrêmement rude $\&$ in- De leursHy(a) Le Pere PAUL, L E JEUNE。

Leur maniere de fe fortifier.

\section{Août.}

1721 .

-

(1) 


\section{$33^{\prime \prime} \mathrm{J} \mathrm{O} \mathrm{UR} \mathrm{NA} \mathrm{L} \mathrm{H} \mathrm{IS} \mathrm{T} \mathrm{OR} \mathrm{I} \mathrm{Q} \mathrm{U} \mathrm{E}$}

- culte, mais il ne l'eft pas encore autant que celui, qu'ils choi-

172 I. fiffent pour leurs Chaffes. Il faut marcher lontems pour $y$ Août. arriver, \& porter fur fon dos tout ce dont on peut avoir befoin pendant cinq ou fix mois, par des Chemins quelquefois $\mathrm{fi}$ affreux, que l'on ne comprend pas comment les Bêtes Fauves peuvent y paffer ; fi on n'avoit pas la précaution de fe fournir d'Ecorces d'Arbres, on ne trouveroit pas de quoi fe mettre à couvert de la Pluye $\&$ de la Neige pendant le Chemin. Dès qu'on eft parvenu au terme, on s'accommode un peu mieux, mais ce mieux ne confifte, qu'en ce qu'on n'y eft pas fans ceffe expofé à toutes les injures de l'air.

Tout le monde y travaille, \& les Miffionnaires, qui dans ces commencemens n'avoient perfonne pour les fervir, \& pour qui les Sauvages n'avoient aucune confidération, n'étoient pas plus épargnés que les autres, on ne leur donnoit pas même de Cabanne feparée, \& il falloit qu'ils fe logeaffent dans la premiere, où l'on vouloit bien les recevoir. Ces Cabannes, parmi la plûpart des Nations Algonquines, font à peu près de la figure de nos Glacieres rondes, \& terminées en Cône : elles n'ont point d'autres foutiens, que des Perches plantées dans la Neige, attachées enfemble par les extrémités, \& couvertes d'Écorces affez mal jointes, \& mal attachées : auffi le vent $y$ entre-t-il de toutes parts.

Leur fabrique eft l'ouvrage d'une demie heure au plus, des Branches de Sapin y tiennent lieu de Nattes, \& on n'y a point d'autres Lits. Ce qu'il y a de commode, c'eft qu'on peut les changer tous les jours : les Neiges ramaffées tout autour forment une efpece de Parapet, qui a fon utilité, les vents n'y pénetrent point, c'eft le long \& à l'abri de cs Parapet, qu'on dort auffi tranquillement fur ces Branchages, couverts d'une méchante Peau, que dans le meilleur Lit; il en coûte à la verité aux Miffionnaires pourr s'y accoûtumer, mais la fatigue \& la néceffité les y réduifent bientôt. Il n'en eft pas tout-à-fait de même de la fumée, qui prefque toujours remplit tellement le haut de la Cabanne, qu'on ne peut y être de bout, fans avoir la tête dans une efpece de tourbillon. Cela ne fait aucune peine aux Sauvages, habitués dès l'enfance à être affis à terre, ou couchés tout le tems qu'ils font dans leurs Cabannes ; mais c'eft un grand fupplice pour les Francois, à qui cette inaction ne convient pas.

D'ailleurs 
D'UN VOYA GE DE L'A MER I Q. LET. XXYII. 337

D'ailleurs le vent, qui entre, comme je l'ai remarqué, par tous les côtés, y fouffle un froid, qui tranfit d'une part, tandis qu'on étouffe, \& qu'on eft grillé de l'autre. Souvent on ne $172 \mathrm{I}$. Août. fe voit point à deux ou trois pieds, on perd les yeux à force de pleurer, \& il y a des tems, où, pour refpirer un peu, il faut fe tenir couché fur le ventre, $\&$ avoir prefque la bouche collée contre la terre : le plus court feroit de fortir dehors, mais la plûpart du tems on ne le peut pas ; tantôt à caufe d'une Neige fi épaiffe, qu'elle obfcurcit le jour, \& tantôt parce quil fouffle un vent fec, qui coupe le Vifage, \& fait éclater les Arbres dans les Forêts. Cependant un Miffionnaire eft obligé de dire fon Office, de célébrer la Meffe, \& de s'acquiter de toutes les autres fonctions de fon Miniftere.

A toutes ces incommodités il en faut ajoûter une autre ; qui d'abord vous paroîtra peu de chofe, mais qui eft réellement très-confidérable; c'eft la perfécution des Chiens. Les Sauvages en ont toujours un fort grand nombre, qui les fuivent partout, \& leur font très-attachés; peu careffans, parce qu'on ne les careffe jamais, mais hardis \& habiles Chaffeurs : j’ai déja dit qu'on les dreffe de bonne heure pour les differentes Chaffes, aufquelles on veut les appliquer ; jajoûte qu'il faut en avoir beaucoup pour chacune, parce qu'il en périt un grand nombre par les dents \& par les cornes des Bêtes fauves, quils attaquent avec un courage, que rien ne rebute. Le foin de les nourrir occupe très - peu leurs Maîtres, ils vivent de ce qu'ils peuvent attraper, \& cela ne va pas bien loin, auffi font-ils toujours fort maigres, d'ailleurs ils ont peu de poil, ce qui les rend fort fenfibles au froid.

Pour s'en garantir, s'ils ne peuvent approcher du feu, où il eft difficile qu'ils puiffent tenir tous, quand même il n'y auroit perfonne dans la Cabanne, ils vont fe coucher fur les premiers qu'ils rencontrent, \& fouvent on fe réveille la nuit en furfaut, prefque étouffé par deux ou trois Chiens. S'ils étoient un peu plus difcrets, \& fe plaçoient mieux, leur compagnie ne feroit pas trop fâcheufe, on s'en accommoderoit même affez, mais ils fe placent où ils peuvent; on a beau les chaffer, ils reviennent d'abord. C'eft bien pis encore le jour; dès qu'il paroît quelque chofe à manger, il faut voir les mouvemens, qu'ils fe donnent pour en avoir leur part. Un pauvre Miffionnaire eft à demi couché auprès du feu pour dire fon Tome III. 


\section{J O UR N A L H I S T O R I Q U E}

Bréviaire, ou pour lire un Livre, en luttant de fon mieux $172 \mathrm{I}$. contre la fumée, \& il faut qu'il effuye encore l'importunité Août. d'une douzaine de Chiens, qui ne font que paffer \& repaffer furr lui, en courant après un morceau de viande, quils ont apperçû. S'il a befoin d'un peu de repos, à peine trouvera-t-il un petit recoin, où il foit à l'abri de cette véxation. Si on lui apporte à manger, les Chiens ont plutôt mis le mufeau dans fon Plat, qu'il n'y a porté la main ; \& fouvent, tandis qu'il eft occupé à défendre fa Portion contre ceux, qui l'attaquent de front, il en vient un par derriere, qui lui en enleve la moitié, ou qui en le heurtant, lui fait tomber le Plat des mains, \& répandre fa Sagamité dans les cendres.

Affez fouvent les maux, dont je viens de parler, font effacés par un plus grand, \& au prix duquel tous les autres ne font rien; c'eft la faim. Les Provifions, qu'on a apportées, ne durent pas lontems, on a compté fur la Chaffe, \& elle ne donne pas toujours. Il eft vrai que les Sauvages fçavent endurer la faim avec autant de patience, qu'ils apportent peu de précautions pour s'en garantir; mais ils fe trouvent quelquefois réduits à une fi grande extrémité, qu'ils y fuccombent. Le Miffionnaire, de qui j’ai tiré ce détail, fut obligé dans fon premier Hyvernement, de manger des peaux d'Anguilles \& d'Elans, dont il ạvoit rapetaffé fa foutanne; après quoi il lui fallut fe nourrir des jeunes branches, \& des plus tendres Ecorces des Arbres. Il foûtint néanmoins cette épreuve, fans que fa fanté en fût alterée, mais tous n'en ont pas eu la force.

Malpropreté La feule malpropreté des Cabannes, \& l'infection, qui en dessauvages. eft une fuite néceffaire, font pour tout autre qu'un Sauvage un vrai fupplice; il eft aifé de juger jufqu'où l'une $\&$ l'autre doivent aller parmi des Gens, qui ne changent de Hardes, que quand les leurs tombent par lambeaux, \& qui n'ont nul foin de les nettoyer. L'Eté ils fe baignent tous les jours, mais ils fe frottent auffi - tôt d'Huile, ou de Graiffe d'une odeur forte. L'Hyver ils demeurent dans leur craffe, \& dans tous les tems on ne peut entrer dans leurs Cabannes, qu'on ne foit empefté.

Non feulement tout ce qu'ils mangent eft fans apprêt, \& ordinairement fort infipide, mais il régne dans leurs Repas une malpropreté, đui pafie tout ce qu'on en peut dire: ce 
D'U N V OYA GEDE L'A MER I Q. LET. XXIII. 339 que j'en ai vû, \& ce qu'on m'en a raconté, vous feroit horreur. Il y a bien peu d'Animaux, qui ne mangent plus proprement, \& quand on a vû ce qui fe paffe en cela parmi ces Peu1721 . Août. ples, on ne fçauroit plus douter, que l'imagination n'ait beaucoup de part à nos répugnances, que bien des Mêts, qui nuifent réellement à notre fanté, ne produifent cet effet par la force même de ces répugnances, \& par le peu de courage, que nous avons à les furmonter.

Il faut néanmoins convenir que les chofes ont un peu changé fur tous ces points, depuis notre arrivée en ce Pays ; j’en ai même vî chercher à fe procurer des commodités, dont ils auront peut-être bientôt de la peine à fe paffer. Quelquesuns commencent auffi à prendre un peu plus leurs précautions pour ne pas fe trouver au dépourvî, quand la Chaffe leur manquera ; \& parmi ceux, qui font domiciliés dans la Colonie, il y a bien peu à ajoûter pour les faire arriver au point d'avoir un néceffaire raifonnable. Mais qu'il eft à craindre que, quand ils en feront là, ils n'aillent bientôt plus loin, \& ne donnent dans un fuperflu, qui les rende plus malheureux encore, qu'ils ne font préfentement dans le fein de la plus grande indigence?

Ce ne fera pas au moins les Miffionnaires, qui les expoferont à ce danger; perfuadés qu'il eft moralement impoffible de bien prendre ce jufte milieu, \& de s'y borner, ils ont beaucoup mieux aimé partager avec ces Peuples ce qu'il y a de pénible dans leur maniere de vivre, que de leur ouvrir les yeux fur les moyens d'y trouver des adouciffemens. Auffe ceux mêmes, qui font tous les jours témoins de leurs fouffrances, ont-ils encore bien de la peine à comprendre comment ils y peuvent réfifter, d'autant plus qu'elles font fans relâche, \& que toutes les Saifons ont leurs incommodités particulieres.

Comme les Villages font toujours fitués, ou auprès des Bois, ou fur le bord de l'Eau, \& fouvent entre les deux, dès que l'Air commence à s'échauffer, les Maringouins, \& une des Sauvages. quantité prodigieufe d'autres Moucherons excitent une perfécution beaucoup plus vive encore, que celle de la fumée, qu'on eft même fouvent obligé d'appeller à fon fecours; car il n'y a prefque point d'autre remede contre les piqûres de ces petits Infectes, qui vous mettent tout le Corps en feeu, 

les Marches fouvent forcées, \& toujours très-rudes, qu'il faut faire à la fuite de ces Barbares, tantôt dans l'eau jufqu'à la ceinture, \& tantôt dans la fange jufqu'aux genoux; dans les Bois, au travers des ronces \& des épines, avec danger d'en être aveuglé ; dans les Campagnes, où rien ne garantit d'un Soleil auffi ardent en Eté, que le vent eft piquant pendant l'Hyver.

Si l'on voyage en Canot, la pofture gênante, où il faut s'y tenir, \& l'appréhenfion, que caufe dans les commencemens l'extrême fragilité de cette Voiture ; l'inaction, où l'on eft, \& qu'il eft impoffible d'éviter; la lenteur de la marche, que la moindre pluye, ou un vent un peu trop fort retarde; le peu de focieté, qu'on peut avoir avec des Gens, qui ne fçavent rien, qui ne parlent jamais, quand ils font occupés, qui vous infectent par leur mauvaife odeur, \& qui vous rempliffent de faletés \& de vermine : les caprices $\&$ les manieres brufques, quil en faut effuyer; les avanies, aufquelles on eft expofé de la part d'un Yvrogne, ou d'un Homme, que quelque accident inopiné, un fonge, un fouvenir fâcheux, font entrer en mauvaife humeur ; la cupidité, qui naît aifément dans le cour de ces Barbares, à la vûë d'un objet capable de les tenter, \& qui a coûté la vie à plus d'un Miffionnaire : \& fi la Guerre eft déclarée entre les Nations, parmi lefquelles on fe trouve, le danger, que l'on court fans ceffe, ou de fe voir tout-à-coup réduit à la plus dure fervitude, ou de périr dans les plus affreux tourmens. Voilà, Madame, la vie, qu'ont menée furtout les premiers Miflionnaires : fi depuis quelque tems elle a été moins rude à certains égards, il y a pour les Ouvriers de l'Evangile d'autres peines intérieures, $\&$ par conféquent plus fenfibles, qui bien loin de diminuer avec le tems, croiffent à mefure que la Colonie augmente, \& que les Naturels du Pays ont plus de communication avec toutes fortes de Perfonnes.

Enfin, pour vous tracer en racourci le Portrait de ces PeuPortrait en ples : avec un extérieur fauvage, des manieres $\&$ des ufages, racourci des Sauvages. qui fe fentent tout-à-fait de la barbarie ; on remarque en eux une focieté exempte de prefque tous les défauts, qui alterent fi fouvent la douceur de la nôtre. Ils paroiffent fans paffion, mais ils font de fang-froid, \& quelquefois par principe, ce que la paffion la plus violente \& la plus effrenée peut infpirer 
D'UN V OYA G E D E L'A M ER I Q. LeT. XXIII. 34 I à ceux, qui n'écoutent plus la raifon. Ils femblent mener la vie du monde la plus miférable, \& ils étoient peut-être les feuls heureux fur la Terre, avant que la connoiffance des objets, 1721 . qui nous remuent $\&$ nous féduifent, eût réveillé en eux une cupidité, que l'ignorance retenoit dans l'affoupiffement, \& qui n'a pourtant pas encore fait de grands ravages parmi eux. On apperçoit en eux un mélange des mœurs les plus féroces \& les plus douces, des défauts de Bêtes carnacieres, \& des vertus \& des qualités de cœur \& d'efprit, qui font le plus d'honneur à l'Humanité. On croiroit d'abord qu'ils n'ont aucune forme de gouvernement, qu'ils ne connoiffent ni loix, ni fubordination, \& que vivant dans une indépendance entiere, ils fe laiffent uniquement conduire au hafard $\&$ au caprice le plus indompté; cependant ils jouiffent de prefque tous les avantages, qu'une autorité bien réglée peut procurer aux Nations les plus policées. Nés libres $\&$ indépendans, ils ont en horreur jufqu'à l'ombre du pouvoir defpotique, mais ils s'écartent rarement de certains principes \& de certains ufages, fondés fur le bon fens, qui leur tiennent lieu de Loix, \& qui fuppléent en quelque façon à l'autorité légitime. Toute contrainte les révolte, mais la raifon toute feule les retient dans une efpéce de fubordination, qui pour être volontaire, n'en atteint pas moins au but, qu'ils fe font propofé.

Un Homme, qu'ils eftimeroient beaucoup, les trouveroit affez dociles, \& leur feroit faire à peu près tout ce qu'il voudroit ; mais il n'eft pas aifé d'avoir leur eftime à ce point. Ils ne la donnent qu'au mérite, \& à un mérite fupérieur, dont ils font auffi bons Juges, que ceux, qui parmi nous fe picquent le plus de l'être. Ils fe prennent furtout par la phyfjonomie, \& il n'eft peut-être pas d'Hommes au Monde, qui s'y connoiffent mieux : c'eft qu'ils n'ont pour qui que ce foit nul de ces égards, qui nous féduifent, \& que n'étudiant que la nature, ils la connoiffent bien. Comme ils ne font point Efclaves de l'ambition \& de l'intérêt, \& qu'il n'y a guéres que ces deux paffions, qui ayent affoibli dans nous ce fentiment de l'humanité, que l'Auteur de la Nature avoit gravé dans nos cœurs, l'inégalité des conditions ne leur eft pas néceffaire pour le maintien de la fociété.

Ainfi, Madame, on ne voit point ici, ou du moins on rencontre rarement de ces efprits hautains, qui pleins de leur

Août. 
1721 grandeur, ou de leur mérite, s'imaginent prefque qu'ils font une Efpéce à part, dédaignent le refte des Hommes, dont par conféquent ils n'ont jamais la confiance \& l'amour; ne connoiffent point leurs femblables, parce que la jaloufie, qui regne entre les Grands, ne leur permet pas de fe voir d'affez près ; ne fe connoiffent pas eux-mêmês, parce qu'ils ne s'étudient jamais, \& qu'ils fe flattent toujours ; ne font pas réfléxion que pour avoir entrée dans le cœur des Hómmes, il faut en quelque façon s'égaler à eux ; de forte qu'avec cette prétendue fupériorité de lumieres, quils regardent comme une propriété effencielle du rang éminent, qu'ils occupent, la plupart croupiffent dans une fuperbe $\&$ irremédiable ignorance de ce qu'il leur importe le plus de fçavoir, \& ne jouiffent jamais des véritables douceurs de la vie. Dans ce Pays tous les Hommes fe croyent également Hommes, \& dans l'Homme ce qu'ils eftiment le plus, c'eft l'Homme. Nulle diftinction de naiffance; nulle prérogative attribuée au rang; qui préjudicie au droit des Particuliers; point de prééminence attachée au mérite, qui infpire l'orgueil, \& qui faffe trop fentir aux autres leur infériorité. Il y a peut-être moins de délicateffe dans les fentimens, que parmi nous, mais plus de droiture, moins de façons, $\&$ de ce qui peut les rendre équivoques; moins de ces retours fur foi-même.

La feule Religion peut perfectionner ce que ces Peuples ont de bon, \& corriger ce qu'ils ont de mauvais : cela ne leur eft point particulier, mais ce qu'ils ont de propre, c'eft qu'ils y apportent moins d'obftacles, quand ils ont commencé à croire, ce qui ne peut être que l'ouvrage d'une grace fpéciale. Il eft encore vrai que pour bien établir l'empire de la Religion fur eux, il faudroit qu'ils la viffent pratiquer dans toute fa pureté, par ceux, qui la profeffent : ils font trèsfufceptibles du fcandale, que donnent les mauvais Chrétiens, comme le font tous ceux, qui font inftruits pour la premiere fois des principes de la Morale évangélique.

Vous me demanderez, Madame, s'ils ont une Religion? A cela je réponds qu'on ne peut pas dịre qu'ils n'en ont point, mais qu'il eft affez difficile de définir celle qu'ils ont. Je vous entretiendrai plus au long fur cet article au premier loifir que $j$ 'aurai ; car quoique $j$ e ne fois pas ici extrémement oc. cupé, je fuis fi fouvent interrompu, quà peine puis-je rế- 
D'U N V OYA G E DE L'A MERIQ. Let. XXIV. 343 pondre de deux heures par jour, où je fois entierement à moi. Cette Lettre, auffi bien que la plûpart de celles, qui l'ont précédée, vous fera affez connoître que je n'écris pas 1721 . Août. de fuite. Je me contente préfentement de vous ajoûter, pour achever le portrait des Sauvages, que jufques dans leurs démarches les plus indifférentes, on apperçoit des traces de la Religion primitive, mais qui échapent à ceux, qui ne les étudient pas affez, par la raifon qu'elles font encore plus effacées par le défaut d'inftruction, qu'altérées par le mélange d'un culte fuperftitieux, \& par des traditions fabuleufes.

Je fuis, \&xc.

\title{
VINT-QUATRIEME LETTRE.
}

\author{
Des Traditions, E de la Religion.des Sauvages \\ du Canada.
}

Au Fort de la Riviere de S. Jofeph, ce huit Septembre, 172 I:

\section{IADAME,}

C E T T E Lettre fera bien longue, s'il ne me furvient pas quelqu'empêchement imprévî, qui m'oblige de remettre à 1721 . une autre occafion à vous entretenir de ce que j’ai pû recueillitr touchant la Croyance, les Traditions \& la Religion de bre. nos Sauvages.

Rien n'eft plus certain, mais rien n'eft en même-tems plus obfcur que l'idée, que les Sauvages de ce Continent ont d'un Premier Etre. Tous s'accordent en général à le regarder comme le premier Efprit, le Maître \& le Créateur du Monde, mais quand on les preffe un peu fur cet article, pour fçavoir ce quils entendent par le Premier Efprit, on ne trouve plus que des imaginations bifarres, des fables fi mal conçuës, des fyftêmes fi peu digérés, \& fi peu d'uniformité, qu'on n'en peut rien dire de fuivi. On prétend que les Sioux approchent beaucoup plus que les autres de ce qu'il faut penfer de ce premier Principe, mais le peu de commerce, qu'on a eu jufqu'ici

SeptentDe l'Origine des Hom.. mes felon les Sauvages. 
avec eux, ne m'a point permis de m'inftruire de leurs Tradi-

tions, autant quill eût été à défirer, pour en parler avec quelbre.

Septem- que forte de certitude.

Prefque toutes les Nations Algonquines ont donné le nom de Grand Liéyre au premier Efprit, quelques-uns l'appellent Michabou; d'autres, Atahocan. La plûpart difent quétant porté fur les Eaux avec toute fa Cour, toute compofée de Quadrupédes comme lui, il forma la Terre d'un grain de fable, tiré du fond de l'Océan; \& les Hommes, des Corps morts des Animaux. Il y en a auffi, qui parlent d'un Dieu des Eaux, lequel s'oppofa au deffein du Grand Liévre, ou refufa du moins de le favorifer. Ce Dieu eft, felon les uns, le Grand Tygre, mais il faut obferver qu'il n'y a point de vrais Tygres en Canada; ainfi cette tradition pourroit bien venir d'ailleurs. Enfin ils ont un troifiéme Dieu, nommé Matcomek, qu'on invoque pendant l'Hyver, \& dont je n'ai rien appris de particulier.

L'Areskoui des Hurons, \& l'Agreskoué des Iroquois eft dans l'opinion de ces Peuples le Souverain Etre, \& le Dieu de la Guerre. Ceux-ci ne donnent point aux Hommes la même origine, que les Algonquins, ils ne remontent pas même jufqu'à la premiere Création. Ils font paroître d'abord fix Hommes dans le Monde, \& quand on leur demande qui les y a placés, ils répondent qu'ils ne le fçavent pas. Ils ajoûtent qu'un de ces Hommes monta au Ciel, pour y chercher une Femme, nommée Atahent fic, avec laquelle il eut commerce, \& qui parut bientôt enceinte : que le Maître du Ciel s'en étant apperçu, la précipita du haut de l'Empirée, \& qu'elle fut reçue fur le dos d'une Tortuë : qu'elle accoucha enfuite de deux Enfans, dont l'un tua l'autre,

Il n'eft plus queftion après cela, ni des cinq autres Hommes, ni même du Mari d'Atahentfic, laquelle, felon quelques-uns, n'eut qu'une Fille, qui fut Mere de Tahouitfaron \& de Jouskeka. Celui-ci, qui étoit l'aîné, tua fon Frere, \& peu de tems après fon Ayeule fe déchargea fur lui du foin de gouverner le Monde. Ils difent encore qu'Atahentfic eft la Lune \& Jouskeka, le Soleil. Il y a, comme vous voyez, Madame, bien peu de fuite dans tout ceci; car le Soleil eft fouvent pris pour Areskoui, en tant qu'il eft le Grand Génie ; mais y a-t'il moins de contradiction dans la Théologie des 
DUN VOYAGE DE L'A MERIQ. LET. XXIV.34;

Egyptiens \& des Grecs, qui font les premiers Sages de l'Antiquité Payenne? C'eft qu'il eft de l'eifence du menfonge de fe contredire, \& de n'avoir aucun principe.

Les Dieux des Sauvages ont des corps, \& vivent à peu près de la mềme maniere que nous; mais fans aucune des incommodités, aufquelles nous fommes fujets. Le terme d' $E f$ prit ne fignifie chez eux qu'un Etre d'une nature plus excellente que les autres. Ils n'en ont point pour exprimer ce qui paffe la portée de leur intelligence, extrêmement bornée cur tout ce qui n'eft pas fenfible, ou d'un ufage commun. Ils donnent néanmoins à leurs prétendus Efprits une efpéce d'immenfité, qui les rend préfens partout, car en quelque lieu, qu'on fe trouve, on les invoque, on leur parle, on fuppofe quils entendent ce qu'on leur dit, \& qu'ils agiffent en conféquence. A toutes les queftions, qu'on fait à ces Barbares, pour en fçavoir davantage, ils répondent que c'eft là tout ce qu'on leur a appris; il n'y a même que quelques Vieillards initiés aux Myfteres, qui en fçachent tant.

Selon les Iroquois, la Pontérité de Joufqueka ne paffa point la troifiéme Génération : il furvint un déluge, dont perfonne ne fe fauva, \& pour repeupler la Terre, il fallut changer les Bêtes en Hommes. Au refte, Madame, cette notion d'un déluge univerfel eft affez répanduë parmi les Amériquains; mais on ne fçauroit guéres douter qu'il n'y en ait eu un autre bien plus récent, qui fut particulier à l'Amérique. Je ne finirois point, fr je voulois marrêter à tout ce que les Sauvages débitent fur le compte de leurs principales Divinités, \& fur l'origine du Monde; mais outre le premier Etre, ou le Grand Efprit, \& les autres Dieux, qui fe trouvent fouvent confondus avec lui, il y a une infinité de Génies, ou d'Efprits fubalternes, bons \& mauvais, qui ont tous leur culte particulier.

Les Iroquois mettent Atahentfic à la tête de Ceux-ci, \& font Jufqueka le Chef des Premiers; ils le confondent même quelquefois avec le Dieu, qui chaffa du Ciel fon Ayeule, pour sêtre laiffé féduire par un Homme. On ne s'adreffe aux mauvais Génies, que pour les prier de ne point faire de mal; mais on fuppofe que les autres font commis à la garde des Hommes, \& que chacun a le fien. Dans la Langue Huronne on les nomme Okkis, \& dans l'Algonquine Manitozss: on a recours à eux dans les périls, où l'on fe trouve, dans Tome III. $\mathrm{X}$ X

I 721 .

Septembre.

Ce que c'cít que les Efprits parmi eux. 


\section{J O UR N A L H I S T O R I Q U E}

1721 . les Entreprifes, que l'on fait, \& quand on veut obtenir quelbre.

que grace extraordinaire; il n'eft rien, qu'on ne croye pouSeptem- voir leur demander, quelque déraifonnable, \& quelque contraire même, qu'il foit aux bonnes moeurs. Miais on n'eft pas fous leur protection en naiffant, il faut fçavoir manier l'Arc \& la Fléche, pour mériter cette faveur, il faut même bien des préparations pour la recevuir ; c'eft la plus importante. affaire de la vie; en voici les principales circontances.

Dirpofitions On commence par noircir le Vifage de l'Enfant, puis on requifes pour le fait jeûner pendant huit jours, fans lui donner quoi que ce nie turélaire. foit à manger, \& il faut que pendant ce tems-là fon futur Génie tutélaire fe manifelte à lui par des Songes. Le cerveau creux d'un pauvre Enfant, qui ne fait que d'entrer dans l'Adolefcence, ne fçauroit manquer de lui fournir des Rêves, $\& x$ tous les matins on a grand foin de les lui faire raconter. Souvent néanmoins le Jeûne finit avant le terme marqué, peu d'Enfans ayant la force de le pouffer $f i$ loin, mais cela ne tait pas une difficulté ; on connoì ici, comme partout ailleurs, l'ufage commode des Diipenfes. Le Génie tutélaire eft toujours la chofe, à quoi l'Enfant a le plus fouvent rêvé, \& $\&$. dans le vrai cette chofe n'eft que comme un fymbole, ou une figure, fous laquelle l'Efprit fe manifefte; mais il eft arrivé à ces Peuples, comme à tous ceux, qui fe font écartés de la Religion primitive, de s'attacher à la figure, $\&$ de perdre de vûë la réalité.

Cependant ces fymboles ne fignifient rien par eux-mêmes, tantôt c'eft une tête d'Oifeau, tantôt le pied d'un Animal, ou un morceau de Bois; en un mot tout ce qu'il y a de plus commun, \& de moins précieux. On les conferve néanmoins. avec autant de foin, que les Anciens en apportoient à la confervation de leurs Dieux Pénates. Il n'eft même rien dans la Nature, fi on en croit les Sauvages, qui n'ait fon Efprit, mais il y en a de tous les Ordres, \& tous n'ont pas la même vertu. Dès qu'ils ne comprennent pas une chofe, ils lui attribuent un Génie fupérieur, \& la maniere de s'exprimer alors, eft de dire : C'eft un Ejprit. Il en eft de même à plus forte raifon des Hommes, ceux qui ont des talens finguliers, ou qui font des chofes extraordinaires, ce font des Eiprits; c'eft-àdire, ils ont un Génie tutélaire d'un Ordre plus relevé que le Commun. 
D'UN V OY A G E D E L'A M ER IQ. Let. XXIV • 347

Quelques-uns, \& furtout les Jongleurs, tâchent de perfuader à la Multitude, qu'ils fouffrent des tranfports extatiques ; cette manie a été dans tous les tems, \& parmi tous les Peuples, \& a enfanté toutes les fauffes Religions: la va-bre.

Septemnité, fi naturelle aux Hommes, n'a point imaginé de refforts plus efficaces pour maîtrifer les Simples, la Multitude entraîne à la fin ceux, qui fe piquent le plus de fageffe. Les Impofteurs Amériquains ne doivent rien aux autres fur ce point, \& ils fçavent en tirer tout l'avantage, qu'ils prétendent. Les Jongleurs ne manquent jamais de publier que durant leurs prétenduës Extafes leurs Génies leur donnent de grandes connoiffances des chofes les plus éloignées, \& de l'avenir; $\&$ comme le hafard, fi on ne veut pas que le Démon s'en mêle, les fait quelquefois deviner, ou conjecturer affez jufte, ils acquierent par-là un grand créáit ; on les croit des Génies du premier Ordre.

Dès qu'on a déclaré à un Enfant ce qu'il doit déformais regarder comme fon Génie Protecteur, on l'inftruit avec foin de l'obligation, où il eft de l'honorer, de fuivre les avis, qu'il en recevra pendant fon fommeil, de mériter fes faveurs, de mettre en lui toute fa confiance, $\&$ de craindre les effets de fon courroux, s'il néglige de s'acquitter de ce qu'il lui doit. La Fête fe termine par un Feftin, \& l'ufage eft auffi de faire piquer fur le corps de l'Enfant, la figure de fon Okki, ou de fon Manitou. Il femble qu'un engagement fi folemnel, \& dont la marque ne peut jamais être effacée, doive être inviolable, il faut néanmoins bien peu de chofes pour le rompre.

Les Sauvages ne conviennent pas volontiers qu'ils ont tort, même avec leurs Dieux, \& ne font nulle difficulté de fe jufcifier à leurs dépens : ainfi à la premiere occafion de fe condamner foi-même, ou de jetter la faute fur fon Génie tutélaire, c'eft toujours fur celui-ci, qu'on la jette; on en cherche un autre fans façon, \& cela fe fait avec les mêmes précautions, que la premiere fois. Les Femmes ont auffi leurs Manitous, ou leurs Окkis, mais elles n'y font pas autant d'attention, que les Hommes, peut-être parce qu'elles leur donnent moins d'occupation.

On fait à tous ces Efprits différentes fortes d'Offrandes, Sacrifices d qu'on appellera, fi l'on veut, des Sacrifices. On jette dans les Saurages. Rivieres \& dans les Lacs du Petun, du Tabac, ou des Oi$\mathrm{X} x$ ij

On change quelquefois re Génie tutélaire, \& pourquoi.

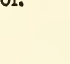


172 I. feaux, qu'on a égorgés, pour fe rendre propice le Dieu des

21. Eaux. En l'honneur du Soleil, \& quelquefois même des Ef-

Septem- prits fubalternes, on met dans le feu de toutes les chofes, dont bre. on fait ufage, \& qu'on reconnoît tenir d'eux. C'eft quelquefois par reconnoiffance, mais plus fouvent par intérêt ; la reconnoiffance même eft intéreffée, car ces Peuples ne connoiffent point les fentimens du cœur envers leurs Divinités. On remarque auffi en quelques occafions des efpeces de $\mathrm{Li}$ bations, \& $\&$ tout cela eft accompagné d'Invocations en termes Myftérieux, que les Sauvages n'ont jamais pû expliquer aux Européens; foit que dans le fond ils ne fignifient rien, foit que le fens n'en ait pas été tranfmis par la Tradition avec les paroles; peut-être auffi nous en font-ils Myftere.

On voit encore des Colliers de Porcelaine, du Tabac, des Epis de Maiz, des Peaux, \& des Animaux tous entiers, furtout des Chiens, fur les bords des Chemins difficiles, ou dangereux , fur des Rochers, ou à côté des Rapides ; \& ce font autant d'Offrandes, qu'on a faites aux Efprits,qui préfident en ces Lieux ; jai dit que le Chien eft la Vietime la plus ordinaire, qu'on leur immole; on les fufpend quelquefois tout vivans à un Arbre par les Pattes de derriere, \& on les y laiffe mourir enragés. Le Feftin de Guerre, qui fe fait toujours de Chiens, peut bien auffi paffer pour un Sacrifice. Enfin on rend à peu près les mêmes honneurs aux Efprits malfaifans, qu'à ceux, qui paffent pour propices, quand on a quelque chofe à craindre de leur malice.

Des Jeûnes. Ainfi, Madame, parmi ces Peuples, qu'on a prétendư' n'avoir aucune idée de Religion, ni de Divinité , prefque tout paroît l'objet d'un Culte Religieux, ou du moins y avoir quelque rapport. Quelques - uns fe font imaginé que leurs Jeûnes n'avoient point d'autre but, que de les accoûtumer à fupporter la faim, \& je conviens que ce motify pourroit bien entrer pour quelque chofe; mais toutes les circonftances, dont ils font accompagnés, ne laiffent aucun lieu de douter que la Religion n'y ait la principale part; n'y eût-il que cette attention, dont j'ai parlé, à obferver les fonges pendant ce tems-là ; car il eft certain que ces fonges font regardés comme de véritables oracles, \& des avertiffemens du Ciel.

Des Vœux. Il eft encore moins douteux que les vœux font parmi ces Peuples de purs actes de Religion, \& l'ufage en eft abfolw- 
D'U N V OYA GE DE L'A M ER IQ. LET. XXIV. 349

ment le même, que parmi nous. Par exemple, lorfqu'ils fe voyent fans vivres, comme il arrive fouvent dans les voyages \& pendant les Chaffes, ils promettent à leurs Génies de donner en leur honneur une portion de la premiere Bête, qu'ils tuëront, à un de leurs Chefs, \& de ne point manger, qu'ils ne fe foient acquittés de leur promeffe. Si la chofe.devient impoffible, parce que le Chef eft trop éloigné, ils brûlent ce qui lui étoit deftiné, \& en font une efpéce de facrifice.

Autrefois les Sauvages voifins de l'Acadie avoient dans leur Pays fur le bord de la Mer un Arbre extrémement vieux, dont ils racontoient bien des merveilles, \& qu'on voyoit toujours chargé d'offrandes. La Mer ayant découvert toute fa racine, il fe foûtint encore lontems prefqu'en l'air contre la violence des vents \& des flots, ce qui confirma ces Sauvages dans la penfée qu'il étoit le fiége de quelque grand Efprit : fa chute ne fut pas même capable de les détromper, \& tant qu'il en parut quelque bout de branches hors de l'eau, on lui rendit les mêmes honneurs, qu'avoit reçûs tout l'Arbre, lorfqu'il étoit fur pied.

La pluppart des feftins, des danfes \& des chanfons me paroiffent avoir auffi leur origine dans la Religion, \& en conferver encore diverfes traces; mais il faut avoir de bons Rapports des Sauvages avec les Hébreux. yeux, ou plutôt une imagination bien vive pour y appercevoir tout ce que certains Voyageurs prétendent y avoir découvert. J'en ai rencontré, qui ne pouvant s'ôter de l'efprit que nos Sauvages font defcendus des Hebreux, trouvoient partout des rapports entre ces Barbares \& le Peuple de Dieu. 11 y en a véritablement quelques-uns, comme de ne point fe fervir de couteaux dans de certains repas, $\&$ de ne point brifer les Os des Bêtes, qu'on y mange; telle eft encore la féparation des Femmes dans le tems de leurs infirmités ordinaires; on leur a même, dit-on, entendu, ou cru entendre prononcer le mot Alleluya dans quelques-unes de leurs chanfons : mais à qui perfuadera-t'on, que quand ils fe percent les oreilles \& les narines, ils le font en vertu de la loi de la Circoncifion? D'ailleurs ne fçait-on pas que l'ufage de la Circoncifion eft plus ancien que la loi, qui en fut faite pour $A$ braham \& pour fa. Poftérité ? Le feftin, qui fe fait au retour de la Chaffe, \& dont il ne faut rien laiffer, a encore été pris pour un efpéce d'holo.

1721 .

Septem. bre. 


\section{$35^{\circ} \mathrm{J} O \mathrm{U} R \mathrm{~N}$ A L H IS TOR I Q U E}

I 72 I. caufte, ou pour un refte de la Pàque des Ifraëlites, d'autant

plus, dit-on, que quand quelqu'un ne fçauroit venir à bout bre. de fa portion, il peut fe faire aider par fes voifins, comme il fe pratiquoit parmi le Peuple de Dieu, quand une Famille ne fuffifoit pas pour manger l'Agneau Pafchal tout entier.

Leurs Prê- Un ancien Miffionnaire ( $a$ ), qui a beaucoup vécu avec tres.

les Outaouais, a écrit que parmi ces Sauvages un Vieillard fait l'office de Prêtre dans les Feftins, dont je viens de parler, qu'il commence par remercier les Efprits du fuccès de la Chaf1e; qu'enfuite un autre prend un pain de Petun, le rompt en deux, \& le jette dans le feu. Ce qui eft certain, c'eft que ceux,qui les ont cités en preuve de la poffibilité de l'Atheifme proprement dit, ne les connoiffoient pas. Il eft vrai qu'ils ne raifonnent jamais fur la Religion, \& que leur extrême indolence fur ce point a toujours été le plus grand obftacle, qu'on ait rencontré à leur converfion au Chriftianifme, mais pour peu qu'on les pratique, on auroit tort d'en conclure qu'ils n'ont point d'idée de Dieu. L'indolence eft leur caractere dominant; elle paroît jufques dans les affaires, qui les intéreffent le plus, mais malgré ce défaut, malgré même cet efprit d'indépendance, dans lequel ils font élevés, nul Peuple au monde n'eft plus dépendant des idées confufes, qui leur font reftées de la Divinité, jufques-là qu'ils n'attribuent rien au hafard, \& qu'ils tirent de tout des préfages, qui felon eux font, comme je l'ai déja remarqué, des avertiffemens du Ciel.

Veftales Sall.

J'ai lu dans quelques Mémoires que plufieurs Nations de ce vages.

Continent ont eu autrefois des Filles, qui vivoient féparées de tout commerce avec les Hommes, \& ne fe marioient jamais. Je ne puis ni garantir, ni contredire ce fait. La Virginité eft par elle-même un état fi parfait, qu'on ne doit pas être furpris qu'elle ait été refpectée dans tous les Pays du Monde; mais nos plus anciens Miffionnaires n'ont point parlé, que je fçache, de ces Veftales, quoique plufieurs conviennent de l'eftime, qu'on faifoit du Célibat dans quelques Contrées. Je trouve même que parmi les Hurons \& les Iroquois on voyoit, il n'y a pas encore lontems, des Solitaires, qui gardoient la continence, \& l'on montre certaines Plantes fort falutaires, qui n'ont point de vertu, difent les Sauvages, fi elles ne font employées par des mains vierges.

(a) Le Pere Claude $A x \leq$ o $¥ z z$, Jéfuite. 
La Croyance la mieux établie parmi nos Amériquains, eft celle de l'immortalité de l'Ame. Ils ne la croyent pourtant pas purement fpirituelle, non plus que leurs Génies, \& il eft vrai de dire qu'ils ne fçauroient bien définir ni les uns, ni les autres. Quand on leur demande ce qu'ils penfent de leurs Ames, ils répondent, qu'elles font comme les ombres \& les images animées du corps, \& c'eft par une fuite de ce principe, qu'ils croyent que tout eft animé dans l'Univers. Ainf c'eft uniquement par tradition, qu'ils tiennent que nos Ames ne meurent point. Dans les differentes expreffions, qu'ils employent pour s'expliquer fur ce fujet, ils confondent fouvent l'Ame avec fes facultés, \& les facultés avec leurs opérations, quoiqu'ils fçachent fort bien en faire la diftinetion, quand ils veulent parler exactement.

Ils difent aufí que l'Ame féparée du corps conferve les mêmes inclinations, qu'elle avoit auparavant, \& c'eft la raifon pourquoi ils enterrent avec les Morts tout ce qui étoit à leur ufage. Ils font même perfuadés qu'elle demeure auprès du Cadavre jufqu'à la Fête des Morts, dont je vous parlerai bientôt; qu'enfuite elle va dans le Pays des Ames, où, felon quelques-uns, elle eft transformée en Tourterelle.

D'autres reconnoiffent dans tous les Hommes deux Ames; ils attribuent à l'une tout ce que je viens de dire, ils prétendent que l'autre ne quitte jamais le corps, fi ce n'eft pour paffer dans un autre; ce qui n'arrive pourtant gueres, difent-ils, qu'aux Ames des Enfans, lefquelles ayant peu joui de la vie, obtiennent d'en recommencer une nouvelle. C'eft pour cela qu'ils enterrent les Enfans le long des grands Chemins, afin que les Femmes puiffent en paffant recueillir leurs Ames. Or ces Ames, qui tiennent fi fidele compagnie à leurs corps, il faut les nourrir, \& c'eft pour fatisfaire à ce devoir, qu'on: porte fur les Tombes de quoi manger; mais cela dure peu, $8 r$ il faut que ces Ames s'accoûtument avec le tems à jeûner. On a quelquefois affez de peine à faire fubfifter les Vivans, fans. fe charger encore de fournir à la nourriture des Morts.

Mais une chofe, fur laquelle ces Peuples ne fe relâchent jamais, en quelqu'extrémité qu'ils fe trouvent, c'eft qu'au lieu que parmi nous la dépouille des Morts enrichit les Vivans, chez eux non-feulement on emporte dans le tombeau tout ce qu'on poffedoit, mais on y reçoit encore des préfens

bre.

I 721 .

Septem.

Ce quilis per:fent de l'immortalité do l'Ame.

\author{
(1)
}


de fes Parens \& de fes Amis. Auffi ont-ils été extrémement

fcandalifés, quand ils ont vû les François ouvrir les fépul-

Septem- cres, pour en tirer les Robes de Caftor, dont on avoit revêtu bre.

les Défunts. Les tombeaux font tellement facrés dans ce Pays, que les profaner, c'eft la plus grande hoftilité, qu'on puiffe commettre contre une Nation, \& la plus grande marque qu'on ne veut plus rien ménager avec elle.

Du Pays des J'ai dit que les Ames, lorfque le tems eft venu qu'elles doiAmes. vent fe féparer pour toujours de leurs corps, vont dans une Région, qui eft deftinée pour être leur demeure éternelle. Cette Région, difent les Sauvages, eft fort éloignée vers l'Occident, \& les Ames mettent plufieurs mois à s'y rendre. Elles ont même de grandes difficultés à furmonter, \& elles courent de grands rifques, avant que d'y arriver. On parle furtout d'un Fleuve, qu'elles ont à paffer, \& fur lequel plufieurs font naufrage; d'un Chien, dont elles ont beaucoup de peine à fe deffendre; d'un lieu de fouffrances, où elles expient leurs fautes; d'un autre, où font tourmentées les Ames des Prifonniers de guerre, qui ont été brûlés, \& où elles fe rendent le plus tard qu'elles peuvent.

Cette idée eft caufe qu'après la mort de ces Malheureux, dans la crainte que leurs Aines ne demeurent autour des $\mathrm{Ca}$ bannes, pour fe venger des tourmens, qu'on leur a fait fouffrir, on a grand foin de vifiter partout, \& de donner fans ceffe des coups de baguette, en pouffant des cris affreux, pour obliger ces Ames à s'éloigner. Les Iroquois difent qu'Atahentfic fair fon féjour ordinaire dans ce Tartare, \& qu'elle y eft uniquement occupée à tromper les Ames, pour les perdre, mais que Juskeka n'omet rien pour les prémunir contre les mauvais deffeins de fon Ayeule. Parmi les récits fabuleux, qu'on fait de ce qui fe paffe dans ces Enfers, fi reffemblans à ceux d'Homere \& de Virgile, il y en a un, qui paroît copié d'après l'aventure d'Orphée \& d'Eurydice ; il n'y a prefque rien à y changer que les noms.

Comment ils

Au refte, Madame, le bonheur, dont les Sauvages fe pićrendent fiattent de jouir dans leur prétendu Elifée, ils ne le regardent mériter d’être pas précifément comme la récompenfe de la Vertu : a voir été beureux.

bon Chaffeur, brave à la Guerre, heureux dans toutes fes Entreprifes, avoir tué \& brûlé un grand nombre d'Ennemis, ce font-là les feuls titres, qui donnent droit à leur Paradis, dont 
D'U N V OY̧A G E D E L'A MER IQ. LET. XXIV. 353 dont toute la félicité confifte à y trouver une Chafe \& une Pêche, qui ne manquent jamais, un Printems éternel, une grande abondance de toutes chofes, fans être obligé de travailler, \& tous les plaifirs des fens. C'eft auffi là tout ce I 721 . Septemqu'ils demandent à leurs Dieux pendant la vie. Toutes leurs Chanfons, qui font originairement leurs Prieres, ne roulent que fur les biens préfens, il n'y eft jamais queftion, non plus que dans leurs Voux, de la vie future; ils fe croyent affûré d'être heureux dans l'autre monde, à proportion de ce qu'ils i'auront été dans celui-ci.

Les Ames des Bêtes ont auffi leur place dans les Enfer's, car, felon les Sauvages, elles ne font pas moins immortelles des Bêtes, que les nôtres; ils leur reconnoiffent même une forte de raifon, \& non feulement chaque efpece, mais chaque Animal, fi on les en croit, a auffi fon Génie confervateur. En un mot ils ne mettent de différence entre nous \& les Brutes, que du plus au moins. L'Homme, difent-ils, eft le Roy des Animaux, qui tous ont les mêmes attributs, mais l'Homme les pofféde dans un dégré fort fupérieur. Ils tiennent encore que dans les Enfers il y a des modéles d'Ames de toutes les efpéces, mais ils s'embarraffent peu de développer cette idée, \& en général toutes celles, qui font de pure fpéculation, ne les occupent pas beaucoup: les plus fages Philofophes de l'Antiquité payenne, qui fe font tant tourmentés pour les éclaircir, ontils beaucoup plus avancé qu'eux ? On ne peut marcher fûrement dans ces obfcurités, qu'avec le flambeau de la Foi.

Il n'y a rien, fur quoi ces Barbares ayent porté plus loin la fuperftition, \& l'extravagance, que ce qui regarde les Songes; mais ils varient beaucoup dans la maniere, dont ils expliquent leurs penfées fur cela. Tantôt c'eft l'Ame raifonnable, qui fe promene, tandis que l'Ame fenfitive continue d'animer le corps. Tantôt c'eft le Génie familier, qui donne des avis falutaires fur ce qui doit arriver : tantôt c'eft une vifite, qu'on reçoit de l'Ame de l'Objet, auquel on rêve; mais de quelque façon, que l'on conçoive le Songe, il eft toujours regardé comme une chofe facrée, , \& comme le moyen le plus ordinaire, dont les Dieux fe fervent pour faire connoître aux Hommes leurs volontés.

Prévenus de cette idée, ils ne peuvent comprendre què rousn'en faffions aucun cas. Le plus fouvent ils les regardent Tome III.

De la nature des Songes felon les Sauvages. 


\section{J O UR N A L H IS T O R I Q U E}

I 721 . ordre de fa part; \& en conféquence de ce principe ils fe font bre.

Septem- un devoir de Religion d'y déférer ; un Sauvage ayant rêvé qu'on lui coupoit un doit, il fe le fit réellement couper à fon réveil, après s'être préparé à cette importante action par un feftin. Un autre s'étant vû en fonge Prifonnier entre les mains de fes Ennemis, fut fort embarraffé ; il confulta les Jongleurs, \& par leur confeil il fe fit lier à un poteau, \& brûler en plufieurs parties du corps.

Il y a des Songes heureux, \& il y en a de funeftes. Par exemple, réver qu'on voit beaucoup d'Elans, c'eft, dit-on, figne de vie: fil l'on a vû des Ours, c'eft figne qu'on mourra bientôt. J'ai déja dit qu'il en faut excepter les tems, où l'on fe prépare à la Chaffe de ces Animaux. Mais pour vous faire voir, Madame, jufqu'où ces Barbares portent l'extravagance au fujet des Songes, je vais vous raconter un fait attefté par deux témoins irréprochables, \& qui ont vû la chofe de leurs propres yeux.

ce fujet.

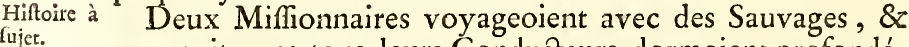
une nuit, que tous leurs Conducteurs dormoient profondément, un d'eux s'éveilla en furfault tout hors d'haleine, palpitant, faifant effort pour crier, \& fe débattant, comme s'il eût été agité de quelque Démon. Au bruit, qu'il fit, tout le Monde fut bientôt fur pied: on crut d'abord que cet Homme étoit tombé dans un accès de phrénéfie; on le faifit, \& on mit tout en ufage pour le calmer; mais ce fut inutilement : fes fureurs croiffoient toujours, \& comme on ne pouvoit plus l'arrêter, on cacha toutes les armes, de peur de quelque accident. Quelques-uns s'aviferent enfuite de lui préparer un breuvage avec de certaines herbes d'une grande vertu; mais lorfqu'on y penfoit le moins, le prétendu Malade fauta dans. la Riviere.

On l'en retira fur le champ, \& il avoua qu'il avoit froid, cependant il ne voulut pas approcher d'un bon feu, qu'on avoit allumé dans l'inftant : il s'affit au pied d'un Arbre, \& comme il paroiffoit plus tranquille, on lui apporta le bouillon, qu'on lui avoit préparé. C'eft à cet Enfant, dit-il, qu'il faut le donner, \& ce qu'il appelloit un Enfant, étoit une Peau d'Ours, qu'on avoit remplie de pailles : on lui obéit, \& l'on verfa tout le bouillon dans la Gueule de l'Animal. On. 
D'U N V OYA GE DE L'A MER IQ. LET. XXIV. 355 lui demanda alors quel étoit fon mal ? J'ai révé, répondit-il, qu'un Huart m'étoit entré dans l'eftomach. On fe mit à rire, mais il falloit guérir fon imagination bleffée, \& voici la maniere, dont on s'y prit.

Tous fe mirent à contrefaire les infenfés, \& à crier de toutes leurs forces qu'ils avoient auffi un Animal dans l'eftomach, mais ils ajoûterent qu'ils n'étoient pas d'humeur de fe jerter dans la Riviere, par le froid qu'il faifoit, pour l'en déloger; qu'ils aimoient mieux fe faire fuer. Notre Hypocondre trouva l'avis fort bon; on dreffa fur le champ une Etuvè, \& \& tous y entrerent en criant à pleine tête, enfuite chacun fe mic à contrefaire l'Animal, dont il feignoit avoir l'eftomach chargé, qui une Oye, qui un Canard, qui une Outarde, qui une Grenouille: le Kéveur contrefit auffi fon Huart. Le plaifant eft que tous les autres battoient la mefure, en frappant fur lui de toutes leurs forces, à deffein de le laffer \& de l'endormir. Pour tout autre, que pour un Sauvage, il y avoit de quoi le mettre en un état à ne pouvoir fermer l'œil de plufieurs jours; toutefois ils vinrent à bout de ce qu'ils vouloient. Le Malade dormit lontems, \& à fon réveil il fe trouva guéri; ne fe fentant, ni de la fueur, qui auroit dû l'épuifer, ni des coups, dont il avoit le corps meurtri, \& ayant perdu jufqu'au fouvenir d'un fonge, qui lui avoit tant coûté.

Mais ce n'eft pas feulement celui, qui a révé, qui doit fatisfaire aux obligations, qu'il s'imagine lui être impofées par fon fonge : ce feroit un crime pour tous ceux, à qui il s'addreffe, que de lui refufer ce qu'il a défiré en révant, $\&$ vous jugez bien, Madame, que cela peut tirer à conféquence. Mais comme les Sauvages ne font point intéreffés, ils abufent beaucoup moins de ce principe, qu'on ne feroic ailleurs; $\&$ puis chacun peut avoir fon tour. Si la chofe défirée eft de nature à ne pouvoir être fournie par un Particulier, le Public s'en charge"; fallut-il l'aller chercher à cinq cens lieuës, il la faut trouver à quelque prix que ce foit, 8 on ne fçauroit dire avec quel foin on la conferve, quand on eft venu à bout de l'avoir. Si c'eft une chofe inanimée, on eft plus tranquille, mais fi c'eft un Animal, fa mort caufe des inquiétudes étonnantes.

L'affaire eft plus férieufe encore, fi quelqu'un s'avife de réver qu'il caffe la rête à un autre, car il la lui caffe en effet, s'il le peut : mais malheur à lui, fi quelqu'autre s'avife à fon tour

Maniere dont on fe débarrafle d'un réve, quand il en coûte trop pour y fatisfaire.

bre. 
1721356 J O U R N A L H IS T O R I Q U E

1721 . de fonger qu'il venge le Mort. D'ailleurs avec un peu de pré-

Septem- fence d'efprit, on fe tire aifément d'embarras; il ne faut que bre.

fçavoir oppofer fur le champ à un tel rêve un autre fonge, qui "le contredife. "Je vois bien, dit alors le premier Réveur,

" que ton Efprit eft plus 'fort que le mien, ainfi n'en parlons

" plus ". Tous ne font pourtant pas fi faciles à démonter ; mais il en eft peu, qu'on ne contente, ou dont on n'appaife le Génie par quelque préfent.

De la Fête Je ne fçai pas, fi la Religion a jamais eu part à ce que l'on des Songes. appelle communément la Fête des Songes, \& de ce que les Iroquois \& quelques autres ont beaucoup mieux nommé le renverfement de la Cervelle. C'eft une efpéce de Bacchanale, qui dure ordinairement quinze jours, \& fe célébre fur la fin de l'Hyver. Il n'eft point ide folie, qu'on ne faffe alors; \& chacun court de Cabanne en Cabanne, déguifé en mille manieres, toutes ridicules: on brife, \& on renverfe tout, \&z perfonne n'ofe s'y oppofer. Quiconque ne veut pas fe trouver dans une telle confufion, ni être expofé à toutes les avanies, qu'il y faut effuyer, doit s'abfenter. Dès qu'on rencontre quelqu'un, on lui donne fon rêve à deviner, \& s'il le devine, c'eft à fes dépens, il faut qu'il donne la chofe, à quoi l'on a rêvé. A la fin on rend tout, on fait un grand feftin, \& l'on ne penfe plus qu'à réparer les triftes effets de la Mafcarade, ce qui le plus fouvent n'eft pas une petite affaire : car c'eft encore là une de ces occafions, qu'on attend fans rien dire, pour bien frotter ceux, dont on croit avoir reçî quelque offenfe : mais la Fête finie, il faut tout oublier.

Defcription Je trouve la defcription d'une de ces Fêtes dans le Journal d'une de cesfềres. d'un Miffionnaire (a), qui en fut bien malgré lui le fpectateur à Onnontagué. La voici. Elle fut proclamée le $22^{\mathrm{e}}$ de Février, \& ce furent les Anciens, qui firent la proclamation avec le même férieux, que s'ịl eût été queftion d'une affaire d'Etat. A peine furent-ils rentrés chez eux, qu'on vit partiơ de la main Hommes, Femmes, Enfans, prefque tout nuds, quoiqu'il fit un froid intolérable. Ils entrerent d'abord dans toutes les Cabannes, puis ils furent quelque tems à errer de tous. côtés, fans fçavoir où ils alloient, ni ce qu'ils vouloient: on les eut pris pour des Perfonmes yvres, ou pour des furieux, qu'un tranfport avoit mis hors d'eux-mêmes.

(a) Le Pere Claude DABIO Ne 
D'U N V OYA GE D E L'A MER I Q. LET. XXIV. 357

Plufieurs bornerent là leur folie, \& ne parurent plus. Les autres voulurent ufer du privilége de la Fête, pendant laquelle on eft réputé hors de fens, par conféquent n'être point refponfable de ce qu'on fait, \& venger fes querelles parti- bre. culieres. Ils ne s'épargnerent affûrement pas. Aux uns ils jettoient de l'eau à pleine cuvée, \& cette eau, qui fe glaçoir d'abord, étoit capable de tranfir de froid ceux, qui la recevoient. lls couvroient les autres de cendres chaudes, ou de toutes fortes d'immondices; quelques-uns prenoient des tifons, ou des charbons allumés, \& les lançoient à la tête du premier, qu'ils rencontroient; d'autres brifoient tout dans les Cabannes, fe ruoient fur ceux, à qui ils en vouloient, \& les chargeoient de coups. Il falloit, pour fe délivrer de cette perfécution, deviner des fonges, où fouvent l'on ne conce. voit rien.

Le Miffionnaire \& fon Compagnon furent fouvent fur le point d'être plus que témọins de ces extravagances: un de ces Phrénetiques entra dans une Cabanne, où il les avoit vû fe réfugier dès le commencement. Heureufement pour eux, ils venoient d'en fortir; car il y avoit tout lieu de croire que ce Furieux vouloit leur faire un mauvais parti. Déconcerté par leur fuite, il s'écria qu'il vouloit qu'on devinât fon fonge, \& qu'on y fatisfit fur l'heure: comme on tardoit trop, il dit: je tuë un François; auffitôt le Maître de la Cabanne jetta un habit François, que ce furieux perça de plufieurs coups.

Alors celui, qui le lui avoit jetté, entrant à fon tour en firreur, dit qu'il vouloit venger le François, \& qu'il alloit réduire en cendres tout le Village : il commença en effet par mettre le feu à fa propre Cabanne, où cette fcene s'étoit paffée, \& tout le monde en étant forti, il s'y enferma. Le feu, qu'il avoit allumé en plufieurs endroits, ne paroiffoit point encore au dehors, quand un des Miffionnaires fe préfenta pour y entrer: on lui dit ce qui venoit d'arriver, \& il craignit que fon Hôte ne fût plus le maître d'en fortir, quand il le voudroit ; il enfonça la porte, faifit le Sauvage, le mit dehors, éteignit le feu, \& s'enferma dans la Cabanne. Son Hôte cependant couroit tout le Village en criant qu'il vouloit touthrûler : on lui jetta un Chien, dans l'efpérance qu'il affouviroit fa rage fur cet Animal, il dit que ce n'étoit pas affez,

1721 .

Septen-

(n) 


\section{$35^{8}$ J O UR N A L H IST OR I Q U E}

17 2 I. pour réparer l'affront, qu'on lui avoit fait, en tuant un Fran-

Septem- çois dans fa Cabanne: on lui jetta un fecond Chien, il le mit bre.

Cet Homme avoit un Frere, qui voulut auffi jouer fon rôle. Il s'habilla à peu près, comme on repréfente les Satyres, fe couvrant de feuilles de Maiz depuis la tête jufqu'aux pieds : il fit équipper deux Femmes en vraies Mégeres, la face noircie, les cheveux épars, une Peau de Loup fur le corps, \& un pieu à la main. Ainfi efcorté il va dans toutes les Cabannes, criant \& hurlant de toute fa force ; il grimpe fur le toit, y fait mille tours avec autant de foupleffe, quauroit pû faire le plus habile Danfeur de Cordes, puis il jette des cris épouvantables, comme s'il étoit arrivé quelque grand malheur; enfuite il defcend, marche gravement précédé de fes deux Bacchantes, qui furieufes à leur tour, renverfent avec leurs pieux tout ce qui fe rencontre fur leur paffage. Elles étoient à peine délivrées de cette manie, ou laffes de faire leur perfonnage, qu'une autre Femme prit leur place, entra dans la $\mathrm{Ca}$ banne, où étoient les deux Jéfuites, \& armée d'une Arquebufe, qu'elle venoit de gagner en faifant deviner fon rêve, elle chanta la guerre, \& fit contre elle-même mille imprécations, fi elle ne ramenoit pas des Prifonniers.

Un Guerrier fuivit de près cette Amazone, l'Arc \& une Fleche d'une main, \& de l'autre une Bayonnette. A près qu'il fe fut bien égofillé à crier, il fe jetta tout à coup fur une $\mathrm{Fem-}$ me, qui ne penfoit à rien, lui porta fa Bayonnette à la gorge, la prit par les cheveux, lui en coupa une poignée, \& feretira. Un Jongleur parut enfuite, ayant à la main un bâton orrié de plumes, par le moyen duquel il fe vantoit de deviner les chofes les plus cachées. Un Sauvage l'accompagnoit portant un vafe rempli de je ne fçai quelle liqueur, dont il lui donnoit de tems en tems à boire; le Charlatan ne l'avoit pas plutôt à la bouche, qu'il la rejettoit, en fouflant fur fes mains \& fur fon bâton, \& à chaque fois il devinoit toutes les énigmes, qu'on lui propofoit.

Deux Femmes vinrent après, \& firent entendre qu'elles avoient des défirs ; l'une étendit d'abord une Natte, on devina qu'elle demandoit du Poiffon, \& on lui en donna. L'autre avoit un Hoyau à la main, on comprit qu'elle vouloit avoir un Champ pour le cultiver; on la mena hors du Village, \& 
D'U N VOYA GE DE L'A MERIQ. LET. XXV. 359 on la mit à même. Un Chef avoit rêvé, difoit-il, qu'il voyoit deux Cœurs humains; on ne pût expliquer fon Songe, $\&$ cela mit tout le Monde en grande peine. Il fit bien du bruit, on prolongea même la Fête d'un jour ; tout fut inutile, \& il fallut qu'il fe tranquillisât. Tantôt on voyoit des Troupes de Gens armés, qui faifoient mine de vouloir fe battre; tantôt des Bandes de Baladins, qui jouoient toutes fortes de Farces. Cette manie dura quatre jours, \& il parut que c'étoit par confidération pour les deux Jéfuites, qu'on en avoit ainfi abregé le tems; mais on y fit bien autant de défordres, qu'on avoit accoûtumé d'en faire en quinze. On eut cependant encore cet égard pour les Miffionnaires, qu'on ne les troubla point dans leurs fonations, \& qu'on n'empêcha point les Chrétiens de s'acquiter de leurs devoirs de Religion. Mais en voila affez fur cet article; je ferme ma Lettre pour la donner à un Voyageur, qui retourne dans la Colonie, en vous afsûrant que je fuis, \&c.

\section{VINT-CINQUIÉME LETTRE.}

Suite des Traditions des Sauvages.

Au Fort de la Riviere de S. Jofeph, ce ${ }_{4}$ Sept. $172 I_{0}$.

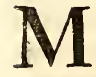

A D A M E,

Il y a trois jours que je partis d'ici pour me rendre à Chicagou, en côtoyant la Rive Méridionale du Lac Michigan: mais nous trouvâmes ce Lac fi fort en fureur, que nous prîmes le parti de revenir ici, \& $x$ de choifir une autre Route pour gagner la Louyfiane. Notre départ eft fixé au feize, \& je vais profiter de ces deux jours de retardement pour reprendre mon Récit fur les Ufages \& les Traditions de nos Amériquains.

Les Sauvages, dans ce que je vous ai dit dans ma derniere Lettre, ne reconnoiffent que l'opération des Bons Génies; les feuls Sorciers, \& ceux, qui ufent de maléfices, paffent

I 72 I.

Septems: bre。 


\section{J O UR N A L H IS T O R I Q U E}

1721 . pour être en commerce avec les Mauvais, $\&$ ce font fur-

Septem- gleurs de profeffion, non feulement ne s'en mêlent pas, au bre. moins ouvertement, mais ils font une étude particuliere pour fçavoir découvrir les Sorts, \& en empêcher les pernicieux effets. Dans le fond, il n'y a gueres dans tout ce qu'on ma raconré fur cela, que de la charlatanerie ; ce font des Serpens, dont on exprime le venin; des Herbes cueillies en certains tems, \& en prononçant de certaines paroles; des Animaux, qu'on égorge, \& dont on jette quelques parties dans le feu.

Chez les Illinois \& dans quelques autres Nations, on fait de petits Marmouzets pour repréfenter ceux, dont on veut abréger les jours, \& qu'on perce au cœur. D'autre fois on prend une Pierre, \& par le moyen de quelques invocations on prétend en former une femblable dans le cœur de fon Ennemi. Je fuis perfuadé que cela réufiit rarement, fi le Diable ne s'en mêle pas; toutefors on appréhende tellement les Magiciens, que le moindre foupçon fuffit pour mettre en pieces quiconque eft tant foit peu loupçonne de l'être. Mais quoique cette Profeffion foit fi dangereufe, ilfe trouve partout des Gens, qui n'en ont point d'autre. Il eft même vrai que les plus fentés \& les moins crédules de ceux, qui ont le plus pratiqué les Sauvages, conviennent qu'il y a quelquefois du réel dans leur Magie.

Ces Infideles, Madame, feroient-ils les feuls, en qui on n'auroit pas reconnu l'opération du Démon ? Et quel autre Maître que cet Efprit mal-faifant, Ė homicide dès le commencement du Monde (a), auroit appris à tant de Peuples, qui n'ont jamais eu de commerce les uns avec les autres, un art, que nous ne fçaurions regarder comme abfolument frivole, fans contredire les Divines Ecritures? Il faut donc avouer que les Puiffances Infernales ont quelques Suppôts fur la Terre, mais que Dieu a mis des bornes très - étroites à leur malignité , \& ne permet quelquefois qu'on reffente les effets du pouvoir, quill a jugé à propos de leur laiffer, que pour fervir tantôt fá Juftice, \& tantôt fa miféricorde.

Des Jon- Il faut dire à peu près la même chofe des Jongleurs du $\mathrm{Ca}$ gleurs. nada, qui font profeffion de n'avoir de commerce qu'avec ce (a) Joan. 8. 44. 
D'UN VOYAGE DE L'A MERIQ. LET. XXV. $36 \mathrm{I}$ qu'ils appellent Génies bienfaifans, \& qui fe vantent de connoître par leurs moyens ce qui fe paffe dans les Pays les plus éloignés, ou ce qui doit arriver dans les tems les plus reculés; de découvrir la fource $\&$ la nature des Maladies les plus ca- bre. chées, \& d'avoir le fecret de les guérir; de difcerner dans les Affaires les plus embroüillées le parti, qu'il faut prendre ; d'expliquer les Songes les plus obfcurs; de faire réuffir les Négociations les plus difficiles; de rendre les Dieux propices aux Guerriers \& aux Chaffeurs. Ces prétendus bons Génies font, comme tous les Dieux du Paganifne, de véritables Démons, lefquels reçoivent des hommages, qui ne font dûs qu'au feul vrai Dieu, \& dont les Preftiges font encore plus dangereux que ceux des mauvais Génies, parce qu'ils contribuent davantage à retenir leurs Adorateurs dans leur aveuglement.

Il eft hors de doute que parmi leurs Suppôts, les plus hardis font les plus refpectés, \& qu'avec un peu de manége ils perfuadent aifément des Peuples élevés dans la Superftition. Quoiqu'on ait vî naître ces Impofteurs, s'il leur prend envie de fe donner une naiffance furnaturelle, ils trouvent des Gens, qui les en croyent fur leur parole, comme s'ils les avoient vû defcendre du Ciel, \& qui prennent pour une efpece d'enchantement \& d'illufion de les avoir cru d'abord nés comme les autres Hommes; leurs artifices font néanmoins pour l'ordinaire fi groffiers \& fi ufés, qu'il n'y a que les Sots, \& les Enfans, qui s'y laiffent prendre ; fi ce n'eit lorfqu'ils agiffent en qualité de Médecins: car qui ne fçait que, lorfqu'il eft queftion de recouvrer la fanté, la crédulité la plus exceffive eft de tous les Pays, de ceux, qui fe piquent le plus de fageffe, comme de ceux, dont les lumieres font plus bornées?

Après tout, Madame, je le repete, il eft difficile de ne pas tomber d'accord que parmi ces Infideles il fe paffe quelquefois tiges. des chofes très - capables de tromper, au moins la Multitude, pour ne rien dire de plus. J'ai oui dire à des Perfonnes, dont je ne pouvois foupçonner, ni la bonne foi, ni la prudence, que lorfque ces lmporteurs s'enferment dans les Etuves pour fe faire fuer, \& c'eft - là une de leurs plus ordinaires préparations pour faire leurs preftiges, ils ne différent en rien desPythoniffes, telles que lesPoëtes nous les ont repréfentées fur le Trépied: qu'onles y voit entrer dans des convulTome III. $\mathrm{Z} \mathrm{z}$ 
362 J O UR N A L H I S T ORIQ U E

7 fions \& des enthoufiafmes, prendre des tons de voix, \& faire des actions, qui paroiffent au-deffus des forces humaines,

Septem- \& qui infpirent aux Spectateurs les plus prévenus contre bre. leurs impoftures une horreur \& $\mathrm{x}$ un faififfement, dont ils ne font pas les maîtres.

On afsûre encore qu'ils fouffrent beaucoup dans ces occafions, \& qu'il s'en trouve, qu'on n'engage pas aifément, même en les payant bien, à fe livrer ainfi a l'Efprit, qui les agite. Mais il ne faut pas croire qu'il y ait du furnaturel en ce qu'au fortir de ces fueurs violentes, ils vont fe jetter dans l'eau froide \& quelquefois glacée, fans en reffentir aucune incommodité. Cela leur eft commun avec tous les autres Sauvages, \& même avec d'autres Peuples du Nord (a). C'eft une expérience, qui déconcerte un peu la Médecine, mais à laquelle le Diable n'a certainement aucune part.

Il eft encore vrai que les Jongleurs rencontrent trop fouvent jufte dans leurs Prédictions, pour croire qu'ils devinent toujours par hazard, \& quil fe paffe dans ces occafions des chofes, qu'il n'eft prefque pas poffible d'attribuer à aucun fecret naturel. On a vủ les pieux, dont ces Etuves étoient fermées, fe courber jufqu'à terre, tandis que le Jongleur fe tenoit tranquille, fans remuer, fans y toucher, quil chantoit, \& qu'il prédifoit l'avenir. Les Lettres des anciens Miffionnaires font remplies de faits, qui ne laiffent aucun doute que ces Séducteurs n'ayent un véritable commerce avec le Pere de la féduction \& du menfonge. Plufieurs François m'ont parlé fur le même ton, je ne vous en citerai qu'un trait, que je fçais de fource.

Vous avez vû à Paris Madame DE MARson , \& elle y eit encore; voici ce que M. le Marquis de Vaudreuil fon Gendre , actuellement notre Gouverneur Général , me raconta cet Hyver, \& qu'il a fçû de cette Dame, qui n'eft rien moins qu'un efprit foible. Elle étoit un jour fort inquiette au fujet de M. de Marfon, fon Mari, lequel commandoit dans un Porte, que nous avions en Acadie; il étoit abfent, \& le tems qu'il avoit marqué pour fon retour, étoit paffé. Une Femme Sauvage, qui vit Madame de Marfon en peine, lui en demanda la caufe, \& l'ayant apprife, lui dit, après y avoir

(a) Le Poëte RE G N A R D nous affûre dans fon Voyage de Lapponie, qu'il a vû faire la même chofe en Bothnie. 
D'UN VOYA GE DE L'A MERI Q. LET. XXV. $36_{3}$ un peu rêvé, de ne plus fe chagriner, que fon Epoux reviendroit tel jour \& à telle heure, qu'elle lui marqua, avec un Chapeau gris fur la tête. Comme elle s'apperçut que la Dame n'ajoûtoit point foi à fa prédiction, au jour \& à l'heure, qu'elle avoit affignée, elle retourna chez elle, lui demanda fi elle ne vouloit pas venir voir arriver fon Mari, \& la preffa de telle forte de la fuivre, qu'elle l'entraîna au bord de la Riviere. A peine y étoient-elles arrivées, que M. de Marfon parut dans un Canot, un chapeau gris fur la tête ; \& ayant appris ce qui s'étoit paffé, affúra qu'il ne pouvoit pas comprendre comment la Sauvageffe avoit pû fçavoir l'heure $\&$ le jour de fon arrivée.

Cet exemple, Madame, \& beaucoup d'autres, que je fçai, \& qui ne font pas moins certains, prouvent qu'il y a quelquefois de l'opération du Démon dans la magie des Sauvages; mais il n'appartient, dit-on, qu'aux Jongleurs de faire les évocations, quand il s'agit des affaires publiques. On prétend que tous les Algonquins \& les Abénaquis pratiquoient autrefois une efpéce de Pyromancie, dont voici tout le myftere. Ils réduifoient en une poudre très-fine du charbon de bois de Cédre ; ils difpofoient cette poudre à leur maniere, puis y mettoient le feu, \& par le tour, que prenoit le feu en courant fur cette poudre, ils connoiffoient, difoient-ils, ce qu'ils cherchoient. On ajoûte que les Abénaquis, en fe convertiffant au Chriftianifine, ont eu bien de la peine à renoncer à un ufage, qu'ils regardoient comme un moyen très-innocent de connoître ce qui fe paffoit loin de chez eux.

Je n'ai pas oui dire que les Particuliers, qui vouloient porfeder ces fortes de fecrets, euffent befoin, pour y être ini- des Jongleurs. tiés, de paffer par aucune épreuve; mais les Jongleurs de profeffion ne font jamais revêtus de ce caractere, qui leur fait contracter une efpéce de pacte avec les Génies, \& qui rend leurs perfonnes refpectables, qu'après s'y être difpofés par des jeûnes, qu'ils pouffent très-loin, \& pendant lefquels ils ne font autre chofe, que battre le tambour, crier, hurler, chanter, \& fumer. L'inftallation fe fait enfuite dans une efpéce de Bacchanale, avec des cérémonies fi extravagantes, \& accompagnées de tant de fureurs, qu'on diroit que le Démon y prend dès-lors poffeffion de leurs perfonnes.

Ils ne font néanmoins les Miniftres de ces Dieux prétendus, $\mathrm{Z}_{\mathrm{z}}$ ij

1721 .

Septembre.

De la Pyros mancie. 


\section{J O U R N A L H IS TOR I Q U E}

que pour annoncer aux Hommes leurs volontés, \& pour être

1721 . leurs Interprétes: car fi l'on peut donner le nom de facrifices bre.

Septem- aux offrandes, que ces Peuples font à leurs Divinités, les Prêtres parmi eux ne font jamais les Jongleurs : dans les cérémonies publiques, ce font les Chefs, \& dans le domeftique, ce font ordinairement les Peres de Famille, ou à leur défaut le plus confidérable de la Cabanne. Mais la principale occupation des Jongleurs, ou du moins celle, dont ils retirent plus de profit, c'eft la Médecine: ils exercent cet art avec des principes fondés fur la connoiffance des Simples, fur l'expérience, \& fur la conjecture, comme on fait par-tout, mais il eft rare qu'ils n'y mêlent pas de la fuperftition, \& de la charlatanerie, dont le Vulgaire eft toujours dupe.

Maladies ordinaires parmi les Sauyages.

Il n'y a peut-être point d'Hommes au Monde, qui le foient plus de ces Impofteurs, que les Sauvages, quoiqu'il y en ait peu, qui ayent moins befoin de recourir à la Médecine. Nonfeulement ils font prefque tous d'une complexion faine \& robufte, mais ils nont connu la plûpart des Maladies, aufquelles nous fommes fujets, que depuis qu'ils nous ont fréquentés. Ils ne fçavoient ce que c'eft que la Petite V'́role, quand ils l'ont reçûë de nous, \& l'on ne doit attribuer les grands ravages, qu'elle a faits parmi eux, qu'à cette ignorance. La Goute, la Gravelle, la Pierre, l'Apoplexie, \& quantité d'autres Maux, fi communs en Europe, n'ont point encore pénétré dans cette partie du Nouveau Monde parmi les Naturels du Pays.

11 eft vrai que les excès, qu'ils font dans leurs feftins, 8 leurs jeûnes outrés, leur caufent des douleurs \& des foibleffes de poitrine $\&$ d'eftomach, qui en font perir un grand nombre. Il meurt aufí quantité de Jeunes-Gens de Phtifie, \& l'on prétend que c'eft une fuite des grandes fatigues, $\&$ des exer. cices violens, aufquels ils s'expofent dès leur enfance, \& avant qu'ils foient en état de les fupporter. C'eft une fottife de croire, comme font quelques-uns, qu'ils ont le fang plus froid que nous, \& d'attribuer à cela leur infenfibilité prétenduë dans les tourmens; mais ils l'ont extrêmément balfamique, \& cela vient fans doute de ce qu'jls n'ufent point de Sel, ni de rien de ce que nous employons, pour relcver le goût des Viandes.

Il eft rare qu'ils regardent une Maladie comme purement vfage, qu'ils naturelle, \& que parmi les remédes ordinaires, dont ils ufent, font de leurs ils en reconnoiffent, qui ayent par eux-mêmes la vertu de
simples. 
D'UN V OYA G E DE L'A M ERIQ. LET. XXV. $3^{6} ;$ guérir. Le grand ufage, qu'ils font de leurs Simples, eft pour les playes, les fractures, les diflocations, les luxations \& les ruptures. Ils blâment les grandes incifions, que font nos Chirurgiens pour nétoyer les playes, ils expriment le fuc $172 \mathrm{I}$. Septem. de plufieurs Plantes, $\&$ avec cette compofition ils en attirent tout le pus, \& jufqu'aux efquilles, les pierres, le fer, \& généralement tous les corps étrangers, qui font demeurés dans la partie bleffée. Ces mêmes fucs font toute la nourriture du Malade, jufqu’à ce que fa playe foit fermée : celui, qui le panfe, en prend auffi, avant que de fuccer la playe, quand il eft obligé d'en venir là : mais il y vient rarement, le plus fouvent il fe contente de feringuer de ce jus dans la playe.

Tout cela eft dans les regles, mais comme il faut à ces $\mathrm{Peu}$ ples du furnaturel par-tout, fouvent le Jongleur déchire la playe avec les dents, \& montrant enfuite un morceau de bois, ou quelqu'autre chofe femblable, qu'il avoit eu la précaution de mettre dans fa bouche, il fait croire au Malade quil l'a tiré de fa playe, \& que c'étoit le charme, qui caufoit tout le danger de fa Maladie. Ce qui eft certain, c'eft qu'ils ont des fecrets \& des remédes admirables. Un os rompu eft bien repris, \& folide en huit jours. Un Soldat François, qui étoit en garnifon dans un Fort de l'Acadie, tomboit du Haut$\mathrm{Mal}, \&$ fes accès étoient devenus prefque journaliers, \& trèsviolens : une Femme Sauvage, qui fe trouva préfente à un de ies accès, lui alla faire deux boles d'une racine pulvérifée, dont elle ne dit point le nom; recommanda qu'on lui en fît prendre un à la fin du premier accès, qu'il aúroit; avertit qu'il fuëroit beaucoup, \& qu'il auroit de grandes évacuations par le vomiffement \& par les felles, \& ajoûta que fi le premier bol n'emportoit pas tout le mal, le fecond le guériroit parfaitement : la chofe arriva, comme elle l'avoit dit; le Malade eut encore un accès après la premiere prife, mais ce fut le dernier. Il jouit dans la fuite d'une fanté parfaite.

Ces Peuples ont encore des remédes prompts $\&$ fouverains contre la Paralyfie, l'Hydropifie, \& les Maux Vénériens. Des rapures de Bois de Gayac \& de Saffafras font leurs Spécifiques ordinaires contre les deux dernieres Maladies; ils en font une boiffon, qui en guérit \& en garantit, pourvû qu'on en faffe un ufage continuel $(a)$. Dans les Maux aigus, com-

(a) On a parlé depuis d'une Poudre, compof́é de trois Simples, qu'un Sauvagea a dontres Remédess. 


\section{J O UR N A L H IS TOR I Q U E}

I 721 me dans la Pleuréfie, ils travaillent fur le côté oppofé à la

douleur; ils y mettent des cataplâmes, qui attirent, \& embre.

pêchent les dépôts. Dans la Fiévre ils ufent de lotions froides, avec des décoctions d'Herbes, \& préviennent par-là l'inflammation \& le tranfport. Ils vantent furtout la diete, mais ils ne la font confifter, qu'à s'abftenir de certains alimens, qu'ils eftiment leur être nuifibles.

Ils n'avoient pas autrefois l'ufage de la Saignée, \& ils y fuppléoient par des Scarifications aux endroits, où ils fentoient du mal : ils y appliquoient enfuite une maniere de ventoufe avec des courges, qu'ils rempliffoient de matieres combuftibles, aufquelles ils mettoient le feu. Les Cauftiques, les Uftulations, les Boutons de feu leur étoient familiers; mais comme ils ne connoiffoient point la Pierre Infernale, ils fe fervoient à fa place de bois pourri. Aujourd'hui la Saignée leur tient lieu de tout cela. Dans les Quartiers du Nord on ufoit beaucoup de Lavemens; une Veffie leur fervoit de Seringue. Ils ont contre la Dyfenterie un reméde, qui a prefque toujours fon effet; c'eft un jus, quils expriment des extrémités des branches de Cédre, après les avoir fait bien bouillir.

De la Sueur. Mais leur grand reméde, \& leur grand préfervatif contre tous les Maux, eft la Sueur. Je viens de vous dire, Madame, qu'au fortir de l'Etuve, \& lorfque l'eau leur découle de toutes les parties du corps, ils vont fe jetter dans la Riviere ; fi elle eft trop éloignée, ils fe font arrofer de l'eau la plus froide. Souvent ils fuent uniquement pour fe délaffer, pour fe tranquillifer l'efprit, \& pour être plus en état de parler d'affaires. Dès qu'un Etranger arrive dans une Cabanne, on lui fait du feu, on lui frotte les pieds avec de l'huile, \& tour de fuite on le conduit dans une Etuve, où fon Hôte lui tient compagnie. Ils ont même une autre maniere de provoquer la fueur, qu'on employe dans de certaines Maladies: elle confifte à étendre le Malade fur une efpéce de Couche un peu élevée, fous laquelle on fait bouillir dans une Chaudiere du bois d'Epinette, \& des branches de Sapin. La vapeur, qui en fort, caufe une fueur des plus abondantes : on prétend même que l'odeur en eft très-falutaire; la fueur des

née à un de nos Miffionnaires, \& qui guérit radicalement en peu de jours le Mal de $\mathrm{Na-}$ ples le plus invétété. 

Etuves, qui n'eft procurée que par la vapeur de l'eau verfée fur des Cailloux, n'a point cet avantage.

Dans l'Acadie, une Maladie n'étoit cenfée bien férieufe, que quand le Malade ne vouloit abfolument rien prendre, $\&$ plufieurs autres Nations font encore dans cette erreur : quelque Fiévre, qu'on ait, fil l'on veut manger, on mange de tout, comme les autres. Mais dès que la Maladie paroît dangereufe, c'eft-à-dire, quand le Malade rejette toutes fortes de nourriture, on y apporte beaucoup d'attention. Il eft vrai que les principes, fur lefquels eft fondée toute la Médecine des Sauvages, font fort extraordinaires, on ne refufe rien au Malade cie ce qu'il demande, parce que, dit - on, fes défirs en cet état font des ordres du Génie, qui veille à fa confervation; \& quand on appelle les Jongleurs, c'eft moins à caufe de leur habileté, que parce qu'on fuppofe, qu'ils peuvent mieux fçavoir des Efprits la caufe du mal, \& les remedes, quili $\mathrm{y}$ faut appliquer.

$D$ 'ailleurs, on ne veut rien avoir à fe reprocber, il femble que la Mort perde une partie de ce qu'elle a d'affreux, quand elle vient à la fuite des Remedes, dût-elle en être l'effet. Nos Sauvages fe font en cela foûmis à la loi commune, $\&$ au préjugé général de toutes les Nations \& de tous les Siécles; \& ils font d'autant plus excufables, ce femble, de porter fi loin la crédulité, que reconnoiffant du furnaturel dans toutes les Maladies, \& faifant entrer la Religion dans l'Art de les guérir, ils fe croyent moins obligés de raifonner, \& fe font un devoir de fe laiffer conduire à l'aveugle.

Souvent le Malade fe met dans la tête que fon mal eft l'effet d'un Maléfice, alors toute l'attention fe porte à le découvrir, $\&$ c'eft le devoir du Jongleur. Il commence lui - même par fe faire fuer, \& quand il s'eft bien fatigué à crier, à fe débattre, \& à invoquer fon Génie, la premiere chofe extraordinaire, qui lui vient en penfée, il lui attribue la caufe de la Maladie. Plufieurs, avant que d'entrer dans l'Etuve, prênnent un Breuvage compofé, fort propre, difent - ils, à leur faire recevoir l'impreffion Célefte, \& l'on prétend que la préfence de l'Efprit fe manifefte par un Vent impétueux, qui fe leve tout à coup; ou par un Mugiffement, que l'on entend fous terre; ou par l'agitation \& l'ébranlement de l'Etuve. Alors, plein de fa prétenduë Divinité , \& plus fémblable à un Ener-

1721 .

Septembre.

Principes, fur quoi roule toute la Médecine des Sauvages.

Idée extravagante fur lss Maladies. 
1721 . gumene, qu'à 'un Homme infpiré du Ciel, il prononce d'un

Septem- ton affirmatif fur l'état du Malade, \& rencontre quelquefoiș bre.

Imponture Mais ces Charlatans ont imaginé un moyen affez fingulier des Jongleurs. de n'être jamais refponfables des événemens. Dès qu'ils voyent un Malade tourner à la Mort, ils ne manquent jamais de faire une Ordonnance, dont l'execution eft fi difficile, qu'ils ont à coup sûr leur recours fur ce qu'elle n'a pas été exactement fuivie. Il n'eft pas concevable à quelles extravagances ils fe portent en ces occafions; il y a des Malades à qui ils commandent de contrefaire les foux; dans certaines Maladies ils ordonnent des Danfes, qui font ordinairement fort lafcives : prefque toujours on diroit quils ont bien moins en vûë de guérir le Malade, que d'avancer fa mort ; mais ce qui fait voir la force de l'imagination fur les Hommes, ces Médecins avec toutes leurs folies, guériffent auffi fouvent que les nôtres.

Leur eruauté

Il y a des Pays, où, quand le Malade eft déferperé, on à l'égard des l'acheve pour l'empêcher de languir. Dans le Canton d'OnMalades défefpérés.

nontagué on fait nourir les petits Enfans, qui perdent leurs Meres, avant que d'être fevrés; on les enterre même tout vivans avec elles, parce qu'on eft perfuadé qu'une autre $F$ emme ne pourroit pas les nourrir, \& qu'ils mourroient de langueur; je ne fçais pourtant pas fi depuis quelque tems, ils nont pas renoncé à cette barbare coûtume. Quelques autres abandonnent les Malades, dès que le Médecin n'en efpere plus rien, \& les laiffent mourir de faim \& de foif. Il y en a, qui pour empêcher ie Moribond de faire des grimaces en expirant, lui ferment les yeux \&z la bouche, dès qu'ils le voyent entrer dans l'agonie.

Des Aut- Dans l'Acadie les Jongleurs s'appelloient Autmoins, \& c'émains de l'A- toit ordinairement le Chef du Village, qui étoit revêtu de cette dignité ; auffi avoient-ils beaucoup plus d'autorité, que tes autres Jongleurs, quoiqu'ils ne fuffent, ni plus habiles, ni moins impofteurs. Dès qu'ils étoient appellés pour voir un Malade, ils commençoient par le confidérer affez lontems, ". Puis ils fouffloient fur lui. Si cela ne produifoit rien , "C'eft que le Diable, difoient-ils, eft au dedans; il faudra pourtant bien qu'il en forte : mais que chacun foit fur fes gardes, car a méchant Efprit pourroit bien de dépit fe jetter fur quel- 
D'U N VOYA GE DE L'A MER I Q. LET. XXV. 369 qu'un des Affiftans". Alors ils entroient dans une efpece de "1721. fureur, ils s'agitoient, ils crioient, ils menaçoient le prétendu Démon ; ils lui parloient, comme s'ils l'euffent vû de leurs yeux, ils lui pouffoient des eftocades; mais tout cela Septemn'étoit qu'un jeu, pour cacher leur fourberie.

En entrant dans la Cabanne ils avoient toujours la précaution d'enfoncer dans la terre un morceau de bois attaché à une corde ; ils préfentoient enfuite le bout de la corde à tous les Spectateurs, en les invitant à retirer ce bois , \&r comme prefque jamais Perfonne n'en pouvoit venir à bout, ils ne manquoient pas de dire, que c'étoit le Diable, qui le retenoit ; puis, feignant de vouloir percer ce prétendu Diable, ils détachoient peu à peu le bois en fouillant la terre tout autour, après quoi ils le retiroient fans peine, \& chacun crioit $V$ ictoire. A ce Bois étoit attaché en deffous un petit $\mathrm{O}$, ou quelque autre chofe femblable, qu'on n'avoit point apperçu d'abord, \& les Charlatans le faifant remarquer aux Affiftans "Voilà, s'écrioient - ils, la caufe du Mal, il a fallu tuer le “ Diable pour l'avoir ".

Cette farce duroit trois ou quatre heures, au bout defquelles le Médecin avoit befoin de repos \& de rafraîchiffement ; il s'en alloit, en afsûrant qu'infailliblement le Malade guériroit , fi le Mal n'avoit pas encore pris le deffus ; c'eft-à-dire, fi le Diable, avant fa retraite, ne l'avoit pas déja bleffé à mort. Et comment le fçavoir ? l'Autmoin prétendoit le connoître par les Songes, mais il fe donnoit bien de garde de parler clairement, quil ne vît le tour que prendroit la Maladie. Dès quil la jugeoit incurable, il fe retiroit, \& à fon exemple tout le monde abandonnoit le Malade. Si au bout de trois jours il vivoit encore; "Le Diable, difoit le Médecin, ne " veut pas qu'il guériffe, \& l'empêche de mourir ; il faut par " charité mettre fin à fes maux \#. Auffitôt les meilleurs Amis “ du Malade alloient chercher de l'Eau froide, \& lui en verfoient fur le Vifage, jufqu'à ce qu'il expirât. L'enchantement étoit tel, qu'on faifoit encore de grands remercimens à l'Autmoin, \& qu'on le payoit graffement.

Quelques Nations Méridionales ont des Maximes toutes contraires, on n'y paye le Médecin qu'après la guérifon; $8 x$ fi le Malade meurt, celui qui l'a traité , n'eft pas en sûreté de fa vie. Selon les Iroquois, toute Maladie eft un défir de Tome III. 
$172 \mathrm{I}$. l'Ame, \& on ne meurt, que parce que le défir n'eft pas ac-

compli. Je finis, Madame, parce que l'article des Morts me bre. meneroit trop loin, \& que tout fe difpofe pour mon Voyage; je retrouverai apparemment bientôt le loifir de vous écrire de nouveau, mais vous n'en ferez pas plus avancée, car d'ici aux Illinois il n'y a nulle apparence que je rencontre aucune occafion de vous faire tenir mes Lettres, de forte que fi je vous en écris quelqu'une avant que d'y arriver, vous la recevrez peut-être aufli tard, que fi je ne vous écrivois qu'au terme.

Je fuis, \&c.

\section{VINT-SIXIEME LETTRE.}

Départ du Fort de la Riviere S. Jofeph. Sources du Theakiki. De ce qui fe paffe à la mort des $S$ auvages, de leurs Funérailles, de leurs Tombeaux. Du Deuil, du Veuvage. De la Fête des Morts.

De la Source du Theakiki, ce dix-fept Septembre, 1721 . MAdAME,

JE ne m'attendois pas de reprendre fitôt la plume pour vous écrire, mais mes Conducteurs viennent de brifer leur Canot, \& me voici arrêté pour tout le jour dans un endroit, où je ne trouve rien, qui puiffe piquer la curiofité d'un Voyageur; ainfi je n'ai rien de mieux à faire, qu’à me livrer au plaifir de vous entretenir.

Je crois vous avoir fait entendre dans ma derniere que $j$ 'avois à choifir de deux Routes pour gagner les Illinois; la premiere étoit de retourner au Lac Michigan, d'en côtoyer toute la Côte Méridionale, \& d'entrer dans la petite Riviere de Chicagou. Après qu'on l'a remonté cinq ou fix lieuës, on paffe dans celle des Illinois par le moyen de deux portages, dont le plus long n'a que cinq quarts de lieuës; mais comme cette Riviere n'eft encore qu'un Ruiffeau en cet endroit, on: 
D'UN VOYA GE DE L'A MER IQ. LET. XXVI. 37 I m'a averti que dans la Saifon, où nous fommes, je n'y trouverois pas affez d'eau pour mon Canot; j'ai donc pris l'autre Route, qui a bien auffi fes incommodités, \& n'eft pas à beaucoup près auffi agréable ; mais elle eft plus sûre.

Je partis hier du Fort de la Riviere de Saint Jofeph, \& je remontai cette Riviere environ fix lieuës. Je débarquai fur la droite, je marchai cinq quarts de lieuës, d'abord en côtoyant le bord de l'eau, enfuite à travers champ dans une Prairie immenfe, toute femée de petits Bouquets de Bois, qui font un très-bel effet; on l'appelle la Prairie de la Téte de Bæuf, parce qu'on y a trouvé, dit-on, une Tête de Bœuf, qui étoit monftrueufe pour fa groffeur. Pourquoi n'y auroit - il pas auffi des Géans parmi ces Animaux ? Je campai dans un fort bel endroit, qu'on appelle le Fort des Renards, parce que les Renards, c'eft-à-dire, les Outagamis, y ont eu, il n'y a pas lontems, un Village fortifié à leur maniere.

Ce matin j'ai encore fait une lieuë dans la Prairie, ayant. prefque toujours les pieds dans l'eau, enfuite j'ai rencontré une efpece de Mare, qui communique avec plufieurs autres de différentes grandeurs, \& dont la plus grande n'a point cent pas de circuit. Ce font-là les fources d'une Riviere, appellée Theakiki, \& que par corruption nos Canadiens nomment Kiakiki. Theak veut dire un Loup, je ne me fouviens plus dans quelle Langue, mais cette Riviere porte ce nom, parce que les Mahingans, qu'on appelle auffi les Loups, s'y étoient autrefois réfugiés.

Nous mîmes notre Canot, que deux Hommes avoient porté jufques-là, dans la feconde de ces fources, \& nous nous y embarquâmes; mais à peine $\mathrm{y}$ avions nous affez d'eau pour y être à flot. Dix Hommes feroient en deux jours un Canal droit \& naviguable, qui épargneroit bien de la peine, \& dix ou douze lieuës de chemîn; car la Riviere, au fortir de fa fource, eft fi étroite, \& il y faut continuellement tourner fi court, qu'à chaque inftant on eft en danger de brifer fon Canot, comme il vient de nous arriver. Mais revenons aux Sauvages, \& après avoir vû de quelle maniere on les traite dans leurs Maladies, voyons-les mourir, \& ce qui fe paffe après leur Mort.

Pour l'ordinaire, quand ils fe croyent hors d'efpérance de Ce qui fe guérir, ils prennent leur parti avec une réfolution vraiement paffe à la mort $A$ a a ij

1721 .

Septen-: bre.

Départ du Fort de Sain: Jofeph. 


\section{JOURNAL HISTOR IQUE}

I 721 . Stoique, \& ils fe voyent avancer leurs jours par les Perfonbre.

Septem- dre chagrin. A peine a - $t$ - on prononcé l'Arrêt du Médecin à un Moribond , qu'il fait un effort pour haranguer ceux, qui font autour de lui. Si c'eft un Chef de Famille, il fait par avance fon Oraifon Funébre, qu'il finit en donnant à fes Enfans de très-bons avis ; il prend enfuite congé de tout le monde, ordonne un Feftin, où il faut employer tout ce qui refte de provifions dans fa Cabanne, puis il reçoit les Préfens de fa Famille.

Pendant ce tems-là on égorge tous les Chiens, qu'on peut attraper, afin que les Ames de ces Animaux aillent donner avis dans l'autre Monde qu'un tel va bientôt partir pour s'y rendre, \& tous les Corps fe mettent dans la Chaudiere pour renforcer le Feftin. A près le Repas, les pleurs commencent; on les interrompt pour faire au Mourant les derniers Adieux, lui fouhaiter un heureux Voyage, le confoler fur ce quil va fe féparer de fes Parens \& de fes Amis, \& l'afsûrer que fes Enfans foûtiendront toute la gloire, qu'il s'eft acquife.

Il faut convenir, Madame, que le fang-froid, avec lequel ces Peuples envifagent la Mort, a quelque chofe d’admirable; $\&$ cela eft fí univerfel, qu'on n'a peut - être jamais vû un Sauvage fe troubler, en apprenant quil n'a plus que quelques heures à vivre; c'eft partout le même principe \& le même génie, quoique les Ufages varient beaucôup fur tout ce que je viens de vous dire, felon les diverfes Nations. Par-tout il $\mathrm{y}$ a des danfes, des chants, des invocations, des feftins ordomnés par les Médecins, prefque toujours des remédes plus propres, felon nos idées, à faire mourir un Homme, qui fe porteroit bien, quà guérir un Malade. En quelques endroits même on n'en fait aucun : on fe contente d'avoir recours aux Efprits, \& fi le Malade recouvre fa fanté, ils en ont tout l'honneur; mais le Mourant eft toujours le plus tranquile fur fon fort.

Ieur Géné-

D'autre part, fi ces Peuples font paroître fi peu de jugement sofité à l'égard des Morts. dans la maniere, dont ils iraitent les Malades, il faut avoues qu'ils fe comportent à l'égard des Morts avec une générofité, $\&$ une affection, qu'on ne peut trop admirer. On a vû des Meres garder des années entieres les cadavres de leurs Enfans, $\&$ ne pouvoir s'en éloigner; \& d'autres fe tirer du lait de la 
D'UN V OYA GE DE L'A MER I Q. LET. XXVI. 373 Mamelle, \& le répandre fur la Tombe de ces petites Créatures. Si le feu prend à un Village, où il y ait des corps morts, c'eft la premiere chofe, qu'on met en fûreté : on fe dépouille de ce qu'on a de plus précieux, pour en parer les Défunts : bre. de tems en tems on découvre leurs Cercueils pour les changer d'habits, \& l'on s'arrache les morceaux de la bouche, pour les porter fur leur fépulture, $\&$ dans les lieux, où l'on s'imagine que leurs Ames fe promenent. En un mot on fait beaucoup plus de dépenfe pour les Morts, que pour les Vivans.

Sitôt que le Malade a rendu les derniers foupirs tout retentit de gémiffemens, \& cela dure autant que la Famille eft en état de fournir à la dépenfe, car il faut tenir table ouverte pendant tout ce tems-là. Le Cadavre paré de fa plus belle robe, le vifage peint, fes armes, \& tout ce qu'il poffedoit à côté de lui, eft expofé à la porte de la Cabanne dans la porture, quil doit avoir dans le Tombeau, \& cette pofture en plufieurs endroits eft celle, où l'Enfant eft dans le fein de $f_{a}$ Mere. L'ufage de quelques Nations eft que les Parens du Défunt jeûnent jufqu'à la fin des funérailles, \& tout cet intervalle fe paffe en pleurs, en éjulations, à régaler tous ceux, dont on reçoit la vifite, à faire l'éloge du Mort, \& en complimens réciproques. Chez d'autres on loue des Pleureufes, qui s'acquittent parfaitement de leur devoir. Elles chantent, elles danfent, elles pleurent fans ceffe, \& toujours en cadence : mais ces démonftrations d'une douleur empruntée ne préjudicient point à ce que la nature exige des Parens du Défunt.

Il me paroît qu'on porte fans aucune cérémonie le corps au lieu de fa fépulture, du moins n'ai-je rien trouvé fur cela dans aucune Relation; mais quand il eft dans la Foffe, on a foin de le couvrir de telle maniere, que la terre ne le touche point: il y eft comme dans une Celiule toute tapiffée de Peaux, beaucoup plus riche \& mieux ornée qu'une Cabanne. On dreffe enfuite un poteau fur la Tombe, \&z on y attache tout ce qui peut marquer l'eftime, qu'on Eaifoir du Mort. On y met quelquefois fon portrait, \& tout ce qui peut fervir à faire connoitre aux Paffans qui il étoit, \& les plus belles actions de fa vie. On y porte tous les matins de nouvelles provifions, \&z comme les Chiens, \& d'autres Bêtes ne manquent point d'en faire leur profit, on veut bien fe perfuader que c'eft

Des Funérailles.

1721 .

Septem. (n) 
1 721 . l'Ame du Défunt, qui eft venuë y prendre fa réfection.

Septem- Il n'eft pas étonnant après cela que les Sauvages croyent bre. aux Revenans : auffi en font-ils des contes de toutes les façons.

Des Reve- J'ai vâ un pauvre Homme, qui à force d'en entendre parler, nalis. s'étoit imaginé qu'il avoit toujours une troupe de Morts à fes trouffes, \& comme on avoit pris plaifir à augmenter fa frayeur, il en étoit devenu fou. Cependant au bout d'un certain nombre d'années, autant qu'on avoit d'abord pris à tâche de conferver le fouvenir de ceux, qu'on a perdus, autant prend-on de précaution pour les effacer de fon efprit, \& cela uniquement pour mettre fin à la douleur, qu'on a reffentie de leur perte.

Des Miffionnaireśs demandant un jour à leurs Néophytes, pourquoi ils fe privoient des chofes les plus néceffaires en fa" veur de leurs Morts? "C'eft, répondirent-ils, non-feulement " pour témoigner à nos Proches l'amour, que nous leur por"tions, mais encore pour n'avoir pas devant les yeux, dans " ce qui a été à leur ufage, des objets, qui renouvelleroient " fans ceffe notre douleur „. C'eft auffi par cette raifon, qu'on s'abftient pendant un certain tems de prononcer leurs noms, \& que fi quelqu'autre de la Famille le porte, il le quitte pendant tout le tems dudeuil. C'eft encore apparemment la raifon, pourquoi le plus fanglant outrage, quon puiffe faire à quelqu'un, c'eft de lui dire : ton Pere eft mort, ou ta Mere eft morte.

Diverfespra- Quand quelqu'un meurt dans le tems de la Chaffe, on extiques au fujet pore fon corps fur un Echafaut fort élevé, \& il y demeure des Morts. jufqu'au départ de la Troupe, qui l'emporte avec elle au Village. Il y a même des Nations, qui en ufent ainfi à l'égard de tous leurs Morts, \& je l'ai vû pratiquer aux Miffifaguez du Détroit. Les corps de ceux, qui meurent en guerre, font brûlés, \& leurs cendres rapportées, pour être mifes dans la Sépulture de leurs Peres. Ces Sépultures font, parmi les Nations les plus fédentaires, des efpéces de Cimetieres près du Village. D'autres enterrent leurs Morts dans les Bois au pied d'un Arbre, ou les font fécher, \& les gardent dans des caiffes jufqu'à la Fête des Morts, dont je vais bientôt parler; mais on obferve en quelques endroits pour ceux, qui fe font noyés, ou qui font morts de froid, un cérémonial affez bifarre. Avant que de vous en donner la defcription, il eft bon, 
Madame, de vous dire que les Sauvages croyent que, quand ces accidens arrivent, les Efprits font irrités, \& que leur colere ne s'appaife, qu’après que les corps font retrouvés. Alors, les préliminaires des pleurs, des danfes, des chants $\&$ bre. des feftins étant achevés, on porte le corps au lieu de fa fépulture, ou, fi on en eft trop éloigné, à l'endroit, où il doit demeurer en dépôt jufqu'à la Fête des Morts. On y creufe une Foffe très-large, \& on y allume un feu. De Jeunes-Gens s'approchent enfuite du Cadavre, coupent les chairs aux parties, qui ont été crayonnées par un Maitre des cérémonies, $\&$ les jettent dans le feu avec les vifceres: puis ils placent le Cadavre ainfi déchiqueté dans le lieu, qui lui eft deftiné. Durant toute cette opération les Femmes, \& $\&$ furtout les $\mathrm{Pa}$ rentes du Défunt, tournent fans ceffe autour de ceux, qui travaillent, les exhortent à bien s'acquitter de leur emploi , \& leur mettent des grains de Porcelaine dans la bouche, comme on y mettroit des dragées aux Enfans pour les engager à quelque chofe, qu'on fouhaiteroit d'eux.

L'enterrement eft fuivi des préfens, qu'on fait à la Famille affligée, \& cela s'appelle couvrir le Mort. Ces préfens fe font au nom du Village, \& quelquefois au nom de la Nation. Les Alliés en font auffi à la mort des Perfonnes confidérables. Mais auparavant la Famille du Défunt fait un grand feftin au nom du Défunt, \& ce feftin eft accompagné de jeux, pour lefquels on propofe des prix. C'eft une efpéce de Joûte, qui fe fait en cette maniere : un Chef jette fur la tombe trois bâtons de la longueur d'un pied, un jeune Homme, une Femme, \& une Fille en prennent chacun un, \& ceux de leur âge, de leur fexe, \& de leur état, s'efforcent de leur arracher des mains. Ceux, à qui ils demeurent, font viktorieux. Il y a auffi des courfes, \& l'on tire quelquefois au blanc; enfin par un ufage, que nous voyons établi dans toute l'Antiquité Payenne, une action toute lugubre eft terminée par des. chants, \& des cris de victoire.

Il eft vrai que la Famille du Mort ne prend aucune part à ces réjouiffances, on obferve même dans fa Cabanne, après les obféques un deuil, dont les loix font fort féveres. Il faut avoir les cheveux coupés, \& la face noircie ; fe tenir debout, la tête enveloppée dans une couverture, ne regarder perfonne, ne faire aucune vifite, ne rien manger de chaud, fe prij-

Ce qui fe palfe après l'Enterrement. 


\section{$376 \mathrm{~J} O \mathrm{O} R$ - N A L H IS T O R I Q U E}

172 I. ver de tous les plaifirs, n'avoir prefque rien fur le corps, \& Septem- grand deuil, qui eft de deux ans, on en commence un fecond, bre. plus moderé, qui dure deux ou trois autres années , \& qu'on peut encore adoucir peu à peu; mais on ne fe difpenfe de rien de ce qui eft prefcrit, qu'avec l'agrément de la Cabanne, à laquelle le Veuf ou la Veuve appartiennent ; ces permiffions, auffi-bien que la fin du deuil, coûtent toujours un Feftin.

Du Veuvage, \& des Secondes Noces.

Enfin, on ne peut fans le confentement de ceux, de qui on dépend, en vertu des loix du Veuvage, convoler à de fecondes Nôces. S'ils n'ont point de Mari à donner à la Veuve, elle n'eft point embarraffée, quand elle a des Garçons en âge de la foûtenir ; elle peut demeurer dans l'état de viduité, fans craindre de manquer jamais de rien. Si elle veut fe remarier, elle peut choifir, \& celui, qu'elle époufe, devient le Pere des Enfans, qu'elle avoit : il entre dans tous les droits, \& dans toutes les obligations du premier Mari. L'Epoux ne pleure point fa Femme, parce que, felon les Sauvages, les larmes ne conviennent point aux Hommes; ce qui n'eft pourtant pas univerfel dans toutes les Nations : mais les Femmes pleurent leur Mari pendant un an, elles l'appellent fans ceffe, \& rempliffent le Village de cris \& d'éjulations, furtout au lever $\&$ au coucher du Soleil, à Midi, \& en quelques endroits, lorfqu'elles vont au travail, \& qu'elles en reviennent; les Mẹres font à peu près la même chofe pour leurs Enfans. Les Chefs ne gardent le deuil que fix mois, \& peuvent enfuite fe remarier.

The des Enfin le premier, \& fouvent le feul compliment, qu'on fafle cauvages fur à un $\mathrm{Ami}$, \& même à un Etranger, qu'on reçoit dans fa $\mathrm{Ca}$ rent de mort violente.

banne, eft de pleurer ceux de fes Proches, qu'il a perdus depuis qu'on ne l'a vû. On lui met la main fur la tête, \& on lui fait entendre celui, qu'on pleure, mais on ne le nomme pas. Tout ceci eft fondé fur la Nature, \& ne fent point le Barbare, mais ce que je vais vous dire ne me paroît excurable par aucun endroit : c'eft la conduite, que ces Peuples tiennent à l'égard de tous ceux, qui ont peri de mort violente, même en guerre, \& pour le fervice de la Patrie.

Ils fe font mis dans la tête que leurs Ames n'ont' dans l'autre Monde aucun commerce avec les autres, \& fur ce principe ils les brûlent, ou les enterrent d'abord, quelquefois 
D'UN VOYA GE DE L'A MERI Q. LET. XXVI. 377 même avant qu'ils ayent expiré. Ils ne les mettent jamais dans le Cimetiere commun, \& ils ne leur donnent aucune part à cette grande cérémonie, qui fe renouvelle tous les huit ans parmi quelques Nations, \& tous les dix ans chez les Hurons \& les Iroquois.

On l'appelle la Fête des Morts, ou le Feftin des Ames; \& voici ce que j’ai pû recueillir de plus uniforme $\&$ de plus remarquable touchant cette action, la plus finguliere \& la plus célebre de toute la Religion des Sauvages. On commence par convenir du Lieu, où fe fera l'Affemblée, puis on choifit le Roy de la Fête, dont le devoir eft de tout ordonner, \& de faire les invitations aux Villages voifns. Le jour marqué étant venu, tous les Sauvages s'affemblent, \& vont proceffionnellement deux à deux au Cimetiere; là , chacun travaille à découvrir les Corps, enfuite on demeure quelque tems à confidérer en filence un fpectacle fi capable de fournir les plus férieufes réfléxions. Les Femmes interrompent les premieres ce religieux filence, en jettant des cris lamentables, qui augmentent encore l'horreur, dont tout le monde eft pénetré.

Ce premier acte fini, on prend ces Cadavres, on ramaffe les offemens fecs \& détachés, on les met en paquets, \& ceux, qui font marqués pour les porter, les chargent fur leurs épaules. S'il y a des Corps, qui ne foient pas entierement corrompus, on les lave, on en détache les chairs pourries, 8 toutes les ordures, \& on les enveloppe dans des Robes de Caftors toutes neuves. Enfuite on s'en retourne dans le même ordre, qu'on avoit gardé en venant, \& quand la Proceffion eft rentrée dans le Village, chacun dépofe dans fa Cabanne le dépôt, dont il étoit chargé. Pendant la marche les Femmes continuent leurs éjulations, \& les Hommes donnent les mêmes marques de douleur, quau jour de la mort de ceux, dont ils viennent de lever les triftes reftes; \& ce fecond acte eft fuivi d'un Feftin dans chaque Cabanne, en l'honneur des Morts de la Famille.

Les jours fuivans on en fait de publics, \& ils font accompagnés, comme le jour de l'Enterrement, de Danfes, de Jeux \& de Combats, pour lefquels il y a auffi des Prix propofés. De tems en tems on jette de certains cris, qui s'appelLent les cris des Ames, on fait des Préfens aux Etrangers, parTome III.

$\mathrm{B}$ bb

De la Fête des Morts. 
1721 . mi lefquels il y en a quelquefois, qui font venus de cent cinSeptem- quante lieuës, \& l'on en reçoit d'eux. On profite même de bre. ces occafions, pour traiter des Affaires communes, ou pour l'élection d'un Chef : tout fe paffe avec beaucoup d'ordre, de décence, \&x de modeftie ; \& chacun y paroît pénetré des fentimens les plus conformes à l'action principale, tout, jufqu'aux Danfes \& aux Chants, y refpire je ne fçai quoi de lugubre, \& l'on y fent des cours percés de la plus vive douleur; les plus indifferens en feroient faifis, à la vûë de ce fpectacle.

Au bout de quelques jours on fe rend encore proceffionnellement dans une grande Salle de Confeil dreffée exprès, on y fufpend contre les Parois les Offemens \& les Cadavres dans le même état, où on les a tirés du Cimetiere, \& on y étale les Préfens deftinés pour les Morts; fi parmi ces triftes reftes il fe trouve ceux d'un Chef, fon Succeffeur donne un grand repas en fon nom, \& chante fa Chanfon. En plufieurs endroits les Corps font promenés de Bourgade en Bourgade, font reçus partout avec de grandes démonftrations de douleur \& de tendreffe, \& partout on leur fait des Préfens; enfin on les porte à l'endroit, où ils doivent être dépofés pour toujours : mais j’ai oublié de vous dire que toutes ces marches fe font au fon des Inftrumens, accompagnés des plus belles Voix , \& que chacun y marche en cadence.

Cette derniere \& commune fépulture eft une grande foffe, qu'on tapiffe des plus belles Pelleteries, \& de ce qu'on a de plus précieux. Les Préfens deftinés pour les Morts, font placés à part: à mefure que la Proceffion arrive, chaque Famille s'arrange fur des efpeces d'Echaffauts dreffés autour de la foffe, \& au moment que les Corps font dépofés, les Femmes recommencent à crier; \& à pleurer. Enfuite tous les Affiftans defcendent dans la foffe, \& il n'eft Perfonne, qui n'en prenne un peu de terre, quife conferve précieufement; on s'eft imaginé que cette terre porte bonheur au Jeu. Les Corps \& les Offemens font arrangés par ordre, couverts de Fourures toutes neuves, \& par deffus, d'écorces fur lefquelles on jette des pierres, du bois, \& de la terre. Chacun fe retire enfuite chez foi, mais des Femmes reviennent pendant quelques jours verfer au même endroit de la Sagamité. Je fuis, \& $\mathrm{x}$. 


\section{DUN V OYA GEDE L'A M E IQ. LET. XXVII. 379}

\section{VINT-SEPTIEME LETTRE.}

I 721 .

Oetobre.

Voyage jufqu'à Pimiteouy. De la Riviere des Illinois ; Réception des Prifonniers parmi ces Peuples. Maniere, dont ils les brûlent. Quelques particularités fur leur maniere de vivre.

A Pimiteouy, ce cinquiéme d'Oktobre, 1721.

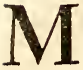

A D A ME,

LA nuit du dix-fept au dix-huit de ce mois, la Gelée, qui depuis huit jours fe faifoit fentir tous les matins, augmenta confidér ablement; c'étoit de bonne heure pour le Climat où nous nous trouvions, car nous étions par les quarante $\&$ un degrés quarante minutes d'élévation du Pole. Les jours fuivans nous voguâmes depuis le matin jufqu'au foir , favorifés par le Courant, qui eft affez fort, \& quelquefois par le Vent; nous faifions en effet beaucoup de chemin, mais nous avancions fort peu : après avoir fait dix ou douze lieuës, nous nous trouvions fi proches de notre dernier Campement, que de l'un à l'autre on auroit pû fe voir, \& fe parler même, au moins avec un Porte-voix.

Ce qui nous confoloit un peu, c'eft que la Riviere \& $x$ fes bords étoient couverts de Gibier engraiffé par la Folle Avoine, qui étoit pour lors dans fa maturité. J'y cueillis auff du Raifin mûr, de la groffeur \& $x$ de la figure d'une balle de Moufquet, \& affez tendre, mais d'un mauvais goût. C'eft apparemment le même, qu'on appelle dans la Louyfiane $R$ aifinPrune. La Riviere peu à peu prend un cours plus droit, mais fes bords ne font agréables qu'après, cinquante lieuës depuis fa fource. Elle eft même dans tout cet efpace fort étroite, \& comme elle eft bordée d'Arbres, qui ont leurs racines dans l'eau, quand il en tombe quelqu'un il barre toute la Riviere, $\&$ il faut perdre un tems infini à fe faire un paflage pour le Canot.

Tous ces embarras paffés, la Riviere, à cinquante lieuës de $\mathrm{B} \mathrm{bb}$ ij

Defcription du Théakiki. 
I 72 I. fa fource forme un petit Lac, \& s'élargit enfuite confidéraOctobre. blement. Le Pays devient beau. Ce font des Prairies à perte de vûë, où les Bœufs vont par troupeaux de deux à trois cent, mais il y faut être fur fes gardes, pour ne point fe laiffer furprendre par des Partis de Sioux \& d'Outagamis, que le voifinage des Illinois, leurs Ennemis mortels, y attire, \& qui ne font pas plus de quartier aux François, qu'ils rencontrent fur leur route. Le mal eft quele Theakiki perd de fa profondeur, à mefure qu'il gagne en largeur, de forte qu'il faut fouvent décharger le canot, \& marcher à pied, ce qui ne fe fait jamais fans quelque rifque, \& que $i$ 'aurois été fort embarraffé, fi on ne mavoit donné une Efcorte à la Riviere de Saint Jofeph.

Ce qui m'a furpris, en voyant fi peu d'eau dans le Theakiki, c'eft que de tems en tems il reçoit d'affez jolies Rivieres; j’en ai vû une entr'autres, qui a plus d'un arpent de large à fon embouchure, \& qu'on a nommée la Riviere des Iroquois, parce que ces Braves s'y laifferent furprendre par les Illinois, qui leur tuerent bien du Monde. Cet échec les humilia d'autant plus, qu'ils méprifoient fort les Illinois, lefquels ordinairement ne tiennent point devant eux..

De la Ri- Le vint-fept de Septembre nous arrivâmes à la-Fourche, viere des Illinois. c'êt le nom, que les.Canadiens ont donné à l'endroit, où lè Theakiki \& la Riviere des Illinois fe joignent. Celle-ci, quoiqu'après foixante lieuës de cours, y eft encore fi peu de chofes, que jy vis un Bouf la traverfer, n'ayant pas de l'eau jufqu'à mi-jambe. Le Theakiki au contraire, outre qu'il y amene fes eaux de cent lieuës, eft une belle Piviere. Cependant il perd ici fon nom, fans doute parce que les Illinois ayant été établis en plufieurs endroits de l'autre, lui ont donné le leur. Enrichie tout-à-coup par cette jonction, elle ne le céde en largeur à aucune, que nous ayons en France, \& jofe vous aflûrer, Madame, qu'il n'eft pas poffible de voir un meilleur, ni un plus beau Pays, que celui, qu'elle arrofe, au moins jufqu'à l'endroit, d'où je vous écris. Mais ce n'ef̂́ que quinze lieuës au-deflous de la Fourche, qu'elle acquiert une profondeur, qui réponde à fa largeur; quoique dans cet intervalle elle reçoive plufieurs autres Rivieres.

La plus grande fe nomme $P$ ifticoui, \& vient du beau Pays des Mafcoutins. Elle à̀ fon embouchure un Rapide, qu'on as 
D'U N V OYA GE DE L'A MER IQ. LET. XXVII. 38 I nommé la Charbonniere, parce que l'on trouve beaucoup de charbon de terre aux environs. On ne voit fur cette route que des Prairies immenfes, femées de petits bouquets de bois, 1721 . qui paroiffent y avoir été plantés à la main, les herbes y font fi hautes, qu'on s'y perd, mais on rencontre partout des fentiers auffi battus, quils le pourroient être dans les Pays les plus peuplés, cependant il n'y paffe que des Bœufs\}, \& de tems en tems quelques troupeaux de Cerfs., \& quelques Chevreuils.

Une lieuë au-deffous de la Charbonniere on apperçoit fur la droite un Rocher tout rond, extrémement élevé, dont le fommet eft en terraffe; on l'appelle le Fort des Miamis, parce que ces Sauvages y ont eu un Village. Au bout d'une autre lieue fur la gauche on en voit un tout femblable, qu'on a nommé fimplement le Rocher. C'eft la pointe d'un Platen fort élevé, qui tourne l'efpace de deux cent pas, en fuivant toujours le bord de la Riviere, laquelle s'élargit beaucoup en cet endroit. Il eft partout à pic, \& de loin on le prendroit pour une Fortereffe. On y voit même encore quelques reftes de Paliffades, parce que les Illinois y avoient fait autrefois un Retranchement, quili leur eft aifé de réparer en cas de quelqu'irruption de la part de leurs Ennemis.

Leur Village eft au pied de ce Roc dans une Ifle q qui avec plufieurs autres, toutes d'une fertilité merveilleufe, féparent en cet endroit la Riviere en deux Canaux affez larges. J'y débarquai le vint-neuf vers les quatre heures du foir, \& j'y rencontrai quelques François, qui y trafquoient avec les Sauvages. A peine avois-je mis pied à terre, que je fus vifité par le Chef de la Bourgade : c'eft un Homme d'environ quarante ans, bienfait, doux, d'une phyfionomie aimable, $8 *$ dont les François me dirent beaucoup de bien.

Je montai enfuite fur le Rocher par un chemin affez aifé, mais fort étroit. Je trouvai une terraffe fort unie, d'une grande étenduë, \& où tous les Sauvages du Canada ne forceroient pas vint Hommes, qui auroient des armes à feu, s'ils pou:voient y avoir de l'eau; car on n'en peut tirer que de la Riviere, '\& pour cela il faut fe découvrir. Toute la reffource de ceux, qui y feroient affiégés, eft l'impatience naturelle d̀ ces Barbares. Dans les petits Partis ils attendront fans peine huit $\&$ dix jours derriere un Buiffon, dans l'efperance qu'id

O\&obre. 
382 JOURNA L H IS TORIQUE

1721 . paffera quelqu'un, à qui ils pourront caffer la tête, ou pour avoir un Prifonnier : mais quand ils font en corps de Guerriers, s'ils ne réuffiffent pas d'abord, ils fe laffent bientôt, \& prennent le premier prétexte pour fe retirer : ils n'en manquent jamais, car il ne faut pour cela qu'un fonge vrai, ou prétendu.

Réception La pluye, \& plus encore un fpectacle, qui me fit horreur, parmi les Illi- découvrir un grand Pays. J'apperçus à l'extrémité, \& immé-
nois. diatement au-deffus du Village, deux corps de Sauvages, qu'on y avoit brûlés peu de jours auparavant, \& qu'on avoit abandonnés, felon la coûtume, aux Oifeaux de proye, dans la même pofture, où ils avoient été exécutés. La façon de brûler les Prifonniers parmi ces Nations Méridionnales a quelque chofe de fingulier, \& elles ont auffi quelques couttumes differentes des autres dans la maniere, dont elles en ufent envers ces Malheureux.

Quand elles ont fait quelqu'expédition militaire, qui leur a reuffi, les Guerriers ménagent tellement leur marche, qu'ils n'arrivent jamais à leur Village, que le foir. Dès qu'ils en font proches, ils s'arrêtent, \& quand la nuit eft venuë, ils députent deux ou trois Jeunes-Gens au Chef, pour lui faire part des principales aventures de la Campagne. Le lendemain à l'aube dı jour ils parent leurs Prifonniers de robes neuves, leur accommodent les cheveux avec du duvet, leur peignent le vifage de differentes couleurs, \& leur mettent à la main un bâton blanc, environné de queuës de Chevreuils. En même-tems le Chef de guerre fait un cri, \& tout le Village s'affemble au bord de l'Eau, fi l'on eft près d'une Riviere.

Dès que les Guerriers paroiffent, quatre Jeunes-Gens bien parés s'embarquent dans une Pirogue $(a)$, les deux Premiers portent chacun un Calumet, \& vont en chantant chercher les Prifonniers, qu'ils amenent, comme en triomphe, jufqu’a la Cabanne, où ils doivent être jugés. Le Maître de la Cabanne, à qui il appartient de décider de leur fort, commence par leur donner à manger, \& pendant ce repas il tient confeil. Si on accorde la vie à quelqu'un, deux Jeunes-Gens vont le délier, le prennent chacun par une main, \& le font cou-

(a) C'eft un Batteau long, fair d'un feul trone d'Arbre. On fe fert peu de Canots d'Ecorces dans ces Quartiers-lä. 
D'U N V OYA G E D E L'A MER IQ. LET. XXVII. 383

rir à toutes jambes à la Riviere, où ils le jettent la tête la premiere. Ils s'y jettent eux-mêmes après lui, le lavent bien, \& le conduifent à celui, dont il doit être Efclave.

Quant à ceux, qui font condamnés à mourir, fitôt que Octobre. la Sentence eft portée, on fait le cri pour affembler le Vil- les brúler. lage, \& l'exécution n'eft differée, qu'autant de tems, qu'en demandent les préparatifs. On commence par dépouiller le Patient tout nud; on plante en terre deux poteaux, aufquels on attache deux traverfes, l'une à deux pieds de terre, l'autre à fix ou fept pieds plus haut, \& c'eft ce qu'on appelle un cadre. On fait monter le Patient fur la premiere traverfe, à laquelle on lui attache les pieds, un peu écartés l'un de l'autre : on lui lie enfuite les mains aux angles, que forme la feconde traverfe, \& en cette pofture on le brûle par-tout le corps.

Tout le Village, Hommes, Femmes \& Enfans s'attroupe autour de lui, \& chacun a droit de lui faire tout le mal, dont il peut s'avifer. Si aucun des Affiftans n'a point de raifon particuliere pour le faire fouffrir lontems, fon fupplice dure peu, \& ordinairement, on l'acheve à coups de Fléches, ou bien on l'enveloppe d'écorces d'Arbres, aufquelles on met le feu. On le laiffe enfuite dans fon cadre, \& fur le foir on parcourt les Cabannes, en frappant avec des baguettes fur les meubles, fur les murailles, \& fur le toit, afin d'empêcher fon Ame d'y refter, pour fe venger du mal, qu'on a fait à fon corps. Le refte de la nuit fe paffe en réjouiffances.

Si le Parti n'a point rencontré d'Ennemis, ou s'il a été contraint de fuir, il rentre de jour dans le Village, en gardant un profond filence : mais sil a été battu, il rentre le foir, après avoir annoncé fon retour par un cri de mort, \& nommé tous ceux, qu'il a perdus, foit par maladie, ou par le fer de l'Ennemi. Quelquefois les Prifonniers font jugés \& exécutés avant qu'on arrive au Village, furtout quand on a lieu de craindre qu'ils ne foient enlevés. Il y a quelque tems qu'un François ayant été pris par des Outagamis, ces Barbares tinrent confeil pendant la route pour fçavoir ce qu'ils en feroient. Le réfultat de la délibération fut de jetter un bâton fur un Arbre, \& s'il y reftoit, de brûler leur Prifonnier, mais de ne le jetter qu'un certain nombre de fois. Par bonheur pour le Captif, quoique l'Arbre fût extrémement touffu, le bâton retomba toujours à terre.

Particularités fur les Pastis de guerse. 
1721.384 Je reftai vint-quatre heures au Rocher, \& pour faire plaifir Oetobre. aux Sauvages, \& leur témoigner une entiere confiance, quoi-

Chants lu- que tous mes Conducteurs tuffent campés de l'autre côté de gubres des 11- la Riviere, je couchai dans une Cabanne au milieu du Villinois. lage. J'y paffai la nuit affez tranquillement, mais je fus réveillé de bon matin par une Femme, qui demeuroit dans la Cabanne voifine; à fon réveil, le fouvenir d'un Fils, qu'elle avoit perdu quelques années auparavant, lui revint à l'ẹfprit, \& auffi-tôt elle fe mit à pleurer, ou à chanter fur un ton fort lugubre.

Les Illinois ont la réputation d'être hardis \& habiles Filoux, $\&$ c'ett la raifon pourquoi j'avois fait tranfporter tout le Bagage à l'autre Bord; mais malgré certe précaution, \& la vigilance de mes Gens, lorfqu'il fallut partir, nous trouvâmes qu'il nous manquoit un Fufil, \& quelques bagatelles, qu'il ne nous fut jamais poffible de recouvrer. Le même foir nous pafsâmes le dernier endroit de la Riviere, où l'on foit obligé de trainer le Canot; après cela elle a partout une largeur \& une profondeur, qui l'égalent à la plûpart des plus grands Fleuves de l'Europe.

Des Terro- Je vis auffi ce jour-là pour la premiere fois des Perroquets: quets de la il y en a lolong du Theakiki, mais en Eté feulement, ceux-ci étoient des traîneurs, qui fe rendoient fur le Miciffipi, où l'on en trouve dans toutes les Saifons; ils ne font gueres plus gros que des Merles, ils ont la tête jaune, avec une tache rouge au milieu, dans le refte de leur Plumage c'eft le verd, qui domine. Les deux jours fuivans nous tráversâmes un Pays charmant, \& le troifiéme d'OEtobre vers le Midi, nous nous trouvâmes à l'entrée du Lac Pimiteouy ; c'eft la Riviere, qui s'élargit, \& qui pendant trois lieuès en a une de large. Au bout de ces trois lieuës on trouve fur la droite un fecond Village d'lllinois, éloigné de quinze lieuës de celui du Rocher.

Du village Rien n'eft plus agréable que fa fituation, il a vis - ̀̀-vis, Gle Pimiteouy. comme en perfpective, une très - belle Forêt , qui étoit alors de toutes les couleurs, \& derriere une Plaine d'une étenáuë immenfe, bordée de Bois. Le Lac \& la Riviere fourmillent Nouvelles, de Poiffons, \& leurs bords de Gibier. Je rencontrai encore 3ue j'y appris. dans ce Village quatre François Canadiens, qui m'apprirent que j'étois entre quatre Partis Ennemis, \& qu'il n'y avoit au- 
cune sûreté pour moi, ni à avancer, ni à retourner fur mes pas ; ils m'ajoûterent que fur la route, que je venois de faire, il y avoit trente Outagamis en embufcade, qu'un pareil nombre des mêmes Sauvages rodoit autour du Village de Pimiteouy, \& que d'autres, au nombre de quatre-vint, fe tenoient au bas de la Riviere, féparés en deux Bandes.

Ce récit me fit faire attention à ce qui nous étoit arrivé la veille; nous nous étions arrêtés au bout d'une Ifle, pour chercher des Outardes, fur lefquelles quelques-uns de mes Conducteurs avoient tiré ; \& nous entendimes quelqu'un, qui coupoit du Bois dans le milieu de l'Inle. La proximité dú Village de Pimiteouy nous avoit fait juger que c'étoit quelque Illinois, \&r nous nous en étions tenus là; mais il y a bien de l'apparence que c'étoient des Outagamis, qui nous ayant découverts, \& $\&$ 'ofant nous attaquer, parce que j'avois douze Hommes bien armés, vouloient attirer quelqu'un de nous dans le Bois, comptant apparemment avoir bon marché des autres; mais notre peu de curiofité nous garantit de ce malheur, que je n'aurois pas évité fans doute, fi je n'avois pas eu une Efcorte commandée par un Homme, qui n'étoit pas d'humeur à s'arrêter inutilement.

Ce qui nous confirma encore les avis des quatre François; c'eit que trente Guerriers de Pimiteouy, commandés par le Chef même du Village étoient en Campagne, pour tâcher d'avoir des nouvelles plus certaines des Ennemis, \& que peu de jours avant leur départ il y avoit eu une Action dans le voifinage, où les deux Partis avoient fait chacun un Prifonnier ; l'Outagami avoit été brûlé à une portée de Fufil du Village, \& il étoit encore dans fon Cadre. Les Canadiens, qui avoient affifté à fon fupplice, me dirent qu'il avoit duré cinq heures, \& que ce Malheureux avoit foûtenu jufqu'à la mort qu'il étoit Illinois, qu'il avoit été pris dans fon enfance par des Outagamis, qui l'avoient adopté.

Il s'étoit pourtant très-bien battu, 8 fans une bleffure; qu'il avoit reçu à la Jambe, il n'auroit pas été pris ; mais comme il n'avoit pû̀ donner des preuves de ce qu'il avançoit, $\&$ que peu s'en étoit fallu qu'il ne fe fût fauvé, on ne l'en avoit pas voulu croire fur fa parole. Il fit voir au milieu des tourmens que la bravoure $8 x$ le courage à fupporter la douleur, font des Vertus bien différentes, 8 q qu'elles ne vont pas Tome III, 
386 J O U R N A L H IS T O R I Q U E

I $72 \mathrm{I}$. toujours enfemble ; car il jettoit des cris lamentables, qui ne faifoient qu'animer fes Bourreaux; il eft vrai qu'une vieille Oßtobre. Illinoife, dont le Fils avoit été tué autrefois par les Outagamis, lui fit tous les maux, que la fureur infpirée par la vengeance, peut inventer; à la fin cependant on eut pitié de fes cris, on l'enveloppa de paille, à laquelle on mit le feu, $\&$ comme il refpiroit encore, après qu'elle eut été confumée, les Enfans le percerent de Fléches: ordinairement, quand un Patient ne meurt pas en Brave, c'eft une Femme, ou des Enfans, qui lui donnent le coup de la mort; il ne mérite pas, dit-on, de mourir de la main d'un Homme.

Embarras, Cependant, Madame, je me trouvai fort embarraffé. D'un où je me trou- côté mes Conducteurs ne croyoient pas, qu'il fût de leur pru-
vai.

dence de paffer outre, \& de l'autre il ne convenoit nullement à mes affaires, d'hyverner à Pimiteouy, j’aurois même été obligé de fuivre les Sauvages dans leur hyvernement, \& cela m'auroit fait perdre une année entiere. Enfin deux Canadiens, des quatre, que javois trouvés à Pimiteouy, s'offrirent à groffir mon Efcorte, \& tout le monde reprit cœur. Je voulois partir dès le lendemain, quatriéme d'Octobre, mais la pluye, \& quelques embarras, qui nous furvinrent, m'arrêterent tout le jour.

L'après-midi les Guerriers, qui étoient allés à la découverte, revinrent, fans avoir fait aucun cri, parce qu'ils n'avoient rien vû. Ils défilerent tous devant moi d'un air affez fier; ils n'étoient armés que de Fléches, \& d'une Rondache de cuir de Bouf, \& ils ne firent pas femblant de me voir: c'eft la coûtume des Guerriers de ne faluer perfonne, quand ils font en corps d'Armée; mais à peine furent-ils rentrès chacun chez eux, que le Chef s'étant mis fur fon propre, vint me rendre une vifite de cérémonie. C'eft un Homme d'environ quarante ans, affez grand, un peu maigre, d'un caraztere doux, \& fort raifonnable. C'eft d'ailleurs le plus brave Soldat de fa Nation, \& il n'eft point d'Illinois, qui mérite mieux que lui le furnom (a), qu'Homere donne par préference au Héros de fon Iliade. C'eft beaucoup dire, car les Illinois font peut-être les Hommes du Monde les plus légers à la courfe; il n'y a que les Miffourites, qui pourroient leur difputer cette gloire.

Hiftoire fin- Comme japperçûs une Croix de cuivre, \& une petite figure (a) Mrócas winuss. 
D'UN VOYA GE DE L'A M E R I Q. LET. XXVII. 387 de la Vierge, qui pendoient au cou de ce Sauvage, je crûs qu'il étoit Chrétien , mais on m'affûra qu'il ne l'étoit point, \& qu'il ne s'étoit mis dans l'équipage, où je le voyois, que pour me faire honneur : on m'ajoûta ce que je vais vous rapporter, fans exiger que vous y donniez plus de croyance, que n'en méritent mes Auteurs ; ce font des Voyageurs Canadiens, qui n'ont affûrément pas inventé ce qu'ils me raconterent, mais qui l'ont oüi dire, comme une chofe conftante. Voici le fait.

L'Image de la Vierge, que portoit le Chef, lui étant tombée entre les mains, je ne fçai comment, il fut curieux de fçavoir qui elle repréfentoit : on lui dit que c'étoit la Mere de Dieu, \& que l'Enfant, qu'elle tenoit entre fes bras, étoit Dieu même, qui s'étoit fait Homme pour le falut du Genre humain : on lui expliqua en peu de mots le Myftere de cette ineffable Incarnation, \& on lui dit que les Chrétiens s'adreffoient toujours à cette divine Mere dans tous les périls, où ils fe trouvoient, \& que rarement ils le faifoient en vain. Le Sauvage écouta ce difcours avec beaucoup d'attention, \& quelque tems après, comme il chaffoit feul dans le Bois, un Outagami, qui s'y étoit mis en embufcade, fe montra à lui, dans le moment, qu'il venoit de tirer fon coup, \& le coucha en jouë. Il fe fouvint alors de ce qu'on lui avoit dit de la Mere de Dieu, il l'invoqua, \& l'Outagami ayant voulu tirer, fon fufil ne prit point feu. Il le rebanda, \& la même chofe arriva jufqu’à cinq fois. Pendant ce tems-là l'Illinois chargea le fien, \& coucha à fon tour en jouë fon Ennemi, qui aima mieux fe rendre, que de fe laiffer tuer. Depuis cette aventure le Chef Illinois ne fort jamais de fon Village, fans porter avec lui $f a$ Sauve-garde, avec laquelle il fe croit invulnérable ; fi le fait eft vrai, il y a bien de l'apparence que le feul défaut de Miffionnaire l'a jufqu'ici empêché de fe faire Chrétien, \& que la Mere de Dieu, après l'avoir préfervé d'une mort temporelle, lui obtiendra la grace d'une fincere converfion. (a)

A peine ce Chef m'eut-il quitté, qu'étant forti moi-même pour vifiter les environs du Village, j’apperçus deux Sauvages, qui alloient de Cabanne en Cabanne, pleurant à peu près fur le même ton, que la Femme du Rocher, dont je vous Maniere de pleurer les Morts parmi les Illinois. ai parlé. L'un avoit perdu fon Ami dans le dernier combat, (a) Il s'eft en effet converti depuis.

$$
\text { C c c ij }
$$


388 J O URNAL HIS TORIQUE

l'autre étoit le Pere du Mort. Ils marchoient à grands pas, \&

mettoient les deux mains fur la tête de tous ceux, qu'ils ren-

Oetobre. controient; apparemment pour les inviter à prendre part à leur douleur. Ceux, qui ont cherché des convenances entre les Hebreux \& les Ameriquains, n'auront pas manqué fans doute de faire attention à cette maniere de pleurer, que quelques expreffions de l'Ecriture pouvoient donner lieu à ces faifeurs de conjectures de juger avoir été en ufage parmi le Peuple de Dieu.

Attentions du

Sur le foir le Chef me fit prier de me trouver dans une Chef pour ma fûreté。 maifon, où un de nos Miffionnaires avoit logé quelques années auparavant, \& où apparemment on avoit accoûtumé de tenir le Confeil ; jy allai , \& je l'y trouvai avec deux ou trois Anciens. Il commença par me dire qu'il vouloit m'inftruire de la grandeur du péril, auquel je m'expofois, en continuant ma route : que tout bien confideré, il me confeilloit d'attendre pour partir que la Saifon fût un peu plus avancée; qu'il efpéroit qualors les Partis ennemis fe retireroient, \& me laifferoient le chemin libre. Comme il pouvoit avoir fes vûës en m'arrêtant à Pimiteouy, je lui témoignai que je n'étois pas fort touché de fes raifons, \& j’ajoûtai que j’en avois de meilleures pour preffer mon départ. 11 me parut que ma réponfe lui faifoit de la peine, \& je reconnus bientôt qu'elle ne venoit que de fon affection pour moi, \& $\&$ de fon zéle pour notre Nation.

"Puifque ta réfolution eft prife, me dit-il, je fuis d'avis que tous les François, qui font ici , fe joignent à toi pour fortifier ton efcorte : je leur ai même déja déclaré ma penfée fur cela, $\&$ je leur ai fortement repréfenté qu'ils feroient à jamais perdus d'honneur, s'ils laiffoient leur Pere dans le danger, fans le partager avec lui. J'aurois bien fouhaitté pouvoir t'accompagner moi-même à la tête de tous mes Soldats, mais tu n'ignores point que mon Village eft tous les jours à la veille d'être attaqué, \& il ne me convient pas de m'en abfenter, ni de le dégarnir dans de pareilles conjonctures. Pour les François, rien ne peut les arrêter ici, qu'un intérêt, qu'ils doivent facrifier à ta confervation. C'eft ce que je leur ai fait entendre, \& je leur ai ajoûté que fi quelqu'un d'eux tomboit. entre les mains des Ennemis, ce ne feroit que la perte d'un. "Homme, au lieu qu'un Pere en valoit lui feul plufieurs, \&. 
DUN V OY A GE DE L'A MERIQ. LET. XXVII. 389

qu'il n'y avoit rien, qu'ils ne dûffent rifquer, pour prévenir un fi grand malheur." "

Je fus charmé, Madame, de la fageffe de cet Homme, \& bre. phus encore de fa générofité, qui le portoit à vouloir bien, par confidération pour moi, fe priver de quatre Hommes, dont le fecours ne devoit pas lui être indifférent dans la fituation, où il fe trouvoit. Je n'avois pas même douté qu'en voulant me retenir chez lui, il n'eût eu en vâë de fe fervir de mon Efcorte dans le befoin. Je lui témoignai beaucoup de reconnoiffance de fon bon cœur \& de fes attentions, \& je l'affurai que j’étois fort content des François : que je voulois les partager avec lui : que je lui en laifferois deux pour le défendre, en cas quill fût attaqué ; que les deux autres m'accompagneroient jufqu’à ce que je fuffe en lieu de fûreté, \& qu'avec ce renfort je me croyois en état d'aller par tout fans rien craindre. Il n'infifta point davantage, \& je me retirai.

Ce matin il eft venu me rendre une feconde vifite, accompagné de fa belle-Mere, qui portoit entre fes bras un petit tiler fá Fille. Enfant. "Tu vois, me dit-il en m'abordant, un Pere bien " affligé. Voici ma Fille, qui fe meurt, fa Mere eft morte en la " mettant au monde, $8 z$ aucune Femme n’a pû encore réuiffir " à la nourrir. Elle rejette tout ce qu'elle prend, \& elle n'a " peut-être plus que peu d'heures à vivre : tu me feras plaifir " de la baptifer, afin qu'elle puiffe aller voir Dieu saprès $f_{a}$ " mort. "L'Enfant étoit effectivement très-mal, \& abfolument ". hors d'efpérance de guérifon, ainfi je ne balançai pas à lui conférer le Baptême.

Mon Voyage dût-il être d'ailleurs tout-à-fait inutile, je vous avouë, Madame, que je n'en regretterois pas les fatigues $\&$ les dangers, puifque felon toutes les apparences, $f_{i}$ je n'étois pas venu à Pimiteouy, cette Enfant ne feroit jamais entrée dans le Ciel, où je ne doute pas qu'elle ne foit bientôt. J'efpere même que ce petit Ange obtieńdra pour fon Pere la même grace, quill lui a procurée. Je parts dans une heure, \& je confie cette Lettre aux deux François, que je laiffe ici, \& qui comptent de profiter de la premiere occafion pour retourner en Canada..

Je fuis, \& 8 . 


\section{VINT-HUITIÉME LETTRE.}

Voyage de Pimiteouy aux Kaskafquias. Du Cours de la Riviere des Illinois. Des Mines de Cuivre. Du Miffouri. Des Mines de la Riviere de Marameg. Defcription du Fort de Chartres, Es de la Miffion des Kaskafquias. Des Arbres Fruitiers de la Louyfiane. Defcription du Miciffipi audeffus des Illinois. Differentes Tribus de cette Nation. Quelques Traditions des Sauvages. Leurs idées fur les Aftres, les Eclypfes, Ele Tonnerre : leur maniere de calculer le tems.

1721 . Octobre. Aux Kaskafquias, ce vintiéme d'Octobre, 1721 .

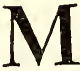

\section{A D A ME,}

JE vous avouë, de bonne foi, que je n'étois pas auffi raffûré en partant de Pimiteouy, que je le feignois de l'être, autant pour mon honneur, que pour ne pas achever de décourager ceux, qui m'accompagnoient, \& dont quelques-uns diffimuloient affez mal leur frayeur. Les allarmes, où j'avois trouvé les Illinois, leur chant lugubre, la vuë des cadavres expofés dans leurs cadres, objets affreux, qui me repréfentoient fans ceffe à quoi l'on doit s'attendre, fi l'on a le malheur de tomber entre les mains de ces Barbares, tout cela faifoit fur moi une impreffion, dont je n'étois pas le maitre, $\&$ pendant fept ou huit jours je ne dormis pas fort tranquillement.

Induftries Je n'appréhendois pas à la verité que l'Ennemi nous attades Sauvages, quât ouvertement, parce que j'avois quatorze hommes bien pour furpren- armez, \& bien commandez; (a) mais il y avoit tout ’̀ dre lcurs En-
nemis. Sauvages ne s'avifent, pour attirer leurs Ennemis dans les piéges, quils leur tendent. Un des plus ordinaire eft de contrefaire le cri d'un Animal, ou le chant d'un Oifeau, \& ils

(a) M. de S. ANGE, qqui s'eft depuis fort diftingué contre les Renards, commandoit mon Efcorte. 
les imitent fi parfaitement, que tous les jours on y eft pris. On eft campé à l'entrée d'un Bois, on croit entendre un Bœuf, un Cerf, un Canard, deux ou trois Hommes y courent dans l'efpérance de faire capture, \& fouvent ne reviennent pas.

On compte foixante $\&$ dix lieuës de Pimiteouy au Miciffipi : j’ai dit qu'il y en avoit quinze du Rocher à Pimiteouy; le premier de ces deux Villages eft par les quarante $\&$ un degrez, l'entrée de la Riviere des Illinois eft par les quarante; ainfi depuis le Rocher cette Riviere coule à l'Oueft, en prenant un peu du Sud, mais elle fait plufieurs circuits. D'efpace en efpace on y rencontre des Ifles, dont quelques-unes font affez grandes : les bords font affez bas en plufieurs endroits; dans le Printems elle inonde la plûpart des Prairies, qu'on trouve à droite \& à gauche, \& qui font enfuite couvertes d'herbes très-hautes. On prétend qu'elle eft par tout fort poiffonneufe, mais nous n'avions pas le tems de pêcher, ni des Filets tels, qu'en demande fa profondeur. Nous avions plutôt fait de tuer un Bœuf, ou un Chevreuil, \& nous avions à choifir.

Le fixiéme, nous apperçûmes quantité de Bœufs, qui traverfoient la Riviere à la nage avec beaucoup de précipitation, \& nous ne doutâmes prefque point qu'ils ne fuffent chaffés par un des Partis ennemis, dont on nous avoit parlé; ce qui nous obligea de naviguer toute la nuit, pour nous éloigner d'un fi dangereux voifinage. Le lendemain avant le jour nous paffàmes le Saguimont, grande Riviere, qui vient du Sud; cinq ou fix lieuës plus bas nous en laiffâmes fur la même main une autre plus petite, appellée la Riviere des Macopines: ce font de groffes racines, qui mangées cruës, font un poifon, mais qui étant cuites à petit feu, pendant cinq ou fix jours $\&$ plus, n'ont aucune mauvaife qualité. Entre ces deux Rivieres, à diftance égale de l'une \& 2 de l'autre, on trouve un Marais , nommé Machoutin, qui eft précifément à moitié chemin de Pimiteouy au Miciffipi.

Peu de tems après avoir paffé la Riviere des Macopines, nous apperçûmes les bords du Fleuve, qui font extrêmement le Micifịịto élevés. Nous voguâmes néanmoins encore plus de vint-quatre heures, \& fouvent à la voile, avant que d'y entrer, parce que la Riviere des Illinois varie en cet endroit depuis l'Oueft jufqu'au Sud par l'Eft. On diroit que de dépit d'être obligée 


\section{J O UR N A L H IS T O R I Q U E}

1721 . de rendre hommage de fes eaux à une autre Riviere, elle Oetobre veut retourner vers fa fource.

Son entrée dans le Miciffipi eft Eft-Sud-Eft. Ce fut le

Cuivre. neuviéme, vers les deux heures \& demie du foir , que nous nous trouvâmes dans ce Fleuve, qui faifoit alors tant de bruit en France, laiffant à main droite une grande Prairie, d'où fort une petite Riviere, où il y a quantité de cuivre. Rien n'eft plus charmant que toute cette Côte. Ce n'eft pas toutà-fait la même chofe à la main gauche. On n'y voit que des Montagnes fort hautes, femées de Rochers, entre lefquels il croît quelques Cédres; mais ce n'eft qu'un rideau , qui a peu de profondeur, \& qui cache de fort belles Prairies.

Le dixiéme, à neuf heures du matin, après avoir fait cinq

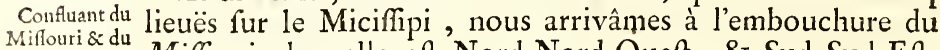
Miciflipi. Miffouri, laquelle eft Nord Nord-Oueft, \& Sud Sud-Eft. Je crois que c'eft le plus beau confluant, qu'on voye dans le Monde. Les deux Rivieres font à peu près de la même largeur, chacune d'environ une demie lieuë; mais le Miffouri eft beaucoup plus rapide, \& il paroît entrer en conquerant dans le Miciffipi, au travers duquel il porte fes eaux blanches jufqu'à l'autre bord, fans les mêler : il lui communique enfuite cette couleur, que le Miciffipi ne perd plus, \& l'entraîne avec précipitation jufqu’à la Mer.

Village des

Nous allâmes coucher le même jour dans un Village des Tamarouas. Caoquias, E des Tamarouas; ce font deux Nations Illinoifes, qui fe font réunies, \& qui ne compofent pas une Bourgade fort nombreufe. Elle eft fituée fur une petite Riviere, qui vient de l'Eft, \& n'a de l'eau que dans le Printems, de forte qu'il nous fallut marcher une bonne demie lieuë pour gagner les Cabannes. Je fus étonné qu'on eût choifi une fituation aufi incommode, ayant à choifir beaucoup mieux, mais on me répondit que le Miciffipi baignoit le pied du Village, quand on le bâtit, \& qu'en trois ans il avoit perdu une demie lieuë de terrein; qu'on fongeoit à chercher un autre Emplacement, ce qui n'eft pas une affaire pour des Sauvages.

Je paffai la nuit dans la Maifon des Miffionnaires, qui font deux Eccléfiaftiques du Séminaire de Quebec, autrefois mes Difciples, \& qui feroient aujourd'hui mes Maitres. Le plus ancien des deux (a) étoit abfent : je trouvai le plus jeune $(b)$

(a) M. I A UM U.

(b) M. LE MERCIER。 
D'UN V OYA GE DE L'A MER. LET. XXVIII. 393

rel, qu'on me l'avoit dépeint dur à lui-même, plein de charité pour les autres, \& rendant en fa perfonne la vertu aimable. Mais il a fi peu de fanté, que je ne crois pas qu'il Oetobre. puiffe foûtenir lontems le genre de vie, qu'il faut mener dans ces Miffions.

L'onziéme, après avoir fait cinq lieuës, je laiffai fur ma droite la Riviere Marameg, où l'on eft actuellement occupé à chercher des Mines d'Argent. Vous ferez peut-être bienaife, Madame, de fçavoir quel fuccès on peut efpérer de cette recherche. Voici ce qu'une perfonne inftruite, \& qui eft ici depuis plufieurs années, m'en a appris. En I 7 I 9 . le fieur DE Lochon, envoyé par la Compagnie d'Occident en qualité de Fondeur, ayant creufé dans un endroit, qu'on lui avoit marqué, en tira une affez grande quantité de Mine, dont une lìvre, qu'il fut quatre jours à fondre, lui produifit, dit-on, deux gros d'Argent; mais quelques-uns l'ont foupçonné de les y avoir mis. Quelques mois après il y retourna, \& fans plus fonger à l'Argent, de deux ou trois milliers de Mine il tira quatorze livres d'un fort mauvais Plomb, qui lui revenoient à quatorze cens francs; rebuté d'un travail fi ingrat, il retourna en France.

La Compagnie, perfuadée de la verité des indications, qu'on lui avoit données, crut que l'incapacité du Fondeur étoit la feule caufe de ce mauvais fuccès, $\&$ envoya à fa place un Efpagnol, nommé Antorne, pris au Siége de Penfacole, \& qui avoit été Forçat fur les Galeres, mais qui fe vantoit d'avoir travaillé à une Mine du Méxique. Elle lui donna des appointemens confidérables, mais il ne réuffit guere mieux, que le fieur de Lochon. Il ne fe rebuta point, \& on voulut bien croire qu'il n'avoit échoué, que par fon peu d'habileté à conftruire des Fourneaux. Il renonça au Plomb , \& entreprit de faire de l'Argent; il vint à bout d'ouvrir le Roc, qui fe trouva à huit ou dix pieds de profondeur, il en fit fauter plufieurs morceaux, qu'il mit dans le creufet; on publia qu'il en avoit tiré trois ou quatre gros d'Argent; mais bien des gens en doutent encore.

Sur ces entrefaites arriva une Brigade de Mineurs du Roi, conduite par un nommé LA RENAUDIERE, qui ayant voulu commencer par la Mine de Plomb, ne fit rien du tout, parce que, ni lui, ni aucun de fa Brigade, n'étoient au fait de la Tome III. D d d

Des Mines de la Riviere Marameg. 


\section{J O URNAL HIST ORIQ UE}

I 72 I. conftruction des Fourneaux. C'étoit une chofe affez furpreOctobre nante, que la facilité, avec laquelle la Compagnie faifoit alors de groffes avances, \& le peu de précaution, qu'elle prenoit pour s'affûrer de la capacité de ceux, qu'elle employoit. La Renaudiere \& fes Mineurs ne pouvant donc venir à bout de faire du Plomb, une Compagnie particuliere entreprit les Mines du Marameg, \& le fieur Renaud, un de fes Directeurs, les vifita avec foin. Il y trouva au mois de Juin dernier une couche de Plomb à deux pieds de profondeur fur toute une chaîne de Montagne, qui s'étend affez loin, \& il y fait actuellement travailler. Il fe flatte même que fous ce Plomb il y a de l'Argent; tout le monde ne penfe pas comme. lui; le tems nous apprendra ce qui en eft.

Defcription J'arrivai le lendemain aux Kaskafquias à neuf heures du mades Kaskaf- tin. Les Jéfuites $y$ avoient une très-floriffante Miffion, qui घuias. vient d'être partagée en deux, parce qu'on a jugé à propos de former deux Bourgades de Sauvages, au lieu d'une. La plus nombreufe eft fur le bord du Miciffipi ; deux Jéfuites (a) en: ont la direction fpirituelle : une demie lieuë plus bas eft le Fort de Chartres, à une portée de fufil du Fleuve. M.Dugué de Boisbrilland, Gentilhomme Canadien, y commande pour la Compagnie, à laquelle cette Place appartient ; \& tout l'entre-deux commence à fe peupler de François. Quatre lieuës plus loin, \& à une lieuë du Fleuve, il y a une groffe Bourgade de François, prefque tous Canadiens, qui ont un Jéfuite pour Curé $(b)$. Le fecond Village des Illinois en eft éloigné de deux lieuës, \& plus avant dans les terres. Un quatriéme Jéfuite en eft chargé (c).

Les François font ici affez à leur aife : un Flamand, Domeftique des Jéfuites, leur a appris à femer du Froment, $\&$ il y vient fort bien. Ils ont des Bêtes à corne \& des Volailles. Les Illinois de leur côté travaillent à la terre à leur maniere, \& font fort laborieux. Ils nourriffent auffi des Volailles, qu'ils vendent aux François. Leurs Femmes font affez adroites; elles filent la laine des. Bœufs, \& la rendent auffi fine que celle des Moutons d'Angleterre, quelquefois même on la prendroit pour de la Soye. Elles en fabriquent des Etoffes, qu'elles teignent en noir, en jaune, $\&$ en rouge foncé.

(a) Le P. IE BOULLANGER, \& le. P. DE KEREBEN. (b) Le P. DEBEA

(c) Le P. G UXMONNEAU., 
D'UN VOYAGE DE L'A MER. LET. XXVIII. 395 Elles s'en font des Robes, qu'elles coufent avec du fil de nerfs de Chevreuils. La maniere, dont elles font ce fil êft très-fimple. Quand le nerf de Chevreuil eft bien décharné, elles le mettent au Soleil pendant deux jours; quand il eft fec, elles le battent, \& elles en tirent fans peine un fil auffi blanc \& auffi fin que celui de Malines, \& beaucoup plus fort.

La Bourgade Françoife eft bornée au Nord par une Riviere, dont les bords font fi élevés, qu'encore que les eaux $\mathrm{y}$ montent quelquefois jufqu'à vint-cinq pieds, elle fort rarement de fon lit. Tout ce Pays eft découvert: ce font de vaftes Prairies, qui s'étendent jufqu’à vint-cinq lieuës, \& qui ne font féparees que par de petits Bofquets, où il n'y a que de bon bois. On y voit furtout des Muriers blancs; mais j'ai été furpris qu'on permit aux Habitans de les abbattre pour bâtir leurs maifons; d'autant plus qu'ils ne manquent point d'autres Arbres propres à cet ufage.

Parmi les fruitiers, qui font particuliers à ce Pays, les plus remarquables font les Pacaniers, les Aciminiers, \& les Piakiminiers. Le Pacane eft une Noix de la longueur \& de la Arbres Frui. tiers de la Louyfiane. figure d'un gros Gland. Il y en a, dont la coque eft fort mince : d'autres l'ont plus dure \& plus épaiffe, \& c'eft autant de défalqué fur le fruit: elles font même un peu plus petites. Toutes font d'un goût fin $\&$ délicat ; l'Arbre, qui les porte, vient fort haut: fon bois, fon écorce, l'odeur \& la figure de fes feüilles m'ont paru affez femblables aux Noyers d'Europe.

L'Acimine eft un fruit de la longueur d'un doit, d'un pouce de diamétre. Sa chair eft tendre, un peu fucrée ; \& toute femée d'une graine, qui reffemble à celle du Melon d'eau. L'Aciminier, ne vient ni fort gros, ni fort haut : tous ceux, que j'ai vîs n'étoient guere que des arbriffeaux, d'un bois tendre. Son écorce eft mince, les feuilles longues $\&$ larges, comme celles du Chataignier, mais d'un verd plus foncé.

La Piakimine a la figure, \& un peu plus que la groffeur d'une prune de Damas: fa peau eft tendre, fa fubftance aqueufe, fa couleur rouge ; \& elle eft d'un goût fort délicat. Elle renferme des graines, qui ne différent de celles de l'Acimine, qu'en ce qu'elles font plus petites. Les Sauvages font une pâte de ce fruit , \& en forment des pains de l'épaif D d d ij 
Octobre. aifément. Ils font fort nourriffans, \& fouverains, dit-on, contre le flux de ventre \& la dyfenterie. Le Piakiminier eft un bel arbre, de la hauteur de nos Pruniers ordinaires. Ses. feuilles font à cinq pointes, fon bois médiocrement dur, \& fon écorce fort rude.

Differens Peuples, qui fontétablisfur le Miffouri, \& aux envirous.

Les $O$ fages, Nation affez nombreufe, établie fur le bord d'une Riviere, qui porte leur nom, \& fe jette dans le Miffouri, environ à quarante lieuës de fa jonction avec le Miciffipi, envoyent tous les ans une ou deux fois chanter le Calumet chez les Kaskafquias, \& ils y font actuellement. Je viens de voir auffi une Femme Miffourite, qui m'a dit que fa Nation: eft la premiere, que l'on rencontre en remontant le Miffouri, d'où lui vient le nom, que nous lui avons donné, faute de: fçavoir fon nom propre. Elle eft à quatre-vint lieuës du confluant de cette Riviere avec le Miciflipi.

Plus haut on trouve les $C_{a n f e r}$, puis les Octotatas, que: quelques-uns nomment Maitotatas; enfuite les Aiouez, puis. les $P$ anis, Nation très-nombreufe, divifée en plufieurs Cantons, qui portent des noms affez differens les uns des autres. Cette Femme m'a confirmé ce que j’avois appris des. Sioux, que le Miffouri fort de Montagnes Pelées, fort hautes, derriere lefquelles il y a un grand Fleuve, qui en fort apparemment aufi, \& qui coule à l'Oueft. Ce témoignage eft de quelque poids, parce que de tous les Sauvages, que nous connoiffons, aucuns ne voyagent plus loin que les Miffourites.

Tous les Peuples, dont je viens de parler, habitent le Defcription, bord Occidental du Miffouri, excepté les Aïouez, qui font à an-- deflus des l'Eft, Voifins des Sioux, \& leurs Alliés. Parmi les Rivie-
llinois. res, qui tombent dans le Miciffipi, au-deffus de la Riviere: des Illinois, les plus confidérables font la Riviere aux Boufs, qui en eft éloignée de vint lieuës, \& qui vient de l'Oueft; on. a découvert dans fon voifinage une très-belle Saline. On en a trouvé de femblables fur les bords du Marameg, \& à vint lieuës d'ici. Environ quarante lieuës plus loin on laife l'Afjenefipi, ou Riviere à la Roche, parce qu'elle eft vis-à-vis d'une Montagne placée dans le Fleuve même, \& où des Voyageurs ont affûré qu'il y avoit du Criftal de Roche.

Vint-cinq lieuës plus haut on trouve fur la main droi- 
DUUN V OYYA G E DE L'A MER. LET. XXVIII. 397 te l'Ouifconfing, par où le Pere Marquette \& le fieur Jóliet entrerent dans le Miciffipi, lorfqu'ils en firent la premiere découverte. Les Aiouez, qui font par cette hauteur, c'eft-à-dire, par les quarante-trois dégrés \& environ trente minuttes d'élévation du Pole, qui voyagent beaucoup, \& qui font, à ce qu'on affûre, vint-cinq à trente lieuës par jour, quand ils n'ont point leurs Familles avec eux, difent qu'en partant de chez eux on arrive en trois jours chez des Peuples, nommés Omans, qui ont la peau blanche \& les cheveux blonds, furtout les Femmes. Ils ajoûtent que cette Nation eft continuellement en guerre avec les Panis, \& d'autres Sauvages plus éloignés vers l'Occident, \& qu'on leur a oui parler d'un grand Lac fort éloigné de chez eux, aux environs duquel il y a des Peuples, qui reffemblent aux François, qui ont des boutons à leurs habits, qui bâtiffent des Villes, qui fe fervent de Chevaux pour la Chaffe du Bouf, ' $\&$ qu'ils couvrent de Peaux de Bufles, mais qui n'ont point d'autres armes, que l'Arc \& la Fléche.

Sur la gauche environ foixante lieuës au-deflus de la Riviere aux Bœufs, on voit fortir du milieu d'une immenfe $\&$ magnifique Prairie, toute couverte de Bœufs \& d'autres Bêtes Fauves, le Moingona : à fon entrée dans le Miciflipi il a: peu d'eau, \& il eft même affez étroit; il a néanmoins, diton, deux cent cinquante lieuës de cours en tournant du Nord à l'Oueft. On ajoûte qu'il prend fa fource dans un Lac, $\& x$ qu'il en forme un Second à cinquante lieuës du Premier.

De ce fecond Lac on tire à gauche, \& on entre dans la $R i$ siere bleüe, ainfi nommée à caufe de fon fond, qui eft une terre de cette couleur. Elle fe décharge dans la Riviere de Saint Pierre. En remontant le Moingona, on trouve beaucoup de Charbon de terre, \& quand on l'a remonté cent cinquante lieuës, on apperçoit un gros Cap, qui fait faire un détour à la Riviere, dont les eaux font roufes \& puantes en: cet endroit. On affûre qu'on a ramaffé fur ce Cap quantité de Pierres de Mines, \& qu'on en a rapporté ici de l'Antimoine.

Une lieuë au-deffus de l'embouchure du Moingona il y a: dans le Micifípi deux Rapides affez longs, où il faut décharger. \& trainer la Pirogue : \& au-deflus du fecond Rapide, c'eft-àdire, à vint \& une lieuës du Moingona, on trouve des deux côtés du Fleuve des Mines de Plomb, découvertes autrefois. 


\section{J O U R N A L H IS T O R I Q U E}

par un fameux Voyageur du Canada, nommé Nicolas P E RR OT, \& qui portent fon nom. Dix lieuës au-deffus de Octobre. l'Ouifconfing, du même côté commence une Prairie de foixante lieuës de long, bordée par des Montagnes, qui font une perfpective charmante; il y en a une autre du côté de l'Oueft, mais qui n'eft pas fi longue. Vint lieuës plus haut que l'extrémité de la Premiere, le Fleuve s'élargit, \& on a nommé cet endroit le Lac de bon Secours. Il a une lieuë de large, \& fept lieuës de circuit, \& il eft encore environné de Prairies. Nicolas Perrot avoit bâti un Fort fur la droite.

Au fortir du Lac on rencontre l'Ife Pelée, ainfi nommée, parce qu'elle n'a pas un feul Arbre; mais c'eft une très-belle Prairie : Les François du Canada en ont fouvent fait le centre de leur commerce dans ces Quartiers Occidentaux, \& plufieurs y ont même hyverné, parce que tout ce Pays eft très-propre pour la Chaffe. Trois lieuës au-deffus de l'Ifle Pelée on laiffe à main droite la Riviere de Sainte $C_{\text {roix }}$, qui vient des environs du Lac Supérieur; on prétend avoir trouvé du Cuivre affez près de fon embouchure. Quelques lieuës plus loin on laiffe à la main gauche la Riviere de Saint Pierre, dont les bords font peuplés de Sioux, \& dont l'embouchure n'eft pas éloignée du Sault Saint Antoine. On ne connoît gueres le Miciffipi, que jufqu'à cette grande Cafcade.

Differentes

Pour revenir aux Illinois, s'il eft vrai, ce qu'on m'a affûré Tribus des 11 linois. en plufieurs endroits, \& ce que la Femme Miffourite, dont je vous ai parlé, Madame, m'a confirmé, qu'eux \& les Miamis, viennent des bords d'une Mer fort éloignée à l'Oueft (a), il paroît que leur premiere ftation, lorfqu'ils defcendirent en ce Pays, fut le Moingona : du moins ett-il certain qu'une de leurs Tribus en porte le nom. Les autres font connuës fous les noms de Pecrias, de Tamarouas, de Caoquias, \& de Kaskafquias: mais ces Tribus font aujourd'hui fort mêlées, \& réduites à très-peu de chofes. Il ne refte plus qu'un très-petit nombre de Kaskafquias, \& les deux Villages, qui portent leurs noms, font prefqu'uniquement compofés de Tamarouas, $\&$ de Mctchligamias, Nation étrangere, fortie des bords d'u-

(a) Une Femme Miamife, Captive des Sioux, a affitré au Pere de Saint $\mathrm{PE}_{\mathrm{E}}$, aujourd'hui Supérieur des Mifíons de la
Nouvelle France, qu'elle a été conduite par les Sioux dans un Village de fa $\mathrm{Na}$ tion, qui étoit fort près de la $\mathrm{Mer}_{\text {. }}$ 
D'UN V OYA G E DE L'A MER. LET. XXVIII. 399 ne petite Riviere, que nous trouverons en defcendant le Miciffipi, \& que les Kaskafquias ont adoptée.

Voilà, Madame, tout ce que je puis préfentement vous apprendre de la Louyfiane, où je ne fais que d'entrer; mais avant que de finir cette Lettre, il faut vous faire part de quelques notices, qui ferviront de fupplément à ce que je vous ai déja dit des Sauvages en général, \& que j’ai apprifes fur ma route depuis la Riviere de S. Joreph jufqu'ici.

Vous avez pû voir dans la Fable d'Atahentfic chaffée du Ciel quelques veftiges de l'hiftoire de la premiere Femme, exilée du Paradis Terreftre, en punition de fa défobéiffance, Traditions du Péché de la premiere Fem\& la tradition du Déluge, auffi-bien que de l'Arche, dans la- luge. quelle Noé fe fauva avec fa Famille. Cette circonftance m’empêche d'adhérer au fentiment du P. de Acofta, qui prétend que cctte tradition ne regarde pas le Déluge Univerfel, mais un déluge particulier à l'A mérique. En effet, les Algonquins, \& prefque tous les Peuples, qui parlent leur Langue, fuppofent la création du premier Homme, difent que fa pofterité ayant péri prefque toute entiere par une inondation générale, un nommé $M e \int f o u$, d'autres l'appellent Saketchak, qui vit toute la Terre abymée fous les eaux par le débordement d'un Lac, envoya un Corbeau au fond de cet abîme, pour lui en rapporter de la terre : que ce Corbeau ayant mal fait fa commiffion, il y envoya un Rat mufqué , qui réuffit mieux; que de ce peu de terre, que l'Animal lui avoit apporté, il rétablit le Monde dans fon premier état : qu'il tira des fléches contre les troncs des Arbres, qui paroiffoient encore, \& que ces fléches fe changerent en branches: qu'il fit plufieurs autres merveilles, \& que par reconnoiffance du fervice, que lui avoit rendu le Rat mufqué, il époufa une fémelle de fon efpéce, dont il eut des enfans, qui repeuplérent le monde : qu'il avoit communiqué fon immortalité à un certain Sauvage, \& la lui avoit donné dans un petit paquet, en lui défendant de ne le point ouvrir, fous peine de perdre un don fi précieux.

Les Hurons \& les Iroquois difent que Taronhiaoulagon, le Roi du Ciel, donna un coup de pied à fa femme, fi rude, qu'il la fit fauter du Ciel en Terre; que cette Femme tomba fur le dos d'une Tortuë, qui en éloignant les eaux du Déluge avec fes pattes, découvrit enfin la Terre, \& porta la Femme 
${ }_{400} \mathrm{JOURN} A \mathrm{~L}$ H I S T O R I Q U E

1721 .

Octobre.

Leurs idées fur les Aftres.

au pied d'un Arbre, où elle accoucha de deux Jumeaux, \& que fon Aîné, qu'ils nomment Tahouiskaron, tua fon Cadet.

Il n'eft pas étonnant que des Peuples, $f$ indifférens fur le paffé, \& que l'avenir mème inquiette fort peu, ne connoiffent quafi rien dans le $\mathrm{Ciel}, \&$ ne mettent point de différence entre les Planettes \& les Etoiles fixes; fi ce n'eft qu'ils partagent celles-ci, comme nous, en Conftellations. Ils nomment les Pleyades, les Danfeurs \& les Danfeufes. Ils donnent le nom d'Ours aux quatre premieres de ce que nous appellons la grande Ourfe ; les trois, qui compofent fa queuë, ou qui font le train du Chariot de David, font, felon eux, trois Chaffeurs, qui pourfuivent l'Ours; \& la petite Etoile, qui accompagne celle dumilieu, eft la Chaudiere, dont le fecond eft chargé. Les Sauvages de l'Acadie nommoient tout fimplement cette Conftellation \& la fuivante, la grande \& la petite Ourfe; mais ne pourroit-on pas juger que quand ils parloient ainfi au fieur Lefcarbot, ils ne répétoient que ce qu'ils avoient oüi dire à plufieurs François ?

Comment ils connoiffent le Nord, quand le Ciel eft couvert.

La plûpart des Sauvages appellent l'Etoile polaire, l'Etoile, qui ne marche pas. C'eft elle, qui les guide dans leurs voyages pendant la nuit, comme le Soleil leur fert de Bouffole pendant le jour. Ils ont encore d'autres marques pour connoitre le Nord. Ils prétendent avoir obfervé que la cime des Arbres panche toujours un peu de ce côté là , \& que les pellicules intérieures de leurs écorces font plus épaifles du même côté. Ils ne s'y fient pourtant pas fi abfolument, qu'ils ne prennent d'ailleurs leurs précautions pour ne point s'égarer, \& pour retrouver leur chemin, quand ils doivent retourner fur leurs pas.

Cequils pen- Quant à ce qui regarde le cours des Aftres, les caufes des fent des Eclyp- Phénomenes, la nature des Méteores, \& autres chofes femnerre.

blables, ils font fur tout cela, comme fur ce qui ne les touche pas fenfiblement, d'une ignorance profonde, \& d'une parfaite indifférence. S'il arrive une Eclipfe, ils s'imaginent qu'il fe fait dans le Ciel quelque grand combat, \& ils tirent quantité de fléches en l'air, pour écarter les prétendus Ennemis du Soleil \& de la Lune. Les Hurons, quand la Lune s'éclipfoit, étoient perfuadés qu'elle fe trouvoit mal, \& pour la faire revenir de cette foibleffe, ils faifoient beaucoup de bruit, 
DUN VOYAGE DE L'A MER. LET. XXVIII. 40I bruit, \& accompagnoient ce tintamarre de beaucoup de cérémonies $\&$ de prieres. Ils ne manquoient pas furtout de donner fur les Chiens à grands coups de bâton $\& x$ de pierres, pour I 721 . les faire crier, parce qu'ils croyoient que la Lune aime ces Animaux.

Ces mêmes Sauvages, \& plufieurs autres, ne pouvoient fe mettre dans l'efprit qu'une Eclipfe fût une chofe indifférente \& purement naturelle : ils en auguroient bien ou mal, fuivant l'endroit du Ciel, où cet Aftre paroiffoit obfcurci. Rien ne les étonna davantage, que de voir avec quelle jufteffe les Miffionnaires prédifoient ces Phénomenes, \& ils en concluoient qu'ils devoient auffi en prévoir les fuites.

Ces Peuples ne connoiffent pas mieux la nature du Tonnerre; quelques-uns le prenoient pour la voix d'une efpéce particuliere d'Hommes, qui voloient dans les airs : d'autres difoient que ce bruit venoit de certains Oifeaux, qui leur étoient inconnus. Selon les Montagnais, c'étoit l'effort, que faifoit un Génie pour vomir une Couleuvre, qu'il avoit avalée; \& ils appuyoient ce fentiment fur ce que, quand le Tonnerre étoit tombé fur un Arbre, on y voyoit une figure affez approchante de celle d'une Couleuvre.

Tous comptent les mois par les Lunes; felon la plûpart, l'année n'en a jamais que douze, \& quelques-uns lui en donnent toujours treize. Les inconvéniens, qui peuvent naître Leur maniere de divifer le tems. de cette diverfité, ne vont pas bien loin parmi des Peuples, qui n'ont point d'Annales, $\&$ dont les affaires ne dépendent point des Epoques annuelles. Il y a auffi parmi eux beaucoup de varieté dans les noms des Saifons \& des Lunes, parce que dans tous les Pays les Chaffes, les Pêches, les Semences, les récoltes, la naiffance \& la chûte des feüilles, les paffages de certaines Bêtes \& de certains Oifeaux; le tems, auquel les Chevreuils changent de poil , \& celui, auquel différens Animaux font en rut, fervent à diftinguer tout cela, \& que ces chofes varient beaucoup, fuivant les différens Cantons.

Il y a des Nations, qui comptent les années par les Signes, fi ce n'eft, lorfqu'il s'agit de marquer fon âge, \& quelques occafions, où ils employent les années Lunaires. Il n'y a nulle part aucune diftinction de femaines, \& les jours n'ont point de nom dans aucune de leur Langue. Ils ont quatre points fixes dans le jour, à fçavoir le lever \& le coucher du Soleil,

$$
\text { Tome III. } \mathrm{E} \text { e e }
$$


402 J OUR N A L H S T OR I Q U E

I 72 I. le Midy \& le Minuit, \& quelque tems qu'il faffe, ils ne s'y Octobre trompent jamais. Du refte, cette exactitude Aftronomique à accorder les années Lunaires avec les Solaires, dont le Baron de la Hontan leur fait honneur, eft une pure imagination de cet Ecrivain.

Ils n'ont point de fupputations chronologiques, \& s'ils confervent les époques de certains événemens remarquables, ils. ne comptent point au jufte le tems, qui s'eft écoulé depuis; ils fe contentent de retenir les faits, \& ils ont imaginé plufieurs moyens de n'en pas perdre la mémoire. Par exemple, les Hurons \& les Iroquois ont dans leurs Tréfors publics des Porcelaines, où il y a des figures, qui leur en rappellent le fouvenir. D'autres fe fervent de nouds faits d'une certaine façon, \& $\mathrm{fi}$ en tout cela leur imagination travaille, elle ne les trompe point. Enfin tous font dans l'ufage de compter les unitez jufqu’à dix, les dizaines par dix jufqu’à cent ; les centaines par dix jufqu'à mille; ils ne vont pas plus loin dans leurs calculs.

Je fuis, \&c.

1721 .

\section{VINT-NEUVIERE LETTRE.}

Novem- De la Colonie des Illinois. Voyage jufqu'aux Akanfas: bre. Defcription du Pays. Aux Kaskafquias, ce huitiéme de Novembre, 1721.

\section{Ma D A ME,}

MA derniere Lettre eft partie pour Ie Canada, d'où l'on mª affûré qu'elle iroit plutôt en France par l'llfe Royale. Au refte, fi elle s'égare fur la route, la perte ne fera pas grande. Je commence encore celle - ci aux Kaskafquias, mais, felon toutes les apparences, je ne l'y acheverai pas. Il y a près d'un mois que j'y fuis, \& je hâte mon départ le plus qu'il m'eft Uilite du poffible.

Poofte des Illi- Comme je n'ai encore vû de la Louyfiane, que ce pofte,
noiss 
D'UN V OYA GE DE L'A MER. LET. XXIX. 403 le premier de tous par droit d'Antiquité, je ne peux encore en juger par comparaifon avec les autres. Ce qui me paroît certain, c'eft qu'il a deux avantages, dont l'un ne lui fera jamais difputé, \& l'autre le rend, quant à préfent, néceffaire à toute la Province. Le premier vient de fa fituation, qui l'approche beaucoup du Canada, avec lequel il aura toujours une communication également utile aux deux Colonies. Le fecond eft, qu'il peut être le grenier de la Louyfiane, à laquelle il pourra fournir des Bleds en abondance, quand bien même elle feroit toute peuplée jufqu'à la Mer.

Non-feulement la terre y eft propre à porter le Froment, mais elle n'a encore rien refufé de tout ce qui eft néceffaire à la nourriture de l'Homme. Le climat y eft fort doux, par les trente-huit degrez trente-neuf minutes de latitude Septentrionale; il fera fort aifé d'y multiplier les Troupeaux; on y pourra même aprivoifer les Boufs fauvages, dont on tireroit une grande utilité pour le commerce de la Laine $\&$ des Cuirs, $\&$ pour la nourriture des Habitans. L'air y eft bon, \& fi on $\mathrm{y}$ voit quelques maladies, il ne les faut attribuer qu'a la mifere, au libertinage, \& peut-être un peu aux terres nouvellement remuées; mais ce dernier inconvénient ne durera pas toujours, \& le changement de climat ne fera rien pour ceux, qui y naîtront dans la fuite.. Enfin on eft affûré des Illinois plus qu'on ne l'eft en Canada d'aucune Nation fauvage, fi on en excepte les Abenaquis. Ils font prefque tous Clrrétiens, d'un naturel doux, \& de tout tems très-affectionnés aux François.

Me voici, Madame, à cent cinquante lieuës de l'endroit, où j'ai commencé cette Lettre : je vais l'achever ici, \& la con-me. fier à un Voyageur, qui compte d'être beaucoup plutôt que moi à la Nouvelle Orleans, parce qu'il ne s'arrêtera nulle part, \& que je dois faire quelque féjour aux Natchez. D'ailleurs j’avois compté fur deux chofes en partant des Illinois; la premiere, qu'ayant à defcendre un Fleuve très-rapide, \& fur lequel je n'avois pas à craindre d'être arrêté par ces Saults \& ces Rapides fi fréquens dans les Rivieres du Canada, je ne ferois pas lontems dans mon Voyage, quoique jeuffe près de quatre cens lieuës à faire à caufe des circuits, que fait le Fleuve; la feconde, que ma route étant toujours au Sud, il n'étoit nullement befoin que je me précautionaffe contre le

Novembre.

\author{
(n)
}


404 J O UR N A L H I S T O R I Q UE

$172 \mathrm{I}$. froid: mais j’ai été trompé des deux côtés. Je me fuis vû contraint de naviguer plus lentement encore, que je n'avois fait Novem- dans les Lacs, qu'il m'a fallu traverfer, \& j'ai effuyé un froid bre. auffi picquant, que ceux, que javois jamais foufferts à Quebec.

Il eft vrai que ce fut encore toute autre chofe aux Kaskaf. quias, d'où j'étois parti peu de jours auparavant, puifque le Fleuve, à ce que j'ai appris fur ma route, y fut d'abord glacé de maniere, qu'on a couru deffus en charette.ll a cependant en cet endroit une bonne demie lieuë de large, \& $x$ il y eft plus rapide encore que le Rhône. Cela eft d'autant plus furprenant, que pour l'ordinaire, à l'exception de quelques gelées paffageres, caufées par les vents du Nord, \& du Nord-Uueft, l'Hyver en ce Pays n'eft prefque pas fenfible. Le Fleuve n'a point gelé où j'étois, mais comme je demeurois tout le jour dans une Pirogue découverte, par conféquent expofé à toutes les injures de l'air, \& que je n'avois pris aucune précaution contre un froid, que je ne prévoyois pas, je l'ai trouvé bien dur $(a)$.

Mariere de

Si j’avois pû faire plus de diligence, j'en aurois éprouvé naviguer fur le Micisipi. chaque jour une diminution fenifible; mais il faut naviguer fagement fur le Miciffipi. On ne fe hazarde pas aifément à s'y embarquer fur des Canots d'écorce, par la raifon que ce Fleuve entrainnant toujours un grand nombre d'arbres, qui tombent de deffus fes bords, ou que les Rivieres, qu'il reçoit, lui amenent; plufieurs de ces Arbres font arrêtés en paffant fur une pointe, ou fur une batture; de forte qu'à chaque moment on eft expofé à heurter contre une branche, ou contre une racine cachée fous l'eau, \& il n'en faudroit pas davantage pour crever ces frêles voitures; furtout quand pour éviter un Parti ennemi, ou pour quelque autre raifon, on veut marcher de nuit, ou partir avant le jour.

On eft donc contraint de fubitituer aux Canots d'écorces des Pirogues, c'eft-à-dire, des troncs d'Arbres creufés, qui ne font pas fujets aux mêmes inconvéniens, mais qui font fort lourds, \& ne fe manient pas comme l'on veut. J'en ai une de bois de Noyer fi étroite, qu'elle ne peut pas porter la voile; \& mes Conducteurs, accoûtumés à ces petites Pagayes, dont on fe fert pour les Canots, ont bien de la peine à fe faire

(a) Cela a duré près de deux mois. 
D'UN VOYA GE DE L'A MER. Let. XYIX. 405 à la rame. De plus, pour peu que le vent foit fort, l'eau entre dans la Pirogue, \& cela arrive fouvent dans la Saifon, où nous fommes.

Ce fut le dixiéme de Novembre, au Soleil couchant, que je m'embarquai fur la petite Riviere de Kaskafquias ; je n'avois que deux lieuës à faire pour gagner le Miciffipi, cependant je fus obligé de camper à moitié chemin, \& le jour fuivant je ne pûs faire que fix lieuës dans le Fleuve. Les feüilles tombent en cet endroit plutôt qu'en France, \& n'en reprennent de nouvelles, qu'à la fin de May; il y neige néanmoins fort rarement, \& j'ai déja obfervé que les hyvers y font ordinairement fort doux. Quelle peut donc être la raifon de ce retardement? Pour moi, je n'en vois point d'autre, que l'épaiffeur des Forêts, qui empêche la terre de s'échauffer affez. tôt, pour faire monter la féve.

Le douziéme, après avoir fait deux lieuës, je laiffai le Cap de $S$. Antoine à la main gauche. C'eft là, que l'on commence à voir des Cannes: elles font affez femblables à celles, qui croiffent en plufieurs endroits de l'Europe, mais elles font plus hautes \&x plus fortes. On prétend qu'elles ne paroiffent jamais, que dans les bonnes Terres; mais il faut que ces Terres foient mouillées, \& par conféquent plus prop:es à porter du Ris, que du Froment. On ne fe donne pas la peine de les arracher, quand on veut défricher le terrein, où elles fe trouvent : la chofe d'ailleurs ne feroit pas aifée, leurs racines noueufes étant très-longues, \& cramponnées par un grand nombre de filamens, qui s'étendent fort loin. Ces racines ont naturellement un affez beau vernis, \& approchent de celles des Bambous du Japon, dont on fait ces belles Cannes, que les Hollandois vendent fous le nom de Rottangs.

On fe contente donc, quand on veut cultiver un Champ couvert de ces Cannes, de les cuuper par le pied : on les laiffe enfuite fécher, puis on y met le feu, les cendres fervent d'engrais, le feu ouvre les pores de la terre, qu'on remuë légérement, \& on y féme tout ce qu'on veut; du Ris, du Maiz, des Melons d'eau, en un mot toutes fortes de grains \& de légumes, excepté le Froment, qui dans ces terres grafles s'épuife en pouilant beaucoup d'herbes, \&x ne produit point de grains. On pourra remédier à ce défaut en jettant du fable fur ce terrein, \& en y femant du Maiz pendant quelques années.

Pourquoi le Froment n'a point réufí dans la Louya fiane.
1721 .

Novembre.

Pourquoi les Feuiilles tom bent fitót, 8s viennent fi tard aux Arbres dans la Louyfiane.

Des Cannes, ine. 
1721. Pour ce qui eft des hauteurs, \& des autres Terroirs, qui

ne font point expofés à l'inondation du Fleuve; ils font dèsbre.

Novem- ̀̀-préfent très-propres à porter du Bled, \& fi les effais, qu'on en a faits en quelques endroits, n'ont pas réuffi, parce que la roüille mangeoit le grain, c'eft que le Pays n'étant pas découvert, l'air n'y eft pas affez libre pour diffiper les brouillards, qui engendrent la roüille. La preuve de ceci eft qu'aux Illinois, où il y a plus de Prairies que de Bois, le Froment pouffe \& mûrit comme en France.

Froid ex- Le treiziéme, après une nuit très-chaude, nous fìmes encellif. viron trois lieuës, malgré un vent du Sud, qui croiffoit toujours, \& qui devint enfin fi violent, qu'il nous obligea de nous arrêter. Une groffe pluye le fit tomber fur le foir, \& vers le minuit il s'éleva un vent de Nord-Oueft, qui commença ce froid exceffif, dont je vous ai parlé. Pour comble de malheur, un accident nous arrêta tout le jour fuivant, quoiqu'il n'y eût point de sûreté à demeurer où nous étions. Il n'y a pas lontems que des Cheraquis y tuerent trente François, qui avoient à leur tête un Fils de M. de Ramezai, Gouverneur de Montreal, \& un du Baron de Longueuil, Lieutenant de Roi de la même Ville. Outre ces Sauvages, qui ne font point encore réconciliés avec nous, les Outagamis, les Sioux, $8 x$ les Chicachas nous tenoient en grande inquiétude, \& je n'avois avec moi que trois Hommes.

Le quinziéme, le vent tourna au Nord, \& le froid augmenta. Nous fìmes quatre lieuës au Sud, puis nous trouvâmes que le Fleuve retournoit quatre autres lieuës au Nord. Immédiaternent après ce grand détour, nous laiffâmes à gauche la belle Riviere Ouabache, par laquelle on peut aller jufques chez les Iroquois, quand les eaux font hautes. Son entrée dans le Micifflipi n'a guere moins d'un quart de lieuë de large. Il n'eft point dans toute la Louyfiane de lieu plus propre à mon avis pour un Etabliffement, que celui-là, ni où il importe davantage d'en avöir un. Tout le Payś, qu'arrofent Ouabache, \& l'Ohio, qui s'y décharge, eft très-fertile; ce font de vaftes Prairies bien arrofées, où les Bceufs fauvages paifient par milliers. D'ailleurs, la communication avec le Canada n'y eft pas moins facile, que par la Riviere des Illinois, \& le chemin eft beaucoup plus court. Un Fort avec une bonne Garnifon y tiendroit en bride les Sauvages, fur- 
tout les Cheraquis, aujourd'hui la plus nombreufe Nation de ce Continent.

Six lieuës au-deffous de l'embouchure d'Ouabache, on trouve fur la même main une côte fort élevée, d'une terre Novemjaune, fur laquelle on prétend qu'il y a des Mines de Fer. Nous fìmes bien du chemin ce jour là , qui étoit le feiziéme, mais nous foufrìmes extrêmement du froid: il augmenta encore les jours fuivans, quoique le vent fe fût tourné au SudSud-Oueft : il nous falloit même pour avancer, caffer une glace, fort mince à la verité, qui fe formoit fur la fuperficie de l'eau. Le dix - neuviéme nous fìmes quatre lieuës, après quoi un vent de Sud nous arrêta tout court. Je n'ai jamais fenti de bife plus piquante que ce vent de Midi. Il y a bien de l'apparence que c'étoit toujours le vent de Nord-Oueft, qui foufloit, mais que les terres refléchiffoient tantôt d'un côté, \& tantôt de l'autre, à mefure que nous tournions avec le Fleuve.

On rencontre fur toute cette route une efpece de Chats fauvages, appellé Pijoux, \& qui reffemblent beaucoup aux nôtres, mais qui font plus grands. J'en ai remarqué, qui avoient la queuë plus courte, \& d'autres, qui l'avoient confidérablement plus longue, \& plus groffe : ils ont auffi la mine extrêmement fiere, $\&$ on m'a affûré qu'ils font fort carnaciers, \& bons chaffeurs. Les Forêts font remplies de Noyers femblables à ceux du Canada, \&x leurs racines ont plufieurs proprietés, qu'on ne m'a point fait obferver dans les autres. Elles font fort tendres, \& leurs écorces teignent en noir ; mais leur principale utilité eft pour la Médecine. Elles arrêtent le flux de ventre, \& font un excellent vomitif.

Le vintiéme, il neigea tout le jour, \& nous ne bougeâmes point : le tems s'adoucit, mais la nuit fuivante le Sud-Oueft nettoya he Ciel, \& le froid recommença de plus belle. Le lendemain matin de l'eau-de-vie, qu'on avoit laiffé dans la Pirogue pendant la nuit fe trouva épaiffe, comme de l'Huile gelée, \& du Vin d'Efpagne, que j’avois pour la Mefle, étoit glacé. Plus nous defcendions, plus nous trouvions que le Fleuve tournoit, le vent fuivoit tous ces détours, \& de quelque côté qu'il vint, le froid étoit toujours exceffif. De mémoire d'Homme on n'avoit rien vû de femblable en cé Pays.

Chats fotre vages. Noģers \& leurs pro= prietés. 
Ce jour là nous apperçûmes fur le bord du Fleuve à droite un Poteau dreffé; nous en approchâmes, \& nous reconnûbre.

mes que c'étoit un Monument dreffé par des Illinois pour une Expédition faite depuis peu fur les Chicachas. Il y avoir deux Marques des figures d'Hommes fans tête, \&r quelques-unes dans leur entier. Guerriers.

Les premieres marquoient les Morts, \& les fecondes, les Captifs. Un de mes Conducteurs mapprit à cette occafion que, quand il y a des François parmi les uns \& les autres, on leur appuye les bras fur les hanches, pour les diftinguer des Sauvages, à qui on les laiffe pendants. Cette diftinction n'eft point purement arbitraire ; elle vient de ce que ces Peuples ont obfervé que les François fe tenoient fouvent dans cette pofture, qui n'eft point en ufage parmi eux.

Des Chica- Garcilasso DE LA VEGA parle des Chicachas dans fon chas.

Hiftoire de la Conquête de la Floride, \& il les place à peu près au même endroit, où ils font encore préfentement. Il les compte parmi les Peuples de la Floride, qui fe foumirent aux Efpagnols, mais cette prétenduë foumiffion n'a duré qu'autant de tems, que les Efpagnols ont été dans leur voifinage, \& il eft certain qu'ils vendirent cher la Victoire, qu'on remporta fur eux. Ce font encore les plus braves Soldats de la Louyfiane : ils étoient beaucoup plus nombreux du tems de Ferdinand de Sото, qu'ils ne font aujourd'hui, mais pour les richeffes, que fon Hiftorien leur attribuë, je ne comprends pas trop, ni d'où ils les avoient pû tirer, ni ce qui en auroit pû tarir la fource, car ils ne font ni plus opulens, ni plus policés que les autres Sauvages.

C'eft notre alliance avec les Illinois, qui nous a mis en guerre avec les Chicachas, \& les Anglois de la Caroline attifent le feu. Notre Etabliffement dans la Louy fiane fait grand mal au cœur à ceux-ci : c'eft une barriere, que nous mettons entre leurs puiffantes Colonies de l'Amérique Septentrionale, \& le Méxique, \& nous devons nous attendre quils employeront toutes fortes de moyens pour la rompre. Les Efpagnols, qui nous voyent avec des yeux fi jaloux nous fortifier dans ce Pays, ne fentent pas encore l'importance du fervice, quenous leur rendons. Peu de jours après que j'eus paffé par l'endroit, où nous avions vî le poteau des Illinois, les Chicachas eurent leur revanche fur deux François, qui me fuivoient dans une Pirogue. Ces Sauvages s'étoient emburqués dans des 
D'UN VOYAGE DE L'A MER I Q. LeT. XXIX. $4 \circ 9$

Cannes fur le bord du Fleuve, \& quand ils virent les François vis-à-vis d'eux, ils remuerent les Cannes, fans fe montrer; les François crurent que c'étoit un Ours, ou quelqu'autre Bête, \& s'approcherent pour faire capture ; mais au moment qu'ils fe difpofoient à débarquer, les Chicachas firent fur eux une décharge de fufils, qui les étendit morts dans leur Pirogue. Je fùs fort heureux qu'ils ne m'eufent pas apperçu, car mes gens ne vouloient manquer aucune occafion de chaffer.

Le vint-troifiéme, après une nuit très-froide, nous eûmes une fort belle journée, \& quoique la terre fût couverte de neige , le froid étoit fupportable. Le lendemain nous paffâmes devant la Riviere des Chicachas, qui eft affez étroite, mais qui vient de fort loin. Son embouchure eft Nord \& Sud. On compte de là quatre-vint-fix lieuës aux Kaskafquias ; mais le chemin feroit de moitié plus court par terre. Rien ne feroit plus agréable que cette navigation, fi la Saifon étoit plus douce : le Pays eft charmant, \& il y a dans les Forêts une quantité d'Arbres toujours verds : le peu de Prairies, qu'on rencontre, confervent auffi leur verdure , \& un nombre confidérable d'Tlles bien boifées, \& dont quelques-unes font affez grandes, forment des Canaux très - agréables, où les plus grands Navires pourroient paffer : car on prétend qu’à plus de cent cinquante lieuës de la Mer on a trouvé dans ce Fleuve jufqu'à foixante braffes de fond.

Pour ce qui eft des Forêts, qui couvrent prefque tout ce Forêts de la grand Pays, il n'en eft peut-être pas dans la Nature, qui leur Louyfiane.

foient comparables, foit que l'on confidere la groffeur \& la hauteur des Arbres, foit qu'on ait égard à leur varieté, \& à l'utilité, qu'on en peut retirer, car à la réferve des bois de couleur, qui demandent un fol plus échauffé, \& qui ne fe trouvent qu'entre les Tropiques, on ne fçauroit dire de quelle forte d'Arbres on n'y voit pas. Il y a des Cyprieres de huit à dix lieuës d'étenduë, tous les Cyprès y font d'une groffeur proportionnée à leur hauteur, qui paffe tout ce que nous avons en France de plus grands. Arbres. On commence à connoître en Europe cette efpéce de Laurier toujours verd, que nous avons appellé Tulipier, à caufe de la figure de fá fleur. Il s'éleve plus haut que nos Maroniers d'Inde, \& a la feiiille encore plus belle. Le Copalme eft ençore plus grand Tome III.

Riviere des Chicachas,

1721 .

Novembre.

(n)




\section{JOURN A L H IS TOR I Q U E}

- \& plus gros, \& il en diftile un baume, qui n'eft peut-être pas beaucoup inférieur à celui du Pérou. Toutes les efpéces bre.

1721. connuës de Noyers y font auffi en très-grande quantité , 8 . tous les bois de conftruction 8 r de charpente, que l'on peut fouhaitter : mais pour les mettre en ouvre, il faut avoir attention de ne point prendre ceux, qui croiflent fur le bord du Fleuve, ni dans tout l'efpace, qu'il inonde dans fes débordemens, parce qu'ayant continuellement leurs racines dans l'eau, ils feroient trop pefants, \& fe pourriroient bien-tôt.

Décenbre.

Enfin jarrivai hier 2. Décembre au premier Village des Akanfas.(a) vers les dix heures du matin. Ce Village eft bâti dans une petite Prairie fur la rive Occideutale du Miciffipi. Il y en a trois autres dans l'efpace de huit lieuës, \&x chacun compofe une Nation, ou Tribu particuliere; il y en a même un des quatre, qui réunit deux Tribus, mais toutes font comprifes fous le nom générique d'Akanfas. On appelle Ouyapes les Sauvages, qui habitent le Village, d'où je vous écris. La Compagnie d'Occident y a un Magafin, qui attend des Marchandifes, \& un Commis, qui fait mauvaife chere en attendant, $\&$ qui s'ennuye beaucoup.

Defcription

La Riviere des Akanfas, qu'on prétend venir de fort loin, de la Riviere fe décharge dans le Fleuve par deux embouchures éloignées des Akanfas.

l'une de l'autre de quatre lieuës. La premiere eft à huit lieuës d'ici. Cette Riviere vient, dit-on, du Pays de certains Sauvages, qu'on appelle Panis noir, \&r je crois que ce font les mêmes, qui font plus connus fous le nom de $P$ anis Ricaras. $J$ 'ai avec moi un Efclave de cette Nation. On remonte difficilement la Riviere des Akanfas, parce qu'elle eft fort embarraffée de rapides, \& quen plufieurs endroits les eaux y font fouvent fi bafies, qu'il y faut traîner les Pirogues.

Différentes La féparation de fes deux branches fe fait à fept lieuës au'Tribus d'A- deffus de la feconde $\& z$ de la plus petite de fes cleux emboukanfas. chures; mais à deux lieuës au-deflus de la premiere. Elle reçoit ume belle Riviere, qui vient du Pays des Ôfages, \& qu'on appelle la Riviere Blanche. Deux lieuës plus haut font les Torimas, \& les Topingas, qui ne font qu'un Village. Deux autres lieuës au-deffus font les Sothouis. Les Kappas font un peu plus loin. Cette Nation étoit très - nombreufe au tems de Ferdinand de Soto, \& même, lorfque M. de la Sale

(a) Ou Akanfeas. 
D'UN VOYAGE DE L'A MER I Q. LET. XXIX. 4II acheva la découverte du Miciffipi. Vis-à-vis de leur Village on voit les triftes débris de la Conceffion de M. Law, dont la Compagnie eft reftée Proprietaire.

C'étoit là, qu'on devoit envoyer les neuf mille Allemands, qui avoient été levés dans le Palatinat, \& c'eft bien dommage qu'ils n'y foient point parvenus. Il n'eft peut-être pas dans toute la Louyfiane de Pảys plus propre, après celui des Illinois, à produire toutes fortes de grains, \& à nourrir des Beftiaux. Mais M. Law a été mal fervi, auffi-bien que la plûpart des autres Conceffionnaires. Il y a bien de l'apparence que de lontems on ne fera de pareilles levées d'Hommes, on en a befoin dans le Royaume, \& puis c'eft affez l'ordinaire parmi nous de fe régler fur le fuccès de pareilles Entreprifes, au lieu d'obferver ce qui les a fait échouer, pour corriger ce qui a été mal fait.

J'ai trouvé le Village des Ouyapes dans la derniere défolation. Il y a quelque-tems qu'un François en paffant par ici fut attaqué de la perite vérole : le mal s'eft communiqué d'abord à quelques Sauvages, \& bientôt après à toute la Bourgade. Le Cimetiere paroît comme une Forêt de Perches $\&$ de Poteaux nouvellement plantés, \& d'où l'on voit pendre toutes fortes de chofes : il y a de tout ce qui eft à l'ufage de ces Barbares.

J'avois dreffé ma Tente affez près du Village, \& toute la nuit j'ai entendu pleurer ; les Hommes s'en mêlent auffi-bien que les Femmes : ils répétoient fans ceffe Nihahani, comme font les Illinois, \& fur le même ton. J'avois auffi apperçû le foir une Femme, qui pleuroit fur la Tombe de fon Fils, \& qui y répandoit force fagamité. Une autre avoit allumé du feu auprès d'une Tombe voifine, apparemment pour réchauffer le Mort. Les Akanfas paffent pour être les plus grands \& les mieux faits de tous les Sauvages de ce Continent, \& on les appelle par diftinction les beaux Hommes. On croit; peutêtre par cette raifon, qu'ils ont la même origine que les Canfez du Miffouri, \& les Pouteouatamis du Canada. Mais voici ma Pirogue chargée, \& je n’ai que le tems de fermer ma Lettre, après vous a voir affûré que je fuis, \&c.

Mortalite parmi les A. kanfas.

1721 .

Décem-

bre.

Conceffion de M. Law.

\section{Aux Akanfasce 2. de Décembre zzzz.}


412 JOURNAL HIST OR I Q U E

\section{TRENTIEME LETTRE.}

Voyage depuis les Akanfas jufqu'aux Natchez. Defcription du Fays, de la Rivicre des Yafous; des Mours, des Ujagis Ë de la Religion des Natchez.

I 72 I. Aux Natchez, ce vint-cinquiéme de Décembre 1721.

Décembre.

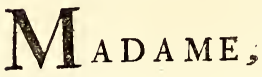

Je partis le 3. de Décembre un peu tard du Village des Ouyapes, cependant jallai camper un peu plus bas que $1 a$ premiere embouchure de la Riviere des Akanfas, qui me parut avoir tout au plus cinq cent pas de large. Je paffai le lendemain la feconde, qui eft fort étroite, \& le cinquiéme je pouffai jufqu'à la Pointe coupée. C'étoit une Pointe affez haute, qui avançoit dans le Fleuve du côté de l'Oueft; le Fleuve l'a coupée, \& en a fait une Ifle, mais le nouveau $\mathrm{Ca}$ nal n'eft encore praticable, que dans les grandes eaux. On compte de cet endroit à la principale branche de la Riviere des Akanfas, vint-deux lieuës, mais il n'y en a peut-être pas dix en droite ligne, car le Fleuve ferpente beaucoup pendant les foixante \& dix lieuës, que l'on fait pour aller du Village des Ouyapes à la Riviere des $\operatorname{Yafous}(a)$, où j'entrai le neuf après midi. Il n’a point neigé ici, comme aux Illinois, \& à Ouabache, mais il y eft tombé un verglas, qui a brifé tous les Arbres tendres, dont les pointes baffes, \& les terres mouillées font couvertes: on diroit qu'on auroit pris plaifir d'en caffer toutes les branches avec un bâton.

Riviere des L'entrée de la Riviere des Yafous eft Nord-Oueft, \& SudYafous.

Eft, \& a environ un arpent de large : fes eaux font rouffes, $\&$ on prétend qu'elles donnent le flux de fang à ceux, qui en boivent. D'ailleurs, l'air y eft très-mauvais. Il me fallut faire trois lieuës pour gagner le Fort, que je trouvai tout en deüil par la mort de M. Bizart, qui y commandoit. Par tout, où

(a) Ou Yachoux. 
D'UN VOYA GE DE L'A MERIQ. LeT. XXX. 4I3 j’avois rencontré des François dans la Louyfiane, j’avois entendu faire des éloges infinis de cet Officier, né en Canada d'un Pere Suifle, Major de Montreal. On me dit aux Yafous des chofes extraordinaires de fa Religion, de fa pieté, de fon zèle, dont il a été la victime. Tous le regrettoient comme leur Pere, \& tout le monde convient que cette Colonie a fait en lui une perte irréparable.

Il avoit mal placé fon Fort, \& il fongeoit, lorfqu'il mourut, à le tranfporter une lieuë plus loin dans une fort belle Prairie, où l'air eft plus fain, \& où il y a un Village d' $Y_{a-}$ fous, mêlés de Couroas, \& d'Ofogoulas, qui tous enfemble peuvent mettre tout au plus deux cens hommes fous les armes. On vit affez bien avec eux, mais on ne s'y fie pas trop à caufe des liaifons, que les Yafous principalement, ont toujours euës avec les Anglois.

11 y a beaucoup de Caimans dans cette Riviere, \& $j$ sell ai Des Caimmans. vû deux, qui avoient bien douze à quinze pieds de long. On ne les entend guére que pendant la nuit, \& leur cri reffemble tellement au meuglement des Taureaux, qu'on y feroit trompé. Nos François ne laiffent pas de s'y baigner auffi librement, qu'ils feroient dans la Seine. Comme je leur en témoignois ma furprife, ils me répondirent qu'il n'y avoit rien à craindre; quà la verité, dès qu'ils étoient dans l'eau, ils s'y voyoient prefque toujours environnés de Caimans, mais qu'aucun n'approchoit d'eux, qu'ils fembloient feulement les guetter pour fe jetter fur eux au moment qu'ils fortiroient de la Riviere; qu'alors pour les écarter, ils re. muoient l'eau avec un bâton, dont ils avoient la précaution de fe prémunir, que cela faifoit fuir ces Animaux affez loin, pour leur donner le tems de fe mettre en sûreté.

La Compagnie a dans ce Pofte un Magafin d'attente, comme aux Akanfas; mais le Fort \& le Terrein appartien- mal placée. nent à une Societé compofée de M. le Blanc, Secretaire d'Etat, de M. le Comte de Belle-Ine, de M. le Marquis d'Affeld, \& de M. le Blond, Brigadier-Ingénieur. Ce dernier eft dans la Colonie avec la qualité de Directeur Général de la Compagnie. Je ne comprends pas trop ce qui leur a fait choifir la Riviere des Yafous, pour y placer leur Conceffion. Ils avoient affûrément à choifir, \& de meilleurs Terreins, \& des fituations plus avantageufes. Il eft vrai qu'il eft

$172 \mathrm{I}$.

Décem. bre.

Du Fort des Yafous. 
172 1. important de s'affûrer de cette Riviere, dont la Source n'eft Décem- pas loin de la Caroline, mais il fuffifoit pour cela d'un Fort bre. avec une bonne Garnifon, pour contenir les Yafous, qui font Alliés des Chicachas. Ce n'eft pas le moyen d'établir folidement une Conceffion, que d'être obligé de fe tenir toujours fur fes gardes, contre des Sauvages voifins des Anglois. Goufre, Car- Je partis des Yafous le dixiéme, \& le treiziéme : fans un siete. Sauvage Natché, qui m’avoit demandé le paffage pour retourner chez lui, je me ferois perdu dans un goufre, quaucun de mes Conducteurs ne connoiffoit, \& dont on ne s'apperçoit, que quand on y eft tellement engagé, qu'il n'eft plus poffible de s'en retirer. Il eft fur la main gauche, au pied d'un gros Cap, où l'on affûre qu'il y a de très-bonnes pierres : c'eft de quoi l'on craint plus de manquer dans cette Colonie, mais en récompenfe on y fera autant de Barques que l'on voudra.

Defription Le quinziéme nous arrivâmes aux Natchę̆. Ce Canton , du Pays des le plus beau, le plus fertile, \& le plus peuplé de toute lá
Natchez. Louyfrane, eft éloigné de quarante lieués des Yafous, \& fut la même main. Le débarquement eft vis-à-vis une butte affez haute, \& fort efcarpée, au pied de laquelle coule un petit Ruiffeau, qui ne peut recevoir que des Chaloupes \& des Pirogues. De cette premiere Butte on monte à une feconde, ou plutôt fur une Colline, dont la pente eft affez douce, \& au fommet de laquelle on a bâti une efpéce de Redoute fermée par une fimple Paliffade. On a donné à ce retranchement le nom de Fort.

Plufieurs Monticules s'élévent au-deffus de cette Colline, \& quand on les a paffées, on apperçoit de toutes parts de grandes Prairies, féparées par de petits Bouquets de bois, qui font un très-bel effet. Les Arbres les plus communs dans ces Bois font le Noyer \& le Chêne, \& par tout les terres font excellentes. Feu M. d'lberville, qui le premier entra dans le Miciffipi par fon embouchure, étant monté jufqu'aux Natchez, trouva ce Pays fi charmant, \& fi avantageufement fitué, qu'il crut ne pouvoir mieux placer la Métropole de la nouvelle Colonie. Il en traça le Plan, \& lui deftina le nom de Rofalie, qui étoit celui de Madame la Chanceliere de Pontchartrain. Mais ce Projet ne paroît pas devoir s'exécuter fi-tôt, quoique nos Géographes ayent toujours à bon 

Natchez.

Il eft certain qu'il faut commencer par un Etabliffement plus près de la Mer ; mais fi la Louyfiane devient jamais une Colonie Floriflante, comme il peut fort bien arriver, il me femble qu'on ne peut mieux placer fa Capitale qu'en cet endroit. Il n'eft point fujet au débordement du Fleuve, l'air y eft pur, le Pays fort étendu, le Terrein propre à tout, \& bien arrofé, il n'eft pas trop loin de la Mer, \& rien n'empêche les Vaiffeaux d'y monter. Enfin il eft à portée de tous les lieux, où l'on paroît avoir deffein de s'établir. La Compagnie y a un Magafin, \& y entretient un Commis principal, qui n'a pas encore beaucoup d'occupation.

Parmi un grand nombre de Conceffions particulieres, qui font déja ici en état de rapporter, il y en a deux de la premiere grandeur, je veux dire de quatre lieuës en quarré, l'une appartient à une Societé de Maloins, qui l'ont achetée de M. Hubert, Commiffaire Ordonnateur, \& Préfident du Confeil de la Louyfiane : l'autre eft à la Compagnie, qui y a envoyé des Ouvriers de Clerac pour y faire du Tabac. Ces deux Concefions font fituées de maniere, qu'elles forment un triangle parfait avec le Fort, \& la diftance d'un angle à l'autre eft d'une lieuë. A moitié chemin des deux Conceffions. eft le grand Village des Natchez. J'ai vifité a vec foin tous ces lieux, \& voici ce que j'y ai remarqué de plus confiderable.

La Conceffion des Maloins eft bien placée, il ne lui manque, pour tirer parti de tout fon Terrein, que des Negres, ou des Engagés. J'aimerois encore mieux les Seconds que les Premiers; le tems de leur Service expiré, ils deviennent des Habitans, \& augmentent le nombre des Sujets naturels du Roi; au lieu que ceux-là font toujours des Etrangers : \& qui peut s'ấsûrer qu'à force de fe multiplier dans nos Colonies, ils ne deviendront pas un jour des Ennemis redoutables? Peut-on compter fur des Efclaves, qui ne nous font attachés que par la crainte, \& pour qui la Terre même, où ils naiffent, n'a jamais le doux nom de Patrie?

La preniere nuit, que je paflai dans cette Habitation, il y eut vers les neuf heures du foir une grande allarme; j’en demandai le fujet, \& on me répondit quill y avoit dans le Voi-

\section{Decem-}


I 72. Inage une Bête d'une efpéce inconnuë, d'une grandeur exbre.

Décem- Animal, que nous connoiffions. Perfonne n'afsûroit pourtant l'avoir vûë, \& on ne jugeoit de fa taille, que par fa force; elle avoit déja enlevé des Moutons \& des Veaux, \& étranglé quelques Vaches. Je dis à ceux, qui me faifoient ce récit, qu'un Loup enragé pouvoit faire tout cela, \& quant au cri, qu'on s'y trompoit tous les jours. Je ne perfuadai perfonne; on vouloit que ce fut une Bête monftrueufe; on venoit de l'entendre, on y courut armé de tout ce qu'on trouva fous fa main , mais ce fut inutilement.

Succès du La Conceffion de la Compagnie eft encore plus avantaTabac dans ce geufement fituée, que celle des Maloins. Une même Riviere arrofe l'une $\&$ l'autre, $\&$ va fe décharger dans le Fleuve à deux lieuës de celle-là, à laquelle une magnifique Cypriere de fix lieuës d'étenduë fait un rideau, qui en couvre tous les derrieres, Le Tabac y a très-bien réuffi, mais les Ouvriers de Clerac s'en font prefque tous retournés en France.

Cotton, In- J'ai vû dans le Jardin du fieur le Noir, Commis principal, digo. de fort beau Cotton fur l'Arbre, \& un peu plus bas on commence à voir de l'Indigo fauvage. On n'en a pas encore fait l'épreuve, mais il y a beaucoup d'apparence qu'il ne réuffira pas moins que celui, qu'on a trouvé dans l'ille de Saint Domingue, où il eft aufi eftimé, que celui, qu'on y a tranfplanté d'ailleurs. Et puis l'expérience nous apprend qu'une terre, qui produit natureliement cette Plante, eft fort propre à porter l'étrangere, qu'on y veut femer.

Defrription Le grand Village des Natchez eft aujour d'hui réduit àfort du grand Vi'-- peu de Cabannes : la raifon qu'on m'en a apportée, eft que les Temple des Natchez. Sauvages, à qui leur grand Chef a droit d'enlever tout ce qu'ils ont, s'éloignent de lui le plus qu'ils peuvent, \& par-là plufieurs Bourgades de cette Nation fé font formées à quelque diftance de celle-ci. Les Tioux, leurs Alliés \& les nôtres, en ont auffi établi une dans leur Voifinage.

Les Cabannes du grand Village des Natchez, le feul que jaye yû, font en forme de Pavillon quarré, fort baffes, \& fans Fenêtres; le Faîte eft arrondi à peu près comme un Four. La plûpart font couvertes de feiiilles \& de pailles de Maïz; quelques-unes font conftruites d'une efpéce de torchi, qui me parut affez bon, \& qui eft revêtu en dehors $\&$ en dedans 
D'UN VOYA GE DE L'A MER. Let. XXX. 417 de Nattes fort minces. Celle du grand Chef eft fort proprement crépie en dedans : elle eft aufli plus grande $\&$ plus haute que les autres; placée fur un Terrein un peu élevé, \& ifolée de toutes parts. Elle donne fur une grande Place, qui n'eft 1721 . Décempas des plus régulieres, \& a fon afpect au Nord. J'y trouvai pour tout meuble une Couche de planches fort étroite, élevée de terre de deux ou trois pieds ; apparemment que quand le Chef veut fe coucher, ily étend une natte ou quelque peau.

Il n'y avoit pas une Ame dans le Village : tout le monde étoit allé dans une Bourgade voifine, où il y avoit une Fête, \& toutes les Portes étoient ouvertes, mais il n'y avoit rien à craindre des Voleurs, car il ne reftoit par tout que les quatre murailles. Ces Cabannes n'ont aucune iffuë pour la fumée, néanmoins toutes celles, où j'entrai, étoient affez blanches. Le Temple eft à côté de celle du grand Chef, tournée vers l'Orient, \& à l'extrêmité de la Place. Il eft compofé des mêmes matériaux que les Cabannes, mais fa figure eft différente; c'eft un quarré long, d'environ quarante pieds fur vint de large, avec un toît tout fimple, de la figure des nôtres. Il y a aux deux extrêmités comme deux girouettes de bois, qui repréfentent fort groffierement deux Aigles.

La Porte eft au milieu de la longueur du Bâtiment, qui n'a point d'autres ouvertures; des deux côtés il y a des Bancs de pierres. Les dedans répondent parfaitement à ces dehors ruftiques. Trois piéces de bois, qui fe joignent par les bouts, \& qui font placées en triangle, ou plutôt également écartées les unes des autres, occupent prefque tout le milieu duTemple, \& brûlent lentement. Un Sauvage, que l'on appelle le Gardien du Temple, eft obligé de les attifer, \& d'empêcher qu'elles ne s'éteignent. S'il fait froid, il peut avoir fon feu à part, mais il ne lui eft pas permis de fe chauffer à celui, qui brûle en l'honneur du Soleil. Ce Gardien étoit auffi à la Fête, du moins je ne le vis point, \& fes tifons jettoient une fumée, qui nous aveugloit.

D'Ornemens, je n'en vis aucuns, ni rien abfolument, qui dût me faire connoitre que j'étois dans un Temple. J'y apperçus feulement trois ou quatre Caiffes rangées fans ordre, où il y avoit quelques Offemens fecs, \& par terre, quelques T'êtes de bois, un peu moins mal travaillées que les deux Tome III. 
17,21. Aigles du toît. Enfin, fi je n'y euffe pas trouvé du feu, j’euffe bre.

Décem- cru que ce Temple étoit abandonné depuis lontems, ou qu'il avoit été pillé. Ces cônes enveloppés de peaux, dont parlent quelques Relations; ces cadavres des Chefs rangés en cercle dans un Temple tout rond, \& terminé en maniere de Dôme ; cet Autel, \&c. Je n'ai rien vî de tout cela; fị les chofes étoient ainfi du tems paffé, elles ont bien changé depuis.

Peut-être auffi, car il ne faut condamner perfonne, que quand il n'y a aucun moyen de l'excufer; peut-être, dis-je, que le Voifinage des François a fait craindre aux Natchez que les corps de leurs Chefs, \& tout ce que leur Temple avoit de plus précieux, ne couruffent quelque rifque, s'ils ne les tranfportoient pas ailleurs, \& que le peu d'attention, qu'on apporte préfentement à bien garder ce Temple, vient de ce qu'on l'a dépouillé de ce qu'il avoit de plus facré pour ces Peuples. Il eft pourtant vrai que contre la muraille, vis-à-vis de la Porte, il y avoit une Table, dont je ne pris pas la peine de mefurer les dimenfions, parce que je ne foupçonnai point que ce fût un Autel : on m'a afsûré depuis qu'elle a trois pieds. de haut, cinq de long, \& quatre de large.

On m'a ajoutté qu'on y fait un petit feu avec des écorces de Chênes, \& qu'il ne s'éteint jamais, ce qui eft faux, car il n'y avoit alors ni feu, ni rien qui fît connoître qu'on y en eût jamais fait. On dit encore que quatre Vieillards couchent tour à tour dans le Temple pour y entretenir ce feu; que celui qui eft de garde, ne doit point fortir pendant les huit jours, qu'il doit être en faction; qu'on a foin de prendre de la braife allumée des bûches, qui brûlent au milieu du Temple, pour mettre fur l'Autel : qu'il y a douze Hommes entretenus pour fournir des écorces de Chênes; qu'il y a des Marmoufets de bois, \& une figure de Serpens à Sonnettes, aufli de bois, qu'on met fur l'Autel, \& aufquels on rend de grands honneurs : que quand le Chef meurt, on l'enterre d'abord, \& que quand on juge que les chairs font confumées, le Gardien du Temple les exhume, lave les Offemens, les enveloppe de ce qu'il peut avoir de plus précieux, \& les met dans de grands panniers faits de cannes, quil ferme bien, qu'il enveloppe ces paniers de peaux de Chevreuils très-pro. 
D'UN VOYAGE DE L'AMERIQ. LET. XXX. 419 pres, $\&$ les place devant l'Autel, où ils reftent jufqu'à la mort du Chef regnant : qualors il renferme ces Offemens dans l'Autel même, pour faire place au dernier Mort.

Je ne puis rien dire fur ce dernier article, finon que je vis quelques Offemens dans une ou deux Caiffes, mais qu'ils ne faifoient pas la moitié d'un corps humain, quilis me paroiffoient bien vieux, \& quills n'étoient point fur la table, qu'on dit être l'Autel. Quant aux autres articles, $\mathrm{I}^{\circ}$. comme je n'ai été que de jour dans le Temple, j'ignore ce qui s'y paffe la nuit. $2^{\circ}$. Il n'y avoit aucun Garde dans le Temple, quand je l'ai vifité. J'y apperçus bien, comme je l'ai déja dit, quelques Marmoufets, mais je n'y remarquai point de figure de Serpent.

Quant à ce que jai vû dans des Relations que ce Temple eft tapiffé, \& fon pavé couvert de nattes de cannes, qu'on y met ce qu'on a de plus propre, \& qu'on y apporte tous les ans les prémices de toutes les récoltes; il en faut affurément rabattre beaucoup : je n'ai jamais rien vû de plus mauffade, de plus mal-propre, qui fût plus en défordre ; les bûches brûloient fur la terre nuë, \& je n'y apperçus point de nattes, non plus qu'aux murailles. M. le Noir, avec qui je'tois, me dit feulement que tous les jours on mettoit au feu une nouvelle bûche, \& qu'au commencement de chaque Lune on en faifoit la provifion pour tout le mois. Il ne le fçavoit pourtant que par oüi-dire, car c'étoit la premiere fois quilil voyoit ce Temple, auffi-bien que moi.

Pour ce qui regarde la Nation des Natchez en général, voici ce que jen ai pû apprendre. On ne voit rien dans leur extérieur, qui les diftingue des autres Sauvages du Canada $\&$ de la Louyfiane. Ils font rarement la guerre, \& ne mettent point leur gloire à détruire des hommes. Ce qui les diftingue plus particulierement, c'eft la forme de leur Gouvernement, tout-à-fait defpotique ; une grande dépendance, qui va même jufquà une elpéce d'efclavage dans les Sujets; plus de fierté $\&$ de grandeur dans les Chefs, \& leur efprit pacifique, qui cependant s'eft un peu démenti depuis plufieurs années.

Les Hurons croyent auffi-bien qu'eux leurs Chefs héréditaires iffus du Soleil, mais il n'y en a pas un, qui voulût être fon valet, ni le fuivre dans l'autre monde pour $\mathrm{y}$ avoir l'honneur de le fervir, comme il arrive fouvent parmi les Natchez.

$$
G g g \text { ij }
$$

1721.

Décembre. 
Garcilaffo de la Vega parle de cette Nation comme d'un 1721 . Peuple puiffant, \& il n'y a pas fix ans qu'on y comptoit bre. quatre mille Guerriers. Il paroît qu'elle étoit encore plus nombreufe du tems de M. de la Sale, \& même lorfque M. d'Iberville découvrit l'embouchure du Micifipi. Aujourd'hui les Natchez ne pourroient pas mettre fur pied deux mille Combattans. On attribuë cette diminution à des maladies contagieufes, qui ces dernieres années ont fait parmi eux de grands ravages.

Du Grand Chef \& de la t Femme-Chef.

Le Grand Chef des Natchez porte le nom de Soleil, \& c'eft toujours, comme parmi les Hurons, le Fils de fa plus proche Parente, qui lui fuccede. On donne à cette Femme la qualité de Femme-Chef, \& quoique pour l'ordinaire elle ne fe mêle pas du Gouvernement, on lui rend de grands honneurs. Elle a même, auffi-bien que le Soleil, droit de vie \& de mort ; dès que quelqu'un a eu le malheur de déplaire à l'un ou à l'autre, ils ordonnent à leurs Gardes, qu'on nomme Allouez, de le tuer. Va me défaire de ce Chien, difent-ils, \& ils font obéis fur le champ. Leurs Sujets, \& les Chefs mêmes des Villages, ne les abordent jamais, qu'ils ne les faluent trois fois, en jettant un cri, qui eft une efpéce de hurlement: ils font la même chofe en fe retirant, \& fe retirent en marchant à reculons. Lors qu'on les rencontre, il faut s'arrêter, fe ranger du chemin , \& jetter les mêmes cris, dont j'ai parlé, jufqu’à ce qu'ils foient paffés. On eft auffi obligé de leur porter ce qu'il y a de meilleur dans les Récoltes, dans le produit de la Chaffe, \& dans celui de la Pêche. Enfin perfonne, non pas même leurs plus proches Parens, \& ceux, qui compofent les Familles Nobles, lorfqu'ils ont l'honneur de manger avec eux, n'ont droit de boire dans le même vafe, ni de mettre la main au plat.

Tous les matins, dès que le Soleil paroît, le grand Chef fe met à la porte de fa Cabanne, fe tourne vers l'Orient, \& hurle trois fois, en fe profternant jufqu'à terte. On lui apporte enfuite un Calumet, qui ne fert qu'en cette occafion, il fume, \& pouffe la fumée de fon Tabac vers l'Aftre du jour; puis il fait la même chofe vers: les trois autres parties du monde. Il ne reconnoît fur la Terre de Maître que le Soleil, dont il prétend tirer fon origine, exerce un pouvoir fans borne fur fes Sujets, peut difipofer de leurs biens \& de leus 
D'UN VOYAGE DE L'A MERIQ. LET. XXX. 42 I vie, \& quelques travaux, qu'il leur commande, ils n'en peuvent exiger aucun falaire.

Lorfque le Chef, ou la Femme - Chef meurent, tous leurs Alloués font obligés de les fuivre en l'autre monde, mais ils ne font pas les feuls, qui ont cet honneur : car c'en eft un, $8 x$ qui eft fort recherché. Il y a tel Chef, dont la mort coûte la vie à plus de cent perfonnes, \& $\approx$ on m’a affûré qu'il meurt peu de Natchez confidérables, à qui quelques-uns de leurs $\mathrm{Pa}$ rens, de leurs Amis, ou de leurs Serviteurs ne faffent pas cortége dans le Pays des Ames. Il paroît par les diverfes Relations, que j'ai vûës de ces horribles cérémonies, qu'elles varient beaucoup. En voici une des Obféques d'une FemmeChef, que je tiens d'un Voyageur, qui en fut témoin, \& fur la fincerité duquel j'ai tout lieu de compter.

Le Mari de cette Femme n'étant pas noble, c'eft-à-dire, de la Famille du Soleil, fon Fils Aîné l'étrangla, felon la coûtume; on vuida enfuite la Cabanne de tout ce qui y étoit, \& on y conftruifit une efpéce de Char de Triomphe, où le corps de la Défunte, \& celui de fon Epoux furent placés. Un moment après on rangea autour de ces cadavres douze petits Enfans, que leurs Parens avoient aufi étranglés par ordre de l'Ainnée des Filles de la Femme-Chef, \& qui fuccedoit à la dignité de fa Mere. Cela fait, on drefía dans la Place publique quatorze Echaffauts ornés de branches d'Arbres, \& de toiles, fur lefquelles on avoit peint différentes figures. Ces Echafauts étoient deftinés pour autant de perfonnes, qui devoient accompagner la Femme-Chef dans l'autre monde. Leurs Parens étoient tout autour d'elles, \& regardoient comme un grand honneur pour leurs familles la permiffion, qu'elles avoient euës, de fe facrifier ainfi. On s'y prend quelquefois dix ans auparavant pour obtenir cette grace, $\&$ il faut que ceux, ou celles, qui l'ont obtenuë, filent eux-mêmes la corde, avec laquelle ils doivent être étranglés.

Ils paroiffent fur leurs Echafauts revêtus de leurs plus riches habits, portant à la main droite une grande Coquille. Leur plus proche Parent eft à leur droite, ayant fous fon bras gauche la corde, qui doit fervir à l'exécution, \& à la main droite un caffe-tête. De tems en tems il fait le cri de mort, \& à ce cri les quatorze Vietimes defcendent de leurs Echafauts, \& vont danfer tous enfemble au milieu de la Place, devant 
422 J O UR N A L H IS T O R I Q U E

1721 .

le Temple, \& devant la Cabanne de la Femme-Chef. On

Décem- leur rend ce jour-là \& les fuivans de grands refpects, ils ont bre.

chacun cinq Domeftiques, \& leur vifage eft peint en rouge. Quelques-uns ajoûtent que pendant les huit jours, qui précédent leur mort, ils portent à la jambe un ruban rouge, $\&$ que pendant tout ce tems-là c'eft à qui les régalera. Quoiqu'il en foit, dans l'occafion dont je parle, les Peres \& les Meres, qui avoient étranglé leurs Enfans, les prirent entre leurs mains, \& fe rangerent des deux côtés de la Cabanne, les quatorze Perfonnes, qui étoient auffi deftinées à mourir, s'y placerent de la même maniere, \& $\mathrm{x}$ ils étoient fuivis des $\mathrm{Pa}$ rens \& des Amis de la Défunte, tous en deüil, c'eft-à-dire, les cheveux coupés : tous faifoient retentir les airs de cris fi affreux, qu'on eut dit que tous les Diables étoient fortis des Enfers pour venir hurler en cet endroit; cela fut fuivi de danfes de la part de ceux, qui devoient mourir, \& de chants de la part des Parens de la Femme-Chef.

Enfin on fe mit en marche. Les Peres \& Meres, qui portoient leurs Enfans morts, paroiffoient les premiers, marchant deux à deux, \& précédoient immédiatement le Brancart, où étoit le corps de la Femme-Chef, que quatre Hommes portoient fur leurs épaules. Tous les autres venoient après dans le même ordre que les premiers. De dix pas en dix pas ceux - ci laiffoient tomber leurs Enfans par terre ; ceux, qui portoient le Brancard, marchoient deffus, puis tournoient tout autour d'eux, enforte que quand le convoi arva au Temple, ces petits Corps étoient en piéces.

Tandis qu'on enterroit dans le Temple le Corps de la Femme-Chef, on déshabilla les quatorze Perfonnes, qui devoient mourir, on les fit affeoir par terre devant la porte, chacun ayant deux Sauvages, dont l'un étoit affis fur fes genoux, \& l'autre lui tenoit les bras par derriere. On leur paffa une corde au col, on leur couvrit la tête d'une peau de Chevreuil, on leur fit avaler trois pilules de tabac, \& boire un verre d'eau, \& les Parens de la Femme-Chef tirerent des deux côtés les cordes en chantant, jufqu’à ce qu'ils fuffent étranglés. Après quoi on jetta tous ces Cadavres dans une même Foffe, qu'on couvrit de terre.

Quand le Grand Chef meurt, s'il a encore fa Nourrice, il faut qu'elle meure auffi. Mais il eft arrivé plufieurs fois que 

la permiffion de baptifer les petits Enfans, qui devoient être étranglés, \& qui par conféquent n’accompagnoient pas ceux, bre. en l'honneur defquels on les immoloit, dans leur prétendu Paradis.

Nous ne connoiffons point de Nation dans ce Continent où le Sexe foit plus débordé, que celle-ci. Il eft même forcé Mours des par le Soleil \& par les Chefs fubalternes à fe proftituer à tout venant; \& une Femme, pour être publique, n'en eft pas moins eftimée. Quoique la Polygamie foit permife, \& que le nombre des Femmes, qu'on peut avoir, ne foit pas limité, ordinairement chacun n'a que la fienne; mais il peut la répudier, quand il veut; liberté, dont il n'y a pourtant guéres que les Chefs, qui faffent ufage. Les Femmes font affez bien faites pour des Sauvageffes, \& affez propres dans leur ajuftement, \& dans tout ce qu'elles font. Les Filles de la Famille noble ne peuvent époufer que des Hommes obfcurs, mais elles font en droit de congédier leur Mari, quand bon leur femble, \& d'en prendre un autre, pourvû qu'il n'y ait point d'alliance entr'eux.

Si leurs Maris leur font une infidélité, elles peuvent leur faire caffer la tête, \& elles ne font point fujettes à la même loi. Elles peuvent même avoir autant de Galans, qu'elles jugent à propos, fans que le Mari puiffe le trouver mauvais, c'eft un privilege attaché au Sang du Soleil. Il fe tient debout en préfence de fa Femme dans une pofture refpectueufe; il ne mange point avec elle; il la faluë du même ton, que fes Domeftiques : le feul privilége, que lui procure une alliance fi onéreufe, c'eit d'être exempt de travail, \& d'avoir autorité fur ceux, qui fervent fon Epoufe.

Les Natchez ont deux Chefs de guerre, deux Maîtres de cérémonies pour le Temple, deux Officiers pour régler ce ges. qui fe doit pratiquer dans les Traités de paix ou de guerre; un, qui a l'infpection fur les ouvrages, \& quatre autres, qui font chargés d'ordonner tout dans les feftins publics. C'eft le Grand Chef, qui donne ces emplois, \& ceux, qui en font revêtus, font reipectés \& obéis, comme il le feroit lui-même. Les recoltes fe font en commun; le Soleil en marque le jour, \& convoque le Village. Vers la fin de Juillet il indique un autre jour pour le commencement d'une Fête, qui en dure trois, $\&$ qui fe paffe en jeux $\&$ en feftins. Natchez. 
1721.

Décembre.

Defcription d'une Fête.

Prémices offertes dans le Temple. ges."

Des Maria- Les Mariages des Natchez ne différent prefque pas de ceux

Chaque Particulier y contribue de fa Chaffe, de fa Pêche \&x de fes autres Provifions, qui confiftent en Maïz, Féves, \& Melons. Le Soleil \& la Femme-Chef y préfident dans une Loge élevée \& couverte de feuillages : on les y porte dans un brancard, \& le Premier tient en fa main une maniere de fceptre orné de plumages de diverfes couleurs. Tous les Nobles font autour d'eux dans une pofture refpectueufe. Le dernier jour le Soleil harangue l'Affemblée, il exhorte tout le monde à remplir exactement fes devoirs, furtout à avoir une grande vénération pour les Efprits, qui réfident dans le Temple, \& à bien inftruire les Enfans. Si quelqu'un s'eft fignalé par quelquaction de zéle, il fait fon éloge. Il y a vint ans que le feu du Ciel ayant réduit le Temple en cendres, fept ou huit Femmes jetterent leurs Enfans au milieu des flammes, pour appaifer les Génies; le Soleil fit auffi-tôt venir ces Héroïnes, leur donna publiquement de grandes louanges, \& finit fon difcours en exhortant les autres Femmes à imiter dans l'occafion un $f i$ bel exemple.

Les Peres de Familles ne manquent jamais d'apporter au Temple les prémices de tout ce qu'ils recueillent, \& on fait le même de tous les préfens, qui font offerts à la Nation. On les expofe à la porte du Temple, dont le Gardien, après les avoir préfentés aux Efprits, les porte chez le Soleil, qui les diftribue à qui bon lui femble. Les Semences font pareillement offertes devant le Temple avec de grandes cérémonies : mais les Offrandes, qui s'y font de pains \& de farines à chaque nouvelle Lune, font pour le profit des Gardiens du Temple. des Sauvages du Canada: la principale différence, qui s'y trouve, confifte en ce qu'ici le futur Epoux commence par faire aux. Parens de la Fille les préfens, dont on eft convenu, $\&$ que les Nôces font fuivies d'un grand Feftin. La raifon, pour laquelle il n'y a guére que les Chefs, qui ayent plufieurs Femmes, c'eft que pouvant faire cultiver leurs Champs par le Peuple, fans qu'il leur en coûte rien, le nombre de leurs Epoufes ne leur eft point à charge. Les Chefs fe marient avec encore moins de cérémonie, que les autres. Ils fe contentent de faire avertir les Parens de la Fille, fur laquelle ils ont jetté les yeux, qu'ils la mettent au nombre de leurs Femmes: mais ils n'ell gardent qu'une ou deux dans leurs Cabannes; 
D'U N VOYAGE DE L'A MER. LET. XXX. 425 les autres reftent chez leurs Parens, où leurs Maris les vifitent, quand il leur plaît. La jaloufie ne régne point dans ces Mariages; les Natchez fe prêtent même fans façon leurs' Femmes, \& c'eft apparemment de - là , que vient la 1721 . Décemfacilité, avec laquelle ils les congédient pour en prendre d'autres.

Lorfqu'un Chef de Guerre veut lever un Parti, il plante dans un endroit marqué pour cela deux Arbres ornés de Plumes, de Fléches, \& de Caffe-têtes, le tout peint en rouge , auffi-bien que les Arbres, qui font encore picqués du côté, où l'on veut porter la guerre. Ceux qui veulent s'enrôler, fe préfentent au Chef, bien parés, le vifage barboüillé de différentes couleurs, \& lui déclarent le defir, qu'ils ont de pouvoir apprendre fous fesordres le métier des Armes; qu'ils font difpofés à endurer toutes les fatigues de la guerre, \& prêts à mourir, s'il le faut, pour la Patrie.

Quand le Chef a le nombre de Soldats, que demande l'expédition, qu'il médite, il fait préparer chez lui un breuvage; qui fe nomme la Médecine de la Guerre. C'eft un vomitif fait avec une racine boüillie dans l'eau : on en donne à chacun deux pots, qu'il faut avaler tout de fuite, \& que l'on rend prefque auffi-tôt avec les plus violens efforts. On travaille enfuite aux préparatifs, \& jufqu’au jour fixé pour le départ, les Guerriers fe rendent foir \& matin dans une Place, où après avoir bien danfé, \& raconté leurs beaux faits d'Armes, chacun chante fa chanfon de mort. Ce peuple n'eft pas moins fuperftitieux fur les fonges, que les Sauvages du Canada: il n'en faut qu'un de mauvais augure, pour rebrouffer chemin, quand on eft en marche.

Les Guerriers marchent avec beaucoup d'ordre , \& prennent de grandes précautions pour camper, \& pour fe rallier. On envoye fouvent à la découverte, mais on ne pofe point de Sentinelles pendant la nuit: on éteint tous les feux, on fe recommande aux Efprits, \& on s'endort avec fécurité, après que le Chef a averti tout le monde de ne point ronfler trop fort, \& d'avoir toujours près de foi fes Armes en bon état. Les Idoles font expofées fur une perche panchée du côté des Ennemis, \& tous les Guerriers, avant que de s'aller coucher, paffent les uns après les autres, le Caffe-tête à la main, devant ces prétenduës Divinités. Ils fe tournent enfuite vers le Tome III.

$\mathrm{Hh} \mathrm{h}$ Des Provifions.

De la Levée des Soldats.

(2)

Des marches \& des campemens. 
$4^{26}$ J O U R N A L H I S T O R I Q U E

1721 .

Pays ennemi, \& font de grandes menaces, que le vent em-

porte fouvent d'un autre cốté.

bre.

Il ne paroît pas que les Natchez exercent fur leurs Prifonniers durant la marche les cruautés, qui font en ufage dans

Des Prifon- le Canada. Lorfque ces Malheureux font arrivés au grand niers.

Village, on les fait chanter \& danfer plufieurs jours de fuite devant le Temple. Après quoi ils font livrés aux Parens de ceux, qui ont été tués durant la Campagne. Ceux-ci, en les recevant, fondent en pleurs, puis après avoir effuyé leurs larmes avec les chevelures, que les Guerriers ont rapportées, ils fe cotifent pour récompenfer ceux, qui leur ont fait préfent de leurs Efclaves, dont le fort eft toujours d'être brûlés.

Noms des Les Guerriers changent de nom à mefure qu'ils font de nouGuerriers. veaux Exploits; ils les reçoivent des anciens Chefs de Guerre, \& ces noms ont toujours quelque rapport à l'action, par laquelle on a mérité cette diftinction; ceux qui pour la premiere fois ont fait un Prifonnier, ou levé une Chevelure, doivent pendant un mois s'abftenir de voir leurs Femmes, \& de manger de la viande. Ils s'imaginent que, s'ils y manquoient, les ames de ceux, qu'ils ont tués ou brûlés, les feroient mourir, ou que la premiere bleffure, qu'ils recevroient, feroit mortelle, ou du moins qu'ils ne remporteraient plus aucun avantage fur leurs Ennemis. Si le Soleil commande fes Sujets en perionne, on a grand foin qu'il ne s'expofe pas trop, moins peut-être par zèle pour fa confervation, quà caufe que les autres Chefs de Guerre, \& les Principaux du Parti feroient mis à mort, pour ne l'avoir pas bien gardé.

Des Jongleurs.

Les Jongleurs des Natchez reffemblent affez à ceux du Canada, \& traitent les Malades à peu près de la même façon. Ils font bien payés, quand le Malade guérit ; mais s'il meurt, il leur en coûte fouvent à eux-mêmes la vie. Il y a dans cette Nation une autre efpéce de Jongleurs, qui ne courent pas moins de rifques, que ces Médecins. Ce font certains Vieillards fainéans, qui pour faire fubfifter leurs Familles, fans être obligés de travailler, entreprennent de procurer la pluye, ou le beau tems, felon les befoins. Vers le Printems on fe cotife pour achetter de ces prétendus Magiciens un tems favorable aux biens de la terre. Si c'eft de la Pluye, qu'on demande, ils fe rempliffent la bouche d'eau, \& avec un chalu- 
D'UN VOYA GE DE L'A MER. Let. XXX. 427 meau, dont l'extrémité eft percée de plufieurs trous, comme un entonnoir, ils fouflent en l'air du côté, où ils apperçoivent quelque nuage, tandis que, le Chichikoué d'une main, \& leur Manitou de l'autre, ils jouent de l'un, \& levent l'autre en l'air, invitant par des cris affreux les nuages à arrofer les campagnes de ceux, qui les ont mis en œuvre.

S'il eft queftion d'avoir du beau tems, ils montent fur le toît de leurs Cabannes, font figne aux nuages de paffer outre, $\& \mathrm{fi}$ les nuages paffent, \& $\mathrm{fe}$ diffipent, ils danfent \& chantent autour de leurs Idoles, puis avalent de la fumée de tabac, \& préfentent au Ciel leurs Calumets. Tout le tems que durent ces opérations, ils obfervent un jeûne rigoureux, \& ne font que danfer \& chanter; fi on obtient ce quils ont promis, ils font bien récompenfés; s'ils ne réuffiffent pas, ils font mis à mort fans miféricorde. Mais ce ne font pas les mêmes, qui fe mêlent de procurer la pluye \& le beau tems; leurs Génies, difent-ils, ne peuvent donner que l'un ou l'autre.

Le deuil parmi ces Sauvages confirte à fe couper les cheveux, à ne fe point peindre le vifage, \& à ne fe point trouver aux Affemblées; mais j'ignore combien il dure. Je n'ai pu fçavoir non plus sills célébrent la grande Fête des Morts, dont je vous ai donné la defcription; il paroît que dans cette Nation, où tout eft en quelque façon efclave de ceux, qui commandent, tous les honneurs mortuaires font pour ceuxci, fur-tout pour le Soleil, \& pour la Femme-Chef.

Les Traités de paix \& d'alliance fe font avec beaucoup d'appareil, \& le Grand Chef y foûtient toujours fa dignité en véritable Souverain. Dès qu'il eft averti du jour de l'arrivée des Ambaffadeurs, il donne fes ordres aux Maîtres des cérémonies pour les préparatifs de leur réception, \& nomme ceux, qui doivent nourrir tour à tour ces Envoyés. Car c'eft aux dépens de fes Sujets, qu'il fait tous les frais de l'Ambaffade. Le jour de l'entrée des Ambaffadeurs, chacun a fa place marquée felon fon rang, \& quand ces Miniftres font à cinq cent pas du Grand Chef, ils s'arrêtent, \& chantent la paix.

Ordinairement l'Ambaffade eft compofée de trente Hommes $\&$ de fix Femmes. Six des meilleures Voix marchent à la tête du cortége, \& entonnent, les autres fuivent, \& le Chichikoué fert à régler la mefure. Quand le Soleil fait figne aux $\mathrm{Hhh}$ ij

I 721 .

Décembre.

Du Deuile

Des Traités. 
428 J OUR N A H T T OR I Q E

I 721 . Ambaffadeurs d'approcher, ils fe remettent en marche; ceux; Décem- qui portent le Calumet, danfent en chantant, fe tournent de bre.

tous côtés, fe donnent de grands mouvemens, \& font quantité de grimaces \& de contorfions. Ils recommencent le même manége autour du Grand Chef, quand ils font arrivés auprès de lui; ils le frottent enfuite avec leur Calumet depuis les pieds jufqu'à la tête, puis ils vont rejoindre leur Troupe.

Comment le Soleil donne audience aux Ambafladeurs

Alors ils rempliffent un Calumet de tabac, \& tenant dis feu d'une main, ils avancent tous enfemble vers le Grand Chef, \& lui préfentent le Calumet allumé. Ils fument avec lui, pouffent vers le Ciel la premiere vapeur de leur Tabac, la feconde vers la Terre, \& la troifiéme autour de l'Horifon. Cela fait, ils préfentent leurs Calumets aux Parens du Soleil, \& aux Chefs fubålternes. Ils vont enfuite frotter de leurs mains l'eftomach du Soleil, puis ils fe frottent eux-mêmes tout le corps; enfin ils pofent leurs Calumets fur des fourches vis-à-vis le Grand Chef, \& l'Orateur de l'Ambaffade commence fa harangue, qui dure une heure.

Quand il a fini, on fait figne aux Ambaffadeurs, qui jufques-là étoient demeurés debout, de s'affeoir fur des bancs placés pour eux près du Soleil, lequel répond à leur difcours, \& parle auffi une heure entiere. Enfuite un Maître des cérémonies allume un grand Calumet de paix, \& y fait fumer les Ambaffadeurs, qui avalent la premiere gorgée. Alors le Soleil leur demande des nouvelles de leur fanté ; tous ceux, qui affiftent à l'audience, leur font le même compliment, puis on les conduit dans la Cabanne, qui leur eft deftinée, $\&$ où on leur donne un grand repas. Le foir du même jour le Soleil leur rend vifite; mais quand ils le fçavent prêt à fortir de chez lui pour leur faire cet honneur, ils le vont chercher, le portent fur leurs épaules dans leur logis, \& le font affeoir fur une grande peau. L'un d'eux fe place derriere lui, appuye fes deux mains fur fes épaules, \& le fecouent affez lontems, tandis que les autres, affis en rond par terre, chantent leurs belles actions à la guerre.

Ces vifites recommencent tous les matins \& tous les foirs; mais à la derniere, le cérémonial change. Les Ambaffadeurs plantent un poteau au milieu de leur Cabanne, \& s'affeoient tout autour : les Guerriers, qui accompagnent le Soleil, parés de leurs plus belles robes, danfent, \& tour à tour frap- 
pent le poteau, \& racontent leurs plus beaux faits d'armes; après quoi ils font des préfens aux Ambaffadeurs. Le lendemain ceux-ci ont pour la premiere fois la permiffion de fe promener dans le Village, \& tous les foirs on leur donne des DécemFétes, qui ne confiftent que dans des danfes. Quand ils font fur leur départ, les Maitres de cérémonies leur font fournir toutes les provifions, dont ils ont befoin pour leur voyage, \& c'eft toujours aux dépens des Particuliers.

La plûpart des Nations de la Louyfiane avoient autrefois leur Temple, auffi-bien que les Natchez, \& dans tous ces Temples il y avoit un feu perpétuel. Il femble même que les Maubiliens avoient fur tous les Peuples de cette Partie de la Floride une efpéce de primatie de Religion, car c'étoit à leur feu, qu'il falloit rallumer celui, que par négligence, ou par malheur on avoit laiffé éteindre. Mais aujourd'hui le Temple des Natchez eft le feul, qui fubfifte, \& il eft en grande vénération parmi tous les Sauvages, qui habitent dans ce vafte Continent, \& dont la diminution eft auffi confidérable , \& a été encore plus prompte, que celles des Peuples du Canada, fans quili foit poffible d'en fçavoir la véritable raifon. Des Nations entieres ont abfolument difparu depuis quarante ans au plus. Celles qui fubfiftent encore, ne font plus que l'ombre de ce qu'elles étoient, lorfque M. de la Sale découvrit ce Pays. Je vous quitte, Madame, pour des raifons, que j'aurai l'honneur de vous expliquer bien-tôt. Je fuis, \&x.

\section{TRENTE-UNIEME LETTRE.}

Voyage depuis les Natchez jufqu'à la Nouvelle Orleans. Defcription du Pays of de plufieurs Bourgades des

Sauvages, Eै de la Capitale de la Louyfiane.

A la Nouvelle Orleans, ce dixiéme de Janvier, 172.2.

MA D A ME,

17220

Janvier.

ME voici enfin arrivé dans cette fameufe Ville, qu'on a Defription 
172 2. nommé la Nouvelle Orleans. Ceux, qui lui ont donné ce nom, Janvier. croyoient qu'Orleans eft du genre féminin : mais qu'importe? de la Nouvel- l'uíage eftétabli, \& il eft au-deffus des régles de la Grammaire. le Orleans.

Cette Ville eft la premiere, qu'un des plus grands Fleuves du Monde ait vû s'élever fur fes bords. Si les huit cent belles Maifons, \& les cinq Paroiffes, que lui donnoit le Mercure il y a deux ans, fe réduifent encore aujourd'hui à une centaine de Barraques, placées fans beaucoup d'ordre ; à un grand Magafin, bâti de bois ; à deux ou trois Maifons, qui ne pareroient pas un Village de France; \& à la moitié d'un méchant magatin, qu'on a bien voulu prêter au Seigneur, \& dont il avoit à peine pris poffeffion, qu'on voulut l'en faire fortir, pour le loger fous une tente; quel plaifir d'un autre côté de voir croître infenfiblement cette future Capitale d'un beau \& vafte Pays, \& de pouvoir dire, non pas en foupirant, comme le Héros de Virgile en parlant de fa chere Patrie confumée par les flammes: É les Champs, où fut la Ville de Troye (a): mais rempli de l'efpérance la mieux fondée; ce lieu lauvage \& défert, que les Cannes \& les Arbres couvrent encore prefque tout entier, fera un jour, \& peut.être ce jour n'eftil pas éloigné, une Ville opulente, \& $<$ la Métropole d'une grande \& riche Colonie.

Vous me demanderez, Madame, fur quoi je fonde cetteefpérance ? Je la fonde fur la fituation de cetteVille à trente-trois lieuës de la Mer, \& au bord d'un Fleuve naviguable, qu'on peut remonter jufques-là en vint-quatre heures : fur la fertilité de fon terroir ; fur la douceur \& la bonté de fon climat, par les trente dégrez de latitude-Nord; fur l'induftrie de fes Habitans; fur le voifinage du Méxique, où l'on peut aller en quinze jours par Mer; fur celui de la Havane, qui eft encore plus proche, des plus belles Ifles de l'Amérique \& des Colonies Angloifes. En faut-il davantage pour rendre une Ville floriffante? Rome \& Paris n'ont pas eu des commencemens fi confidérables,n'ont pas été bâtis fous de fi heureux aufpices, $\&$ leurs Fondateurs n'ont pas rencontré fur la Seine \& fur le Tybre les avantages, que nous avons trouvés fur le Miciflipi, auprès duquel ces deux Rivieres ne font que des ruiffeaux. Mais avant que de m'engager à vous parler de ce qui peut ici exciter votre curiofité, je vais, Madame, pour aller par or-

(a) Et Campos, ubi Troja fuit. 
dre, reprendre mon Journal, où je l'ai interrompu.

Je reftai aux Natchez beaucoup plus lontems, que je ne m'y étois attendu, \& ce fut l'abandon, où j'y trouvai les François par rapport aux fecours fpirituels, qui m'y retint jufqu'après Noël. La rofée du Ciel n'eft point encore tombée fur ce beau Pays, qui plus quaucun autre, peut fe vanter d'avoir en partage la graiffe de la terre. Feu M. d'Iberville y a voit deftiné un Jéfuite $(a)$, qui l'accompagnoit au fecond voyage, qu'il fit à la Louyfiane, dans le deffein d'établir le Chriftianifme dans une Nation, dont il ne doutoit pas que la converfion n'entraînât celle de toutes les autres ; mais ce Mifionnaire, en paffant par le Village des Bayagoulas, crut y trouver des difpofitions plus favorables à la Keligion, \& comme il fongeoit à fixer fa demeure parmi eux, il fut rappellé en France par des ordres fupérieurs.

Dans la fuite un Eccléfiaftique $(b)$ du Canada fut envoyé aux Natchez, \& il y demeura affez lontems, mais il n'y fit point de Profélytes, quoiqu'il eut gagné les bonnes graces de la Femme-Chef, qui par confidération pour lui donna fon nom à un de fes Fils. Ce Miffionnaire ayant été obligé de faire un voyage à la Maubile, fut tué en chemin par des Sauvages, qui ne vouloient apparemment que profiter de fon bagage, ainfi qu'il étoit déja arrivé à un autre Prêtre (c) du côté des Akanfas. Depuis ce tems-là toute la Louyfiane aú-deffous des Illinois eft demeurée fans Prêtre, fi on en excepte les Tonicas, lefquels ont eu pendant plufieurs années un Eccléfiaftique (d), qu'ils aimoient, qu'ils eftimoient, qu'ils ont même voulu faire leur Chef, \& qui cependant n'a pû perfuader à un feul d'embraffer le Chriftianifme.

Mais comment fongeroit-on à prendre des mefures pour la converfion des Infidéles, tandis que les Domeftiques mêmes de la Foi font prefque tous fans Pafteurs. J'ai déja eu l'honneur de vous dire, Madame, que le Canton des Natchez étoit le plus peuplé de la Colonie; cependant il y avoit cinq ans qu'aucun François n'y avoit entendu la Meffe, ni même vû un Prêtre. Je m’apperçus bien à la vérité que la privation des Sacremens avoit produit dans la plûpart cette indifférence pour les exercices de la Religion, qui en eft le

Les François dépourvûs de fecours fpirituels.

1722 .

Janvier.

Miftionnaires aux Natchez fans fruiz.

chezlansfruic. 
plus ordinaire effet ; toutefois plufieurs me témoignerent 1722. beaucoup d'empreffement de profiter de l'occafion de mon Janvier. voyage pour mettre ordre aux affaires de leur Confcience, \& je crus qu'il étoit de mon devoir de ne me pas faire prier pour leur procurer cette confolation.

La premiere propofition, que l'on me fit, ce fut de vouloir bien marier en face d'Eglife des Habitans, qui en vertu d'un contrat civil, dreffé en préfence du Commandant $\&$ du Commis principal, habitoient enfemble, fans aucun fcrupule, alléguant, aufi-bien que ceux, qui avoient autorifé ce concubinage, la néceffité de peupler le Pays, \& l'impoffibilité d'avoir un Prêtre. Je leur reprefentai qu'il y en avoit aux Yafous \& à la Nouvelle Orleans, \& que la chofe valoit bien la peine de faire le voyage; on me répondit que les Contractans n’étoient en état, ni de s'éloigner, ni de fournir à la dépenfe néceflaire pour faire venir un Prêtre. Enfin le mal étoit fait; il n'étoit plus queftion que d'y remédier, \& je le fis. Je confeffai enfuite tous ceux, qui le préfenterent, mais le nombre n'en fut pas auffi grand que je l'avois efperé.

Départ des Rien ne me retenant plus aux Natchez. j’en partis le vintNatchez. fix de Décembre affez tard, accompagné de M. DE PAUGER, Ingénieur du Roi, qui vifitoit la Colonie pour examiner les endroits, où il étoit à propos de conftruire des Forts. Nous fîmes quatre lieuës, \& nous campâmes fur le bord d'une petite Riviere, que nous rencontrâmes à gauche, nous nous rembarquâmes le lendemain deux heures avant le jour, avec un vent contraire affez fort. Le Fleuve fait en cet endroit un circuit de quatorze lieuës, \& à mefure que nous tournions, le vent tournoit avec nous, réfléchi par les terres $\&$ par les Ifles, que nous trouvâmes en grand nombre, de forte que nous l'eûmes tout le jour dans le nez. Nous ne laiffâmes pourtant pas de faire cncore dix lieuës; \& nous entrâmes dans une autre petite Riviere, qui eft fur la même main gauche. Toute la nuit nous entendîmes un fort grand bruit, \& je ne doutai point que ce ne fût l'effet du vent, qui s'étoit renforcé, mais on m'affûra que la Riviere avoit été fort tranquille, \& que le bruit, qui m’avoit éveillé, avoit été caufé par des Poiffons, qui battoient l'eau de leur queuë.

Deteription Le vint-huit, après avoir fait deux lieuës, nous arrivâmes dun village des à la Riviere des Tonicas, qui ne paroît d'abord qu'un ruiffeau; mais 

mais à une portée de fufil de fon embouchure elle forme un très-joli Lac. Si le Fleuve continue à fe jetter, comme il fait de l'autre côté, tout cet endroit deviendra inabordable. La 1722. Janvier. Riviere des Tonicas prend fa fource dans le Pays des Tchactas, \& fon cours eft fort embarraffé de Rapides. Le Village eft au-delà du Lac fur un terrein. affez élevé ; cependant on affûre que l'air y eft mauvais, ce que l'on attribue à la qualité des eaux de la Riviere; mais je croirois plutôt que cela vient de ce que ces eaux croupiffent dans le Lac. Ce Village eft bâti en rond autour d'une très - grande Place, fans enceinte, \& médiocrement peuplé.

La Cabanne du Chef eft fort ornée en-dehors pour une Cabanne de Sauvage : on y voit des figures en relief, qui ne font pas auffi mal faites, qu'on s'attend de les trouver. Le dedans eft obfcur, \& je n'y remarquai que des cofres, qu'on m'affûra être remplis de hardes \& d'argent. Ce Chef nous reçut très-poliment ; il étoit vêtu à la Françoife, \& n'étoit nullement embarraffé dans cet habit. C'eft de tous les Sauvages de la Louy fiane celui, fur lequel nos Commandans comptent le plus : il aime notre Nation, \& n'a pas lieu de fe repentir des fervices, qu'il lui a rendus. Il négocie avec les François, aufquels il fournit des Chevaux \& des Volailles, \& il entend très-bien fon commerce. Il a appris de nous à théfaurifer, \& il paffe pour être fort riche. Il y a lontems qu'il ne paroît plus habillé en Sauvage, \& il fe pique même d'être toujours bien mis.

Les autres Cabannes de ce Village font partie de figure quarrée, comme celle du Chef, partie rondes, comme aux Nation. Natchez; la Place, fur laquelle elles donnent toutes, a environ cent pas de diamétre, \& malgré un chaud étouffant, qu'il faifoit ce jour-là , les Jeunes-Gens fe divertiffoient à une efpéce de truc affez femblable au nôtre. Il y a deux autres Villages de cette Nation, peu éloignés de celui-ci, \& c'eft tout ce qui refte d'un Peuple autrefois très-nombreux. J'ai dit qu'ils avoient un Miffionnaire, qu'ils aimoient beaucoup; jai appris qu'ils l'avoient chaffé, il y a quelque tems, parce qu'il avoit brûlé leur Temple, qu'ils n'ont pourtant point rebâti, ni rallumé leur feu, preuve certaine de leur peu d'attachement à leur fauffe Religion ; ils rappellerent même bientôt le Miffionwaire, mais ils écoutoient tout ce qu'il vouloit leur dire avec. Tome III.

Du Chef des Tonicas. 
1722.434 J O U R N A L H I S T O R I Q U E Janvier. donnés à fon tour.

De la Riviere Du fond du Lac, ou de la Baye des Tonicas, on pourroit, Rouge.

Conceffions fi l'on naviguoit avec des Canots d'Ecorces, faire un portage de deux lieuës, qui en épargneroient dix fur ce Fleuve; mais avec des Pirogues cela n'eft point pratiquable. Deux lieuës plus bas que la Riviere des Tonicas on laiffe à main droite la Kiviere rouge, ou Rio Colorado, à l'entrée de laquelle le fameux Ferdinand de Soto, le Conquérant de la Floride, termina fes jours \& fes exploits, ou plutôt fa courfe vagabonde. Cette Riviere court Eft \& Oueft pendant quelque tems, puis tourne au Sud. Elle n'eft guéres navigable pour les Pirogues, que pendant quarante lieuës, après quoi on ne trouve plus que des Marais impratiquables. Son embouchure me parut avoir environ deux cent toifes de large. Dix lieuës au-deflus elle reçoit fur la main droite la Riviere Noire, autrement appellée la Riviere des Ouatchitas, laquelle vient du Nord, \& n'a prefque point d'eau pendant fept mois de l'année. mal placées.

On n'a pourtant pas laiffé d'y placer plufieurs Conceffions, qui felon toutes les apparences n'y feront pas fortune; le motif de cet Etabliffement eft le voifinage des Efpagnols, qui de tout tems a été un appas funefte à cette Colonie; dans l'efpérance de trafiquer avec eux, on laifle en friche les meilleurs terreins du Monde. Les Natchitoches font établis fur la Riviere Rouge, \& nous avons jugé à propos de bâtir chez eux un Fort, pour empêcher les Efpagnols de s'établir plus près de nous. Nous campâmes le vint-neuf un peu au-deffous de l'embouchure de la Riviere Rouge dans une fort belle anfe.

pointe cou. Le trentiéme, après avoir fait cinq lieuës, nous paffâmes pée. . une feconde Pointe coupée : le Fleuve faifoit en cet endroit-là un fort grand détour; des Canadiens, à force de creufer un petit ruifleau, qui étoit derriere une pointe, $y$ ont fait entrer les eaux du Fleuve, lefquelles fe répandant avec impétuofité dans ce nouveau Canal, ont achevé de couper la pointe, \& ont épargné aux Voyageurs quatorze lieuës de chemin. L'ancien lit eft actuellement à fec, \& n'a d'eau, que dans le tems. de l'inondation, preuve évidente que le Miciffipi fe jette ici du côté de l'Ełt, \& c'eft à quoi on ne fçauroit faire trop d'attention, en s'établiffant fur l'une \&z l'autre rive du Fleuve. On a depuis peu fondé ce nouveau Canal, \& on y a filé 
Immédiatement au-deffous, \&z fur la même main gauche, nous vîmes les foibles commencemens d'une Conceftion, qui Janvier. porte le nom de Sainte Reyne, \& à la tête de laquelle font MM. DE COETL G GN \& K OLLI. Elle eft fituée fur un de Sainte Reyne, \& celle de terrein très-fertile, \& où l'on n'a point à craindre le déborde- Mezieres. ment duFleuve; mais avec rien on ne fait rien, furtout quand les Hommes manquent au travail, \& l'amour du travail aux Hommes; \& c'eft l'état, où nous parut cette Conceffion. Nous fimes encore une lieuë ce jour-là, \& nous gagnâmes la Conceffion de Madame DE MEZIERES, où la pluye nous arrêta tout le jour fuivant. Quelques Huttes couvertes de feuilles de Lattaniers, \&z une grande Tente de coutil forment préfentement cette Conceffion; on y attend des Hommes \& des Marchandifes de la Riviere Noire, où font les Magafins, \& qu'on ne veut pas abandonner. J'ai bien peur qu'en voulant faire deux Etabliffemens à la fois, on ne les manque tous deux.

Le terrein, fur lequel on a commencé celui-ci, eft fort bon, mais il faut bâtir à un quart de lieuë duFleuve, derriere une Cypriere, dont le fond eft marécageux, \& 2 dont on pourroit tirer parti en $y$ femant $d u R i s, \&$ en $y$ faifant des Jardinages. Deux lieuës plus avant dans le Bois il y a un Lac de deux lieuës de circuit, dont les bords font couverts de gibier, \& qui fournira peut-être du poiffon, quand on en aura exterminé les Caïmans, qui y fourmillent. J'appris en cet endroit quelques fecrets, que je vais, Madame, vous donner pour le prix qu'ils m'ont coûté ; car je n'ai pas le loifir d'en faire l'épreuve.

Le Cyprès mâle porte en ce Pays une gouffe, qu'il faut, dit-on, cueillir verte, \& dans laquelle on trouve un baume tions.

Obfervafouverain pour les coupures. Celui, qui diftile du Copalme, a entr'autres vertus, celle de guérir de l'Hydropifie. La racine de ces grands Cotonniers, dont j’ai parlé ailleurs, \& qu'on ce ceffe point de trouver dans toute la route, que j'ai faite depuis le Lac Ontario, eft un reméde affûré contre toıtes fortes d'écorchures: il en faut prendre la pellicule intérieurc, la faire bouillir dans l'eau, baffiner la playe de cette eau, \& y mettre enfuite de la cendre de la pellicule même.

Le premier jour de l'année $\mathbf{1 7 2 2}$ nous allâmes dire la Meffe 
172 2. fron très-bien placée, \& qui appartient à M. Diron D'ART AJanvier. GUETTE, Infpecteur Général des Troupes de la Louyfiane $(a)$. On nous y apporta uneTortuë. monftrueufe, \& on nous affûra que ces Animaux venoient à bout de rompre une groffe barre de fer: fi le fait eft vrai, \& je voudrois l'avoir vû pour le croire, il faut que la falive de ces Animaux foit un grand diffolvant: pour la jambe d'un Homme, je ne voudrois pas la rifquer dans leur gueule. Ce qui eft certain, c'eft qu'avec celle, que je vis il y avoit dequoi raffafier dix Perfonnes de bon appétit. Nous reftâmes tout le jour dans cette Conceffion, qui. n'eft pas plus avancée que les autres, \& qu'on appelle le $B \hat{a}-$ ton Rouge.

Ies Baya- Le lendemain nous fìmes onze lieuës, \& nous campâmes goulas.

un peu au-deffous des Bayagoulas, que nous avions laiffés à main droite, après y avoir vifité les ruines de l'ancien Village, dont je vous ai parlé. I! étoit très-peuplé il n'y a que vint ans; la Petite Vérole a fait périr une partie de fes Habitans, les autres fe font éloignés 8 difperfés, on n'en a même aucune nouvelle depuis plufieurs années, $\&$ on doute qu'il eı refte une feule Famille. Le terrein, qu'ils occupoient eft magnifique.; MM. PA R Is y ont une Conceffion, où l'on a planté à la ligne quantité de Mûriers blancs, \& on y fait déja de fort belle Soye. On commence auffi à y cultiver avec fuccès le Tabac \& l'Indigo. Si on travailloit partout de même, les Propriétaires des Conceffions, feroient bien-tôt plus que dédommagés de leurs avances.

Le troifiéme de Janvier nous arrivâmes vers les dix heures

Des Oumas \& des Chetimachase. du matin au petit Village des Oumas, qui eft fur la gauche, \& où il y a quelques Maifons Françoifes. Un quart de lieuë. plus avant dans. les terres eft le grand Village. Cette Nation nous eft fort affeßtionnée. Le Micifipi commence à fourcher deux lieuës plus haut : il s'eft creufé fur la droite, où fa pente. le porte toujours, un Canal, qu'on appelle la Fourche des Chetimachas $(b)$, \& qui avant que de porter fes eaux à la Mer, forme un Lac affez grand. La Nation des Chetimachas. eft prefque entiérement détruite, le peu, qui en refte, eft ESclave dans la Colonie.

(a) Il eft mort depuis peu Lieutenant $\mid$ gue.

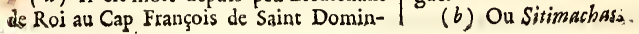


Nous fìmes encore ce jour-là fix lieuës au-delà des Oumas, \& nous allâmes paffer la nuit fur le bel Emplacement, où l'on avoit établi la Conceffion de M. le Marquis D'ANCENIS (a), qu'un incendie du Magafin Général, \& plufieurs autres accidens arrivés coup fur coup ont réduite à rien. Les Colapiffas y. avoient formé un petit Village, qui n'a pas fubfifté lontems. Le quatriéme nous arrivâmes avant midi au grand Village des Colapiffas. C'eft le plus beau de la Louyfrane, toutefois on n'y compte que deux cent Guerriers, qui ont la réputation. d'être fort braves. Leurs Cabannes ont la figure d'un Pavillon, comme celle des.Sioux, auffi n'y fait-on du feu que rarement. Elles ont une double couverture; celle du dedans eft un tiffu de feuilles de Latanniers, celle du dehors eit compofée de Nattes.

La Cabanne du Chef a trente-fix pieds de diamétre : je n'en avois pas encore vû de fi grande; car celle du Soleil des Natchez n'en a que trente. Dès que nous parûmes à la vûë de ces Villages, on y battit la quaiffe, \& nous fûmes à peine débarqués, qu'on vint me complimenter de la part du Chef. Je fus affez furpris en avançant vers. le. Village, de voir le Tambour vêtu d'une longue robe partie rouge, \& partie blanche avec les manches rouges du côté du blanc, \& blanches. du côté du rouge. Je demandai l'origine de cet ufage, \& on me répondit qu'il n'étoit pas ancien; qu'un Gouverneur de la Louyfiane avoit fait préfent d'un Tambour à ces Sauvages, qui ont toujours été nos-Alliés fidéles, \& que cette efpéce d'habit de Bedeau étoit de leur invention. Les Femmes font ici mieux faites que celles du Canada, \& leur maniere de s'habiller a auffi quelque chofe de plus propre.

L'après-dîner nous fìmes encore cinq lieuës, \& nous nous' arrêtâmes aux Cannes brûlées, où la Conceffion de M. le Comte D'ARt A GNAN a une Habitation, qui doit lui fervir d'entrede M. le Comte d'Artaguan. pôt, fi elle n'a pas le fort de prefque toutes les autres. Cette Habitation eft fur la gauche, 8 le premier objet, qui fe préfenta à ma vûë, fut une grande Croix élevée fur le bord du Fleuve, autour de laquelle on chantoit actuellement les Vêpres. C'eft le premier endroit de la Colonie, depuis les Illinois, où j’aye trouvé cette marque de notre Religion. Deux Moufquetaires, Meffieurs D'A R T G IERE, \& DE B.

(a) Aujourd'hui Dur D E BETHU.N E. 
$43^{\circ}$ J O UR N A L H I S T O R I Q U E N A C (a) font les Directeurs de cette Conceffion, \& c'étoit

17 I 2. M. de Benac, qui avoit la direction de l'Habitation des CanJanvier. nes brûlées, avec M. Chevalier, Neveu du Maître de Mathématiques des Pages du Roi. Ils n'avoient point de Prêtre, \& ce n'étoit pas leur faute : on leur en avoit donné un, dont ils ont été obligés de fe défaire, parce que c'étoit un yvrogne, \& qu'ils ont bien jugé qu'un mauvais Prêtre eft plus capable de faire du mal dans un nouvel Etabliffement, où il n'a point de Superieur, qui veille fur fa conduite, qu'on n'en peut tirer de fervice.

Des Taenfas." Entre les Colapiffas \& les Cannes brûlées on laiffe à main droite le Terrein, où étoient autrefois les Taenfas, qui du tems de M. de la Sale faifoient une grande figure dans ce Pays-ci, \& qui ont entierement difparu depuis quelques années. C'eft le plus bel endroit, \& le meilleur Terroir de toute la Louyfiane. M. de Meufe, à qui il a été concedé , n'y a encore rien fait: il y entretient néanmoins un Directeur, qui n'a ni Hommes ni Marchandifes.

DesChapi- Le cinquiéme nous nous arrêtâmes pour dîner à un entoulas. droit, qu'on appelle les Chapitoulas, \& qui n'eft éloigné que de trois lieuës de la Nouvelle Orleans, où nous arrivâmes à cinq hetures du foir. Les Chapitoulas \& quelques Habitations voifines font en très-bon état; le terrein en eft fertile, \& il eft tombé entre les mains de Gens habiles \& laborieux. C'eft le fieur du Breuil \& troisFreres Canadiens, nommés Chauvins: ceux-ci n'y ont apporté que leur induftrie, laquelle s'eft perfectionnée par la néceffité de travailler pour fubfifter. Ils n'ont point perdu de tems, ils ne fe font épargnés en rien, \& leur exemple eft une leçon pour ces Fainéans, dont la mifere décrie mal-à-propos un Pays, qui peut rendre au centuple tout ce qu'on y fémera.

Je fuis, \&c.

(a) Ce Dernier eft préfentement Capitaine dans les Troupes de la Louyfiane. 


\section{TRENTE-DEUXIÉME LETTRE.}

Voyage de la Nouvelle Orleans à l'embouchure du Micifipi, defcription de ce Fleuve jufqu'à la Mer. Réflexions fur les Concefions.

A l'inle Touloufe, ou de la Balife, ce 26 de Janvier 1722.

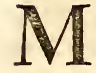

\section{A D A M E,}

Les Environs de la Nouvelle Orleans n'ont rien de fort remarquable. Je n'ai pas trouvé cette Ville auffi-bien fituée qu'on me l'avoit dit: d'autres penfent autrement, voici les raifons, fur quoi ils fe fondent; je vous expoferai enfuite les miennes. La premiere eft qu'à une lieuë de-là, en tirant au Nord-Eft, on a découvert une petite Riviere, qu'on a nom- leans. mée le Bayouc de S. Jean (a), laquelle au bout de deux lieuës fe décharge dans le Lac Pontchartrain, qui communique à la Mer; par ce moyen, dit-on, il eft aifé d'entretenir un Commerce fûr entre la Capitale, \& la Maubile, le Biloxi, \& tous les autres poftes, que nous occupons près. de la Mer. La feconde eft qu'au deffous de la Ville, le Fleuve fait un très-grand détour, qu'on a nommé le détour aux $A n-$ glois, lequel peut caufer un retardement, qu'on a jugé trèsavantageux pour éviter une furprife.

Ces raifons font fpécieufes, mais elles ne me paroiffent pas folides ; car en premier lieu, ceux mêmes, qui ont ainfi raifonné,fuppofoient que l'entrée du Fleuve ne pouvoit recevoir que de petits Bâtimens : or dans cette fuppofition qu'a-t'on à craindre de la furprife, pour peu que la Ville foit fortifiée, comme je fuppore à mon tour qu'elle le fera bien-tôt ? Viendra-t'on l'attaquer avec des Chaloupes, ou avec des Bâtimens, qui ne peuvent point porter de Canons? D'ailleừrs en quelque endroit que la Ville foit placée, l'embouchure du Fleuve ne doit-elle pas être défenduë par de bonnes Batteries ,

(a) Bayouc en Langue Sauvage veut dire Ruij/ean.

I 72 2.

Janvier. Remarques: fur la fituartion de las nouvelle Or- 


\section{JOURNAL HISTORIQUE}

\& par un Fort, qui donneront au moins le tems d'être averti, 1722 . \& de fe tenir prêts à recevoir les Ennemis ? En fecond lieu, Janvier. quelle néceffité d'avoir cette communication, qui ne peur être que par le moyen des Chaloupes, avec des Poftes, qu'on ne pourroit pas fecourir, s'ils étoient attaqués; dont réciproquement on ne pourroit tirer que de foibles fecours, \& qui ne font bons à rien pour la plûpart? J'ajoûte que quand il faut faire remonter à un Vaiffeau le détour aux Anglois, il faut d'un moment à l'autre changer de vent, ce qui peut les arrêter des femaines entieres pour faire fept ou huit lieuës. Peu de pro- Un peu au-deffous de la Nouvelle Orleans, le terrein com-
fondeur du Pays all-deffous de la Nouvelle Orleans.

mence à n'avoir pas beaucoup de profondeur des deux côtez du Miciffipi , \& cela va toujours en diminuant jưfqu'à la Mer. C'eft une pointe de Terre, qui ne paroît pas fort ancienne ; car pour peu qu'on y creure, on y trouve l'eau, \& la quantité de battures \& de petites Ifles, qu'on a vû fe former depuis vint ans à toutes les embouchures du Fleuve, ne laiffe aucun doute que cette langue de terre ne fe foit formée de la même maniere. Il paroît certain, que quand $\mathbf{M}$. de la Sale defcendît le Miciffipi jufqu'à la Mer, l'embouchure de ce Fleuve n'étoit pas telle, qu'on la voit aujourd'hui.

Changemens Plus on approche de la Mer, plus ce que je dis devient arrivés à l'em- fenfible : la Barre n'a prefque point d'eau dans la plûpart de

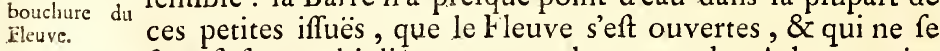
font $\mathrm{fi}$ fort multipliées, que par le moyen des Arbres, qui.y font entrainés avec le courant, $\&$ dont un feul arrêté par fes branches, ou par fes racines dans un endroit, où il y a peu de profondeur, en arrête mille. J'en ai vû à deux cent lieuës d'ici des amas, dont un feul auroit rempli tous les Chantiers de Paris. Rien alors n'eft capable de les détacher, le limon, que charie le Fleuve, leur fert de ciment, \& $\mathrm{x}$ les couvre peu à peu; chaque inondation en laiffe une nouvelle couche, $\&$ après dix ans au plus les Cannes $\&$ les Arbriffeaux commencent à y croître. C'eft ainfi que fe font formées la plûpart des Pointes \& des Ifles, qui font fi fouvent changer de cours au Fleuve.

Dépatt de Je n'ai rien à ajoûter à ce que je vous ai dit au commencela Nouvelle Orleans. ment de la Lettre précédente, de l'état préfent de la nouvelle Orleans. L'idée la plus jufte, que vous puiffiez vous en former, eft de vous figurer deux cent Perionnes, qu'on a envoyées 
$+$ 


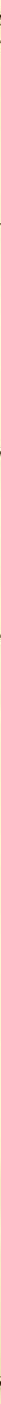


DUUN VOYAGE DE L'AMERIQ. LET. XXYII. $44 \mathrm{I}$ voyées pour bâtir une Ville, \& qui font campés au bord d'un grand Fleuve, oì ils n'ont fongé qu'à fe mettre à couvert des injures de l'air, en attendant qu'on leur ait dreffé 1722. Janvier. un Plan, \& qu'ils ayent bâti des maifons. M. de Pauger, que j'ai encore l'honneur d'accompagner, vient de me montrer un Plan de fa façon: il eft fort beau, \& fort régulier ; mais il ne fera pas auffi aifé de l'exécuter, qu'il l'a été de le tracer fur le papier. Nous partimes le vint-deux de Juillet pour nous rendre au Biloxi, où eft le Quartier général. Entre la Nouvelle Orleans \& la Mer, il n'y a point de Conceffions; elles auroient trop peu de profondeur, mais feulement de petites Habitations particulieres, \& des Entrepots pour les grandes Conceffions.

Derriere une de ces Habitations, qui eft fur la droite, immédiatement au-deffous du Détour aux Anglois, on voyoit il n'y a pas lontems un Village de Chaouachas, dont j'ai vifité Des Chaouachas. les ruines. Je n'y trouvai d'entier que la Cabanne du Chef, qui reffembloit affez à une Maifon de nos Payfans de France, avec cette feule différence, qu'elle n'avoit point de fenêtres. Elle étoit conftruite de branches d'Arbres, dont les vuides étoient remplis de feüilles de Lataniers; la couverture étoit de même ftructure. Ce Chef eft très-abfolu, comme le font tous ceux de la Floride; il ne chaffe que pour fon plaifir, car fes Sujets font obligés de lui faire part de leur Gibier. Son Village eft préfentement de l'autre côté du Fleuve, une demie lieuë plus bas, \& les Sauvages y ont tranfporté jufqu'aux offemens de leurs Morts.

Un peu au-deffous de leur nouvelle demeure la Côte eft beaucoup plus élevée, que par tout ailleurs, \& il me paroît que c'eft là, qu'il falloit placer laVille. Elle n'y feroit qu'à vint lieuës de la Mer, \& avec un vent de Sud, ou de Sud-Eft médiocre, un Navire y monteroit aifément en quinze heures. Le foir du vint-troifiéme nous quittâmes la Chaloupe, qui nous avoit amenés jufques - là , \& nous nous embarquâmes dans un Brigantin, fur lequel nous nous laifâmes dériver toute la nuit. Le lendemain au point du jour nous avions paffé un nouveau circuit, que fait le Fleuve, \& qu'on appelle le Détour aux Piakimines.

Nous nous trouvâmes peu de tems après au milieu des paffes du Micifipi; il y faut manœuvrer avec bien de l'attention, Tome III.

$\mathrm{K} \mathrm{k} \mathrm{k}$ 


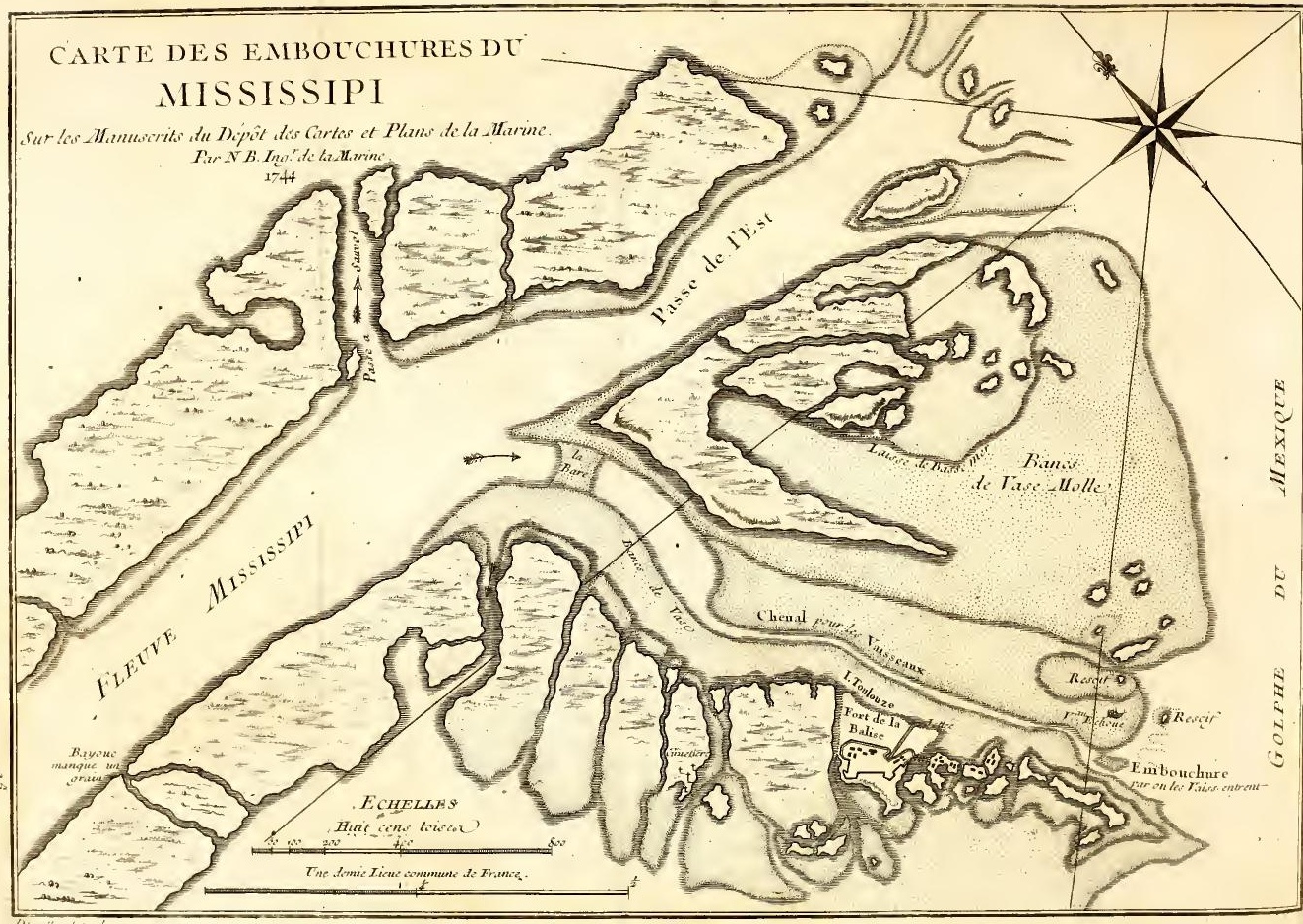


DUN VOYAGE DE L'AMERIQ. LET. XXYII. $44 \mathrm{I}$ voyées pour bâtir une Ville, \& qui font campés au bord d'un grand Fleuve, oì ils n'ont fongé qu'à fe mettre à couvert des injures de l'air, en attendant qu'on leur ait dreffé 1722. un Plan, \& qu'ils ayent bâti des maifons. M. de Pauger, que j'ai encore l'honneur d'accompagner, vient de me montrer un Plan de fa façon: il eft fort beau, \& fort régulier; mais il ne fera pas aufí aifé de l'exécuter, qu'il l'a été de le tracer fur le papier. Nous partîmes le vint-deux de Juillet pour nous rendre au Biloxi, où eft le Quartier général. Entre la Nouvelle Orleans \& la Mer, il n'y a point de Conceffions; elles auroient trop peu de profondeur, mais feulement de petites Habitations particulieres, \& des Entrepots pour les grandes Conceffions.

Derriere une de ces Habitations, qui eft fur la droite, immédiatement au-deffous du Détour aux Anglois, on voyoit il n'y a pas lontems un Village de Chaouachas, dont j'ai vifité les ruines. Je n'y trouvai d'entier que la Cabanne du Chef, qui reffembloit affez à une Maifon de nos Payfans de France, avec cette feule différence, qu'elle n'âvoit point de fenêtres. Elle étoit conftruite de branches d'Arbres, dont les vuides étoient remplis de feüilles de Lataniers; la couverture étoit de même ftructure. Ce Chef eft très-abfolu, comme le font tous ceux de la Floride; il ne chaffe que pour fon plaifir, car fes Sujets font obligés de lui faire part de leur Gibier. Son Village eft préfentement de l'autre côté du Fleuve, une demie lieuë plus bas, \& les Sauvages y ont tranfporté jufqu'aux offemens de leurs Morts.

Un peu au-deffous de leur nouvelle demeure la Côte eft beaucoup plus élevée, que par tout ailleurs, \& il me paroît que c'eft là,qu'il falloit placer laVille. Elle n'y feroit quà vint lieuës de la Mer, \& avec un vent de Sud, ou de Sud-Eft médiocre, un Navire y monteroit aifément en quinze heures. Le foir du vint-troifiéme nous quittâmes la Chaloupe, qui nous avoit amenés jufques - là , \& nous nous embarquâmes dans un Brigantin, fur lequel nous nous laiflàmes dériver toute la nuit. Le lendemain au point du jour nous avions paffé un nouveau circuit, que fait le Fleuve, \& qu'on appelle le Détour aux Piakimines.

Nous nous trouvâmes peu de tems après au milieu des paffes du Miciffipi; il y faut manœuvrer avec bien de l'attention, Tome III.

$\mathrm{K} \mathrm{k} \mathrm{k}$

Des Chaouachas.

Janvier. 
$722.442 \mathrm{~J} O U R \mathrm{~N} A \mathrm{~L}$ H I S T O R I Q U E

pour ne pas être entraîné dans quelqu'une, d'où il feroit Janvier. prefque impoffible de fe tirer. La plûpart ne font que des petits ruiffeaux, \& quelques - unes mêmes ne font féparées que par des hauts fonds prefque à fleur d'eau. C'eft la barre du Miciffipi, qui a fi fort multiplié ces paffes; car il eft aifé de concevoir par la maniere, dont j'ai dit qu'il fe formoit tous les jours de nouvelles terres, comment le Fleuve cherchant à s'échaper par où il trouve moins de réfiftance, fe fait un paffage, tantôt d'un côté, \& tantôt d'un autre : d'où il pourroit arriver, fi l'on n'y prenoit garde, qu'aucune de ces. iffuës ne fût pratiquable pour les $V$ aiffeaux. Le foir du vintquatre nous moüillâmes aude-là de la Barre, vis-à-vis la Balife.

Dc "rife Le vent contraire nous y retenant encore, nous voulumes

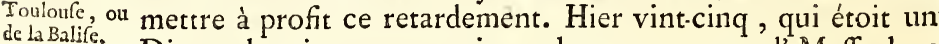
Dimanche, je commençai par chanter une grand'-Meffe dans l'ifle, qu'on nommoit de la Balife, à caufe d'une Balife, qu'on y avoit plantée pour la commodité des Navires. Je la benis enfuite, nous la nommâmes Ifle Touloufe, \& nous. chantâmes le Te Deum. Cette Ifle n'a gueres plus d'une demie lieuë de circuit, en y comprenant même une autre Inle, qui en eft féparée par une Ravine, où il y a toujours de l'eau. D'ailleurs elle eft très-baffe, excepté un feul endroit, où l'inondation ne monte jamais, \& où il y a affez d'efpace, pour y conftruire un Fort $\&$ des Magafins. On pourroit y décharger les Vaiffeaux, qui auroient de la peine à paffer la Barre avec toute leur charge.

5alines. $\quad$ M. de Pauger fonda cet endroit avec l'aiguille de fonde, $\& z$ en trouva le fond affez dur, \& de terre glaife, quoiqu'il en forte cinq ou fix petites Sources, qui ne jettent pas beaucoup d'eau; mais cette eau laiffe fur la terre, où elle coule un trèsbeau fel. Quand le Fleuve eft le plus bas, c'eft-à-dire, pendant trois mois des plus grandes chaleurs de l'année, l'eau eft falée autour de cette Ifle : dans le tems de l'inondation, elle eft tout-à-fait douce, \& le Fleuve conferve fa douceur une bonne lieuë dans la Mer. Dans le refte du tems on la trouve un peu faumatre, quand on a paffé la Barre. Ainfi c'eft une pure fable, que ce qu'on a débité, que pendant vint lieuës. le Miciffipi ne mêle point fes eaux avec celles de la Mer.

De la princi- Nous paffàmes le refte du jour M. de Pauger \& moi, avec 
D'UN VOYAGE DE L'AMERIQ. LET. XXXII. 443 le Pilote Kerlafio , qui commandoit le Brigantin , à fonder $\&$ à relever la feule embouchure du Fleuve, qui foit navigable; \& voici au jufte nos obfervations fur l'état, où nous 1722. Janvier. l'avons trouvée, car je ne réponds point des changemens, qui pourroient y arriver. Elle court Nord-Oueft \& Sud-Eft l'efpace de trois cent toifes en montant de la pleine Mer jufqu'à l'Ifle Touloufe, vis-à-vis de laquelle il y a trois petites lifes, qui n'ont point encore d'herbes, quoiqu'elles foient affez hautes. Dans tout cet intervale, fa largeur eft de deux cent cinquante toifes, fa profondeur de dix-huit pieds au milieu, fond de vafe molle : mais il faut y naviger la fonde à la main, quand on n'eft pas pratique.

De-là en remontant, on fait encore le Nord-Oueft l'efpace de quatre cent toifes, au bout defquelles il y a encore quinze pieds d'eau, même fond : \& il eft à obferver que par tout là l'ancrage eft fûr, \& qu'on y eft à l'abri de tous les vents, excepté de ceux du Sud, \& du Sud-Eft, qui pourroient, quand ils font violens, faire chaffer les Navires fur leurs ancres, mais fans danger, parce qu'ils iroient échouer fur la Barre, qui eft auffi de vafe molle : on fait enfuite le NordOueft, quart de Nord-Eft pendant cinq cent toifes. C'eft-là proprement la Barre, douze pieds d'eau, moyenne profondeur, encore faut-il y manœuvrer avec attention, car on y rencontre des Bancs, cette Barre a deux cent cinquante toifes de large entre des terres baffes, \& couvertes de rofeaux.

Dans la paffe de l'Eft, qui eft immédiatement au-deffus, Autres paftes. on fait l'Oueft en plein pendant une lieuë : elle a deux cent cinquante toifes de largeur, \& depuis quatre jufqu’à quinze pieds de profondeur. Puis tout à coup on ne trouve plus de fond. En reprenant la grande paffe au fortir de la Barre, on fait encore le Nord-Oueft l'efpace de trois cent toifes, \& on y a toujours quarante-cinq pieds d'eau. On laiffe à droite la pafje à Sauvole, par où les Chaloupes peuvent aller au $\mathrm{Bi}$ loxi, en faifant le Nord: elle a pris fon nom d'un Officier, que M. d'Iberville établit Commandant de la Colonie, en retournant en France.

Il faut enfuite retourner à l'Oueft, quart Nord-Oueft, pendant cinquante toifes, \& dans une maniere de Baye, qu'on laiffe à gauche, au bout de cet efpace, il y a trois paf res, une au Sud Sud-Eft, une autre au Sud, \& la troifiéme à

$\mathrm{Kkk}$ ij

pale embouchure du Micifipi.

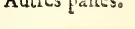


444 JOURNAL H IS TORIQUE

1722 . l'Ouef-Sud-Oueft. Cette Baye n'a néanmoins que dix toifes Je profondeur, \& vint de diamétre ; mais ces paffes ont peu Janvier. d'eau. On continuë de fuivre le même rhumb de vent, \& au bout de cinquante autres toifes il y a fur la même main une feconde Baye, qui a vint toifes de diamétre, \& cinquante de profondeur. Elle contient deux petits paffes, d'où les Canots d'écorce auroient bien de la peine à fe tirer, aufli ne les. compte-t'on pas pour l'ordinaire.

De-là on tire à l'Oueft pendant l'efpace de cinq cent toifes, \& on fe trouve vis-à-vis de la pafje à la Loutre. Elle eft fur la main droite, \& tournée au Sud-Sud-Eft. Elle a cinq cent toifes de large, mais il n'y peut entrer que des Pirogues. Enfuite on tourne au Sud-Oueft pendant vint toifes; on revient à l'Oueft pendant trois cent, puis à l'Oueft, quart de NordOueft, l'efpace de cent : à l'Oueft-Nord-Oueft autant, au Nord-Oueft huit cent; alors on trouve à gauche la pafje du Sud, laquelle a deux cent cinquante toifes de large, neuf braffes d'eau à fon entrée du côté du Fleuve, \& deux pieds. feulement à fa fortie dans la Mer.

Deux cent cinquante toifes plus loin eft la paffe du SudOuft, même largeur à peu près; jamais moins de fept à huit pieds d'eau. Par ce travers le Pays commence à n'être plus fi marécageux, mais il eft noyé pendant quatre mois de l'année. Il eft borné à gauche par une fuite de petits Lacs, qui font au bout de celui des Chetimachas, \& à droite, par les Ifles de la Chandeleur: on croit qu'entre ces Ifles il y a paflage pour les plus grands Navires, \& qu'il feroit aifé d'y faire un très-bon Port. De grandes Barques peuvent remonter de la Mer jufqu'au Lac des Chetimachas, \& rien n'empêche d'y aller couper les plus beaux Chênes du monde, dont toute cette Côte eft couverte.

Moyen de Je ferois auffi d'avis qu'on bouchât toutes les paffes, à l'excreufer la principale paffe.

ception de la principale, \& rien ne feroit plus aifé ; il n'y auroit qu'à y faire entrer les Arbres flotans, dont le Fleuve eft prefque toujours couvert. Il arriveroit de-là en premier lieu que le Fleuve ne feroit abordable, même aux Barques \& aux Canots, que par un côté , ce qui mettroit la Colonie à l'abri des furprifes; en fecond lieu, que toute la force du courant du Fleuve étant réunie, fon unique embouchure fe creuferoit d'elle-même auff - bien que la Barre. Je fonde cette con- 
D'UN VOYAGE DE L'AMERIQ. LET. XXXII.

je vous ai parlé. Il n'y auroit plus alors qu'à entretenir le Canal, \&zà empêcher que les Arbres flottans n'y caufent aucun embarras, ce qui ne me paroît pas bien difficile.

Pour ce qui eft de la largeur du Fleuve entre les paffes, c'eft-à-dire, pendant les quatre lieuës qu'il y a de l'Ifle Touloufe à la paffe du Sud-Oueft, elle n'eft jamais plus que de cinquante toifes : mais immédiatement au-deffus de cette paffe, le Miciffipi reprend infenfiblement fa largeur ordinaire, qui n'a jamais moins d'un mille, \& rarement plus de deux milles. Sa profondeur va aufi toujours en augmentant depuis la Barre, ce qui eft le contraire de tous les autres. Fleuves, qui font ordinairement plus profonds à mefure qu'ils approchent de la Mer.

Ce feroit ici, Madame, le lieu de vous entretenir fur ce qui a fait échouer ces nombreufes Conceffions, qui ont fait tant de bruit en France, \& fur lefquelles tant de perfonnes. avoient fondé les plus grandes efpérances; mais j'aime mieux remettre cela à notre premiere entrevuë, \& me borner préfentement à vous faire part des réflexions, que jai faites fur la maniere de s'établir en ce Pays, fi le mauvais fuccès de tant d'efforts \& d'avances inutiles n'en dégoûte pas notre Nation.

Il me paroît que ce n'eft point fur le bord du Fleuve, qu'il faudroit placer les Habitations; mais je voudrois qu'on les reculât au moins d'un quart de lieuë, ou même d'une demie les

lieue. Je n'ignore pas qu'il eft poffible de fe garantir des débordemens ordinaires par de bons Foffés; mais je trouve que c'eft une grande incommodité que de fe loger fur un terrein, où, pour peu que l'on creufe, on trouve l'eau d'abord: par' conféquent l'on ne peut avoir ni Cellier ni Cave. Je penfe même qu'on gagneroit beaucoup en abandonnant le champ. libre à l'inondation annuelle du Fleuve furtout le terrein, qui. n'eft pas bien fec, \& ce terrein ne refteroit pas inutile.

Le limon, qui y demeure, quand les eaux fe font retirées, le renouvellent \&z l'engraiffent; on pourroit en employer une partie en pâturages, on femeroit fur l'autre du Ris, des Légumes, \& généralement tout ce qui demande des terres graffes \& mouillées. Avec le tems fur les deux Rives du: Miciffipi on ne verroit plus que des Jardins, des Vergers $8 \times$

Largeur dis Fleuve entre les paffes.

(1)




\section{J O URNA L H IS TOR I Q U E}

1722 . des Prairies, qui fuffiroient pour nourrir le Peuple, \& fourniroient même la matiere d'un commerce utile avec nos Ifles, Janvier. \& les autres Colonies voifines. Enfin je crois pouvoir répondre , pour avoir mis pied à terre deux ou trois fois tous les jours, dans le tems que je defcendois le Fleuve, que prefque par tout, à très-peu de diftance des bords, on trouve des terreins élevés, où l'on pourroit bâtir fur un fond folide, $\&$ où le Froment viendroit fort bien, quand on y auroit donné de l'air, en éclairciffant les Bois.

Difficulté de Pour ce qui eft de la navigation fur leFleuve, elle fera tounaviger fur jours difficile, quand il s'agira de le remonter, à caufe de la force du courant, qui oblige même à une grande attention en defcendant, parce qu'il porte fouvent fur les pointes avancées, \& fur les battures. Ainfi pour y naviger fûrement, il faut des Bâtimens, qui aillent à la voile $\& x$ à la rame. D'ailleurs, comme il n'eft pas poffible de marcher la nuit, quand le tems eft obfcur, ces voyages feront toujours fort longs \& fort coûteux, du moins jufqu'à ce que les bords du Fleuve foient peuplés de proche en proche dans toute l'étenduë du Pays, qui eft entre les Illinois \& la Mer.

D'oú vient Voilà, Madame, quel eft ce Pays, dont on a tant parlé lidée peu juf- depuis quelques années, \& dont fi peu de perfonnes ont te, quon a
en France de une idée jufte. Nous n'avons pas été les premiers Européens ce Pays. à en reconnoître la bonté, \& à le négliger : Ferdinand de Soto l'a parcouru pendant trois années entieres, \& fon Hiftorien (a) n'a pû lui pardonner de n'y avoir point fait un Etabliffement folide. "Où pouvoit-il aller, dit-il, pour trouver mieux?" "

Enfin, je n'ai encore oüi parler peu avantageufement de la Louyfiane, qu'à trois fortes de perfonnes, qui ont été fur les lieux , \& clont il eft certain que le témoignage n'eft nullement recevable. Les premiers font les Marins, qui de la rade de l'Ifle aux Vaiffeaux, ou de l'Ifle Dauphine, n'ont pû voir que cette Ifle toute couverte d'un fable fterile, \& la côte plus fablonneufe encore du Biloxi , \& fe font laiffé perfuader que l'entrée du Miciffipi étoit impratiquable aux Navires d'une certaine grandeur, ou qu'il falloit faire cinquante lieuës dans ce Fleuve, pour y trouver un terrein, qu'on pût habiter. Ils auroient bien changé de fentiment, s'ils avoient pû

(a) GarcillafTo de la Yega, Hiftoire de la Conquête de la Floride. 
D'UN VOYAGE DE L'AMERIQ. LeT. XXXII. 447 fe défier de ceux, qui leur tenoient ce langage, \& pénétrer les motifs, qui les faifoient parler ainfi.

Les feconds font des Malheureux, qui chaffés de France

1722 . Janvier. pour leurs crimes, ou leur mauvaife conduite, vraye ou fuppofée, ou qui pour éviter les pourfuites de leurs Créanciers, fe font engagés dans les Troupes \& dans les Conceffions. Les uns \& les autres ne regardant ce Pays, que comme un lieu d'exil, tout les y rebute: rien ne les intéreffe au progrès d'une Colonie, dont ils ne font membres, que malgré eux, \& ils s'embarraffent fort peu des avantages, qu'elle peut procurer à l'Etat : la plûpart même ne font pas capables de les. connoître.

Les troifiémes font ceux, qui n'ayant vû que de la nifere dans un pays, pour lequel on a fait d'exceffives dépenfes, lui attribuent fans réflexion, ce qu'il faut uniquement rejetter fur lincapacité, ou fur la négligence de ceux, qu'on avoit chargés de l'établir. Vous n'ignorez pas non plus les. raifons, qu'on avoit euës de publier que la Louyfiane poffedoit dans fon fein de grands tréfors, \& qu'elle nous approchoit des fameufes Mines de Sainte Barbe, \&x d'autres plus. riches encore, dont on fe flattoit de chaffer aifément les Porfeffeurs : \& parce que ces contes ridicules avoient trouvé créance dans l'efprit des Sots, au lieu de s'imputer à eux-mêmes l'erreur, où les avoit engagés leur folle crédulité, ils. ont déchargé leur mauvaife humeur fur ce Pays, où ils n'ons rien trouvé de ce qu'on leur avoit promis.

Je fuis, \&zc.

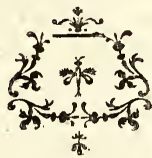




\section{TRENTE-TR O ISIEME LETTRE.}

Defcription du Biloxi. De la Cafine, ou Apalachine. De la Cire de Myrthe, de la Maubile, des Tchactas, de la Baye $S$. Bernard. Voyage du Biloxi à la Nouvelle Orleans par le Lac de Pontchartrain.

A bord de l'Adour, ce cinquiéme Avril 1722.

\section{WADAME,}

1722 .

Février.

Arrivée au Biloxi.

Defcription de la côte \& de la rade.

Le vint-fix , après avoir fermé ma Lettre, je m'embarquai, \& nous appareillâmes, mais après avoir couru une bordée au Sud, le vent redevenu contraire nous força de retourner à notre moüillage, \& nous y reftâmes encore les deux jours fuivans. Le vint-neuf, nous levâmes l'ancre de bon matin, mais le Vent étoit fi foible, \& la Mer fi groffe, qu'en vintquatre heures nous ne fìmes que quatorze lieuës, c'étoit la moitié du chemin, que nous avions à faire. Le trente nous n'eûmes ni le Vent plus favorable, ni la Mer plus tranquille jufques vers les quatre heures du foir, qu'une pluye déchargea le tems, qui étoit fort embrumé, \& calma la Mer : mais au bout d'une heure ou deux la brume recommença, \& devint fi épaiffe, que ne voyant pas à nous conduire ; nous prîmes le parti de moüiller l'ancre. Le lendemain la brume ne fe diffipant point, nous nous mîmes dans la Chaloupe, M. de Pauger \& moi, pour gagner la rade de l'Ifle aux Vaiffeaux : nous y vifitâmes quelques Navires de France, \& nous nous rendìmes vers les cinq heures du foir au Biloxi.

Toute cette Côte eft extrêmement platte ; les Vaiffeaux Marchands n'en fçauroient approcher plus près, que de quatre lieuës, \& les plus petits Brigantins de deux. Il faut même que ceux-ci s'éloignent, quand le vent vient du Nord, ou du Nord-Oueft, ou bien ils demeurent entierement à fec, comme il arriva la nuit même après que je fus débarqué. La rade eft tout le long de l'Ille aux Vaiffeaux, qui s'étend une petite 
D'UN VOYAGE DE L'AMER. LET. XXXIII. 449 petite lieuë de l'Eft à l'Oueft, mais qui a très-peu de largeur. A l'Eft de cette Inle eft l'Ifle Dauphine, autrefois l'Ifle Maffacre, où il y avoit un Port affez commode, qu'un coup de vent ferma en deux heures, il y a un peu plus d'un an, en comblant de fable fon entrée. A l'Oueft de l'Ifle aux Vaiffeaux font tout de fuite l'Ifle des Chats, ou de Bienville, l'Ifle à Corne, \& les Ifes de la Chandeleur.

Ce qu'on åppelle le Biloxi eft la Côte de la Terre-Ferme, qui eft au Nord de la rade. Ce nom eft celui d'une Nation Sauvage, qui étoir là autrefois, \& qui s'eft retirée vers le Nord-Oueft, fur les bords d'une petite Riviere, appellée la Riviere des Perles, parce qu'on y a pêché d'affez méchantes Perles. On ne pouvoit choifir un plus mauvais endroit, pour y établir le Quartier général de la Colonie; il ne peut, ni recevoir aucun fecours des Vaiffeaux, ni leur en donner, pour les raifons, que j'ai dites. D'ailleurs, la rade a deux granḑs défauts, l'ancrage n'y eft pas bon, \& elle eft pleine de vers, qui perdent tous les Navires : la feule utilité, qu'on en peut tirer eft de s'en fervir à mettre à couvert les Vaiffeaux. d'un coup de vent, lorfqu'ils viendront pour reconnoître l'embouchure du Miciffipi, laquelle n'ayant que des terres baffes, il feroit dangereux d'en approcher dans un mauvais tems, fans l'avoir reconnuë.

Le Biloxi ne vaut pas mieux pour la Terre, que pour la De la Caffine. Mer. Ce n'eft que du fable, \& il n'y croît guere que des Pins \& des Cédres. La CafJine, autrement nommée Apalachine, $\mathrm{y}$ pouffe auffi par tout en abondance : c'eft un trèspetit arbriffeau, dont la feüille, infufée comme celle du Thé, paffe pour un bon diffolvant, \& un excellent fudorifique : mais fa principale qualité eft d'être diuretique. Les Efpagnols en font un grand ufage dans toute la Floride; c'eft même leur boiffon ordinaire. Elle commençoit à faire quelque fortune à Paris, lorfque j'en fuis parti : mais nous étions dans un tems de mauvais augure pour les fortunes; elles paffoient. auffi rapidement, qu'elles étoient promptes. Je fçai pourtant que bien des perfonnes, qui font ufage de l'Apalachine, s'enl loüent beaucoup.

Il y en a de deux efpéces, qui ne différent, quie par la grandeur des feüilles. Celles de la grande efpéce ont plus d'un pouce de longueur, les autres font prefque de moitié plus petites. Tome III. $\quad$ L11 


\section{$45^{\circ}$ JOURNAL HISTORIQUE}

Leur figure \& leur fubftance font à peu près comme celles 1722. des feiilles de Bouys, excepté qu'elles font plus arrondies Février. par les extrêmités, \& d'un verd plus clair. Le nom d'Apalachine, que nous avons donné à cet Arbriffeau, vient des Apalaches, Peuples de la Floride; de qui les Efpagnols en ont appris l'ufage, "\& voici la maniere de la préparer parmi les uns \& les autres.

On met fur le feu dans un pot de terre une certaine quantité de feuilles, \& on les y fait griller.jufquà ce que la couleur en foit devenuë rouffâtre ; on y verfe enfuite lentement de l'eau, jufqu'à ce que le pot foit plein. Cette eau prend la couleur des feülles, $\$$ mouffe, quand elle eft verfée, comme de la bierre. On la prend la plus chaude, qu'il eft poffible, $\&$ les Sauvages fe pafferoient plutôt de manger, que d'en boire le foir \& le matin ; ils croiroient tomber malades, s'ils s'en abftenoient, \& on prétend que les Efpagnols de la Floride font dans le même principe.

Une demie heure après, qu'on l'a prifé, on commence à la rendre, \& cela dure une heure. Il eft difficile de concevoir comment une boiffon, qui ne fait prefque que couler, peutêtre auffi nourriffante, qu'on affîre qu'elle l'eft: on comprend. mieux qu'èlle nettoye tout ce qui embaraffe le paffage des urines, \& caufe les maux de reins. Quand"les Sauvages veulent fe purger, ils y mêlent de l'eau de Mer, \& cela produit de grandes évacuations; mais fi la dofe d'eau de $M$ er étoit trop forte, ils en pourroient mourir, \& cela n'eft pas fans exemple. Je l'ai vî̀ prendre en France fans tant de façon, \& comme on fait le Thé, mais en doublant la dofe, \& en la faifant boüillir près d'un demi quart d'heure, $\&$ je ne doute pas qu'alors elle n'ait beaucoup effet.

De la Cire On trouve encore ici une efpéce de Myrthe à larges feuilđc Myrthe. les, que je fçavois déja être fort commune fur les Côtes de l'Acadie, \& des Colonies Angloifes de ce Continent. Quelques-uns lui donnent le nom de Laurier, mais ils fe trompent, fa feüille a lodeur du Myrthe, \& les Anglois ne l'appellent point autrement que le Myrthe à chandelle. Cet Arbriffeau porte une petite graine, qui dans le Printems eft remplie d'une matiere balf́amique, laquelle étant jettée dans l'eau boüillante, y furnage, \& devient une cire verte, moins gluante, \& $x$ plus friable, que celle des Abeilles, mais aufir 
D'UN VOYAGE DE L'AMER. LET. XXXIII. 451

bonne à brûler. Le feul inconvénient, qu'on y a remarqué, eft qu'elle fe caffe aifément, mais on la pourroit mêler avec une autre cire extrêmement liquide, qu'on recüeille dans les 1722 . Février. Bois des Inles de l'Amérique, ce qui n'eft pourtant néceflaire, que fuppofé qu'on en voulût faire des Cierges. J'en ai vû des Bougies, qui donnoient une aufi belle lumiere, \& qui duroient autant que les nôtres. Nos Miffionnaires du Voifinage de l'Acadie y mêlent du fuif, ce qui les rend fujettes à coulèr, parce que le fuif ne s'allie pas bien avec cette cire. Le fieur AleXANDRE, qui eft ici au fervice de la Compagnie en qualité de Chirurgien \& de Botanifte, n'y met rien du tout, \& fes bougies n'ont point ce défaut, la lumiere en eft douce $\&$ fort claire, \& la fumée, qui en fort, quand on les a fouflées, a une odeur de Myrthe fort agréable. Il efpere même venir à bout de la blanchir, \& il m'en a montré une malle, qui étoit plus qu'à demie blanche $(a)$. Il prétend que fi on lui donnoit cinq ou fix Efclaves de ceux, qui font les moins propres aux travaux ordinaires, pour cueillir la graine dans la faifon, il en feroit affez de cire pour en charger un Vaiffeau tous les ans.

A treize ou quatorze lieuës du Biloxi, en tirant à l'Eft, on De la Maur trouve la Riviere de la Maubile, qui coule du Nord au Sud, \&r bile. dont l'embouchure eft vis-à-vis de l'Ifle Dauphine. Elle prend fa-fource dans le Pays des Chicachas, \& fon cours eft d'environ cent trente lieuës. Son lit eft très-étroit, \& elle ferpente beaucoup, ce qui n'empêche pas qu'elle ne foit fort rapide : mais il n'y a guere que les petites Pirogues, qui puiffent la remonter, quand les eaux font baffes. Nous avons fur cette Riviere un Fort, qui a été lontems le Pofte principal de la Colonie; les terres n'y font pourtant pas bonnes, mais on y étoit à portée de trafiquer avec les Efpagnols, \& c'étoit alors uniquement ce qu'on cherchoit.

On pretend qu'à quelques lieuës ąu-delà du Fort, on a découvert une Carriere; fi cette découverte eft réelle, \& que la Carriere foit abondante, elle pourra bien empêcher l'abandonnement entier de ce Pofte, que plufieurs Habitans commencent à quitter, ne pouvant fe réfoudre à cultiver plus lontems un terrein, qui ne répond pas aux peines, quils pren-

(a) On y a renoncé, dit-on, parce que cette Cire en blanchiffant s'altere confiderablement. 
$45^{2}$ JOUR N A H IS TOR I Q U E

1722 . nent pour le faire valoir. Je ne crois pourtant pas qu'on fe détermine aifément à évacuer le Fort de la Maubile, quand il Février. ne ferviroit qu'à entretenir dans notre Alliance les Tchactas, Peuple nombreux, qui nous font une barriere néceffaire contre les Chicachas, \& contre les Sauvages voifins de la Caroline. Garcilaffo de la Vega, dans fon Hiftoire de la Floride, parle d'une Bourgade appellée Mauvilla, laquelle a fans doute donné fon nom à la Riviere, $8 x$ à la Nation, qui étoit établie fur fes bords. Ces Mauviliens étoient alors très-puiffans; à peine en refte-t $t$ il aujourd'hui quelques veftiges.

De la Baye On eft préfentement occupé à chercher à l'Oueft du Mis. Bernard. ciffipi un endroit propre à faire un Etabliffement, qui nous approche du Mexique, $\&$ on croit l'avoir trouvé à cent lieuës de l'embouchure du Fleuve, dans une Baye, qui porte tantôt le nom de Sainte Magdeleine, tantôt celui de S. Louiis, \& plus communément celui de S. Bernard. Elle reçoit plufieurs Rivieres, dont quelques-unes font affez grandes, \& c'eft-là, que M. de la Sale prit terre, quand il eut manqué l'embouchure du Miciffipi. On y a envoyé depuis peu un Brigantin pour la reconnoître, mais on y a trouvé des Sauvages, qui paroiffent peu difpofés à nous recevoir, \& qu'on n'a pas traites de maniere à les gagner. J'entends mêême dire quo les Efpagnols viennent de nous prévenir.

Il y a dans le vrai quelque chofe de plus preffé, \& de meilleur à faire, que cette Entreprife. Je fçai que le Commerce eft l'ame des Colonies, qu'elles ne font même utiles à un Royaume tel que le nôtre, que par cet endroit, $\&$. pour empêcher nos Voifins de fe rendre trop puiffants; mais fi on ne commence pas la culture des terres, le Commerce, après avoir enrichi quelques Particuliers , tombera bientôr, \& la Colonie ne s'établira point. Le voifinage des Efpagnols peut avoir fon utilité, mais laiffons-les s'approcher de nous tant qu'ils voudront, nous ne fommes point en état, \& nous n'avons aucun befoin de nous étendre davantage. Ils font affez pacifiques en ce Pays-ci, \& ils n'y feront jamais affez forts pour nous inquieter; il n'eft pas même de leur intérêt de nous chaffer de ce Pays; \& sils ne comprennent pas encore, ils comprendront fans doute bien-tôt qu'ils ne fçauroient avoir de meilleur barriere, que la Louyfiane, contre Jes Anglois. 
D'UN VOYAGE DE L'AMERIQ. LET. XXXIII. 453
Les chaleurs étoient déja bien incommodes au Biloxi dès
la mi-Mars, \& je conçois que quand le Soleil a une fois em-
brafé le fable fur lequel on y marche, le chaud doit y être clima
exceflif. On dit en effet que fans la brife, qui s'éleve aftez ré- Biloxi.

D'UN VOYAGE DE L'AMERIQ. LET. XXXIII. 453
Les chaleurs étoient déja bien incommodes au Biloxi dès
la mi-Mars, \& je conçois que quand le Soleil a une fois em-
brafé le fable fur lequel on y marche, le chaud doit y être clima
exceflif. On dit en effet que fans la brife, qui s'éleve aftez ré- Biloxi.

D'UN VOYAGE DE L'AMERIQ. LET. XXXIII. 453
Les chaleurs étoient déja bien incommodes au Biloxi dès
la mi-Mars, \& je conçois que quand le Soleil a une fois em-
brafé le fable fur lequel on y marche, le chaud doit y être clima
exceflif. On dit en effet que fans la brife, qui s'éleve aftez ré- Biloxi.

D'UN VOYAGE DE L'AMERIQ. LET. XXXIII. 453
Les chaleurs étoient déja bien incommodes au Biloxi dès
la mi-Mars, \& je conçois que quand le Soleil a une fois em-
brafé le fable fur lequel on y marche, le chaud doit y être clima
exceflif. On dit en effet que fans la brife, qui s'éleve aftez ré- Biloxi. gulierement tous les jours, entre neuf $\&$ dix heures du matin, \& ne tombe quavec le Soleil, il ne feroit pas poffible d'y vivre. L'embouchure du Miciffipi eft par les vint-neuf degrez de latitude, \& la Côte du Biloxi par les trente : nous $\mathrm{y}$ eûmes dans le mois de Février quelques froids affez picquants, lorfque le vent foufloit du Nord \& du Nord-Oueft, mais ils ne duroient pas ; ils étoient même quelquefois fuivis de chaleurs affez vives, de tonnerres \& d'orages, de forte que le matin nous étions en $\mathrm{H}_{y}$ ver , \& l'après-midi en Eté. Avec quelques petits intervales de Printems \& d'Automne, entre deux : la brife vient ordinairement de l'Eft; quand elle vient du Sud, ce n'eft qu'un vent refléchi, lequel rafraîchit beaucoup moins, mais c'eft toujours du vent, \& quand il manque tout-à-fait, on ne refpire point.

Le vint-quatre de Mars je partis du Biloxi, où j’avois été arrêté par une jauniffe, qui me dura plus d'un mois, $\&$ je repris la route de la Nouvelle Orleans, où je devois m'embarquer fur une Flûte de la Compagnie, nommée l' Adour. Je fis ce voyage dans une Pirogue, \& je n'en avois point encore fait de plus défagréable. A cinq lieuës du Biloxi le vent d'Oueft, qui en trois heures m'avoit amené jufques-là , fit place à un vent de Sud fi violent, que je fus contraint de m'arrêter. J'avois eu à peine le tems de dreffer ma Tente, qu’une pluye épouvantable, accompagnée de tonnerre, noous. inoinda.

Deux petits Bâtimens, qui étoient partis en même-terns que moi, voulurent profiter du vent, qui leur fit faire bien du chemin en peu d'heures, \& je regrettois fort de n'en pouvoir pas faire autant, mais jappris bien-tôt que leur fort avoit été plus digne de pitié que d'envie; le premier fut dans un continuel danger du nautrage, \& fes Pafflagers arriverent à la Nouvelle Orleans plus morts que vifs. Le fecond échoua à moitié chemin, \& cinq Perfonnes fe noyerent dans une Prairie, dortt l'orage avoit fait un étang. Le vent dura toute la nuit avec la même violence, $\&$ la pluye ne ceffa que lé lendemain à midi. Elle recommença le foir, \& continua jufqu’au jour avec le tonnerre,

Départ dus Biloxi. .

.

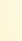

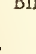

\author{
列
}

\title{
.
} . 


\section{J O U R N A L H IS T O R I Q U E}

1722 .

Mars.

Obfervation fur cette Côte.

Quand on range cette Côte à la vûë, elle paroît très-agréable, mais de plus près ce n'eft pas la neême chofe. C'eft toujours un fond de fable, comme au Biloxi, \& on n'y trouve que de méchans Bois. J'y ai remarqué une efpéce d'ozeille, qui a le même goût que la nôtre, mais dont les feüilles font plus étroites, \& qui caufe, dit-on, la dyfenterie. Il y a auffi dans ces quartiers-là une efpéce de Frefne, qu'on appelle Bois d'amourette, \& dont l'écorce, qui eft pleine de picquants, paffe pour être un reméde fouverain, \& très-prompt contre le mal de dents.

Le vint-fix il plut tout le jour, \& quoique la Mer fût calme, nous fìmes peu de chemin. Nous avançâmes un peu plus le vint-fept, mais la nuit fuivante nous nous égarâmes autour de l'Ille aux Perles. Le lendemain nous allâmes camper à l'entrée du Lac Pontchartrain, ayant laiffé peu de tems auparavant fur la droite la Riviere aux Perles, qui a trois embouchures. La féparation de ces trois branches fe fait à quatre lieuës de la Mer, \& c'eft un peu au-deffus que les Biloxis fe font placés.

Du Lac de Pontchartrain.

Après midi nous traverfâmes le Lac de Pontchartrain, cette traverfe eft de fept à huit lieuës, \& à minuit nous entrâmes dans la Baye $S$. Jean. Ceux, qui les premiers naviguerent fur le Lac, le trouverent, dit-on, tellement rempli de Caïmans, qu'ils ne pouvoient prefque pas donner un coup d'aviron, fans en toucher quelqu'un. Ils y font préfentement très-rares, \& nous en vîmes feulement quelques traces à notre campement, car ces Animaux font leurs œufs à terre. Après m'être un peu repofé à la fortie du Lac, je pourfuivis mon chemin par Terre, \& j’arrivai avant le jour à la Nouvelle Orleans.

Difficulté de

Je n'y trouvai plus l'Adour, mais elle n'étoit pas loin, \& naviguer fur le Fleuve en defcendant.

I 722 . Avril. je la joignis le lendemain premier Avril. L'inondation étoit dans fon plein , par conféquent le Fleuve beaucoup plus rapide, que je ne l'avois trouvé deux mois auparavant. D'ailleurs un Navire, furtout une Flûte, ne fe manie pas auffi aifément qu'un Traverfier, \& comme notre équipage n'étoit pas accoûtumé à cette navigation, nous eûmes bien de la peine à fortir du Fleuve. Le Navire entraîné tantôt fur un bord, \& tantôt fur un autre, engageoit fouvent fes vergues $\&$ fes manœuvres dans les Arbres, \& il fallut plus d'une 
D'UN VOYAGE DE L'A MER. LET. XXXIII. 455 fois couper des manœuvres pour fe tirer de cet embarras.

Ce fut bien pis encore, quand nous eûmes gagné les paffes, car les courants nous entraînoient toujours dans-la premiere avec une violence extrême. Nous nous enfournâmes même dans une des plus petites, \& je ne conçois pas même encore comment nous pûmes nous en tirer. Nous en fûmes pourtant quittes pour un ancre, que nous y laiffâmes; on en avoit déja perdu un deux jours auparavant, de forte qu'il ne nous en reftoit plus que deux. Un fi fâcheux début ne laiffa point de nous donner à penfer, mais la jeuneffe \& le peu d'habileté de ceux, à qui on nous avoit confiés, nous inquietoit encore davantage.

L'Adour eft un très-joli Bâtiment, du port de trois cent Tonneaux ; cette Flûte étoit partie de France avec un bon Equipage, fous la conduite d'un Capitaine, qui fçavoit fon Métier, \& d'un Lieutenant, dont on difoit auff beaucoup de bien. Celui-ci étoit refté malade à S. Domingue : le Capitaine, peu après fon arrivée au Biloxi, fe brouillla avec un des Direeteurs de la Compagnie, qui le démonta. Pour rếmplacer ces deux premiers Officiers, on a jetté les yeux fur un jeune Maloin, qui eft venu, il y a trois ans, à la Louyfrane en qualité de Pilotin, ou apprentif Pilote, \& qui depuis ce tems là eft parvenu à commander un Traverfier dans. la rade du Biloxi, pour aller tantốt à la Maubile, \& tantôt à la Nouvelle Orleans, y porter des provifions. Il paroît avoir tout ce qu'il faut pour devenir habile Homme; il aime fon métier, \& il s'y applique, mais nous nous paferions bien de voir fon apprentiffage, furtout dans une navigation, qui a de grandes difficultés.

Il a pour fecond l'Officier, qui eft venu de France en qualité d'Enfeigne, c'eft encore un jeune homme, fort propre à être Subalterne fous des Chefs expérimentés, qui ne lui laif-. feroient que le foin d'exécuter leurs ordres. Il feroit difficile de trouver un Matelot plus brave contre la Tempête, qu'il a dès l'enfance affrontée dans les pénibles Pêches de TerreNeuve, \& deux ou trois naufrages, dont il s'eft tiré heureufement, lui ont infpiré une conirance, dont je ferai fort furpris, fi à la fin il n'eft pas mauvais marchand.

Notre premier Pilote paroît un peu plus mûr, que ces deux Officiers, \& l'on fait furtout bien valoir la connoiffance, qu'il

1722 . Avril.

Le Navíre mal commasdé.

\author{
(1)
}




\section{${ }_{456}$ J O U R N A L H IS T O R I Q U E}

I 7 22. à du Canal de Bahama, qu'il a déja paffé une fois. C'eft ceAvril. pendant bien peu pour connoître ce paffage, le plus dangereux, qui foit dans les Mers de l'Amerique, où l'on compte les naufrages par milliers. D'ailleurs je crains fort qu'un petit air fuffifant, que je lui trouve, ne produife quelque effet funefte. Il a deux Subalternes, qui font de bons Enfans; nous avons cinquante Matelots Bretons, un peu mutins, mais forts \& vigoureux, prefque tous ont été à la Pêche de la Moruë, $\&$ c'eft une bonne école : leurs Officiers-Mariniers me paroiffent gens de tête \& d'exécution.

Cependant, malgré tous les retardemens, dont je vous ai parlé, nous moüillâmes le deuxiéme au foir en de-çà de la Barre; nous la pafiàmes le trois, \& faute de vent, nous ne pûmes aller plus loin. Hier, nous fûmes encore arrêtés tout le jour, \& cette nuit nous avons effuyé une tempête de vent du Sud, qui nous a fait remercier le Seigneur de n'avoir pas été en Mer fi près de la Côte. J'efpere, Madame, vous écrire dans peu de $S$. Domingue, où notre Flûte va prendre une Cârgaifon de Sucre, qui y eft toute prête. Je profite de l'occafion d'un Traverfier, qui remonte à la nouvelle Orleans, pour vous envoyer cette Lettre par un Vaiffeau, qui doit aller en France en droiture.

Je fuis, \&c.

TRENTE-QUATRIÉME LETTRE.

Voyage jufqu'au Canal de Bahama. Naufrage de l'Adour; retour à la Louyfiane le long de la Côte de la Floride: Defcription de cette Côte.

Au Biloxi, le cinquiéme de Juin 1722.

NA D A ME,

Je vous avois promis de vous écrire inceffamment de Saint Domingue. M'en voici après deux mois auffi loin, que j’en étois alors; le récit du trifte évenement, qui m’a ramené dans 
cette Colonie, \& qui n’a que trop juftifié mes preffentimens, avec quelques obfervations fur un Pays, que je n'avois pas compté de parcourir, vont faire la matiere de cette Lettre. 1722 . Avril. Je ne fuis pas au refte autant à plaindre, que vous croyez. Je fuis bien délaffé de mes fatigues, $j$ 'ai couru de grands dangers, mais je m’en fuis heureufement tiré ; le mal paffé n’eft que fonge, \& fouvent un fonge agréable.

Il y avoit une demie heure au plus, que javois fermé ma L'Adour mact Lettre, lorfque le vent s'étant rangé au Nord-Oueft, nous à la voile. appareillâmes. J'aurois crû que le refpect dû au faint Jour de Pâques auroit engagé le Capitaine à differer au lendemain, d'autant plus quili etoit midi paffé ; mais il avoit peu de vivres, \& un jour de retardement peut avoir des fuites fàcheufes. Notre précipitation en a eû de plus funeftes encore. Nous perdîmes bientôt la Terre de vuë, $\& \mathrm{x}$ au bout d'une heure, après avoir eu le plaifir de voir les eaux de la Mer \& celles du Fleuve fe mêler fans fe confondre, nous n'apperçûmes plus aucune différence, \& nous ne trouvâmes plus que de l'eau falée.

On me dira, peut-être, que nous avions quitté le droit Canal, \& je conviens que cela étoit peut-être, mais ce combat, que nous avions obfervé fi près de l'embouchure, ne marque pas un Fleuve victorieux, qui s'ouvre un libre paffage, \& fait pendant vint lieuës la loy à l'Ocean. D'ailleurs, fi ce fait étoit vrai, du moins dans le tems de l'inondation, où nous étions alors, comment auroit-on eu tant de peine à trouver l'embouchure du Fleuve? La feule différence de la couleur des eaux l'auroit indiquée aux moins attentifs?

A propos de cette couleur ; jai dit que le Miciffipi, après fa jonction avec le Miffoury, prenoit la couleur des eaux de cette Riviere, qui font blanches: mais croiriez-vous bien, Madame, que de toutes les eaux, qu'on peut embarquer pour la provifion des Vaiffeaux, il n'y en a point, qui fe confervent fil lontems que celles-ci fans fe corrompre? D'ailleurs, elles font excellentes à boire, quand on les a laiffé repofer dans des Jarres, au fond defquelles on trouve une efpéce de tartre blanc, qui, felon toutes les apparences, fert également à leur donner la couleur, qu'elles ont, à les purifier , \& à les conferver.

Le douziéme à midi, après avoir effuyé pendant plufieurs jours des chaleurs exceffives, \& plus intolérables encore la de la CorctsoperTome III.

$\mathrm{Mmm}$

Obfervation fur l'cau du Miciflipi. 


\section{$45^{8}$ J O U R N A L H IS T O R I Q U E}

1722 . nuit, que le jour, nous découvrîmes le $C_{a p}$ de $S e d$, qui eft Avril. fur la Côte Septentrionale de l'Ifle de Cubą, \& fort élevé. tentrionale de Au Soleil couchant nous étions par fon travers, nous mîmes Cuba. le Cap à l'Eft, \& nous rangeâmes la Côte à la vûë; le lendemain au point du jour nous étions vis-à-vis de la Havane ; cette Ville eft à dix-huit lieuës du Cap de Sed, \& à moitié chemin on découvre une Montagne affez haute, dont le fommet eft une efpéce de platon : on l'appelle la Table à Marianne.

Deux lieuës plus loin que la Havanne, il y a fur la Côte un petit Fort, qui porte le nom de la Hougue, \& de-là on commence à découvrir le Pain de Matance. C'eft une Montagne, dont le fommet a la forme d'un four, ou fil'on veut, d'un pain. Elle fert à reconnoître la Baye de Matance, qui eft éloignée de quatorze lieuës de la Havane. Le chaud augmentoit toujours, auffi étions-nous fur les confins de la Zone Torride : avec cela nous n'avions prefque point de vent, \& nous n'avancions qu'à la faveur du courant, qui porte à l'Eft.

Mauvaife

Le quatorziéme, vers les fix heures du foir, on apperçut manceuvre. du haut du grand Mât la Terre de la Floride. Il n'eft point de Navigateur prudent, qui à cette vûë, s'il n'a pas du moins fix à fept heures de jour à courir, ne revire de bord, \& ne fe foûtienne au large jufquau lendemain, n'y ayant point de parage au monde, où il foit plus important de voir clair, à caufe de la diverfité des courants, qu'il ne faut jamais fe flatter de bien connoître. Nous avions l'exemple affez récent des Galions d'Efpagne, qui y périrent il y a quelques années, pour n'avoir pas pris la précaution, que je viens de dire. Le Chevalier D'Her E, Capitaine de Vaiffeau, qui les accompagnoit, fit tout fon poffible pour engager le Général de la Flotte à attendre le jour pour entrer dans le Canal : il n'y réuffit pas, \& ne jugea point à propos de fe jetter avec lui dans le précipice.

Notre Capitaine, à qui on avoit donné fur cela de bons. avis, étoit bien réfolu d'en profiter : mais trop de docilité fis fur lui le même effet, qu'avoit produit la préfomption du Général Efpagnol. Son premier Pilote, qui fe croyoit le plus habile Homme du monde. \& fon Lieutenant, qui ne fçavoit douter de rien, furent d'avis de continuer la route, \& il n'eut pas la force de leur réfifter. Il propofa de faire au moins le 
D'UN VOYAGE DE L'AMERIQ. LET. XXXIV. 459

Nord-Eft, \& la fuite nous a montré que, fi fon fentiment avoit prévalu, nous aurions échapé au naufrage. Mais il ne put obtenir que le Nord-Nord-Eft, le Pilote affurrant que les courants portoient avec impétuofité à l'Eft. Il difoit vrai, mais ce n'eft que quand on eft près des terres de ce côté-là, comme ils portent à l'Oueft de l'autre côté, où nous étions alors.

A fept heures la terre paroiffoit encore affez éloignée, \& Naufrage de on ne la pouvoit même découvrir que de la Hune; mais au bout d'une demie heure, le tems s'étant couvert, un Matelot remarqua à la faveur des éclairs que l'eau avoit changé de couleur. Il en avertit, mais fon avis fut reçû aveç rifée, on lui dit que c'étoit les éclairs, qui faifoient paroitre l'eau blanche. Il ne fe rebuta point, plufieurs de fes Camarades furent bientôt de fon fentiment : on voulut encore fe mocquer d'eux, mais ils crierent fi haut, \& ils étoient en fi grand nombre, que le Capitaine fit jetter la fonde.

On ne trouva que fix braffes d'eau; l'unique parti sûr, qu'il $\mathrm{y}$ avoit à prendre, étoit de moüiller dans le moment, mais il n'y avoit point d'ancre paré. On vouloit revirer de bord, \& peut-être qu'il en étoit encore tems, fi on eût fait diligence ; mais on s'amufa à fonder de nouveau, \& on ne trouva plus que cing braffes. On jetta tout de fuite une troifiéme fois la fonde, 8 il n'y en avoit plus que trois. Imaginez-vous, Madame, des Enfans, qui fe voyant entrainés dans un précipice, font uniquement attentifs à en connoître la profondeur, fans prendre aucune mefure pour l'éviter.

Alors il s'éleva un bruit confus, chacun crioit à pleine tête, les Officiers ne pouvoient $f e$ faire entendre, \& deux ou trois minutes après le Navire échoüa, il furvint dans l'inftant une efpéce d'orage, \& la pluye, qui fuivit de près, fit tomber le vent : mais il fe releva bientôt, fe rangea au Sud, \& devint plus fort qu'auparavant. Le Navire commença auffi-tôt à talonner fur fon gouvernail ; on craignit avec raifon que le grand Mât, qui à chaque fecouffe fautoit affez haut, ne fit ouvrir le Navire, \& fon procès lui fut fait dans les formes ordinaires : il fut condamné $\&$ abbatu fur le champ, après que le Capitaine lui eut donné le premier coup de hache, felon la régle.

Le Lieutenant s'embarqua enfuite dans la Chaloupe, pour tâcher de découvrir en quel lieu nous étions, \& en quel état $\mathrm{Mmm}$ ij 


\section{${ }_{4}^{60} \mathrm{~J} O \mathrm{O} R \mathrm{~N}$ A L H I S T O R I Q U E}

1722 fe trouvoit le Vaiffeau. Il remarqua que fur le devant nous Avril. n'avions que quatre pieds d'eau, \& que le banc, fur lequel nous étions échoués, étoit fi petit, qu'il n'y avoit quafi que la place du Navire, \& que tout autour il auroit été à flot. Mais quand nous l'aurions évité, nous ne pouvions manquer de donner fur un autre, car il en étoit environné, \& à coup sûr, nous n'en aurions pas rencontré un fi commode.

Le vent foufloit toujours avec violence; notre Flûte continuoit à talonner, \& à chaque fecouffe nous nous attendions qu'elle alloit s'ouvrir. Tous les effets de la frayeur étoient peints fur les vifages, \& après le premier tumulte formé par les cris des Matelots, qui manœuvroient, \& par les gémiffemens des Paffagers, qui fe croyoient au moment de périr, un morne $\&$ profond filence fe répandit fur tout le Bâtiment. Nous fçûmes depuis que quelques - uns prenoient fecrettement leurs mefures pour n'être point furpris, au cas que le Vaiffeau fe brisât : non-feulement la Chalouppe, mais encore le Canot étoient à l'eau tout parés, \& des Matelots affidés, avertis fous main de fe tenir prêts au premier fignal. On m’affûra dans la fuite, qu'on avoit bien compté de ne me pas laiffer dans le danger.

Ce qui eft certain; c'eft que je paffai la nuit fans fermer l'œil, \& dans la fituation d'un homme, qui ne s'attend point à revoir le jour. Il parut néanmoins, \& il nous découvrit la terre à plus de deux grandes lieuës de nous. Cen'étoit point celle, que nous avions découverte d'abord, \& que nous appercevions encore dans un grand éloignement, mais une terre baffe, \& qui nous fembloit très-peu propre à être habitée. Cette vûë ne laifla pourtant pas de nous faire plaifir , \& de nous raffûrer un peu.

Mefures, qu on prend pour fe fauver.

On examina enfuite s'il y avoit quelque apparence de pouvoir remettre l'Adour à flot, \& parce qu'il étoit bon d'avoir plufieurs cordes à fon arc, on fongea en même-tems aux moyens de fe tirer d'un auffi mauvais endroit, fuppofé qu'il fût impoffible de relever le Navire. On fe fouvint alors qu'on avoit embarqué un Batteau plat en botte, dans le deffein de s'en fervir à S. Domingue, pour charger les Sucres, qu'on y devoit prendre. C'étoit une précaution fort fage du Capitaine, qui avoit été averti qu'en ce Pays-là le chargement retient fouvent les Navires en rade beaucoup plus lontems, qu'il ne 
D'UN V OYA G E DE L'AMER. LET. XXXIV. $46 \mathrm{I}$ convient aux intérêts des Armateurs, \& à la fanté des Equipages; mais la Providence avoit eu fans doute une autre vûe , en lui infpirant cette penfée. Ce Batteau fut notre

I 722 . Avril. falut.

Je ne fçai pas bien ce qui fe paffa le même jour entre les Officiers \& le Pilote, mais on ne parla plus de relever le Bâtiment. Plufieurs ont prétendu qu'on auroit fait pour y réuffir des efforts inutiles; mais le Capitaine s'eft plaint plus d'une fois à moi de ce qu'on n'avoit pas voulu lui laiffer faire cette tentative, comme îl le fouhaittoit. On réfolut donc dès le même jour de tranfporter tout le monde à terre, \& l'on travailla tout le matin à conftruire un Radeau, pour n'être par obligé de faire plufieurs voyages.

On ne jugea pourtant pas à propos d'abandonner encore le Navire, \& il n'y eut même que les Paffagers, qui furent embarqués dans la Chaloupe \& fur le Radeau. A une portée de Canon du Bâtiment nous trouvâmes la Mer fort haute, \& le Bifcuit, que l'on portoit à terre, fut moüillé ; une petite Pirogue, qui fuivoit la Chaloupe, eut bien de la peine à fe foûtenir, \& le Radeau, qui portoit vint-deux hommes, fut emporté fi loin par le courant, qu'on le crut perdu.

La Chaloupe, où j'étois, faifoit diligence pour arriver, afin d'aller enfuite au fecours des autres, mais comme nous étions prêts à débarquer, nous apperçûmes une affez grande Sauvages fur les Intes des Martyrs. troupe de Sauvages armés d'Arcs \& de Fléches, qui s'approchoient du rivage. Cette vîë nous fit faire réflexion, que nous nous étions embarqués fans armes, \& nous nous arrêtâmes quelque-tems fans ofer avancer. Nous crûmes même, tout bien confideré, qu'il étoit contre la prudence d'aller plus loin. Les Sauvages s'aperçurent de notre embarras , \& en comprirent aifément la caufe. Ils s'approcherent, \& nous crierent en Efpagnols qu'ils étoient amis. Comme ils virent que cela ne nous raffûroit pas, ils quitterent leurs armes, \& vinrent nous trouver ayant de l'eau jufqu'à la ceinture.

Nous en fûmes bientôt environnés, \& il eft certain qu'embarraffés, comme nous étions de hardes dans une Chaloupe, pafa entreux où nous ne pouvions nous remuer, il leur étoit fort aifé de fe défaire de nous. Ils nous demanderent d'abord fi nous étions Anglois : nous leur répondìmes, que non, mais Alliés $\&$ bons Amis des Efpagnols : ils en témoignerent beaucoup 


\section{J O UR N A L H IS TOR I Q U E}

1722 . de joye, nous inviterent à débarquer dans leur Ifle, \& nous affûrérent que nous $\mathrm{y}$ ferions aufh fûrement que dans notre Avril. Bord. La défiance en certaines occafions ne fert qu'à marquer de la foibleffe, \& fait naître des foupçons dangereux. Nous crûmes donc devoir nous rendre à l'invitation de ces Barbares, \& nous les fuivimes dans leur Ifle, que nous reconnûmes être une des Martyrs.

Ce qu'il y eut de plaifant, eft que ce qui acheva de nous déterminer à prendre ce parti, fut que la Pirogue, où il n'y avoit que quatre ou cinq Hommes, nous joignit, tandis que nous parlementions avec les Sauvages : nous rifquions afiûrément beaucoup à nous livrer fans armes entre les mains de ces Floridiens, \& nous le reconnûmes bien dans la fuite : quatre ou cinq Hommes de plus n'étoient pas capables de leur faire changer de fentiment, fuppofé que ces Barbares euffent eû de mauvais deffeins contre nous ; \& je ne penfe point à la confiance, que nous infpira un renfort fi léger, que je ne me repréfente ces Perfonnes, qui n'oferoient marcher feuls dans les ténébres, \& que la préfence d'un Enfant raffûre d'abord, en occupant leur imagination, qui feule caufe toute leur frayeur.

Ies Paffa- Cependant nous ne fûmes pas plutôt débarqués dans l'Ifle, gers entrent en défiance de l'Equipage. qu’afiés peu raffûrés de la part des Sauvages, nous entrâmes encore en défiance contre nos Officiers. Le Capitaine de l'Adour nous avoit conduit jufques-là ; mais dès quil nous eut mis à terre, il prit congé de nous, difant qu'il étoit obligé de retourner à fon Bord, où il avoit encore bien des arrangemens à prendre, \& quil nous enverroit inceffamment tout ce qui pouvoit nous manquer, fur tout des armes. Il n'y avoit rien en cela que de raifonnable, $\&$ nous concevions bien que fa préfence étoit néceffaire fur fon Navire: mais nous fìmes réflexion qu'il n'en avoit fait fortir que les Paffagers, \& que tout l'Equipage alloit être réuni à bord, dès que cet Officier y feroit retourné.

Cela nous fit foupçonner que le Batteau, dont on nous avoit parlé, n'étoit qu'un leurre pour nous amufer, \& qu'on ne nous avoit conduit à terre, que comme des Perfonnes, dont on étoit embarraffé, afin de pouvoir profiter de la Chaloupe $\&$ du Canot pour paffer à la Havane, ou à S. Auguftin de la Floride. Ces foupçons fe fortifierent dans chacun de 
D'UN VOYAGE DE L'A MER. LeT. XXXIV. $4_{3}$ nous, quand nous vîmes que nous avions tous eu la même penfée, ce concert nous fit juger qu'ils n'étoient point fans fondement : fur quoi il fut réfolu entre nous que je retournerois au Navire avec le Capitaine, afin d'empêcher les réfolutions violentes, fi on étoit tenté d'en prendre quelqu'une.

Je déclarai donc au Capitaine que, puifque fon Aumônier vouloit demeurer dans l'Ifle, il ne convenoit point que j'y demeuraffe auffi : qu'il étoit plus à propos de nous partager, \& que j'étois réfolu de ne point découcher du Bord, tandis qu'il y refteroit quelqu'un. Il parut un peu furpris de mon difcours, mais il ne fit aucune réfiftance, \& nous partîmes. Je trouvai en arrivant au Vaiffeau, qu'on avoit éventé les voiles, pour voir, difoit-on, s'il y avoit moyen de le dégager : mais il $\mathrm{y}$ avoit bien d'autres manœuvres à faire pour cela, \& on ne jugea pas à propos de les employer.

Au bout d'une demie heure le vent fe jetta à l'Eft, \& devint très-fort, ce qui obligea de ferrer les voiles; mais cet orage fut le falut de ceux, qui étoient fur le Radeau, \& qui avoient été emportés bien loin à la dérive. Les lames les rechafferent vers nous, \& dès que nous les apperçûmes, le Capitaine leur envoya fa Chaloupe, qui remorqua le Radeau, \& nous les ramena. Ces Malheureux, qui pour la plûpart étoient de pauvres Paffagers, n'attendoient plus que la mort, \& de notre côté nous commencions à défefperer de les pouvoir fauver, lorfque la Providence excita cette petite tempête pour les garantir du naufrage.

Au refte ma préfence étoit plus néceffaire encore fur le Vaiffeau, que je ne l'avois cru. Nos Matelots Bretons, pendant l'abfence du Capitaine, avoient voulu noyer dans le vin leur chagrin \& leurs inquiétudes : malgré le Lieutenant, qu'ils ne refpectoient pas beaucoup, \& que plufieurs n'aimoient point, ils avoient enfoncé la Cantine, \& nous les trouvâmes prefque tous yvres-morts. J'entrevis même dans l'Equipage quelques femences de divifion \& de révolte, dont je crus qu'on devoit tout appréhender, fi l'on n'y remédioit pas de bonne heure; d'autant plus que le Capitaine, quoiquaffez aimé des Matelots, ne fçavoit pas fe faire obéir des OfficiersMariniers, la plûpart fort portés à la mutinerie, \& qui ne: pouvoient fouffrir fon Lieutenant.

Pour furcroît d'embarras, une troupe de Sauvages nous Embarras d? 
1722 .

Avril.

la part des Sauvages.

Qui étoient ces Sauvages.
JOURNA L HISTORIQUE

avoit fuivis de près, \& nous comprîmes que, fi nous n'avions point à craindre de violence de leur part, il ne nous feroit pas facile de nous délivrer de leurs importunités, furtout qu'il faudroit bien garder ce que nous ne voulions pas perdre. Le plus apparent fe faifoit nommer Dom Antonio, \& parloit affez bien Caftillan. Il avoit encore mieux pris la gravité \& les manieres des Efpagnols. Dès qu'il voyoit quelqu'un bien mis, il lui demandoit s'il étoit Cavallero, \& il avoit commencé par nous dire qu'il l'étoit lui-même, \& des plus diftingués de fa Nation.Il n'avoit pourtant pas les inclinations fort nobles; tout ce qu'il voyoit, lui faifoit envie, \& $\mathrm{fi}$ on ne l'eût empêché, lui \& fa troupe ne nous auroient rien laiffé, que ce qu'ils n'auroient pu emporter. Il me demanda ma Ceinture; je lui dis que j’en avois befoin, il comprit qu'elle ne m'étoit néceffaire que pour ma Soutane, $\&$ il me la demanda avec de grandes inftances.

Nous apprîmes de cet Homme que prefque tous les Sauvages de fa Bourgade avoient été baptifés à la Havane, où ils faifoient tous les ans un voyage. Ils en font éloignés de quarante-cinq lieuës, \& ils font ce trajet dans de petites Pirogues fort plattes, fur lefquelles on n'oferoit affûrément fe rifquer pour paffer la Seine à Paris. Dom Antonio nous ajoûta qu'ils avoient un Roi, qui fe nommoit Dom Diego, \& que nous verrions le lendemain. Il nous demanda enfuite quel parti nous voulions prendre, \& s'offrit à nous conduire à Saint $\mathrm{Au}$ guftin. Nous témoignâmes lui fçavoir gré de fon offre, on le régala bien \& $\&$ tous ceux de fa fuite, \& ils s'en retournerent affez contens en apparence.

Ces Sauvages ont le corps plus rouge 'qu'aucun de ceux, que j’aye encore vûs : nous n'avons jamais pu fçavoir le nom de leur Nation : mais quoiqu'ils n'ayent pas trop bonne réputation, ils ne nous ont point paru affez méchans, pour être de ces Calos, ou Carlos, fi décriés par leurs cruautés, \& dont le Pays n'eft pas loin des Martyrs. Je ne crois pas même ceuxci Antropophages; mais peut-être ne nous parurent-ils fi traitables, que parce que nous étions plus forts qu'eux. Je ne fçai ce qu'ils ont eu à démêler avec les Anglois, mais nous eûmes tout lieu de juger qu'ils ne les aimoient pas. La vifite de Dom Antonio pouvoit bien n'avoir eu d'autre motif, que d'examiner fi nous n'étions pas de cette Nation, ou s'ils ne rifqueroient pas trop en nous attaquant. 
Le feiziéme je crus devoir aller rafûrer ceux, qui étoient reftés dans l'Ifle, \& à qui on tint la parole, qu'on leur avoit donnée la veille: je paffai prefque tout le jour avec eux, \& le foir à mon retour je trouvai tour le Navire en combuftion. Les Auteurs du défordre étoient des Officiers Mariniers, \& tout ce qu'il y avoit de meilleurs Matelots s'étolent rangés de leur parti. Ils en vouloient au Lieutenant, qui jufques-là , difoient-ils, les avoient traités avec beaucoup de hauteur $\&$ de dureté. Le vin, qu'ils avoient à difcrétion, leur échauffoit de plus en plus la tête, \& il n'étoit prefque plus poffible de leur faire entendre raifon.

Le Capitaine montra en cette rencontre une fageffe, une fermeté, $\&$ une modération, qu'on n'auroit pas dû attendre de fon âge, de fon peu d'expérience, $\&$ de fa conduite paffée : il f̧̧ut fe faire aimer \& craindre de Gens, qui n'écoutoient preique plus que leur fureur $\&$ leur caprice. Le Lieutenant de fon côté étonna les plus mutins par fon intrépidité, \& ayant trouvé moyen de les féparer \& de les occuper, il vint à bout de s'en faire obéir. On avoit enfin tiré du fond de Calle le Batteau tant promis, \& on l'avoit porté dans l'ille; il falloit le monter fe loger en attendant qu'il fût prêt, tirer du $\mathrm{Na}$ vire les provifions de bouche, \& les munitions, fe fortifier contre les furprifes des Sauvages; le Capitaine employa à ces travaux tous ceux, dont il étoit plus néceffaire de s'affùrer, $\&$ me pria de refter à bord, pour aider au Lieutenant à contenir les autres.

Le dix - feptiéme à la pointe du jour il parut une voile à deux bonnes lieuës de nous. Nous mîmes Pavillon en berne $(a), \&$ quelque tems après nous remarquâmes qu'il avoit ne $(a)$, \& quelque tems après nous remarquâmes qu'il avoit courir l'Equi-
mis en panne pour nous attendre. Auffi-tôt le Lieutenant s'em- page.

barqua dans le Canot, \& alla à bord demander au Capitaine s'il voudroit bien nous recevoir tous. Mais ce n'étoit qu'un Brigantin de cent tonneaux, qui avoit été pillé par les Forbans, \& qui depuis trois jours faifoit bien des efforts pour fe tirer de cette Baye, où les Courans, difoit-il, plus forts cette année, qu'on ne les avoit jamais vûs, l'avoient entraịné malgré lui, \& quoiqu'il eut fait l'Eft-Nord-Eft. Il eft vrai que nous n'avons fçu cela que par l'Officier, que quelques-uns foup-

(a) Mettre Pavillon en Berne, c'eft l'é- $\mid$ ployer : cela fe fait pour demander du felever au haut de fon bâton, fans le dé- $\mid$ coufs.
Tome III.
$\mathrm{N} n \mathrm{n}$

1722.

Avril.

- Diffenfion dans l'Equipage.

Fermeté des Officiers.

Un Navire Anglois tâche en vain de fepage. (1) 


\section{J O UR N A L H IS T O R I Q U E}

I 722 . çonnerent d'avoir imaginé ce récit, afin de pouvoir rejetter Avril. fur la force \& l'irr égularité des Courans, le malheur, où fon obftination nous avoit précipités.

Quoiquil en foit, le Patron Anglois confentit à embarquer vint Perfonnes, pourvû qu'on lui donnât des vivres \& $\mathrm{x}$ de l'eau, dont il avoit un extrême befoin. La condition fut acceptée, \& le Patron s'approcha en effet à deffein de mouiller un ancre le plus près de nous, qu'il feroit poffible : mais un gros vent duS Sud s'étant levé tout-à coup, il fut contraint de faire fa route, pour ne pas s'expofer à perir lui-même, en voulant nous fecourir. Le dix-neuviéme on apperçut encore trois Bâtimens à la voile ; on alla leur faire les mêmes propofitions, qu'au Premier, mais on n'en put rien obtenir. C'étoit encore des Anglois, qui fe plaignoient d'avoir été pillés par les Forbans.

Ce même jour, comme il ne reftoit plus rien fur l'Adour, que nous puffions emporter, nous lui dìmes le dernier adieu, avec d'autant plus de regret que depuis quatre jours, qu'il étoit échoué, il n'y étoit pas encore entré une goutte d'eau, 8 nous nous rendîmes tous à terre après le Soleil couché. Nous y trouvâmes des Tentes, qu'on y avoit dreffées avec les Voiles du Navire, un Corps-de-Garde en bon état, où nuit $\&$ jour on faifoit exactement la fentinelle ; $\&$ des vivres, bien arrangés dans un Magafin, où l'on faifoit auffi la garde.

Defrription L'Ifle, où nous étions, pouvoit avoir quatre lieuës de cirdes Martyrs. cuit. Il y en avoit à droite $\&$ à gauche de differentes grandeurs, \& celle, où les Sauvages avoient leurs Cabannes, étoit la plus petite de toutes, \& la plus proche de la nôtre. Ils y vivoient uniquement de pêche, \& toute cette Côte eft auff abondante en Poiffon, que la terre y eft incapable de rien fournir pour la vie.' $Q$ uant à leurs vêtemens, quelques feuilles d'Arbres, ou un morceau d'écorce leur fuffifent; ils n'ont de couvert, que ce que la pudeur enfeigne à tous les Hommes de couvrir.

Le fond de toutes ces Ifles eft un fable très-fin, ou plutôt une efpéce de chaulx calcinée, $\&$ toute femée d'un corail blanc, qui s'écrafe fans peine. Auffi n'y voit-on que des broffailles, \& quelques Arbriffeaux. Les bords de la Mer font couverts d'affez beaux coquillages, $\&$ on y trouve quelques Eponges, qui paroiffent y avoir été jettées par les vagues 
D'UN VOYAGE DE L'A MER. LET. XXXIV. 467 dans les gros tems. On prétend que ce qui y retient les Sauvages, ce font les naufrages, qui arrivent affez fréquemment à l'entrée du Canal de Bahama, \& dont ils profitent toujours. On ne voit pas même une feule Bête dans ces Ifles, qui paroiflent maudites de Dieu \& des Hommes, \& où il n'y auroit aucun Habitant, sil ne fe trouvoit pas des Hommes uniquement attentifs à tirer avantage du malheur des autres, \& fouvent à y mettre le comble.

Le vintiéme Dom D I É Go nous rendit vifite. C'eft un vifiteduca. jeune Homme d'une taille au-deffous de la médiocre, \& d'af- cique des Saufez mauvaife mine. Il s'en falloit peu qu'il ne fût auffi nud que fes Sujets, \& le peu qu'il avoit de hardes fur le corps, ne valoit pas la peine d'être ramaffées. On lui voyoit autour de la tête une efpéce de bandeau de je ne fçai quelle matiere, $\&$ que certains Voyageurs n'auroient pas manqué de prendre pour un diademe. Il n'avoit point de fuite, nulle marque de dignité, rien en un mot, qui annonçât ce qu'il étoit. Une jeune Femme affez bien faite, \& décemment vêtuë en Sauvageffe, l'accompagnoit, \& on nous dit que c'étoit la Reyne Ion Epoufe.

Nous reçûmes Leurs Majeftés Floridiennes affez cavalierement : nous leur fìmes cependant amitié, \& elles parurent affez contentes de nous; mais nous ne reconnûmes point ces Caciques, dont l'Hiftorien de la Floride nous vante fi fort la puiffance $\&$ les richeffes. Nous dìmes deux mots à Dom Diegue de l'offre, que Dom Antonio nous avoit faite de nous conduire à Saint Auguftin, \& il nous donna lieu d'efperer qu'il nous rendroit tous les fervices, qui dépendroient de lui. Pour l'y engager davantage, je lui fis prefent d'une de mes Chemifes, \& il la reçut avec beaucoup de reconnoiffance.

Il revint le lendemain ayant par-deffus fes haillons ma chemife, qui lui traînoit prefqu'à terre; \& il nous fit entendre ce Cacique. qu'il n'étoit pas proprement le Souverain de fa Nation, mais qu'il relevoit d'un autre Cacique plus éloigné. Il ne laiffe pourtant pas d'être abfolu dans fon Village, \& il venoit d'en donner une bonne preuve. Dom Antonio, qui paroiffoit bien avoir deux fois fon âge, \& qui en auroit battufans peine deux comme lui, nous vint voir peu de tems après, \& nous dit que Dom Diégue l'avoit repaffé de la bonne maniere, parce qu'il s'étoit enyvré fur l'Adour, où l'on avoit apparemment 


\section{J O UR N A L H I S T O R I Q U E}

1722 . oublié quelques reftes d'Eau-de-vie. La différence la plus fenfible, qui fe trouve entre les Sauvages du Canada \& ceux de la Avril. Floride, eft cette dépendance, où ceux-ci font de leurs Chefs, \& le refpect, quils leur portent. Auffi ne voit-on point en eux, comme dans les Premiers, ces fentimens élevés, \& cette fierté, que produit l'indépendance, \& à laquelle on fupplée dans les Etats civilifés par les principes de religion $\&$ d'honneur, que donne l'éducation.

Dom Diégue s'excufe de nous donner des Guides pour Saint Auguftin,

On délibere fur le parti, quion doir prendre.

Le vint-deux Dom Diégue vint dîner avec nous fans façon, vétu comme la veille. Il fembloit prendre beaucoup de complaifance dans cette parure, qui lui donnoit pourtant un air fort ridicule, ce qui joint à fa mauvaife mine, le faifoit juftement reffembler à un Homme, qui va faire amende honorable. Soit religion, foit répugnance, nous ne pûmes jamais l'engager à manger de la viande; nous avions encore un refte de Poiffon, que lui-même nous avoit envoyé la veille : il en mangea, \& but de l'eau.

A près le repas nous voulûmes parler d'affaires; mais il nous dit d'abord, qu'après avoir bien réfléchi à ce que nous lui avions propofé, il ne pouvoit nous donner, ni Dom Antonio, ni aucun de fes Gens pour nous conduire à $S$. Augurtin, parce que fur la route, qu'il nous faudroit tenir, il y avoit de nombreufes Nations, avec lefquelles il étoit en guerre. Je ne fçai fi alors on ne fe repentit pas d'avoir abandonné fi légerement l'Adour, car après que Dom Diégue nous eut quittés, on y envoya le Canot; mais ceux qui vifiterent ce Bâtiment, Hous dirent à leur retour que les Sauvages y avoient tout brifé, \& qu'il s'empliffoit d'eau.

Le vint-trois le Batteau fe trouva achevé, \& on fongea tout-de-bon à prendre un parti. Il s'en préfentoit deux, \& il y eut deux fentimens, les uns étoient d'avis de hafarder le trajet à la Havane, les autres vouloient fuivre la Côte jufquà Saint Auguftin. Ce dernier avis paroiffoit le plus fûr, le premier étoit le plus court; mais s'il avoit pu être pris fagement, il auroit fallu le prendre dès le lendemain de notre naufrage; ou plutôt faire partir la Chaloupe pour la Havane, afin d'ar vertir le Gouverneur de notre fituation, \& le prier de nous envoyer un Brigantin. Les feuls agrès de l'A dour auroient été plus que fuffifans pour le dédommager de fes frais.

on fe divife.- Quoiqu'il en foit, la plus grande partie del'Equipage étoit 
1 


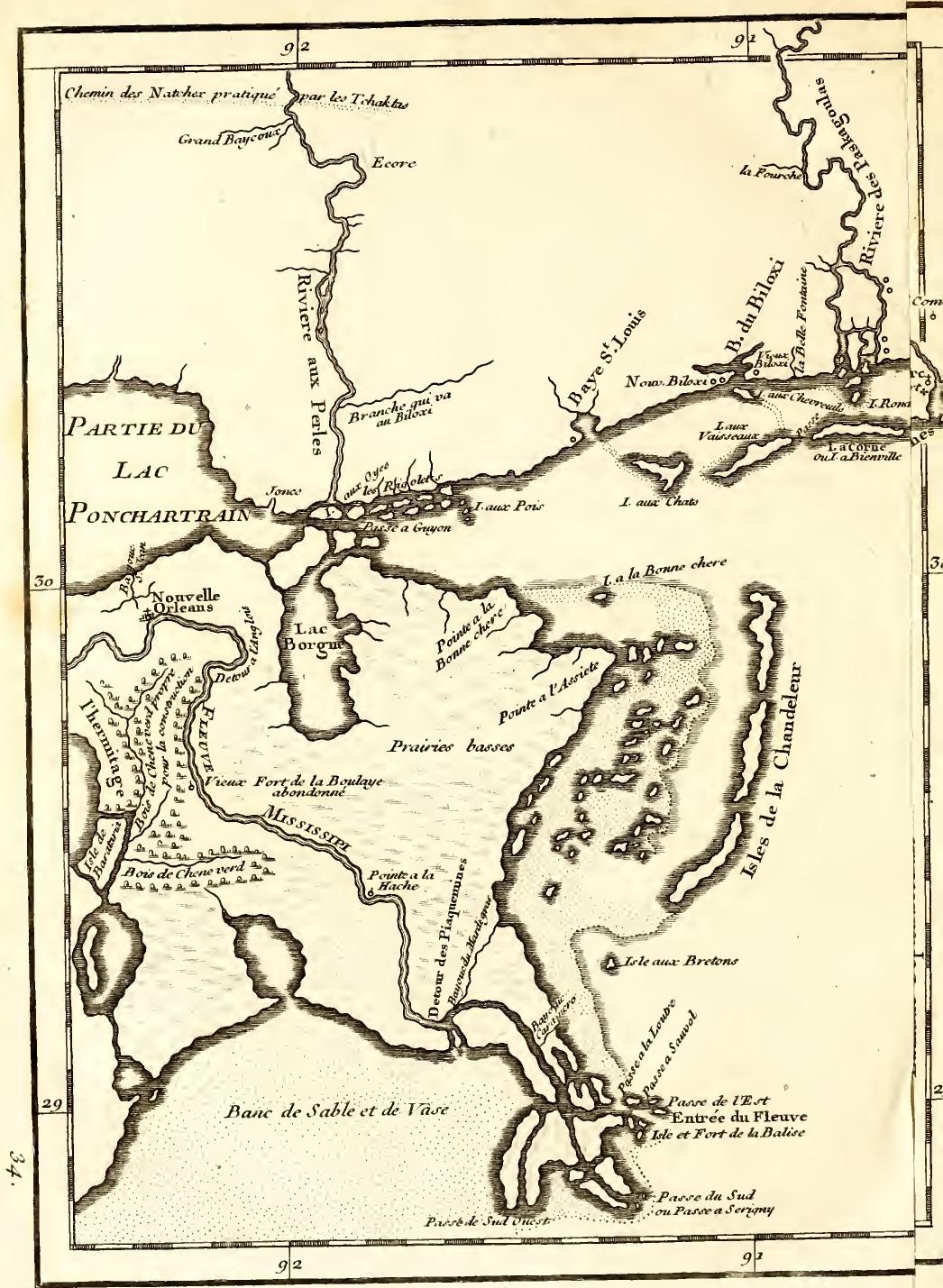


D'UN V OYAGE DE L'A MER. LET. XXXIV. 469 de ce dernier avis, il ne fut pas pofible de leur en faire prendre un autre. Ils étoient quarante, ils demanderent la Chaloupe \& le Canot, \& il fallut les fatisfaire, l'Aumônier de 1722. Avril. l'Adour étoit de ce nombre : fans cela je me ferois cru obligé de les accompagner; mais il falloit partager les fecours ipirituels, comme on fit les vivres, \& les autres provifions. Le lendemain matin, après la Meffe, l'Aumônier, qui étoit un Pere Dominiquain, voulut que je bénîffe les trois Bâtimens; jobéis \& je baptifai le Batteau, auquel je donnai le nom de Saint Sauveur. Le foir après la priere je fis un dernier effort, pour ramener tout le Monde à l'unité : jobtins fans peine que le jour fuivant on partiroit tous enfemble, qu'on iroit camper dans l'Ifle la plus avancée au large, \& que là on fe détermineroit felon le vent.

Nous partìmes en effet le vint-cinq fur le midi, \& nous voguâmes de concert pendant plufieurs lieuës, mais vers le coucher du Soleil, nous vîmes la Chaloupe enfilcr le Canal, qu'il falloit traverfer pour gagner la Havane, fans fe mettre en peine du Canot, dont elle portoit les vivres, \& qui ne pouvant la fuivre, fut contraint de fe joindre à nous. Nous le reçûmes avec bonté, quoique parmi ceux, qui y étoient, il y en eût, dont on n'avoit pas fujet d'être content. Nous débarquâmes dans l'Ifle, où nous avions compté de nous réunir, \&xoù une bande de Sauvages s'étoit déja renduë, je ne fçai à quel deffein. Nous fîmes fur nos gardes toute la nuit, \& nous partîmes de grand matin.

Le tems étoit charmant, la Mer belle, \& notre Equipage commença à envier le fort de la Chaloupe. Il en vint même bientôt aux murmures, \& nos Chefs crurent qu'il falloit au moins faire femblant de les contenter. On prit donc la routs du Canal. Au bout de deux heures le vent devint plus fort, $\&$ on s'imagina voir les apparences d'un orage. Il n'y eut alors perfonne, qui ne convint qu'il y auroit de la témérité à s'engager dans une fi longue traverfe avec des Bâtimens tels que les nôtres: car rien n'étoit plus foible que notre Batteau, \& l'eau y entroit déja de toutes parts : mais comme pour aller à Saint Auguftin, il auroit fallu refaire tout le chemin, que nous avions fait jufques-là, on prit affez unanimement la ré folution de tourner du côté du Biloxi.

Nous fìmes donc l'Oueft, mais nous n'avançâmes pas beaư-

Ie Batteain prend larrouts: du Biloxi. 


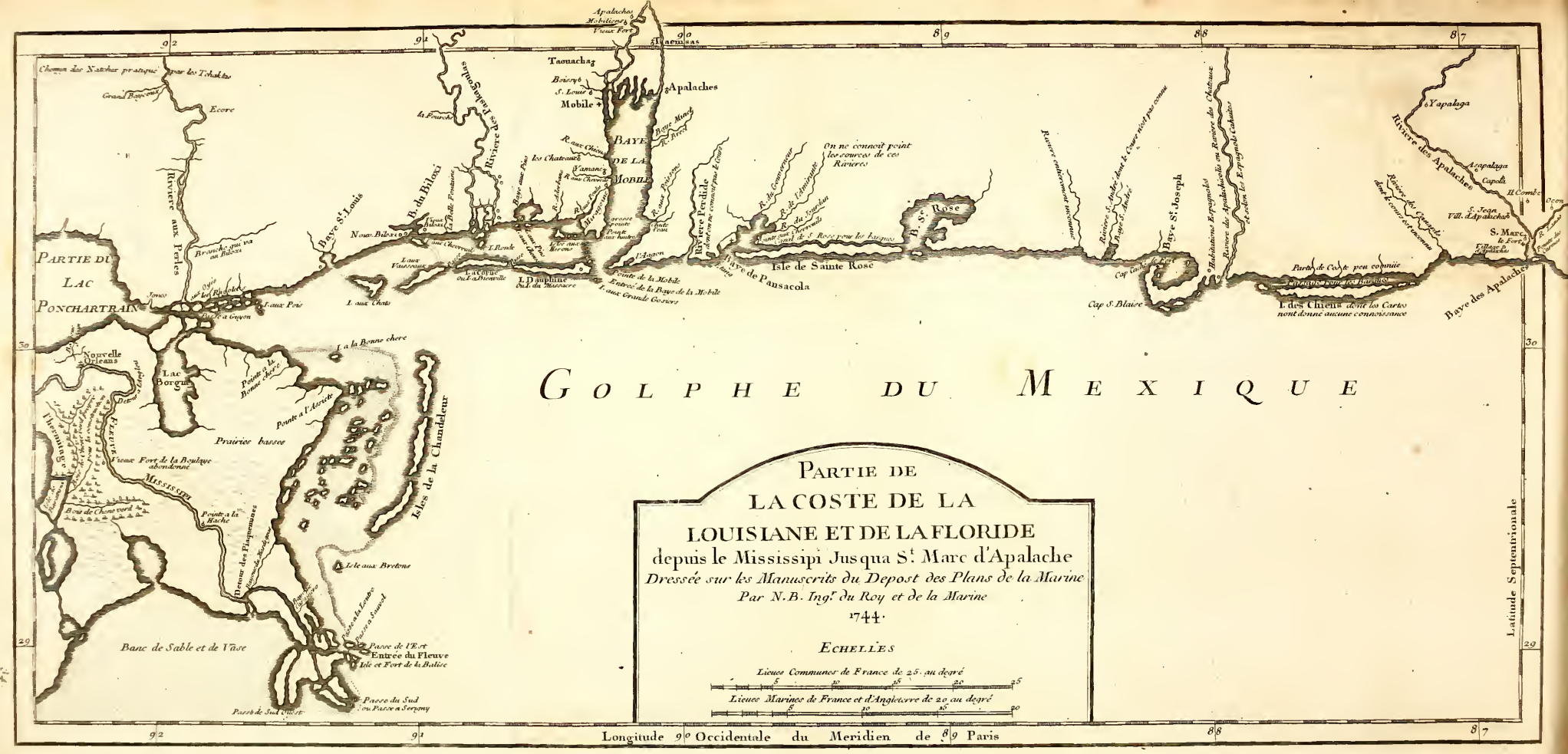


D'UN V OYA G E DE L'A MER. LET. XXXIV. 469 de ce dernier avis, il ne fut pas poffible de leur en faire prendre un autre. Ils étoient quarante, ils demanderent la Chaloupe \& le Canot, \& il fallut les fatisfaire, l'Aumônier de l'Adour étoit de ce nombre : fans cela je me ferois cru obligé de les accompagner; mais il falloit partager les fecours ipirituels, comme on fit les vivres, \& les autres provifions. Le lendemain matin, après la Meffe, l'Aumônier, qui étoie un Pere Dominiquain, voulut que je bénîffe les trois Bâtimens; jobéis \& je baptifai le Batteau, auquel je donnai le nom de Saint Sauveur. Le foir après la priere je fis un dernier effort, pour ramener tout le Monde à l'unité : jobtins fans peine que le jour fuivant on partiroit tous enfemble, qu'on iroit camper dans l'Inle la plus avancée au large, \& que là on fe détermineroit felon le vent.

Nous partîmes en effet le vint-cinq fur le midi, \& nous voguâmes de concert pendant plufieurs lieuës, mais vers le coucher duSoleil, nous vìmes la Chaloupe enfiler le Canal, qu'il falloit traverfer pour gagnce la Havane, fans fe mettre en peine du Canot, dont elle portoit les vivres, \& qui ne pouvant la fuivre, fut contraint de fe joindre à nous. Nous le reçûmes avec bonté, quoique parmi ceux , qui y étoient, il y en eût, dont on n'avoit pas fujet d'être content. Nous débarquâmes dans l'Ifle, où nous avions compté de nous réunir, \& où une bande de Sauvages s'étoit déja renduë, je ne fçai à quel dêfein. Nous fûmes fur nos gardes toute la nuit, \& nous partîmes de grand matin.

Le tems étoit charmant, la Mer belle, \& notre Equipage commença à envier le fort de la Chaloupe. Il en vint même bientôt aux murmures, \& nos Chefs crurent qu'il falloit au prend lar routs: di B̈iloxi. moins faire femblant de les contenter. On prit donc la routs du Canal. Au bout de deux heures le vent devint plus fort, $\& z$ on s'imagina voir les apparences d'un orage. Il n'y eut alors perfonne, qui ne convînt qu'il y auroit de la témérité à s'engager dans une fi longue traverfe avec des Bâtimens tels que les nôtres : car rien n'étoit plus foible que notre Batteau, \& l'eau y entroit déja de toutes parts : mais comme pour aller à Saint Auguftin, il auroit fallu refaire tout le chemin, que nous avions fait jufques-là, on prit affez unanimement la réfolution de tourner du côté du Biloxi.

Nous fimes donc l'Oueft, mais nous n'avançâmes pas beaư- 
1722 . coup ce jour-là, \& il nous fallut paffer la nuit dans le Batteau; Avril. où il s'en falloit bien que chacun eût affez de place pour s'éGrands Cou- tendre. Le vint-fept nous campâmes dans une Ifle, où nous rans entre les trouvâmes des Cabannes abandonnées, des chemins frayés, Martyrs \& les $\&$ des veftiges de fouliers Efpagnols. Cette Ifle eft le commen-
Tortués. cement des Tortuës. C'eft le même terrein qu'aux Martyrs : je ne comprends pas ce que des Hommes viennent faire dans un fi mauvais Pays, \& fi écarté de toute Habitation humaine. Nous faifions toujours l'Oueft, \& nous voguions avec une rapidité , qui ne pouvoit venir que des Courans.

Nous fîmes encore bien du chemin le vint-huit jufqu’à midi : quoique nous euffions très-peu de vent, il fembloit que les Ifles couroient la pofte à côté de nous. A midi nous prìmes hauteur, \& nous trouvâmes vint-quatre dégrez, quinze minutes. Si nos Cartes Marines étoient exactes, nous étions à l'extrêmité occidentale des Tortuës : c'étoit beaucoup nous engager en pleine Mcr, \& il n'avoit pas tenu à moi que nous n'euflions laiffé toutes ces Illes à gauclıe; mais nos Officiers craignoient de ne pas trouver de paffage entr'elle \& le Contitinent. Ils eurent tout lieu de s'en repentir, car nous fümes enfuite deux jours fans voir de terre, quoique nous fiffions toujours le Nord ou le Nord-Eft.

Décépoir de Alors le défefpoir faifit notre Equipage, \& il ne falloit en l'Equipage. effet qu'un coup de vent, tel que nous en avions déja effuyé plus d'un, pour nous faire perir. Le calme même avoit fes in-

1722 . convéniens, il falloit ramer tout le jour, \& la chaleur étoit May. exceffive. Les Matelots n'avoient pas tort d'être mécontens, l'obftination de deux ou trois Perfonnes nous avoit expofés au danger, où nous nous trouvions; mais le mal étoit fait, $\&$ demandoit un autre remede, que des murmures. Depuis notre départ de la Louyfiane je n'avois pu gagner fur la plue part qu'ils approchaffent des Sacremens, très - peu mème avoient fatisfait au devoir Pafchal. Je profitai de l'occafion, pour engager tout le monde à promettre de fe confeffer $\&$ de communier, fi-tôt que nous aurions retrouvé la terre; à peine la promeffe étoit faite, que la terre parut devant nous.

PncommoNous courûmes deffus, \& nous y arrivâmes avant midi. dités de cette Le quatriéme à midi nous étions par les vint-fix dégrez, cin-
Cốte.

quante-fix minutes. Nous avions toujours la grande terre en perfpective, fans pouvoir en approcher, parce qu'elle eft 
D'U N VOYAGE DE L'AMERIQ. LET. XXXIV. 471 bordée d'Ifles \& de prefqu'Ifles, la plûpart très-baffes, ftériles, entre lefquelles à peine y a-t'il paffage pour des Canots d'écorce. Ce qui nous faifoit le plus fouffrir, eft que nous n'y trouvions point d'eau. Les jours fuivans nous fûmes fouvent arrêtés par les vents contraires, mais nous trouvions par-tout des abris, \& quelquefois un peu de chaffe $\&$ de pêche. L'eau feule nous manquoit; je profitai de ce retardement pour faire tenir à tout notre monde la promeffe, quils avoient faite de s'approcher des Sacremens.

Il paroît qu'il y a peu de Sauvages dans tout ce Pays. Nous en vîmes feulement un jour quatre, qui venoient à nous dans une Pirogue: nous les attendimes; mais quand ils nous eurent reconnus, ils n'oferent approcher, \& regagnerent au plus vîte le Rivage. Le dixiéme on fut obligé de retrancher la ration d'eau-de-vie, qu'on avoit jufques-là donnée tous les jours à l'Equipage, n’y en ayant plus que très-peu, qu'on jugea à propos de réferver pour les plus preffans befoins. On commença auffi à ménager beaucoup les vivres, furtout le bifcuit, dont une partie avoit été gâtée : de forte que nous fûmes réduits au pur néceffaire; n'ayant fouvent à chaque repas qu'une poignée de ris, qu'il falloit faire cuire dans de l'eau faumâtre.

Mais cette Côte eft le Royaume des Huitres, comme le grand Banc de Terre-neuve, le Golphe \& le Fleuve Saint
Laurent font celui des Moruës. Toutes ces terres baffes, que nous rangions le plus près, quili étoit poffible, font bordées de Mangliers, aufquels s'attachent une prodigieufe quantité de petites Huitres, d'un goût exquis : D'autres, beaucoup plus grandes \& moins délicates, font dans la Mer même en fi grand nombre, qu'elles y forment des. Ecueils, qu'on prend d'abord pour des Rochers à fleur d'eau. Comme nous n'ofions nous éloigner de la terre, nous entrions fouvent dans des Anfes affez profondes, dont il falloit faire le tour, ce qui prolongeoit beaucoup notre chemin; mais dès que les terres difparoiffoient, nos Gens fe croyoient perdus.

Le quinziéme au matin, nous rencontrâmes une Chaloupe Efpagnole, où il y avoit environ quinze Perfonnes : c'étoit une partie de l'Equipage d'un Navire, qui avoit fait naufrage vers la Riviere de Saint Martin. Il y avoit vint-cinq jours que ce malheur étoit arrivé, \& pour quarante-deux Perfonnes

1.722. May.

Ies Vivres manquent.

$$
\text { manuent. }
$$

\author{
(n)
}

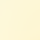


472 JOURNAL HISTORIQUE

1722 ils n'avoient qu'une afiez petite Chaloupe, dont ils fe fervoient les uns après les autres, ce qui les obligeoit à faire de May. très-petites journées. Cette rencontre fut pour nous un coup du Ciel, car fans les inftructions, que nous donna le Capitaine Efpagnol, nous íneuffions jamais trouvé la route, qu'il nous falloit tenir, \& l'incertitude de ce que nous pouvions devenir auroit peut-être porté nos Mutins à quelque violence, ou à quelque coup de défefpoir.

Danger d'ê- La nuit fuivante nous courûmes un grand danger. Nous tre degradés étions tous couchés dans une petite Ifle, à la réferve de trois fansreffource, ou quatre Perfonnes, qui gardoient le Batteau. Un d'eux après avoir allumé fa pipe, mit imprudemment fa méche fur le bord du Batteau, précifément à l'endroit, où les armes, la poudre, \& les vivres étoient renfermées dans un Cofre couvert d'une toile godronnée. Il s'endormit enfuite, \& tandis qu'il dormoit, le feu prit à la toile. La flamme le réveilla, auffi-bien que fes Camarades, mais un moment plus tard, le Batteau fautoit, ou s'entrouvroit, \& je vous laiffe à penfer ce qu'il feroit arrivé de nous, n'ayant plus qu'un Canot, qui ne pouvoit pas contenir la fixiéme partie de ce que nous étions, fans vivres, fans munitions, fans armes, 8 dans une Ifle de fable, où il ne croiffoit que quelques herbes fauvages.

Le lendemain feiziéme le Canot nous quitta pour aller joindre les Efpagnols. Nous avions le vent contraire, \& nous ne pouvions aller que la Sonde à la main, parce que la Côte étoit fi platte, \& tellement pavée de cạilloux pointus, qu’à fix lieuës au large notre Bâtiment, qui ne tiroit que deux pieds d'eau, étoit à cliaque inftant en danger de toucher, \& de fe crever. Nous fûmes encore dans le même cmbarras les deux jours fuivans, \& le vintiéme nous campâmes dans une Inle, qui fait la pointe orientale de la Baye des Apalaches. Toute la nuit, nous apperçûmes des feux dans la grande terre, dont nous étions fort proches, \& il y avoit quelques jours, que nous obfervions la même chofe.

Arrivée à Le vint - uniéme nous partịmes avec un brouillard fort Saint Marc épais, lequel s'étant bientôt diffipé, nous apperçûmes des ". Apalache. Balifes, que les Efpagnols nous avoient avertis de fuivre. Nous les fuivîmes en faifaint le Nord, \& nous reconnûmes que fans ce fecours il auroit été impoffible d'éviter des bancs de fable, dont toute cette Côte eft femée, \&x qui pour la plûpart font 
D'UN VOYAGE DE L'AMERIQ. LET. XXXIV. 473 couverts d'Huitres. Sur les dix heures nous apperçûmes un petit fort de pierre, quarré \& baftionné affez régulierement, nous arborâmes auffi-tôt le Pavillon blanc, \& un moment après on nous cria en François de ne pas avancer davantage.

Nous nous arrêtâmes, "Ž dans le moment nous vìmes venir à nous une Pirogue, où il y avoit trois Hommes: un des trois étoit Bafque; il avoit été Canonnier à la Louyfrane, \& il avoit le même Emploi à Saint Marc. Après les demandes ordinaires, le Bafque fut d'avis que le Capitaine de l'Adour \& moi allaffions feuls parler au Commandant : nous y allâmes, \& nous fûmes bien reçûs. Ce Commandant étoit un fimple Lieutenant, Homme d'efprit; il ne fit aucune dificulté de faire avancer notre Batteau vis-à-vis du Fort, \& il invita nos Officiers \& les principaux Pafiagers à dìner : mais ce ne fut qu'après avoir fait vifiter le Batteau, $\&$ en avoir fait tranfporter dans fon Magafin les armes \& les munitions, avec parole de nous les rendre, quand nous voudrions partir.

Ce Pofte, que $M$. Delille a marqué dans fa Carte fous le nom de Sainte Marie d'Apalache, n’a jamais porté que celui de Saint Marc. Les Efpagnols y ont eu autrefois un Etabliffement confidérable, mais qui étoit déja réduit à peu de chofes, lorfqu'en I 704 il fut entierement détruit par les Anglois de la Caroline, accompagnés d'un grand nombre de Sauvages Alibamons. La Garnifon Efpagnole, qui étoit de trentedeux Hommes, fut faite Prifonniere de guerre; mais les Sauvages en brûlerent dix-fept, parmi lefquels il y avoit trois Religieux de Saint François ; \& de fept mille Apalaches, qui étoient dans ce Canton, \& qui avoient prefque tous embraffé le Chriftianifme, il n'en refta à S. Marc que quatre cent, qui fe retirerent du côté de la Maubile, où ils font encore pour la plûpart.

Les Forêts \& les Prairies voifines du Fort font remplies de Boufs \& de Chevaux, que les Efpagnols y avoient laiffés courir, \& à mefure qu'on en a befoin, on envoye des Sauvages, qui les prennent avec des lacets. Ces Sauvages font encore des Apalaches, qui s'étoient apparemment éloignés dans le tems de l'irruption des Anglois, \& qui revinrent après que ceux-ci fe furent retirés. Au refte cette Baye eft précifément ce que Garcilaffo de la Véga appelle dans fon Hiftoire de la Floride le Port d'Auté. Le Fort eft bâti fur une petite Tome III.

1722. May.

Defcription du Pays. 


\section{J O URNAL H IS T OR I Q U E}

I 722 éminence environnée de Marécages, \& un peu au-defous

May. \&z. l'autre du Nord-Oueft. Elles font peu larges, \& remplies de Caimans, \& néanmoins affez poiffonneufes.

ches.

Des Apala- Deux lieuës plus haut il y a fur la Riviere du Nord-Oueft
un Village d'Apalaches, $8 \mathrm{z}$ dans les terres à l'Oueft, à une lieuë \& demie du Fort, il y en a un fecond. Cette Nation, autrefois très-nombreufe, \& qui, partagée en plufieurs Cantons, occupoit un très-grand Pays, eft aujourd'hui réduite à très-peu de chofes. Elle a embraffé le Chriftianifme, il y a lontems: toutefois les Efpagnols ne s'y ficnt pas, \& font trèsbien : car outre que ces Chrétiens, deftitués de tous fecours fpirituels depuis un très-grand nombre d'années, ne le font plus guéres que de nom, leurs Vainqueurs les ont traités d'abord avec tant de dureté, qu'ils doivent toujours les regarder comme des Ennemis mal réconciliés. Il eft difficile qu'on faffe de bons Chrétiens de Gens, à qui l'on a commencé par rendre le Chriftianifme odieux.

On nous a dit à Saint Marc que la réfolution étoit prife de rétablir ce Pofte dans fon premier état, \& qu'on y attendoit cinq mille Familles : c'eft beaucoup plus que les Efpagnols de la Floride n'en peuvent fournir. Le Pays eft beau, bien boifé, bien arrofé, \& on prétend que plus on avance dans la profondeur des terres, plus on les trouve fertiles. On nous confirma dans ce Fort, ce que les Efpagnols, que nous avions rencontrès, nous avoient déja dit, que les Sauvages des Martyrs \& leur Roi Dom Diégue ne valoient rien, \& que fi nous n'euffions été bien fur nos gardes, ils nous auroient fait un mauvais parti. On nous ajoûta qu'un Brigantin Efpagnol s'étant brifé depuis peu vers l'endroit, où nous avions trouvé quatre Sauvages dans une Pirogue, tout l'Equipage avoit été empalé \& mangé par ces Barbares.

Saint Marc dépend de Saint Auguttin pour le Militaire \& pour le Civil, \& de la Havane pour le Spirituel : cependant c'eft le Couvent des Cordeliers de Saint Auguftin, qui eft chargé d'y envoyer un Aumônier; jy en rencontrai un, qui étoit un très-aimable Homme, \& qui nous rendit un grand fervice : il nous avertit que le Commandant de Saint Marc vouloit nous retenir, jufqu'à ce qu'il eût donné avis de notre arrivée au Gouverneur de Saint Auguftin, \& reçu fes ordres, 
Je le priai de demander à cet Officier s'il étoit en état de nous nourrir tout le tems, que nous ferions chez lui, puifque ce qui nous reftoit de vivres, fuffifoit à peine pour nous conduire à la Louyfiane.

Il s'acquirta fort bien de fa commiffion, \& fon difcours, accompagué de quelques préfens, qu'on nous infinua quiil falloit offrir au Commandant, eut tout l'effet, que nous en avions efperé. Cet Officier nous accorda même de bonne grace des Guides, que nous lui demandâmes pour faint Jofeph, qui eft à trente lieuës de Saint Marc, \& $<$ dont on nous avertit que le chemin n'étoit pas facile à trouver. Cela nous obligea de féjourner le lendemain , \& je n'en fus point fâché, parce qu'outre que j’étois affez bien logé dans le Fort avec le Pere Cordelier , (diftin̨ion, qui ne fut faite quà moi, \& dont je fus redevable à mon habit, ) jétois bien aife de parcourir un peu les environs du Fort. On va par terre de Saint Marc à Saint Auguftin, le voyage eft de quatre-vint lieuës, \& le chemin fort mauvais.

Nous parîmes le vint-trois au matin, \& le vint-cinq vers les dix heures nos Guides nous firent entreprendre une traverfe de trois lieuës, pour entrer dans une efpéce de Canal formé d'un côté par le Continent, \& de l'autre par une fuite d'Ifles de differentes grandeurs. Sans eux nous n'aurions jamais ofé nous y engager, \& nous aurions manqué la Baye de Saint Jofeph. Cependant nous étions au bout de nos vivres, \& la difficulté de trouver de l'eau croiffoit tous les jours. Un foir que l'on avoit creufé à dix pas de la Mer fur un terrein affez élevé, nous ne tirâmes que de l'eau faumâtre, dont il étoit impoffible de boire. Je m’avifai de faire un trou affez peu profond fur le bord même de la Mer $\&$ dans le fable ; il fe remplit d'abord d'une eau auffi douce $\&$ auffi claire, que fi on l'eût puifée dans la plus belle Fontaine; mais après que j'en eus rempli un Pot, la Source en tarit entiérement, ce qui me fit juger que c'étoit de l'eau de Pluye, qui s'étoit amaffée en cet endroit, ayant rencontré un fond dur, $\& x$ je conçois que cela doit arriver fouvent.

Dès que nous eûmes gagné la tête des Ifles, nous allâmes à la voile jufqu'à dix heures du foir. Alors le vent tomba, mais la Marée, qui commençoit à defcendre, y fuppléa, \& nous marchâmes toute la nuit. C'eft la premiere fois que jai vû des

$$
\mathrm{O} \text { oo ij }
$$

1722 .

May.

Départ de Saint Mazc. 


\section{$476 \mathrm{~J} O \mathrm{O} R \mathrm{~N}$ A. L H I S T O R I Q U E}

I 72 2. Marées réglées dans le Golphe Mexique, \& nos deux Efpagnols nous dirent que depuis cet endroit jufqu'à Penfacole, le May. flux eft de douze heures, \& le reflux d'autant. Le lendemain vint-fix, le vent contraire nous retint jufqu'au foir dars une Ifle affez bien boifée, qui a dix ou douze lieuës de long, \& où nous tuâmes tant que nous voulûmes d'Allouettes \& de Becaffes. Nous y vîmes auffi quantité de Serpens à Sonnettes. Nos Guides la nommoient l'Ifle des Chiens, \& de fon commencement ils comptoient dix lieuës à $S$. Marc, \& quinze à S. Jofeph; mais à coup fûr ils fe trompoient pour ce dernier article, car il y en a au moins vint, \& bien longues.

Le vint-fept, à onze heures de nuit, nous échouâmes fur un Banc d'Huitres larges comme la forme de mon Chapeau, $8 x$ nous fûmes plus d'une heure à nous en tirer. Nous allàmes de-là paffer le refte de la nuit dans une Maifon de campagne appartenante à un Capitaine de la Garnifon de S. Jofeph, nommé Dioniz, oì à notre arrivée on nous débita les plus étranges nouvelles.

Fauffes al- On nous affùra que toute la Louyfiane étoit évacuée par larmes. les François ; qu'un grand Navire de France avoit paru à l'ile aux Vaiffeaux, \& y avoit embarqué le Commandant, les Directeurs \&r tous les Oficiers; quaprès leur départ les Sauvages avoient fait main-baffe fur tout ce qui étoit refté d'Habitans \& de Soldats, à la réferve d'un petit nombre, qui s'étoient fauvés fur deux Traverfiers; que manquant de vivres, ils étoient allés à la Baye $\mathrm{S}$. Jofeph; que les premiers venus $y$ avoient été bien reçus, mais qu'on n'avoit pas voulu permettre aux autres de débarquer, dans la crainte que tant de François fe trouvant réunis, ils ne fuffent tentés de fe rendre maitres de ce Pofte, que nous avons autrefois occupé.

Tout ce narré avoit fi peu de vrai-femblance, qu'il ne me fut pas poffible d'y ajoûter foi, mais il étoit fi bien circonftancié, \& fait par des Gens, qui avoient fi peu d'intérêt à nous en impofer, \& qui n'étant qu'à fept lieuës de S. Jofeph, pouvoient en avoir tous les jours des nouvelles, qu'il paroiffoit difficile qu'il n'eût quelque fondement. La plûpart des Nôtres en furent confternés ; j'éprouvai même que ces confternations générales fe communiquent au cœur malgré toutes les lumieres de l'efprit, \& qu'il eft auffi impoffible de ne pas 
reffentir quelque frayeur au milieu des Gens, qui en font faifis, que de ne pas s'affliger avec ceux, qui pleurent. Je ne 1722 . croyois nullement ce quon venoit de nous dire, malgré cela May. je n'étois pas trop raffûré.

Cependant notre Equipage, malgré fon défefpoir, trouvant des vivres en quantité, \& les Domeftiques du fieur Dioniz très-gracieux, fit bonne chere pendant tout le refte de la nuit: le matin nos Guides prirent congé de nous, fuivant l'ordre, qu'ils en avoient. Nous n'avions plus befoin d'eux, car outre qu'il n'y avoit plus à s'égarer pour gagner $S$. Jofeph, nous avions rencontré chez M. Dioniz un François, Soldat dans fa Compagnie, \& ancien déferteur de la Maubile, qui s'ennuyoit fort du Service des Efpagnols , parmi lefquels il mouroit fouvent de faim, difoit-il, quoiqu'il fût bien payé : ainfi nous n'eûmes point de peine à l'engager de nous fuivre à $S$. Jofeph, \& de-là à la Louyfiane, fuppofé qu'il pût avoir fon congé.

Nous arrivâmes fur les cinq heures du foir à S. Jofeph, où nous fûmes parfaitement bien reçûs du Gouverneur. Nous y trouvâmes deux grandes Chaloupes du Biloxi, avec quatre Officiers François, qui étoient venus reclamer des Déferteurs, mais ils ne les y avoient point trouvés. Nous les avions apperçus le vint-quatre, jour de la Pentecôte, dans une Barque, qui alloit à la voile, \& qui paffa affez près de nous. Il y a bien de l'apparence qu'ils avoient touché à S. Jofeph, \& que pour colorer leur défertion ils y avoient débité ce qui nous avoit caufé la veille une fi grande allarme. Deux Peres Cordeliers, qui deffervoient la Chapelle du Fort, ayant appris mon arrivée, vinrent m'offrir un lit dans leur Maifon, \& je l'acceptai avec reconnoiffance.

Au refte, je ne crois pas qu'il y ait au monde un lieu, où l'on dût moins s'attendre de rencontrer des Hommes, \& furtout des Européens, qu'à S. Jofeph. La fituation de cette Baye, fes Rivages, fon Terroir, tout ce qui l'environne, rien ne peut faire comprendre les raifons d'un tel choix. Une Côte platte $\&$ en plein vent, un Sable ftérile, un Pays perdu, \& qui ne peut avoir aucune forte de Commerce, ni même fervir d'Entrepôt, voilà où la jaloufie que les Efpagnols ont euë jufqu'ici de notre Etabliffement à la Louyfiane, les a conduits. Nous en avions fait la folie avant eux, mais

Arrivée à S. Joleph. 
$47^{8} \mathrm{~J} O \mathrm{U} R \mathrm{~N}$ A L H IST ORIQ U E

1722 elle a été courte. Il y a lieu de croire qu'ils fe corrigeront auffi bientôt, \& que quand on leur aura reftitué Penfacole, May. ils y tranfporteront tout ce qu'ils ont à S. Jofeph.

Ce n'eft pas dans la Baye même, qu'eft fitué le Fort, mais dans le retour d'une Pointe recourbée, \& qui renferme une Ine. Ce Fort n'eft que de terre, mais bien revêtu de Paliffades, \& défendu d'une bonne Artillerie. Il a une affez nombreufe Garnifon, un Etat Major complet, \& prefque tous les Officiers ont leurs Familles avec eux. Leurs Mailons font propres \& commodes, pas trop mal meublées, mais dans les ruës on enfonce par tout dans le fable jufqu’à la cheville du pied. Les Dames ne fortent que pour aller à l'Eglife, \& c'eft toujours avec un appareil, \& une gravité, qu'on ne voit que parmi les Efpagnols.

Le lendemain de notre arrivée, qui étoit le vint-neuf, il y eut un grand Dîner chez le Sergent Major. On avoit vû cet Officier à la Louyfiane, \& on lui avoit fait grande chere, il fut ravi de trouver cette occafion, de nous rendre la pareille.

Politeffes du Il avoit furtout lié amitié dans fon Voyage de la Louyfiane Gouverneur. avec M. HUBERT, qui y étoit alors Commiffaire-Ordonnateur, \& que nous avions avec nous : il fçut qu'une Fille de fon Ami, âgée de trois ans, \& que fon Pere ramenoit en France, n'étoit qu'ondoyée, il fouhaitta qu'on lui fuppléât à S. Jofeph les cérémonies du Baptême, \& voulut être fon Parrein. Cela fut fait avec grand appareil \& $\mathrm{au}$ bruit du $\mathrm{Ca}$ non; la Maraine fut une Niéce du Gouverneur, lequel donna le foir un Souper magnifique, \& par un excès de politeffe, affez rare chez les Efpagnols, voulut que les Dames en fuffent. Il mit le comble à tant de bonnes manieres, en nous fourniffant abondamment des vivres pour continuer notre route, quoiqu'il n'eût pas encore reçu le Convoy, qui devoit lui apporter des provifions de la Havane, \& que par cette raifon il en eût refufé aux Officiers du Biloxi : mais notre fituation l'avoit extrêmement touché.

Départ de 5. Joleph,

Nous partîmes le trente avec les deux Chaloupes, \& le Fort nous falua de cinq coups de Canon. Nous fìmes fept lieuës ce jour-là , \& nous moüillâmes à l'entrée d'une Riviere, qui fort d'une Baye ouverte au Sud-Eft. A onze heures de nuit, le vent étant devenu bon, nous en profitâmes, \& nous fìmes l'Oueft- 
Nord-Oueft ; toute la Côte court fur le même air de vent pendant vint lieuës, jufqu'à l'Ifle de Sainte Roje, \& l'on n'y trouve pas un feul endroit, où l'on puiffe fe mettre à l'abri d'un coup de vent, qui viendroit du large. Le trente-uniéme, à quatre heures du foir, nous avions fait les vint lieuës, \&z nous moüillâmes derrierè une Ifle, qui ferme la grande Baye de Sainte Rofe, dont l'entrée eft dangereufe, quand la Mer eft groffe. Un moment plus tard nous aurions été fort embarraffés, car le vent tourna tout-à-coup du Nord-Eft au SudOueft, \& les lames devinrent fi groffes dans le même inftant, qu'il nous eût été impoffible de paffer.

Le premier de Juin, vers les deux ou trois heures du matin, la Marée commençant à monter, nous nous rembarquâmes , \& après avoir fait une petite lieuë, nous entrâmes dans le Canal de Sainte Rofe, qui en a quatorze de long. Il eft formé par l'Ille de Sainte Rore, qui a toute cette longueur, mais qui eft fort étroite, qui paroît toute couverte de fable, \& qui néanmoins n'eft pas mal boifée: le Continent eft fort élevé, $\&$ porte des Arbres de toutes les efpéces; le Terrein y eft prefque auffi fabloneux qu'à $S$. Marc, mais pour peu qu'on $y$ creufe, on rencontre l'eau, auffi le bois y eft fort dur, \& fe pourrit aifément. Toute cette Côte fourmille de Gibier, \&z la Mer de Poifíns. Ce Canal eft étroit à fon entrée, jl s'élargit enfuite, \& conferve jufqu'à la Baye de Penfacole une largeur de demie lieuë; le courant y eft fort, \& nous étoit favorable.

Vers les onze heures nous doublâmes la Pointe aux Cheyreuils, au détour de laquelle commence la Baye. On y tourne au Nord, puis au Nord-Eft. Le Fort eft une petite lieuë plus loin, \& on l'apperçoit de la Pointe aux Chevreuils. Nous y arrivâmes à midi, \& nous fûmes étonnés de le voir en fi mauvais état: il paroît bien qu'on ne s'attend point à le garder. Le fieur Carpeau de Montigni, qui y commande, étoit allé au Biloxi, \& nous n'y rencontrâmes que quelques Soldats. Le Fort des Efpagnols, qui fut pris, il y a deux ans, par le Comte de Champmêlin, étoit derriere, \& il n'en refte qu'une fort belle Cîterne, laquelle a, dit-on, coûté quatorze mille Piaftres à bâtir. L'un \& l'autre ont été conftruits dans. une Ifle, qui tient prefque à la Terre-Ferme, qui n'a pas. quinze toifes de long, \& dont le Terroir ne paroit pas des. meilleurs.

1722.

Juin.

Canal \& life de Ste Ró́c.
Arrivée à Penfacole. En: quel état ćtoir: ce Pofte. 
La Baye de Penfacole feroit un affez bon Port, fi les Vers

1722. n'y perçoient pas les Navires, \& fi fon entrée avoit un peu

Juin. plus d'eau; mais l'Hercules, que montoit M. de Champmêlın,

Defrription y toucha. Cette entrée eft directement enire l'extrèmité occide la Baye. dentale de l'tlle de Sainte Role, où les Efpagnols avoient encore bâti un petit Fort, \& un Récif. Elle eft fi étroite, qu'il n'y peut palier qu'un Navire à la fois : fon ouverture eft Nord \& Sud. De l'autre côté du Récif il y a une autre paffe, où il n'y a de l'eau, que pour des Barques, \& qui eft ouverte au Sud-Oueft. Elle eft auffi fort étroite. Le moüillage des Navires dans la Baye de Penfacole eft le long de l'Ifle de Sainte Rofe, où l'ancrage eft fûr.

Arrivée au Nous partîmes de Penfacole à minuit, \& fur les quatre heuBiloxi. res du matin, nous laiffames à droite Rio de los Perdicios: cette Riviere fut nommée ainfi, parce qu'un Bâtiment Efpagnol y fit naufrage, \& que tout l'Equipage y périt. L'ille Dauphine eft cinq lieuës plus loin, fur la main gauche, \& elle a cinq lieuës de long, mais peu de largeur. Il y a au moins une moitié de cette lfle, où on ne voit pas un Arbre, \& l'autre ne vaut guére mieux. Le Fort \& la feule Habitation, qui y reftent, font dans la partie Occidentale. Entre cette Ifle \& l'Inle à Corne, qui en eft éloignée d'une lieuë, il y a peu d'eau. Au bout de celle-ci, il y en a une autre fort petite, qu'on appelle l'Ifle Ronde, à caufe de fa figure : nous y paffâmes la nuit.

Vis-à-vis eft la Baye des Pafcagoulas, où Madame de Chaumont a une Conceffion, qui n'eft pas prête de la dédommager de fes avances. Une Riviere du même nom, \& qui vient du Nord, fe décharge dans cette Baye. Le lendemain vers les dix heures, il nous mourut un Matelot d'une efquinancie. C'eft le feul Homme, que nous avons perdu dans notre pénible \& périlleufe Campagne. Une heure après nous moüillâmes auBiloxi, où l'on fut étrangement furpris de nous voir. J'allai fur le champ célébrer la 1ainte Mefle, pour remercier Dieu de nous avoir foûtenus au milieu de tant de fatigues, \& délivrés de tant de dangers.

Je fuis, \&c. 
BA)

E...

50

$\square$

parrenter

222

$-\infty$

and

ind

9

$+$

ocanes.

2 a 2

$-10 e^{90}$

L.

$=20$.

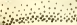




\section{JOURNAL HISTORIQUE}

La Baye de Penfacole feroit un affez bon Port, fi les Vers

1722. n'y perçoient pas les Navires, \& fi fon entrée avoit un peu Juin. plus d'eau; mais l'Hercules, que montoit M. de Champmêtın, Defcription y toucha. Cette entrée eft directement enire l'extrêmité occide la Raye. dentale de l'flle de Sainte Rofe, où les Efpagnols avoient encore bâti un petit Fort, \& un Récif̣. Elle eft fi étroite, qu'il n'y peut pafier qu'un Navire à la fois: fon ouverture eft Nord \& Sud. De l'autre côté du Récif il y a une autre paffe, où il n'y a de l'eau, que pour des Barques, \& qui eft ouverte au Sud-Oueft. Elle eft auffi fort étroite. Le moüillage des Navires dans la Baye de Penfacole eft le long de l'íle de Sainte Rofe, où l'ancrage eft fûr.

Arrivée au Nous partîmes de Penfacole à minuit, \& fur les quatre heuBiloxi. res du matin, nous laiffames à droite Rio de los Perdicios: cette Riviere fut nommée ainfi, parce qu'un Bâtiment Efpagnol y fit naufrage, \& que tout l'Equipage y périt. L'inle Dauphine eft cinq lieuës plus loin, fur la main gauche, \& elle a cinq lieuës de long, mais peu de largeur. Il y a au moins une moitié de cette lifle, où on ne voit pas un Arbre, \& l'autre ne vaut guére mieux. Le Fort \& la feule Habitation, qui y reftent, font dans la partie Occidentale. Entre cette lfle \& l'Ifle à Corne, qui en eft éloignée d'une lieuë, il y a peu d'eau. Au bout de celle-ci, il y en a une autre fort petite, qu'on appelle l'Ifle Ronde, à caufe de fa figure : nous y paffâmes la nuit.

Vis-à-vis eft la Baye des Pafcagoulas, où Madame de Chaumont a une Conceffion, qui n'eft pas prête de la dédommager de fes avances. Une Riviere du même nom, \& qui vient du Nord, fe décharge dans cette Baye. Le lendemain vers les dix heures, il nous mourut un Matelot d'une efquinancie. C'eft le feul Homme, que nous avons perdu dans notre pénible $\&$ périlleufe Campagne. Une heure après nous moiiillâmes auBiloxi, où l'on fut étrangement furpris de nous voir. J'allai fur le champ célébrer la iainte Mefle, pour remercier Dieu de nous avoir foûtenus au milieu de tant de fatigues, \& délivrés de tant de dangers.

Je fuis, \&c. 


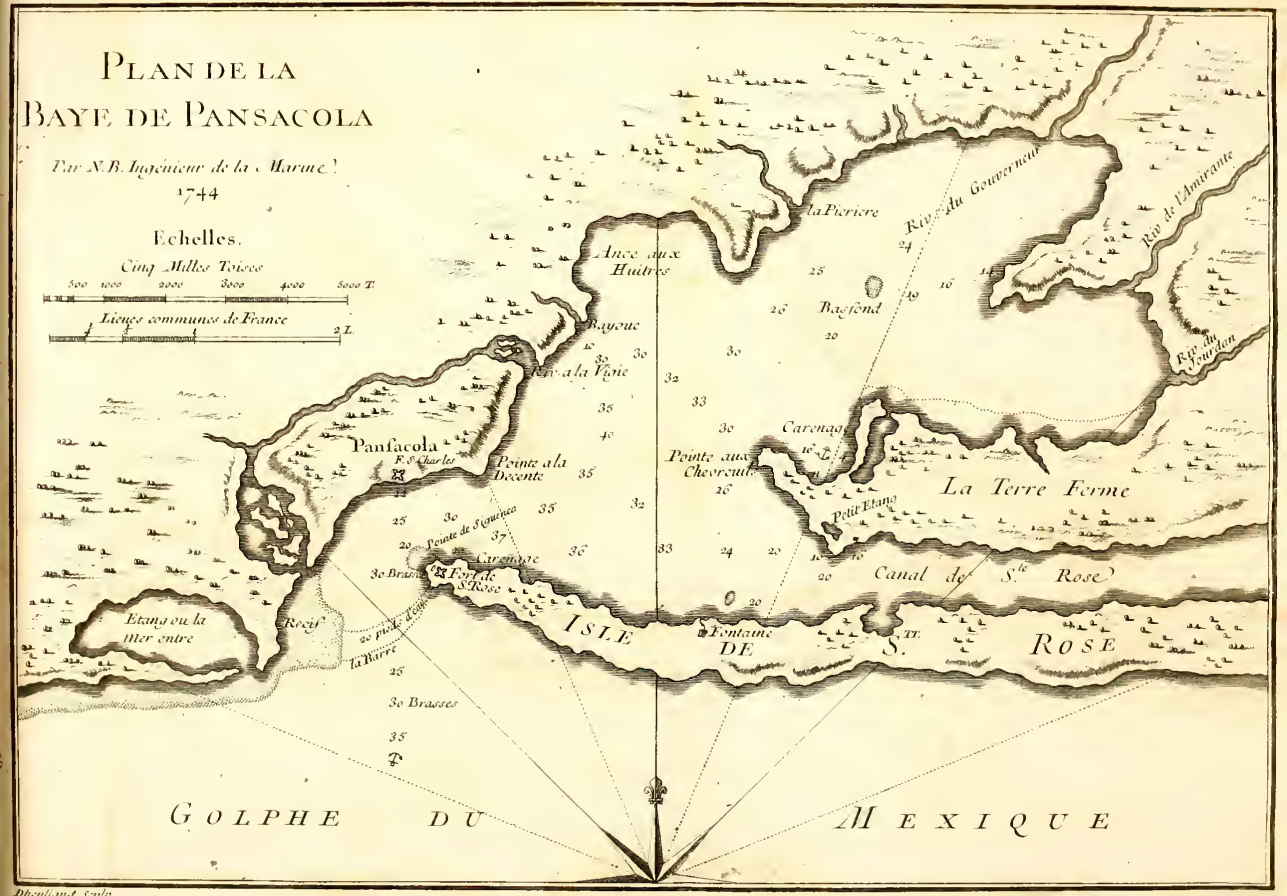





\section{TRENTE-CIN QUIEME LETTRE.}

Voyage du Biloxi au Cap François de S. Domingue. Au Cap François, ce fixiéme de Septembre 1722.

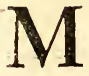

\section{A D A ME,}

JE n'avois pas ofé vous annoncer dans ma derniere, comme je l'avois fait dans la précedente, que je ne vous écrirois plus que du Cap François, de peur d'être encore obligé

1722 :

Juin. de me dédire, \& peu s'en eft fallu que ma crainte n'ait été juf. tifiée par l'événement. M'y voici enfin, dans ce Port fi lontems defiré, après foixante-quatre jours de navigation, \& nous y fommes entrés dans le tems, que nous avions prefque perdu toute efpérance d'y parvenir. Mais avant que d'entamer le récit des aventures de ce Voyage, il faut reprendre la fuite de mon Journal.

La premiere nouvelle, que nous apprimes en arrivant au Biloxi, fut celle de la Paix concluë avec l'Efpagne, \& de la double Alliance entre ces deux Couronnes. Un des Articles

Penfacole rendu aux $\mathrm{E}$ pagnols. de la Paix étoit la reftitution de Penfacole, \& cet Article avoit été apporté à la Louyfiane par D. Alexandre W ALCOP, Irlandois, \& Capitaine de Vaiffeaux dans la Nouvelle Efpagne. Il s'étoit embarqué à la Vera-Cruz, fur un Brigantin de cent cinquante Hommes d'Equipage, monté de quatorze piéces de Canon, \& commandé par D. Auguftin Spinola. On prétend que le deffein des Efpagnols eft de faire un grand Etabliffement à Penfacole, \& dy tranfporter la Garnifon, $\&$ tous les Habitans de S. Jofeph. On ajoûte que D. Alexandre Walcop en eft défigné Gouverneur : c'eft un Homme de trèsbonne mine, extrêmement fage, \& plein de religion.

D. Auguftin Spinola eft un jeune Homme plein de feu, Interlope And'un caractere très-aimable, dont les fentimens annoncent glois au Bifa haure Naiffance, \& font dignes du nom qu'il porte. Il eft Lieutenant de Vaiffeau, \& s'eft engagé à fervir trois ans dans Tome III. 
482 J O UR N A L H I S T O R I Q U E

1722 . le Mexique, après quoi il compte de retourner en Efpagne, Juin. \& d'y faire fon chemin. Il fut bien mortifié d'apprendre qu'un Interlope Anglois, nommé Marshal, ne s'étoit retiré de la Rade du Biloxi, où il avoit fait un Commerce confidérable avec les François, que quand il y étoit entré lui-même. Cet Armateur ne vouloit pas même s'éloigner, difant qu'il ne craiछnoit point les Efpagnols, mais M. de Bienville l'y obligea,ne voulant pas être fpeetateur d'un Combat, dont nos Officiers prétendoient que le fuccès n'auroit pas été favorable aux Aggreffeurs, quoique fuperieurs en forces. Nous verrons bientôt qu'ils fe trompoient dans l'idée avantageufe, qu'ils avoient de Marshal. Déertions Cependant, quoique depuis le départ de l'Adour, quelques
fiéquentes dans la Louyfiane.

Navires de la Compagnie euffent un peu ravitaillé la Louyfiane, la mifere ne laiffoit pas d'y être encore bien grande, \& le mécontentement y croiffoit tous les jours: malgré les foins, que fe donnoit $\mathrm{M}$. de Bienville pour $\mathrm{y}$ foulager les Habitans, on n'entendoit parler que de complots pour déferter. Ostre le Batteau, que nous avions rencontré fur la route de S. Marc à S. Jofeph; tous les Suiffes, qui étoient au Biloxi, le Capitaine \& les Officiers à la tête, ayant eu ordre de paffer à la Nouvelle Orleans fur un Traverfier, armé exprès pour eux, \& qu'ils avoient eu foin de bien fournir de vivres, au lieu de prendre la route du Miciffipi, avoient tourné , Enfeignes déployés, à l'Eft, \& on ne doutoit point qu'ils n'euffent pris la route de la Caroline, parce qu'étant Proteftans, il n'y avoit nulle apparence qu'ils fe fuffent arrêtés chez les Efpagnols (a).

Confpira- Enfin, je découvris le huitiéme de Juin une confpiration tion dícouver- formée pour enlever le Brigantin Efpagnol. Il étoit fept heures
ze. du foir, lorfqu'on m'en donna fecretement avis, \& l'on m'affûra qu'avant neuf heures le projet feroit executé, le Commandant du Brigantin n'ayant pas accoûtumé de fe retirer à fon Bord avant cette heure-là. Les Conjurés étoient a nombre de cent cinquante, \& leur projet étoit, s'ils réuffiffoient dans leur entreprife, de fe faire Forbans. J'envoyai fur le champ avertir M. de Bienville, qui étoit à table avec D. Auguftin Spinola, lequel fe leva auffi-tôt, \& fe rendit à fon Bord, \& le Major du Biloxi eut ordre de commencer inceffamment fa ronde.

(a) On a ç̂û depuis qư ils étoient allés à la Caroline. 
D'UN VOYAGE DE L'AMERIQ. LET. XXXV. 483

Ces mouvemens firent comprendre aux Conjurés que leur deffein étoit éventé, \& le Major n'apperçut que quatre ou cinq Hommes attroupés, qui difparurent, dès qu'ils le virent, \& dont il ne put joindre aucun, de forte qu'on crut que javois donné une fauffe allarme : mais outre que les jours fuivans on n'entendic parler que d'Habitans \& $\&$ de Soldats, qui avoient difparu, quelques-uns de ces Déferteurs, ayant été repris, déclarerent le complot, dont j'avois donné avis.

Le douziéme, un Chef des Tchactas vint dire à M. de Bienville, que les Anglois leur faifoient de grandes promeffes, pour 'fe les attacher, \& pour les engager à ne plus avoir de Alliés. commerce avec les François : le Commandant donna en cette occafion une grande preuve du talent, qu'il a de manier à fon gré les efprits des Sauvages. Il fçut fi bien cajoler ce Chef, qu'avec quelques préfens de peu de conféquence il le renvoya très-difpofé à demeurer ferme dans notre alliance. Cette Nation nous cauferoit de grands embarras, fi elle fe déclaroit contre nous; les Chicachas, les Natchez \& les Yafous lui donneroient bien-tôt la main, \& il n'y auroit plus de fûreté à naviger fur le Micifipi, quand bien même ces quatre $\mathrm{Na}$ tions n'entraîneroient pas toutes les autres, ce qui, felon toutes les apparences, ne manqueroit pas-d'arriver.

Sur la fin du mois un Habitant des Illinois, qui étoit allé en traite dans le Miffouri, arriva au Biloxi, \& rapporta, que lui \& un ou deux autres François ayant pénétré jufqu'aux Octotatas, qui en 1719 . défirent les Efpagnols, dont je vous ai parlé, ils en avoient été bien reçus, \& q que des Marchandifes, qu'ils leur avoient portées, ils en avoient tiré pour fept ou huit cent francs d'argent, partie ouvragé, \& partie en lingots; que quelques-uns de ces Sauvages les avoient accompagnés jufqu'aux Illinois, $\&$ avoient aifúré à $M$. de Boisbrillant que les Efpagnols, à qui ils avoient enlevé cet argent, le tiroient d'une Mine peu éloignée du lieu, où il les avoient rencontrés, \& qu'ils lui avoient offert d'y mener des François, ce que ce Commandant avoit accepté. Le tems nous apprendra, fi ces Sauvages ont parlé plus fincerement que tant d'autres, qui depuis lontems ne cherchent qu'à attirer les François chez eux par l'appas des Mines, dont aucune ne s'eft encore trouvée réelle $(a)$.

(a) On n'a plus entendu parler de cette Mine depuis ce tems-là.

Les Anglois tâchent d'artiè à eux nos 


\section{J O UR N A L H IS T O R I Q UE}

I 72 2. Le vint-deux je m'embarquai fur la Bellone, qui mit à la

Juillet.

Départ du Biloxi.

Obfervation fur le chaud. voile le trente. Le fecond de Juillet nous nous eftimions Nord \& Sud de Penfacole, d'où nous voulions affurrer notre point de longitude, parce que celle de l'embouchure du Miciffipi n'eft pas encore bien fixée. Depuis ce tems-là jufqu'au vintiéme, il ne fe paffa rien de particulier. Nous avions alors le Soleil directement fur notre tête, \& dans notre voyage des Martyrs au Biloxi, nous avions effuyé les plus grandes chaleurs du Solftice, fans pouvoir nous en garantir en aucune maniere, non plus que des rofées, qui tomboient en abondance pendant les nuits. Croiriez-vous bien cependant, $\mathrm{Ma}$ dame, que nous fouffrimes beaucoup moins du chaud dans. cette Saifon, que nous n'en avions fouffert au mois d'Avril avant notre naufrage?

Rien n'eft pourtant plus vrai, \& je me fouvins alors, que javois été plus d'une fois fort furpris de voir des perfonnes nées fous la Zone fe plaindre beaucoup des grandes chaleurs de France. Nous étions dans le même cas au mois d'Avril , nous avions les mêmes chaleurs qu'on reffent en France, \& même en Italie au mois de Juillet; dans le mois de Juillet, pendant la Canicule, nous étions fous la Zone, \& la chaleur étoit affûrément plus grande, mais elle étoit plus fupportable, Cette différence ne venoit pas des vents; nous eumes les mềmes, \& nous en eûmes toujours dans les deux Saifons. Ce n'étoit pas non plus feulement que nous y fuffions plus accoutumés, car nous n'étions pas fujets à ces fueurs continuelles, qui nous avoient fi fort incommodés au mois d'Aivril.

Il en faut donc chercher une autre raifon, \& voici celle, qui fe préfente à mon efprit. Dans le Printems l'air eft encore rempli de vapeurs, que l'Hyver y affemble. Ces vapeurs, quand le Soleil fe rapproche, en font d'abord embrafées, \& 8 voilà ce qui caufoit ces chaleurs pefantes, \& ces abondantes fueurs, dont nous étions accablés au mois d'Avril; nous étions prefque toujours au Bain Marie. Au mois de Juillet ces vapeurs étoient diffipées, \& quoique le Soleil fut beaucoup plus près de nous, le moindre vent fuffifoit pour nous rafraîchir, en émouffant la vivacité de fes rayons prefque perpendiculaires fur notre tête. Or en France le Soleil ne diffipe jamais bien les vapeurs, comme il fait entre les Tropiques, du moins elles font ici beaucoup moins groffieres, \& 
D'UN VOYAGE DE L'AMER. LET. XXXV. 485 c'eft ce qui produit, non la différence du chaud, mais celle de la fenfation de la chaleur.

Le vintiéme nous découvrîmes la Terre de Cuba, ce que nous avions fait en fept jours, trois mois auparavant. Deux chofes cauferent ce retardement. La premiere eft qu'on ne fçauroit compter fur les hauteurs, quand le Soleil eft fi proche, parce que fes rayons ne forment point d'angle fenfible. Cela fait que, dès qu'on a le moindre foupçon de la proximité des terres, on n'ofe porter beaucoup de voiles pendant la nuit. La feconde eft que le Capitaine de la Bellone vouloit aller à la Havane, \& dans la perfuafion, où il étoit, que les courants portoient à l'Eft, il fit l'Oueft autant qu'il le jugea néceffaire, pour ne pas manquer fon but.

II s'en fallut pourtant bien peu qu'il ne paffât devant la Havane fans le fçavoir. On vint me dire de grand matin qu'on voyoit la terre; je demandai comment elle paroifoit, \&x fur la réponfe, qu'on me fit, jaffûrai que c'étoit le Cap de Sed. On fe mocqua de moi , \& les deux Officiers de l'Adour, qui étoient avec nous, furent les premiers à foûtenir, que je me trompois. Je montai fur le Pont, \& je perfiftai dans mon fentiment contre celui de tout le Navire ; nos Pilotes affûrant que nous étions foixante lieuës plus à l'Oueft. Au coucher du Soleil je reconnus la Table à Marianne, mais je fus encore feul de mon avis : cependant nous avions le vent contraire, \& toute la nuit nous ne fìmes que courir des bordées au large $\&$ à terre.

Le lendemain à midi nous étions encore à la vûë des deux terres, qui faifoient le fujet de notre conteftation, lorfque nous étant un peu plus approchés de terre, nous apperçûmes la Havane devant nous, ce qui fit grand plaifr au Capitaine, lequel avoit une bonne Pacotille, fur laquelle il efperoit de faire un grand profit avec.les Efpagnols. Son interêt me touchoit peu, mais fi nous euffions été plus au large, \& que le vent ne nous eût pas contrariés pendant la nuit, l'erreur \& l'entêtement de nos Pilotes \& de nos Officiers nous auroient coûté bien cher. Le vent étoit bon pour entrer dans la Havane, \& à cinq heures du foir nous n'en étions qu'à une lieuë; nous tirâmes alors deux coups de Canon, l'un pour affûrer notre $\mathrm{Pa}$. villon, l'autre, après qu'on eut mis le Pavillon en berne, pour demander un Pilote du Port.

I 722.

Juillet.

Et fur les hauteurs. 
1722.

Juillet. du Port de la Havane.

Defription L'entrée du Port de la Havane regarde le Nord-Oueft-

Rien ne parut, \& il fut réfolu d'envoyer le Canot pour demander la permiffion d'y entrer: mais comme il étoit déja tard, la partie fut remife au lendemain, \& toute la nuit nous nous foûtînmes en courant des bordées. Le vint-trois un Officier de la Bellone s'embarqua pour aller prier le Gouverneur de vouloir bien confentir que nous fiffions de l'eau dans fon Port, \& que nous y achetaffions des vivres, parce que l'on n'avoit pû nous en donner fuffifamment au Biloxi. Ce n'étoit qu'un prétexte, mais je ne le fçavois pas, \& le Capitaine mayant prié d'accompagner fon Officier, je ne crus pas devoir le refufer. Quart-d'Oueft: fur la gauche, en y entrant, on trouve un Fort bâti fur un Rocher, au pied duquel il faut paffer : on l'appelle le Fort du More. Il eft folidement conftruit, \& a trois bonnes batteries de Canons de Fonte l'une fur l'autre. A la droite il y a une fuite de Baftions, qui me parurent nouvellement achevés, ou réparés depuis peu. L'entrée n'a en cet en-droit que cinq ou fix cent pas de largeur, \& on la ferme par une chaîne de fer, qui peut arrêter un Navire affez lontems, pour qu'il foit criblé de coups de Canons, avant qu'il foit venu à bout de la couper.

La paffe s'élargit enfuite un peu jufqu'à la Ville, c'eft-à-dire, pendant trois ou quatre cent pas. Le Canal tourne de-là à gauche beaucoup au-delà de la Ville, qui eft fur la droite. C'eft tout ce que j'en puis dire, n'ayant pas été plus loin. Je fçai feulement que la Ville occupe la tête d'une prefqu'Ifle, \& que le cóté de la terre, quieft toute fa longueur, eft fermé d'une bonne muraille baftionnée. L'afpect en eft fort agréable, \& bien développé, dès qu'on a paffé le Fort du More. Les Ruës y font bien percées, le Quay large \& bien entretenu, les Maifons bien bâties pour la plûpart : des Eglifes en affez grand nombre, \& qui paroiffent affez belles. Mais je ne fuis entré dans aucune. En un mot une Ville de vint mile Ames n'a point plus d'apparence; mais la Havane, m'a-t'on 'dit, n'en a pas tant à beaucoup près.

Sort del'ino Je rencontrai en débarquant plufieurs des Matelots de l'Aterlope Mars dour, tant de la Chaloupe, que du Canot. Les Premiers me dirent que de l'endroit, où nous avions fait naufrage, ils avoient été cinq jours à fe rendre dans ce Port, \& prefque 
toujours à deux doits de la mort. Je n'eus pas le tems de m'informer par quelle aventure les Seconds étoient venus là. Mais le Sergent, qui étoit entré dans notre Canot au pied du Fort $\mathrm{du}$ More, pour nous conduire, eut grand foin de nous montrer le Brigantin de l'Interlope Marshal, dont je vous ai parlé au commencement de cette Lettre. Il étoit mouillé auprès d'un Batteau fi petit, qu'à peine pouvoit-il contenir quinze ou vint Hommes, qui cependant avoient enlevé ce Brigantin à l'abordage. Il faut avouer que les Armateurs de Cuba \& des Ifles voifines font braves : nos Flibutiers les ont aguerris; mais vû la difproportion des forces, la valeur \& le Canon des Anglois, il falloit que ceux-ci euffent été furpris.

Le Gouverneur de la Havane nous reçut froidement, \& après nous avoir entendus, il nous dit qu'il auroit été charmé de pouvoir nous accorder ce que nous lui demandions, mais que le Roi fon Maître lui avoit lié fur cela les mains, \& qu'il avoit furtout des défenfes expreffes de recevoir dans fon Port aucun Bâtiment venant de la Louyfiane. Il ajoûta qu'il y avoit fur la même Côte plufieurs endroits, où nous pourrions nous arrêter fans aucun rifque, \& où l'on nous fourniroit tous les rafraichiffemens, dont nous avions befoin. Il fallut nous contenter de cette réponfe, \& après avoir été faluer le Rekteur du Collége, que nous avons dans cette Ville, je me rembarquai.

Le lendemain vint-quatre à fix heures du matin nous étions Nord \& Sud du Pain de Matance, \& à onze heures \& demie, par le travers de Rio dé Ciroca, où il y a une Habitation Ef pagnole. Mais comme le Capitaine vouloit voir s'il réuffiroit mieux à Matance, qu'il n'avoit fait à la Havane, \& que nous avions encore fept lieuës à faire pour y arriver, il prit le parti de louvoyer toute la nuit, \& le vint-cinq au point du jour nous nous trouvâmes à l'entrée de la Baye, qui a deux lieuës d'ouverture.

Pour y entrer il faut d'abord doubler une Pointe, qui n'avance pas beaucoup dans la Mer, puis faire l'Oueft pendant une lieuë : on apperçoit enfuite fur la même main droite une autre Pointe, derriere laquelle eft le Fort; \& un grand quart de lieuë plus loin le Bourg de Matance entre deux Rivieres, qui baignent fes murs des deux côtés. Vers les dix heures du matin on y envoya le Canot avec un Officier, qui ne trouva

1722. Juillet.

Le Gouverneut de la Havane refufe 12 permiftion d'entrer dans fon Iort.
Defcription de la Baye de Matances 


\section{J OUR N A L H I S T O R I Q U E}

1722 . point le Commandant du Fort dans fa Place. Il expofa au LieuJuillet. tenant le prétendu befoin, où nous étions ; mais cet Officier lui dit qu'il n'ofoit prendre fur foi de lui accorder la permiffion, quil demandoit; que tout ce qu'il pouvoit faire pour fon fervice, étoit d'envoyer un Courrièr à la Havane, pour fçavoir les intentions du Gouverneur de cette Ville, qui étoit fon Général, \& que, fi ce parti nous convenoit, nous pouvions en attendant mouiller de l'autre côté de la Pointe, où nous ferions plus en fûreté.

Cette réponfe \& la déclaration, que nos Pilotes s'aviferent alors de taire, qu'ils ne fe chargeroient pas d'entrer le Navire dans la Baye de Matance, par la raifon qu'ils ne la connoiffoient pas affez, déterminerent enfin le Capitaine à continuer fa route avec toute fa Pacotille, pour laquelle il nous avoit fait perdre au moins quinze jours d'un tems précieux. Le lendemain à fix heures du matin nous avions encore derriere nous à la vûë le Pain de Matance, dont nous nous eftimions éloignés de douze à quinze lieuës, \& le vint-fept à cinq heures du matin on découvrit du haut des Mâts la terre de la Floride.

Débouquement du Canal de Bahama.

A cette vûë on mit le Cap au Nord-Nord-Eft: deux heures après on revira de bord, pour prendre un peu plus de l'Eft; à neuf heures on fe remit en route, $\&$ nous nous trouvâmes dans le vrai Courant, qui va au Canal de Bahama, car nous paffions comme un trait. Nous vîmes en ce moment l'Adour, qui montroit encore un bout du Mât, mais dont la carcaffe étoit prefque toute couverte d'eau, \& nous reconnûmes qu'il s'en falloit bien qu'elle eût échoué vis-à-vis de la plus feprentrionnale des Martyrs, comme quelques - uns l'avoient cru; car nous l'avions par notre travers à dix heures $\&$ demie, \& à une heure \& demie la derniere de ces flles nous reftoit au Nord.

Vers les trois heures on apperçut de la Hune un brifant, que nous allions ranger de bien près, \& $\mathrm{x}$ plus loin une batture, qui avançoit beaucoup au large. Cette batture étoit apparemment la fin des Martyrs, \&r pour la parer nous reprîmes le refte du jour du Sud $\&$ de l'Eft, le courant nous portant toujours au Nord, \& fur le foir nous fìmes le Nord-Eft. Le vint-huit à midi, le Pilote s'eftimoit à l'entrée du Canal, par les vint-cinq degrez trente minutes, à fept heures $\&$ demie du foir il craignît d'ệtre trop près de terre, \& mit le Cap 
au Sud-Sud-Eft jufqu'à minuit, avec un très-bon vent. A minuit il reprit fa route, \& le vint-neuf nous ne vìmes plus de terres. Le foir on fe crut hors du Canal, mais pour plus 1722. Août. grande fûreté on continua jufqu'à dix heures du foir à faire le Nord-Nord-Eft.

Dans tout le refte de notre navigation, jufqu'au Cap François, nous eûmes prefque toujours des vents foibles, \& fouvent des calmes. De tems en tems il s'éle voit des orages, le Ciel \& la Mer étoient en feu, \& le Navire, panché d'un côté, alloit comme le vent, mais cela ne duroit pas, \& une pluye d'un quart-d'heure déchargeoit le $\mathrm{Ciel}, \&$ abaiffoit les vagues de la Mer, laquelle reffembloit à ces perfonnes d'un caractere doux \& tranquille, qui ont quelquefois des accès de colere affez vifs, mais qui s'apaifent d'abord. Je crois que ce qui contribuë à calmer la Mer fi promptement, après ces agitations fi violentes, cè font les courants. Ils font en effet trèsfenfibles dans ces parages, d'ailleurs ils varient fans ceffe, ce qui déconcerte toute l'habileté des Pilotes.

Quand on eft forti du Canal de Bahama, la droite route pour gagner l'Inle de S. Domingue, feroit le Sud-Eft. Mais les vents, qui fouflent prefque toujours de la partie de l'Eeft, ne permettent pas de la prendre, $\&$ il faut par une ligne parabolique s'élever jufqu'à la hauteur de la Vermude, qu'il feroit même à propos de reconnoître, s'il étoit poffible, afin d'affûrer fon point de longitude. Faute de cette connoiffance on eft quelquefois obligé d'aller jufqu'au grand Banc de TerreNeuve, avant que de pouvoir s'affûrer d'être affez à l'Êt de tous les écueils, qui font au Nord \& à l'Orient de l'Ille de S. Domingue.

On n'a pourtant pas toujours pris ce grand détour pour aller du Golphe Mexique à cette Ifle. Dans les premiers tems Vieux Canal de Bahama. de la découverte du nouveau Monde, après avoir fuivi la Côte Septentrionale de l'Ille de Cuba, jufqu'à la Pointe d'Itaque, qui en eft l'extrêmité Orientale, à quatorze lieuës de Matance, on tournoit à droite, \& on laiffoit à gauche toutes les Ifles Lucayes, dont celle de Bahama eft du nombre. C'eft ce qu'on appelle le vieux Canal de Bahama. Il y a de l'eau pour les plus grands Navires, mais on y rencontre tant d'écueils, qu'aujourd'hui il n'y a plus que des Barques, qui ofent s'y engager.

Roure, qu'il faut prendre pour aller du Canal de Bahana à S. Domingue. 
I 72 2. Après nous être élevés jufqu'aux trente degrez $\&$ demi, nos Pilotes fe jugerent fuffifamment à l'EAt, pour n'avoir plus Août. à craindre en faifant le Sud, de donner fur aucun des écueils, Erreur des dont j'ai parlé. On porta donc avec confiance au Sud, \& en Pilotes dans leur eftime. peu de jours nous fimes beaucoup de chemin, voguant fur une Mer toujours belle, \& conduits par les vents Alifés. Le vint-fept d'Août, à huit heures du matin, le Matelot, qui étoit en vigie fur la Hune, cria Terre, ce qui caufa une grande joye, mais elle fut courte, car ce Matelot étant defcendu, on lui demanda fi cette terre étoit haute, \& il répondit, qu'elle étoit fort baffe, par conféquent ce ne pouvoit être qu'une des Caïques, ou des Ifles Turques.

Nous étions encore bien heureux de les avoir vûës de jour, car le naufrage étoit inévitable , fi nous euffions donné deffus pendant la nuit, \& perfonne n'en feroit échapé , par la raifon que toutes ces Ifles font fans rivages, que la plûpart font bordées de récifs, qui avancent beaucoup au large, $\& x$ qu'elles font entrecoupées de petits canaux, où il n'y a pas affez d'eau pour des Chaloupes. D'ailleurs, elles font fort baffes, \& on ne les apperçoit de nuit, que quand on eft deffus.

Embarras, où l'on fe trouve en découvrant la Terre.

Mais pour avoir reconnu le danger, nous n'étions pas fauvés; la Terre, que nous avions devant nous, paroifloit une Ifle affez grande, \& affez bien boifée en quelques endroits; cela nous fit juger, que c'étoit la grande Caique, par conféquent, que nous étions quarante ou cinquante lieuës trop à l'Oueft. Pour nous remettre en longitude, il auroit fallu peutêtre remonter au Nord plus de deux ou trois cent lieuës, \& 8 compter fur cinq ou fix femaines de navigation. Mais nous avions à peine de l'eau $\&$ des vivres pour quinze jours, en économifant beaucoup. Le Capitaine étoit fort embarraffé ; il voyoit fes Pilotes en défaut, \& il avoit à fe reprocher de s'être trop repofé fur eux, de n'avoir pas pris hauteur luimême plus de deux ou trois fois, \& d'avoir toujours préferé l'eftime du fecond Pilote, jeune Homme fort étourdi, \& fort préfomptueux, à celle du premier, qui étoit plus habile $\&$ plus experimenté, \& qui n'avoit jamais approuvé la manœuvre, qu'on faifoit.

Quel parti Cependant il falloit prendre fon parti fur le champ: un on prend. coup du vent du Nord, qui nous auroit accueilli, \& nous 
D'UN V OYA G E DE L'AMER. Let. XXXV. 491 auroit jetté furces terres baffes, nous auroit immanquablement fait périr. Mais comme on ne pouvoit prendre de réfolution, qui n'eût fes inconvéniens; le Capitaine voulut avoir l'avis de tout le monde. Quelqu'un propofa d'aller au plus fûr, \& de faire vent arriere pour gagner la Caroline, où l'on pouvoit arriver en dix ou douze. jours, \& y acheter des provifions. Cet avis fut rejetté, \& on en fuivit un autre, où il y avoit tout à rifquer, \& qu'il me parut que le feul défefpoir pouvoit infpirer, ce fut de ranger la grande Caïque de fort près jufqu'au débouquement, c'eft-à-dire, jufqu'à la féparation de tous ces écueils, \& d'avec les Lucayes.

C'eft par-là , que paffent tous les Vaiffeaux, qui fortent de $S$. Domingue pour retourner en France, \& alors il n'y a rien à craindre, parce qu'on peut prendre fon tems pour débouquer, \& que ce paffage étant ouvert au Nord-Oueft, on eft prefque affûré d'avoir le tems favorable pour en fortir. Mais pour y entrer du côté, où nous étions, il faut compter fur le NordEft , \& c'eft un grand hazard, que de trouver ce vent à point nommé. Auffi perfonne, que l'on fçache, n'a encore tenté ce paffage. Enfin on voulut bien s'expofer à tous les hazards, \& on s'approcha de la grande Caique.

A deux heures après midi nous n'en étions plus qu'à une bonne portée de Canon, \& nous fommes peut-être les premiers, qui, fans une néceffité indifpenfable, ayions ofé la vifiter de fi près fur unVaiffeau. La Côte en eft pourtant fort faine,élevée, a ce qu'il m'a paru,de fept ou huit pieds, quelquefois d'un peu plus, mais elle eft à pic, \& fans aucun rivage. Son terroir n'a point du tout l'apparence d'être fterile. Les Géographes la placent directement fous le Tropique, \& c'eft ce que nous ne pûmes pas verifier, parce que le tems étoit couvert; mais je la crois un peu plus au Sud, car il n'y a certainement pas trois degrez de différence entre cette Ifle \& le Cap François.

Nous cotoyâmes la grande Caïque jufqu'à quatre heures du foir, ayant pour nous le vent $\&$ les courants. Alors on fit monter un Matelot au haut du Mât, pour obferver ce que nous avions devant nous, \& il revint bientôt nous dire qu'il avoit vû l'extrêmité de l'Ille, mais qu'au de-là on ne découvroit que des terres encore plus baffes, entrecoupées de Canaux, où les eaux paroiffoient toutes blanches. Sur ce récit, on jugea à propos de revirer de bord, \& on mit le Cap au de la grande Caique.

1722.

Août.

(1)

Qqq ij 


\section{J O UR N A L H IS T O R I Q U E}

Nord-Nord-Eft. A minuit on fit le Sud-Sud-Eft, \& il fem-

172 2. bloit que le vent tournât à notre gré ; mais il étoit bien foible, Août. \& les courants nous entraînoient avec tant de violence à l'Oueft, qu'au point du jour les terres baffes $\&$ les hauts fonds, que nous avions la veille fi loin devant nous, étoient prefque auffi loin derriere, \& que le paffage, que nous cherchions commençoit à s'ouvrir.

Nous touchions au moment décifif de notre fort , \& ce qui nous faifoit bien efperer, c'eft que le vent fe rangeoit peu à peu au Nord-Eft. A onze heures nous faifions le Sud-Eft, quart de Sud; peu après nous eûmes le Cap au Sud-Eft, mais les courants nous faifoient tellement dériver, qu'à peine la route nous valoit le Sud. A midi nous ne pûmes prendre hauteur, \& la Pointe Occidentale de la Caique nous reftoit au Nord, quart de Nord-Eft. Enfin à une heure nous étions parés, \& je ne puis mieux vous exprimer ce qui paroiffoit fur tous les vifages, à mefure que nous avancions dans le débouquement, que par la comparaifon de ce qui arrive à ces Animaux, quon a mis dans le récipient de la machine pneumatique,qui y paroiffent morts, quand on en a pompé prefque tout l'air, \& à qui on rend la vie peu à peu, en le faifant rentrer lentement.

Nous n'ofions néanmoins nous flatter encore de pouvoir gagner le Cap François, qui nous reftoit au vent, mais nous avions le Port de Paix, ou du moins Léogane, que nous ne pouvions pas manquer, $\&$ après le péril extrême, que nous venions de courir, tout nous étoit bon, pourvû que nous trouvaffions un Port. A minuit nous effuyâmes un grain de vent du Sud affez violent, mais de peu de durée, \& le lendemain, fur les neuf heures au matin, nous apperçûmes la Terre de S. Domingue, mais fans y pouvoir rien diftinguer de tout le jour, parce qu'elle étoit fort embrumée. Un Navire, qu'on jugea à fa manœuvre pouvoir être un Corfaire, nous occupa une bonne partie de l'après-dîner : nous nous préparâmes fé. rieufement à le combattre, ou plutôt à nous défendre, s'illui prenoit envie de nous attaquer, car nous n'aurions pas changé une voile pour l'aller chercher.

Àrrivée au Cap Itançois.

A la fin nous reconnûmes que ce n'étoit qu'un petit Bâtiment de cent cinquante Tonneaux au plus, \& il avoit eu apparemment plus de peur que nous. Nous jugeâmes à fa ma- 
D'UN VOYAGE DE L'AMERIQ. LET. XXXVI. 493 nœuvre qu'il fortoit du Cap François, \& il paroiffoit bien chargé. Toute la nuit nous courûmes des bordées au Nord$E$ ft, en variant un peu, ce qui nous éleva, $\&$ dès qu'il fut jour, nous reconnûmes avec bien de la joye, que nous étions

Septemau vent du Cap François. Nous le voyions à plein, nous y touchions prefque, mais nous avions fi peu de vent, que nous ne pûmes y entrer que le premier de Septembre, à quatre heures du foir. Depuis ce tems-là je n'ai pas encore eu un moment à moi pour vous entretenir de ce Pays, \& on me demande ma Lettre pour la porter à un Vaiffeau, qui appareille pour Nantes. Je compte de partir moi-même dans quinze jours pour le Havre de Grace, d'où j'aurai l'honneur de vous écrire encore une fois.

Je fuis, \&c.

\section{TRENTE-SIXIEMME LETTRE.}

Defcription du Cap François de Saint Domingue. Retous en France, relâche en Angleterre.

A Roüen, ce cinquiéme Janvier 1723.

\section{MADAME,}

Je n'ai été qu'un jour au Havre, parce que je ne voulois pas manquer le Caroffe de Roüen, \& je fuis venu ici me délaffer à mon aife du plus long \& du plus rude Voyage, que j'euffe encore fait fur Mer. Enfin il n'y paroît plus, \& je vais profiter d'un peu de loifir, qui me refte en attendant le Coche de Paris, pour achever de vous inftruire de toutes mes aventures, depuis deux ans $\&$ demi, que je cours le Monde.

Le Cap François de S. Domingue, d'où ma derniere Lettre étoit dattée. eft un des Ports de toure l'Amérique, où les François faffent un plus grand Commerce. Ce n'eft à proprement parler qu'une Baye, qui n'a pas tout-à-fait une lieué de profondeur, \& dont l'ouverture eft fort large : mais cette

Defcriprion du Cap Fran. çois. 


\section{J O U R N A L H I S T O R I Q U E}

17.22 . ouverture eft femée de récifs, entre lefquels on ne fçauroit bre.

Septem- naviger avec trop de précaution. Pour y entrer il faut prendre à droite le long d'une Pointe, où il y a une Redoute $\&$ du Canon; mais l'ufage eft qu'avant que de s'engager dans ces Pafies étroites, où deux Navires ne fçauroient aller de front, on appelle un Pilote du Port; \& pour empêcher que l'envie d'épargner une piftole, qu'il lui faut donner, ne faffe rifquer le falut d'un Equipage, il a été fagement ordonné que, quand bien même on feroit entré fans fon fecours, on ne laiffera pas de le payer.

La Ville eft dans le fond de la Baye, fur la droite. Elle n'eft pas confidérable, parce que prefque tout ce qui n'eft pas Artifan, Marchand en détail, Soldat, ou Cabaretier, demeure dans la Plaine, autant que le Service le permet aux Officiers, la Juftice aux Magiftrats, \& les affaires du Commerce à ceux, qui y font intereffés, c'eft-à-dire, à prefque tout ce qu'il y a ici d'honnêtes Gens : de forte que, pour voir le beau Monde, il faut aller à la Campagne. Auffi rien n'eft plus charmant que la Plaine, \& les Vallées, qui font entre les Montagnes, dont elle eft bordée. Les Maifons n'y font pas magnifiques, mais elles font propres \& commodes, les Chemins tirés au cordeau, d'une belle largeur, bordés de hayes de Citronniers, quelquefois plantés de grands Arbres, \& d'efpace en efpace coupés de ruiffeaux d'une eau claire, fraîche $\&$ fort faine. Toutes les Habitations paroiffent bien cultivées, \& ce font réellement de très-belles Maifons de plaifance : par tout on voit un air d'aifance, qui fait plaifir.

De la Plaine du Cap.

Cette Plaine eft l'extrêmité du Nord-Oueft de cette fameufe $V$ ega-Real, dont il eft tant parlé dans les Hiftoires Caftillanes de $S$. Domingue, qu'òn affûre avoir quatre-vint lieuës de long, \& que le célébre Evêque de Chiappa , Barthelemy de las Cafas, prétend être arrofée de vint-cinq mille Rivieres. Les grands noms ne coûtent rien aux Efpagnols ; ces prétenduës Rivieres ne font pour la plûpart que de petits Ruiffeaux, dont le nombre eft effectivement incroyable, \& qui feroient de cette Plaine royale quelque chofe de plus charmant $\&$ de plus délicieux , que la Vallée de Tempé, fi vantée par les Grecs, fi elle n'étoit pas fous la Zone Torride. Il y a même des Cantons, où l'air eft très-fain, \& la chaleur fupportable, tel que celui, où a été bâtie la Ville de Sant-Yago de los 
Cavalleros ; \& on peut dire la même chore des Vallées, qui font entre les Montagnes, dont la Plaine du Cap eft bornée au Midi. Elles commencent à fe peupler, \& elles le feront bien-tôt plus que la Plaine même, par la raifon qu'on y voit peu de Malades, \& que ceux, qui y viennent d'ailleurs, y guériffent en peu de tems de maladies, que tous les remédes n'avoient pû furmonter.

J'ai parcouru les Habitations les plus proches de la Ville, mais je n'ai pas eu le loifir d'y faire beaucoup d'obfervations. D'ailleurs, pendant le jour le chaud étoit extrême, \& le foir, dès que le Soleil étoit couché, les Coufins \& d'autres Moucherons femblables, ne me permettoient pas de me promener lon-tems. Ces petits Infectes s'attachent furtout aux nouveaux venus, qui ont la peau plus tendre, \& le fang plus frais. On m'a affûré, que dans la partie Efpagnole de l'tlle, on eft exempt de cette incommodité, mais en récompenfe nous n'avons point de Serpens venimeux, \& ils en ont beaucoup. On m'a fait auffi remarquer, qu'à l'exception de la Laituë, tous les Légumes fe doivent renouveller tous les ans dans cette Ine avec des graines d'Europe.

Ce que jy ai vû de plus curieux, font les Moulins à Sucre. Je ne vous en dirai rien, parce que le P. Labat en a parlé beaucoup mieux, que je ne pourrois faire. Après le Sucre, la plus grande richeffe de cette Colonie eft l'Indigo, dont le même Auteur a auffi très-f̧çavamment traité. Cette Plante a une ennemie irréconciliable, \& qui fait fur elle bien d'autres ravages, que l'Yvroye dans nos Bleds. C'eft une herbe, qu'on appelle Mal-nommée, \& qui en fortant de la terre porte fa graine, qu'elle répand par tout. Elle vient en touffe, \& par fon volume, \& fa prodigieufe fécondité, elle étouffe tellement l'Indigo, qu'elle le fait mourir : de forte que, quand elle a fait le moindre progrès dans un champ, il eft entierement perdu, \& qu'il en faut défricher un autre.

Les Côtes de Saint Domingue ne font pas abondantes en Poiffons, mais pour peu, qu'on aille en pleine Mer, on y en trouve de toutes les fortes. Nous pêchâmes furtout, en y venant de la Louyfiame, beaucoup de Dorades, fur lefquelles nos Marins prétendent avoir fait une obfervation affez finguliere. C'eft que, quand on prend ce Poiffon dans le Croiffant de la Lune, la chair en eft ferme, $\&$ d'un goût exquis, au fur les Dora-

1722 .

Septembre.

Obfervations, des. 
1722 . lieu que, fi on le pêche dans le décours, il eft infipide, fa chair n'a point de confiftance, \& elle s'en va comme de la charpie. bre.

Septem- Il eft vrai que nous éprouvâmes l'un \& l'autre dans les deux tems ; mais que cela arrive toujours, \& que veritablement la Lune en foit caufe, c'eft ce que je n'ai garde d'affûrer.

Cap.

Départ du Nous partîmes du Cap François le vint-cinq de Septembre fur un Navire Marchand du Havre appellé le Louis de Bourbon, commandé par un des plus habiles Navigateurs, que jaye connus : mais à peine fûmes-nous en Mer, que nous apperçûmes qu'il faifoit deux voyes d'eau, de forte que pendant toute la traverfée, qui fut de quatre-vint-douze jours, il fallut pomper foir \& matin, ce qui, joint au défaut des vivres, qu'on avoit cependant embarqués en abondance, mais qu'on ne ménagea nullement pendant le premier mois, fit que notre Capitaine fut plufieurs fois fur le point de relâcher aux Açorres. Nous aurions encore été plus embarraffés, fi nous euffions donné dans le piége, que nous tendit le Capitaine d'un $\mathrm{Na-}$ vire Anglois, que nous rencontrâmes à moitié chemin.

Rencontre Il étoit parti de la Jamaïque avec une Flotte, dont il avoit d'un Navire d'abord été, difoit-il, le meilleur Voilier ; mais comme, en Anglois.

1722 . arrimant fon Navire, il avoit eu l'imprudence de placer toutes les provifions de bouche dans le même endroit, il étoit arrivé qu'à mefure qu'il les confumoit, le Bâtiment perdant fon Ottobre. équilibre, perdit peu à peu l'avantage, qu'il avoit fur les auNovem- tres, \& demeura enfin bien loin derriere la Flotte; nous le bre. rencontrâmes en effet feul, \& allant fi lentement, qu'au prix de lui, notre Vaiffeau, qui n'étoit rien moins qu'un fin Voilier, alloit comme un Oifeau, \& qu'il craignit que les vivres ne lui manquaffent tout-à-fait, avant qu'il pût aborder en Angleterre. Il nous témoigna fa peine, $\&$ pour nous l'expliquer mieux, il s'invita à dìner fur notre Bord. On lui répondit qu'il feroit le bien-venu, \& notre Capitaine fit ferrer une partie de fes Voiles pour l'attendre.

Pendant le repas il jetta le difcours fur notre route, \& nous demanda où nous croyions être. Le Capitaine lui montra fon point de la veille, \& il en parut étonné. ll nous affûra enfuite que nous étions au moins deux cent lieuès plus avancés, que nous ne penfions; ce qu'il tâcha de prouver par les dernieres Terres, qu'il avoit reconnuës. Cela fit grand plaifir à la plûpart des Nôtres, qui s'ennuyoient déja beaucoup d'une fi 
D'UN VOYAGE DE L'AMERIQ. LET. XXXVI. 497 longue navigation, \& d'avoir fans ceffe à lutter contre des Vents violens \& une Mer orageufe fur un très-mauvais $\mathrm{Na}$ vire. Mais j'eus quelque foupçon que le Capitaine Anglois ne fe difoit fi fort avance , que pour nous engager à lui faire part de nos vivres. Le nôtre, à qui je communiquai mon foupçon, 1722. Octobre. Novembre. me dit qu'il penfoit de même, fe contenta de bien régaler fon Hôte, \& éluda fa demande. Il continua à naviger fur fa propre eftime, laquelle fe trouva fi jufte, quil entra dans la Manche au jour, \& prefqu'à l'heure, que peu auparavant il avoit dit qu'il y entreroit.

Le fecond de Décembre nous entrâmes fans aucune néceffité apparente dans le Port de Plimouth; mais notre Capitaine y avoit fans doute quelque affaire. Nous y trouvâmes la Fregate du Roi, la Thetis, qu'un coup de vent venoit d'y jetter toute défemparée, quoique ce fût fa premiere fortie du Havre de grace, où elle avoit été conftruite. Elle étoit montée par le Chevalier DE Fontenay , Capitaine de Vaiffeau, dont la deftination étoit d'aller aux liles de l'Amérique, donner la chaffe aux Forbans, qui y avoient enlevé depuis peu plufieurs Navires. Dès qu'il fçut que j'étois dans le Port, il me fit l'honneur de me vifiter, avant que $j$ 'euffe pu avoir la commodité de lui aller rendre mes devoirs, \& il me mena fur fon Bord, où je paffai bien agréablement tout le tems, que nous fûmes dans ce Port.

Plimouth eft un des cinq grands Ports d'Angleterre, \& un des plus beaux de l'Europe. Il eft double, \& avant que d'y Defcription de Plimouth. entrer, il faut paffer fous le Canon de la Citadelle. De-là on tourne à droite pour entrer dans le Port de la Ville, qui eft le plus petit, \& d'où il faut partir pour fortir de la Manche, \& c'eft là,que la Thetis étoit mouillée. On tourne à gauche pour entrer dans l'autre Port, où les Vaiffeaux du Roi d'Angleterre font défarmés, vis-à-vis un magnifique Arfenal. Ce Port s'étend fort loin, \& nous mouillâmes à l'entrée, parce que les vents, qui y fouflent, font bons pour aller plus avant dans la Manche.

La Ville de Plimouth eft peu de chofes, mais fes environs où je me fuis bien promené, font très-agréables. Je n'ai point vû de Pays plus gras: le tems étoit fort doux, les Campagnes auffi vertes, que dans le Printems, \& j'y vis paître des Tome III.

Arrivée à Plimouth.

1722 .

Décembre. 


\section{J O UR N A L H IS T O RIQUE}

1722 . Moutons monftrueux. La Laine en eft fort bonne, mais leur chair trop graffe a un mauvais goût. En récompenfe les Bœufs bre.

Décem- $\mathrm{y}$ font excellens, par la raifon qu'ils font fort gras.

La veille de la Conception, \& tout le jour de la Fête, on ne ceffa de carillonner à un des deux feuls Clochers, qui foient à Plimouth, \& quoiqu'il n'y eût que deux cloches, je n'ai point encore entendu de carillon, qui m'ait fait tant de plaifir. Je demandai en l'honneur de qui cela fe faifoit, car je me doutois bien que ce n'étoit pas pour honorer la Sainte Vierge, $\&$ on me répondit que la coûtume dans ce Pays-là étoit, quand quelqu'un donnoit un grand repas, de payer les Sonneurs pour faire carillonner. J'apperçus auffi fur le Port même, \& affez près de la Ville un grand Bâtiment fort ancien, qui fervoit d'Hôtellerie, \& qui ne paroiffọt pas avoir eté conftruit pour cet ufage; on mapprit que c'étoit les reftes d'une Abbaye célébre de Bénédietins.

Je n'aurois pas été fâché de faire un tour à Plimouth, \& de pouvoir avancer un peu plus dans la Campagne, pour en connoître tous les environs; mais $\mathbf{M}$. le Chevalier de Fontenay ne me le confeilla point, parce que tout étoit alors furpect en Angleterre, à caufe de l'affaire toute récente de l'Evêque de Rochefter. Je n'aurois pu en effet paroitre avec mon habit dans la Ville, ni dans les endroits peuplés, fans être expofé à quelqu'infulte, $\&$ il étoit trop tard pour prendre un autre habit, plufieurs Anglois m’ayant vû avec le mien : de forte que je me vis réduit à me promener dans quelques $\mathrm{Cam}$ pagnes voifnes du Port, où il n'y avoit perfonne. D'ailleurs. j'étois en bonne compagnie fur la Thetis. M. le Chevalier de Fontenny a parcouru toutes les Mers, auffi a-t'il l'efprit extrêmement orné. J'ai vî \& j’ai appris de lui des traits d'une gé. nérofité vraiment héroïque. Mais ce qui met le comble à tamt de qualirés fi eftimables, c'eft un grand fond de religion, \& une pieté fincere. Il femb'e avoir communiqué ces fentimens à fes Officiers; que je vis prefque tous approcher des Sacremens, \& rien n'eft plus édifiant, que tout fon Equipage, dont il eft adoré $(a)$.

Induftrie des Anglois pour furprendre les Forbans.

E_fin la nuit de Noël, après que j'eus célébré les trois Mef-

(a) Il eft mort pendant fon Expédition | dans la Guadaloupe, \& un de fes Officiers, 
fes, nous mîmes à la voile, \& tout le jour nous eûmes le vent favorable. Deux Fregates de cinquante Canons avoient levé les ancres deux heures avant nous, \& nous les joignîmes bientôt. Cela me furprit, parceque nous n'allions pas trop bien nous-mêmes: mais ce qui m'étonna encore davantage, ce fut qu'à voir ces deux Bâtimens fous voiles, fi je ne les avois pas vû appareiller, je n'aurois jamais pu croire que ce fuffent les mêmes, qui m'avoient paru fi grands dans le Port; fur quoi on me dit que cela venoit d'une conftruction \& d'une voilure particulieres, faites exprès pour attirer dans le piége les Forbans, ce qui en ftile de Matelots les fait appeller des Attrapes-lourdeaux. En effet, dit-on, les Pirates les voyant, $\&$ en jugeant par les apparences, les prennent pour des $\mathrm{Na}$ vires Marchands, \& fondent fur eux, comme fur une proye affûrée. Mais quand ils font engagés de maniere à ne pouvoir plus s'en dédire, ils trouvent à qui parler, \& font pris au trébuchet, fans pouvoir faire aucune réfiftance: auffi de toutes les Nations de l'Europe les Anglois font ceux, que les Forbans craignent le plus, \& qu'ils traitent plus mal, quand ils peuvent les avoir entre les mains.

La nuit fuivante nous effuyâmes une des plus horribles tempêtes, qu'on ait vûes de lontems dans la Manche. Le lendemain matin, quoique le vent fût prefque tout-à-fait tombé, la Mer étoit encore dans une agitation capable d'effrayer les plus hardis ; nous reçûmes même quelques paquets de Mer, qui nous mirent en grand danger : il y en eut un furtout, qui inonda la grande Chambre dans le tems que je commençois à dire la Melfe, \& me mit hors d'état de la célébrer ; auffi lorfque vers le midi nous entrâmes au Havre de grace, chacun nous demandoit comment nous avions pû réfifter à la tourmente, qui s'étoit fait fentir jufques dans le Port ?

Mais on aura encore été bien plus furpris que nous y ayions réfifté, lorfque deux jours après notre Navire ayant été tiré à terre, on l'aura vû tomber en piéces de pourriture. C'eft la premiere nouvelle, que jai apprife en arrivant ici. Jugez, Madame, à quoi tenoit notre vie fur un tel Bâtiment, pendant

qui vint mapprendre cette trifte nouvelle au retour de fa Campagne, me dit qu'étant prêt de mourir, il leur avoit fait, fur l'état, où il fe trouvoit, \& où chacun d'eux fe trouveroit un jour, un difcours, qui lcur avoit tiré les larmes des yeux.
1722 .

Décenbre.
Arrivće an Havre de Grace.

\section{R r r ij}




\section{J O U R N A L H IS T O R I Q U E}

1721 . dix-huit cent lieuës de navigation, dans une faifon, où la Mer eft toujours en fureur; \& quelles actions de graces

Décem- nous avons à rendre à Dieu, non-feulement de nous avoir bre. délivrés d'un danger fi éminent, mais encore de nous en avoir ôté la connoiffance, qui feule étoit capable de nous faire mourir mille fois de frayeur.

Je fuis, \& $\mathrm{c}$.

Fin du troifléme Tome.

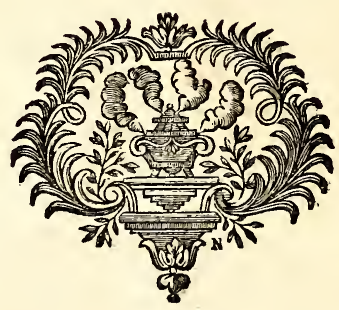




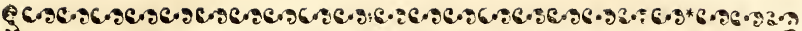

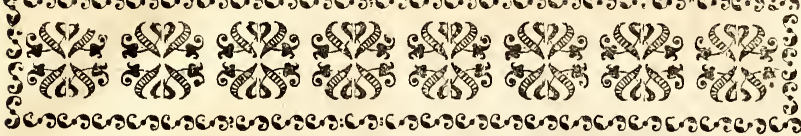
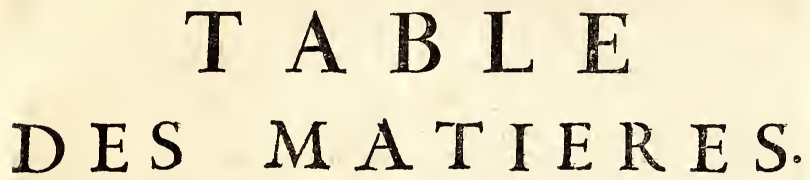

A.

BDIAS. Faufe application $A$ d'une Prophéne d'Abdias à la publication de l'Evangile dans le nouveau Monde.

pag. 10. Abinaquis. Voyez les deux premiers Volumes. Ont été pendant les dernieres Guerres le principal Boulevard de la Colonie, 90. Village Abenaqui, à Beckancourt, 109. Utilité,qu'en retire le Baton de Beckancourt, $1: 0$. Utilité de cet Etabliffement pour la Colonie. Bravoure des Abcnayuis. Caufe du relâchement de leur ferveur, 111. 112. Du Vilage d'Abénaquis de faine François, 121. (es Sauvages font prefque les feuls da Canada, que les Iroquois n'onr ofé attaquer chc $z$ eux, 202. Des Abénaquis défont un Parti d'Anglois, qui étorenr vint conrre un. Mépris, qu'ils font de ces Ennemis, 307 08: De quelle forte de Pyromancie ils ufoient pour connoître les chofes éloignées, $\quad 363$. Acadie Comment on pouvoit établir folidement cette Province par la Pêche, 53 . Objers de Commerces, qui fe préfenterent d'abord en Acadie, 85 . Ce qui a le plus contribué à nous faire perdre cetre Péninfule, 86. Ce qui a empêché qu'on n'y fit un Etabliffement folide. Qui font ceux, qui nous ont fait comprendre ce que vaut l'Acadie, 87 . Quanrité de Pouffons fur les Côtes, \& dans les Rivieres de PAcadie, 1 22 I 4 . Les Chefs des Sauvages étoient plus Souverains en Acadie que par tout ailleurs, 266 .

Acadiens. Ce que Lefcatbot rapporte Ide la notion, qu'ils avoienc de la grande \& de la perite Ourfe. Il fe peut faire qu'ils ayent pris ces notions des François, 401 . Achus an. Elpecede Poiffon fort conmune dans le Canada, 121.154. Acimine. Fruit de la Louyfiane, fa Defcription, Acofta. (le P Jofeph de) J95.

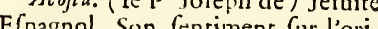
Efpagnol. Sun fentiment fur l'origine des Amériquains, s. \& fuiv. En quoi il eft réfuté par Jean de Laët , 8, is fuiv. Ce qu'il dit des Peuples que les Mexiquains trouverent autour du Lac Mexico, 18. Il a cru que la Nouvelle Guinée éroit un Continent peu éloigné des Inles de Salomon, 22. Il rapporte que Vafco de Gama trouva l'ufage de la Bouffole établi au Mozambique, 40.11 fe trompe au fujer de la. tradition du Déluge, confervée par. les Ameriquains,

Adoptiun. Droits des Prifonniers de Guerre, qui font adoptés, 245 . Réception, qu'on leur fait dans la: 
Cabanne, où ils font adoptés, 246. Comment ils font traités, sils fe fauvent, \& qu'ils foient repris, 248. Adour. Flûte de la Compagnie d'Occident, en quel érat elle arrive à l'embouchure du Miciflipi. Par qui elle eft commandée. Etat de fon Equipage, $454-56$. Naufrage de ce Bâtiment, \& fes caufes, 458 . \& futv. Il eft abandonné par l'Equipage, 466. On paroît fe repentir de l'avoir abandonné, mais on le trouve rempli d'eau, \& brifé par les Sauvages, 46S. En quel état l'Aureur le rrouva en repaflant par l'endroit, où il étoit échoué,

Agnier. Le Canton Iroquois d'Agnier a été celni, qui a le plus perfecuté les Miffionnaires, \& qui a produit un plus grand nombre de fervens Chrétiens,

176. Aigles. Deux ef́peces d'Aigles en Canada, \& leur defcription, iss. Aiglons d'une groffeur extraordinaire,

207.

Aigremon:. ( M. de Clerambaut d') Commifaire Général de Marine en Canada, 79. Ses Obfervations fur le Fort de Catarocouy, 191. Aiouez. Nation Sauvage, fituation de leur Pays. Ce qu'on y trouve de particulier, 211.396 . Ils font grands Voyageurs, font trente lieuës par jour, ce qu'ils difent des Omans,

Akunfas. Sauvages de la Louyfiane, leurs Tribus, leur Riviere. On les appelle les beaux Hommes. Beauté du Pays, 410.0 furv. Alexandre. ( le $\mathrm{Sr}$ ) Botanifte \& Chimilte de la Compagnie d'Occident à la Louyfiane. Ce qu'il dit à l'Auteur au fujet de la Cire de Myrthe ,

$45 \mathrm{~s}$.

Algonquins. Stratagême de ces Sauvages pour vaincre la Nation de l'Iroquet, 110 11. Ce qui empêche des Algonquins de quitter le voifinage des'Trois Rivieres, 114 . Algonquins dans la Miflion de S. François, 121. On prétend qu'à force de manger de la chair d'Orignal, ils étoient fu. jets à l'épilepfie, I 26. De la Langue Algonquine, \& de ceux,qui la parlent, 185 . \& juiv. De la Langue Algonquine, 196. \& fuiv. Ils faifoient autrefois la premiere figure dans le Canada. Origine de leurs Guerres avec les Iroyuois, 200. \& fuiv. La dignité de Chef eft élective parmi tous les Sauvages de la Langue Algonquine, 267 . Ils ont deux fortes de Femmes, 283. De quelle forte de Pyromancie ils ufoient pour connoîrre les chofes éloignées, ${ }_{3} 63$. Tradition des Nations Algonquines fur la création du premier $\mathrm{Hom}-$ me,

Alibamons. Sauvages de la Louyfiane. Ils fe joignent aux Anglois pour détruire l'E tabliffement desECpagnols à S. Marc d'Apalache ; cruautés, qu'ils y exercent, 473 . Allemands. Neuf mille Allemands levés dans le Palatinar, deftinés à établir la Conceffion de M. Law aux $A$ Kanfas, font prefque réduits à rien,

Allouttes. Pointe aux Allonettes, oì elle eft, 66 .

Allouiz. (le P. Claude) Jéfuite, ce qu'il dit des Prêtres Outaouais, 3 so.

Almanack des Sauvages pour connoître la durée des Hyvers, 102. Alvarado. Un des Capicaines de Cortez. Conjecture de Laët fur cet Officier,

15 .

Amérique. Auteurs, qui ont cru qu'avant les Efpagnols il n'y avoit aucune communication entre l'Amérique Septentrionale \& la Méridionale, 12. Grotius \& Laët ont eu tort de fuppofer qu'il n'y avoit point d'Antropophages dans l'Amérique Septentrionale, 2 r. De Hornn prétend mal-à-propos que l'Amérique n'a pû être peuplée avant le Dé- 
luge, 24. Les deux Amériques font pleines d'eau, 28. Les Amériquains n'ont point de barbe ni de poil fur le corps, 42. Ames. Idée des Sauvages fur les Ames, \& les conféquences, qu'ils en tirent, 351.0 jurv. Ce que les Sauvages penfent de l'ame des Bêtes,

353.

Ami. Tous les Sauvages ont cha. cun un Ami. A quel deffein. Quel eft le ricud \& le but de cette bocieté,

Anikoús Narion Sauvage, 310. la Nation du Cisttur. Son origine, felon les Sauvages. Oì ils demeurent,

187283.

Amorrbéens. De Hornn prétend qu'ils ont peuplé la Gomara, une des Lanalies, 29.

Ander. Montagnes de l'A mérique cruës par Arias $A$ ontanus la Montagne Sephar de Moyfe,

Nouvelle $A$ gleterre, s'eft enrichie par la Pêthe fur les Côtes de l'Acadie,

53.

Anglois. Rencontre d'un Navire Anglois, 55. Aurre Navire Anglois, 56. Leur Florte deftınée à prendre Quebec, périt en partie dans !e Fleuve, 78 . Parallele de leur maniere de vivre dans leurs Colonies, \& de celle des François, So. Hls ont prévenu les François en Terre-Neuve : comment ils s'y font fuîtenus, quoiqu'ils y ayent toujours été bat. tus. Ce fonr etix, qui ont fair comprendre aux François ce que valoit l'Acadie, 87. Comment ils ont peuplé leurs 1 olonies, 91. Leurs prérentions au fujet des Cantons Iroquois, 226. Ils fe plaiunent de ce que les Tfunnontouans ont accordé un hofpice chez cux au fieur de Joncaire: en demandent aufi un \& ce qu'on leur répond, 227. Pourquoi ils auront toniours la rréference pour le Commeice de la part des Sauvages, 257. Un grand Parti
d'Anglois défait par les Abénaquis, quoiqu'ils fultent vint conte un, 3c8. Ils excient les Chicachas à farre la Guerre aux Françors, \& pourquoi, 408. Détour aux Anglois, ce que c'eft, 4;9. Vojez le jecond Tome de l'Hiftoire. Les Sauvages des Martyrs haillent les Anglois, 46r. 464. Quelques Navires Anglois parorllent à la vîëde l'Adour échouće, \& ce qui les empêche de fecourir les Françors , $465-66$. Ils détruifent S. Marc d'A palache, 473 . Ils veulent nous débaucher les Tchactas, 483 . Induftic d'un Capitaine Anglois, qui uianyuoit de vivres, pour engager le Capitaine d'un Navire François à lui en ceder, 496. Induftrie des Anglois pour attraper les Forbins, Ariguilles. Abondance de ces Poiffons, comment on en fait la pêche. Leur qualité, maniere de les accommoder, 170.71. Anthropothages. Grotius \& Läer ont fuppofé mal-à-propos qu'il n'y en avoit point dans l'Amerique Septentrionale, 2 I. Anticofti. Danger, que le Vaiffeau du Roy court d'échouer furla pointe de cette Ifle, 62. Sa Defcription. On croyoit y avoir trouvé une Mine d'argent, \& fur quoi on fe fondoir. Cerre ine eft concedée au fieur Joliet .

63. Anilles. Ines de l'Amerique; cruës les Hefperides des A nciens, 3 . Antimuine. On en trouve en remontant le Moingona, 397. Auroine. Mineur envoyé pas la Compagnie d'Occident, ne réuffic puint

3930 Annnio. Sauvage des Martyrs, qui le faifoit nommer D. Antonio. Son avideré pour tour ce qu'il voit. Il offre à l'Equipage de l'Adour de le conduire à faint Auguftin , 464 . Il eft bien frotté par fon Pinice pour s'être enyvré fur l'Adour. Pouryuoi 
504

T A B L E

il n'a pas permillion de conduire les François à faint Auguftin, 467. Apalaibes. Peuples de la Floride.

De Hornn les fait defcendre des Apaléens, dont parle Solin, $\mathbf{3 2}$. Les Efpagnols ont appris d'enx l'ufage de l'Apalachine. Baye des A palaches, 471 . Sept mille Apalaches tués, ou diflipés par les Anglois. royez $S$. Marc. Quelques-uns re. rournent à $S$. Marc, \& pourquoi on ne s'y fie pas, 474. Apalacbine, ou Caffine. Arbrifleau de la Floride. D'où vient le premier de ces deux noms. Vertus de fes feuilles. Maniere d'en ufer. Voyez la defcription des Plantes, 449-50. Apaléens. Peuples du Nord, Voifins des Meffagetes, felon Solin. pline dit qu'ils ont difparu, \& ce qu'on en peut conclurre. De Hornn allùre que les A palaches de la Floride en tirent leur origine,

Arbre fingulier en Acadie, \& 2 l'objet du culte des Sauvages, 34\%. Pourquoi les Arbres de la Louyfiane pouffent leurs feuilles fi tard,

Archives.Quelles font les Archives des Sanvages,

210. Areskoui, ou Agreskoué. Le Dieu de la Guerre parmi les Iroquois \& les Hurons, \& leur fouverain Dieu. Son étymologie grecque, 208.344 . Ariftote a cru que la Zone Torride n'étoit point peuplée, \& qu'on n'avoit paint navigé. à l'Occident de l'Europe au-delà des Colonnes d'Hercules, s. On lui attribuël'Hiftoire des Carthaginois, qui furent portés fort loin à l'Occident par un vent forcé, \& y découvrirent de nouvelles Terres,

6.

Armes. Anciennes Armes des Sauvages,

222.

Afton-Gaber. De Hornn écrit que ce Port étoir fur la Méditerrannée,

28.

Affafinat. Quand \& comment les
Sauvages le puniffoient, 273-74。 276.

Afjiniboils. Peuple Sauvage de la Langue Sioufe, vont trafiquer à la Baye d'Hudlon, 180 . Leur véritable Pays, 184. Nom, qu'on leur donne dans les Cartes, 185.

Lac des Afjiniboils. Particularités de ce Lac, 184. \& fuiv.

Atabentfic. Divinité des Sauvages, ce qu'ils en difent, $344-45$.

348.

Atahocan. Divinité des Sauvages, 344.

Atlantide. Ce que penfoit le P. de Acofta de cette prétenduë Ifle de Platon, 6. 7. Budbeck la place dans le Nord, 3. De Hornn croir qu'elle étoit dans l'Amerique, \& qu'elle a été fubmergée par le Déluge, 23. Atlantides. Poftel a cru que les Atlantides, Habitans de la Mauritanie, avoient peuplé l'Amerique Septentrionale,

Atoca. Sorte de Fruit du Canada, dont on fait des Confitures, 163. Attikamegues. Leur Pays propre, I 86. Voyez le premier Volume.

Aubery. ( le P. Jofeph) Jéfuite, Mifionnaire à faint François, 121 . Avoine. Folle A voine, Légume; ufage, qu'on en fait en Canada,

Auté. Port de la Floride, le même, qui porte aujourd hui le nom de fainr Marc d'A palache,

475

Autololes. Peuples voifins des Carthaginois, felon Pline, qui ils étoient, leurs Mœurs reffemblent beaucoup à celles des Brafiliens,

20.

\section{B}

$B \begin{aligned} & \text { ACCALAOS. Peuples del'Inle } \\ & \text { Royale, ou de Terre-Neuve; }\end{aligned}$ Grotius prétend qu'ils reffemblent aux Lappons,

Babama. Débouquement du Canal de Bahama, 488. Vieux Canal 


\section{DES MATIERES.}

de Bahama. Pourquoi on l'a abandonné,

489 .

Bain. Comment les Sauvages fe baignent,

115.

Baleine. Quantité de ce Poiffon dans la Mer du Canada, \& dans le Fleuve faint Laurent. Combat de la Baleine contre l'Efpadon, 54 . Fort communes dans le Fleuve faint Laurent : où l'on en peut faire plus commodément la pêche, 65 . Cequi l'a fait difcontinuer aux Bafques,

148.

Balife. Ine de la Balife, fa fituation, fa defcription. A vantages, qu'on en peut retirer. Autre nom, qu'on lui donne,

Banc. Le Grand Banc de Terreneuve, fa defcription, 48. \& fuiv. Caufes des mauvais tems, qu'on effuye vers les Ecorres du Grand Banc,

Baptême. En quoi les Sauvages reconnoiffent la vertu du Baptême,

249.

Barbe. Ameriquains, qui ont de la barbe,

25.

Barcia. (D. André Gonfalez de) fait réimprimer l'Ouvrage du P. de Garcia fur l'origine des Ameriquains,

Bars. Quantité de ce Poiffon dans le Lac de laint Pierre,

121.

Bafques. Ifle aux Barques, fa fituation. Les $B a f q u e s$ y ont fait avec fuccès la pêche de la Baleine, 6.5. Pourquoi ils ont difcontinué. La pêche des Baleines dans le Fleuve S. Lausent, 149. On a cru fans fondement, que les Eskimaux font Bafques d'origine,

179.

Batteau. Un Batteau plat embarqué fur l'Adour eft le falut de l'Equipage, $460-61$. Il eft mis en érat, 468. Il eft béni \& baptifé, il fait beaucoup d'eaus,

469.

Bayagoulas. Sauvages de la Louyfiane. Voyez le fecond Volume de l'Hif:oire. Un Jéfuite veut s'établir parmi Tome III. eux, \& pourquoi, 43 r. Cette $\mathrm{Na}$ tion eft réduite d̀ rien, 436 .

Baye des Tfonnanihocians. Sa fituation, 223 . Sa defcription, 224.

La Baye des Puants, ou la grande Baye. Sa defcription, 292. \& Juiv. Les Sauvages y font plus fuperftitieux quailleurs, 299-300.

Becan donne dans les idées d'Arias Montanus fur le nouveau Monde ,

Beckancourt. (M. Robineau, Baron de ) Grand Maître des Eaux \& Forêts de la Nouvelle France, 79. La vie, qu'il méne dans Con $\mathrm{Habi-}$ tation, i ro. Riviere de Beckancourt, fa fituation, fon ancien nom,

110.

Begon. (M.) Intendant en Cansda, 79. Monfieur \& Madame Begon vont en Pélerinage à Lorette, réception, qu'on leur fait, $83 . \sigma^{\circ}$ fuiv.

Bellone. Navire de la Compagnie d'Occident. Elle part de la Louyfiane pour Saint Domingue, 484 . Mauvaife manæuvre du Capitaine, \&z quelles en furent les fuites, 485 . Danger, que court ce Bâtiment fứ les Caïques, 490. Comment il s'en tire, 491. Il périt dans le Port,

Benac. (M. de) Moufqueraise. Benac. (M. de Moufquetaire, \& enfuite Officier dans la Louyfiane. Sa pieté , 437-38. Voyez le Jecond Tome de l'Hiftoire.

Bertbelot (François.) achette l'Ifle d'Orleans, \& obtient qu'elle foir érigée en Comté fous le nom de $S$. Laurent, 67.

Bétes. Les Sauvages croyent leurs ames immortelles, \& qu'elles ne different de nous, que du plus, ou moins,

Bête puante ou 353. ble purnie, ou Enfant da Diable. Efpéce de Foüine, fa defcription,

133.

Bienville ( $\mathrm{M}$. de) Il oblige un Interlope Anglois à s'éloigner à l'are

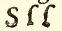


rivée d'un Brigantin Efpagnol, \& pourquoi. Avis, gue lui donne l'Auteur, $4^{82}$. Il regagne les Tch ictas, que les Anglois vouloient nous débaucher, 483 .

Bievre. Nom que l'on donnoit aux Caftors en Europe. Leur différence d'avec ceux du Canada, 95 . Endroits de l'Europe, où on en a trouvé,

Bigot (le P. Vincene) Jéfuite. Témoin d'un coup de vigueur des Abénaquis, contre les Anglois, 308 . Biloxi. Defcription de ce Polte, de la Côre \& de la Rade, 458 . O 0 . Biloxis. Nation Sauvage de la Lonyfiane, qui a donné fon nom an Pofte ci-deffus: où ils fe font retirés,

Bizart. Officier Canadien, Commandant aux Yafous, fa mort, \& fon éloge,

$412-13$. Blanc. Jean le Blanc. Sauvage Ouraouais. Sa répartie ingérieufe au Comte de Frontenac, 306. B!euet. Eft le même én Canada, qu'en Europe, fes proprietés, 163. Bloźd (M. le.) Brigadier - Ingénieur, Directeur de la Compagnie des Indes Occidentales à la Louyfrane, \& d'une Conceffion, où il eft affocié ,

Bouf. De la Chaffe du Bouf en Canada. Defcription de cet Animal. Sa laine, 1,30-32. Bœufs mufqués, leur defcription,

J32.

Ouvrages, que font les Femmes Illinoifes de la laine de Bœiufs, 294.

Bois blanc. Qualités de cet Arbre, \& l'ufage, qu'on en fait, 162. Boisbriant (le fieur du Guéde.) Commandant aux 11 linois, 394 . Ses diligences fur l'avis de ladécouverte d'une Mine d'argent,

Bois d'Amourette. Efpéce de Frefme de la Floride, fes vertus, 454. Boniventure (Ifle de.) Sa fituarion,

61 . arrivé parmi eux fur la Religion, \& fur les Mæurs à S. Domingue, 37. Boucliers des Sauvages, 222 .

Boulanger (le P. le.) Miffionnaire aux Illinois,

Bourbon. Fleuve de l'Amérique. Les Eskimaux le remontent aflez loin, 178. Toyez l'Hijtoire.

Bouffole. Le P. de Acofta prétend qu'aucun ancien Auteur n'a parlé de la Bouffole, 6. Il paroît fe contredire fur l'antiquité de cette invention, 8. Ufage de la Bouffole établi au Mozambique avant l'arrivée des Portugais dans cette Ine,

Brejjani ( le P. Jofeph) Jéfuite. Voyez la Lifte ó l'Examen des Auteurs. Son fentiment fur la durée $\&$ la rigueur des froids du Canada, 167. \& fuiv.

Breverood (Edouard de) Anglois. Son fentiment fur l'origine des Amériquains, \& le jugement, qu'en porte Jean de Laër, I $1-12$.

Breuil (le fieur du.) Met fon $\mathrm{Ha}$ bitation des Chapitoulas en bon état.

Brifans contre lefquels le 438 . meau fur en danger d'échouer, 56 . 62 .

Brolle. Cap Brolle, fa fituation,

Brumes. Caufes \& effers des Brumes aux environs du grand Banc de Terre neuve,

Budbeck. Sçavant du Nord, place l'Atlantide de Platon, \& les Colomnes d'Hercules dansle Nord, 3 . Buiffon, rapide, I90.

\section{C.}

CABLIAU. Petite Moruë;
qu'on pêche dans la Manche \&
ailleurs.

Caimans dans la Louyfiane. Leur grofieur, leurs cris, danger, qu'on court de leur part en fe baignant, \& comment on s'en garantit, 413 . 


\section{DES MATIERES.}

Quantité de Caïmans dans un petit Lac, 435 . lls éroient autrefois par milliers dans le Lac Pontchartrain, ilsy font fort:rares aujourd'hui, 454 . Caiques. Ines, qui bordent en parie la Côte Septentrionnald de l'Ihe Efpagnole. Defcription de la grande Caique, 490-91.

Californie. Prefqu'ine de l'Amérique, oil Grotius trouve un Peuple Alavard, qu'il fair defcendre des Lombards, 15 . Cortès a le premier découvert ce Pays, 16. Les premiers Habitans du Mexique venoient de la Californie, is. Callieres. (Le Chevalier de) Voyez l'Hift. Etant Gouverneur de Montreal il a fermé la Ville de Paliffades,

138.

Calumet. Ce que c'eft. Ses différens ufages, fon origine vraie \& prétenduë. N'eft point le Caducée de Mercure, 211 . 巳 fuiv. Danfe du Calumet, 206 . \& fuiv.

Carnada ou Nouvelle France. Idée fauffe, qu'on s'en fit d'abord, \& ce qu'elle produifit, 85. \& fuiv. Son Commerce, \& fautes, qu'on y a faites, 86. \& fuiv. ¿Comment on auroit pûle peupler, g1. Comment le dérangement des monnoyes a fait tomber fon commerce. Sur quoi ce commerce rouloit en mil fept cent fix, 93. Ce qui a ruiné fes Habitans, 94. D'où vient lidée défavantageufe, qu'on a en France du Canada, 164 . \& fuiv. Rigueur de l'hyver, 165 . \& fuiv. En quoi elle eft compenfée, i 66 . Avantages $\&$ défavantages du Canada pour la vie, 170, \& fuiv. Combien il feroit important de le peupler, 175 . Etenduë du Canada, ou de la Nouvelle France, 183 . On n'a pu fçavoir en quel état il étoit, lorfqu'on en fir la découverte,

Canadiens. Creols du Canada, leur caractere, 79. Paralelle de leur maniere de vivre avec celle des Créoles
Anglois, So. Leur inconftance leur fait abandonner ce qu'ils ont conquis avec le plus de facilité, 87. La bonne opinion, qu'ils ont de leur' bravoure, fait qu'il eft plus aifé de les furprendre, que de les vaincre, I 38 . Avantages, dont ils jouiffent: leur caractere, 172 . \& Juiv. Eloges des Canadiennes, 172. Gentilhomme Canadien brûlé pendant huit jours par les Iroquois, 248. Ils ne fçauroient plus goûter la vie reglée, quand ils ont goûté celle des Sauvages,

322.

Cananéens. Quelques Auteurs prétendent que ces Peuples, chaffés de la Paleftine par Jofué, ont paffé en A mérique, \& ont feuls peuplé cette Partie du Monde, 4. De Hornn les comprend fous le nom de Phéniciens,

27.

Canards. Grand nombre d'efpéces de Canards en Canada. Du Canard branchu, is 6.

Citiaries. Preuves, qu'on a qu'elles ont été autrefois peuplées, \& ce qu'en conclut Jean de Laet, 20. De Hornn croit que la grande Canarie eft la Cerné des Anciens, \& que toutes ces Ifles ont été peuplées par les Canaréens, 29.

Cannes. Defcription de celles, qu'on trouve dans la Louyfiane. Elles ne croiffent que dans les bonnes Terres. Comment on peut les extirper,

Canots. Maniere de les porter, 190. Leur defcription, 192. \& fuiv.

Croquias. Tribu Illinoife. Sont réunis avec les Tamarouas,

Cap François. Defcription du Port de la Ville, \& de la plaine du Cap François dans l'Ine de Saint Domingue. Précautions, qu'il faut prendre pour entrer dans le Porr, $493^{\circ}$. \& $\int$.

Cap Saint Antoine. Sa fituation, \& ce qu'on y remarque,

Capillaire, 164 .. Voyez le Defcrip. tion des Plantes. Il s'en troure beaus. $S \int f \mathrm{ij}$ 
coup fur la Riviere de Saint Jofeph, 315. Carcajou ou Quincajou. Efpéce de Chat, fa defcription. Comment il fait la guerre à l'Orignal., 129.

Cardinaux. Efpéce d'Oifeaux. Sa defcription, 157.

Cariboн. Maniere finguliere de le chaffer, 128 . Sa defcription. $\mathrm{O} \hat{\mathbf{u}}$ il s'en trouve davantage, I29-30.

Carthaginois. Ce qui a pu les engager à paffer en Amérique, $2 a$.

Cartier. (Jacques.) Navigateur Malouin, a vû un Ours de la groffeur d'une Vache faire quatorze lieuës de fuite à la nâge, 10. Nom, qu'il: donne à l'Inle d'Orleans, \& pourquoi, 69. Il ne faut pas fe fier à fes Vocabulaites, 196. Ce qu'il dit d'un coquillage, qu'il trouva à Montreal,

Cafas. (Dom Barthelemy delas) Evêque de Chiappa. Comment il faut entendre les vint-cinq mille $\mathrm{Ri}$ vieres, qu'il.dit arrofer la Vega Real de l'inle Efpagnole,

494.

Cafcades. Rapide, fa firuation, 190.

Cafconcbiagon. Riviere, qui fe jette dans le Lac Ontario. Ce qu'elle a de fingulier,

$223-24$.

Calfetéte. Cequec'eft, 222.238 .

Caftor. Les Peaux de Caltor ont roujours fait le principal objet du commerce de la Nouvelle France. Leur abondance ruine ce commerce, 88. \& fuiv. Hiftoire \& defcription des Caftors, 94. \& fuiv. Caftors rerriers, 95. 103. Leur chair eft déclarée viande de Carême. Erreur de M. Lemery à ce. fujet, 97. Ce que c'eft que le Caftor gras, \& le Caftor fec, y9. Maniere, dont ils bâtiffent, 300. $O$ finv. Chaffe du Caftor, 104 . \& fuiv. Particularités fur les Caftors, 106.

Ifles du Caftor. Leur fituation, 313. Des Outaouais s'y établiffent, 282 .

Caftoreum. Ceque c'eft, 95. Quel eft!emeilleur. Ses proprićtés, 100.
Catarocoui. Voyez l' Hiftoire. Le Fort de Catarocoui auroit été mieux placé à la Galette, 191. Situation. \& defcription de ce Fort, connu lontems fous le nom de Frontenac,

Cavagnal.Voyez Vaudreuil. $194-95 \%$

Cédres. Deux fortes de Cédres en Canada, 160-61. Leur difference, 525 . Ufage, qu'on en fait, 255. 366.

Les Cédres. Rapide. Sa fituation, I 91.

Cerfs. Maniere finguliere de les chafler, 128. Leur defcription, 129.

Chambly. (M. de) Fondateur da Fort de Chambly, 1 50- $\{1$. Situation \& defcription de ce Fort, 1 5o.

Champigny. (M. de) Voyez les deux premiers Volumes. Pourquoi ib donna cours à des billets', qui tenoient lieu de monnoye, 92 . Embarras, où il fe trouva à cetre occafion,

Champlain. Voyez le premier Volume. Comment il vouloit s'y prendre pour peupler le Canada, 91. Defcription, qu'il fait d'une chaffe des Sauvages, 128. Ce qu'il dir du Poiffon armé du Lac Champlain, $152-$ 53.

Lac Champlain. Sa fituation, 150. Chandeleur. Ines de la Chandeleur. Leur fituation. On prétend qu'on y: pourroit faire un très-bon Port,

Chanfon de Guerre. Chacun a la fienne, qu'il n'eft pas permis d'autres de chanter, 217. Quel eft le fens de ces Chanfons, 243. Chaouacbas. Ancien Village des Chaonachas abandonné. Defcription de la Cabanne du Chef. Ils emportent avec eux les offemens des Morts. Où ils fe font placés,

Chapeau rouge. Ce que c'eft. Sa fituation, 58. Chupitoulas. Quartier de la Louy: 
fiane en bon état,

438.

Charbon de Terre. On en trouve beaucoup fur le Moingona, 397. Charbonniere. Rapide. Sa fituation, $\&$ pouryuoi on l'a ainfi nommé, $380-81$.

Chardon. (Le Pere Jean) Miffion. naire à la Baye, fait peu de fruit parmi les Sakis, 292. Ce qui lui fair efperer qu'ils feront plus dociles, 295.

Charlevoix. (Le Pere de) Auteur du Journal. Danger, qu'il court vis-àvis de Langets, 45, au Cap de Ra$z e, 56$. par la rencontre d'une glace énorme, 58 . A la pointe d'Anticortie, 62. A la pointe de la Trinité, 64. Son arrivée à Quebec, 69. Danger, qu'il courut fur le Lac Ontario, 206. Les Sakis de la Baye l'invitent à un Confell, \& de quoi il s'agiffoit, 294-95. Danger, qu'il courut d'être tué par un de fes Gens, 315-16. Il fe trouve entre quatre Partis ennemis: le parti, qu'il prend, \& ce qui fe paffe à ce fujet entre lui \& le Chef des Illinois de Pimiteouy, 384 . \& fuiv. Il baptife la Fille de ce Chef, 389 . Ce qui l'oblige à refter quelque tems aux Natchez, 437. Il elt arrêté par une Jauniffe au Biloxi. Il évite une tempête, 453 . Il s'embarque fur l'Adour. Ses preffentimens de ce qui atriva dans la fuite, \& fur quoi ils étoient fondés, $455-56$. Il débarque dans une des Ines des Martyrs, \& pourquoi il recourne au Navire, 462. \& fuiv. Il bénit \& baptife le Batteat, fur lequel une partie de l'Equipage de l'A dour s'embarque, 469. Danger, qu'il court avec une partie de l'Equipage. Il va trouver le Commandant de Saint Marc d'A palache Un Pere Cordelier le loge avec lui dans le Fort, 473: Denx autres Religieux du mêne Ordre le logent, 477. Il découvre une confpiration de plufieurs François, qui devoient enlever un Brigantin Elpagnol, 482.
Ses réfléxions fur les chaleurs de la Zone, 484. Danger, que court la Bellone, parce que l'Equipage ne veut pas le croire fur le Cap de $S_{e d}$, 48 s.

Charron. (Jacques) a cru que les feuls Gaulois avoient peuplé l'A mérique,

Charron. (Le fieur) Fondateur de l'Hôpital Général de Montreal. Son zele, fa conftance, fon défintéreffement,

139.

Chartres. Fort de Chartres aux Illinois. Sa fituation,

Chaffe. Elle eft aufi noble parmi les Sauvages, que la guerre. Devoir des Chaffeurs. Ce qu'il faut faire pour être eftimé Chaffeur, 114 . Elle eft de droit commun en Canada, i 72 . Chats. Voyez Erié, \& Carcajou.

Chat-buant. Particularités fur le Char-huant du Canada, is s. Chaviteau. Premier Pilote du Roi fur le Chameau, 47.Il devine jufte oì il doic être après une brume de plufieurs jours, 57 . Il veut rifque: un palfage pendant la nuit, $\&$ on ne le lui permet pas,

Chauvignerie. (Le fieur de la) Officicr, Interpréte pour la Langue Ircquoife, eft envoyé à Niagara \& à Onnontagué, \& pourquoi, 228. Chatuvin. Quatre Freres Canadiens établis aux Chapitoulas. Leur éloge,

Checoutimi Peninfule 433 . Comment \& quand elle fut formée, 68. Les Directeurs de la Compagnie. des Indes y raffemblent plufieurs Sauvages fous la conduite d'un Jéfuite,

114.

Chefs. Des differens Chefs des Sauvages, de leur fucreflion, de leur élection. De leurs noms, de leur autoriré, 266. ¿́ iuiv. Les Chefs après fix mois de deuil peuvent fe re:marier, 376. Des Chefs \& de la Femme-Chef des Natchez, 420 . O fuiv. Chemin. Grand Chemin double de: 
Quito à Cuzco ruiné par les Efpagnols,

Chenaux du Lac. Rapide, 193. Chênes. Deux fortes de Chênes en Canada, 16 6 . Belle Chêniere autour du Lac des Chetimachas, 444.

Ciseraquis. Peuple Sauvage du Ca. nada. Situation de leur Pays. Les Iroquois ont engagé les Milfiflagués à leur faire la guerre, \& s'en font eux-mêmes laffés, 207-08. Ils tuent un grand nombre de François, 406.

Chetimachas. Nation fauvage de la Louyfiane, prefque détruite. Ce qui en refte eft efclave des François. Fourche des Chetimachas, 434. Chevalier. (Le fieur) Directeur de la Conceflion de M.d'Artagnan, 436. Cheoreuils. Particularités des Chevreuils du Canada, I32-35. Clicicacbas. Sauvages de la Louyfiane, infectent les Chemins, 406. Ils reçoivent un échec de la part des Illinois. Garcilaffo de la Vega n'en parle pas exactement. Les Anglois les animent contre nous. Ils tuent deux François, \& comment ils les furprennent, 408-09. Situation de la Riviere des Chicachas, 409. Les Tchactas nous forment une barriere néceffaire contre eux dans la Louyfiane,

$4\{2$.

Chicagou. Situation de ce Pofte.Incommodité de prendre par-là fa roure pour aller aux Illinois, $\quad 370$.

Chicbimeques. En quel tems cette Nation s'établit fur le Lac de Mexico; d'où ils venoient,

18.

Chiens. Des Chiens des Sauvages. Comment ils les dreffent, 1 19. On les dreffe aifément à donner la chaffe aux Liévres \& aux Lapins, \& ils la font rudement aux Renards, 133 . On les ftile à la Pêche des Loups Marins, 146. On tue les Chiens, quand quelqu'un eft prêt de mourir, \& pourquoi, 372 . Les Sauvages battent les Chiens, quand la Lune eft éclipfée, \& pourquoi,
Chili. Auteurs, qui ont avancé que fes premiers Habitans venoient de la Frife,

Chinois. Grotius ne doute point qu'ils n'ayent fondé l'Empire du Pérou. Ses preuves, r 3 . Elles font réfurées par Jean de Laët, 16. 17. Il n'eft pas vrai qu'ils ayent jamais adoré le Soleil, ni qu'on ait trouvé des débris de leurs Navires dans la Mer du Sud, 17. Grotius a eu tort de dire qu'ils ne connoiffoient point l'Imprimerie avant l'arrivée des Portugais chez eux, 19 . Ils ont eu autrefois des Flottes, \& la tradition des Infulaires de Madagafcar porte que ce font les Chinois, qui ont peuplé certe ifle,

Chouguen. Voyez Rivicre d'Onnontagué.

Cibao. Mines de Saint Domingue, crues l'Ophir de Salomon. Ce qu'ón a dit que Colomb y avoit trouvé , 2 .

Cigale. Ce que c'eft que fon chant, 159.

Citronniers du Détroir. Leur bonne \& leur marvaife qualité, 264 . Citrouitles. Petites Citrouilles de Canada, qu'on mange cuites fous la cendre, ou dans l'eau, 164 . Cloches. Ulage, qu'on fait des Cleches en Angleterre, \& leur harmonie,

Colapiffas. Sauvages de la Louyfiane fott braves. Voyez le econd Volume de l'Hiftoire. Deux Villages de ces Sauvages, leur fituation. Politeffe de leur grand Chef. Sa Cabanne. Singularité d'un Tambour, 435 . Colliers. Defcription des Colliers de Porcelaine \& leur ufage, 2 ro.Colliers, dont on fe fert pour porter des fardeaux, \& pour tirer les Traînes, 221.

Colomb. (Chriftophe) Ses idées fur l'Ifle Efpagnole, 2. Le Pere de Acofta regarde comme vraie l'Hiftoire du Pilote, qu'on difoit lui avoir laiffé des Mémoires fur la découverte du 


\section{DES M A T I E R E.}

Nouveau Monde, 6. Jean de Laët la réfute, \& à qui il attribue cette calomnie,

Commerce. Sur quoi il a roulé lon. rems en Canada, \& fautes, qu'on y a faites, 86. \& fuiv. Ce qui l'a fait tomber en Canada, 93. Sur quoi il rouloit en 1706, 95. Il eft permis aux Gentilshommes en Canada, 109. 172. De quelle maniere fe faifoir le Commerce des Pellereries à Montreal, 142 .Il feroir à fouhaiter qu'on eût continuéà le fairelà, 143 . Compagnie des Indes. Elle raffermble à Checoutimi plufieurs Sauvages fous la conduite d'un Jefuite, Ir 4 . La Compagnie d'Occident envoye des Mineurs à la Louyfiane, 393. Sa facilité à faire de grandes dépenfes pour les Mines, \& fon peu de précaurion pour bien choifir les $\mathrm{Mi}$ neurs, 394. Son Magafin aux A Kanfas, 410 . Elle eft Proprietaire de la Conceffion de M. Law, 4II. Son Magafin aux Yafous, 413. Sa Conceffion aux Narchez,

415 .

Comte (Robert le) a cru que les Phéniciens avoient feuls peuplé l'Amerique,

Conceffions dans la Louyfiane, $\&$ en quel état elles font, 434 . $\mathcal{W}$ fuiv. 4 So.

Condé. Nom, qu'on avoit donné au Lac Supérieur, \& qu'il n'a point gardé,

Congés. Ce que c'eft, 89 . Leurs inconvéniens,

Congrígation. Maifon des Filles de la Congrégation à Quebec, 73. à Montreal. Eloge de ces Filles,

I39.

Confeil de trois Nations au Dérooit. Idée de ces Affemblées, 257. \& fuiv. Sageffe des Confeils des Sauvages, $269-70$ Confeil chez les $\mathrm{Sa}-$ xis, \& ce qui s'y paffe,

294.95 .

Conti. Eloge de quelques Officiers, du. Régiment de Conti Infanterie,
Nom, que l'on avoit donné au Lac Erié, \& qu'il n'a point gardé,

Copalme 253. bre, 409 . Vertus du Baume de Copalme,

Corbeaux. Difference des 435. beaux du Canada \& de ceux d'Europe. On prétend que ceux-là font bons à manger, is5. L'OifeauMoucheleur fait rudement la guerre, 158. Fable des Sauvages du Canada fur un Corbeau, à l'occafion du Déluge,

399.

Cortez. (Fernand) En le premier, qui ait découvert la Californie, 15 . 16. Pourquoi les Méxiquains le nom. merent Fils du Soleil,

17.

Corvo. La plus feptentrionnale des Açorres. Monument, qu'on y.a rrouvé,

Côteau du Lac. Rapide, 192 .

Coton. Il réuffit fort bien à la Louyfianne, $4: 6$.

Cotonnier. Plante du Canada. Ce qu'elle a de fingulier, d'où lui vien: le nom, qu'elle porte, 163.

Cotonner, Arbre. D'où lui vient ce nom, 206. Vertus de fa racine,

Coudres. Ine aux Coudres. Sa fituation. Changement, qu'y a produit un tremblement de terre, 66.

Courage. Idée, que les Sauvages ont du véritable courage, 218.

Courans. Inconftance \& force des Courans aux environs du grand Banc de Terre-neuve, \& leurs effets, so. Courans des Lacs, leurs fources \& leurs effers, 298-99. le long des Ifles des Tortues, 471 . dans le Canal de fainte Roze, 479. Eifers des Courans dansles Mers des. Ines de l'Amérique, $48 \%$.

Coureurs de Bo.s. Ce que c'eft. Plua fieurs vont s'établir chez les Anglois, d'autres demeurent avec les Sauvages. Ce qu'on fait pour s'oppofer à ce défordre, 89. Plufieurs reften: 
farmi les Sauvages, \& vivent comme ces Barbares,

322.

Couroas. Sauvages alliés des Yafous, 413 . Voyez le fecond Volume.

Crifaly. (Le Chevalier de) Voyez l' Hift. vient au fecours du Fort des Vercheres, \& le trouve délivré, 125.

Criftal de Roche. Où l'on en trouve,

Criftinaux ou Killiftinons. Peuples, avec qui on trafique à la Baye d'Hudfon, \& d'où ils y viennent, 180 . \& dans le Lac Superieur,

187.

Cuiraffes. Defcription des Cuiraffes des Sauvages,

222.

Cuivre dans le Lac Supérieur. Imagination des Sauvages à ce fujet, 281 . à l'entrée de la Riviere des Illinois, dans le Miciflipi, 392. Mines de Cuivre à l'Embouchure de la Riviere de Sainte Croix,

Cyprès. Vertus de cet Arbre dans la Louyfiane,

\section{D}

435 .

D $A B L O N$ (Le Pere Claude) Jéfuite. Récit, qu'il fait d'une Bacchanale Iroquoife,

Danfes des Sauvages \& leur Chant. Ce que c'eit, 84. Danfe du Calumet, 295. \& fuiv. Danfe de la Découverte, 297. Danfe du Bœuf \& autres,

298-99.

Dantzic. Le Caftoreum de Dantzic eft le plus eftimé de tous, 98 .

Davion. (M.) Eccléfiaftique, Miffronnaire aux Tonicas, fort aimé des Sauvages, qui veulent même le choifir pour leur Chef; mais il ne peut perfuader à aucun de fe faire Chrétien, 43 I. Il eft chaffé pour avoir brûlé leur Temple. 11 eft rappellé, 433 .Il feretire, \& pourquoi,

Dauphine Siruacion \& defcipton. de l'Ine Dauphine, 480.

Debeaubois. (Le Pere Nicolas-Ignace) Jéfuite, Curé des François aux Kafrafquias 。

394.
Déclinaifon. Obfervation fur la declinaifon de la Bouflole, depuis les Ports de France jufques bien avant dans le Canada, 68.

Delille. M. Delille s'eft trompẹ fur la hauteur du Saule de Niagara, 2.33 .

Déluge. Le Pere de Acolta croir que le Déluge, dont la tradition s'eft confervée en Amérique, n'eft pas le Déluge Univerfel, 8. Laët penfe le contraire, 9. Si l'A mérique avoit eu des Habitans avant le Déluge, 24. Traces du Déluge en Amérique, 28. Notion du Déluge communecá tous les Peuples. Déluge particulier à l'Amérique, 345 . Ce n'eft point ce Dernier, que regarde la tradition des Sauvages, 396.

Denys. (M.) Voyez la Lifte \& l'Examen des Auteurs. Son Traité de la Pêche des Moruës. Ce qu'il dit du Grand Banc, 48. Il prétend qu'on n'a jamais trouvé moins de vintcinq braffes d'eau fur le grand Banc, \& s'eft trompé, 49. Il dit qu'il a vu faire de très-beau Sel en Canada ; mais qu'on n'a pas voulu continuer, 53. Son fyftême pour la Pêche en Acadie, 53. 54. Ce qu'il dit des Loups Marins de l'Acadie, 144 . Ce qu'il dit des Corbeaux de l'Acadie, is 5 . Son Centiment fur la fonte des Neiges critiqué. 167. Défertions frequentes à la Louyfiane, 482.

Détroit. L'entre-deux du Lac Erié $\&$ du I ac Huron. Sa fituation, fon étenduë, fa defcription, $2\left\{6 . \sigma^{\sigma} \int u i v\right.$. Objections contre l'Etabliffement du Détroit, \& les réponfes, 257. Ses Simples, \& fes autres productions, $266_{3}-6_{4}$. Les airs de vent, que court le Détroit, beauté du Pays., 277.

Diégo. (Dom) Cacique des Sauvages des Martyrs, rend vifite aux François avec fa Femme. Son Equipage. Il refufe des Guides pour aller à Saint Auguftin, \& pourquoi.ll repaffe 


\section{E S M A T I E R E S.}

paffe Dom Antonio pour s'être enyvré. Son abtinence, 467.68. Opinion, que les $E$ fpagnols avoient de lui,

474 .

Diodore de Sicile. Il prétend que les Indiens n'ont jamais envoyé de Colonie hors de chez eux, 25 . Ce qu'il dit des navigations des l'héniciens,

28.

Dorades. Obfervation fur ce Poiffon,

$495-96$.

Dragon. Lefcarbot entend par le Dragon, qui gardoit les Pommes d'or des Hefpétides, les differens \& dangereux Détroits, qui ferpentent autour des Antilles,

II.

\section{E}

TCLIPSES. Idée des Sauvages Hiur les Eclipfes, 400.

Ecureuits. Trois efpéces d'Ecureuils en Canada; leur defcription, 134 .

135 .

Egyptiens. Le Pere Kirker a cru qu'ils avoient feuls peuplé l'Amérique,

4 .

Elien. On croit trouver dans cet Auteur quelques veftiges de la connoiffance de l'A mérique.

Io.

Engagés. Pourquoi il eft plus à propos d'envoyer des Engagés dans nos Colonies, que des Négres, 41 s.

Enrollemeni. En quoi il confifte pour les Sauvages, à quoi il les engage,

217-18.

Enfeignes. Defcription des Enfeignes des Sauvages,

222.

Epinette. Sapin de Canada. Il y en a de deux efpeces. Laquelle fournit la Terebenthine, ou Baumeblanc du Canada, 160. Ses qualités, 161 .

Equipage de l'A dour s'enyvre après le naufrage, \& femutine, 463 . Il $\mathrm{fe}$ divife, une partie veut aller à la $\mathrm{Ha}$ vane, l'autre à faint Auguftin. Ces derniers fe repentent de n'avoir pas fuivi les Premiers, 468-69. Ils veulent abfolument aller à la Havane, Tome III.
\& ce qui les fait changer de fentiment. Ils tombent dans le defefpoir, $\&$ pourquoi. L'Auteur en profite pour les obliger à s'approcher des Sacremens, 470. Danger, qu'ils collrent. Une partie fe joint à des Efpagnols, 472 . Equipage Efpagnol mangé par les Sauvages de la Floride, 474. Un feul Matelor de l'Adour meurt en arrivant au Biloxi, 480 .

Erable. De l'eau \& du fucre d'Erable, 121 . U fuiv. Erable mâle \& Erable femelle, 161.

Erié. Defcription da Lac Erié : d'où vient ce nom, \& ce qu'il fignifie.

253.

Eskimaux. Sauvages du Nord de l'Amérique, n'ont rien de commun avec ceux du Canada, 30. 41. Leur caractere, leur maniere de fe vêtir, leur langue, leur origine, $178 . \sigma^{\circ}$ suiv.

Espadons. Figure de ce Poiffon, fon combat contre la Baleine. Il s'en trouve beaucoup dans les Mers du Canada, 54.

Efpagnols. Leurs idées fur les Hefpérides, 3. Pourquoi ils avoient inventé la fable du Pilote, qui avoit laiffé des Mémoires à Chriftophe Co. lomb pour la déconverte du Nouveau Monde, \& celle des Indiens envoyés par le Roi des Suéves à Métellus Celer, 9. Pourquoi on attribuoit auxEfpagnols \& aux François une Prophétie d'Abdias, 9. Laër croit que plufieurs $E f$ pagnols inquierés par les Carthaginois \& les Romains, ont paffé en Amérique, 20. Ils ont détruit les plus beaux monumens anciens de l'Amérique, 24. Hiftoire d'une Efpagnole de ta Floride transferée en Tartarie, 31. Des Efpagnols détruifent deux Villages d'Octotatas. Ils font furpris \& maffa. crés par les Habitans d'un troifiéme. D'ot̀ ils venoient, \& quel étoit leur deffein, 293. Comment un de leurs Aumôniers fe tite des mains des T t $t$ 
Miffourites, 293-94: On croit qu'il y a des Efpagnols au haut du Miffouri, 397. Ils ont tort d'être jaloux de notre Etabliffement fur le Micifipi, \& pourquoi, 408. Ufage, qu'ils font del'A palachine, 449. De qui ils l'ont appris, 450 . Ils ont intérêt à ne point nous inquieter dans la Louyfiane, $\&$ pourquoi. Ils fe faififfent de la Baye faint Bernard, \& nous y préviennent, 452. Les Sauvages des Martyrs fe difent Amis des Efpagnols, 461. Des Efpagnols, qui avoient fait naufrage, font rencontrés par l'Equipage de l'Adour, utilité de cette rencontre, 471-72. Quelques François vont les joindre, 472. Ils font chaffés de faint Marc d'Apalache, 473 .Ils s'y rétabliffent, \& projettent d'y faire un grand Etabliffement. Tout un Equipage d'Efpagnols, qui avoient fait naufrage à la Côte de la Floride, eft mangé par les Sauvages, 474. En quel état ils font à la Baye de faint Jofeph, 477. \& fuiv.

Efprits, ou Génies tutélaires. Idée des Sauvages fur les Efprits. Des bons \& des mauvais Génies. Diffpofitions requifes pour avoir un Génie zutélaire. Pourquoi on en change quelquefois. Tout dans la narure a fon génie tutélaire felon les Sauvages, ; 45 . \& fuiv. Les Sauvages crö̈ent qu'ils ont tous leurs Génies tutélaires, 353 . Des mauvais Génies, \& qui font ceux, qui ont commerce avec eux,

Eftotiland. Pays imaginaire, dont les deux Freres Zanis ont publié des merveilles, \& qui a difparu : Grorius y fait paffer les Norvégiens pour aller en Amérique, $12-15$. Efturgeon. Defcription de ce Poiffon, qui fe pêche en Canada fur les côtes de la Mer, $\&$ dans l'eau douce. Maniere de le pêcher. Deux efpéces d'Efturgeons,

$153-54$.

Efurgny, Coquillage, fa vertu, où il fe trouve;

Ethiopiens. S'ils ont peuplé l'Yucatan, $12,13-16,19$.

Etienne. (Robert') a cru que c'étoit dans l'A mérique, que Salomon envoyoit fes Flottes chercher de l'or,

H $A M I N E$. La grande \& la petite Famine. Rivieres, leur fituation, 205. Anfe à la Famine. Defcription du Pays; d'où lui vient ce nom, 206.

Farine froide. Ce que c'eft, \& fon ufage, 332.

Femmes fauvages. Leur emploi à la Chaffe, 201. Elles on la voix fort belle, $2 ; 0 . L a$ dignitédeChef fe perpetuë parmi les Hurons dans la ligne Féminine, 267. Si elle eftéteinte, c'ef: la plus noble Femme, qui choifit le Chef. Les Femmes nomment les Confeillers du Chef, 268. A quoi fe réduit, \& en quoi confifte leur autorité, 269 . Condition dure des Femmes, \& le mépris, où elles font parmi les Sauvages, 286-87. Elles accouchent facilement, ce qui s'obferve devant $\&$ après leurs couches, 288. Les Femmes Sauvages font fore lafcives, 303 . Pourquoi elles ne font point fécondes, 304 . Ornement des Femmes, 329. Leurs occupations, 330. Leurs ouvrages, 333 . Les Femmes Satuvages font celles, qui fe mê. lent le plus de forcileges, $\quad 360$.

Femme-Chef des Natchez, ce que c'eit, fes droits, honneurs, qu'on lui rend pendant $f_{a}$ vie, \& après $f_{2}$ mort, 420 . \& fuiv.

Feftins. Dans les Feftins d'appareil, celui, qui en fait les honneurs, ne touche à rien, 218. Feftins pout les Morts, \& pour les Funerailles,

Fête des Morts, ou Feftindes Ames. Sa defcription, 


\section{E S M T I E R E .}

Feu. La Religion du Feu fort ancienne dans les Indes, \& dans l'Amérique, 25 . Danfe du Feu. Secret pour s'empêcher d'être brûlé en touchant du feu, 229. \& fuiv. La Religion du feu établie dans toute la Louyfiane,

429.

Févier. Arbre, qui porre des Féves, qu'on n'a jamais pâ faire cuire,

Fil. Comment les Femmes 317. noifes tirent des nerfs de Chevreuil un fil auffi beau \& plus fort que le fil de Malines,

395 .

Flet. Poiflon, diminutif du Flettan,

Flettan. Defcription \& bonté de ce Poiffon, qui fe trouve en quantité dans la Mer du Canada, 54-55.

Floride. Defcription de la Côte, 470-71.

Fontaines. Deux Fontaines fingulieres auprès de l'Ohio,

Fontenay (le Chevalier de.) $\mathrm{Ca}$ piraine de Vaiffeau, prévient l'Auteur, \& le mene fur fon Bord, 497. Son éloge, 498. Sa mort,

Forbans. Les Anglois leur font une plus cruelle guerre, que les autres, $\&$ en font plus haïs. Comment ils les font romber dans le piége, soo.

Forêts. Beauté des Forêrs de la Louyfiane: Arbres, qu'on y trouve, Forts bâtis dans les Habitations, en quoi ils confiftoienr, pourquoi les Iroquois ne les attaquoient point,

124.

Foffe. Ce que c'eft que la Folle fur le grand Banc,

49.

Foucaut (M.) Eccléfraftique, tué par des Sauvages dans la Louyfiane,

Fouines. Plufieursefpéces de Fouines en Canada,

$133-34$.

Fourche. $\mathrm{On}$ appelle la Fourche, le Confluant de la Riviere des Illinois \& du Theakiki,

380.

Francifquains. Un Pere Francif- quain rend un grand fervice aux François à faint Marc d'Apalache, \& fair politeffe à l'Auteur, 474-75. Deux autres logent l'Auteur chez eux à la Baye faint Jofeph, 477.

François. Ils fe fone laiffé prévenir en Terre-neuve par les Anglois: fautes, qu'ils ont fait en Acadie, \& en Canada, au fujer des Pelleteries, 87. o fuiv. Ce qui a fait périr un grand nombre de jeunes Gens en Canada, 89. Seul moyen de francifer les Sauvages, 90. Voyez Coureurs de Bois. Comment un François pris par les Outagamis évite le feu, 383. Deux François fe joignent à l'Auteur, ce que leur dit le Chef Illinois de Pimiceoui à ce fujet, $386-$ 88. Les François établis aux Illinois font à leur aife, 394. Peuples reffemblans aux François, fort éloignés à l'Occident du Miciffipi, 397. Comment dans les marques des Guerriers les François font repréfentés, \& pourquoi , 408. Deux François font tués par des Chicachas, \& comment ils furent furpris, 408-09. Abandon, où l'Auteur les trouve aux Natchez, \& dans toute la Louyfiane, 431-32. Plufieurs François défertenr de la Louyfiane, $477.4^{82}$. Plufieurs confpirent d'enlever un Brigantin Efpagnol. Ce qui fait échouer ce deflein, $482-83$. Fiefne. Sucre de Frefne fort eftimé, 123 . Trois efpéces de Frefnes,

162.

Frillande. On ne fçair bien ce que c'eft que ce Pays. Il ne faut pas croire tout ce qu'en ont dit les deux Freres Zanis, Nobles Vénitiens; Jean de Laër croit qu'il fair partie duGroenland, ou de l'Inande, 15 . Frifons. Auteurs, qui ont dit, que les premiers Habirans du Pérou, \& du Chili étoient Frifons,

Froid. Durée \& rigueur du froid en Canada, 165. \& fuiv. Quelles en peuvent être les caufes, 177 . 
Froid extrême \& extraordinaire dans la Loayfiane, 404-406. ó fuiv. Froment. Il vient fort bien aux Illinois, 394:403. Pourquoi il ne vient pas fi bien en d'autres endroits de la Louyfiane, \& conment on y peur remédier, 405-06. 446 .

Frontenac. Lac \& Fort de Frontenac. Voyez Catarocoui, \& Ontario,

Funerailles. En quoi elles confiftent parmi les Sauvages, $373 . \& 5$. Parmi les Natchez, 420. W juiv.

\section{G:}

G ALETTE (la) Anfe du Fleuve $\checkmark$ faint Laurent, fa fituation. Lieu propre pour un Fort, Gallions. Naufrage des Gallions d'Efpagne, 458. Galots. Les Galors, rapide, 193. Ifte aux Galots, fa fituation, 20 s. Ganos. Lieu fitué fur l'Ohio, ce qu'on y trouve de fingulier, 224 . Garcia (le P. Gregorio.) Dominiquain Efpagnol; fon fentiment fur l'origine des Amériquains,

Gafpé, ou Gacbepé. Baye \& Cap. $S a$ fituation, 6 r.

Gaul. L'eftomach d'une Moruë,ce qu'il a de particulier,

52.

Gaulois. Paul Jove a imaginé qu'ils defcendoient des Mexiquains. Joltel a cru quils avoient envoyé des Colonies en Amérique,

Géants. On ne doit rien conclure des Géants, qu'on a vîs dans l'A mérique, par rapport à l'origine des Ainériquains,

27.

Génebrard donne dans les Idées d'Arias Montanus fur le nouveau Monde,

Gin-Seng. Cette racine eft augi bonne en Canada, qu'en Corée, \& pourquoi. Où elle fe trouve. Idée, qu'en ont les Sauvages, nom qu'ils lui donnent, 315 . E fuiv. Voyez la Defcription des Plantes.

Giros (D. Pierre Ferdinand.) Ses
L E

découvertes dans la Terre Auftrale; 22.

Glaces enormes. Danger, qu'elles font courir fur Mer, s8.

Goberge, ou Poiffon S. Pierre. Defcription de ce Poiflon. Pourquoi on le nomme Poiffon S. Pierre, I $\{2$.

Gomara. Aureur Efpagnol, fait defcendre les Amériquains des $\mathrm{C}_{2-}$ nanéens chaffés de la Paleftine par Jofué , 4. En quel tems il dir, que les Chichimaquas.s'établiffent fur le Lac de Mexico, $\approx 18$. Goufre. Vis-à-vis l'Ifle aux Coudres; à quelle occafion il a paru, 66 . Aurre fur le Micifipi, 414. Goyogouins. Baye des Goyogouins, fa defcription, 214.

Grains \& Légumes. Qui font ceux, que les Sauvages culcivent, \& quel ufage ils en font, 330 . \& fuiv. Grellon (le Pere) Jéfuite, ce qu'il dit d'une Huronne tranfportée en Tartarie,

Groënland. Grotius fait paffer les Norvégiens par-le Groenland, pour aller en Amérique, 12. Idée, que Jean de Laët donne de ce Pays, 14 is. Laët convient, que le Groenland avoir été peuplé par les Norvégiens. En quel rems ce Pays a commencé à être peuplé , 18 . Il paroît que les Ef kimaux en font originaires, 179.

Grotius (Hugues.) Son fentimene fur l'origine des Amériquains : fss démêlés à ce fujet avec Jean de Laës, 12. \& fuiv.

Gruës. Deux efpéces de Gruës en Canada, leur defcription, I s5. Guarigues. Efpéce de Champignons qui croiffent fur les Pins blancs; leur ufage dans la Médecine des Sauvages, 160.

Guella (François) Efpagnol, croit qu'il y a communication par Terre entre l'Afie \& l'Amérique, \& fur quoi il fe fonde, $3 \mathrm{i}$.

Guerre. Comment les Guerres en. 
tre les Sauvages ont dépeuplé le $\mathrm{Ca}-$ nada, 203. Maniere de chanter la Guerre, 207. De la déclaration de la Guerre, 208. \& fuiv. Des préparatifs, 2 10. Des motifs, quil la font entreprendre, 215 . \& fuiv. Des préparatifs duChef, 2,6 . \& fuiv. Comment on y prépare les Guerriers, en leur faifant toutes fortes d'avanies, \& quel eft le principe des Sauvages fur cela , 218-19. Adien des Guerriers, 221 . Leur marche, leur cam. pement, leur confiance préfompEueufe : leur attaque, leur retraire : maniere, dont ils en ufent avec leurs Prifonniers : leur arrivée à leur Village. Maniere, dont ils inftruifent le Public de leur Victoire, 236 . ¿ fuiv. Lenrs Guerres font éternelles, $25 \mathrm{I}$. Quelques circonftances rouchant la Guerre parmi les Sauvages Occidentaux , 382 . \& fuiv. De quelle maniere les Natchez font la Guerre, 225 . \& fuiv.

Guigues (le $\mathrm{Sr}$ ) Fermier du Caf. tor. De quoi il s'avife pour faciliter la confommation de cette Pelleterie, dont il étoit furchargé,

Guimonneau ( le P. ) Miffionnaire aux Illinois,

394.

Guinée. Nouvelle Guinée, cruë wne Ifle, reconnuë Continent, 22.

\section{$\mathrm{H}$}

$H$ ABIT ANS. Pourquoi les $\mathrm{Ha}$ bitans font plus à leur aife en Canada, que les Seigneurs, 108-09. H.imcunius. Son fentiment fur les premiers Habitans du Pérou \& du Chili,

Havane. La Havane, Ville de line de Cuba. Sa fituation, 458 . Defcription du Port $\&$ de la Ville. Le Gouverneur refufe d'y recevoir la Bellone. L'Auteur y rencontre des François de l'Adour, 486-\$7. Havvkins (le Chevalier Richard) prérend avoir verifié, que la Nou- velle Guinée eft une Ifle,

Hebreux. Voyez Ifraelites. Le P. de Acofta ne croit point que les Amériquains en defcendent : fes preuves, 7. Rapports entr'eux \& les Sauvages,

Hinnepin (le P. Louis) Récolle. Voyez l'Hiftoire \&o la Lifte des Auteurs. Il s'eft trompé fur la hauteur du Sault de Niagara,

233.

Herbe à la Puce. Ses effers, $263_{3}$.

Hercules. Colomnes d'Hercules. Budbeck les place dans le Nord, 3 . Here (le Chevalier d') Capitaine de Vaiffeau, évite le naufrage, fans pouvoir le faire éviter aux Gallions Efpagnols,

Hermine. Defcription de l'Hermi. ne du Canada,

Herrera (Antoine de.) En quel rems il dir que lesChichimeques s'établirent fur le Lac du Mexico, 18.

Hefperides. Idées des Efpagnols fur ces Ifles, 3. Budbeck les place dans le Nord, ibid.

Hefperus. Idées des Efpagnols fur ce prétenda Roi,

Hetres. Abondans en Canada : ${ }^{3}$ : quoi ils font bons,

162 .

Hollandois. Ils donnent des Armes. à feu aux Iroquois, \& par là mettent les François dans la néccffité d'en donner auffì leurs Alliés, 222 .

Hontan ( le Baron de la.) Voyczo l'Hiftoire or la Lifte des Auteurs. Faufferé, qu'il avance au fujet du grand Autel de l'Eglife des Jéfuites, 76. Réfutation de ce qu'il dit des Femmes de Montréal, I42. Il paroît n'avoir point vâ le Sault de Niagara, 233-34. C'eft une fable, que ce qu'il dit de l'exactitude des Sauvages à accorder les années Solaires avec les Lunaires,

Hornn (Georges de ) Hollandois. Son fentiment fur l'origine des Amériquains, 24. Ej fuiv. Hofpitalieres. Defcription de leus. Hôpital à Quebec, 76. \& del'Hồ- 
5 18

\section{$T$}

pital Général, 77. Différence entre les Religieufes de ces deıx Maifons, 77. Hôpital des Trois $\mathrm{Ri}$ vieres, par qui fondé, par qui deffervi,

I 13.

Hougue. Fort Efpagnol dans l'Ifle de Cuba , fa fituation, 458.

Huarts. Efféce de Cormotants. Son cri, \& ce qu'il préfage, 193. Hulert (M. ) Commiffaire-Ordonnateur de la Louyfrane, vend fa Conceffion des Natchez, 415 . Amitiés, qu'on lui fait à la Baye de faint Jofeph. Sa Fille y eft baptifée avec grand appareil , 473.

Hudfon. Baye d'Hudfon. Voyez l'Hiftoire. Peuples, qui y font leCommerce, 180. \& fuiv.

Huitres. Maniere de les pêcher en Acadie, I I I-s2. Huitres de deux fortes fur la Côte de la Floride, $47 \mathrm{I}$.

473.476 .

Huns. Sentiment \& contradiction de Georges de Hornn au fujet des Huns,

29-30.

Hurons. Nation Sauvage du Canada. Huronne rranfportée en Tartarié, 30-31. Idée de Georges de Hornn furl'origine de ces Sauvages, 32. Ferveur des Hurons de la Lorette, 82 . \& fuiv. Les Hurons plus naturellement portés, que les autres Sauvages, à la fierté \& à l'indépendance, 83 . De la Langue Huronne, 189. Leur génie élevé, nobleffe de leur Langue, 196 . Les Peuples de la Langue Huronne ont été plus occupés que les autres de la culture des Terres, \& ce qui s'en eft enfuivi, 198. Ils font encore l'ame des Confeils, 199. C'étoic la feule $\mathrm{Na}$ tion, qui pût difputer la préémidence aux Algonquins, 200. Comment ils fe font trouvés engagés dans la guerre contre les Iroquois, qui les ont prefque détruits, 202 . Maladie extraordinaire d'une $\mathrm{Hu}-$ ronre, façon ridicule, dont elle fe guérit, 230 . ¿ fuiv. Village des

\section{E}

Hurons au Détroit, 256. Ils y affiftent à un Confeil. Leur Orateur porte la parole felon la Coûtume, 257. \& fuiv. Sans etux lesautres Satrvages y mouroient de faim. Leur efprit intéreffé. Les Matrones fe plaignent de ce qu'on empêche, qu'on ne leur donne un Miffionnaire, 260. Comment la Nation eft divifée en Tribus, 266. La dignité de Chef y elt héréditaire dans la ligne féminine, 267. Comment ils puniffoient l'affafinat, 274. \& le vol, auquel ils étoient fort fujets, 276 . Les Mariages ne font point ftables parmi eux, 284. En quoi ils furpaffent les autres Sauvages, 305.309. Ils étoient autrefois fort lafcifs, 326. Eftime, qu'ils ont toujours faire de la continence, 350 . Leur Tradition fur la premiere Femme. Leur idée fur les Eclipfes, 399-400. Les Hurons ne fe rendent pas les Efclaves de leurs Chefs, comme font les Natchez, 4'9.

Hyver. Rigueur \& durée de l'Hyver en Canada, 164. \& Juiv.

\section{J}

\section{TACQUET. Le Banc Jacquet, ce que c'eft, 49. Jaloufie. Les Sauvages des deux fexes y font fort fujets, 285 . Iberville (M. le Moine d'.) Il décou-} vre un paffage fûr \& commode; 66 . Eloge de cer Officier; eftime, qu'en faifoient les Canadiens, 174. Il trace le Plan d'une Ville aux Natchez. Quel nom il lui défigne, 414 . Il deftine un Miffionnaire aux $\mathrm{Nat}$ chez, Jéremie (le fieur.) Voyez la Lifte \& l'Examen des Auteurs, \& les deux précédens Volumes: ce qu'il dit des Caribous, 130. \& des Baufs mufqués,

332. Jéfnites. Defcription de leur College de Quebec, 75. O fuiv. Ils con- 
duifent leurs Sauvages des Trois Rivieres au Cap de la Magdeleine. Un Jéfuire eft établi Miffionnaire à Checoutimi , 1. 4. Pourquoi, \& comment ils ont formé la Bourgade du Sault faint Louis, 175. \& fuiv. Dangers, qu'ils couroient parmi les Iroquois, $2\{2$. Danger, que coururent deux Jéfuites dans une Bacchanale Iroquoife, 357.6 fuiv.

Jeu. Jeu du Plar, ou des Offelets, en quoi il confifte, à quel point il intérefle les Sativages, 260. \& fuiv. Jeu des Pailles, de la Croffe, \& autres chez les Miamis, 318. \& fuiv. Jeux pour les Funérailles, 373 . Jeu du Truc parmi les Tonicas,

433.

Jeune. (le P. Paul le) Jéfuite, fa Relation d'un hyvernement des Sativages,

335. of fuiv.

Jeûne. En quoi confíte le jeûne des Sauvages, II . Quelques uns le pouffent fort loin, 300 . Les jen̂nes des Sauvages font un exercice de Religion,

$346-48$.

Illinois. Nation Sauvage. Voyez l'Hiftoire. Elle paroît avoir la même origine, que la Miamife, 188 . Ils défont un grand nombre d'Otcha. gras, 292. Corruption de leurs mocurs. Ils ont corrompu les Iroquois, 303. Mépris, où ils font parmi les autres Sauvages, 307. Leurs maléfices, 360 . Ils font habiles \& hardis voleurs, 384 . Action entre les Illinois \& les Outagamis. Chaque Parti faic un Prifonnier. Celui des Illinois fe dit Illinois, n'eft point cru, \& il eft brûlé, 385 . Un Parti d'Illinois revient à Pimiteoni. Caractere de leur Chef. Miracle arrivé en fa perfonne; ce qui fe paffa entre l'Auteur \& lui, 386 . \& fuiv. Il prie l'Auteur de baptifer fa Fille, $\&$ il fe convertit, 389. Deux Villages Illinois près du Miciffipi. Leur commerce avec les François. Induftrie des Femmes Illinoifes, 394.95.
On prétend que les Illinois font originaires du Voifinage de la Mer. Leurs différentes Tribus, 398. Avantages du Polte des Illinois, 402. \& fuiv. Attachement de ces Sauvages pour les François, 403. Marques des Illinois après une expédition heureufe contre les Chicachas. Notre Alliance avec eux nous a attiré les Chicachas, 408.

Incas. Grotius prétend que le premier des Incas du Pérou étoit Chinois,

$=17$.

Indigo. Il croît naturellement dans la Louyfiane, 4 16. Ce qui fait périr quantiré de ces Plantes dans l'Ifle Elpagnole, 495. Joliet (le fieur. ) L'Ifle d'Anticorty lui eft concelée au retour de la découverte du Micillipi, \& on ne lui fair pas un grand préfent, $66_{3}$. Jonas (Angrimuss.) Sçavant Iflandois; en quel rems il affûre, que le Groenland a commencé d'être peuplé,

18.

Jongleurs. Leurs charlataneries dans la préparation \& dans l'épreuve des Drogues, qu'ils font pour ceux, qui feront blelfés à la Guerre, 219 . హ fuiv. Ils fe fervent de Serpens pour leurs preftiges, 235 . C'eft à eux à régler la marche des Guerriers, $2 ; 6$. Ils fe vantent d'avoir des tranfports extatiques, 347. Ils ne fe mêlent point de maléfices, \& s'étudient même à les découvrir, \& à en empêcher l'effet. Ils prétendent n'avoir de commerce quavec les bons Génies, 360 . Leurs preftiges, 361 62. Leur inftallation, 363. Comment ils exercent la Médecine, 364 . \& fuiv. Leur impolture pour n'être point refponfables des événemens. Jongleurs de l'Acadie, 368 . \& fuiv. Dans quelques Nations ils ne font pas en fúreté de leur vie, fi le Malade meurt, 369. Deux fortes de Jongleurs parmi les Natchez, 42627. 
Jove (Paul.) Sur quoi il fondoit fon opinion, que les Mexiquains étoient venus dans les Gaules, 4.

Iroquet. La Narion de l'Iroquer combe dans une embufcade des Algonquins, \& y reçoit un échec, dont elle ne s'eft jamais relevée. Elle doit $f_{a}$ deftruction principalement aux Hurons,

I $10-11$.

Iroquois. Sauvages du Canada. De qui de Hornn les fait defcendre,'32. Par où ils entroient dans la Colonie : cruautez, qu'ils y exercoient, 123 . O f fuiv. Ils font deux fois repouffés par une Dame \& une Demoifelle, 124-25. Ils feroient bons Voifins, fi on étuit en état de ne les pas craindre, $1 \xi 1$. Parti, qu'on prend pour les gagner à J. C. 176 . Eloge des Iroquois du Sault faint Louis, 177. Les Cantons Iroquois ont chacun leur Langue, 189. Leur Commerce avec les François à Cararocoui, dunr le Fort avoit été bâri à leut occafion, 194 . Origine de leurs Guerres. avec les Algonquins, 200. \& fuiv. Comment ils fe font difpofés à faire la Guerre aux Algonquins. Maniere, dons ils la font. Ils ont dérruit, ou fort mal-. traité prefque toures les Nations, \& font eux-mêmes fort diminués, 202-03. Ceux de Cararocoui refufent de continuer la Guerre contre les Cheraquis, 207・08. Du Pays des Iroquois, 220. Ce font les premiers Sauvages, à qui on a donné des armes à feu, \& qui les leur a données, 224. Les Cantons lroquois font indépendans les uns des autres, 227 . Ils feroient réduits à rien fans les Prifonniers, qu'ils ont adoptés, 243 . Ils brûlent des François, qui traitoient chez eux de la part du Gouverneur Général ; \& les Jéfuites, quoique fous la fauve garde publique, n'y éroient pas en fûreté, 252 . La Narion Iroquoife a les mênes noms que la Huronne, avec quel-

que différence, 267. Ce qui a le plus contribué à la rendre formidable. Sa polirique à l'égard des François \& des Anglois, 271. Ils font fort jaloux, 285 . Ce qui a corrompu les mæurs des Iroquois, 30;. En quoi ils furpaffent les autres Sauvages, 305-06. Leur fierté \& leur hauteur, 309 . Ce que des Iro. quois trouverent de beau à Paris, 322 . Ils travailloient autrefois leurs Cabannes mieux que les aurres, \& mieux, qu'ils ne font aujourd'hui, $335^{\circ}$. Eftime, qu'ils ont toujours faite de la continence, 350 . Ce qu'ils penfent de la narure des maladies, 37071 . Leurs fables au fujet de la premiere Femme,

399.

Ihande. Grotius croit que les Norvégiens ont paflé par cette Ifle pour aller* peupler l'Amérique Seprentrionale, I2. Quand cette Iffe a commencé d'être peuplée par les Norvégiens, 14. Ifles. Ifle aux Chevreuils, 204-05. Ifle Bizard, 140. Ifle du Bois blanc, $\quad 282$. Ifles du Caftor, 313. Ifle des Chats, oude Bienville, 449. jle des Chiens, 476. Ifle à Corne, 449. Ihe Daupbine, ou Maffacre, 449. Ifle Efpagnole, ou de S. Domingue, 2. 2829. Ifle de Jefus. Son premier nom. Sa fituation, fon étenduë,

Ifle Pelée,

Ile Perrot,

Ile Ronde,

Ifle Rouge,

140.

Jles de Salomon,

Ifles aux Serpens à Sonnettes, 255. Ifle de fainte Claire,

Ifraelites. Qujelques Auteurs fone paffer les Ifraëlires, que Salmanafar emmena Captifs, en Amérique, 4. Bréverood croir que tous les Tarrares defcendent deux, i 1 . Moraez a cru que les Ifraëlites avoient peuplé 
1'Amérique en partie. Réfutation de çe fentiment, 23. Itaque. Pointe d'Itaque. C'eft l'ex. trémité Orientale de Cuba, 489. Jufqueka. Divinité des Sauvages, $344-45 \cdot 348$.

K

T. AMOURASKA. Paroifle du 1 Canada, d'où vient ce nom. Pêche des Marfouins établie en ce lieu, Kappas. Sauvages de la Louyfiane prefque détruits, 410 . Kereben (le P. de. ) Miffionnaire aux Illinois,

Kicapous. Nation Sauvage. Son Pays propre,

Killiftinons. Voyez Criffinaux.

Kirker. (le P. Athanafe) Jéfuite,a cru que les Amériquains tiroient leur origine des feuls Egyptiens, 4. Kompfer (Engelbert.) Quand \& par qui il prétend que la Mérempficofe a été portée aux Indes, 25 .

\section{L}

\section{$L$}

$A B R A D O R$. Situation de ce Pays, 178.11 n'eft bon à rien, 179 . Lacs. Les vagues font auffi fortes dans les grands Lacs du Canada, que dans la Mer, 205. Flux \& reflux, qu'on y remarque, 206. Erenduë de ces Lacs, 280 . Lacs à l'entrée des Rivieres, qui fe déchargent dans la partie Orientale du Lac Michigan ; d'où cela peut venir, 313 . Lacs de la Louyfiane,

Lac Huron,

Lacs des deux Montagnes,

Lac de Pimiteouy,

435 .

278.

Lac de Pontchartrain. Voyez Pontchartrain.

Lac de S. François,

193.

Lac de $S$. Louis. Sa fituation, 1 40. C'eft le premier nom du Lac Ontario,

195 .

Lac de $S$. Pierre, 112, Il n'a que Tome III. peu d'eau, fi ce n'eft au milieu. Il eft fort poiffonneux, 113 . Il partage le Canada en deux climats, comme la Loire en France, Lacs du Moingona, 136. Lac de bon Secours, 397. 398.

Lacs des Chetimachas, 436.444 . Lac Superieur. Son origine felon les Sauvages, qui lui rendent un culte, 281 .

Laët (Jean de.) Sçavant, natif d'Anvers. Sa Critique au fujet de diverfes opinions fur l'origine des Amériquains, 8. O fuiv. Ses Démêlés avec Grotius fur ce fujet, 12. \& f fuiv. Son fentiment propre, 19. \& fuiv. Réflexions fur fes preuves, 21. ¿ fuiv. Il expofe le fentiment de Moraez, 23. Il prétend que la $\mathrm{Na}$ vigation eft un effer de l'audace des Hommes, \& n'eft point entrée dans les vuës directes du Créatcur, \& fe trompe,

39.

Laffitan (le P. Jofeph.) a le premier apporté en France le Gin-feng du Canada. Le nom, qu'il lui a donné,

316.

Laine de Mofrovie. Nom, que l'on donnoit autrefois au poil du Caftor, 96.

Langets. L'A uteur court rifque de périr vis-à-vis Langets,

Langues. La connoiffance des Langues néceffaire pour découvrir l'origine des Nations, 36. \& fuiv. Les trois Langues Meres du Canada, 183. Des trois Langues Meres du Canada, \& de leurs dialectes, 184. \& fuiv. Caractere des trois Langues Meres du Canada, 296. \& fuiv. Embarras, où l'on a éré pour fe faire entendre des-Sauvages, \& quelle en étoit la caufe, 1 97-98. Laval (Fránçois de.) Premier Evêque de Quebec, vend l'Ille d'Orleans à $M$. Berthelor, 67 . Law. (M. ) Sa Conceffion aux A xanfas prefque ruinée. Il a été mal fervi, 411 . 
Légumes. Il les faut renouveller tous les ans dans l'Ine Efpagnole, à l'exception de la Laituë, 495 . Lemery. (M.) Il s'eft trompé en difant, qu'il n'y avoit que le train de derriere du Caftor, qu'il fût permis de manger en Carême, $97 . \mathrm{Ce}$ qu'il dit des Caftors, ou Biévres d'Europe,

Lencornet. Efpece de Séche, fa defcription, maniere de le pêcher,

I 52 .

Lery (Jean de.) Fait defcendre tous les Amériquains des Cananéens chaflés de la Palętine par Jofué, 4 .

Lery. (M. de Chauffegros de) envoye en France le Plan en relief de Quebec,

Lefcarbot (Marc.) Voyez les premiers Volumes. Avocat au Parlement de Paris. Son fentiment fur l'origine des Amériquains, 9. \& fuiv. Laër le critique, \& quelquefois $\mathrm{mal}, \mathrm{ir}$. De Hornn lui fait dire ce qu'il ne dit point, 24. Fautes, qu'il reproche aux François, qui étoient de fon tems en Acadie, $85-86$. Ce qu'il dit des Loups Marins de l'Acadie, 143 .

Liévres, \& Lapins. Ce qu'ils ont de particulier en Canada, 135 .

Lions inconnus dans les Ifles de l'A mérique, 7. Comment ils ont pût paffer en Amérique,

31.

Lochon ( le fieur de.) Ne réuffit point à trouver des Mines, 393 .

Longueil. (Le fieur le Moine, Baron de ) va négocier à Onontagué, \& vifite en paffant l'Etabliffement de Niagara,

228.

Lorette. Miffion Huronne, fa defcription. Ferveur des Sauvages : 82 -

Loups, Loups Serviers, Voy SerServiers. Petits Loups au haut du Miciflipi,

Loups. Voyez Mabingans.

133.

Loups Marins. Defcription de cet Animal, fes différentes efpéces. Maniere, dont on en fait la pêche.
Avantages, qu'on en peut retirer, 143 . \& fuiv.

Loutres. Communs en Canada,

Louis XIV. Pourquoi il ôte le droit de Patronage aux Seigneurs en Canada. Il y permet le Commerce aux Gentils-Hommes, 109.

Loulis de Bourbon, Navire du Havre. Il tombe en piéce en arrivant de S. Domingue, 500.

Louyfiane. Comment il faudroit y placer les Habitations, \& profiter du Terrein, que le Fleuve inonde tous les ans, 445-46. Ce que Garcilafto de la Vega en dit, 446. Idée peu jufte, qu'ón a de ce Pays, 8 d'oti cela vient, 446 47. Faulfe nouvelle de l'évacuation de la Louyfiane, d'où elle pouvoit venir, $476-$ 77.

Luc. Le Frere Luc, Récollet, a fait quelques bons Tableaux en $\mathrm{Ca}$ nada,

75.

\section{M}

ACHOUTIN. Marais. Sa fi-
tuation,
Macopine. Racine, fes propriérés,
$39 \mathrm{I}$. Madagafcar. Il y a apparence que les Chinois ont envoyé des Colonies dans cetre Ifle, $\Delta 0$. Magdeleine. (M. l'Abbé de la) Qui il étoir. Terrein, qu'il concede aux Jéfuites, I 14.

Cap de la Magdeleine. Les Jéfuites y conduifent les Sauvages des Trois Rivieres, qui n'y reftent pas lontems, 114. Maguelon. Une des Ifles de faine Pierre,

Mabingans. D'oùces Sauvages font verius dans la Miffion de faint François, 121. Ce font les mêmes que les Loups. Leur ancienne habitation, Maïz. Differens ufages, qu'er 
font les Sauvages \& les François, 331 . O fuiv. Pour dégraiffer les Terres trop grafles, on peut y femer du Maiz, 405 . Maladies. Nature des Maladies felon les Iroquois, 369. Malefice. Crime irremifible parmi les Sauvages, \& comment ils le puniffoient, 274-75. En quoi ils confiftent chez quelques Nations. Les Jongleurss'étudient àles rendre inutiles, 360.

Malhomines. Nation Sauvage, auttrement dits les Folles Avoines. Son Pays propre, I 88. Ces Sauvages font bien faits, ont un langage myftérieux, \& paffent pour un peu Sorciers, 291.

Mal-nommée. Plante de l'Ine Efpagnole, ennemie de l'Indigo, 494. Mango-Capa. Le Premier des Incas du Pérou. Grotius croir fans fondement qu'il étoit Chinois, 17.

Manicougan. Batture \& Riviere dangereufe pour les Vailfeaux. Autre nom de la Riviere, 64.

Manitouolin. Ifle du Lac Huton, 187.

Manitous. Ce que c'eft. Attention des Sauvages à les.porter à la guerre, 223. Honneurs, qu'ils leur rendent, $\&$ confiance, qu'ils ont en eux, 236 . \& fuiv. En quelles occafions on s'adreffe à eux, \& pourquoi, 145 . Difpofitions requifes pour avoir un Manitou, ou un Génie tutélaire. Manitous plus ou moins puiffans. On confond le Manitou avec fon fymbole. On en change quelquefois, \& pourquoi, $147-48$. Marais. Le grand Marais, ce que c'eft, fa fituation,

225. Marameg. Riviere, fa fituation. Ses Mines prétenduës, 393.6 fuiv. Marbre. Fort commun à Tadouffac , 6 g. Efpece de Marbre daus le Pays des Aiouez, $21 \mathrm{I}$. Marées. Où elles commencent à être fortes dans le Fleuve faint Lau- rent, 64. Obfervations fur les $\mathrm{Ma}$ rẻes du Fleuve \& du Golphede faint Laurent, 67. ש fuiv. Efpéce de flux $\&$ de reflux momentanés dans les Lacs, \& d'où cela peut venir, 206. Marées vers Penfacole, $275-76$. Mariage des Sauvages, 283.05 . Marıe. La Mere Marie de l'Incarnation, Urfuline. Danger, qu'elle courut en allant en Canada par la rencontre d'une glace énorme, s8. Marinous. Aureur Sicilien : fur quoi il s'eft imaginé que les Romains avoient envoyé une Colonie en Amérique,

Mirquette. (Le Pere Jofeph) Jéfuite. Voyez l'Hiftoire $\mathcal{O}$ la Lifte des Auteurs. Ce qu'il dit d'une Riviere, qui fort du Lac des Affiniboils, 185 . D'où eft venu le nom de Rivirre du Pere Marqueite. Mort de ce Miffionnaire, \& l'idée, que l'on a de fa fainteté, $3 ! 3-14$. Marshal. Interlope Anglois, au Biloxi. On l'oblige à s'éloigner à l'arrivée des Efpagnols, 482 . Il eft pris \& conduit à la Havane, 487. Marfon. (Monfieur \& Madame de) Prédiction finguliere d'une Sauvageffe à leur égard, 262. Marfouins de deux efpéces. Leur defcription. Avantages, qu'on en peut tirer, 1 47. Ce qui a fait difcontinuer la Pêche des Marfouins blancs au-deffous de Quebec, 148 . Martres. Particularités touchant ces Animaux. Obfervation des Sauvages à leur fujet,

Martyr. D. Pierre Martyr d'Anglerie, fon fentiment fur l'origine des Peuples de l'Yucatan, 13. Jean de Laèr réfure fes preuves, IG.

Martyrs. Ifles de la Floride. L'Auteur y débarque après fon naufrage: Il y trouve des Sauvages, $461-62$. Defcription de ces Ifles, 466. Ce qui $y$ retient les Sauvages, 467. Mafcoutins. Nation fauvage. Voyez l'Hiftoire. Son Pays propre. Mal-àVuu ij 
propos nommés Nation du Feu, 188. Ils ont eu un Village fur la Riviere de fainr Jofeph, tion, Mafquinongé. Poifton. Sa defcripMata I 2 I. que c'eft. Sa firtration, 458. Defcription de cetre Baye. Efforts inutiles du Capitaine de la Bellone pour y être reçu, $487-88$.

Matanes. Mamelles de Matanes, Montagne à deux têtes, 64 . Mateomek. Divinité des Sauvages,

344 .

Maubiliens. Sauvages de la Louyfane. Ils avoient une efpéce de Primatie parmi les autres par rapport à la Religion, 429. Ils étoient trèspuiffans du rems de Ferdinand de Soto; préfen:ement ils font prefque réduits à rien, $4 \mathrm{~s} 2$. Fort de la Maus bile. De quelle importance il eft de le conferver. Pourquoi les Habitans veulent quitter cette Riviere. Carriere au-detfus du Fort, $4 \varsigma^{1-52}$.

Mauville. Bourgade, dont parle Garcilaffo de la Vega, fituée au niême endroit, où eft préfentement le Fort de la Maubile,

$4\{2$.

Médecine. Comment les Sauvages l'exercent, 2 leurs principes, 364 . $\checkmark$ fuiv. Médecine de la guerre parmi les Natchez, ce que c'eft, $42 j$. Medoc. Fils du Prince de Galles. Hiftoire de fon paflage en Amérique,

20.

Melons. Deux fortes de Melons en Canada,

Mercier. (M. le) Eccléfiaftique Canadien, Miffionnaire aux Illinois. Son éloge,

Mérifier. Sucre de Mérifier, i 23. Il ne perd point fon amertume. A quoi eft bon le bois de cer Arbre,

Merluche. Ce que c'eft,

162.

Meffou, ou Sakescbak. Repare le Monde, felon les Sauvages, après le déluge,

399.
Metchigamias. Nation fauvage de la Louyfiane, adoptée par les KafKafquias, \& confondue avec eux , 39899. Metellus Celer. Fauffe Hiftoire de Pline de quelques Indiens envoyés à ce Romain par le Roi des Sueves, 6. Pourquoi les Eৎpagnols ont fair valoir cette fable,

Mexico. Les Mexiquains, lorfqu'ils s'érablirent au Mexique, trouverent plufieurs Nations Barbares autour du Lac Mexico, 1.5 . Mexiquains. 1ls trouverent en arrivant au Lac Mexico plufieuts $\mathrm{Na}$ tions Barbares, qui y étoient établies, dont ils n'entendoient point la langue, \& qu'ils affujettirent, i g. Pourquoi ils donnerent à Cottez le nom de Fils du Soleil, 17. Leur rradir tion fur les Peuples, qu'ils trouverent fur les bords du Lac de Mexicos Quand ils fonderent leur Empite : d'où ils venoient, 18 . Les premiers Mexiquains étoient moins policés, que les Fondateurs de l'Empire du Perou, 33. Miamis. Nation fauvage. Voyez l'Hiftoire. Lieux, où elle réfide. Elle paroît avoir une origine commune avec les Illinois, 1 \$S. Maniere, dont ces Sauvages fe préparent à la guerre, 220. Comment ils traitent leurs Femmes fugitives, 284. Village de Miamis à la Riviere de faint Jofeph, 312-16. Comment leur Chef reçoir P'Aureur, 3 I 8. Jeux en ufage parmi ces Sauvages, 318 . \& fuiv. Ils rapportent de l'Eau-de-vie de chez les Anglois, \& ce qui en arrive, 320. Fort des Miamis, ce que c'eft: fa fituation, 381 . Ces Sauvages font originaires des bords de la Mer, 398. Michabou, ou le Dieu des Eaux, fuivant quelques Sauvages. Ouvrages, qu'ils lui attribuent, $28_{1}$. 6 juiv. Son Tombeaa, 283. Autres noms, qu'on lui donne; pouvoir, qu'on lui attribue. Comment on dit 


\section{E S M A T I E R E S.}

qu'il forma le Monde \& les Hommes. Contradiction des Sauvages à fon fujet,

Michigan. Le Lac Michigan. Sa fituation, mal à-propos nommé Lac des Illinois, 187 . Il n'a point confervé le nom d'Orleans, qu'on lui avoir donné, 253 . Ce Lac \& la Baye, qui s'y déchargent, reçoivent beaucoup de Rivieres, dont la plûpart font fort grandes. Ce qu'clles y produifent, 302. Singularité fur les Rivieres, qui fe déchargent dans le Lac Michigan, du côté de l'Êt,

313.

Micbillimakinac. Defcription \& fituation de ce Pofte. Son utilité pour le commerce, 279-80. Ifte de Michillimakinac, $28 \mathrm{r}$. Sauvages de ce nom, détruits à ce qu'on croit, par les Iroquois,

$2 S_{2}$.

Micifjipi. Sa jonction avec le Miffouri, 392. CeFleuve eft peu connu au deflus du Sault faint Antoine, 398. Le Miciflipi gele extraordinairement. Difficulté de naviger fur ce Fleuve, 404. Profondeur de ce Fleuve, 409. Ce Fieuve fe jette beau. coup du côté de l'E̊t, 434 . Etat, où eft ce Fleuve au deffous de la Nouvelle Orleans. Changemens, qui s'y font faits depuis quarante ans, \& qui en eft la caufe, 440. Des Palfes ou Embouchures du Miciflipi: leurs incommodités, le moyen d'y remédier, 44r. of fuiv. Comment on pourroit creufer la principale de toutes, 444. Largeur du Fleuve, 445 . Difficulté d'y naviger, 446.Par quelle hauteur eft l'embouchure de ce Fleuve, 453 . Il n'eft pas vrai qu'il porte fes eaux douces vint lieuës dans la Mer. Bonne qualité de fes eaux, 457 .

Milius. (Georges.) Miniftre Proteftant, a cru que les Celtes avoient peuplé l'Amérique : $4 . \&$ que les Habitans des deux Amériques n'avoient eu entr'eux aucune communication avant l'arrivée des Efpagnols,
Milles Ifles. Leut fituation, 195. Mines de Fer aux environs des -Trois Rivieres, 113. Des Mines de la Louyfiane, \& furtout de celles de la Riviere Marameg. - 395. \& fuiv. Mineurs du Roi à la Louyfiane, 393. \& fuiv. Mines de Plomb fur le Micillipi, au deffus du Moingona, 397. Sur le Miciflipi, 407. Avis d'une Mine d'argent donné par les Octatas,

Mirâcle, 483.

Miracle, 347. Mifcou (Ifle.) Sa fituation, 65 . Particularité d'une Fontaine d'eat douce au large de cetre Inte, $\quad 62$. Miffionaires. Leur avis pour peupler le Canada de proche en proche, go. Des Miffionnaires font invités à une Fête, où ils fuppofent, qu'il y a de la fuperfition, 230 . Ils refufent une Couverture bleuë, qu'on leur demande, \& pourquoi, $2 ; 1$. Ils font remarquer la vanité des promelfes des Génies, \& ce qu’on leur répond, 232. Pourquoi les. Sauvages voudroient, qu'ils affiftaffent à leurs Jeux, 262. Mauvaife humeur, \& reproche de ces Barbares fur leurs refus, \& ce que ceux-ci répondent, 263. Ce qu'ils avoient à fouffrix dans les hyvernemens des Sauvages, 33 ). Or fuiv. Les Miffonnaires ont mieux aimé fouffir avec eux biea des incommodirés, que de leur ouvrir trop les yeux fur les commodi. rez de la vie, 339. Les Sauvages furpris de voir les Milionnaires prédire les Eclipfes, \& ce qu'ils en concluent, 401. Miffionnaires à ha Louyfiane, \& le peu de fruit, qu'ils $y$ font, 431. Mifjisuguez. Nation fauvage, dont une partie eftétablie à Cataroconi', 195 . Ils chanrent la guerre à Catarocoui , 207. Village de Miflifaguez à Niagara, 225 . Un Milfifagué danfe \& chante avec du feu dans la bouche, 228-29. Village de ces Sauvages dans le Détroit, 277 
Miffouri. Sa jonction avec le $\mathrm{Mi}$ ciffipi, 392. Miffourites. Peuples habitans fur le Miflouri. Un A umônier Elpagnol leur échape, \& comment, $293 \% 94$. Sont les meilleurs coureurs des Sauvages du Canada , 386 . Raport d'une Femme Miffourite fur la Source du Miffouri. Situation des Miffourites, ces Sauvages voyagent fort loin, 396.

Miftaffins. Peuple fauvage des Environs de la Baye d'Hudfon. Quelle Langue ils parlent, 180.

Moingona. Situation \& defcription de cette-Riviere, ce qu'on y trouve, 397. Il parôir, que les Illinois font defcendus par certe $\mathrm{Ri}$ viere dans la Louyfiane, parce qu'une Tribu Illinoile en porte le nom. 398.

Monnoyes. Leur variation en $\mathrm{Ca}$ nada, mauvais effets que cela a produit, 91. Ú juiv. Monfonis. Peuple fauvage, voifin de la Baye d'Hudfon, quelle Langue ils parlent, 180.

Morues. Prodigieufe quantité de ces Poiffons fur le grand Banc, 49 . Bonré de ce Poiffon : ce qu'il y a de meilleur. Sa voraciré. ll n'eft pas vrai, qu'il digere le fer. Comment il fe décharge de ce qui l'incommode, s2. Ce que c'eft que la Moruë verte \& la Moruë féche. Comment on auroit dû faire la pêche de la Moruë en Acadie,

Monftre Marin. Un Miffonnaire croit en avoir vâ un dans la Riviere de Sorel,

Montjoly. Sa fituation,

154.

Mant-Louis Sa ficuarion. Dequelle importance il feroit d'y faire un Etabliffement,

62.

Montmorency. Sault de Montmorency, 70-71.

Montreal. Defcription de la Ville \& de l'ille de Montreal, 137.0
Mont Notre-Dame,

62.

Montagne. Village Iroquois de la Montagne; d'où lui vient ce nom, 141. Utilité de ce Village, par qui il eft dirigé, 176. Montanus (Arias.) Ses idées fur plufieurs endroits du nouveau Monde,

Montigny (le fieur de.) Capitaine François, commandanr à la Baye. Sun éloge, =90-95. Réception, que lui font les Sakis,

Moraez (Emmanuel de.) Portugais. Examen de fon fentiment fur l'origıne des Amériquains, 23. Motezuma. Idée plaifance de Georges de Hornn fur ce Prince, Moulin-Baude. Ce que c'eft. 34 . fituation, 64. Moulin à Planches, auquel des Caftors fourniffent de l'eau, 103. Mou!inet rapide,

Mozambique. On y connoifloit l'ufage de la Bouffole lontems avant le XV. fiécle, 8.40. Múriers. Quantité de Mûriers blancs aux Illinois. Les Habitans en bâtiffenr leurs maifons, 395 . Myrthe à Chandelle. Arbriffeau, qui porte une racine, dont on faic de la cire. Qualité de cette cire, 450 si. Voyez la Lifte des Plantes.

\section{N}

$\bigwedge_{\text {fioux. Nom propre des Sioux, }}^{A D O U E S \text {, }}$ $18_{3}$. Natchez. Sauvages de la Lonyfiane. Situation \& beauté de leur pays. Ville projettée aux Natchez. Pourquoi on y doit érablir la Métropole de la Colonie. Conceflions, \& leur defcription, \& fituation du grand Villing des Natchez, 414 . 6 fuiv. Leur Temple, 417 . \& fuiv. Caractere de cette Narion, 419 . \& fuiv. Leurs Mœurs, leurs Ufages, leurs 
Mariages, $423 . \dot{0}$ fuiv. Leur maniere de fe préparer à la Guerre, \& de la faire, 425 . O luiv. De leur Devis, 427. De leurs Traités, \& de la réception des Ambaffadeurs, 427. ó fuiv. II n'y a plus que leur Temple, qui fublifte dans la Louyfiane,

429.

Natchitaches. Sauvages de la Louyfiane. Voyez le fecond Tome de l'Hiftoire, leur fituation,

Naufrage. Voyez Adour.

434.

Navigation. Preuves que la Navigation étoit affez parfaite après le Déluge, pour que l'Amérique ait éré peuplée peu de tems après, 38-39. Un des plusgrands dangers dela $\mathrm{Na}$ vigation pour aller en Canada, ss.

Négociations. Habileté des Sauvages dans leurs Négociations, $25 \mathrm{I}$. \& fuiv.

Négres. Ne deviennent jamais blancs, fous quelque climat qu'jls foient, 19. Les Négres, qu'on a trouvés dans la Province de Careta en Amérique, y étoient fans doute venus d'ailleurs, 2 f. Pourquoi il ne faudroit pas les laifler multiplier dans nos Colonies, - 4is.

Niagara. Ce que c'eft que la Riviere de Niagara, 225 . Idée du pays de Niagara, 227. Defcription de la Cataracte de Niagara , 233 . \& fuiv. Portage de Niagara, 235. Nipiffings font les vrais Algonquins, 186. Lac Nipifling, 187. Voyez le premier Volume. Origine du Lac Nipiffing felon les Sauvages, 283.

Nobleßse. D'où il eft arrivé qu'elle eft devenuë fort nombreufe en $\mathrm{Ca}$. nada,

Noé. Il n'eft pas croyable, felon Lef́carbot, que Noé ait ignoré l'A. mérique, Io. Il n'a point dir, comme le prétend de Hornn, que ce $\mathrm{Pa}$ triarche y foit né,

24.

Noir (le fieur le. ) Commis principal de la Compagnie d'Occident aux Natchez, 415. Il vifite avec l'Aureur le Temple des Narchez, \& ce qu'il en dit,

419.

Noms des Tribus Huronnes, \& Iroquoifes, \& des Chefs, 266-67. De l'impofition des noms \& de leurs changemens, 288-89. On ne prononce pas le nom des Morts pendant le Deiiil, \& fi quelqu'autre le porte, il le quitte, 374-376. Noms des Guerriers parmi les Natchez,

$$
\text { Noquets, Narion Sauvere } 426 \text {. }
$$
Noguets. Nation Sauvage, Baye des Noquets, 88. Origine de ces Sauvages,

Norimbegue. Grotius y fait paffer les Norvégiens pour aller en Amérique, 12. Nom imaginaire \& factice Situation de ce Pays; nom, que les Naturels lui donnent, 15 . Norvégiens. Grotius prétend qu'ils ont peuplé l'Amérique Septentrionale, fes preuves, 12-13. En quel. tems ils ont commencé à peupler l'lllande, 14. Difficuliez, qu'ils auroient euës à paffer en Amérique. Foibleffe des preuves de Grotius,

Noyer. Sucre de Noyer, IS-16。 Noyer. Sucre deNoyer, 123 . Trois efpéces de Noyers, \& leur différence, 162. Proprietez des Noyers de la Louyfiane, 407.

\section{$\mathrm{O}$}

O CTOTATAS, ou Mattotata: Sauvages habitans fur le Miffouri. Deux de leurs villages font dérruits par des Efpagnols. Ceux d'un troifiéme furprennent \& égorgent tous les Efpagnols. Leur origine, 293. Situation de leur Pays, 396. Des Octotatas promettent de conduire les François à une Mine d'argent; 483. Offogoulas. Sauvages alliés des Yafous, $4 \mathrm{I}$ 3. Voyez le fecond Volume.

Obio. Surnommée la belle Riviere. Sa fituation,

224 은. 
Oifeaux. Plufieurs, mais non pas tous, ont pû paffer d'eux-mêmes en Amérique, 24. Des principales efpéces d'Oifeaux, qu'on voit en $\mathrm{Ca}$ nada, 155 . \& fuv.

Oifeau blanc. Efpéce d'Ortholan, fon chant, 156.

Oifeau-Mouche. D'où lui vient ce nom. Sa defcription, $f a$ difference du Colibry. Comment il fait la guerre aux Corbeaux, $157-58$. Ifes aux Oifeaux. Leur ficuation, leur defcription, 60-61. Okkis. Nom, que les Hurons \& les Iroquois donnent à leurs Manitoux,

Omans. Peuples du Canada, différens des autres, leur fituation,

397.

Onanguicée. Chef Pouteouatami. Il parle bien dans un Confeil, 259 . $S a$ politefle \& fon mérite, 260 .

Onneyoutb. Courage d'un Capitaine Onneyouth brû̉lé par les Hu. rons, 249. \& fuiv. Dans ce Canton l'autorité eft alternative entre les Hommes \& les Femmes, 269.

Onnontagué. Riviere d'Onnontagué , fa fituation, $f_{a}$ fource, 214. Barbare Coûtume de ce Canton,

368 .

Opmeer (Pierre.) Sçavant Hollandois, a cru que les Afriquains des environs du Mont Atlas avoient navigé en Amétique avant le Déluge,

28.

Orignal. Defcription de cet Animal, particularités, qu'on en rapporre. Maniere de le chaffer, 126. \& fuv. Conment le Carcajou lui donne la chafle, 129.11 eft devenu rare en Canada ,

130.

Orleans. Ifle d'Orleans. Sa fituarion, fon étenduë; érigée en Comré fous le nom de faint Laurent, 67. Par qui découverte, fon premier nom,

69.

Lac d'Orleans. On avoit ainfi nommé le Lac Michigan, 253.
Nouvelle Orleans. En quel état elle étoit en 1721 . Incommoditez de fa fituation. Képonfe à ceux, qqui la croyent bien placée, 439-40. Où elle feroit mieux placée, $44 \mathrm{I}$.

Ormes. Deux efpéces d'Ormes en Canada. Leur différence, leur groffeur, leur ufage, 163.

Ofages. Sauvages de la Louyfiane, leur fituation \& leur Riviere, 396 . Otchagras. Nation fauvage. Son Pays propre, 188 . Ils reçoivent un grand échec de la part des Illinois, \& voulant avoir leur revanche, un grand nombre d'entr'eux périt dans le Lac Michigan. D'où vient le nom de Puants, qu'on leur a donné. Leurs différentes tranfmigrations, 290. Leur défaur, leur Langue, 292. Plaifante idée d'un de ces Sauvages fur un onguent, qui lui étoit tonbé entre les mains, 294. Leur agilicé dans la danfe du Calumet, $296-97$. Otomias. Peuple établi fur le Lac de Mexico, fubjugué par les Mexiquains,

18.

Ouabache. Riviere, fa fituation. Importance de bâtir un Fort à fon embouchure,

Ouaschitas. Riviere des Ouatchitas, ou Riviere noire ,

Ovide. Defcription, qu'il fait d'une Cataracte affez femblable à celle de Niagara, 235.

Ovicdo. Auteur Efpagnol, fes idées fur les Hefpérides,

3 .

Ouilameck. Orateur Pouteonata$\mathrm{mi}$, fon éloge,

320.

Ouifcorfing. Situation de cette Riviere,

Oumas. Sauvages de la Louyfiane. Deux Villages de cette Nation, leur fituation, 436.

Ours monfrueux, ì qui Cartier vit faire quatorze lievës à la nage, fans fe repofer, ro. La chaffe de l'Ours eft la premiere parmi les Sauvages, 115 . Comment elle fe fait. 
ni manger, 1 17 . Vénération de Quelques Sauvages pour les Ours: leur prarique pour les appaifer, 300 . L'Ours fe drefle fur les partes de derriere quand il entend du bruit, \& ce qui penfa arriver à l'Auteur à ce fujet,

316.

L'Ours qui dort, ce que c'eft,

Outagamis, on les Renards. Voyez l'Hiftoire. Leur Pays propre, 188. On veut engager les Sauvages à recommencer la guerre contre eux, \& pourquoi, 298 . Ils pouffent fort loin leurs jeûnes pour fe difpofer à la chaffe. Leur caractere, ce qui les a engagés à nous faire la guerre. Ils fe font points pour cela aux Sioux, \& ce qui en eft arrivé, ;02. Un Outagami infulte cruellement des Illinois qui le brûlorenr, $306-07$. Leur Fort auprès de lakiviere de faint Jofeph, nommé le Forr des Renards, $37 \mathrm{t}$. Ils infectent tous les paffages pour aller du Canada à la Louyfiane, 380.406 . Des Outagamis prennent un François, \& pourquoi ils nele biûlent pas, 383 . Action entre eux \& les Illinois. Un Ouragami eft brulé par les Illinois, 385 . Un Outagami ne peur $f$ tire prendre feu à fon fufil, \& il eft pris par un 11 linois, $33^{-}$. Outaonis. Nation Sauvage du Canada. Voyez l'Hiftoire. Leur ancienne demeure, 187. Des Outaouais pourfuivis par des Iroquois tombent dans la Cataracte de Niagara , 234. Village d Outaouais au Dérroit, $2\{6$. 11 s y affiftent à un Confeil, \& fe contentene d'aprouver ce que lOrateur Huron avoit dit, 259. Village d Ouraonais dans le Saguinam. Ils reftene feuls à Michillimakinac, quelques uns vont s'établir dans les Ifles du Caftor. Leur indociliré envers les Miffion. naires, 279. 28o. Plufieurs fe retirent dans les Inles du Caftor, \& y Tome $I I I$. cultivent la terte, à l'exemple des Hurons, $282-83$. Ouyapes. Tribu des Axanfas; 410 . Morralité parmi eux, caufée par la petite vérole,

411.

Ouystanons, Tribu Miamife, 188.

Ozeille fauvage fur la Côte de la Floride. Sa mauvaife qualité ,

\section{p}

454.

D ACANE. Fruitier de la Louy-
fiane, defcription del'Arbre \& de fon fruit, 395 .

Panama. L'Inthme de Panama crû́ impratiquable avant l'arrivée des ESpagnols en Amérique,

3. 12.

Panis. Nation lauvage. Siruation de leur Pays Sont les premicrs, qui ont fait ufage du Calumet, qu'ils ont prétendu avoir reçû́ du Soleil. Ce qu'on doir conclure de cette Tradition, 212. \& juiv. Panis noirs, ou Ricaras, 4 to.

Paracelfe (Theophrafte) a cru que chaque Hemifphere a eu fon Adam,

Puradis. Idée, que les Sauvages ont de leur Paradis, ce qu'il faut avoir fair pour le mériter. Raport de ce Paradis avec celui des anciens Grecs, 35 I. ó friv.

Parmenides. Ancien Philofophe, a cru que la Zone Torride n'étoit point peuplée, \& qu'on n'avoir point navigé à l'Occident de l'Europe, au delà des Colonnes d'Hercules,

Parvaim. Arias Montanus le place dans le nouveau Monile,

Pafagor:Las. Baye \& Riviere. Conceffion de M. de Chaumont, 480 .

Paffagers. On débarque rous les Paflagers, qui éroient fur l'Adour. Danger, que courent les uns. Réfléxion, que font les autres, 16162 . Paffes, Ou embouchures du Miciffipi. Voyez Miciffipi.

Pauger ( M. de. ) Ingénieur du $\mathrm{X} \times \mathrm{x}$ 
Roi à la Louyfrane, vifite le Pays pour examiner oû l'on pourra conftruire des Forts. L'Aurteur part avec lui des Natchez, 432 . Il fait un fort beau Plan pour la Nouvelle Orleans, $44:$. Il fonde l'inle Touloufe, \& les Paffes du Miciffipi, 442. Il arrive au Biloxi avec l'Auteur', 448.

Pavillons. Ufage, que les Sauvages en font. De qui ils l'ont pris,

Pays plats. Ce que c'elt. Leur fiiuation,

277.

Pécan. Chat fauvage, fa defcriprion,

134.

Pelleteries. Faures, qu'on a faites en Canada au fujer du Commerce des Pellereries, 86. \& fuiv.

Pemine. Arbriffeau. Qualité de fon fruit, $16_{3}$.

Penfacole. Def́cription de la Baye \& du Forr de Penfacole, 479-80. Ce Pofte eft refticué aux Efpagnols, qui propofent d'y tran'porter l'Etabliffement de la Baye de S. Jofeph, $48 \mathrm{r}$.

Penfionnaires entrerenus par les Sauvages, on n'écoute point leurs avis, qu'ils ne foient appuyés de préfens, \& pourquoi ,

252.

Péorias. Tribullinoife, 398.

Perdrix. Trois efpéces de Perdrix en Canada. Ce qu'elles ont de parziculier,

155 .

Perles. Riviere des Perles. Sa fituation. D'où lui vient ce nom, auffi-bien qu'à une Ifle, qu'elle forane,

449.454 .

P.rmiffion, ce que c'étoit, 89 .

Perroquets du Canada \& de la Louyfiane. Leur defcription, 384 .

Pérou. Qui a cru que fes premiers Habitans éroient forris de la Frife,4. Leur furprife à la vuë des Vaiffeaux Efpagnols , 7. Ce que Grotius penfoir de leur origine, 13. Comment réfu'é par Jean de Laër, 36. \& juiv. Difficulté d'aller de la Chine au Pérou, Pourquoi les Péruvens ne peuvent être fuppofés defcendus des Chinois. Laër a cru que le Pérou a éré peuplé par quelque Nation Indienne, 17. Les Fondateurs del'Empire du Pérou paroillent avoir été plus policés que ceux de la Monarchie du Méxique,

Perrot ( Nicolas.) Voyez les deux Volumes de l'Hftoire. Il découvre des. Mines de Plomb fur le Micıffipi. Il bâtit un Fort fur la Rive droite du Lac de Bon-Secours, 398.

Péruffe. Efpéce de Sapin du Canada, 160. Ufages, que les Sauvages font de fon écorce, $16 \mathrm{I}$ 。 Pefcbe. La Pefiche auroit pâ enrichir le Canada, \& comment, 143. Elle eft de droit commun en Cana$\mathrm{d} a$,

172 .

Petri (Suffidus) a crû que les Frifons avoient peuplé le Pérou \& le Chili,

Petun. Erreur à l'occafion de l'urage, que les Sauvages faifoient de leur Petun. Ils y one renoncé dès qu'ils ont pû avoir de notre Tabac.

333.

Phéniciens. Roberr le Comte a cru qu'ils avoient teuls peuplé l'A méri. que, 4. Différentes tranfmigrations des Phéniciens en Amérique, felon De Hornn, 26. \& fuir.

Piakiminier. Defcription de cet Arbre \& de fon fruit. A quoi font bons les pains, que les Sauvages fon: des piakimines,

Détour aux Piakimines, 395.95.

Picverts, ou Piquebois. Plufienrs efpéces de cet Oifeau en Canada. Ce qu'ils one de particulier, 1 gG.

Pijoux. Efpéces de Chats fauvages de la Louyfiane, 407.

Pilote. Un bon Pilore doit touyours être de l'avant de fon Vaif. feau, 48.

Pimiteoni. Lac \& Village des Illinois. Leur fituation. Defcription dis Pays. L'Aureur y féiourne, \& ce qui s'y paffe. Il eft environné de Partis 
Ennemis, 384. Of fuiv. Pins. Deux fortes de Pins en $\mathrm{Ca}-$ nada, 160.

Pirémon. Chef Pouteouatami. Son éloge,

320.

Pirozues. Ce que c'eft. Incommoditez de ces voitures,

Pifticoui. Riviere. Sa fituation,

Pitoi Ef 380. cription,

Plane. Sucre de Plane,

Plaque La Plaque. Iroquois, qui a été Officier dans nos Troupes, épargne fon Pere dans un Combat, \& ce qu'il lui dit, 309-10. Il retourne par goût à la vie des Sauvages, quoiqu'il fût Lieutenant dans nos Troupes. On délibere dans fon Canton, fi on ne le fera point mourir, on conclud à le laiffer vivre, \& pourquoi,

32I-22.

Platon. On croit tronver dans fes Ouvrages quelques veftiges de la connoiffance de l'Antiquité. Ce qu'il en dit dans fon Timée parôit une fiction au Pere de Acofta , 3, 6, 7, 10.

Plats-côtez de Chiens. Sauvages des Environs de la Baye d'Hudfon, I 8 I.

Plie de Mer, en quoi elle differe de celle des Rivieres, maniere de les pefcher,

- Pline a crû que la Zone Torride n'étoit point peuplée, \& qu'on n’avoit point navigé à l'Occident de l'Europe au-delà des Colonnes d'Hercules, s. Il avance qu'un Roi des Sueves avoic envoyé des Indiens à Metellus Celer, 6. Il a cru que le nom de Scythe éroit autrefois commun à toutes les Nations du Nord de l'Afie, \& de l'Europe, il ajoutre, queles Scythes fe picquoient d'avoir beaucoup de Chevaux; mais il ne le dit pas de cous, 21. Il fe plaignoit, que la Navigation n'étoit pas auffi parfaite de fon terns, qu'elle l'avoit éré plufieurs fiécles auparavant, 39.
Poil. Pourquoi les Sauvages n'one point de poil fur le corps. Ils trouvent en cela une grande beauté, 3 I r.

Pointe. Longue Pointe, fa fituation. Elle eft couverte de Vignes,

Pointe coupée,

Pointe aux Cherreuils 412.434. Commencement de la Baye de Penfacole, 479. Pointe pelée. Sa fituation, 255 . Poiffons dorés. Fort communs dans le Lac faint Pierre, 12 1. 1 54 . Abondance de Poiflons dans le Lac de faint Pierre, \& dans la Riviere de faint François, 120 . Dans le Fleuve faint Laurent, \& fur les Côtes de l'Acadie,

Poiffon armé is $2-53 . \mathrm{Man}$. Poiffon armé. 1 52-53. Maniere, dont il donne la chalfe aux Oifeaux, utilitez, qu'on peut tirer de ce Poiffon, Is3. Poiffons, qui fe pêchent autour de Michillimakinac, $2 \delta_{2}$.

Poiffon blanc, 282. Bruit, que font certains Poiffons en battant l'eau de leur queuë,

Polygamie. Chez quelles Nations du Canada elle eft établie, $283-84$.

Pommes, Elles font 423. Pommes. Elles font toutes d'une excellente qualité en Canada, i 6 s.

Pontchartrain (Lac de.) Autrefois rempli de Caïmans. Sa longueur,

Porcelaine D'où $454^{\circ}$ Porcelaine. D'oú les Sauvages la tirent. Ufage quils en font, des coliers $\&$ des branches de Porcelaines, 209. \& fuiv.

Porc-Epi. Les Sauvages empêchent leurs Chiens de caffer les os de cet Animal, à caufe de lenr dureté, ro6. Defcription du Porc-Epi, \& ce qu'il a de fingulier, 135 . Porphyre dans les Ines de S. Pierre,

Portage. Ce que c'eft, 59.

I90. Portneuf. Terre érigée en Baronic rous le nom de Beckancourt, 109.

Portugais. Les Efpagnols, pour leur enlever la gloire d'avoir lespre- 
miers frayé un chemin aux Indes, donnene cours à l'Hiftoire des Indiens envoyés à Metellus Celer par le Roi des Suéves, 9. compris fous le nom d'Efpagnols, aufquels on appliquoit une l'rophétie d'Abdias,

Poffevin (le P. Antoine) Jéfuite, donne dans les idées d'Arias Montanus fur le nouveau Monde, 3 . Pojt:i( Guillaume.) Ses idées fur le nouveau Monde, $\quad 3.4$. Poulaluls. Voyez Affiniboils, p. 185. Pourcelles, Voyez Marfouins.

Pouteouatamis. Village de ces Sauvages au Détroit, 256 . Ils affiftent à un Confeil au Détroit, 258 . Leur Chef y parle fort bien, 259 . Réception, qu'ils font à l'Auteur. Eloge de certe Nation, 260 . Situation de leurs Inles. Leur affection pour les François, 290-91. Village de Pouteouatamis à la Riviere de faint Jofeph, 312. 316. Ils apportent de l'eau-de-vie de chez les Anglois, \& ce qui en arrive,

Powel (David.) Ce qu'il dit dans fon Hiftoire du Pays de Galles, d'une tranfmigration de ces Peuples en Amérique, 20. Prairie de la téte de Bauf. Sa fituation. D'où vient ce nom, 371 . Prétres. Qui font les Prêtres parmi les Sauvages, $350 . ; 64$.

Prifonniers de Guerre. Comment ils font rtaités, \& leurs bravades: de qui leur fort dépend, 242 . O fuiv. Comment ils font traités parmi les Natchez, 426. Provençal. Aventure finguliere d'un Navire Provençal, 8'. Puants. Voyez Otchagras. Baye des Puants, ou fimplement $\operatorname{la} B$ ye. $\mathrm{Sa}$ fituation, 188. Beauté du !ays, qualité du Terroir, d'oû lui êt venu le nom de Baye des Ptiants, 29192. Pyromancie. Comment les Algonquins \& les Abénaquis l'cxerçorent, 263.

$Q$ UAQUER. Iroquois, Seigneur de l'ifle Tonihata, 194. Whart. Ce que c'elt que le Quart fur un Vaiffeau,

5s.

Quebec. Siruation \& defcription de certe Ville. O rgine de fon nom, 70. \& fuiv. Ses Forififications. Son Plan en relief, 78. Maniere,dont on y vit,

Quiros (D. Ferdinand de.) ${ }^{79}$. qu'il mande au Roi d'tefpagne de fes découvertes dans la Terre Auftrale,

22.

R

RADEAU. Plufieurs Palfagers 1 de l'Adour font embarqués fur un Radeau, qui court rifque de $f e$ perdre, $46_{1}$. Une tempête le garantit du naufrage, $4^{6} 3$. Rai (M.) Sa defcription du Mus Alpinus convient au Rat mufqué du Canada, 107. Raifin-Prune. Oì il fe trouve, Rapide. Dans le Saguenay, 379. Voyez Sault S. Louis. Des Rapides du Fleuve faint Laurent, 190. \& fuiv. Rapide plar, 194. Voyez Calconchiagon. Deux Rapides dans le Micifipi,

Raquettes, Defcription des Kaquerres, avec lefquelles on marche fur la nege, 221 . Rat mus lué. Sa defcription, ce qu'il a de fingulier, 107. Rat de bois. Sa defcription, 134. Fable des Sauvages au fujet de cet Animal, Raye. Cap de Raye. Sa fituation, $58-59$.

Rayes. Trois efpéces de ce Poiffon en Canada , $15 \mathrm{I}$. Raze. Cap de Raze, fa fituation. Le Vaiffeau du Roi s'y trouve affalé, $57-58$. 


\section{DES M A T IER ES.}

Récollets. Defcription de leur Maifon à Quebec, 74. Leur premiere demenre, 77. Leur Etabliffement aux Trois Rivieres. Ils y deffervent la Cure,

Régent. Nom, que donnoient les François à l'Orateur Huron du Détroit , \& pourquoi. Son difcours dans un Confeil, 258.

Regnart. Poëte Comique, ce qu'il rapporte de la maniere, dont les Habitans de Bothnie fe comportent après s'être fair fuer, 362 .

Relingues du Flettan. Ce que c'eft,

Renards. Ils fe joignent aux $\mathrm{Car}$ cajoux pour faire la guerre à l'Orignal, 229. Renards noirs dans le Nord du Canada, 1 33. Les Renards font la guerte aux Oifeaux de Riviere, 133. aux Liévres, aux Lapins, \& les Chiens la leur font avec fuccès, 135 . Fort des Renards.Voyez Outagamis.

Renaud (le Sr.) Directeur d'une Compagnie particuliere, entreprend les Mines de la Louyfiane,

Renaudicre (le fieur de la.) duit à la Louyfiane une Brigade de Mineurs du Roi, \& ne réufit point,

Revenants. D'où vient que les Sat1vages croyent aux Revenants, 374 . Rbéne. Erable femelle, 161.

Ricaras, ou Panis noirs, $4 \mathrm{IO}$

Richclicu. Intes \& Riviere de $\mathrm{Ri}$ chelieu. Autres noms de la Riviere. Commodité, que fourniffoient la Riviere \& les Ifles aux Iroquois pour faire des courfes dans la Colonie, 124. Effer charmant, que font ces Ifles, quand on voyage par leut travers, 136.

Richer (le P. Pierte Daniel.) Miffionnaire à Loretre, $8,-5$.

Rio de los Perdidos. Sa fituation, d'ot̀ lui vient ce nom, 480.

Rio de Ciroca. Riviere de l'Ine de Cuba, ou il y a une Habitation Ef- gnole,

489.

Riviere noire, 64. On y trouve du Gin-Seng,

316. Riviere puante, ou de Beck.tncourt. Origine de fon premier nom, I10-

111.

Riviere des Outaouais, ou grande Riviere,

Riviere des Prairies, $\quad$ ibid.

Rivicre de S. Jean, ou les mille Ifles,

140.

Riviere du Loup Marin, 132.

$18 \mathrm{I}$.

Riviere aux Banfs. Pourquoi fon entrée fe trouve bouchée, 224. Autre du même nom,

Rivieres, qui fe décharger

déchargent dans

Lac Ontario, 205.

Riviere des Hurons, 277.

Riviere de la Manjftie, abondante en Efturgeons,

290.

Riviere du P. Marquette. D'où vient ce nom. Changement arrivé à fon embouchure,

Riviere de $S$. Nicolas,

Riviere du Saguinont,

31314.

315.

$39 \mathrm{r}$.

Riviere des Illinois. Pourquoi elle conferve fon nom après fa jonction avec le Theakiki. Oû elle commence à être navigable, 380 . Son cours. Sa jonction avec le Miciflipi , $391-$

Riviere des Macopines, 92.

Riviere des Kafkalkias, 391.

Riviere à la Roche, d'où lui vient ce nom,

Riviere Blerie, 396.

Riviere de fainte Croix,

Riviere de Saint Pierre,

397.

398. Riviere Blanche, 410 . Combien il y a de Rivieres dans leVega-Real de faint Domingue,

Kiviere Rouge,

494.

Rucher. Village des Illinois. 434. defcription ,

Roitelet. Il chante mieux $39 \mathrm{r}$. da, qu'en Europe, 1 s 6 .

Romains. Sur quel fondement Marincus a imaginé, qu'ils avoient 


\section{T A B L E}

envoyé une Colonie en Amérique,

Rofalie. Ville projettée aux Natchez, \& qui n'a jamais été qu'en projet,

$4^{1} 4$.

Rofiers. Cap des Rofiers, fa fituation. L'embouchure du Fleuve faint Laurent, commence là,

61 .

Roffgnol. Il chante moins bien en Canada, qu'en Europe, 156. $R u$ (le P. Paul du) Jéfuite. Mr. d'tberville le deftine aux Natchez. Il aime mieux refter aux Bayagoulas: il eft obligé de retourner en France,

$43 \mathrm{I}$.

CABREVOIS (M. de.) Com$\omega$ mandant au Fort de Chambly,

Sacrifices. Différens Sacrifices des Sauvages, $347-48$.

Sagamos. Nom des Chefs des Sauvages de l'Acadie. Ils avoient plus d'autolité que les Chefs des autres Nations, 266. Ils étoient ordinairement Jongleurs \& Médecins, 368.

Sagliart (le Frere Gabriel.) Voyez la Lifte é l'Examen des Auteurs, o le premier Volume de l' Hiftoire. Défaut de fon Vocabulaire Huron, fur la foi duquel de Laët a voulu juger de cette Langue.

Sagucnay. Riviere, fa fituation, Fa profondeur, 65. Effer de fa rapidité, 67-68. D'où vient en partie fa rapidité. Singularité fur les Marées dans certe Riviere, 68.

Sagnimont: Riviere, fa fituation,

Suguinam. Baye du Lac Huron. 391. fa fituation. Village d'Outaouais dans cette Baye,

279.

Saint Arige (le fleur de.) Son éloge,

Saint Barmald. Lac. Sa fiutuation,

390.

Saint Charles. Riviere faint Charles. Sa fituation,
$S$. Côme ( M. de.) Eccléfiaftique Canadien, travaille infructueufement parmi les Natchez, quoiyu'il fût protegé par la Femme. Chef. II eft tué par d'autres Sauvages, $43 \mathrm{I}$. S. Elme. Feu S. Elme, prunoftic d'une tempête,

$S$. François. Ifles, Riviere \& Can. ton de faint François, 112. Des Ifles, de la Riviere \& du Canton de faint Françuis, : 20. É fuiv. Situation \& defcription du Lac de faint François, 193.

$S$. Jean. Riviere, ou Bayouc faine Jean, fa fituation, fa defcription, 439.

S. Joleph Riviere. Sa fituation, 187. 312. Du Fort de la Riviere de faint Jofeph. Sauvages, qui y font érablis, 312 . Origine \& defcription de cette Riviere, 3 $15-16$. Baye de S. Jofeph. Sa defcription. Réception, qu'on y fait à l'Auteur $\&$ à ceux, qui l'accompagnoient, 477. \& fuiv. Deffein d'abandonner cet Etabliffenent, \& de le tranfporter à Penfacole, $48 \%$

$S$. Laurent. Cap faint Laurent, $f_{2}$ fituation, 60.

Flenve faint Laurent, où commence fon embouchure, fa largeur, 6o. Jufqu'où fon eau tft falée, 67. Poiffons du Fleuve faint Lausent, is 1. On y trouve prefque tous les Poiffons de Mer \& d'eau douce, $154^{\circ}$

Golphe de S. Laurent. Sa longueur, 60.

Comté de S. Laurent. Ce que c'eft, pour qui érigée, 67. - S. Marc. Baye de faint Marc d'Apalache. Nom, que lui donne Garcilaffo de la Vega. Defcriprion da Pays \& du Forr des ECpagnols, qui y avoient autrefois un plus grand Etabliffement, lequel a été détruit par les Anglois. Arrivée de l'Auteur dans le Fort, \& réception, qu'on lui fait, 473 . do fuia. 
S. Paul. Ifle de faint Paul, fa firuation, 59. Incommodité du paffage entre cette Ifle \& l'Ifle Royale,

60.

Baye S. Paul. Sa ficuation, ce qu'elle a de particulier, qui en eft Seigneur, 66 Pefche des Marfouins dans la Baye faine Paul, 148.

$S$. Pé (le P. Jean B. de.) Jéfuite, Supérieur des Miffions de la Nouvelle France, ce qu'il apprend d'une Femme Miamile, $S$. Pierre. Ifles de faint Pierre. Zeur defcriprion \& leurfituation, 59 .

Lac de $S$. Pierre. Voyez Lac.

Poißson S. Pierre. Voyez Goberge.

S. Simon (M. Denis de ) Voyez le premier volume de l'Hituire. Grand Piévôt de la Nouvelle France, 79.

S. Sulpice. M M. du Séminaire de faint Sulpice, Seigneurs de l'Ifle \&s de la Ville de Montreal. Le bien, qu'ils y ont fait. Nom, qu'ils ont donné à la Ville, 137 . Ils ont la direction du Village de la Montagne, compofé d'Iroyurois Chrétiens , 176.

$S$. Thomas. luée de Georges de Horn fur ce Saint,

$S$. Vallier (M. de.) Evêque 'de Quebec. Bâtimens, qu'il a conftruits en Canada. Fondation de l'Hôpital Général. Son éloge, 7\%. Il fonde l'Hôpital des Trois Rivieres, IIz. Témoignage, yu’il rend aux Chrétiens Iroquois du Sault faint Louis, 177. Voyez l'Hftoire.

Ste Claire. Ifle \& Lac de fainte Claire, 277. ऊ juiv.

Sie Rofe. Ifle \& Canal de fainte Role,

479 .

Sakis Sauvages du Canada, ont un Village à la Baye. Ils font divifés en deux Factions. Réception, qu'ils fonr à $M$ de Montigny, 292.93. Ils invitent l'Auteur à un Confeil \& ce qui s'y palfe, 294.95. Ils chantent le Calumet à M. de Montigny

$290^{\circ}$

Samojedes. Erablis fur le Fleuve
Oby : leur conformité avec les Anériquains, 21.22. Sant-Yago de las Cava!leros. Ville de l'Ifle Efpagnole, fameufe par le bon air, quion y refpire,

Supins. Quatre efpéces de Sapin en Canada, 160.

Sarrafin. (M.) Sa Defcription anatomique du Caltor. Son éloge, 97. 98. 11 prérend que le Loup Servier du Canada eft un vrai Chat, 133. Salfafras. On en trouve beaucoup fur la Riviere faint Jofeph, $317^{\circ}$ Voyez la Defcription di's Pl.ntes.

Safteratfi. Chef héréditaire des Huruns. Affifte à un Confeil, mais il n'y parle point, \& pourquoi, 258 . Zele de fon Ayeule pour avoit: un Miflionnaire, 260.

Savanois. Sauvages des environs de la Baye d'Hudfon. Particularités fur leurs mœurs, leur Religion, \& leurs Courumes, 181 . \& fuiv.

Sault de la Chaudiere. Sa fituation; premiereftation des Abénaquis dans la Colonie,

Sault au Récollet, 121. 140.

Sault Saint Louis, 141. Eloge des Habitans decette Bourgade, \&z com ment elle a été établie, $175-77$.

Long-Sault,

Suult Sainte Marie. Sa fituation. 187. Tradition des Sauvages fur la maniere, dont il a été formé, 281 . Voyez la Carte.

Saufteurs. Narion fauvage, d'où leur vient ce nom: leur nom propre,

Sauvages. Lurs 187. is 87. 82. Leur Mufique \& leurs Danfes, 84. Moyen de les francifer \& de les rendre Chrétiens, 90. Ils difparoiffent d'une maniere incompréhenfible, 91. Leur Almanach pour onnoître la durée du froid, 02 . I eurs imaginarions fur les Ciafturs oz. 106. Leurs prépararifs \& leur fuperftitions pour la Chaffe de l'Ours. En quoi confifte leur jeûne, 115. 
juiv. Avantages, qu'ils ont pour la chatle. Leul complatiance, 115 . Leur vîtefle à la courle, 116 . Leurs bains. 116 Leur maniere de fane la guerre, 12 g. Iciée, qu'ils ont de l'Orignal $\&$ del'Ours, 127 Comment ils oblervent par les Martres que la chaffe ferabonne, 134. Il n'y a rien à craindre de leur part pour 1 honneur des Femmes Françoifes, \& poutquoi, $142-43$. Ils font devenus infolens, quand ils fe font vût recherchés, 143. Ils marient la Seine, avant que de l'employer pour la pefche. Leur adrefle a pelcher dans les Rapides, 153 . Leur piincipal défaut, 172. Leur attachemeat à leurs Familes \& à leur Pays natal, 176. Comment les Sauvages de Langues differentes traitent entr'eux, 189. Enibartas, oì l'on a été pour fe faitre entendre de ces Barbares, 19798 . Leur ftyle Afiatiyue, 198. Le peu de fonds, qu'un doir faire fur leurs traditions, \& pourquoi, 199. la guerre a conrribué à les réduire prefque à rien, 203. Ce qui peur les purter à entreprendre une guerre, 215 . o fuivantes. Leur confiance prélomptueufe à la guerre, \& quel en eft le principe, 236 . Ce qui les rend comme infenfibles dans les tourmens, \& comment ils font parvenus ì cette inhumanité envers leurs Prifonniers', qui a tant furpris, 247-48. Leur habileté dans les négociations. En quelle occafion on ne peut pas compter fur un Traitéde Paix entr'eux, 251 . \& juiv, Leurs Confeils, 258 . Leur fureur pour le jeu, 260. Ó juiv. Ils conviennent de la lupériorité de nos Génies tutélaires fut les leurs, 263 . Ils font plus aités à convertir que les Peuples folicés, 265 . Idée de leur gouvernement, 266. ơ juivinntes. De leurs intérêts, \& de leurs Traicés, \& de la manie- re, dont ils s'y comportent ; 270. Du gouvernement des Villages, 271. Des défauts de leur gouvernement, \& de leurs principes fur cela $: 272$. O jutv. P'incipes, fur quoi ils érabliffent limpunité des crimes, 273 . Ce qui empêche que cette impunité n'ait de plus fâcheufes fuites. Ils craignent fut tout d'être taxés d'avatice, 276 . Soin, que les jeunes Sauvages ont de fe parer, 278 . De leurs Mariages, 283 . $\mathcal{O}$ juiv. Ils fone fort jaloux, 254 . Les Sauvages de la Baye plus groffiers \& plus fuperftrieux que les autres, excepté les Pouréouatamis, 299-300. Leur bonne conftitution, leur farce: ce qui altere leur tempéramment, 302-03. Leurs vices. $\mathrm{Ce}$ qui les empêche de peupler, 303-04. Avantages, qu'ils ont fur nous. Perfection de leur fens, 304. Leur éloquence, leur mémoire. De quoi ils le fervent pour l'aider. Leur jugement. Pourquoi ils ne réufliroiens pas arfément dans les Arts \&: les Sciences abftraites, 305 . Leur grandeur d'ame, \& leur conftance dans les tourmens, 306. Leur valeur 2307 . Les égards, qu'ils ont pour les autres, Principe, fur quoi cela eft fondé. Leur fierté, \& leuts défaurs jufyues dans leurs vertus, 308 . Ils n'unt point les qualités du cœur, ni aucun naturel pour leurs Parens, 309. D'où vient leur couleur, \& qu'ils n'ont point de poil fur le corps, 310-11. Pourquoi ils ne communiquent point aux Françors leurs Simples, \& ne leur décou. vient point les Mines de leur Pays. Ils ufent de leurs Simples à l'aventure, 3 i7 II faut racheter d'eux tout ce qu'ils on tronvé ou volé, $3: 8$. Ce quils répondent aux françois, quand on leur reproche leur jvrognerie. Suites de ce défordre parmi enx; pourquoi elles ne vont pas plus loin. En quoi ils font heurenx \& eftimables. 
rimables. Mépris, qu'ils font de ce que nous eftımons, \& de notre maniere de vivre. Soin, que les Meres ont de leurs Enfans. Figure ridicule, que quelques - unes leur donnent, $321-24$. Ce qui les fortifie \& les rend bien faits. Leurs premiers exercices: leur émulation entr'eux. A quoi fe réduit l'éducation, qu'on leur donne. Leurs paffions, leur habillement. Comment ils fe picquent le corps, \& fe peignent le vifage, $\&$ à quoi l'un \& l'autre leur eft urile. Ils peignent leurs Efelaves \& leurs Morts, 329-30. Elfets du dépit parmi les Sauvages. Leurs paffrons, 326. Leur habillement \& leurs parures. Comment \& pourquoi ils fe picquent \& fe peignent, 327. Oे fuiv. Leurs occupations, leurs femences \& leurs recoltes. Leur nourriture. Ouvrages des Hommes, \& leur oifiveré. Leur maniere de fe loger \& de fe fortifier. De leurs hyvernemens pour la chaffe, 330. Ov fuiv. Leur malpropreté \& fes fuites, 338 . \& fuiv. Leur portrait en racourci, 340 . \& fuiv. Ce qu'ils penfent de l'origine des Hommes, de la création du Monde; leurs Traditions différentes fur le premier Etre, 343. \& Suivantes. Ce qu'ils entendent par les Efprits, 345 . Leurs facrifices, leurs jeûnes, leurs vœux. Rapports entr'eux \& les Ifraëlites, 344 . $\mathcal{O}$ fuiv. Ce qu'ils penfent de la nature $\&$ de l'immortalité de l'Ame. Leur refpect pour les tombeaux, $35 \mathrm{I}$. Leur Patadis, \& comment ils prétendent mériter d'être éternellement heureux, 352. Leurs idées fur les Ames des Bêtes \& fur la nature des fonges. Leur conduite $\grave{a}$ cetreoccafion, 353 . \& fuiv. Ce qu'ils fenfent des mauvais Génies \& des Sorciers, 359. \& fuiv. Leurs preftiges, ${ }^{61}$. \& fuiv. Maladies ordinaires parmi eux: leurs remédes, leurs idées extravagantes fur les Maladies, Tome III.
364. Oo fuiv.Principes de leur Médecine : leur cruauté à l'égard des $\mathrm{Ma}$ lades défefpérés, 367-68. Comment on fe comporte dans quelques $\mathrm{Na-}$ tions à l'égard des Médecins, 369. Leur fermeté Stoïque à la mort, 371 . O fuiv. Leur générofité à l'égard des Morts : leur deuil, leurs tombeaux, leurs funérailles. Regles pour le veuvage. Differentes pratiques a l'égard des Morts, 373. E fuiv. Idée ridicule à l'égard de ceux, qui meurent de mort violente, 376 . Quelques coutumes des Sauvages Occidentaux par rapport à la guerre, \& comment ils traitent leurs Prifonniers, 382 . \& fuiv. Comment ils en ufent avec les Captifs, qui ne meurent point en Braves: leur fierté, quand ils font en corps de Guerriers, 386 . Comment ils pleurent les Morts, 387 . Leur habileté à contrefaire toutes fortes d'Animaux, pour attirer leurs Ennemis dans le piége, 390-91. Differentes traditions des Sauvages : leurs idées fur les Aftres. Comment ils connoiffent le Nord : leurs idées fur les Eclipfes, 399-400. fur le Tonnere, $40 t$. Leur maniere de divifer le tems, 401-02. Ceux de la Louyfiane dépériffent encore plus que ceux du Canada, 429. Les Sauvages des Martyrs viennent au-devant de la Chaloupe, oi étoit une partie de l'Equipage de l'Adour. Ils fe difent Amis des ECpagnols, \& paroiffent Ennemis des Anglois, 461 . Ils vont en grand nombre vifiter l'Adour échouée, \& ce qu'ils y font , $463-64$. Ils avoient tous été baprifés à la Havane, oì ils vont tous les ans, \& dans quelle Voiture, ${ }_{464}$. Demeure de ces Sauvages : leur figure \& leur habillement, 466. Ce qui les retient aux Martyrs, 467. Difference de ces Sauvages \& de cenx du Canada, \& d'où elle vient. Ils pillent tout cequi étoit refté fur l'Adour, \& brifent ce BâY y y 
538

\section{T A B}

timent, 468.Ils fuivent les François dans leur retraite, 469. Quatre antres Sauvages paroiflent à la vûë du Batreau, qui portoir l'Auteur; on les attend, \& ils fe retirent, 471 . Idée, que les Efpagnols ont des Sauvages des Martyrs,

474.

Scythes. Grotius ne croit point qu'ils ayent peuplé l'A mérique: fes preuves, 13 . De Laëtles détruit, 15 . Pline présend que le nom de Scythes étoit commun à routes les Nations du Nord de l'A fie \& de l'Europe, \& qu'il y avoit parmi eux beaucoup d'Anthropophages. Ce qu'il rapporte de leurs mœurs, a beaucoup de rapport à celles de plufieurs Amériquains, 21 . Il y a bien de l'apparence que des Scythes ont paffée en Amérique,

31.32.

Sed. Le Cap de Sed; fa fituation, 458. Danger, que court la Bellone pour ne l'avoir pas reconnu, 485 . Seigneurs. Pourquoi ils ne font pas riches en Canada, 108-09. Pourquoi ils n'ont pas le droit de Patronnage, 109.

Seine. Les Sauvages, avant que de fe fervir de ce Filer, le marient avec deux Filles Vierges, 153 .

Sel. Suline. On a fait de fort beau Sel en Canada, $\&$ il y a eu ordre de difcontinuer, 53. Salines de Gannentah3, 214 . Salines aux environs de la Riviere aux Bœufs, 396 ; à l'inte Touloufe, ou de la Balife 442 .

Sénéchal. Par qui la Jurifdiction du Sénéchal de la Nouvelle France a été abforbée,

II 3 .

Séneque le Tragique. Ce qu'on doir penfer de fa prétenduëPro hétie fur la découverte des Nouvelles Terres,

Senneville, (Le Sieur de) Capitaine, eft député pour négocier à Onnonragué, \&z pour vifier en paffant l'Etabliffement du fieur de Joncaire à Niagara , 228.

Serpens. Les Sauvages n'en ont point d'horreur, les manient fans
L E

crainte, les mettent dans leur feir, après les avou engoudis, \& les mangent. Les Jongleurs s'en fervont pour leurs enchantemens, $23 \%$. co Juiv.lfle aux Serpens à Sonnettes, 2 s 5 . Serpent à Sonnettes. D'où lus vient ce nom. En quoi il eft dangereux : reméde contre fa morfure, is $x$ - 59 .

Serviers. Chars ou Loups Serviers. D'où vient le nom de Loup, qu'on. leur a donné.Celui de Char leur convient mieux felon M. Sariafin, 135 .

Simples. Les Sauvages gardent un grand fecrec fur leurs Simples, \& pourquoi. Ils en ufent un peu à l'aventure, 317. Avec quel fuccès ils. en ufent,

Sioux. Peuples fauvages du Canada : leur maniere de vivre. On dir qu'ils ont l'ascent Chinois. Quelques-uns de leurs ufages: leur fituation, leur nom propre, $1 \$_{3}$. C fuiv. leur maniere de parler, 196. Ils fe joignent aux Outagamis pour nous faite la guerre. Relation des Sioux. fur le Pays au-delà du Miffouri, 300. On dit quils ont une connoifance plus jufte du premier principe, que les autres Sauvages, 343 . Ils infectent tous les parfages pour aller ì la Louyfiane, 3 So. 406 . Sikukis. Dans la Miffion de Saint François,

121 .

Solit. Le culte du Soleil fort ancien dans les Indes \& dans l'Amérigue,

Soleil. Plante. Ufage, qu'en font les Sauvages, 163 .

Soleil. Nom, qu'on donne ats Grand Chef des Narchez, \& pourquoi. Ses droits. Honneurs, qu'on lui rend fendant fa vie $\&$ après $f_{a}$ mort, 420. friv. Comment il reçoir les Ambalfadeurs, 427. ¿- friv.

Solorzaro Pircyra. (Jean de)Jurifconfulte trpagnol. Rapporte les divers fentimens fur l origine des Amériquains, 9.

Songes. De la nature des Songes felon les Sauvages. Superftitions de 


\section{DES M A T I E R E S.}

ces Barbares à ce fujet: leur maniere de les éluder. De la Fête des Songes, 353. O fuiv. Les Médecins de l'Acadie prétendoient connoître par les Songes, fi les Malades guériroient ou non,

Sorciers. Voyez Maléfices.

Sorel. Riviere de Sorel. Ses premiers noms, 124. Fort de Sorel,

I 50.

Sothouis. Tribu des Akanfas, 410 .

Soto. (D. Ferdinand de) Conquérant de la Floride, où il eft mort, 434. voyez le premier volume de l'Hiftoire.

Soufleurs. Petires Baleines, fe trouvent en grand nombre dans la Mer du Canada,

54.

Souliers. Def́cription des Souliers des Sauvages, 221.

Souriquous. Sauvages du Canada. De qui de Hornn les fait defcendre, 32 .

Soye. On y travaille avec fuccès dans la Louyfiane,

$43^{6}$.

Spinola (D. Auguftin). Vient au Biloxi apporter la nouvelle du Traité de paix, 481 . Il court rifque de voir enlever fon Navire par des Deferteurs François, \& comment il évite ce danger, $482-83$.

Strabon. Ce qu'il dit des Scythes, qui demeuroient au Nord de la Mer Cafpienne, 2 1. De Hornn lui fait dire que les Phéniciens font entrés dans la Mer Atlanriquıe, \& ont bâti des Villes an - delà des Colonnes d'Hercules; qu'ils ont eu de grandes guerres, \& fair de grandes pertes en Afrique, 27. Il a écrit yue les Habitans de Cadix \& tous les. Efpagnols avoient de giands Vaiffeaux, \& excelloient dans l'art de naviger,

Sueur. (le Pere Euftache le) Jéfuite, Miffionnaire des Abénayuis de Beckancourt, gémit fur les défordies de la Miffion, auxquels il ne peut remédier,

II 2.

Sueur. Differens ufages de la Sueur parmi les Sauvages, $362-66, \&$ fuiv. Suiffes. Une Compagnie entiere de Suiffes déferte de la Louyfiane, \& va à la Caroline,

482.

\section{$T$}

$7 A B A C$. Il réuffit fort bien à la Louyfiane, 416. Tabiens. Peuples du Nord, dont parle Ptolomée, \& que Pline aftûre avoir difparu; ce quon en peut conclure. De Hornn en fait defcendre les Tombas du Perou, 32. Table a Rolland. Sa fituation, $6 \mathbf{1}$. Table à Marianne. Montagne de l'ine de Cuba,

Tudouffac. Port fur le Fleuve faint Laurent: fa fituation, fa defcription; erreur des Géographes à ce fujet, \& ce qui y a donné lieu,

Taenfas. Narion fauvage de la Louyfiane, autrefois fort nombreufe, aujourd hur détruite. Conceffion. Beau-

té du Pays,
Tabouiskiron. Fils du Roi du Ciel, felon les Hurons \& les Iroquois, tue fon Frere,

Tabouttfaron. Divinité des Sauvages,

Tamarouas Tribu lllinoife 344. ge, où ils fe font joints avec les Caoquias,

Taronbiauagon. Le Roi du Ciel, felon les Hurons \& les Iroquois, chatfe d'un coup de pied fa Femme du Ciel,

Turtar. Fleuve, d'où eft venu le nom de Tartares.

Tartares. Breverood détruit le fentiment, qui les fait defcendre des Hébreux. Origine de ce non. Breverood prétend yu'ils onr feuls peuplé l'Amérique: fes preuves, $11, \mathrm{I}_{2}$. Peu de conformité des Tartares avec les Amériquains feptentrionnaux, felon Grotius. De Laër n'eft pas de cet avis, 14. Il y a bien de l'appaY y ij 
rence que plus d'une Nation Amériquaine a une origine scyibe ou Tartare, 32. Tasmutr. (M.) Eccléfiaftique Ca. nadien, Mifionnaire aux Illınois,

Tchactas. Sauvages de la Louyfiane, font une bonne barriere à cetre Colonie contre les Chicachas, 452. Les Tchactas font follicités par les Anglois à n'avoir plus aucun commerce avec les François. Importance de cette affaire. M. de Bienville les gagne par fes manieres $\&$ fes préfens,

$4 \delta_{3}$.

Teintures. D'où les Sauvages tirent les couleurs, dont ils fe fervent pour la Teinture,

$329,407$.

Temifcamings. Nation Algonquine. Lac Temifcaming , 187. voyez l'Hiftoire.

Tempête fur le grand Banc, $5 \mathrm{I}$, à l'entrée du Golphe, 59, fur la Côte de la Floride, \& fes fuites, 453 , à l'embouchure du Miciflipi, 456 . Tempêres dans les Mers des Ifles de peu de durée, 489. Tempête dans la Manche, $499,500$.

Temple des Natchez. En quel état l'Auteur le trouva, 417. \& fuiv. les autres Nations de la Louyfiane avoient leur Temple. Celui des Natchez fubfifte feul. Quel étoir le principal \& comme la Métropole de tous, 429.

Térébentbine, ou Baume Blanc dis Canada. D'où elle fe tire : fes propriérés, $160-61$.

Terre-neuve Cette Ille ne paroît pas avoir d'Habitans naturels, 178 .

Tétes de Boule. Nation Algonquine. D'où leur vient ce nom is7. Comment on leur donne cette figure,

Theakili. Sources de cetre Riviere. D'où vient ce nom, 371. Defcription de cetre Riviere. Pourquoi elle perd fon nom en fe joignant à celle des Illinois,

379-80.
Tréfor. De quoi eft compolé le Tréfor des Sauvages, \& à qui la garde en eft confiée, 210.

t betis, Fregate du.Roi. Eft fi mal. traitée de la tempête au fortir dit Havre de Grace, qu'elle eft obligée d'entrer dans le Port de llimouth. Parqui elle étoit commandée, 497.

Thevet (André) a cru que les Ifraëlites emmenés Captifs par Salmanazar, fe font sépandus par-tout, \& onr peuplé l'Amérique, 4.

Tionnontatez. Voyez l'Hiftoire. Ce font les vrais Hurons, 199. Village de Tionnontatez au Détroit, 256. On les appelle la Nation du Petun, 267.

Tioux. Sauvages de la Louyfiane, Voifins \& Alliés des Natchez, 416.

Tombas. Peuples du Férou. De qui de Hornn les fait defcendre,

Tombeaux. Combien ils font refpectés des Sauvages, \& pourquoi, $3\{1-52$. Des Tombeaux des Sauvages,

Tonicar. Sauvages de la Louy fiane, voyez le fecond volume de l'Hiftoire: leur affection pour les François. Aucun ne veur fe faire Chrétien, $43 \mathrm{I}$. Riviere \& Lac, ou Baye des Tonicas, 432 . \& juiv. Situation du grand Village des Tonicas: leur GrandChef. Son atrachement aux François. Il s habille à la Françoife. Il eft fort riche. Etar de certe Narion. Ces Sauvages chaffent leur Miflionnaire pour avoir brîtlé leur Temple, qu'ils ne rérabliffent point. Ils le rappellent; il les quitte, \& pourquoi, 433 , 434.

Tonibata. Ine, fa fituation, concédée à un Iroquois, qui y avoit alfemblé une Bourgade, 194. Tonnerre. Anfe du Tonnere, fa fituation, 279.

I tée des Sauvages fur le Tonnerre, 401. Tonti. (M. de) Capitaine. Com. 
mandatit au Détroit, y affemble un Confeil, 297. Il promet de travailler à procurer un Miffionnaire aux Hurons, 260. Topingas. Tribu des Akanfas,

Torimas. Tribu des Akanfas, 410.

Torniel. (le Pere Auguftin) Barnabite ; fon fentiment fur l'origine des Amériquains,

Tortués. en Canada \& dans l'Acadie. Ce qu'elles ont de particulier, 152 . Fable des Sauvages fur une Torruë, 399. Tortuë monftrueufe. Force de cet Animal,

Thes des Tortuës: leur ficuacio. nature du Pays,

470.

Touloufe. Ifle Touloufe, voyez Ba life.

Tourmente. Cap Tourmente, fa fieuation,

Tourtes.Efpéces de Ramiers; font d'une grande reflource pour la vie en Canada, $17 \mathrm{I}$.

Tracy. Nom, qu'on avdit donné au Lac tiuron, \& quil n'a point gardé,

253.

Traines. Defcription des Traînes, fur lefquelles on met le Bagage \& les Bleflés,

$2.2 \%$.

Traite de l'Eau-de-vie. Ses inconvéniens à Beckancourt, voyez Beckancourt; à faint François, voyez faint François, à Montreal, au Sault faint Louis, \& parmi les Iroquois de la Montagne, 141-42. Tort, qu'elle a fait aux Sauvages, 302, 320 . Pourquoi, \& comment on pourroit permettre cette Traite, $32 \mathrm{I}$.

Trautés. Des differens Traités des Sauvages, 297-98, 427. \& fuiv.

Tremblement de Terre arrivé en 1663 en Canada. Quelques-uns de fes effers, 66, 68. Voyez le I. Vol.

Trinité. La Pointe de la Trinité : fa fituation. Le Vaiffeau du Ro: court rifque de s'y bilfer,

IroisRivieres, Oingue de certeVil- le, \& du nom, qu'elle porre: fa defcription, 112 . E fuiv. Trou. Le Trou. Rapide: fa fituation,

190.

I fonnonthouans. Canton Iroquois. Ces Sauvages paffent pour avoir un langage groflier, 197. Leur Village à Niagara, qui eft de leur Canton, 22 . Ils y accordent un Etabliffement au fieur de Joncaire, \& pourquoi ils en refufent un aux Anglois, 227. La pluralitédes Maris en ufage dans ce Canton,

Tulipier. Voyez la Lifte do lis Defcription des Plantes.

Tygres. Inconnus dans les Ifles de l'Amérique, 7. Tygres chez les Iroquois. D'où les Tygres ont pu paffer en Amérique, 31. Tygres plus petits que les autres au haut du Miciffipi, 33. Il n'y a point de vrais Tygres en Canada, cependant quelquesSauvages reconnoiffent leGrand Tygre pour le Dieu des Eaus, 344.

\section{$\mathrm{V}$}

\section{Y7} ACHES MARINES. LeUr defcription, \& leur pêche, 147. Vatable. a cru que c'étoit dans l'Amérique, que Salomon envoyoir fes Flottes chercher de l'or, 2. Vaudreuil. (M. le Comte de) Capitaine en fecond fur le Chameau, 47. Il reconnoît la Terre.Précaution, qu'il prend pour ne la point appro. cher de nuit, sGo M. le Marquis de I"audreuil, Pere du Précédent, Gouverneur Général de la Nouvclle France, 79. Ordres, qu'il envoye au Détroir, ce qu'sl raconte à l'Auteur d'une prédiction finguliere d'une Sauvagefle, 362 , $36_{3}$.

Le Marquis de Cavagnal-Vaudreuil un des Fils duPrécédent, eft député vers les Iroquois, 228. Viga. (Garcilaffo de la) Aureuz Efpagnol. Voyez la Lifte ć l'Examese 
$54^{2}$

T A B

des Auteurs. Il étoit de la Maifon des Incas du Pérou par $f_{2}$ Mere. Il affûre qu'on ne connoiffoit au Pérou avant l'arrivéedes Efpagnols niCaracteres, ni aucune forte d'Ecriture, $17 . \mathrm{Ce}$ qu'il dit des Chicachas de la Louyfiane, n'eft pas exact, 408. Ce qu'il dit des Narchez, 420. Ce qu'il dit du Pays de la Louyfiane, 446. Il parle d'une Bourgade appellée Mauvilla, d'où eft venu le nom de Mauviliens, ou Maubiliens, 452. On ne grouve point dans les Caciques Indiens les richelfes, qu'il leur attribue, 467. Ce qu'il appelle le Port d'Auré ,

473.

Verits. Ce qui rend les Vents im. pétueux aux environs du Grand Banc de Terre-neuve, so. Vents nommés Brifes, \& leur utilité, 453 .

Vercheres. Les Iroquois attaquent deux fois le Fort de Vercheres, \& en font repouffés par Madame \& par Madomoifelle de Vercheres, 124 ,

125.

Vermude. Il eft bon de reconnoître cette Ifle, quand on va du Canal de Bahrma à S. Domingue, 48\%.

Veftales. S'il y en a eu parmi les Sauvages,

350.

Viuvage. Régles pour le Veuvage $\&$ les fecondes Nôces parmi les Sauvages,

376.

Vocux. L'ufage des Vœux eft le même parmi les Sauvages, que parmi nous, 348-49. Ils n'ont pour objet, que les biens préfens, 353 . Villages des Sauvages, leur figure, leurs Fortifications, 334-35. Ville-Marie. Nom, que les Fondateus de la Ville de Montreal lui ont donné, \& qui n'a point paffé dans l'ufage,

137.

Vinaigrier. Arbriffeau, d'où lui vient ce nom, 163.

$V o l$. Les Sauvages font enclins au vol. Réglement fur cela, \& fur les chofes trouvées, 275. Comment les Hurons les puniffoient,

276.
L E

Voutron (M. de.) Commandane le Chameau. Son expérience pour la Navigation du Canada, 47. Il donne un oidre, qui fauve fon $\mathrm{Na}$ vire,

Viyages. Maniere commode de voyager fur la glace \& fur la nege, \& d'y courir la pofte, 108. Incommodirés des Voyages en Canada, 220. Agrément \& utilité des Voya. ges, 254.55 . Incommodités des Voyages pendant l'Hyver , 336 . Pendant l'Eré,

$339-40$.

U

TRSULINES. Elles deffervent l'Hôpital des Trois Rivieres,

W

II 3 .

TTALCOP (D. Alexandre.) $\checkmark$ Capitaine de Vaifleauau fervice des Efpagnols. Apporre au Biloxi le Traité de Paix; eft défigné Gouverneur de P'enfacole, $48 \mathrm{I}$.

\section{$\mathrm{X}$}

T IMENEZ prétend, qu'on peut défaler de l'eau faumârre avec du Saffafras. Voyez la Defcription des Plantes au mot Saffafras.

\section{$\mathrm{Y}$}

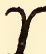
ASOUS. Riviere des Yafous, fa largeur, mauvaife qualité de fes eaux, 412. Village des Yafous. Fort \& Conceftion mal placés, 413 . Les Yafous alliés des Chicachas. Importance de s'affurer de leur Riviere $4 \mathrm{I} 3-14$. Tucatan. Province de la Nouvelle Efpagne. Par qui Grotius \& Dom Pierre Marryr ont cru qu'elle avoit éré peuplée. Leurs preuves, $12-13$. De Laët les rêfute, 16. Baptême \& Confeffion ufités dans l'Yucatan, I 9. 
Fin de la Table des Matieres du troifiéme Tome.

\section{Fautes à corriger dans ce Volume.}

$P$ Age 18 . ligne 6. donc les Habitans, li/ez dont les Habitans.

Page 32. ligne 36. Paieuma, lijez Paicuma.

Fage 35 . ligne 6. de plus grandes, lifez de moins grandes.

Page $4 y$. ligne 38 . celle, lijez celles.

Page 88. ligne 18 . les prix, lifez le prix.

Paje ror. ligne i 8. qu'ils portent à plat, lifez qu'ils pofent à plat:

Page 172. ligne 5. mais, lifez car.

Ligne 35 . Ce font là, Madame, les défauts, lifez C’eft là, Madame, le dẻfaut:

Page I 93. ligne 27. Chenaux des Lacs, lifez Chenaux du Lac.

Page 201. ligize 37. de ce Pays, lifez de ce Pays-ci.

Page 211 . ligne I7. Ajouez, lifez Aiouez.

Page 217. ligne 2. qu'il n'elt pas permis à nul autre, lifez qu'il n'eft permis à nul autre.

Page 22. ligne 25. oraffades, lifez Braftarts.

Page 226 ligne 24. après ce mor Saluvage, lifez qu'ils l'adopterent, \&.

Prge 246. ligne 16. où il doit être, li e $z$ où il doit demeurer.

Page 282. ligne 13 . jai vî, $l_{2} / e z$ j’ai lít.

Page 295 . dans la note, le P. Pierre Chardon, lifez le P. Jean Chardon.

Page 308. ligne 13. S. Gregoire Pape. lifez S. Chryfoltome.

Page 310 . ligne 26. volonrairement, lifez volontiers.

Page ; 12 . ligne 28 . on le temonte, lifez on la remonte.

Page 315. ligne derniere, au perit pas, lifez lentement,

Page 357 ligne 5 . affurément, lijez affürément.

Page 4 s as. la Baye S. Jean, lifez le Bay ouc S. Jean. 


$$
+
$$


a 
(6)
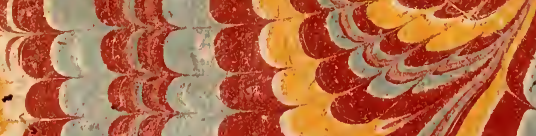

लेखिए

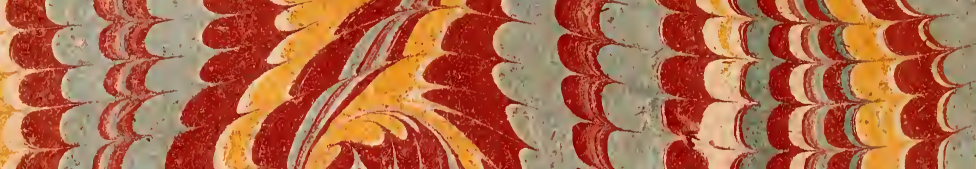

acs 20$)$ es acece

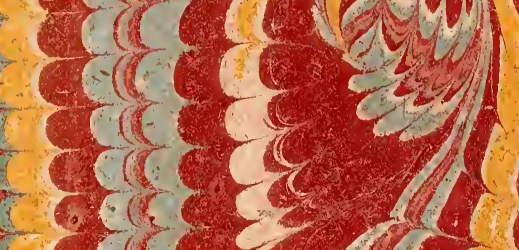

K.

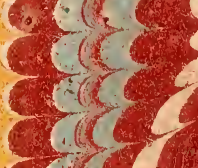

7 .

cles

arce

(2) -1

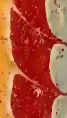

$\operatorname{cosects}$

$18+1)$

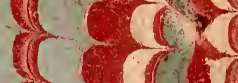

$18+(6)$

(1)

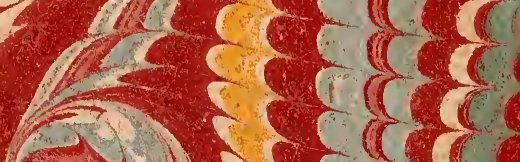

icिए

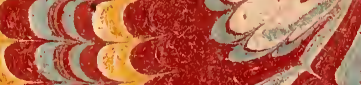

$\operatorname{coscc}(5)$

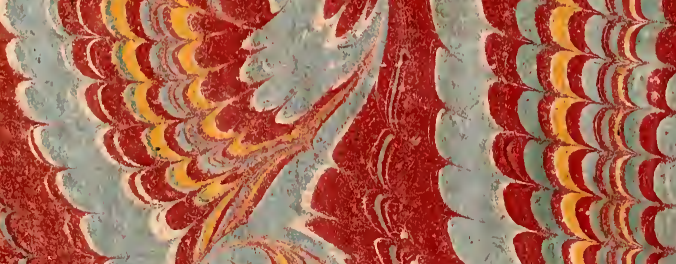

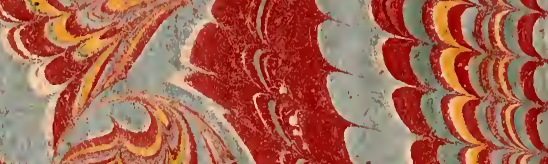




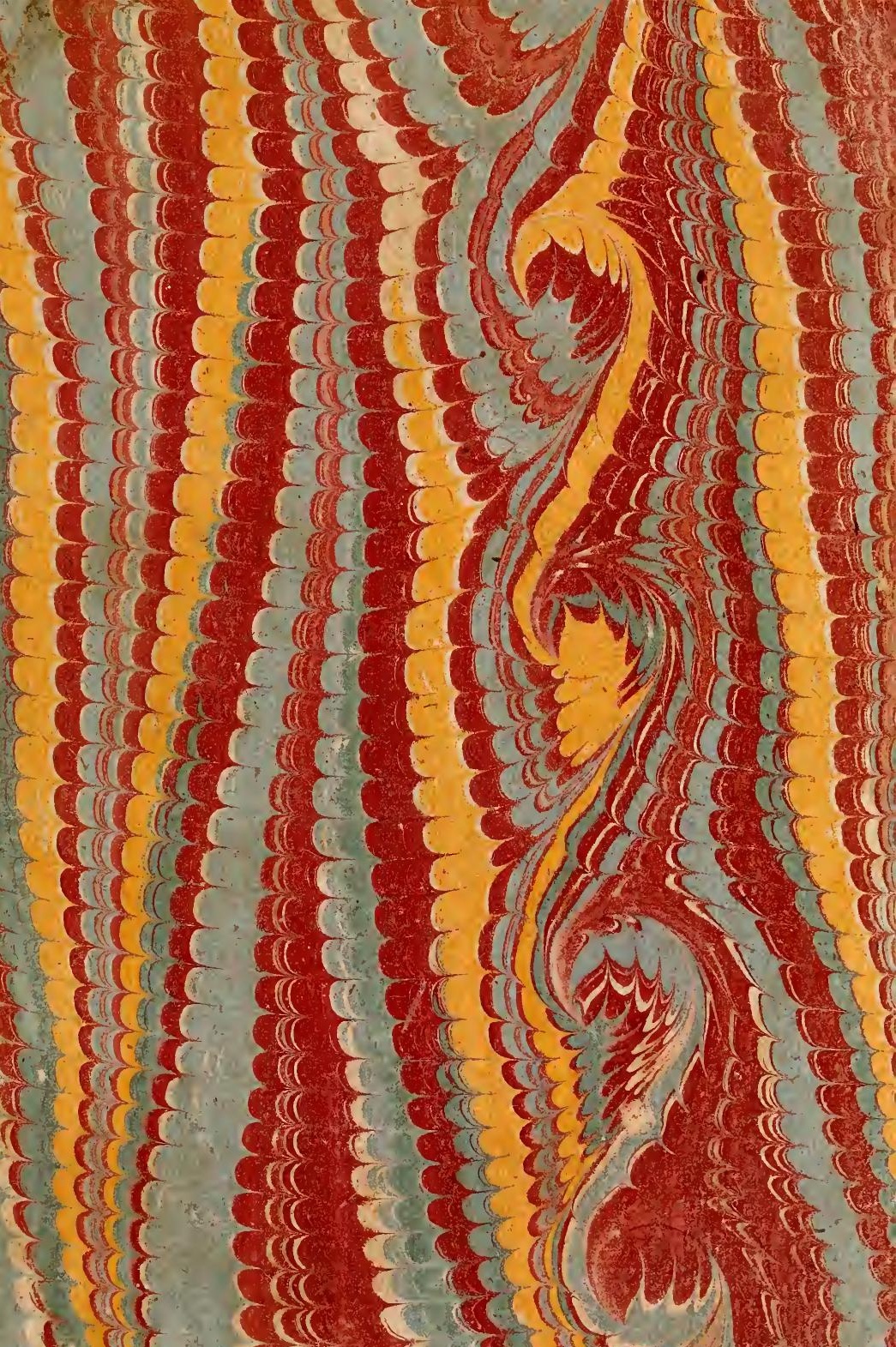


